\title{
Landnutzung und Kulturlandschaft
}

- Wandel vom 18. ins 21. Jahrhundert -

\section{Gemarkung Lachendorf am Rande der Südheide}

\section{Dissertation}

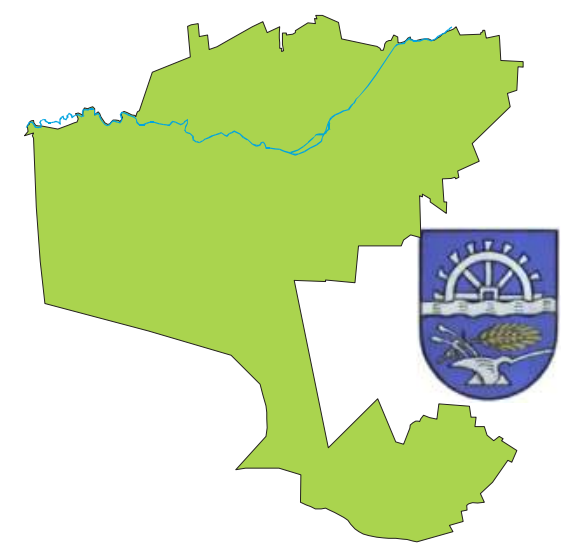

zur Erlangung des mathematisch-naturwissenschaftlichen Doktorgrades

"Doctor rerum naturalium"

der Georg-August-Universität Göttingen

im Promotionsprogramm Geowissenschaften / Geographie der Georg-August University School of Science (GAUSS)

vorgelegt von

Artur Behr

aus Horndorf, Kr. Lüneburg

Göttingen 2013 


\section{Mitglieder der Prüfungskommission}

Referent: Professor Dr. K.-H. Pörtge, Geographisches Institut

Korreferent: Professor Dr. W. Kreisel, Geographisches Institut

weitere Mitglieder der Prüfungskommission:

Prof. Dr. Hansjörg Küster, Institut für Geobotanik, Universität Hannover

Prof. Dr. Hans Ruppert, Geowissenschaftliches Zentrum

Prof. Dr. Renate Bürger-Arndt, Fakultät für Forstwissenschaften und Waldökologie Dr. Stefan Erasmi, Geographisches Institut

Tag der mündlichen Prüfung: 14. Oktober 2013 


\section{Danksagung}

Aufgewachsen in einem bäuerlichen Familienbetrieb in den 1940er und 1950er Jahren und einem Studium am Geographischen Institut der Universität Hamburg: Das sind Prägungen, die eine lebenslange Beschäftigung mit agrargeographischen Themen nahe legten.

Daher sei diese Arbeit auch meiner Familie, meinen Eltern und Geschwistern, sowie meinen Lehrern im Fach Geographie, insbesondere Prof. Dr. A. Kolb und Prof. Dr. G Borchert, gewidmet.

Besonderer Dank gilt Herrn Prof. Dr. H. Küster, der mich zum Promotionsvorhaben ermunterte und mich an das Geographische Institut der Georg August Universität in Göttingen vermittelte, und Herrn Prof. Dr. K.-H. Pörtge, der alle Formalitäten für eine externe Promotion für mich erledigte und mich in kollegialer Weise bei der Endfassung meiner Dissertation betreute!

Für die Bereitstellung von Material danke ich dem Deutschen Wetterdienst (DWD) in Offenbach, dem Niedersächsischen Landesbetrieb für Wasserwirtschaft, Küsten- und Naturschutz (NLWKN) in Verden sowie der Landwirtschaftskammer Niedersachen - Soltau-Fallingbostel in Uelzen.

Ohne die Bereitschaft der Gemeindeverwaltung Lachendorf, mir Einblick in Gemeindestatistiken zu gewähren, wäre meine Staatsexamensarbeit 1966 zur agrargeographischen Struktur der Lachendorfer Flur nicht möglich gewesen. Und ohne Zugang zum Archiv mit den Akten zu den Agrarreformen des 19. Jahrhunderts hätten wesentliche Teile dieser Dissertation nicht verfasst werden können. Dafür danke ich Gemeindedirektor W. Hennies und Bürgermeister J. Warncke sehr!

In den Dank für die Bereitstellung von Material sei auch Herr StD M. Zilk eingeschlossen, der für die Digitalisierung der großen handkolorierten Karten von 1967 sorgte und mir so die weitere Bearbeitung und Verwendung ermöglichte.

Mein ganz besonderer Dank aber gilt den Landwirten in Lachendorf, die stets meine Arbeit unterstützten und mir bereitwillig betriebsinterne Daten zur Verfügung stellten. Dies gilt neben den hier nicht namentlich Genannten insbesondere für Landwirtschaftsmeister Karsten Koch, der meine Fragen beantwortete und mich mit Material und nützlichen Hinweisen versorgte und mit dem mich seit unserer ersten Begegnung auf dem Acker eine langjährige Freundschaft verbindet.

Eine ganz persönliche Anerkennung gebührt meiner Frau Barbara, durch deren 1. Lehrerstelle ich überhaupt erst nach Lachendorf kam und das Dorf und die Gemarkung als geeigneten Untersuchungsraum kennenlernte, die mich während meiner Berufstätigkeit selbstlos unterstützte und die für meine zeitaufwändige Arbeit - auch im Ruhestand - viel Verständnis aufbrachte: herzlichen Dank!

Artur Behr, Hermannsburg, Januar 2014 


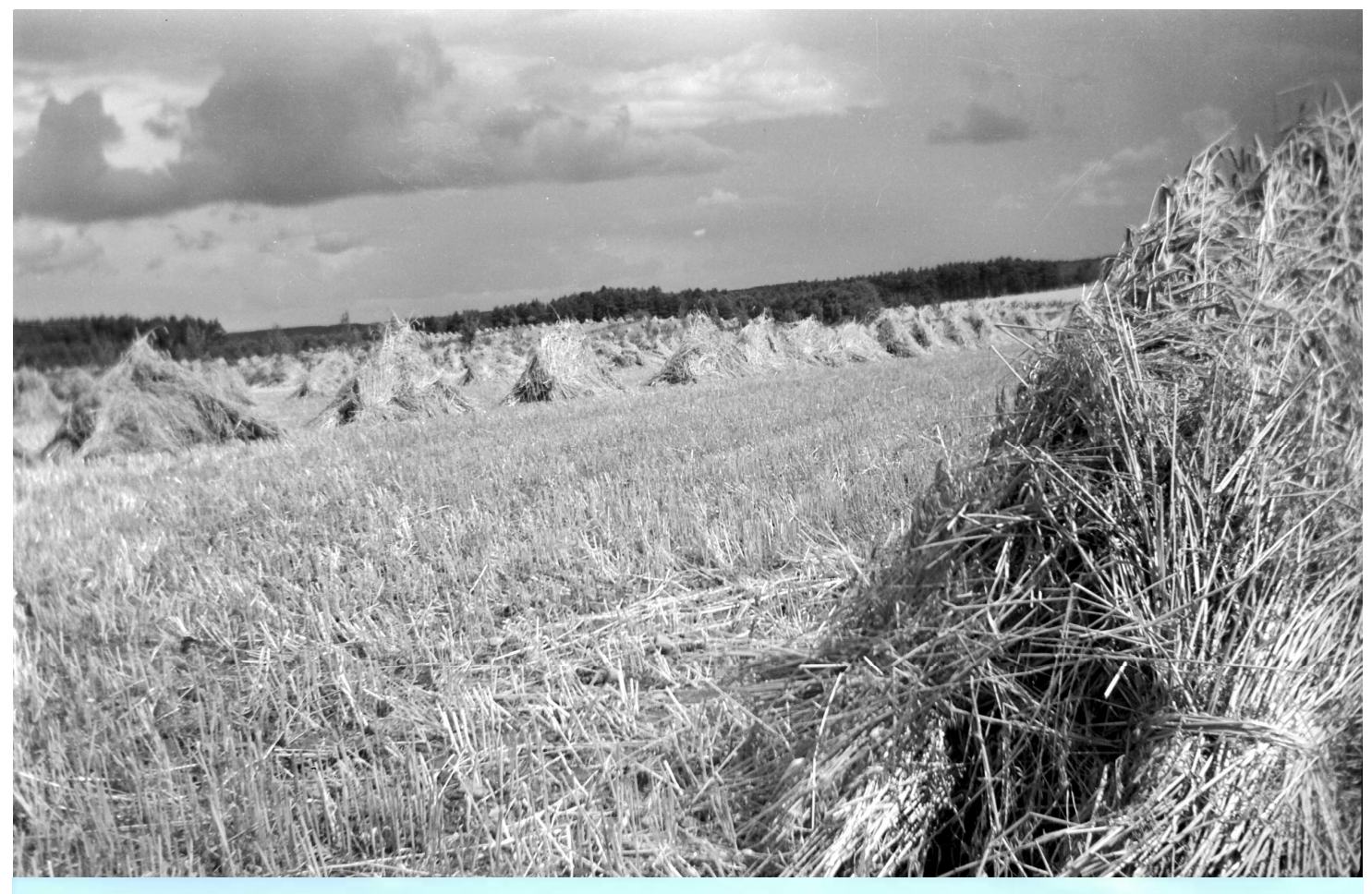

\section{Vom Wandel der Kulturlandschaft}

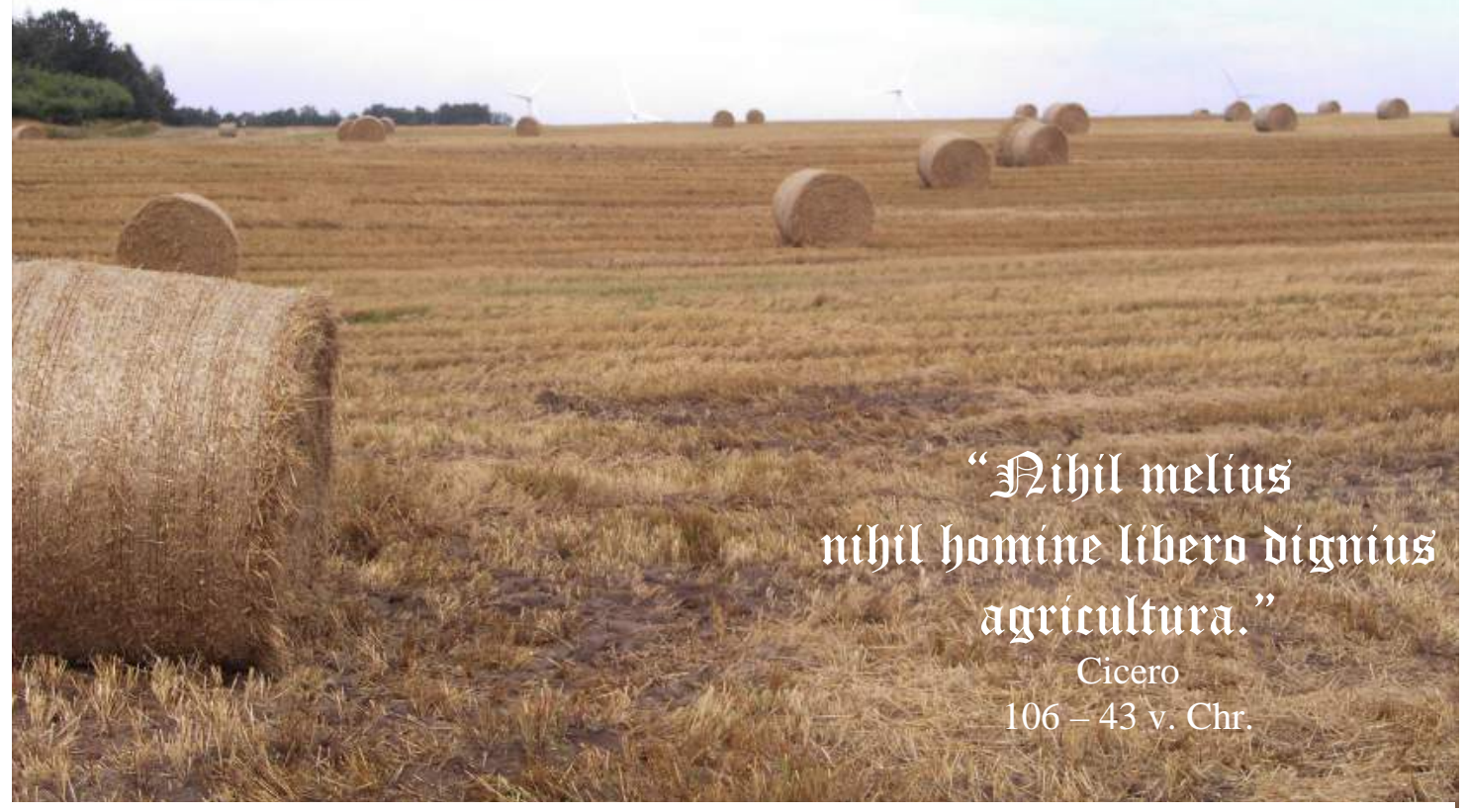

Aufnahmen: oben: um 1955; unten: 2011; A. Behr 


\section{Inhaltsverzeichnis}

$\begin{array}{lll}\text { Kapitel } 1 \text { Einleitung } & 8\end{array}$

Kap. 1.1 Gemarkung Lachendorf - Untersuchungsobjekt und Beispiel 8

$\begin{array}{ll}\text { Kap. } 1.2 & \text { Epochen der Landnutzung }\end{array}$

$\begin{array}{ll}\text { Kap. } 1.3 \quad \text { Landwirtschaft } & 13\end{array}$

$\begin{array}{ll}\text { Kap. } 1.4 \quad \text { Landschaft } & 14\end{array}$

$\begin{array}{ll}\text { Kap. } 1.5 & \text { Absichten und Ziele }\end{array}$

Kapitel 2 Der Naturraum 22

Kap. 2.1 Naturräumliche Struktur der "Südheide“ 22

2.1.1 Glazialmorphologische Grundstruktur des Raumes 22

2.1.2 Relief der Südheide $\quad 25$

2.1.3 Naturräumliche Gliederung der Mittleren Südheide 27

2.1.4 Die Lachter Geest $\quad 29$

2.1.5 Das Mittlere Allertal 31

2.1.6 Relief und Geologie des Lachendorfer Raumes 33

$\begin{array}{lll}\text { Kap. } 2.2 & \text { Hydrologie } & 37\end{array}$

2.2.1 Hydrologische Räume und orohydrographische Struktur 37

$\begin{array}{ll}\text { 2.2.2 Einzugsgebiet Südheide } & 37\end{array}$

$\begin{array}{ll}2.2 .3 \text { Lachte } & 38\end{array}$

$\begin{array}{lll}2.2 .4 \text { Aller } & 43\end{array}$

$\begin{array}{ll}2.2 .5 \text { Schwarzwasser } & 45\end{array}$

2.2.6 Schelprieth $\quad 47$

2.2.7 Grundwasser 48

Kap. 2.3 Böden 52

2.3.1 Böden und naturräumliche Gliederung 52

2.3.2 Bodenlandschaften und Bodentypen 52

$\begin{array}{lll}\text { Kap. 2.4 Klima - Witterung - Wetter } & 58\end{array}$

2.4.0 Vorbemerkung 58

2.4.1 Klima, Klimabezirke 58

2.4.2 Niederschläge in den Klimabezirken

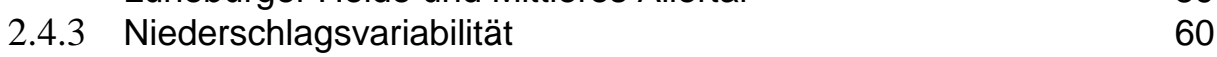

$\begin{array}{lll}\text { Kap.2.5 Standorte und Potenziale } & 68\end{array}$

2.5.1 Die Gemarkung Lachendorf im naturräumlichen Gefüge $\quad 68$

2.5.2 Standorte in der Gemarkung $\quad 69$

2.5.2.1 Geestplatten $\quad 70$

2.5.2.2 Allerheide - Flurbezeichnung auf dem Schwemmfächer 72

2.5.2.3 Allertal $\quad 75$

2.5.2.4 Kleine Moore $\quad 77$

2.5.2.5 Lachtetal $\quad 80$

2.5.2.6 Binnendünen $\quad 81$

2.5.3 Raumpotenziale 82

2.5.3.1 Naturpotenzial und Nutzungspotenzial 82

2.5.3.2 Natürliche Vegetation und allgemeine Bestandesgeschichte 82

2.5.4 Nutzungspotenzial 83

2.5.4.1 Wirtschaftliches Nutzungspotenzial $\quad 83$

2.5.4.2 Niederschlag und Nutzungspotenzial $\quad 84$

2.5.5. Wandel des Nutzungspotenzials 86 
Kap.3.1 Das Landschaftsbild um 1800 im zeitgenössischen Kartenbild 89

3.1.1 Gewässer $\quad 90$

3.1.2 Brüche und Moore $\quad 92$

3.1.3 Lachtetal 93

3.1.4 Geestplatten bzw. Grundmoränenplatten 94

$\begin{array}{ll}3.1 .5 \text { Wald } & 96\end{array}$

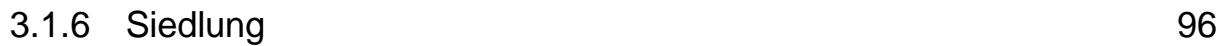

$\begin{array}{lll} & & 97 \\ \text { Kap. 3.2 } & \text { Das Landschaftsbild im Spiegel der Rezesse } & 98\end{array}$

3.2.1 Die allgemeine Verfassung der Flur 98

$\begin{array}{ll}\text { 3.2.2 Taxation der Landschaft } & 100\end{array}$

3.2.3 Das Landschaftsbild der privat genutzten Flächen

3.2.4 Das Landschaftsbild der Allerheide und angrenzender Reviere 103

3.2.5 Das Landschaftsbild in den Aller- und Trockenen Wiesen 106

$\begin{array}{ll}\text { Kap. 3.3 Naturraum - Landnutzung } & 107\end{array}$

$\begin{array}{lll}\text { Kap. 3.4 Landschaft und Wirtschaftsweise } & 109\end{array}$

3.4.1 Landschaft - Gewanne - Wölbäcker 109

3.4.2 Landschaft und Dreifelderwirtschaft 113

3.4.3 Landschaft - Gemeinheit/Allmende - Gemeinschaftsweide 114

3.4.4 Das System der Heidebauernwirtschaft 120

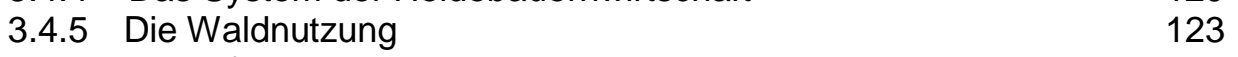

3.4.6 Bodenfruchtbarkeit und Nachhaltigkeit 124

3.4.7 Naturabhängigkeit statt Nachhaltigkeit 125

Kapitel 4 Das 19. Jahrhundert - Zeitalter der Agrarreformen 128

Kap. 4.1 Aufbruch in die Moderne: Fördernde und retardierende Aspekte 128

4.1.1 Gesellschaftliche Stellung der Landwirtschaft um $1800 \quad 128$

$\begin{array}{ll}\text { 4.1.2 Die Rückständigkeit der Heide } & 131\end{array}$

4.1.3 Die „benachteiligte“ Heide 133

4.1.4 Späte Reformen in der Südheide 134

Kap. 4.2 Agrarreformen im Lachendorfer Raum 136

4.2.1. Allgemeine Notwendigkeit der Reformen 136

4.2.2 Reformen in der Flur Lachendorfs $\quad 139$

4.2.2.1 Die Rezesse 139

4.2.2.2 Von der der gemeinsamen „Hut- und Weide“
zu getrennten Dorfgemarkungen

4.2.2.3 Von der Taxation und Vermessung zur
Spezialteilung und Verkoppelung

4.2.2.4 Ergebnis der Spezialteilung und Verkoppelung
der Feldmark Lachendorf

4.2.3 Entfrettung und Verkoppelung der Aller- und Trockenen Wiesen 166

4.2.4 Gesamtergebnis der Teilungen und Verkoppelungen für die Lachendorfer Höfe 171

4.2.5 Veränderungen in der Landschaft durch die Reformen 174

4.2.6 Feldmark, Gemarkung und Naturraum 175

Kap. 4.3 Niedergang und Überwindung der Heidebauernwirtschaft 177

4.3.1 Ökologische Probleme 177

4.3.2 Wirtschaftliche Probleme 181

4.3.2.1 Reproduktive und produktive Arbeit in der Heidelandschaft $\quad 181$

4.3.2.2 Wirtschaftliche Konkurrenz für die Heidebauernwirtschaft 182

Kap. 4.4 Landwirtschaft und Landschaft in der 2. Hälfte des 19. Jahrhunderts 183

4.4.1 Neue Möglichkeiten für die Landwirtschaft 183 
4.4.1.1 Neue Bodennutzung 184

4.4.1.2 Bildung 184

4.4.1.3 Reform der Düngung 185

4.4.2 Landschaft nach den Agrarreformen

4.4.2.1 Die Höfe $\quad 187$

4.4.2.2 Ackerland $\quad 189$

4.4.2.3 Grünland 190

4.4.2.4 Allerheide - Heide - Wald 193

4.4.2.5 Neue Kulturlandschaft um $1900 \quad 197$

$\begin{array}{ll}\text { Kapitel } 5 \text { Kulturlandschaft im 20. Jahrhundert } & 198\end{array}$

Kap. 5.1 Ausbau und Stagnation in der 1. Hälfte des 20. Jahrhunderts 198

Kap. 5.2 Landwirtschaft und Landschaft Mitte der 60er Jahre 199

5.2.1 Gestalter der Kulturlandschaft 199

5.2.2 Wirtschaftssystem und Landnutzung der Betriebe (1965) 201

5.2.3 Grünland um $1966 \quad 208$

Kap.5.3 Prägung der Kulturlandschaft durch Reformen 211

$\begin{array}{lll}\text { Kap. 5.4 Strukturwandel und Kulturlandschaft } & 212\end{array}$

5.4.1 Stauwiesen am Schwarzwasser 212

5.4.2 Vom Strukturwandel zum Landschaftswandel 216

$\begin{array}{lll}\text { Kap. 5.5 Siedlung und Kulturlandschaft } & 229\end{array}$

Kapitel 6 Wirtschaftsystem, Landnutzung und Landschaft 240

Kap. 6.1 Von Hofstellen zu landwirtschaftlichen Betrieben 240

Kap. 6.2 Prognose und Wirklichkeit 243

Kap. 6.3 Wirtschaftssysteme und Kulturlandschaft 245

6.3.1 Geschlossene Hauswirtschaft 246

6.3.2 Familienbäuerliche Mischwirtschaft 248

6.3.3 Spezialisierte Agrarwirtschaft 250

6.3.3.1 „Wachse oder weiche“ 250

6.3.3.2 Spezialisierung und Kulturlandschaft - Beispiel Mais 255

$\begin{array}{lll}\text { Kap. 6.4 } & \text { Von der Kulturlandschaft der bäuerlichen Mischwirtschaft } & \\ & \text { zur Kulturlandschaft der spezialisierten Agrarwirtschaft. } & 258\end{array}$

Kapitel 7 Natur - Nutzung - Kulturlandschaft 263

$\begin{array}{lll}\text { Kap. 7.1 Naturräume und Kulturlandschaft } & 263\end{array}$

Kap. 7.2 Landnutzung und Artenvielfalt 264

7.2.1 Von den Heiden zum Wald 265

7.2.2 Wandel auf dem Acker 266

7.2.3 Veränderungen im Grünland 267

7.2.4 Wandel durch Spezialisierte Agrarwirtschaft 269

7.2.5 Reinkultur und Artenvielfalt $\quad 271$

7.2.6 Naturräumliche Einheiten und Artenvielfalt 272

$\begin{array}{lll}\text { Kap. 7.3 Natur-, Arten-, Landschaftsschutz } & 272\end{array}$

$\begin{array}{lll}\text { Kap. 7.4 Zukunft der Lachendorfer Kulturlandschaft } & 277\end{array}$

$\begin{array}{ll}\text { Kapitel } 8 \text { Zusammenfassung } & 284\end{array}$

$\begin{array}{ll}\text { Materialverzeichnis } & 288\end{array}$

Literaturverzeichnis 293

Lebenslauf $\quad 298$

$\begin{array}{ll}\text { Anhang } & 300\end{array}$ 


\section{Kapitel 1 Einleitung}

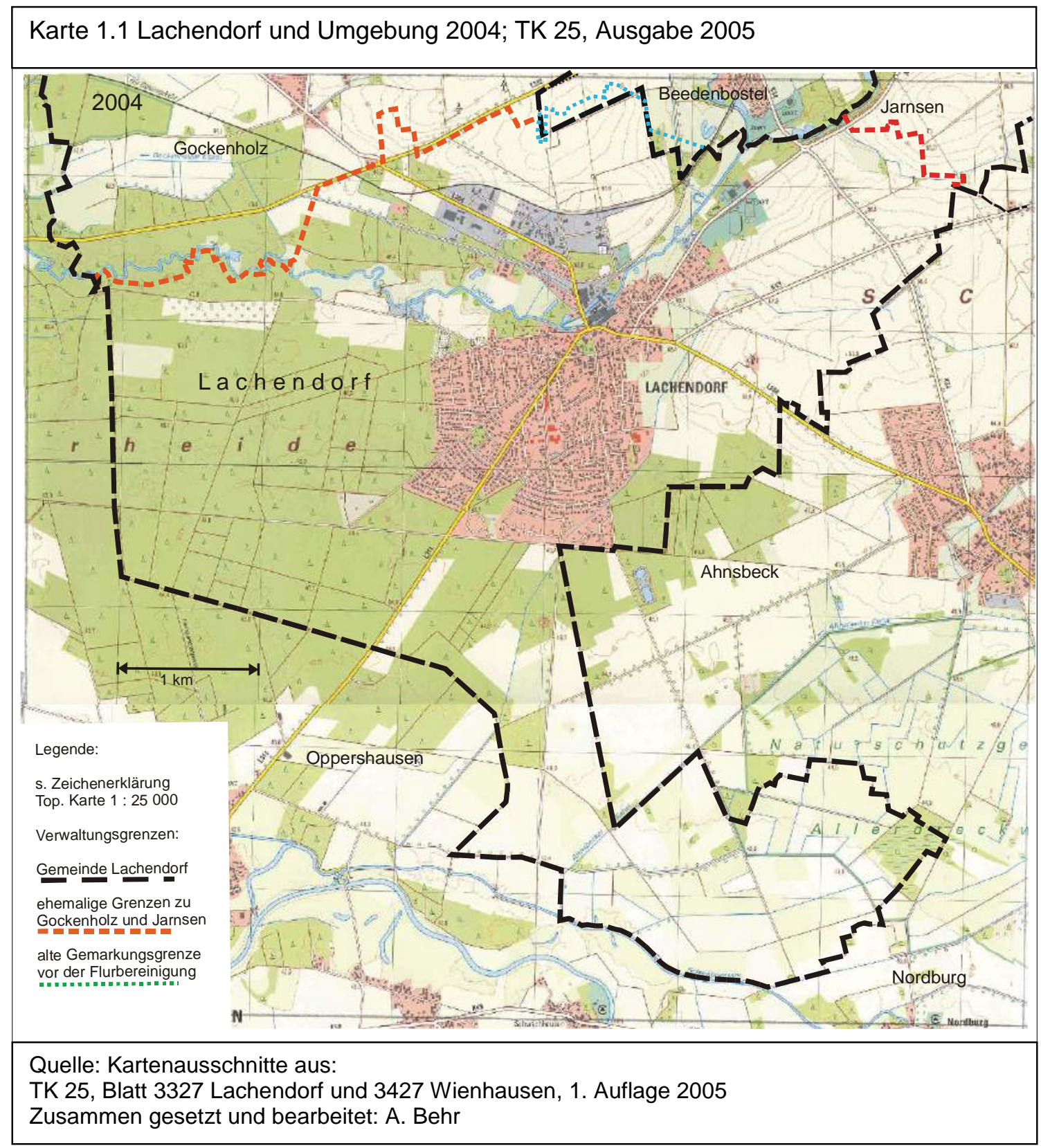

\subsection{Gemarkung Lachendorf - Untersuchungsobjekt und Beispiel}

Die Gemarkung des Ortes Lachendorf kam 1965/66 in den Blick des Verfassers. Die seinerzeit durchgeführte Untersuchung des Naturraumes und die Momentaufnahme der örtlichen Agrarwirtschaft wurden Grundlage einer schriftlichen Hausarbeit ${ }^{1}$ für das 1. Staatsexamen für das Höhere Lehramt.

Die Gemarkung bot ein vielfältiges, abwechslungsreiches und reich strukturiertes Untersuchungsgebiet, weil sie in verschiedenen Naturräumen mit jeweils differenzierter naturräumlicher Struktur liegt und neben Ackerland auch einen beträchtlichen Wald- und Grünlandanteil aufwies. Auch der Ort erwies sich als ein interessantes Untersuchungsobjekt, weil es wenige

\footnotetext{
${ }^{1}$ Thema: Die agrargeographische Struktur der Lachendorfer Flur; Prüfer: Prof. Dr. Albert Kolb, Universität Hamburg, SS 1967
} 
Bauerndörfer mit einem sehr alten Industriebetrieb gibt und weil das Dorf sich bereits im Wandel vom „Dorf mit Fabrik“ zu einem regionalen Grundzentrum befand.

Die Landwirtschaft wurde Mitte der 1960er Jahre noch von einer größeren Zahl echter bäuerlicher Familienbetriebe im Vollerwerb und einer ganzen Reihe von Kleinbetrieben im Nebenerwerb betrieben. Die Betriebsstrukturen der Vollerwerbsbetriebe differierten zwar in der Größe erheblich, nicht aber in der Wirtschaftsweise, der Gemischtwirtschaft mit Ackerbau und Veredelungswirtschaft auf der Grundlage verschiedener Nutztiere.

In den folgenden Jahren blieben die Gemarkung, der Ort $^{1}$ und das Thema immer im Blickfeld durch mehrere Nutzungskartierungen und Kontakte mit Landwirten. Schließlich wurden die damaligen Studien durch neue Materialien und Datenerhebungen vor Ort ergänzt und vertieft sowie der Zeithorizont der Betrachtung erheblich rückwärts bis ins 18. Jahrhundert erweitert. Zweifellos hat die Arbeit monographische Züge, sie versucht aber stets, die am Beispiel aufgezeigten Entwicklungen in einen größeren wirtschaftlichen, gesellschaftlichen und politischen Gesamtzusammenhang zu stellen. Denn Lachendorf ist zwar einerseits einzigartig, so wie jeder willkürliche Ausschnitt der Erdoberfläche, aber andererseits auch beispielhaft für die Entwicklung der Landwirtschaft und der von ihr geprägten Kulturlandschaft.

\subsection{Epochen der Landnutzung}

Seit dem Neolithikum gestalten sesshafte Bauern durch ihre Landnutzung als Ackerbau mit Nutztierhaltung die vorgefundene Naturlandschaft, die damit zur Kulturlandschaft wurde.

Ziel jeder Landnutzung war und ist zu allen Zeiten die Erzeugung von Nahrungsmitteln für Mensch und Nutztier durch möglichst gute und vor allem gesicherte Ernten auf dem Acker und ausreichend Futter für das Vieh.

Permanenter Ackerbau ist - wie die Natur auch - abhängig von den Wachstumsfaktoren ${ }^{2}$, die am jeweiligen Standort gegeben sind. Der Landnutzung betreibende Mensch hat diese Faktoren teils von Beginn an beeinflusst oder als unabänderlich - von Gott oder der Natur gegeben - hingenommen, je nach Erfahrung, Kenntnisstand und technischen Möglichkeiten. Die Beeinflussung von Wachstumsfaktoren ${ }^{3}$ geschah im Laufe der Agrargeschichte in sehr unterschiedlicher Intensität, mit unterschiedlichem Erfolg und auch unabhängig von genauen Kenntnissen über bestimmte Wachstumsfaktoren.

Der biotische Wachstumsfaktor „Erbanlagen“ wurde schon sehr früh durch Züchtung von Kulturpflanzen und Haustieren sehr erfolgreich manipuliert, völlig ohne genaue Kenntnisse über Vererbung und Genetik. Auch der Eingriff in den Wachstumsfaktor "Schädlinge“ bzw. „unerwünschte Nahrungskonkurrenten“ wurde frühzeitig aufgenommen, blieb aber für den Landwirt ein Dauerthema ohne abschließenden Erfolg, der naturgesetzlich auch durch den Einsatz modernster Mittel und Technik nicht möglich ist.

Der Klimafaktor, hauptsächlich wirksam über Temperatur und Licht und abhängig von der zonalen und hypsometrischen Lage eines Standortes, galt bis in die Neuzeit als kaum veränderbar. Erst durch den Einsatz von Gewächshäusern und technisch erzeugter Energie werden Licht und vor allem Temperatur großflächig für die Agrarproduktion beeinflusst.

Die beiden Hauptwachstumsfaktoren Wasser und Boden stellen den Landbau treibenden Menschen vor sehr unterschiedliche Probleme:

Der Faktor Wasser ist hinsichtlich der Verfügbarkeit, dem Wasserdargebot, klimatisch bestimmt. Hinsichtlich der Verfügbarkeit für Pflanzenwachstum spielt aber der Boden mit seiner Perkolation und Speicherkapazität eine entscheidende Rolle.

Wassermangel kann gut durch technische Maßnahmen ausgeglichen werden. Daher haben Techniken zur Beschaffung und Verteilung von Wasser eine sehr lange Tradition und reichen von der Archimedischen Schraube bis zur Tiefbohrung; von den Foggaras oder Qanaten bis zum Great Manmade River, von der Überschwemmungsbewässerung zur Kreisberegnung ${ }^{4}$

\footnotetext{
${ }^{1}$ Bis 1990 war Lachendorf auch der Wohnort des Verfassers.

${ }^{2}$ s. Finck, A.; Pflanzenernährung in Stichworten, a.a.O., S. $15 \mathrm{ff}$

${ }^{3}$ Auf sog. konstante Wachstumsfaktoren wie z.B. Gravitation oder Strahlung wird hier nicht eingegangen.

${ }^{4}$ Fachbegriff: center-pivot irrigation
} 
oder von der Furchen- zur Tröpfchenbewässerung. Bewässerung wird nicht nur in ariden Gebieten als Voraussetzung von Ackerbau eingesetzt, auch in humiden Gebieten zur Unterstützung des Wachstums sowie zur Erhöhung und Sicherung der Ernte.

Bewässerungslandwirtschaft gehört zu den ältesten und effizientesten Agrarmethoden bei der Umgestaltung einer Natur- in eine Kulturlandschaft. Bewässerungslandwirtschaft hat raffinierte Systeme zur Ausnutzung der natürlichen Gegebenheiten und großartige Bauwerke zur Realisierung dieser Wirtschaftsweise hervorgebracht. Bewässerungslandwirtschaft war die Grundlage früher Hochkulturen ${ }^{1}$ und ist bis heute ein wichtiger Faktor in der weltweiten Agrarproduktion.

Im Untersuchungsgebiet dienten Stauwiesen zur Verbesserung der Futterbasis und Beregnungsanlagen werden zum Ausgleich der Niederschlagsvariabilität eingesetzt.

Bei Bodenfruchtbarkeit und Versorgung mit Nährstoffen haben sich die Probleme im Laufe der Entwicklung des Ackerbaus wesentlich schwieriger gestaltet: Zum einen, weil bis ins 19 . Jahrhundert die genauen Kenntnisse über das Pflanzenwachstum fehlten, und zum anderen, weil man Nährstoffe nicht wie Wasser zur Verfügung hatte bzw. transportieren konnte. Aus Erfahrung war nur bekannt, dass Mist und Fäkalien düngende Wirkung haben. Daraus mag sich die falsche Vorstellung entwickelt haben, dass organische Substanz direkt düngt. Die Prozesse der Humifizierung und Mineralisation sowie der Speicherkapazität von Boden und der Aufnahme von Nährelementen über Ionenaustausch wurden erst mit der naturwissenschaftlichen Forschung der Neuzeit aufgeklärt.

Aus Erfahrung war Bauern unter allen klimatischen Bedingungen bekannt, dass der Auftrag von Biomasse auf den Acker zum Wachstum und damit zur Erntesicherung beiträgt. Aus dieser vorwissenschaftlichen Grunderkenntnis haben sich sehr unterschiedliche, im Prinzip aber übereinstimmende Düngemethoden entwickelt. Hier sei nur auf das für Afrika beschriebene System "Chitimene“2 hingewiesen, bei dem Sträucher, Äste und Baumrinden einem Gebiet entnommen und zum Acker zur dortigen Verbrennung transportiert werden. Die Übereinstimmung bzgl. Bodendüngung zwischen der afrikanischen Chitimene und der Plaggendüngung in der Heide ist offensichtlich.

Über Jahrtausende hatten Bauern grundsätzlich nur die Möglichkeit, sich Böden mit hoher natürlicher Fruchtbarkeit zu suchen und diese durch Aufbringen von organischem Material möglichst lange zu erhalten und bei Erschöpfung des Bodens dauerhaft oder vorübergehend das Feld und ggf. auch den Siedlungsplatz zu wechseln.

Die Beschaffung des zur Düngung notwendigen organischen Materials kann durch Entnahme von Flächen außerhalb des Ackerlandes oder durch Brachezeiten auf dem Ackerland selbst vorgenommen werden. Bei externer Beschaffung wird auf den dazu genutzten Flächen Raubbau betrieben, bei der Brache werden die Reserven im Boden langfristig aufgebraucht.

Landnutzung bedeutet immer Nährstoffentzug aus dem Boden, der grundsätzlich nicht vollständig ausgeglichen werden kann. Auch eine Landnutzung, die auf Nachhaltigkeit ausgerichtet ist, kann aus sich heraus keine dauerhafte Stabilität schaffen, weil dies dem ökologischen Prinzip der Veränderung zuwider läuft ${ }^{3}$.

Scheinbare Ausnahmen vom Problem der Stabilität in Agrarlandschaften gab und gibt es nur dort, wo durch natürlich zufließendes Wasser auch ständig neue Nährelemente zugeführt werden. Dies ist nur an Flüssen mit schwebstoff- und mineralhaltigem Flusswasser und an jungen Vulkanen der Fall. Daher sind diese Gebiete auch die ältesten und am dichtesten besiedelten Ackerbaugebiete der Welt. In diesen Fällen stabilisiert die Natur selbst durch ständige Veränderung und Stoffflüsse die Fruchtbarkeit des vom Menschen genutzten Kulturlandes, der mit dauerhafter Pflege dafür sorgen muss, dass die natürlich ablaufenden

\footnotetext{
${ }_{1}^{1}$ Prof. Dr. A. Kolb sprach von „Hydraulischen Kulturen“, Geogr. Institut der Universität Hamburg

${ }^{2}$ Manshard, W.; Einführung in die Agrargeographie der Tropen, a.a.O., S. 89

${ }^{3}$ vergl. H. Küster; Das ist Ökologie, a.a.O., S. $90 \mathrm{ff}$
} 
Prozesse auf dem Kulturland im Sinne des Nutzungszweckes reguliert und gesteuert werden.

Überall dort, wo die Natur nicht diese Vorteile der „Selbstdüngung“ der Böden bot, mussten die Bauern versuchen, den durch permanenten Ackerbau unvermeidlichen Nährstoffverlust soweit irgend möglich auszugleichen oder wenigstens aufzuhalten.

Vormoderne, vorwissenschaftliche Ackerbaumethoden, die das notwendige Ziel der Stabilität der Bodenfruchtbarkeit und damit der bäuerlichen Kulturlandschaft verfolgen, werden - je nach Standpunkt - als primitiv oder als „im Einklang mit der Natur“ bezeichnet. Beide Sichtweisen sind aber falsch.

Vorwissenschaftliche, auf Dauernutzung angelegte Ackerbaumethoden haben aufgrund langer Erfahrungen über viele Generationen ein System entwickelt, das die natürlichen Standortbedingungen mit den zur Verfügung stehenden Kenntnissen und technischen Mitteln optimal nutzt. Solche hoch angepassten Nutzungssysteme sind keineswegs primitiv.

Die Sichtweise, dass vorwissenschaftliche, „einfache“ Landnutzungssysteme in besonderer Weise „im Einklang mit der Natur" stehen, verkennt, dass Ackerbau immer das ökologisch unrealistische Ziel hat, mit dauerhafter Bodenfruchtbarkeit eine stabile Agrarlandschaft zu schaffen, die der Mensch aber ständig gegen die auf Veränderung ausgerichtete Natur verteidigen muss. Die Überhöhung alter, einfacher und an die Standortfaktoren eng angepasster Landnutzungsformen als besonders naturverbunden und ökologisch wertvoll beruht auf einer falschen ökologischen Beurteilung von Landnutzung bzw. einer romantischen Verklärung ehemaliger Landnutzungsformen anhand der dazu gehörigen Kulturlandschaft.

In der mitteleuropäischen Agrarwirtschaft gibt es zwei große Epochen: Die Epoche der Erfahrungslandwirtschaft und die Epoche der wissenschaftlich begründeten Landnutzung, zwei Epochen, die sich hinsichtlich der Wirtschaftsweise, insbesondere in der Gestaltung der Bodenfruchtbarkeit, fundamental unterscheiden. Während die Erfahrungslandwirtschaft grundsätzlich von der wissenschaftlich begründeten Landwirtschaft überwunden und abgelöst wurde, ging letztere ohne Aufgabe der wissenschaftlichen Grundlegung in eine neue Epoche der Landwirtschaft über, nämlich in die Epoche der totalen Anwendung modernster Technik und Forschung.

Die Epoche der Erfahrungslandwirtschaft beruhte auf der Weitergabe des notwendigen und vorhandenen Wissens von einer Generation zur nächsten, weitgehend ohne Einfluss von außen. Ein französischer Wissenschaftler berichtet, dies noch Mitte des 19. Jahrhunderts in der Südheide beobachtet ${ }^{1} \mathrm{zu}$ haben. Die etwas verklärt wirkende Darstellung bringt das Prinzip aber gut zur Geltung:

„Der Erbe verkörpert in höchstem Maße alle Familientraditionen: Er hat diese zunächst in seiner Kindheit selbst empfangen, aus dem Mund seines Vaters, genau wie seine Geschwister. Diese werden jedoch eines Tages das Haus verlassen, während der Erbe beim Vater bleibt, unter dessen Aufsicht arbeitet, von ihm die traditionellen Methoden der Landwirtschaft erlernt; das zukünftige Familienoberhaupt hat also im Vater und Lehrmeister denselben Vorfahren. So ist dies der Grund, weshalb sich über Jahrhunderte hinweg nichts auf diesem Bauernhof verändert hat; eine Generation löst die nächste ab, ohne dabei durch den plötzlichen Tod des Vaters all den furchteinflößenden Gefahren ausgesetzt zu sein, mit denen instabile Familien konfrontiert sind. Der Übergang von Generation zu Generation ist hier fließend - unbemerkt folgt der Sohn auf den Vater. ${ }^{2}$

Der Übergang zwischen den beiden grundverschiedenen Epochen war insgesamt gleitend. Er begann in Mitteleuropa im 18. Jahrhundert und Mitte des 19. Jahrhunderts hatten wissenschaftliche Erkenntnisse die landwirtschaftliche Wirtschaftsweise soweit und so grundlegend durchdrungen, dass auch eine neue Kulturlandschaft entstand. Die ehemalige Kulturland-

\footnotetext{
${ }^{1}$ s. nächste Fußnote; Die Beobachtung von Demolins stammt aus dem Jahr 1867, dem Jahr seines Besuches in der Südheide.

${ }^{2}$ aus: E. Demolins, Geschlossene Hauswirtschaft (La petite culture en famille-souche), Paris 1888; Übersetzung aus dem Französischen: Dipl. Übersetzerin Martina Behr; zitiert aus: A. Behr (Hg); Der Lutterhof bei Hermannsburg; Verlag Ludwig-Harms-Haus, 2006, S. 41
} 
schaft war immer mehr zur Reliktlandschaft geworden, wurde fälschlicherweise manchenorts als Naturlandschaft unter Naturschutz gestellt.

Die großen Agrarreformen des 19. Jahrhunderts bilden hinsichtlich der Agrarverfassung und der Flurordnung für alle landwirtschaftlichen Betriebe und damit auch für Gemarkungen das Ende der alten und den Anfang der neuen Epoche.

Die neue Wirtschaftsweise mit Fruchtwechsel, Grün- und Mineraldüngung, neuen Kulturpflanzen sowie Pflanzen- und Tierzucht führte zu einem ungeahnten Aufschwung der Landwirtschaft mit ständig steigenden Flächenerträgen und Tierleistungen. Diese Leistungssteigerung musste sich auch auf die Kulturlandschaft auswirken.

In der Epoche der wissenschaftlich begründeten Wirtschaftsweise und Landnutzung begann mit der Motorisierung der Einzug der Technik in die landwirtschaftliche Arbeitswelt. Zunächst wurden die schweren Arbeiten des Pflügens und der umfangreichen Transporte motorisiert. Aber allmählich wurden für immer mehr Arbeiten auf dem Acker und dem Grünland neue und leistungsfähigere Geräte und Maschinen entwickelt, die zunächst die schwere Landarbeit enorm erleichterten, dann die Arbeitstiere überflüssig machten und schließlich auch die Handarbeit fast völlig verdrängten. Dieser Prozess der Technisierung der landwirtschaftlichen Tätigkeiten begann in der Außenwirtschaft und erfasste mit einer zeitlichen Verzögerung dann auch die Binnenwirtschaft und damit auch alle Formen der Nutztierhaltung.

Dieser Prozess, der in den Betrieben ablief, führte ganz langsam in der 2. Hälfte des 20. Jahrhunderts in eine neue Epoche der Landwirtschaft, nämlich die Epoche der Vollmechanisierung und totalen Technisierung nahezu fast aller Arbeitsabläufe.

Dies lässt sich exemplarisch am Anbau der Zuckerrübe demonstrieren: Während der Getreideanbau beim Säen mit der Drillmaschine sowie bei der Ernte durch den Selbstbinder und die Dreschmaschine schon weitgehend durch Maschinen erledigt wurde, war der Zuckerrübenanbau bis in die 1950er und 1960er Jahre noch sehr stark von Hand- und Spannarbeit geprägt: Das im Frühjahr notwendige Pflügen wurde ab den 1950e Jahren durchweg mit dem Traktor und einem meist zweischarigen Pflug erledigt. Das Säen übernahm bereits die Drillmaschine, aber aus den Samenknäueln wuchsen ganze Pflanzenbüschel, die mit der Hacke und von Hand vereinzelt werden mussten. Während der Wachstumszeit wurden Unkräuter per Hackgerät und Handhacke bekämpft. Zur Ernte kam nach der Köpfschippe der von Pferden gezogene Köpfschlitten zum Einsatz, um die Rübe vom Blatt zu befreien. Das Blatt wurde per Hand aufgeladen, abgeladen und siliert. Die Rüben holte ein spezieller Rübenrodepflug aus der Erde. Von dort wurden die Rüben per Hand verladen, zunächst auf dem Feld auf den Ackerwagen, dann auf den Eisenbahnwaggon oder den LKW. Allein der große Arbeitsaufwand begrenzte die mögliche Anbaufläche für Rüben in den Betrieben. Heute ist die gesamte Rübenproduktion von der Aussaat über Pflege bis zur Ernte und zum Verladen vollmechanisiert. Auf das Pflügen wird aus Kostengründen zunehmend verzichtet, seit die Unkrautbekämpfung mittels chemischer Mittel möglich ist. Die Anbaufläche für Rüben ist also nicht mehr arbeitskräftemäßig begrenzt.

Es gibt keinen Grund, der schweren körperlichen Landarbeit der Vergangenheit sentimental nachzutrauern. Bezüglich der Arbeit auf dem Feld, der Wiese und im Stall war es keineswegs die "gute alte Zeit“. „Die Mähmaschine war eine Wohltat, schon allein in menschlicher Hinsicht. ... Es wird immer erzählt, wie schön es früher mit all den Pferden war, aber ... es war überhaupt nicht schön, schon gar nicht für die Pferde. ... Jetzt sitzt man warm und trocken auf dem Trecker und hat das Radio an; es lebe der Fortschritt." ${ }^{1}$

Für die Binnenwirtschaft lässt sich der Prozess der Technisierung der Arbeitsabläufe am besten an der Milchviehhaltung darlegen:

Bäuerliche Familienbetriebe hatten bis in die 1950er bzw. 1960er Jahre selten mehr als 6 - 10 Milchkühe, weil für das Melken, Füttern und Ausmisten dann eine Arbeitskraft bereits fast vollständig ausgelastet war. Größere Betriebe hatten eine volle Fremdarbeitskraft, meist als Schweitzer bezeichnet, beschäftigt, der zusammen mit seiner Familie 20 - 25 Milchkühe einschließlich Nachzucht hinsichtlich Melken, Füttern und Misten betreute. Ein Bauer „war 1755 mit jeder Kuh vermutlich über 300 Stunden pro Jahr beschäftigt; nicht anders als die meisten Bauern kurz nach dem Krieg... Durch den Einsatz der Melkmaschine, des Traktors und der Heupresse sparte der Bauer aber schon etwa 70 Stunden pro Kuh und Jahr. Ende der fünfziger Jahre konnte ein Bauer ohne fremde Hilfe daher etwa 14 Kühe

\footnotetext{
${ }^{1}$ G. Mak, Wie Gott verschwand aus Jorwerd, a.a.O., S. 90
} 
halten. ... Vierzig Jahre nach dem Aufkommen der Melkmaschine konnte ein einziger Bauer 80 oder auch 100 Kühe melken, ....,.'

In der Epoche der technikbasierten, marktorientierten und subventionsabhängigen Agrarwirtschaft veränderte sich die landwirtschaftliche Wirtschaftsweise im Grunde nur wenig, aber der gegenwärtig noch nicht abgeschlossene Strukturwandel betrifft die Betriebsgrößen, die Aufspaltung in reine Ackerbau- und meist nur auf ein Nutztier spezialisierte Veredelungsbetriebe. Der Strukturwandel in der Landwirtschaft ist begleitet von einem grundlegenden Wandel des Dorfes, der mit dem Begriff der Verstädterung nur unzureichend erfasst wird.

„In den fünfziger Jahren ging die echte, tiefe Stille von ... verloren. ... Wenn man frühmorgens ein Pferd einspannte, dann lag so eine ruhige Stimmung in der Luft. ... Mit einem Pferd hörte man alles, die Vögel, das Vieh, die Geräusche des Dorfes.... Ebenso subtil veränderten sich seit den sechziger Jahren die Farben des Dorfes. Die gelben Heuhaufen der kleinen Bauern verschwanden. Unbemerkt wurde die bunte Sommerszenerie der Heuwagen und der heuenden Familien zu einem Teil der Vergangenheit. ... Nach den Geräuschen und den Farben begannen sich schließlich auch die Gerüche rings um ... zu verändern. Früher hatte der Dung einen warmen Geruch - häufig gar nicht unangenehm. Aber die Jauche, die seit den siebziger Jahren aus den Liegeboxställen kam, roch scharf nach dem Kraftfutter, mit dem die Produktion der Kühe gesteigert wurde, säuerlich nach dem Spülwasser, das hinein geraten war, ordinär nach den Nachgeburten, die durch die Betonbalken getreten worden waren, und manchmal konnte es um ... ganz schön stinken. ${ }^{2}$

Das Dorf als Verkörperung des bäuerlich geprägten Landlebens hat sich nicht nur nach Funktion und Grundriss, sondern auch gesellschaftlich und soziologisch bis hin zum Verschwinden alter bäuerlicher Familienstrukturen und der Stellung des Bauernstandes in den Dörfern gewandelt. Auch dieser Prozess kann nicht ohne Auswirkungen auf die Kulturlandschaft sein.

Während der erste Epochenwechsel sich über die veränderte Wirtschaftsweise vor allem auf das Bild der Kulturlandschaft auswirkte, veränderte der zweite Epochenwechsel vor allem die Betriebe, die Betriebsstrukturen und dann auch die Dörfer ${ }^{3}$, aber zunächst weniger bzw. nur punktuell die Agrarlandschaft außerhalb der Siedlungen.

\subsection{Landwirtschaft}

Der Zugang zur Landwirtschaft eines bestimmten Gebietes ist bei Vorhandensein klarer Besitzverhältnisse und guter Verwaltungsstruktur leicht möglich, weil es dann zu den landwirtschaftlichen Betrieben über deren Landnutzung und der jeweiligen Betriebsstruktur umfangreiche und verlässliche Daten gibt, die von den Kommunen für das Statistische Landesamt und von der Landwirtschaftskammer erhoben wurden. Bei der Nutzung statistischer Daten auf Gemeindeebene hat sich im konkreten Fall eine Schwierigkeit ergeben: Durch die Gebietsreform 1972 wurden die Nachbarorte Gockenholz, Jarnsen und Bunkenburg in die Gemeinde Lachendorf integriert und die bis dahin eigenständigen Gemarkungen zusammengefasst. Statistische Daten zur Landnutzung haben vor und nach 1972 also nicht denselben räumlichen Bezug, sind daher nicht direkt vergleichbar.

Im Rahmen der Erfassung der jeweiligen Betriebsflächen für die Berechnung der Agrarsubventionen durch die Landwirtschaftkammer gibt es für jeden Betrieb genaueste jährliche Angaben zu den Flächen, deren Lage in der Flur und deren Nutzung. Da sich diese Daten jeweils auf den Betrieb beziehen, ist die Zuordnung zum Standort des Betriebes gegeben.

\footnotetext{
${ }^{1}$ G. Mak, ebenda, S. 93; Die Daten beziehen sich auf Friesland in den Niederlanden, gelten aber mindestens auch für Norddeutschland in gleicher Weise.

${ }^{2}$ G. Mak; ebenda, S. 96 ff; Der Text bezieht sich auf das friesische Dorf Jorwerd, dessen Name im Zitat vom Verfasser absichtlich ausgelassen wurde, weil die Beschreibung auch für viele andere Dörfer gilt.

${ }^{3}$ Der Prozess der Veränderung des Dorfes wird eindrücklich von Geert Mak am Beispiel des Dorfes Jorwerd in Friesland in den Niederlanden beschrieben. Das Beispiel steht - wie es im Untertitel richtig heißt - für das Verschwinden des bäuerlich geprägten Dorfes in ganz Europa. G. Mak; Wie Gott verschwand aus Jorwerd, Der Untergang des Dorfes in Europa, btb-Verlag, München 2007
} 
Historische Daten stehen in guter Qualität in den Akten zu den Rezessen der Agrarreformen des 19. Jahrhunderts zur Verfügung.

Die Datenbeschaffung für die landwirtschaftlichen Betriebe ist also problemlos, insbesondere dann, wenn auch noch Daten zur Verfügung stehen, die durch schriftliche und mündliche Befragungen bei den Betriebsleitern direkt vor Ort erhoben werden konnten.

Eine detaillierte Analyse der landwirtschaftlichen Betriebe nach Betriebstyp und Bodennutzungssystem wurde aus zwei Gründen nur ansatzweise vorgenommen: Die Untersuchung zielt nicht auf die einzelnen Betriebe, sondern auf die Wirkung der Betriebe insgesamt in der Kulturlandschaft. Zum anderen ist die Anzahl der Betriebe so klein, dass nur die Unterscheidung zwischen drei grundsätzlich verschiedenen Betriebstypen Sinn macht: Betriebe mit Mischwirtschaft, also mit Ackerbau und Nutztierhaltung, reine Ackerbaubetriebe und Veredelungsbetriebe.

Bei einer Analyse, die sich auf genau eine Gemarkung, nämlich Lachendorf, konzentriert bzw. beschränkt, tritt aber ein Zuordnungsproblem auf: Die Fläche der Gemarkung ist nicht kongruent mit den Nutzflächen aller landwirtschaftlicher Betriebe des Ortes. Die Betriebsflächen der örtlichen Betriebe bilden auch keine zusammenhängende Fläche. Es gibt auswärtige Landnutzer und die Betriebe des Ortes bewirtschaften Flächen außerhalb der eigenen Gemarkung. Mit zunehmender Betriebsgröße hat diese Tendenz in den letzten Jahrzehnten stark zugenommen. Gerade für reine Ackerbaubetriebe spielt die Entfernung zwischen Betriebshof und Nutzfläche nur noch eine untergeordnete Rolle.

Die Inkongruenz zwischen Gemarkungsfläche und Summe aller Betriebsflächen muss im Rahmen dieser Arbeit hingenommen werden. Die Auswirkung auf die zentrale Fragestellung nach dem Verhältnis von Landnutzung und Kulturlandschaft sind aber sehr begrenzt, da die Wirtschafts- und Landnutzungsstruktur der benachbarten Dörfer und Gemarkungen sich nicht grundsätzlich von der Lachendorfs unterscheiden. Die Homogenität der landwirtschaftlichen Betriebsstrukturen und der Landnutzung der benachbarten Dörfer macht es möglich, trotz der erwähnten Inkongruenz am Beispiel der Lachendorfer Gemarkung und der Lachendorfer Agrarbetriebe das Verhältnis von Landwirtschaft und Kulturlandschaft zu untersuchen.

\subsection{Landschaft}

Der Zugang zur Landschaft gestaltet sich ambivalent:

Landschaft als natürlich oder künstlich-administrativ abgegrenzter Ausschnitt der Erdoberfläche lässt sich sektoral aus verschiedenen Perspektiven und mit unterschiedlichen Absichten oder Zwecken objektiv analysieren.

Im vorliegenden Fall stehen die beiden „disziplinären Landschaftszugänge“ der naturräumlich-ökologischen und der ökonomischen Dimension im Vordergrund. Diese Analyse erfolgte durch intensives Quellenstudium, Datenaufbereitung, Geländearbeit und mehrfache Nutzungskartierungen.

Bei einer Jahrzehnte langen Beschäftigung mit einer Kulturlandschaft und der sie gestaltenden Landwirtschaft ist aber auch unweigerlich der subjektive Pol des Individuums mit der körperlich-sinnlichen, identifikatorischen und auch ästhetischen Dimension beteiligt. Dieser Wahrnehmungszugang wird besonders wirksam bei Bewertungsfragen zu ökologischen Sachverhalten sowie insbesondere bei der Bewertung von unterschiedlichen Nutzungsansprüchen und Fragen des Natur- bzw. Landschaftsschutzes.

Landschaft ist aber auch ein sehr komplexer Begriff, der nicht nur sektoral analytisch betrachtet und monokausal erklärt werden kann. Landschaft ist ein gesamt-sinnlich ${ }^{1}$ wirkendes und erfassbares subjektives Phänomen, das letztlich aufgrund von vielfältigen

\footnotetext{
${ }^{1}$ Beim Verfasser lässt der Geruch von frisch gemähtem Gras oder frischem Heu in der Erinnerung sofort das Landschaftsbild der Wiesenlandschaft in der Bleckeder Elbmarsch entstehen, weil dieser positiv besetzte - Geruch unauslöschlich mit der Arbeit bei der Heuernte verbunden ist, die meist in den Anfang der Sommerferien der eigenen Schulzeit fiel.
} 
Sinneseindrücken, Erfahrungen und Erlebnissen sowie Prägungen im Kopf desjenigen entsteht, der die konkrete Landschaft wahrnimmt. „Wenn wir Landschaft sinnlich wahrnehmen, entsteht in uns ein Gesamteindruck, der mehr ist als ein Bild." ${ }^{1}$ Dass bei dieser Landschaftswahrnehmung ${ }^{2}$ das Optische im Vordergrund steht, liegt an der Wertigkeit der Sinnesorgane beim Menschen, einem ausgeprägten "Augentier“.

Gerade weil die visuelle Erfassung den weitaus größten Teil der Landschaftswahrnehmung ausmacht, ist die Benutzung des Begriffes "Landschaftsbild“ gerechtfertigt, sofern stets im Blick bleibt, dass über die rein visuell vermittelten

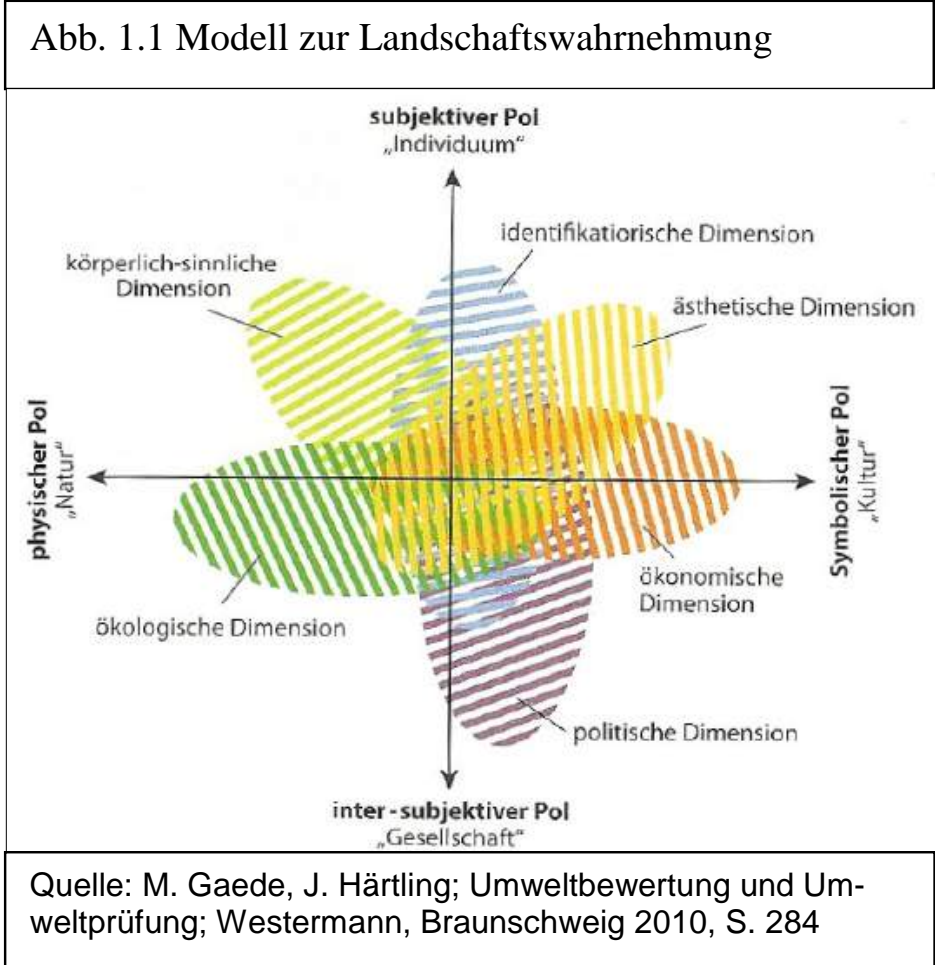
Sinneseindrücke hinaus auch andere Sinneswahrnehmungen zum Gesamteindruck einer Landschaft beitragen. „Der Begriff Landschaftsbild umfasst die Gesamtwirkung der für den Menschen wahrnehmbaren Merkmale und Eigenschaften von Natur und Landschaft. “3

Ein bezeichnendes Beispiel für die menschliche Fähigkeit, sinnlich wahrgenommene Naturphänomene als „lebendige“ Landschaften zu erleben, sind Tropfsteinhöhlen. Dort haben sich in völliger Dunkelheit aufgrund von wert- und zweckfreien physikalisch-chemischen Prozessen formenreiche Landschaften gebildet, in denen der Besucher, nachdem die Höhlenwelt durch künstliches Licht auch noch farbig geworden ist, die verschiedensten Figuren und Gegenstände zu erkennen meint. Das kann nur geschehen, weil der Besucher die oft als skurril empfundenen Formen mit seinem Erfahrungs- und Formenschatz vergleicht und ihnen eine Bedeutung verleihen möchte. Hier wird die Fähigkeit zur subjektiven Bedeutungszumessung geradezu zu einem Bedürfnis ${ }^{4}$.

Dieser Prozess, sinnfreie und unbekannte Naturformen in unsere Vorstellungswelt durch vergleichendes Benennen zu integrieren, hängt sicherlich mit dem menschlichen Grundbedürfnis zusammen, sich die Welt durch Namensgebung anzueignen. Für die Natur ist es völlig belanglos, ob eine Art, eine Landschaft einen Namen hat, für den Menschen bedeutet die Namensgebung Einordnung in seinen Erkenntnisbereich und damit Aneignung.

Jede Landschaft, auch die Naturlandschaft, hat eine Geschichte, weil in ihr die Natur mit ihren abiotischen und biotischen Kräften und Prozessen wirkt, die dafür sorgen, dass eine Naturlandschaft grundsätzlich instabil ist. Diese Instabilität ist je nach Reliefenergie, Klima, Boden, Gewässer sowie Flora und Fauna sehr unterschiedlich, aber immer vorhanden.

Die unbelebte Natur ist dem Kreislauf der Gesteine in enger Verbindung mit dem Kreislauf des Wassers ausgesetzt, in denen physikalische und chemische Prozesse im Zusammenwirken mit Transport und Verlagerung für dauernde Veränderung sorgen, manchmal sehr

\footnotetext{
${ }^{1}$ H. Wöbse, Landschaftsästhetik - eine Aufgabe für den Naturschutz, in: : NNA-Berichte, 1/93, S. 3

${ }^{2}$ vergl. H. Wöbse, a.a.O., S. $3 f$

${ }^{3}$ B. Köhler, A. Preiß; Erfassung und Bewertung des Landschaftsbildes; Informationsdienst Naturschutz Niedersachsen, 1/2000, S. 18;

${ }^{4}$ Der Verfasser konnte dieses Bedürfnis, in unbekannten, zufällig entstandenen Naturformen bekannte Formen und Gegenstände zu sehen, bei Führungen sowohl in europäischen wie chinesischen Karsthöhlen beobachten.
} 
spontan, etwa durch Erdbeben und Vulkane, meist aber langsam und stetig in geologischen Zeiträumen, etwa durch Verwitterung, Erosion, Sedimentation und Diagenese.

Die belebte Natur ist aufgrund der Evolution von innerer Dynamik geprägt. Dies gilt besonders auch für alle Ökosysteme, denn „stabile, gleichbleibende Ökosysteme gibt es grundsätzlich nicht"“1.

Der Mensch, der diese durch Veränderung und Dynamik bestimmte Natur zum Überleben nutzen muss, ist zum Erreichen stabiler Lebensbedingungen darauf angewiesen, der dynamischen Natur eine möglichst große Stabilität zu verleihen, besser: abzuringen oder aufzuzwingen.

Dieser Antagonismus zwischen Dynamik und Stabilität, nämlich der Dynamik der Natur und dem menschlichem Ringen nach Stabilität seiner Umwelt, ist Grundbedingung und Triebfeder für die Schaffung bzw. Entstehung von Kulturlandschaften. Dies Bemühen wird im Begriff Agrikultur auf den Punkt gebracht: ager (lat.): Acker und Kultur vom lat. colere: wohnen, pflegen, verehren, den Acker bestellen ${ }^{2}$. Agrikultur im umfassenden Sinne ist also die ständige Aufgabe, aus der Wildnis einer dynamischen Natur eine stabile, zweckorientierte Kulturlandschaft zu gestalten.

Die Spannbreite bei Kulturlandschaften reicht von minimalen Eingriffen in das jeweils vorgefundene Stadium der Naturlandschaft bis zu Gärten und Parklandschaften als völlig „durchgestylte" Landschaften. Mit der Idee der Gartenstadt ${ }^{3}$ ist es sogar gelungen, eine Siedlungsform zu entwickeln, die als Ideal einer völlig durchgestalteten Kulturlandschaft bezeichnet werden kann. Der Grad der Umwandlung der Wildnis in Kulturland korreliert mit dem Bewirtschaftungs- und Pflegeaufwand: Gärten und Parks, oft Landschaften höchster Artenvielfalt, sind besonders instabile Ökotope, die nur mit äußerst intensiver und ständiger Pflege ${ }^{4}$ erhalten werden können. ${ }^{5}$ Gärten und Parks sowie land- und forstwirtschaftlich geprägte Flächen sind genau deshalb pflegebedürftig, weil sie mit Elementen der dynamischen Natur stabile Landschaften oder Landschaftselemente formen. Insofern sind diese Formen der Kulturlandschaft, anders als Bauwerke aller Art, nicht künstlich sondern gestaltete Natur.

Auf der einen Seite steht die Natur mit ihrer räumlichen Struktur unterschiedlicher Standorte und Ökosysteme und auf der anderen Seite die Landnutzung des Menschen mit seinen Erfahrungen und seinem wissenschaftlich-technischen Know-how.

Wegen der Dynamik sowohl der Natur als auch des menschlichen Kenntnisstandes sind sowohl Natur- als auch Kulturlandschaften auf Veränderung angelegt, haben also eine Geschichte. Die Zeit ist folglich ein wichtiger Faktor bei der Entstehung und Entwicklung von Landschaften. Landschaftsbilder sind demnach Momentaufnahmen aus einer Landschaftsgeschichte.

Also kann es weder eine normale noch eine optimale Landschaft geben, selbst eine Klimaxlandschaft ist prinzipiell nicht möglich, weil es eine solche Landschaft als Endzustand, als „Vollendungsstadium"6 einer Entwicklung nur geben könnte, wenn auf Dauer alle Bedingungen konstant stabil blieben; ein Widerspruch zur Dynamik der Natur.

Aus der Geschichtlichkeit von Landschaft folgt weiter, dass es weder eine komplette Renaturierung noch Ersatz an anderer Stelle durch Ausgleichsmaßnahmen geben kann. ${ }^{7}$

Bewertungen von Ökosystemen und Landschaften beruhen grundsätzlich auf Werten, die sich nicht ökologisch ableiten oder begründen lassen. Vielmehr sind Bewertungen von Landschaften interessen- und zweckorientiert und so ökonomisch, ideologisch, ästhetisch oder auch ethisch-religiös bedingt. Dies wird deutlich an den Begriffen Artenvielfalt oder Biodiversität, ein Begriff, der seit der Umweltkonferenz von Rio 1992 in der internationalen Umweltund Naturschutzdebatte eine große Rolle spielt.

\footnotetext{
${ }^{1}$ H. Küster; Das ist Ökologie, a.a.O.; S. 88

2 http://de.wikipedia.org/wiki/Kultur

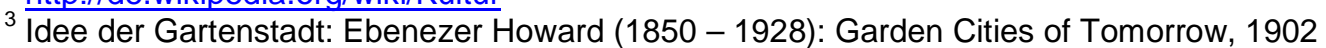

${ }^{4}$ Eine Bauernregel besagt: Ein Garten will jeden Tag seinen Besitzer sehen! (unbekannte Quelle)

${ }^{5}$ vergl. J. Radkau; Die Ära der Ökologie, a.a.O., S. 589

${ }^{6}$ vergl. H. Küster; Das ist Ökologie, a.a.O., S. 156

${ }^{7}$ s. ebenda, S. 159
} 
Aus rein ökologischer Sicht dürfte der Begriff Biodiversität nicht als Wertbegriff sondern nur zur Sachstandsbeschreibung verwendet werden, gibt es doch in der Natur Biotope hoher und geringer, sogar extrem geringer Artenvielfalt. Aus großer Artenvielfalt kann auch in natürlichen Ökosystemen nicht auf optimale Bedingungen aller Wachstumsfaktoren geschlossen werden. Im tropischen Regenwald mit sehr großer Artenfülle und geringer Individuenzahl herrscht - jedenfalls außerhalb von Vulkan- oder Überschwemmungsgebieten von Weißwasserflüssen - Nährstoffmangel in den Böden. Im borealen Klima gibt es bei Mangel an Wärme und Licht Ökosysteme mit sehr geringer Artenvielfalt aber hoher Individuenzahl.

Biodiversität als ökologisch orientierter Wertbegriff dürfte daher nur das Ziel verfolgen, vorhandene Biodiversität zu schützen bzw. zu erhalten oder die Sukzession zu mehr oder minder großer natürlicher Vielfalt zu ermöglichen.

Unsere Kulturlandschaft - wie am Beispiel der Gemarkung Lachendorf in der Südheide gezeigt wird - ist seit dem 19. Jahrhundert im Wald häufig durch forstliche Monokulturen geprägt und auf den landwirtschaftlichen Nutzflächen sind in den letzten Jahrzehnten die Tendenzen zum Ackerland auf Kosten von Grünland, zu möglichst großen, einheitlich bestellten Nutzparzellen in absoluter Reinkultur ohne Wildpflanzen und zu einfacheren Fruchtfolgen zu beobachten. Die beobachtete Vereinheitlichung und empfundene Verarmung der Kulturlandschaft erklärt das vielfach erkennbare und geäußerte Bedürfnis ${ }^{1}$ nach Schutz und Erhalt einer artenreichen Kulturlandschaft. Aber auch diese Tendenzen sind zeitbedingt und müssen - wie sich am Beispiel der behandelten Gemarkung zeigen wird - im Zusammenhang mit der Geschichte unserer Kulturlandschaft gesehen werden.

Die Bewertung der Landschaft hat sich im Laufe der Geschichte von der Wildnis zur Kulturlandschaft grundlegend gewandelt. Solange die Menschen aufgrund ihres begrenzten Wissens und ihrer einfachen Agrartechnik den Unbilden der wilden Natur direkt ausgesetzt waren, lagen reine Nützlichkeitserwägungen im Vordergrund.

Für die Bergbauern in den Alpen waren die Berge oberhalb der Wachstumsgrenze „montes horribiles"2, auf Neudeutsch "no-go-areas". Am südlichen Rand des LachteSchwemmfächers gab es auf ganz leichten Sandböden den Flurnamen „Hungerfeld““3. Heide wurde zum „Unland“, als sie landwirtschaftlich nutzlos wurde. Landschaftsbenennung und bewertung ergaben sich aus dem landwirtschaftlichen Gebrauchs- bzw. Nutzwert.

Inzwischen hat sich die Bewertung von Landschaft, auch und besonders der Kulturlandschaft, vom ursprünglich nur auf landwirtschaftliche Nutzung ausgerichteten Gebrauchswert gelöst. Andere ökonomische Werte, z.B. für Tourismus oder Erholung, sowie ästhetische Werte und Werte, die aus der Ökologie oder dem Naturschutz abgeleitet oder durch diese gesetzt und begründet werden, sind in den Vordergrund gerückt.

Dieser Wandel der Werteskala für Landschaftsbewertung zeigt sich deutlich in $\S 1$, Zif. 1 des Niedersächsischen Naturschutzgesetzes:

„(1) Natur und Landschaft sind im besiedelten und unbesiedelten Bereich so zu schützen, zu pflegen und zu entwickeln, dass

1. die Leistungsfähigkeit des Naturhaushalts,

2. die Nutzbarkeit der Naturgüter,

3. die Pflanzen- und Tierwelt sowie

4. die Vielfalt, Eigenart und Schönheit von Natur und Landschaft ${ }^{4}$

als Lebensgrundlage des Menschen und als Voraussetzung für seine Erholung in Natur und Landschaft nachhaltig gesichert sind. ${ }^{5}$

\footnotetext{
${ }^{1}$ Das Bedürfnis nach Artenvielfalt und Vielfalt im Landschaftsbild kann durchaus gestützt werden durch die Hypothese von der „Biophilie“ als menschlichem Naturtrieb. S. J. Radkau, a.a.O., S. 588

${ }^{2}$ W. Bätzing; Die Alpen, a.a.O., S. 101

${ }^{3}$ s. Kurh. Landesaufnahme, Blatt 111, Gr. Eicklingen, 1781

${ }^{4}$ Hervorhebung durch den Verf.

${ }^{5}$ Niedersächsisches Naturschutzgesetz
} 
Die beiden ersten Ziele sind ökonomisch orientiert, indem Ziel 1) von der Leistungsfähigkeit des Naturhaushaltes und Ziel 2) von der Nutzbarkeit der natürlichen Ressourcen spricht. Allerdings sind beide Ziele allgemein ökonomisch und nicht rein landwirtschaftlich orientiert. Bei spezieller Orientierung auf die Leistungskraft der Landwirtschaft zur Erzeugung von Nahrung müsste dem Boden eine weit größere und explizit formulierte Bedeutung zukommen. Die jeweils relativ fruchtbarsten Böden eines Raumes müssten bei Priorität der agrarwirtschaftlichen Landnutzung von jeder anderen Nutzung ausgeschlossen werden.

Erst in §2) des Niedersächsischen Naturschutzgesetzes wird unter dem Thema „Grundsätze des Naturschutzes und der Landschaftspflege“ in Ziffer 5) der Boden erwähnt: „Boden ist zu erhalten; ein Verlust oder eine Verminderung seiner natürlichen Fruchtbarkeit und Ertragsfähigkeit ist zu vermeiden“. Da Boden weder vermehrbar noch recycelbar und unverzichtbar ist, wäre eine schärfere Gesetzesformulierung zu seinem Schutz erforderlich.

Die Ziele 3) und 4) sind dagegen auf Naturschutz und Ästhetik der Landschaft ausgerichtet. Insbesondere in Ziel 4) sind Landschaftswerte festgelegt, die sich weder gesamt- noch agrarökonomisch und auch nicht ökologisch herleiten oder begründen lassen. Aber gerade diese Werte spielen z.B. in Umweltverträglichkeitsprüfungen ${ }^{1}$ eine wichtige Rolle.

Offenbar spielen die Begriffe „Vielfalt“, „Eigenart“ und „Schönheit“ für unser Verständnis und unsere Bewertung von Landschaft eine ganz zentrale Rolle. In Mitteleuropa könnten diese Landschaftswerte von einer Wildnis, einer reinen Naturlandschaft, in historischer Zeit nirgends erfüllt werden, denn Mitteleuropa hat sich seit dem Postglazial zu einem geschlossenes Waldland entwickelt. Dagegen sind diese so positiv bewerteten Eigenschaften gerade in vielen Kulturlandschaften Mitteleuropas ${ }^{2}$ erfüllt.

Folgt man Erkenntnissen der Anthropologie, so gehen diese Grundwerte eines positiv empfundenen und bewerteten Landschaftsbildes auf die "ökologische Einnischung“3 des Menschen in der Savanne Ostafrikas zurück, gehören also zu seiner genetischen Grundausstattung.

Wenn man dieser Theorie folgt, verwundert es nicht, dass im 19. Jahrhundert gerade die "Allmenden zum Idyll der Naturfreunde"“4 wurden. Die bis in die Mitte des 19. Jahrhunderts weit verbreiteten Allmenden hatten als Gemeinschaftsweiden ohne Eigentums- und Parzellengrenzen einen parkartigen Charakter, mit jeweils standorttypischer natürlicher, aber durch Beweidung selektierter Vegetation. Durch die jeweiligen natürlichen Standortbedingungen und die Nutzung als freie Weide ohne gezielte Pflege konnten sich Landschaften entwickeln, die das Bedürfnis nach Vielfalt, Eigenart und Schönheit besonders erfüllten und dabei dem landwirtschaftlich unkundigen Betrachter auch noch den Eindruck von Natürlichkeit und Natur vermittelten. Diese als Allmenden entstandenen Kulturlandschaften wurden im 19. Jahrhundert im Zuge der Agrarreformen weitgehend aufgegeben und anderer Nutzung zugeführt. Wenn man diesen Landschaftstyp, der durch Intensivierung der Landwirtschaft und durch Aufforstungen immer mehr verschwand, fälschlicherweise für „natürliche Landschaft“, für Natur hielt, dann wird das Bemühen verständlich, gerade diese Landschaften unter „Naturschutz" zu stellen.

Die anthropologische Theorie der ökologischen Einnischung erklärt aber noch nicht, warum sich erst in den vergangenen zwei Jahrhunderten die ästhetische und ökologische Bewertung unserer Landschaft so stark durchsetzen und die Bewertung nach dem landwirtschaftlichen Gebrauchswert so stark in den Hintergrund drängen konnte.

Wichtige Ursachen sind sicherlich im Naturverständnis des 18. und 19. Jahrhunderts, dem Zeitalter der Naturphilosophie von Rousseau bis zum Zeitalter der Romantik ${ }^{5}$, zu finden. Die Hinwendung zur Natur hatte aber ganz reale Hintergründe: Der Jahrhunderte währende

\footnotetext{
${ }^{1}$ s.u. Kapitel 5.4

${ }^{2}$ Diese offenbar zentralen Eigenschaften für ein vom Menschen positiv bewertetes Landschaftsbild finden sich auch in vielen Kulturlandschaften, die von Natur aus nicht zu den Waldländern gehören.

${ }^{3}$ s. B. Köhler, A. Preiß; Informationsdienst Naturschutz Niedersachsen, 1/2000, S. 30

${ }^{4}$ J. Radkau, Die Ära der Ökologie, a.a.O., S. 75

${ }^{5}$ vergl. J. Radkau, Die Ära der Ökologie, a.a.O., S. $38 \mathrm{ff}$
} 
Raubbau am Wald führte zu einer immer größeren Holznot ${ }^{1}$, dem wichtigsten Baustoff und Energieträger vor der Industrialisierung. Wachsende Bevölkerung und magere Ernten auf ausgelaugten Böden rückten die Ernährungssicherheit ins Bewusstsein. Schlechtere Witterungsbedingungen aufgrund der „Kleinen Eiszeit“2 und Vulkanausbrüchen ${ }^{3}$ mit weltweiten Folgen brachten Hungersnöte und Teuerungszeiten.

Die teils katastrophalen ökologischen Bedingungen für die Landnutzung und die häufig prekäre Lage in der Nahrungsversorgung hätten eigentlich dazu führen müssen, den Gebrauchs- und Nutzwert des Bodens im Besonderen und der Landschaft allgemein über alle Werte zu stellen, weil die Not keine anderen Werte zuließ.

Die weitgehende Abkehr vom (landwirtschaftlichen) Gebrauchswert der Landschaft zu ökologischen und ästhetischen Bewertungen wurde durch die Entwicklung der Landwirtschaft selbst und durch die Industrialisierung seit dem 19. Jahrhundert ermöglicht.

Bergbau und Industrie haben für neue Bau- und Energierohstoffe gesorgt und den chronischen Holzmangel behoben.

Die Landwirtschaft hat aufgrund naturwissenschaftlicher Erkenntnisse, neuer Kulturpflanzen und bergbaulich oder industriell erzeugter Mineraldünger sowie den Einsatz von Bioziden und die Integration in einen globalen Futtermittelhandel einen früher ungeahnten und unvorstellbaren Aufschwung genommen. Immer weniger Bauern auf dem Lande ernähren seit Mitte des 19. Jahrhunderts immer mehr Menschen außerhalb der Landwirtschaft.

Gab es um 1800 außer in wenigen hoheitlich geschützten Wäldern kein Fleckchen Erde, das nicht für Ackerbau oder wenigstens als Viehweide genutzt werden musste, schieden mit dem Aufschwung der Landwirtschaft immer mehr Flächen aus der landwirtschaftlichen Produktion aus. Das begann mit der strikten Trennung ${ }^{4}$ von Landwirtschaftlicher Nutzfläche und Wald, die es vorher nicht gegeben hat. Sog. leichte Böden, also magere, nährstoffarme Sandböden mit weniger als 20 Bodenpunkten wurden zu „Grenzertragsböden“, die gern aus der Nutzung genommen wurden, insbesondere wenn sie als Bauland ${ }^{5}$ oder Gewerbeflächen veräußert werden konnten.

Die Entwicklung der Landwirtschaft ermöglichte in Norddeutschland die Aufforstungen der Heiden, überall die „Renaturierung“ von Flussläufen und Bachtälern, die Einrichtung von Naturschutzgebieten bis hin zu Nationalparks und die Anlage von "Ökotopen" auf Kosten von Nutzland.

Zugespitzt ausgedrückt: Die Steigerung von Produktion und Effizienz in der Landwirtschaft ermöglichte den "Luxus“ von Flächen für außerlandwirtschaftliche Nutzung, für Freizeit, Sport, Erholung sowie Landschafts- und Naturschutz.

In dieser Entwicklung der Landwirtschaft liegt eine gewisse Tragik:

Moderne Landwirtschaft ist die Voraussetzung für Ernährungs- und Nahrungssicherheit sowie einen großen, außerhalb der Landwirtschaft tätigen Bevölkerungsanteil, der häufig wenig Kenntnis von der Agrargeschichte und aktueller Landwirtschaft hat.

Andererseits steht die moderne Landwirtschaft unter dem Verdacht, Umwelt und Landschaft zu zerstören; ein Verdacht, in den sie teils durch Unkenntnis außerhalb der Landwirtschaft geraten ist, für den sie teils aber auch selbst verantwortlich ${ }^{6}$ ist. Beispiele dafür sind der heutige Maisanbau und das Gülleproblem. Maisanbau wird häufig wegen seiner Beeinträchtigung bzw. Veränderung des optischen Landschaftsbildes und aus Unkenntnis der Ökologie der Maispflanze kritisiert. Das Gülleproblem bei Intensivtierhaltung und zu geringer Fläche

\footnotetext{
${ }^{1}$ vergl. H. Küster; Das ist Ökologie, a.a.O., S. $128 f f$

${ }^{2}$ vergl. R. Glaser; Klimageschichte Mitteleuropas, a.a.O., S. $195 \mathrm{ff}$

${ }^{3}$ Der Ausbruch des Tambora 1815 verursachte Hungersnöte in ganz Europa; Caspar David Friedrich malte keine romantischen Phantasielandschaften sonder "dokumentierte“ in seinen Landschaftsbildern auch die durch den Vulkanausbruch verursachten Farben in der Atmosphäre. S dazu. R. Gläser, ebenda, S. 203

${ }^{4}$ s. a. H. Küster, ebenda, S, $108 \mathrm{ff}$

${ }^{5}$ Sprichwort in der Heide: Die beste Fruchtfolge ist zweimal Roggen und dann Bauland. (Quelle unbekannt)

${ }^{6}$ Auf die weltweit zu beobachtenden Überschreitungen der regionalen agraren Tragfähigkeit durch Raubbau und unangepasste Landnutzungsformen kann hier nicht weiter eingegangen werden.
} 
führt zur Grundwasserbelastung und bildet ein objektiv messbares Problem moderner Landwirtschaft.

Heute besteht in unserer Gesellschaft ein deutliches Spannungsverhältnis zwischen Gesellschaft und Landwirtschaft sowie den jeweilige Ansprüche an die Landschaft.

Unsere Kulturlandschaft ist über viele Jahrhunderte allein durch die Landwirtschaft gestaltet worden. Erst seit dem 19. Jahrhundert gehört zu den Landschaft gestaltenden und prägenden Kräften auch die Forstwirtschaft und seit gut einem Jahrhundert auch Siedlung, Gewerbe und Infrastruktur.

Am konkreten Beispiel der Gemarkung Lachendorf am Rande der Südheide wird diesem Kräftespiel bei der Gestaltung der Kulturlandschaft seit dem 18. Jahrhundert bis ins erste Jahrzehnt des 21. Jahrhunderts nachgegangen.

\subsection{Absichten und Ziele}

Die Untersuchung am Beispiel der Gemarkung des Ortes Lachendorf verfolgt folgende Hauptziele:

Es kann gezeigt werden, dass unabhängig vom Stand der Agrartechnik in jeder landwirtschaftlich geprägten Kulturlandschaft die naturräumliche Struktur einer Landschaft erkennbar bleibt. Die Abhängigkeit der Kulturlandschaft von den naturräumlichen Standortbedingungen nimmt von der vorwissenschaftlichen Erfahrungslandwirtschaft über die wissensorientierte Landwirtschaft zur modernen Agrarwirtschaft ab, allerdings je nach Standorteigenschaften in unterschiedlichem Ausmaß.

Es kann weiter gezeigt werden, dass sich mit Änderungen in der Agrarverfassung und der Agrartechnik sowie der politisch-gesellschaftlichen Rahmenbedingungen auch die landwirtschaftliche Wirtschaftsweise oder die landwirtschaftliche Betriebsstrukturen verändern. Änderungen der Wirtschaftsweisen haben gravierende Auswirkungen auf die Kulturlandschaft. Betrieblicher Strukturwandel hat geringere und eher punktuelle Auswirkungen in der Kulturlandschaft, solange es sich allein um betriebliches Wachstum und unterschiedliche Spezialisierungen handelt und nicht ganze landwirtschaftliche Betriebszweige aus dem Ort und der Gemarkung verschwinden.

Es kann weiter beispielhaft gezeigt werden, wie eng jede zeitgenössische Form der Landnutzung mit der jeweiligen Kulturlandschaft verknüpft ist. Es wird sich zeigen, dass im Betrachtungszeitraum der letzten etwa 200 Jahre jede Epoche der Landwirtschaft sich im Rahmen der natürlichen Standortbedingungen eine genau dazu gehörige Kulturlandschaft geschaffen hat.

$\mathrm{Da}$ jede landwirtschaftliche Kulturlandschaft eine Folge einer bestimmten zeitgenössischen Agrarverfassung, landwirtschaftlichen Wirtschaftsweise und eingesetzter Agrartechnik ist, kann diese je spezielle Kulturlandschaft bei Änderung der Wirtschaftsweise und anderer Agrartechnik keinen Bestand haben. Kulturlandschaften einschließlich aller typischen Kulturlandschaftselemente werden ohne die zugehörige Form der Landnutzung entweder umgestaltet oder zu Reliktlandschaften.

Erhaltungsmaßnahmen solcher Reliktlandschaften sind gezielter Landschaftsschutz, nämlich der Schutz einer ganz bestimmten Form von Kulturlandschaft, die ohne Pflege und beim Zulassen natürlicher Sukzession keinen Bestand haben kann. Diese Form des Landschaftsschutzes ist dann gezielter, selektiver Naturschutz in einer anthropogen geschaffenen und erhaltenen Landschaft.

In dieser Untersuchung geht es also wesentlich um das Verhältnis von landwirtschaftlicher Wirtschaftsweise und Gestaltung bzw. Ausbildung der ländlichen Kulturlandschaft auf dem naturräumlichen Hintergrund.

Agrarhistorischen Ausführungen und Darstellungen zu den Betriebsstrukturen haben daher nur dienende Funktion, sind also nur Mittel zum Zweck der Arbeit, weshalb zu diesen Themen auch keine Vollständigkeit angestrebt wurde. 
Weil das Verhältnis von landwirtschaftlicher Wirtschaftsweise und Kulturlandschaft einerseits und naturräumlicher Landschaftsstruktur andererseits ein zentrales Thema ist, spielen Fragen der Ökologie, insbesondere der Bodenfruchtbarkeit und der Biodiversität eine wichtige Rolle.

Wegen der grundsätzlichen Bedeutung natürlicher Standortfaktoren für jede Form der landund forstwirtschaftlichen Nutzung wird im Kapitel 2 die naturräumliche Struktur der Südheide, an deren Südrand die Gemarkung Lachendorf liegt, dargelegt. Auf diesem Hintergrund werden die Naturfaktoren Hydrologie, Böden und Klima für den Untersuchungsraum näher untersucht, um dann die Standorte in der Gemarkung und deren Potenziale analysieren und bewerten zu können.

Kapitel 3 ist der Landwirtschaft und der Landschaft um 1800 gewidmet. Aus zeitgenössischen Karten und aus den Bewertungen (Taxationen) der Nutzflächen, die zur Vorbereitung der Agrarreformen des 19. Jahrhunderts erstellt wurden, kann das zeitgenössische Bild der Kulturlandschaft recht genau nachvollzogen werden. Die Darstellung der damaligen Flurordnung und Wirtschaftsweise führt zu dem Schluss, dass die vorwissenschaftliche Erfahrungslandwirtschaft im Rahmen der natürlichen Standorte eine hoch angepasste Kulturlandschaft geschaffen hatte.

Kapitel 4 widmet sich dann den großen Agrarreformen des 19. Jahrhunderts, ihren Auslösern, den Durchführungen und dem Ergebnis, einer neuen Agrar- und Flurstruktur, die bis heute formale Grundlage unserer Kulturlandschaft sind. Zur Verdeutlichung der Bedeutung und der Auswirkungen werden die Reformen anhand der vorhandenen Rezesse ausführlich analysiert.

Aus den neuen Möglichkeiten und neuer Wirtschaftsweise, der wissensbasierten bäuerlichen Mischwirtschaft, ergibt sich, ebenfalls auf dem Hintergrund der natürlichen Standortgunst, eine neue Kulturlandschaft.

In Kapitel 5 werden weiterer Ausbau der neuen Kulturlandschaft und erste Veränderungen aufgrund des beginnenden landwirtschaftlichen Strukturwandels erfasst. Der Zeitpunkt der intensiven Analyse der landwirtschaftlichen Betriebe und deren Landnutzung Mitte der 1960er Jahre erwies sich im Nachhinein als ein Glücksfall, weil der Zeitpunkt günstig am Beginn des Übergangs von der familienbäuerlichen Mischwirtschaft zur marktorientierten und technikbasierten Agrarwirtschaft lag.

Kapitel 6 belegt und erläutert dann die Veränderungen in der Landwirtschaft und in der Kulturlandschaft in der 2. Hälfte des 20. Jahrhunderts bis zu den Jahren 2010/2012. Schwerpunkt dieses Kapitels ist der Zusammenhang von Wirtschaftssystem, Landnutzung und Landschaft.

Das Kapitel 7 versucht, die Beziehungen zwischen Naturräumen und Kulturlandschaft sowie der Landnutzung und der Artenvielfalt zu erhellen. Damit kommen dann auch Fragen des Natur-, Arten- und Landschaftsschutzes in den Blick.

Kapitel 8 fasst dann die wesentlichen Ergebnisse der Untersuchung kurz zusammen.

Im Focus der Arbeit steht das komplexe Beziehungsgeflecht zwischen Landwirtschaft, natürlichen Standorten und Kulturlandschaft. Dieses vielschichtige Themenfeld wird aus unterschiedlichen Perspektiven untersucht und dargestellt. Daher war es unvermeidlich, Ortsbezeichnungen in der Gemarkung und gelegentlich auch Sachbezüge beim jeweiligen thematischen Bezug zu wiederholen. Der des Ortes unkundige Leser wird dadurch aber zunehmend mit den örtlichen Verhältnissen vertraut, ohne die der Bezug zum konkreten Raumbeispiel, der Gemarkung Lachendorf, verloren gehen würde. 


\section{Kapitel 2 Der Naturraum}

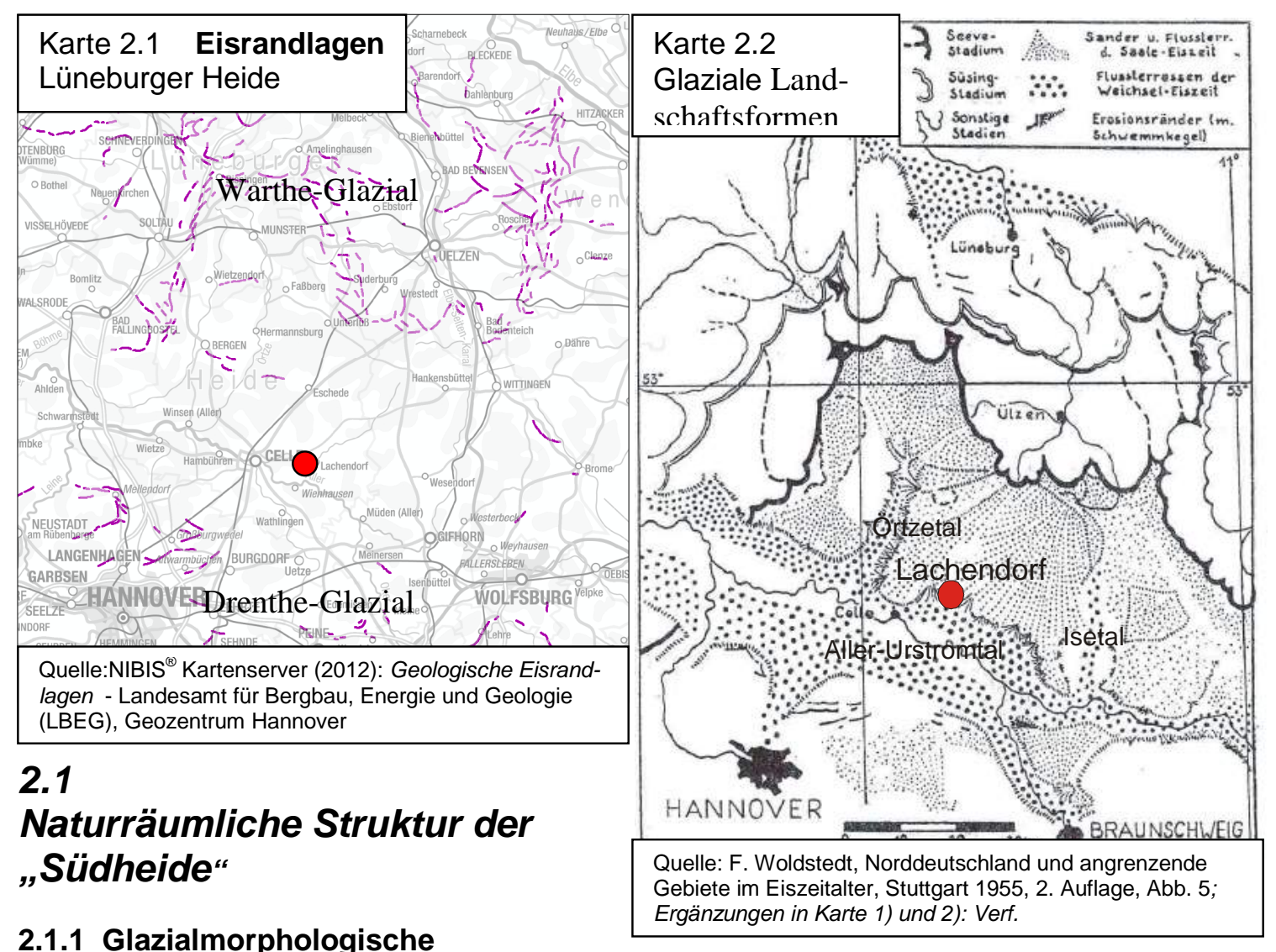

\subsubsection{Glazialmorphologische Grundstruktur des Raumes}

Die naturgeographische Einordnung des Lachendorfer Raumes erfolgt schrittweise, von der großräumigen Glaziallandschaft Norddeutschlands hin zur kleinräumigen naturgeographischen Gliederung. Auf diese Weise ist gewährleistet, dass alle Einzelaspekte und Teilräume in ihrem genetischen und räumlichen Zusammenhang dargestellt und erklärt werden können.

Der Raum um Lachendorf im östlichen Kreis Celle ist Teil der niedersächsischen glazialen Aufschüttungslandschaft des Saale-Glazials ${ }^{1}$, topographisch zwischen Elbe und Aller, genetisch zwischen den Endmoränenzügen des Rehburger Stadiums zum Ende des DrentheGlazials im Süden und den Endmoränenzügen des Warthestadiums im Norden².

Dieser Landschaftsraum wird im Folgenden als Südheide bezeichnet.

Karte 2.2 vermittelt den Eindruck, dass der Landschaftsaufbau der Südheide dem klassischen Schema der Glazialen Serie ${ }^{3}$ folgt.

Lachendorf selbst liegt dann am Übergang von den Sanderflächen in das Urstromtal.

Aufgrund dieser genetischen Struktur ist zu erwarten, dass das Gelände von dem warthezeitlichen Endmoränenzug relativ gleichmäßig zum zugehörigen Urstromtal der Aller hin abdacht und fließend in dieses übergeht.

\footnotetext{
${ }^{1}$ s. Karten 2.1

${ }^{2}$ Vergl. Geologische Übersichtskarte 1 : 200 000, Blatt CC 2926 Braunschweig (1974) und Blatt CC 3126 Hamburg-Ost (1977), Bundesanstalt für Geowissenschaften und Rohstoffe, Hannover

${ }^{3}$ s. Karte 2.2
} 
Die nach südsüdwest abfallenden Sanderflächen der Südheide werden durch zwei nordsüdlich verlaufende Schmelzwasserrinnen, dem Örtzetal im Westen und dem Isetal im Osten, gegliedert. Der Raum auf der Abdachungsfläche der Südheide zwischen dem Örtze- und Isetal wird hier als Mittlere Südheide bezeichnet.

Diese Landschaftsstruktur wird durch das Gewässernetz voll bestätigt: Die gesamte Entwässerung Südheide folgt der Abdachung des Reliefs von Norden nach Süden, entsprechend dem Gefälle von

Endmoränenzügen den Sanderflächen zum Urstromtal.

Örtze und Ise mit wenigen und sehr kleinen Zuflüssen entwässern die ehemaligen Schmelzwasserrinnen und die Mittlere Südheide dazwischen bildet die Einzugsgebiete der Lachte mit ihren Nebenflüssen im zentralen Teil und dem Schwarzwasser im östlichen Randbereich.

Die Interpretation der Landschaftsstruktur als Typ einer einfachen Glazialen Serie muss aufgrund zweier wesentlicher Merkmale deutlich differenziert werden:

- Zwischen Celle und Gifhorn ist der nördliche Rand des Urstromtales meist sehr deutlich ausgeprägt. Der Talhang ist hier ein auffälliges morphologisches, die Landschaft prägendes Merkmal. Dieser Talhang ist besonders gut ausgeprägt zwischen Gockenholz im Westen von Lachendorf und Ahnsbeck

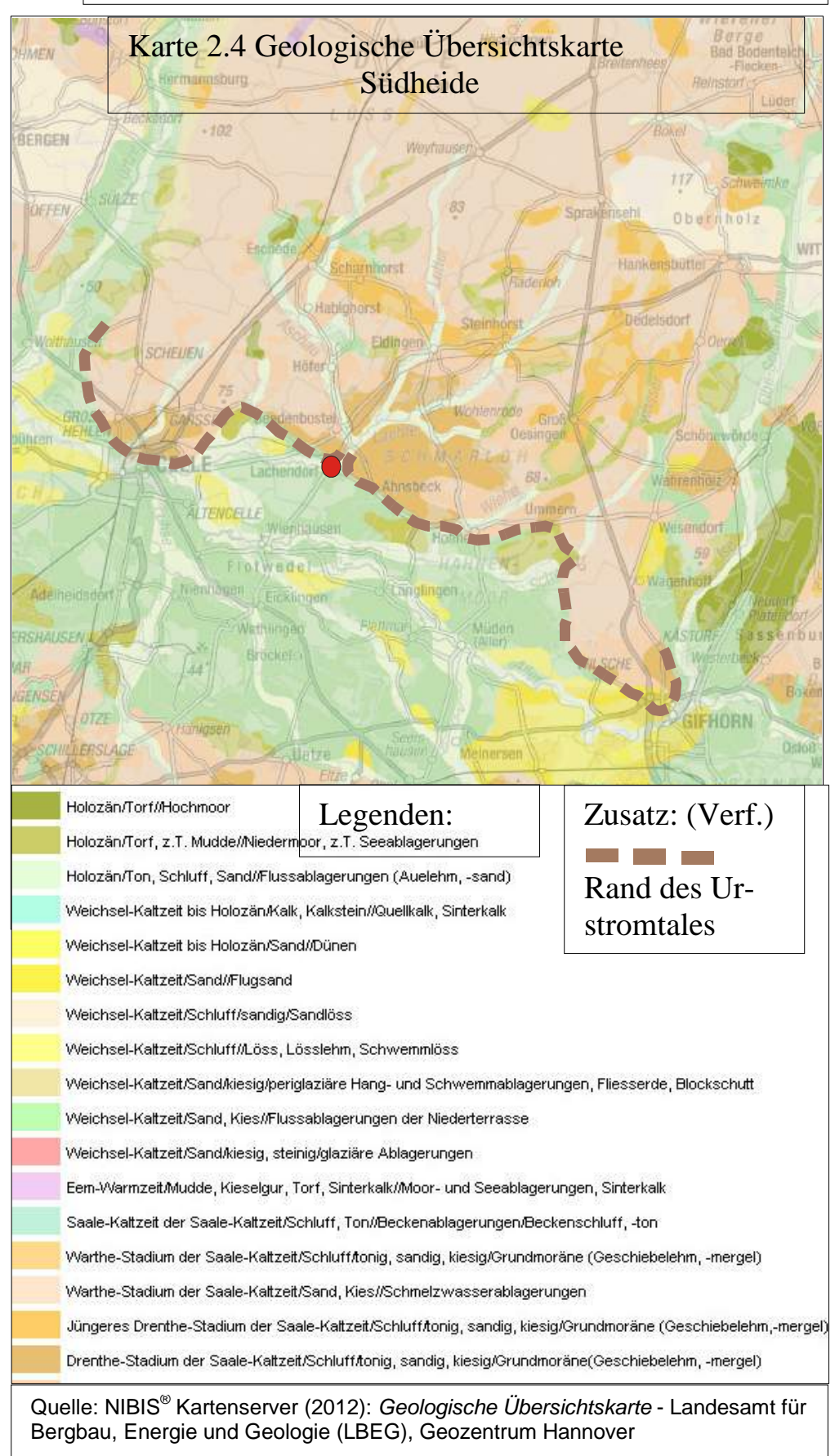

Quelle: Übersichtskarte 1: 200 000, Blatt 73 Celle, Blatt 74 Salzwedel, Institut für Angewandte Geodäsie, 1967 Zeichnung: Verf.

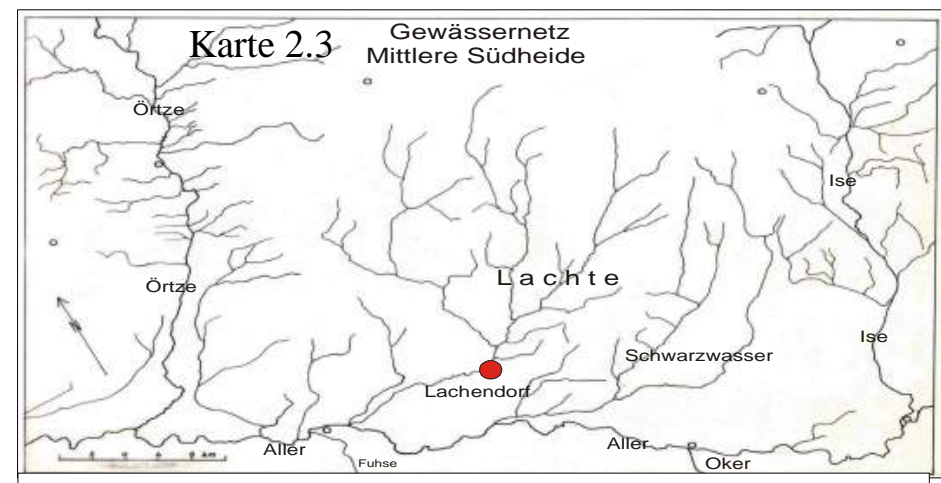


im Osten. Die Landesstraße führt westlich von Lachendorf am Hangfuß und jenseits des Lachtetales bis Ahnsbeck am oberen Rand entlang.

Dieser sehr deutlich im Gelände sichtbare Talhang ist im Bereich der Mittleren Südheide das auffälligste morphologische Merkmal, das auch an der deutlich engeren Scharung der Isohypsen auf entsprechenden Topographischen Karten erkennbar ist.

Dies widerspricht einem fließenden, unmerklichen Übergang von den Sanderflächen ins Urstromtal ${ }^{1}$.

- Die Geologische Übersichtskarte verzeichnet nördlich des Urstromtalrandes Ablagerungen des Drenthestadiums, nämlich Grundmoräne mit Geschiebelehm und -mergel.

Die nördlich an die Grundmoräne anschließenden Ablagerungen werden dagegen dem Warthestadium zugerechnet.

Daraus ergibt sich eine Landschaftsstruktur, die aus zwei ineinander verschränkten Glazialen Serien aufgebaut ist: Am Südrand der warthezeitlichen glazifluvialen Ablagerungen stehen drenthezeitliche Grundmoränenreste an. Diese wurden wegen des relativ großen Erosionswiderstandes von den Schmelzwässern des Urstromtales zum Erosionsrand des Tales herauspräpariert.

Weichselzeitlich wurde die Landschaft dann noch deutlich solifluidal zu einem Relief mit sanften Oberflächenformen überprägt und mit dem Material wurde das Urstromtal des Warthe-Stadiums, das Aller-Urstromtal, aufgefüllt.

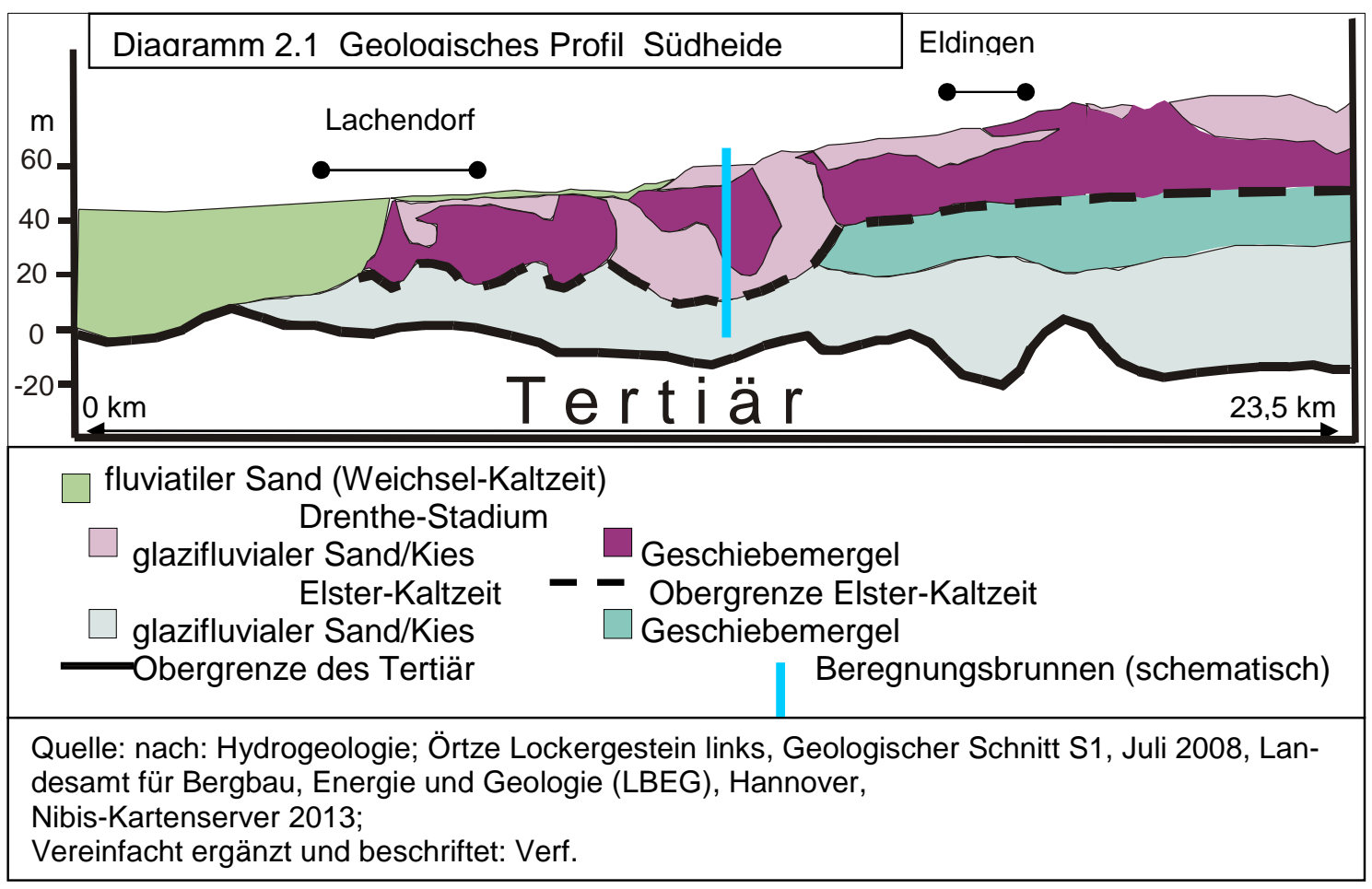

Diese Interpretation wird durch das Profil (Diagramm 2.1) durch die Mittlere Südheide über Lachendorf bis ins Allertal voll bestätigt.

Aufgrund dieser Landschaftsstruktur erklärt sich auch der offensichtliche Gegensatz der morphologischen Prägung zwischen der glazialen Aufschüttungslandschaft im Norden und dem Urstromtal im Süden.

Das Lüßplateau bietet das Bild einer flach-welligen Hochfläche mit einer Höhe von etwa 100 bis 130 m über NN. Die breiten Höhenrücken, massige, verwaschene Erhebungen², verlaufen vom östlichen Rande des Örtzetales im wesentlichen in west-östlicher Richtung; der

\footnotetext{
${ }^{1}$ vgl.. Karte 2.2

${ }^{2}$ vgl. Woldstedt, P., Über Endmoränen in der südlichen Lüneburger Heide, in: Abh. der naturwiss. Ver. Bremen, Bd. 31, 1939/40, H. 213, S. 241
} 
Haupthöhenzug im östlichen Teil schwingt südlich von Breitenhees in einem weiten Bogen nach SE in Richtung Hankensbüttel und setzt sich noch ein Stück in südlicher Richtung etwa parallel zum westlichen Rand des Isetales bis Oerrel fort.

Bei diesen Höhenzügen handelt es sich um warthezeitliche Staffeln von Endmoränen, die zu dem Hauptendmoränenzug ${ }^{1}$ des Warthestadiums gehören. Ein kleiner, etwas isoliert liegender Höhenzug am Rande des Örtzetales westlich von Rebberlah, bestimmt durch den Citronenberg nordöstlich des Forstamtes Miele, wird dem Rehburger Stadium zugerechnet ${ }^{2}$, stellt also hier in genetischer Sicht eine Fremdform dar, passt aber physiognomisch ganz in das übrige Landschaftsbild.

Nach S schließt sich an das Lüßplateau ein ebenes, schwach zur Aller hin geneigtes Sandergebiet an, das den Endmoränen vorgelagert ist. Hier sind vor allem der Sprakensehler Sander und der von Breitenhees ${ }^{3}$ zu nennen, weiter auch das Sandergebiet von Starkshorn ${ }^{4}$. Die südliche Grenze dieses Sandergebietes fällt etwa mit der 80 m - Isohypse zusammen.

Am südlichen Randbereich der Sanderflächen, in denen fast alle Bäche und Flüsse dieses Gebietes entspringen, erstreckt sich eine Niederungszone, die im Landschaftsbild gut zur Geltung kommt und sich von Miele -Rebberlah im W, nördlich Eschede und Bargfeld, südlich Steinhorst in einem weiten Bogen über das Gr. Ösinger Moor bis zu den Fischteichen südöstlich von Gr. Ösingen gut verfolgen lässt.

Nach $S$ folgt auf diese Niederungszone, die besonders im Westteil der Mittleren Südheide ausgeprägt ist, ein Gebiet von Sand- und Lehmplatten, das sich mit sehr sanftem, ausgeglichenem Relief fast unmerklich zum deutlich ausgeprägten Rand des Aller-Urstromtales abdacht.

Diese Abdachungsfläche der Mittleren Südheide nach Süden zum Allertal zwischen Örtze und Isetal wird durch zwei markante Geestsporne begrenzt, im W durch den Arloh und im E durch Ringelahs Heide. Diese Geestsporne ${ }^{5}$ sind überwiegend aus Kiesen und Sanden aufgebaut, der Charakter eines Geestsporns im Urstromtal wird aber jeweils durch Geschiebelehm begründet, der durch den relativ großen Erosionswiderstand den Geestsporn erhalten hat. Dies tritt besonders markant in Celle am Hangfuß des Harburger Berges in der Aller hervor.

Südlich dieses recht markanten Talrandes erstreckt sich das breite Allertal, das zum Urstromtal des Warthestadiums gehört. Die fast völlig ebene Talfläche wird nur durch einzelne Dünen punktuell unterbrochen.

\subsubsection{Relief ${ }^{6}$ der Südheide}

Die Mittlere Südheide dacht vom Lüßplateau sanft nach $S$ zum Allertal hin ab und weist in diesem Bereich nur eine Reliefenergie von etwa $50 \mathrm{~m}$ auf. Der größte Teil der Reliefenergie steckt in den Talhängen der Fluss- und Bachtäler sowie der zahlreichen kleineren und gröBeren Trockentäler in den Rändern der Geestplatten. Besonders markant als prägendes Landschaftselement mit deutlicher Reliefenergie tritt morphographisch nur der Rand des Aller-Urstromtales hervor. Die periglazial überformte glaziale Aufschüttungslandschaft weist dagegen insgesamt sehr sanfte und ausgeglichene morphographische Formen auf. Nur die rezenten Flüsse haben in die Talsedimente oft scharfkantig begrenzte Talauen eingetieft, die linienhaft im sonst sanften Relief deutlich hervortreten.

Das Gewässernetz hat die Oberfläche der glazialen Aufschüttungslandschaft nachträglich stark gegliedert, die Geestplatte südlich der Sanderflächen in viele Inseln aufgelöst und dabei insbesondere die heutigen Grundmoränenplatten inselartig herausgearbeitet.

\footnotetext{
${ }^{1}$ vgl. Woldstedt, P., a.a.O., S. $240 \mathrm{f}$

2 vgl. Woldstedt, P., a.a.O., S. 239

${ }^{3}$ vgl. Schroeder-Lanz, H. "Glazialmorphologische Übersichtskarte der Lüneburger Heide", in: Hamburger Geogr. Studien, H. 18, Hamburg 1964, Karte 2 ,

${ }^{4}$ vgl. Meisel, S., a.a.O., S. 34

${ }^{5}$ Beide Geestsporne haben sich als Verkehrsleitlinien (B3 und B4) und als siedlungsfreundlich (Celle und Gifhorn) erwiesen.

${ }^{6}$ s. Karte 2.7
} 
Das breite Urstromtal weist im hier betrachteten Abschnitt eine Reliefenergie von weniger als $10 \mathrm{~m}$ auf. Als besonders flache Landschaftselemente treten der Lachte-Schwemmfächer und die Randmoore hervor. Dieser Charakter war in den Aller-Dreckwiesen und im Bereich der Trocken- und Stauwiesen ${ }^{1}$ aufgrund der offenen, teils parkähnlichen Landschaftsbildes früher ganzjährig und heute je nach Stand der Ackerfrüchte augenfällig. In der weiten Ebenheit des Schwemmfächers verhindert heute der ausgedehnte und dichte Wald den Weit- und Rundblick, ganz im Gegensatz zu den offenen Heideflächen früherer Jahrhunderte.

Die Dünengebiete, wie z.B. der Lorkberg am Schwarzwasser, wirken aufgrund des deutlichen Reliefs und des Baumbestandes mit vorwiegend Kiefern wie Inseln in der Weite des Urstromtales.

Die nähere Umgebung Lachendorfs zeigt nur eine Reliefenergie von maximal $25 \mathrm{~m}$. Das ganze Gelände liegt echt zwischen +40 und +65 m über NN, d.h. die $40 \mathrm{~m}$ - und $65 \mathrm{~m}$ Isohypse werden auf der Relief-Karte nicht mehr erreicht.

Im NE des Blattes hebt sich als relativ ebene und geschlossene Platte in dem Dreieck zwischen Lachendorf im W, Hohnhorst im NE und Helmerkamp im SE die Bunkenburger Lehmgeest mit Höhen zwischen 50 und fast $65 \mathrm{~m}$ über NN gut heraus.

Im NW tritt ebenso klar die Gockenholzer Geestinsel mit einer Höhenlage zwischen 50 und $61 \mathrm{~m}$ hervor. Hier betont besonders die $55 \mathrm{~m}$-Isohypse die isolierte Lage der Platte.

Dazwischen ist das Lachtetal mit den Nebentälern der Aschau und der Lutter eingetieft. Im N reicht noch die Geestplatte von Beedenbostel ins Kartenblatt, die etwa durch die $55 \mathrm{~m}$ Isohypse begrenzt wird.

Sehr deutlich sichtbar wird auf der Relief-Karte der Rand des Urstromtales durch die etwa SE -NW verlaufenden parallelen engen Höhenlinien, die den Erosionsrand des Tales anzeigen. Oberhalb Lachendorfs sind es die 50, 47,50 und 46,25 m-Isohypse und unterhalb des Ortes die 45, 46,25 und 47,50 m-Isohypse, die eng geschart verlaufen, womit auch das allgemeine Gefälle des gesamten Aller-Urstromtales zum Ausdruck kommt.

Südlich des Talrandes als markanter morphologischer Leitlinie verlaufen die Isohypsen in weitem Abstand ${ }^{2}$, im NW fast parallel zum Talrand, vor der Lachtetalmündung schwingen sie in einem weiten Bogen aus, laufen dann noch ein Stück wieder fast parallel zum Talrand, um dann ins Tal hinein umzubiegen.

Besonders regelmäßig verlaufen die Isohypsen vor dem Ausgang des Lachtetales, das zwischen 47,50 und 50 m über NN liegt. Die weiten Bögen der Höhenlinien nach SW machen die morphographische Struktur des Schwemmfächers deutlich, der sich ganz schwach gewölbt weit in das Urstromtal vorschiebt und besonders im SW Lachendorfs die Landschaft gestaltet und ihr ein völlig flaches, schwach nach SW geneigtes Gepräge verleiht ${ }^{3}$. Diese Regelmäßigkeit wird nur im W Lachendorfs am Nordwest-Rand des Fächers durch den Einschnitt der Talaue gestört.

Ein ganz eigenes Element in diesem meist sanftem Relief bieten Dünen mit ihrem kuppigen und fein modellierten Relief, die in größerer Anzahl im S und SW des Raumes auftreten.

Trotz der geringen Reliefunterschiede ergibt sich so ein klar gegliedertes morphographisches Bild mit deutlich ausgeprägten morphologischen Einheiten und Leitlinien.

Das Lachtetal ist um etwa 10-15 m in die Grundmoränenplatten eingetieft. Die Talhänge sind offenbar solifluidal verflacht ${ }^{4}$ und heute mit ganz sanftem Anstieg ausgebildet. Den Talboden nimmt eine pleistozäne Terrasse ein, in die die Talaue um etwa 1,50- $2 \mathrm{~m}$ eingetieft

\footnotetext{
${ }^{1}$ s. Kap .über den Nutzungswandel in den Allerwiesen

${ }^{2}$ Bei der Relief-Karte ist zu beachten, dass keine einheitlichen Äquidistanzen gewählt wurden für die Darstellung der Hochflächen und der Morphographie des Allertales.

${ }^{3}$ Eine Messung auf der Straße Lachendorf-Oppershausen ergab eine Neigung des Geländes nach SW um weniger als $1^{\circ}$.

${ }^{4}$ vgl. Illies, H., Formengeschichte und Entwässerung des Unterelbe-Gebietes während der Eiszeiten, Hamburg 1951, S. $10 \mathrm{f}$
} 
ist, wobei der Steilrand der Aue teilweise sehr markant ausgeprägt ist. Die Talaue ist nicht nur in den Terrassenkörper eingeschnitten, sondern auch in gleicher Weise in den Schwemmfächer im Bereich des Urstromtales.

In die Grundmoränenplatten sind einige ebenfalls solifluidal verflachte Trockentäler $^{1}$ eingetieft. Diese bestimmen wegen ihrer breiten muldenartigen Form das morphographische Bild nur wenig, sind aber für das kulturräumliche Gefüge, wie sich zeigen wird, von besonderer Bedeutung. Hinzuweisen ist für die Lachendorfer Flur auf die beiden ostwestlich verlaufenden Trockentäler am Westrand der Bunkenburger Lehmgeest und auf das etwa nordsüdlich verlaufende Trockental am Südost-Rand der Gockenholzer Geestinsel nordwestlich des Ortes, wie sie auf der Geomorphologischen Karte dargestellt sind.

In dem schwach reliefierten Gebiet gibt es einige Kleinformen unterschiedlicher Entstehung: Natürlicher Entstehung sind die bereits erwähnten Binnendünen, deren größtes Exemplar der Lorkberg an der alten Schwarzwassermündung ist. Dazu gehören aber auch kleinere Dünen bzw. Dünenreste, die sich am Ausgang des Lachtetales im NE des Ortes auf der Terrasse und am Westrand der Siedlung auf dem Schwemmfächer finden. Die Dünen am früheren Ortsrand sind heute durch Überbauung oder Umnutzung weitgehend überformt und anders als bei der Kartierung 1966 - im Gelände meist nicht mehr zu erkennen. Einzelne Exemplare solch kleiner Dünen treten auch heute noch sichtbar im äußersten W der Gemarkung nahe der Lachte auf.

Die sehr flachen Dünen in der Abteilung $210^{2}$ der ehemaligen Klosterforst wurden von der forstlichen Standortaufnahme als rezente Bildungen angesprochen ${ }^{3}$, sie sind auch auf der amtlichen Geologischen Karte nicht verzeichnet ${ }^{4}$.

Sehr fein modelliert war die Oberfläche der Allerwiesen zwischen dem Bärengraben und dem Schwarzwasser im südlichsten Gemarkungsteil. Hier wechselten natürlicherweise immer wieder lang gestreckte Sandköpfe und etwas tiefer gelegene flache Rinnen.

Anthropogener Entstehung sind dagegen andere Kleinformen:

Etwa $2 \mathrm{~km}$ südlich des Ortes unweit des Trockenwiesenweges findet sich auf der Topographischen Karte 1:25000 eine Signatur ${ }^{5}$, die eine kreisförmige Vollform anzeigt, jedoch keine Düne darstellen soll. Beim Geländevergleich zeigte sich, dass es sich um drei etwa konzentrische Ringwälle von gut 0,5 m Höhe handelt. In der Feldmark fanden sich noch zwei weitere solche Bildungen in der Abteilung 217 und ungefähr $600 \mathrm{~m}$ östlich am Waldrand.

Diese Wälle auf der ebenen Fläche des Schwemmfächers erwiesen sich aufgrund von Befragungen und nach der .Aussage des Blattes Beedenbostel der Königl. Preuss. Landesaufnahme von 1901 als ehemalige Plätze für Bienenzäune.

Als weitere anthropogen bedingte Kleinformen sind die Pflugbeete und Wölbäcker ${ }^{6}$ zu nennen, die beide das Ergebnis des Pflügens sind. Beide Formen sind morphologisch sehr ähnlich und daher leicht zu verwechseln, haben aber nach ihrer Entstehung nichts miteinander zu tun.

\subsubsection{Naturräumliche Gliederung der Mittleren Südheide}

Die glazialmorphologische Grundstruktur der Mittleren Südheide, dargestellt in Karte 2.5, wirkt sich prägend auf fast alle Naturfaktoren dieses Raumes aus und lässt sich im räumlichen Muster der verschiedenen Landschaftselemente immer wieder deutlich zeigen bzw. nachweisen.

Die weitere Untersuchung konzentriert sich auf zwei Teilbereiche dieses Raumes:

\footnotetext{
${ }^{1}$ Diese kommen auf der Relief-Karte nicht zum Ausdruck, vgl. daher mit der Geomorphologischen Karte.

2 s. Topogr. Karte, im SW des Ortes liegt die Abt. 210

${ }^{3}$ vgl. Erläuterungen Miele, S. 10; s. auch Bodenkarten

${ }^{4}$ s. Geologische Karte $1: 25000$, Blatt Beedenbostel 58

${ }^{5}$ s. Topogr. Karte, Planquadrat 3584 Recht und 30 Hoch

${ }^{6}$ Entstehung und Unterscheidung beider Formen: s. Kapitel 3
} 
- Den südlichen Teil der Mittleren Südheide, die Lachter Geest nördlich des Urstromtalrandes und

- den nördlichen Teil des Mittleren Allertales zwischen Aller und Schwarzwasser im Süden und dem Urstromtalrand im Norden.

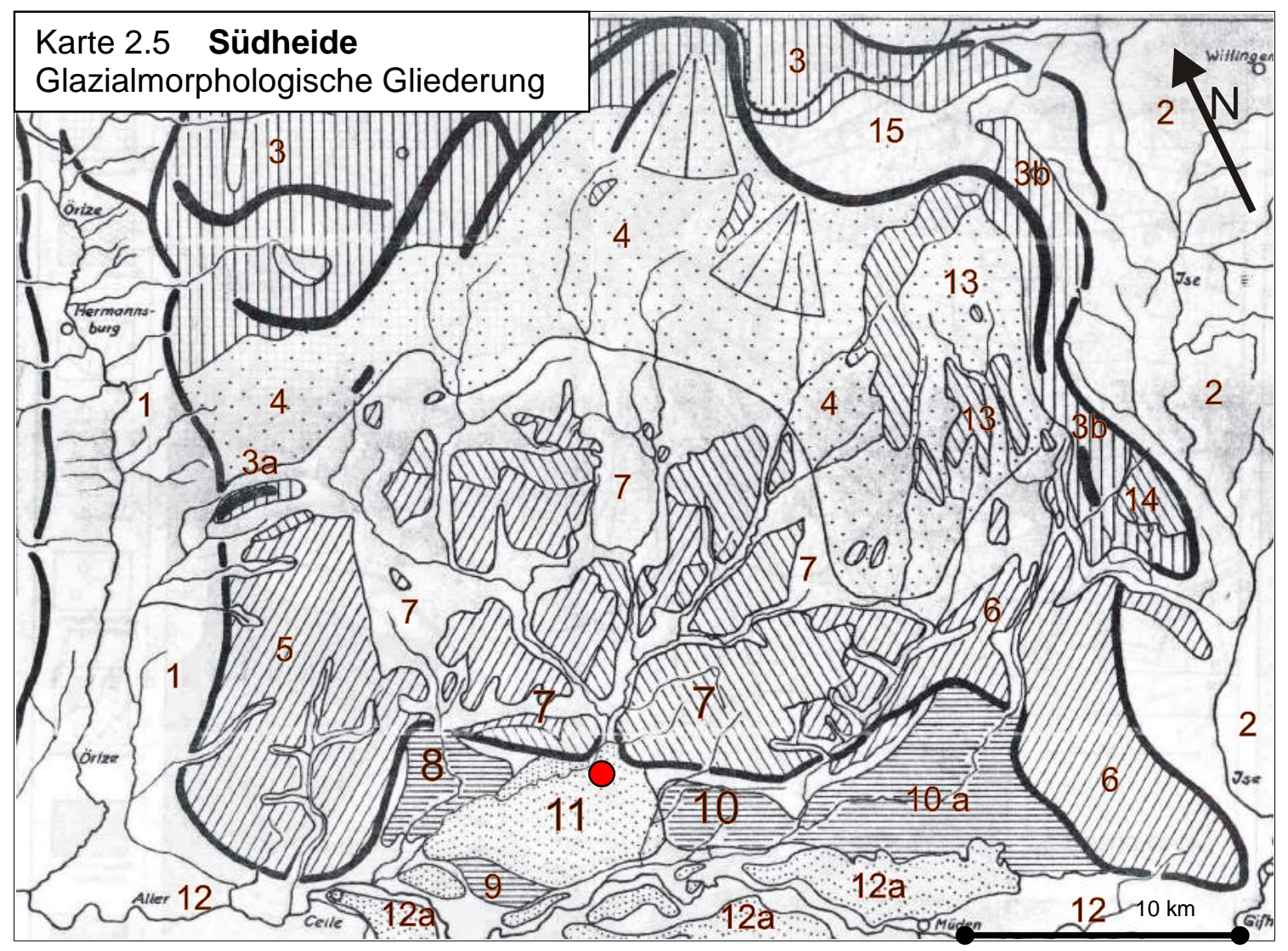

\begin{tabular}{|c|c|c|}
\hline $\begin{array}{l}\text { Legende: } \\
\text { Urstromtäler }\end{array}$ & Geest & Randmoore \\
\hline 1 Örtzetal & 4 Örreler Sander & 8 Schweinebruch \\
\hline 2 Isetal & 5 Arloh & 9 Osterbruch \\
\hline 12 Allertal & $\begin{array}{l}6 \text { Ringelahs Heide } \\
7 \text { Lachter Geest }\end{array}$ & $\begin{array}{l}10 \text { Dreckwiesen } \\
10 \text { a Hahnenmoor }\end{array}$ \\
\hline Endmoränen & 13 Reker Geest & \\
\hline $\begin{array}{l}\text { Lüßplateau } \\
\text { 3a Miele }\end{array}$ & $\begin{array}{c}14 \text { Wahrenholzer } \\
\text { Lehmgeest }\end{array}$ & $\frac{\text { Talsande }}{11 \text { Schwemmfächer }}$ \\
\hline 3b Hankensbüttel & $\begin{array}{l}15 \text { Wettendorfer } \\
\text { Flottsandinsel }\end{array}$ & 12 a Talsandinseln \\
\hline
\end{tabular}

Quellen: Kartengrundlage: TK 1:200000, Blatt 73 Celle und Blatt 74 Salzwedel Inhalte:

Bentz, A.; Geologische Übersichtskarte von Nordwest-Deutschland, 1:30000, Hannover 1951;

Brüning, K., Hg.; Wasserwirtschaftsatlas von Niedersachsen, 1:100000, Teil II, Blatt 237 Soltau,

Blatt 238 Uelzen, Hannover 1961;

Hövermann, J. und W. Tietze; Die naturräumlichen Landschaften Niedersachsens, Geogr. Rdsch. Jg. 9, 1957, S. 163-168;

Meisel, S.; Die naturräumlichen Einheiten auf Blatt 73 Celle, Geogr. Landesaufnahme 1:200000, Bad Godesberg 1960;

Schroeder-Lanz, H.; Glazialmorphologische Übersichtskarte der Lüneburger Heide, Hamburger Geogr. Studien, H. 18, Karte 2, Hamburg 1964

Bearbeituna. Eraänzuna. Zeichnuna: A. Behr (Oriainal auf Transparent) 


\subsubsection{Die Lachter Geest}

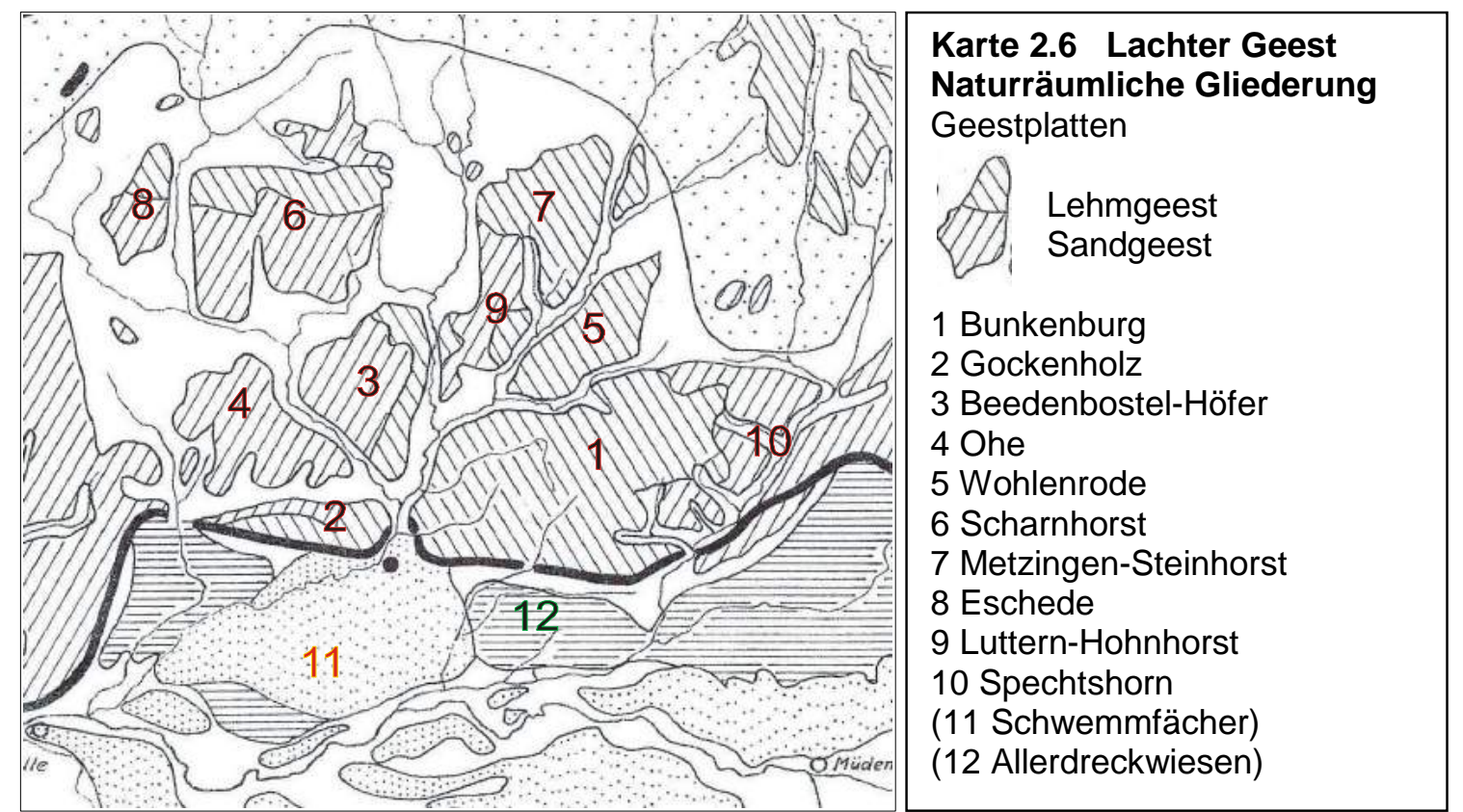

Zwischen den beiden Geestspornen von Celle und Gifhorn ${ }^{1}$, dem Arloh im W und Ringelahs Heide im E, erstreckt sich, vielfach gegliedert und aufgelöst durch die Täler der Lachte und ihrer Zuflüsse, eine Geestplatte von Alvern im SW, Eschede im NW bis Steinhorst im NE und Spechtshorn im SE, die hier als "Lachter Geest" bezeichnet werden soll2. Die flächenhaften, ebenen bis schwach welligen Geestinseln der Lachter Geest heben sich auch morphographisch deutlich im Gelände ab und bilden ein wesentliches Element in der Physiognomie der Landschaft ${ }^{3}$. Diese Platten, aus fluvioglazialen Sanden einerseits und aus Geschiebelehm andererseits aufgebaut, erheben sich mit einem sanften, aber deutlichen Anstieg aus den Niederungen und Talbereichen. Hier und dort sind die Plattenränder durch kürzere oder längere Trockentäler zerlappt. Die Täler, warthezeitlicher Entstehung, werden bestimmt durch pleistozäne Aufschüttungsterrassen, in die die heutigen Talauen meist recht scharfkantig eingetieft sind.

Alle Formen dieser Landschaft, bis auf die Ränder der Talauen, sind sehr ausgeglichen, alle Übergänge sind sanft und gleitend. Unter dem Einfluss des Periglazialklimas ist diese Landschaft durch Solifluktion sehr stark überformt, und dadurch sind weiche Übergänge zwischen den einzelnen Formelementen geschaffen worden ${ }^{4}$. Die Einschneidung der Flüsse und damit die Ausbildung der Talauen geschah erst später, weshalb die Steilränder der Talauen nicht mehr solifluidal eingeebnet worden sind.

\footnotetext{
${ }^{1}$ s. Karte 2.5

2 Einer naturräumlichen Gliederung dieser hier als "Lachter Geest" bezeichneten Geestplatten in "Escheder Geest" und "Ahnsbecker Lehmgeest", wie sie von Meisel vorgenommen wird, konnte nicht gefolgt werden, da dort ein recht einheitlicher Naturraum mit gleichmäßigem Gefügemuster ohne Grund aufgeteilt wird; vgl. dazu Meisel, S., a.a.O., s. 35 f und Kartenbeilage

${ }^{3}$ Diese Prägung der Landschaft kann man besonders deutlich beobachten, wenn man mit der Bahn von Unterlüß nach Celle fährt und auf der Strecke die Escheder Geestinsel quert, die sich sehr deutlich aus dem Niederungsgebiet mit den zahlreichen Fischteichen erhebt, während die Geestplatte selbst durchweg von Ackerland geprägt ist.

${ }^{4}$ vgl. Gripp, K., Über die äußerste Grenze der letzten Vereisung in Nordwest-Deutschland, Mitt. d. Geogr. Ges. Hamburg, Bd. 36, Harnburg 1924 S. 159-245, dort S. 242, und Illies, H., Formengeschichte und Entwässerung des Unterelbe-Gebietes während der Eiszeit, Harnburg 1951, S.10 ff
} 
Während der westliche Teil der Lachter Geest aus Sanden und Kiesen aufgebaut ist, zieht sich von Alvern über Gockenholz, Lachendorf, Ahnsbeck bis Hohne am Rande des AllerUrstromtales eine Grundmoränenplatte hin ${ }^{1}$, die sich um und südlich von Bunkenburg flächenhaft bis in den Schmarloh ausdehnt. Im N zieht sich die Grundmoräne von Hohnhorst über Metzingen - Eldingen bis nach Steinhorst im NE hin, ein Ausläufer von Eldingen über Endeholz reicht bis nordwestlich von Eschede ${ }^{2}$. Innerhalb dieses weiten Bogens erscheint die Grundmoräne noch in einem schmalen Streifen zwischen Beedenbostel und Luttern, am Ostrand der Geestplatte von Höfer. Bei Luttern greift die Grundmoräne noch ein Stück auf die östlich der Lutter gelegene Geestplatte hinauf.

\begin{tabular}{|c|c|c|c|}
\hline Bohrprofile in d & ler Mündung des Lachte & tales in das A & Aller-Urstromtal \\
\hline Bohrprofil & Nr. 1: Wasserwerk & & hrprofil Nr. 2: Papierfabrik \\
\hline $49,85 \mathrm{~m}$ ü. NN & & & \\
\hline entspr. $0,0 \mathrm{~m}$ & & Oberfläche & \\
\hline bis $0,60 \mathrm{~m}$ & Mutterboden & & Grobsand, mittelsandig \\
\hline bis $3,50 \mathrm{~m}$ & Mitelsand & bis $1,50 \mathrm{~m}$ & mittelgraubraun, kalkfrei \\
\hline bis $3,70 \mathrm{~m}$ & Fein-, Mittel-, Grobkies & & Geschiebemergel, \\
\hline bis $4,80 \mathrm{~m}$ & Geschiebemergel & & sandig, schluffig, kiesig \\
\hline bis $5,00 \mathrm{~m}$ & Mittelsand & bis $14,50 \mathrm{~m}$ & mittelgrünlichgrau, kalkhaltig \\
\hline & Geschiebemergel, & bis $17,00 \mathrm{~m}$ & Mittelsand, mittelgrau, kalkhaltig \\
\hline bis $17,80 \mathrm{~m}$ & fest gelagert & & Schluff, tonig, sandig, kiesig \\
\hline bis $18,30 \mathrm{~m}$ & Fein-, Mittelsand & & gunkelgrünlichgrau, kalkhaltig \\
\hline & Geschiebemergel, & bis $24,00 \mathrm{~m}$ & Geschiebemergel \\
\hline bis 34,60 & fest gelagert & & Feinsand, stark schluffig \\
\hline bis $39,60 \mathrm{~m}$ & Mittelsand & bis $32,00 \mathrm{~m}$ & mittelgrünlichgrau, kalkhaltig \\
\hline bis $41,80 \mathrm{~m}$ & Grobsand, Feinkies & & Feinsand, schluffig \\
\hline bis $42,50 \mathrm{~m}$ & Feinsand & bis $35,00 \mathrm{~m}$ & mittelgrünlichgrau, kalkhaltig \\
\hline bis $44,10 \mathrm{~m}$ & Fein-, Mittel-, Grobkies & & Mittelsand, grobsandig, \\
\hline bis $47,20 \mathrm{~m}$ & Mittelsand & & feinsandig. kiesig, \\
\hline bis $47,50 \mathrm{~m}$ & Grobsand, Feinkies & bis $45,00 \mathrm{~m}$ & hellgelblichgrau, kalkhaltig \\
\hline $50,00 \mathrm{~m}$ & $\begin{array}{l}\text { Tonstein, sehr hart } \\
\text { gelagert, klüftig }\end{array}$ & $47,00 \mathrm{~m}$ & $\begin{array}{l}\text { Grobsand, mittelsandig, feinkiesig } \\
\text { hellgelblichgrau, kalkhaltig }\end{array}$ \\
\hline Quelle: Bohra & hiv, TK 25, Nr. 3327, L & d. Nr. 88 und & \\
\hline
\end{tabular}

Die Grundmoränenplatten, die dem Erosionsrand des Urstromtales zu besonders markanter Ausprägung verholfen haben, gehören zu den ältesten Bildungen dieses Gebietes. Der Geschiebelehm ist präwarthezeitlicher Entstehung, er wird weiter im N, W und $E$ von warthezeitlichen Sanden und Kiesen in einer Mächtigkeit bis zu $12 \mathrm{~m}$ überlagert ${ }^{3}$.

Die Decksandschicht ist periglazial entschichtet und heute recht stark mit Geschieben durchsetzt, eine Erscheinung, die ebenfalls auf Frostwirkung zurückzuführen ist ${ }^{4}$.

Die Lachter Geest bietet mit ihren zahlreichen durch Täler und Niederungen gegliederten Geestinseln, den isolierten Platten und eingetieften, früher ${ }^{5}$ meist vermoorten Rinnen das Bild einer typischen Geest im Sinne Hövermanns und Tietzes ${ }^{6}$.

\footnotetext{
${ }^{1}$ vgl. Karte 1 und die Geologische Übersichtskarte von Nordwest-Deutschland $1: 300000$.

2 vgl. Geol. Übersichtskarte von Nordwest-Deutschland $1: 300000$ und Helmke, Fr. und H. Hohls, Der Speicher, Heimatbuch für den Landkreis Celle, Celle 1930, im folgenden zitiert als "Der Speicher", S. $40 \mathrm{f}$

${ }^{3}$ vgl. Harbort, E., Wissenschaftliche Ergebnisse der Aufnahme der Blätter Celle und Beedenbostel, in: Ber. über die wiss. Ergebnisse der geol. Aufnahme im Jahre $1911 \mathrm{im} \mathrm{Jb.} \mathrm{d.} \mathrm{kgl.preuß.} \mathrm{Landesanstalt}$ von 1911, Bd. 32, T. 2, S. 497-503, Berlin 1914, s. 501

${ }^{4}$ Illies, H., a.a.O., S. 11

${ }^{5}$ Die natürlicherweise vernässten und dadurch leicht vermoorten Tiefenlinien der Mulden und Trockentäler in den Geestplatten sind durch „Melioration“ meist entwässert und kultiviert.

${ }^{6}$ vgl. Hövermann, J. und W. Tietze, Die natürlichen Landschaften Niedersachsens, Geogr. Rdsch., Jg. 9, 1957, S. 163-168, dort S. 165 f
} 
Insgesamt hat das Pleistozän im Lachendorfer Raum eine Aufschüttungslandschaft hinterlassen, die mächtige Schichten von Geschiebemergel aus einer Grundmoräne, aber auch Schichten von Sanden und Kiesen mit sehr unterschiedlicher Mächtigkeit. Mündungsbereich des Lachtetales sind glaziofluviale Ablagerungen mit einer Mächtigkeit von 50 $\mathrm{m}$ erbohrt, die sicherlich im bereich der Geestplatten noch übertroffen wird.

\subsubsection{Das Mittlere Allertal}

Das Mittlere Allertal ${ }^{1}$, ein Abschnitt des großen Abb. 2.1 Profil Allertal warthezeitlichen

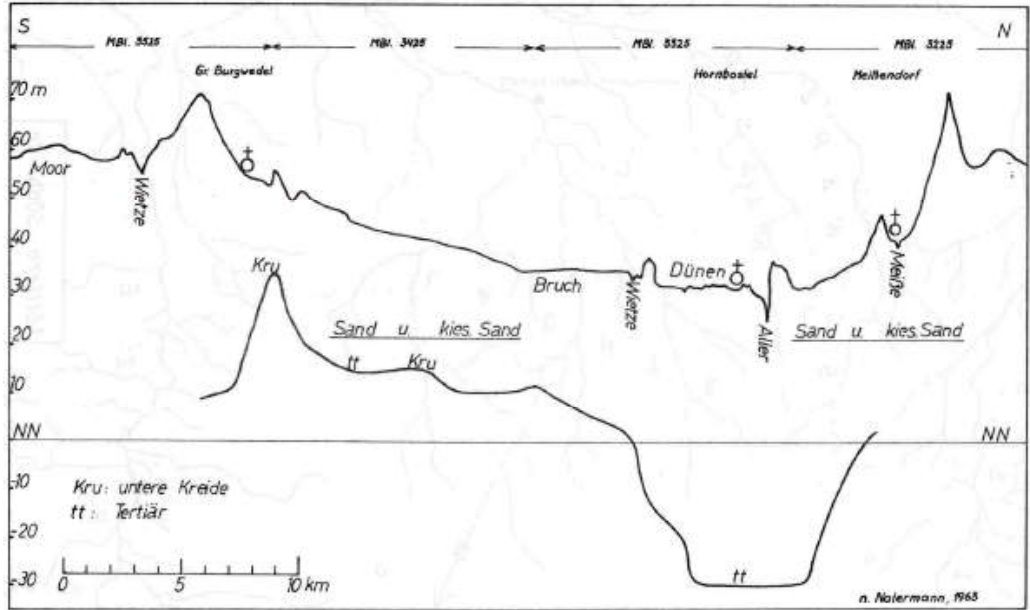

Urstromtales, hat in seinem Verlauf von ESE nach WNW zwischen Gifhorn und Celle eine durchschnittliche Breite von 18- $20 \mathrm{~km}$. Bei Gifhorn wird es durch einen von Norden vorspringenden Geestsporn auf $5 \mathrm{~km}$ eingeengt und zwischen Celle und Ehlershause ist es etwa 10 - 12 km breit.

Das Profil Allertal ${ }^{2}$ belegt, dass das sog. Aller-Urstromtal einem bereits im Präglazial angelegten Tal folgt, in und über diesem Tal eine mächtige Aufschüttungslandschaft schuf, in der die rezente Aller mäandrieren und durch Hochwässer auch immer wieder ihren Lauf verändern konnte. Wie bei Flüssen in Urstromtälern üblich, passen heutiger Fluss und Tal gröBenmäßig nicht zusammen.

Die weitere Darstellung bezieht sich nur auf den nördlichen Teil des Mittleren Allertales, da nur dieser für den Untersuchungsraum relevant ist.

Der nördliche Rand des Urstromtales schwingt von Gifhorn zunächst in nördliche Richtung und biegt in einem weiten Bogen, der das Hahnenmoor einschließt, bei Ummern in nordwestliche Richtung um. Morphologisch und geologisch klar ausgeprägt verläuft der Talrand fast gradlinig über Helmerkamp, Ahnsbeck und Lachendorf bis Alvern, wo er wiederum in einem weiten Bogen, hier den Schweinebruch umschließend, nach SW umbiegt, von Celle aus ein kleines Stück wieder nordwestlich streicht und dann in den Rand des ÖrtzeUrstromtales nach $\mathrm{N}$ übergeht.

Die Aller selbst bot ursprünglich zwischen Gifhorn und Celle, an beiden Stellen den Geestsporn tangierend, das typische Bild eines mäandrieren Tieflandflusses in einem breiten Urstromtal. Heute ist die Aller weitgehend „reguliert“ und stark begradigt.

Dieser Abschnitt des Allertales nördlich des Flusslaufes zeigt bei fast völliger Ebenheit ein recht differenziertes Bild. Im Randbereich des Urstromtales, besonders in den großen Buchten bei Celle und Gifhorn, haben sich große Brüche und Moore gebildet Dabei handelt es sich um typische Randmoore im Schatten der Geestsporne am Rand des Urstromtales.

Die Talsandflächen, zum Bereich der Niederterrasse gehörig, sind inselartig aufgelöst und von den heutigen Flussläufen der Aller und des Schwarzwassers vielfach gegliedert. Breite

\footnotetext{
${ }^{1}$ bei Meynen, E., Handbuch der naturräumlichen Gliederung Deutschlands, Bad Godesberg 1961, S. 944, als "Obere Allerniederung" bezeichnet.

${ }^{2}$ Profil des Allertales nach Natermann, a.a.O.1963
} 
Flutmulden, mit Schlick und tonigem Material angefüllt, durchziehen das Tal und bilden die Leitlinien der - besonders früher - zahlreichen Hochwässer ${ }^{1}$.

Eine Besonderheit stellt der weite Talsandbereich vor der Mündung des Lachtetales in das Urstromtal dar. Die fast tischebene, schwach zur Aller geneigte Sandfläche ist randlich von vermoortem Gelände umgeben vom Schweinebruch im NW, von den Osterbruchwiesen im SW und von den Aller-Dreckwiesen im SE. Auf allen thematischen Karten kommt der Gegensatz zwischen dem Sandgebiet vor der Lachtetalmündung und den angrenzenden Brüchen ganz besonders gut zur Geltung Die trockenen Sandgebiete stehen in scharfem Gegensatz zu dem durch hohen Grundwasserstand geprägten Brüchen und Feuchtgebieten.

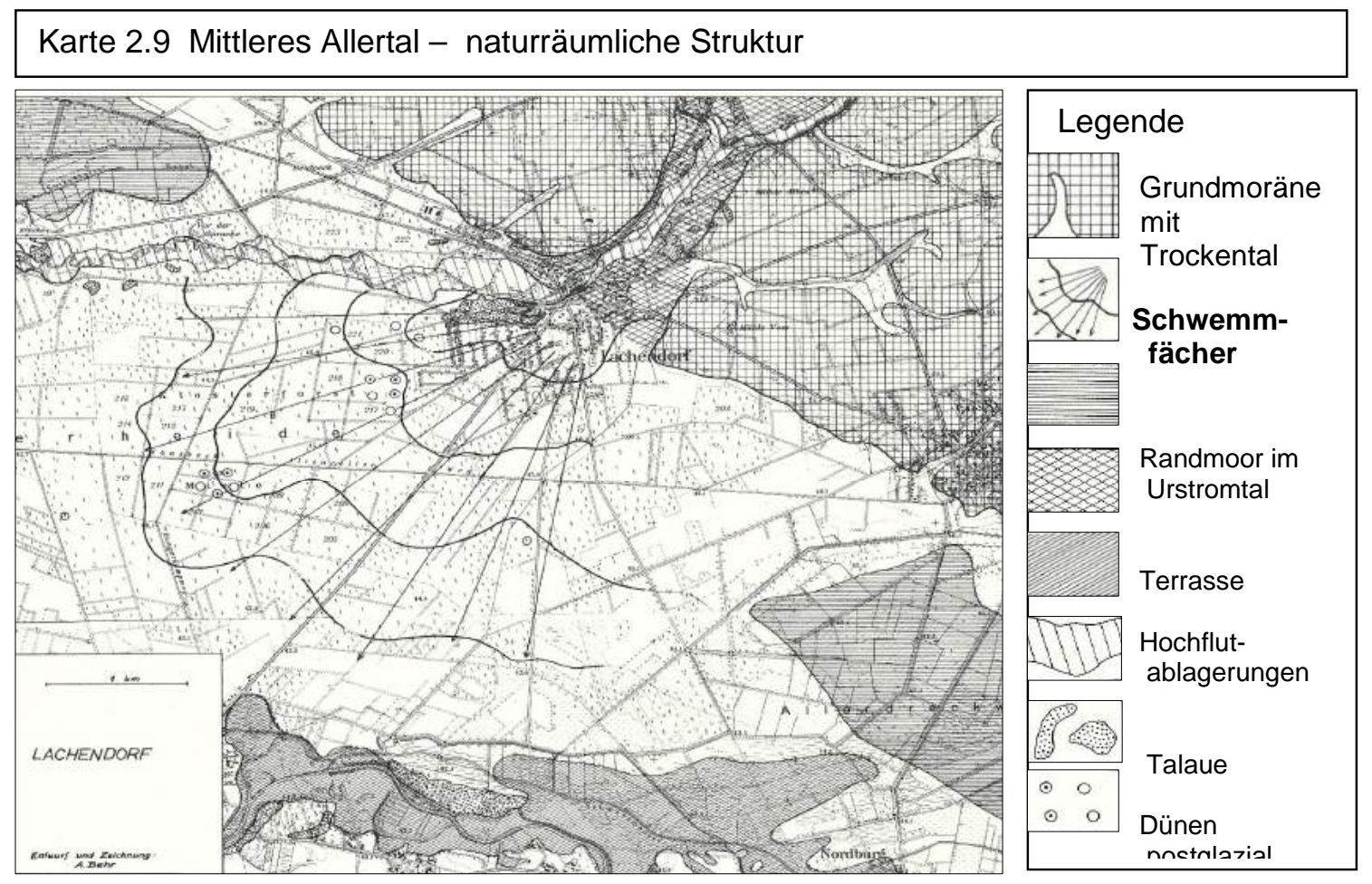

Quelle: A. Behr, Feldarbeit - agrarökologische Raumanalyse (UE S II); In: Praxis Geographie, Heft 10, 1982, S, 14, Westermann Verlag Braunschweig Kartengrundlage: TK 25, Blatt Beedenbostel; Entwurf und Zeichnung: A. Behr

Bei dieser großflächigen Bildung handelt es sich um einen riesigen Schwemmfächer, der sich vor der Mündung des Lachtetales ins Urstromtal der Aller gebildet hat ${ }^{2}$. Dieser Schwemmfächer ist nicht der heutigen Lachte zuzuschreiben, sondern ebenso wie das Lachtetal selbst den aus Norden abfließenden Schmelzwassern, die das mitgeführte Material beim Eintritt in das Allertal aufgrund der dort stark verminderten Fließgeschwindigkeit ablagerten.

Ein weiteres Landschaftselement stellen die Binnendünen ${ }^{3}$ dar, die sich in einzelnen Exemplaren auch noch im Mündungsbereich des Lachtetales und in der Wurzelzone des Schwemmfächers befinden ${ }^{4}$. Im Mittleren Allertal erheben sich aus der sonst ganz ebenen Landschaft mehrere größere Dünengebiete, wie z.B. bei Sandlingen, bei Offensen und östlich von Müden-Dieckhorst. Im engeren Untersuchungsgebiet ist besonders der Lorkberg am Schwarzwasser zu nennen.

\footnotetext{
${ }^{1}$ vgl. Der Speicher, a.a.Q., S. 303

${ }^{2}$ vgl. Meisel, S, , a.a.O., S. 12

${ }^{3}$ s. Geol. Karte 2.8

4 ebenda; Aufgrund der Siedlungserweiterung Lachendorfs sind einige der kleinen Dünen durch Bebauung nicht mehr im Gelände erkennbar.
} 
Bei den größeren Bildungen handelt es sich zweifellos um spätpleistozäne bzw. postglaziale Aufwehungen ${ }^{1}$. In historischer bzw. in jüngster Zeit haben aber beträchtliche Umlagerungen und erneute Verwehungen stattgefunden².

So konnte Moll ${ }^{3}$ im Zuge forstlicher Standortkartierungen einwandfrei aufgrund von Profilvergleichen postglaziale Dünen und Bildungen jüngerer Zeit unterscheiden ${ }^{4}$. Bei letzteren fehlt bisher eine stärkere Humusanreicherung und auch ein sekundärer Illuvialhorizont ist nicht festzustellen, während sich unter den jüngeren Aufwehungen ein gut ausgeprägtes Podsolprofil fand, das ganz der Bodenbildung auf ungestörten Flächen glich ${ }^{5}$. Das Alter dieser jungen Bildungen im Lachendorfer Bereich konnte nicht genau festgestellt werden, jedoch bezeugen Urkunden aus benachbarten Gebieten, dass es besonders in der 2. Hälfte des 19. Jahrhunderts in den alten Heideflächen zu besonders starken Verwehungen gekommen ist ${ }^{6}$. Vom Dünengebiet nordwestlich des damaligen Ortes, dem heutigen Quäloh', wird berichtet, dass die Gemeinde seitens der Regierung aufgefordert wurde, das Gelände zu befestigen und aufzuforsten. Durch übermäßigen Schnuckentritt war die ohnehin schon schüttere Vegetationsdecke von Heide und spärlichen Gräsern zerstört worden und der Wind hatte begonnen, sein Spiel mit dem Sand zu treiben, so dass es bis ins Dorf zu Sandanwehungen kam.

Ein entsprechendes Bodenprofil (s. Profil 1) $)^{8}$ zeigt eine Aufwehung mit Horizontstörung über einem gekappten Podsolprofil. In der jüngeren Aufwehung hat bisher noch keine nennenswerte Bodenbildung stattgefunden, es handelt sich noch um einen ausgesprochenen Rohboden, der sich langfristig - ohne Umnutzung zu Bau- und Gartengrundstück

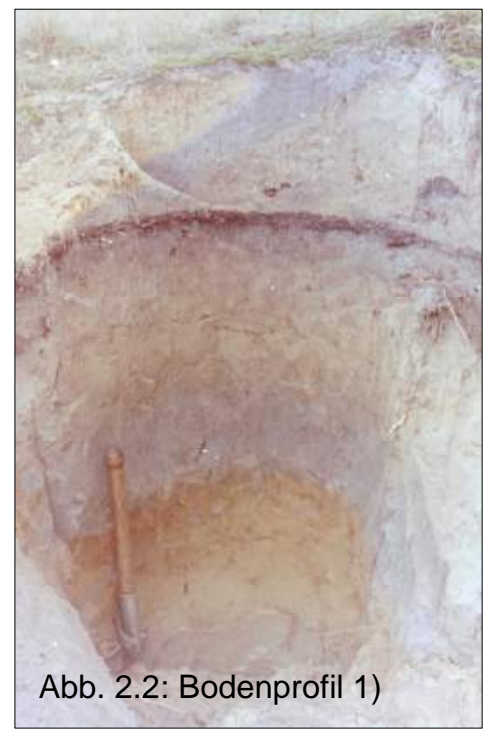
- zu einem Podsol entwickelt hätte.

Dagegen unterscheiden sich die postglazialen Dünen von den angrenzenden Flächen hinsichtlich der Bodendynamik und dem Grad der Podsolierung nicht".

Bei den kleineren Dünenbildungen ist es oftmals schwierig, natürliche Bildung und anthropogen bedingte Umwandlungen und Neubildungen zu unterscheiden.

\subsubsection{Relief und Geologie des Lachendorfer Raumes}

s. Karte 2.7 Relief und Karte 2.8 Geologie

Im Lachendorfer Raum erkennt man anhand der Karten eine sehr deutliche Entsprechung der geologischen Struktur und des Reliefs: Die geologisch bedingten Geestplatten aus dem Drenthe-Stadium heben sich durch den markanten Rand des Urstromtales und die kuppige

\footnotetext{
${ }^{1}$ Die Geologische Übersichtskarte 1:200000 von 1977 ordnet die Dünen zeitlich dem Übergangsbereich von der Weichsel-Kaltzeit zum Holozän zu.

${ }^{2}$ Dies deutet auch ein Heidjer-Sprichwort an:: "De Wind weiht woll Barge tosamen", aus: Moll, H.W. , Erläuterungsbericht zur Standorts- und Vegetationskartierung des Klosterforstamtes Miele, Aufnahme abgeschlossen im Dez. 1959, unveröffentlicht, Sachverzeichnis der Forstmeisterstelle Miele, Nr. I, 25; im folgenden zitiert als "Erläuterungen Miele " ; S. 19

${ }^{3}$ ebenda, S. $18 \mathrm{ff}$

${ }_{5}^{4}$ Auf die ökologische Bedeutung dieser Unterschiede wird noch näher eingegangen.

${ }^{5}$ s. Erläuterungen Miele, S. 19

${ }^{6}$ Für den Raum Soltau sind mit Sicherheit Dünenbildungen zur Zeit der Großaufforstungen in der 2. Hälfte "des 19. Jahrhunderts nachgewiesen. Vgl. Erläuterungen Miele,S.19

${ }^{7}$ vgl. Schulchronik II, S. 48 f

${ }^{8}$ Profil 1) Ortsausgang an der Jarnser Straße, auf der Terrasse des Lachtetales, heute überbaut Aufnahme: A. Behr, 1966

${ }^{9}$ Erläuterungen Miele, s. 18
} 
Oberfläche sehr deutlich vom Allertal mit dem Schwemmfächer der Lachte ab, das geologisch und morphologisch im krassen Gegensatz dazu steht.

Dieser naturräumliche Gegensatz hatte in der Landnutzung und in der Gestaltung der Kulturlandschaft stets eine große Bedeutung und wird daher in den weiteren Darstellungen immer wieder auftauchen.

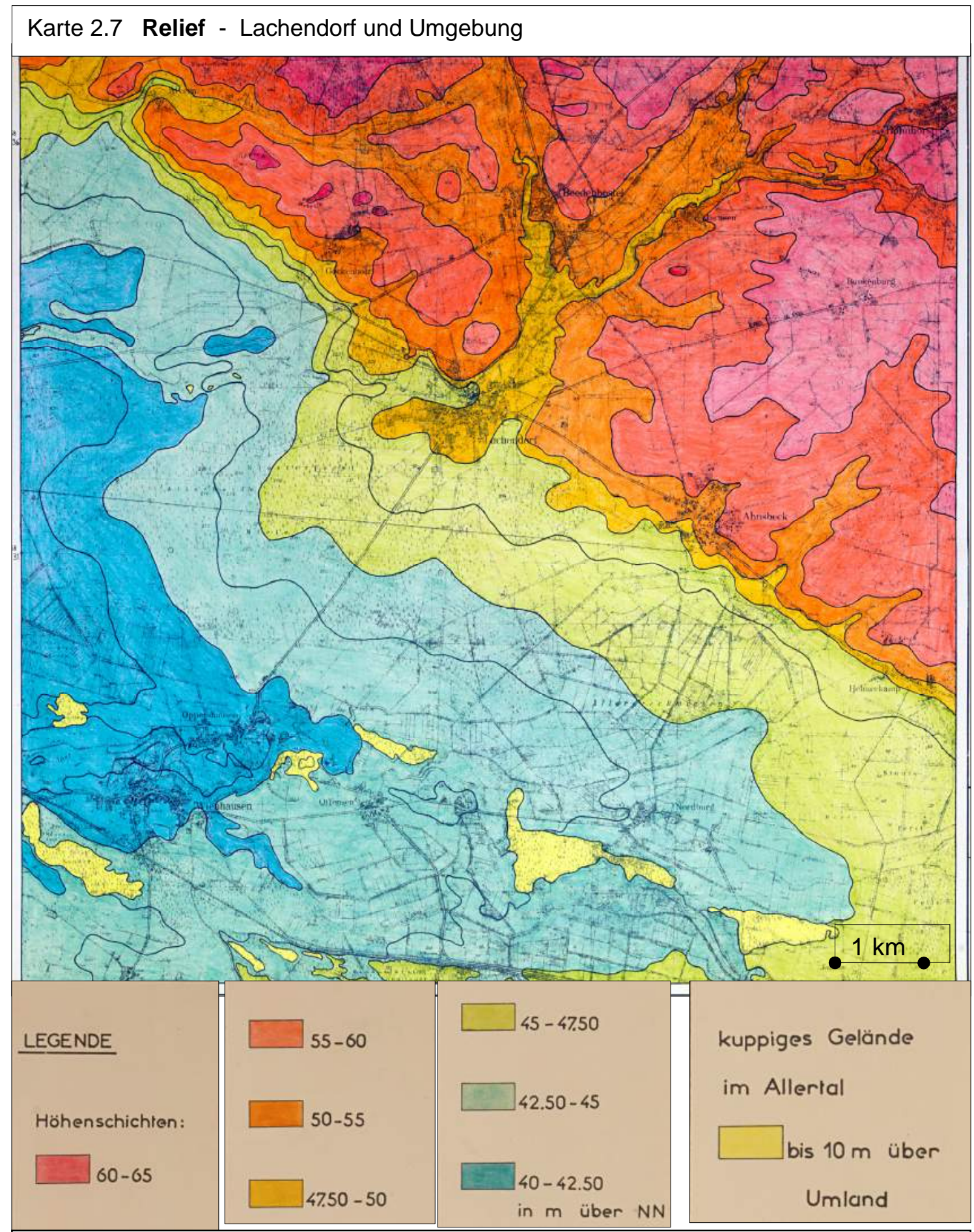

Quelle:

Kartengrundlage: Mutterpause aus der TK 25, Blätter 3327 und 3427,

Wasserwirtschaftsamt Celle,

handkolorierte Höhenschichten: A. Behr, 1967, digitalisiert 2012 


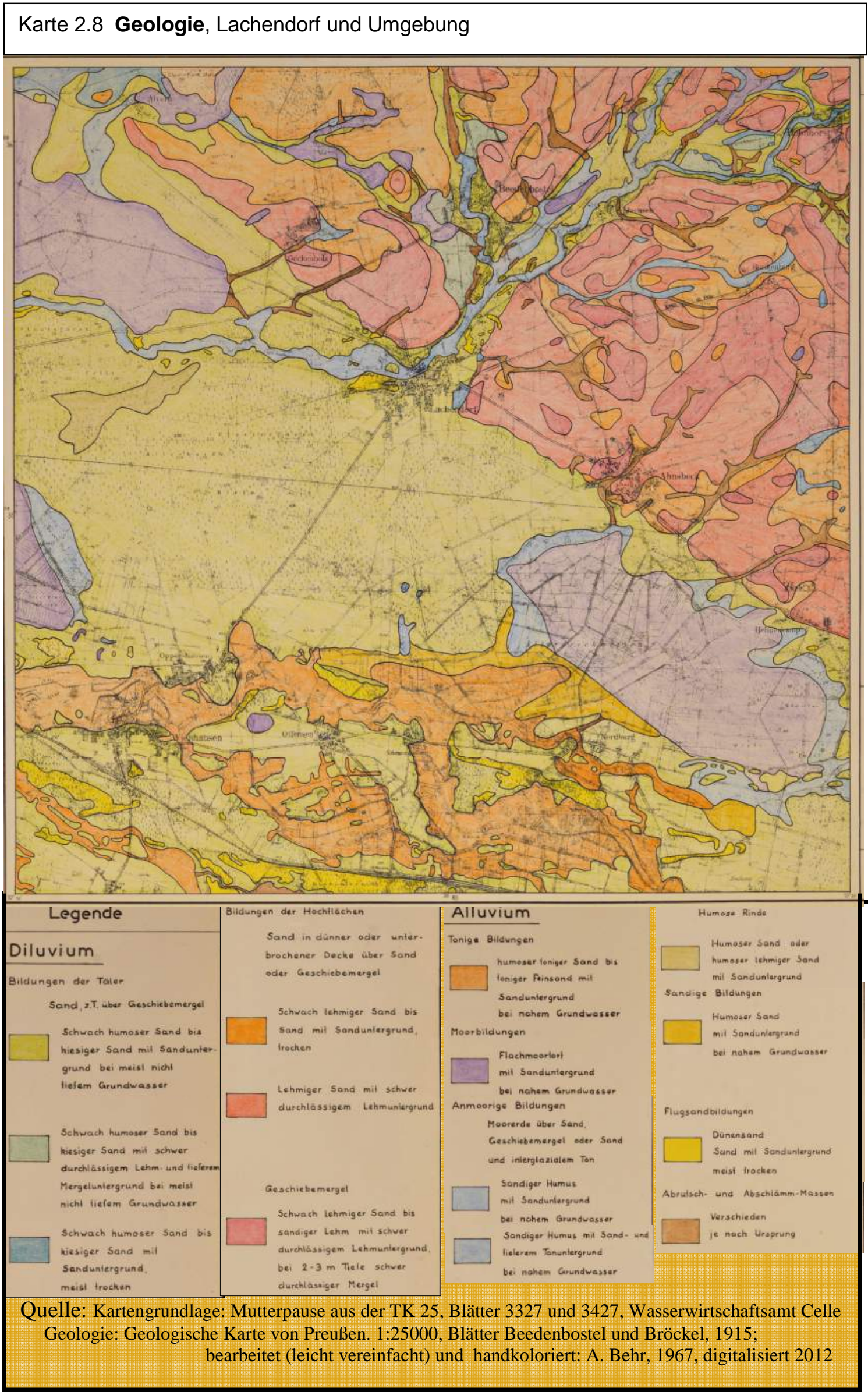


Die Grenze zwischen den Geestplatten im NE und dem Allertal im SW des Blattes tritt zwischen Alvern und Helmerkamp deutlich hervor. Die Geestplatten (Gockenholzer Geestinsel und Bunkenburger Lehmgeest) werden von schwach lehmigen bis lehmigen Sanden über schwer durchlässigem Lehm- und Mergeluntergrund aufgebaut.

Die Trockentäler greifen als schmale lang gestreckte Zungen in die Geestplatten hinein und sind durch Abrutsch- und Abschlämmassen, also durch umgelagertes Material der Hochflächen, gekennzeichnet.

Der größte Teil der Lachendorfer Feldmark wird von Talsanden ${ }^{1}$, Sanden bis kiesigen Sanden mit Sanduntergrund, eingenommen, die die Lachteterrasse und den Schwemmfächer aufbauen. Die Talsandflächen werden von der Flussaue durchzogen, die sich durch anmoorige Bildungen klar abhebt. Die Talsandfläche des Fächers ist umgeben von Moorbildungen, in denen Flachmoortorf über Sand bei nahem Grundwasser ansteht. Die Lachendorfer Flur hat in den Aller-Dreckwiesen gerade noch einen geringen Anteil daran. Der übrige südliche Gemarkungsteil nördlich des Schwarzwassers wird im Randbereich des Niedermoores und im Krähenmoor ${ }^{2}$ von anmoorigen Bildungen bestimmt, die aber sehr sandiger Prägung sind.

Der Hauptteil der südlichen Gemarkung wird von alluvialen, teils sandigen, teils tonigen und schlickigen Ablagerungen aufgebaut. Die tonigen Ablagerungen, die den heutigen Allerlauf und den Mühlenkanal begleiten, greifen hier über das Schwarzwasser weit nach $\mathrm{N}$ hinaus. Diese Sedimente stehen in Zusammenhang mit flächenhaften Überschwemmungen von der Aller her $^{3}$, die hier östlich des Lorkberges stark wirksam waren. Dies Gebiet entspricht auch genau den fein modellierten Flächen in den Allerwiesen, auf die weiter oben bereits hingewiesen wurde.

Das Urstromtal im südwestlichen Bereich des Blattes ist geprägt durch die stark zerlappten diluvialen Talsandinseln und die alluvialen Flusssedimente, wobei das Gelände von größeren Flächen mit Dünensanden durchsetzt ist.

Im ganzen ergibt sich eine direkte Entsprechung der morphologischen und geologischen Strukturen, besonders im Gegensatz der pleistozänen Hochflächen, die von Geschiebelehm und -sanden ${ }^{4}$ aufgebaut sind, und dem Urstromtalboden mit weiten diluvialen Talsandflächen $^{5}$, den holozänen Niedermoorbildungen und den alluvialen Flussablagerungen.

In den Kapiteln 2.3 zur Hydrologie und 2.4 zu den Böden wird weiter aufgezeigt, wie auch die hydrologischen und pedologischen Merkmale und deren räumliche Anordnung das Bild der natürlichen Raumstruktur bzw. naturräumlichen Gliederung widerspiegeln, aber auch ergänzen und vertiefen.

\footnotetext{
${ }^{1}$ vgl. Harbort, E., Wissenschaftliche Ergebnisse der Aufnahme der Blätter Celle und Beedenbostel, Berlin 1914, in: Jb. d. .Königl. Preuss. Geol. Landesanstalt, Bd. 32, T. 2, S. 497-503, dort S. 500 f

${ }^{2}$ Im Verbindungsstück zwischen dem südlichen Wiesengelände und dem nördlichen Waldgelände der Gemarkung gelegen, am Südrand des Planquadrates mit 384 Rechts und 5830 Hoch.

${ }^{3}$ Diese Verhältnisse werden im Zusammenhang mit dem Schwarzwasser noch näher erläutert.

${ }^{4}$ vgl. Harbort, E., a.a.O., S. 501

${ }^{5}$ vgl. ebenda, S. 500
} 


\subsection{Hydrologie}

\subsubsection{Hydrologische Räume und orohydrographische Struktur}

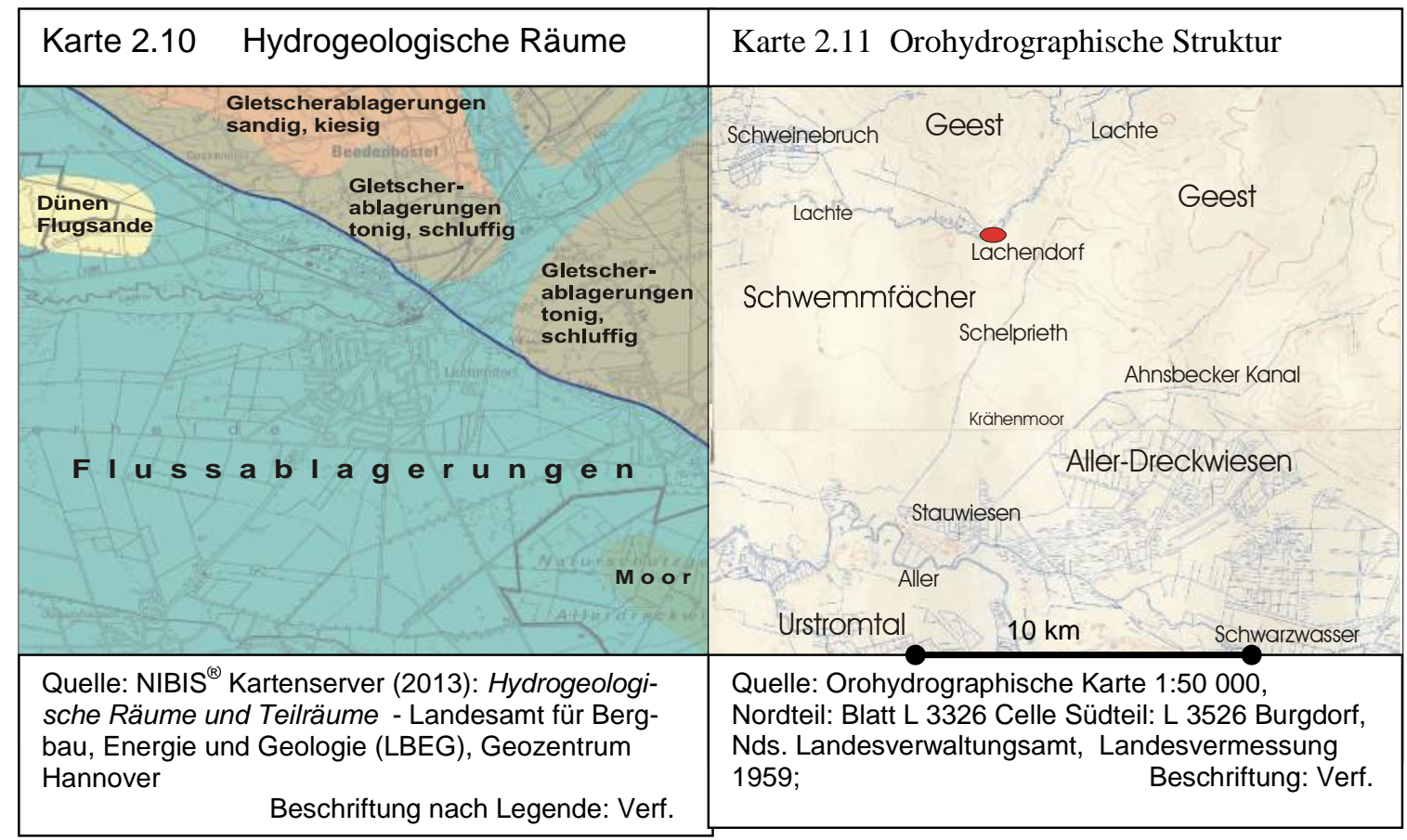

Die Hydrogeologischen Räume bestätigen bzw. entsprechen sehr genau der naturräumlichen Gliederung mit den Geestplatten, die vom Lachtetal getrennt werden, im N bzw. NE, und dem Urstromtal im S. Der Rand des Urstromtales ${ }^{1}$ bildet auch die Grenze (blaue Linie, Karte 2.10) zwischen zwei hydrogeologischen Großräumen.

Die orohydrographische Karte ergänzt dieses Bild, indem die hydrologische Raumstruktur mit der orographischen verknüpft wird. Auch darin spiegelt sich klar die naturräumliche Gliederung:

Die kuppigen Geestplatten im Norden entwässern nach SSW und werden durch den von SE nach NW verlaufenden Talrand des südlich angrenzenden Aller-Urstromtales begrenzt. Der Schwemmfächer im Urstromtal vor der Mündung des Lachtetales ist umgeben von den Randmooren Schweinebruch und Aller-Dreckwiesen sowie dem Osterbruch².

Während Aller und Schwarzwasser auf der Karte von 1959 noch das Bild vor der letzten "Regulierung“ zeigen, sind Schweinebruch und Aller-Dreckwiesen von einem dichten Grabensystem durchzogen, das zur Entwässerung künstlich angelegt worden ist.

Schelpriethgraben und Ahnsbecker Kanal, beide der Vorflut zur Entwässerung aus den Geestplatten dienend, sind ebenfalls anthropogene Eingriffe aus früheren Zeiten ${ }^{3}$ in den Landschaftshaushalt

\subsubsection{Einzugsgebiet Südheide}

\section{s. Karte 2.3: Gewässernetz der Südheide}

Die Südheide entwässert entsprechend dem Relief mit der Abdachung nach Süden direkt oder indirekt ausschließlich zur Aller.

Die Mittlere Südheide gehört zum größten Teil zum Einzugsgebiet der Lachte, die mit ihren Nebenflüssen oberhalb von Lachendorf, also außerhalb des Aller-Urstromtales auf der Lachter Geest ein Niederschlagsgebiet von 434,7 (435) ${ }^{1} \mathrm{~km}^{2}$ umfasst.

\footnotetext{
${ }^{1}$ Vgl. dazu die Karten zum Relief und zur Geologie sowie zur naturräumlichen Gliederung in Kap. 2.1.

${ }^{2}$ Der Osterbruch liegt westlich außerhalb des Kartenblattes der Karte 2.14

${ }^{3}$ Darauf wird im weiteren Verlauf der Arbeit noch hingewiesen.
} 
Das Gebiet des Arloh im W entwässert in die Örtze oder direkt in die Aller, während schon die Habighorster Niederung ${ }^{2}$ unmittelbar östlich des Arloh der Lachte tributär ist.

Der Bereich östlich der Linie Ahnsbeck Zahrenholz - Repke entwässert über das Schwarzwasser und seinen wichtigsten Zufluss, die Wiehe, in die Aller.

Da die der Aller von Norden tributären Nebenflüsse im Unterlauf innerhalb des Urstromtales fließen, greifen die Niederschlagsgebiete über die wichtigste naturgeographische Leitlinie, den Urstromtalrand, hinweg. Daher kommt auf der thematischen Karte der Niederschlagsgebiete die naturräumliche Gliederung nicht zum Ausdruck.

Die morphologische Gestalt des LachteSchwemmfächers ist mit seiner leichten

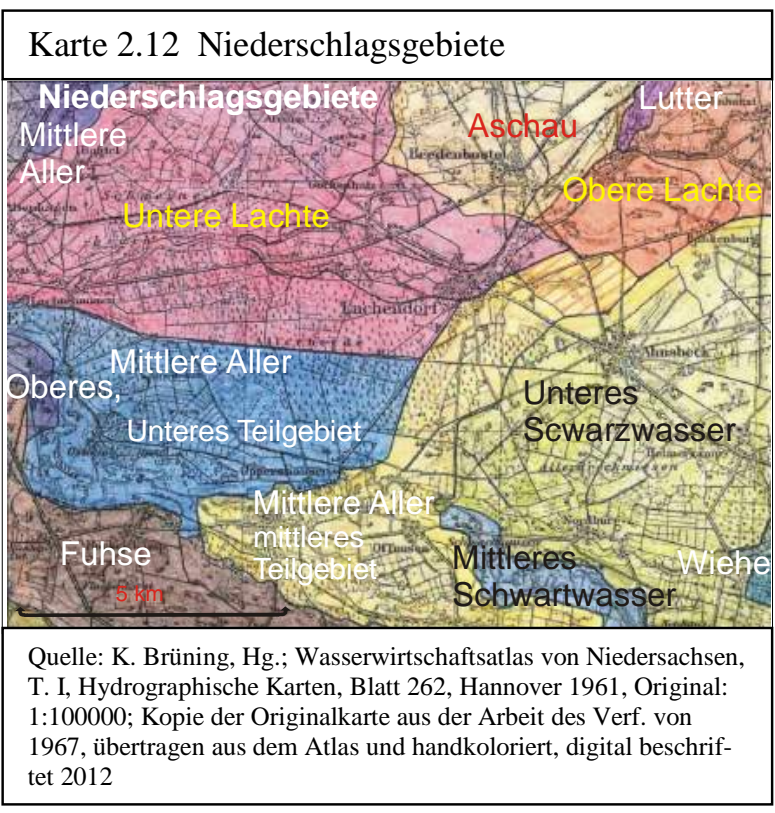
Wölbung auch bei den Niederschlagsgebieten gut erkennbar ${ }^{3}$. Die Aller-Dreckwiesen und der östliche Randbereich des Fächers entwässern zum Schwarzwasser, der schon erwähnte Zwischenteil im E direkt in die Aller, ebenso der ganze südliche Teil, dagegen entwässert der ganze nordwestliche Teil zur Lachte.

Allerdings ist die Grenzziehung zwischen den beiden zuletzt erwähnten Niederschlagsgebieten etwas willkürlich entlang des Ahnsbeck-Altenceller-Weges. Nun ist in diesem fast völlig ebenen Gebiet auf den leichten und durchlässigen Sanden des Fächers, in dem fast alle Niederschläge sofort versickern, eine Wasserscheide nur sehr schwer zu fixieren ${ }^{4}$. Einerseits ist es möglich, dass dieser alte Richtweg ganz intuitiv an der günstigsten Stelle in diesem flachen Gebiet, nämlich auf der Wasserscheide, gezogen worden ist; andererseits kann auch die Straße mit ihren seitlichen Gräben jedenfalls oberflächlich eine künstliche Wasserscheide bilden.

\subsubsection{Lachte}

Die Lachte entspringt nördlich von Lüsche im Sprakensehler Sander in einer Höhenlage von knapp 100 m über $\mathrm{NN}^{5}$. Auf ihrem Lauf durch das Lachtetal in der Mittleren Südheide in südwestlicher Richtung sammelt sie mehrere Bäche und kleine Nebenflüsse. Bei ihrem Eintritt in das Aller-Urstromtal hat die Lachte eine Höhe von etwa 46 m über NN erreicht. Der Fluss hat in diesem Talabschnitt also ein Gefälle von etwa $50 \mathrm{~m}$ und ein Einzuggebiet ${ }^{6}$ von $435 \mathrm{~km}^{2}$. Auf den letzten 9,4 km ihres Laufes unterhalb von Lachendorf hat die Lachte nur noch ein Gefälle von $6 \mathrm{~m}^{7}$.

Die Lachte besteht also aus zwei unterschiedlichen Flussabschnitten: Oberhalb von Lachendorf in einem glazial angelegten Tal im Bereich der Sander und Grundmoränenplatten und

\footnotetext{
${ }^{1} 434,7 \mathrm{~km}^{2}$ It. Pegelstammbuch, Pegel Lachendorf, Wasserwirtschaftsamt Celle (1966); 435 km² It. Pegelstandstabellen, NLWKN Verden (2012). Im Jahr 1989 wurde die Pegelmessstelle It. Auskunft von Herrn Neubauer, NLWKN Verden, etwa 100 m flussaufwärts verlegt. Durch die Verlegung flussaufwärts hätte sich eine geringfügige Verkleinerung des $F_{N}$ ergeben müssen. Daher ist der Unterschied vermutlich auf Rundung zurück zu führen.

${ }^{2}$ s. auch Meisel, S., a.a.O.,; S. 35

${ }^{3}$ ebenda

${ }_{5}^{4} \mathrm{vgl}$. Einzugsgebiete der unteren Lachte und des unteren Teilgebietes der mittleren Aller

${ }^{5}$ vgl. Topogr. Karte 1:50000, Blatt Hankensbüttel

${ }^{6}$ Pegelstammbuch, Pegel Lachendorf, WWA Celle, jetzt NLWKN Verden, Wasserstandslisten

7 vgl. Topogr .Karte 1:50000, Blatt Celle
} 
unterhalb des Ortes in einem Erosionstal auf bzw. am Rande des Schwemmfächers im Urstromtal.

Der Übergang in das Urstromtal stellt eine deutliche Änderung in der Gefällekurve des Flusses dar. Das unterschiedliche Gefälle ober- und unterhalb von Lachendorf dürfte die Überschwemmungsgefahr im und unterhalb des Ortes deutlich verstärken.

Der Verlauf der Lachte ab Lachendorf im Urstromtal ist bedingt durch die leichte Wölbung des Schwemmfächers und das allgemeine Gefälle

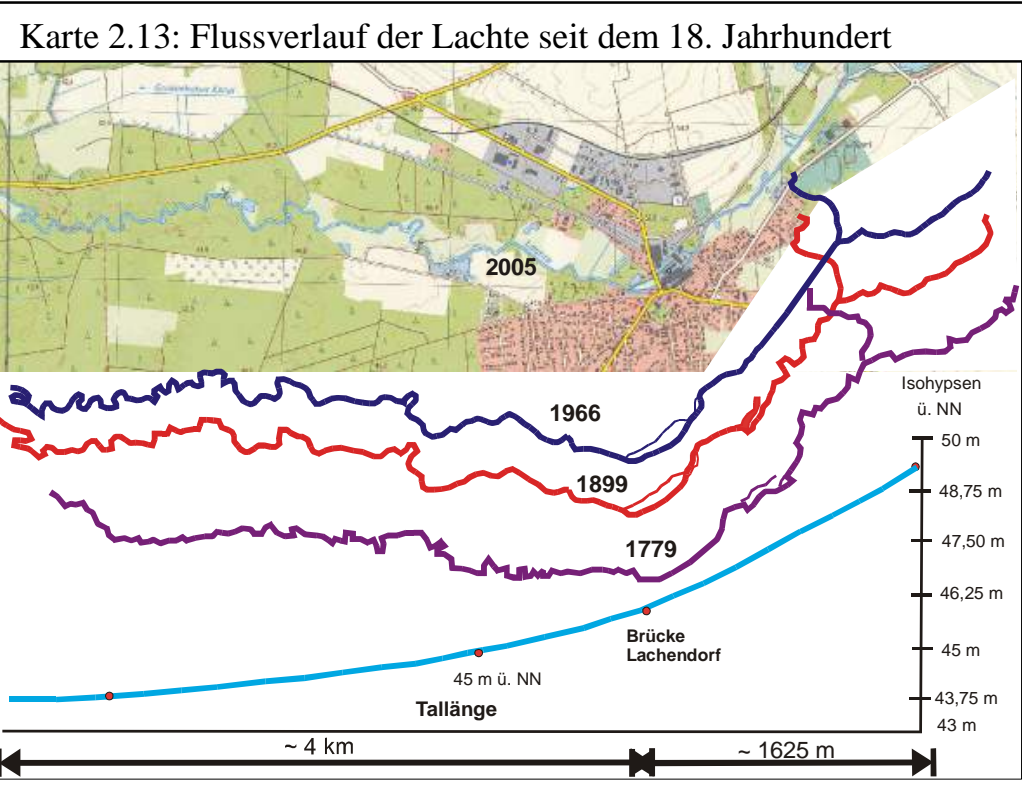

Quelle: TK 1:25000, Blatt 3327 Lachendorf, Flussverläufe aus den historischen Karten von 1781, 1899 und 1966 sowie Längsprofil der Lachte, eigener Entwurf

des Allertales: Dadurch ist die Lachte an den Nordwest-Rand ihres eigenen Schwemmkegels abgedrängt und fließt aufgrund einer verschleppten Mündung noch fast $10 \mathrm{~km}$ im AllerUrstromtal.

In früheren Zeiten hat es immer wieder Überschwemmungen mit teils erheblichen Schäden im Ort gegeben. Nach einem verheerenden Hochwasser 1841, dem die Papiermühle teilweise zum Opfer fiel, wurde die Lachte unterhalb des Ortes etwas begradigt. ${ }^{1}$

Der Kartenvergleich zeigt, dass die Lachte im Bereich des Ortes bzw. der Papiermühle bereits Ende des 18. Jahrhunderts begradigt worden war, unterhalb aber noch sehr stark mäandrierte. Diese vielen kleinen Flussschleifen sind auf der Karte von 1899 etwas begradigt, allerdings wurde der Fluss nicht kanalisiert. Ganz anders erfolgte der Eingriff dann nach 1900 oberhalb des Ortes bis zum Zusammenfluss von Aschau und Lachte: Die Lachte wurde 1933/34 auf einer Länge von etwa 1600 m kanalisiert, wodurch eine erheblich Verkürzung ${ }^{2}$ des Flusslaufes erzeugt wurde.

Danach kam es 1941, genau nach 100 Jahren, wieder zu einem extremen Hochwasser, das die Lachtebrücke im Ort zerstörte ${ }^{3}$. Offenbar war durch die Kanalisierung der Staueffekt des Gefällesprungs wieder verstärkt worden, da man unterhalb des Ortes keine Regulierung vorgenommen hatte. Auch beim Mai-Hochwasser 2013 kam es zu Überschwemmungen im Ort und zur Störung in der Papierfabrik.

Bis zur Kanalisierung oberhalb des Ortes zeigte die Lachte in diesem Abschnitt mit einigen Mäandern einen naturnahen Verlauf. Die Darstellung des Flussverlaufes auf den Karten von 1901 und 1781 lässt aber schon frühere Eingriffe vermuten.

Unterhalb des Ortes bietet die Lachte bis heute trotz geringfügiger Eingriffe ein recht naturnahes Bild ${ }^{4}$. Für diese Annahme sprechen zwei Merkmale: Der Flussverlauf ist auf den verfügbaren topographischen Karten sehr ähnlich mit den vielen Mäandern dargestellt und dort,

\footnotetext{
${ }^{1}$ Schulchronik II, S. 45

2 Bei einem Tieflandfluss kann man annehmen, dass bei einer Tallänge $L$ die Flusslänge $I=\pi \cdot L$ beträgt. Selbst wenn man wegen des größeren Talgefälles eine geringere Flusslänge durch Mäander zugrunde legt, wurde der Flusslauf um mehr als die Hälfte verkürzt.

${ }^{3}$ Mündliche Mitteilung von Herrn Müller, Lachendorf

${ }^{4}$ Das unterschiedliche. Alter der abgetrennten Flussschlinge oberhalb und unterhalb des Ortes ist sehr gut am Grad der Verlandung zu erkennen.
} 
wo der Fluss im 19. Jahrhundert zur Gemarkungsgrenze gewählt wurde, bildet auch heute noch der Fluss die Grenze.

Die Diagramme ${ }^{1} 2.2$ und 2.3 charakterisieren das Abflussverhalten der Lachte:

Für das jährliche Abflussverhalten wurde das sehr niederschlagsreiche Jahr 2007 ausgewählt, weil dadurch die Abhängigkeit der Abflusskurve vom Niederschlag gut demonstriert wird: Der Abfluss folgt sehr direkt, mit sehr geringer zeitlicher Verzögerung, den Tageswerten des Niederschlags, bleibt je nach Anzahl der folgenden Tage mit Niederschlag auf hohem oder noch steigendem Niveau ${ }^{2}$ und fällt dann mit Einsetzen der niederschlagsfreien Tage recht schnell - meist innerhalb von 5 bis 10 Tagen in Abhängigkeit von der vorauf gegangenen Regenmenge - exponentiell ab, um sich asymptotisch einem Abflussniveau in den Trockenphasen anzunähern. Innerhalb längerer Trockenphasen ${ }^{3}$ sinkt dann der Pegelstand nur noch ganz langsam - fast linear $-a b^{4}$, in den Wintermonaten auf einen Pegelstand um $100 \mathrm{~cm}^{5}$.

Jahreszeitliche Unterschiede ergeben sich einerseits im Winter aus dem Witterungsverlauf mit Regen oder Frost, Schnee und Eisbildung und andererseits im Sommer in Abhängigkeit von der Verdunstung und dem Verbrauch durch die Vegetation (Evapotranspiration). Frostperioden sorgen bei Schneefall auch für einen ausgeglichenen Abfluss (s. Diagramm 2.2, Dezember/Januar 1972/73)

Diagramm 2.2 Abflussverhalten der Lachte; Winter- und Sommermonate
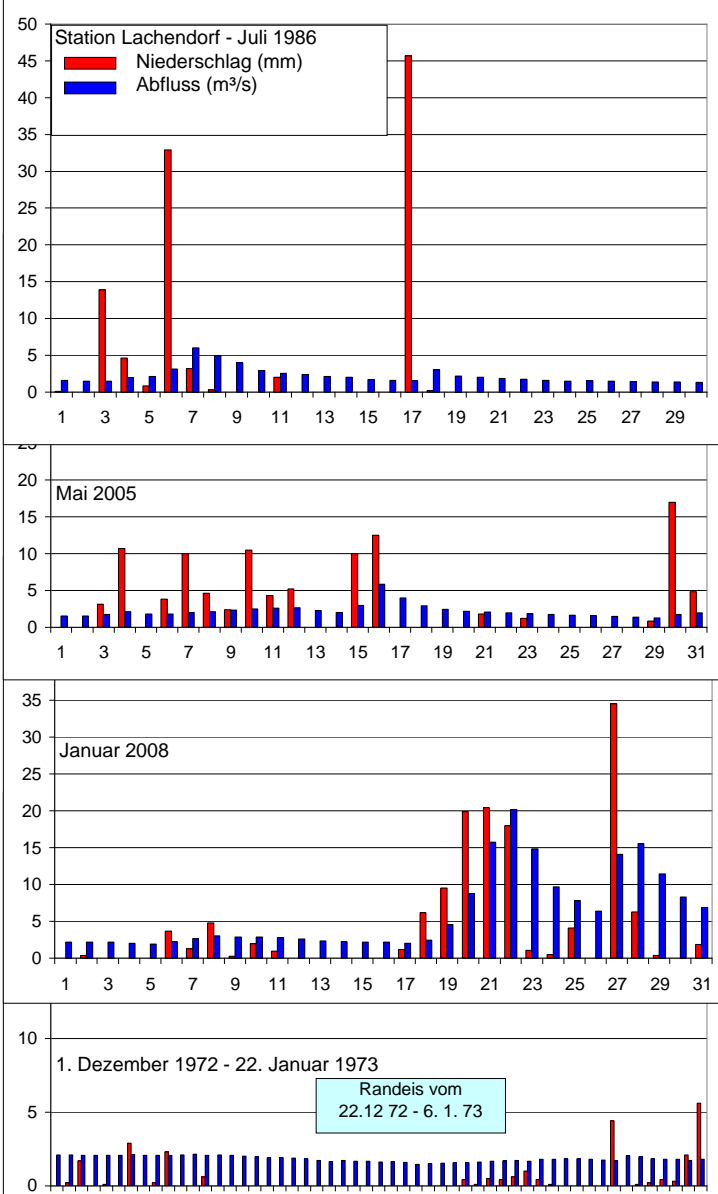

13557911131517192123252729313335373941434547495153

Datenquellen: Pegelstände: NLWKN Verden

Niederschlag: Messstation Lachendorf, K. Koch

\footnotetext{
${ }^{1}$ Der Lachendorfer Pegel wurde It. Auskunft des NLWKN 1989 etwa 100 m stromaufwärts verlegt: Standort 1: Pegel-Null bei 42,81 m ü. NN, Standort 2: Pegelnull bei 45,17 $\mathrm{m}$ ü. NN ${ }^{2}$ Maximaler Pegelstand: $268 \mathrm{~cm}$ (29.10.1998), Periode 1960 - 2011: NLWKN Verden

${ }^{3}$ s. Monat April im Jahr 2007: Diagramm 2.10

${ }^{4}$ Minimaler Pegelstand: $54 \mathrm{~cm}$ (14.5.1960), Periode 1960 - 2011: NLWKN Verden, s. Fußnote 10

${ }^{5}$ Mittelwert: $104 \mathrm{~cm}$ in der Periode 1981 - 2011: NLWKN Verden, s. Fußnote 10
} 
Diagramm 2.3.2 Station Lachendorf; Abflussverhalten der Lachte (Beispieljahr 2007)

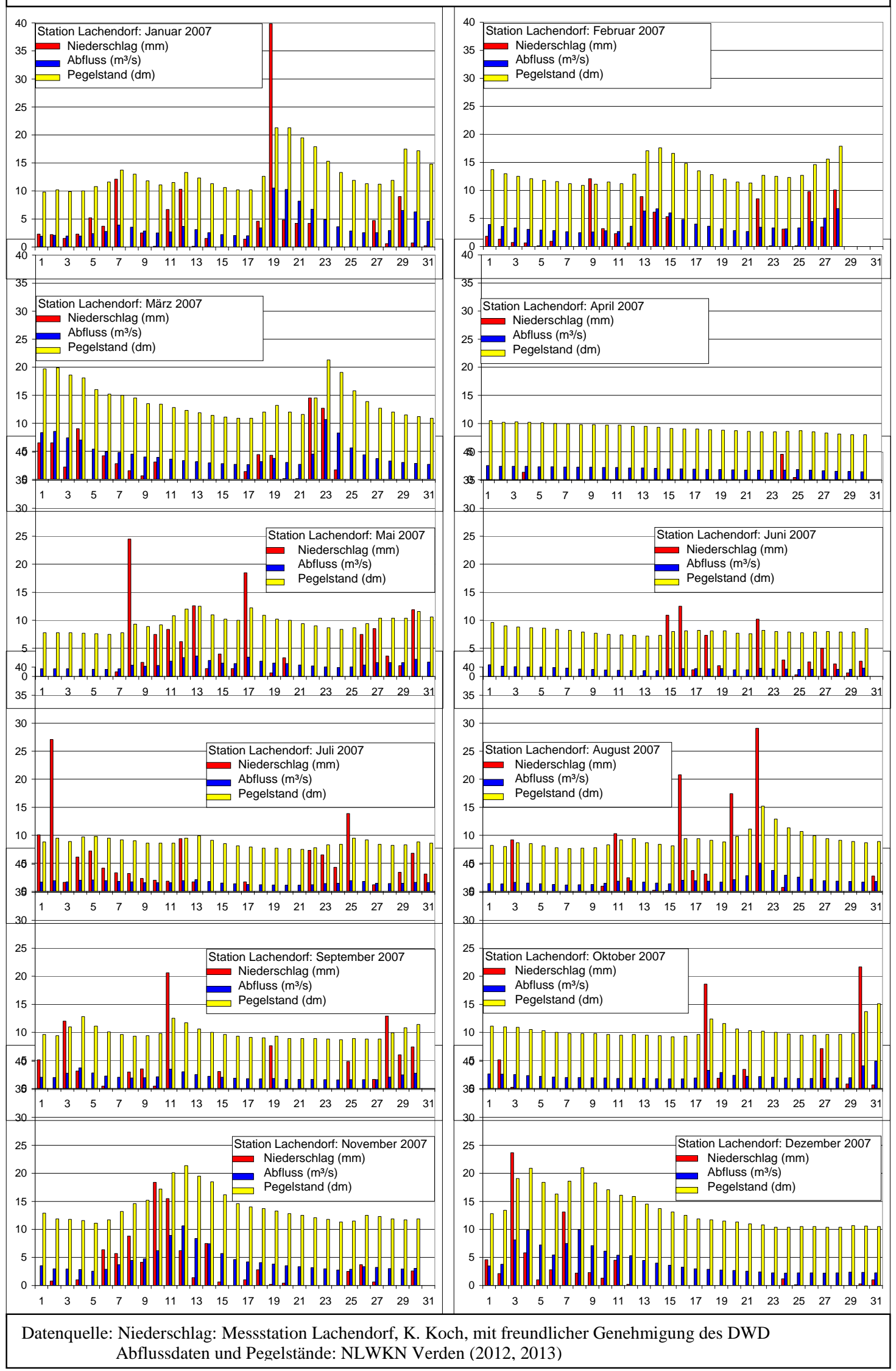


Starke Winterregen führen zu sehr hohen Pegelständen und hohen Abflusswerten mit Hochwasser in der Talaue, da dann der Oberflächenabfluss wegen des meist gesättigten Bodenwasserhaushaltes und der fehlenden Vegetation schnell und stark erfolgt.

Sommerliche Regenperioden und auch sommerliche Starkregen führen nur zu einem moderaten Pegelanstieg, weil die Verdunstung hoch ist, die Vegetation einen hohen Verbrauch hat und der meist nicht voll

gesättigte Boden als Zwischenspeicher zur Verfügung steht. Gerade sommerliche Starkregen, meist Gewitter, treten vorwiegend in oder nach längeren Trockenperioden auf, die zu einer niedrigen Auslastung der Bodenwasserkapazität geführt haben.

Das Diagramm 2.3.1 zeigt, dass extreme Niederschläge auch in der Vegetationsperiode zu Pegelhöchststand und Überschwemmungen führen können.

In der Zeit vom 8. Mai bis zum 1. Juni 2013 wurden in Lachendorf insgesamt 203,4 mm Niederschlag gemessen ( Monatssumme Mai:
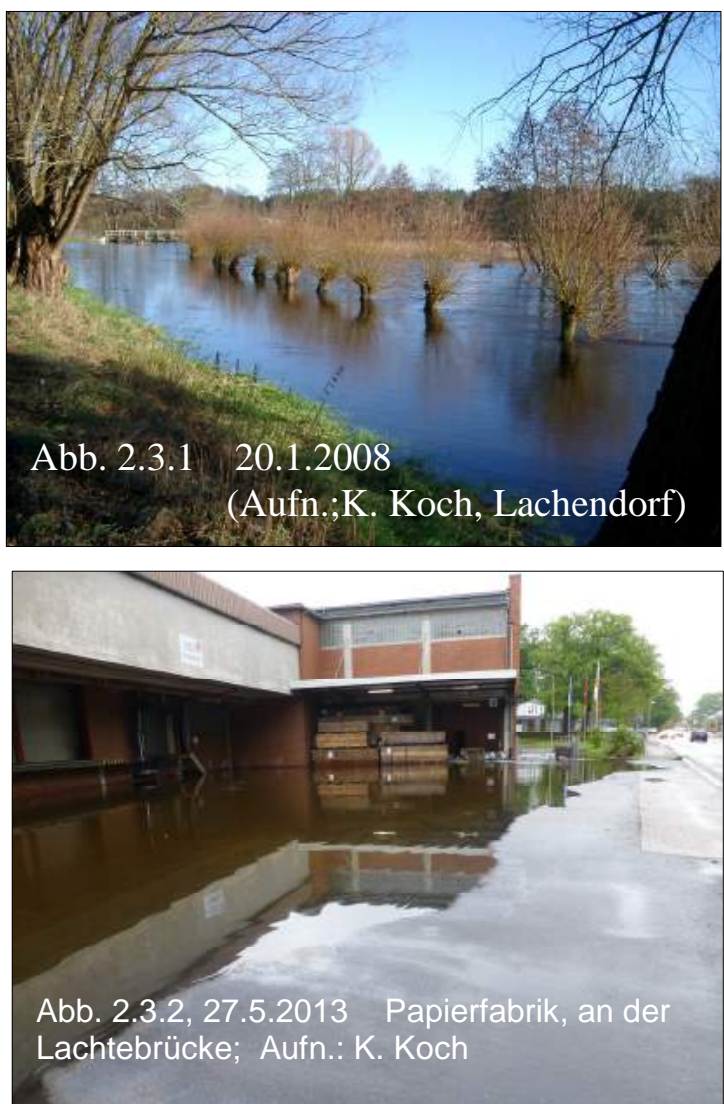
201,4 mm, Mittel der Periode 1971 -2010: 54,53 mm¹) Dies führte zu einem extremen Hochwasser mit Überschwemmungen auch im Ort.

Die Verladerampe der Papierfabrik unmittelbar oberhalb der Lachtebrücke stand unter Wasser. Das erinnerte an die Januarflut von $1841^{2}$, als die Lachte die Brücke - allerdings noch aus Holz - wegriss.

Die Tageswerte des Niederschlags wurden vom 8. Mai bis zum 1. Juni gemessen. Ein Tageswert erfasst aber 17 Stunden des Vortages und nur 7 Stunden des Messtages. Die Pegelstände wurden als Tagesmitteln aus den Messwerten errechnet, die alle 15 Minuten zwischen 0.00 und $32.45 \mathrm{Uhr}$ automatisch erfasst wurden. Daher wurden die Tageswerte des Niederschlags im Diagramm 2.3.2 um einen Tag vorverlegt, weil dann die Abhängigkeit des Pegelstandes vom Niederschlag deutlicher wird.

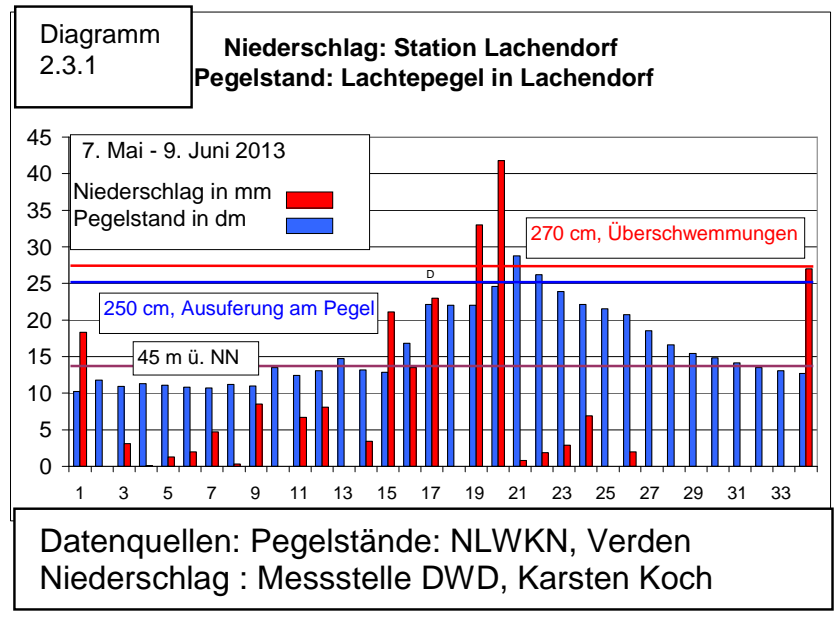

\footnotetext{
${ }^{1} \mathrm{~N}-$ Werte: DWD Offenbach

${ }^{2}$ Wittmann, M.; Lachendorf, Bd. I; a.a.O., S. 61
} 


\subsubsection{Aller}

Die Aller berührt zwar die Lachendorfer Feldmark nicht direkt, inr Einfluss auf den Landschaftshaushalt und auf die agrarwirtschaftliche Nutzung ist bzw. war aber für große Bereiche der Lachendorfer Flur von größter Bedeutung. Der indirekte Einfluss war besonders groß über das Schwarzwasser, wovon noch zu berichten sein wird.

Unverändert groß ist der Einfluss der Aller auf das Grundwasserregime im gesamten Urstromtal, bis an den Randbereich der Siedlung. In vielen Mäandern durchzog die Aller das weite Urstromtal und veränderte die Landschaft immer wieder durch ihre Hochwässer ${ }^{1}$, die

Karte 2. 14 Überschwemmungsgebiet der Aller und südliche Gemarkung Lachendorf

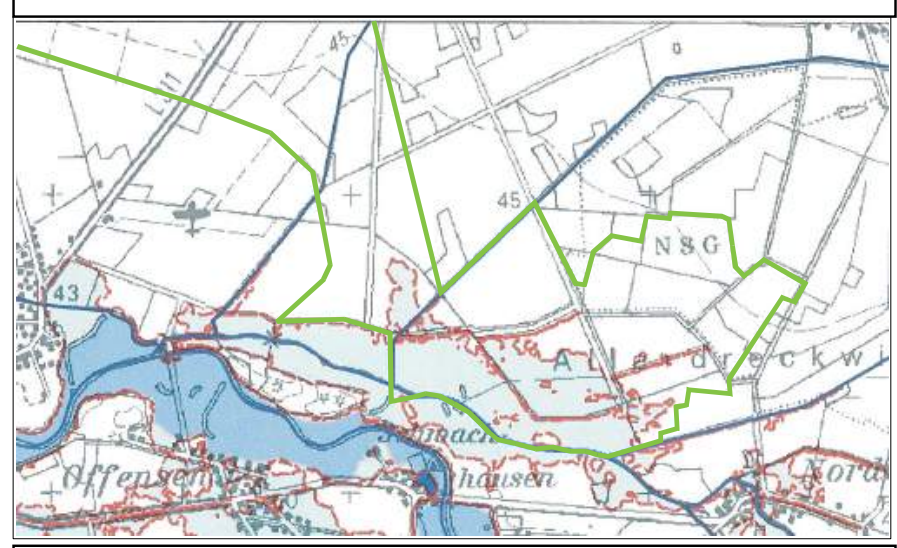

Quelle: Ausschnitt aus: Überschwemmungsgebiete in Niedersachsen und Bremen, LGLN, 2011;

Gemarkungsgrenze eingefügt vom Verf. weite Bereiche des flachen Tales unter Wasser setzten.

Solange an der Aller und insbesondere an der Oker keine umfangreichen Maßnahmen zur Flussregulierung und zum Hochwasserschutz umgesetzt worden sind, konnte man folgendermaßen formulieren:

Die Hochwässer der Aller sind hauptsächlich durch die Wasserführung der Oker bedingt, die bei Müden/Aller einmündet, dort doppelt soviel Wasser wie die Aller selbst führt, obwohl deren Niederschlagsgebiet nur um 12\% kleiner als das der Oker ist $t^{2}$. Durch den Zufluss der Oker verliert die Aller den Charakter eines Flachlandflusses ${ }^{3}$. Die Schwankungen der extremen Wasserstände wie auch die Abweichungen vom mittleren Wasserstand sind, verglichen mit Lachte und Schwarzwasser, recht groß. Auch im Jahresgang der Wasserstände ergeben sich Unterschiede: Während bei Lachte und Schwarzwasser die mittleren Wasserstände im Dezember und Februar ihre Höchststände erreichen und im Juni und Juli ein ausgeprägtes Minimum liegt, erreicht die Aller im Februar und April die höchsten und im Oktober die niedrigsten mittleren Wasserstände. Die Aller zeigt im Juli ein relatives Minimum der mittleren Wasserstände und im August einen minimalen Anstieg; Lachte und Schwarzwasser haben einen ziemlich starken Anstieg im August gegenüber Juni/Juli und ein relatives Minimum der mittleren Wasserstände im September. ${ }^{4}$

Bei Müden vereinigen sich zwei Flüsse ganz unterschiedlichen Charakters: Die Aller kommt aus weiten Moorgebieten und führt dunkles, nährstoffarmes Wasser heran, während die Oker stark schwebstoffhaltiges und nährstoffreiches Wasser zu Tal bringt. Man sagt, in Müden komme "die Milch zum Kaffee", und charakterisiert damit treffend die unterschiedliche Beschaffenheit von Aller und Oker".

An der „Regulierung“ von Aller und Oker ${ }^{6}$ wird offenbar seit Jahrhunderten gearbeitet ${ }^{1}$. Lange Zeit dienten die Eingriffe vorrangig der „Melioration“ der landwirtschaftlich genutzten Flä-

\footnotetext{
${ }^{1}$ Abflussspende der Aller im Gebiet des Allerunterhaltungsverbandes Wienhausen im Sommer: bei Mittelwasser: $4 \mathrm{l} / \mathrm{s} \mathrm{km}^{2}$, bei Hochwasser: $17 \mathrm{l} / \mathrm{s} \mathrm{km}^{2}$, aus: Wasserwirtschaftsatlas von Niedersachsen, Teil la, Erläuterungen, S. 128

2 Der Speicher, a.a.O., s. 304

${ }^{3}$ vgl. Temme, A., Gelle, Siedlungs- und Wirtschaftsgeographie einer niedersächsischen Stadt und ihres Lebensraumes, in: Jb. d. geogr. Ges. zu Hannover 19)6/37, Hannover 1937, S. 11

${ }^{4}$ Daten zu Wasserständen und Abflussmengen: Wasserwirtschaftsamt Celle

${ }^{5}$ Diese Tatsache ist agrargeographisch deswegen relevant, weil sie entscheidend für die Anlage von Stauwiesen war, wie noch zu zeigen sein wird.

${ }^{6}$ Auf die Regulierung der Oker kann hier nicht weiter eingegangen werden.
} 
chen, in neuerer Zeit steht der Hochwasserschutz für Siedlungen und Gewerbe im Vordergrund.

Das Abflussregime der Aller war natürlicherweise überwiegend durch die Oker gesteuert, also abhängig von den Niederschlägen und Abflüssen des Harzes.

Der Flussverlauf der Mittelaller auf der Kurhannoverschen Landesaufnahme von 1781 weicht nicht wesentlich vom Verlauf auf der Karte der preußischen Landesaufnahme von 1899 ab. Die Unterschiede könnten in der Ungenauigkeit der ersten Kartierung, aber auch in natürlichen Veränderungen der Mäander begründet sein.

Der Flussverlauf, wie er 1899 kartiert wurde, hatte sich aber seit Mitte des 19. Jahrhunderts kaum verändert. An den Gemarkungsgrenzen, die im Zuge der Agrarreformen Mitte des 19. Jahrhunderts oft den Flüssen folgend festgelegt wurden und unverändert blieben, kann man nachvollziehen, welche Veränderungen an den Flussläufen in der 2. Hälfte des 19. Jahrhunderts vorgenommen worden sind.

In der 1. Hälfte der 1960er Jahre erfolgte dann ein sehr starker „Ausbau“ der Mittelaller ${ }^{2}$, bei dem allerdings eine Kanalisation vermieden wurde. Das durch Flusslaufverkürzung erhöhte Gefälle wurde im Sohlabsturz des neuen Wehres oberhalb von Oppershausen aufgefangen. Der Ausbau der Mittelaller, neue Verwallungen und insbesondere Maßnahmen an der Oker

Karte 2.15: Aller und Schwarzwasser - Flussregulierungen

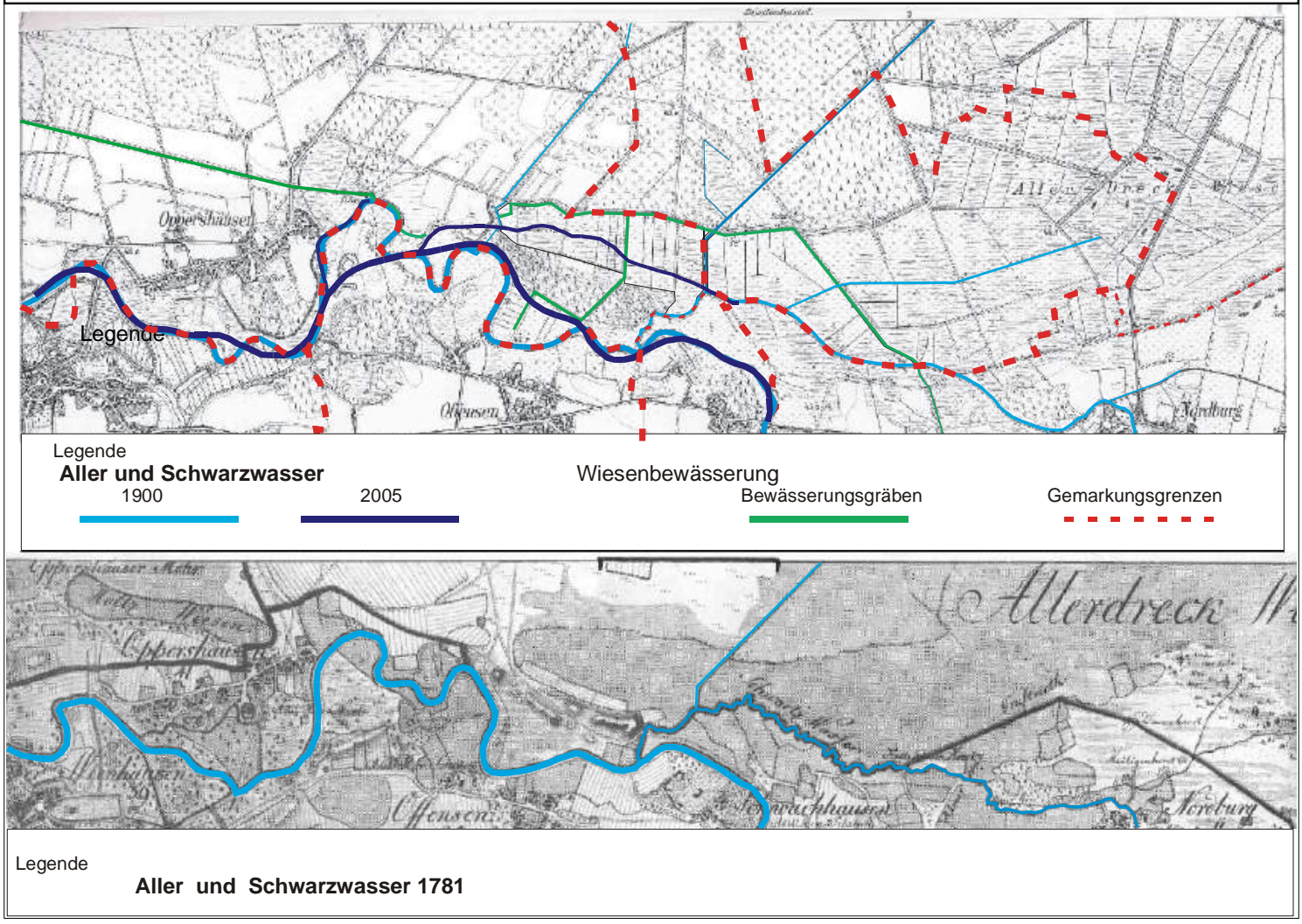

Quelle: Kurhann. Landesaufnahme, Blatt 111 Gr. Eicklingen, Königl. Preuß. Landesaufnahme 1:25000, 1899, TK 25, Ausgaben 1955 und 1966

\footnotetext{
${ }^{1}$ Einen Eindruck von dem Ausmaß der Arbeiten zur Flussregulierung und Melioration mögen die Kosten geben: im Wasserverband Mittelaller hatten die Baukosten in der Mitte der 60er-Jahre des 20. Jhd. bereits ein Gesamtvolumen von 7670000,- DM erreicht. Quelle:: Notiz in der Gelleschen Zeitung vom 3. März 1967

${ }^{2}$ Vgl. W. C. Seiler, Die Aller, Celle 2002
} 
haben die früher häufigen Überflutung der Agrarflächen nördlich der Aller durch Hochwasser weitgehend unterbunden.

Diagramm 2.4.1 Pegelstände an Lachte, Schwarzwasser und Aller (1961-1965)

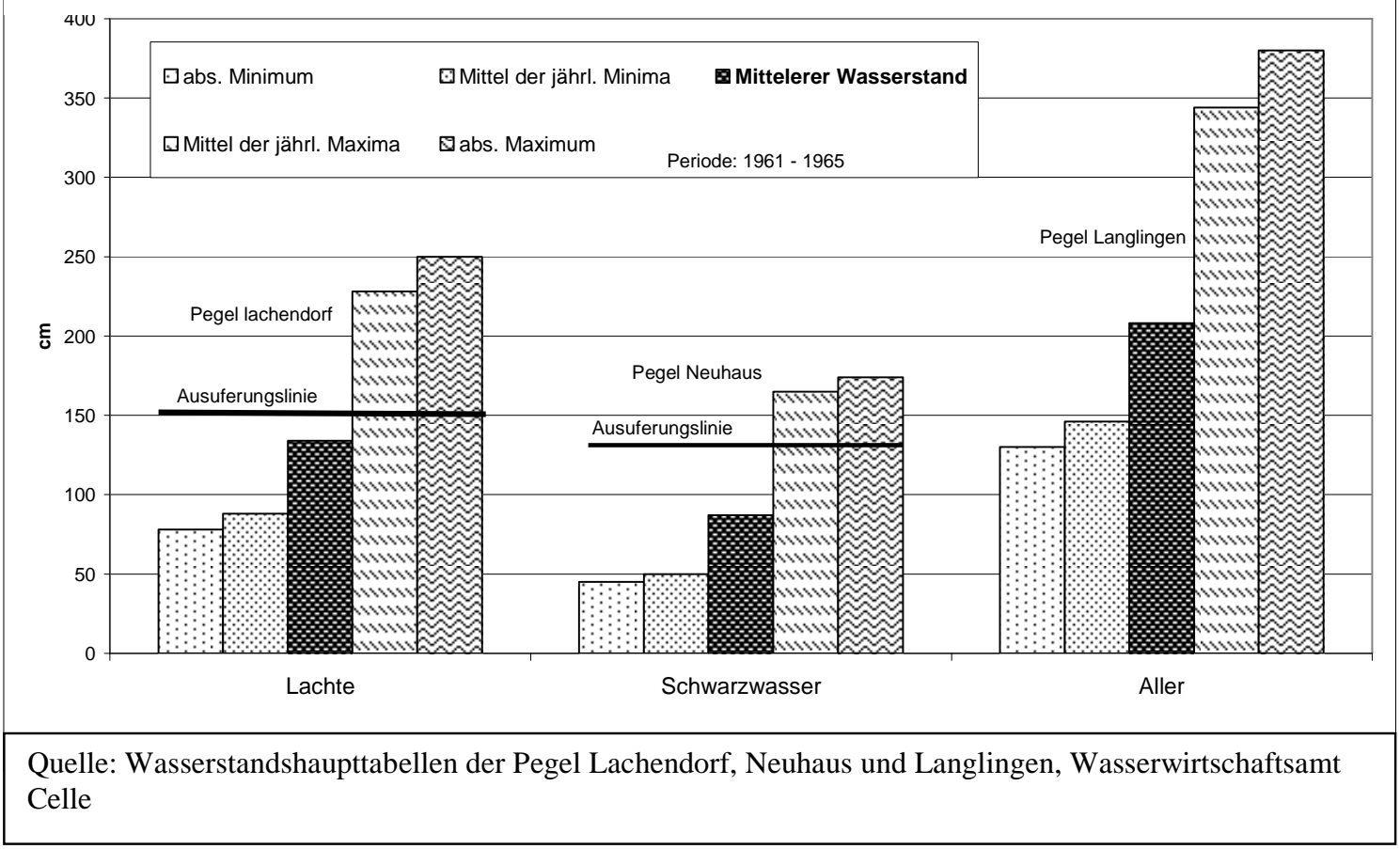

\subsubsection{Schwarzwasser}

Das Schwarzwasser entspringt fast am Ostrand der Mittleren Südheide bei Repke in einer Höhe von knapp 100 m über NN. Das Quellgebiet liegt im Sanderbereich der Mittleren Südheide und wird im W durch die lang gestreckte Lehmplatte von Mahrenholz -Dedelsdorf Weddersehl vom Quellbereich der Lachte, im E von dem nach S vorspringenden Moränenrücken des östlichen Lüßplateaus von dem Isetal getrennt. Die beiden Quellflüsse vereinigen sich bei Langwedel, das Bachtal trennt dann die beiden Geestinseln von Lingwedel und Langwedel $^{1}$, durchzieht das Bruchgebiet der Örreler Heide, gliedert die Gifhorner Geestplat$t^{2}{ }^{2}$ und erreicht südöstlich von Ummern das Urstromtal, um diesem bis zur Mündung in die Aller bei Schwachhausen zu folgen.

Der wichtigste Zufluss ist die Wiehe, die ebenfalls nahe Repke entspringt, die Geestplatte bei Mahrenholz gliedert, den Schmarloh von der Sandplatte um Pollhöfen trennt und bei Hohne ebenfalls das Urstromtal erreicht. Das Schwarzwasser hat bei einer Gesamtlänge von etwa $20 \mathrm{~km}$ ein Einzugsgebiet von $264,2 \mathrm{~km}^{2}$ aufzuweisen ${ }^{3}$.

Bei seinem Lauf durch das Hahnenmoor nimmt das Schwarzwasser den Charakter eines Moorflusses mit dunklem, saurem und humusreichem, aber nährstoffarmem Wasser an, wie es auch der Name verdeutlicht. Dadurch wird auch der Jahresgang der Wasserstände ausgeglichener, und die mittleren und extremen Wasserstände schwanken nicht so stark wie bei der Lachte, obwohl das Gesamtbild der Jahresgänge doch recht ähnlich ist.

Das Mündungsgebiet des Schwarzwassers wurde bis zur Verlegung im Jahr 1964/65 sehr stark von der Aller her beeinflusst. Bei einer allgemeinen Höhenlage um 43,50 m über NN liegt an der Schwarzwassermündung direkt östlich des Dünengebietes „Lorkberg“ auf $180 \mathrm{~m}$

\footnotetext{
1 ebenda

2 ebenda

${ }^{3}$ s. Schwarzwasserverlegung und Entwurfsbericht zur Schwarzwasserverlegung, Wasserwirtschaftsamt Celle
} 
eine Senke um 42,50 m über $N^{1}{ }^{1}$. Schon bei kleineren Hochwässern der Aller kam es zu erheblichem Rückstau der Aller in das Schwarzwasser und damit zur Überflutung eines weiten Talbereiches, wodurch besonders die „Trockenen Wiesen“ nördlich des Lorkberges, die ebenfalls zum Teil bei 42,50 m über NN liegen, und die Aller-Dreckwiesen betroffen waren². Durch diesen Rückstau wurde die Lachendorfer Flur bei starkem Hochwasser bis zum südlichen Bereich des Krähenmoores und bis in die Dreckwiesen hin überschwemmt ${ }^{3}$.

Die Karten von 1781 und 1839 lassen vermuten, dass das Schwarzwasser im Bereich von Nordburg schon vor 1800 stark begradigt worden ist. Der nächste Abschnitt entlang der Lachendorfer Gemarkungsgrenze erfuhr dann eine Begradigung im Rahmen der Agrarreformen $^{4}$ mit der Festlegung dieser Grenze. Das letzte Stück östlich vom Lorkberg blieb auch damals unverändert und wurde erst 1964/65 verlegt und eingeebnet.

Um die Vorflut des Schwarzwassers zu verbessern und die Überschwemmungsgefahr der Wiesen im Bereich des Oppershausen-Lachendorfer Stauwiesenverbandes ${ }^{5}$ und der angrenzenden Parzellen zu beheben, wurde das Schwarzwasser im N um den Lorkberg herumgeführt und mündet jetzt erst bei Oppershausen in die Aller. Die Linienführung der Verlegung folgt weitgehend den Parzellengrenzen und dem bestehenden Entwässerungssystem ${ }^{6}$. Um einen Rückstau der Aller in das Schwarzwasser zu unterbinden, mündet die neue Schwarzwassermündung in das Unterwasser des Allerwehres. Dadurch wurde es nötig, die neue Schwarzwassermündung unmittelbar vor der Mündung in die Aller mit einem Sperrwerk zu versehen, weil anders im Unterlauf ein hohes Gefälle eingetreten wäre. Andererseits musste beim Bau in den 1960er Jahren noch die Bewässerung des Osterbruches sichergestellt werden.

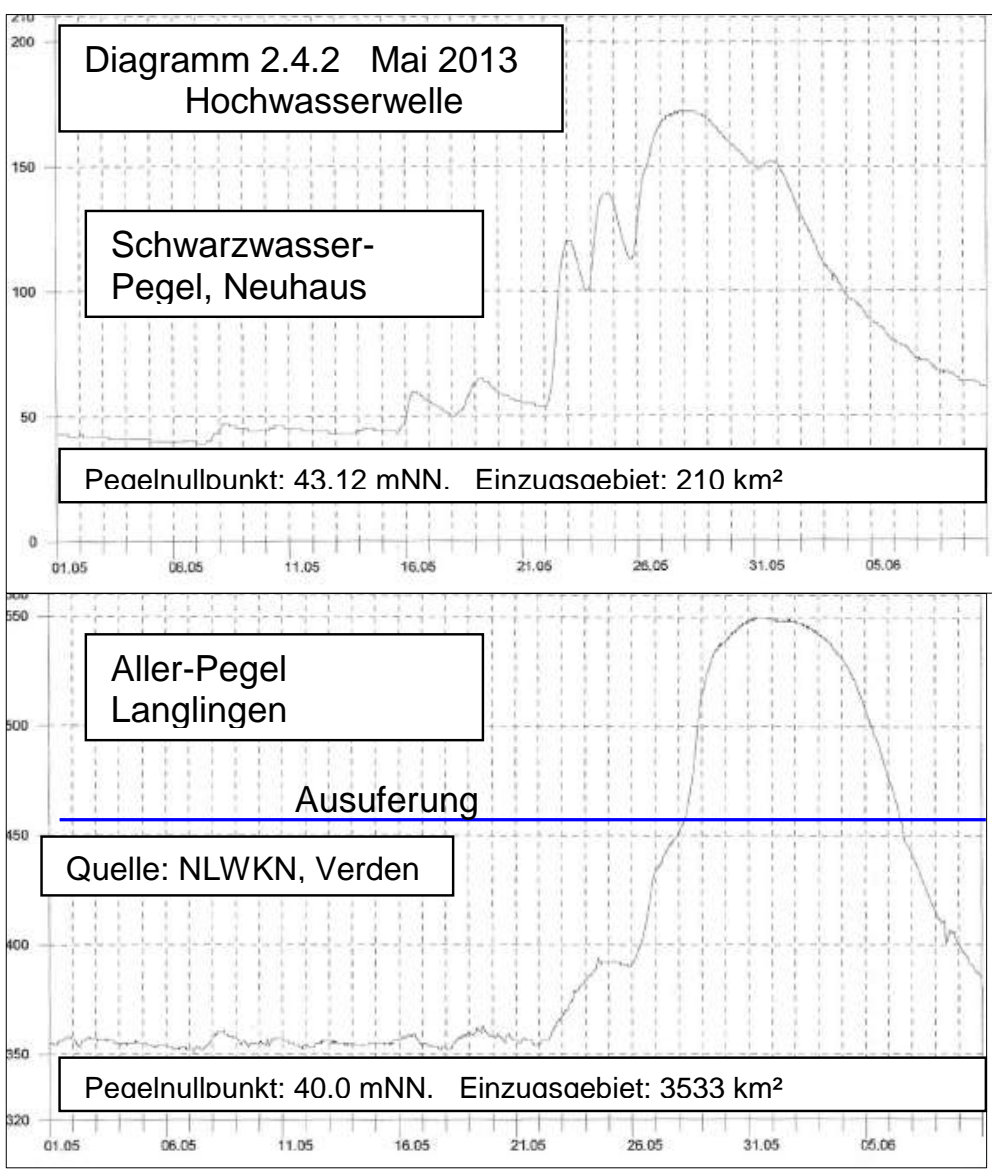
Osterbruchkanal musste wegen der Höhenlage aus dem Oberwasser des Allerwehres gespeist werden. Dies machte es nötig, den Zuleiter zum Osterbruchkanal als Dyker unter dem Schwarzwasser unmittelbar neben dem Wehr hindurch zu führen. Außerdem wurde im Bereich der alten Schwarzwassermündung im Osten des Lorkberges eine Verwallung angelegt, die einen Rückstau der Aller und damit eine Überschwemmung weiter Flächen unterbinden sollte ${ }^{7}$.

\footnotetext{
${ }^{1}$ Entwurfsbericht Schwarzwasserverlegung, Wasserwirtschaftsamt Celle

${ }^{2}$ ebenda

${ }^{3}$ Mündliche Mitteilung des Landwirts Karsten Koch, Lachendorf

${ }^{4}$ s. Rezess „Entfrettung und Verkoppelung der Aller- und Trockenen Wiesen, § 6, 1866, Samtgemeinde Lachendorf, Archiv, Sign.: 140/8

${ }^{5}$ Entwurfsbericht Schwarzwasserverlegung, Wasserwirtschaftsamt Celle

${ }^{6}$ ebenda

${ }^{7}$ Mündliche Auskunft, Herr Krammaicke, Wasserwirtschaftsamt Celle
} 
Das Jahr 1966 hat gezeigt, dass allein schon die Schwarzwasserverlegung eine weitgehende Verminderung der Überflutungen im südlichen Bereich der Lachendorfer Flur bewirkt hat ${ }^{1}$. Die Abflussperiode 1961 - 1965 zeigt die Verhältnisse vor den großen Flussbaumaßnahmen der 60 er Jahre. Darin werden die unterschiedlichen Abflussregime der drei Flüsse aufgrund der unterschiedlichen Strukturen der Einzugsgebiete recht deutlich.

Durch die Flussregulierungen und Verwallungen an Aller/Oker und Schwarzwasser sollten das gesamte Grünlandgebiet nördlich von Aller und Schwarzwasser dem Abflussregime beider Flüsse entzogen werden, um Überschwemmungen bei Hochwasser zu verhindern.

Das besonders extreme Hochwasser im Mai 2013 hat aber verdeutlicht, dass großflächige Überschwemmungen nördlich von Aller und Schwarzwasser dennoch nicht ausgeschlossen sind, wenn es im Einzugsgebiet von Aller und Schwarzwasser zu Perioden mit weit über durchschnittlichen Niederschlägen kommt.

In der Zeit vom 8. - 31. Mai 2013 hat es $200 \mathrm{~mm}^{2}$ geregnet, das Vierfache ${ }^{3}$ des lang-jährigen Monatsmittels. Dadurch kam es in beiden Flüssen zu fast gleichzeitigen ${ }^{4}$ Hochwasserwellen $^{3}$ mit einer wie früher üblichen Überschwemmung des südlichen Teils der Gemarkung Lachendorf, in nördlicher Richtung bis ans Krähenmoor ${ }^{5}$ und in nordöstlicher Richtung bis weit in die Dreckwiesen hinein.

Auch die Lachte

Diese seit den 1950er Jahren nicht mehr aufgetretene Überschwemmung, sogar zu Beginn der Hauptvegetationszeit, wird den Hochwasserschutz bzw. die landwirtschaftliche Nutzungen in den Aller- und Dreckwiesen vor neue Herausforderungen stellen.

\subsubsection{Schelprieth}

Unter hydrologischen Gesichtspunkten müssen in der Gemarkung einige, meist sehr kleinräumige Sondergebiete betrachtet werden, von denen hier nur der Schelprieth und das Kleine Moor betrachtet werden sollen. Die anderen kleinen Moore in der Gemarkung werden im Kapitel 2.5 - Standorte und Potenziale - behandelt.

Ein lokal bedeutendes Sondergebiet stellt ein Trockental ${ }^{6}$ östlich von Lachendorf dar, das in die Südwest-Ecke der Bunkenburger Lehmgeest eingetieft ist und in ost-westlicher Richtung verläuft. Die geologische Karte zeigt, dass dieses Trockental eigentlich in einem kleinen Anmoorgebiet, dem Kleinen Moor, östlich Lachendorfs am Rande der Grundmoräne auf dem Schwemmfächer in dessen Sanden endet. Dies ehemalige Moorgebiet bestimmt bis heute am Ostrand des Ortes die Nutzung als Grünland, das allerdings mit Grünlandzahlen um 25 nur mäßige Standortqualität aufweist.

Zwischen der Mündung des Trockentales in das Lachtetal und der Talaue der Lachte lag ein heute überformtes kleines Dünengebiet, das eine lokale Wasserscheide darstellte. Das Trockental und das kleine Anmoorgebiet am Ostrand des Dorfes entwässerten offenbar natürlicherweise in den Schwemmfächer in südliche Richtung. Aufgrund der geringen Abflussmengen und der sehr wasserdurchlässigen Sande des Schwemmfächers hatte sich kein natürlicher Abfluss zur Aller hin gebildet. So hatte der nördlichste Teil des Abflussgebietes „mittlere Aller - mittleres Teilgebiet" eine schlechte Vorflut und bedurfte für eine Landwirtschaftliche Nutzung der künstlichen Entwässerung.

\footnotetext{
${ }^{1}$ Mündliche .Auskunft, Herr Landwirt K. Koch. Lachendorf

${ }^{2}$ Messstation Lachendorf des DWD, Karsten Koch

${ }^{3}$ Messdaten des DWD, 1941 - 2012

${ }^{4}$ Der Pegel Neuhaus am Schwarzwasser liegt 7,5 km oberhalb der Mündung in die Aller; der Allerpegel in Langlingen etwa 4,5 km oberhalb dieser Mündung.

${ }^{5}$ Mdl. Information von Landwirt Karsten Koch

${ }^{6}$ s. Karte 2.10: Niederschlagsgebiete, dort: Nordteil (rote Streifen) des Abflussgebietes „mittlere Aller - mittleres Teilgebiet,

${ }^{7}$ Bodenschätzung, Flurkarte Lachendorf
} 
Diese erfolgte lange Zeit über den im 19. Jahrhundert angelegten Schelpriethgraben, der das Trockental einschließlich der Dränagewässer aus den angrenzenden Geestplatten abführte sowie das Kleine Moor östlich des Dorfes nach S in die Aller entwässerte.

Im 20. Jahrhundert ist durch einen Stichgraben ${ }^{1}$ eine entscheidende Veränderung eingetreten: Die Wasserscheide (Dünengebiet) zwischen Trockental und Lachte wurde durchstochen, so dass der Entwässerungsgraben bei seinem Austritt aus der Geestplatte nicht nach $S$ zur Aller geführt wird, sondern direkt nach W zur Lachte ${ }^{2}$, womit für die Entwässerung des Trockentales und der angrenzenden Ackerflächen auf Geschiebelehm wesentlich bessere Vorflutverhältnisse geschaffen worden sind.

Vom Niederschlagsgebiet der mittleren Aller, mittleres Teilgebiet, ist damit der obere Teil abgetrennt und zum unteren Teilgebiet der mittleren

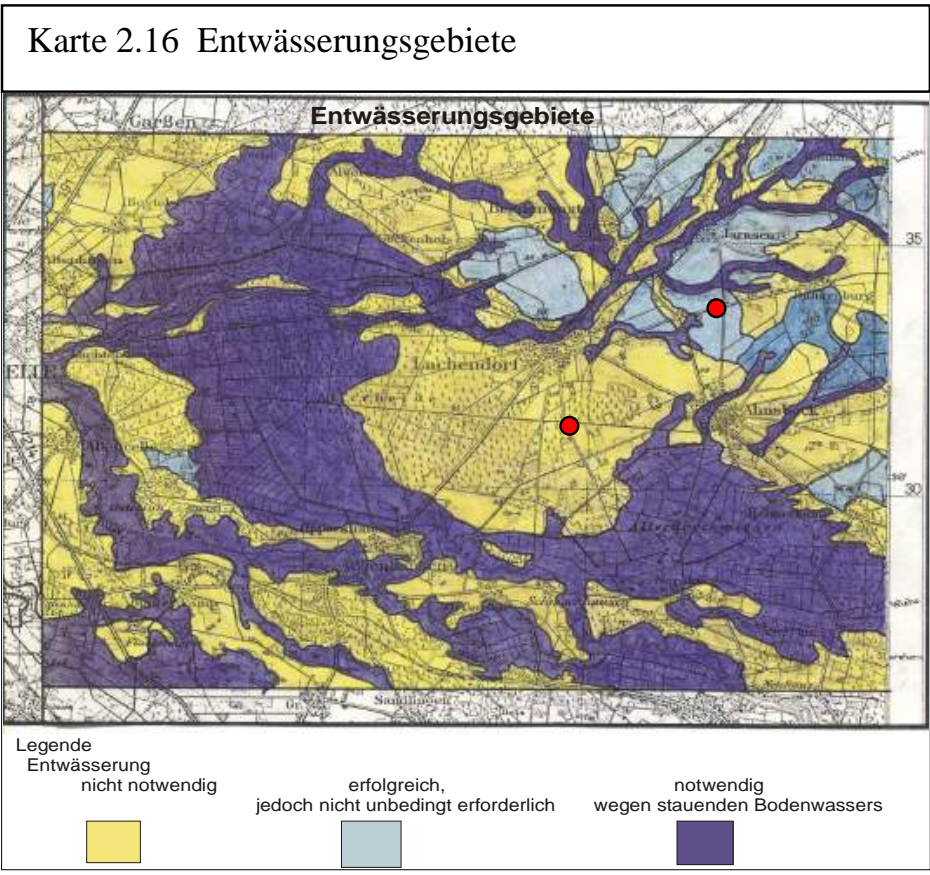

Quelle: Wirtschaftswiss. Gesellschaft zum Studium Niedersachsens, Hg.; Bodenkundlicher Atlas von Niedersachsen, 1:100000, Abteilung C, Entwässerungskarte, Blatt 262 Celle, Oldenburg i.O. 1938, Ausschnitt; Kopie der Originalkarte aus der Arbeit des verf. von 1967, aus dem Atlas übernommen und handkoloriert.

- Grundwassermessstellen des NLWKN Verden Lachte geschlagen worden ${ }^{3}$.

Im Laufe der letzten Jahrzehnte hat der Schelpriethgraben seine ursprüngliche Funktion verloren, fiel daher trocken und konnte innerhalb eines Neubaugebietes als „Grünstreifen" umgewidmet werden.

\subsubsection{Grundwasser}

Das Grundwasserregime folgt dem geomorphologischen Bau, muss aber im Einzelnen noch differenziert betrachtet werden.

Die Grundmoränenplatten sind in den höheren und ebeneren Teilen wenig direkt vom Grundwasser beeinflusst, dagegen leiden die etwas tiefer gelegenen Partien und besonders die Trockentäler wegen des wasserstauenden Geschiebelehms leicht unter stauender Nässe und schlechter Drainung. Deshalb verläuft in allen etwas stärker ausgeprägten Trockentälern ein Graben, um die Talungen zu entwässern und um das Drainwasser abzuführen.

Wie die Karte der Entwässerung zeigt, sind nämlich die Trockentäler im Geschiebelehm bei landwirtschaftlicher Nutzung stark entwässerungsbedürftig ${ }^{4}$.

Das Lachtetal gliedert sich in zwei sehr unterschiedliche Räume. Die Terrassenflächen mit ihren durchlässigen Sanden sind nicht Grundwasser beeinflusst und bedürfen keiner Entwässerung, sie sind eher für agrarische Nutzung zu trocken.

\footnotetext{
${ }^{1}$ Die Anlage des Stichgrabens konnte zeitlich nicht fixiert werden; z.Z. der Flurkartierung im Jahr 1966 existierte der Graben bereits.

${ }^{2} \mathrm{~s}$. Lachendorf, Ostrand des Ortes

${ }^{3}$ s. Karte 12: Niederschlagsgebiete

${ }^{4}$ s. Karte der Entwässerung: Trockentäler im E und NE von Lachendorf, vgl. dazu auch die Geomorphologische Karte
} 
Das Grundwasser der Talaue ist natürlich völlig mit der Wasserführung der Lachte gekoppelt, ist also starken Schwankungen unterworfen. Im Bereich der Talaue ist der Wasserstand der Lachte und damit der Grundwasserstand der dominierende naturgeographische Faktor, hinter den alle anderen in der Bedeutung weit zurücktreten. Dadurch sind anthropogenen Eingriffen in den Haushalt sehr enge Grenzen gesetzt, was sich auch im kulturräumlichen Gefüge zeigen wird.

Der etwas höher als das angrenzende Gelände im Aller-Urstromtal gelegene Schwemmfächer mit seinem durchlässigen Material wirkt oberflächlich recht trocken. Jedoch zeigen die Bohrungen der forstlichen Standortaufnahme, dass der Grundwasserspiegel zwischen 1,0 und 2,5 m liegt und nur selten bis $4 \mathrm{~m}$ unter Flur absinkt ${ }^{1}$. Dadurch erhalten diese Standorte eine recht bedeutsame Grundfrische bei leichter oberflächlicher Austrocknung.

Der stark schwankende und bei Allerhochwasser nur wenige Dezimeter unter Flur stehende Grundwasserspiegel machte sich auch im südlichen Baugebiet des Ortes stark bemerkbar durch in Keller ${ }^{2}$ eindringendes Wasser, wenn aus Unkenntnis der örtlichen Verhältnisse keine wasserdichte Wanne gebaut worden war.

Im ganzen Urstromtal beherrscht die Aller das Grundwasser völlig, dagegen hat die Lachte außer im Auebereich fast keinen Einfluss ${ }^{3}$. Als Beweis mag die Tatsache gelten, dass ein Keller eines Gebäudes, das nur 30 m vom Lachteufer entfernt steht, und zwar auf der Südseite des Lachteknies am Rande des Urstromtales, auch bei höchsten Wasserständen der Lachte nicht voll Wasser steht, dagegen bei jedem Hochwasser der Aller, besonders nach der Schneeschmelze, vom Grundwasser her voll gedrückt wird ${ }^{4}$.

Die Grundwasserganglinie im Schwemmfächer der Jahre 1968 bis 2012 zeigt ein unperiodisches Verhalten mit einer leicht sinkender Gesamttendenz und einer deutlichen Korrelation mit den Jahressummen der Niederschläge. Die deutliche Absenkung der Grundwasserstände Ende der 1960er und 1970er Jahre könnte auch eine Folge der Regulierungen an Aller und Schwarzwasser Mitte der 1960er Jahre. Allerdings sind auch Experten unsicher in der Interpretation. Sowohl seitens des NLWKN Verden ${ }^{5}$ als auch seitens der örtlichen Landwirtschaft wird ein Einfluss des Baugebietes, das bis an den Ahnsbeck-Altenceller Weg nach Süden vorgedrungen ist, nicht ausgeschlossen. Ein etwas weiter östlich des Grundwasserpegels angelegter Beregnungsbrunnen musste jedenfalls nach der Erweiterung der Siedlungsfläche im Süden und Südosten vertieft werden ${ }^{6}$.

Der immer noch relative hohe Grundwasserstand macht dieses Gebiet für tiefwurzelnde Pflanzen zu einem günstigeren Standort als es die Bodenart mit ausgesprochen guter Perkolation erwarten lässt.

Die angrenzenden Moor- und Bruchflächen, die Aller-Dreckwiesen, die Osterbruchwiesen und der Schweinebruch sind äußerst stark Grundwasser beeinflusst und bedürfen einer gut regulierten Entwässerung, wenn eine agrarische Nutzung ertragreich sein soll, aber auch dann sind die Nutzungsmöglichkeiten begrenzt. In diesen Bereichen ist ebenfalls das Grundwasser der beherrschende Faktor, wenngleich durch Flussregulierungen und Grundwasserabsenkungen die Einschränkungen geringer geworden sind.

\footnotetext{
${ }^{1}$ Standortkartierung der Klosterforst Miele, Erläuterungen Miele, S. 10

2 Durch die „Regulierung“ von Aller und Schwarzwasser ist im südlichen Ortsbereich der Grundwasserspiegel zwar abgesunken, einige Keller sind noch immer bei lang anhaltendem Aller-Hochwasser bedroht. Eigene Beobachtungen des Verf. in den Jahren 1973 u.f..

${ }^{3}$ Der Erläuterungsbericht der forstlichen Standortaufnahme schreibt der Lachte einen stärkeren Einfluss auf die Grundwasserstände zu. Dies muss aber aufgrund der eingeholten Auskünfte, die meist auf langjährigen Beobachtungen fußen, vom Verf. Bezweifelt werden.

${ }^{4}$ Mdl. Auskunft von Herrn Landwirt K. Koch, Lachendorf

${ }^{5}$ Mdl. Auskunft von Herrn Roschmann, NLWKN Verden

${ }^{6}$ Mdl. Mittelung von Landwirt K. Koch, Lachendorf
} 


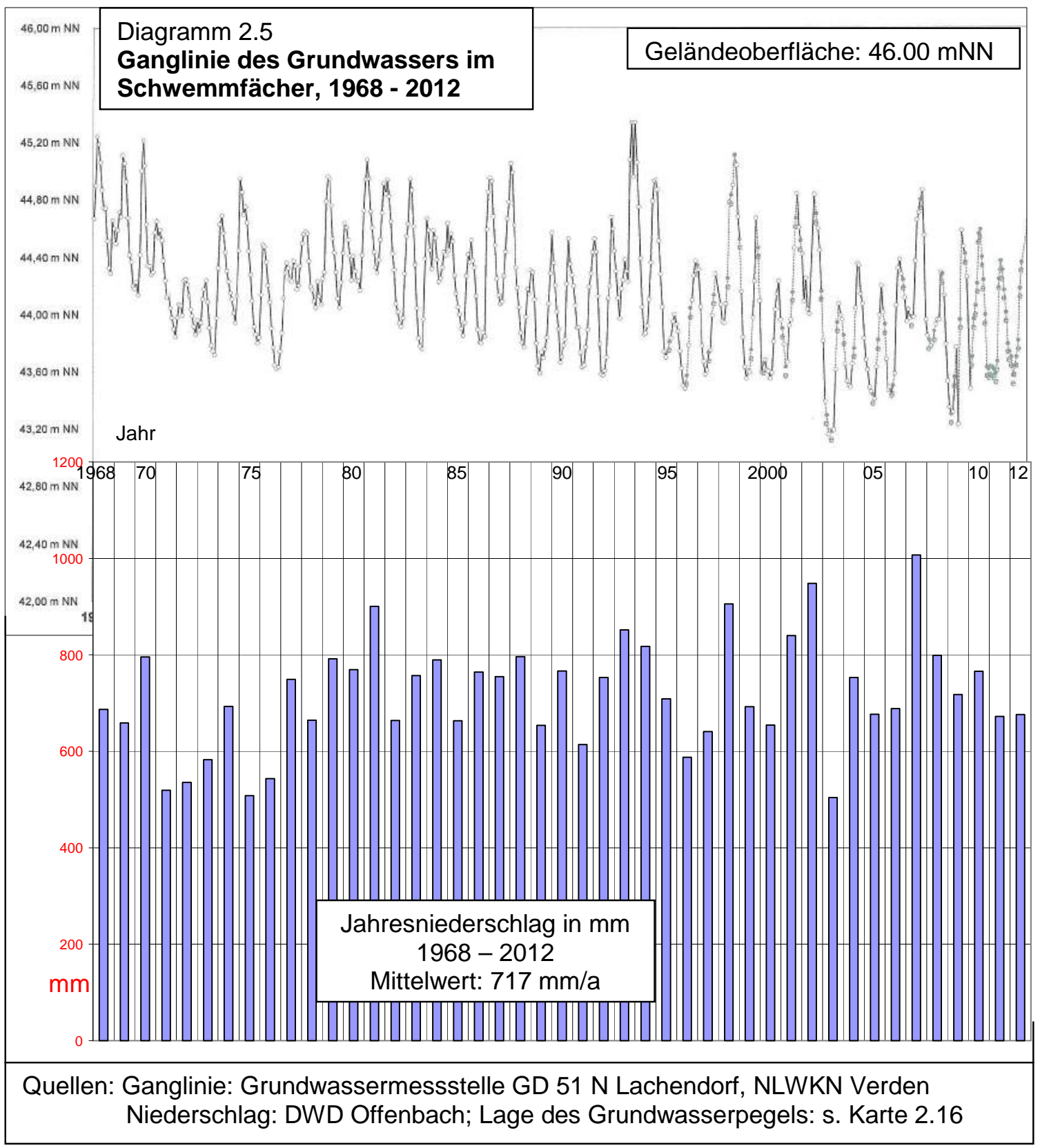

Bei Ackerbau mit annuellen Kulturpflanzen kann aber wegen der recht geringen Speicherfähigkeit der vorherrschenden Talsande in der Vegetationszeit Mangel im Bodenwasser auftreten, sodass auch im Allertal bei anhaltender Trockenheit Beregnungsanlagen zum Einsatz kommen.

Der südlichste Gemarkungsteil, der über das Schwarzwasser von der Aller her durch Rückstau direkt unter Wasser gesetzt wurde und früher häufigen Überschwemmungen ausgesetzt war, ähnelte bezüglich der Grundwasserverhältnisse der Lachtetalaue in der direkten Abhängigkeit vom Wasserstand des Flusses.

Nach der Regulierung von Aller und Schwarzwasser mit der fertig gestellten Verwallung wird dieses Gebiet weiter unter dem allgemeinen Grundwasserregime des Urstromtales bleiben, aber nicht mehr häufig direkt überflutet werden können.

Die Karte der Entwässerungsgebiete ist zwar im Hinblick auf eine Verbesserung des Raumes für landwirtschaftliche Nutzung erstellt, macht aber gerade dadurch die naturgeographische Struktur des Raumes deutlich: Der trockene Schwemmfächer vor der Mündung des 
Lachtetales ins Urstromtal ist umgeben von nassen und grundwassernahen Bereichen der Randmoore.

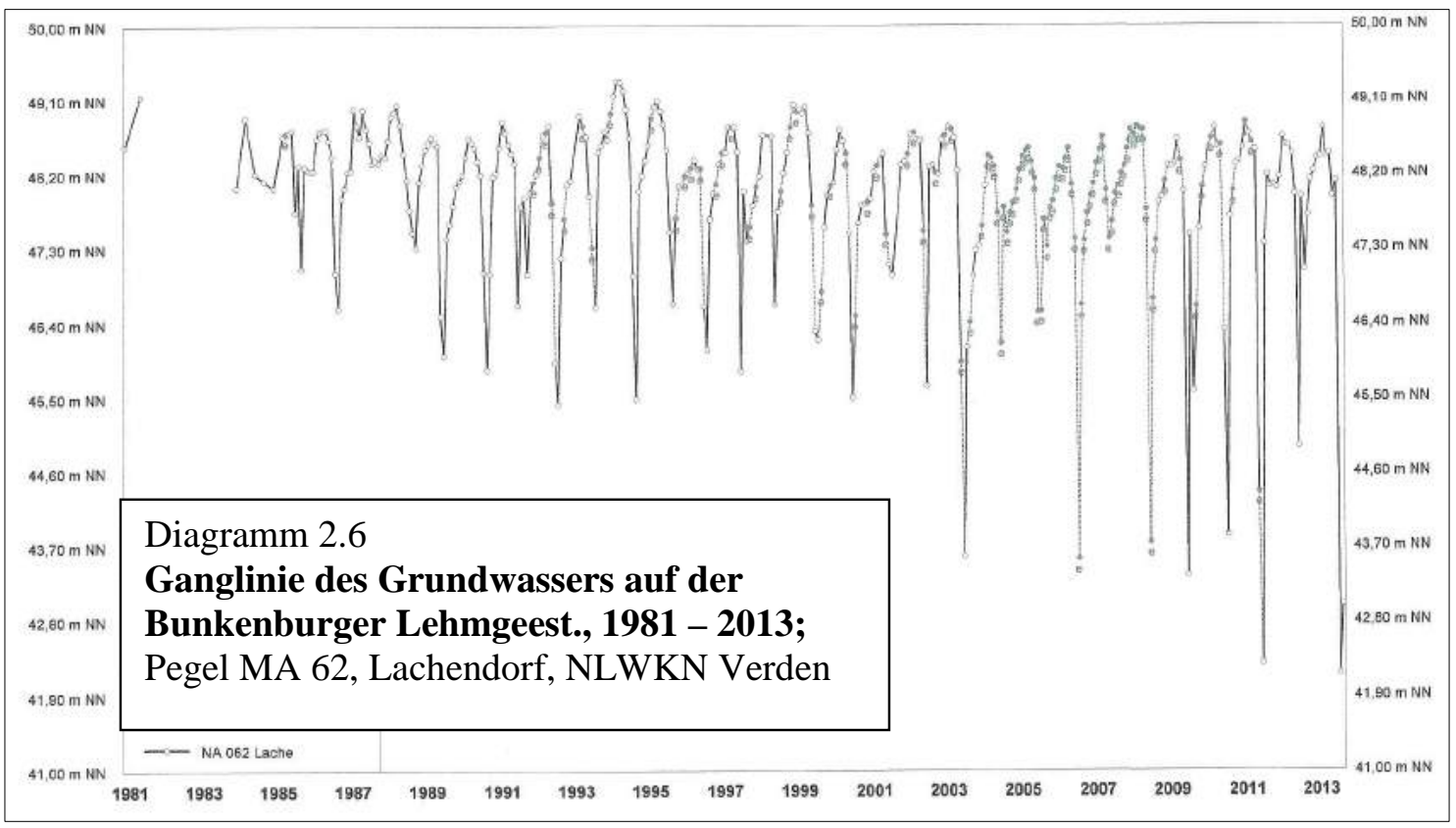

Auf den Geestplatten mit ihren Lehmböden spielt das Grundwasserregime einen andere Rolle: Einmal wegen der wesentlich höheren Speicherfähigkeit an Bodenwasser aufgrund der vorherrschenden Bodenart und zum anderen, weil es bei Höchststand $1-2$ unter Flur ansteht und auf dem Ackerland von annuellen Kulturpflanzen bei Flachwurzlern nicht oder von tiefer wurzelnden Pflanzen nur nach voller Entfaltung erreicht werden kann.

Nun zeigt der Grundwasserpegel auf der Bunkenburger Lehmgeest eine zunehmende Schwankung mit einer Jahresamplitude, die in den 1980er Jahren von $1-2 \mathrm{~m}$ auf bis zu $4 \mathrm{~m}$ zunahm und dann ab 2003 sprunghaft auf bis zu fast $8 \mathrm{~m}$ stieg. Allerdings handelte es sich immer um kurzfristige Absenkungen und einem Wiederanstieg auf das vorherige Niveau. Der Grundwasserkörper hat sich also immer wieder im Laufe des Jahres aufgefüllt.

Diese saisonale Absenkung des Grundwassers wird nach eindeutiger Aussage des NLWKN ${ }^{1}$ mit zunehmender Beregnung der Ackerkulturen erklärt.

Im Jahr 2003 nahmen in Ahnsbeck im östlichen bereich der Geestplatte und auf dem Lachendorfer Bereich zwei Gemeinschaftsberegnungen ihre Arbeit auf. Allein auf dem Lachendorfer Flurteil der Bunkenburger Geest sind im vergangenen Jahrzehnt fünf Beregnungsbrunnen angelegt worden, die eine Tiefe von 65-85 m erreichen ${ }^{2}$. Sie entnehmen also das Grundwasser aus den glazifluvialen Sanden und Kiesen, die in der Saale-Vereisung auf der tertiären Landoberfläche abgelagert und dann von Geschiebemergel überdeckt wurden ${ }^{3}$.

Der Grundwasserköper ist offenbar so leistungsfähig, dass bisher eine Auffüllung stets möglich war und es - jedenfalls bisher - zu keiner grundsätzlichen und dauerhaften Absenkung des Grundwasserspiegels gekommen ist.

Die starke Absenkung in der Hauptvegetationszeit könnte aber zur Folge haben, dass die Beregnungsnotwendigkeit sich selbst verstärkt. Denn wenn Beregnung zur Ertragssicherung und -optimierung den Grundwasserspiegel stark absenkt, dann müssen auch andere und benachbarte Kulturen beregnet werden, weil der Wurzelraum den natürlichen Grundwasserspiegel nicht mehr erreicht. Auch tief wurzelnde Kulturpflanzen sind dann allein auf das Bodenwasser angewiesen, das auch auf den Lehmböden bei längeren Trockenphasen für ein optimales Wachstum nicht ausreicht.

\footnotetext{
${ }^{1}$ Mdl. Auskunft von Herrn Roschmann, NLWKN, Verden

${ }^{2}$ Schr. Mittelung von Landwirt K. Koch, Lachendorf

${ }^{3}$ Vergl. Diagramm 2.6: Geologisches Profil
} 


\subsection{Böden}

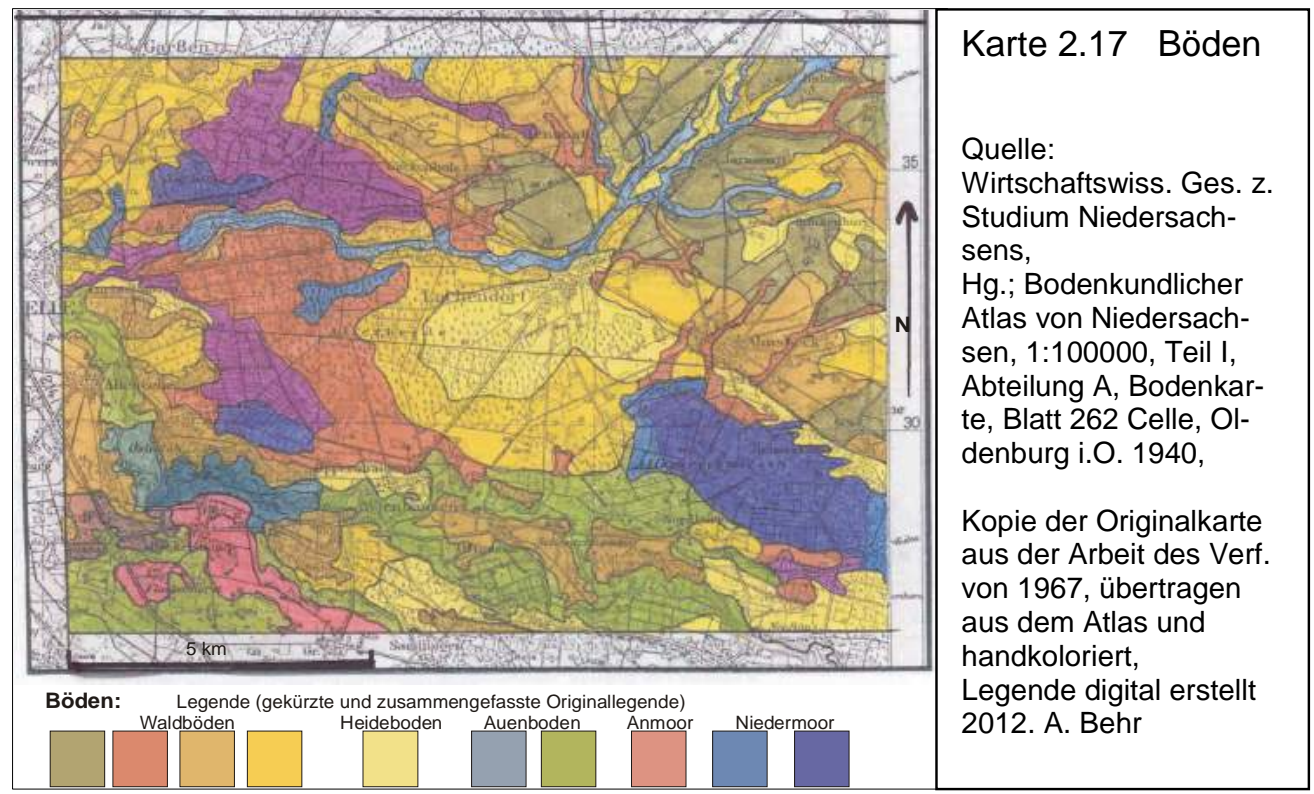

\subsubsection{Böden und naturräumliche Gliederung}

Die Karte 2.17 der Böden ${ }^{1}$ aus dem Bodenkundlichen Atlas von Niedersachsen aus dem Jahr 1940 weist eine längst veraltete Nomenklatur der Böden auf. Wegen der räumlichen Aussage wird die Karte hier aber dennoch benutzt.

Diese räumliche Aussage ähnelt nämlich sehr stark der räumlichen Darstellung der Entwässerungs-gebiete auf Karte 2.15 und macht damit deutlich, dass auch die räumliche Anordnung der Böden der in Kap. 2.1 entwickelten naturräumlichen Struktur voll entspricht:

Auf den Geestplatten dominieren die Waldböden und auf dem Schwemmfächer besonders der Heideboden. Die Randmoore sind durch Niedermoor geprägt. Das Urstromtal weist ein buntes Mosaik auf, weil Flussaue, Flutmulden und Niederterrassenreste mit Flugsandinseln und Dünen kleinräumig wechseln.

\subsubsection{Bodenlandschaften und Bodentypen}

Um die pedologischen Bedingungen des Untersuchungsraumes näher verstehen zu können, bedarf es genauerer Darstellung der vorkommenden Bodenarten und -typen sowie deren räumlicher Verteilung bzw. Anordnung.

Einen ersten Zugang zu den Bodeneigenschaften vermittelt die Karte der Bodenlandschaften (Karte 2.18), weil die Legende Hinweise auf die geologische Entstehung und die Bodenart, also zum Ausgangssubstrat für die Bodenbildung, gibt: Die Verbreitung von Lehmböden entspricht den Grundmoränenplatten, Talsande bestimmen weitgehend das Allertal sowie deren Neben- und Trockentäler in den Geestplatten. Der Schwemmfächer der Lachte wird durch fluviatile und glazifluviatile Sedimente, also Sande unterschiedlicher Korngrößen, bestimmt. Im Auenbereich der Aller sind Talsedimente verzeichnet, also feinkörnige Ablagerungen unterschiedlichen Alters wie Auelehm und Sande. Der Lorkberg im Bereich der Schwarzwassermündung ist durch Dünensand richtig charakterisiert.

\footnotetext{
${ }^{1}$ Wegen der veralteten Nomenklatur wird im Zusammenhang mit dieser Karte der Begriff „Bodentyp“ bewusst nicht genutzt.
} 


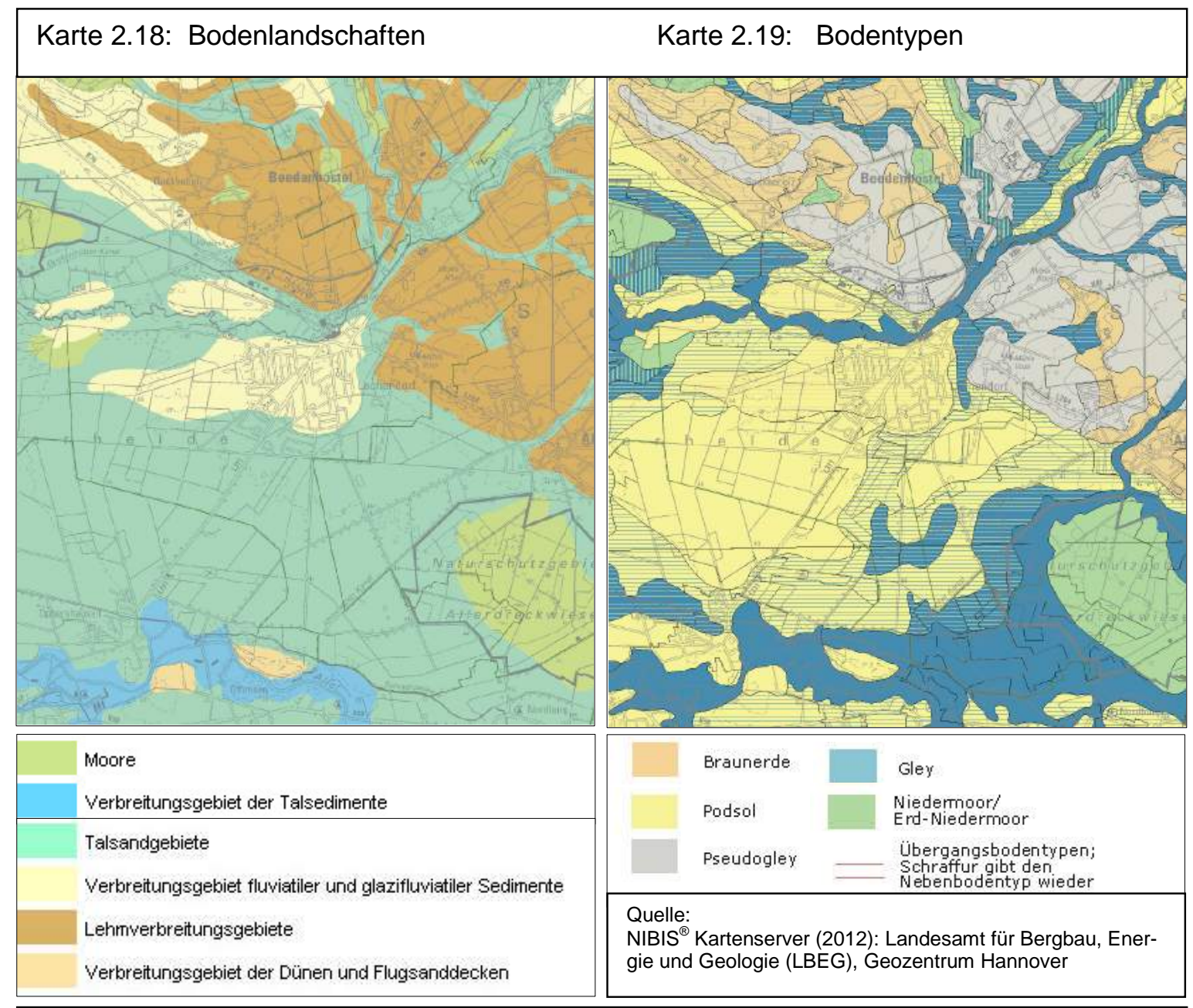

Karte 17: Ausschnitt aus: Bodenlandschaften 1:500 000

Karte 18: Ausschnitt aus: Bodenübersichtskarte 1:50 000, Bodentypen in Niedersachsen

Wie Karte 2.19 (Bodentypen) zeigt, haben sich entsprechend den Ausgangssubstraten und klimatischen Bedingungen standorttypische Böden entwickelt, die allgemein zur sog. Mergelserie ${ }^{1}$ gehören.

Auf dem Lehm der Grundmoränenplatten bildeten sich je nach Wasserhaushalt bzw. Staunässe Braunerden und Pseudogleye, auf den fluviatilen und glazifluviatilen und äolischen Sanden Podsole, in den Auen und im Randbereich der Randmoore im Urstromtal Gleye und in den Randmooren selbst Niedermoor.

Besonders im Allertal gibt es wegen des hohen Grundwasserstandes einen deutlichen Übergangsbereich zwischen den Podsolen im zentralen, trockenen Bereich des Schwemmfächers und den Gleyen. Dort finden sich Übergangsbodentypen vom Gley-Podsol zum Podsol-Gley.

Entsprechendes gilt am Rand der Grundmoränenplatten zum Urstromtal, aber auch zum Lachtetal, wo es im Übergangsbereich von den Braunerden und Pseudogleyen auf Lehm zu den Talsanden zu einer zunehmenden Podsolierung kommt. Aufgrund von Bodenaufschlüssen im Bereich der Grundmoränenplatte östlich von Lachendorf, auf der Bunkenburger Geest, muss auf der Karte der Bodentypen (Karte 2.19) die einheitliche und großfächige Zuordnung zum Pseudogley differenzierter betrachtet werden:

\footnotetext{
${ }^{1}$ s. K. Stahr u.a.; Bodenkunde und Standortlehre, UTB Stuttgart ,2. Auf., 2002, S. $143 \mathrm{ff}$
} 
Die Verbreitung des Pseudogleys nordöstlich des Ortes bis direkt an die Talaue verkennt die Tatsache, dass sich zwischen dem Geesthang und der Flussaue eine Verebnungsfläche, eine Terrasse ${ }^{1}$, befindet, die aus fluviatilen Sanden ${ }^{2}$ aufgebaut ist und daher für Pseudovergleyung nicht infrage kommt.

Auch im Zentrum der Grundmoränenplatte ist die Bodenbildung nicht einheitlich, wie die Profilaufnahmen in Abb. 2.4) ${ }^{3}$ zeigen: Die Bodenbildung reicht von podsolierten Pseudogleyen bis zu pseudovergleyten Braunerden.

Wegen der Größe des Schwemmfächers und der Talsande ist der Podsol im Lachendorfer Raum der am weitesten verbreitete Bodentyp, der aber keineswegs einheitlich ausgeprägt ist, wie die folgenden Abbildungen zeigen:

Profil in Abb. 2.5: Reliktpodsol ${ }^{4}$

Ort: Baugrube, Ecke Rehrkamp/Ellernkamp im Westen des Ortes, im Wurzelbereich des Schwemmfächers Profilbeschreibung:

AL,h $5 \mathrm{~cm}$, grau-schwarz, Kiefernnadelstreu, schwacher Rohhumus, Sand, humos

Ae $6 \mathrm{~cm}$, braun-grau, Sand, schwach gebleicht, schwach durchwurzelt

C $\quad 20 \mathrm{~cm}$, hellbraun bis grau-braun, Sand, schwach durchwurzelt

$20 \mathrm{~cm}$, braun bis grau-braun, Feinsand, schwach durchwurzelt

rAh $31 \mathrm{~cm}$, grau-schwarz, Sand, einzelne Wuzeln, humos, etwas verfestigt

rAe $\quad 35 \mathrm{~cm}$, weiß-grau, (tw. grau-hellviolett), Sand, gleichmäßig gefärbt, stark podsoliert

rBh $12 \mathrm{~cm}$, dunkel kaffeebraun, Sand, Humusorterde, recht fest, Zapfenbildung

rBS $28 \mathrm{~cm}$, kräftig ockergelb bis rostfarben, Sand, Humusbändchen

$20 \mathrm{~cm}$ lehmiger Sand, z.T. tonig, grau-gelb, tw. auch etwas bläulich-gelb, fest und trocken, z.T etwas plastisch $18 \mathrm{~cm}$, schwach anlehmiger Sand, rostbraun mit grau-gelben Flecken

$\mathrm{C} / \mathrm{rB} \quad 60 \mathrm{~cm}$, gelblich-weiß, Sand, geschichtet, kräftig rot-rostbraun gefärbte Nester und Bänder mit Eisenoxid-Konkretionen, typische Verwürgung (Kryoturbation)

C (ab 2,55 m u.F.): flivio-glazial geschichtete Sande in ungestörter Lagerung, gleichmäßig gelb-weiß.

\footnotetext{
${ }^{1}$ Diese Terrasse im Lachtetal ist besonders gut ausgeprägt an der Straße von Lachendorf nach Jarnsen, nordöstlich des Ortes.

${ }^{2}$ s.a. Karte 2.17

${ }^{3}$ Lage: Flurstück Pannstätte östlich des Ortes, südlich der Straße nach Ahnsbeck, oberhalb des Talhanges. Aufnahme: A. Behr, 1970

${ }^{4}$ Aufnahme am 25.10.1966: A. Behr
} 
Profil in Abb. 2.6: Heidepodsol ${ }^{1}$

Ort: Sandgrube, östlich Ortsteil „Im Gehege“, südlich

Rehrkampsweg

Profilbeschreibung

AL $\quad 4 \mathrm{~cm}$, Rohhumusauflage aus Bestandsabfall von Calluna vulgaris

Ah $5 \mathrm{~cm}$, Sand, dunkel braub bis schwarz, humos, gut durchwurzelt

Ae $\quad 8 \mathrm{~cm}$, Sand, hellgrau bis aschgrau, stark gebleicht, mäßig durchwurzelt

Bh $5 \mathrm{~cm}$, Sand, kaffeebraun bis schwarz, fest, bröckelig, Orterde

BS $22 \mathrm{~cm}$, hell kaffeebraun bis grau-braun, rostfarbene Flecken, leicht verfestigt, Humusbändchen

C $\quad 53 \mathrm{~cm}$, Sand, tw. kiesig, Humusbändchen, Wurzelbahn mit Humusilluviation, $4 \mathrm{~cm}$, Humusband, dunkel kaffeebraun bis schwarz, leicht verfestigt, bröckelig.

$5 \mathrm{~cm}$, Band aus sandigem Lehm, rostbraun bis grau-gelb, tw. grau-blau gefleckt, $15 \mathrm{~cm}$, sandiger Lehm, tw. tonig, gelblich-grau, sehr fest bis hart, wasserstauend, darunter: grau-weißer Sand, sehr durchlässig

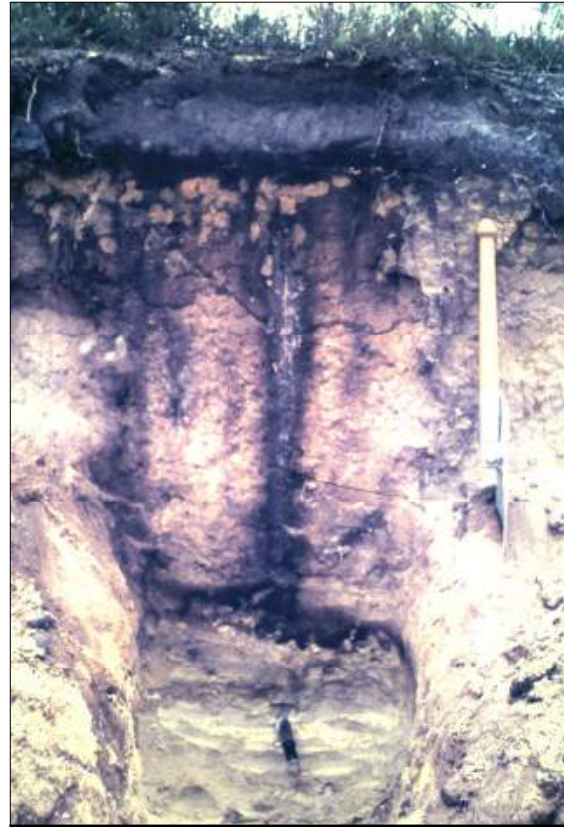

Abb. 2.6: Heidepodsol

Die Podsolbildung auf dem Schwemmfächer ist sehr vielfältig, sowohl hinsichtlich der Podsolierung wie auch hinsichtlich der Ausprägung des B-Horizontes².

Das ist sicherlich z.T. auch auf die Vegetations- bzw. Nutzungsgeschichte zurückzuführen, aber vorwiegend wohl doch auf die jeweilige Ausprägung des Substrats und der Höhe des Grundwasserspiegels.

Da der Schwemmfächer in sich leicht gewölbt ist und ganz im Urstromtal mit dem Grundwasserregime der Aller liegt, gibt es eine typische zentral-periphere Abfolge ${ }^{3}$ vom trockenen Podsol (Normpodsol) über den Gley-Podsol zum Podsol-Gley am äußeren Rand, im Übergang zu den Randmooren.

Einen weiteren Faktor bilden eingelagerte Lehmbänder ${ }^{4}$ unterschiedlicher Stärke und Tiefe, die den Bodenwasserhaushalt in den durchlässigen Sanden positiv beeinflussen. Solche Stellen machen sich durch typische Zeigerpflanzen wie Pfeifengras ${ }^{5}$ bemerkbar.

In den kleinen Mooren, Kleines Moor, Krummes Moor, Krähenmoor und Postmoor - alle im Bereich des Schwemmfächers gelegen -, haben sich in den fluviatilen Sanden je nach Grundwasserstand Podsole mit tief angelegtem Grundwassergley und bei hohem Grundwasserstand Podsol-Gleye ${ }^{6}$ entwickelt.

Auf den trockenen Talsandflächen im Allertal nördlich der Schwarzwassermündung, als „Trockene Wiesen“ bezeichnet, herrschen auch Podsole vor.

In den Aller-Dreckwiesen, zum Randmoor im Urstromtal gehörend, finden sich echte Anmoor-Gleye ${ }^{7}$ mit einer bis zu einigen Dezimeter mächtigen Niedermoorauflage.

\footnotetext{
${ }^{1}$ Aufnahme: 13.10.1966: A..Behr

2 s. Abb. 2.7: Podsol-Profile unter Acker auf dem Flurstück „Reitbahn“, südlich des Ortes, östlich der Straße Lachendorf-Oppershausen; Aufnahme 1970, A. Behr

${ }^{3}$ s. dazu Karte 2.18

s. Standorttypenkarten Klosterforstamt Miele, Kartenband, unveröffentlicht

${ }^{5} \mathrm{Im}$ zentralen Teil des Schwemmfächers, westlich des Trockenwiesenweges, am südlichen Rand des Grünlandes, befindet sich ein Bestand von Pfeifengras. Dieses Gebiet wurde bis ins 19. Jahrhundert zum Bultenhieb (s.u. Heidebauernwirtschaft, Plaggenhieb) genutzt.

${ }^{6}$ vgl. Erläuterungen Miele, S. 85 ff und Bodenkarte der Standorttypenkarte der Klosterforst Miele

${ }^{7}$ s. Abb. 2.8: Lage: Aller-Dreckwiesen, südöstlicher Gemarkungsteil; Aufnahme A. Behr, 1970
} 
Das Bodenmosaik folgt erwartungsgemäß genau dem naturräumlichen Muster, wobei für die Geestplatten Braunerden und Pseudogleye typisch sind, auf dem Schwemmfächer und den Lachtetal-Terrassen sind es Podsole und im Bereich der Randmoore dann Gleye.

Augrund der Substrate und des Klimas sind fast überall auch podsolierte Formen des Hauptbodentyps zu finden.
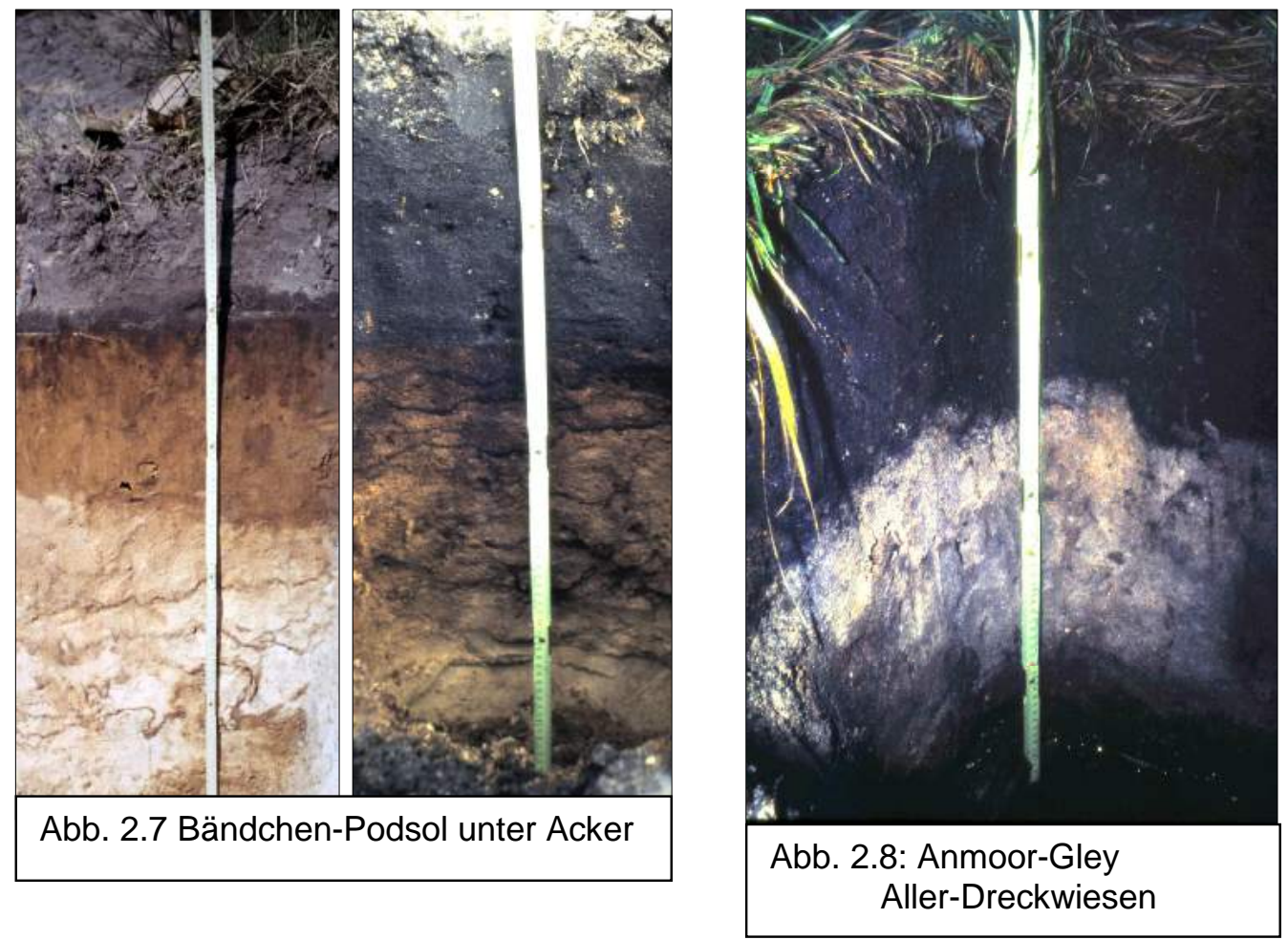

Entsprechend der geologischen und morphologischen Struktur sowie der Nutzungsgeschichte bildet der Schwemmfächer der Lachte im Allertal ein sehr großes Gebiet, das flächendeckend von der Bodenform Podsol auf Sand bestimmt ist. Aufgrund von Lehmbändern, die bei der Sedimentation des Schwemmfächers entstanden sind, kommt es zu Unterschieden im Bodenwasserhaushalt. Die leichte Wölbung des Fächers führt auch zu einem unterschiedlichen tiefen Grundwasserhorizont. Beide Faktoren führen zu unterschiedlichen Standortbedingungen auf den Podsolen: von sehr trocken bis grundfrisch.

Diese kleinräumigen Unterschiede führten und führen sowohl in der Heidelandschaft vor 1850 sowie auch in der Waldlandschaft der Gegenwart zu einer deutlichen ökologischen Differenzierung der Allerheide, die aufgrund fehlender Reliefenergie und früher wie heute recht einheitlicher Nutzung leicht als homogener Naturraum angesehen werden könnte.

Im weiteren Verlauf der Raumanalyse wird sich zeigen, dass es sowohl Standortunterschiede in der ehemaligen Heidelandschaft gab und dass im heutigen wald- und Forstgebiet die Unterschiede der Bodenvegetation dieses ökologische Mosaik bestätigen.

Abbildung 2.9 demonstriert, dass es auch kleinräumig auf einer Ackerparzelle zu unterschiedlichen Ausprägungen des Podsols kommen kann. 


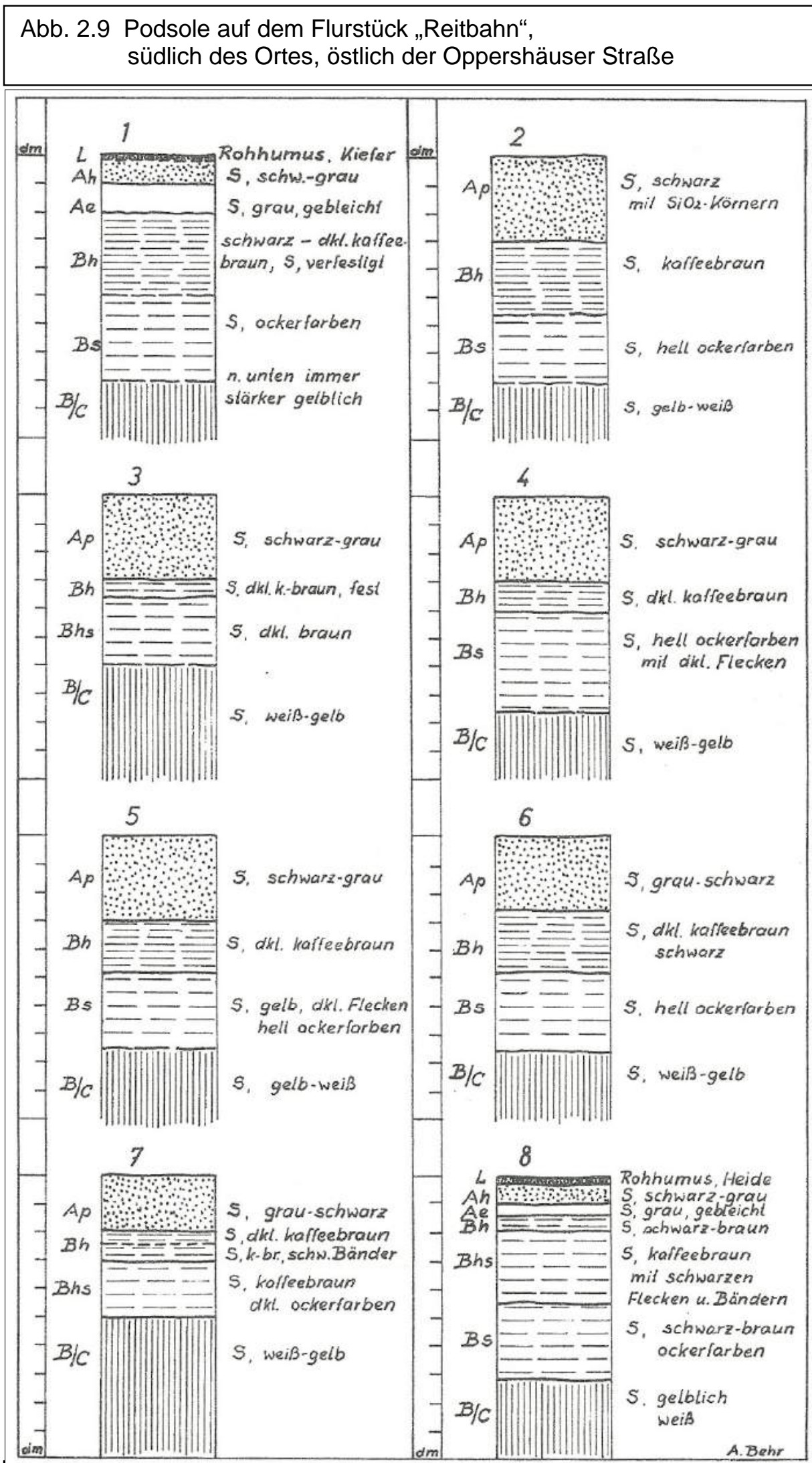

Die Bodenform Podsol auf Sand beherrscht das Gebiet des Schwemmfächers.

Die dargestellten Profile zeigen aber auch kleinräumige Differenzierungen.

Profilaufnahmen und Zeichnung: A. Behr 1970 


\subsection{Klima ${ }^{1}$ - Witterung - Wetter}

\subsubsection{Vorbemerkung}

Für eine so kleinräumige agrargeographische Untersuchung wäre es an sich wünschenswert, über ausreichende Messdaten und Untersuchungen des Lokalklimas und des mikroklimatischen Bereichs zu verfügen. Mit Sicherheit würden sich daraus interessante und aufschlussreiche Unterschiede kleinklimatischer .Art der einzelnen Standorte innerhalb der Feldmark ergeben.

Hilfreich für die Beurteilung der Standorteigenschaften und des wirtschaftlichen Nutzungspotenzials dürften die Niederschlagswerte ${ }^{2}$ der Station Lachendorf sein, die seit 1941 - mit einer Lücke von 1945 und 1946 - als Tageswerte vollständig vorliegen.

Im Übrigen muss auf Werte überregionaler Messstationen zurück gegriffen werden.

\subsubsection{Klima, Klimabezirke}

Die großräumige Einordnung des

Untersuchungsgebietes ist sicher wegen der

räumlichen Nähe und des Reliefs im Großraum

Hannover-Celle durch das Walter-Lieth Klimadiagramm von Hannover-Langenhagen ${ }^{3}$ gut möglich.

In das Diagramm der Station Hannover-Langenhagen wurden die Niederschlagswerte der Station Lachendorf eingearbeitet. Die Übernahme der Temperaturkurve ist aus zwei Gründen vertretbar: Die durchschnittlichen Monatswerte der Temperatur dürften aufgrund von Lage und Relief zwischen den beiden Stationen nur unwesentlich differieren. Da die Monate durchweg deutlich humid sind, würde eine leichte Änderung der Temperaturkurve keine Änderung der grundsätzlichen Aussage dieses Diagrammtyps nach sich ziehen. Im Vergleich der beiden Stationen ist bemerkenswert,

Diagramm 2.5: Klimadiagramm

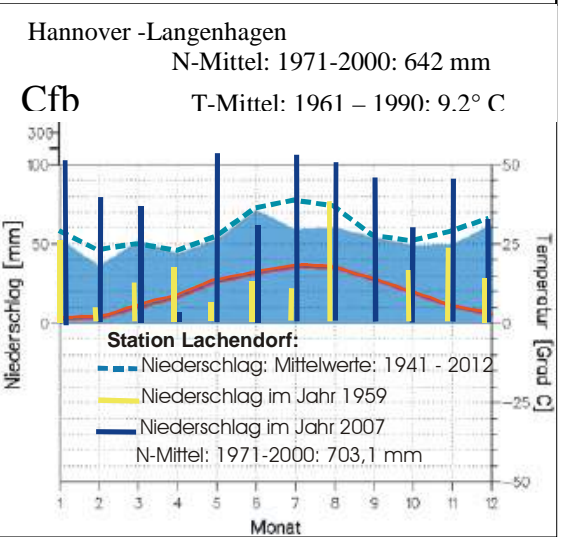
dass Lachendorf in den Wintermonaten geringfügig und in den Monaten Juli - August deutlich humider ist. Bei gleicher Periode (1971 - 2000) liegt der mittlere Jahresniederschlag in Lachendorf um 61,1 mm höher.

Der Lachendorfer Raum kann also der warmgemäßigten, perhumiden Klimaregion ${ }^{4}$ mit atlantischer Prägung, wie es auch die Windhäufigkeit ${ }^{5}$ belegt, zugeordnet werden.

Bei den Klimabezirken wird bereits die Zweiteilung des

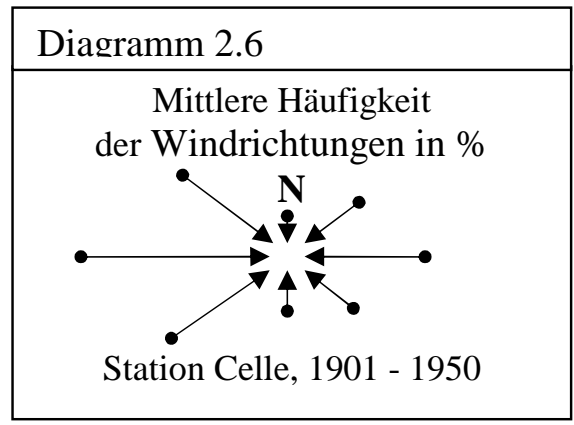
Untersuchungsraumes deutlich: Die Mittlere Südheide gehört zum Klimabezirk Lüneburger Heide und das Mittlere Allertal zu dem des Weser-Aller-Gebietes. Die Grenze - besser gesagt: die Übergangszone - zwischen beiden Bezirken fällt zwischen Celle und Gifhorn etwa mit dem Rand des Aller-Urstromtales zusammen, verläuft also genau durch Lachendorf und

\footnotetext{
${ }^{1}$ vgl. dazu: Deutscher Wetterdienst, Hrsg. Klima-Atlas von Niedersachsen, Offenbach/Main, 1964, im folgenden zitiert als "Klima-Atlas von Niedersachsen"

${ }^{2}$ Niederschlagsdaten: 1941 - 2004 freundlicherweise vom Deutschen Wetterdienst, Offenbach, und 2005 - 2012 vom Betreuer der Messstation, Herrn Koch, mit Genehmigung des Deutschen Wetterdienstes zur Verfügung gestellt.

${ }^{3}$ Quelle: Station Hannover-L.:www.klimadiagramme.de/Deutschland/Hannover.htm (2012), Station Lachendorf: Daten vom DWD, Offenbach

${ }^{4} \mathrm{Cfb}$ nach Köppen. Warmgemäßigt, immer feucht, wärmster Monat im Mittel $<22^{\circ} \mathrm{C}$.

${ }^{5}$ Diagramm 2.6: Quelle der Daten: Deutscher Wetterdienst, Hg.; Klima-Atlas von Niedersachsen, Offenbach a. M., Karte 5; Zeichnung: Verf.
} 
dessen Gemarkung ${ }^{1}$. Hier muss allerdings die Frage gestellt werden, was bei dieser Grenzziehung entlang einer morphographischen Leitlinie ursächlich war: Messwerte zum Klima oder Orientierung an dieser markanten Linie? Vermutlich legten Messwerte hier eine Gliederung in zwei Klimabezirke, Lüneburger Heide und Mittleres Allertal, nahe, während die konkrete Grenzziehung sich doch stark am Relief orientierte.

Obwohl die Unterschiede beim Faktor Temperatur nur recht gering sind, zeigt sich doch im Ganzen, dass die klimatischen Verhältnisse im Allertal etwas milder und ausgeglichener sind als auf den Geestplatten der Mittleren Südheide. Diese leichte Besserstellung

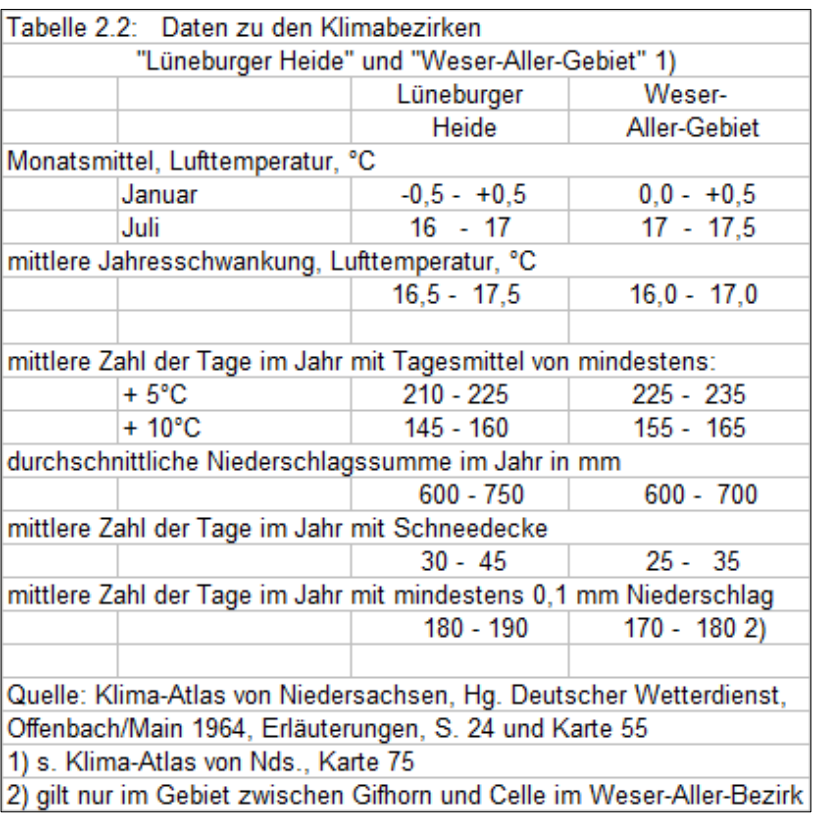
- von Gegensatz kann aufgrund der geringen Unterschiede nicht gesprochen werden - des Allertales kommt besonders in den Temperaturen ${ }^{2}$ und damit z.B. auch beim Beginn der Apfelblüte und der Aussaat ${ }^{3}$ als günstige Indizes für den Beginn der Vegetationsperiode zur Geltung.

Auffällig ist, dass diese Isolinien stets parallel zum Urstromtalrand verlaufen und im Bereich der Mündung des Lachtetales in einem Bogen nach $\mathrm{N}$ ausbiegen ${ }^{4}$. So lag der Beginn der Apfelblüte im Allertal und in der Lachtemündung im Durchschnitt um den 5. Mai, auf den Geestplatten dagegen erst zwischen dem 10. und 15. Mai ${ }^{5}$.

Die schwachen Reliefunterschiede machen sich in dieser feinen klimatischen Differenzierung - unabhängig von klimatischen Veränderungen - doch recht deutlich bemerkbar ${ }^{6}$. Das Allertal ist hinsichtlich des Wärmehaushaltes etwas günstiger gestellt als die höher gelegenen Geestplatten?.

Im weiteren Verlauf dieses Kapitels konzentriert sich die Analyse auf den Niederschlag. Das liegt formal an der Datenlage, die hinsichtlich der Niederschlagsdaten für Lachendorf mit eigener Messstation besonders gut ist. Andererseits ist der Niederschlag hinsichtlich der Landnutzung ein besonders bedeutsamer Faktor, zumal in einem gemäßigten Jahreszeitenklima, in dem der Wachstumsfaktor Wärme, außer in seltenen Extremwetterlagen, in der Vegetationsperiode keine limitierende Rolle spielt.

\subsubsection{Niederschläge in den Klimabezirken Lüneburger Heide und Mittleres Allertal}

Lt. Klima-Atlas von Niedersachsen aus dem Jahr 1964 nehmen die Niederschläge in diesem Raum von W nach $E$ geringfügig ab. Während Celle ein Jahresmittel von $700 \mathrm{~mm}$ aufwies, betrug die Jahressumme im Raum Lachendorf noch 650-700 mm, im Gebiet der mittleren Ise und im Hahnenmoor noch 600-650 $\mathrm{mm}^{8}$. Am Rande des Lüßplateaus, also im nördlichen

\footnotetext{
${ }^{1}$ Klima-Atlas von Niedersachsen, Karte 75

2 Klima-Atlas von Niedersachsen, Karten 6-10: Mittlere wirkliche Lufttemperaturen

3 ebenda, Karten 61-73

${ }^{4}$ vgl. ebenda, Karte 69: Beginn der Apfelblüte

${ }^{5}$ vgl. ebenda, Karte 69: Beginn der Apfelblüte

${ }^{6}$ vgl. auch Anzahl der Tage mit Schneedecke in Tab. Nr. 5

${ }^{7}$ Dieser Unterschied wird auf den Karten des Klima-Atlas durch die dekadische Einteilung der Messwerte in Intervalle gleicher Flächenfarbe besonders betont, obwohl es sich natürlich in Wirklichkeit um gleitende Übergänge handelt.

${ }^{8}$ Klima-Atlas von Niedersachsen, Karte 50 und 51 (Hrsg. Deutscher Wetterdienst Offenbach, 1964)
} 
Bereich der Mittleren Südheide, sind die Niederschläge - bedingt durch das Relief - etwas höher, nehmen aber auch hier von W nach $\mathrm{E} \mathrm{ab}{ }^{1}$.

Für den Klimabezirk Lüneburger Heide gibt der Klima-Atlas von Niedersachsen eine Jahres-

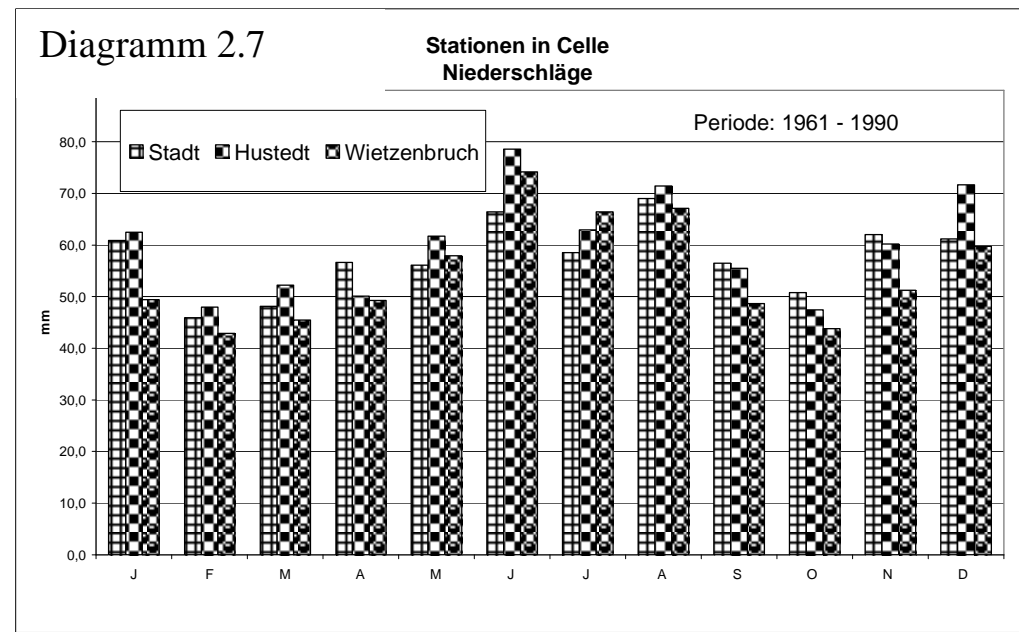

summe von 600-750 mm und für den Bezirk Weser-Aller-Gebiet $600-700 \mathrm{~mm} \mathrm{an}^{2}$.

Bei den Niederschlägen zeigen sich ebenfalls geringe Unterschiede zwischen dem Allertal und den Geestplatten. Wie geringfügig, aber doch nicht zu vernachlässigen, diese Unterschiede sind, verdeutlichen folgende Merkmale:

Das Diagramm 2.7) ${ }^{3}$ zeigt für Celle sehr kleinräumige Unterschiede der Niederschlagswerte an drei räumlich eng benachbarten Messstellen.

Die mittlere Zahl der Tage im Jahr mit mindestens $0,1 \mathrm{~mm}$ Niederschlag betragen im Allertal zwischen Celle und Gifhorn 170-180 Tage und im nördlich angrenzenden Gebiet um Lachendorf 180-190 Tage ${ }^{4}$.

Die drei Stationen in Celle zeigen zwar den gleichen Jahresgang. In allen Monaten bis auf April und Juli liegen die Monatswerte in Wietzenbruch niedriger als in Hustedt: Wietzenbruch liegt südlich der Stadt Celle im Aller-Urstromtal bei $39 \mathrm{~m}$ ü. NN und Hustedt ist ein nördlicher Vorort auf dem Geestsporn des Arloh bei $47 \mathrm{~m}$ ü. NN.

Diese kleinräumigen Unterschiede zwischen Allertal und Geestplatten dürften auch für den Raum Lachendorf, also das Mittlere Allertal und die Lachter Geest, gelten. Für Lachendorf selbst liegen aber nur Messwerte einer Station im Ort selbst vor, sodass kleinräumige Unterschiede hier nicht verifiziert werden können.

\subsubsection{Niederschlagsvariabilität}

Die in Lachendorf direkt gemessenen Niederschlagswerte ${ }^{5}$ der vergangenen sieben Jahrzehnte zeigen eine deutliche Variabilität in mehrfacher Hinsicht:

Die Variabilität der Jahressummen des Niederschlags bewegte sich in der Periode von 1941 bis $2010^{6}$ zwischen 368,1 mm im Jahr 1959 und 1006,9 mm im Jahr 2007 bei einem Mittel von $707,64 \mathrm{~mm}$.

\footnotetext{
${ }^{1}$ ebenda, Karte 51

${ }^{2}$ Klima-Atlas von Niedersachsen, Karte 51

3 www.dwd.de/Klimadaten - Stationen in Celle, 2012

4 Klimaatlas von Niedersachsen, Karte 55

${ }^{5}$ Quelle der für alle Diagramme zum Niederschlag in Lachendorf zugrunde liegenden Daten:

Tages- und Monatswerte der Station Lachendorf, Deutscher Wetterdienst, Offenbach (Datenreihe 1941 - 2004); K. Koch, Lachendorf, Tagebücher der Station Lachendorf, 2005 - 20012, mit freundlicher Zustimmung des Deutschen Wetterdienstes.

${ }^{6}$ Für die Darstellung der Niederschlagsverhältnisse wurde die Periode 1941 - 2010 gewählt, die eine Lücke der Jahre 1945 und 1946 aufweist, also 68 Jahre umfasst.
} 
Die Abweichungen bei den Jahressummen betragen in beiden Richtungen um $50 \%$. Es handelt sich also innerhalb des warmgemäßigten, perhumiden Klimas um eine erhebliche Niederschlagsvariabilität, auf deren Bedeutung für die verschiedenen Standorte in der Gemarkung später noch eingegangen wird.

Die Entwicklung der Jahresniederschläge folgt dem allgemeinen Trend ${ }^{1}$ einer leichten $\mathrm{Zu}-$ nahme. Bezogen auf die fast identischen langjährigen Mittelwerte der Perioden $1941-2010$ $(705,9 \mathrm{~mm})$ und der derzeitigen Normperiode 1961 - $1990(706,1 \mathrm{~mm})$ liegen von sieben Dekadenmitteln insgesamt vier über diesen Mittelwerten, davon allein drei davon in den letzten drei Jahrzehnten seit 1981.

\begin{abstract}
Diagramm Station Lachendorf
2.8 Niederschläge: Abweichung vom Mittelwert der Periode 1941 - 2010

Zwar hat die Häufigkeit der überdurchschnittlichen Jahressummen ${ }^{2}$ leicht zugenommen, es sind aber auch immer wieder Jahre mit unterdurchschnittlicher Jahresmenge einzeln oder in Zweiergruppen aufgetreten.

Der Vergleich mit den landesweiten Daten zeigt, dass es vor 1941 zahlreiche unterdurchschnittliche Jahesniederschläge gab und dass die Jahre 1945/46 keine feuchten Jahre waren. Letzteres hätte wegen der Datenlücke im Bestand der Station Lachendorf zu einem höheren Dekadenmittel geführt.

Der Anstieg der Dekadenmittel, s. Diagramm 2.8, in den drei Jahrzehnten seit 1941 kann durchaus als leichter Trend gedeutet werden, auch wenn das Mittel der 70er-Jahre unter den vorauf gegangenen Dekadenmitteln lag.

Die Dekaden mit den höchsten Mittelwerten liegen in den 80er Jahren und dem ersten Jahrzehnt des 21.

Diagramm 2.9

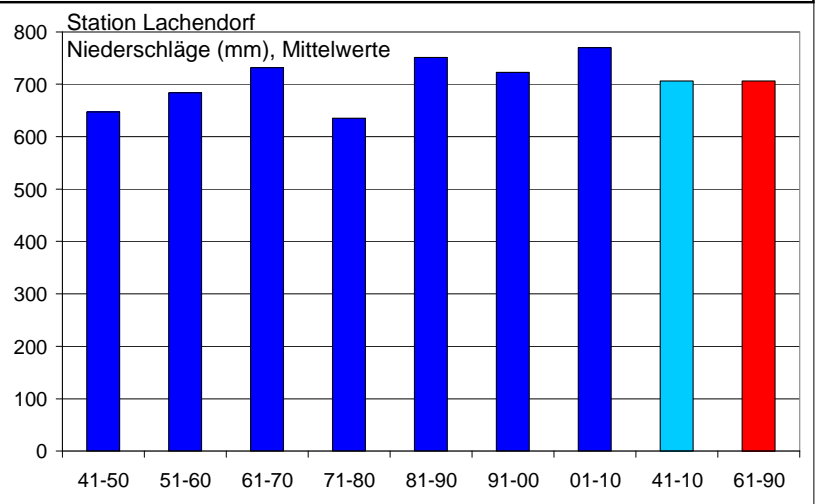

Jahrhunderts. Die Jahre 2011 mit 672,7 mm und $2012^{3}$ mit 676,3 mm haben diesen Trend aber nicht noch nicht bestätigt. In der Periode 1941 - 2010 betrug der langjährige Mittelwert der Jahressumme 706,7 mm und ist unwesentlich in der um zwei Jahre verlängerten Periode $1941-2012$ auf 706,7 mm gesunken.
\end{abstract}

\footnotetext{
${ }^{1} \mathrm{~s}$. Anhang: Veränderung der durchschnittlichen Jahresniederschläge seit 1881, DWD

2 vgl. Diagramm 2.12: Jahressummen seit 1941

${ }^{3}$ Datenquelle für 2011 und 2012: K. Koch, Messwart der Station Lachendorf, Verwendung mit freundlicher Zustimmung des DWD Offenbach
} 
So wie die Jahressummen in der Periode 1941 - 2010 einer starken Schwankung unterlagen, so ist auch eine starke Variabilität der Monatssummen der einzelnen Monate in dieser Periode zu verzeichnen. Dies zeigt die Diagrammreihe 2.10 in aller Deutlichkeit.

Die Mittelwerte der jeweiligen Monatssummen zeigen einen deutlichen mittleren Jahresgang der Niederschläge mit einem absoluten Minimum im Frühjahr und einem relativen Minimum im Herbst, sowie ein relatives Maximum im Winter und ein absolutes Maximum im Sommer. Auch die Reihe der Monatsminima und -maxima zeigt ein recht ähnliches Bild mit größter Trockenheit im Frühjahr und Herbst. Immerhin beträgt die maximale Abweichung vom Mittel in diesen Monaten über 90 bis fast $100 \%$, d.h. es gab im Frühjahr und Herbst Monate ohne nennenswerten Niederschlag. In anderen Jahren konnten gerade diese Monate besonders nass ausfallen, im Frühjahr bis über $150 \%$ und im Herbst sogar bis über $200 \%$.

Der Blick auf die einzelnen Monate ${ }^{2}$ in der gesamten Periode $1941-2010$ lässt auch keinen Trend erkennen, verdeutlicht aber die hohe Variabilität der Monatssummen (Diagramm 2.10) in aufeinander folgenden Jahren.

Zwar deuten die Monate Januar und März auf eine Zunahme der Monatssummen ab Mitte der 70er Jahre hin, aber auch danach traten große Unterschiede und sehr trockene Januarmonate (1989, 1996 und 1997) und Märzmonate (1993 und 1996) auf. Die Februar- und Aprilreihen zeigen große Schwankungen und Unregelmäßigkeit über die gesamte Periode.

Die Monatsniederschläge im Mai und Juni schwanken durchgehend unregelmäßig. Auffällig ist aber, dass in einer größeren Zahl von Jahren geringe Mairegen mit stärkeren Juniwerten korrespondieren. Hinsichtlich der Wachstumsbedingungen ist aber bemerkenswert, dass es im Mai (1956, 1959, 1989 und 2008) und auch im Juni (1959, 1960, 1997, 2005 und 2010) immer wieder sehr trockene Jahre gab. Die Anzahl der Jahre mit Niederschlagsmengen unter dem langjährigen Mittel, also eher trockene Jahre, ist größer als die Zahl der Jahre mit Regenmengen über dem Mittel, also eher nasse Jahre. ${ }^{3}$

Der Monat Mai 2013 erwies sich als

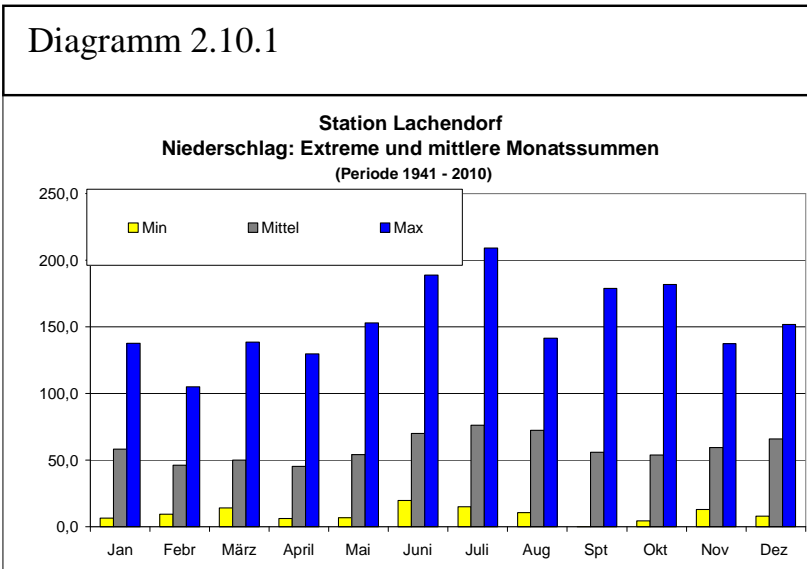

Diagramm 2.10.2

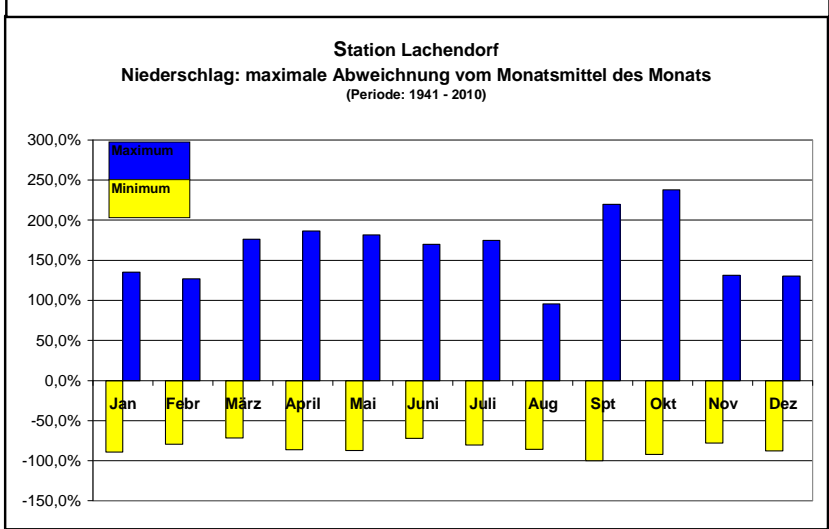

besonders extrem: Nach trockenen Monaten März mit nur 23,0 mm und April mit 35,1 mm fielen ab dem 8. Mai bis zum Monatsende insgesamt 201,4 mm Regen. In der Periode 19611990 betrug das Mai-Monatsmittel 59,9 mm und in der Periode 1981-2010 nur 54,5 mm.

\footnotetext{
${ }^{1}$ Quelle: s. Diagramm 2.9.1. Der Monatswert im September 1959 ist mit 0,1 mm vorhanden, kann aber aus Maßstabsgründen hier nicht dargestellt werden.

${ }^{2} \mathrm{~s}$. Monatsdiagramme in Diagrammreihe 2.10

${ }^{3}$ Dieses Merkmal hat aber auch formal-statistische Gründe: Die Monatssumme kann nicht unter Null sinken, in Extremfällen aber weit höher als das Doppelte des Mittelwertes ausfallen. Wenige Monate mit extrem hohen Niederschlägen beeinflussen die Mittelwertbildung also überproportional.
} 


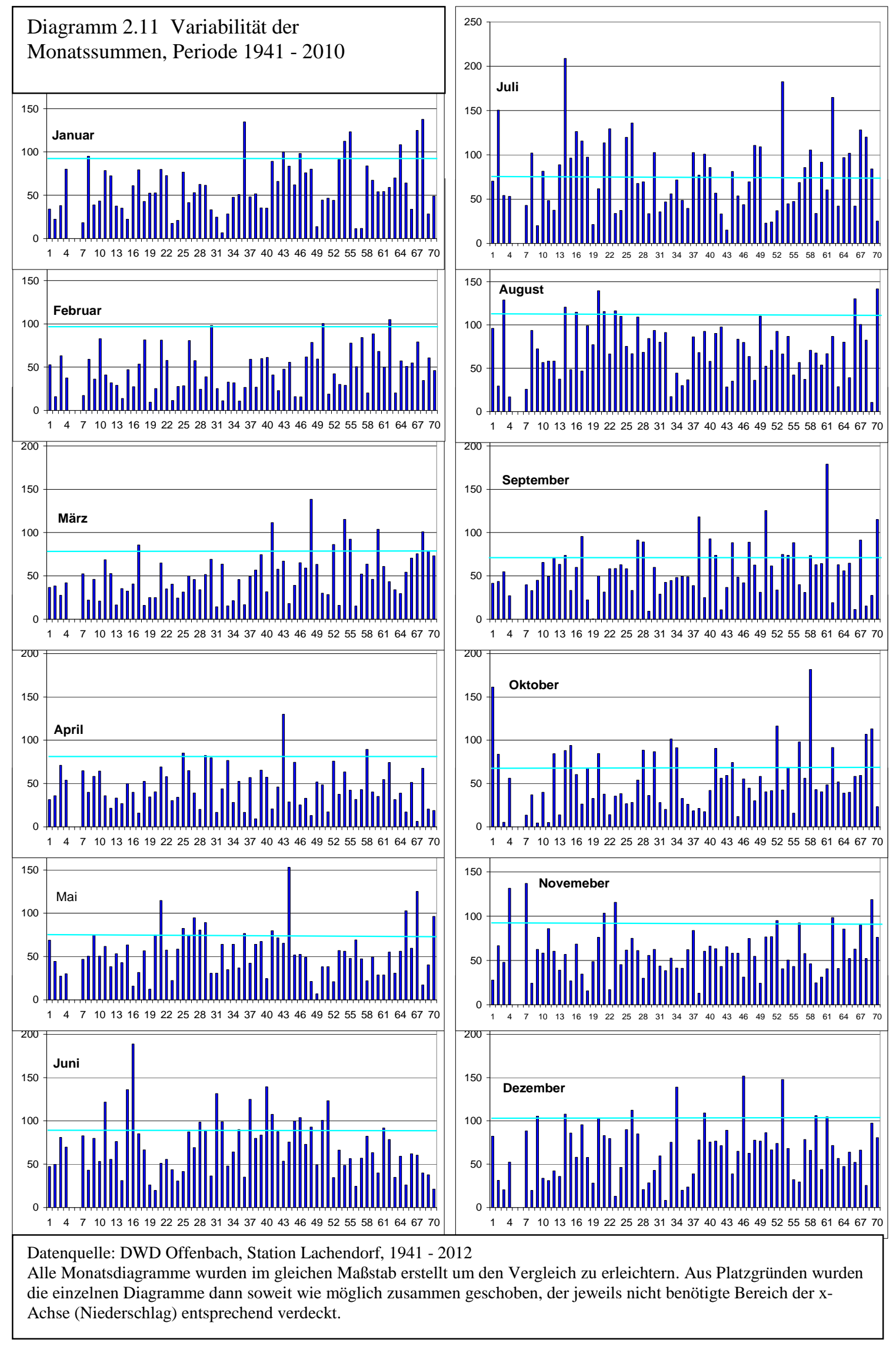


Von Jahr zu Jahr kommt es auch zu einer starken Variabilität des Jahresganges der Monatssummen, also einer sehr unterschiedlichen Verteilung der Niederschläge im Jahresverlauf, selbst dann, wenn die Jahressummen etwa gleich sind. Die Jahressumme allein ist also wenig aussagefähig hinsichtlich der jährlichen Einschätzung des Niederschlags als Wachstumsfaktor.

Das Diagramm 2.12 1 macht dies im Vergleich mit dem mittleren monatlichen Jahresgang an den beiden Extremjahren 1959 und 2007 sowie an 3 weiteren Jahren deutlich, die sich in den Jahressummen nur unwesentlich vom Mittel mit 707,64 mm unterscheiden, hinsichtlich der Jahressummen also zu den „Normaljahren“ gezählt werden könnten.

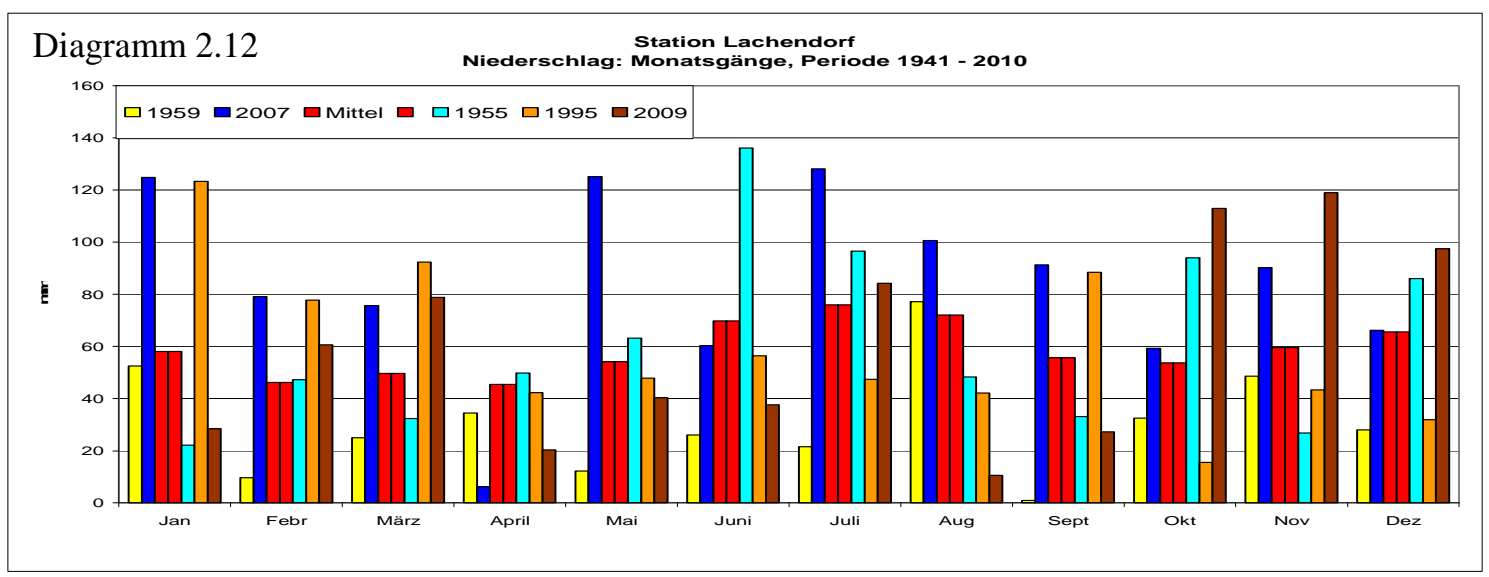

Das Trockenjahr 1959 blieb außer im August in allen Monaten unter dem langjährigen Mittel, wobei der September mit nur 0,1 mm Niederschlag als arid bezeichnet werden kann.

Das regenreichste Jahr 2007 hatte einen extrem trockenen April und knapp unter durchschnittliche Regenmengen im Juni, aber im Januar, Mai und Juli besonders ergiebige Niederschläge.

Die ausgewählten Jahre 1955, 1995 und 2009 hatten alle eine Jahressumme des Niederschlags, die nicht wesentlich vom Jahresmittel abwich, aber eine ganz unterschiedliche Verteilung im Jahresverlauf.

Während sich das Jahr 1955 durch sehr starke Sommerniederschläge und geringe Niederschläge in den Monaten Januar bis April und Mai auszeichnete, war es im Jahr 1995 umgekehrt mit hohen Werten im ersten Quartal und geringen Sommerregen. Das Jahr 2009 war besonders niederschlagsreich im vierten Quartal und sehr geringen Niederschlägen im 2. Quartal.

Die Variabilität des Monatsganges der Tagessummen (s. Tabelle 2.3) des Niederschlags wird deutlich, wenn man die täglichen Messwerte einzelner Monate verschiedener Jahre vergleicht. Diese Variabilität soll beispielhaft an je einigen Winter- und Sommermonaten ${ }^{2}$ dargestellt werden.

Für den Januar wurde je ein trockener, ein nasser und ein Beispielmonat mit fast mittlerem Niederschlag ausgewählt, für den Februar zwei Beispiele mit hohem Monatsniederschlag, für den Monat Juni zwei sehr regenreiche Beispielmonate.

Die Anzahl der Tage mit Niederschlag schwankt im Januar zwischen 16 und 27 und die Monatssumme zwischen $58 \%$ und $213 \%$ des langjährigen Mittelwertes. Im Laufe des Monats wechseln unregelmäßig einige oder mehrer zusammenhängende Tage jeweils mit oder ohne Niederschlag, so wie es dem typischen Witterungsverlauf mit dem Durchzug von

\footnotetext{
${ }^{1}$ Quelle: s. Diagramm 2.4; Die langjährigen Monatsmittelwerte (rote Säulen) wurden zur besseren Lesbarkeit im Diagramm doppelt dargestellt. Um den Niederschlag von 0,1 mm im September $1959 \mathrm{im}$ Diagramm sichtbar zu machen, wurde der Wert in der zugehörigen Tabelle auf den Wert 1,0 gesetzt.

${ }^{2}$ s. Tabelle 2.3: Monatsgang der Tagessummen
} 


\begin{tabular}{|c|c|c|c|c|c|c|c|c|c|c|c|c|c|c|}
\hline \multirow[b]{2}{*}{ Dat. } & \multicolumn{3}{|c|}{ Januar } & \multicolumn{2}{|c|}{ Februar } & \multicolumn{2}{|c|}{ Juni } & \multicolumn{7}{|c|}{ Juli } \\
\hline & 1941 & 1985 & 2007 & 1958 & 1966 & 1980 & 1986 & 1954 & 1975 & 1984 & 1993 & 1994 & 2007 & 2008 \\
\hline 1. & & 1,3 & 2,3 & & 2,9 & & 0,1 & & 1,9 & & & & 10,1 & \\
\hline 2. & & 1,9 & 2,2 & 5,0 & & & & 1,0 & & 9,7 & & & 27,1 & \\
\hline 3. & 0,9 & 0,4 & 1,5 & 0,1 & 0,3 & & 13,9 & 1,2 & & 2,0 & & & 1,6 & \\
\hline 4. & 0,2 & 0,3 & 2,3 & 9,5 & 2,9 & & 4,6 & 5,5 & & & & 12,1 & 6,1 & 48,9 \\
\hline 5. & 0,1 & 0,2 & 5,2 & 13,3 & 10,2 & 0,1 & 0,8 & 0,7 & & 0,6 & & & 7,2 & 5,2 \\
\hline 6. & & 1,3 & 3,7 & 0,2 & 16,2 & & 32,9 & 2,7 & & & 0,4 & & 4,1 & \\
\hline 7. & 0,1 & 0,5 & 12,1 & & 4,8 & & 3,2 & & & & 0,1 & 32,7 & 3,3 & 9,1 \\
\hline 8. & 0,1 & 1,6 & & 0,3 & 19,9 & 0,5 & 0,3 & & & & & & 3,2 & 2,7 \\
\hline 9. & & 3,1 & 2,5 & 0,1 & 2,7 & 0,2 & & & 0,4 & & & & 2,3 & 3,5 \\
\hline 10. & & 0,4 & 0,1 & & 4,6 & 8,0 & & 25,1 & & & 3,3 & & 2,0 & 15,6 \\
\hline 11. & & 3,0 & 6,7 & 0,5 & 0,2 & 4,3 & 2,0 & 63,4 & 4,1 & 26,4 & & & 1,8 & \\
\hline 12. & 0,6 & 0,1 & 10,3 & 4,7 & 10,1 & 1,5 & & 10,2 & & & & & 9,4 & \\
\hline 13. & 0,7 & 0,3 & 0,1 & 0,1 & & & & & & 14,8 & 0,1 & & 1,7 & \\
\hline 14. & 4,1 & 2,2 & 1,5 & 1,1 & & & & 4,0 & 3,5 & 3,4 & 22,7 & & & \\
\hline 15. & & 1,2 & & 4,4 & & 49,8 & & 7,9 & & 8,2 & 19,0 & & & \\
\hline 16. & & & & 2,5 & & 1,2 & & 4,7 & 1,2 & 1,7 & 6,9 & & & 6,4 \\
\hline 17. & 0,1 & 1,9 & 1,4 & 3,0 & & 5,6 & 45,7 & 16,4 & 5,2 & & 6,2 & & 1,7 & 0, \\
\hline 18. & 0,2 & & 4,6 & 0,9 & & 2,7 & 0,2 & 11,5 & 8,3 & 8,0 & 1,5 & & & 3,0 \\
\hline 19. & 4,2 & & 39,9 & 1,5 & 1,4 & 2,3 & & 2,3 & 0,5 & 0,1 & 10,2 & & & 5,2 \\
\hline 20. & 11,0 & 0,4 & 4,8 & 14,8 & 1,5 & 2,8 & & & 0,2 & 0,4 & 15,1 & & & 1,7 \\
\hline 21. & 2,9 & 1,5 & 4,2 & 2,1 & & 4,5 & & 1,5 & 1,7 & 0,3 & 5,7 & & & 10,9 \\
\hline 22. & 5,0 & 1,0 & 4,2 & 2,0 & & 3,8 & & & 0,7 & 0,1 & 0,1 & & 7,3 & \\
\hline 23. & 0,1 & & & 0,8 & & 4,2 & & 5,0 & 2,3 & & 6,0 & & 6,5 & \\
\hline 24. & 3,7 & 11,4 & & 0,5 & 0,3 & 4,0 & & 3,7 & 1,9 & & 0,1 & & 4,3 & \\
\hline 25. & & 15,2 & & 13,5 & 0,5 & 10,3 & & 18,7 & 16,8 & & 8,7 & & 13,9 & \\
\hline 26. & & 3,7 & & 0,3 & 1,8 & 10,9 & & 6,4 & 0,1 & 0,1 & 7,6 & & & 7,1 \\
\hline 27. & & 0,1 & 4,7 & 0,2 & & 4,7 & & & & 0,8 & 16,3 & & 1,2 & \\
\hline 28. & & 0,1 & 0,6 & & 0,4 & 2,9 & & 9,0 & & 1,7 & 5,1 & & & \\
\hline 29. & & 7,3 & 9,0 & & & 0,8 & & 1,6 & & & 3,1 & & 3,4 & \\
\hline 30. & & 0,1 & 0,7 & & & 5,2 & & 6,5 & & & 29,2 & & 6,8 & \\
\hline 31. & & 1,5 & 0,2 & & & & & & & 3,1 & 15,1 & & 3,1 & \\
\hline Min. & 0,1 & 0,1 & 0,1 & 0,1 & 0,2 & 0,1 & 0,1 & 0,7 & 0,1 & 0,1 & 0,1 & 12,1 & 1,2 & 0,8 \\
\hline$\Sigma$ & 34,0 & 62,0 & 124,8 & 81,4 & 80,7 & 130,3 & 103,7 & 209,0 & 48,8 & 81,4 & 182,5 & 44,8 & $(128,1\rangle$ & 120,1 \\
\hline Max. & 11,0 & 15,2 & 39,9 & 14,8 & 19,9 & 49,8 & 45,7 & 63,4 & 16,8 & 26,4 & 29,2 & 32,7 & $27,1^{\mathbf{2}}$ & 48,9 \\
\hline Tage & 16 & 27 & 24 & 24 & 17 & 22 & 10 & 22 & 15 & 17 & 22 & & 22 & $\begin{array}{r}-13 \\
\end{array}$ \\
\hline \multicolumn{15}{|c|}{ langjährige Monatsmittel; Periode 1941 - 2010} \\
\hline & Jan & : 58,4 & $\mathrm{~mm}$ & Febr: & 46,2 & Juni: & 70,0 & & & Jul & i: 76,1 & $\mathrm{~mm}$ & & \\
\hline
\end{tabular}

Tiefdruckgebieten und dem Einfluss von Hochdruck in dieser Klimaregion entspricht. Die Januar- und Februarmonate zeigen, dass es auch im Winter Tage mit recht hohen Tagessummen gibt, die als Regen oder Schnee, je nach Temperatur, niedergehen können.

Für den Juni wurden zwei regenreiche Beispiele ausgewählt, um zu zeigen, dass es auch bei einer hohen Monatssumme zu sehr unterschiedlicher Verteilung kommen kann. Der Juni 1980 galt mit 22 Regentagen, einem Starkregen mit 49,8 mm am 15.6. und einer anschlieBenden durchgehenden Regenphase von 16 Tagen sicherlich als „verregnet“. Der Juni 1986 war mit 103,7 mm Monatssumme ebenfalls überdurchschnittlich nass, wies aber nur $10 \mathrm{Re}-$ gentage auf, eine sechstägige Regenphase in der ersten Dekade mit zwei kräftigen Regentagen $(13,9$ und $32,9 \mathrm{~mm})$ und anschließend nur noch drei Regentage am 11. d. M. mit nur 2 $\mathrm{mm}$ und am 17./18. d. M. mit zusammen 45,9 mm. Anschließend folgte bis zum Monatsende eine „Schönwetterperiode“ ohne Regentage. Durch diese Verteilung wurde dieser Juni sicherlich als „schöner“ Sommermonat empfunden.

Für den Juli wurden sieben Beispielmonat ausgewählt, um an diesem Sommermonat in besonderer Weise die hohe Variabilität des Monatsganges aufzuzeigen.

Der Juli war in der Messperiode nicht nur der regenreichste Monat sondern auch der Monat mit der höchsten Monatssumme (209,0 mm 1954) gegenüber einem Monatsminimum von 15,1 mm im Jahr 1983.

Der auch im Durchschnitt regenreichste Monat des Jahres kann längere Trockenphasen und sehr wenige Regentage aufweisen. Bei den länger anhaltenden sommerlichen „Schönwetterperioden" handelt es sich um ausgedehnte Hochdruckwetterlagen, meist als Ausläufer des Azoren-Hochs oder als Hochdruckbrücke zum kontinentalen Hochdruckgebiet. Zu einer sol- 
chen Witterung gehören nicht selten starke Wärmegewitter, wie z.B. $1994^{1}$ mit nur zwei Regentagen im Juli, die aber immerhin 58\% der durchschnittlichen Monatssumme erbrachten. Die Trockenheit des Monats Juli im Jahr 1994 wurde durch die extrem ungleichmäßige Verteilung im Monatsgang erheblich verschärft.

Ganz anders war der Juli im Vorjahr, 1993, verlaufen: Die weit überdurchschnittliche Monatssumme war auf 22 Regentage mit drei Schwerpunkten zur Monatsmitte, um den 20. d. M. und am Monatsende verteilt.

Im noch regenreicheren Juli 1954 fielen in 22 Regentagen 275\% der mittleren Monatssumme. Ein dreitägiger Dauerregen mit insgesamt 98,7 mm überstieg allein den langjährigen Monatsdurchschnitt von $76,1 \mathrm{~mm}$ deutlich. Dadurch kam es aber trotz vieler Regentage zu einer recht unregelmäßigen Verteilung im Monatsverlauf.

Hauptmerkmal ${ }^{2}$ für alle Monate ist, dass die Niederschlagsverteilung im Laufe eines Monats von Jahr zu Jahr sehr unterschiedlich sein kann. Auf die Bedeutung gerade dieser Variabilität als Wachstumsfaktor wird unter dem Gesichtspunkt des Naturpotenzials für die Landnutzung noch näher eingegangen.

Hier ist anzumerken, dass das subjektive Empfinden hinsichtlich regenreicher und trockener Monate mehr von der Anzahl der Regentage abhängt als von der Monatssumme. Dies gilt besonders für die Sommermonate, die bei wenigen Regentagen als „schön“ gelten, weil sonnige und dann auch meist warme Tage vorgeherrscht haben. Diese Bewertung ist aber kein geeigneter Maßstab hinsichtlich der Wachstumsbedingungen.

Zur Niederschlagsvariabilität einer Station der Jahres- und Monatsgänge kommt noch eine kleinräumige örtliche Variabilität zwischen benachbarten Stationen hinzu.

Die beiden Messstationen Lachendorf und Bargfeld, die nur $12 \mathrm{~km}$ Luftlinie auseinander liegen, zeigen im Messzeitraum von 2000 bis 2012 zwar unterschiedliche Jahressummen, insgesamt aber die gleiche Tendenz bei der Abfolge von feuchten und trockenen Jahren. Die meist höhere Niederschlagsmenge in Bargfeld kann durch die Exposition bedingt sein, denn Lachendorf liegt am Fuß der Mittleren Südheide und Bargfeld etwas höher auf einer der Geestinseln.

Diese kleinräumige Variabilität wird auch

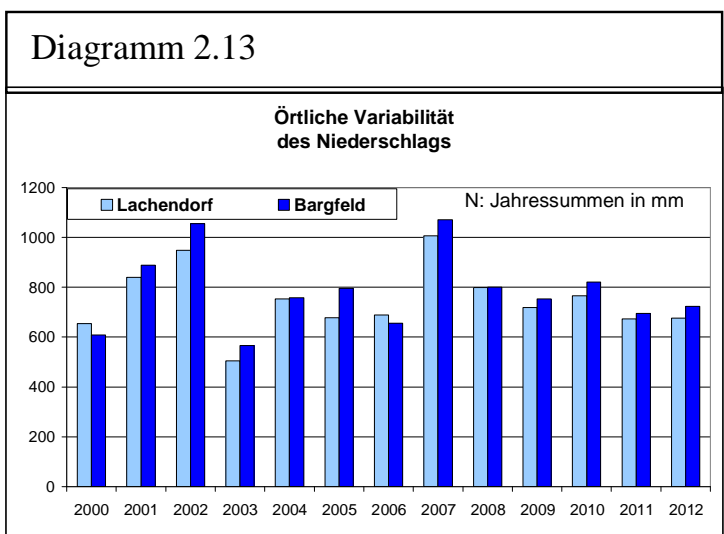

Quelle: Lachendorf: DWD; Bargfeld:

nrivate Messu ınd von Herr Frnst-Aıınıst Dettmer durch den Monatsniederschlag von August 2006 bestätigt. In Lachendorf wurden 130,1 mm gemessen, ein hoher Monatswert bei einem Mittel von 69,6 mm in der Periode 1981-2010. Die Kartoffeln auf Acker in den Allerwiesen konnten teilweise nicht geerntet werden, weil entlang der Aller Gewittergüsse noch höhere Regenmengen ergeben haben ${ }^{3}$.

Das Fazit aus der Betrachtung der örtlichen Niederschlagsverhältnisse lautet: Sowohl bei den Jahressummen ${ }^{4}$ wie auch beim Jahresgang der Monatssummen und beim Monatsgang der Tagessummen gibt es eine große Variabilität, die wiederum kleinräumig auch sehr unterschiedlich ausfallen kann.

\footnotetext{
${ }^{1}$ s. Tabelle 2.3: Monatsgang der Tagessummen. Die Monatsgänge der Tagessummen eignen sich nicht zur Darstellung im Diagramm, deshalb wurde die Tabellenform gewählt.

${ }^{2}$ Das Tagesminimum der meisten Monate liegt bei 0,1 mm. Dies wird nicht als besonderes Merkmal gewichtet, weil es sich durch die Messtechnik ergibt: 0,1 mm ist der kleinste erfasste Messwert der Tagessummen.

${ }^{3}$ Mdl. Mitteilung von Landwirtschaftsmeister Karsten Koch, Lachendorf

${ }^{4}$ Diagramm 2.9: Datenquelle: 1941 - 204: DWD Offenbach, 2005 - 2012: K. Koch, Messstation Lachendorf, mit freundlicher Genehmigung des DWD; Datenlücke für 1945 und 1946 wegen fehlender Messdaten.
} 
Die leichte Tendenz zu erhöhten Jahresniederschlägen wird gestützt durch die Beobachtung, dass drei der 5 Jahre mit $900 \mathrm{~mm}$ und mehr mm Jahresniederschlag und das nasseste Jahr (2007) nach 1997 lagen. Die beiden letzten Jahre, 2011 und 2012, weisen allerdings nur ein Jahresmittel von $674,5 \mathrm{~mm}$ auf.

Auf ein wichtiges Merkmal dieser Variabilität muss noch hingewiesen werden: Weder sind in sehr nassen Jahren alle Monate überdurchschnittlich feucht noch in trockenen Jahren alle Monate durchgehend trocken ${ }^{1}$. Als Beispiele sei auf 1959 und 2007 verwiesen: Im trockensten Jahr der Messperiode, 1959, lag der Monat August mit 77,2 mm knapp über dem langjährigen Augustmittel von 72,4 mm. Im nassesten Jahr der Messperiode, 2007, war der April mit nur 6,2 mm weit unter dem langjährigen Aprilmittel von 45,1 mm.

Aufgrund der hohen Niederschlagsvariabilität, die sich aus den wechselnden Witterungsbedingungen und Wetterlagen ergibt und die sich auch auf die Tages- und Monatstemperaturen indirekt auswirkt, gibt es kein „Normaljahr" schnittsjahr gibt. Im Vergleich mit diesem nicht real existierenden Durchschnittsjahr lassen sich zwar längerfristige Trends aufzeigen, aber keine Einzeljahre voraussagen oder messen.

Diese große Niederschlagsvariabilität ist ein wesentlicher Standortfaktor, insbesondere im Zusammenhang mit den Böden, die einerseits reichliche Niederschläge aufnehmen, speichern und ableiten und andererseits Trockenphasen durch ihre Speicherkapazität überbrücken müssen. Die für jedes Jahr individuelle Niederschlagssumme und -verteilung ist ein ganz besonders wichtiger Wachstumsfaktor, insbesondere für die meist einjährigen Kulturpflanzen, weniger für mehrjährige Wild- und Kulturpflanzen.

Daher wird im Kapitel über Standorte und Potenziale nochmals auf die Niederschlagsvariabilität eingegangen.

Diagramm 2.14: Station Lachendorf: Jahresniederschläge 1941 - 2012

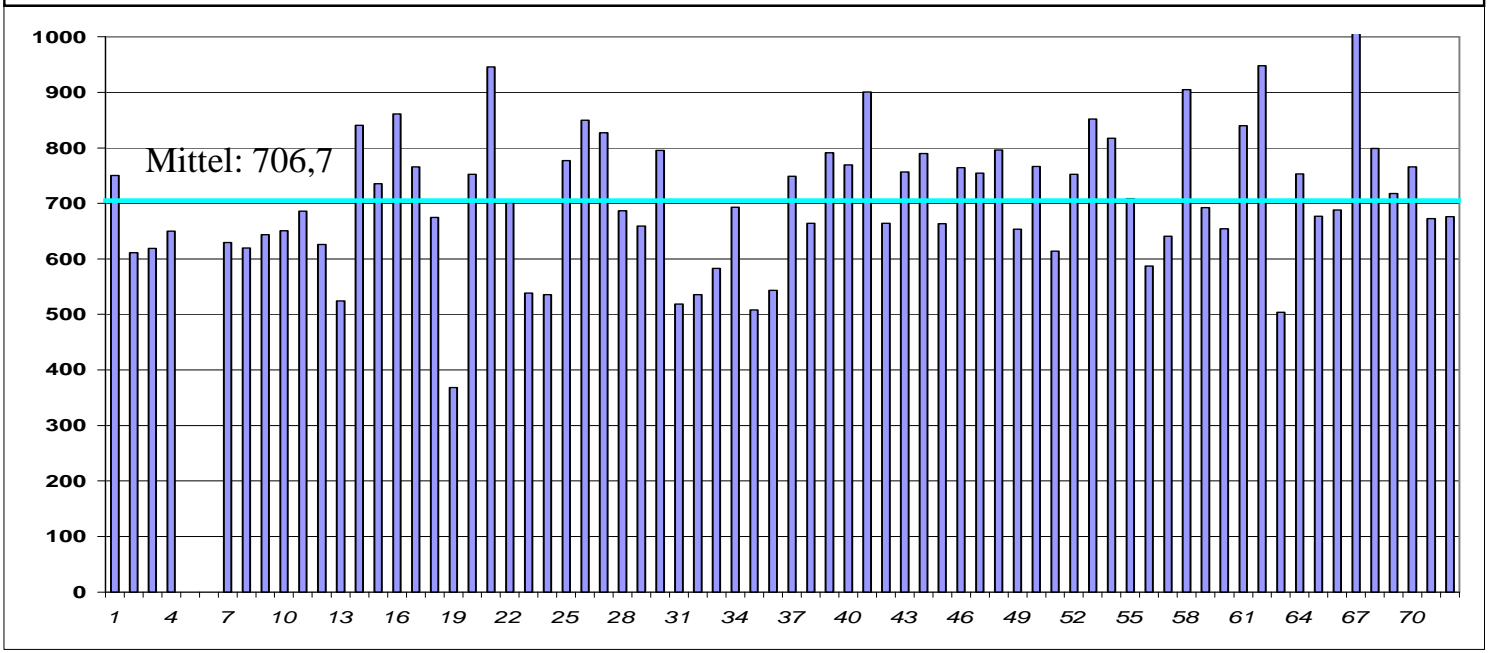

\footnotetext{
${ }^{1}$ vgl. Diagramm 2.1; Klimadiagramm mit Ergänzungen

${ }^{2}$ Eine Formulierung wie „nasser oder trockener bzw. kälter oder wärmer als normal“ ist sachlich falsch und könnte im Wetterbericht als nicht belegbare Trendaussage missverstanden werden.
} 


\subsection{Standorte und Potenziale}

\subsubsection{Die Gemarkung Lachendorf im naturräumlichen Gefüge}

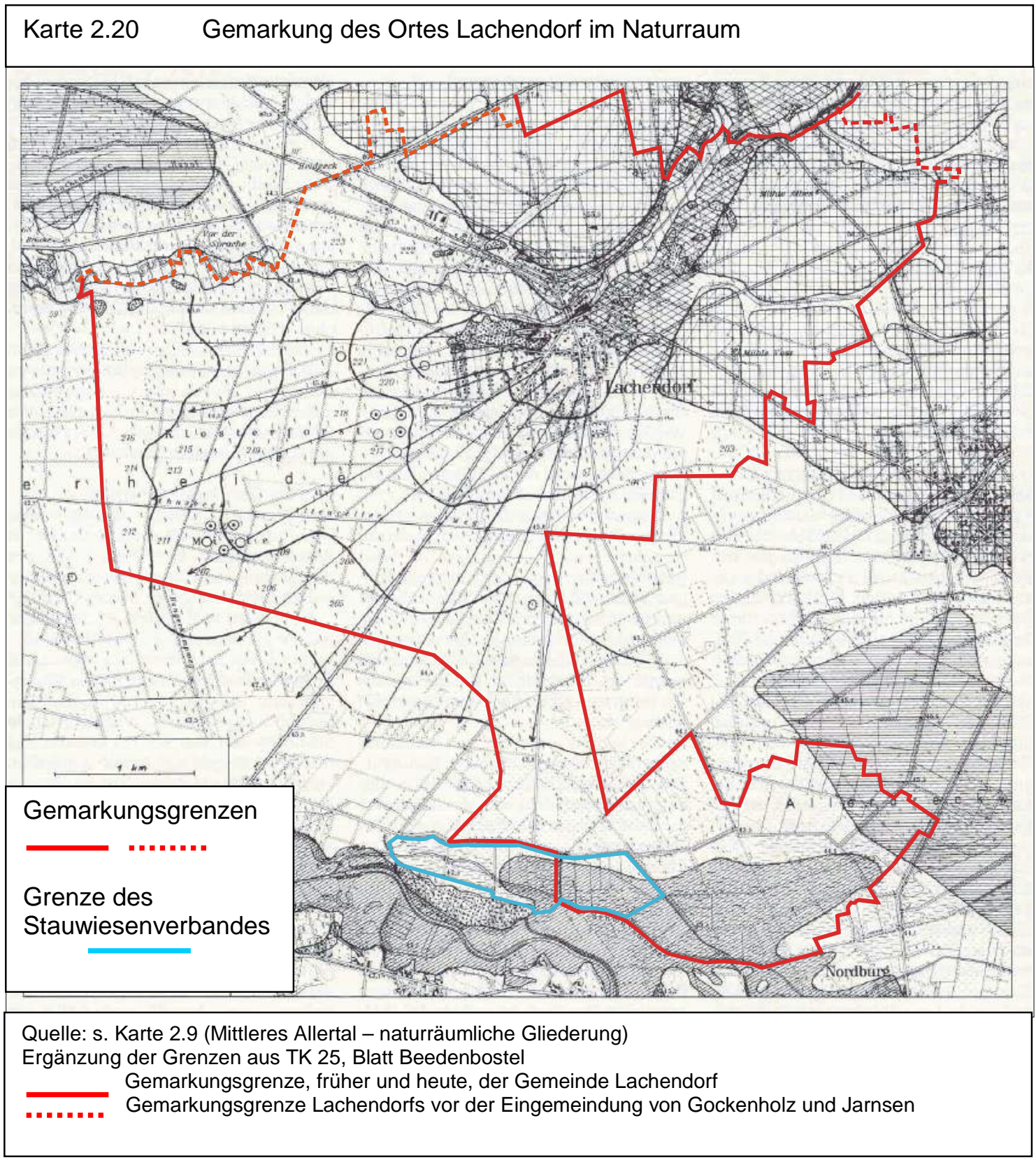

Die Gemarkung der ehemals selbständigen Gemeinde Lachendorf ist mit roter Grenzlinie gekennzeichnet, als durchgezogene Linie im unveränderten Verlauf, als gestrichelte Linie im Verlauf der alten Gemarkungsgrenze gegen die früher ebenfalls selbständigen Gemeinden Gockenholz und Jarnsen.

Im weiteren Verlauf beschränkt sich die Arbeit im Wesentlichen, insbesondere in der kartographischen Darstellung, auf diese ehemalige Dorfgemarkung. Als im Jahr 1966 die erste genaue Nutzungskartierung durchgeführt wurde, war das Dorf Lachendorf noch als politische Gemeinde selbständig. Die Gebietsreform und Eingemeindungen erfolgten erst ab den 70er Jahren. Aus Gründen der Vergleichbarkeit beschränkten sich auch die späteren Kartierungen auf diese ehemalige Dorfgemarkung. 
Einbezogen in die Nutzungskartierung wurde seit 1966 ein Stauwiesenverband, dessen Gebiet teilweise in der Lachendorfer Gemarkung liegt, an dem Lachendorfer Bauern beteiligt waren und der 1966 noch funktionsfähig existierte.

Die Karte 2.20 verdeutlicht, dass die Gemarkung Lachendorf Anteil hat an allen wesentlichen Naturräumen, die es auf der Lachter Geest und im Mittleren Allertal gibt:

Im Norden der Gemarkung liegt der Anteil an der Lehmgeest, hier der Gockenholzer und Bunkenburger Lehmgeest und im Südosten ein großer Gemarkungsteil auf dem Schwemmfächer der Lachte im Urstromtal. Innerhalb dieser beiden Naturräume gelegen, gehört jeweils ein Stück des Lachtetales mit Aueböden oberhalb und unterhalb des Ortes zur Gemarkung.

Verbunden mit einem schmalen Korridor nach Süden hat die Gemarkung Anteil an den trockenen Talsanden nördlich des Schwarzwassers und an den feuchten Aller-Dreckwiesen, die im Randmoor des Urstromtales liegen.

Während der Ort ziemlich zentral im nördlichen, kompakten Hauptteil der Gemarkung liegt, wirkt der südliche Teil als weit entfernt liegendes Anhängsel.

Aber mit dieser räumlichen Zuordnung sind in der Gemarkung alle hier sich bietenden Möglichkeiten der Bodenfruchtbarkeit abgedeckt: Lehmböden mit Braunerden und Pseudogleyen im Norden, Podsole im Südwesten und Süden, Anmoor im äußersten Südosten und Aueböden in der Lachtetalaue.

Daraus lässt sich eindeutig ableiten, dass die Gemarkung allein aus der Sicht der Bodennutzung für die Landwirtschaft eingerichtet bzw. festgelegt wurde. Es ist also in erster Linie die Gemarkung der Bauern als Landnutzer und weniger die Verwaltungseinheit eines Dorfes. Die etwas ungewöhnlich wirkende Form der Gemarkung ist kein Zufallsprodukt. Sie hat sich aus der Notwendigkeit ergeben, den Bauern in ihrer Gemarkung Zugang zu allen in der Region vorkommenden Standorten der Bodenfruchtbarkeit zu ermöglichen. Daher auch das weite Ausgreifen der Gemarkung bis ans Schwarzwasser und bis in die Aller-Dreckwiesen.

Der Südwesten der Gemarkung auf dem Schwemmfächer hat einen sehr großen Flächenanteil an der Gemarkung. Das ist aus heutiger Sicht verwunderlich, da dieses Gebiet fast ausschließlich Wald umfasst, der heute nicht zur Landwirtschaftlichen Nutzfläche zählt, und auBerdem zu einem wesentlichen Teil zur Niedersächsischen Staatsforst gehört, also nicht der bäuerlichen landwirtschaftlichen Nutzung unterliegt.

Für diesen großen Gemarkungsteil muss es also eine Begründung geben, die nichts mit der heutigen Landnutzung durch die Landwirte zu tun hat.

\subsubsection{Standorte in der Gemarkung}

Nachdem der übergeordnete Naturraum nach Genese und Struktur dargelegt worden ist, werden die einzelnen Standorte in der Gemarkung, wie sie sich aus der naturräumlichen Struktur ergeben, einer näheren Analyse unterzogen.

Dabei wird, insbesondere im Kartenmaterial, auch auf die im Jahr 1966 erfolgte intensive Feldarbeit und deren kartographische Dokumentation zurückgegriffen. Dies erscheint trotz des großen zeitlichen Abstandes vertretbar, weil sich Daten zu den Böden, insbesondere der Bodenschätzung, seither nicht verändert haben. Dies gilt auch weithin für die Kartierung der Vegetation, insbesondere in den Forstflächen, wo es außer in den Baugebieten "Im Gehege“ (Westrand des Ortes, 70er Jahre) und „Südhang“ (Südostrand des Ortes, nach 2000) keinen Nutzungswandel gegeben hat.

In den Forstflächen hat sich seitdem die Bodenvegetation nicht aufgrund von Standortänderungen sondern im Zuge der Bestandsentwicklung der Forstkulturen verändert. Insbesondere aufgrund der Veränderung der Lichtverhältnisse im Laufe der Bestandsentwicklung kann die Veränderung der Bodenvegetation allerdings recht gravierend sein.

Im Jahr 1966 stand die aktuelle Agrarstruktur der Gemarkung Lachendorf im Fokus, daher wurden fast alle Themen auch flächendeckend für die gesamte Gemarkung kartographisch erfasst und dargestellt. 
In dieser Arbeit liegt das Augenmerk auf dem langzeitlichen Wandel der Kulturlandschaft. Dafür genügen beispielhafte Kartenausschnitte, die die jeweiligen Standorteigenschaften charakterisieren bzw. verdeutlichen.

\subsubsection{Geestplatten}

Diese Grundmoränenplatten bieten in sich ein kleinräumig sehr differenziertes Bild, je nach Tiefe des anstehenden Geschiebelehms oder -mergels, Mächtigkeit der Decksandschicht, Grundwasserstand sowie daraus folgender Wasserspeicherkapazität, Perkolation oder Staunässe. Im Vergleich zu den anderen Standorten bieten die Geestplatten die weitaus besten Böden in der Gemarkung.

Der Gemarkungsteil ${ }^{1}$ auf der Bunkenburger Lehmgeest ist an den Hängen der Geestplatte von anlehmigen Sanden und auf der Hochfläche selbst durchweg von lehmigen Sanden geprägt. Die anlehmigen Sande sind mit Bodenzahlen ${ }^{2}$ von 30 bis 39 bewertet, die lehmigen Sande mit Werten zwischen 36 und 45.

Ähnlich liegen die Verhältnisse westlich der Lachte auf dem Ostteil der Gockenholzer Geestinsel. Hier bestimmen anlehmige Sande mit Bodenzahlen von 28 - 37 und lehmige Sande mit einer Bewertung von 38 - 45 die Böden.

Der Boden ist auch oberflächlich recht stark mit Geschieben durchsetzt, die zur Tiefe hin an Größe und Anzahl zunehmen. Entsprechend nimmt die sandige Komponente nach unten hin ab und es erfolgt in recht unterschiedlicher Tiefe der Übergang zum Geschiebelehm, der die Wasserführung und den Bodenwasserhaushalt sehr nachhaltig beeinflusst. Steht der Geschiebelehm sehr flach an oder bildet er gar selbst die Oberfläche, so bedürfen die Böden meist einer Drainage, um die ungünstige Staunässe für Bodenbearbeitung und Kulturpflanzen zu mindern ${ }^{3}$.

An einzelnen Stellen ist auf den

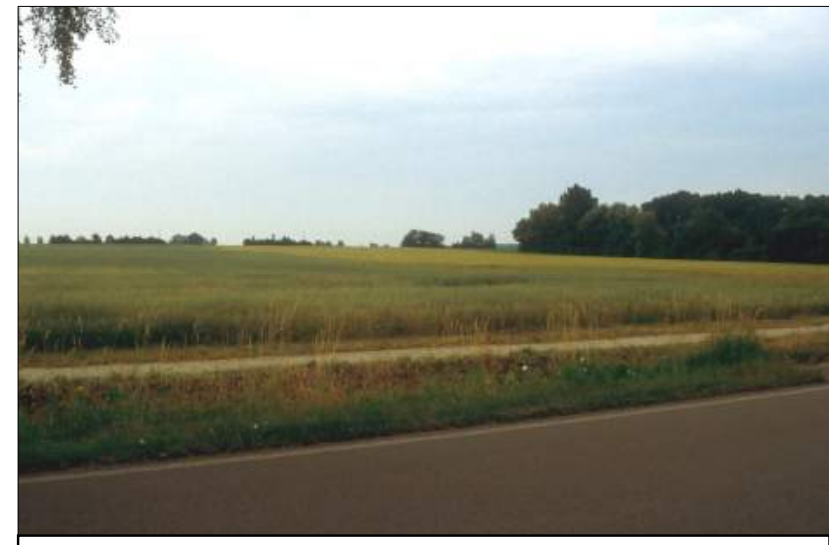

Abb. 2.10 Blick von der Terrasse des Lachtetales an der Jarnser Straße nach Südosten auf den Hang der Bunkenburger Geest: Getreideanbau 2006, Aufn. A. Behr

Geestplatten die Decksandschicht sehr mächtig, hier gibt die Bonitierung nur noch Sande $\mathrm{an}^{4}$, die bei Bodenzahlen um 20 unverhältnismäßig trockene und arme Standorte im Vergleich zur direkten Umgebung liefern. Die flachen Hänge der Geestplatten unterscheiden sich nicht wesentlich von den Kuppen, weisen nur ein etwas erhöhtes Erosionsrisiko auf, wenn wegen der Parzellenform nicht hangparallel gepflügt werden kann.

Einen Sonderstatus haben die Standorte entlang der Tiefenlinie in den muldenförmigen Trockentälern in den Geestplatten, die sich durch Staunässe und hohen Grundwasserstand auszeichnen. In den flachen Mulden werden bei mäßigen Wasserverhältnissen auf lehmigem Sand Grünlandzahlen ${ }^{5}$ von 38 - 40 erreicht

\footnotetext{
${ }^{1}$ s. Karte 2.20

${ }^{2}$ Alle Angaben zur Bonitierung sind den amtlichen Flurkarten der Gemarkung Lachendorf beim Katasteramt in Celle entnommen.

${ }^{3}$ Mündliche Auskunft von Landwirt K. Koch, Lachendorf

${ }^{4}$ s. Bonitierung der Flurkarten von Lachendorf

${ }^{5}$ Grünlandzahlen: 75-teilige Skala, Bodenzahlen: 100-teilige Skala
} 
Diese Standorte unterscheiden sich von den Hochflächen nicht durch das Bodensubstrat, wohl aber sehr deutlich durch den Bodenwasserhaushalt.

Die Flächen am Fuß der
Geestplatten sind rein
sandiger Natur ohne Geschiebe mit Bodenzahlen von 18 - 28, fallen also in ihrer Qualität deutlich gegen die Geestplatten ab. Einzelne Äcker zeigten 1966 eine starke Verunkrautung durch Windhalm, was auf die natürliche Kalkarmut dieser Sande schließen lässt ${ }^{1}$.

Etwas günstiger gestellt sind einige Fußflächen, deren Sande sich durch günstige Wasserverhältnisse auszeichnen. Offenbar werden sie durch Hangwasser von den Hochflächen mit schwer durchlässigem Untergrund her günstig beeinflusst.

Auf allen Flurstücken liegt die Ackerzahl, die den örtlichen Verhältnissen entsprechend den tatsächlichen Wert angibt, überall um einige Einheiten höher als die Bodenzahl. Auf den günstigsten Parzellen erreicht die Ackerzahl Werte bis zu 49, liegt aber auf den Sandflächen auch nur bei 20 . Insgesamt verfügt die Lachendorfer Flur auf den Geestplatten über geringe bis mäßig gute Böden, die je nach Substrat, Perkolation und Wasserhaushalt recht stark in ihrem ökologischen Verhalten

Karte 2.21 Bunkenburger Geest: Bodenschätzung

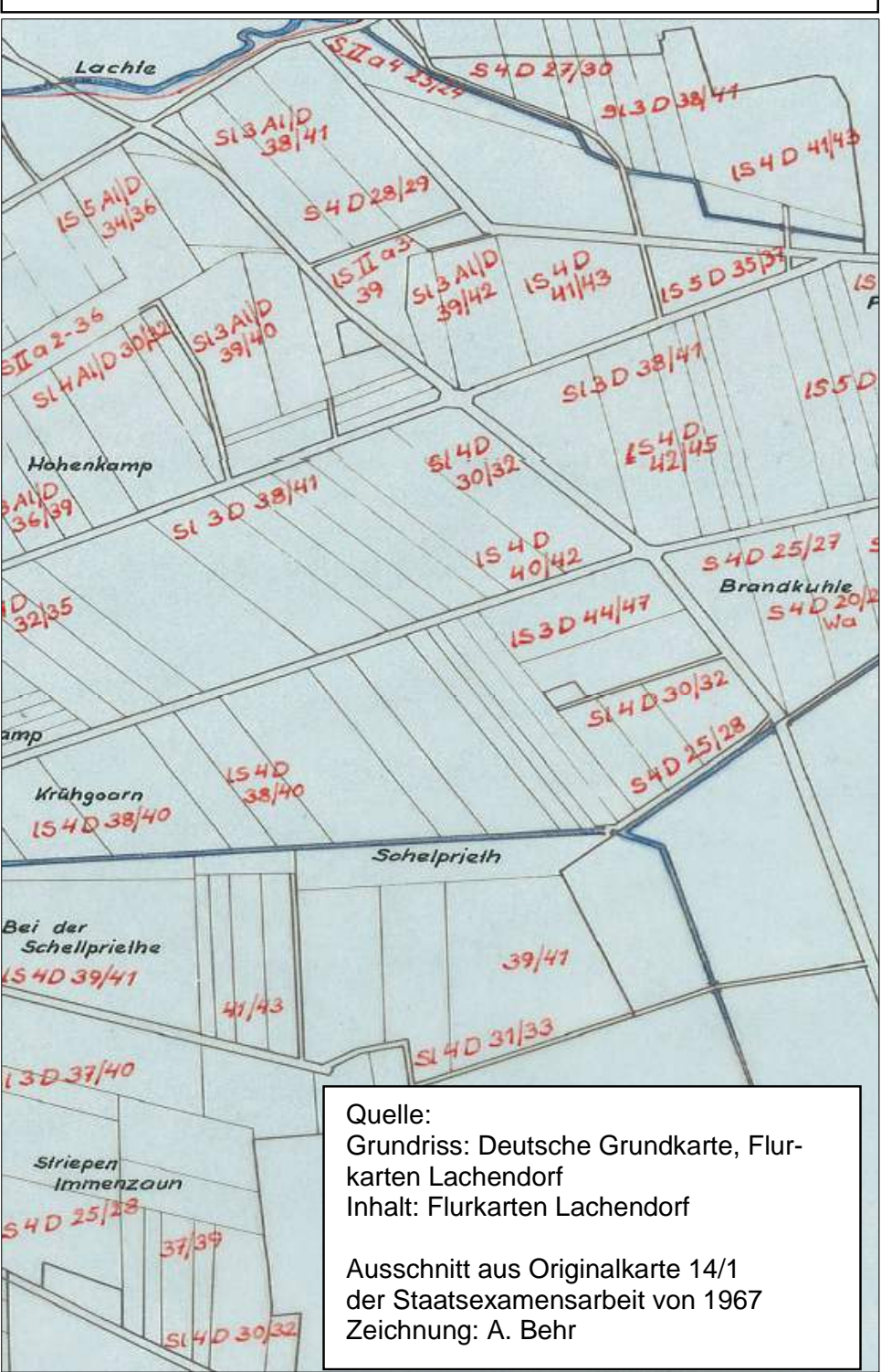
differieren.

\footnotetext{
${ }^{1}$ Der Windhalm (Apera spica venti) tritt nur auf schlecht bewirtschafteten Äckern im Wintergetreide auf, da er eine Düngung mit Kalkstickstoff nicht verträgt. Auf brachliegendem, kalkarmem Ödland hält sich der Windhalm nicht lange, da er lockere, luftreiche Böden zur Entwicklung braucht. Alkalische Böden werden ganz gemieden, saure Standorte mit einem pH-Wert von ungefähr 6 - 5,5 sind am günstigsten, so dass man beim Auftreten von Windhalm durchaus auf starken Kalkmangel schließen kann. - Vgl. dazu Raabe, E., Über die Gräser in Schleswig-Holstein, Mitt. d. Arbeitsgem. f. Floristik in Schleswig-Holstein und Hamburg, H. 3, Kiel 1951, S. 65 f
} 


\subsubsection{Allerheide - Flurbezeichnung} auf dem Schwemmfächer

Der grüßte Teil des Schwemmfächers trägt den historischen Namen "Allerheide“, auf dessen Entstehung später eingegangen wird, der aber im weiteren Verlauf der Darstellung als Gebietsbezeichnung verwendet wird.

Völlig eben im Relief, mit einem recht einheitlichen Grundwasserspiegel um 2 $m$ unter Flur ${ }^{1}$ und den sehr durchlässigen Sanden und Kiesen fluviatiler diluvialer Ablagerung, bietet die Allerheide zunächst das Bild einer äußerst homogenen Landschaft mit einheitlichem ökologischen Gepräge.

Bei näherer Betrachtung ergibt sich aber doch ein kleinräumig

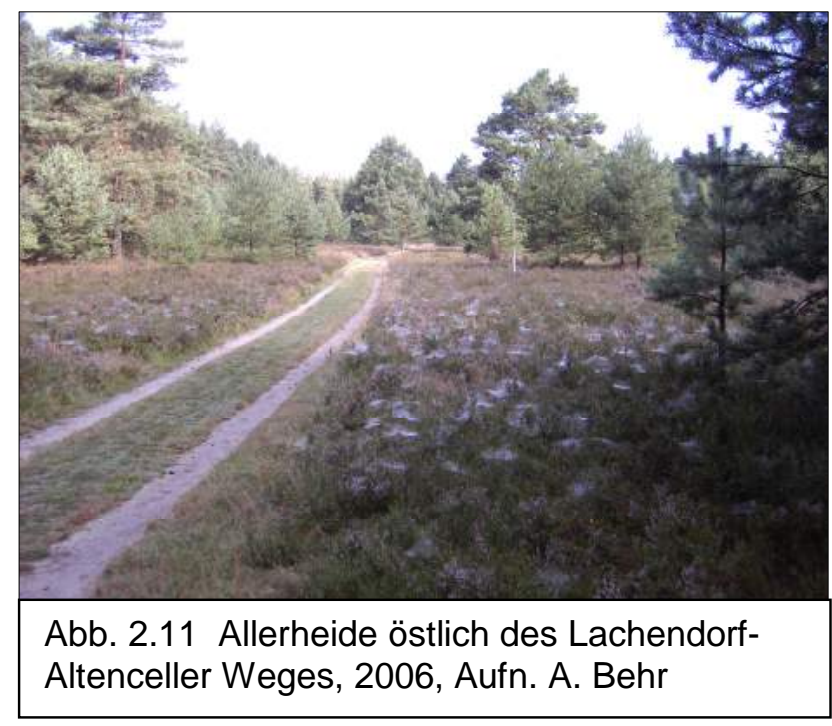
differenziertes Bild:

Gebiete mit hohem Grundwasserstand weisen einen eigenen Landschaftshaushalt auf, was sich deutlich an Zeigerpflanzen in der Bodenvegetation (Pfeifengras und Glockenheide) zeigt.

Der Bodenwasserhaushalt wird gerade auch auf den durchlässigen Sanden durch Lehmbänder ${ }^{2}$ in unterschiedlicher Tiefe positiv beeinflusst

Einige kleine Dünenkuppen heben sich auch reliefmäßig aus der einförmigen Landschaft heraus.

Die heutigen Waldflächen der Allerheide sind im wesentlichen durch stark gebleichte Podsole auf nährstoffarmen Sanden und kalkarmem Grundwasser bestimmt $^{3}$, die z.T. gut ausgeprägte Orterde, aber nur selten typischen Ortstein aufweisen. Das relativ nahe Grundwasser verleiht

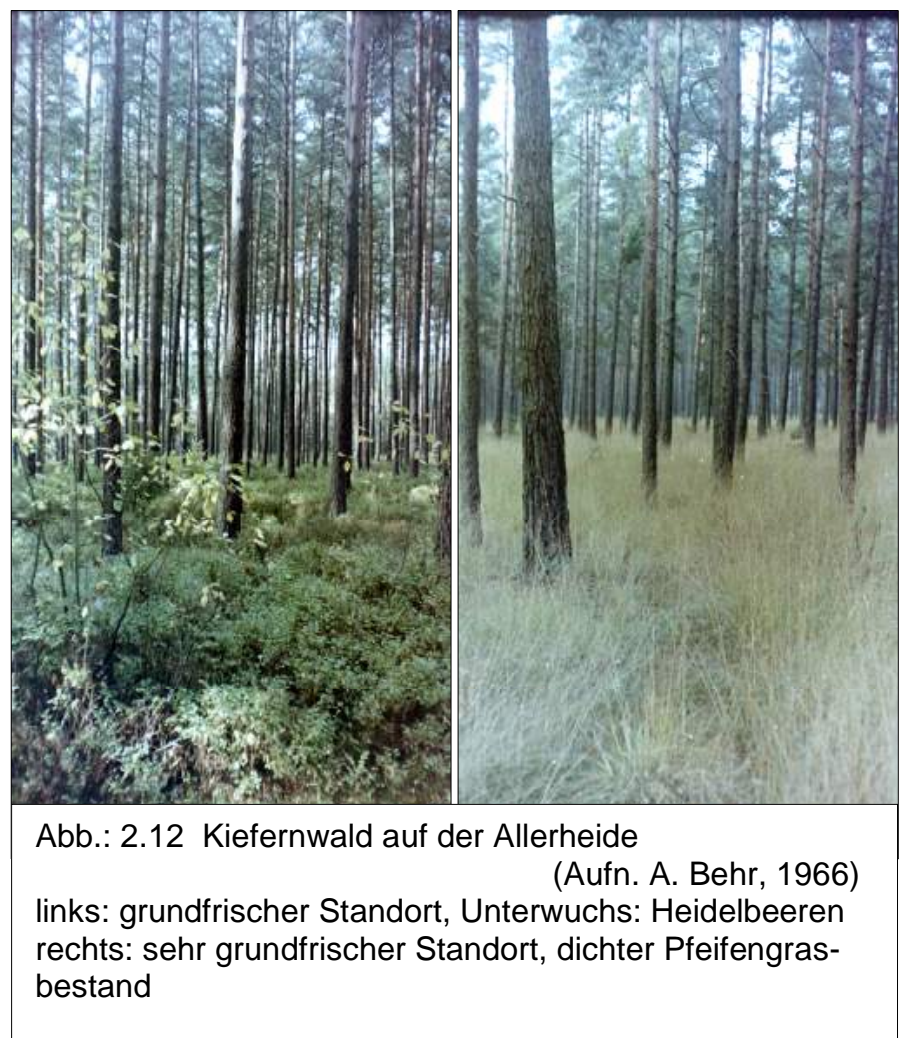
den Standorten eine günstige Grundfrische, wozu auch noch die zahlreichen Lehmbänder ${ }^{4}$ nicht unwesentlich beitragen.

Die natürliche Waldgesellschaft dieses Standortes war der Eichen-Birkenwald in grundfrischer Ausprägung. Nach längerem Heidestadium mit starker Degradierung der Böden stockt hier heute eine Sekundärgesellschaft unter Kiefern ${ }^{5}$.

\footnotetext{
${ }^{1}$ s. Erläuterungen Miele, S. 10

2 s. Forstliche Standortkartierung Klosterforst Miele

${ }^{3}$ vgl. Erläuterungen Miele, S. 67

${ }_{5}^{4}$ Die Verbreitung der Lehmbänder ist nur im Bereich der Klosterforst erfasst. Vgl. auch Abb.6

5 vgl. Erläuterungen Miele, S. 67
} 
Das Profil in Abb. 2.6 (Heidepodsol) lässt Rückschlüsse auf die Bestandesgeschichte dieses Standortes zu. Die dünnen Humusbändchen können wohl als Hinweis auf einen trockenen Stieleichen- Birkenwald ${ }^{1}$ gedeutet werden. Auch die durch Eisen-Humusilluviation sichtbar gewordene Wurzelbahn, die bis zum schmalen Lehmband vorgedrungen ist, gehört zum Eichen-Birkenwald, da sie das Orterdeband nicht durchstößt und deshalb keine Kiefernpfahlwurzel aus jüngster Zeit sein kann.

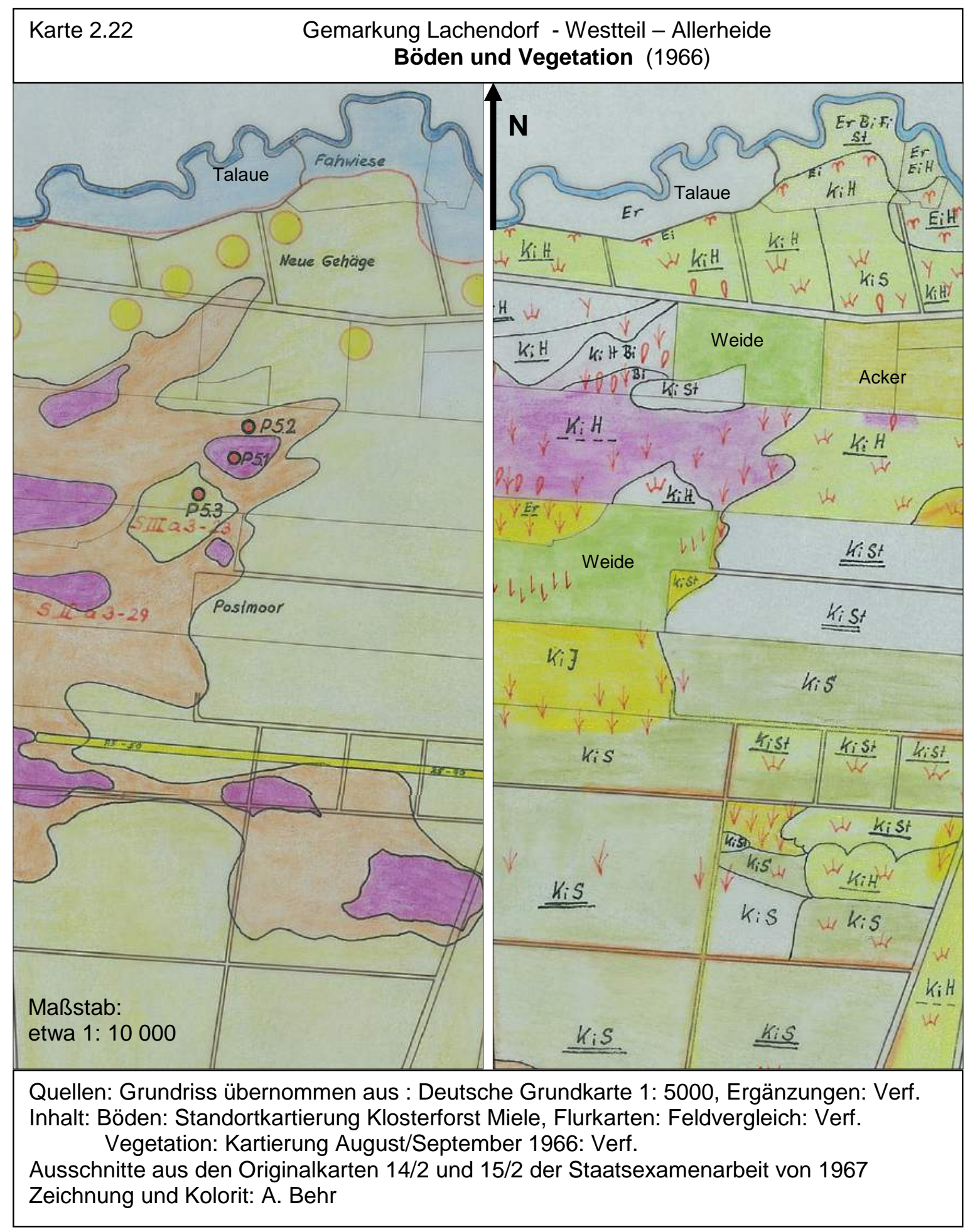

\footnotetext{
${ }^{1}$ vgl. Tüxen, R., Die Schrift des Bodens, Angewandte Pflanzensoziologie, Hrsg. R. Tüxen, H. 14, Stolzenau/ Weser 1957, S. 9
} 


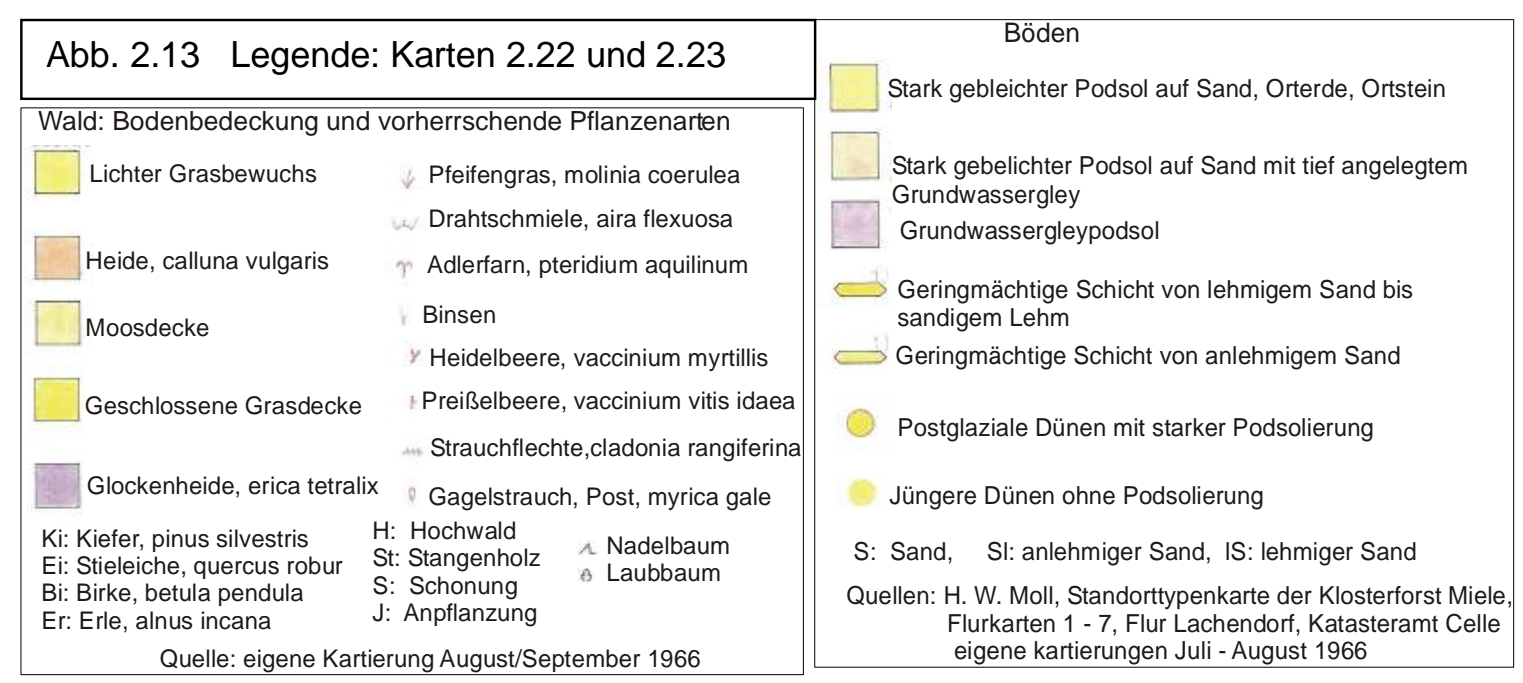

Die deutliche Einfärbung ist allerdings erst unter dem Einfluss der Heide geschehen ${ }^{1}$. Darüber hat sich ein gut gebleichter Podsol mit kräftig gefärbter Orterde unter Heide entwickelt. Dieser Bodentyp ist für die trockenen Flächen der Allerheide charakteristisch und lässt genaue Schlüsse auf den Nutzungswandel dieser Standorte zu.

Zwar neigen diese durchlässigen Sande auch primär zur Podsolierung, die starke Degradierung und die Ausbildung von typischer Orterde bzw. Ortstein ist aber eine Folge der Verheidung $^{2}$. Wie die meisten mitteleuropäischen Waldböden ist auch dieser Boden durch langen Stoffentzug in Folge von Beweidung und Plaggenhieb und durch starke Auswaschung ${ }^{3}$ sehr stark verarmt. Der Boden ist heute allgemein ärmer als er von Natur aus eigentlich wäre ${ }^{4}$.

Auf diesen verarmten, degradierten Sanden wirkt für tief wurzelnde Baumarten das erreichbare Grundwasser kompensierend ${ }^{5}$, so dass der Standort trotz jahreszeitlicher Austrocknung des Oberbodens für Pflanzen mit einer Pfahlwurzel nicht so schlecht ist.

Für die Ackerflächen auf der Allerheide sind meist Bodenzahlen von 17 - 19 Punkten ausgewiesen, südlich der Lachteaue auf dem Westerkamp gibt es Ausnahmen mit 26 - 36 Bodenpunkten, auf dem Südfeld (heute Baugebiet) kommen dagegen sogar Bewertungen mit 14 Punkten vor. Die Höchstwerte werden hier bei anlehmiger Komponente an wenigen Stellen mit 31 und 33 Punkten erreicht.

Es handelt sich also überwiegend um äußerst geringwertige Böden (s. Abb. 2.9, Podsole unter Acker) die auf sehr armen, leicht zu trockenen Sanden wohl zu den landwirtschaftlichen Grenzböden gerechnet werden müssen.

Das nicht sehr tiefe Grundwasser ist für annuelle Kulturpflanzen doch noch zu tief und nicht verwertbar. Niederschläge versickern aufgrund der äußerst guten Perkolation sehr schnell, die Wasserkapazität der Böden ist sehr gering. Der geringen natürlichen Fruchtbarkeit als negativer Faktor steht eine leichte und überwiegend witterungsunabhängige Möglichkeit zur Bodenbearbeitung als positiver Faktor gegenüber. Diese beiden gegenläufigen Faktoren haben allerdings je nach Stand der Agrartechnik ein sehr unterschiedliches Gewicht.

\footnotetext{
${ }^{1}$ vgl. Tüxen, R., a.a.O., S. $17 \mathrm{f}$

${ }^{2}$ vgl. ebenda, S. $17 \mathrm{ff}$

${ }^{3}$ vgl. Walter, H., a.a.O., S. 39

${ }^{4}$ vgl. ebenda, S. $41 \mathrm{f}$

${ }^{5}$ vgl. Erläuterungen Miele, S. 68
} 


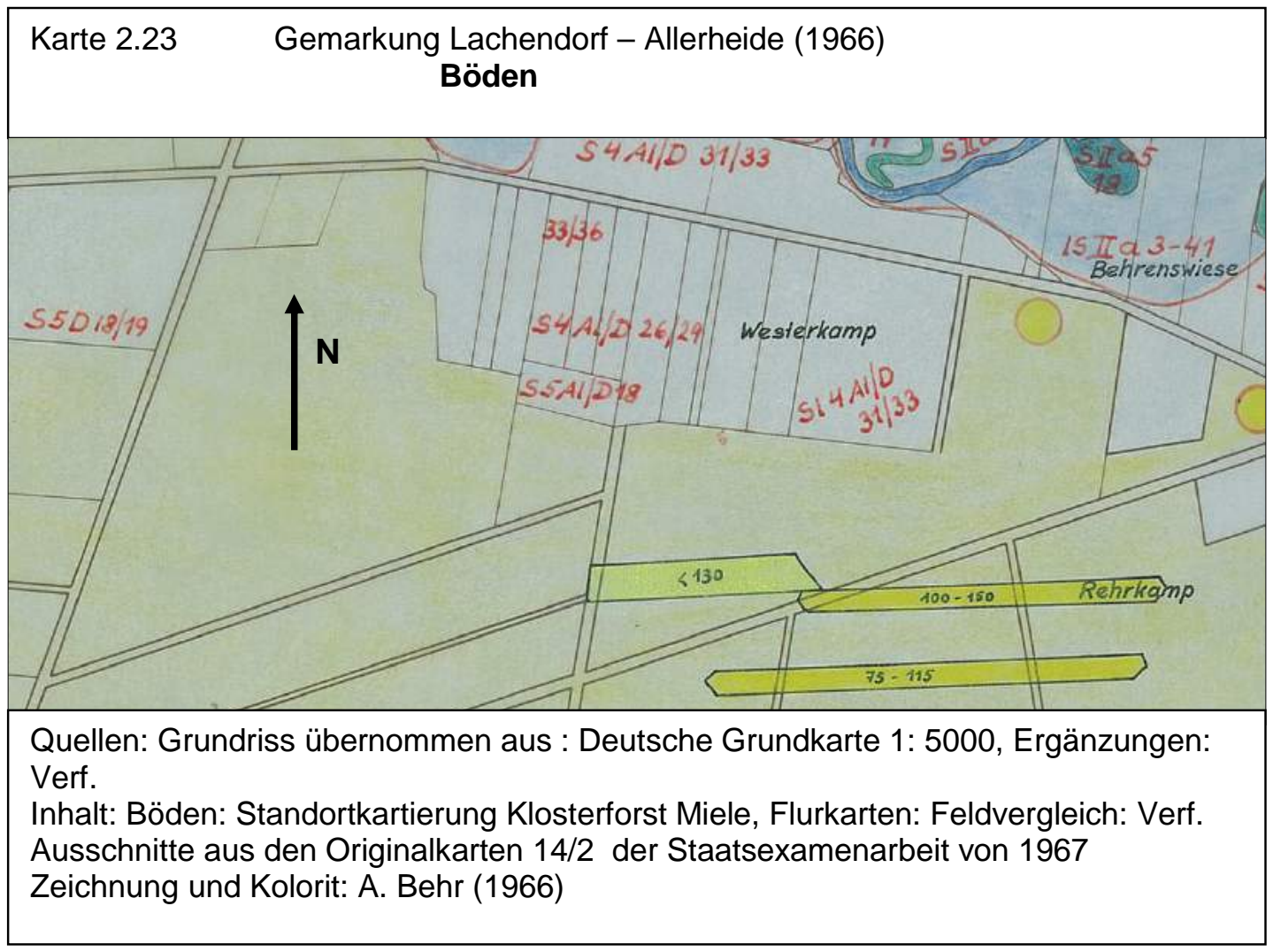

\subsubsection{Allertal}

Die Flächen im Allertal zwischen Schwarzwasser und Aller im Süden und dem Schwemmfächer im Norden und Nordwesten umfassen Räume, die in ihrem Landschaftshaushalt und damit auch im Erscheinungsbild sehr unterschiedlicher Natur sind.

\section{Aller-Dreckwiesen \\ Dieser südöstlichste Gemarkungsteil ist ökologisch geprägt von typischem Niedermoor. Aufgrund des Wasserhaushaltes und der äußerst weichen anmoorigen Böden galten diese Flächen lange Zeit als „absolutes Grünland“, das wegen der empfindlichen Grasnarbe teilweise nicht einmal Beweidung zuließ. Ein Erlenbruchwald am äußersten östlichen Rand der zu Lachendorf gehörenden Dreckwiesen könnte als naturnah eingestuft werden. \\ Das Artenspektrum des Grünlandes war stark durch Sauergräser und Seggen bestimmt. Dennoch sind diese Niedermoorböden mit} Grünlandzahlen um 40 bewertet, da

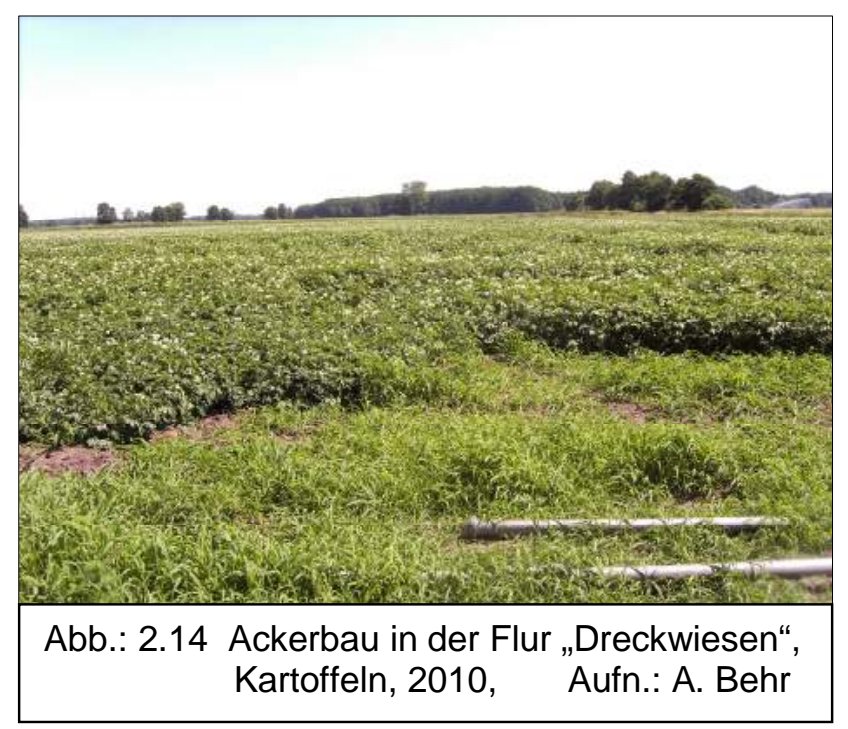
sie auch in trockenen Sommern gute Wuchsleistungen erbringen. Durch die Flussregulierungen haben die Aller-Dreckwiesen eine tiefgreifende Veränderung des Naturpotenzials erfah- 
ren. Dies hat sich in den vergangenen Jahrzehnten auch deutlich auf das landwirtschaftliche Nutzungspotenzial ausgewirkt, wie weiter unten erläutert wird.

\section{Trockene Wiesen}

Der westlich an die Dreckwiesen anschließende Teil, etwa zwischen Schwarzwasser im $S$ und Burbuschsowie Dammweg im N, gehörte auch zum Überschwemmungsbereich von Aller und Schwarzwasser, muss aber wegen der fehlenden Anmoorauflage zu den "Trockenen Wiesen" gerechnet werden. Schon bei der Behandlung des Reliefs wurden diese Flächen gesondert betrachtet wegen des raschen Wechsels von trockenen Sandköpfen und tieferen, Grundwasser beeinflussten Stellen. Hier wechseln lehmige Sande mit Grünlandzahlen von 34 - 42 bei mäßigen Wasserverhältnissen und Sande mit

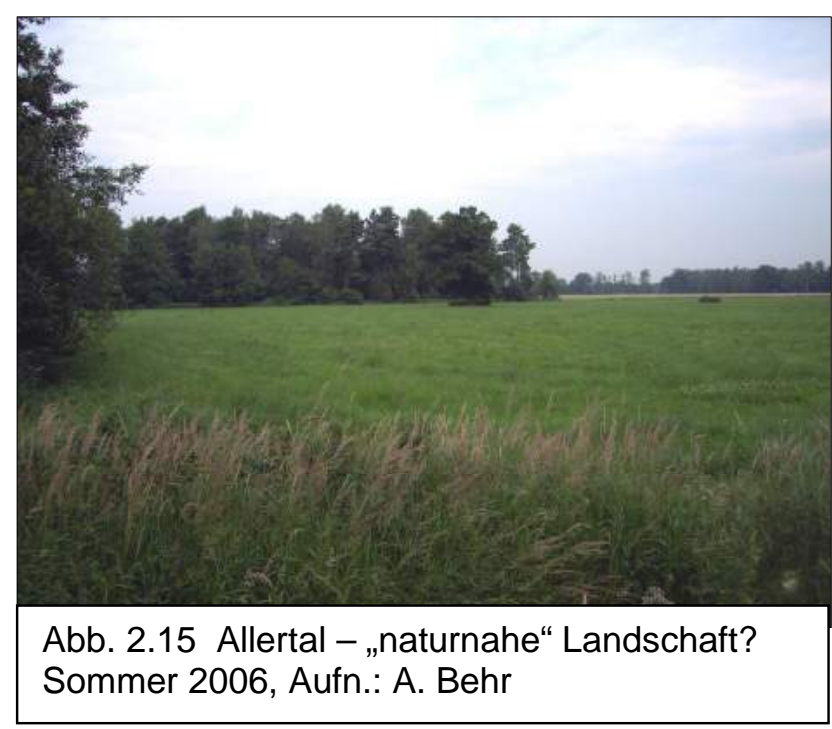
Grünlandzahlen um 30.

Die zahlreichen Sandbuckel im Grünland, oft durch harte Gräser, die vom Vieh gemieden werden, charakterisiert, und die tieferen Lagen, häufig durch Binsenwuchs bestimmt, erlauben keinen gleichmäßigen Graswuchs und auch keine einheitliche Artenkombination der Gräser.

Das Gebiet der ehemaligen Stauwiesen gehörte ebenfalls zum Bereich der „Trockenwiesen, zeigte 1965/66 für Grünland aber Wertzahlen über 40, eine Folge der wesentlichen Verbesserung des Standortes durch künstliche Zuführung nährstoffreichen Okerwassers.

Der Burbusch zwischen Burbuschweg und Ahnsbecker Kanal ist ökologisch äußerst differenziert gebaut, denn dort wechseln lehmige Sande mit Sanden und anmoorigen Flächen auf kleinstem Raum. Zur Zeit der Feldarbeit im Jahr 1966 konnte wegen der meist extensiven Nutzung die ökologische Differenzierung noch recht gut erfasst werden. Soweit es sich noch um Waldweide handelte, verriet die Vegetation den unterschiedlichen Landschaftshaushalt sehr deutlich. Auf den sandigen Stellen stockten Birken und Stieleichen mit Grasunterwuchs, die anmoorigen Partien waren durch den

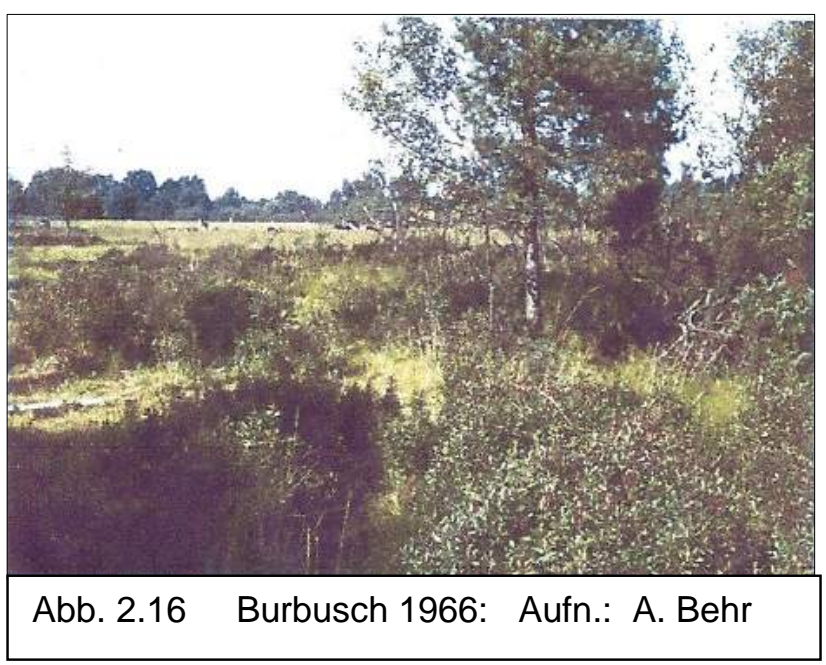
Gagelstrauch (Myrica gale) charakterisiert oder trugen Erlen-Birkenwald. Auf den trockenen, aber grundfrischen Standorten wuchs Glockenheide (Erica tetralix), ein typischer Standortzeiger.

Aufgrund des geringen Kultivierungsgrades könnte die Vorstellung aufkommen, beim Burbusch handele es sich wegen der unklaren Grenzen zwischen den verschiedenen Wuchsstandorten und der Artenvielfalt um einen naturbelassenen Landschaftsteil. Dies wäre allerdings eine völlig falsche Einordnung, denn der Burbusch ist - wie später belegt wird - altes Kulturland. Auf diesen nur unvollständig kultivierten Weiden konnte man dagegen sehr gut die Weideselektion durch das grasende Rindvieh beobachten. Die Artenvielfalt und die Ar- 
tenzusammensetzung werden zwar durch die Standorteigenschaften ermöglicht, aber die Weidenutzung hat das Landschaftsbild geschaffen.

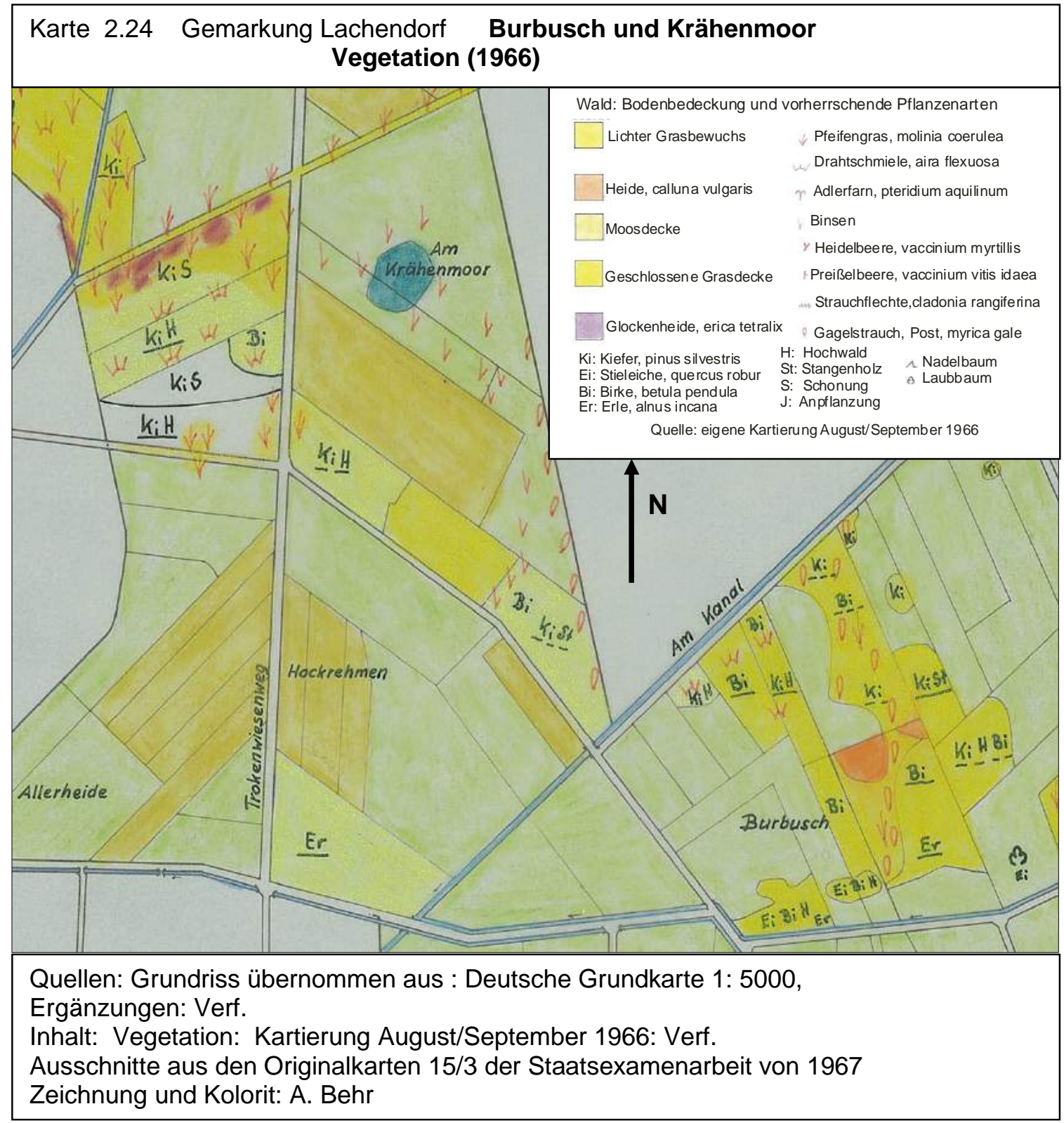

\subsubsection{Kleine Moore}

Auf das „Kleine Moor" am östlichen Ortsrand wurde bereits im Zusammenhang mit dem Schelprieth in Kapitel 2.2 hingewiesen.

\section{Postmoor}

An der Westgrenze der Gemarkung reicht das Postmoor “' ${ }^{\text {'1 }}$ mit einem östlichen Ausläufer bis in die Lachendorfer Gemarkung. Es gehört zu den Randbereichen des Schwemmfächers mit hohem Grundwasserstand. Da das Postmoor weder vollständig zu Grünland noch gar zu Acker urbar gemacht wurde und auch nicht vollständig aufgeforstet worden ist, wirkt es mit seinem Mosaik aus Pfeifengrasbulten, Porst, dicken Moospolstern und Glockenheide ${ }^{2}$ auf

\footnotetext{
${ }^{1}$ Postmoor, vermutlich abgeleitet von Porst (Gagelstrauch, Myrica gale), s. H. Türschmann, Das Postmoor, Endeholz 2010, S. 11

${ }^{2}$ Glockenheide (erica tetralix): Zeigerpflanze für Grundfeuchte
} 
den feuchten Bereichen sowie den dazwischen aufragenden Sandköpfen mit Heide, Birken und Kiefern sehr „naturnah“, wenngleich klar ist, dass es sich nicht um einen Naturzustand handelt.

Bei höherem Grundwasserstand haben sich Podsole mit tief angelegtem Grundwassergley und bei hohem Grundwasserstand Gley-Podsole entwickelt ${ }^{1}$. Im engeren Bereich des Postmoores findet sich auch ein typischer Anmoorgley, aus dem sich die erhöhten Sandköpfe deutlich mit ihrem stark gebleichten Podsol herausheben.

Die Gley-Podsole auf nährstoffarmen Sanden und kalkarmem Grundwasser trugen als natürliche Vegetation einen Pfeifengras-Eichen-Birkenwald ${ }^{2}$. Der Oberboden ist nach einem längeren Heidestadium stark podsoliert, die ausgesprochen nährstoffarmen, sehr sauren Bildungen neigen bei Freilage zu starker Vergrasung mit Molinia coerulea, auch Erica tetralix gedeiht gut ${ }^{3}$. Diese Flächen würden sich bei Baumfreiheit zu ausgesprochenen PfeifengrasStreuwiesen entwickeln, können aber durch Düngung und Beweidung in relativ günstiges Grünland umgewandelt werden ${ }^{4}$, was auch auf manchen Flächen bereits geschehen ist.

Die Flächen mit Anmoor-Gley trugen wohl Birkenbruchwald mit Myrica gale (Gagelstrauch) ${ }^{5}$ und Sphagnum, die heute unter lichtem Kiefernwuchs noch stark zur Entfaltung kommen ${ }^{6}$. Besonders die Glockenheide bildet hier dichte Rasen, die teils mit Molinia durchsetzt sind. Diese Flächen dürfen wohl zum Glockenheide-Anmoor mit stagnierendem Grundwasser $\left(\mathrm{H}_{2} \mathrm{~S}\right.$-Geruch) gerechnet werden, das schon natürlicherweise recht baumarm ist ${ }^{7}$.

Zur Baumfreiheit haben während des Heidestadiums aber besonders Beweidung und Plaggenhieb beigetragen. Glockenheide-Anmoor wurde wegen der mächtigen Humusschicht besonders gern zum Plaggenhieb genutzt, dagegen eignete sich die Glockenheide wegen ihres bitteren Geschmacks wenig als Weide ${ }^{8}$.

\section{Krähenmoor}

Im Übergangsbereich zwischen Schwemmfächer und Allerwiesen, in dem schmalen Streifen, der den nördlichen und südlichen Gemarkungsteil verbindet, liegt das Krähenmoor.

Dort liegt unter dem Anmoor eine Lehmschicht ${ }^{9}$, die Wasser stauend wirkt, zur Vermoorung geführt hat und ein eigenes, flachgründiges Grundwasserregime bewirkt. Bei lang anhaltender sommerlicher Trockenheit kam es hier oberflächlich zu weitgehender Austrocknung, so dass der Weiher in der Mitte des Moores dann eher die Eigenschaften eines Tümpels ${ }^{10}$ aufwies.

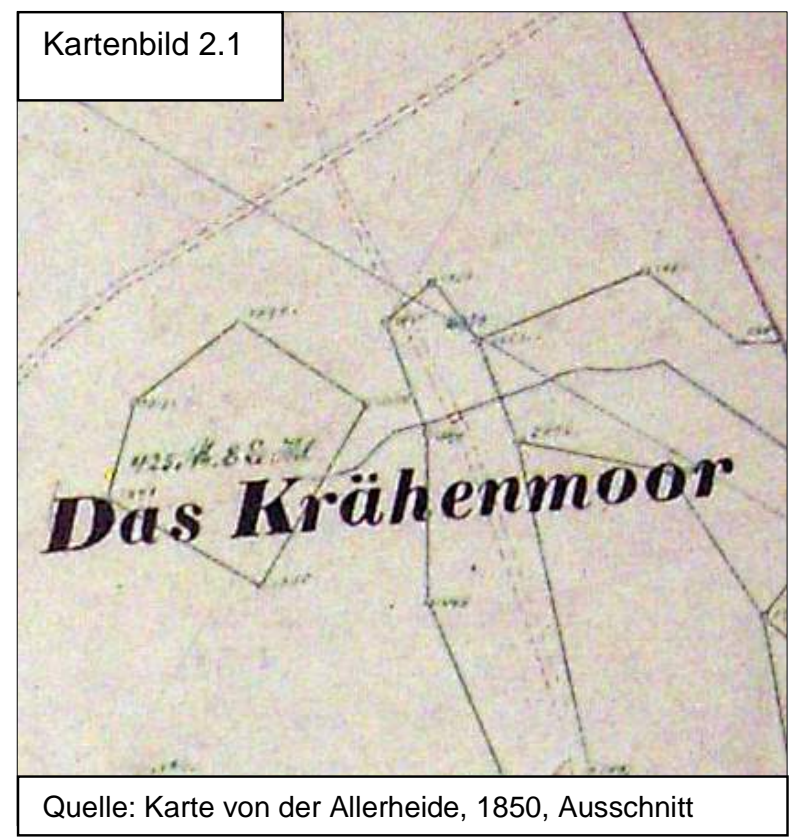

\footnotetext{
${ }^{1}$ vgl. Erläuterungen Miele, S. 85 ff und zugehörige Bodenkarte der Standorttypenkarte der Klosterforst Miele; s. auch Karte 2.22

2 .vgl. Erläuterungen Miele, S. 86

${ }^{3}$ vgl. ebenda, S. 87

${ }^{4}$ vgl. Ellenberg, H., Wiesen und Weiden, Landwirtschaftl. Pflanzensoziologie, Bd. II, Stuttgart 1952, S. $42 \mathrm{ff}$

${ }^{5} \mathrm{vgl}$. Erläuterungen Miele, S. 40

${ }_{7}^{6}$ s. Karte 3.3, Aktuelle Vegetation 1966

${ }^{7}$ vgl. Walter, H., a.a.O, So $644 \mathrm{f}$

${ }^{8} \mathrm{vgl}$. ebenda, S. 644

${ }^{9}$ Mündliche Auskunft von Herrn Landwirt K. Koch, Lachendorf

${ }^{10}$ Seit 1966 ist das Krähenmoor immer stärker ausgetrocknet und kultiviert worden und heute nicht mehr als Moor erkennbar. (s. Abb. 2.17 unten)
} 
Die Unabhängigkeit des lokalen Oberflächenwassers von dem allgemeinen Grundwasser des Urstromtales zeigen Beobachtungen an einem Brunnen, der mitten im Krähenmoor fast am Rande des Moorweihers steht. Hier können ein tiefer Wasserspiegel im Brunnen bei gleichzeitig hohem Wasserstand im Moor und ein hoher Wasserspiegel im Brunnen bei fast eingetrocknetem Moortümpel beobachtet werden. Es ist vorgekommen, dass die oberirdischen Brunnenringe im Wasser standen, während im Brunnen selbst der Wasserspiegel recht tief $\operatorname{lag}^{1}$. Der Wasserhaushalt dieses kleinen Moores ist also aufgrund der Abhängigkeit von den Niederschlägen sehr unausgeglichen und sowohl jahreszeitlich als auch von Jahr zu Jahr sehr unterschiedlich.

Während das Krähenmoor 1850 noch als großes eigenständiges Landschaftselement kartiert wurde, ist durch abgesunkenen Grundwasserstand und fast vollständige agrarische Nutzung in den jüngsten Jahrzehnten sein besonderer ökologischer Charakter allerdings vollständig verloren gegangen.

Im direkt umliegenden Ackerland sind die Böden mit sehr dunkel gefärbter, gut
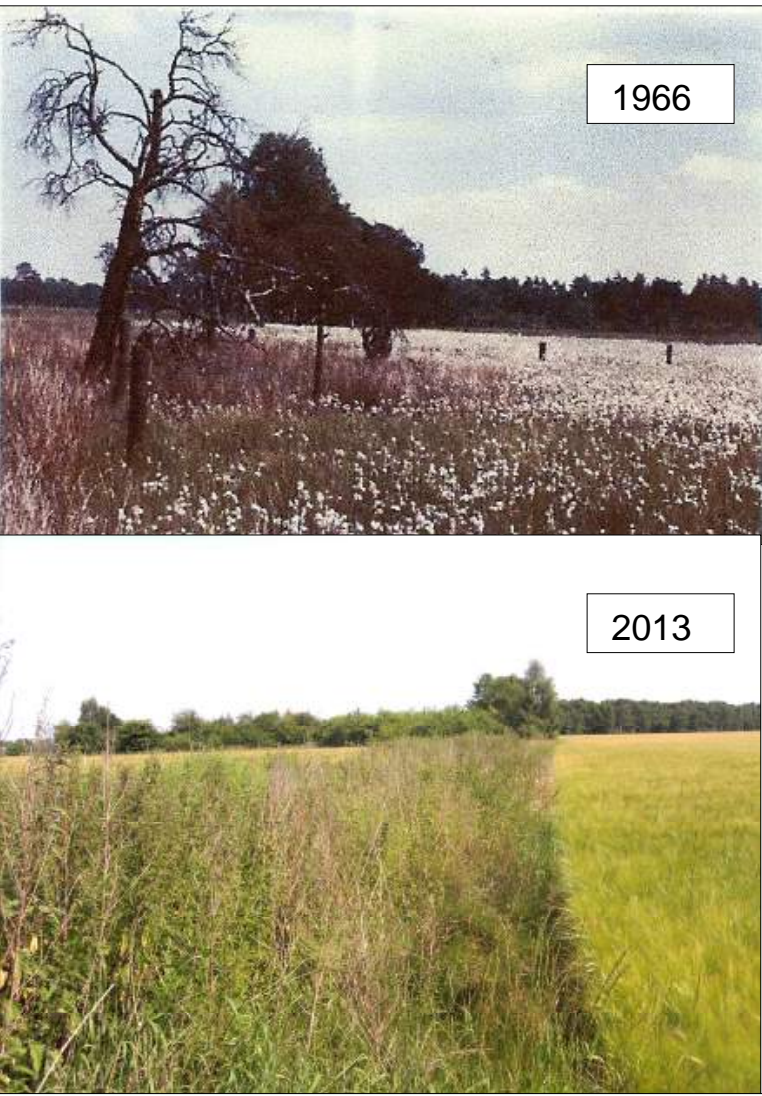

Abb. 2.17 Das Krähenmoor

Aufn.: A. Behr humoser Krume mit 24 - 25 Punkten

bewertet, das Grünland mit nur 23 Punkten. Die niedrige Einstufung dieses Standortes beruht auf dem ungünstigen, lokal bedingten Wasserhaushalt.

Soweit noch nicht kultiviert, verriet noch 1966 der Gagelstrauch die feuchten, anmoorigen Verhältnisse am Krähenmoor, dessen Zentrum 1966 noch ein stark verlandeter Moorweiher bildete. Die angrenzenden „Grünflächen“ ließen auch noch mit Binsen und Wollgras (s. Abb. 2.17) den nassen Standort erkennen.

Nach NW, auf der Westseite des Trockenwiesenweges, schließt sich ein grundfrisches bis feuchtes Gebiet an, das bei ausgeprägter Grundfrische von Podsolen (wohl primäre Podsole auf Sand mit tief angelegtem Grundwassergley $^{2}$ ) und bei höherem Grundwasserstand von Gley-Podsolen bestimmt ist. Als Feuchtigkeitszeiger ${ }^{3}$ beherrschte das Pfeifengras (Molinia coerulea) mit Glockenheide und Moosen die Krautschicht. Auch dieses grundfrische Gebiet im sonst trockenen Schwemmfächer wurde zu Grünland umgewandelt und überwiegend bis heute so genutzt.

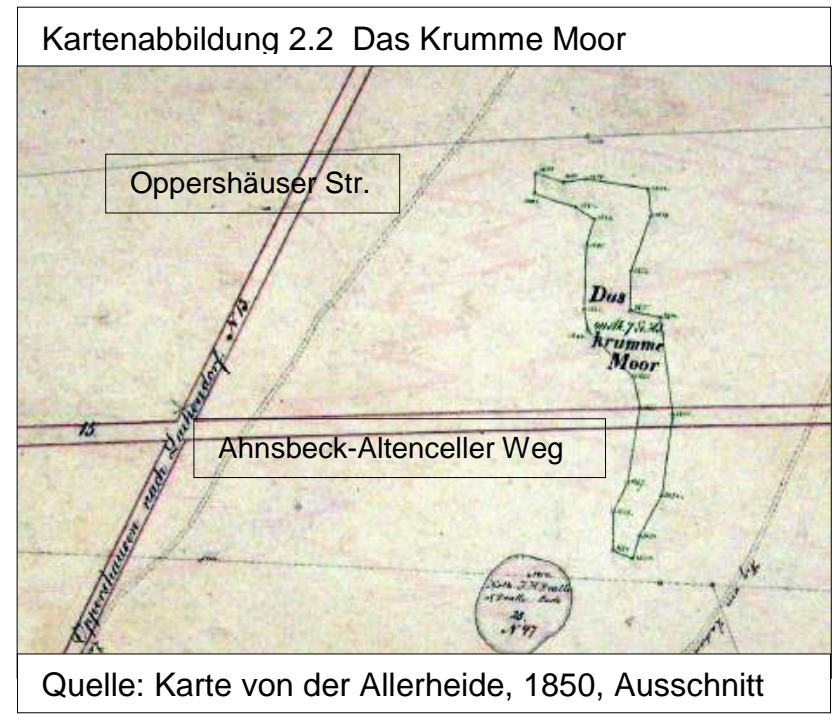

\footnotetext{
${ }_{1}^{1}$ Mündliche Auskunft von Herrn Landwirt K. Koch, Lachendorf

${ }^{2} \mathrm{vgl}$. Erläuterungen Miele, S. 86

${ }^{3}$ Walter, H., a.a.O., S. 655 und Raabe, E., a.a.O.; S. 102
} 


\section{Krumme Moor}

Ähnliche Verhältnisse wie im Krähenmoor gab es im sog. Krummen Moor ${ }^{1}$, das früher beiderseits des Ahnsbeck-Altenceller Weges etwas östlich der Straße nach Oppershausen lag. Auf der Karte für die Generalteilung der Allerheide wurde es noch als auffälliges und eigenständiges Landschaftselement kartiert. Bis Anfang der 1960er Jahre war es teils ungenutzte Fläche mit Ruderalvegetation und teils auch wilde Müllkippe ${ }^{2}$. In den folgenden Jahrzehnten trocknete es - wie das Krähenmoor - mehr und mehr aus, wurde nach und nach zugeschüttet und ist inzwischen sogar am Südrand der Siedlung weitgehend überbaut und im Landschaftsbild vollständig verschwunden. Der Name lebt fort in einer Straße „Am Krummen Moor", die aber (fälschlicherweise) heute westlich der Oppershäuser Straße liegt.

\subsubsection{Lachtetal}

\section{Terrassen des Lachtetales}

Oberhalb des Ortes sind im Lachtetal Terrassen ausgebildet, besonders gut östlich der Talaue zwischen Lachendorf und Jarnsen, die ganz sanft in den Geesthang übergehen. Die Terrassensande sind überwiegend podsoliert und wie die Böden des Schwemmfächers mit 18 25 Bodenpunkten bewertet.

Am Nordwestrand des Ortes, an der Jarnser Straße, sind auf diesen Flächen, ehemals als Acker genutzt,

Karte 2.25 Lachte, Überschwemmungsbereich

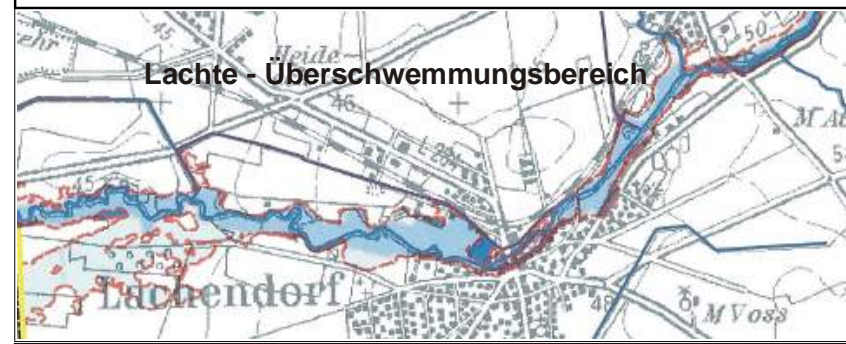

Quelle: NLWKN. 2011. s. Karte 2.14 (Aller) Sportanlagen angelegt worden.

\section{Talaue der Lachte}

Die Talaue, der Überschwemmungsbereich der Lachte, bietet ein ziemlich einheitliches ökologisches Gefüge ${ }^{3}$. Die Grünländereien sind als vorwiegend lehmige Sande mit der Klimastufe a (günstig für Grünland) und meist mäßigen Wasserverhältnissen (Stufe 3 bei fünfteiliger Wertskala) mit Grünlandzahlen zwischen 37 und 43 ausgewiesen. Bei diesen Flächen handelt es sich also um relativ gutes Grünland.

Die Aue wird sicherlich schon sehr lange als Grünland genutzt. Der typische Weidebaum auf Abb. 2.18, eine Eiche mit deutlicher Fraßkante, zeugt von langer Beweidung.

Einzelne Gebiete auf sandigen Substraten und mäßigen bis guten Wasserverhältnissen sind nur mit $24-37$ bewertet, wobei die Bewertung mit wachsender Entfernung vom Fluss abnimmt, da dort die Sande bei bester Perkolation keine guten Grünlandstandorte mehr bieten.

Als Standorte eigener ökologischer Prägung müssen die künstlich abgetrennten, in starker Verlandung begriffenen Flussschlingen betrachtet werden, auf deren

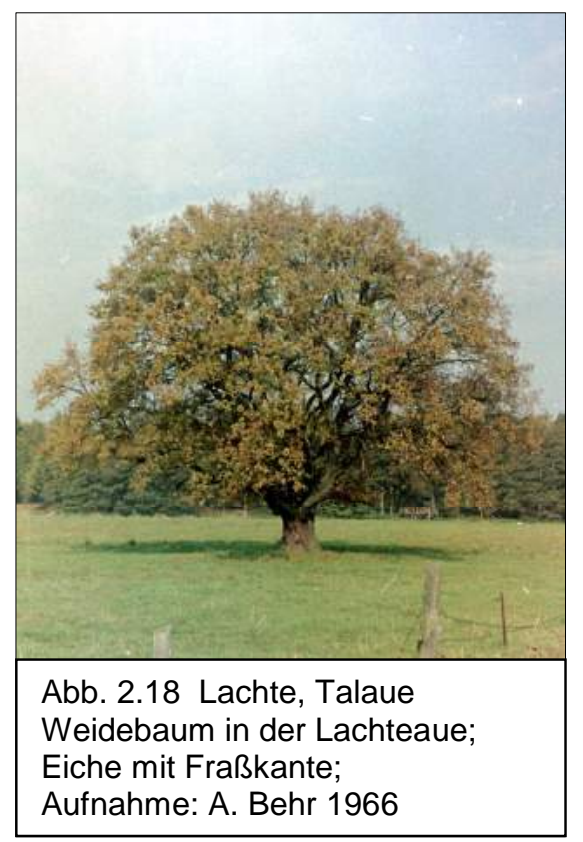
unterschiedliches Alter schon hingewiesen wurde. Diese alten Flussschlingen liefern, soweit sie schon völlig verlandet sind, mit einem Pflanzenbestand, der reich an Schilf und vor allem

\footnotetext{
1 s. Karte 4; Landwirtschaftliche Nutzung um 1900

2 Beobachtungen des Verf.

${ }^{3}$ Auf den entscheidenden Faktor dieses Landschaftshaushaltes, den schwankenden Grundwasserstand gekoppelt mit den Wasserständen der Lachte, wurde schon hingewiesen.
} 
Großseggen ist, ein sehr schlechtes Futter, sind daher agrarwirtschaftlich fast wertlos und deshalb auch entsprechend niedrig bewertet ${ }^{1}$.

Noch nicht verlandete Flussschlingen weisen mit sehr dunkel gefärbtem Wasser dystrophe Verhältnisse auf, werden im offenen Wasser von Pflanzen der Schwimmblattzone besiedelt und sind von den typischen Pflanzen der Verlandungszone umgeben. Der Uferrand ist meist etwas wallartig erhöht und bietet daher etwas trockenere Standorte. Nach außen fällt das Terrain wieder etwas ab und ist bei leichter Vernässung meist durch Binsenwuchs charakterisiert.

Die Aueböden der Talaue bieten meist direkt am Ufer, auf den ganz flach gewölbten kleinen Uferwällen die besten Standorte. Zum Auenrand fällt die Oberfläche wieder etwas ab, ist dort stärker Grundwasser beeinflusst und meist schwach vermoort.

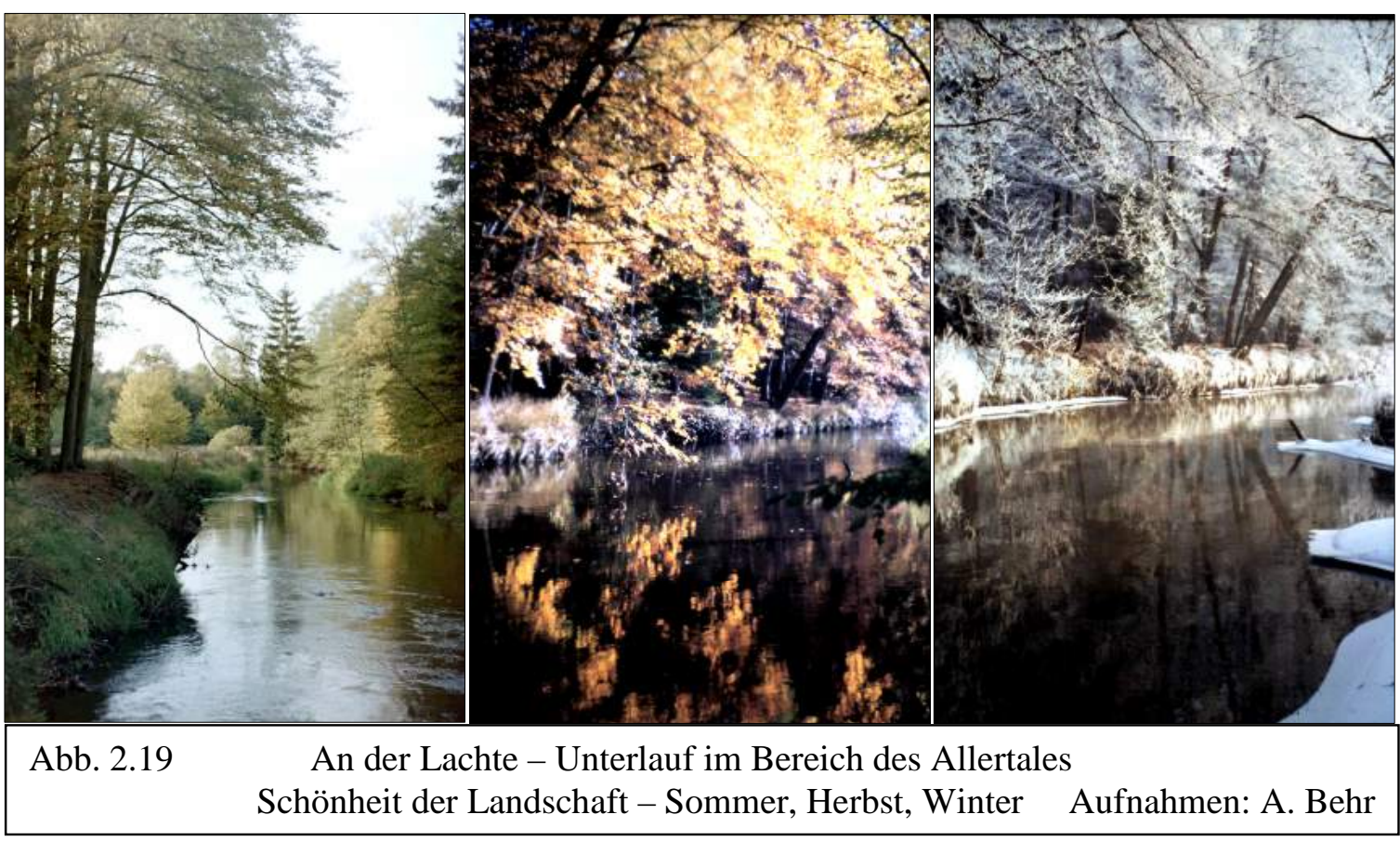

\subsubsection{Binnendünen}

Standorte ganz eigener Prägung bilden die Dünen, wenngleich ihr Flächenanteil sehr gering ist. Am Bodenprofil Nr.12 (s. Abb. 2.2, Kap. 2.1) lassen sich wichtige Merkmale ablesen: Mehrfache Bildungsphasen eines Podsols mit deutlicher Störung in den oberen Horizonten. Für den Landschaftshaushalt und die Standortqualitäten ist das Bildungsalter entscheidend. Die postglazialen Dünen ${ }^{3}$ unterscheiden sich in Bodendynamik und Wuchsleistung nicht von den angrenzenden Flächen ${ }^{4}$. Auf den Dünen haben sich ebenfalls starke Podsol-Profile mit Orterde ausgebildet ${ }^{5}$.

Auf den jungen Dünen ${ }^{6}$, vielfach nur Umlagerungen und Überwehungen alter Dünen in Folge anthropogener Eingriffe in die Vegetation ${ }^{7}$, findet sich noch kein Podsol ${ }^{8}$. Es hat sich meist

\footnotetext{
${ }^{1}$ Die niedrigste in der Talaue der Lachte auftretende Grünlandzahl 13 bei Wasserverhältnissen, die mit sehr schlechter (Stufe 5) bewertet wurden.

${ }^{2}$ Aufnahme 1966 vom Verf.

${ }^{3}$ z.B. die Dünen in Abt. 122 der Klosterforst, vgl. auch Erläuterungen Miele, S. 18

${ }^{4}$ Erläuterungen Miele, S. 19

${ }^{5}$ vgl. Tüxen, R.,. Vegetationsstudien im nordwestdeutschen Flachland, I. Über die Vegetation der nordwestdeutschen Binnendünen, in: Jb. d. geogr. Ges. Hannover, Hannover 1928, S. 71-93, dort S. 76

${ }^{6}$ In der Abt. 210 nachgewiesen, vgl. Erläuterungen Miele, S. 19

7 Tüxen, R., a.a.O., S. 76

${ }^{8}$ ebenda, S. 72, s. a. Profil Nr. 6.1 und $6 . .2$
} 
noch nicht einmal eine nennenswerte Humusanreicherung im Oberboden vollzogen, nur verschiedentlich findet sich der allererste Beginn einer Podsolierung ${ }^{1}$. Die zugehörigen Ausblasungsflächen zeigen ein gekapptes Podsolprofil, das unter den jungen Dünen erhalten ist ${ }^{2}$.

Die jungen Ausblasungsflächen und rezenten Dünenbildungen sind mit ihren unentwickelten Böden auf armen Dünensanden mit sehr geringer Wasserkapazität ausgesprochen minderwertige Standorte. Diese rezenten Bildungen bieten in der Gemarkung die bei weitem schlechtesten Standorte hinsichtlich einer agrarwirtschaftlichen Nutzung.

Am Nordwestrand des Ortes, an der Jarnser Straße auf der Terrasse des Lachtetales, konnten einige flache Kuppen 1966 noch als Relikte von Binnendünen bestimmt werden, die heute durch Überbauung und Umnutzung nicht mehr erkennbar sind.

Auch die forstliche Standortkartierung der Klosterforst hat im Forstgebiet ${ }^{3}$ westlich des Ortes solche Dünen kartiert.

Die größte, sicherlich postglaziale Düne, ist an der ehemaligen Mündung des Schwarzwassers im Allertal der Lorkberg, der allerdings knapp außerhalb der Gemarkung Lachendorfs liegt. Diese Düne fällt im Landschaftsbild des Allertales sehr ins Auge, einmal durch das Relief und zum anderen durch den Bewuchs mit Kiefern.

\subsubsection{Raumpotenziale}

\subsubsection{Naturpotenzial und Nutzungspotenzial}

Für die Gemarkung Lachendorf hat sich insgesamt eine klare standörtliche Differenzierung der einzelnen Gemarkungsteile ergeben, die in sich relativ homogen sind, sich aber voneinander sehr deutlich hinsichtlich der ökologischen Bedingungen unterscheiden.

Das Naturpotenzial dieser verschiedenen Standorte würde sich ohne Zweifel am besten in der natürlichen Flora und Fauna zeigen, da diese sich langfristig auf der Basis der geologisch-pedologischen, hydrologischen und klimatischen Faktoren und in Interaktion mit diesen abiotischen Faktoren entwickelt und sich dem Standort angepasst haben.

Die Vegetation zeigt dabei, besser als die Fauna, wegen der ortsfesten Gebundenheit an den Standort dessen Wuchsleistung bzw. -potenzial.

Nun ist menschliche Aktivität mindestens seit der Bronzezeit, also seit knapp 4000 Jahren, durch den Fund ${ }^{4}$ einer Bestattung am Fuß des Urstromtalhanges östlich des Dorfes nachgewiesen. Möglicherweise boten aber das Allertal mit fischreichen Gewässern und den Weichholzbeständen sowie die Wälder auf den Geestplatten den Menschen des Neolithikums bereits günstige Voraussetzungen für den Übergang zu Ackerbau und Viehzucht. Diese frühe Siedlungsstelle kann daher auch schon als Ökotopgrenzlage ${ }^{5}$ bezeichnet werden.

Der menschliche Einfluss auf die natürliche Flor und Fauna hat dann im Laufe der Kultivierung durch Rodungen, Beweidung und Holznutzung zwar nicht immer kontinuierlich zugenommen, aber letztlich doch schon vor Jahrhunderten zu einer vollständigen Kulturlandschaft geführt.

\subsubsection{Natürliche Vegetation und Bestandesgeschichte}

Natürlicherweise gehört das Untersuchungsgebiet seit dem Postglazial zum Waldland Mitteleuropas, in dem Birke, Eiche und Buche begünstigt sind und der Unterwuchs hauptsächlich durch die klimatisch gut angepassten Hemikryptophyten und Geophyten bestimmt wird ${ }^{6}$. Die armen diluvialen Sande trugen Eichen-Birkenwälder, in denen auch der Wacholder und die

\footnotetext{
${ }^{1}$ vgl. Erläuterungen Miele, S. 19

${ }^{2}$ ebenda

${ }^{3} \mathrm{vgl}$. Erläuterungen Miele, S. 18

${ }^{4}$ Grabungsbericht, S. 1; Anm.: d. Verf.: Der Fund, beim Pflügen gemacht, konnte nur deshalb wissenschaftlich aufgenommen und datiert werden, weil der Landwirt K. Koch den Fund in seinem Acker meldete, da er erkannt hatte, dass am Rand des Urstromtales keine größeren Steine natürlicherweise vorkommen, es sich also um einen archäologischen Fund handeln müsse.

${ }^{5}$ s. Küster, a.a.O. S. 177

${ }^{6}$ Walter, H., Einführung in die Phytologie, Bd. IV, T. 2, Stuttgart 1963, Vegetation Mitteleuropas mit den Alpen, von H. Ellenberg, S. 19
} 
Heide bereits als Unterwuchs vorkamen. Auf besseren Böden, also vornehmlich auf den Grundmoränenplatten, stockten Eichen-Buchenwälder ${ }^{1}$ bzw. Birken-Eichenwälder ${ }^{2}$. Heute geht man davon aus, dass vor etwa „8000 Jahren schon fast alle der heute natürlicherweise häufig in Mitteleuropa vorkommenden Baumarten vertreten“3 ${ }^{\text {w3 }}$ waren. „Es fehlten nur noch Tanne, Buche und Hainbuche"4. Die später in der Waldnutzung so wichtigen Baumarten wie Rotbuche und Hainbuche wanderten also erst während des Beginns der menschlichen Landnutzung ein.

Während die Birke-Eichen- und Eichen-Buchenwälder wegen der besseren Standortqualitäten schon sehr früh weitgehend in Ackerland umgewandelt wurden, gingen die EichenBirkenwälder meist in baumlose Zwergstrauchheiden über ${ }^{5}$, die in neuerer Zeit fast ausnahmslos in Kiefern-Fichtenforste überführt wurden ${ }^{6}$. Die Jahrhunderte dauernde intensive Nutzung der ursprünglich natürlichen Wälder trug nicht nur zu deren Zerstörung bei, sondern hatte z. B. durch das Schneiteln ${ }^{7}$ bzw. die Laubheugewinnung ${ }^{8}$ auch erheblichen Einfluss auf die Artenzusamensetzung.

Auch die Talauen trugen natürlicherweise Wald, in dem Weichhölzer vorherrschten. Auch die Anmoor- und Niedermoorfläche waren nicht großflächig baumfrei wie echte Hochmoore, vielmehr dürften in den Feuchtgebieten der Randmoore im Urstromtal Bruchwaldgesellschaften heimisch gewesen sein. Natürliches baumfreies Grünland gab es auch im Auebereich nicht $^{9}$, dies wurde erst im Zuge der Umwandlung in eine Kulturlandschaft geschaffen.

Die Interaktion zwischen den abiotischen und biotischen Standortfaktoren zeigt sich gut darin, dass der vollständige Wandel in der Vegetation auf die Bodendynamik und die Wuchsleistung ganz erheblichen Einfluss nahm, wie die zunehmende, teils extreme Podsolierung unter Heide besonders deutlich macht.

\subsubsection{Nutzungspotenzial}

\subsubsection{Wirtschaftliches Nutzungspotenzial}

Die räumliche Aussage der Karte 2.26 aus den 30er Jahren des 20. Jhd. zum wirtschaftlichen Nutzungspotenzial ähnelt ganz stark den entsprechenden Karten zu den Böden (Kap. 2.3 Pedologie, Karte 2.17) und zur Entwässerung (Kap. 2.2 Hydrologie, Karte 2.16). Es liegt nahe anzunehmen, dass die Karte des Nutzungspotenzials allein aufgrund der geologisch-

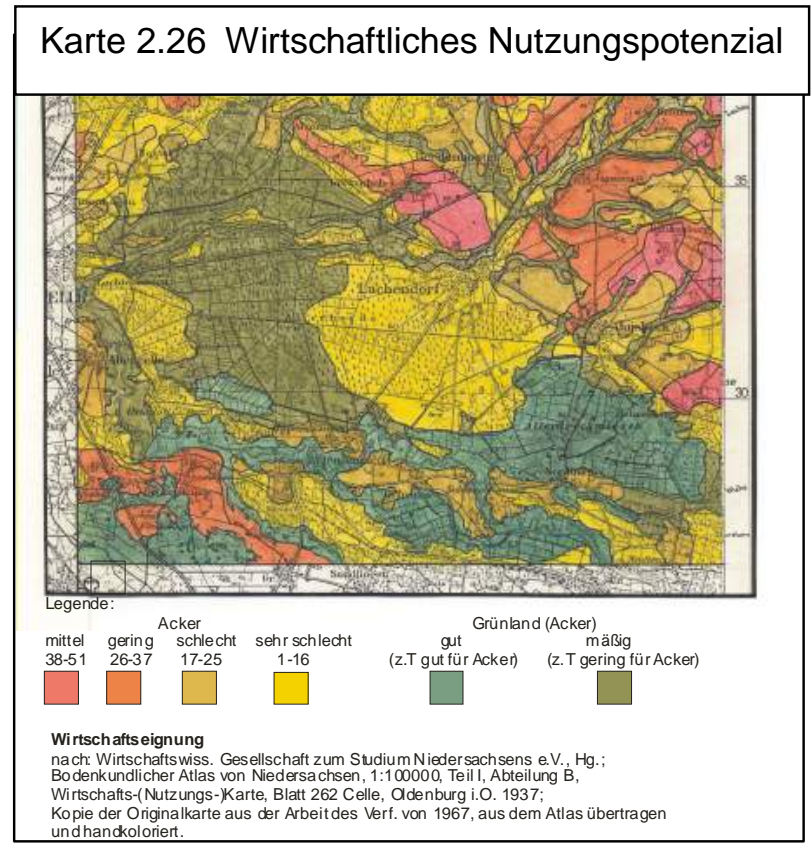

\footnotetext{
${ }^{1}$ Der Bodenkunde entsprechend wird bei den Mischwaldtypen die Begriffsbildung auch so gewählt, dass das Schwergewicht der Vegetation auf der zweiten Pflanzenart liegt. (Anm. d. Verf.)

${ }^{2}$ Walter H. , a.a.O. , s. $35 \mathrm{ff}$

${ }^{3}$ s. Küster, a.a.O., S. 66

${ }^{4}$ ebenda

${ }^{5}$ ebenda, S. 31

${ }^{6}$ Gradmann, R., Unsere Flusstäler im Urzustand, in: Z. d. Ges. f. Erdk. Berlin 1932, S. 1-17, dort S. 9 f und Walter, H., a.a.O., S. $51 \mathrm{f}$

${ }^{7}$ Das Schneiteln trug zur Ausbreitung der Hainbuche stark bei, da sie gegen diese Nutzungsform unempfindlich ist. Vergl. dazu Küster, a.a.O. S 233

${ }^{8}$ vgl. Küster, a.a.O., S. 106

${ }^{9}$ Gradmann, R., Unsere Flusstäler im Urzustand, in: Z. d Ges. f. Edk., Berlin 1932, S.1-17, dort S. 9 f, und Walter, H. , a. a. 0. , S. $51 \mathrm{f}$
} 
pedologischen und hydrographischen Raumstruktur entworfen wurde.

Aufgrund dieser Darstellungsweise wird allerdings die naturräumliche Gliederung des Raumes auch in der Darstellung des wirtschaftlichen Nutzungspotentials sehr deutlich.

Dies ist allerdings nicht verwunderlich, da die naturräumliche Gliederung, auf eben diesen geologisch-hydrographischen Bedingungen und dem Relief gründend, offenbar auch zur Grundlage ${ }^{1}$ des Nutzungspotenzials gemacht worden ist.

Diese Karte könnte eher als Hinweis auf das Wuchspotenzial für die natürliche Vegetation dienen, die sich langfristig an einen Standort anpasst. Die agrarwirtschaftliche Nutzung ist aber - vom Dauergrünland abgesehen - fast ausschließlich auf einjährige Kulturpflanzen ausgerichtet. Für diese hat der jeweilige Witterungsverlauf ebenfalls eine herausragende Bedeutung.

Das (agrarwirtschaftliche) Nutzungspotenzial kann nicht allein aus den geologisch-pedologischen Bedingungen zusammen mit dem Relief abgeleitet werden. Unter den natürlichen Faktoren spielen auch klimatische eine wichtige Rolle, darunter insbesondere die Variabilität von Temperatur und Niederschlag bzw. die Variabilität des jeweiligen Witterungsverlaufs.

Als Beleg für die Wirkung der Niederschlagsvariabilität auf das

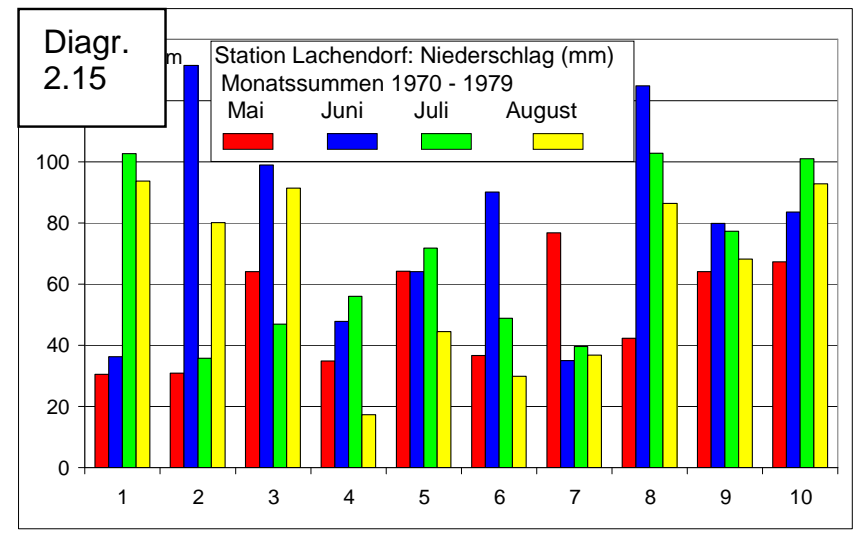
Nutzungspotenzial mögen einige konkrete Beispiele dienen:

\subsubsection{Niederschlag und Nutzungspotenzial}

Beregnungsjahre:

In dem Jahrzehnt von 1970 - 1979 gab es intensive Beregnungsjahre ${ }^{2}$, nämlich die Jahre 1970 und 1971, sowie 1974 - 1976 und $1978^{3}$. Dies deckt sich deutlich mit den Sommerniederschlägen, wie sie im Diagramm 2.15. dargestellt sind. Die Notwendigkeit der Feldberegnung zur Stabilisierung der Ernte ist ebenfalls ein unkalkulierbarer Aufwand, der beim Einsatz mit Kosten für Arbeit, Energie und Wasser verbunden ist und ein kostenintensives ständiges Vorhalten der Beregnungsanlagen voraussetzt.

\section{Milchviehhaltung und Lachteaue:}

So lange die landwirtschaftlichen Betriebe Milchkuhhaltung betrieben, wurde die Aue der Lachte intensiv als Sommerweide genutzt. Trotz ihres geringen Flächenanteils (s. Karte 2.25) war die Talaue ein wichtiger Grünlandstandort, zumal die Allerwiesen $5 \mathrm{~km}$ vom Dorf entfernt sind.

\begin{tabular}{|c|c|c|c|c|c|c|c|c|}
\hline \multicolumn{9}{|c|}{ Tabelle 2.4: Pegel Lachendorf: Lachte, 1961 - 1980} \\
\hline \multicolumn{9}{|c|}{ Pegelstand: $>150 \mathrm{~cm}$ und $<100 \mathrm{~cm}$ : } \\
\hline \multicolumn{9}{|c|}{ Anzahl der Tage im Monat } \\
\hline Jahr & \multicolumn{2}{|c|}{ Mai } & \multicolumn{2}{|c|}{ Juni } & \multicolumn{2}{|c|}{ Juli } & \multicolumn{2}{|c|}{ Aug } \\
\hline $\mathrm{cm}$ & $>150$ & $<100$ & $>150$ & $<100$ & $>150$ & $<100$ & $>150$ & $<100$ \\
\hline 61 & 9 & & 4 & & 2 & 2 & 10 & 0 \\
\hline 62 & 3 & & & & 7 & & 1 & \\
\hline 63 & & 11 & & 31 & & 31 & & 17 \\
\hline 64 & 3 & 12 & & 29 & & 31 & 1 & 17 \\
\hline 65 & 7 & & & 14 & 1 & 7 & & 2 \\
\hline 66 & 3 & & 5 & 12 & 9 & & 2 & \\
\hline 67 & 1 & 4 & 3 & & & 6 & 4 & \\
\hline 68 & 3 & & & 11 & & 16 & & 31 \\
\hline 69 & 3 & & 1 & & & 11 & & 15 \\
\hline 70 & 4 & & & 25 & & 6 & 2 & 6 \\
\hline 71 & & 31 & 3 & 12 & & 24 & 1 & 22 \\
\hline 72 & & 28 & & 19 & & 29 & & 28 \\
\hline 73 & & 27 & & 28 & & 31 & & 31 \\
\hline 74 & & 28 & & 30 & & 18 & & 10 \\
\hline 75 & & 20 & & 30 & & 31 & & 31 \\
\hline 76 & & 25 & & 26 & & 31 & & 31 \\
\hline 77 & & 24 & & 21 & & 26 & & 24 \\
\hline 78 & & 28 & & 29 & & 17 & & 30 \\
\hline 79 & 1 & 7 & 1 & 24 & & 29 & 1 & 18 \\
\hline 80 & & 30 & 3 & 14 & 6 & 4 & & 27 \\
\hline \multicolumn{9}{|c|}{ Quelle: Wasserstandstabellen Pegel Lachendorf } \\
\hline \multicolumn{9}{|c|}{ NLWKN Verden } \\
\hline
\end{tabular}

\footnotetext{
${ }^{1}$ Logisch gesehen liegt hier eine Tautologie vor. Die Aussage der Karte 2. 23 bringt gegenüber den Karten 2.15 und 2.16 eigentlich keine neue Erkenntnis, fasst diese allenfalls unter einem neuen Gesichtspunkt, dem Nutzungspotenzial, zusammen.

${ }^{2}$ Mdl. Mitteilung von Herrn Landwirt Karsten Koch

${ }^{3}$ s. die Nummern 10,11, 14, 15, 16, und 18 in Diagramm 2.14
} 
Diese Nutzung, die großen Einfluss auf die Milchleistung hatte, war stets unsicher, weil es wegen der Niederschlagsvariabilität und dem damit zusammenhängenden Wasserstand der Lachte immer zu Ausuferungen ${ }^{1}$ der Lachte kommen konnte. In diesen Tagen war dann der übliche Weidegang unterbrochen, was zusätzliche Arbeit, mehr Aufwand und weniger Milchleistung zur Folge hatte. Da diese Ausuferungen in allen Weidemonaten (s. Tab. 2.4) sehr unregelmäßig auftraten, führten sie zu einer unkalkulierbaren Beeinträchtigung des Nutzungspotenzials. Werden in der Aue nur Jungrinder gehalten, machen sich diese Tage praktisch nicht bemerkbar, da am Rand der Aue immer trockene Lagerflächen bleiben und kurzfristige Einschränkung im Futterangebot über einige Tage keine sichtbaren Folgen hat

\section{Feldkapazität der Böden \\ Die Wasserspeicherfähigkeit der vorkommenden Bodenarten ist je nach Sand- bzw. Lehmanteil sehr unterschiedlich. \\ Die jeweilige Feldkapazität beeinflusst besonders augenfällig das Nutzungspotenzial am Talhang des Allertales, weil vom oberen Rand zum Hangfuß der Lehmanteil kontinuierlich ab- und der Sandanteil ebenso zunimmt. In längeren sommerlichen}

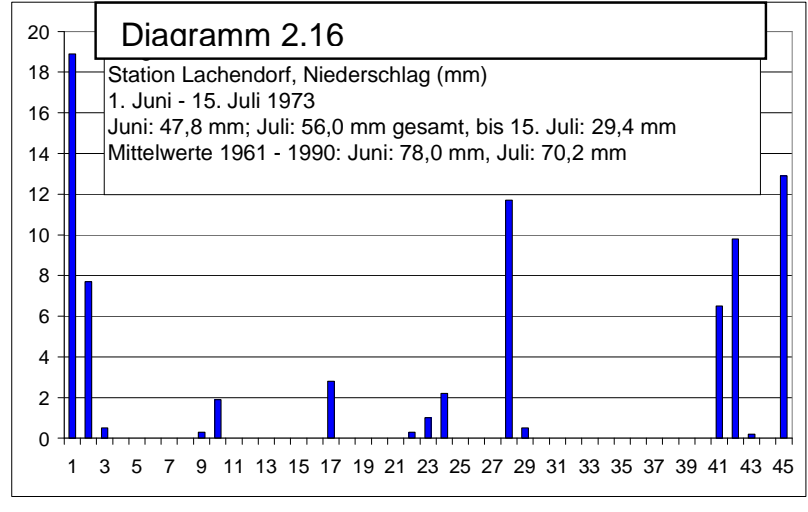
Trockenphasen, wie sie witterungsbedingt immer mal wieder auftreten, kann man dann insbesondere an Hackfrüchten gut sehen, wo das Bodenwasser erschöpft ist: Am Hangfuß ist bereits der permanente Welkepunkt ${ }^{2}$ erreicht, während im oberen Hangabschnitt und auf der Geestkuppe die Pflanzen noch keine Welkeerscheinung zeigen. Die Grenze verläuft ganz scharf hangparallel (s. Abb. 2.20 b).

In Jahren gleichmäßiger Wasserversorgung durch Regen oder Beregnung lassen sich keine Wuchsunterschiede am Talhang erkennen.

Die Wuchsleistung bei optimaler Wasserversorgung im Boden zeigt Abb. 2.16 c: Trotz des Grenzertragsbodens, nämlich Sand mit 17 - 19 Bodenpunkten, ist ein lückenloser, kräftiger Pflanzenbestand möglich.

\section{Bodenerosion}

Starkregen führen dann zur Gefahr der Bodenerosion, wenn der Boden nicht ausreichend durch Vegetation bedeckt ist. Das ist beim Anbau von Hackfrüchten wie Zuckerrüben (s. Abb.: 2.21 a) und auch besonders beim Maisanbau der Fall, wenn die Ackerfläche mehr als 4\% Gefälle aufweist. Diese Voraussetzungen sind z.B. am Talhang des Allertales westlich des Ortes, nördlich der Straße Lachendorf Heideeck ${ }^{3}$, erfüllt. Der Anbau und die Hangneigung sind aber keine hinreichenden Bedingungen für die dort häufig aufgetretene Bodenerosion. Diese wird erst ermöglicht bzw. gefördert durch die Pflugund Ackerrichtung senkrecht zum Hang.

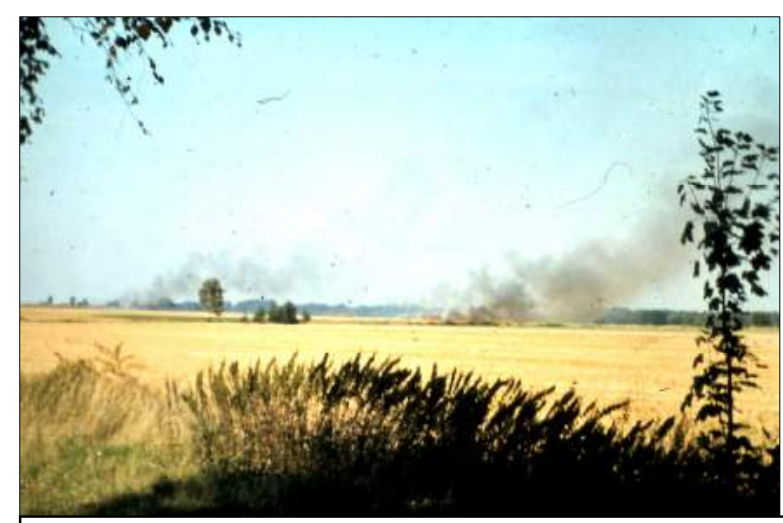

Abb. 2.20 Bodenerosion bei Bodenbearbeitung in spätsommerlicher Trockenphase, Nordkreis Celle auf reinen Sandböden;

Aufn. A. Behr

\footnotetext{
${ }^{1}$ Lt. Mitteilung des Wasserwirtschaftsamtes Celle (1966) kam es bzgl. des alten Pegelstandortes (1961 - 1989) ab $150 \mathrm{~cm}$ Pegelstand (Tagesmittelwert) zu Ausuferungen.

2 Diese Erscheinung konnte vom Verf. mehrfach beobachtet werden.

${ }^{3}$ Dieser Bereich ist heute vollständig als Gewerbegebiet genutzt und weitgehend überbaut.
} 


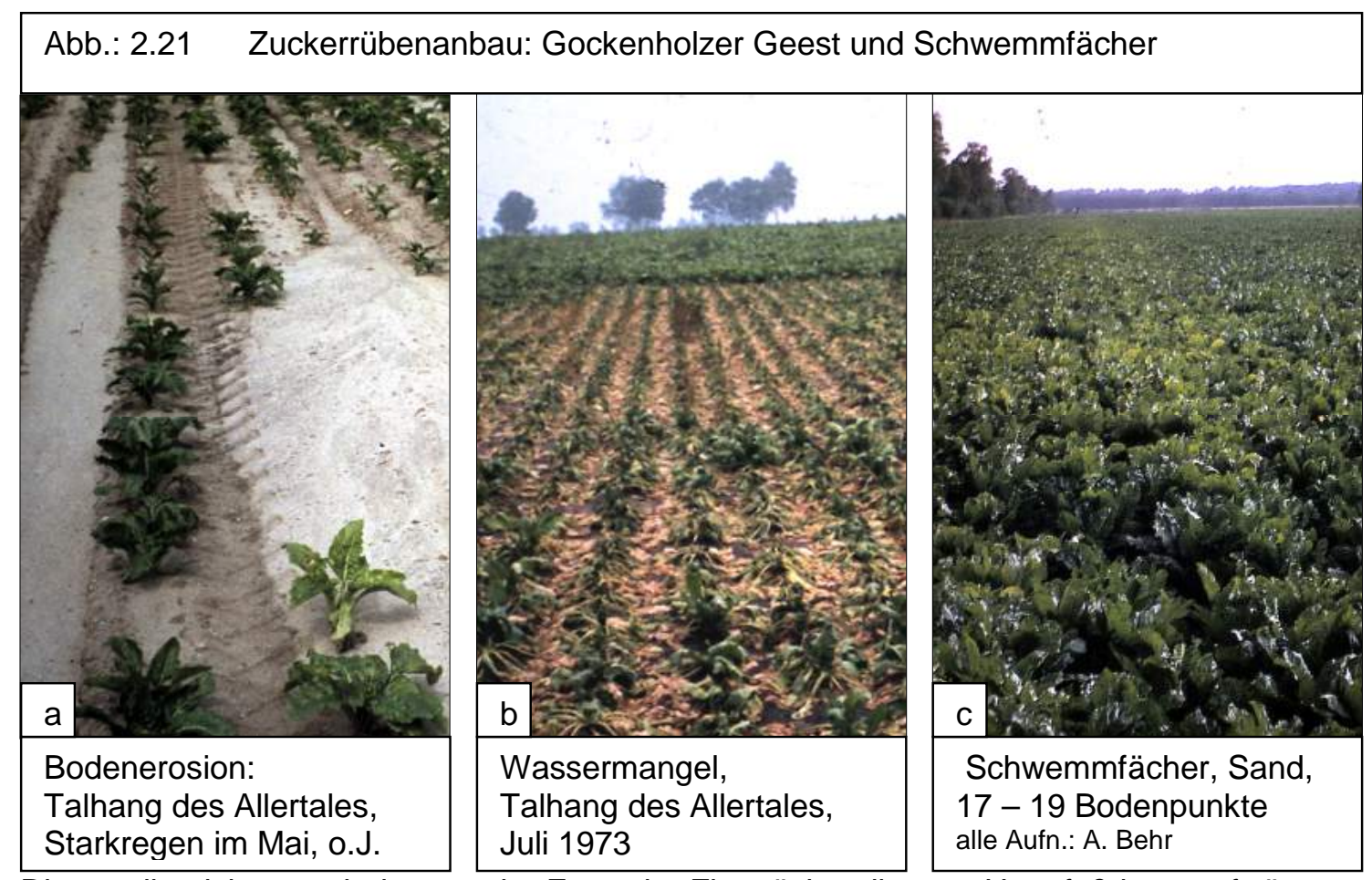

Dies ergibt sich nun wieder aus der Form der Flurstücke, die vom Hangfuß hangaufwärts zur Geestkuppe verlaufen und so schmal sind, dass ein hangparalleles Pflügen und Ackern nicht möglich ist. Die Einteilung des Hanges in parallele, senkrecht zum Hang verlaufende Nutzparzellen ist vorgenommen worden aus Gründen der Bodeneigenschaften. So verläuft jede Nutzparzelle von den reinen Sandböden am Hangfuß zu den Lehmböden der Geestplatte. Eine hangparallele Einteilung in Nutzparzellen hätte dazu geführt, dass Eigentümer am oberen Rand nur Lehmböden und am unteren Rand nur Sandboden zum Anbau zur Verfügung gehabt hätten. Die Anlage der Flurstücke in Richtung des Gefälles über die gesamte Bodencatena ist Folge einer „gerechten“ Verteilung der natürlichen Bodenfruchtbarkeit auf die verschiedenen Nutzer. Damit hat man aber beste Voraussetzungen für Bodenerosion geschaffen. Wäre der gesamte Hang eine einzige Nutzparzelle gewesen, hätte man stets hangparallel pflügen und ackern können, was unabhängig von der Feldfrucht die Bodenerosion bereits weitgehend verhindert hätte.

Die aktuelle Gefahr der Bodenerosion ist aber in jedem Jahr von der Höhe und insbesondere von der Verteilung und der Art der Niederschläge abhängig. Jahre wie 1973 sind wegen der geringen Niederschläge, die auch noch sehr ungleichmäßig verteilt waren und teils als Starkregen niedergingen, besonders hinsichtlich der Bodenerosion auf allen Flächen mit entsprechender Hangneigung und unzureichender Vegetationsdecke gefährdet.

Bodenerosion durch Wind ist im Lachendorfer Raum äußerst selten, weil die Flur aufgrund der Strukturierung keine großen Nutzparzellen zulässt und die Landschaft durch Baumgruppen, -reihen, Gehölze gut aufgelockert ist. Die freiesten Flächen auf den Geestkuppen haben, anders als Ackerflächen im Nordkreis, keine reinen Sandböden sondern lehmige und anlehmige Sande, die weniger anfällig gegen äolische Bodenerosion sind.

\subsubsection{Wandel des Nutzungspotenzials}

Das agrarwirtschaftliche Nutzungspotenzial bestimmen aber noch zwei weitere Faktoren: Zum einen sind es die dauerhaften und auch die regelmäßigen Eingriffe in den Naturhaushalt, zum anderen sind es die Agrarverfassung zusammen mit dem Stand der Agrarwissenschaft und der Agrartechnik. 
Die Abhängigkeit der landwirtschaftlichen Nutzung allein von den von der Natur vorgegebenen Bedingungen hat sich im Laufe der Agrargeschichte lange Zeit nur unwesentlich verändert.

Im 19. Jahrhundert trat dann für das Verhältnis zwischen den lange als unabänderlich gehaltenen Naturbedingungen und den anthropogenen Möglichkeiten ein Paradigmenwechsel ein, der durch die Kurve der Ertragsentwicklung bei Weizen gut dokumentiert wird: Der Name Mendel steht für die Begründung der Vererbungslehre und damit der systematischen Pflanzenzüchtung, der Name Liebig für die Begründung der Pflanzenernährung und damit für die mineralische Düngung und der Name Schlüter als Beispiel für die Pioniere der Landtechnik. Hier muss auch der Name Albrecht Thaer ${ }^{1}$ unbedingt hinzugefügt werden, der die Grundlagen für die moderne Agrarwissenschaft legte und z.B. den Fruchtwechsel erfolgreich propagierte.

Zur wissenschaftlich-technischen Entwicklung, die diesen Paradigmenwechsel in der Agrarwirtschaft zum ungeahnten Erfolg führte, gehören aber auch die gesellschaftlichen und politischen Rahmenbedingungen, auf deren Bedeutung später noch eingegangen wird.

Zu den dauerhaften Eingriffen in den Naturhaushalt, die das Nutzungspotenzial verändern, zählen insbesondere Wasserbaumaßnahmen, im hier betrachteten Raum die Maßnahmen zur Aller- und Schwarzwasserregulierung. Dazu wird hier auch die Anlage von Stauwiesen gezählt, da sie als Dauerlösung geplant und umgesetzt wurde, wenngleich die Entwicklung der Agrarwirtschaft wieder zu deren Auflassung geführt hat. Beide Bereiche werden in späteren Kapiteln ausführlich behandelt.

Zu den regelmäßigen, teilweise auch sporadischen, Eingriffen in das Naturpotenzial gehören die mineralische Düngung, die seit dem Beginn dieser Düngung mit Mergel und Guano im 19. Jhd. im Zusammenspiel mit den verschiedenen Böden eine zentrale Rolle für das Nutzungspotenzial spielt. Dazu gehört aber auch die künstliche Beregnung bei unzureichenden Niederschlägen in der Wachstumsphase der Kulturpflanzen.

Die Möglichkeiten heutiger Agrarwirtschaft führen teils zu verändertem Nutzungspotenzial und teils zu einer Neubewertung des sog. natürlichen Nutzungspotenzials. Ein Beispiel dafür sind die leichten Böden, deren Fruchtbarkeit durch Bodenpflege, Düngung und Beregnung dauerhaft verbessert werden kann und deren gute Bearbeitbarkeit bei fast jedem Wetter dann das Nutzungspotenzial zusätzlich erhöht.

$\mathrm{Zu}$ einer Neubewertung des natürlichen Nutzungspotenzials kommt es aber auch durch die Einführung neuer Kulturpflanzen. So hat beispielsweise der Anbau der Kartoffel seit dem 19. Jhd. zu einer deutlichen Neubewertung des Nutzungspotenzials der leichteren Böden geführt. Gegenwärtig führt die Möglichkeit des gewinnbringenden Anbaus von (Energie)-Mais zu einer Neubewertung von Böden, die noch vor wenigen Jahrzehnten als dauerhafte Grünlandstandorte galten.

Gerade die beiden letzten Beispiel zeigen, dass das natürliche Nutzungspotential wenn nicht in der Substanz so doch in der

Abb. 2.22: Ertragsentwicklung bei Weizen

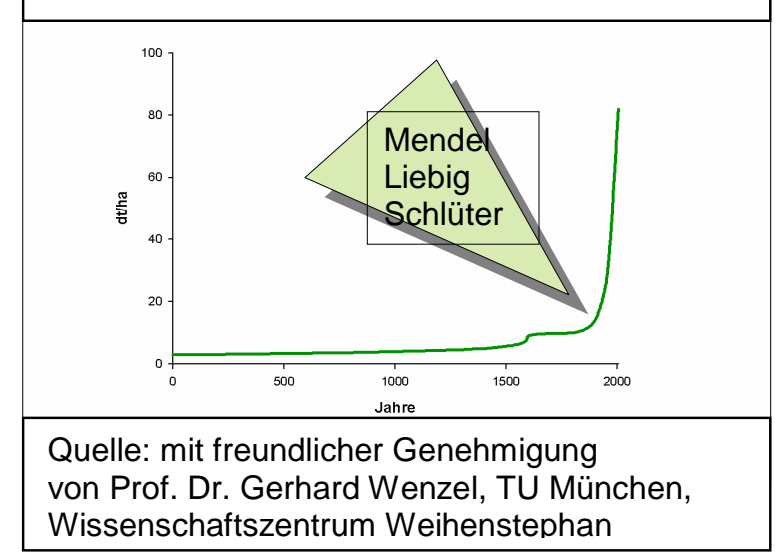
Bewertung - von Möglichkeiten der Agrartechnik einerseits und sogar von Rahmenbedingungen der Agrarpolitik abhängen.

Neben den reinen Naturbedingungen sind heute Maßnahmen des Landschaftsbaus und der modernen, technisch-wissenschaftlich basierten und marktwirtschaftlich orientierten Land-

\footnotetext{
${ }^{1}$ s.a. K. Panne (Hrsg.); Albrecht Daniel Thaer, Der Mann gehört der Welt, Celle 2002
} 
wirtschaft in hohem Maße für die Ausgestaltung unserer Kulturlandschaft bzw. deren Wandel verantwortlich.

Diesem Zusammenspiel natürlicher und anthropogener Faktoren, das unsere Kulturlandschaft prägt, wird in den folgenden Kapiteln nachgespürt.

Kap. 3: Landschaft und Landwirtschaft vor 1850 


\section{Kapitel 3 Landschaft und Landwirtschaft vor 1850}

\subsection{Das Landschaftsbild um 1800 im zeitgenössischen Kartenbild}

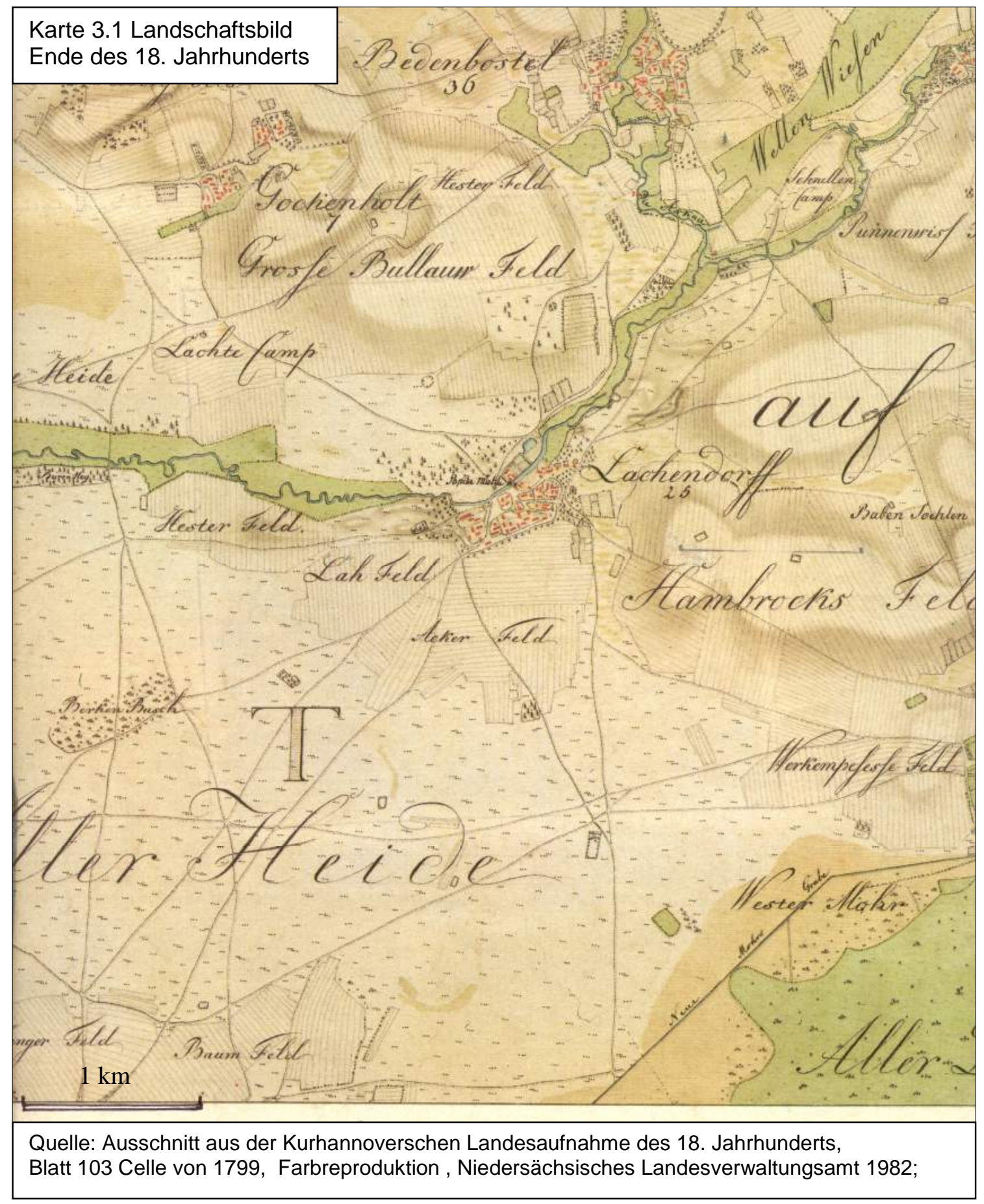

Die Kurhannoversche Landesaufnahme, die Ende des 18. Jahrhunderts von Offizieren des Hannoverschen Ingenieurscorps angefertigt worden ist, bietet einen verlässlichen und genauen Einblick in das zeitgenössische Landschaftsbild. 


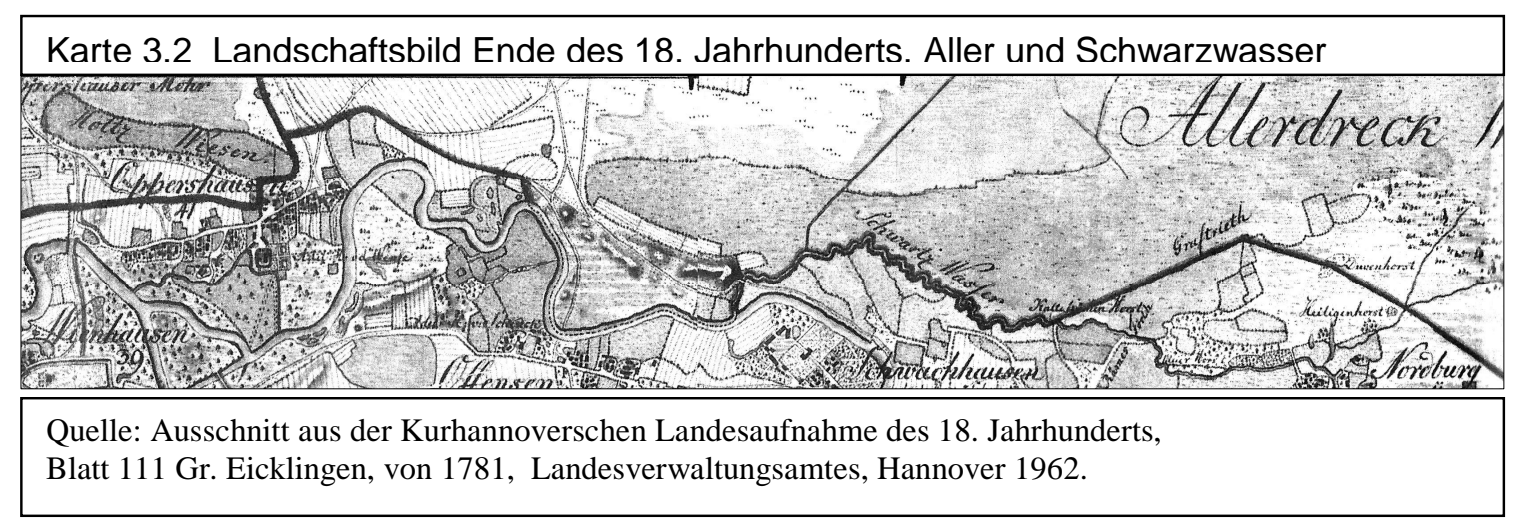

Der Lachendorfer Raum, dargestellt auf den Kartenblättern ${ }^{1}$ Celle und Gr. Eicklingen, ist gekennzeichnet durch eine deutliche Raumgliederung: Ackerkämpe mit einer Langstreifenflur umgeben den Ort, haben aber ihren Schwerpunkt nördlich und nordöstlich des Ortes beiderseits des Lachtetales. Besonders markant ist südöstlich des Ortes die große Heidefläche auf der Allerheide, die im Westen und Osten von Brüchen und Mooren sowie im Süden von Ackerkämpen des Ortes Oppershausen an der Aller eingerahmt wird.

Diese historische Karte gibt genaue Auskunft über das Landschaftsbild und indirekt auch über die damalige Nutzung.

Die Karten ${ }^{2}$ zur Generalteilung der Allerheide sowie zur Verkoppelung der Feldmark von Lachendorf und der Aller- und trockenen Wiesen belegen, dass sich die Landnutzung bis zu den Reformjahren von 1850 bis 1866 nicht verändert hat.

\subsubsection{Gewässer}

\section{Eingriffe in das Gewässernetz}

Die Flussläufe selbst befanden sich um 1800 noch überwiegend in einem natürlichen oder naturnahen Zustand, wie die vielen Mäander ${ }^{3}$ der Lachte und der Aller zeigen.

Auch die Unterläufe von Lachte und Schwarzwasser als rechte Nebenflüsse der Aller zeigen beide im Aller-Urstromtal den typischen Verlauf einer stromabwärts verschleppten Mündung.

Jeder Fluss lagert im natürlichen Zustand bei Hochwasser beiderseits des Flussbettes im Überschwemmungsbereich Sedimente ab. Dies geschieht in Abhängigkeit von der Fließgeschwindigkeit und der mitgeführten Sedimentfracht. Da beim Ausufern eines Flusses unmittelbar am Rand des Flussbettes die Fließgeschwindigkeit sprunghaft abnimmt, erfolgt hier entlang des Flusses die stärkste Sedimentation, es bilden sich also Uferwälle.

Durch diese Sedimentation werden die Mündungen der Nebenflüsse talabwärts abgedrängt. So kommt es zu verschleppten Mündungen, sodass in großen Tälern Nebenflüsse über gröBere Distanzen fast parallel zum Hauptfluss fließen und deshalb beim Einmünden in das Haupttal eine auffällige Richtungsänderung vornehmen.

Aber es hat schon vor 1800 deutliche Eingriffe in die Hydrologie gegeben:

Der „Neue Mohr Graben“, heute Ahnsbecker Kanal, war bereits angelegt. Er diente, wie man aus dem Verlauf schließen kann, bis heute der Entwässerung eines Trockentales in der Geestplatte östlich von Ahnsbeck, musste aber zur Gewährleistung einer ausreichenden Vorflut an den Dreckwiesen vorbei bis zum Schwarzwasser geführt werden. Ebenso war bereits ein kleinerer Entwässerungsgraben am Südrand der Allerdreckwiesen angelegt, der „Gruftrieth“ nordwestlich von Nordburg, auch zum Schwarzwasser entwässernd.

\footnotetext{
${ }^{1}$ Kurhannoversche Landesaufnahme, Blatt 103 Celle von 1779 und Blatt 111 Gr. Eicklingen von 1781, herausgegeben vom Nieders. Landesverwaltungsamt - Landesvermessung;

Karte 3.1 zeigt den nördlichen Teil aus Blatt 103 und Karte 3.2 den südlichen Teil aus Blatt 111.

${ }^{2}$ Karte von der Allerheide, Charte der Feldmark Lachendorf und von den Aller- und trockenen Wiesen, a.a.O

${ }^{3}$ ebd. und Blatt 111, Gr. Eicklingen
} 
Den Schelpriethgraben ${ }^{1}$, der später ein entsprechendes Trockental östlich von Lachendorf entwässerte, gab es dagegen noch nicht.

\section{Aller und Oker}

Natürlicherweise bestimmt die Oker ab der Mündung in die Aller das Abflussregime der Mittelaller.

Das Abflussregime der Oker wird aber durch das Einzugsgebiet im Harz bestimmt. Durch die Oker-Hochwässer wurden immer wieder die Ortschaften und Ländereien im Flotwedel bedroht. Die Sedimentfracht der Oker hatte aber auch in Flutmulden des Aller-Urstromtals lehmige und schluffige Ablagerungen hinterlassen, die als fruchtbares Grünland einen hohen Nutzwert hatten und schon früh eine intensive Viehwirtschaft aufgrund dieser natürlichen Futterbasis ermöglichten.

Diese damals sehr positiven natürlichen Bedingungen konnten nur dann besser genutzt werden, wenn man die Überschwemmungsgefahr durch das Okerwasser aus dem Harz wenigstens eindämmte. Diese Überlegungen zum Nutzwert im Überschwemmungsgebiet entlang der Oker ab ihrer Mündung in das Urstromtal südlich von Meinersen stützen die Theorie ${ }^{2}$, dass die Okermündung bereits im Mittelalter verlegt wurde. Von der Einmündung ins Urstromtal wurde ein direkter Zufluss nach Norden zur Aller mit der Mündung bei Müden/Aller geschaffen und die ehemals auch hier vorhandene stark verschleppte Mündung beseitigt, die bei Bockelskamp ${ }^{3}$ westlich von Wienhausen gelegen haben könnte.

Möglicherweise war auch die Verbesserung der Schiffbarkeit ${ }^{4}$ auf der Mittelaller aufgrund der größeren Wasserführung durch das zusätzliche Okerwasser ein, vielleicht auch der bestimmende Grund für die Verlegung der Okermündung.

Sicherlich war aber der Gewinn an fruchtbarem Weideland und Bruchwald mit viel Weichbzw. Laubholzarten eine sehr willkommene Verbesserung für die landwirtschaftliche Nutzung im Flotwedel. Der für die damalige Landwirtschaft typische und oft chronische Mangel an Viehfutter machte es nötig, nicht nur Gräser und Kräuter der Naturweiden sondern auch die Laubbäume zu nutzen.

Die Mittelaller war schon um 1800 sehr stark verändert, durch einige Begradigungen und insbesondere durch den Mühlenkanal südlich der Aller zwischen Langlinger Schleuse und Wienhausen.

\section{Lachte}

Auch an der Lachte hat es vor 1850 bereits Eingriffe gegeben, nämlich direkt oberhalb und auch unterhalb der Papierfabrik, die hier seit $1538^{5}$ produziert. Die Lachte war für die Papiermühle, wie es früher hieß, in zwei Arme aufgespalten und der eine Arm mit einem Wehr versehen.

Die Kartierung 1852 macht aber sehr deutlich, dass der Flussverlauf oberhalb und unterhalb des Ortes noch sehr stark mäandrierte und sogar größere Altwässer erhalten waren. Das Grünland in der Aue hat sich als sehr stabiles Element der Kulturlandschaft erwiesen, wurde es doch bis in die 2. Hälfte des 20. Jahrhunderts völlig unverändert und überwiegend auch heute noch genutzt. Zwischen dem Grünland der Aue in den „Alten Wiesen“ und „im Bunger“ setzten die Wiesen aus und Ackerstreifen bzw. Heide reicht bis an den Flusslauf heran. Dies hat sich bis zur Kartierung 1966 und teilweise ebenfalls bis heute erhalten.

Schwarzwasser Der stark verschleppte Unterlauf des Schwarzwassers zeigt auf der Kurh. Karte von 1781 und auch auf der Karte von A. Papen von 1839 zwischen Nordburg und der Mündung in die Aller einen sehr stark mäandrierenden Verlauf. Offenbar wurden die Abflussverhältnisse als sehr schlecht beurteilt, denn im Rahmen der Verkoppelung der Aller- und Trockenen Wiesen wurde eine Begradigung vorgenommen. In $\S 6$ des Rezesses von 1866 werden die Flächen nachgewiesen, die zur "Correction des Schwarzwasserflusses" abgetre-

\footnotetext{
${ }^{1}$ s. Kap. 2.2.6

${ }^{2}$ s. Seiler, Chr., Die Aller - ein Fluss verändert seinen Lauf, Celle 2002, S. 16 und 45

${ }^{3}$ ebenda, S. 45

${ }^{4}$ ebd.

${ }^{5}$ Der Speicher, Celle 1930, Nachdruck von 1990, S. 514
} 
ten werden mussten. Die Karte von 1961 zum Rezess über die Aller- und trockenen Wiesen verdeutlicht dieses Vorhaben. Die Karte der Preußischen Landesaufnahme von 1899 belegt dann auch die Flussregulierung mit dem vollständig geglätteten Flussverlauf im Vergleich zu den älteren Kartendarstellungen.

\subsubsection{Brüche und Moore}

Die Randmoore und Brüche im Urstromtal treten sehr deutlich als

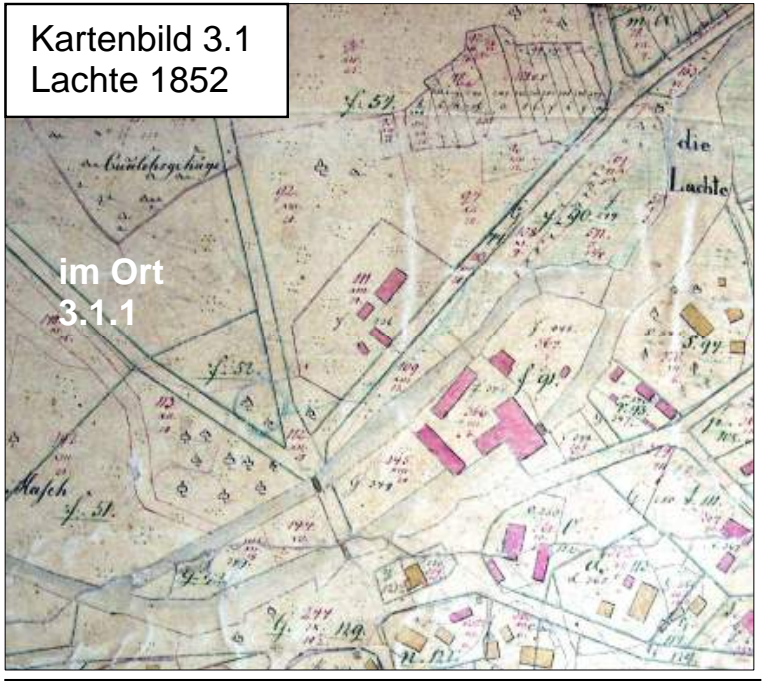

Quelle: Charte von der Feldmark Lachendorf, 1852, Ausschnitte

Aufnahmen und Bearbeitung: A. Behr
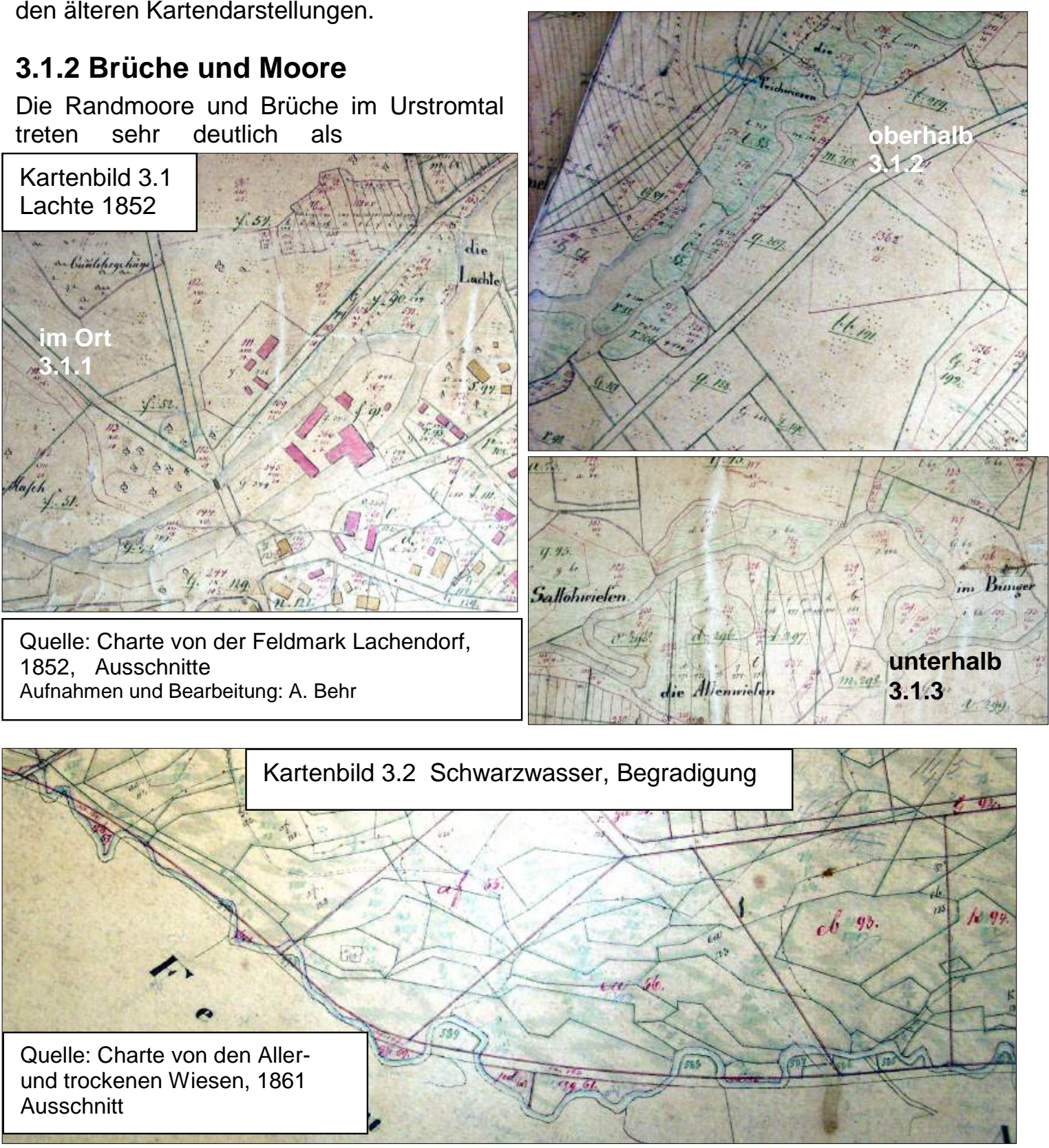

eigenständiges Landschaftselement hervor. Namen wie Wester Mohr $^{1}$ am Rand der Allerdreckwiesen, Osterbruch Wiesen südlich vom Osterbruch Mohr und Busch Mohr nördlich des Schweinebruches sowie der Flurname Postmoor am Westrand der Lachendorfer Gemarkung sind Zeugnisse des Landschaftsbildes einerseits und der landwirtschaftlichen Nutzung andererseits.

Diese Randmoore im Urstromtal sind überwiegend durch Niedermoor und am Rande durch anmoorige Bodenauflage gekennzeichnet. Da es sich nicht um Hochmoore handelt, waren sie sicherlich schon seit dem Mittelalter in die landwirtschaftliche Nutzung mit einbezogen.

\footnotetext{
${ }^{1}$ Schreibweise auf der Kurhann. Landesaufnahme
} 
So entsprechen denn auch die Brüche in den Allerdreckwiesen ${ }^{1}$ und im Schweinebruch ${ }^{2}$ in ihrer Ausdehnung den natürlichen Randmooren im Aller-Urstromtal. Sie werden auf der Kurhann. Karte von 1779 durch die auffällige Grünfärbung sowie durch Busch- und Baumsignatur als Bruchwiesen hervorgehoben.

Sicherlich gab es noch eine naturnahe Vegetation bzgl. des Artenspektrums. Aber der Name Allerdreck-Wiesen bestätigt ganz klar, dass es sich auch hier um Kulturland handelte, das der Futterversorgung für das Nutzvieh diente.

Also war auch in den Brüchen die Natur durch Weide und Mahd stark überformt und in eine Kulturlandschaft umgewandelt. Die Signaturen auf den Bruchwiesen bestätigen, dass es sich nicht um reines Grünland gehandelt hat, sondern um eine Art Waldweide, einer halboffenen Weidelandschaft mit standorttypischen Bäumen und Sträuchern, die heute auf viele Betrachter den Eindruck einer natürlichen Landschaft (Parklandschaft) vermitteln würde.

Ein vermutlicher Rest, mindestens im Erscheinungsbild, war noch bis in die 60er Jahre des 20. Jahrhunderts am Rande der Allerdreckwiesen zu betrachten: Eine Weide mit einzelnen Bäumen und größeren Flächen mit Sträuchern, darunter der Gagelstrauch. Diese Vegetation entspricht einer wenig gepflegten „Naturweide“, auf der sich die Vegetation der Beweidung einerseits anpasst und andererseits Formen der negativen Weideselektion auftreten, weil das Weidevieh bestimmte Pflanzen meidet, hier den standorttypischen Gagelstrauch.

Bei einer Nutzung als ungepflegte Waldweide ist das Artenspektrum naturbedingt eine Folge der natürlichen Standortbedingungen, die Häufigkeitsverteilung im Artenspektrum aber kulturbedingt eine Folge der Nutzung.

Die Bruch- und Niedermoorgebiete auf den Randmooren des Urstromtales können um 1800 als naturnahe Weideareale, also Elemente der Kulturlandschaft bezeichnet werden. Aus dem urkundlich belegten Streit ${ }^{3}$ um die Holznutzung im Kammerwinkel muss man folgern, dass auch Reste des ursprünglichen Bruchwaldes durch Nutzung ebenfalls stark überformt waren, also eher den Anblick von Hude- als von Urwald boten.

\subsubsection{Lachtetal}

Das Lachtetal oberhalb des Ortes ist auf der Kurhann. Landesaufnahme von 1779 kartographisch gut erkennbar dargestellt durch die deutliche Schummerung ${ }^{4}$ der Talhänge, die Lachteterrasse beiderseits der Talaue und den mäandrierenden Flusslauf.

Das gesamte Tal ist vollständig als Kulturland ausgewiesen, allerdings standorttypisch dreigeteilt:

Die sanften Talhänge zu den lehmigen Grundmoränenplatten sind Ackerland, die trockenen Standorte auf den schmalen Terrassenflächen des Lachtetales zwischen Grundmoränenplatte und Talaue Heideflächen und die Talaue ist als Grünland gekennzeichnet.

Der Ausschnitt (Kartenbild 3.1.2) aus der Karte von 1850 bestätigt diese Nutzungsstruktur: Im Nordwesten reichen die Ackerstreifen bis an den Auenrand und östlich der Aue sind keine Ackerstreifen vorhanden. Beides belegt die deutliche naturräumliche Anpassung: Im Nordwesten reicht die Bunkenburger Geestplatte bis an die Aue und im Osten erstreckt sich bis zum Talrand die Lachteterrasse mit mageren Sandböden, die erst jenseits des Jarnser Weges in besseres Land am Rand der Bunkenburger Geestplatte mit Ackerstreifen ${ }^{5}$ übergehen. Die Flussaue war ebenfalls bereits vor 1850 nicht mehr in einem Naturzustand, denn die natürlichen Bruchwälder waren längst in Grünland ${ }^{6}$ umgewandelt. Angesichts der Futternot für das Nutzvieh in der damaligen Wirtschaftsweise konnten die Bauern auch auf keinen Standort zur Grünlandnutzung verzichten, der auch nur annähernd dafür geeignet war.

\footnotetext{
${ }^{1}$ Allerdreckwiesen : östlich der Allerheide, südlich von Ahnsbeck, Blatt 103 Celle

${ }^{2}$ Schweinebruch: rechts der Lachte unterhalb Lachendorfs, nördlich der Sprache, Blatt 103 Celle

${ }^{3}$ Streit um Holzhieb im Kammerwinkel, Actum Amtsvogtei Beedenbostel vom 27.April 1843, unveröffentl. Akte, Gemeindeverwaltung Lachendorf, s.a. Kap. 3.4.3

${ }^{4}$ s. Kurhann. Landesaufnahme, Blatt 103 Celle

${ }^{5}$ Diese Ackerstreifen werden auf der Karte 3.1.2 gerade noch auf der unteren rechten Ecke angeschnitten.

${ }^{6}$ s. Kartenbild 3.1
} 


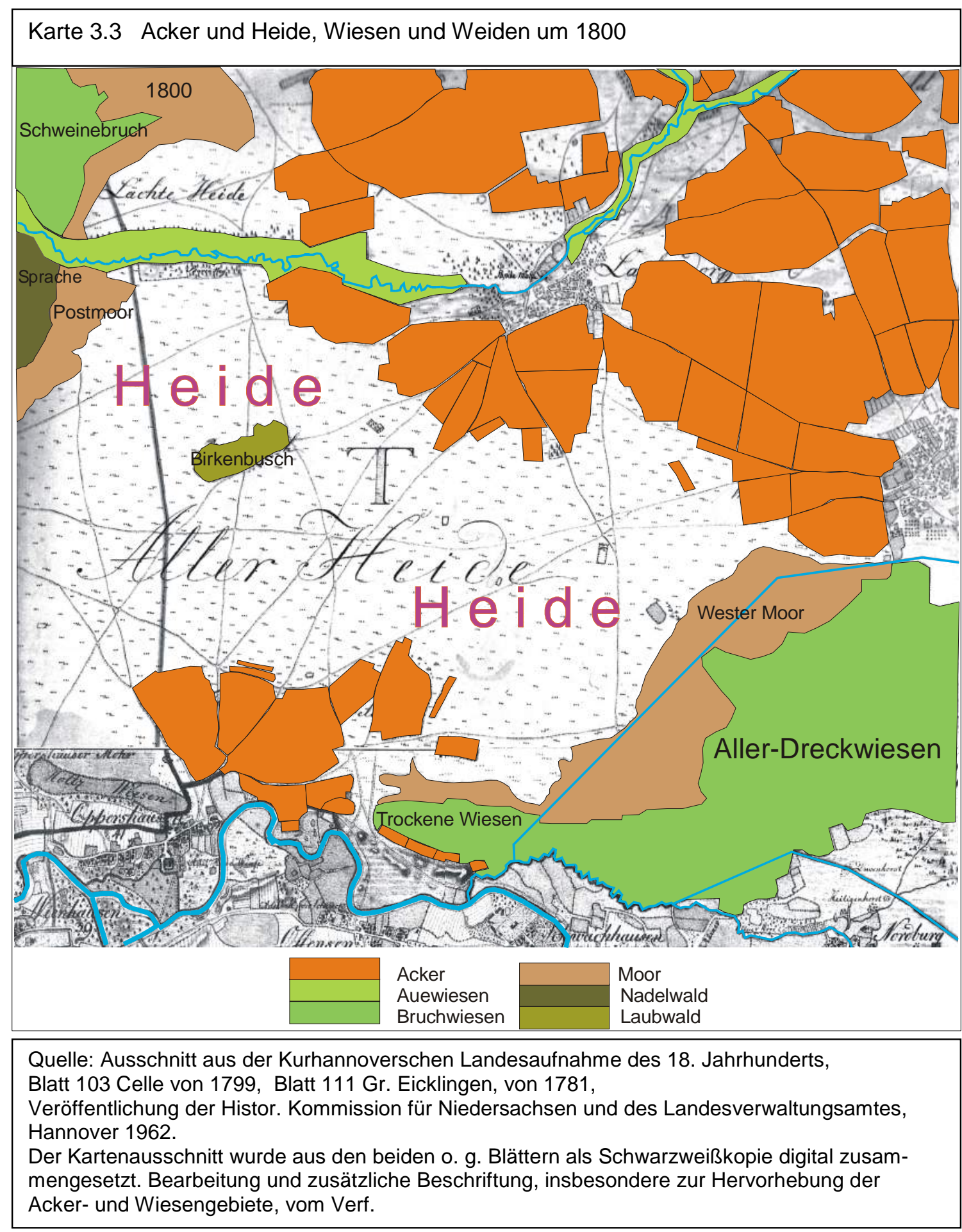

Der natürliche Überschwemmungsbereich der Lachte bot in Dorfnähe das beste und sicherste Grünland. Der geringe Flächenanteil machte es allerdings nötig, auch die weit entfernten Bruchwiesen, die Allerdreckwiesen zu nutzen.

Die Karte von der Feldmark Lachendorf, die 1852 zur Taxation der Landschaft und zur Vorbereitung der Verkoppelung angefertigt wurde, bestätigt das von der Kurh. Landesaufnahme vermittelte Landschaftsbild. 


\subsubsection{Geestplatten bzw. Grundmoränenplatten}

Die leicht kuppigen Geestflächen mit anlehmigen und lehmigen Böden sind durchweg auf der Kurhann. Landesaufnahme als Ackerland ausgewiesen. Der Rand des AllerUrstromtales mit seinem leichten, aber markanten Geesthang markiert zwischen Ahnsbeck und Alvern auch deutlich den südlichen Rand des Ackerlandes.

Die Lachendorfer Gewanne mit Ackerland liegen alle in unmittelbarer Dorfnähe, vor allem auf der Gockenholzer Geestplatte im Nordwesten und der Bunkenburger Geestplatte im Nordosten, außerdem unmittelbar südlich des damaligen Ortes in der Wurzelzone des Schwemmfächers sowie westlich des Dorfes auf dem Westerfeld. Damit lag der Schwerpunkt auf den lehmigen Böden zweier Grundmoränenplatten der Mittleren Südheide.

Vermutlich wegen der Begrenztheit dieser lehmigen Böden wurden auch Ackergewanne auf dem Schwemmfächer angelegt, aber nur in unmittelbarer Nähe zu den Höfen. Der Acker auf dem Westerfeld südlich der Lachte rechtfertigt sich auch aus heutiger Sicht, weil dort sogar 24 - 33 Bodenpunkte ${ }^{1}$ erreicht werden.

Das Ackerland passte sich damals den natürlichen Bedingungen im Bereich der Geestplatten sehr eng an: Die Talformen in der Grundmoränenplatte waren entlang der Tiefenlinie zwischen den Flurstücken von Ackernutzung ausgenommen. Die Kurhann. Landesaufname weist diese nicht als Acker genutzten Streifen in den Talböden von Trockentälern als teils trockene und teils moorige Heide aus.

$\mathrm{Da}$ es sich um recht feuchte Standorte handelt, kann geschlossen werden, dass bis zur Umwandlung in Grünland die Feuchtigkeit liebende Erikaheide (erica tetralix) reichlich vorkam, während auf dem trockenen Schwemmfächer und auf der Lachteterrasse die Besenheide (calluna vulgaris) die Landschaft prägte.

Diese Deutung entspricht auch der alten Weisheit und Standortkenntnis der Heidebauern, die besagt, dass man Doppheide (Erica-Heide), wie Pfeifengras ein Standortanzeiger für Grundfeuchte, zu Grünland machen kann. Diese, meist sehr schmalen, Grünlandstreifen entlang der Tiefenlinien von Trockentälern gab es bis nach $1966^{2}$.

Beispiele dafür sind die Trockentäler östlich des Dorfes, südlich vom Punnewisch Feld und im südöstlichen Teil vom Großen Bullauer Feld (heute: Im Bulloh) sowie der südwestliche Rand vom Hambrocks Feld auf der Geestplatte zwischen Lachendorf und Ahnsbeck.

Die Kurhan. Landesaufnahme (s. Karte 3.1 und 3.3), auf der die Ackerkämpe bzw. Gewanne mit den Ackerstreifen als Signaturen dargestellt sind, vermittelt den Eindruck, dass die Geestplatten (Gockenholzer und Bunkenburger Geest) außer in den Trockentälern komplett als Ackerland genutzt wurden. Die Verkoppelungskarte von 1852 zeigt dagegen ein etwas differenzierteres Nutzungsgefüge. Für einen Ausschnitt aus der Bunkenburger Geestplatt und dem westlich anschließenden Lachtetal mit den Flurstücken Osteraden, Rischkamp, Melmau und Hohenkamp (s. Kartenbild 4.3) zeigt die Tabelle zwar erwartungsgemäß überwiegend Ackerland, aber auch Wiesen-, Anger und Heidboden.

So wird im Vermessungsregister ${ }^{3}$ der Osteraden

\begin{tabular}{|c|c|c|c|c|c|c|c|}
\hline \multicolumn{2}{|r|}{ Tabelle 3.0} & \\
\hline \multicolumn{4}{|c|}{ Landnutzung auf der Bunkenburger Geest 1852} & & & & \\
\hline $\mathrm{Nr}$ & Boden & M & QR & $\mathrm{Nr}$ & Boden & $\mathrm{M}$ & QR \\
\hline 58 & Ackerland & 2 & 72 & 104 & Angerboden & & 79 \\
\hline 59 & Ackerland & 2 & 19 & 482 & Angerboden & 14 & 8 \\
\hline 60 & Ackerland & & 111 & 483 & Angerboden & 6 & 100 \\
\hline 156 & Ackerland & 21 & 7 & 487 & Angerboden & 5 & 60 \\
\hline 318 & Ackerland & 17 & 85 & 515 & Angerboden & 15 & 106 \\
\hline 394 & Ackerland & 4 & 104 & 516 & Angerboden & 4 & 62 \\
\hline 440 & Ackerland & 102 & 51 & 518 & Angerboden & & 54 \\
\hline 441 & Ackerland & 12 & 1 & 531 & Angerboden & 1 & \\
\hline 504 & Ackerland & 19 & 85 & 535 & Angerboden & & 62 \\
\hline 505 & Ackerland & 2 & 66 & 543 & Angerboden & 5 & 86 \\
\hline 506 & Ackerland & 3 & 40 & 545 & Angerboden & & 45 \\
\hline 508 & Ackerland & 1 & 75 & 547 & Angerboden & & 46 \\
\hline 509 & Ackerland & 37 & 41 & 549 & Angerboden & & 50 \\
\hline 510 & Ackerland & 2 & 13 & 552 & Angerboden & 5 & 1 \\
\hline 511 & Ackerland & 6 & 89 & 556 & Angerboden & 3 & 83 \\
\hline 512 & Ackerland & 45 & 30 & 575 & Angerboden & & 104 \\
\hline 513 & Ackerland & 1 & 112 & 514 & Heidboden & 5 & 62 \\
\hline 538 & Ackerland & 2 & 12 & 519 & Heidboden & 12 & 50 \\
\hline 539 & Ackerland & 1 & 76 & 542 & Heidboden & & 88 \\
\hline 540 & Ackerland & 1 & 100 & 544 & Heidboden & 6 & 15 \\
\hline 541 & Ackerland & 2 & 20 & 554 & Heidboden & 4 & 78 \\
\hline 536 & Wiesenboden & 2 & 20 & 558 & Heidboden & & 83 \\
\hline 546 & Wiesenboden & 2 & 8 & 565 & Heidboden & 49 & 97 \\
\hline 548 & Wiesenboden & 1 & 3 & Que & & & \\
\hline 550 & Wiesenboden & 1 & 8 & Clas & sifikationsreg & iste & \\
\hline 557 & Wiesenboden & 1 & 58 & Sign & 1. $61 / 9$, Geme & inde & \\
\hline 560 & Wiesenboden & & 84 & & ite von der $\mathrm{Fe}$ & $\mathrm{dm}$ & \\
\hline 576 & Wiesenboden & 11 & 68 & Lach & nendorf, 1852 & & \\
\hline
\end{tabular}

\footnotetext{
${ }^{1}$ Auf dem heutigen Westerkamp, s. Flurkarte von Lachendorf

2 s. Nutzungskartierung von 1966 durch den Verf.

${ }^{3}$ Taxations- und Vermessungs-Register von 1852, Samtgemeinde Lachendorf, Sign. 61/5
} 
auf der Bunkenburger Geest östlich des Lachtetales als gutes Ackerland ausgewiesen, die westlich anschließende Terrasse des Lachtetales, die Melmau, aber überwiegend als Heide klassifiziert.

Die Ackerkämpe boten also kein einheitliches Flurbild mit Ackerstreifen sondern ein buntes Mosaik unterschiedlicher Nutzung. Typisch dabei war, dass die Ackerflächen zu dem privat genutzten Land gehörten und die Heideflächen, z.T. von beträchtlicher Größe, Gemeinheit des Dorfes waren.

\subsubsection{Wald}

Eine Ausnahme in der sehr waldarmen Landschaft der damaligen Zeit bilden die Sprache ${ }^{1}$ und die Müsse ${ }^{2}$. Beides sind königliche Waldgebiete ${ }^{3}$, heute Staatsforsten ${ }^{4}$, die Sprache am westlichen Rand des Lachte-Schwemmfächers zwischen dem Schweinebruch im Norden und dem Osterbruch im Süden, die Müsse nördlich des Schwarzwassers und östlich der Allerdreckwiesen. Der Name Sprache ${ }^{5}$ soll vom angelsächsischen „spracen“, zu Deutsch Erle, abgeleitet sein.

Wenn man dieser Deutung folgt, könnte man schließen, dass es sich bei der Sprache damals um einen standorttypischen Bruchwald gehandelt habe. Die Kurhan. Landesaufnahme verzeichnet die Sprache aber als reinen Nadelwald.

Die Müsse, ebenfalls königlich, wird dagegen durch die zahlreichen Busch- und auch Laubbaumsignaturen als typischer Bruch charakterisiert, sie grenzt unmittelbar östlich an die Allerdreckwiesen und ist sicherlich auch als Waldweide genutzt worden. Damit wird auch die

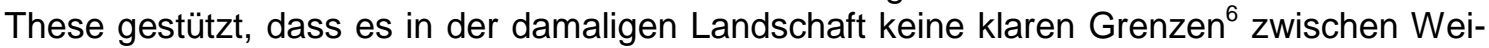
den und Wald gab.

\subsubsection{Siedlung}

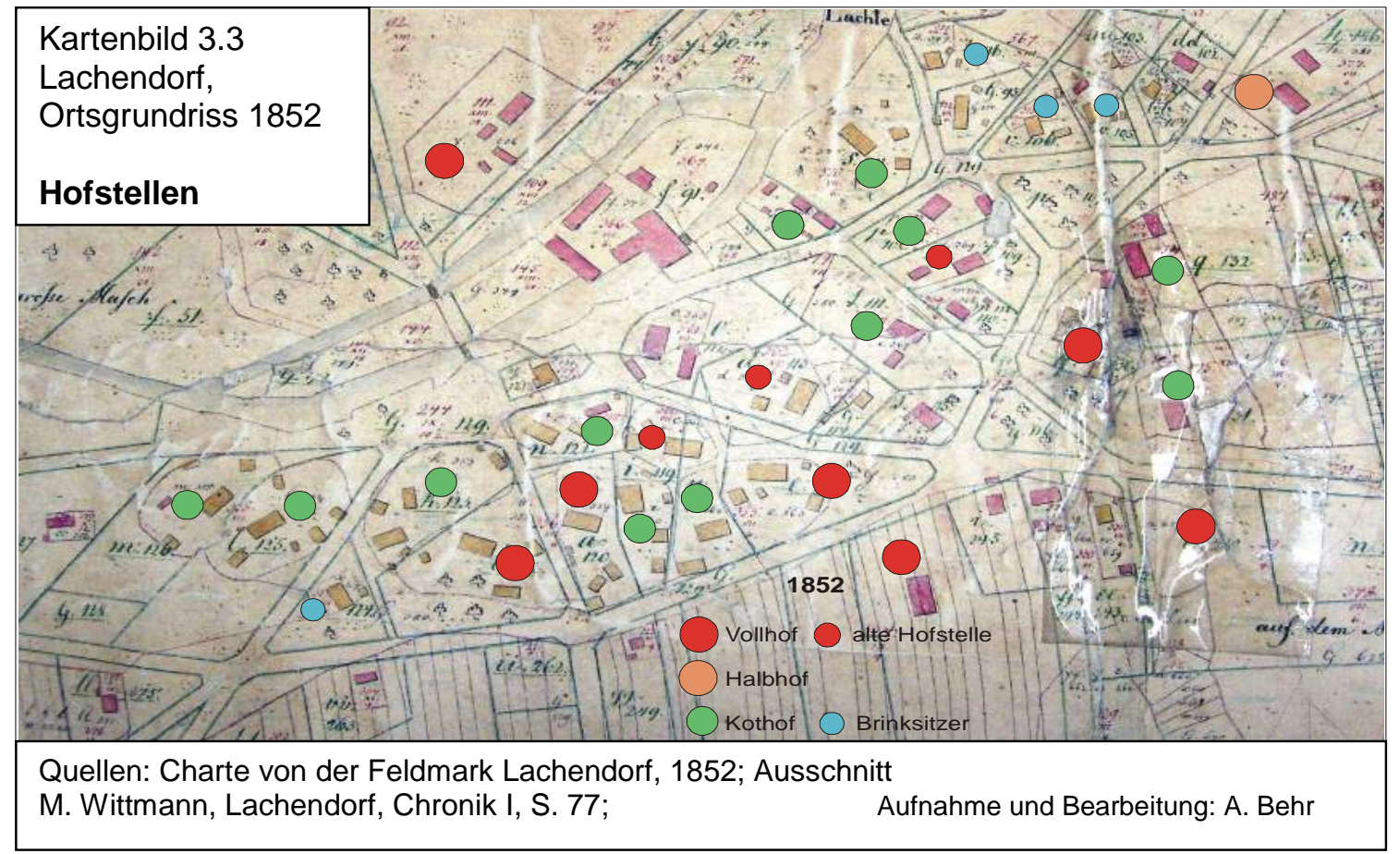

\footnotetext{
${ }^{1}$ Spuren und Zeichen, Hg. Landkreis Celle, 1991, S. $230 \mathrm{ff}$

2 s. Kurhanno. Landesaufnahme, Blatt 111 Gr. Eicklingen

${ }^{3}$ auf der Kurhann. Landesaufnahme als „königlich“ bezeichnet

${ }^{4}$ s. TK 25, Blätter 3327 Beedenbostel (Sprache) und 3427 Bröckel (Müsse) und

${ }^{5}$ Spuren und Zeichen, Hg. Landkreis Celle, 1991, S. 231

${ }^{6}$ s. Küster, Geschichte der Landschaft in Mitteleuropa, a.a.O. S. 251
} 
Die Dörfer im Untersuchungsgebiet sind auf den Karten von 1779 und 1781 als Haufendörfer dargestellt, von denen Ahnsbeck (48 Feuerstellen), Beedenbostel (36) und Lachendorf (25) ${ }^{1}$ die weitaus größten sind.

Ahnsbeck und Lachendorf haben eine ökologisch sinnvolle Lage am Rande des Urstromtales am Übergang zu den Grundmoränenplatten. Beedenbostel liegt zentral auf einer Grundmoränenplatte und, wie auch Lachendorf, am Rande einer Talaue mit Zugang zu den Flüssen Aschau bzw. Lachte.

Es handelt sich also bei den Ortslagen von Ahnsbeck und Lachendorf um besonders ausgeprägte „Ökotopgrenzlage“2, wie sie für sehr viele alte Dörfer typisch ist.

Die Karte von 1852 zeigt den Zustand vor und nach der Verkoppelung, nämlich die Ackerstreifen (schwarz) der alten Flurordnung südlich des Dorfes und die neue Struktur der StraBen und Parzellen (grün). Für die unterschiedliche Farbgebung der Gebäude gibt es auf der Karte selbst keine Legende, aufgrund einer allgemeinen Erläuterung ${ }^{3}$ kann man aber annehmen, dass die rot markierten Gebäude bereits ein Ziegeldach hatten und die gelbe Markierung Strohdächer darstellt. Diese Interpretation stützt auch Berichte ${ }^{4}$, dass erst nach dem großen Brand im Jahr 1850 die ersten Häuser mit Ziegeldächern gebaut wurden. Außerdem wurden einige Hofstellen aus der ehemaligen engen Lage weiter an den Ortsrand verlegt. Als Hinweis auf die geringe Wirtschaftskraft der Bauernhöfe vor 1850 kann gewertet werden, dass selbst die Wohnhäuser der Vollhöfe, die nicht vom Brand erfasst worden waren, noch mit Stroh eingedeckte Dächer hatten. Vermutlich hatten vor dem Brand alle Bauerngehöfte Strohdächer und zahlreiche Häuser sind sicherlich noch Rauchhäuser gewesen.

\subsubsection{Allerheide auf dem Schwemmfächer}

Auf dem gesamtem Schwemmfächer, der Terrasse des Lachtetales nordöstlich des Ortes sowie dem Rand des Urstromtales zwischen der Lachte und dem Geestrand breiteten sich am Ende des 18. Jahrhunderts Heideflächen aus. Baumbestand gab es nur im unmittelbaren Umfeld der Höfe im Dorf, nördlich des Lachteknies und mitten in der Allerheide einen kleinen Birkenbusch.

Der Naturraum des Lachte-Schwemmfächers hat wohl zu Recht den Namen Allerheide ${ }^{5}$ erhalten. Der Kartenausschnitt aus der Karte von 1850, die zur Generalteilung der Allerheide und angrenzender Reviere angefertigt wurde, vermittelt auch im kleinen Ausschnitt einen Eindruck von dem einheitlichen, ja eintönigen Landschaftsbild. Die Taxatoren, die für die Bewertung zuständig waren, konnten eine großflächige Bewertung vornehmen und nur wenige Gebiete mit besonderen Standorteigenschaften ausgliedern.

Auf den leichten, armen Sandböden verzeichnet die Karte von 1779 nur zwei Gebiete mit Ackernutzung: Am unmittelbaren Ortsrand von Lachendorf greift das Ackerland auf die Wurzelzone des Lachte-Schwemmfächers aus und am Südrand des Schwemmfächers bis zur Aller lagen einige Ackerkämpe, die aber bereits zu Oppershausen gehörten.

Bezeichnend für diesen Standort auf trockenen Talsanden sind die Flurnamen „Hungerfeld“ und „Hungerkamps Weg“,

Die Nutzflächen für Acker und Grünland, die also den Schwemmfächer der Lachte kranzförmig $^{6}$ umgeben, umschließen eine große Heidefläche, die Allerheide, deren Stellung im Landschaftsbild und Bedeutung im Nutzflächengefüge sich nicht unmittelbar aus der Karte erschließt.

\footnotetext{
${ }_{1}^{1}$ Angaben zur Anzahl der Feuerstellen: Kurhann. Landesaufnahme, Blatt 103 Celle von 1879

2 s. H. Küster, Geschichte der Landschaft in Mitteleuropa, a.a.O., S. 78

${ }^{3}$ Mdl. Mitteilung von Frau Doß, Zentrale Altablage beim LGLN, Regionaldirektion Hannover

${ }^{4}$ s. M. Wirrmann, Lachendorf, Chronik I, a.a.O., S. $70 \mathrm{ff}$

${ }^{5}$ In der Chronik von Lachendorf, Bd. I von M. Wittmann und K. Seebo wird allerdings die These vertreten, dass der Name Allerheide nichts mit dem Fluss Aller zu tun hat, sondern sich von „Ellern“, also Erlen ableitet. (s. dort S. 88)

${ }^{6}$ s. Karte 3.3; Acker, Wiesen und Weiden um 1800
} 


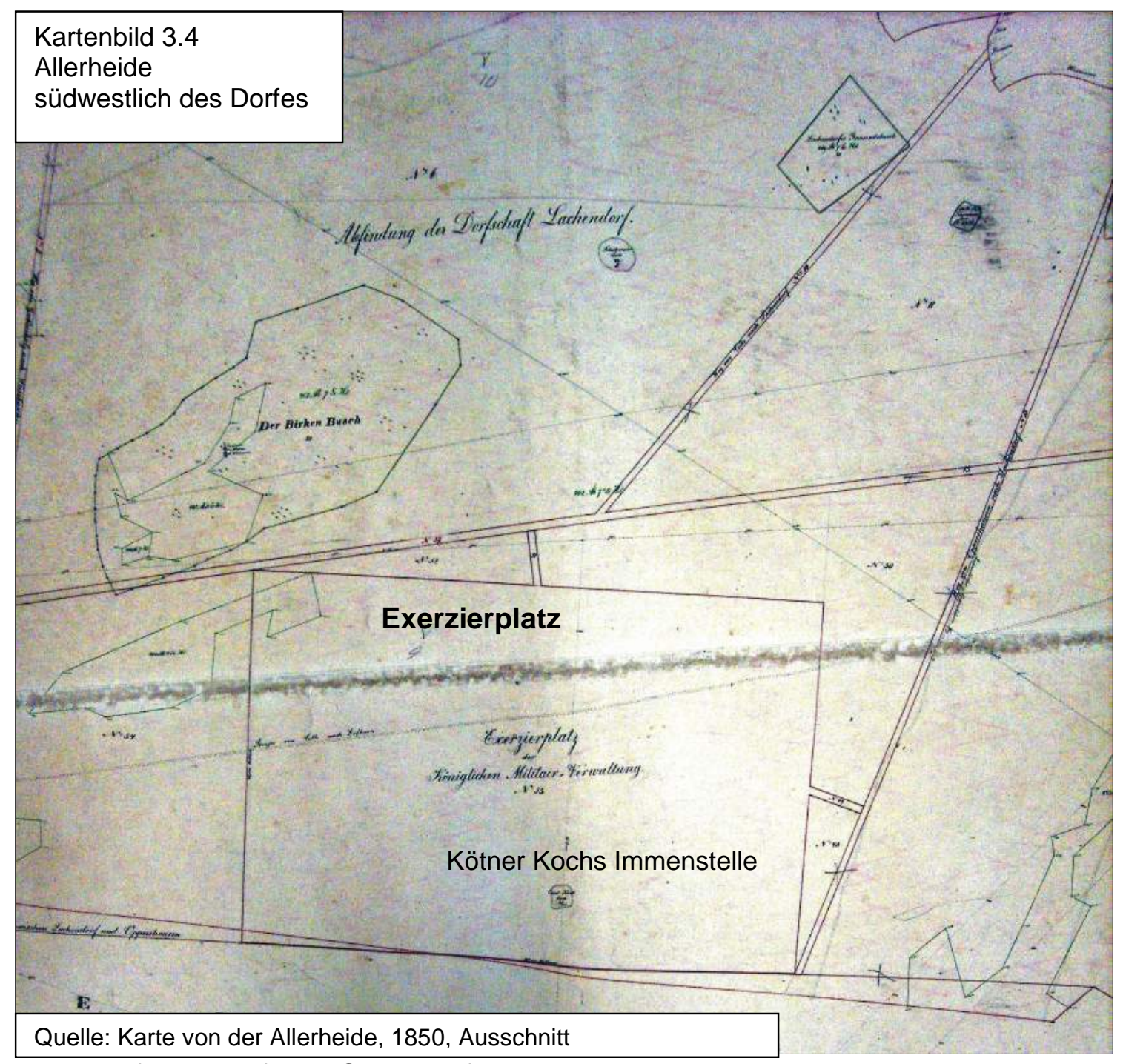

Die Heideflächen auf dem Schwemmfächer, den Talsandinseln im Urstromtal und den Terrassen des Lachtetales sind nicht zwingend eine Folge der dort vorherrschenden Sandböden und Podsole.

Zum näheren Verständnis der landwirtschaftlichen Nutzung und deren Auswirkungen auf das Landschaftsbild im Allgemeinen und die Erklärung für die Allerheide auf dem Schwemmfächer im Besonderen muss die zeitgenössische Agrarverfassung untersucht werden.

\subsection{Das Landschaftsbild im Spiegel der Rezesse}

Die sog. Rezesse, die für die Agrarreformen des 19. Jahrhunderts angefertigt wurden, geben aufgrund der Ausführlichkeit und Genauigkeit bei der Erhebung des Ist-Zustandes vor den Reformen einen sehr genauen Einblick in die Agrarstruktur und die Landnutzung um 1800.

Ein wichtiges und wegen der Freiwilligkeit der Zustimmung auch notwendiges Ziel der Reformen war offenbar die wertmäßige Erhaltung der Nutzfläche eines jeden Hofes. Daher wurden alle Flächen nach Wert und Größe genau erfasst und in einem Taxationsregister dokumentiert. Aus diesen Unterlagen lassen sich die damalige Landschaft und ihre Nutzung recht genau rekonstruieren.

Da es im Rahmen dieser Arbeit um das Zusammenwirken bzw. das Wechselspiel von Naturbedingungen und Landnutzung im Hinblick auf die Gestaltung der Landschaft geht, werden hier zunächst nur die Aspekte der Agrarverfassung behandelt, die sich auf das Landschaftsbild direkt auswirken. 


\subsubsection{Die allgemeine Verfassung der Flur}

Die betriebliche Struktur der Landwirtschaft hat sich nachweislich erhaltener Urkunden seit dem 14. Jahrhundert nur unwesentlich verändert.

Die Gewanne, die ackerbaulich genutzt wurden, waren durch eine Langstreifenflur geprägt, wie es noch auf der Kurhannoverschen Landesaufnahme als Signatur dargestellt ist. Die Höfe verfügten über Streubesitz in den verschiedenen Gewannen, die wiederum dem Flurzwang unterlagen und in der Wirtschaftsweise der Dreifelderwirtschaft oder ähnlichen, fest gefügten Nutzungssystemen genutzt wurden

Der Streubesitz der Höfe in den verschiedenen Gewannen war ein beabsichtigtes Merkmal der Flurverfassung. Da man durchweg beobachten kann, dass die Höfe Parzellen in den unterschiedlich ausgestatteten naturräumlichen Einheiten hatten, kann man davon ausgehen, dass die Streulage in den verschiedenen Gewannen sicher stellen sollte, dass alle Höfe einer Dorfschaft über etwa ähnliche Boden- und Fruchtbarkeitsbedingungen und damit über annähernd gleiche Ertragssicherheit verfügten.

Im Untersuchungsgebiet der Lachendorfer Gemarkung ist der Streubesitz urkundlich für das Jahr 1747 dokumentiert.

Gerade bei den geringen Flächenerträgen, die bei der traditionellen mittelalterlichen Landbewirtschaftung nicht wesentlich verbessert werden konnten, war die Ertragssicherheit ein sehr hohes Gut. Eine ähnliche Ausstattung der Höfe war also ein soziales Element in der Dorfgemeinschaft und wirkte sicherlich gesellschaftlich stabilisierend, sowohl in guten wie in schlechten Erntejahren ${ }^{1}$, die regelmäßig witterungsbedingt auftraten.

Dieser extreme Streubesitz wird gemeinhin als besonders hinderlich für die Bewirtschaftung angesehen. Dabei muss man aber bedenken, dass bis auf das Pflügen und Eggen sowie das Einfahren der Garben mit dem Erntewagen alle Feldarbeit Handarbeit war: Sähen, Unkraut bekämpfen, Mähen, Garben binden, zu Stiegen (oder Hocken) aufstellen, Garben aufund abladen ${ }^{2}$ sowie auf dem Erntewagen packen ${ }^{3}$, einschließlich dreschen und Korn säubern auf dem Hof. Komplexere Geräte und mechanische Maschinen waren in der deutschen Landwirtschaft vor 1800 noch unbekannt.

Bei fast ausschließlicher Handarbeit sind kleinere, überschaubare Ackerflächen ökonomisch nicht hinderlich, psychologisch dagegen von Vorteil, weil man auf kleinen Feldern eher das Gefühl hat, etwas geschafft zu haben als auf einem großen Feld, auf dem die Arbeit kein Ende zu nehmen scheint. ${ }^{4}$ Wegen des Flurzwanges wurden die benachbarten Parzellen ohnehin im Jahresrhythmus einheitlich und weitgehend gleichzeitig bearbeitet und in den Brachzeiten beweidet und das Vieh gemeinschaftlich gehütet.

Die vielen kleinen, schmalen Ackerparzellen sind vermutlich in der alten Wirtschaftsweise nicht als negativ empfunden worden und wurden so nicht in Frage gestellt.

Die Streulage der Ackerparzellen der einzelnen Höfe und die schmalen Ackerstreifen führten keineswegs zu einem bunten Mosaik der Feldflur. Dafür sorgten

\begin{tabular}{|c|c|c|c|c|c|c|c|}
\hline \multicolumn{8}{|c|}{ Hofstellen und Streubesitz Ende des 18. Jahrhunderts (1747) } \\
\hline \multirow[t]{2}{*}{$\mathrm{Nr}$} & Höfe & Acker & Rottland & $\mathrm{Nr}$ & Höfe & Acker & Rottland \\
\hline & & Stücke & Stücke & & & Stücke & Stücke \\
\hline 3 & Vollhof & 124 & & 11 & Köthner & 63 & 10 \\
\hline 4 & Vollhof & 111 & 3 & 12 & Köthner & 91 & \\
\hline 5 & Vollhof & 175 & & 13 & Köthner & 119 & 24 \\
\hline 6 & Vollhof & 121 & & 14 & Köthner & 47 & 3 \\
\hline 7 & Vollhof & 146 & & 15 & Köthner & 115 & \\
\hline 8 & Vollhof & 126 & 4 & 16 & Köthner & 1 & 50 \\
\hline 9 & Vollhof & 127 & 1 & 17 & Köthner & 114 & 1 \\
\hline \multirow[t]{6}{*}{10} & Halbhof & 131 & 4 & 18 & Köthner & 138 & 1 \\
\hline & & & & 19 & Köthner & 89 & 4 \\
\hline & & & & 20 & Köthner & 72 & \\
\hline & & & & 21 & Köthner & 139 & \\
\hline & & & & 22 & Köthner & 38 & 1 \\
\hline & & & & & Summen & 2087 & 106 \\
\hline
\end{tabular}
zwei Merkmale, nämlich die einfache Fruchtfolge der Dreifelderwirtschaft und der Flurzwang.

\footnotetext{
${ }^{1}$ vergl. R. Glaser; Klimageschichte Mitteleuropas, a-a-O.; S. 93 ff: Das Klima von 1500 bis 2000

2 in Norddeutschland "auf- und abstaken“ genannt. (Anm. d. Verf.)

3 in Norddeutschland "laden" genannt. (Anm. d. Verf.)

${ }^{4}$ Diese ,psychologische Deutung“ beruht auch auf eigenen Erfahrungen des Verf.
} 
Der Flurzwang bewirkte, dass jedes Gewann unabhängig von den Eigentumsverhältnissen der Ackerstreifen einheitlich genutzt werden musste. Alle Ackerstreifen eines Gewannes wurden also gleichzeitig bearbeitet, eingesät und abgeerntet.

Der Flurzwang wird häufig mit dem fehlenden Wegenetz in der Feldflur begründet, was nicht auszuschließen ist. Viel wichtiger für den Flurzwang war aber sicherlich das Beweiden. Die Brache wurde immer beweidet und nicht selten auch das Wintergetreide im Frühjahr vor dem Schossen. Auf die zeitweise Beweidung der Ackerflächen konnte bei der zur Versorgung notwendigen Viehhaltung einerseits und dem chronischen Futtermangel anderseits auf keinen Fall verzichtet werden.

Eine gemeinsame Beweidung von Ackerflächen, die man nicht einzäunen ${ }^{1}$ kann, ist aber nur möglich, wenn benachbarte Ackerflächen einheitlich genutzt werden.

Die Notwendigkeit der Beweidung erforderte also unbedingt - unabhängig von anderen Gründen - den Flurzwang.

Die Dreifelderwirtschaft ${ }^{2}$ sorgte dafür, dass es auf den Gewannen zu einer geregelten Rotation kam, einer Vorform der Fruchtfolge. Dadurch konnte eine gewisse Versorgungssicherheit erreicht und die Bodenfruchtbarkeit unter den gegebenen Bedingungen einigermaßen erhalten werden.

\subsubsection{Taxation der Landschaft}

Da in Lachendorf die Reformen erst um die Jahrhundertmitte vollzogen wurden, ist die Landnutzung dann noch bis etwa 1850 unverändert geblieben.

Besonders das Taxationsregister ${ }^{3}$ von 1852 sowie die Rezesse von $1859^{4}, 1861^{5}$ und $1866^{6}$ geben über die Böden, die Landnutzung und die standörtliche Beurteilung der Gebiete genaueste Auskünfte. Daraus kann man recht genau das Bild der damaligen Landschaft rekonstruieren.

\section{Bodenkategorien}

In den Taxationen und Rezessen wird überwiegend nur zwischen vier Kategorien unterschieden, nämlich Ackerland, Wiesenboden, Angerboden und Heidboden. Nur bei der Taxation der Allerheide und angrenzender Reviere werden auch Moor- und Bruchboden ausgewiesen.

Die Begriffe stehen ganz offenbar nicht für Bodenarten im heutigen bodenkundlichen Sinne, sondern für die Art der (vorwiegenden) Landnutzung, so wie es der Begriff Ackerland direkt ausdrückt.

Während die drei Begriffe Ackerland, Wiesenboden und Heidboden auch heute im alten Sinne verständlich sind und keiner Definition bedürfen, muss der Begriff „Angerboden“ genauer untersucht werden, zumal sich aus dem Wort keine Nutzung ableiten lässt.

Die Taxations-Tabelle von 1852 zur Vorbereitung der Agrarreform weist von 690 Parzellen, die durch Flurbezeichnungen unterschieden werden, 136 als Anger aus, darunter 50 als totale Weide, weitere 19 mit Weideanteilen zwischen 2/10 und 9/10, nur 4 Angerparzellen hatten einen Holzanteil zwischen 1/10 und 4/10. Sieben Angerstücke dienten mit Anteilen von 2/10

\footnotetext{
${ }^{1}$ Das Einzäunen der einzelnen Parzellen eines Gewannes hätte wegen der geringen Breite die Bearbeitung sehr erschwert, ja fast unmöglich gemacht. Aber auch das Einzäunen von Parzellen in einer großflächigen Blockflur wäre nicht möglich gewesen, denn woher hätte man das Holz für die Zäune nehmen sollen, solange es noch keine Drahtzäune gab. (Anm. d. Verf.)

${ }^{2}$ Das System der Dreifelderwirtschaft wird weiter unten genauer erläutert.

${ }^{3}$ Taxations-Register - Tabelle zur Teilung und Verkoppelung der Feldmark von Lachendorf, 1852, Akten der Samtgemeinde Lachendorf, Fach/Nr. 61/4

${ }^{4}$ Rezess über die Spezialteilung und Verkoppelung der Feldmark Lachendorf, Sign. 61/5

${ }^{5}$ Rezess über die Generalteilung der Allerheide ..., Sign. 61/8

${ }^{6}$ Rezess über die Verkoppelung der Aller- und Trockenen Wiesen, Sign. 140/8

${ }^{7}$ Taxations-Register, a.a.O., Samtgemeinde Lachendorf
} 
bis 6/10 dem Plaggenhieb und 8 Angerstücke sind als „verfahren und vergraben“ mit Anteilen von $2 / 10$ bis $8 / 10$ eingestuft.

Die Flurbezeichnungen für Angerboden sind sehr unterschiedlich, was einige Beispiele aus der Taxations-Tabelle verdeutlichen mögen:

- Der gute Angerwinkel an der Lachte unterm Krümmel, der Weg zwischen Drallen Garten und den Moorgärten, Weg zwischen dem Westerkampe u. Farkenkampe, Der Rand am Dorfe, Die Punnewischrieth, Ein guter Angerwinkel an der Lachte, (Beispiele für Anger als totale Weide)

- Der Eichenbestand am Beedenbostler Wege (0,9 Weide, 0,1 Holz), Der Krümmelbusch $(0,6$ Weide, $0,4 \mathrm{Holz})$, Sämtliche Straßen und die Gemeinheit im Dorfe $(0,6$ Weide, 0,4 Holz),

- Die Ostseite der Punnewisch (0,5 Weide, 0,5 Plaggenhieb), Die Grund neben dem Osterberge (0,4 Weide, 0,6 Plaggenhieb)

- $\quad$ Alte Lehmkuhlen am Ahnsbecker Wege neben der Brücke (0,7 Weide, 0,3 verfahren und vergraben), Alte Lehmkuhlen nördlich am Ahnsbecker Wege (0,3 Weide, 0,7 verfahren und vergraben );

- Ahnsbecker Weg, weiter westl. (total verfahren und vergraben) Angerstücke ohne zusätzliche Spezifikation:

Die Ostseite vom Farkenkampe, Grabenaufwurf an den Behrenswiesen, Der Schulhof und Garten, Bergmanns u. Misselhorns Hof und Baustelle, Kohlmeyers Hof und Baustel$\mathrm{le}^{1}$, Anbauer Kochs Hof und Baustelle, Drewsen Erben Frabrikgebäude und Hof, Das Gemeinde Hirtenhaus, Der Rand an Bunkenburgs Osterwiese, Grabenauswurf an Drallen Wiese, Der Rand an der Aschau', Schmidt Knoops Immenstelle in der Punnewisch, Im Classifikationsregister ${ }^{3}$ werden alle Hofstellen und teilweise auch zugehörige Baustellen ${ }^{4}$ als Anger eingeordnet

In die Kategorie „Angerboden“ wurden offenbar alle Flurstücke eingeordnet, die nicht zum Acker, zur Wiese oder zur Heide zählten. Die Angerstücke waren vermutlich überwiegend mit $\mathrm{Gras}^{5}$, einzelnen Bäumen oder Baumgruppen oder lockerem Holzbestand bewachsen und dienten sicherlich allgemein als Weide oder Hutung und auch als Hofplatz, der vermutlich auch von Kleinvieh genutzt wurde. Vermutlich wurden die Angerflächen regelmäßig abgeweidet oder per Hand mit der Sense gemäht, sodass die Grasnarbe gepflegt und eine Ausbreitung von unerwünschten Wildkräutern oder Buschwerk verhindert wurde. Dazu passt auch die Erklärung von Anger „als Grünlandfläche, oft in der Mitte oder am Rand des Dorfes".6.

\subsubsection{Das Landschaftsbild der privat genutzten Flächen und der dorfei- genen Gemeinschaftsflächen (Gemeinheiten)}

Zur Feldmark des Dorfes Lachendorf zählte vor den Reformen, als es die heutige Gemarkung noch nicht gab, die privat genutzten Flächen der Höfe und die Gemeinheiten des Dorfes, die nicht zu den großen Gemeinheiten (Allmenden) der Allerheide und angrenzender Reviere gehörten.

Diese alte Feldmark erstreckte sich also über die Flächen auf den Geestplatten, das Lachtetal eingeschlossen, und die Flächen in unmittelbarer Ortsnähe südlich und westlich des Dorfes.

\footnotetext{
${ }^{1}$ Die Taxations-Tabelle von 1852 verzeichnet mehrere Höfe als Baustelle, eine Folge des Großbrandes im Jahr 1850.

${ }^{2}$ Aschau: rechter Nebenfluss der Lachte

${ }^{3}$ Classifikations- und Vermessungs-Register, Sign. 61/9

${ }^{4}$ Die mehrfach auftretende Bezeichnung als „Hof und Baustelle“ hängt mit dem großen Brand von 1850 zusammen, dem zahlreiche Bauergehöfte zum Opfer gefallen waren. (vergl. M. Wittmann u.a., Lachendorf, Chronik Bd. I, a.a.O., S.198)

${ }^{5}$ Diese Deutung wurde freundlicherweise von Prof. Dr. Hansjörg Küster mündlich bestätigt.

${ }^{6}$ Tödter, Helmut R.; Kulturhistorisches Lexikon, Heidenau 2010, S. 10
} 
Die alte Feldmark bestand zu knapp Zweidrittel aus Acker und einem Viertel Heide sowie einem Zehntel Angerboden. Da außer in der schmalen Lachteaue keine Wiesen zur Verfügung standen, gab es fast keinen Wiesenboden in Dorfnähe.

\begin{tabular}{|c|c|c|c|c|c|c|c|c|}
\hline & \multicolumn{3}{|l|}{ Tabelle 3.2} & \multicolumn{5}{|l|}{ Tabelle 3.3} \\
\hline & \multicolumn{3}{|c|}{ Feldmark Lachendorf, 1852} & \multicolumn{5}{|c|}{ Gemeinheit in der Feldmark des Dorfes, 1852} \\
\hline & \multicolumn{3}{|c|}{$\begin{array}{l}\text { Feldmark Lachendorf, } 1852 \\
\text { Boden }\end{array}$} & \multirow{5}{*}{ 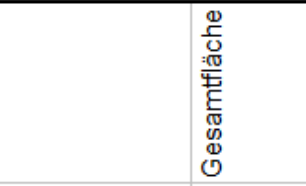 } & \multirow{5}{*}{ 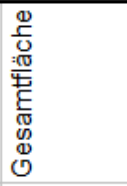 } & \multirow{5}{*}{ 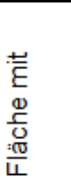 } & \multirow{5}{*}{ 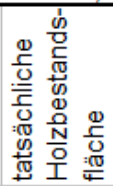 } & \multirow{5}{*}{ 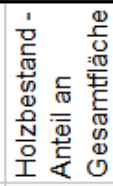 } \\
\hline & Ackerland & 540,896 & 60,91 & & & & & \\
\hline $\begin{array}{l}\text { Da It. Kurh. } \\
\text { Landesaufnahme das } \\
\text { Ackerland in Kämpen } \\
\text { mit jeweils }\end{array}$ & Wiesenboden & 33,1335 & 3,73 & & & & & \\
\hline \multirow{6}{*}{$\begin{array}{l}\text { zusammengefasst } \\
\text { war, ergibt sich für die } \\
\text { Feldmark ein klares } \\
\text { Landschaftsbild: }\end{array}$} & Angerboden & & & & & & & \\
\hline & Heide & 222 , & & & & & & \\
\hline & gesamt & 888,0472 & 100 & Boden & ha & ha & \multicolumn{2}{|c|}{\begin{tabular}{c|c} 
ha & $\%$ \\
\end{tabular}} \\
\hline & \multirow{3}{*}{\multicolumn{3}{|c|}{$\begin{array}{l}\text { Quelle: Taxationsregister, } 1852 \\
\text { Sign.: 61/4, Teil I, Gmd. Lachendo } \\
\text { Um- und Berechnungen: Verf. }\end{array}$}} & Ackerland & 1,1051 & & & \\
\hline & & & & Wiesenb & & & 0 & \\
\hline & & & & & & 8,1 & 3,2895 & $4,38 \%$ \\
\hline Die Ackerkämpe & \multirow{2}{*}{\multicolumn{3}{|c|}{ des Flurzwanges }} & & 197,0339 & 47,8263 & 19,9509 & $10,13 \%$ \\
\hline wechselten wegen & & & & \multicolumn{5}{|c|}{$\begin{array}{l}\text { Quelle: Taxationsregister, Sign.: 61/4, Lachendorf } \\
\text { Umrechnung in ha und Berechnungen: Verf. }\end{array}$} \\
\hline
\end{tabular}

Jahreszeit das Aussehen zwischen dem Braun oder meist Grün der Brache und dem Grün bzw. Gelb des Getreideanbaus.

Die Restflächen zwischen den Gewannen wurden als Heide oder als mit Gras und Baumbestand bewachsenen Angerflächen genutzt. Der äußerst geringe Baumbestand wird besonders deutlich bei den Flächen an Anger- und Heidboden, über die die Dorfgemeinschaft in der eigenen Feldmark

(s. Diagramme 3.1) verfügte.

Für die 1,9 ha Gemeinschaftsbesitz an Acker und Wiese ist kein Holzbestand verzeichnet.

In den 75 ha Angerboden gab es nur vier Parzellen mit einem Holzbestand von zusammen 3,3 ha, insgesamt also nur 4,38 \%.

Auf den 197 ha Heidboden der Gemeinheitsflächen gab es 47,8 ha, also rund $34 \%$ mit Holzbestand.

Die genaue Auswertung von Diagramm 3.1 und Tabelle 3.4 ergibt aber ein differenzierteres Bild:

Die 25 Parzellen mit Holzbeständen wiesen einen Deckungsgrad von 1 $100 \%$ auf, woraus sich rechnerisch nur 19,5 ha Holzestand ergeben. Das sind zwar $41,7 \%$ der

\begin{tabular}{|c|c|c|c|}
\hline \multicolumn{4}{|l|}{ Heidboden mit Holzbestand } \\
\hline $\begin{array}{l}\text { Parzellen in der Gemeinheit der Lachendorfer } \\
\text { Gemarkung mit Holzbestand }\end{array}$ & 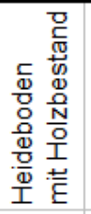 & 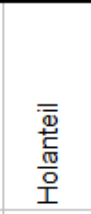 & 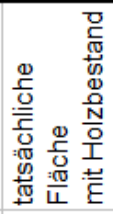 \\
\hline $\begin{array}{r}\text { Flurbezeichnung } \\
\end{array}$ & ha & $\%$ & ha \\
\hline Heidstrich an Wolfs-Busche & 0,36 & $10 \%$ & 0,04 \\
\hline Eine bessere Grund daselbst & 0,28 & $20 \%$ & 0,06 \\
\hline Eine Grund am Kirchwege & 0,86 & $10 \%$ & 0,09 \\
\hline Auf den Teichwiesen & 0,62 & $10 \%$ & 0,06 \\
\hline Östlich am Beedenbosteler Wege & 1,92 & $1 \%$ & 0,02 \\
\hline Am Krümmelfelde & 0,79 & $10 \%$ & 0,08 \\
\hline An der Beedenbosteler Grenze & 0,94 & $1 \%$ & 0,01 \\
\hline An den Moorgärten & 0,43 & $40 \%$ & 0,17 \\
\hline Das Quälohsgehäge & 1,87 & $100 \%$ & 1,87 \\
\hline Nördlich an Drewsen neuen Hofe & 3,1 & $2 \%$ & 0,06 \\
\hline Zwischen d.Teichwiesen u.d. Beedenb. Wege & 0,17 & $5 \%$ & 0,01 \\
\hline Neben Drewsen neuen Hofe & 0,33 & $4 \%$ & 0,01 \\
\hline Westlich Drewsen neuen Hofe & 1,01 & $70 \%$ & 0,71 \\
\hline An der alten Lachte & 0,53 & $10 \%$ & 0,05 \\
\hline Der Rest der großen Masch & 2,95 & $40 \%$ & 1,18 \\
\hline Der Gemeinde Ihlpohlsgehäge & 0,74 & $100 \%$ & 0,74 \\
\hline Der schlechteste Teil der Gemeindeforst & 10,51 & $100 \%$ & 10,51 \\
\hline Der bessere Teil derselben & 0,64 & $100 \%$ & 0,64 \\
\hline Neben Bergmanns Spötzkampe & 0,29 & $100 \%$ & 0,29 \\
\hline Sandwehen am linken Lachteufer & 11,97 & $3 \%$ & 0,4 \\
\hline An Drallen Bunckenburgs g. Höfen & 3,07 & $10 \%$ & 0,31 \\
\hline An Drewswn Gehäge & 2,01 & $10 \%$ & 0,2 \\
\hline Beim Ahnsbecker Wege & 0,55 & $100 \%$ & 0,55 \\
\hline daselbst & 0,55 & $100 \%$ & 0,55 \\
\hline Der Gemeinde Wolfsbusch & 1,34 & $100 \%$ & 1,34 \\
\hline Heidboden mit Holzanteilen insgesamt & 47,83 & davon: & 19,95 \\
\hline & entsp & pricht: & $41,72 \%$ \\
\hline
\end{tabular}
Holzbestandsfläche von 47,8 ha, aber nur $10,13 \%$ der gesamten Heidbodenfläche.

Unter den Heidboden-Parzellen mit Holzbestand gab es auch nur ganz wenige mit vollständigem Holzbestand, insgesamt nur 8 Parzellen mit 16,5 ha Holzbestand, davon nur eine Parzelle mit mehr als 2 ha'.

\footnotetext{
${ }^{1}$ s. Tab. 3.4 Heidboden mit Holzbestand 1852
} 


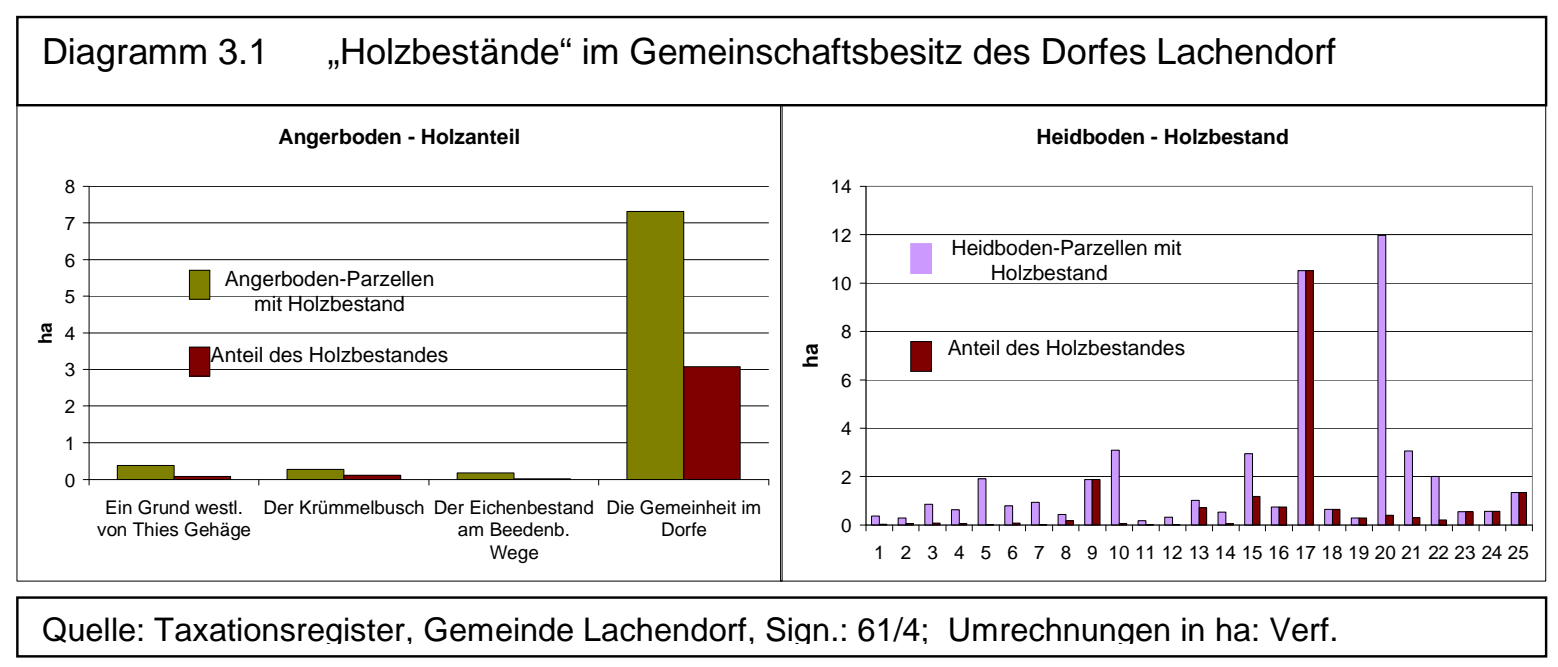

Es kann also geschlossen werden, dass es in der Gemeinheit des Dorfes, vielleicht bis auf eine Parzelle, keinen Wald im heutigen Sinne gab.

Wenn man für die privaten Anger- und Heidböden denselben Holzanteil wie bei der Gemeinheit zugrunde legt, kommt man nur auf knapp $3 \%$ der Fläche mit Holzbestand ${ }^{1}$ für die gesamte damalige Feldmark Es handelte sich also in der Feldmark auf den Geestplatten, im Lachtetal und der unmittelbaren Ortsnähe im Süden und Westen nicht nur um eine waldarme sondern sogar um eine baumarme Landschaft!

\subsubsection{Das Landschaftsbild der Allerheide und angrenzender Reviere}

Die Allerheide und angrenzende Reviere wurden zwischen 1844 und 1861 einer Generalteilung unterzogen, die die Gemeinschaftsreviere Allerheide, Lachendorfer Moor, Westernmoor, Allerhorn und Allerohe in den Ämtern Celle und Beedenbostel umfasste, insgesamt eine Fläche von 1670,3113 ha² $^{2}$.

Aus dem Rezess von $1861^{3}$ kann man das zeitgenössische Landschaftsbild dieser großen Allmende bzw. Gemeinheit gut rekonstruieren.

Tabelle und Diagramm 3.5 verdeutlichen die Landschaftsstruktur der Gemeinschaftsreviere auf der Allerheide.

Diese Gemeinschaftsreviere waren ganz wesentlich und unentbehrlich für die Landwirtschaft und damit ein bedeutender Faktor in der zeitgenössischen Kulturlandschaft.

\footnotetext{
${ }^{1}$ Bei der Interpretation des Landschaftsbildes aufgrund der Daten im Taxationsregister von 1852 wird durchgängig der Begriff „Holzbestand“ benutzt und absichtlich nicht der Begriff „Wald“, weil außer beim Eichenbestand am Beedenbosteler Weg keine Angaben zum Baumbestand gemacht wurden. Anm. d. Verf.

${ }^{2}$ Die Flächenangaben im Original sind in Morgen (M) und Quadratruten (QR) gefasst und zu 21,8425 $\mathrm{m}^{2} / \mathrm{QR}$ umgerechnet.

${ }^{3}$ Plan-Rezess über die Generalteilung ...von 1861; Sign. 61/8
} 


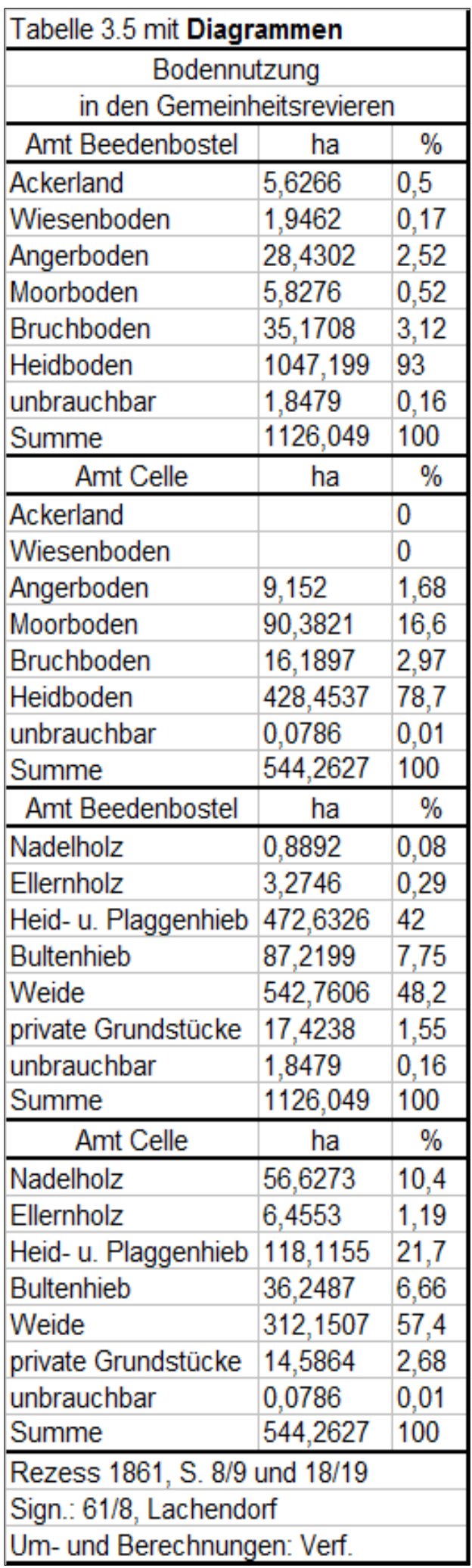
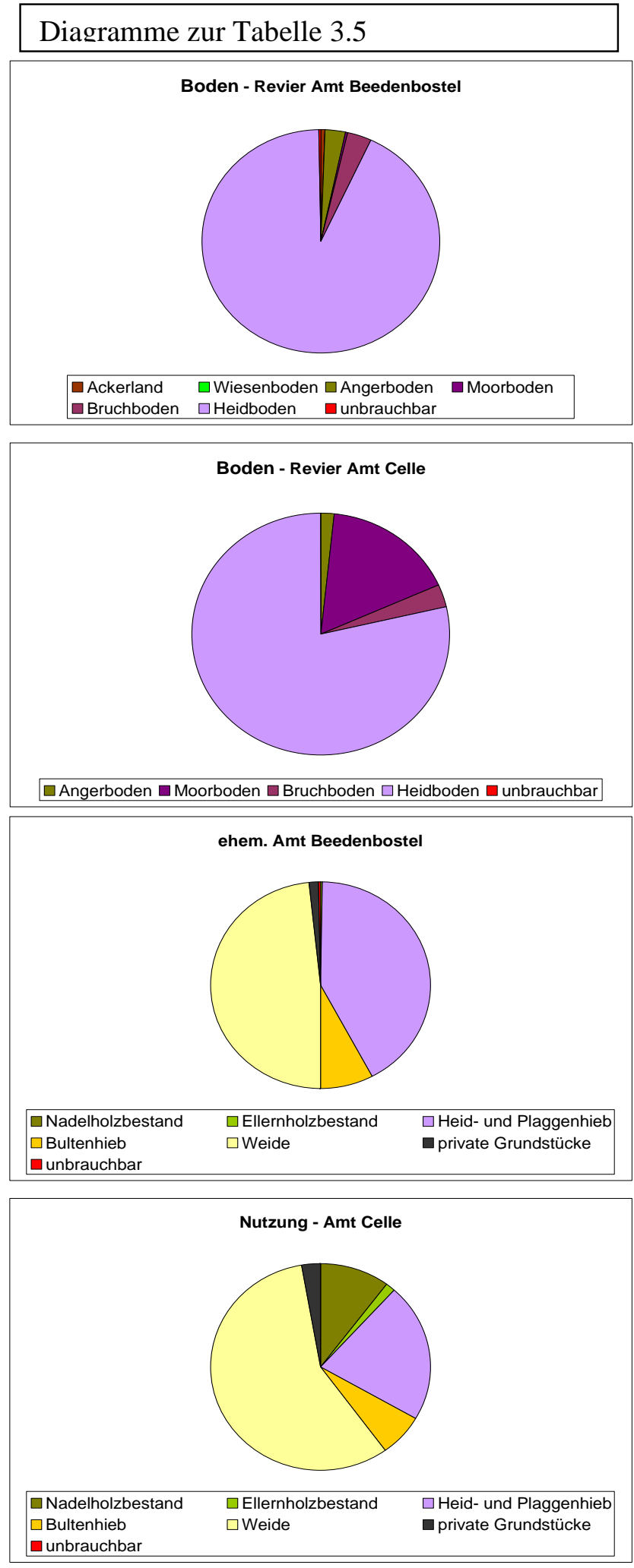
Die Bedeutung dieser sehr großen Gemeinheit (Allmende) ergibt sich aus der großen Zahl der Weideberechtigten, aus der Art der Nutztierhaltung, die keine ganzjährige Stallhaltung bzw. -fütterung kannte, sowie der hohen Besatzdichte mit Nutzvieh.

Für Lachendorf werden 640 Kuhhäupter angegeben, für Ahnsbeck 600, für das Gut Oppershausen 520 und für Altencelle $480^{1}$. Bei entsprechender Umrechnung ${ }^{2}$ kommt Lachendorf im Jahr 1965, als noch alle Haupterwerbsbetriebe Nutztiere hielten, auf 717 Kuhhäupter $^{3}$, was bei völlig anderer Futtergrundlage und Haltung nur eine Steigerung von $12 \%$ ausmacht. Daraus lässt sich schließen, dass die Weideflächen sehr stark bestockt waren und eine Überweidung angesichts der geringen natürlichen Leistungsfähigkeit der Weideareale angenommen werden kann.

Auf diesen Gemeinschaftsrevieren dominierte der Heidboden, im Amt Beedenbostel, dem zentralen Teil der Allerheide, mit $93 \%$ und im Amt Celle mit $78 \%$, zusammen mit Bruchund Moorboden sogar mit $98 \%$ der Fläche.

Noch deutlicher wird das Landschaftsbild durch die Nutzung beschrieben: Die Gemeinschaftsreviere dienten weit überwiegend zur Weide und zum Heid- und Plaggen- sowie Bultenhieb. Wenn man die Angaben zum Boden und zur Nutzung im Zusammenhang sieht, muss man schließen, dass es sich bei den Weiden um Heide und trockene Grasfluren handelte, keineswegs um echtes Grünland. Wiesenboden ist nur im Amt Beedenbostel mit unbedeutenden 0,17\% ausgewiesen Die Bultenhiebsflächen dürften sich auf die Standorte mit hoher Grundfeuchte mit Pfeifengras, das zur Bultenbildung neigt, konzentriert haben. Solche Restflächen waren um 1966 im südlichen Teil der Lachendorfer Allerheide noch vorhanden.

Der Waldanteil war äußerst gering, nur im Amt Celle, also in der Nähe der Stadt, mit knapp $12 \%$ Flächenanteil von Bedeutung.

Die Landschaft auf den Gemeinschaftsrevieren des Lachte-Schwemmfächers war also äuBerst waldarm, vermutlich sogar baumarm und von der Heide dominiert. Allerdings darf man sich diese Hutungen und Plaggenhiebsflächen nicht als reine, geschlossene Heideflächen vorstellen, sondern als abwechslungsreiches Mosaik einer niedrigen Bodenvegetation mit Vorherrschaft von Besenheide (calluna vulgaris) und Drahtschmiele (deschampsia flexuosa) an den trockenen Standorten und Pfeifengras (molinia coerulea) sowie Erikaheide (calluna tetralix) auf den feuchten Orten.

Bemerkenswert ist, dass in beiden Bezirken (Celle und Beedenbostel) der Anteil der Bultenhiebsfläche mit rund $7 \%$ und der Weideanteils sogar mit rund $50 \%$ angegeben wurde. Das große Gemeinschaftsrevier hatte also eine enorme Bedeutung als Weidefläche für die umlegenden Orte. Selbst die Stadt Celle hatte eine Weideberechtigung

\begin{tabular}{|l|l|l|}
\hline \multicolumn{3}{|c|}{ Tabelle 3.6. } \\
\hline \multicolumn{3}{|c|}{ Abfindungen in der Allerheide } \\
\hline \multicolumn{1}{|c|}{ private Grundstücke } & \multicolumn{1}{|c|}{ ha } & $\%$ \\
\hline Ackerland & 3,0121 & 38 \\
\hline Wiesenboden & 0,9873 & 12,5 \\
\hline Heidboden & 1,802 & 22,7 \\
\hline 11 Immenstellen - Heide & 2,1275 & 26,8 \\
\hline privat gesamt & 7,9288 & 100 \\
\hline \multicolumn{1}{|c|}{ Abfindung Gemeinde } & ha & $\%$ \\
\hline Angerboden & 20,3856 & 2,75 \\
\hline Moorboden & 1,2144 & 0,16 \\
\hline Heide & 720,567 & 97,1 \\
\hline Gemeinde gesamt & 742,167 & 100 \\
\hline Exerzierplatz - Heide & 63,1772 & \\
\hline Rezess 1861, Sign.: 61/8, Lachendorf \\
\hline Um- und Berechnungen: Verf. \\
\hline
\end{tabular}
für „einige städtische Kühe samt Bullen“ und wurde in der Generalteilung mit 40 Thalern abgefunden. ${ }^{4}$

Das Landschaftsbild dieser Gemeinschaftsreviere im Allertal, die hauptsächlich den LachteSchwemmfächer und dessen Randbereiche im Urstromtal einnahmen, dürfte in den trockeneren Bereichen einer Heide-Gras-Landschaft mit Wacholder und in den feuchteren Berei-

\footnotetext{
${ }_{1}^{1}$ Plan-Rezess über die Generalteilung der Allerheide ..., 1861, S. 24 und 29, Sign.: 61/8

${ }^{2}$ K. Schneider U. H.H Seedorf, Bauernbefreiung und Agrarreformen in Niedersachsen, Hildesheim 1989, S. 89

${ }^{3}$ Wegen fehlender Daten sind hier die Neben- und Zuerwerbsbetriebe nicht erfasst, die sicherlich mindestens jeweils einige Schweine gehalten haben. Anm. d. Verf.

${ }^{4}$ Plan-Rezess, § 10, S. 20; Samtgemeinde Lachendorf, Sign. 61/8
} 
chen einer Hutweide entsprochen haben, wie sie heute als Relikt in der Hornbosteler Hutweide westlich von Celle im Allertal erhalten wird.

Die Interpretation des Landschaftsbildes aus den Daten der Rezesse kann noch unterstützt werden, wenn man die Daten der Lachendorfer Abfindungen aus der Generalteilung der Allerheide heranzieht.

Das private Ackerland in der Allerheide gehörte zu einem Kothof und die kleine Fläche Wiesenboden teilten sich zwei Kothöfe. Dagegen hatten insgesamt 12 Höfe eine Immenstelle in der Allerheide, 11 davon blieben privat erhalten. Eine Immenstelle von 61 Quadratruten eines Kothofes lag auf dem ausgegliederten Exerzierplatz und wurde von der Gemeinde entschädigt ${ }^{1}$.

In dem gesamten Generalteilungsgebiet wurden insgesamt 123 ha Bultenhiebsfläche ausgewiesen, von denen unter den Lachendorfer Bauern auf der Allerheide 45,52 ${ }^{2}$ ha verteilt wurden. Bultenhiebsflächen waren höchstwahrscheinlich Bestände mit Pfeifengras, das von Natur zur Bultenbildung neigt und das auch heute noch am Rande des Postmoores und westlich des Krähenmoores unter Wald vorkommt.

Flächen für Heid- und Plaggenhieb wurden gesondert ausgewiesen, nämlich 590 ha im gesamten Teilungsgebiet.

Da diese Flächen zur Gewinnung von Bulten, Plaggen und Heidekrautstreu im Rahmen der Wirtschaftsweise dringend gebraucht wurden, hat auf diesen Flächen über Jahrhunderte eine intensive Nutzung stattgefunden. Daraus muss man weiter schließen, dass das Vegetationsmuster auf der Allerheide ein sehr kleinräumiges Mosaik aus Flächen mit unterschiedlichem Alter der Vegetation bestand, nämlich von gerade frisch abgeplaggt mit frei gelegtem Boden über alle Zwischenstadien bis zum reifen Pfeifengras und alter, verholzender Heide, die ja dringend als Winterweide ${ }^{3}$ für Schnucken gebraucht wurde.

Auch der Bestand an Wacholder dürfte eher spärlich gewesen sein, da der Wacholder als Weideunkraut galt und aus der Sicht der Weidenutzung natürlich anders beurteilt wurde als heute aus der Sicht der Ästhetik bzw. des Tourismus.

Ein Vergleich einer Heidelandschaft vor 1850 mit einer heutigen Heidelandschaft legt die Vermutung nahe, dass ein Bedeutungswandel des Begriffes stattgefunden hat. Heid war ehemals eine offene, sehr abwechslungsreiche Landschaft mit Grasfluren und Heidevegetation zur Beweidung sowie zum Bulten- und Plaggenhieb, also eine landwirtschaftliche Nutzfläche. Heute wird unter Heide eher ein Vegetationstyp verstanden, in dem die Heidepflanze dominiert und ein Wacholderbestand in der Fläche sowie Birken an den Wegen für ein ästhetisch schönes Landschaftsbild sorgen.

\subsubsection{Das Landschaftsbild in den Aller- und Trockenen Wiesen}

Das Verkoppelungsgebiet der Aller- und Trockenen Wiesen bildete eine zusammenhängende Wiesenfläche zwischen den Feldmarken benachbarter Dörfer wie Oppershausen, Lachendorf, Ahnsbeck, Nordburg und Schwachhausen, von den beiden zuletzt genannten Feldmarken durch den Lauf des Schwarzwassers ${ }^{4}$ getrennt. Tabellen und Graphiken zeigen einheitlich, dass es sich zu über $90 \%$ um Wiesenflächen handelte. Aus dem Streit um Rechte zur Vor- und Nachweide kann man schließen, dass die Wiesen im Frühjahr und im Herbst beweidet wurden und im Sommer als Wiese zur Gras- bzw. Heugewinnung dienten. Aus der Nutzung als Vor- und Nachweide folgt auch, dass die Wiesen nur einschürig waren, also nur eine Mahd erfolgte.

\footnotetext{
${ }^{1}$ Rezess von 1861, Sign.: 61/8, S. 91

${ }^{2}$ Rezess zur Spezialteilung und Verkoppelung der Gemarkung Lachendorf, § 5, Gemeinde Lachendorf, Sign. $61 / 5$

${ }^{3}$ Lt. Information von Landwirt und Schuckenzüchter Carl-Wilhelm Kuhlmann, Niederohe, braucht man zur Winterweide einen Bestand an alter Heide, die auch nach Schneefall beweidet werden kann.

${ }^{4}$ Entfrettung und Verkoppelung der Aller- und Trockenen Wiesen bei Lachendorf, Rezess von 1861, § 2, Samtgemeinde Lachendorf, Sign.: 140/8
} 


\begin{tabular}{|l|l|l|l|l|}
\hline Tabelle 3.7 mit Diagramm & \multicolumn{2}{|c|}{ Aller- und Trockene Wiesen } \\
\hline \multicolumn{2}{|l|}{ Verkoppelungsgebiet in den } \\
\hline \multicolumn{2}{|l|}{ Aller- und Trockenen Wiesen } \\
\hline Boden & $\mathrm{M}$ & $\mathrm{QR}$ & ha \\
\hline Wiesenboden & 803 & 3 & 210,4809 \\
\hline Ackerland & 33 & 62 & 8,7851 \\
\hline Angerboden & 14 & 4 & 3,6783 \\
\hline Heidboden & 22 & 108 & 6,0023 \\
\hline Summe & 873 & 57 & 228,9465 \\
\hline Teilungs-Urkunde über Entfrettung \\
\hline und Verkoppelung der Aller- und \\
\hline Trockenen Wiesen, 1866 \\
\hline Sign.:140/8, S. 6, Lachendorf \\
\hline
\end{tabular}

Bei dieser Nutzung zur Weide und zur regelmäßigen Mahd, die per Hand und Sense erfolgte, kann man davon ausgehen, dass es sich um eine offene Wiesenlandschaft ohne Buschund Strauchwerk auf den Wiesenparzellen und mit geringem Baumbestand gehandelt hat. Wegen der Vorweide wird die Mahd erst Ende Juni bzw. im Juli erfolgt sein, wie es wegen des starken Anteils von Handarbeit bei der Heuwerbung bis ins 20. jahrhundert üblich war. Aus diesem - im Vergleich zu heute - späten Termin der Grasmahd ergibt sich ein Pflanzenbestand auf den Wiesen, der neben Gräsern auch viele Kräuter enthielt, also sehr artenreich war.

Die späte Mahd erfolgte auch, weil ausgereifte Gräser und Kräuter leichter zu Heu zu trocknen sind als frisches Gras. Dies bedeutete wiederum, dass sich gerade die Gräser und Kräuter gut vermehren konnten, die bis zur Mahd die Samenreife erreichten, sich also über Samen vermehrten.

Der Verbiss durch Weidevieh hat einen anderen Effekt als die

\begin{tabular}{|c|c|c|c|c|c|}
\hline \multicolumn{3}{|l|}{ Tabelle 3.8} & \multicolumn{3}{|l|}{ Tabelle 3.9} \\
\hline \multicolumn{3}{|c|}{ Lachendorfer Anteil } & \multicolumn{3}{|c|}{ Anteile aller anderen Interessenten } \\
\hline \multicolumn{3}{|c|}{ Aller- und Trockene Wiesen } & \multicolumn{3}{|c|}{ Aller- und Trockene Wiesen } \\
\hline Boden & ha & $\%$ & Boden & ha & $\%$ \\
\hline Wiesenboden & 94,3115 & 92,69 & Wiesenboden & 211,7827 & 91,98 \\
\hline Ackerland & 0,9086 & 0,89 & Ackerland & 8,7851 & 3,815 \\
\hline Angerboden & 3,1846 & 3,13 & Angerboden & 3,687 & 1,601 \\
\hline Heidboden & 3,3441 & 3,29 & Heidboden & 6,0023 & 2,607 \\
\hline gesamt & 101,7489 & 100 & gesamt & 230,2571 & 100 \\
\hline \multicolumn{3}{|c|}{ Quelle: Verkoppelung der Aller- } & \multicolumn{3}{|c|}{ Quelle: Rezess 1866, S. $24 \mathrm{ff}$} \\
\hline \multirow{2}{*}{\multicolumn{3}{|c|}{$\begin{array}{l}\text { und Trockenen Wiesen, } 1866 \\
\text { Sign.: 140/8, § 5, S. } 24 \mathrm{ff}\end{array}$}} & \multirow{2}{*}{\multicolumn{3}{|c|}{ Sign.: 140/8, Lachendorf }} \\
\hline & & & & & \\
\hline
\end{tabular}
Mahd, weil das Vieh - je nach Art unterschiedlich - selektiv den Pflanzenbestand beweidet und dabei sog. Weideunkräuter meidet, die dadurch einen Wachstumsvorteil erlangen. Der Effekt der negativen Weideselektion und die Bildung von Lägerfluren mit Stickstoff liebenden Pflanzen an den Dungplätzen wurde durch die regelmäßige Mahd weitgehend verhindert.

Die Landschaft der Aller- und Trockenen Wiesen darf man sich um 1850 als eine weite und offene, optisch recht einheitliche Wiesenlandschaft mit wenig Strauch- und Baumbestand, aber mit einer reichen Gras- und Krautflora vorstellen. Die Standortunterschiede nach Anmoor- oder Sandboden, nach Wasserhaushalt und Grundwasserstand haben sicherlich zu einem standorttypischen Mosaik der Pflanzengesellschaften geführt. Dies dürfte besonders durch die Verteilung von Süß- und Sauergräsern sowie Seggen und Binsen deutlich geworden sein.

\subsection{Naturraum - Landnutzung}

Die alte Feldmark mit überwiegend Ackerland erstreckte sich hauptsächlich auf den Geestplatten nördlich des Ortes sowie auf den ortsnahen Flächen im Wurzelbereich des Schwemmfächers und in der Talaue der Lachte.

Die Allerheide und die angrenzenden Reviere überdeckten den Schwemmfächer der Lachte im Urstromtal und dessen Randbereiche. Dort beherrschten offene, baumarme Hutungen, Bultenhiebsflächen und vor allem Heide die Landschaft. 
Die Aller- und Trockenen Wiesen lagen auf dem Randmoorbereich im Urstromtal östlich und südöstlich des Schwemmfächers. ${ }^{1}$

Damit ist gezeigt, dass sich die Landnutzung um 1800 ganz eng an das naturräumliche Gefüge angepasst hatte: Die besten Böden waren der Schwerpunkt des Ackerlandes, die trockensten und magersten Sandböden bestimmten das Heidegebiet und die grundfeuchten Böden, das Anmoor und der Überschwemmungsbereich wurden als Wiesenböden eingestuft, dienten also als Grünland.

Ein weiteres Merkmal ergibt sich aus der flächendeckenden Nutzung durch die Landwirtschaft: Zusätzlich zu den privat bewirtschafteten Ackerflächen wurden die Gemeinheit des Dorfes, die Allerheide mit den angrenzenden

Revieren sowie die Aller- und trockenen Wiesen als Allmenden bzw. Gemeinheiten von den Bauern gemeinsam genutzt.

Es gab also keine Trennung von Landwirtschaftlicher Nutzfläche und Wald, vielmehr war die gesamte Landschaft landwirtschaftliche Nutzfläche ${ }^{2}$.Die Landnutzung hatte sich aufgrund der sehr begrenzten Hilfsmittel sehr genau den naturräumlichen Bedingungen angepasst. Die Landwirtschaft des 18. Jahrhunderts war also eindeutig naturbedingt bzw. naturbasiert. Andererseits hatte die Form der Landnutzung ${ }^{3}$ das Landschaftsbild total überprägt und zu einer vollständigen Kulturlandschaft umgewandelt.

\footnotetext{
${ }^{1}$ Vergl. dazu Karte 3.3: Acker, Wiesen und Weiden um 1800 sowie die Karten $2.5-2.9$

${ }^{2}$ Nur herrschaftliche Forsten wie die Sprache waren rechtlich und bzgl. der Nutzung aus der bäuerlich genutzten Landschaft ausgesondert.

${ }^{3}$ s. folgendes Kapitel, Kap. 3.4
} 


\subsection{Landschaft und Wirtschaftsweise}

Die konkrete Landnutzung eines bestimmten Naturraumes ergibt sich nicht zwingend allein aus den natürlichen Bedingungen. Ebenso entscheidend wie die Naturbedingungen sind die bäuerliche Wirtschaftsweise und die zeitgenössische Agrartechnik.

Daher muss zur vollständigen Erklärung der Kulturlandschaft ein Blick auf diese beiden Bereiche geworfen werden.

\subsubsection{Landschaft - Gewanne - Pflugtechnik}

Bis zu den Reformen des 19. Jahrhunderts bot die Feldmark ${ }^{1}$ eines Dorfes ein charakteristisches Bild:

\section{Gewanne mit Streifenflur}

Seit dem frühen Mittelalter ${ }^{2}$ setzte sich bei den Ackerparzellen eine längliche Form gegenüber den mehr quadratischen Ackerformen durch, die seit der Eisenzeit die

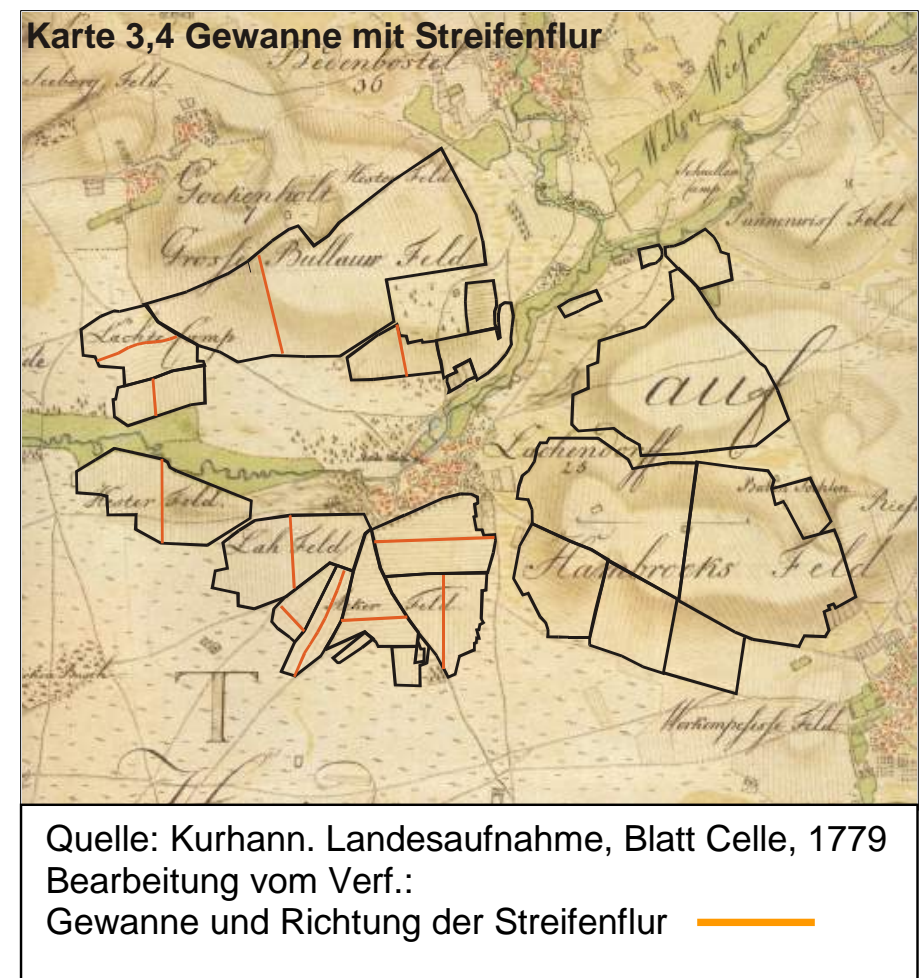
Ackerflur bestimmt hatten. Als Ursache für die beiden unterschiedlichen Ackerformen wird die Pflugtechnik ${ }^{3}$ angenommen: Mit dem Hakenpflug, mit dem man kreuz und quer pflügen konnte und musste, um ein einigermaßen ebenes Pflugbeet zu bekommen, bot sich ein quadratisches Feld an. Mit dem Schar- bzw. Beetpflug, der eine Furche zieht, mit dem Schar den Boden teilt und mit dem Streichbrett ${ }^{4}$ zur Seite wirft und wendet, musste man parallele Furchen pflügen und jeweils am Ende der Furche wenden. Bei dieser bis heute üblichen Pflugtechnik sind Pflugbeete günstig, die wesentlich länger als breit sind ${ }^{5}$. Die Form der Ackerparzellen hängt also sicherlich ganz wesentlich mit der Pflugtechnik zusammen.

Die Länge der Pflugparzellen könnte auch damit zusammen hängen, dass die Bauern ein Gewann nicht in einem Zuge in Kultur genommen haben, sondern gemeinsam in nebeneinander liegenden Ackerstreifen auf einer Seite des Gewanns begannen und die Ackerstreifen bei gleich bleibender, unveränderbarer Breite in die unkultivierte „Wildnis““6 vorschoben bzw. verlängerten.

\footnotetext{
${ }^{1}$ Die Gleichsetzung der Begriffe Feldmark und Gemarkung ist historisch nicht korrekt. (s. Kap. 4)

${ }^{2}$ Miedaner, Th., Von der Hacke bis zur Gentechnik, Frankfurt a.M., 2005, S. 100

${ }^{3}$ s. Küster, a.a.O., S. $180 \mathrm{ff}$.

${ }^{4}$ Das Streichbrett war ursprünglich gerade und aus Holz. Das Streichblech aus Eisen ist leicht geschwungen und bewirkt ein besseres Wenden des Bodens.

${ }^{5}$ Miedaner, Th., Von der Hacke bis zur Gentechnik, Frankfurt a.M., 2005, S. 100

${ }^{6}$ s. Küster, a.a.O., S. 182
} 


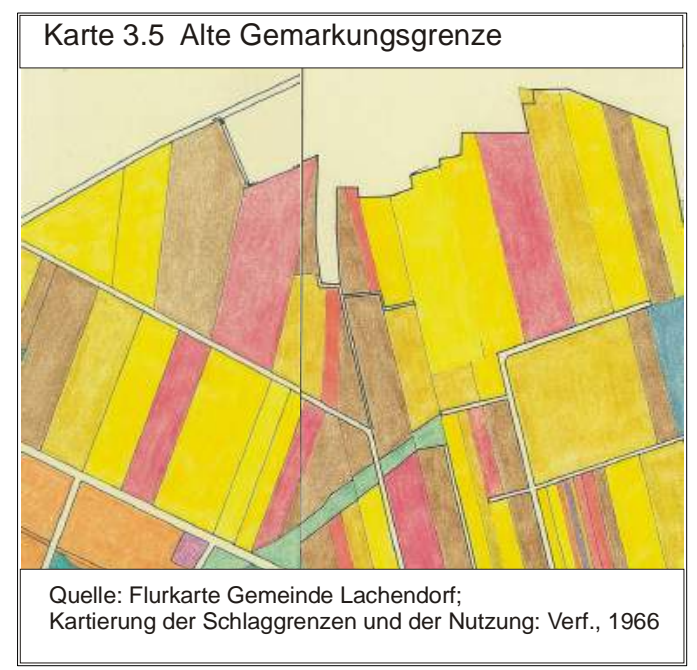

Die alte Gemarkungsgrenze

der Lachendorfer Gemarkung ${ }^{1}$ östlich der Straße nach Beedenbostel gibt ebenfalls einen deutlichen Hinweis auf die alte Flurform mit geschwungenen Langstreifen: Eine schmale und geschwungene Ausbuchtung der Gemarkungsgrenze $^{2}$ ist das Relikt aus der Reform der Flureinteilung, die mit dem Rezess von 1859 abgeschlossen wurde, weil ein Interessent seine Zustimmung zur Neueinteilung der Flur verweigerte. Auch der Parzellenverlauf erinnert noch an die

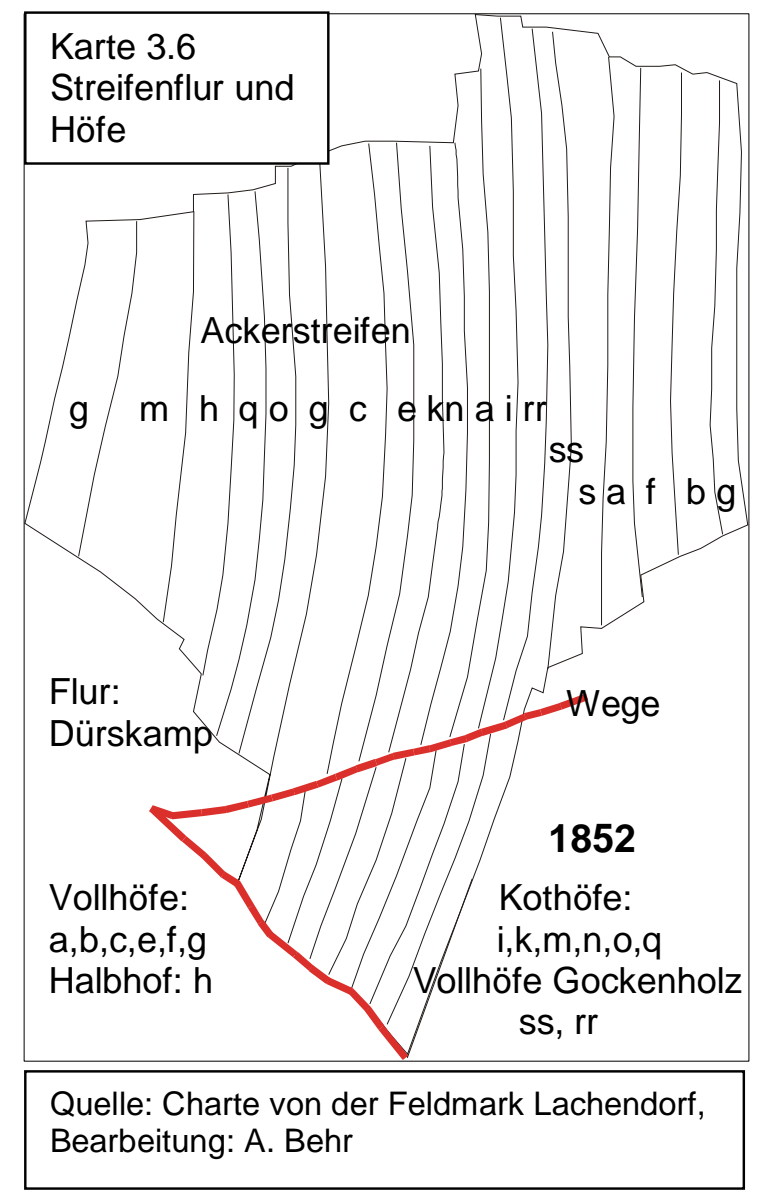

Quelle: Charte von der Feldmark Lachendorf Bearbeitung: A. Behr alte Flurform. Dies Relikt wurde mit der Flurbereinigung nach 1966 beseitigt.

Die Zusammenfassung benachbarter Ackerstreifen in einer sog. Langstreifenflur zu Zelgen oder Gewannen war eine Folge der Wirtschaftsweise, nämlich der Dreifelderwirtschaft und des Flurzwangs, also eigentlich Folge der Gemeinschaftsweide.

Die einzelnen Gewanne bestanden aus einer unterschiedlichen Zahl von Langstreifen, also Pflugbeeten mit jeweils verschiedenen Besitzern.

Im Beispielflurstück „Dürskamp“, das auf der Gockenholzer Geestinsel lag, hatten 6 von 7 Vollhöfen, der Halbhof, 6 von 12 Kothöfen und zwei Vollhöfe aus Gockenholz jeweils einen, maximal 2, Langstreifen. Aus diesem System ergab sich zwangsläufig die sehr große Anzahl der Flurstücke (s. Tab. 3.1), die zu einem Hof gehörten.

An den Böden dieses Gewannes, die später im südlichen Teil mit 37 - 40 und im nördlichen Teil sogar mit 45 - 49 Bodenpunkten bewertet wurden, hatten die Brinksitzer sowie die Anund Abbauern keinen Anteil.

Während es sich bei der Kartierung der Streifenflur auf der Kurhann. Karte (s. Karte 3.4) um eine Signatur handelt, darf man annehmen, dass auf der Verkoppelungskarte von 1852 wegen der Notwendigkeit der genauen Besitzerfassung die einzelnen Ackerstreifen entsprechend Form und Größe richtig dargestellt sind.

Dann ist es bemerkenswert, dass diese weder untereinander von gleicher Breite noch in sich gleich breit waren. Die Frage bleibt offen, wie solche ungleich breiten Ackerstreifen mit einem einscharigen Beetpflug gleichmäßig zu pflügen waren. Eine rationelle Bodenbearbeitung war auf solchen schmalen und unregelmäßigen Ackerbeeten kaum möglich.

\footnotetext{
${ }^{1}$ s. Karte 3.5

2 s. Karte 3.5, dort: alte Gemarkungsgrenze zwischen Lachendorf und Beedenbostel
} 
Diese Gemengelage der Ackerparzellen und die große Parzellenzahl eines Hofes wird teils mit den mittelalterlichen Teilungen ${ }^{1}$ der Höfe und auch mit einer gerechten Verteilung der unterschiedlichen Bodenfruchtbarkeit begründet. Bei diesem System sind schmale Ackerparzellen günstig, da sonst die Gewanne sehr groß und bzgl. der Bodenfruchtbarkeit zu unterschiedlich ausfallen würden, was einer gerechten Verteilung zuwider laufen würde.

Während es bei den Besitzparzellen eine sehr große Vielfalt und Streulage gab, haben die Gewanne dennoch wegen der einheitlichen Bewirtschaftung unter dem Flurzwang ein recht einheitliches Landschaftsbild erzeugt. Aus der Vielzahl der Ackerstreifen und der extremen Streulage darf man also nicht auf ein buntes Mosaik der ackerbaulichen Kulturlandschaft schließen. Eine extreme Streulage der zu jedem Hof gehörenden Nutzparzellen stand vor 1850 aufgrund der Wirtschaftsweise einem relativ großflächigen und einheitlichen optischen Bild der Kulturlandschaft im Ackerbereich gegenüber.

\section{Wölbäcker}

Die Langstreifen waren als Pflugbeete jeweils durch eine Furche getrennt und wiesen im Querprofil eine leichte Aufwölbung zur Mitte hin auf.

Solche gewölbten und langgestreckten Parzellen sind morphologisch heute nur noch als Reliktformen, den sog. Wölbäckern, als Zeugen ehemaliger Ackernutzung unter Wald erhalten. Gelegentlich lässt sich diese alte Langstreifenflur aber auch noch auf Luftbildern aufgrund der unterschiedlichen Bodenfeuchte auf Ackerfluren, die nicht bewachsen sind, erkennen.

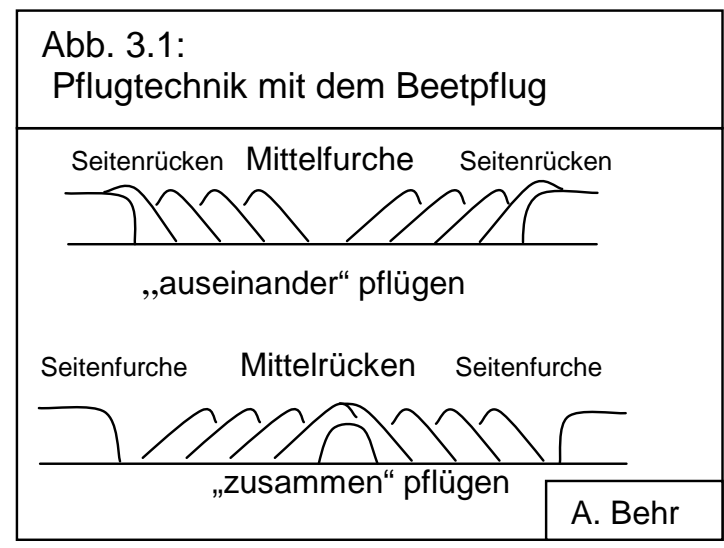

Die Gründe für die Anlage der Wölbäcker in der Ackernutzung sind bis heute ungeklärt.

Mit Sicherheit ausschließen kann man die oft vertretene und auch publizierte Theorie ${ }^{2}$, die Wölbäcker seien eine Folge des Beetpfluges.

Beetpflüge mit einem Schar und einem Streichbrett ${ }^{3}$ waren eine sehr vorteilhafte Weiterentwicklung des Hakenpfluges, denn der Ackerboden wird nicht nur gelockert, sondern gewendet und gekrümelt. Bis zur Entwicklung des Kipp- oder Drehpfluges wendeten die Beetpflüge den Boden immer nur zur selben Seite. Bekannt aus der Literatur ${ }^{4}$ und der Anschauung moderner Pflüge wenden alle Pflüge den Boden nach rechts.

Daraus wurde geschlossen, dass beim Pflügen notwendigerweise in der Mitte der Parzelle ein Rücken oder Wall entsteht, an beiden Rändern dagegen eine Furche, und sich so ein gewölbtes Pflugbeet ergibt.

Dies geschieht aber nur, wenn mit einem rechtswendigen Pflug immer rechts herum, also im Uhrzeigersinn, gepflügt wird. Würde man immer links herum, also gegen den Uhrzeigersinn, pflügen, ergäben sich Rücken an den Seiten und eine Furche in der Mitte.

Nun ist bekannt, dass sich durch gleichgerichtetes Pflügen mit einem wendenden Beetpflug schon nach wenigen Pflugperioden erhebliche Höhenunterschiede ergeben. Dies wird durch Ackerterrassen in Hanglagen sowie durch Ackerraine ${ }^{5}$ in Altsiedelgebieten ohne Flurbereini-

\footnotetext{
${ }^{1}$ Schneider und Seedorf, Bauernbefreiung und Agrarreformen i Niedersachsen, Hildesheim 1989, S. 17

${ }^{2}$ vergl. Hansjörg Küster, Geschichte der Landschaft in Mitteleuropa, München 1999, S. 127/128 und H. Küster; Das ist Ökologie, München 2005, S. 124.

${ }^{3}$ Die ersten Beetpflüge hatten nur ein Metallschar und noch ein hölzernes „Streichbrett", das heute als "Streichblech" bezeichnet wird, seit es aus Eisen bzw. Stahl hergestellt wird.

${ }^{4}$ W. Hamm, Das Ganze der Landwirtschaft, Leipzig 1872, S. 96 f: Der Pflug

${ }^{5}$ Noch 1999 konnte der Verfasser im südpolnischen Altsiedelgebiet Ackerraine mit erheblicher Höhendifferenz beobachten, die ganz offensichtlich einen Folge des Pflügens waren.
} 
gung bis heute bestätigt. Auch bei der damals noch üblichen sehr flachen Pflugtiefe hätte sich bei ständigem „Zusammenpflügen“ schon nach wenigen Jahrzehnten ein beträchtlicher Höhenunterschied zwischen Rücken und Furche ergeben, der gerade bei der sehr geringen Breite der Parzellen besonders stark ins Gewicht gefallen wäre.

Es kann mit Sicherheit angenommen werden, dass die Bauern nach Einführung des Beetpfluges sehr bald erkannten, wie man auch mit einem einseitig wendenden Beetpflug ein langfristig ebenes Pflugbeet erhält. Dies Verfahren wird auch heute überall dort angewandt, wo nicht mit einem Drehpflug gearbeitet wird, dessen gegenüber liegende Pflugkörper einmal rechts und einmal links wendend sind.

Man erreicht dies, indem man bei jedem Pflügen der Parzelle die Pflugrichtung ändert: Fängt man in der Mitte an, pflügt man rechts herum im Uhrzeigersinn und erhält in der Mitte einen Mittelrücken (sog. „Zusammenpflügen“) und an den Seiten bleibt die letzte Furche offen. Beim nächsten Pflügen beginnt man an den Außenrändern und pflügt links herum im Gegenuhrzeigersinn, sodass zum Schluss in der Mitte eine nicht geschlossene Furche (sog. „Auseinanderpflügen“) bleibt.

Nun muss man beim Pflügen mit dem Beetpflug in parallelen Furchen am Ende jeder Furche mit einer „Leerfahrt" auf der sog. „Wende“ zur nächsten Furche in der Gegenrichtung wechseln. Um die Zeit dieses Leerlaufs nicht zu groß werden zu lassen im Gegensatz zur wirklichen Pflugzeit, dürfen die Pflugbeete nicht zu breit und nicht zu kurz sein.

Auch dies wird gelegentlich als Begründung für die Entstehung der Langstreifenflur herangezogen, kann aber ebenfalls leicht widerlegt werden: Will man die Zeit auf der Wende einer breiten Ackerparzelle verringern, so unterteilt man den Acker in zwei Hälften, fängt auf der einen Hälfte in der Mitte mit einem Rücken an, pflügt diese Hälfte vollständig um, pflügt dann auf der anderen Hälfte weiter und endet dort in der Mitte mit einer Furche. Insgesamt ergibt sich so insgesamt in der Mitte des Ackers ein doppelt breites und ebenes Pflugbeet.

Solange man mit Pferden pflügte, hat man auch besonders lange Schläge unterteilt, obgleich ein durchgehendes Pflügen der Schlaggröße durchaus sinnvoll gewesen wäre. Das hing mit der Leistungsfähigkeit der Pferde zusammen. Entlang der Pflugfurche gehen die Pferde durchgehend stramm im Geschirr und bei einer Anspannung mit einem Sielengeschirr, wie es in Norddeutschland durchweg üblich war, drückt das Brustblatt beim schweren Ziehen den Brustkorb des Pferdes zusammen. Auf der Wende, wo der Pflug nur lose mitgeschleift wird, gibt es für die Pferde jeweils eine kurze Verschnaufpause.

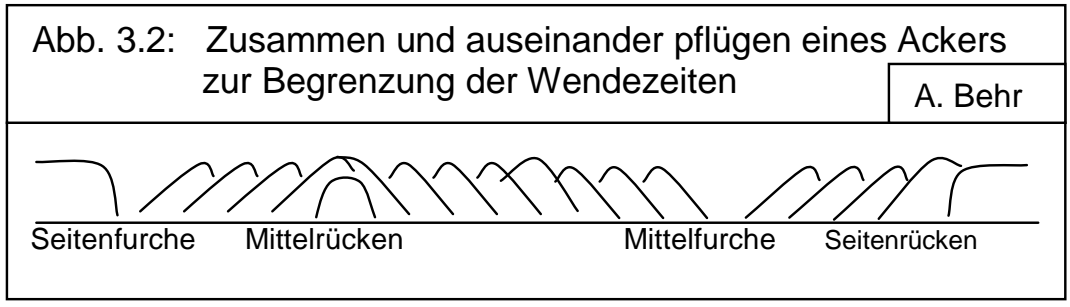

Zur Erklärung der Langstreifenflur und der Wölbäcker können also weder der Beetpflug noch die Pflugtechnik herangezogen werden ${ }^{1}$.

So bleiben als Erklärungsversuche nur Argumente aus der Bodenfruchtbarkeit. Ein Grund für die schmalen Langstreifen könnte die Drainagewirkung der Trennfurchen gewesen sein. Mit der Klimaänderung im ausgehenden Mittelalter, der einsetzenden „Kleinen Eiszeit"“2, könnten sich die Bodenwasserverhältnisse verschlechtert haben. Der Beetpflug bot nun die günstige Möglichkeit, die Ackerparzellen durch eine Furche zu trennen, die gleichzeitig der Entwässerung diente. Dagegen spricht allerdings, dass auch die Gewanne auf sehr leichtem Sandboden, wie z. B. auf dem Lachte-Schwemmfächer, ebenfalls in Langstreifen unterteilt waren.

\footnotetext{
${ }^{1}$ vergl. H. Becker; Allgemeine historische Agrargeographie, a.a.O., S. $102 \mathrm{ff}$

${ }^{2}$ s. R. Glaser, Klimageschichte Mitteleuropas, a.a.O., S. $195 \mathrm{ff}$
} 
Die Drainage als Begründung ${ }^{1}$ für die Wölbäcker ist auch deshalb fraglich, weil die Wölbäcker mit den Verkoppelungen im 19. Jahrhundert verschwanden, bevor man nasse Böden flächenhaft durch Tonröhren im Untergrund drainierte.

Die leichte Wölbung wurde sicherlich absichtlich erzeugt, in dem man häufiger zusammen als auseinander pflügte. Das könnte mit der damals sehr dünnen Ackerkrume zusammenhängen. Beim Zusammenpflügen war wenigstens in der Mitte der Parzelle eine etwas mächtigere Ackerkrume vorhanden. Das Kulturhistorische Lexikon führt auch die Bodenfruchtbarkeit als Grund für die Wölbäcker durch ständiges „Zusammenpflügen“ an, „da der Bauer seinen kostbar gedüngten Mutterboden zusammen halten wollte“2. Die Begründung klingt plausibel, ein dauerndes „Zusammenpflügen“, also ein stetiges Wenden des Bodens zur Mitte mit der Bildung eines Mitterückens, würde - wie oben bereits ausgeführt - in wenigen Jahren zu einem zu starken Niveauunterschied zwischen Mitterücken und den Trennfurchen zum nächsten Langstreifen führen. Eine sehr bzw. zu starke Wölbung durch einheitliches Pflügen hätte man auch durch starkes bzw. mehrfaches Eggen wieder weitgehend einebnen können. Das hätte aber einen zusätzlichen Arbeitsaufwand verursacht, der durch - wenigstens gelegentliches - „Auseinanderpflügen“ leicht zu vermeiden war.

\subsubsection{Landschaft und Dreifelderwirtschaft}

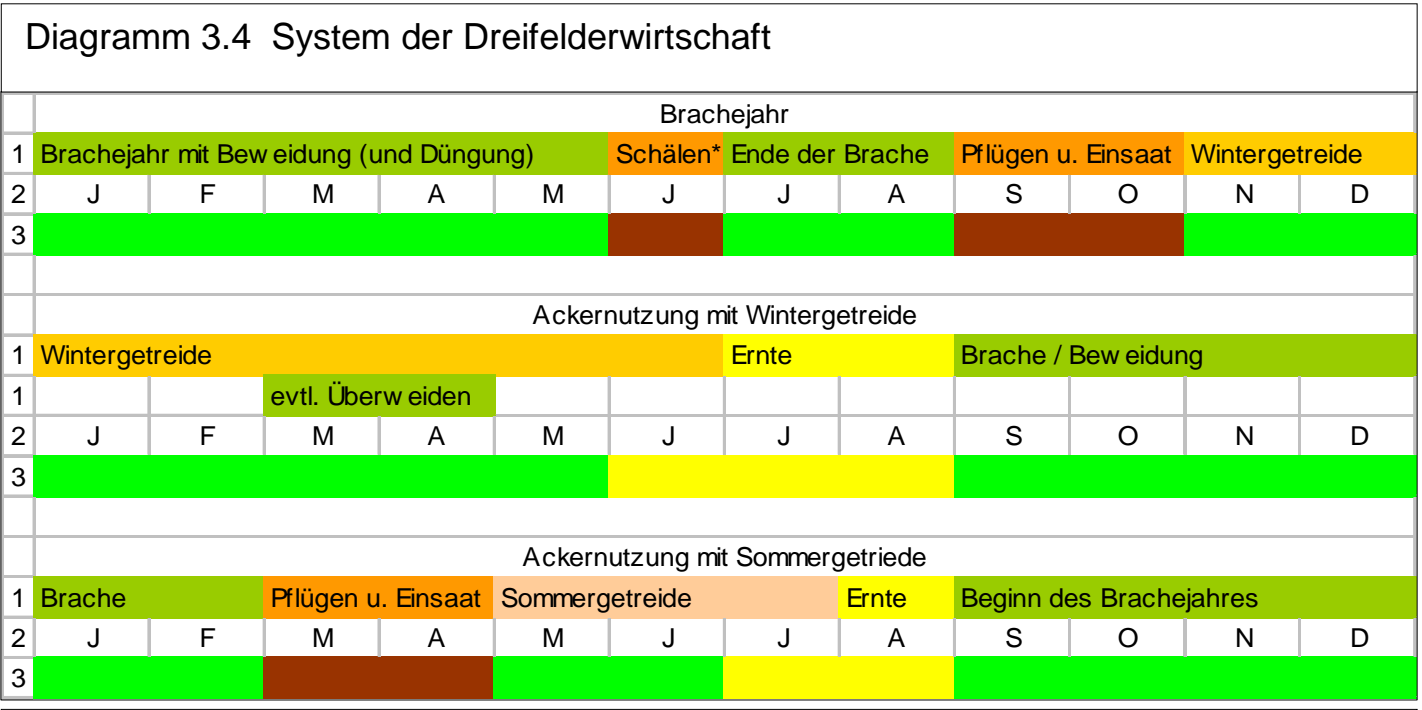

Legende: Zeilen 1: Nutzung, Zeilen 2: Monate des Jahres; Zeilen 3: vorherrschende Färbung der Ackerflächen; *) Schälen: ganz flaches Pflügen, eigener Entwurf

Die Dreifelderwirtschaft, über viele Jahrhunderte die vorherrschende Wirtschaftsweise, trug zu einem einfachen und ziemlich einheitlichen Bild der Flur ganz wesentlich bei. Die Dreifelderwirtschaft ließ ja nur drei Nutzungsarten in der festen Fruchtfolge auf den Gewannen zu. Bei der Rotation der Nutzungsart gäbe es in der Dreifelderwirtschaft grundsätzlich zwei unterschiedliche Reihenfolgen ${ }^{3}$ :

- Sommergetreide - Wintergetreide - Brache

- Wintergetreide - Sommergetreide - Brache

Da es einerseits keine chemische Bekämpfung des „Unkrautes“" , also der Wildkräuter, im Getreide gab und andererseits nach der jeweiligen Getreideernte ein schnelles Begrünen der

\footnotetext{
${ }^{1}$ s. H. Becker, a.a.O., S. 103

2 Tödter, Helmut R.; Kulturhistorisches Lexikon, Heidenau 2010, S. 143

${ }^{3}$ In der Lit. Konnte keine Beweis über die tatsächliche Reihenfolge in der Dreifelderwirtschaft gefunden werden. Küster, s. a.a.O. S. , geht von der Reihenfolge „Winterfrucht, Sommerfrucht, Brache“. Ein Beweis für diese Reihenfolge liegt aber nicht vor. (mdl. Mitteilung von Prof. Dr. Hansjörg Küster)
} 
Stoppelfelder wegen der Beweidung durchaus erwünscht war, herrschte auf den Äckern auBer zur Zeit des Pflügens und anschließender Bestellung (Aussaat) in den Wachstumszeiten die Farbe grün und zur Reife- und Erntezeit des Getreides die Farbe gelb vor.

Die Agrarlandschaft zur Zeit der Dreifelderwirtschaft bot also ein ziemlich einheitliches Bild und hinsichtlich der Nutzung keineswegs eine ökologische Vielfalt. Diese ökologische Vielfalt herrschte nur hinsichtlich der Anzahl der Gräser und Kräuter auf den Brachflächen, da sich diese wild besamten, bevor der gezielte Anbau bestimmter Gräser, Klee, Luzerne und Lupinen auf den Brachfeldern und als Untersaat im Getreide zur Gründüngung und Futtergewinnung üblich wurde.

In der Heide hatten sich auch Fruchtfolgen mit mehrjährigem Getreideanbau, besonders mit Roggen, eingebürgert, wie es Tabelle 3.12 mit einer typischen Fruchtfolge der Heidebauernwirtschaft zeigt. Es handelt sich dabei aber im Grunde auch um eine Dreifelderwirtschaft, nur nicht im dreijährigen Rhythmus.

Solange die Dreifelderwirtschaft in ihrer ursprünglichen Form von allen Dorfgenossen ohne Alternative angewandt wurde und die Feldarbeit wesentlich auf Handarbeit beruhte, bot die tradierte Verfassung der Flur mit den zu Gewannen zusammengefassten Ackerstreifen, der Streulage und dem Flurzwang einen angemessenen Rahmen für die Landwirtschaft, der ihren Bedürfnissen und Möglichkeiten bestens angepasst war. Daher wäre es falsch, diese Agrar- und Flurstruktur als hinderlich für die damalige Landnutzung bzw. die Arbeit der Bauern einzustufen.

Die Dreifelderwirtschaft mit großen Gemeinschaftsflächen, den Gemeinheiten bzw. Allmenden, für Beweidung, Hutung und Plaggenhieb hatte sich eine dazu passende Agrarlandschaft geschaffen. Typische Merkmale dieser zeitgenössischen Agrarlandschaft waren die meist ortsnah gelegenen Ackergewanne, das Grünland in den Flussauen und am Rand von Mooren sowie die großen, überwiegend waldarmen und waldlosen Hutungen, die sich in Nordwestdeutschland zu großen Heideflächen entwickelt hatten. In dieser offenen, vollständig landwirtschaftlich genutzten Landschaft lagen die Dörfer wie Inseln, da sie sich durch reichen Baumbestand auszeichneten. Dieser Baumbestand war dringend erforderlich, um vor allem Bauholz und Früchte zur Schweinemast zu liefern.

\subsubsection{Landschaft - Gemeinheit/Allmende - Gemeinschaftsweide}

Was den Bauern damals wirklich große Schwierigkeiten bereitete, waren die vielfältigen Nutzungskonflikte zwischen den einzelnen Bauern und insbesondere zwischen den Interessenten der benachbarten Dörfer. Die Gründe für diese Streitigkeiten lagen vor allem darin, dass es keine klaren Eigentums- und Gemarkungsgrenzen gab und sich die Nutzungsrechte in der freien Landschaft oft überschnitten bzw. große Flächen nicht nur von den Eingesessenen eines Dorfes gemeinsam zur Weide genutzt werden durften, sondern ganze Dorfschaften gemeinsame Nutzungsrechte hatten.

Die Akte von 1728 macht deutlich, wie groß die Weidegebiete der einzelnen Dörfer waren und wie stark sich diese überschnitten. Alles Land außerhalb der Ackerflächen diente eben zur gemeinsamen Weide, die sich zu bestimmten Jahreszeiten auch auf die Ackerflächen bezog.

Lachendorf

Das Dorf Lachendorf hat Ihre Huedt und weyde für der [unleserlich] Schneede ${ }^{3}$, als Oppershausen her, für dem Osterbruche, bey der Sprache, hinter Gockenholtz herumb, hinter Beydenbostell nacher Höfer, Jarnsen Bunkenburg, für Spechtshorn Helmercampe und Ahnsbecker Felde, und mögen alle hier beschriebene Dörfer wieder [ ] den Lachendorfern, weil sie alle mit einander gesambt Hued haben, hüten und eintreiben,

$$
\text { (Unterschrift) Ernst Ebling }
$$

\footnotetext{
${ }^{1}$ Das Artenspektrum der Wildkräuter (Unkräuter) war geringer als heute wg. des Nährstoffmangels. Besonders Stickstoff liebende Wildkräuter waren noch kaum vertreten.

${ }_{2}^{2}$ ]: Markierung unleserlicher Stellen

${ }^{3}$ Schneede: Grenze
} 
Extrahiret auß dem Ambts-Lagerbuch

Beedenbostell am 10ten July $1728^{1}$

Über die zahlreichen Prozesse, die von den Vogteien bearbeitet und entschieden werden mussten, geben alte $A_{k t e n}{ }^{2}$ aus dem 18. und der 1. Hälfte des 19. Jahrhunderts beredtes Zeugnis.

\section{Streitigkeiten um Nutzungsrechte und Grenzen}

\section{Immenstelle im Bulloh ${ }^{3}, 1708$}

„Actum jenseits den Lachendorfer Stege den 15.ten Juny 1708

Als die Eingesessene zu Lachendorff angezeiget, dass die von Hans Jürgen Ohlmann zu Beedenbostel in der Bullow angelegte Immenstelle auf ihrer Acht ${ }^{4}$ belegen, und zu Regulierung der streitigen Schneede heute der Augenschein eingenommen wurde, so erschienen beyderseitige Dorfs Geschworene nebst verschiedenen Eingesessenen, und verlangten von Amtswegen dass zuvorderst jeder Theil seine vermeintliche Acht bezeichnen solle.

\section{Die Beedenbosteler}

behaupteten solche von dem Herrschaftlichen Vogel-Herd auf einen Eichen Baum, welcher auf Meyers Land zu Lachendorff stand, von da auf Cohrs Dorn Busch nach einer Wende an Drallen Land in der [ ] herunter den Zeller Weg.

Die Lachendorffer

hingegen gaben ihre Schneede an, von dem Kirch Stege über Hunen ausgepflügtes Land, vor Müllers Gehäge über durch die Bullow auf Meyers Ellern ${ }^{5}$ Busch, den Graben entlang, in den Zeller Weg hinauf und so weiter an den Spetzen Föhrt ${ }^{6}$.

Adendo daß unter den Kirch Stege eine Eiche ehedem gestanden, wovon das Stamm Geld unter den Geschworenene zu Beedenbostel und Lachendorff getheilet, und vorhin bemerktermaßen das Ochsen Gehäge jederzeit bestochen worden.

Die Lachendorffer schlugen zu Behauptung ihres asperti Hans Hinr. Grellen und Hinrich Drallen zu Zeugen vor.

Die Beedenbosteler verwarfen solche als membra universitatis.

Wie es nun hauptsächlich auf die Differents zwischen den hinc inde angegebenen Ellernund Wacholdern Busch ankam, so etwas über 300 Schritte betrug, welches umsoweniger einen Rechts-Streit verdiente, da die Koppel Weide nach [ ] verblieb, so wurde dieser Tractus Confessus Partium getheilet und eine Schneede ${ }^{7}$ heute vor Drögemüllers Land aufgeworfen, dabey aber Lüsmanns, Drögemüllern, und Werner Meyern der Plaggen Hieb auf 30 Schritt von dem Graben und bis an Öhlmanns Immen Zaun, behuf Düngung ihres hieselbst belegenen Landes zugestanden, jedoch dass diese Plaggen nicht nach Hause gefahren und der Hieb sonst von Niemanden exerciret werden sollte.

\footnotetext{
${ }_{1}^{1}$ Quelle: Unveröffentlichte Akte der Samtgemeinde Lachendorf, ohne Signatur. Transkription vom Verf.

${ }^{2}$ Alle Beispiele sind unveröffentlichten Akten der Samtgemeinde Lachendorf entnommen. Der Text der Akten ist handschriftlich in Sütterlin verfasst und wird hier vom Verf. in der originalen Orthographie wiedergegeben. Die zitierten Aktentexte sind kursiv gedruckt. Unleserliche Stellen sind durch Lücken im text erkennbar.

${ }^{3}$ Bulloh, früher Bullow: Flurbezeichnung

${ }_{5}^{4}$ Acht, die ; nach Grimmschen Wörterbuch: Grundbesitz

${ }^{5}$ Ellern, niederdtsch.: Erlen

${ }^{6}$ Flurbezeichnung

${ }^{7}$ Schneede: Grenze, Grenzmarkierung,; heute nur noch gebräuchlich in Flur- oder Straßennamen: z.B. Altenceller Schneede, Straße im heutigen Celle, zwischen altem Stadtgebiet und heutigem Stadtteil Altencelle
} 
Es wurde solchemnach fest gesetzet, dass beyder Dorfschaften Schneede von dem Lachendorfer Stege auf Müllers Gehäge gerade nach den nun aufgeworfenen Haufen, von da den Graben entlang den Zeller Weg hinauf gehen, mithin Öhlmanns Immen Zaun Beedenbosteler Acht verbleiben, Übrigens aber diese regulirung der bisherigen Huet und Weide im mindesten nicht praejudiciren sollte."

Unterschrift (unleserlich)

Hier geht es um einen Grenzkonflikt in der Feldmark nordwestlich des Dorfes, nördlich der heutigen Straße vom Ort zum Heideck, dem jetzigen Gewerbegebiet „Im Bulloh“.

Zum einen wird deutlich, dass es noch keinen Besitzkataster und keine vermessenen Grenzen gab, die eine eindeutige besitzrechtliche Zuordnung erlaubten.

Zum anderen wird auch dargelegt, wie genau und detailliert Nutzungsrechte festgelegt wurden, wenn drei Bauern das Recht zum Plaggenhieb auf 30 Schritt von der Grenze erlaubt wird, dies aber nur zur Düngung der angrenzenden Felder, nicht zum weiteren Gebrauch, weder für sich noch für andere. Der Immenzaun blieb im Beedenbosteler Besitz, insofern die Klage der Lachendorfer abgewiesen wurde, aber mit der Einschränkung, dass die bisherigen Hut- und Weiderechte davon unberührt blieben.

\section{Streit um Nutzungsrechte in der Allerheide (1822)}

Actum Burgvogtei Celle

Auf der sogenannten Allerheide, den 17. April 1822

Praesentes (Anwesende)

Herr Amts-Assessor Kaufmann

und ich, der Endes unterschriebene Titulair-Amts-Assessor Bergmann

In Sachen

der Eingesessenen zu Lachendorf, Imploranten (Antragsteller auf gerichtliche Hilfe)

wider

die Dorfgemeinschaft Altencelle, Imploratin, (Gegner der Imploranten)

in pto. spolii.

Zu dem auf heute angesetzten Termine zur Einnehmung des Augenscheins waren erschienen:

1) Von Seiten der Imploranten, die Syndici der Gemeinde Lachendorf, Johann Jürgen Thies, und Köthner Heinrich Koch sowie auch der Geschworene Johann Jürgen Thies, sämtlich aus Lachendorf.

2) Von Seiten der Imploratin hatten sich im Beistande des Oberrappellations-GerichtsProcurators Dr. jur. Wöttje aus Celle, nachstehende Männer eingefunden, als:

die Syndici der Imploratin, die Amtsgeschworenen Höper und Thies aus Altencelle, der Vollhöfner Wilhelm Ebeling,

der Vollhöfner Wilhelm Viet, der Vollhöfner Heinrich Düwel, der Vollhöfner Christoph Walheincke, der Vollhöfner Johann Heinrich Marwedel, der Kleinköthner Johann Brockelmann, der Amtsgeschworene Christoph Ohlens, sämtlich aus Altencelle, auch der Gemeindegeschworene Christian Walheincke aus Osterloh.

Als Zeugen waren ebenfalls erschienen:

Johann Jürgen Lielje,

Heinrich Baumann und Hans Heinrich Lüßmann, alle aus Lachendorf, 
wurde gerichtsseitig zuvörderst das Local (die Örtlichkeit) in Augenschein genommen und anliegende Handzeichnung davon angefertigt. Als man darauf inter partes die Güte versuchte, so kam nach langen Verhandlungen folgender Vergleich unter beiden Teilen zu Stande:

Die Eingesessenen zu Lachendorf inskünftige bis zu einer neu aufzuwerfenden Schnede auf der Allerheide mit Hornvieh und Schafen hüten dürfen, und zwar gemeinschaftlich mit der Dorfschaft Altencelle.

Gedachte Schnede soll heute über acht Tage, als am 24. dieses Monats, durch Aufwerfung von fünf Schnedehügeln ausgemacht und bezeichnet werden, und soll von dem nahe an der Sprache stehenden Fichtenbaum, welcher gerichtsseitig mit drei Kreuzen bezeichnet worden und welcher von Johann Heinrich Lindemanns Immenstelle, so vor der Sprache belegen, zweihundert Schritte nach Lachendorf zu, befindlich ist, in gerader Linie und Richtung auf Rehwinkels zu Oppershausen Immenstelle, zu laufen, und in diesem Zwischenraum, nämlich zwischen dem bezeichneten Baume vor der Sprache, rückwärts von diesem Baume bis an den Wald, und vorwärts bis an gedachte Rehwinkels Immenstelle, durch die aufgeworfenen Schnedehügel bezeichnet und festgestellt werden. Dabei soll es aber in Ansehung der Berechtigung der Altenceller, bis an die sogenannte Lachendorfer Schnede, Plaggen zu hauen, so verbleiben und dieser Vergleich darauf keinen Einfluß haben. Dagegen entsagen die Lachendorfer allen ferneren Ansprüchen auf Hut und Weide auf dem Teile der Allerhede, welcher über der oben beschriebenen Grenze hinaus nach Altencelle zu liegt, damit gänzlich.

Für die gepfändeten 7 Stück Schafe zahlt die Dorfschaft Altencelle der Dorfschaft Lachendorf 6 (Einheit: unleserlich) Conventionsmünze, vorausgesetzt, dass die Eigner dieser Schafe hiermit zufrieden sind, im entgegengesetzten Falle soll es diesen letzteren unbenommen bleiben, den Prozeß wegen Herausgabe dieser 7 Stück Schafe, auf eigene Kosten fortzusetzen., als worüber eine Erklärung von Seiten der Dorfschaft Lachendorf, am 24. dieses erfolgen soll.

Sämtliche auf diesen Prozeß verwandten Kosten, diejenigen mit eingeschlossen, über welche bereits erkannt worden, werden hiermit verglichen.

Schließlich wird noch bemerkt, dass auf den Vortrag des Gemeindegeschworenen Wallheincke von Osterloh, die sämtlichen erschienenen Mitglieder der Dorfschaft Altencelle, in hodierno anzuerkennen sich bereit erklärten, dass alle Gerechtsame, welche die Altenceller auf der Allerheide hätten, gleichmäßig der Dorfschaft Osterloh zuständen.

Vorgelesen und genehmigt. Actum ut supra. in fidem Bergmann Copia für die Eingesessenen zu Lachendorf

Pro.conf.rot.test.prob.

12 Bogen, à 3 ggr 4 Pf.

„term. Dim.

„prot. Cop.u.?

"Fuhrlohn, div.

, inf.

\begin{tabular}{ccc}
1 Rthl. 16 ggr. \\
1, & 2, & $8 P f$ \\
& 13 “ & $8 P f$. \\
1, & 2, & $8 P f$. \\
& 1, & $8 P f$ \\
\hline
\end{tabular}

\section{Streit um Nutzung in den Allerdreckwiesen}

„Actum Amt Beedenbostel, den 17. April 1837

Zu dem zur Errichtung eines Syndicats, von Seiten der Dorfschaft Ahnsbeck wider die Dorfschaft Lachendorf, wegen Behutung der Allerdreckwiesen, gegenwärtig anhebenden Processe, auf heute anbemahnten Termine erschienen aus Ahnsbeck."

Namentlich als anwesend werden aufgeführt: 10 Vollmeier, 1 Sattelhöfner, 1 Halbhöfner, 17 Köthner, 15 Brinksitzer und ein Abbauer. Es fehlten also zu diesem offenbar wichtigen Termin lediglich 3 der 48 Eingesessenen zu Ahnsbeck, nämlich ein Vollmeier, ein Brinksitzer und ein Anbauer, wobei ausdrücklich vermerkt ist, dass der Brinksitzer „durch erlittenen Armbruch zu kommen gehindert" war. 
„Die Comparenten erkennen einstimmig die Notwendigkeit an, mit Lachendorf einen Proceß zu erheben, da diese Dorfschaft in den letzten Jahren angefangen, es sich herauszunehmen, gleich ihnen die Allerdreckwiesen bis alten Maitag ${ }^{1}$ mit Hornvieh zu behüten, was jenen um so weniger zugestanden werden könne, als Gesetz und Herkommen dem entgegen sei, und sie nur bis zum 1sten May zur Ausübung der Weide daselbst mit Hornvieh ein Recht hätten."

Nach Vorbringen des Klagegrundes werden als bevollmächtigte Vertreter, sog. Syndicis, der Köthner Carsten Heinrich Thies und der Brinksitzer Heinrich Christoph Dierks sowie zwei Ersatzmänner gewählt, die die Wahl annehmen und alle Vollmachten zur Führung des Prozesses erhalten. Danach werden alle anderen Comparenten entlassen.

Die Bevollmächtigten tragen den Sachverhalt der Klage vor:

„In südwestlicher Richtung von Ahnsbeck aus, erstrecke sich eine weite Fläche von Wiesen, die sogenannten Allerdreckwiesen, welche teils ihnen, den Ahnsbeckern, teils den meisten Eingesessenen von Lachendorf, teils einzelnen Einwohnern aus den verschiedenen Dorfschaften hiesigen amtseigentümlich zugehörten.

Auf diesen Allerdreckwiesen seien nun die beiden Dorfschaften Ahnsbeck und Lachendorf zur Hut und Weide mit Hornvieh berechtigt, den Termin der im Spätsommer anfangenden Hütung sei für die beiden Dorfschaften gleich, da dieselbe gleich anhebe, wenn das Heu von den einschürigen Wiesen herunter sei.

Der Endtermin sei aber ein ungleicher, da sie, die Ahnsbecker, laut rechtskräftigem Erkenntnisse, sie meinten de 1776, bis 11. Mai, alten Maitag, hüten dürften, wogegen die Lachendorfer sowohl nach diesfalls bestehenden Landesgesetzen, als nach dem Herkommen von den ältesten Zeiten her, stets nur berechtigt gewesen, bis zum 1. Mai ihre Hut auszuüben, da jene gegenwärtig es sich aber beigehen ließen, gleich ihnen, eine Ausübung bis alten Maitag in Anspruch zu nehmen, so wollten sie bitten, dieselben schuldig zu verurteilen, mit 1. Mai jeden Jahres ihre Hude mit Hornvieh einzustellen, auch alle Kosten zu tragen.

Könnten sie, die Lachendorfer freilich nun auch wohl nicht zwingen, ihr Eigentum nach Willkür zu benutzen, so werde ihre Bitte doch dahin gerichtet werden dürfen, dass die Lachendorfer vom 1. - 11. Mai ihre einzelnen Wiesen, jedem einzeln, nur mit seinem Hornvieh, nicht durch die Dorfherde oder das Vieh anderer, und auch dann behüten zu lassen haben, wenn er seine Wiese erreichen könne ohne die anderen Angrenzen zu übertreiben."

Vorgelesen und genehmigt

ut supra in fidem

Wittings

Actum Amt Beedenbostel 19. April 1837

Im Amt wird dem Vollmeier und dem Anbauer, die zwei Tage vorher nicht anwesend waren, das Protokoll vom 17.4. wortwörtlich vorgelesen. Nach Zustimmung werden sie entlassen.

„Bei Mitteilung vorstehender Protokolle an die Gemeinde Lachendorf, ist Letztere geladen, Mann für Mann, jeder bei 12 ggr. Strafe am Sonnabend dem 6. März, 9 Uhr morgens zur Errichtung eines Syndicats vor hiesiger Amtsstube zu erscheinen, und hat der Geschworene ein Verzeichniß sämtlicher Gemeindeglieder in termino vorzulegen. "

Beschlossen Beedenbostel den 19. April 1837 Königliches Amt

Wittings

${ }^{1}$ Alter Maitag: 11. Mai 
Die Bevollmächtigten haben offenbar einen Vergleich ausgehandelt, der am 9. Juni 1837 amtlich bestätigt und rechtsgültig wird.

Actum laut Beedenbostel den 9. Juni $1837^{1}$

„In Sachen

der Gemeinde Ahnsbeck, modo deren Syndiken Köthner Carsten Heinrich Thies und Brinksitzer Heinrich Christoph Dierks daselbst, Klägerin

wider

die Gemeinde Lachendorf, modo deren Syndiken Vollmeier Meyer und Köthner Koch, daselbst, Beklagte

wegen

Behutung der Allerdreckwiesen.

Erschienen beide Teile und zeigen einen hier getroffenen Vergleich mit Bitte um dessen Bestätigung an:

Der Endtermin der Behutung der Dreckwiesen ist für Lachendorf, ebenso wie für Ahnsbeck der 11. Mai jeden Jahres, nur steht Lachendorf in soweit hinter der letzten Dorfschaft zurück, dass alles Hornvieh der Lachendorfer, soweit es vom Gemeindehirten, nicht von Einzelhirten der einzelnen Hauswirte getrieben wird, schon nach dem 4. Mai jeden Jahres auf die Dreckwiesen nicht weiter aufgehütet werden soll und darf, daß Lachendorf ebenso die Weide für Pferde daselbst nicht länger bis 4. Mai jeden Jahres in Anspruch nimmt, der Weide für Gänse daselbst völlig entsagt, mit ihren Schweineherden vom Gemeindehirten dagegen bis 11. Mai einschließlich auch ferner zugelassen wird, dass die Schafweide für beide Teile hinkünftig auf den Dreckwiesen endlich völlig erloschen sein soll.

Die Kosten des geführten Prozesses sollen jeden Teil treffen, der sie ausgelegt hat, oder noch auslegen muß.

vorgelesen und genehmigt unterschrieben Heinrich Christoph Dierks, Carsten Heinrich Thies, Jürgen Heinrich Meyer, Karsten Heinrich Koch ist vorstehender Vergleich gerichtlich bestätigt

$$
\text { ut supra in fide Wittig }
$$

\section{Holzhieb im Kammerwinkel (1843) ${ }^{2}$}

An den Allerwiesen zwischen Lachendorf und Nordburg gab es einen kleinen „Bruchforst", offenbar ein Bruchwald auf moorigem Standort, der sog. Kammerwinkel, der den beiden Gemeinden Ahnsbeck und Lachendorf zur gemeinsamen Nutzung diente.

Den Ahnsbeckern wurde seitens der Lachendorfer das Recht auf Holzhieb im Kammerwinkel bestritten. Die Ahnsbecker Dorfgemeinschaft beschloss einstimmig, trotz des Hinweises auf einen unsicheren Prozessausgang und der möglichen Folgen für das Gemeindevermögen, es auf einen Prozess ankommen zu lassen. Sie wünschten allerdings eher eine gütliche Einigung, waren einig, dass die ganze Angelegenheit „bedeutende Prozesskosten" nicht rechtfertige, und wollten auf eine grundsätzliche Auseinandersetzung hinsichtlich der gemeinsamen Nutzungsrechte mit Lachendorf (Kopplungsberechtigungen) und Generalteilung klagen.

Der Vergleich zeigt deutlich, dass es nur um den Holzhieb ging, denn die übrigen Nutzungsrechte blieben unberührt und der Holzhieb im Kammerwinkel ohne allseitige Zustimmung wurde unter Strafe gestellt:

„Obgleich jeder Gemeinde diesen Kammerwinkel mit Hutung, Torfstich und sonstiger Nutzung nach Gefallen benutzt, so darf doch der Holzhieb in dem Kammerwinkel von keiner Gemeinde und von keinem Gemeindemitglied ausgeübt werden, bevor nicht beide

\footnotetext{
${ }^{1}$ dito
}

${ }^{2}$ dito 
Gemeinden dazu ihre Zustimmung gegeben haben. Wer ohne solche Zustimmung im Kammerwinkel Holz haut unterwirft sich der Landgerichtsstrafe."1

Die Beispiele für derartige Auseinandersetzungen ließen sich noch fast beliebig ausweiten. Daraus kann man vor allem Zweierlei ableiten:

Die althergebrachten Nutzungsrechte waren offenbar oft nicht hinreichend genau und schriftlich fixiert, insbesondere waren Umfang und Zeitraum der Nutzung sowie die örtlichen Grenzen deshalb oft strittig.

Besonders deutlich werden aber die große Bedeutung der Weiderechte auf den Allmenden und der stetig vorhandene Futtermangel. Exemplarisch sei die Auseinandersetzung um Beweidung in den Allerdreckwiesen erwähnt: Wegen eines Streits um wenige Tage Beweidung zwischen dem 4. und 11. Mai wurde ein aufwändiger, kostenpflichtiger Prozess geführt.

Man kann nach dieser Erkenntnis auch die These vertreten, dass es aufgrund der Gemeinschaftsweiden und der Tatsache, dass auch landlose „Häuslinge“ Vieh ${ }^{2}$ hielten und Weiderechte hatten, die Weiden und Hutungen mit zu viel Vieh bestockt wurden, sodass es zu Formen der Überweidung ${ }^{3}$ bzw. Übernutzung gekommen ist.

Die Nutzung der „freien“ Landschaft als Gemeinschaftsweide durch viele Berechtigte muss auch erhebliche Folgen für die Vegetation gehabt haben. Neben Formen der negativen Weideselektion hat es auch völlige Zerstörung der Vegetationsdecke mit Bodenerosion gegeben. Als Beispiel für Bodenerosion bzw. Übernutzung diene folgender Eintrag im Rezess zur Verkoppelung der Feldmark von Lachendorf: Am 5. Februar 1858 wird vor dem Amt in Beedenbostel zu Protokoll genommen: „Der Vollmeier Lüßmann verlangt zum Schutze seiner neu angelegten Wiese einen Streifen aus der angrenzenden Gemeinheit, den er zum Schutz gegen Sandverwehungen mit Holz bepflanzen wolle." Der Eigentumsübertragung aus der Gemeinheit wird zwar nicht stattgegeben, der Einwand aber sachlich anerkannt und soll durch Vereinbarung beseitigt werden. ${ }^{4}$

Die intensive freie Beweidung der Gemeinheiten war sicherlich ein Hauptgrund für die geringen Holzbestände und weitgehende Baumfreiheit der Kulturlandschaft. Eine natürliche Verjüngung in der freien Landschaft - insbesondere mit standorttypischen Laubhölzern - war unter den gegebenen Nutzungsformen ausgeschlossen.

Die Waldarmut der Kulturlandschaft um 1800 war also auch ganz wesentlich eine Folge der rechtlichen und wirtschaftlichen Bedingungen auf den Gemeinheiten (Allmenden), die flächenmäßig den weitaus größten Teil der Landschaft einnahmen.

\subsubsection{Das System der Heidebauernwirtschaft}

Grundlage des bäuerlichen Lebens in der Heide, mindestens seit dem späten Mittelalter bis ins 19.Jahrhundert, war ein charakteristisches Wirtschaftssystem der Heidebauern, die Heidebauernwirtschaft.

Diese Wirtschaftsform stellt eine Sonder- bzw. Extremform der spätmittelalterlichen Agrarwirtschaft dar, die sich aufgrund der besonderen naturräumlichen Bedingungen herausgebildet hatte.

\footnotetext{
${ }^{1}$ Akte der Gemeinde Lachendorf, geschehen Amtsvogtei Beedenbostel d. 24. März 1843

2 s. H. Küster; Geschichte der Landschaft in Mitteleuropa, a.a.O., S. 231

${ }^{3}$ Formen der Überweidung (overgrazing) sind heute gut aus Savannen Afrikas bekannt, wo es traditionell keinen Individualbesitz an Weideflächen gibt und Nutzvieh nicht nur unter rein ökonomischen Bedingungen gehalten wird. (Anm. d. Verf.)

${ }^{4}$ Rezess über die Spezialteilung und Verkoppelung der Feldmark von Lachendorf, Archiv Akten der Samtgemeinde Lachendorf, Fach/Nr. 61/5, dort § 9
} 


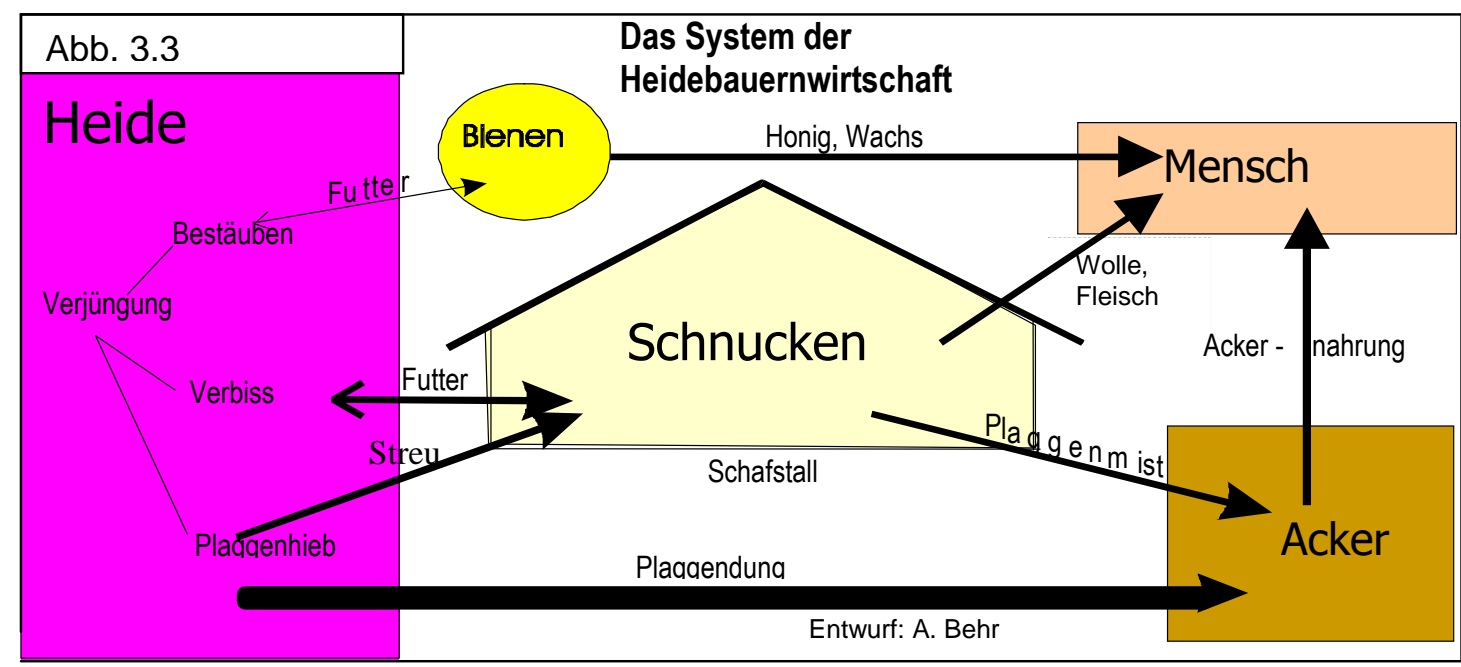

Die Heide lieferte also Nahrung für Schnucken und Immen sowie Dung für den Acker. Andererseits führte die ständige Nutzung der Heide zu ihrer regelmäßigen Verjüngung und damit zum Erhalt des Systems. Zur Erhaltung der Heidelandschaft hat vermutlich auch das Abbrennen ${ }^{1}$ beigetragen, der Beitrag zum Wirtschaftsystem war aber sicherlich marginal, weil das Brennen der Heide weder Futter oder Streu für das Vieh noch Dung für den Acker lieferte.

Schwierig war in der Heidebauernwirtschaft stets die Futterversorgung, insbesondere im Winter, von Rind und Schwein. Die meist kleinen Bachtäler boten nur wenig natürliches Grünland und damit wenig Raum für die Heugewinnung, auch Futterpflanzen wie Rüben und Mais vom Acker waren ja noch unbekannt.

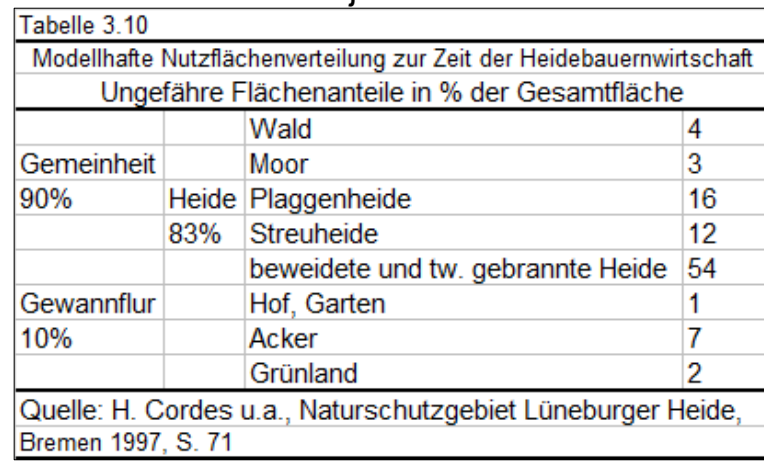

\begin{tabular}{|l|l|l|}
\hline \multicolumn{2}{|c|}{ Tabelle 3.11} \\
\hline Jahr & \multicolumn{2}{|c|}{ Typische Fruchtfolgen der Heidebauernwirtschaft } \\
\hline 1. & Buchweizen, gedüngt & Buchweizen, gedüngt \\
\hline 2. & Roggen, gedüngt & Roggen, gedüngt \\
\hline 3. & Roggen & Roggen \\
\hline 4. & Roggen & Hafer \\
\hline 5. & Buchweizen & Roggen \\
\hline 6. & Roggen & Weide \\
\hline 7. & Weide & Weide \\
\hline 8. & Weide & \\
\hline 9. & Weide & \\
\hline Quelle: Th. Kaiser; Beiträge Zur räumlichen Planung, \\
\hline Landschaftswandel im Kreis Celle, Hannover 1994, S. 128 f. \\
\hline
\end{tabular}

Der geringe Wert des Plaggendungs ließ ohnehin nur eine kleine Ackerfläche zu, deren Ertrag an Korn (meist Roggen), Buchweizen ${ }^{2}$, Flachs und Hanf dringend für die menschliche Versorgung gebraucht wurde. Deshalb wurde das Getreidestroh ausschließlich als Winterfutter für die Kühe benötigt und konnte nicht als Einstreu zur Dungproduktion verwendet werden.

Die Schweinemast war abhängig vom Ertrag der Eichen und Buchen und so nur im Herbst erfolgreich, denn Kartoffeln waren noch unbekannt und Getreide als Schweinefutter viel zu kostbar. Deshalb mussten die Schweine am Ende der Eichel- und Bucheckernmast, wenn sie einigermaßen Fleisch und Speck angesetzt hatten, zu Beginn des Winters geschlachtet

\footnotetext{
${ }^{1}$ vergl. Svein Haaland; Feuer und Flamme für die Heide, a.a.O., S. 47

2 Buchweizen ist kein Getreide sondern ein Verwandter von Knöterich und Sauerampfer
} 
werden. Fleisch und Würste wurden dann entweder in der Pökeltonne mit Salz oder im Rauch des Rauchhauses haltbar gemacht ${ }^{1}$.

Auf dem Ackerland dominierte der Roggen, der das Brotgetreide ${ }^{2}$ lieferte. Die Fruchtfolge begann mit gedüngtem Roggenanbau, dem weitere Jahre mit Roggen und Buchweizen folgten, bis sich der Boden in einer Brachephase, die allerdings auch zur Beweidung genutzt wurde, etwas regenerieren konnte.

Diese Feld-Graswirtschaft mit mehrjährigem Roggenanbau hatte sich auf den mageren Sandböden als vorteilhaft gegenüber der sonst in Europa weit verbreiteten Drei-FelderWirtschaft erwiesen. Die Dominanz des Roggens ergab sich aus seiner Eigenschaft, im Vergleich zu anderen Getreidearten auf sauren, nährstoffarmen Böden noch einigermaßen gute und sichere Erträge zu erbringen.

Die Heidebauernwirtschaft war allerdings eine echte Plaggerei ${ }^{3}$ : „Der Bedarf eines normalen Vollhofes lag bei jährlich 850 Fuder Heidplaggen. Mit dem Plaggenhieb waren jährlich 2 Hauer beschäftigt." ${ }^{4}$

Die Nutzflächenverteilung belegt die überragende Bedeutung der Heide für die Landwirtschaft. Heide war keineswegs Unland oder gar ungenutztes Land. Sie war vielmehr ein unverzichtbarer,

Abb. 3.4: Plaqgenhieb und Plaqgentransport

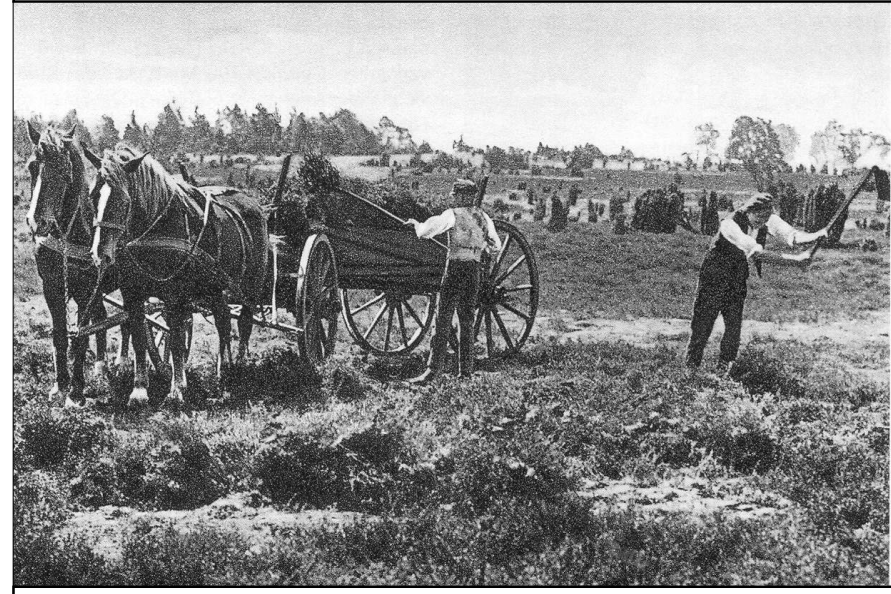

Quelle: F. Rose, Heideschulmeister Uwe Karsten, BerlinLeipzig 1933, S. 158 integraler Bestandteil der bäuerli-

chen Wirtschaft: Denn die Heide allein lieferte über die Plaggen und den Schafmist aus Plaggenstreu den sonst unersetzlichen Dünger für den Acker sowie Weidefläche für Schnucke und Biene (Imme).

In der Heide, in der mittelalterlichen Agrarverfassung Gemeinschaftsbesitz, also Allmende oder Gemeinheit, hatten die Höfe keine Eigentums-, aber festgelegte Nutzungsrechte. Rechte auf Schafweide und Plaggenhieb in der Gemeinheit der Heide waren daher wichtige Rechtsgüter bzw. wertvolle und unveräußerliche Nutzungsrechte der Heidehöfe. Die Bedeutung der Gemeinheiten ${ }^{5}$ für die Weidenutzung und insbesondere den Plaggenhieb mag an folgenden Beispielen verdeutlicht werden:

„So hatten sich z.B. die Ortschaften Oberohe, Niederohe, Altensothrieth, Neuensothrieth, Lutterloh, Gerdehaus, Hankenbostel, Müden und Weesen im nördlichen Kreis Celle zu einer

\footnotetext{
${ }^{1}$ bei den damaligen Möglichkeiten der Fleischkonservierung wäre eigentlich eine am Bedarf von Frischfleisch orientierte Schlachtung zweckmäßig gewesen. Dies war aber aufgrund der Futtersituation nicht möglich. Über Winter wurden nur die für die Nachzucht nötigen Schweine durchgefüttert. ${ }^{2}$ Norddeutschland ist berühmt für sein Schwarzbrot, das eigentlich dem regionalen Mangel an Weizen, dem besseren Brotgetreide, entstammt. Heute gelten manche Produkte und Gerichte aus der sog. guten alten Zeit, die ursprünglich eher Mangel und Armut dokumentierten, als regionale Spezialitäten und Delikatessen, wie z.B. der Buchweizen, die Grützwurst, der Saumagen u.a..

${ }^{3}$ It. Duden: Plackerei, in der Heide wäre die Schreibweise Plaggerei angebracht.

${ }^{4}$ aus: Brockhoff, H., u.a., a.a.O., Ehestorf 1998, S.66

5 in der deutschsprachigen Literatur wird meistens der aus dem Süddeutschen stammende Begriff „Allmende" verwendet.
} 
Weidegenossenschaft vereinigt, die zusammen über eine Heideweide von 4224 ha verfügte. Diese riesige Fläche auf der Höhe des Lüß enthielt nur noch 115 ha Wald." 1

In der Heide hatte sich eine ökologisch fein abgestimmte Wirtschaftsweise entwickelt, die eine weitgehende Selbstversorgung der Höfe zuließ. Dieses Wirtschaftssystem, das über einige Jahrhunderte eine große Stabilität entwickelt hatte, aber aufgrund der geringen natürlichen Fruchtbarkeit auf einem sehr niedrigen Niveau verharrte, war verbunden mit einem fest gefügten Sozialsystem der Großfamilie und des Anerbenrechtes. Nur die ungeteilte Vererbung des Hofes konnte das Überleben der nächsten Generation sichern.

\subsubsection{Die Waldnutzung}

Die Wälder wurden seit alters her nicht wie heute rein forstwirtschaftlich sonder vorwiegend landwirtschaftlich genutzt, sie unterlagen einer Mehrfachnutzung und ständigem Raubbau: Besonders geschätzt waren weitständige Eichen und Buchen, insbesondere in Siedlungsnähe, die mit ihren großen Kronen am ehesten Eicheln und Bucheckern zur Schweinemast ansetzten und außerdem dann auch Bauholz lieferten.

Der übrige Baumbestand wurde regelmäßig schon bei Armdicke der Stämme als Brennholz geschlagen. Deshalb herrschten Baumarten wie Eiche, Esche und Erle vor, die aus dem Stamm bzw. dem Wurzelstock wieder austreiben. Laubbäume wurden regelmäßig geschneitelt oder gesträufelt, d.h. die frischen Zweige wurden abgeschnitten oder die Blätter von den Zweigen gestreift um Laubheu als Futter zu gewinnen. Auch die Laubstreu wurde als Einstreu für das Vieh zur Gewinnung von Dung dem Wald entnommen.

Insbesondere wurden die Wälder als Waldweide vom Nutzvieh genutzt. Diese Hudewälder waren Niederwälder, die in Norddeutschland auch Krattwälder oder Stühbüsche ${ }^{2}$ genannt werden.

Es ist daher nicht verwunderlich, dass viele zeitgenössische Landschaftsbilder Baumformen mit den typischen Merkmalen des Schneitelns zeigen: Dicke, oft knorrige Stämme und starkes Astwerk, aus denen Büschel

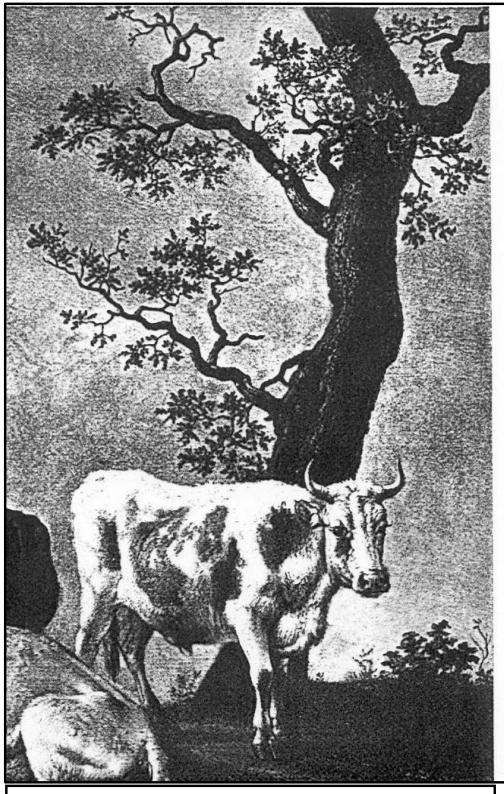

Abb. 3.5

Weidelandschaft

P. Potter, 1648 von dicht belaubten Zweigen sprießen.

Die Bauern brauchten also unbedingt den $\mathrm{Wald}^{3}$, den sie in mehrfacher Form intensiv nutzten. Deshalb war der Wald - ganz anders als heute - ein unverzichtbarer und integraler Bestandteil der Landwirtschaft und damit auch der Agrarlandschaft. Der Wald hatte für die bäuerliche Wirtschaft eine unverzichtbare Subsistenzfunktion.

In der trockenen und sandigen Diluviallandschaft zwischen Elbe und Aller hatte nach der Waldvernichtung die „Heide ${ }^{4 \text { “ }}$ als Sekundärvegetation die Subsistenzfunktion für die Gesamtwirtschaft übernommen.

Die ständige Wald- und Heidenutzung führte aufgrund von Raubbau zur Übernutzung, teils zu stark devastierten Wäldern und Heiden mit zunehmender äolischer Bodenerosion.

\footnotetext{
${ }^{1}$ zitiert bei: H. Brockhoff u.a., Ja , grün ist die Heide ..., Aspekte einer besonderen Landschaft, Ehestorf 1998, S. 20

${ }^{2}$ H. Küster, Geschichte der Landschaft in Mitteleuropa, München 1999, S. 238

${ }^{3}$ Vergl. Miedaner, Von der Hacke bis zur Gentechnik, Frankfurt a.M., 2005, S. 48 f.

${ }^{4}$ Heide als Landschafts-, nicht als Vegetationsbegriff
} 


\subsubsection{Bodenfruchtbarkeit und Nachhaltigkeit}

Der Landwirtschaft standen vor dem Paradigmenwechsel ${ }^{1}$ im 19. Jahrhundert ${ }^{2}$ aus heutiger Sicht nur sehr eingeschränkte Möglichkeiten zur Erhaltung oder gar Verbesserung der Bodenfruchtbarkeit ${ }^{3}$ zur Verfügung. Als Nährstofflieferanten kamen nur der Restmineralgehalt, also die "nachschaffende Kraft" des Bodens, und Naturdung in Form von Biomasse oder Tierdung und Fäkalien in Frage. In vorindustrieller Zeit waren auch die Einträge aus der Luft äußerst gering.

In der Brache wurden aus dem Restmineralgehalt des Bodens aufgeschlossene Mineralien biotisch fixiert und durch Humifizierung und Mineralisierung den nächsten Ernten zur Verfügung gestellt. Die Beweidung der Brache führte zu einer geringen, allerdings sehr punktuell und ungleichmäßig verteilten Düngung durch Tierdung. Da das Vieh überwiegend geweidet wurde, war die Produktion von Stallmist recht gering. Daher war eine regelmäßige Dunggabe mit Stallmist auf den Äckern nicht möglich.

Den Bauern standen weder das Wissen noch der Mineraldünger selbst zur Verfügung und auch der Anbau von Leguminosen zur natürlichen Stickstoffanreicherung im Boden war unbekannt.

Der Ackerbau litt also unter permanenter Unterversorgung mit Pflanzennährstoffen, die durch Zuführung mit Biomasse aus dem Wald und über Tierdung nur sehr unvollständig ausgeglichen werden konnte.

Nährstoffmangel auf dem Acker und Raubbau auf den Allmenden (Hutungen, Weiden und Wald) waren also zwei zusammenhängende und typische Merkmale der vormodernen Landwirtschaft.

Entsprechend niedrig waren auch die Flächenerträge bei Getreide, dem Hauptnahrungsmittel vom Acker: Die Ernten betrugen nur das Drei- bis höchstens Siebenfache der Aussaat, d.h. sie lagen zwischen $2 \mathrm{dt}$ und maximal $10 \mathrm{dt} / \mathrm{ha}$ bei Roggen. Bei einem Verhältnis von Aussaat zu Ernte von 1:34 lag man am Existenzminimum, das Hunger und Teuerung bedeutete ${ }^{5}$.

Die Dreifelderwirtschaft mit Wintergetreide, Sommergetreide und Brache hat in Europa über 1000 Jahre $^{6}$ die landwirtschaftliche Wirtschaftsweise beherrscht, war aber ab dem 18. Jahrhundert nicht mehr in der Lage, die Versorgung mit Nahrungsgütern zu gewährleisten und erwies sich aufgrund der Starrheit des Systems schließlich als Hindernis für eine Modernisierung der Landwirtschaft.

Die grundsätzlichen Probleme der Bodenfruchtbarkeit traten im Untersuchungsgebiet und in der gesamten Lüneburger Heide in verschärfter Form auf, weil die weit verbreiteten Sandböden von Natur aus über einen geringen Restmineralgehalt, einen sehr geringen Kalkgehalt, eine geringe Austauschkapazität und geringe Wasserspeicherkapazität verfügen.

Auf diesen Standorten musste eine spezielle Wirtschaftsweise entwickelt werden, die die natürlichen Standortnachteile zwar nicht beseitigen konnte, sich aber diesen möglichst gut anpassen musste.

Während man die trockenen sandigen Standorte der Besenheide den Schnucken überließ, wurden feuchtere Standorte gern in Weiden, sog. natürliches Grünland umgewandelt. Die Bauern erkannten diese Standorte am Pfeifengras und an der Erikaheide, der Doppheide ${ }^{7}$, dem Standortanzeiger für mögliches Grünland.

\footnotetext{
${ }^{1}$ s. Kap. 2.5 und Abb. 2.19

${ }^{2}$ In England begann die Modernisierung bereits im 18. Jahrhundert. In Deutschland begann sie um 1800, konnte sich aber erst nach den Agrarreformen richtig entfalten, die überwiegend Mitte des Jahrhunderts umgesetzt und beendet wurden.

${ }^{3}$ Bis ins 19. Jahrhundert herrschte auch wissenschaftlich Unkenntnis über die Bodenfruchtbarkeit und die Prozesse der Pflanzenernährung. Erst die Erkenntnisse von A. Thaer und insbesondere von J. v. Liebig legten den Grundstein für das heutige Wissen zur Bodenfruchtbarkeit.

${ }^{4}$ Bei Roggen beträgt das Verhältnis von Aussaat und Ernte heute im Durchschnitte $1: 60$, bei neuen

Sorten und guten Böden bis $1: 100$. s. Miedaner, a.a.O., S. 107

${ }^{5}$ Miedaner, Th., Von der Hacke bis zur Gentechnik, Frankfurt a.M., 2005, S. $107 \mathrm{ff}$.

${ }^{6}$ ebd., S. $145 \mathrm{ff}$

${ }^{7}$ s.o.: Bauernweisheit über Hinweis durch Doppheide
} 
Die Weisheit "die Heide ernährt den Acker" bringt das System der Heidebauernwirtschaft auf den Punkt, denn unter den gegebenen ökologischen Bedingungen war dies die einzig mögliche Form einer einigermaßen nachhaltigen Wirtschaftsweise.

Der Beweis für eine Plaggendüngung über viele Generationen sind die Plaggenböden, ein besonderer Bodentyp, der als Plaggenesch ${ }^{1}$ bezeichnet wird. Die humose Plaggenauflage kann bis zu $80 \mathrm{~cm}$ mächtig sein. Da die Heide sehr schwer zersetzbar ist und die entkalkten, recht sauren Böden ohnehin bei sehr geringem Bodenleben eine rasche Zersetzung verhindern, wuchs im Laufe der Jahrhunderte die Mächtigkeit des Plaggenesch langsam und stetig an.

Das System war auch lange Zeit ökologisch sehr stabil, weil einerseits die Ackererträge auf einem niedrigen Niveau recht sicher blieben und weil vor allem das System die Heidelandschaft stabilisierte:

Der Verbiss der Heide durch die Schnucken verhinderte eine Verbuschung und Überalterung, vor allem aber wurde eine Wiederausbreitung von Laubbäumen, die der Heide das Licht genommen hätten, verhindert.

Das Plaggen, das flächenhafte Abtragen des Heidekrautes einschließlich der Wurzeln, legte immer wieder Sandboden frei, auf dem die Heide besonders gut keimt. Um eine natürliche Neueinsaat der Heide auf den abgeplaggten Flächen zu erreichen, wurde die Heide zwar systematisch, aber nur streifenweise geplaggt. So führten Verbiss und Plaggen sowie das Mähen alter Heide und gelegentliches Brennen zur stetigen Verjüngung der Heide und damit zu reicher Blüte.

Dies diente wiederum der weit verbreiteten Bienenhaltung zur Honiggewinnung. Die Bienen wiederum sorgten für eine gute Bestäubung und damit Samenbildung der Heide und die Schafherden zerstörten beim Durchziehen der Heide viele Spinnennetze, was einen ungehinderten Flug der Bienen förderte.

Der stachelige Wacholder dagegen, heute als Charakterbaum der Heide bekannt, galt bei den Heidebauern als Unkraut und wurde bekämpft, weil die Schnucken inn meiden und nicht verbeißen, seine Ausbreitung die Weidefläche also einschränkt hätte.

Die Heideflächen waren also ein unverzichtbarer Bestandteil der Heidebauernwirtschaft: Die Heide lieferte Fleisch, Wolle, Honig und vor allem Dung für den nährstoffarmen Acker. Der Acker lieferte die Grundnahrungsmittel Roggen als Brotgetreide und Buchweizen ${ }^{2}$ sowie Flachs für Leinen. Die Erträge waren sehr niedrig, dank der Plaggendüngung aber relativ stabil. Eine Intensivierung war ebenfalls nicht möglich, und so verharrte das System bei einer recht niedrigen Tragfähigkeit, die sich in einer dünnen Besiedlung bemerkbar machte.

Dieses höchst komplexe und ökologisch sehr gut angepasste Nutzungssystem machte es möglich, unter den mageren natürlichen Bedingungen die Menschen über einen langen Zeitraum - oft allerdings nur kümmerlich - zu ernähren, ohne fremde Ressourcen in Anspruch zu nehmen.

\subsubsection{Naturabhängigkeit statt Nachhaltigkeit}

Die Landschaft der Südheide (und angrenzender Gebiete) war bereits im 18. Jahrhundert eine seit langer Zeit intensiv genutzte Kulturlandschaft.

Die Nutzflächenverteilung entspricht sehr genau den naturräumlichen Einheiten, und damit dem räumlichen Muster der Bodengüte und der hydrologischen Verhältnisse, so wie es Karte 3.3 verdeutlicht: Geest- bzw. Grundmoränenplatten für Ackerland, Randmoor im Urstromtal

\footnotetext{
${ }^{1}$ s. Mückenhausen, E.; Entstehung, Eigenschaften und Systematik der Böden ..., a.a.O. S. 7 und Abb. Nr. 45 und 46

${ }^{2}$ Buchweizen wurde meist als Grütze mit Wasser oder Milch gegessen und war ein typisches Nahrungsmittel ärmerer Gegenden. Heute erfährt der Buchweizen in der Buchweizentorte eine Wiedergeburt als Delikatesse und regionale Spezialität.
} 
für Wiesen und der Schwemmfächer mit Randbereichen als Heide für Hutungen sowie für den Plaggen- und Bultenhieb.

Die Ausgestaltung, das Landschaftsbild der jeweiligen Nutzflächen ist das Ergebnis bäuerlicher Wirtschaftsweise, die sich aufgrund der gesellschaftlichen Rahmenbedingungen, besonders aber auch aufgrund des Wissenstandes und der zur Verfügung stehenden Hilfsmittel entwickeln konnte: Dreifelderwirtschaft (oder lokal abgewandelte Systeme) mit Flurzwang, gemeinsame Nutzung der Gemeinheiten für Weide, Heid- und Plaggenhieb im System der Heidebauernwirtschaft.

Die Naturbedingungen lieferten zwar notwendige aber doch nicht hinreichende Bedingungen für genau diese Ausgestaltung dieser zeittypischen Kulturlandschaft.

Die bäuerliche Kulturlandschaft des 18. und beginnenden 19. Jahrhunderts würde aus heutiger Sicht sicherlich von manchem Betrachter wegen der Wald- und Baumarmut und wegen der weiten Heideflächen als eine „ausgeräumte Kultursteppe“ bezeichnet. Die Waldarmut war aber ein typisches und zwangsläufiges Ergebnis der zeittypischen Landwirtschaft, nicht nur in der Heide.

Wer die Heidebauernwirtschaft als ein Wirtschaftssystem beurteilt, das sich „im Einklang mit der Natur" befand, unterliegt einem krassen Fehlurteil, einem völligen Missverständnis von sog. einfachen und „naturnahen" Wirtschaftsweisen.

Die Heidebauernwirtschaft war in hohem Maße direkt von der Natur, den natürlichen Standortbedingungen abhängig und an diese angepasst, aber eben keinesfalls nachhaltig.

Diese Kulturlandschaft zeichnete sich aufgrund der natürlichen Bedingungen einerseits und der intensiven Nutzungsformen aller zur Verfügung stehender Flächen durch eine speziell angepasste Flora aus, die wiederum ein daran angepasstes Artenspektrum der Fauna ermöglichte.

Das Beziehungsgeflecht zwischen Kulturlandschaft und Fauna hat sich besonders in den Wildtierbeständen deutlich dokumentiert: Da die Nahrungsbedingungen z.B. für Reh-, Rotund Schwarzwild erheblich schlechter waren als heute und die Bauern wegen der ohnehin geringen Ernten Wild, das sie selbst nicht jagen durften, als Schadwild betrachteten, ja betrachten mussten, waren die Wildbestände ganz wesentlich niedriger als heute.

Trotz späterer Versuche, diese Kulturlandschaft unter Schutz zu stellen, konnte es nicht gelingen, den Landschaftscharakter, wie er durch die Kurhannoversche Landesaufnahme überliefert und bezeugt ist, großräumig zu erhalten.

Die Höfe hatten im Zuge der Separation oder Spezialteilung der Abfindung, die der Dorfgenossenschaft aufgrund der Generalteilung der großen Gemeinschaftsreviere zugefallen war, erhebliche Heideflächen zur privaten Nutzung zugeteilt bekommen.

Da die Höfe die Heide aufgrund veränderter Wirtschaftsweise im Laufe der 2. Hälfte des 19. Jahrhunderts nicht mehr als Düngerlieferant und zunehmend auch nicht mehr als Schnuckenweide benötigten, konnten die Heideflächen einer neuen Nutzung zugeführt werden.

Ein Umbrechen der Heide zu Ackerland, das sog. Urbarmachen, verbot sich im 19. Jahrhundert allerdings aus zwei Gründen: Die Heideböden waren durch lange Übernutzung so verarmt, dass ein Ackerbau nicht rentabel gewesen wäre. Die Höfe wären aber auch wegen fehlender Zugkraft, geeigneter Geräte und fehlender Arbeitskräfte damals nicht in der Lage gewesen, die neuen Flächen unter den Pflug zu nehmen. Die Höfe waren auf die seit Generationen bewirtschafteten Ackerflächen ausgerichtet, deren Intensivierung viel mehr ökonomischen Erfolg versprach als die Beackerung ehemaliger Heiden.

Erst im 20. Jahrhundert waren die technischen und Boden verbessernden Möglichkeiten vorhanden, um ehemalige Heideflächen in Ackerland umzuwandeln. Dies ist auf dem Flurstück Reitbahn östlich der Oppershäuser Straße Anfang der 1960er Jahre durchgeführt worden. Dort wird auf Böden mit 17 - 19 Bodenpunkten ${ }^{1}$ seither Ackerbau mit Getreide (außer Weizen), Kartoffeln, Zuckerrüben und Mais betrieben. Ohne Beregnung sind auf den Sand-

\footnotetext{
${ }^{1}$ s. Abbildung 2.9: Podsole auf dem Flurstück Reitbahn
} 
böden mit geringer Wasserspeicherkapazität allerdings keine sicheren Erträge zu erzielen, die den Aufwand - insbesondere an Dünger - rechtfertigen.

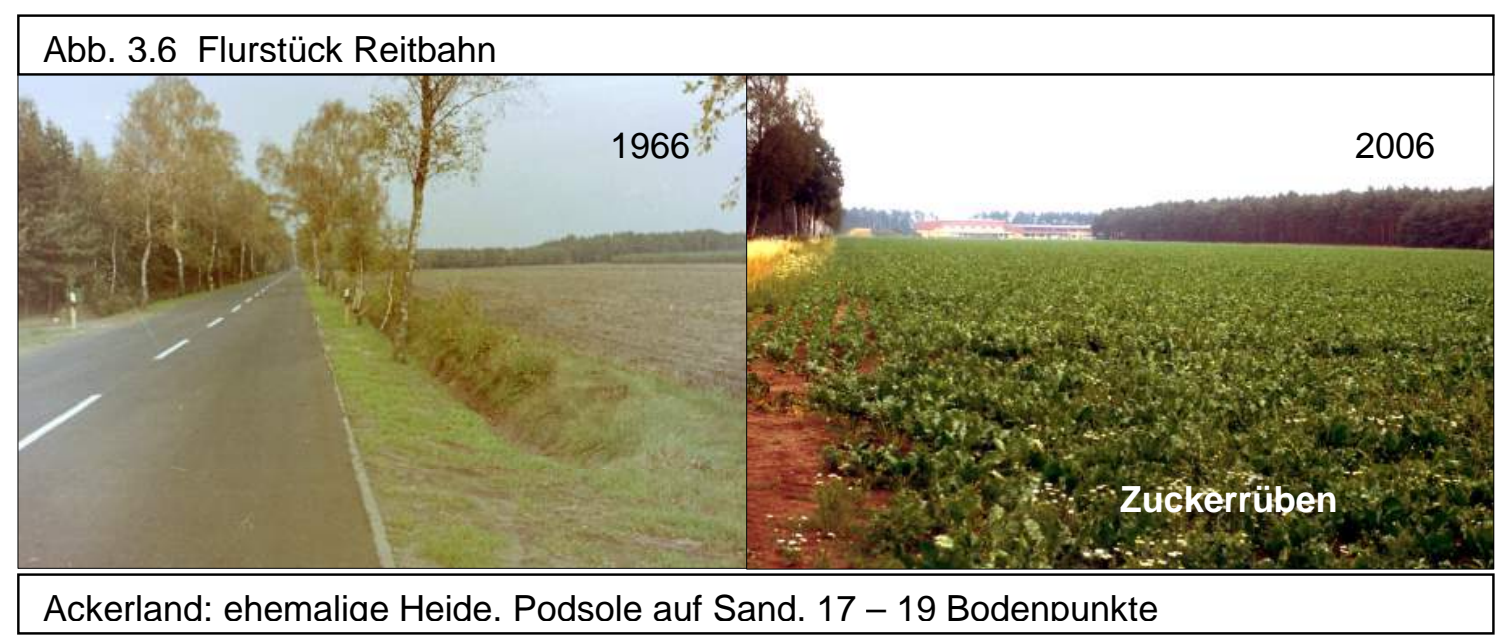

Kap. 4: Das 19. Jahrhundert - Zeitalter der Agrarreformen 


\section{Kapitel 4 Das 19. Jahrhundert - Zeitalter der Agrarreformen}

\section{Kap. 4.1 Aufbruch in die Moderne - fördernde und retardierende Aspekte}

\subsubsection{Gesellschaftliche Stellung der Landwirtschaft um 1800}

Den tatsächlichen und grundlegenden Agrarreformen in den deutschen Staaten des 19. Jahrhunderts ging ein Gesinnungswandel gegenüber der bäuerlichen Bevölkerung und dem Landleben bei den Eliten und der nichtbäuerlichen Bevölkerung voraus.

Die geistige Aufgeschlossenheit gegenüber der Landwirtschaft und die gesellschaftliche Akzeptanz des Landlebens und des Bauernstandes hatten sich bereits in der 2. Hälfte des 18. Jahrhunderts sehr positiv entwickelt, sodass von dieser Seite einer tief greifenden Neuausrichtung der Landwirtschaft nichts im Wege stand.

- Viele Landesherren betrieben Bauernschutzpolitik, weil in den vorwiegend agrarisch geprägten Regionen bei Steuerfreiheit des Adels der Bauernstand einen erheblichen Teil der staatlichen Ausgaben ${ }^{1}$ zu finanzieren hatte und weil die Peuplierungspolitik aufstrebender Territorialstaaten eine gesicherte Ernährungslage der wachsenden Bevölkerung erforderte.

- Den positiven Zeitgeist gegenüber der bäuerlichen Bevölkerung und ihrer Arbeit beeinflussten von der theoretischen Seite insbesondere die Physiokraten ${ }^{2}$, für die allein der Bauernstand etwas Neues hervorbringen konnte.

Der Ausspruch von König Friedrich II., „Die Landwirtschaft ist die erste aller Künste; .... Nur das ist wahrer Reichtum, was die Erde hervorbringt. “3 und eigenhändiges Pflügen durch Kaiser Joseph II. ${ }^{4}$ bezeugen diese Wertschätzung des Bauernstandes auf höchster Ebene.

- Im Bildungsbürgertum trug die Romantik in Deutschland ganz wesentlich zu einem neuen Bild vom Landleben und der Natur bei, das allerdings auch ganz wesentlich zu einer Verklärung beider Bereiche beitrug. Gerade die Darstellung von Kulturlandschaften wie der Heide als eine harmonische, unberührte Natur hat bis auf den heutigen Tag Auswirkungen auf das weit verbreitete Naturverständnis und den Naturschutz. ${ }^{5}$

- In England war die Landwirtschaft bereits im 18. Jahrhundert stark modernisiert worden, und zwar durch neue Fruchtfolgen, Bewirtschaftungsformen und neue Ackergeräte. ${ }^{6}$

Diese Errungenschaften waren vielen führenden Köpfen der deutschen Landwirtschaft durchaus von Reisen und aus der Literatur bekannt, wurden aber zunächst nur von wenigen Landwirten, insbesondere einigen Gutsbesitzern übernommen.

- Auch aus England kommend entwickelte sich auf der Grundlage des Naturrechts eine Bewegung, die die Ästhetik und die Ökonomie in der Ausgestaltung der Kulturlandschaft ${ }^{7}$ verband. Dies führte zur Entwicklung des englischen Landschaftsparks

\footnotetext{
${ }^{1}$ Könenkamp, W.; Zur Situation der Landwirtschaft um 1800; in: K. Panne, Albrecht Thaer, Celle 2002, S. 25

2 ebd.

3 ebd.

${ }^{4}$ ebd., S. 26 (Der sensationelle Vorgang wird bei Könenkamp erwähnt und auf den 19. August 1769 datiert.)

${ }^{5}$ Küster, Hansjörg, Die Entdeckung der Lüneburger Heide als „schöne Natur“. Themenportal Europäische Geschichte 2010. http://www.europa.clio-online.de/2010/Article=429 (16.5.2010)

${ }^{6}$ vgl. Hamm, W.; Das Ganze der Landwirtschaft, Leipzig 1872, Nachdruck Hannover 2002

${ }^{7}$ Herbert Pruns; Albrecht Thaer und die ästhetische Gestaltung der Kulturlandschaft; in: K. Panne, Albrecht Thaer, Celle 2002, S. 185
} 
und insbesondere zum Typ der „Ornamented Farm"1. Dieses Idealbild einer gestalteten Kulturlandschaft, in der die Ästhetik gleichberechtigt neben der Ökonomie stand, fand unter den größeren und geistig aufgeschlossenen Gutsbesitzern viele Anhänger, insbesondere in Mecklenburg und Brandenburg. ${ }^{2}$

- Das vollkommenste und berühmteste deutsche Beispiel einer nach ästhetischen und ökonomischen Prinzipien durchgestalteten Kulturlandschaft als Gesamtkunstwerk ist das Gartenreich Wörlitz. ${ }^{3}$

- In unmittelbarer Nähe der Südheide war auch ein positives Umfeld für eine grundsätzliche Erneuerung der Landwirtschaft gegeben: Schon im Jahr 1764 wurde unter Georg III. ${ }^{4}$ die „Königlich Großbritannisch Churfürstlich Braunschweig-Lüneburgische Landwirtschaftsgesellschaft" in Celle ${ }^{5}$ gegründet, deren Mitglied der Arzt Dr. Albrecht Thaer, Begründer der modernen Agrarwissenschaft, bereits $1780^{6}$ wurde.

- Auf Vorschlag der Gesellschaft beauftragte König Georg III. zwei Celler Experten, die Ämter und Amtsvogteien im Lüneburgischen zu bereisen und Grundsätze für eine Gemeinheitsteilung zu ermitteln ${ }^{7}$.

- Die Landesverwaltung in Hannover zeigte sich offenbar ebenfalls aufgeschlossen, denn bereits 1802 leitete die „Lüneburger Gemeinheitsteilungsordnung“ eine Reformphase ein. ${ }^{8}$

- Die Ablösung aller Abgaben und Dienste wurde im Königreich Hannover endlich im Jahr 1831 durch ein umfassendes und detailliertes Gesetz geregelt. ${ }^{9}$

Im Laufe des 18. Jahrhunderts wurde auch der rein ökonomische Zwang, die Landwirtschaft leistungsfähiger zu machen, immer deutlicher und zwingender:

- Die Bevölkerung war nach den großen Verlusten durch Seuchen und Kriege wieder beträchtlich angewachsen. Bei unverändert geringer Leistungskraft der Landwirtschaft wurde es immer schwieriger, die Bevölkerung angemessen zu ernähren. Die geringe Agrarproduktion stand auch der Peuplierungspolitik der aufstrebenden Territorialstaaten im Wege. Jahre mit weniger günstiger Witterung zur Wachstums- und Erntezeit führten regelmäßig zu Engpässen in der Nahrungsversorgung, zumal regionaler Mangel wegen mangelnder Transportmöglichkeiten nur schwer aus Überschussgebieten ausgeglichen werden konnte. So zwangen Hungersnöte wie die von $1771-1773^{10}$ die Regierungen zum Handeln.

Der allgemeine Bevölkerungsanstieg, Missernten mit Hungersnöten sowie Jahre mit stark steigenden Preisen der Nahrungsmittel bei stagnierenden Löhnen sind Merkmale einer Epoche, die später zu Recht den Namen Pauperismus ${ }^{11}$ erhielt.

- Der Obrigkeit war natürlich auch die desolate Verfassung der heimischen Landwirtschaft nicht verborgen geblieben. Sie versuchte, durch eine Reihe von Gesetzen und

\footnotetext{
1 ebd. S. 187

${ }^{2}$ vgl. ebd., S. $201 \mathrm{ff}$.

${ }^{3}$ vgl. E. Hirsch, Das Gartenreich Dessau-Wörlitz, Hamburg 1996

${ }^{4}$ Kurfürst von Hannover (ab 1814 König von Hannover) und König von Großbritannien in Personalunion

${ }^{5}$ W. Könenkamp, a.a.O., S. 39

${ }^{6}$ R. Hessler, Die Geschichte der Albrecht-Thaer-Gesellschaft, in: K. Panne; Albrecht Thaer, Celle 2002, S. 229

${ }^{7}$ Veth, F.; Landwirtschaftlicher Verein Beedenbostel, Festschrift zum hundertjährigen Bestehen, 1961, S. 25

${ }^{8}$ Karl H. Schneider, Agrarreformen in regionaler Perspektive, 2002

Veröffentlicht in der Lernwerkstatt Geschichte des Historischen Seminars der Leibniz

Universität Hannover 2007, S. 3 (http://www.Iwg.uni-hannover.de).

${ }^{9}$ Veth, F.; a.a.O., S. $26 / 27$

${ }^{10}$ Karl H. Schneider, Bauernbefreiung und Agrarreformen, pdf - Hannover 2007, S. 2 und W. Könenkamp, a.a.O., S. 28

${ }^{11}$ vgl. W. Abel, Der Pauperismus in Deutschland, Hannover 1970
} 
Verordnungen, die Rechtsstellung der Bauern sowie die Wirtschaftsleistung der Höfe zu verbessern.

Eine Polizeiverordnung von 1618 des Herzogs von Lüneburg-Celle ordnete die Prüfung von Hofteilungen an und verbot die Erhöhung des Meyerzinses ${ }^{1}$.

Im Jahr 1682 sah sich die Obrigkeit genötigt, den Bauern die Abmeierung anzudrohen, falls nicht binnen eines halben Jahres der Zustand des Betriebes verbessert würde. ${ }^{2}$

Ab 1754 wurde der Anbau der Kartoffel behördlich empfohlen ${ }^{3}$, 1772/73 setzte die Landwirtschaftliche Gesellschaft in Celle für den Kartoffelanbau in der Heide Prämien aus $^{4}$, ab 1773 verdrängte der Kartoffelanbau allmählich die Eichelmast und die Stoppelweide ${ }^{5}$, verbesserte also ganz entscheidend die Schweinemast.

Die Obrigkeit versuchte auch der zunehmenden Waldverwüstung durch die Übernutzung der Hudewälder zu begegnen. Johann Friedrich, Herzog zu BraunschweigLüneburg, erließ 1678 eine Forstordnung, die erste Schritte zur Regeneration und Aufforstung der Wälder anordnete. Angesichts der Praxis allgemeiner Waldweide war dies nur möglich, wenn für Einsaat oder Pflanzungen eingezäunte Kämpe angelegt wurden, „damit die jungen Eichen, Büchen und Dannen ungehindert und unverletzt aufwachsen"6

Für den Aufschwung der Landwirtschaft ${ }^{7}$ insgesamt, nicht nur in der Heide, waren ganz unzweifelhaft die Arbeiten zweier Männer von besonderer Bedeutung: Albrecht Daniel Thaer (1752 - 1828), der Arzt aus Celle und Begründer der modernen Agrarwissenschaft einerseits und Justus v. Liebig (1803 - 1873) Chemiker und Begründer der Agrikulturchemie andererseits.

Die Entwicklungen bzw. Entdeckungen im Bereich der Agrarwissenschaft und Agrarchemie waren insbesondere für die von Natur benachteiligten Agrarräume wie die Heide von entscheidender Bedeutung. Beide Bereiche ermöglichten es, dass die Bodenfruchtbarkeit auch ärmerer Geest- und armer Sandböden ganz wesentlich verbessert wurde und die Flächenerträge in vorher nicht vorstellbarem Maße gesteigert werden konnten.

Die Einführung von Fruchtfolgen mit Hackfrüchten und der Anbau von hochwertigen Futterpflanzen erhöhte in Verbindung mit einer gezielten Humuswirtschaft die natürliche Bodenfruchtbarkeit. Die Mineraldüngung war dann in der Lage, den Pflanzen auch auf armen und verarmten Böden die zum optimalen Wachstum erforderlichen Nährelemente zur Verfügung zu stellen.

Auf den armen Sandböden geriet nach dem Gesetz vom Minimum nun das Bodenwasser zum begrenzenden Faktor, der auf Grünland in der 2. Hälfte des 19. Jahrhunderts durch Bewässerungsanlagen ${ }^{8}$ und auf Acker ab dem 20. Jahrhundert durch Feldberegnung begegnet werden kann.

Seit dem 19. Jahrhundert spielen auch die Faktoren Pflanzenzüchtung und Agrarchemie eine wesentliche Rolle mit zunehmender Bedeutung.

Der Aufschwung in der Landwirtschaft seit dem 19. Jahrhundert wird exemplarisch deutlich an Zuwächsen des Flächenertrages bei Getreide:

Lag das Ertragsverhältnis von Aussaat und Ernte bei Roggen im Mittelalter bei $1: 3^{9} \mathrm{bzw}$. maximal bei $1: 7$, so werden heute Saat-Erntemengenverhältnisse von $1: 40-50$ im Durchschnitt und sogar bis zu $1: 100$ auf guten Standorten erzielt ${ }^{1}$.

\footnotetext{
${ }^{1}$ Brockhoff, u.a., a.a.O., S. 63

2 ebd. S. 63

${ }^{3}$ ebd., S. $63 / 64$

${ }^{4}$ Tödter, H.; Kulturhistorisches Lexikon, Heidenau 2010, S. 69

${ }^{5}$ ebd., S. 69

${ }^{6}$ Herzogliche Forstordnung von 1678, zitiert in: CZ vom 21.5.05,S. 39, Sachsenspiegel 20

${ }^{7}$ s. a. Abb. 2.19: Ertragsentwicklung bei Weizen

${ }^{8}$ s. dazu Kap. 4.7

${ }^{9}$ Man brauchte $150 \mathrm{~kg} / \mathrm{ha}$ Saatgut für maximal $750 \mathrm{~kg} / \mathrm{ha}$ Erntemenge, blieben also $600 \mathrm{~kg} / \mathrm{ha}$ für die Ernährung.
} 


\subsubsection{Die Rückständigkeit der Heide}

Obgleich nun die gesellschaftlichen und geistigen Voraussetzungen, sogar direkt vor der Haustür der Südheide, und der ökonomische Druck zur Reform der Agrarwirtschaft um 1800 in hohem Maße gegeben waren, dauerte es in der Heide noch ein halbes Jahrhundert, ehe sich die Landwirtschaft grundlegend wandelte und dann auch die Kulturlandschaft sehr stark veränderte.

Die Heide bot allen, den betroffenen Bauern wie auch den fachkundigen und interessierten Beobachtern und Reisenden ein Bild allgemeiner Armut in den Siedlungen und großer Öde auf den weiten Heideflächen.

Unter diesen Prämissen waren die Beobachtungen von Demolins ${ }^{2} 1867$ und auch noch von Roux $^{3} 1906$ richtig, dass sich die Heide nicht aus eigener Kraft würde wirtschaftlich entwickeln können.

Hier traf in ganz besonderer Weise der Ausspruch „die große Armut ... kommt von der groBen Poverteh" ${ }^{4}$ zu, mit dem Fritz Reuter die ländliche Entwicklung noch im Mecklenburg des 19. Jahrhunderts charakterisierte.

Auf den Heidehöfen hätten nicht die erforderlichen Mittel erwirtschaftet werden können, die zur Modernisierung notwendig gewesen wären und die in anderen deutschen Landesteilen bereits vor 1800 in Angriff genommen worden waren.

Die Stagnation in der Heide bis in die Mitte des 19. Jahrhunderts war auch nicht durch mangelndes Wissen, nachahmenswerte Beispiele oder Desinteresse der Gesellschaft begründet.

Diese Verzögerung lässt sich erklären aus den politischen Wirrungen der Zeit, aber ebenso mit agrarstrukturellen und nicht zuletzt naturräumlichen Gegebenheiten.

- Die politischen Verhältnisse zu Beginn des 19. Jahrhunderts ließen keine staatlich geordnete Reform der überkommenen Agrarstruktur zu. Die Lüneburgische Gemeinheitsteilungsordnung konnte zunächst nicht umgesetzt werden wegen der französischen Besetzung unter Napoleon. Erfolg versprechende Reformen im Königreich Westphalen blieben wegen der kurzen Dauer dieser napoleonischen Neuordnung von 1807 bis 1813 ohne Wirkung. So wurden die westfälischen Gesetze von 1809, die die persönliche Unfreiheit der Bauern abgeschafft und Ablösungsmöglichkeiten für die Abgabenlast ermöglicht hatten, im neuen Königreich Hannover 1814 zunächst wieder aufgehoben. ${ }^{5}$

- Die unter Napoleon erzwungene Kontinentalsperre hat sicherlich auch sehr stark die Übernahme von Neuerungen aus England, insbesondere die Einführung der dort bereits vielfach eingesetzten neu entwickelten Ackergeräte ${ }^{6}$ be- bzw. verhindert.

- Es dauerte dann im Königreich Hannover lange, bis alte Reformansätze wieder aufgegriffen und weitergehende entwickelt wurden. Erst 1830 bzw. 1831 begann durch Erlass und Verordnung ${ }^{7}$ die Ablösung der Abgaben und Dienstleistungen, die auf den Höfen lagen. Die hannoversche Ablösungsordnung ${ }^{8}$ von 1833 legte dafür genaue Regelungen fest, die bis 1868 abschließend umgesetzt wurden.

- Die Verkoppelungen wurden im Königreich Hannover erst 1842 per Gesetz ${ }^{9}$ geregelt und die Umsetzung zog sich bis in die 1860er Jahre hin.

\footnotetext{
s. Miedaner, Th., Roggen, DLG Verlag, Frankfurt/Main 1997, S. 46

${ }^{1}$ s. ebd.

2 Edmond Demolins; La petite culture en famille-souche, le „Bauer" du Lunebourg, Science sociale, Bd. III, Paris 1888; übersetzt ins Deutsche von Martina Behr; in: A. Behr, Hg.; Der Lutterhof, Hermannsburg 2005, S. 58 ff.

${ }^{3}$ Paul Roux; Der Bauer in der Lüneburger Heide, Ehestorf 1993, S. 27

${ }^{4}$ Fritz Reuter, Ut mine Stromtid, (Hrsg. K. Batt), Rostock, 1990, S. 571

${ }^{5}$ M. Stöber, A. D. Thaer und die Agrarreformen in Hannover und Preußen; in: K. Panne, Albrecht Thaer, a.a.O., S. 71

${ }^{6}$ vgl. W. Hamm; Das Ganze der Landwirtschaft in Bildern, Leipzig 1872, Nachdruck Hannover 2002

${ }^{7}$ s. in: K. Panne, Albrecht Thaer, a.a.O., S. 71

${ }^{8}$ Dorf in der Neuzeit, S. 1/2; <http://www.öwg.uni-hannover.de/wiki/Dorf_in_der-Neuzeit>

${ }^{9}$ ebd. S. 3
} 
- Die agrarstrukturellen Bedingungen im Hannoverschen waren nicht so günstig für Neuerungen wie etwa in Mecklenburg und Brandenburg. Dort waren große Güter des Adels vielfach die Beispiel gebenden Vorreiter für die Modernisierung der Landwirtschaft, sowohl im ökonomischen Bereich des Ackerbaus und der Tierhaltung wie auch in der ästhetischen Ausgestaltung der Kulturlandschaft mit großen Parks und herrschaftlichen Gebäudekomplexen nach dem englischen Vorbild der „Ornamented Farm"“. Die landwirtschaftlich engagierten Eigentümer dieser Güter verfügten nicht nur über die nötige Bildung durch Studium und Reisen sondern auch über die nötigen finanziellen Mittel und ausreichend großen Besitz, um die Wirtschaft neu zu organisieren und die Landschaft durch Parks zu gestalten.

- Im Hannoverschen hätten die Staatsdomänen und die Rittergüter des alteingesessenen Landadels diese Rolle übernehmen müssen. Deren Güter verfügten aber nicht über die nötige Größe und Wirtschaftskraft, um den Reformprozess aus eigenen Mitteln in Gang zu setzen. Die durchschnittliche Größe der Rittergüter im Fürstentum Lüneburg betrug um 1830 nur etwa $166 \mathrm{ha}^{2}$. Dieser Besitz war nicht arrondiert, befand sich in Gemengelage mit den Nutzflächen der Bauern und war auch eingebunden in die Nutzungsrechte der Gemeinheiten (Allmenden). ${ }^{3}$

- Da im Hannoverschen die Gemeinheitsteilungen und Verkoppelungen auf freiwilliger Basis aller Interessenten, also aller Betroffenen, erfolgten, waren die Verfahren sehr kompliziert und langwierig. Neben örtlicher Uneinigkeit der Bauernschaft gab es auch Widerstände von Beamten und Gutsbesitzern, die den Verlust von Weiderechten auf im Herbst und Winter freigegebenen Allmenden für ihre Schafherden fürchteten ${ }^{4}$.

- Als regionales Beispiel sei hier der Streit von $1737^{5}$ zwischen den Lachendorfer Bauern und dem Gutsbesitzer von der Wense in Oppershausen erwähnt:

Die Lachendorfer Bauern hatten beantragt, in der Nähe von Oppershausen nahe der Aller ertragreiche Wiesen anzulegen. Wegen des günstigen Standortes nahm man den Nachteil der großen Entfernung von Lachendorf offenbar gern in Kauf. Der Plan scheiterte trotz behördlicher Befürwortung an der Halsstarrigkeit des Gutsbesitzers in Oppershausen, der trotz eines möglichen eigenen Vorteils sich einer Verbesserung der Grünlandwirtschaft widersetzte.

Der Amtmann schreibt an die vorgesetzte Behörde am 22. Mai 1737, nachdem er am 29. April höchstpersönlich den Ort in Augenschein genommen hatte:

„Und weil gedachter von Wense mit einer verunglückten Aderlaß sich entschuldigte, daß er selbst in re praesenti nicht erscheinen könte; so habe ich mich zu ihm nach Oppershausen begeben, und alle mir mögliche Vorstellung angewand, ihn von seinem Widerspruch abzuleiten. Allein er blieb zu hartnäckig bey seiner Meynung, wollte auch das Ablatum von einer eigenthümlichen Wiese nicht annehmen, und versicherte, daß er alle Wege es auf einen Prozess ankommen ließe.

Wenn also die Sache, wie wohl zu vermuthen, bey weiterem Fortgange hier hinaus schlagen solte, so bin ich der ohnvergrießlichen Meynung, der von Wense würde mit seinem Widerspruch fortkommen.

1. Weil der Orth meist aus einer neuen ergiebigen Angerweide besteht, die dem Gut Opppershausen, wegen ihrer Nähe und Vorzüglichkeit sehr wohl zu statten komt.

2. die Supplivirende Lachendorffer ihr an dem Orthe habendes Mitrecht, der Entfernung wegen, selten exerciren können, und also den Orth dem Gut Oppershausen und einigen Einwohnern fast allein überlassen müßen, letztere also 3. den Abgang, welcher aus den

\footnotetext{
${ }^{1}$ s. H. Pruns, a.a.O., S. 201

${ }^{2}$ Ulrike Hindermann; Agrarökonomischer Fortschritt auf lüneburgischen Rittergütern im 19. jahrhundert;

in: K. Panne, Albrecht Thaer, a.a.O., S. 84

${ }^{3}$ ebd.

${ }^{4}$ Schneider, Karl H.; Bauernbefreiung und Agrarreformen. Eine Einführung. Hannover 2007

<http://www.öwg.uni-hannover.de/w/images/5/5a/Kt7_bauernbefreiung_agrarreformen.pdf>

${ }^{5}$ Kopie einer unveröffentlichten Akte der Samtgemeinde Lachendorf, ohne Signatur, Original ausgestellt am 22. May 1737 zu Hermannsburg und unterschrieben von Wedemann.
} 
drei Renter Wiesen entstünde, mehr als Supplivirende Lachendorffer empfinden würden. "1

Die Lachendorfer sahen die Aussichtslosigkeit ihrer Forderung ein und gaben ihren Anspruch in der Aller-Ohe nahe Oppershausen auf.

Die Verbesserung einer Weide, die offenbar nicht nur den Lachendorfern Vorteile gebracht hätte, scheiterte an der Hartnäckigkeit und Uneinsichtigkeit eines Gutsbesitzers, der unnachgiebig an seinen formalen Rechten, ohne Rücksicht auf eigene ökonomische Vorteile, festhielt.

- Wesentlich zur Entwicklung der Landwirtschaft und zur Qualifizierung der Bauern trugen die Landwirtschaftlichen Vereine bei, im Raum Lachendorf seit 1861 der Filialverein Beedenbostel $^{2}$ im Provinzialverein für das Fürstentum Lüneburg.

\subsubsection{Die „benachteiligte“ Heide}

Die naturräumlich-ökologischen Bedingungen der Lüneburger Heide stellten eine beträchtliche Behinderung für die Modernisierung der Landwirtschaft dar.

- „Es handelt sich um eine Geest-Landschaft, also einen Boden aus vielen dicken Sandschichten, die von Lehm und Mergel durchzogen sind. An manchen Stellen ist der Sand so locker, dass der Wind inn nahezu wellenförmig aufwirft. Dieser gesamte Landstrich trägt den Namen ,Die Heide'.

Ein solcher Boden bringt nur eine wenig reiche Flora und Fauna hervor. Die Vegetation besteht aus Wald und Heide, aus kargen Äckern und mageren Wiesen. Buchweizen wächst anstelle von Hafer und Weizen. ${ }^{\text {‘3 }}$

- Die nährstoffarmen Sandböden ließen damals einfach keine hohen Ernteerträge zu. Eine Verbesserung der Bodenfruchtbarkeit, das hat Thaer immer wieder betont, war damals, bevor man den Mineraldünger kannte, natürlich nur möglich, wenn Naturdung in ausreichendem Maße zur Verfügung stand. Naturdung, also Stalldung, setzte aber eine intensive Tierhaltung mit Stallfütterung voraus. Bei dem geringen Grünlandanteil in der Heide wäre dies nur über den Anbau von Feldfutter möglich gewesen. Gegen einen ertragreichen Kleeanbau zu Futterzwecken sprach eben auch die Bodengüte.

- Eine deutliche Benachteiligung der Heide hinsichtlich der Infrastruktur darf auch hier nicht unerwähnt bleiben: Das Transportsystem war bis Ende des 19. Jahrhunderts noch immer auf Pferd und Wagen angewiesen. Erst die Bahnstrecken Lüneburg - Soltau - Celle sowie Winsen/Luhe - Hützel erschlossen die zentrale Heide und banden sie in Winsen/Luhe, Lüneburg, Soltau und Celle an das überregionale Bahnnetz an. Dies wirkte sich sehr positiv auf den Transport landwirtschaftlicher Massengüter wie Kartoffeln, Zuckerrüben und Mineraldünger aus.

- $\quad$ Für den Raum Lachendorf wurde der Bahnanschluss erst 1904 durch die Kleinbahnstrecke Celle-Wittingen ${ }^{4}$ realisiert. Bis dahin war Celle der nächst gelegene Bahnhof.

\footnotetext{
${ }^{1}$ Unveröffentlichte Akte der Samtgemeinde Lachendorf, ohne Signatur, hier in der originalen Orthographie der handschriftlichen Akte, Original ausgestellt am 22. May 1737.

${ }^{2}$ F. Veth, Hg.; Landwirtschaftlicher Verein Beedenbostel, 1961, Festschrift zum hundertjährigen Bestehen; S. 9

${ }^{3}$ So schrieb der französische Forscher E. Demolins nach einem Besuch in der Heide im Jahr 1867. s. Behr, A.; Der Lutterhof bei Hermannsburg, Verlag Ludwig-Harms-Haus, Hermannsburg 2005, S. $13 / 14$

${ }^{4}$ Landkreis Celle (Hrsg.); Spuren und Zeichen, , S. 155
} 
- $\quad$ Ein Beispiel aus der Tierhaltung belegt deutlich die natürliche Benachteiligung der Heide: Seit Ende des 18. Jahrhunderts war die Haltung von Merinoschafen ${ }^{1}$ ein einträglicher Wirtschaftszweig, weil die feine Wolle in England sehr begehrt war. Die Schnucken auf den Heideflächen konnten nicht durch das Merinoschaf ersetzt werden, weil die Heide dem Merinoschaf keine Futtergrundlage bietet. Und die Schnuckenwolle (eigentlich Haare) konnte die Qualitätsanforderungen der englischen Wollindustrie nicht erfüllen. So war die Schnuckenhaltung der Konkurrenz der Merino-Schafhaltung hoffnungslos unterlegen.

Erst die volle Anwendung der neuen Erkenntnisse der Agrarwissenschaft, der Agrartechnik und Agrarchemie sowie neue Kulturpflanzen wie Kartoffel und Zuckerrübe (19. Jahrhundert) sowie Mais (20./21. Jahrhundert) ermöglichten es auch der Heide, zu einem leistungsfähigen Agrarraum zu werden.

Diese Entwicklungen entfalteten erst ab der 2. Hälfte des 19. Jahrhunderts ihre volle Wirkung in der Agrarstruktur und in der Um- bzw. Ausgestaltung der Kulturlandschaft der Heide.

\subsubsection{Späte Reformen in der Südheide}

Aus den bisherigen Überlegungen lässt sich die Frage klären, wie die Reformbereitschaft hinsichtlich der Agrarwirtschaft in der Heide um 1800 zu beurteilen ist.

- $\quad$ Das zeitgenössische allgemeine Bewusstsein der gesellschaftlichen Eliten war für eine grundlegende Reform der Agrarwirtschaft bereits seit etwa 1750 äußerst günstig.

- $\quad$ Der allgemein vorhandene ökonomische Druck zur Steigerung der landwirtschaftlichen Leistungsfähigkeit war offenkundig.

- Die ökologische Situation der Heidebauernwirtschaft zeigte katastrophale Züge.

- $\quad$ Die geringe Leistungskraft der Heidebauernwirtschaft bot den staatlichen Stellen sicherlich wenig Anreiz zu Reformen, die das Steueraufkommen hätten verbessern können.

- $\quad$ Der Land besitzende Adel war nicht reformorientiert und verfügte auch weitgehend nicht über die notwendigen Mittel.

Die politischen Umwälzungen sowie die Belastungen insbesondere der ländlichen Bevölkerung durch Besatzungen und Kriegsfolgen waren in der Zeit Napoleons I. einer Reform der hergebrachten Landwirtschaft sehr abträglich. Die Personalunion zwischen Hannover und Großbritannien erwies sich für Hannover ehr als ein retardierendes Moment, trotz der großen Aufgeschlossenheit Georg III. für die Landwirtschaft.

- $\quad$ Die bäuerliche Bevölkerung war abhängig, eingebunden in ein Wirtschaftssystem mit Flurzwang und genossenschaftlicher Nutzung der Gemeinheiten und verfügte weder über den notwendigen Bildungsstand noch hinreichende politische und finanzielle Mittel, um aus eigener Kraft die notwendigen Reformen in Gang zu setzen.

Offenbar überwogen in der Heide die negativen und retardierenden Faktoren hinsichtlich einer Agrarreform bis weit in das 19. Jahrhundert hinein.

Der Vergleich der Karte von Papen, aufgenommen 1839, mit der Kurhannoverschen Landesaufnahme aus dem Ende des 18. Jahrhunderts zeigt, dass sich das Landschaftsbild und damit auch die Landnutzung in der ersten Hälfte des 19. Jahrhunderts nicht verändert haben. Aus dem unveränderten Landnutzungsmuster kann man schließen, dass bis zur Jahrhundertmitte die Agrarwirtschaft in der überkommenen Tradition verharrte und das System der Heidebauernwirtschaft unverändert praktiziert wurde.

\footnotetext{
${ }^{1}$ H. Pruns, a.a.O., S. 200
} 
Trotz aller Reformansätze, trotz des bereits vorhandenen wissenschaftlich-technischen Fortschritts verharrte die Kulturlandschaft der Südheide in der ersten Hälfte des 19. Jahrhunderts weiterhin in der überkommenen Verfassung und Nutzung.

Es hat also über viele Generationen bis zu den Agrarreformen um die Mitte des 19. Jahrhunderts keine wesentlichen Veränderungen im Nutzungssystem und demzufolge auch nicht im Landschaftsbild gegeben.

Es ist daher auch nicht verwunderlich, wenn in der Landbevölkerung die Skepsis gegen Reformen weit verbreitet war.

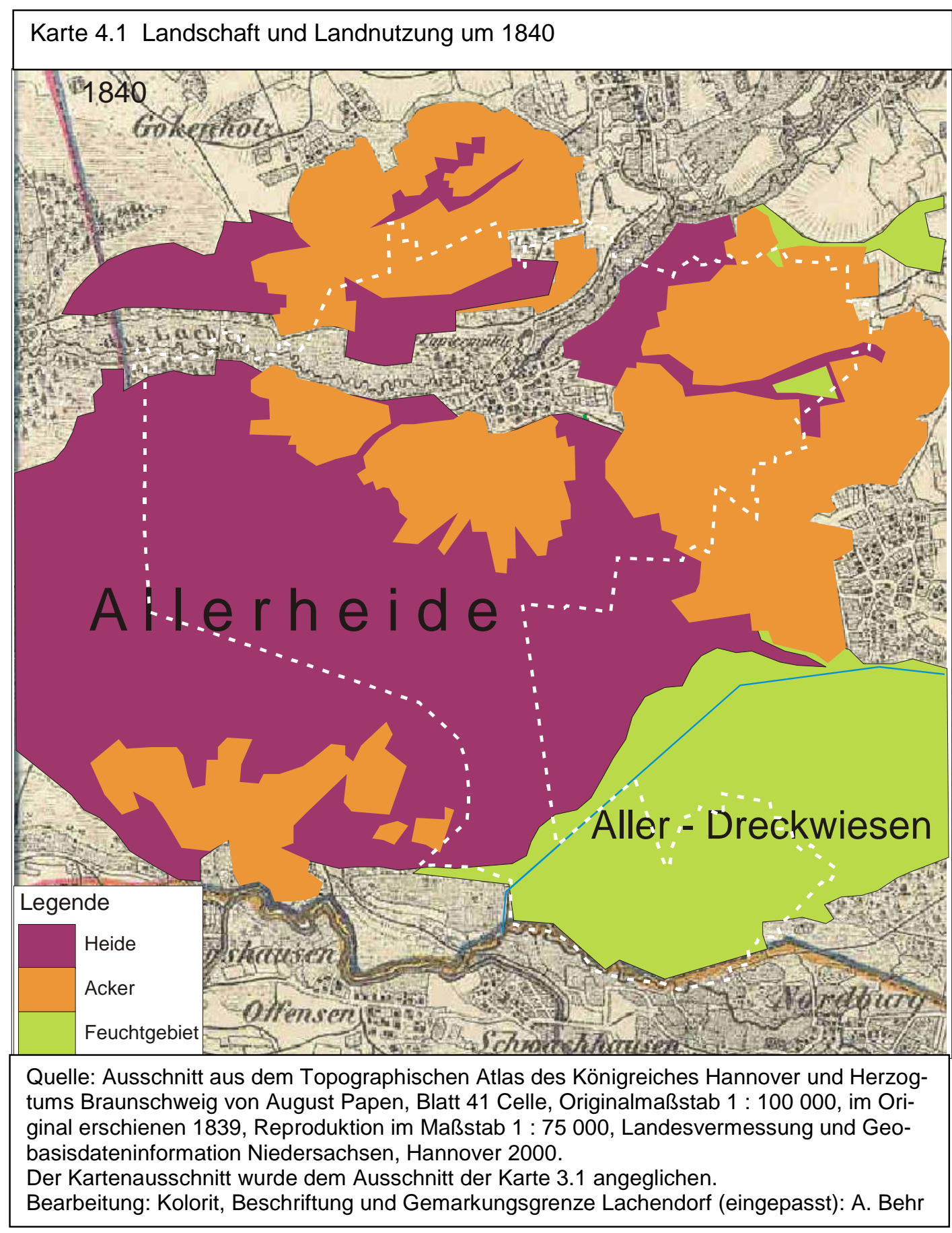

Die Karten zu den Agrarreformen von 1850 (Allerheide), 1852 (Feldmark Lachendorf) und 1861 (Aller- und trockene Wiesen) belegen eindeutig, dass sich Landnutzung, Landnut- 
zungsmuster und damit auch die Kulturlandschaft der Gemarkung Lachendorf erst nach den Reformen änderten.

\section{Kap. 4.2 Agrarreformen im Lachendorfer Raum}

\subsubsection{Allgemeine Notwendigkeit der Reformen}

Die bäuerliche Agrarlandschaft kannte bis zu den Agrarreformen verschiedene Nutzungsbereiche mit unterschiedlichen Rechten:

Den Höfen standen Ackerland und Wiesen zur eigenen („privativen“"1) Nutzung zur Verfügung. Diese Flächen unterlagen aber auch überwiegend der gemeinschaftlichen Stoppel-, Vor- und Nachweide sowie deshalb auch dem Flurzwang.

Aus diesen gemeinschaftlichen Nutzungsrechten auf den „privaten“ Nutzflächen der Höfe ergaben sich zwangsläufig Einschränkungen für die Nutzung hinsichtlich der Fruchtfolge und bei terminlicher Gestaltung von Saat und Ernte.

Die Dorfschaften verfügten in meist ausgedehnte Gemeinheiten (Allmenden) über gemeinschaftliche Nutzungsrechte, die in der Heide Rechte zur Weide und Hutung, zum Plaggenund Bultenhieb und zur Holznutzung umfassten.

In den Allmenden überschnitten sich die Nutzungsrechte mehrerer umliegender Dorfschaften. Da sich die verschiedenen Nutzungsrechte, insbesondere die Weideberechtigungen, nicht nur räumlich sondern teilweise auch jahreszeitlich und nach verschiedenen Nutztieren unterschieden, hatte sich ein äußerst komplexes System herausgebildet.

Die Reformen ${ }^{2}$ beseitigten die Grundlagen der überkommenen Agrarstruktur und rechtlichen Verfassung der Dorfgemeinschaften in vier grundsätzlichen Schritten:

\section{1) Ablösung}

Die Bauern in der Heide waren zwar keine Leibeigenen ${ }^{3}$ der Grundherrschaft, insofern war keine Bauernbefreiung nötig. Die Höfe unterlagen aber dem Meierrecht und waren stark durch Abgaben sowie Hand- und Spanndienste belastet.

Die Ablösung der Lasten und Dienste regelten der Erlass von 1831 und die zugehörige Verordnung von $1833^{4}$.

Als lokales Beispiel sei die Ablösung ${ }^{5}$ des Fleischzehnten von 1829 erwähnt:

„Nachdem in Folge der statt gehabten Verhandlungen betreffend die Zugeldesetzung der unter den Domanial-Intraden vorkommenden Naturalien, die Königl. Domänen-Cammer in seinem Rescripte vom 16. März d. J. an die Rentey des hiesigen Amts Folgendes erlassen hat:

Von den Fleischzehntpflichtigen der Probstey Wienhausen haben nur die von den nachfolgenden 3 Dorfschaften abgegebenen Gebote als

1) von Lachendorf $13 \mathrm{rthr} 8 \mathrm{ggr}$

2) von Metzingen $3 \mathrm{rthr}$

3) von Eldingen $\quad 1$ rthr 2 ggr $3 d \quad$ (d bzw. p: Denarius bzw. Penning)

für annehmlich befunden werden können.

Wir erklären daher die Fleichzehntpflichtigen aus den ebengedachten 3 Dorfschaften damit auf immer für abgelöset, und authorisieren die Rentey die im Ganzen dafür aufkommenden 19 rthr 10 ggr 3 d schon vom 1. July 1829 an in den Registern unter den ständigen Gefällen aufzuführen, ....

Beedenbostel, d. 21. May 1829, Königl. Großbr. Hannoversches Amt“

\footnotetext{
${ }^{1}$ Häufige Formulierung in den Rezessen

2 Die Reformen zur Bauernbefreiung von Leibeigenschaft, Abgaben sowie Hand- und Spanndiensten werden hier nur am Rande thematisiert, obgleich sie ebenfalls zu den grundlegenden Agrarreformen des 19. Jahrhunderts gehören. Diese Arbeit konzentriert sich im Rahmen ihrer Zielsetzung auf die Reformen mit räumlichen, landschaftlichen Auswirkungen.

${ }^{3}$ M. Stöber, a.a.O., S. 71

${ }^{4}$ ebd., S. 71 (Einzelne Ablösungen gab es offenbar auch schon vor 1830, wie das zitierte Beispiel über die Ablösung des Fleischzehnten vom 21.4.1829 belegt., Anm. d. Verf.)

${ }^{5}$ Unveröffentlichte Akten der Samtgemeinde Lachendorf, ohne Signatur
} 
Zur Erhaltung bzw. Schaffung eines leistungsfähigen bäuerlichen Mittelstandes blieb im Königreich Hannover das aus dem Meierrecht stammende Anerbenrecht mit ungeteilter Hofübergabe bestehen. Diese Maßnahme schütze die Voll- und Halbhöfe sowie die Kötner und benachteiligte die landlosen Dorfbewohner'.

Lachendorf war hinsichtlich der gesellschaftlichen Struktur des Dorfes eine Ausnahme unter den Bauerndörfern der Region, weil die Papierfabrik die Entstehung einer selbstbewussten und wirtschaftlich recht gut gestellten nichtbäuerlichen Gruppe ermöglichte.

\section{2) Generalteilung}

Die räumliche Ausdehnung und Überschneidungen mit anderen Dorfschaften bei den gemeinsamen Nutzungsrechten belegt folgende Aktennotiz ${ }^{2}$ von 1728:

\section{Lachendorf haben, hüten und eintreiben, \\ $\begin{array}{ll}\text { (Unterschrift) } & \text { Ernst } \\ \text { Extrahiret auß dem Ambts-Lagerbuch } & 1663\end{array}$ \\ Beedenbostell am 10ten July 1728}

Das Dorf Lachendorf hat Ihre Huedt und weyde für der (...unleserlich) Schneede, als Oppershausen her, für dem Osterbruche ${ }^{3}$, bey der Sprache ${ }^{4}$, hinter Gockenholtz herumb, hinter Beydenbostell nacher Höfer, Jarnsen Bunkenburg, für Spechtshorn, Hellmercampe und Ahnsbecker Felde, und mögen alle hier beschriebene Dörfer wieder den Lachendorfern, weil Sie alle mit einander gesambt Hued

Die Gemeinheitsteilungen begannen formal mit der Lüneburger Gemeinheitsteilungsordnung von 1802, konnten aber in den meisten Landesteilen wegen der politischen Verhältnisse erst etwa 20 Jahre später in Angriff genommen werden. ${ }^{5}$

Die gemeinschaftliche Nutzung durch die Dorfgenossen verschiedener Dörfer führte immer wieder zu gerichtlichen Auseinandersetzungen zwischen den Dörfern über bestimmte Nutzungsrechte. Durch Abgrenzung der Gemeinheiten der verschiedenen Dorfgemeinschaften erhielt jedes Dorf eine klar gegen andere Dörfer abgegrenzte Flur sodass räumliche Überschneidungen der Nutzungsrechte verschiedener Dorfschaften nicht mehr vorkamen.

Auf den Streit ${ }^{6}$ zwischen Ahnsbeck und Lachendorf über Nutzungsrechte in den Allerdreckwiesen sei hier nochmals verwiesen:

Offenbar wurden die Wiesen, die eigentlich der Heugewinnung dienten, im Frühjahr noch beweidet. Das ist ein sicherer Hinweis auf den Futtermangel im ausgehenden Winter und Frühling, denn den Bauern ist sicherlich klar gewesen, dass dies den Grasaufwuchs zum Heuen schmälern würde. Besonders deutlich zeigt sich der Futterengpass der bäuerlichen Wirtschaft in der Tatsache, dass es im Streit um das Beweidungsrecht um nur wenige Tage vom 1. bis 11. Mai ging. Während also Ahnsbeck den Lachendorfern grundsätzlich nach dem 1. Mai keine Nutzung mehr zustehen will, so kommt der Vergleich zu einer differenzierten Lösung, nach der die Lachendorfer ihr Hornvieh vom Gemeindehirten doch wenigstens bis zum 4. Mai auftreiben dürfen. Ganz offenbar waren diese wenigen Tage Nutzungsrecht ein Erfolg für die Lachendorfer. Dies bestätigt wiederum die Annahme des grundsätzlichen Futtermangels in der alten Agrarwirtschaft.

Die Wiesen werden in der Quelle als einschürig bezeichnet, es war also nur ein Grasschnitt für Heu möglich. Auf den feuchten Standorten der Allerdreckwiesen wäre ohne Düngung und

\footnotetext{
${ }^{1}$ ebd. S. $71 \mathrm{f}$.

${ }^{2}$ Archiv der Gemeinde Lachendorf, unveröffentlicht, zeitgenössische Rechtschreibung beibehalten

${ }^{3}$ Osterbruch zwischen Oppershausen und Altencelle, später als Stauwiesen ausgebaut.

${ }^{4}$ Sprache: Waldgebiet zwischen Lachendorf und Lachtehausen

${ }^{5}$ Schneider, K.H. u. H.H. Seedorf; Bauernbefreiung und Agrarreformen in Nds., , Hildesheim 1989, S. $80 \mathrm{f}$.

${ }^{6}$ s. Kap. 3.4.3, Ziffer 3 und 4
} 
Entwässerung ein zweiter Schnitt sicherlich auch ohne Beweidung im Frühjahr und im Herbst nicht möglich gewesen.

Die notwendige Aufteilung der großen ungegliederten Gemeinheiten wurde sorgfältig vor Ort vorbereitet und das Ergebnis in rechtsverbindlichen Rezessen festgehalten.

Die Grenzziehungen für die einzelnen Dorfgemarkungen berücksichtigten sehr genau die ökologischen Bedingungen und Nutzungsinteressen der Bauern eines jeden Dorfes. Dies lässt sich am Beispiel der Gemarkungen von Ahnsbeck und Lachendorf besonders gut zeigen;

Beide Bauerndörfer liegen am Nordrand des Aller-Urstromtales, haben Anteil an den nördlich gelegenen Grundmoränenplatten mit lehmigen Böden und Anteil an den südlich im Urstromtal gelegenen trockenen Flächen auf reinen Sandböden und feuchteren Standorten auf Anmmor im Bereich eines Randmoores im Urstromtal. Besonders bemerkenswert ist bei der Flur Lachendorfs der $5 \mathrm{~km}$ vom Ort entfern liegende Anteil an den Allerdreckwiesen mit dem natürlichen Grünland. So haben die Lachendorfer Höfe auch Anteil an allen hier zur Verfügung stehenden Naturräumen: Günstigen Acker- und Grünlandböden sowie große Heideflächen auf der Allerheide.

\section{3) Spezialteilung oder Separation}

Nachdem die großen Gemeinschaftsreviere unter den nutzungsberechtigten Dorfschaften aufgeteilt worden waren, konnten die nun jedem Dorf allein zustehenden Gemeinheiten unter den Bauern aufgeteilt werden, also separiert werden. Der Schlüssel dazu waren die Nutzungsrechte der Höfe. Das bedeutete, dass vor allem die Voll- und Halbhöfe und auch die Kötner davon profitierten, ihre Betriebsflächen erheblich vergrößerten und die unterbäuerliche Schicht, die keine verbrieften Nutzungsrechte in der Gemeinheit hatte, weitgehend leer ausging.

\section{4) Verkoppelung}

In der alten Flurordnung mit den schmalen Langstreifen, die zu Gewannen zusammengefasst waren, gehörten in jedem Gewann ein oder mehrere nicht nebeneinander liegende Ackerstreifen zu jedem Hof. Jedes Gewann unterlag dem Flurzwang, d.h. alle Parzellen eines Gewannes wurden einheitlich genutzt. Dies war hinsichtlich der gleichzeitigen Saat- und Erntetermine der jeweiligen selben Feldfrucht sinnvoll und praktisch. Unbedingt notwendig war der Flurzwang aber bei der Brache, weil nur so eine Beweidung durch gehütetes Vieh möglich war. Das Abhüten der Brache (Stoppelweide nach Getreideanbau) brachte eine gewisse natürliche Düngung mit sich, vor allem aber konnte man auf die Beweidung der Brache aus Futtermangel nicht verzichten.

Erst mit den Thaerschen Reformen, dem Anbau von Klee und anderen Zwischenfrüchten und schließlich mit dem Anbau von Hackfrüchten änderte sich das Futterangebot, insbesondere für das Hornvieh, grundlegend. Die Bauern konnten zur Stallfütterung übergehen und so Mist produzieren, der dringend als Dung auf den stark ausgelaugten Ackerböden benötigt wurde.

Die starke Besitzzersplitterung und Gemengelage der Flurparzellen der einzelnen Höfe verhinderte zusammen mit dem Flurzwang jede individuelle Nutzung. Insbesondere war auch ohne Aufgabe der alten Dreifelderwirtschaft mit dem gemeinsamen Brachfeld keine verbesserte Dreifelderwirtschaft mit Hackfruchtanbau möglich.

So war als letzte, aber unverzichtbare Maßnahme zu einer neuen Agrarstruktur, die die individuelle Bewirtschaftung leistungsfähiger Höfe ermöglichte, die Verkoppelung unbedingt erforderlich. Ziel der Verkoppelung war die Zusammenlegung der zersplitterten Nutzparzellen zu möglichst arrondiertem landwirtschaftlichem Besitz. Das dafür notwendige Verkoppe- 
lungsgesetz wurde 1842 erlassen und die Umsetzungen waren weitgehend bis zum Ende des Königreiches Hannover 1866 abgeschlossen¹.

\section{Verkoppelung}

Es geht ein Mann durch das bunte Land; Die Meßkette hält er in der Hand.

Steht vor sich hin und sieht sich um; "Hier ist ja alles schief und krumm!"

Er mißt wohl hin und mißt wohl her; "Hier geht ja alles kreuz und quer!"

Er blickt zum Bach im Tale hin; "Das Buschwerk dort hat keinen Sinn!"

Zum Teiche zeigt er mit der Hand; "Das gibt ein Stück Kartoffelland!"

Der Weg macht seinen Augen Pein; "Der muß fortan schnurgerade sein!"

Die Hecke dünket ihm ein Graus; "Die roden wir natürlich aus!"

Der Wildbirnbaum ist ihm zu krumm; "Den hauen wir als ersten um!"

Die Pappel scheint ihm ohne Zweck; "Die muß ja selbstverständlich weg!"

Und also wird mit vieler Kunst. Die Feldmark regelrecht verhunzt.

Hermann Löns (1866 - 1914)

Das Gedicht von Hermann Löns über die Verkoppelung ist keineswegs zeitgenössisch oder zeittypisch, es ist vielmehr ein bezeichnendes Beispiel für die Veränderung der Landschaftsbetrachtung und des Landschaftsempfindens von der Mitte des 19. Jahrhunderts bis zur Jahrhundertwende. Während die bäuerliche Bevölkerung von der Einengung durch die alte Agrarordnung durch die Verkoppelung endgültig befreit war, Heideflächen, ehemals wichtige Hutungen, zu nutzlosem „Unland“ wurden und die Landwirtschaft einen vor den Reformen unmöglichen Aufschwung nahm, wurde in nichtbäuerlichen Kreisen die alte Agrarlandschaft als Naturlandschaft verklärt und die Neuerungen negativ als Natur zerstörend bewertet. Diese auf ästhetischem Landschaftsempfinden und romantischer Verklärung des Landlebens gründende Sicht von Städtern und Künstlern hatte sich vom Gebrauchswert der bäuerlichen Nutzlandschaft abgelöst. Im Gegensatz zum Stadtleben meinte man im Landleben das Unverfälschte und Natürliche zu erkennen. Das war aber nur möglich, weil man die Mängel der alten Agrarordnung und die Mühen und Qualen des damaligen Landlebens nicht aus persönlichem Erleben kannte.

Vermutlich hat Friedrich Hebbel im Jahr 1844 - also zu Beginn der Reformen - die Situation in der Heide zutreffender beschrieben:

„Und alles so still, und alles so stumm, man sieht sich umsonst nach Lebendigem um, nur hungrige Vögel schießen aus Wolken, um Würmer zu spießen." ${ }^{2}$

\subsubsection{Reformen in der Flur Lachendorfs}

\subsubsection{Die Rezesse}

Die umfangreichen Maßnahmen zur Neuordnung der Lachendorfer Flur sind in mehreren Dokumenten festgehalten, deren beglaubigte Kopien bei der Gemeinde bis heute im Archiv aufbewahrt werden:

1. Plan-Receß über die Generaltheilung der Communion-Reviere Allerheide, Lachendorfer Moor, Westermoor, Allerhorn und Allerohe, Amt Celle und Beedenbostel, 1861, (Sign.: 61/8)

2. Register über die Abfindung der Dorfschaft Lachendorf auf der Allerheide, Amt Beedenbostel, o.J., (Sign.: 61/6)

\footnotetext{
${ }^{1}$ vgl. M. Stöber, in : A. D. Thaer (K. Panne, Hrsg.), a.a.O., S. 73

${ }^{2}$ zitiert in „Die Zeit“, Nr. 32, 1.8.2013, S. 51
} 
3. Recess über die Generaltheilung verschiedener Gemeinheiten von Gockenholz und Alvern, Gockenholz, Alvern und Ohe und Gockenholz und Lachendorf, Amt Beedenbostel, 1839, Fotokopie, ohne Signatur

4. Recess über die Generaltheilung des Schweinebruchs 1832 - 1838, (Sign.:Stadtarchiv Celle, 4 A 85)

5. Rezess über die Generaltheilung der Gemeinheiten und der Vor- und Nachweide auf den Wiesen im Schweinebruch in der Vogtei Celle, 1834, (Stadtarchiv Celle)

6. Classifications- und Vermessungs-Register der Feldmark Lachendorf, o.J., (Sign.: 61/9)

7. Vermessungsregister von der Feldmark Lachendorf, Amt Beedenbostel, o.J. (Sign. 61/10)

8. Taxations-Tabelle über die Abschätzung der Feldmark Lachendorf, 1852, (Sign.: 61/4)

9. Taxations-Register zur Spezial-Theilung und Verkoppelung der Feldmark Lachendorf, o.J., (Sign.: 61/4)

10. Receß über die Spezialtheilung und Verkoppelung der Feldmark Lachendorf, Amt Beedenbostel, 1858/59, (Sign.: 61/5)

11. Regulativ über die künftige Benutzung der Abfindungen, über Befriedigung der Koppeln, erste Instandsetzung und künftige Unterhaltung der Wege, der Wegegräben, der Brücken, Siele und Abzugsgräben pp. Gegenseitige Verpflichtungen der beteiligten hinsichtlich des Wasserlaufs, Concurrenz zu den Theilungskosten pp. In Spezial-Theilungs und Verkoppelungs-Angelegenheit von

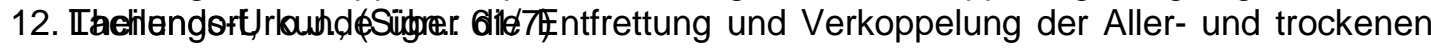
Wiesen bei Lachendorf, Amt Celle, 1866, (Sign.: 140/8)

Die Verfahren zur Neuordnung der Flur im Lachendorfer Raum wurden in den Jahren zwischen 1830 und 1866 vollzogen, die für die Lachendorfer Bauern maßgeblichen Verfahren aber erst ab 1842.

Die Generalteilung der Allerheide und angrenzender Reviere wurde 1844 beantragt und erst 1861 endgültig abgeschlossen. Die Taxations- und Vermessungsregister für die Spezialteilung und Verkoppelung der Feldmark lagen 1852 vor. Die Separationen der Gemeinheiten in der alten Feldmark und in der Abfindung Lachendorfs aus der Generalteilung der Allerheide wurden zusammen vorgenommen und im Rezess 1859 rechtlich abgeschlossen. Die Spezialteilung der dörflichen Gemeinheiten und die Verkoppelung in der Feldmark liefen also zeitlich parallel zur Generalteilung der Allerheide und der Spezialteilung der dortigen Lachendorfer Abfindung.

Die Aller- und Trockenen Wiesen wurden in einem sehr langen Extraverfahren zwischen 1842 bis 1866 entfrettet ${ }^{1}$ und verkoppelt.

Während also die Generalteilung der Allerheide erst viele Jahre nach Erlass der gesetzlichen Grundlage von 1802 erfolgte, wurden die Verkoppelungen der Feldmark und der Aller- und Trockenen Wiesen unmittelbar nach Verabschiedung des Gesetzes 1842 in Angriff genommen.

\subsubsection{Von der der gemeinsamen „Hut und Weide“ zu getrennten Dorfgemarkungen}

Der „Plan-Receß über die Generaltheilung der Communion-Reviere Allerheide, Lachendorfer Moor, Westernmoor, Allerhorn und Allerohe, Amt Celle und Beedenbostel“2 gibt detailliert und exemplarisch Einblick in das Verfahren einer Generalteilung:

Das Teilungsobjekt bildete eine zusammenhängende Fläche von etwa $2000^{3}$ ha, die im Norden durch die herrschaftliche Forst Sprache und die Lachendorfer Feldmark ${ }^{1}$, im Osten

\footnotetext{
${ }^{1}$ Frettung: Recht zur gemeinschaftlichen Abweidung durch Vieh; Entfrettung: Ablösung der gemeinschaftlichen Weiderechte.

${ }^{2}$ Rezess über die Spezialteilung und Verkoppelung der Feldmark von Lachendorf, 1859, Archiv der Samtgemeinde Lachendorf, Sign.: 61/5

${ }^{3}$ Der Rezess gibt nur die Flächengröße für das Teilungsgebiet ohne Allerohe und Allerhorn an.
} 
durch die Lachendorfer und Ahnsbecker Feldmarken, im Süden durch die Dreck- und Allerwiesen, durch die Aller und durch die Feldmark von Oppershausen und im Westen durch die Osterbruchwiesen ${ }^{2}$ begrenzt wurde.

Diese Lagebeschreibung belegt, dass diese große Gemeinheit mehrerer Dörfer naturgeographisch recht genau dem Lachte-Schwemmfächer im Aller-Urstromtal entsprach.

Die Beteiligten an dieser Generalteilung waren die Grundherrschaft, die Gemeinden Ahnsbeck, Altencelle, Lachendorf, Lachtehausen, Oppershausen und Osterloh, die Stadt Celle, die Güter Oppershausen, Offensen und Schwachhausen sowie die Königliche Militärverwaltung in Hannover ${ }^{3}$. Die Vermessung war $1853^{4}$ abgeschlossen, die Abfindung der „a.g.Grundherrschaft“5 und der Güter $1851^{6}$, die Ausweisung eines Exerzierplatzes von 240 Morgen $1853^{7}$. Anschließend erfolgten die Auseinandersetzungen zwischen den beteiligten Dorfschaften, die Festlegung der Grenzen, Wege und Triften.

Die entscheidende rechtliche Veränderung enthält $\S 22^{8}$ :

Der Rezess wurde dann 1861 abschließend genehmigt und damit rechtsverbindlich. Damit war die alte Agrarordnung mit gemeinschaftlicher Nutzung auf der Allerheide und Umgebung beseitigt.

Es gab jetzt klare Grenzen zwischen den Gebieten der verschiedenen

\begin{tabular}{|c|c|c|c|c|c|c|}
\hline \multicolumn{7}{|l|}{ Tabelle 4.1} \\
\hline \multirow{2}{*}{\multicolumn{7}{|c|}{$\begin{array}{c}\text { Gesamtfläche der Generalteilung: Vermessung und Bonitierung } \\
\text { Allerheide inkl. Lachendorfer Moor und Western Moor }\end{array}$}} \\
\hline & & & & & & \\
\hline \multicolumn{4}{|c|}{ 1. auf dem Reviere } & \multicolumn{3}{|c|}{ 2. auf dem Reviere } \\
\hline \multicolumn{4}{|c|}{ im Amte Celle } & \multicolumn{3}{|c|}{ im früheren Amte Beedenbostel } \\
\hline Bodenart & $\mathrm{M}$ & QR & Kuhw. & $M$ & QR & Kuhw. \\
\hline Ackerland & & & & 21 & 56 & 1,177 \\
\hline Wiesenboden & & & & 7 & 51 & 1,4074 \\
\hline Angerboden & 34 & 113 & 4,7175 & 108 & 56 & 14,8793 \\
\hline Moorboden & 344 & 99 & 28,6784 & 22 & 28 & 1,5346 \\
\hline Bruchboden & 61 & 92 & 6,5964 & 134 & 22 & 11,1819 \\
\hline Heidboden & 1634 & 76 & 102,558 & 3995 & 32 & 187,0308 \\
\hline Summe & 2076 & 20 & 142,55 & 4289 & 5 & 217,211 \\
\hline unbrauchbar & & 36 & & 7 & 6 & \\
\hline \multirow[t]{2}{*}{ Summe } & 2076 & 56 & 285,101 & 4296 & 11 & 434,422 \\
\hline & & & gesamt & 6372 & 67 & 719,5228 \\
\hline \multicolumn{4}{|c|}{ Plan-Rezess, S. 8/9; Sign.: 61/8 } & \multicolumn{3}{|c|}{ entspricht: 1670,311 ha } \\
\hline
\end{tabular}
Dorfschaften und eindeutige Zuordnungen der Flächen. Die Abfindungen der einzelnen Dorfschaften, die neuen Gemarkungsteile aus der Generalteilung, gehörten jetzt zu den dörflichen Gemeinheiten, die dann in der Separation bzw. Spezialteilung auf die Höfe des Ortes verteilt wurden.

Der „Plan-Receß über die Generaltheilung“ und das „Register über die Abfindung der Dorfschaft Lachendorf auf der Allerheide" vermitteln einen sehr guten Eindruck über Inhalt, Umfang und Exaktheit des Verfahrens und der dabei ausgeführten Arbeiten zur örtlichen Bewertung der Flur (Taxation), deren Vermessung und den umfangreichen Wertberechnungen.

„Alle auf den verteilten Revieren als der Allerheide incl. den Osterbruchwiesen, dem Lachendorfer Moore, dem Westernmoore, der Allerohe und dem Allerhorn, sowie auch den nicht zum Teilungsgebiete gehörenden Reviere, dem Altenceller Rieth und den Altenceller Fuhren bisher mitgeübten gemeinschaftlichen Nutzungen werden in Folge der Generalteilung hiermit aufgehoben, und gehen die statt der seitherigen gemeinschaftlichen Gerechtsamen für die einzelnen Berechtigten ausgemittelten Äquivalente in einen völlig privativen Zustand auf die einzelnen Ortschaften über."

\footnotetext{
${ }^{1}$ Die Quelle belegt, dass ursprünglich Feldmark und Gemarkung keine synonymen Begriffe waren. Die Feldmark umfasste nur die privat genutzten Ackerflächen und die Gemeinheiten der zugehörigen Dorfschaft, aber nicht die Gemeinheiten mehrerer Dörfer wie die Allerheide. Der Rezess zur Generalteilung nennt auf S. 6 z.B. die Feldmark Lachendorfs als nördliche Grenze der Allerheide, die als gemeinsames Weide- und Hutungsgebiet mehrerer Ortschaften und Güter zu keiner der angrenzenden Feldmarken gehörte. Die heutigen Dorfgemarkungen sind also das Ergebnis der Generalteilungen.

${ }^{2}$ Plan-Rezess über die Generalteilung ..., § 4, Archiv der Samtgemeinde Lachendorf, Sign. 61/8

3 ebd. § 7

${ }^{4}$ ebd., $\S 5$

5 a.g. Grundherrschaft: aller gnädigste

${ }^{6}$ ebd., $\S 13$

7 ebd., § 16

${ }^{8}$ Plan-Rezess über die Generalteilung, §22, S. 72, Sign. 61/8
} 
Bevor jedoch die Allerheide und angrenzende Reviere an die benachbarten Dörfer verteilt werden konnten, musste spezielle Weiderechte abgefunden werden:

- Durch Abfindung des Gutes und Dorfes Oppershausen verblieben für das Teilungsgebiet noch die Allerheide mit dem Lachendorfer Moor und Western Moor. ${ }^{1}$

- Die Weiderechte der Stadt Celle mit Hornvieh auf der Allerheide wurden mit 40 Rth. abgefunden. Die Abfindung hatten alle beteiligten Interessenten zu tragen. ${ }^{2}$

- Das Gut Schwachhausen zur Winterweide auf der Allerheide mit Schafen wurde mit 60 Rth, das Gut Offensen für entsprechende Rechte mit 45 Rth. abgefunden. Die Abfindung dieser Weiderechte ging zu Lasten von Lachendorf, Ahnsbeck sowie Gut und Dorf Oppershausen. ${ }^{3}$

Der Beitrag zu den Abfindungen wurde nach dem Viehbestand, gemessen in „Viehhäuptern“, berechnet.

Die Teilungsfläche auf der Allerheide inklusive Lachendorfer und Western Moor wurde $1850^{4}$ sorgfältig vermessen und von beeideten Taxatoren bewertet.

Der damals benutzte Maßstab für den Wert einer Flur war die „Kuhweide“, eine fiktive Einheitsfläche, die zur Ernährung einer Kuh für ein Jahr notwendig war.

Die Vermessung unterteilte die Gemeinheitsfläche der Allerheide zur genauen Wertermittlung in 184 Parzellen und erfasste die dort belegenen privaten Flächen in 16 Bewertungsflächen.

Auf der Allerheide wurde folgender Bewertungsschlüssel (Tabelle 4.2) angewendet: Durch diese Bewertung erhielt man ein sehr kleinräumiges, differenziertes und genaues Wertgutachten der Teilungsflächen.

Bemerkenswert ist die schlechte Bewertung des Ackerlandes auf der Allerheide, denn die beiden Klassen entsprechen nur der 5. und 6. Klasse bei der Heide und werden noch schlechter bewertet als die 12. Klasse Ackerland in der Feldmark, also auf den besseren Ackerböden. ${ }^{5}$

Die Bewertung ist - völlig im Einklang mit den naturgeographischen Bedingungen - insgesamt recht gering. Selbst die 1 . Klasse beim

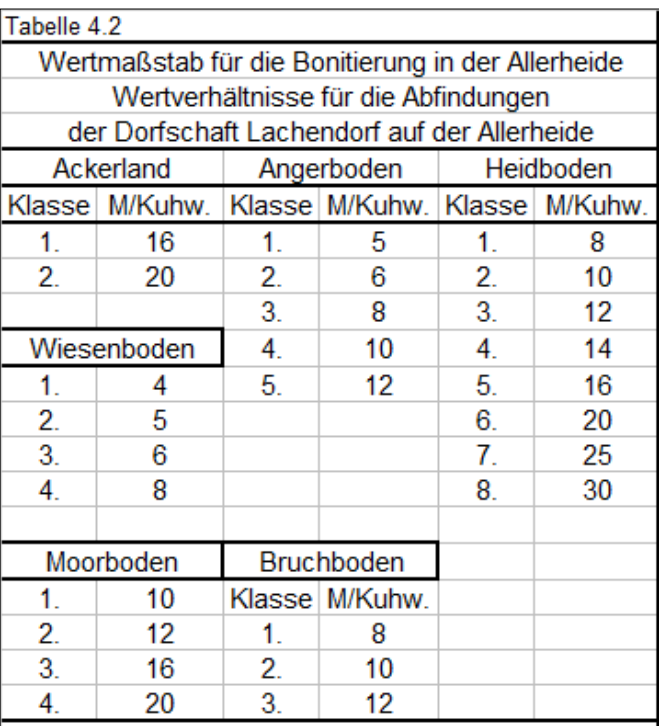
Register über die Abfindung der Dorfschaft Lachendorf Samtgemeinde Lachendorf, Archiv, Fach/Nr. 61/6 Wiesenboden weist einer Kuhweide 4 Morgen zu, also nur $1 / 4$ des Idealwertes einer Kuhweide. In allen anderen Fällen wird ein geringerer Wert zugrunde gelegt.

Für jede Bewertungsfläche wurde entsprechend der „Bodenart“ und der Wertklasse der Wert in „Kuhweiden“ berechnet.

\footnotetext{
${ }^{1}$ Plan-Rezess, $\S 5$, S. 7

2 Plan-Rezess, $\S 10$, S. $19 \mathrm{ff}$.

${ }^{3}$ Plan-Rezess, § 11, S. $21 \mathrm{ff}$.

${ }^{4}$ Plan-Rezess, S. 7

${ }^{5}$ Vergl. dazu die Tabellen 4.2 und 4.9: Bewertungsmaßstäbe
} 
Die Tabelle 4.3 gibt beispielhaft diese Leistung hinsichtlich Vermessung, Bewertung und Wertermittlung bzw. Rechenaufwand wieder. Bei der meist geringen Größe der einzelnen Bewertungsflächen und dem geringen Bodenwert wurde der Wert in Kuhweiden auf vier Nachkommastellen berechnet. Heutige, Programm gestützte Kontrollrechnungen zeigen die Genauigkeit der damaligen Arbeiten, denn in den geprüften Beispielen gibt es nur Abweichungen in der 4. Nachkommastelle als Rundungsfehler.

Nach vielen Verhandlungen und Einzelregelungen sowie den Grenzfestlegungen erhielten die beteiligten Gemeinden folgende Abfindungen:

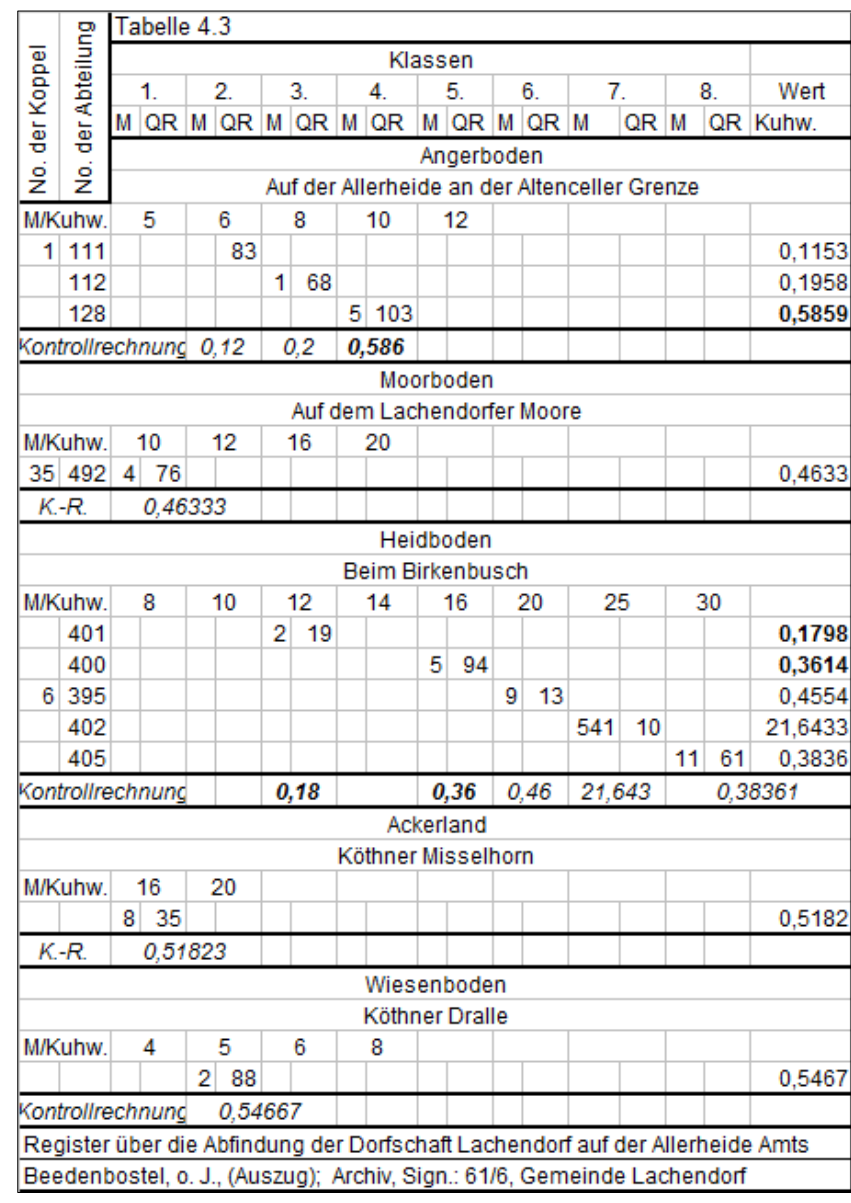

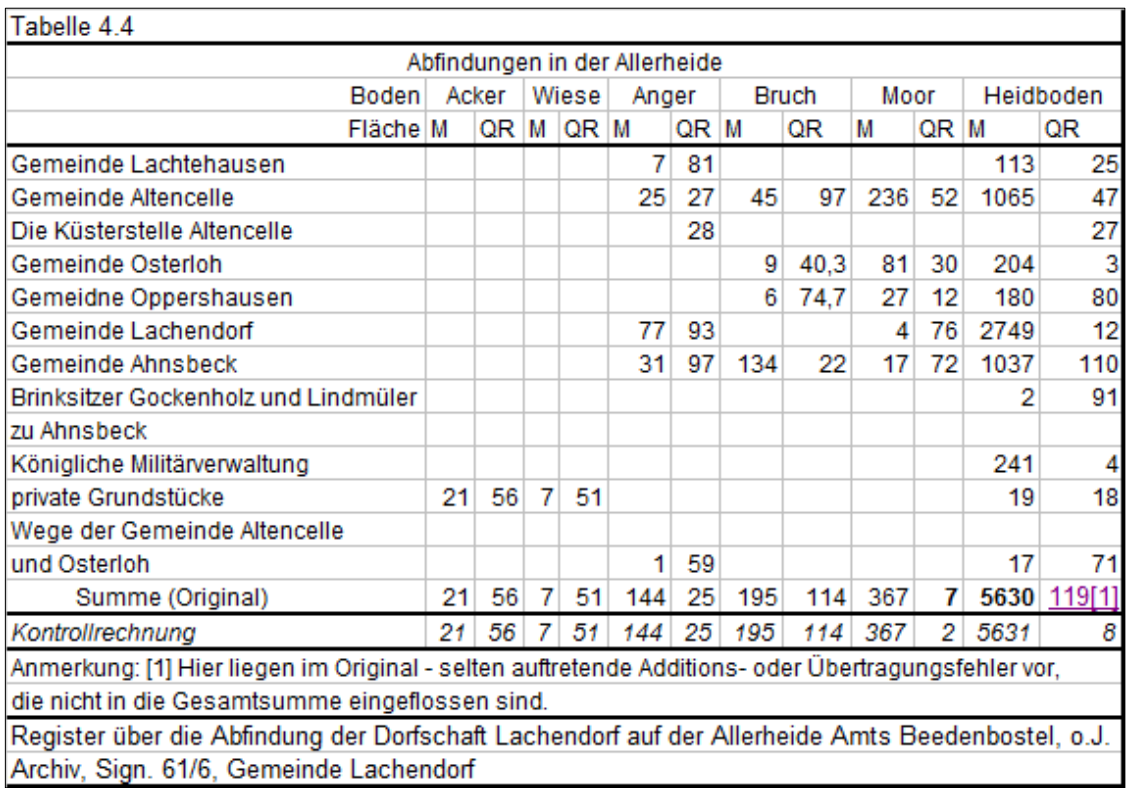

Die Abfindungsflächen standen mit Abschluss des Verfahrens den Dorfschaften als Gemeinheiten zur Verfügung und konnten mit den Gemeinheiten in der alten Feldmark zusammengefasst der Separation unterzogen werden. Beide Verfahren, Separation und Verkoppelung, wurden für Lachendorf formal 1859 zum Abschluss gebracht, nachdem alle Einsprüche bearbeitet und die Genehmigung der Behörde, dem Königlichen Amt zu Celle, vorlag. 


\subsubsection{Von der Taxation und Vermessung zur Spezialteilung und Verkoppelung}

In die Spezialteilung und Verkoppelung wurden die privat genutzten Flächen aller Höfe, die alten Gemeinheiten des Dorfes und die Abfindung aus der Generalteilung der Allerheide einbezogen.

Anhand der verschiedenen Unterlagen zur Vorbereitung und Durchführung der Spezialteilung und Verkoppelung der Feldmark Lachendorf sollen hier exemplarisch Komplexität, Umfang und Inhalt einer solchen grundlegenden Reform der Agrarlandschaft dargestellt werden.

Das Vorhaben begann mit Anträgen bei der Behörde, die das Verfahren eröffnete, Geschworene als Vertreter der Interessenten berief und vereidigte sowie vereidigte Geometer und Taxatoren mit Vermessung und Bewertung beauftragte.

Zur Taxation, also Bewertung oder Werterfassung, und Vermessung liegen mehrere Dokumente vor, die sich inhaltlich gegenseitig

\begin{tabular}{|c|c|c|c|c|c|c|c|c|}
\hline \multicolumn{9}{|c|}{ Gesamtfläche zur Spezialteilung und Verkoppelung } \\
\hline \multirow[b]{2}{*}{ Bestand } & \multicolumn{2}{|c|}{ Ackerland } & \multicolumn{2}{|c|}{ Wiesenboden } & \multicolumn{2}{|c|}{ Angerboden } & \multicolumn{2}{|c|}{ Heidboden } \\
\hline & M & QR & M & QR & M & QR & M & QR \\
\hline privater Besitzstand & 2063 & 103 & 126 & 51 & 349 & 102 & 848 & 39 \\
\hline Gemeinheiten beim Dorfe & & & & & 273 & 40 & 675 & 83 \\
\hline Abfindung auf der Allerheide & & & & & 77 & 93 & 2753 & $88^{*}$ \\
\hline Exerzierplatz & & & & & & & 160 & 1 \\
\hline \multicolumn{9}{|c|}{ hinzu wg. irrtümlicher Vermessung } \\
\hline der Allerheidegrenze & & & & & & 109 & & 61 \\
\hline \multicolumn{9}{|l|}{ ab wg.ilrrtümlicher Berechnung } \\
\hline der 309. Abteilung & & & & & & & 1 & \\
\hline Summe & 2063 & 103 & 126 & 51 & 671 & 104 & 4439 & 32 \\
\hline Summe in ha & \multicolumn{2}{|c|}{540,958} & \multicolumn{2}{|c|}{33,137} & \multicolumn{2}{|c|}{176,103} & \multicolumn{2}{|c|}{1163,576} \\
\hline gesamt in ha & \multicolumn{4}{|c|}{1913,774} & & & & \\
\hline \multicolumn{5}{|c|}{${ }^{*}$ ) incl. Moorboden (4 M 76 QR, 0,4633 Kuhw.) } & & & & \\
\hline \multicolumn{9}{|c|}{ Rezess von $1858 / 59$ und Taxationsregister, Sign. $61 / 5$ und $61 / 4$} \\
\hline \multicolumn{9}{|c|}{ Umrechnungen in ha: Verf. } \\
\hline
\end{tabular}
ergänzen und teilweise auch überschneiden. ${ }^{1}$

Die Taxations-Tabelle ${ }^{2}$ enthält Angaben zu insgesamt 664 Flurstücken in der Feldmark einschließlich der Dreck- und Allerwiesen, ausgenommen natürlich die Gemeinheiten auf der Allerheide, die im Rahmen der Generalteilung taxiert und vermessen wurden. ${ }^{3}$.

Zu jeder der 664 „Belegenheiten“ (Flurstücke) erfährt man die Bodenart, den Wert (Classe mit Morgen pro Kuhweide) sowie genaue Angaben zu Weide, Holzbestand, Plaggenhieb und Wertlosigkeit (verfahren und vergraben bzw. verweht). Allerdings handelt es sich um eine reine Bewertungs-Tabelle ohne Flächenangaben aus einer Vermessung.

Aus diesen Tabellen kann man erschließen, welchen Wert den verschiedenen Klassen je nach Bodenart, gemessen in „Kuhweiden“, zugemessen wurde.

Das „Classifications- und Vermessungs-Register der Feldmark Lachendorf" vermittelt den genauesten Eindruck von Umfang und Exaktheit der Vermessung und Taxation.

\footnotetext{
${ }^{1}$ Im Archiv der Samtgemeinde Lachendorf liegen die o.g. handschriftlichen Abschriften der Originale vor.

${ }^{2}$ Sign.: 61/4, Archiv der Samtgemeinde Lachendorf

${ }^{3}$ Rezess über die Spezialteilung und Verkoppelung, § 3, Sign. 61/5
} 
Tabelle 4.10 Gesamtergebnis der Bonitierung der Feldmark

Aus dem Classifications- und Vermessungs-Register für die Feldmark Lachendorf

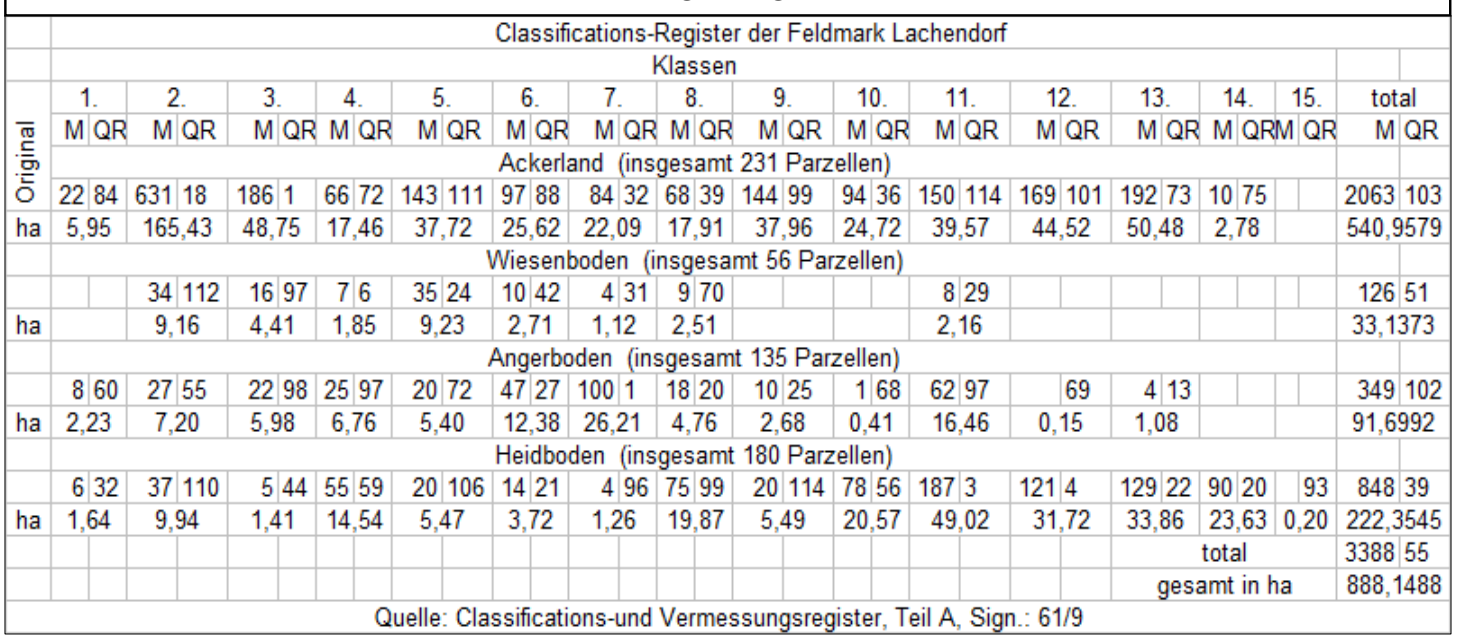

In Tabelle 4.11 wird am Beispiel Ackerland der Vollhöfe (a-g), des Halbhofes (h) und der Kothöfe ( $i-u)$ der Aufwand für Vermessung und Bewertung sowie für Bearbeitung bzw. Berechnung verdeutlicht: Der Wertermittlung lagen 15 Klassen (beim Acker nur 14 erreicht) zugrunde und für jeden Boden - Acker, Wiese, Anger, Heide - gab es einen eigenen Bewertungsschlüssel (Tab. 4.9), der für jede Klasse die Anzahl Morgen pro Kuhweide ausweist. Nun musste für jede Fläche jeder Klasse nach diesem Schlüssel der Wert in Kuhweiden berechnet werden. Im Vermessungsregister ist dann nur der Gesamtwert für die Ackerfläche eines jeden Hofes angegeben.

Die Kontrollrechnungen (in der Tabelle 4.11 jeweils 2. Zeile für jeden Hof) zeigen aber, dass jeder Wert pro Klasse berechnet und dann erst die Gesamtsumme gebildet wurde. Die Berechnungen erfolgten offenbar auf 3 Nachkommastellen abbrechend ohne Rundung. Die überwiegende Übereinstimmung der Werte im handschriftlichen Original mit der heutigen, programmgestützten Kontrollrechnung belegt die große Akribie der Arbeiten im 19. Jahrhundert. Bei den Flächensummen gibt es keine Fehler, bei den Werten in Kuhweiden bei den Höfen c, f und $m$ Abweichungen von 1/1000. Diese Fehler sind nicht zu klären, zumal das Taxations-Register, Sign. 61/4, die gleichen Werte enthält.

Ein zu klärender Einzelfall betrifft Hof n: Die Flächensumme der Originaldaten (s. 1. Zeile Hof $\mathrm{n}$ in Tabelle 4.11) beträgt $51 \mathrm{M}$ und 113 Quadratruten, also $100 \mathrm{QR}$ mehr als im Original ${ }^{1}$. Die Kontrollrechnung mit diesen Daten ergibt einen Kuhweiden-Wert von 5,3155 (Hof n, 2. Zeile in der Tabelle), also deutlich mehr als 5,246 im Original. Daher ist ein Fehler bei den Flächenangaben der einzelnen Klassen zu vermuten. Ändert man in Klasse 11 den Wert für QR von 115 auf 15, so stimmt die Kontrollrechnung perfekt mit dem Originalwert überein (Hof n, 3-und 4. Zeile in der Tabelle). Es handelt sich also um einen der sehr seltenen Fehler beim Abschreiben bzw. Übertragen, der nur durch nachträgliche Einzelberechnung je Klasse geklärt werden konnte.

Die Berechnungen des eingebrachten Besitzes sowie der verschiedenen Abfindungen und Beiträge je nach Flächengröße und Wert waren sehr differenziert und genau. Man war offenbar um höchstmögliche Genauigkeit bemüht, um Einsprüche zu vermeiden, allen Ansprüchen gerecht zu werden und schließlich die freiwillige Zustimmung aller Betroffenen zu erhalten.

\footnotetext{
${ }^{1}$ Der Originalwert von $51 \mathrm{M}$ und $13 \mathrm{QR}$ wird durch das Taxations-Register (Sig. 61/4) bestätigt.
} 
Tabelle 4.11 Klassifizierung des Ackerlandes Lachendorfer Höfe

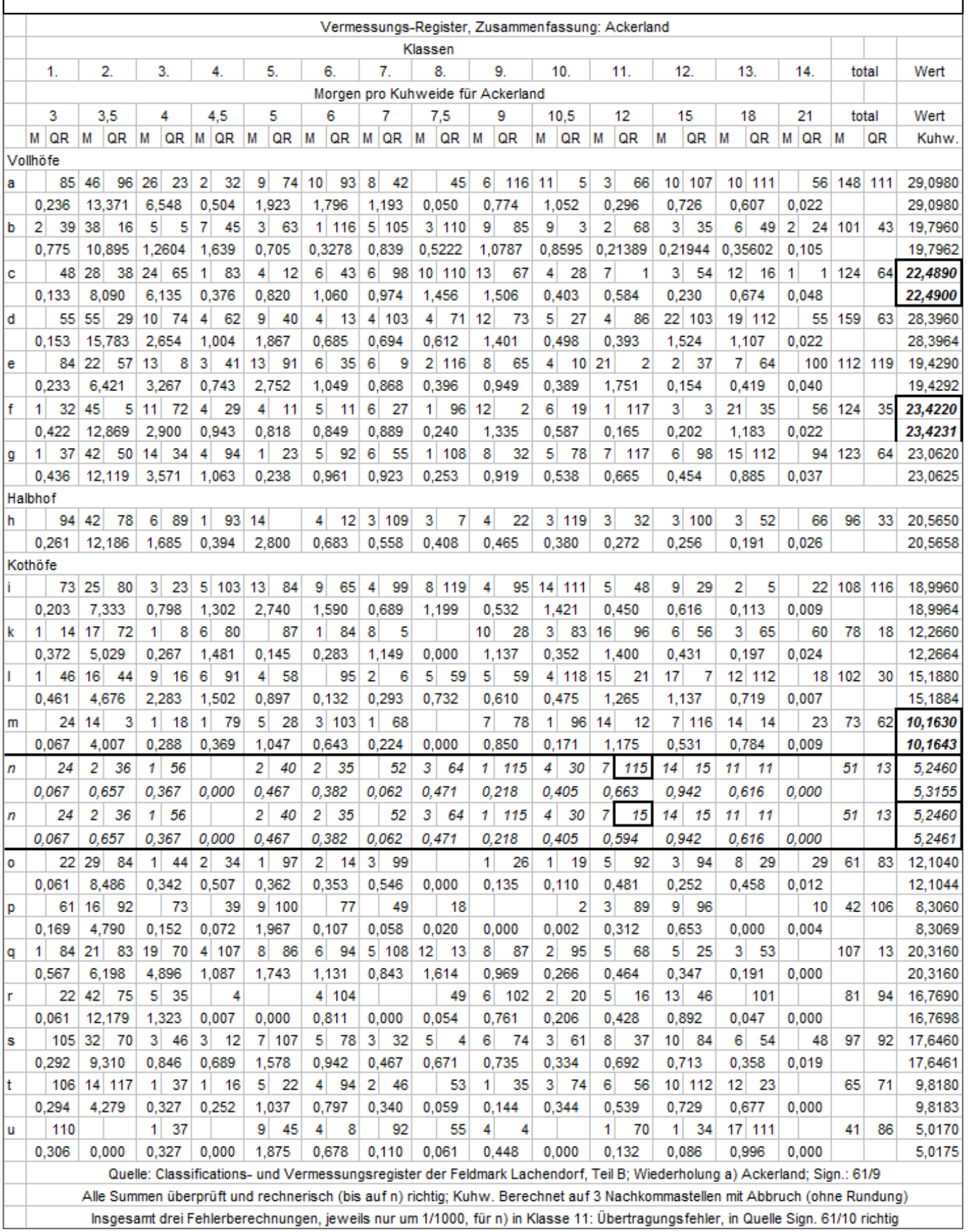


Das Verfahren wird nun beispielhaft an $5^{1}$ Höfen, einem Vollhof, einem Kothof, einem Brinksitzer sowie einem An- und Abbauern, einzeln oder gesamt, in den folgenden tabellarischen Darstellungen demonstriert:

Das Beispiel des Brinksitzers zeigt besonders deutlich anhand der Flurbezeichnungen, wie stark verstreut das Ackerland in der Feldmark lag und wie genau auch kleine Flächen von weit weniger als 1 Morgen, z.B 12 Quadratruten, erfasst wurden.

Es fällt auf, dass Vollhof und Kothof sich nicht wesentlich unterscheiden, um so größer ist deren Unterschied zum Brinksitzer sowie An- und Abbauern, die keine privaten Wiesen- und Heidflächen besitzen und jeweils nur eine sehr kleine Angerfläche, die im Original als Hofraum bezeichnet sind.

Daraus ergibt sich, dass es im alten Agrarsystem im Grunde zwei Gruppen unter den Bauern gab: Voll-, Halb- und Kothof auf der einen Seite und Brinksitzer sowie An- und Abbauern auf der anderen Seite. Die erste Gruppe bildete die seit alters her überlieferten bzw. bestehenden Hofstellen und die 2. Gruppe die später dazu gekommen.

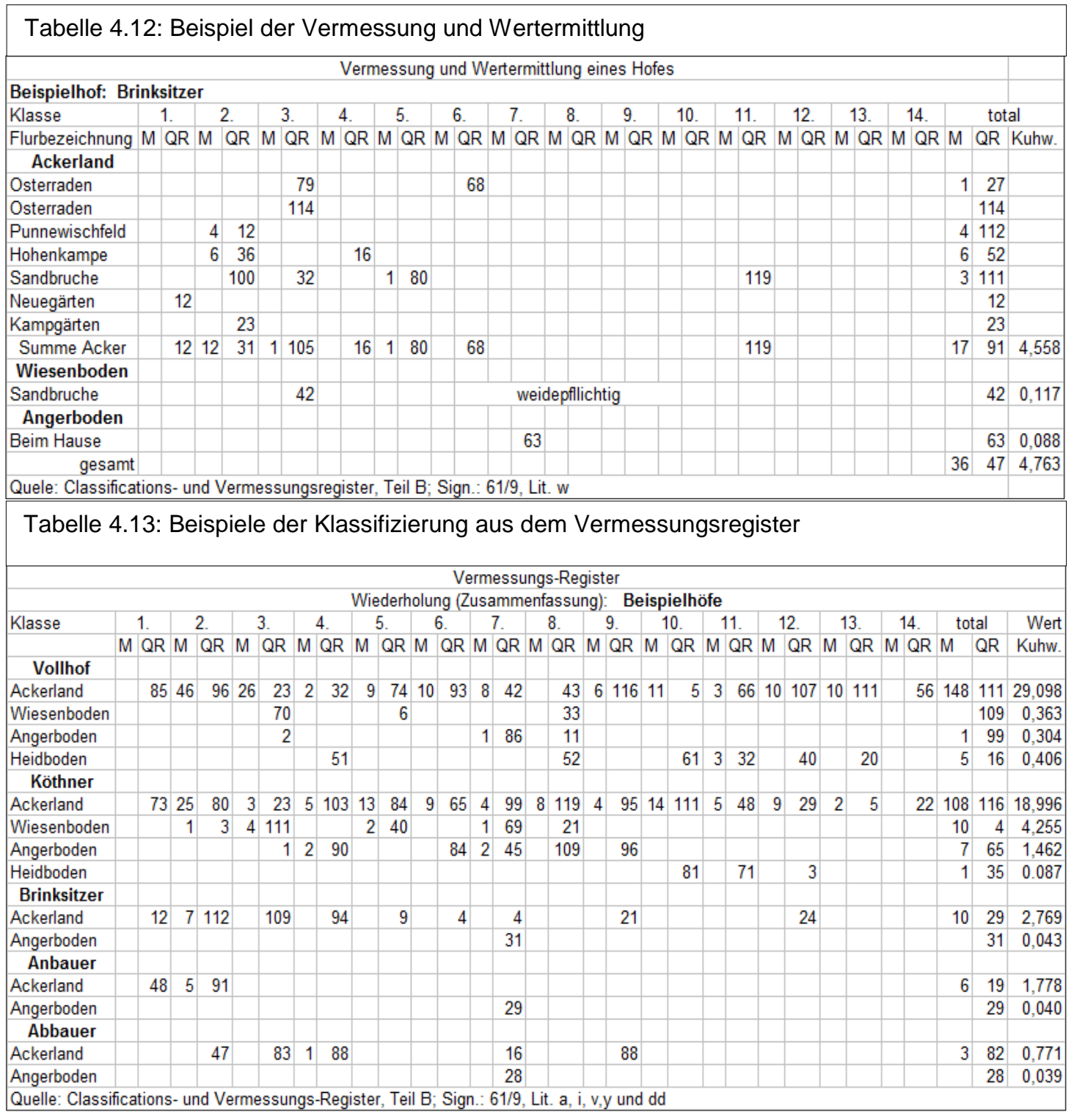

\footnotetext{
${ }^{1}$ Die Beispielhöfe haben im Vermessungsregister die Bezeichnungen (Lit,): Vollhof: a; Kothof: i; Brinksitzer: v; Anbauer: y; Abbauer: dd; s. Quelle, Sign.: 61/9
} 
Ein weiteres Beispiel für die sehr sorgsam vorgenommene Vermessung und Wertermittlung und die Verteilung besonders wertvoller Flächen zeigt die Separation der Gemeinheit des Dorfes innerhalb der alten Feldmark.

\begin{tabular}{|c|c|c|c|}
\hline \multicolumn{4}{|c|}{ Tab. 4.14.1 } \\
\hline \multicolumn{4}{|c|}{$\begin{array}{c}\text { Gemeinheiten in der Feldmark Lachendorf } \\
\text { Gemeindebesitz }\end{array}$} \\
\hline Boden & ha & $\%$ & ha \\
\hline Ackerland & 2,132 & 0,78 & \\
\hline \multicolumn{2}{|c|}{ davon Gemeinde } & & 1,027 \\
\hline Wiesenboden & 0,795 & 0,29 & \\
\hline \multicolumn{2}{|c|}{ davon Gemeinde } & & $0,00 \mathrm{c}$ \\
\hline Angerboden & 75,055 & 27,29 & \\
\hline \multicolumn{3}{|c|}{ davon zur allgem. Verteilung } & 71,635 \\
\hline Heidboden & 197,034 & 71,64 & \\
\hline \multicolumn{3}{|c|}{ davon zur allgem. Verteilung } & 177,085 \\
\hline gesamt & 275,016 & 100 & 249,747 \\
\hline \multicolumn{4}{|c|}{ Umrechnung: Verf. } \\
\hline \multicolumn{4}{|c|}{ Taxationsregister, Sign.: $61 / 4$, Teil IV } \\
\hline
\end{tabular}

Die Gemeinheiten in der alten Feldmark waren allein im Besitz der Gemeinde.

Auf diesen Gemeinheiten innerhalb der Feldmark gab es keinen Besitz und keine Rechte anderer Dörfer, es Tab. 4.14.2 handelte sich - anders als bei den Gemeinheiten auf der Allerheide - also nicht um Gemeinschaftsreviere.

Diese Dorfgemeinheit unterlag nun der Spezialteilung bzw. Separation, die äußerst differenziert vorgenommen wurde.

Ein Teil des Ackerlandes sollte im Besitz der Dorfgemeinschaft bleiben, offenbar die Ausstattung des bzw. der Hirten mit etwas Ackerland.

\begin{tabular}{|c|c|c|c|c|c|c|c|c|c|c|c|c|c|c|}
\hline \multicolumn{15}{|c|}{ Tabelle 4.15: Wertberechnung zur Gemeinh } \\
\hline \multicolumn{15}{|c|}{ IV. Werthberchnung der Weide-, Plaggen- und Bultenhiebs-Masse } \\
\hline \multicolumn{15}{|c|}{ Die sämmtlichen genossenschaftlichen Grundstücke betragen nach der unter I zugelegten Wertberechnung } \\
\hline \multicolumn{3}{|c|}{ Ackerland } & \multicolumn{3}{|c|}{ Wiesenboden } & \multicolumn{3}{|c|}{ Angerboden } & \multicolumn{3}{|c|}{ Heidboden } & \multicolumn{3}{|c|}{ Total } \\
\hline M & QR & Kuhw. & M & QR & Kuhw. & M & QR & Kuhw. & M & QR & Kuhw. & M & QR & Kuhw. \\
\hline 8 & 16 & 1,706 & 3 & 4 & 0,979 & 286 & 46 & 57,08 & 751 & 97 & 62,3 & 1049 & 43 & 122,1 \\
\hline & & & & & & & & & & & & & & \\
\hline \multicolumn{15}{|c|}{ Davon gehen $a b$ : } \\
\hline \multicolumn{15}{|c|}{ Die sub III berechneten cultivierten Gemeinde-Grundstücke und Holzbestandsräume mit } \\
\hline 4 & 26 & 1,22 & 3 & 4 & 0,979 & 13 & 6 & 2,171 & 76 & 14 & 7,241 & 96 & 50 & 11,61 \\
\hline & & & & & & & & & & & & & & \\
\hline \multicolumn{15}{|c|}{ Es bleiben also dann an genossenschaftlicher Weide-, Plaggen- und Bultenhiebsmasse übrig } \\
\hline \multicolumn{3}{|c|}{ Ackerland } & \multicolumn{3}{|c|}{ Wiesenboden } & \multicolumn{3}{|c|}{ Angerboden } & \multicolumn{3}{|c|}{ Heidboden } & \multicolumn{3}{|c|}{ Total } \\
\hline M & QR & Kuhw. & M & QR & Kuhw. & M & $\mathrm{QR}$ & Kuhw. & M & $\mathrm{QR}$ & Kuhw. & M & QR & Kuhw. \\
\hline 3 & 110 & 0,486 & & & & 273 & 40 & 54,91 & 675 & 83 & 55,06 & 952 & 113 & 110,4 \\
\hline & & & & & elle: Ta & & & & & & & & & \\
\hline
\end{tabular}

Der gemeinschaftliche Wiesenboden, meist Bullenwiesen, verblieb ganz im Gemeinschaftsbesitz.

Weit komplizierter war die Separation der Anger- und Heidflächen, weil davon geringe Teile bzw. einzelne Flurstücke mit Holz bestanden waren. Diese Holzbestände wurden gesondert erfasst und verteilt.

Das Beispiel eines Vollhofes mag in den Tabelle 4.16. 1 - 4 das umfangreiche Verfahren, das in gleicher Weise auf alle Höfe sowie Schule, Kirche, Gemeinde, Papierfabrik und auswärtige Besitzer (Ausmärker) angewandt wurde, exemplarisch darstellen. 
Da alle privat genutzten Wiesen auch weidepflichtig waren, also der Vor- bzw. Nachweide durch Vieh der Dorfgemeinschaft zur Verfügung standen, musste dieser Nutzungsanteil von der privaten Fläche in Abzug gebracht werden. Aus diesem sog. Weide-Äquivalent erhielt der Vollhof wiederum eine Abfindung nach Maßgabe eines Verteilerschlüssels, den sog. "Simpla“, die sich aus dem privaten Besitz an Acker und Wiesen - einschließlich Acker und Wiesen außerhalb der Verkoppelung - errechneten, also ein Abbild der bisherigen HofgröBen waren.

Insgesamt wurden für Lachendorf 4040 „Simpla“ zugrunde gelegt, wobei die „Simpla“ der Vollhöfe zwischen 279 und 242 lagen, der Halbhof bei 204, die Kötner zwischen 220 und 110, die Brinksitzer von 4 - 17 und die An- und Abbauern zwischen 1 und 26. An diesem Verteilerschlüssel wird wiederum die Zweiteilung der Höfe deutlich: Vollhöfe, Halbhof und Kötner einerseits und Brinksitzer sowie An- und Abbauern anderseits.

Der hier vorgestellte Vollhof hatte 279 der insgesamt 4040 "Simpla“ erhalten, erhielt daraus 0,429 Kuhw. und damit 1 M 14 QR Wiesenfläche, also nur 15 QR mehr als der Hof in das Wiesen-Äquivalent eingebracht hatte, nämlich 119 Quadratruten.

Tabellen 4.16.1:

Ein Vollhof im Verfahren der Spezialteiluna und Verkoppeluna (Teil a) Taxationsregister zur Spezialteilung und Verkoppelung (Sign 61/4)

Wertberechnung des bisherigen Besitzstandes (von 1852) \begin{tabular}{c|c|c|c|c|c|}
\hline Acker & Wiese & Anger & Heide & total & rechner. \\
\hline
\end{tabular} M QR Kuhw. M QR Kuhw. M QR Kuhw. M QR Kuhw. M QR Kuhw. Kontrolle

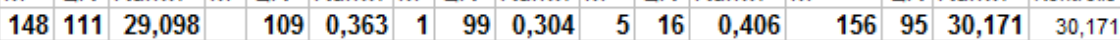
Der Wiesenweide unterworfene Flächen Wertberechnung der Wiesenweide

Größe des Wiesenweide-Äquivalents 150,052

rechnerisches Ergebnis des Taxationsregisters \begin{tabular}{|l|l|l|r|r|r|r|r|r|r|r|r|r|r|r|}
\hline 148 & 111 & 29,098 & $\mathbf{9 4}$ & $\mathbf{0 , 3 1 1}$ & $\mathbf{1}$ & $\mathbf{9 9}$ & 0,304 & 5 & 16 & 0,406 & 156 & 95 & 30,171 & 30,171 \\
\hline
\end{tabular}

Tabelle 4.16.2: Vollhof im Verfahren (Teil b)

Rezess über die Spezialteilung und Verkoppelung der Feldmark Lachendorf (Sign.: 61/5) \begin{tabular}{|l|l|l|l|l|} 
Acker & Wiese & Anger & Heide & total rechner.
\end{tabular} M QR Kuhw. M QR Kuhw. M QR Kuhw. M QR Kuhw. M QR Kuhw. Kontrolle Zusammenstellung des privaten Besitzes nach Abzug des Wiesenweide-Äquivalentes

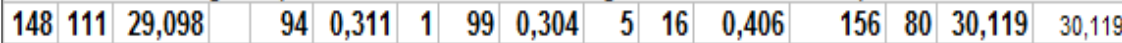
Von der Wiesenweide erhaltener Wiesenboden

\begin{tabular}{lll|l|l}
1 & 14 & 0,429 & 279 & "Simpla"
\end{tabular}

$\begin{array}{llll}1 & 14 & 0,429 & 0,429\end{array}$

Anteil an den Holzbestandsräumwn, den kultivierten Gemeindegrundstücken und -baulichkeiten

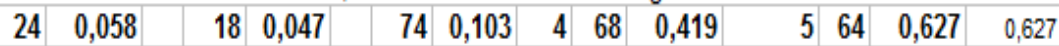
Anteil an der Bultenhiebsmasse

\begin{tabular}{ll|l|l|l|l|}
5 & 93 & 0,404 & 0,404 \\
\hline
\end{tabular}

Abfindung für Haushaltsbedürnis u. vergleichsweise festgestellten Abfindungen

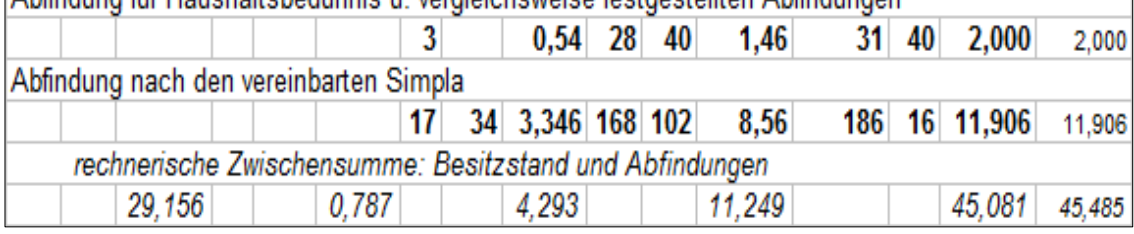

Weitere Abfindungen standen dem Hof zu aus den Flächen mit Holzbeständen auf verschiedenen Böden, aus der Bultenhiebsmasse auf Heidboden, für das Haushaltsbedürfnis Angerund Heidboden und nach Maßgabe der "Simpla" einen entsprechend großen Anteil aus der Separation der Gemeinheiten, hier 17 M Anger und eine große Fläche Heidboden von 181 Morgen.

Natürlich waren auch Beiträge für öffentliche Aufgaben zu leisten, nämlich Flächen für Wege, Abzugsgräben, Forsten und verschiedenen Gemeindegrundstücken. 


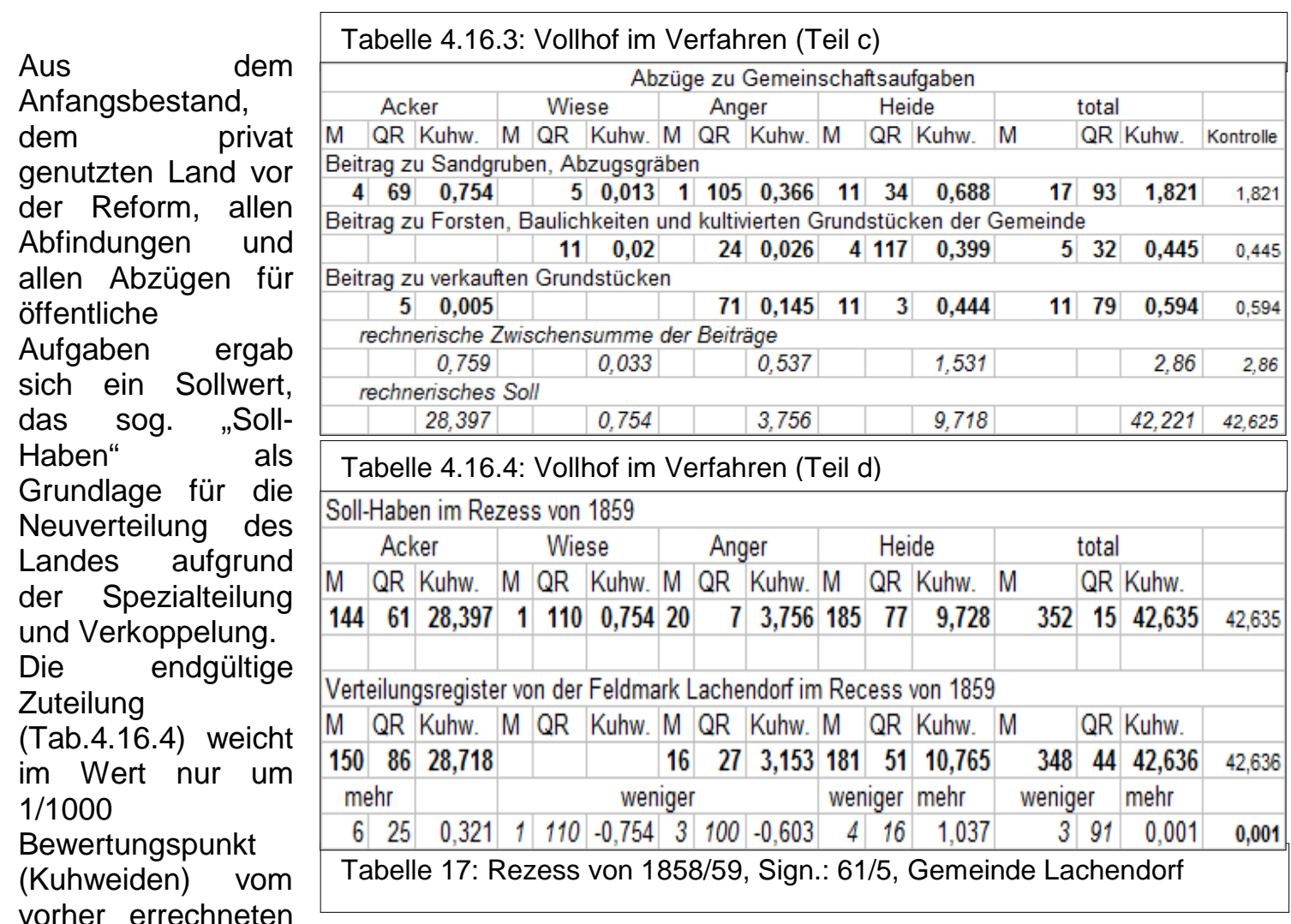

„Soll-Haben“ ab. Bei den „Bodenarten“ gibt es kleine Abweichungen zwischen Soll und Zuteilung: Acker erhält der Hof 6 Morgen und 25 Quadratruten mehr, dafür weniger Wiese, Anger und Heide. Die Daten zur Heide machen die genaue Bewertung innerhalb einer „Bodenart“ deutlich, denn wertmäßig erhält der Betrieb hier 1,037 Punkte mehr, aber als Heidefläche 4 Morgen und 16 Quadratruten weniger. Der Hof hat also offenbar wertmäßig bessere Heideflächen erhalten als im Soll angegeben war.

Das Vermessungsregister enthält für alle Höfe die bis zu den Reformen genutzten Flächen nach Belegenheit in der Flur, Bonität („Classification“) und Größe. In der Zusammenfassung ist dann auch der aufgrund der Klassifikation und Vermessung ermittelte Wert in Kuhweiden für Acker, Wiese, Anger und Heide aufgeführt.

Diese Werte bilden dann in der Spezialteilung und Verkoppelung die Grundlage für die Zuteilungen, die das Verteilungs-Register des Rezesses für alle Höfe ebenfalls nach Belegenheit, Boden und Bewertung auflistet.

Das Beispiel des Köthners (Lit.s, Tab. 4.16.5 - 7) verdeutlicht das Verfahren beispielhaft und zeigt, dass die Ackerfläche etwa gleich blieb, die Anger- und Heideflächen sich aber beträchtlich vergrößerten als Ergebnis der Abfindungen aus der Allerheide im Zuge der Spezialteilung.

Besonders deutlich wird das Ergebnis der Verkoppelung im Vergleich des eingebrachten mit dem zugeteilten Besitz (Tabellen 4.16.5 und 4.16.7). 
Tabelle 4.16.5: Nutzflächen vor der Reform

\begin{tabular}{|c|c|c|c|c|c|c|c|c|c|c|c|c|c|c|c|c|c|c|c|c|c|c|}
\hline 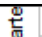 & Litt s & & & & & & & & & & & & & & & Ack & kerlan & & & & & \\
\hline ¿ & Der Köthner Carsten Heinr. & & & & & & & & & & & & & & Klass & & & & & & & \\
\hline i & Koch & & 1. & & 2. & & 3. & & 4. & & 5. & & 6. & 7 & 7. & 8 & 8. & 9. & & 10. & & 11. \\
\hline 은 & Benennung & M & QR & M & QR & M & QR & $M$ & QR & M & $Q R$ & M & QR & M & $Q R$ & M & QR 1 & M QR & $\mathrm{M}$ & QR & $M$ & QR \\
\hline 15 & Auf dem Dürskampe & & & 4 & 102 & & & & & & & & & & & & & & & & & \\
\hline 52 & Auf der Salloh & & & & & & & & & & & & & & 3 & & & & & & & \\
\hline 81 & Auf dem Lerchenberge & & & & & & & & & & & & & & 107 & & & & & & 1 & 75 \\
\hline 86 & & & & & & & & & & & & & & & & & & & & & 1 & 16 \\
\hline 89 & & & & & & & & & & & & & & & & & & & & & & 66 \\
\hline 118 & Auf der Salloh & & & & 112 & & & & & & & & 118 & & & & & & & & & \\
\hline 121 & & & & & 29 & & & & & & & & 90 & & & & & & & & & \\
\hline 149 & & & & 2 & 4 & & & & & & 6 & & & & 33 & & & & & & & \\
\hline 156 & & & & 1 & 51 & & 26 & & & & 5 & & & & 39 & & & & & & & \\
\hline 177 & & & & 2 & 28 & & & 1 & & & & & & & & & & & & & & \\
\hline 209 & Auf dem Flottkamp & & & & & & 54 & & 72 & & & & & & & & & & & & & \\
\hline 218 & & & & 1 & 2 & & & & 10 & & & & & & & & & & & & & \\
\hline 242 & Der Moorgarten & & & & & & & & & & 27 & & & & & & & & & & & \\
\hline 284 & Auf dem Krümmel & & & 1 & 14 & & & & 92 & & & & 22 & & & & & & & & & \\
\hline 287 & & & & & 73 & & & & 44 & & & & 8 & & & & & & & & & \\
\hline 301 & & & & & 56 & & & & 24 & & & & & & & & & 30 & 0 & & & \\
\hline 335 & Der Osterkamp & & & & & & & & & & & & & & & 2 & 12 & 1100 & & & 1 & 76 \\
\hline 406 & Auf dem Osterraden & & & & & & 92 & & & & & & & & 2 & & & & & & & \\
\hline 416 & & & & & & 1 & 114 & & & & & & 47 & & & & & & & & & \\
\hline 436 & Auf dem Hohenkampe & & & & 13 & & & & & & 3 & & 46 & & & & & & 1 & 21 & & \\
\hline 454 & Auf dem Punnewischfelde & & & 8 & 54 & & & & & & & & & & & & & & & & & \\
\hline 458 & Bei Bolten Immenzaun & & & 3 & 114 & & & & & & & & & & & 2 & 30 & & & & & \\
\hline 506 & Auf dem osterraden & & & & 24 & & & & 10 & & & & & & & & & & & & & \\
\hline 559 & Der Kurzekamp & & & & & & & & & 2 & 96 & & & & & & & & & & & \\
\hline 565 & Auf dem Sandbruche & & & & 61 & & & & & 4 & 90 & & & & & & & & & & & 84 \\
\hline 578 & & & & & 80 & & & & & & & & & & & & & & & & & \\
\hline 608 & In den Neuengärten & & 25 & & & & & & & & & & & & & & & & & & & \\
\hline 614 & Der alte Garten & & 80 & & & & & & & & & & & & & & & & & & & \\
\hline 616 & Auf dem Sandbruche, südl. & & & 1 & 28 & & & & & & & & & & & & & & & & & \\
\hline 624 & Auf dem Sandruche, sūdl. & & & & 97 & & & & & & & & & & & & & & & & & \\
\hline 674 & Der Schwarzekamp & & & & & & & & & & & 2 & 94 & & & & & & & & & \\
\hline 688 & In den Ackern & & & & & & & & & & & & 13 & & & & & 1 & 0 & 83 & & \\
\hline 714 & & & & & & & & & & & & & & & & & & 101 & & & & 116 \\
\hline 753 & & & & & & & & & & & & & & & & & & $\begin{array}{ll}135 \\
\end{array}$ & 5 & 8 & & 4 \\
\hline 718 & & & & & & & & & & & & & & & & & & 45 & 5 & & & 92 \\
\hline 775 & Das Neueland & & & & & & & & & & & & & & & & & & & & & \\
\hline 727 & & & & & & & & & & & & & & & & & & & & & & 24 \\
\hline 737 & Übern Ackern & & & & & & & & & & & & & & & & & & & & & \\
\hline 793 & & & & & & & & & & & & & & & & & & & & & & \\
\hline 800 & Auf dem Lohfelde & & & & & & & & & & & & & & & & & & & 88 & & 42 \\
\hline 872 & & & & & & & & & & & & & & & & & & 11 & 1 & 51 & & 42 \\
\hline 831 & Zwischen dem Oppersh. u. Celle & er W & & & & & & & & & & & & & & & 25 & & & & & \\
\hline 841 & & & & & & & & & & & & & & & & & 44 & & & & & \\
\hline 857 & Auf dem Westerfelde & & & & & & & & & & & & & & & & 13 & & & 51 & & \\
\hline 867 & & & & & & & & & & & & & & & 98 & & & & & & & \\
\hline 431 & Auf dem hohen Kampe & & & 1 & 52 & & & & & & & & & & & & & & & & & \\
\hline 911 & Auf dem Westerkampe & & & & & & & & & & & & & & & & & 37 & 7 & & & \\
\hline 931 & & & & & & & & & & & & & & & 110 & & & 45 & 5 & & & \\
\hline & Litt. s, Summa Ackerland & & 105 & 32 & 70 & 3 & 46 & 3 & 12 & 7 & 107 & 5 & 78 & 3 & 32 & 5 & 4 & \begin{tabular}{|l|l}
6 & 74 \\
\end{tabular} & 43 & 61 & 8 & 37 \\
\hline 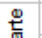 & & & & & & & & & & & & & & & $\mathrm{b}, \mathrm{Wi}$ & iese & enbod & den & & & & \\
\hline$\frac{10}{0}$ & Der Köthner Carsten Heinr. & & & & & & & & & & & & & & Klass & & & & & & & \\
\hline i & Koch & & 1. & & 2. & & 3. & & 4. & & 5. & & 6. & 7 & 7. & & 8. & 9. & & 10. & & 11. \\
\hline$\stackrel{0}{2}$ & Benennung & M & QR & M & QR & M & $Q R$ & $M$ & QR & $M$ & $Q R$ & M & $Q R$ & M & QR & M & QR 1 & M QR & $M$ & QR & M & $Q R$ \\
\hline 333 & Die Osterwiese & & & 2 & 20 & & & & & & & & & & & & & & & & & \\
\hline 343 & Der Grashof & & & 2 & 112 & & & & & & & & & & & & & & & & & \\
\hline 578 & Auf dem Sandbruche & & & & & & & & 4 & & & & & & & & & & & & & \\
\hline 953 & Der Farkenkamp & & & & & & & & & & & & & & & 1 & 33 & & & & & \\
\hline 956 & & & & & & & & & 40 & & & & & & & & & & & & & \\
\hline & Litt. s, Summa Wiesenboden & & & 5 & 12 & & & & 44 & & & & & & & 1 & 33 & & & & & \\
\hline & & & & & & & & & & & & & & & $\mathrm{c}, \mathrm{Ar}$ & nge & erbod & den & & & & \\
\hline 333 & An der Osterwiese & & & & & & & & & & & & & & 62 & & & & & & & \\
\hline 343 & An dem Grashofe & & & & & & & & & & & & & & & & & & & & & 90 \\
\hline 345 & Hofraum & & & & & & & & & & & & & 3 & 82 & & & & & & & \\
\hline 422 & Immenstelle unterm Osterraden & & & & & & & & & & & & & & 54 & & & & & & & \\
\hline 953 & Am Farkenkampe & & & & & & & & & & & & & & & 1 & 24 & & & & & \\
\hline 956 & & & & & & & & & & & & & & & 1 & & & & & & & \\
\hline 242 & Am Moorgarten & & & & & & & & & & & & & & & & 10 & & & & & \\
\hline & Litt. s, Summa Angerboden & & & & & & & & & & & & & 4 & 79 & 1 & 34 & & & & & 90 \\
\hline & & & & & & & & & & & & & & & d, $\mathrm{H}$ & leidg & dabod & den & & & & \\
\hline 335 & Auf dem Osterkampe & & & & & & & & & & & & & & & & & & & & & \\
\hline 902 & In den Büschen vor dem Wester & rkpe & & & & & & & & & & & & & & & & & & & & 32 \\
\hline & Litt. s, Summa Heideboden & & & & & & & & & & & & & & & & & & & & & 32 \\
\hline
\end{tabular}


Tabelle 4.16.6 Zusammenfassuna

\begin{tabular}{|c|c|c|c|c|c|c|c|c|c|c|c|c|c|c|c|c|c|c|c|c|c|c|c|c|c|c|c|c|c|c|}
\hline \multicolumn{31}{|c|}{ Wiederholung (Zusammenfassung) } \\
\hline Klassen & 1 & 1. & 2 & & & 3. & & 4. & & 5. & \multicolumn{2}{|c|}{6.} & \multicolumn{2}{|c|}{7.} & 8. & \multicolumn{2}{|r|}{9.} & \multicolumn{2}{|c|}{10.} & \multicolumn{2}{|c|}{11.} & \multicolumn{2}{|c|}{12.} & \multicolumn{2}{|c|}{13.} & \multicolumn{2}{|c|}{14.} & \multicolumn{2}{|c|}{ Allem } & 믐 \\
\hline & M & QR & M & $Q R$ & M & $Q R$ & M & $Q R$ & M & QR & M & $Q R$ & $M Q$ & $2 \mathrm{R} / \mathrm{M}$ & $M Q F$ & M & Q $Q R$ & M & $Q R$ & M & QR & M & QR & M & QR & M & QR & M & $Q R$ & 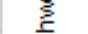 \\
\hline Köthner & \multicolumn{29}{|c|}{ a, das Ackerland } & $\underline{z}$ \\
\hline Carsten & & 105 & 32 & 70 & 3 & 46 & 3 & 12 & 7 & 107 & 5 & 78 & 33 & 325 & 5 & 46 & \begin{tabular}{l|l}
6 & 74
\end{tabular} & 3 & 61 & 8 & 37 & 10 & 84 & 6 & 54 & & 48 & 97 & 92 & 17,646 \\
\hline Heinrich & \multicolumn{29}{|c|}{ b, der Wiesenboden } & \\
\hline Koch & & & 5 & 12 & & & & 44 & & & & & & & 13 & 3 & & & & & & & & & & & & 6 & 89 & 3,291 \\
\hline & \multicolumn{29}{|c|}{ c, der Angerboden } & \\
\hline & & & & & & & & & & & & & 47 & 791 & $\begin{array}{lll}1 & 3\end{array}$ & 4 & & & & & 90 & & & & & & & 6 & 83 & 1,043 \\
\hline & \multicolumn{29}{|c|}{ d, der Heideboden } & \\
\hline & & & & & & & & & & & & & & & & & & & & & 32 & & 58 & & 88 & & & 1 & 58 & 0,080 \\
\hline
\end{tabular}

Tabelle 4.16.7: Ergebnis der Reformen in der Feldmark Lachendorf

\begin{tabular}{|c|c|c|c|c|c|c|c|c|c|c|c|c|c|c|c|c|c|}
\hline \multicolumn{18}{|c|}{ Zuteilung durch die Reform } \\
\hline \multirow{5}{*}{ 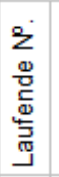 } & \multirow{5}{*}{ 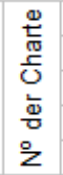 } & & & & & & & & & & & & & & & & \\
\hline & & Litt: $s$ & & & & & & & & & & & & & \multicolumn{3}{|c|}{ Überhaupt } \\
\hline & & Der Köthner Carsten Heinr. & & & & & & & & & & & & & \multicolumn{3}{|c|}{ brauchbarer } \\
\hline & & Koch & \multicolumn{3}{|c|}{ Ackerland } & \multicolumn{3}{|c|}{ Wiesenboden } & \multicolumn{3}{|c|}{ Angerboden } & \multicolumn{3}{|c|}{ Heidboden } & \multicolumn{3}{|c|}{ Boden } \\
\hline & & hat zugeteilt erhalten. & M & QR & Kuhw. & M & QR & Kuhw. & M & QR & Kuhw. & $M$ & QR & Kuhw. & $\mathrm{M}$ & QR & Kuhw. \\
\hline 1 & 233 & Auf der Pannstätte 7 & 23 & 67 & 3,591 & & & & & 90 & 0,008 & & 4 & 0,002 & 23 & 80 & 3,601 \\
\hline 2 & 196 & Auf dem Osterraden 6 & 8 & 37 & 1,850 & & & & 6 & 88 & 1,221 & 1 & 42 & 0,112 & 16 & 47 & 3,183 \\
\hline 3 & 216 & \& 221 Bei Bolten Immenzaun 8 & 33 & 21 & 5,327 & & & & & 45 & 0,119 & 3 & 21 & 0,412 & 36 & 85 & 5,858 \\
\hline 4 & 218 & Auf dem Punnewischefelde 9 & 18 & 41 & 5,205 & & & & 4 & 98 & 0,943 & & & & 23 & 19 & 6,148 \\
\hline 5 & 210 & Der Osterkamp 5 & 7 & 88 & 0,740 & 2 & 20 & 1,238 & 4 & 50 & 0,579 & 1 & 29 & 0,067 & 15 & 67 & 2,624 \\
\hline 6 & 235 & Der alte Garten 3 & & 88 & 0,244 & & & & 1 & 33 & 0,356 & & & & 2 & 1 & 0,600 \\
\hline 7 & 97 & Der Grashof 2 & & & & 2 & 112 & 1,676 & 1 & 107 & 0,178 & & 54 & 0,025 & 5 & 33 & 1,879 \\
\hline 8 & 94 & Beim Hause 1 & & & & & & & 3 & 100 & 0,639 & & & & 3 & 100 & 0,639 \\
\hline 9 & 194 & In der kleinen Mellmau 4 & & & & & & & 6 & 48 & 0,745 & 12 & 58 & 0,845 & 18 & 106 & 1,590 \\
\hline 10 & & Vor den Wiesen 12 & & & & & & & & & & & 19 & 0,020 & & 19 & 0,020 \\
\hline 11 & & Hinterm Krähenmoor 11 & & & & & & & & 16 & 0,013 & 41 & 92 & 2,065 & 41 & 108 & 2,078 \\
\hline 12 & & Am Oppershäuser Felde & & & & & & & & & & & & & & & \\
\hline 13 & & zwische den Wegen 10 & & & & & & & & & & 15 & 45 & 0,721 & 15 & 45 & 0,721 \\
\hline 14 & & Am Oppershäuser Wege 13 & & & & & & & & & & 48 & 80 & 1,947 & 48 & 80 & 1,947 \\
\hline 15 & & Am Exerzierolatz 14 & & & & & & & & & & 5 & 68 & 0,223 & 5 & 68 & 0,223 \\
\hline 16 & & An der Pannstätte ad 7 & & & & & & & & & & 4 & 66 & 0,191 & 4 & 66 & 0,191 \\
\hline & & (rechnerische Kontrolle) & & & 16,957 & & & 2,914 & & & 4,801 & & & 6,630 & & & 31,302 \\
\hline & & Summa: & 91 & 102 & 16,957 & 5 & 12 & 2,914 & 29 & 112 & 4,801 & 134 & 98 & 6,630 & 261 & 84 & 31,302 \\
\hline
\end{tabular}

Die Taxatoren verfügten ganz offenbar über genaueste Kenntnisse der örtlichen Bodenverhältnisse und der Bodenfruchtbarkeit, wie sie aufgrund der zeitgenössischen Wirtschaftsweise eingeschätzt wurde.

Die Zuordnung einiger Ackerklassen zu Flurnamen und deren Lage in der Gemarkung beim Vergleich der Tabelle 4.17 mit der Karte 4.4 belegt dies in eindrucksvoller Weise:

Die Flurstücke der Klassen 2, 3 und 4 liegen vorwiegend auf der Gockenholzer und Bunkenburger Lehmgeest, die Flurstücke der Klase 9 und 12 dagegen südlich und westlich des damaligen Ortes auf der Wurzelzone des Schwemmfächers, also auf Sandböden. Ein Flurstück der Klasse 14, also das schlechteste Ackerland, liegt auf der Allerheide, auf magerem Sandboden. 


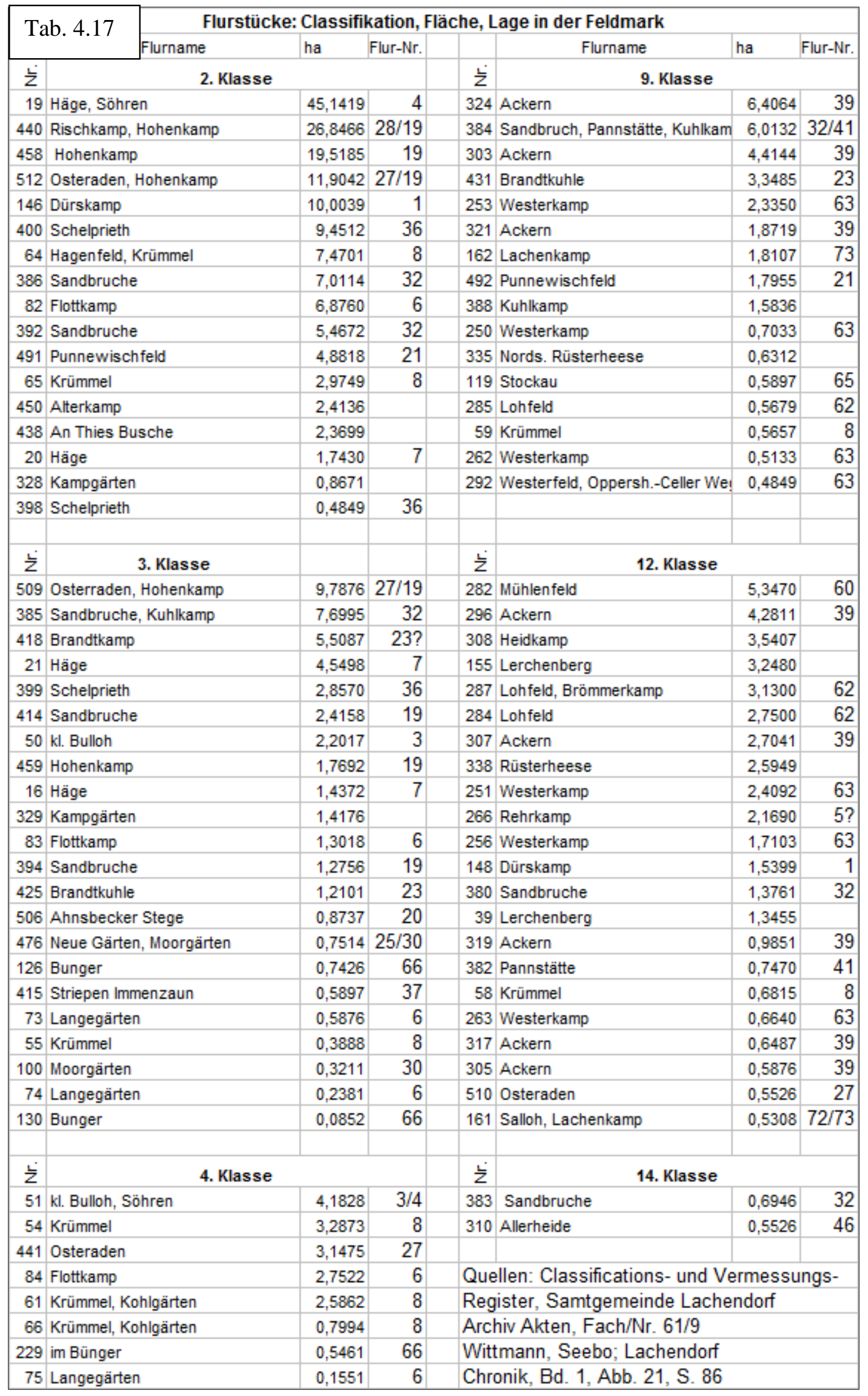




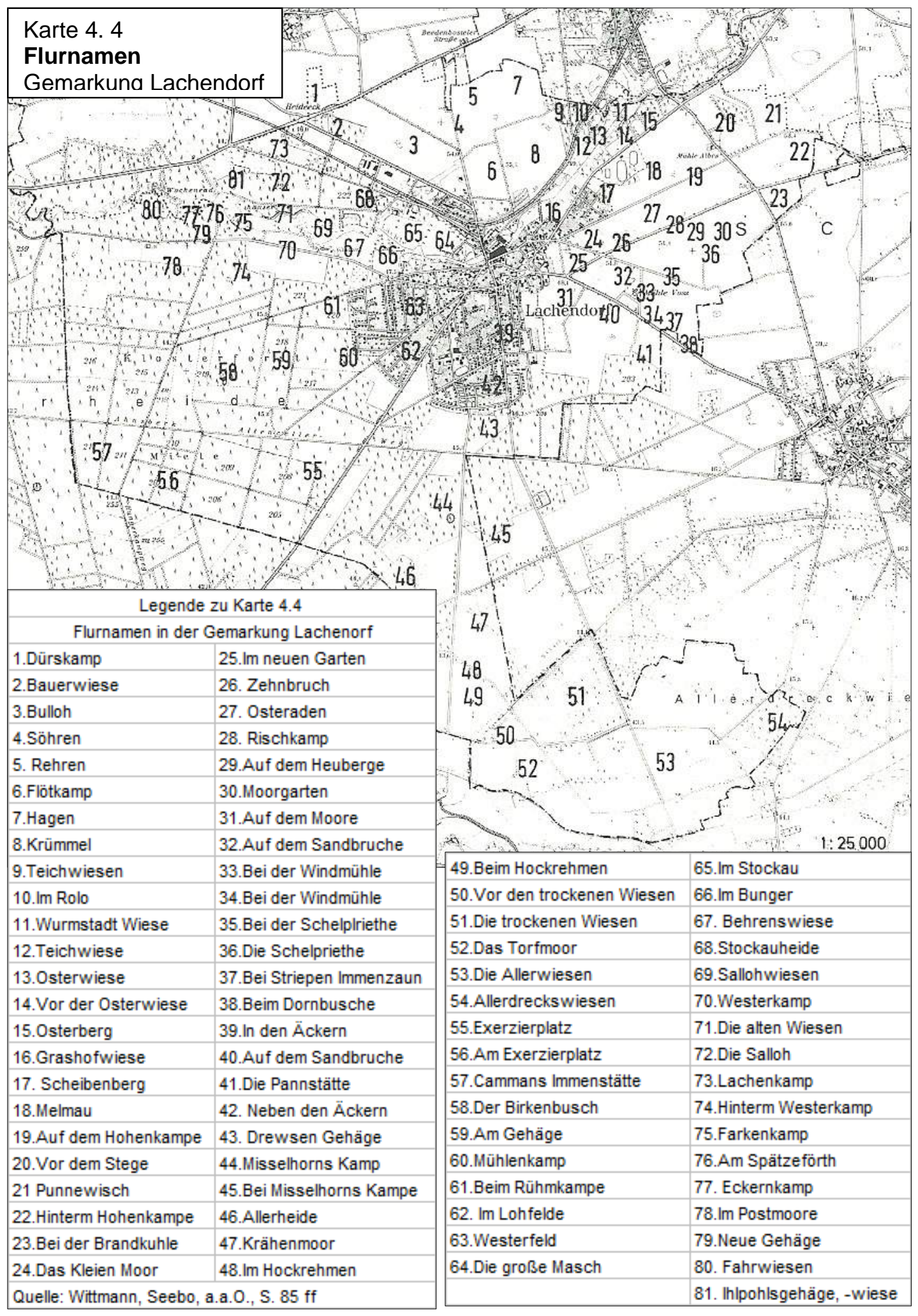




\subsubsection{Gesamtergebnis der Spezialteilung und Verkoppelung der Feldmark Lachendorf}

Die folgenden Tabellen ${ }^{1}$ aus dem Rezess dokumentieren den privaten Besitzstand ${ }^{2}$, den die Höfe in das Verfahren einbrachten, die jeweils zugeteilten Abfindungen ${ }^{3}$ sowie die Beiträge zu Gemeinschaftsaufgaben.

In diesem Rezess sind die Aller- und Trockenen Wiesen allerdings noch nicht erfasst.

Dieses Gebiet wurde einem eigenen, gesonderten Verfahren unterzogen, womit die Wichtigkeit dieses Wiesengebietes für die beteiligten Dörfer deutlich unterstrichen wird.

Vorab wurden individuelle Abfindungen ${ }^{4}$ geregelt, die je unterschiedliche, individuelle Gründe hatten:

- Lüßmann hatte bereits früher wegen eines Immengehäges Heideboden von 30 QR zu 0,010 Kuhweiden abgegeben.

- $\quad$ Meyer hatte bereits 59 QR Angerboden zu 0,084 Kuhweiden abgegeben: Zum Weg an den langen Gärten und zum Weg zu den Allerwiesen.

Tabelle 4.18 Individuelle Abfindungen

\begin{tabular}{|c|c|c|c|c|c|c|c|c|}
\hline & & \multicolumn{5}{|c|}{ Individuelle Abfindung } & \multicolumn{2}{|c|}{ rechner. } \\
\hline & \multirow{3}{*}{$\begin{array}{l}\text { Name der } \\
\text { Interessenten }\end{array}$} & \multicolumn{5}{|c|}{ Rezess, $\$ 5$, Zif. 8; 1-16 } & \multirow{2}{*}{\multicolumn{2}{|c|}{$\begin{array}{c}\text { Zusammen- } \\
\text { fassung }\end{array}$}} \\
\hline & & \multicolumn{2}{|c|}{ Angerboden } & \multicolumn{3}{|c|}{ Heidboden } & & \\
\hline & & QR & Kuhw. & $\mathrm{M}$ & QR & Kuhw. & ha & Kuhw. \\
\hline \multirow[t]{5}{*}{ Vollhöfner } & Lüßmann & & & & 30 & 0,010 & 0,0655 & 0,010 \\
\hline & Meyer & 59 & 0,084 & & & & 0,1289 & 0,084 \\
\hline & Thies /Bock & 30 & 0,042 & & & & 0,0655 & 0,042 \\
\hline & Bergmann & & & 1 & 24 & 0,160 & 0,3145 & 0,160 \\
\hline & Drewsen & 2 & 0,004 & & & & 0,0044 & 0,004 \\
\hline Halbhof & Schöndube & 3 & 0,006 & & 117 & 0,086 & 0,2621 & 0,092 \\
\hline \multirow[t]{6}{*}{ Köthner } & Joh. Hr. Thies (Cammann) & 3 & 0,006 & & & & 0,0066 & 0,006 \\
\hline & Joh. Hr. Bunkenburg & & & & 30 & 0,021 & 0,0655 & 0,021 \\
\hline & Carst. Hr. Schwägermann & 3 & 0,006 & & & & 0,0066 & 0,006 \\
\hline & Joh. Hr. Thies (Theis) & 11 & 0,015 & & & & 0,0240 & 0,015 \\
\hline & Carst. Hr. Koch & 61 & 0,020 & & & & 0,1332 & 0,020 \\
\hline & Jürgen $\mathrm{Hr}$. Hermanns & 4 & 0,008 & & & & 0,0087 & 0,008 \\
\hline \multirow[t]{4}{*}{ Abbauer } & Friedrich Ramberg & 30 & 0,067 & & & & 0,0655 & 0,067 \\
\hline & Christoph Suderburg & & & & 48 & 0,049 & 0,1048 & 0,049 \\
\hline & Carsten Hr. Thölke & & & & 96 & 0,140 & 0,2097 & 0,140 \\
\hline & Heinrich Koch & 37 & 0,051 & & & & 0,0808 & 0,051 \\
\hline \multicolumn{2}{|c|}{ Gemeinde Gockenholz, (Ackerland) } & 98 & 0,231 & & & & 0,2141 & 0,231 \\
\hline \multicolumn{2}{|c|}{ Abfindung aus Stoppelweideäquivalent } & & & & Su & Imme & 1,7605 & 1,006 \\
\hline \multicolumn{7}{|c|}{ Rezess, \$6, Zif. 3} & \multicolumn{2}{|c|}{ Verf. } \\
\hline
\end{tabular}

Quelle: Rezess über die Spezialteilung und Verkoppelung der Feldmark Lachendorf Samtgemeidne Lachendorf, Archiv, Sign. 61/5, 1859 Hofplatz für die Dorfstraße abgegeben.

- Bergmann erhielt 1M 24 QR Heidboden zu 0,160 Kuhweiden erstattet, die irrtümlich der Gemeinde zugerechnet worden waren.

- Drewsen hatte bereits zum Weg an den langen Gärten 2 QR Angerboden zu 0,004 Kuhweiden abgetreten.

- Schönduve musste wegen unterschiedlicher Gründe für 3 QR Angerboden zu 0,006 Kuhw., 60 QR Heidboden zu 0,067 Kuhw. und 57 QR Heideboden zu 0,019 Kuhw. entschädigt werden.

- Thies/Cammann hatte von den langen Gärten zum Beedenbosteler Wege bereits 3 QR Angerboden zu 0,006 Kuhw. abgetreten.

- Bunkenburg hatte 30 QR Heidboden zu 0,021 Kuhw. zu zwei Wegen abgetreten.

- Schwägermann hatte auch bereits von den langen Gärten zum Beedenbosteler Wege 3 QR Angerboden zu 0,006 Kuhw. abgetreten.

- $\quad$ Thies hatte für die neue Hofstelle 11 QR Angerboden zu 0,015 Kuhw. zu wenig erhalten.

- Koch musste für die im Exerzierplatz gelegene Immenstelle mit 61 QR Heidboden zu 0,020 Kuhw. entschädigt werden. (s. Kartenbild 3.4 - Kötner Kochs Immenstelle)

\footnotetext{
${ }^{1}$ Die Daten wurden dem Rezess entnommen und vom Verfasser rechnerisch kontrolliert sowie zusammengefasst und in ha umgerechnet. (1 Morgen $=120$ Quadratruten; $1 \mathrm{QR}=21,8425 \mathrm{~m}^{2}$ )

${ }^{2}$ s. Tabelle 4.17

${ }^{3}$ s. Tabellen $4.18-4.20$

${ }^{4}$ s. Rezess, a.a.O., §5, Ziffer 8, 1, - 16
} 
- Hermann hatte auch bereits zum Beedenbosteler Wege mit 4 QR Angerboden zu $0,008 \mathrm{Kuhw}$. beigetragen.

- Ramberg hatte eine Fläche zu Walters Hofstelle abgetreten: 30 QR Angerboden zu 0,067 Kuhw.

- Suderburg hatte 48 QR Heidboden zu 0,049 Kuhw. und Thölke 96 QR Heidboden zu 0,140 Kuhw. für Sandberge zur Verfügung gestellt.

- Koch hatte vom Hofraum und für die Umsetzung seines Brunnens 37 QR Angerboden zu 0,051 Kuhw. abgetreten.

- Das Nachbardorf Gockenholz wurde für die abgelöste Stoppelweide in der Lachendorfer Feldmark entschädigt.

Alle individuellen Entschädigungen waren Einzelfälle, die auf Antrag reguliert wurden. Überwiegend handelte es sich um kleine Flächen, die vorab für Wege abgetreten worden waren, aber auch um die Berichtigung eines Irrtums und um die Entschädigung für eine Immenstelle auf der Fläche, die als zukünftiger Exerzierplatz an den Staat verkauft wurde.

Die Erläuterungen zeigen besonders gut, mit welcher Genauigkeit und Sorgfalt jeder Anspruch geprüft und abgegolten wurde.

\begin{tabular}{|c|c|c|c|c|c|c|c|c|c|c|c|c|c|c|c|c|}
\hline \multicolumn{3}{|c|}{ Tabelle 4.19} & \multicolumn{12}{|c|}{ Zusammenstellung } & \multirow{3}{*}{\multicolumn{2}{|c|}{$\begin{array}{c}\text { rechnerische } \\
\text { Zusammen- } \\
\text { fassung }\end{array}$}} \\
\hline \multirow{2}{*}{\multicolumn{15}{|c|}{$\begin{array}{l}\text { des privaten Besitzes der Interessenten } \\
\text { nach Abzug der Wiesenweide Äquivalente (1/7 der Wiesenfläche als Abzug) }\end{array}$}} & & \\
\hline & & & & & & & & & & & & & & & & \\
\hline & & \multirow{2}{*}{$\begin{array}{l}\text { Name der } \\
\text { Interessenten }\end{array}$} & \multicolumn{3}{|c|}{ Ackerland } & \multicolumn{3}{|c|}{ Wiesenboden } & \multicolumn{3}{|c|}{ Angerboden } & \multicolumn{3}{|c|}{ Heidboden } & \multirow[t]{2}{*}{ ha } & \multirow[t]{2}{*}{ Kuhw. } \\
\hline & & & $\mathrm{M}$ & $Q R$ & Kuhw. & $\mathrm{M}$ & QR & Kuhw. & $\mathrm{M}$ & $Q R$ & Kuhw. & $\mathrm{M}$ & QR & Kuhw. & & \\
\hline \multirow[t]{7}{*}{ Vollhöfner } & 1 & Lüßmann & 148 & 111 & 29,098 & & 94 & 0,311 & 1 & 99 & 0,304 & 5 & 16 & 0,406 & 41,06 & 30,119 \\
\hline & 2 & Meyer & 101 & 43 & 19,796 & 10 & 26 & 2,740 & 3 & 73 & 0,580 & 6 & & 0,707 & 31,76 & 23,823 \\
\hline & 3 & KohImeyer & 124 & 64 & 22,489 & & & & & 115 & 0,161 & 1 & 77 & 0,137 & 33,32 & 22,787 \\
\hline & 4 & Thies /Bock & 159 & 63 & 28,396 & 10 & 90 & 3,768 & 2 & 56 & 0,392 & 6 & 84 & 0,629 & 47,03 & 33,185 \\
\hline & 5 & Bergmann & 112 & 119 & 19,429 & 4 & 60 & 2,302 & 2 & 7 & 0,372 & 3 & 70 & 0,396 & 32,27 & 22,499 \\
\hline & 6 & Drewsen & 125 & 35 & 23,505 & 2 & 92 & 1,235 & 2 & 17 & 0,370 & 6 & 32 & 0,774 & 35,77 & 25,884 \\
\hline & 7 & Schumeyer & 123 & 64 & 23,062 & 15 & 89 & 5,049 & 4 & 30 & 0,805 & 1 & 72 & 0,086 & 38,04 & 29,002 \\
\hline Halbhof & 8 & Schöndube & 96 & 33 & 20,565 & 3 & 117 & 1,215 & 2 & 85 & 0,445 & 2 & 43 & 0,122 & 27,60 & 22,347 \\
\hline \multirow[t]{12}{*}{ Köthner } & 1 & Joh. Hr. Thies & 108 & 116 & 18,996 & 8 & 71 & 3,647 & 7 & 65 & 1,462 & 1 & 108 & 0,121 & 33,29 & 24,226 \\
\hline & 2 & Joh. Hr. Bunkenburg & 78 & 18 & 12,266 & 3 & 112 & 1,663 & 3 & 36 & 0,523 & 6 & 111 & 0,417 & 24,19 & 14,869 \\
\hline & 3 & Joh. Hr. Dralle & 102 & 30 & 15,188 & 10 & 8 & 3,501 & 3 & 108 & 0,614 & 5 & 85 & 0,414 & 31,96 & 19,717 \\
\hline & 4 & Chr. Hr. Dralle & 73 & 62 & 10,163 & 3 & 88 & 1,392 & 2 & 20 & 0,361 & 4 & 54 & 0,594 & 21,98 & 12,510 \\
\hline & 5 & Joh. Hr. Bühring & 51 & 13 & 5,246 & & & & 1 & 10 & 0,181 & & 69 & 0,032 & 13,83 & 5,459 \\
\hline & 6 & Joh. Hr. Thies (Krüger) & 61 & 83 & 12,104 & 8 & & 3,784 & 1 & 94 & 0,329 & 10 & 106 & 1,281 & 21,59 & 17,498 \\
\hline & 7 & Carst. Schwägermann & 42 & 106 & 8,306 & & 67 & 0,186 & 1 & 67 & 0,251 & & 77 & 0,049 & 11,96 & 8,792 \\
\hline & 8 & Joh. Hr. Thies (Theis) & 107 & 13 & 20,316 & 1 & 111 & 0,842 & 1 & 76 & 0,271 & 3 & 59 & 0,190 & 29,92 & 21,619 \\
\hline & 9 & Chr-Thies (Graue) & 81 & 94 & 16,769 & 8 & 49 & 3,909 & 1 & 41 & 0,180 & & & & 23,99 & 20,858 \\
\hline & 10 & Carst. Hr. Koch & 97 & 92 & 17,646 & 6 & 24 & 3,060 & 6 & 83 & 1,043 & 1 & 58 & 0,080 & 29,39 & 21,829 \\
\hline & 11 & Jürgen Hr. Hermanns & 65 & 71 & 9,818 & 6 & 47 & 3,179 & 2 & & 0,363 & & 69 & 0,064 & 19,54 & 13,424 \\
\hline & 12 & Carst. Hr. Misselhorn & 53 & 25 & 5,695 & & & & 1 & 13 & 0,185 & 7 & 48 & 0,461 & 16,18 & 6,341 \\
\hline \multirow[t]{3}{*}{ Brinksitzer } & 1 & Joh. Hr. Wulf & 10 & 29 & 2,769 & & & & & 31 & 0,043 & & & & 2,75 & 2,812 \\
\hline & 2 & Christ. Lüßmann & 17 & 91 & 4,558 & & 36 & 0,100 & & 63 & 0,088 & & & & 4,87 & 4,746 \\
\hline & 3. & Joh. Hr. Lilie & 3 & 117 & 0,821 & & & & & 40 & 0,056 & & & & 1,13 & 0,877 \\
\hline Anbauer & 1 & Chr. Thies & 6 & 19 & 1,778 & & & & & 29 & 0,040 & & & & 1,68 & 1,818 \\
\hline & 2 & Chr. Hr. Meyer & 15 & 73 & 3,326 & & 10 & 0,028 & & 51 & 0,071 & 1 & 80 & 0,129 & 4,66 & 3,554 \\
\hline & 3 & Hr. Bergmann & & 30 & 0,071 & & & & & 29 & 0,040 & & & & 0,13 & 0,111 \\
\hline & 4 & Joh. Hr. Knoop & 26 & 116 & 5,886 & & & & & 104 & 0,145 & & & & 7,30 & 6,031 \\
\hline & 5 & Wilh. Herbold & 2 & 42 & 0,123 & & & & & 10 & 0,007 & & & & 0,64 & 0,130 \\
\hline Abbauer & 1 & Freidrich Meyer & 3 & 82 & 0,771 & & & & & 28 & 0,039 & & & & 1,03 & 0,810 \\
\hline & 2 & Friedrich Ramberg & 1 & 116 & 0,369 & & & & & 70 & 0,097 & & & & 0,67 & 0,466 \\
\hline & 3 & Gottfried Walter & 1 & 109 & 0,380 & & & & & 56 & 0,078 & & & & 0,62 & 0,458 \\
\hline & 4 & Heinrich Ahrens & 1 & 63 & 0,170 & & & & & 26 & 0,024 & & & & 0,46 & 0,194 \\
\hline & 5 & Christoph Suderburg & 1 & 88 & 0,172 & & & & & 45 & 0,036 & & & & 0,55 & 0,208 \\
\hline & 6 & Hr. Lilie & 2 & 25 & 0,155 & & & & & 18 & 0,017 & & & & 0,62 & 0,172 \\
\hline & 7 & Carsten Hr. Thölke & 1 & 88 & 0,193 & & & & & 24 & 0,019 & & & & 0,51 & 0,212 \\
\hline & 8 & Heinrich Koch & & & & & & & & 59 & 0,082 & & & & 0,13 & 0,082 \\
\hline Hirte & & Joh. Hr. Meyer & 5 & 108 & 1,639 & & & & & & & & & & 1,55 & 1,639 \\
\hline Häusling & & Meyer Erben & 6 & 30 & 1,786 & & & & & & & & & & 1,64 & 1,786 \\
\hline Abbauer & 9 & Joh. Hr. Graue & 1 & 32 & 0,135 & & & & & 34 & 0,032 & & & & 0,41 & 0,167 \\
\hline Georg Dren & vsen & n Erben Papierfabrik & 20 & 119 & 5,948 & & 84 & 0,350 & 2 & 114 & 0,492 & 31 & 41 & 2,919 & 14,67 & 9,709 \\
\hline Die Schule & zu L & -achendorf & & 118 & 0,270 & & & & & 50 & 0,069 & & & & 0,37 & 0,339 \\
\hline & & Ausmärker & & & & & & & & & & & & & & \\
\hline Die Kirche $z$ & zu B & eedenbostel & 5 & 99 & 1,235 & & & & & & & & & & 1,53 & 1,235 \\
\hline Vollmeier & Vetr & h, Gockenholz & 3 & 72 & 0,946 & & & & & & & & 113 & 0,135 & 1,19 & 1,081 \\
\hline & Sch & humeier, daselbst & 8 & 105 & 2,301 & & & & & & & & & & 2,33 & 2,301 \\
\hline & Thie & es, Höfer & & & & 2 & 114 & 1,180 & & & & & & & 0,77 & 1,180 \\
\hline & Mis: & selhorn, Gockenholz & & & & 1 & 93 & 0,312 & & & & & 26 & 0,031 & 0,52 & 0,343 \\
\hline & Klos & ster Wienhausen & & & & & & & & & & & 3 & 0,001 & 0,01 & 0,001 \\
\hline & & & & & & & & zess, §ु & 80,2 & Zif 5 & & & & & & erf. \\
\hline
\end{tabular}

Sodann brachten alle Höfe die bereits vor den Reformen privat genutzten bzw. bewirtschafteten Flächen in das Verfahren ein (Tabelle 4.19): 
Der Schwerpunkt des privaten Besitzes lag natürlich beim Ackerland, das bereits seit langer Zeit, wenn auch unter Flurzwang, in eigener Bewirtschaftung der Höfe lag.

Es gab unter den Hoftypen eine klare Hierarchie, allerdings entsprach die Hofgröße nicht immer dem Hoftyp, denn drei Kothöfe waren größer als der Halbhof und zwei dieser Kothöfe sogar größer als der kleinste Vollhof. Der Grundbesitz von Drewsen, Eigentümer der Papierfabrik, spielte schon zu Beginn der Reformen eine besondere Rolle, denn der Vollhof umfasste zusammen mit den gesondert für $G$. Drewsen Erben ausgewiesenen Flächen insgesamt 50,44 ha, also mehr als der damals größte Vollhof mit 41,06 ha.

Von den privaten Wiesenflächen wurde 1/7 abgezogen als Gegenwert für die gemeinschaftliche Vor- und Nachweide. Dazu wurden alle einheimischen Interessenten und der Ausmärker Thies aus Höfer herangezogen ${ }^{1}$, weil sie die Vor- und Nachweide gemeinsam genutzt hatten.

Dieses Wiesenweideäquivalent von nur 4,1436 ha wurde dann wieder verteilt, allerdings nur unter Voll- und Halbhöfe sowie Kothöfe und Brinksitzer; die Ab- und Anbauern erhielten daraus nichts. Grundlage war die gemeinschaftliche „Weide, Heid- und Plaggenhiebsmasse“2.

In Tabelle 4.20 werden die eingebrachten, bereits reduzierten Wiesenbodenflächen und die Abfindungen aus dem Wiesenweideäquivalent samt Umrechnung in ha gesondert zusammen gestellt. Bei einer gesamten Wiesenfläche von 33,6 ha wurden 29,4 ha von den Höfen als private Flächen in die Reform eingebracht und nur 4,1435 ha als Wiesenweideäquivalent umverteilt. Alle Höfe erhielten aus diesem Äquivalent jeweils deutlich weniger als einen halben Hektar.

Der Umgang mit diesem Nutzungsrecht, der Vor- und Nachweide auf den sonst privaten Wiesen, und der kleinen Fläche von gut 4 ha verdeutlicht zum einen die Wichtigkeit des Wiesenbodens, also das Futterproblem, und zum anderen die äußerste Sorgfalt der Reform, die in allen Punkten nötig war, um die freiwillige Zustimmung aller Betroffenen zu erreichen.

Die weiteren Abfindungen ${ }^{3}$ gliederten sich in vier Bereiche:

- Das „Haushaltsbedürfnis“: nur Anger- und Heidboden

- Die Bultenhiebsmasse: nur Heidboden

- Holzbestände und Gemeindeeigentum

- Rest der Gemeinheit, im wesentlichen also die Zuteilung aus der Generalteilung der Allerheide

Beim sog. Haushaltsbedürfnis, einer Abfindung, die nach der Bezeichnung einen Grundbedarf abdecken sollte, hielt sich die soziale Komponente in Grenzen: Es profitierten Vollhöfe, Halbhof, Kothöfe und Brinksitzer mit je 3 M Angerboden und 28 M 40 QR Heidboden, die 5 Anbauern mit je $2 \mathrm{M} 30$ QR Anger und $21 \mathrm{M} 30$ QR Heide und nur ein Abbauer (von 8) mit 23 QR Anger und $1 \mathrm{M} 92$ QR Heide. Die Schule erhielt aus dieser Abfindung 4 M 60 QR Anger und 42 M 60 QR Heide sowie die Papierfabrik 15 M 27 QR Anger und 143 M 95 QR Heidboden.

Von den Abbauern erhielt nur einer beim Haushaltsbedürfnis einen halben Hektar, alle anderen gingen zusammen mit Hirte und Häusling selbst beim Grundbedürfnis „Haushaltsbedürfnis" leer aus.

Aus dieser Anrechnung erklärt sich der Antrag ${ }^{4}$ von vier Abbauern auf Abfindung als Anbauern, der aber als „unbegründet verworfen"5 wurde. Bei einer Hochstufung im Hoftyp wären sie besser abgefunden worden.

\footnotetext{
${ }^{1}$ s. Rezess, §2, Zif. 5

${ }^{2}$ ebenda

${ }^{3}$ s. Tabellen 4.21 und 4.22

${ }^{4}$ s. Rezess, §2, Zif. 9, b)

${ }^{5}$ s. Rezess, §2, Zif.9, ad b)
} 


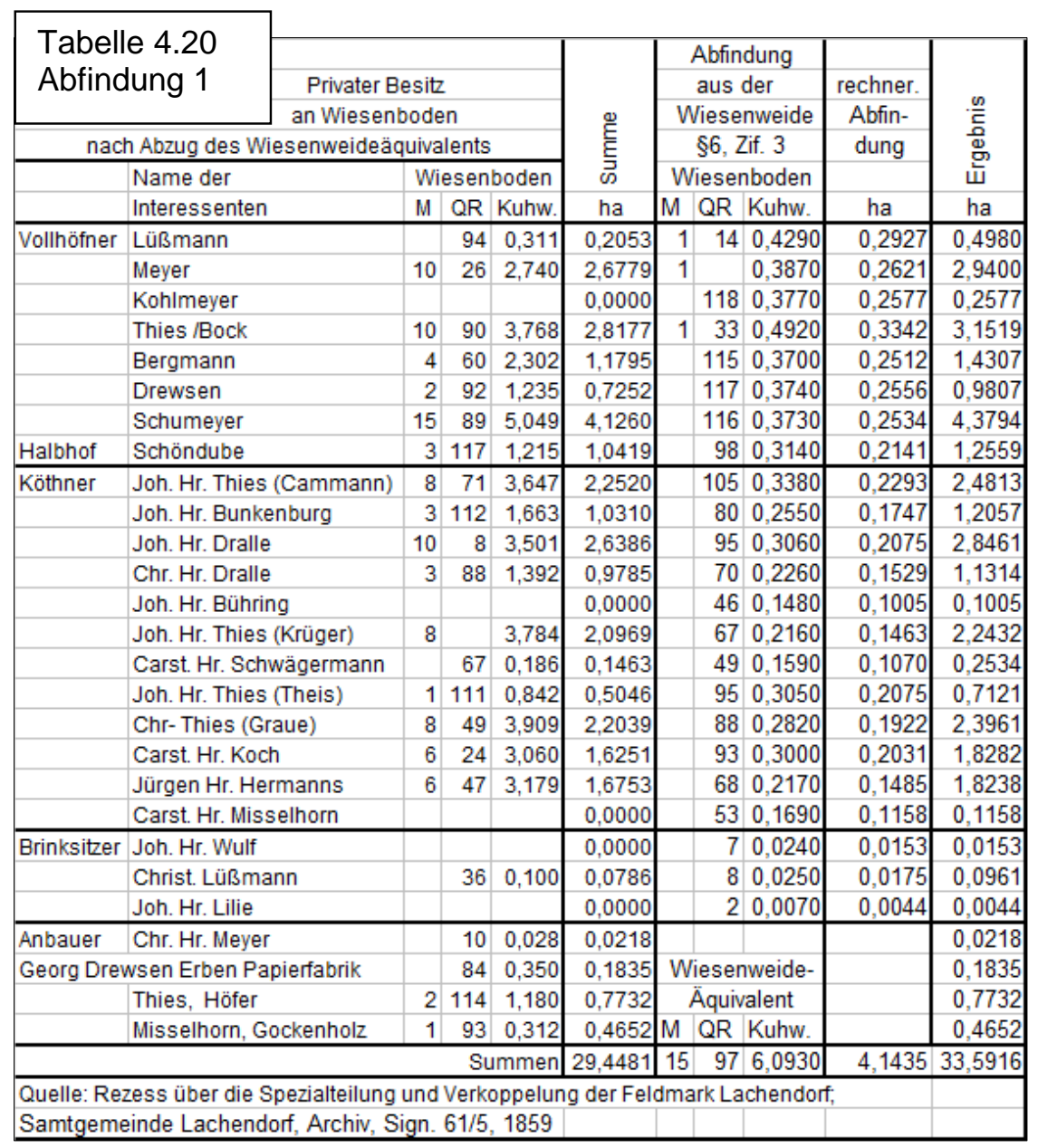

Die Bultenhiebsmasse dagegen unterlag gleichmäßigerer Verteilung, allerdings auch nicht an alle: Die Vollhöfe, der Halbhof, die Kötner und ein Brinksitzer erhielten je Hof 5 M 95 QR und alle anderen einschließlich Schule und Papierfabrik 5 M 94 QR, womit 173 M 81 QR Bultenhiebsfläche verteilt waren.

Drewsen Erben und die Schule wurden bei der Bultenhiebsmasse wie die Höfe bedacht und hatten beim Haushaltsbedürfnis offenbar Sonderrechte.

Die gleichmäßige und lückenlose Anrechnung der Bultenhiebsfläche auf Vollhöfe, Halbhof, Kötner, Brinksitzer und Anbauern belegt die Wichtigkeit dieser Nutzflächen im alten Nutzungssystem. Der Bultenhieb lieferte nämlich reichlich Streu, die sicherlich auch als Notbzw. Erhaltungsfutter bei Futtermangel eingesetzt wurde.

Nur die Abbauern mit den geringsten Ackerflächen waren auch von dieser damals betriebswirtschaftlich bedeutsamen Nutzung ausgeschlossen.

Auch bei den Abfindungen ${ }^{1}$ aus den Holzbeständen und besonderen Grundstücken der Gemeinde, ging es nicht nach Hofgröße, aber deutlich nach Hoftyp. Insofern war der soziale Ansatz der Abfindungen doch sehr eingeschränkt.

Von den Abfindungen aus den Holzbeständen, immerhin 30,47 ha, profitierten nur Vollhöfe, Halbhof und Kothöfe mit je 24 QR (2 Vollhöfe mit 25 QR) Acker, 17 QR Wiesenboden ( 6 Höfe mit 18 QR), 74 oder 75 QR Anger und 68 oder 69 QR Heidboden, während die drei Brinksitzer zusammen die gleichen Flächen erhielten.

\footnotetext{
${ }^{1}$ s. Tabelle 4.22
} 


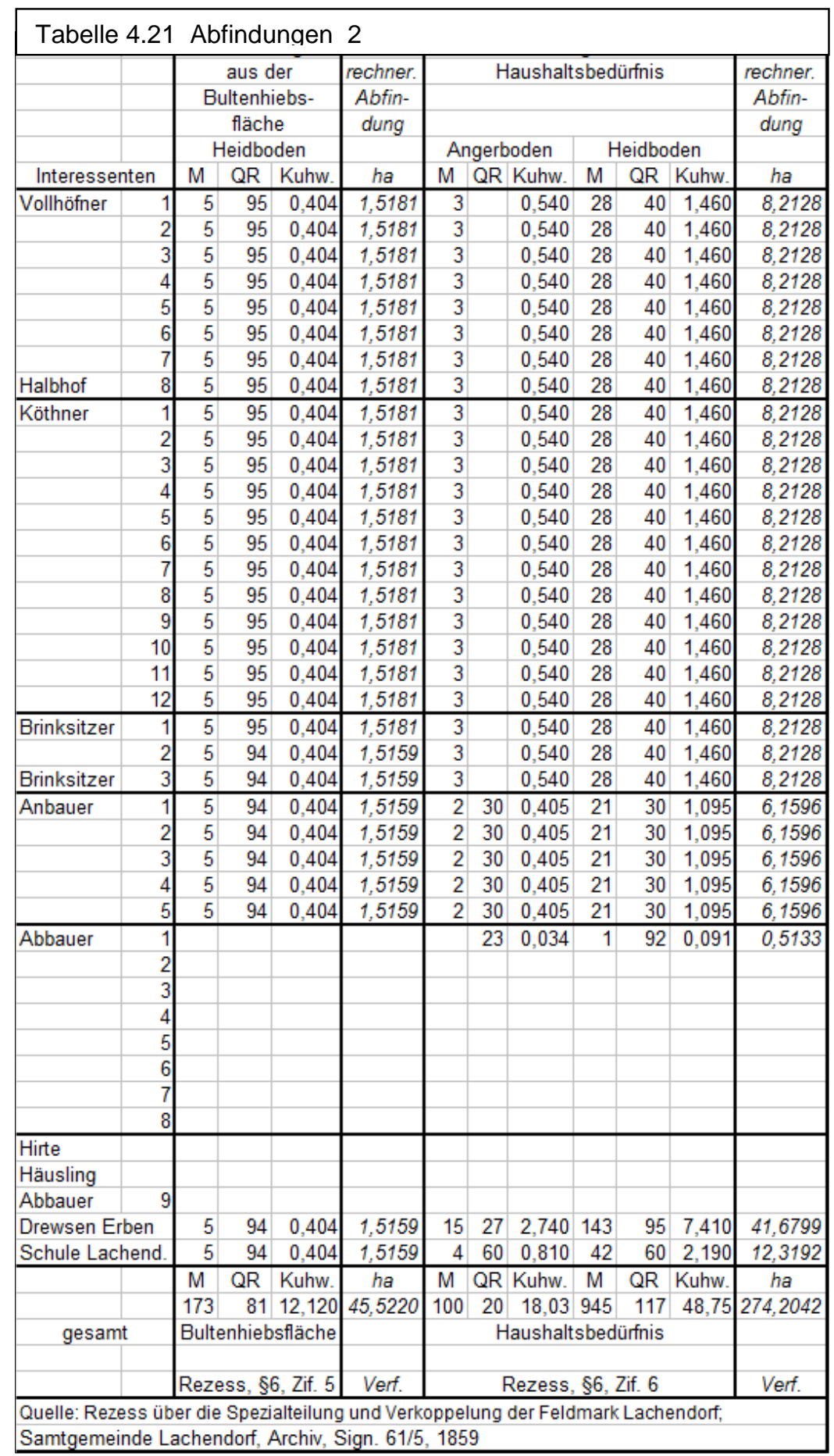

Die Verteilung der restlichen Gemeinheiten, Anger- und vor allem Heidboden mit 706,5 ha, auf alle Interessenten des Dorfes, also auch auf Abbauern, (mit drei Ausnahmen), den Hirten und Häusling, belegt, dass alle berücksichtigten Interessenten dort offenbar Nutzungsrechte, als Weiderechte für Vieh, gehabt haben, sonst wären sie beim Berechnungsschlüssel der „Simpla"1 schon leer ausgegangen. Allerdings erhielten aufgrund dieses Schlüssels die

\footnotetext{
${ }^{1}$ Über den Berechnungsschlüssel für die „Simpla“ gibt der Rezess leider keine Auskunft. Man darf annehmen, dass der Viehbestand zugrunde gelegt wurde, für den eine Weideberechtigung bestand. (Anm. d. Verf.)
} 
Brinksitzer , Abbauern, Hirte und Häusling nur geringe Flächenanteile von maximal knapp drei Hektar.

Die Anrechnung dieser Gemeinheitsflächen richtete sich nicht nach Hoftyp sondern auch nach den sog. „Simpla“, einem Verteilerschlüssel, der aufgrund des eingebrachten „privaten Besitzes an Ackerland und Wiesen, unter Berücksichtigung auch der der Verkoppelung nicht unterzogenen Ackerländereien und Wiesen"1 berechnet worden war. Die Anrechnung erfolgte nach Hofgröße mit Flächen zwischen 56 ha und knapp 17 ha, wobei es auch hier, entsprechend den eingebrachten privaten Besitzungen, eine Überschneidung zwischen den Vollhöfen und Kothöfen gab.

\begin{tabular}{|c|c|c|c|c|c|c|c|c|c|c|c|c|c|c|c|c|c|c|}
\hline \multicolumn{3}{|c|}{ Tabelle 4.22} & \multicolumn{16}{|c|}{ Abfindunaen 3} \\
\hline & & \multicolumn{9}{|c|}{ Abfindung } & & \multicolumn{6}{|c|}{ Abfindung } & \\
\hline & & \multicolumn{9}{|c|}{ aus den Holzbeständen, } & rechn. & \multicolumn{6}{|c|}{ nach den vereinbarten Simpla } & rechn. \\
\hline & & \multicolumn{9}{|c|}{ den cultivierten Gemeinde Grundstücken } & Zusammen- & \multicolumn{6}{|c|}{ aus dem Rest der } & Zusammen- \\
\hline & & \multicolumn{9}{|c|}{ und Gemeinde Baulichkeiten } & fassung & \multicolumn{6}{|c|}{ Gemeinheiten } & fassung \\
\hline & & \multicolumn{2}{|c|}{ Ackerland } & \multicolumn{4}{|c|}{ Wiesenboden Angerboden } & \multicolumn{3}{|c|}{ Heidboden } & & \multicolumn{3}{|c|}{ Angerboden } & \multicolumn{3}{|c|}{ Heidboden } & \\
\hline \multicolumn{2}{|c|}{ Interessenten } & $Q R$ & Kuhw. & QR & Kuhw. & $\mathrm{QR}$ & Kuhw. & $\mathrm{M}$ & $\mathrm{QR}$ & Kuhw. & ha & $\mathrm{M}$ & $\mathrm{QR}$ & Kuhw. & $\mathrm{M}$ & QR & Kuhw. & ha \\
\hline Vollhöfner & 1 & 24 & 0,058 & 18 & 0,047 & 74 & 0,103 & 4 & 68 & 0,419 & 1,4503 & 17 & 34 & 3,346 & 168 & 102 & 8,560 & 48,7874 \\
\hline & 2 & 25 & 0,058 & 17 & 0,047 & 74 & 0,103 & 4 & 68 & 0,419 & 1,4503 & 15 & 66 & 3,01 & 151 & 108 & 7,701 & 43,8903 \\
\hline & 3 & 24 & 0,059 & 18 & 0,046 & 74 & 0,103 & 4 & 68 & 0,420 & 1,4503 & 15 & 22 & 2,938 & 148 & 33 & 7,517 & 42,8441 \\
\hline & 4 & 25 & 0,058 & 17 & 0,047 & 74 & 0,103 & 4 & 68 & 0,420 & 1,4503 & 19 & 99 & 3,837 & 193 & 80 & 9,818 & 55,9583 \\
\hline & 5 & 24 & 0,059 & 18 & 0,046 & 74 & 0,103 & 4 & 68 & 0,420 & 1,4503 & 14 & 105 & 2,878 & 145 & 30 & 7,363 & 41,9704 \\
\hline & 6 & 24 & 0,058 & 18 & 0,047 & 74 & 0,103 & 4 & 68 & 0,420 & 1,4503 & 15 & 7 & 2,914 & 147 & 8 & 7,455 & 42,4946 \\
\hline & 7 & 24 & 0,058 & 18 & 0,047 & 74 & 0,103 & 4 & 68 & 0,420 & 1,4503 & 14 & 119 & 2,902 & 146 & 55 & 7,425 & 42,3177 \\
\hline Halbhof & 8 & 24 & 0,058 & 18 & 0,047 & 74 & 0,103 & 4 & 68 & 0,420 & 1,4503 & 12 & 77 & 2,446 & 123 & 55 & 6,259 & 35,6732 \\
\hline Köthner & 1 & 24 & 0,058 & 18 & 0,047 & 74 & 0,103 & 4 & 68 & 0,420 & 1,4503 & 13 & 76 & 2,638 & 133 & $\overline{17}$ & 6,750 & 38,4712 \\
\hline & 2 & 24 & 0,058 & 17 & 0,047 & 75 & 0,103 & 4 & 68 & 0,420 & 1,4503 & 10 & 34 & 1,991 & 100 & 56 & 5,093 & 29,0287 \\
\hline & 3 & 24 & 0,058 & 17 & 0,047 & 75 & 0,103 & 4 & 68 & 0,420 & 1,4503 & 12 & 40 & 2,386 & 120 & 52 & 6,106 & 34,7995 \\
\hline & 4 & 24 & 0,058 & 17 & 0,047 & 75 & 0,103 & 4 & 68 & 0,420 & 1,4503 & 9 & 13 & \begin{tabular}{|l|l|}
3,763 \\
\end{tabular} & 88 & 116 & 4,510 & 25,7064 \\
\hline & 5 & 24 & 0,058 & 17 & 0,047 & 75 & 0,103 & 4 & 68 & 0,420 & 1,4503 & 5 & 113 & $\begin{array}{ll}3,151 \\
3\end{array}$ & 58 & 18 & 2,946 & 16,7991 \\
\hline & 6 & 24 & 0,058 & 17 & 0,047 & 75 & 0,104 & 4 & 68 & 0,419 & 1,4503 & 8 & 81 & 1,678 & 84 & 87 & 4,295 & 24,4811 \\
\hline & 7 & 24 & 0,058 & 17 & 0,047 & 75 & 0,104 & 4 & 68 & 0,419 & 1,4503 & 6 & 46 & 1,235 & 62 & 40 & 3,160 & 18,0113 \\
\hline & 8 & 24 & 0,058 & 17 & 0,046 & 75 & 0,104 & 4 & 69 & 0,420 & 1,4525 & 12 & 33 & 2,374 & 119 & 100 & 6,075 & 34,6269 \\
\hline & 9 & 24 & 0,058 & 17 & 0,046 & 75 & 0,104 & 4 & 69 & 0,420 & 1,4525 & 11 & 41 & 2,195 & 110 & 90 & 5,615 & 32,0014 \\
\hline & 10 & 24 & 0,058 & 17 & 0,046 & 75 & 0,104 & 4 & 69 & 0,419 & 1,4525 & \begin{tabular}{|l|}
12 \\
\end{tabular} & 10 & 2,338 & 118 & 2 & 5,983 & 34,1005 \\
\hline & 11 & 24 & 0,058 & 17 & 0,046 & 75 & 0,104 & 4 & 69 & 0,419 & 1,4525 & 8 & 89 & 1,69 & 85 & 40 & 4,326 & 24,6580 \\
\hline & 12 & 24 & 0,058 & 17 & 0,046 & 75 & 0,104 & 4 & 69 & 0,419 & 1,4525 & 6 & 98 & 1,319 & 66 & 69 & 3,375 & 19,2367 \\
\hline Brinksitzer & 1 & & & & & & & & & & & & 119 & 0,192 & 9 & 82 & 0,491 & 2,7980 \\
\hline & 2 & 24 & 0,058 & 17 & 0,046 & 75 & 0,104 & 4 & 69 & 0,420 & 1,4525 & 1 & 7 & 0,204 & 10 & 35 & 0,522 & 2,9749 \\
\hline Brinksitzer & 3 & & & & & & & & & & & & 30 & 0,048 & 2 & 51 & 0,123 & 0,7011 \\
\hline Anbauer & 1 & & & & & & & & & & & & 89 & 0,144 & 7 & 31 & 0,368 & 2,0969 \\
\hline & 2 & & & & & & & & & & & & 96 & 0,156 & 7 & 104 & 0,399 & 2,2716 \\
\hline & 3 & & & & & & & & & & & & 7 & 0,012 & & 73 & 0,031 & 0,1747 \\
\hline & 4 & & & & & & & & & & & 1 & 73 & 0,312 & 15 & 88 & 0,798 & 4,5454 \\
\hline & 5 & & & & & & & & & & & & 15 & 0,024 & 1 & 25 & 0,061 & 0,3495 \\
\hline Abbauer & 1 & & & & & & & & & & & & 37 & 0,06 & 3 & 3 & 0,153 & 0,8737 \\
\hline & 2 & & & & & & & & & & & & 15 & 0,024 & 1 & 25 & 0,0 & 0,3495 \\
\hline & 3 & & & & & & & & & & & & 30 & 0,048 & 2 & 50 & 0,123 & 0,6990 \\
\hline & 4 & & & & & & & & & & & & 7 & 0,012 & & 73 & 0,031 & 0,1747 \\
\hline & 5 & & & & & & & & & & & & & & & & & \\
\hline & 6 & & & & & & & & & & & & 7 & 0,012 & & 73 & 0,031 & 0,1747 \\
\hline & 7 & & & & & & & & & & & & 15 & 0,024 & 1 & 25 & 0,061 & 0,3495 \\
\hline & 8 & & & & & & & & & & & & & & & & & \\
\hline Hirte & & & & & & & & & & & & & 45 & 0,072 & 3 & 76 & 0,184 & 1,0506 \\
\hline Häusling & & & & & & & & & & & & & 45 & 0,072 & 3 & 76 & 0,184 & 1,0506 \\
\hline Abbauer & 9 & & & & & & & & & & & & & & & & & \\
\hline & & & & & & & & & ummer & en (ha) & 30,4703 & & & & & & & 706,4913 \\
\hline & & & & & Rezes & s, §6, & Zif. 4 & & & & Verf. & & & Rezess & $\S 6, \mathrm{Z}$ & Zif.5 & & Verf. \\
\hline
\end{tabular}

Für die Gemeinschaftsaufgaben waren auch Flächenbeiträge zu erbringen, die von den Abfindungen in Abzug gebracht wurden.

${ }^{1}$ s. Rezess, §2, Zif. 21 
Während sich die Abfindungen teils am Hoftyp und teils an der Hofgröße orientierten, war bei der Verteilung der Lasten fast ausschließlich der Hoftyp maßgeblich.

Der punktuell erkennbare soziale Aspekt der Spezialteilung und Verkoppelung orientierte sich fast ausschließlich am Hoftyp und nicht am individuellen Besitz.

\begin{tabular}{|c|c|c|c|c|c|c|c|c|c|c|c|c|c|c|}
\hline \multicolumn{3}{|c|}{$\begin{array}{l}\text { Tabelle } 4.23 \\
\text { Beiträge } 1\end{array}$} & \multicolumn{11}{|c|}{$\begin{array}{c}\text { Zu den neuen Wegen, } \\
\text { den Sandgruben, Abzugsgräben } \\
\text { haben beizutragen. }\end{array}$} & \multirow{3}{*}{ 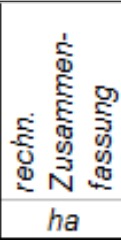 } \\
\hline & & Name der & \multicolumn{3}{|c|}{ Ackerland } & \multicolumn{2}{|c|}{ Niesenbode } & \multicolumn{3}{|c|}{ Angerboden } & \multicolumn{3}{|c|}{ Heidboden } & \\
\hline & & Interessenten & $M$ & QR & Kuhw. & QR & Kuhw. & $\mathrm{M}$ & $Q R$ & Kuhw. & $\mathrm{M}$ & QR & Kuhw. & \\
\hline \multirow[t]{7}{*}{ Vollhöfner } & & Lüßmann & 4 & 69 & 0,754 & 5 & 0,013 & 1 & 105 & 0,366 & 11 & 34 & 0,688 & 4,6088 \\
\hline & & Meyer & 3 & 99 & 0,629 & 4 & 0,010 & 1 & 69 & 0,307 & 9 & 51 & 0,575 & 3,8028 \\
\hline & & Kohlmeyer & 3 & 83 & 0,607 & 3 & 0,009 & 1 & 62 & 0,296 & 9 & 20 & 0,554 & 3,7504 \\
\hline & 4 & Thies /Bock & 5 & 10 & 0,834 & 5 & 0,013 & 2 & 10 & 0,406 & 12 & 58 & 0,763 & 5,0609 \\
\hline & 5 & Bergmann & 3 & 79 & 0,602 & 3 & 0,009 & 1 & 60 & 0,29 & 9 & & 0,551 & 3,7373 \\
\hline & 6 & Drewsen & 4 & & 0,657 & 4 & 0,011 & 1 & 77 & 0,32 & 9 & 98 & 0,599 & 3,8661 \\
\hline & 7 & Schumeyer & 4 & 37 & 0,707 & 4 & 0,011 & 1 & 91 & 0,342 & 10 & 71 & 0,649 & 4,2418 \\
\hline Halbhof & & Schöndube & 3 & 57 & 0,571 & 3 & 0,010 & 1 & 50 & 0,276 & 8 & 66 & 0,523 & 3,4031 \\
\hline \multirow[t]{12}{*}{ Köthner } & & Joh. Hr. Thies (Cammann) & 3 & 87 & 0,612 & 4 & 0,011 & 1 & 63 & 0,296 & 9 & 20 & 0,561 & 3,7635 \\
\hline & & Joh. Hr. Bunkenburg & 2 & 66 & 0,418 & 2 & 0,007 & 1 & 6 & 0,203 & 6 & 30 & 0,382 & 2,5337 \\
\hline & & Joh. Hr. Dralle & 3 & 22 & 0,522 & 3 & 0,009 & 1 & 36 & 0,254 & 7 & 98 & 0,477 & 3,0317 \\
\hline & 4 & Chr. Hr. Dralle & 2 & 26 & 0,364 & 2 & 0,006 & & 110 & 0,176 & 5 & 55 & 0,336 & 2,1471 \\
\hline & & Joh. Hr. Bühring & 1 & 34 & 0,210 & 1 & 0,004 & & 63 & 0,102 & 3 & 19 & 0,193 & 1,2690 \\
\hline & & Joh. Hr. Thies (Krüger) & 2 & 82 & 0,441 & 3 & 0,007 & 1 & 12 & 0,215 & 6 & 75 & 0,406 & 2,5840 \\
\hline & & Carst. Hr. Schwägermann & 1 & 76 & 0,270 & 2 & 0,004 & & 81 & 0,134 & 4 & 9 & 0,247 & 1,6666 \\
\hline & & Joh. Hr. Thies (Theis) & 3 & 43 & 0,552 & 3 & 0,009 & 1 & 46 & 0,27 & 8 & 34 & 0,506 & 3,3637 \\
\hline & 9 & Chr- Thies (Graue) & 3 & 27 & 0,528 & 3 & 0,008 & 1 & 38 & 0,26 & 7 & 111 & 0,483 & 3,0470 \\
\hline & 10 & Carst. Hr. Koch & 3 & 46 & 0,554 & 3 & 0,009 & 1 & 46 & 0,27 & 8 & 35 & 0,507 & 3,3703 \\
\hline & 11 & Jürgen $\mathrm{Hr}$. Hermanns & 2 & 35 & 0,375 & 2 & 0,006 & & 113 & 0,185 & 5 & 74 & 0,342 & 2,1733 \\
\hline & 12 & Carst. Hr. Misselhorn & 1 & 52 & 0,235 & 1 & 0,003 & & 71 & 0,113 & 3 & 63 & 0,218 & 1,3258 \\
\hline \multirow[t]{3}{*}{ Brinksitzer } & & Joh. Hr. Wulf & & 74 & 0,101 & 1 & 0,001 & & 30 & 0,049 & 1 & 62 & 0,094 & 0,4936 \\
\hline & & Christ. Lüßmann & & 98 & 0,134 & 1 & 0,002 & & 40 & 0,064 & 2 & 1 & 0,124 & 0,8322 \\
\hline & & Joh. Hr. Lilie & & 44 & 0,060 & & & & 18 & 0,03 & & 110 & 0,057 & 0,1354 \\
\hline \multicolumn{3}{|c|}{ Georg Drewsen Erben Papierfabrik } & 2 & 5 & 0,335 & 2 & 0,005 & & 101 & 0,163 & 5 & 2 & 0,308 & 2,0816 \\
\hline & & & & & & & & & & \multicolumn{4}{|c|}{ Summe (ha) } & 66,2898 \\
\hline & & \multicolumn{12}{|c|}{ Rezess, $\$ 6$, Zif. 6} & Verf. \\
\hline
\end{tabular}

Alle Voll- Halb- und Kothöfe sowie die Brinksitzer und die Papierfabrik hatten zu den gemeinschaftlichen Sandgruben und Abzugsgräben ziemlich gleichmäßig beizutragen mit Flächen zwischen $4 \mathrm{M} 69 \mathrm{QR}$ und $44 \mathrm{QR}$, in den meisten Fällen zwischen 3 und $4 \mathrm{M}$ Ackerland, zwischen 5 und 1 QR Wiesenboden, zwischen $2 \mathrm{M} 10$ QR und 18 QR Anger sowie 12 M 58 QR und 110 QR Heidboden. Insgesamt wurden dafür 29 ha benötigt.

Auch die Beiträge zu den Grundstücken der Gemeinde erfolgte recht gleichmäßig: Voll-, Halb- und Kothöfe mit 10 oder 11 QR Wiesenboden, 24 oder 25 QR Anger und 4 M 116 (oder117) QR Heidboden. Außerdem wurden nur die Brinksitzer mit je 3 oder 4 QR Wiesenboden, 8 QR Anger und $1 \mathrm{M} 79$ QR Heide herangezogen.

Die Beiträge zu den verkauften Grundstücken mit 45 ha wurde ähnlich geregelt: Voll-, Halbund Kothöfe trugen 2 bis 6 QR Ackerland, 28 - 71 QR Anger und zwischen 3 und $12 \mathrm{M}$ Heide bei; die Brinksitzer nur 1 oder 4 QR Anger und zwischen 19 und 76 QR Heide sowie die Papierfabrik 3 QR Acker, 46 QR Anger und 7 M 29 QR Heide.

Nachdem alle Abfindungen und Beiträge mit dem eingebrachten privaten Besitz zusammengefasst worden waren, ergab sich für jede Hofstelle das sog. „Soll-Haben“ (Tabelle 4.25 - 1), also der jedem Hof individuell zustehende Anspruch, aufgeteilt nach Ackerland, Wiesen-, Anger- und Heidboden und bewertet nach dem Vergleichsmaß „Kuhweiden“. 


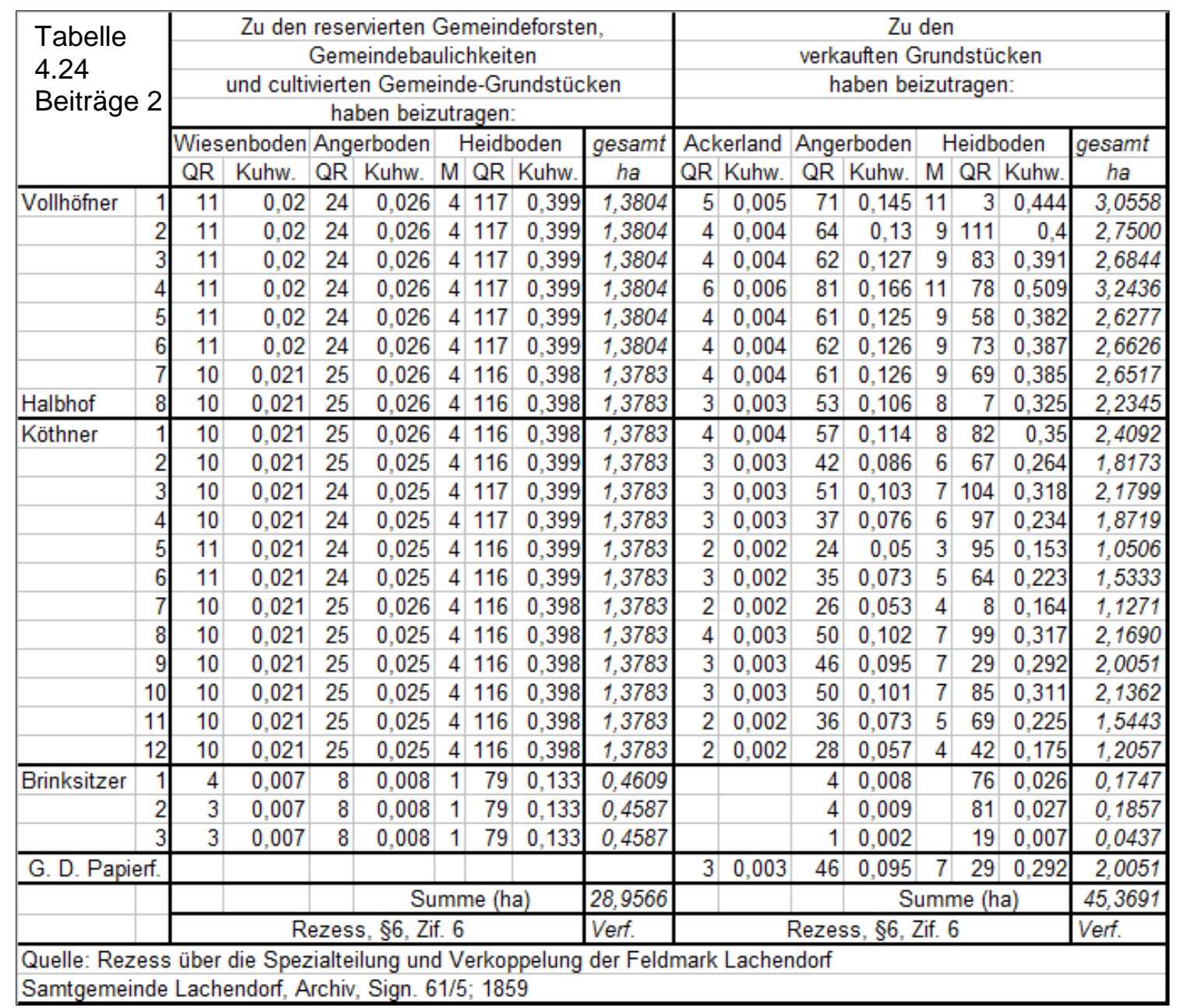

Die dann aufgrund der Spezialteilung und Verkoppelung tatsächlich zugeteilten Flächen (Tabelle $4.25-2$ ) entsprechen bei den einzelnen „Bodenarten“ flächenmäßig dem Soll nicht genau sondern nur größenordnungsmäßig. Der Bewertungsmaßstab in Kuhweiden stimmt aber beim Soll und bei der endgültigen Zuteilung sehr genau überein.

Die sehr genau und sorgfältig vorgenommene Taxation aller Flächen diente also einerseits zur exakten Erfassung des Ist-Zustandes vor den Reformen und zur gerechten Zuteilung durch die Reformen.

Die freiwillige Zustimmung der Bauern war dadurch gesichert, weil sie wertmäßig in ihrem bisherigen Besitz und ihren in Land abgegoltenen Nutzungsrechten nicht beeinträchtigt wurden.

Andererseits blieb durch diese Form der Zuteilung die alte ständische Gliederung in unterschiedliche Hoftypen nicht nur voll erhalten, wurde vielmehr durch den Flächenzuwachs, der sich überwiegend nach der bisherigen Hofgröße bemaß, sogar noch vergrößert.

Schließlich fasst der Rezess für alle Interessenten, die Höfe des Ortes, einige Ausmärker sowie Gemeinden, Kirche, Schule und Papierfabrik das „Soll-Haben“ (Tab. 4.25 - 1) und die endgültige Zuteilung (Tab. 4.25 - 2) aus der Spezialteilung und Verkoppelung der Feldmark tabellarisch zusammen.

Zwar stimmen die Flächen im „Soll“ und im „Haben“ nicht völlig und überall überein, der Wert im „Soll“ und im „Haben“, gemessen in Kuhweiden, differiert aber nur beim Vollhof, Lit.f um 0,03 und beim Vollhof, Lit.a, nur um 1/1000 Kuhweide.

Die Abweichung beim Vollhof, Lit.f, erklärt sich aus den besonderen Besitzverhältnissen bzw. Zuordnungen: Der Besitzer der Papierfabrik hatte bereits vor den Reformen den Vollhof, Lit.f, gekauft. Im „Soll-Haben“ ist dieser Vollhof mit 37,144 Kuhweiden ausgewiesen und Drewsen 
Erben mit 19,062 Kuhweiden, zusammen 56,206 Kuhweiden. Im „Haben“ wird der Drewsensche Vollhof mit 56,176 Kuhweiden ausgewiesen, in denen der Anteil der Papierfabrik bzw. Drewsen Erben enthalten ist.

Die Tabelle $4.25-2$ weist die Papierfabrik nochmals zusätzlich aus, um den Vergleich mit dem „Soll“, beides mit 19,062 Kuhweiden, zu ermöglichen.

\begin{tabular}{|c|c|c|c|c|c|c|c|c|c|c|c|c|c|c|c|c|c|}
\hline \multicolumn{18}{|c|}{ Tabelle 4.25 - 1 - Soll } \\
\hline \multirow{2}{*}{ 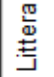 } & \multicolumn{2}{|c|}{ Name der Interessenten } & \multicolumn{3}{|c|}{ Ackerland } & \multicolumn{3}{|c|}{ Wiesenboden } & \multicolumn{3}{|c|}{ Angerboden } & \multicolumn{3}{|c|}{ Heidboden } & \multicolumn{3}{|c|}{ In Allem } \\
\hline & & & M & QR & Kuhw. & $\mathrm{M}$ & QR & Kuhw. & $\mathrm{M}$ & QR & Kuhw. & M & QR & Kuhw. & M & QR & Kuhw. \\
\hline $\bar{a}$ & Vollhöfner & Lüßmann & 144 & 61 & 28,397 & & 1110 & 0,754 & 20 & 7 & 3,756 & 185 & 77 & 9,728 & 352 & 215 & 42,635 \\
\hline b & - & Meyer & 97 & 85 & 19,221 & 11 & 128 & 3,144 & 20 & 115 & 3,854 & 172 & 32 & 9,317 & 302 & 20 & 35,536 \\
\hline c & - & Kohlmeyer & 121 & 1 & 21,937 & 1 & 2 & 0,394 & 17 & 63 & 3,293 & 164 & 93 & 8,594 & 304 & 39 & 34,218 \\
\hline $\mathrm{d}$ & - & Thies /Bock & 154 & 72 & 27,614 & 12 & 4 & 4,274 & 23 & 24 & 4,316 & 209 & 114 & 11,060 & 399 & 94 & 47,264 \\
\hline e & - & Bergmann & 109 & 60 & 18,882 & 5 & 59 & 2,689 & 18 & 41 & 3,452 & 165 & 32 & 8,871 & 298 & 72 & 33,894 \\
\hline$f$ & - & Drewsen & 121 & 55 & 22,902 & 3 & 92 & 1,625 & 18 & 57 & 3,459 & 167 & 75 & 9,128 & 311 & 39 & 37,114 \\
\hline$g$ & - & Schumeyer & 119 & 47 & 22,409 & 16 & 89 & 5,437 & 20 & 46 & 3,856 & 161 & 74 & 8,363 & 318 & 16 & 40,065 \\
\hline $\mathrm{h}$ & Halbmeier & Schöndube & 92 & 117 & 20,049 & 4 & 4100 & 1,545 & 16 & 111 & 3,132 & 143 & 109 & 7,505 & 258 & 77 & 32,231 \\
\hline i & Köthner & Thies & 105 & 49 & 18,438 & 9 & \begin{tabular}{|c|}
960 \\
9
\end{tabular} & 4,000 & 22 & 73 & 4,313 & 150 & 110 & 7,846 & 288 & 52 & 34,597 \\
\hline$k$ & - & Bunkenburg & 75 & 93 & 11,903 & 4 & 77 & 1,937 & 15 & 72 & 2,843 & 128 & 67 & 6,770 & 224 & 69 & 23,453 \\
\hline I & - & J. H. Dralle & 99 & 29 & 14,721 & 10 & 107 & 3,824 & 17 & 112 & 3,261 & 144 & 21 & 7,610 & 272 & 29 & 29,416 \\
\hline $\mathrm{m}$ & - & C. H. Dralle & 71 & 57 & 9,854 & 4 & 43 & 1,638 & 13 & 57 & 2,490 & 114 & 104 & 6,419 & 204 & 21 & 20,401 \\
\hline$n$ & - & Bühring & 50 & 1 & 5,092 & & 51 & 0,170 & 9 & 87 & 1,798 & 85 & 60 & 4,517 & 145 & 79 & 11,577 \\
\hline 0 & - & Thies (Krüger) & 59 & 22 & 11,719 & 88 & 70 & 4,019 & 12 & 59 & 2,338 & 117 & 21 & 6,831 & 197 & 52 & 24,907 \\
\hline$p$ & - & Schwägermann & 41 & 52 & 8,092 & 1 & 1 & 0,367 & 10 & 59 & 1,923 & 88 & 67 & 4,683 & 141 & 59 & 15,065 \\
\hline$q$ & - & Thies (Theis) & 103 & 110 & 19,819 & 2 & 90 & 1,163 & 15 & 74 & 2,907 & 140 & 114 & 7,328 & 263 & 28 & 31,217 \\
\hline r & - & Thies (Graue) & 78 & 88 & 16,296 & 9 & 21 & 4,208 & 14 & 48 & 2,639 & 129 & 38 & 6,726 & 231 & 75 & 29,869 \\
\hline s & - & C. H. Koch & 94 & 67 & 17,147 & 7 & 1 & 3,376 & 20 & 47 & 3,629 & 137 & 89 & 7,150 & 259 & \begin{tabular}{|l|l|}
9 & 84
\end{tabular} & 31,302 \\
\hline$t$ & - & Hermanns & 63 & 58 & 9,499 & 7 & & 3,415 & 12 & 114 & 2,422 & 108 & 54 & 5,708 & 191 & 1106 & 21,044 \\
\hline u & - & Misselhorn & 51 & 115 & 5,516 & & 59 & 0,191 & 10 & 62 & 1,953 & 99 & 100 & 5,328 & 162 & 296 & 12,988 \\
\hline $\mathrm{v}$ & Brinksitzer & Wulf & 9 & 83 & 2,688 & & 8 & 0,0 & 4 & 13 & 0,745 & 41 & 63 & 242 & 55 & 47 & 5,706 \\
\hline w & - & Lüßmann & 17 & 1 & 4,443 & & 45 & 0,132 & 4 & 43 & 0,785 & 41 & 71 & 2,242 & 63 & 40 & 7,602 \\
\hline$x$ & - & Lilie & 3 & 81 & 0,780 & & 5 & 0,015 & 3 & 68 & 0,639 & 35 & 40 & 1,930 & 42 & 74 & 3,364 \\
\hline$y$ & - & Thies & 6 & 19 & 1,778 & & & & 3 & 28 & 0,589 & 34 & 35 & 1,867 & 43 & 82 & 4,234 \\
\hline$z$ & Abbauer & Meyer & 15 & 73 & 3,326 & & 10 & 0,028 & 3 & 57 & & 36 & 68 & & 55 & 38 & $\overline{013}$ \\
\hline aa & Anbauer & Bergman & & 30 & 0,071 & & & & 2 & 66 & & 27 & 77 & & 30 & & 058 \\
\hline $\mathrm{bb}$ & - & Knoop & 26 & 116 & 5,886 & & & & 4 & 87 & 0,562 & 42 & 92 & 2,297 & 74 & 55 & 9,045 \\
\hline $\mathrm{cc}$ & - & Herbold & 2 & 42 & 0,123 & & & & 2 & 55 & 0,436 & 28 & 29 & 1,560 & 33 & & 2,119 \\
\hline dd & Abbauer & Meyer & 3 & 82 & 0,771 & & & & & 88 & 0,133 & 4 & 95 & 244 & 9 & 25 & 1,148 \\
\hline ee & - & Ramberg & 1 & 116 & 0,369 & & & & & 115 & 0,188 & 1 & 25 & 0,061 & 4 & 16 & 0,618 \\
\hline ff & - & Walter & 1 & 109 & 0,380 & & & & & 86 & 0,126 & 2 & 50 & 0,123 & 5 & 5 & 0,629 \\
\hline gg & - & Ahrens & 1 & 63 & 0,170 & & & & & 33 & 0,036 & & 73 & 0,031 & 2 & 49 & 0,237 \\
\hline hh & $=$ & Suderburg & 1 & 88 & 0,172 & & & & & 45 & 0,036 & & 48 & 0,049 & 2 & 61 & 0,257 \\
\hline ii & - & Hr. Lilie & 2 & 25 & 0,155 & & & & & 25 & 0,029 & & 73 & 0,031 & 3 & 3 & 0,215 \\
\hline$\|$ & - & Thölke & 1 & 88 & 0,193 & & & & & 39 & 0,043 & 2 & 1 & 0,201 & 4 & 8 & 0,437 \\
\hline $\mathrm{mm}$ & - & Hr. Koch & & & & & & & & 96 & 0,133 & & & & & 96 & 0,133 \\
\hline $\mathrm{nn}$ & Hirte & J. H. Meyer & 5 & 108 & 1,639 & & & & & 45 & 0,072 & 3 & 76 & 0,184 & 9 & 9109 & 1,895 \\
\hline 00 & Häusling & Meyer Erben & 6 & 30 & 1,756 & & & & & 45 & 0,072 & 3 & 76 & 0,184 & 10 & $\begin{array}{l}31 \\
0\end{array}$ & 2,042 \\
\hline v v & Abbauer & Graue & 1 & 32 & 0,135 & & & & & 34 & 0,032 & & & & 1 & 66 & 0,167 \\
\hline $\mathrm{pp}$ & \multicolumn{2}{|c|}{ G. Drewsen Erben } & 18 & 111 & 5,610 & & 82 & 0,345 & 16 & 114 & 2,974 & 168 & 79 & 10,133 & 205 & 26 & 19,062 \\
\hline S & \multicolumn{2}{|c|}{ Schule Lachendorf } & & 118 & 0,270 & & & & 4 & 110 & 0,879 & 48 & 34 & 2,594 & 54 & 22 & 3,743 \\
\hline$\overline{\mathrm{K}}$ & \multicolumn{2}{|c|}{ Kirche Beedenbostel } & 5 & 99 & 1,235 & & & & & & & & & & 5 & 99 & 1,235 \\
\hline $\mathrm{rr}$ & \multicolumn{2}{|c|}{ Vollh.Veth, Gockenholz } & 3 & 72 & 0,946 & & & & & & & & 113 & 0,135 & 4 & 65 & 1,081 \\
\hline ss & \multicolumn{2}{|c|}{ Vollh. Schumeier, dort } & 8 & 105 & 2,301 & & & & & & & & & & 8 & 105 & 2,301 \\
\hline tt & \multicolumn{2}{|c|}{ Vollh. Thies, Höfer } & & & & 2 & 114 & 1,180 & & & & & & & 2 & 2114 & 1,180 \\
\hline uu & Vollh. Miss & selhorn, Gock. & & & & 1 & 93 & 0,312 & & & & & 26 & 0,031 & 1 & 1119 & 0,343 \\
\hline & Kloster Wie & enhausen & & & & & & & & & & & 3 & 0,001 & & 3 & 0,001 \\
\hline GG & Gemeinde & Gockenholz & & 98 & 0,231 & & & & & & & & & & & 98 & 0,231 \\
\hline & rechner.t & Kontrolle & & & 364,965 & & & 50,213 & & & 71,532 & & & 179,179 & & & 665,889 \\
\hline Orig & ginal) Summ & e Summarum & 2005 & 28 & 364,965 & 128 & 101 & 50,213 & 387 & 100 & 71,532 & 3342 & 58 & 179,179 & 5864 & 47 & 665,889 \\
\hline
\end{tabular}


Tabelle 4.25-2:

Ergebnis der Spezialteilung und Verkoppelung in der Feldmark Lachendorf

\begin{tabular}{|c|c|c|c|c|c|c|c|c|c|c|c|c|c|c|c|c|}
\hline \multicolumn{17}{|c|}{ Rezess über die Spezialteilung und Verkoppelung der Feldmark Lachendorf } \\
\hline \multicolumn{17}{|c|}{ Verteilungs-Register von der Feldmark Lachendorf } \\
\hline \multirow[t]{2}{*}{ Littera } & & \multicolumn{3}{|c|}{ Ackerland } & \multicolumn{3}{|c|}{ Wiesenboden } & \multicolumn{3}{|c|}{ Angerboden } & \multicolumn{3}{|c|}{ Heidboden } & \multicolumn{3}{|c|}{ Summe } \\
\hline & & M & QR & Kuhw. & M & QR & Kuhw. & M & QR & Kuhw. & M & QR & Kuhw. & M & QR & Kuhw. \\
\hline $\bar{a}$ & Vollhöfner & 150 & 86 & 28,718 & & & & 16 & 27 & 3,153 & 181 & 51 & 10,765 & 348 & 44 & 42,636 \\
\hline b & & 93 & 101 & 17,707 & 13 & 5 & 3,687 & 20 & 86 & 3,621 & 142 & 100 & 10,521 & 270 & 52 & 35,536 \\
\hline c & & 132 & 91 & 23,995 & & & & 24 & 107 & 4,535 & 96 & 13 & 5,688 & 253 & 91 & 34,218 \\
\hline d & & 181 & 11 & 30,359 & 16 & 5 & 5,479 & 19 & 75 & 2,592 & 179 & 27 & 8,834 & 395 & 118 & 47,264 \\
\hline e & & 104 & 94 & 17,657 & 5 & 2 & 2,615 & 23 & 103 & 4,444 & 188 & 18 & 9,178 & 321 & 97 & 33,894 \\
\hline$f$ & & 92 & 15 & 23,416 & 2 & 62 & 1,269 & 12 & 100 & 1,989 & 521 & 25 & 29,502 & 628 & 82 & 56,176 \\
\hline g & & 112 & 71 & 20,047 & 18 & 56 & 5,903 & 36 & 112 & 5,435 & 179 & 42 & 8,680 & 347 & 41 & 40,065 \\
\hline $\mathrm{h}$ & Halbhof & 89 & 101 & 19,318 & 2 & 116 & 1,402 & 24 & 6 & 4,996 & 122 & 76 & 6,515 & 239 & 59 & 32,231 \\
\hline i & Kötner & 107 & 95 & 20,651 & 9 & 30 & 4,087 & 19 & 14 & 3,991 & 116 & 37 & 5,868 & 252 & 56 & 34,597 \\
\hline$k$ & & 112 & 13 & 14,969 & 6 & 1 & 1,879 & 4 & 104 & 1,118 & 108 & 34 & 5,487 & 231 & 32 & 23,453 \\
\hline I & & 94 & 20 & 16,125 & 13 & 83 & 4,696 & 11 & 42 & 2,006 & 125 & 104 & 6,589 & 245 & 9 & 29,416 \\
\hline $\mathrm{m}$ & & 71 & 2 & 10,820 & 4 & 43 & 1,624 & 9 & 1 & 1,610 & 113 & 55 & 6,347 & 197 & 101 & 20,401 \\
\hline $\mathrm{n}$ & & 42 & 114 & 6,246 & & & & 13 & 13 & 2,175 & 66 & 63 & 3,156 & 122 & 70 & 11,577 \\
\hline 0 & & 64 & 25 & 10,887 & 9 & 63 & 4,576 & 5 & 57 & 1,052 & 116 & 59 & 8,392 & 195 & 84 & 24,907 \\
\hline p & & 38 & 93 & 7,833 & & 8 & 0,022 & 11 & 54 & 2,704 & 94 & 95 & 4,506 & 145 & 10 & 15,065 \\
\hline q & & 101 & 38 & 17,756 & 1 & 72 & 0,741 & 14 & 46 & 3,347 & 171 & 97 & 9,373 & 289 & 13 & 31,217 \\
\hline r & & 84 & 15 & 16,338 & 8 & 68 & 4,000 & 22 & 80 & 4,920 & 99 & 59 & 4,611 & 214 & 102 & 29,869 \\
\hline s & & 91 & 102 & 16,957 & 5 & 12 & 2,914 & 29 & 112 & 4,801 & 134 & 98 & 6,630 & 261 & 84 & 1,302 \\
\hline$t$ & & 61 & 82 & 9,546 & 7 & 58 & 3,688 & 6 & 112 & 1,448 & 133 & 2 & 6,362 & 209 & 14 & 21,044 \\
\hline $\mathrm{u}$ & & 46 & 101 & 5,142 & & & & 8 & 49 & 1,754 & 123 & 111 & 6,092 & 179 & 21 & 12,988 \\
\hline $\bar{v}$ & Brinksitzer & 10 & 17 & 2,790 & & & & 11 & 99 & 1,873 & 21 & 118 & 1,043 & 43 & 114 & 5,706 \\
\hline w & & 17 & 113 & 4,233 & & & & 8 & 104 & 1,451 & 40 & 38 & 1,918 & 67 & 15 & 7,602 \\
\hline $\mathrm{x}$ & & 5 & 40 & 1,116 & & & & 3 & 27 & 1,041 & 23 & 38 & 1,207 & 31 & 105 & 3,364 \\
\hline$y$ & Anbauern & 6 & 72 & 1,663 & & & & 4 & 51 & 0,720 & 39 & 1 & 1,851 & 50 & 4 & 4,234 \\
\hline$z$ & & 13 & 5 & 2,817 & & 50 & 0,139 & 7 & 4 & 1,655 & 24 & 76 & 1,402 & 45 & 15 & 6,013 \\
\hline aa & & & 82 & 0,228 & & & & 2 & 110 & 0,480 & 30 & 27 & 1,350 & 33 & 99 & 2,058 \\
\hline bb & & 23 & 77 & 5,637 & & & & 2 & 76 & 0,575 & 60 & 59 & 2,833 & 86 & 92 & 9,045 \\
\hline $\mathrm{CC}$ & & & 29 & 0,020 & & & & 2 & 58 & 0,452 & 35 & 41 & 1,647 & 38 & 8 & 2,119 \\
\hline$\overline{d d}$ & Abba & 4 & $\overline{17}$ & 0,862 & & & & 1 & 37 & 0,229 & & 116 & 0,057 & 6 & 50 & 1,148 \\
\hline ee & & 1 & 94 & 0,373 & & & & & 96 & 0,133 & 2 & 24 & 0,112 & 4 & 94 & 0,618 \\
\hline ff & & 1 & 109 & 0,364 & & & & 1 & 15 & 0,207 & & 105 & 0,058 & 3 & 109 & 0,629 \\
\hline$g g$ & & 1 & 56 & 0,163 & & & & & 26 & 0,024 & 1 & 6 & 0,050 & 2 & 88 & 0,237 \\
\hline $\mathrm{hh}$ & & 1 & 91 & 0,169 & & & & & 45 & 0,036 & & 65 & 0,052 & 2 & 81 & 0,257 \\
\hline ii & & 2 & 9 & 0,197 & & & & & 18 & 0,017 & & 1 & 0,001 & 2 & 28 & 0,215 \\
\hline$\|$ & & 1 & 100 & 0,207 & & & & & 24 & 0,019 & 3 & 84 & 0,211 & 5 & 88 & 0,437 \\
\hline $\mathrm{mm}$ & & & & & & & & & 96 & 0,133 & & & & & 96 & 0,133 \\
\hline $\mathrm{nn}$ & Hirte & 5 & 92 & 1,596 & & & & & 117 & 0,195 & 1 & 59 & 0,104 & 8 & 28 & 1,895 \\
\hline 00 & Häusling & 6 & 30 & 1,786 & & & & & & & 6 & 50 & 0,256 & 12 & 80 & 2,042 \\
\hline w & Abbauer & 1 & 25 & 0,130 & & & & & 34 & 0,031 & & 7 & 0,006 & 1 & 66 & 0,167 \\
\hline $\mathrm{pp}$ & Papierfabrik & & & & & & & & & & & & & & & 0,000 \\
\hline S & Schule zu L. & 6 & 32 & 1,534 & & & & 2 & 19 & 0,513 & 32 & 50 & 1,696 & 40 & 101 & 3,743 \\
\hline G & Gemeinde L. & 70 & 109 & 11,407 & & 64 & 0,177 & 27 & 78 & 5,387 & 165 & 116 & 10,143 & 265 & 7 & 27,114 \\
\hline $\bar{K}$ & Kirche zu Beed. & 6 & 76 & 1,172 & & & & & & & & 68 & 0,063 & 7 & 24 & 1,235 \\
\hline rr & Veth, Gockenhol & 3 & 14 & 0,906 & & & & & 17 & 0,040 & & 113 & 0,135 & 4 & 24 & 1,081 \\
\hline ss & Schumeier, das. & 8 & & 2,284 & & & & & 7 & 0,017 & & & & 8 & 7 & 2,301 \\
\hline $\mathrm{tt}$ & Thies, Höfer & & & & 2 & 114 & 1,180 & & & & & & & 2 & 114 & 1,180 \\
\hline uu & Misselhorn, Gock & enholz & & & 1 & 93 & 0,312 & & & & & 26 & 0,031 & 1 & 119 & 0,343 \\
\hline ww & Gemeinde Gock. & & 98 & 0,231 & & & & & & & & & & & 9 & 0,231 \\
\hline & Gemeinde & & 71 & 0,069 & 1 & 98 & 0,435 & 13 & 6 & \begin{tabular}{|l|}
2,682 \\
\end{tabular} & 268 & 13 & 14,971 & 283 & 68 & 18,157 \\
\hline & Summe & 2076 & 88 & 376,441 & 131 & 23 & 50,825 & 428 & 64 & 79,601 & 3776 & 67 & 204,293 & 6413 & 2 & 711,160 \\
\hline & Papierfabrik & 18 & 4 & 4,512 & 2 & 62 & 1,269 & 9 & 23 & 1,326 & 181 & 57 & 11,955 & & & 19,062 \\
\hline
\end{tabular}




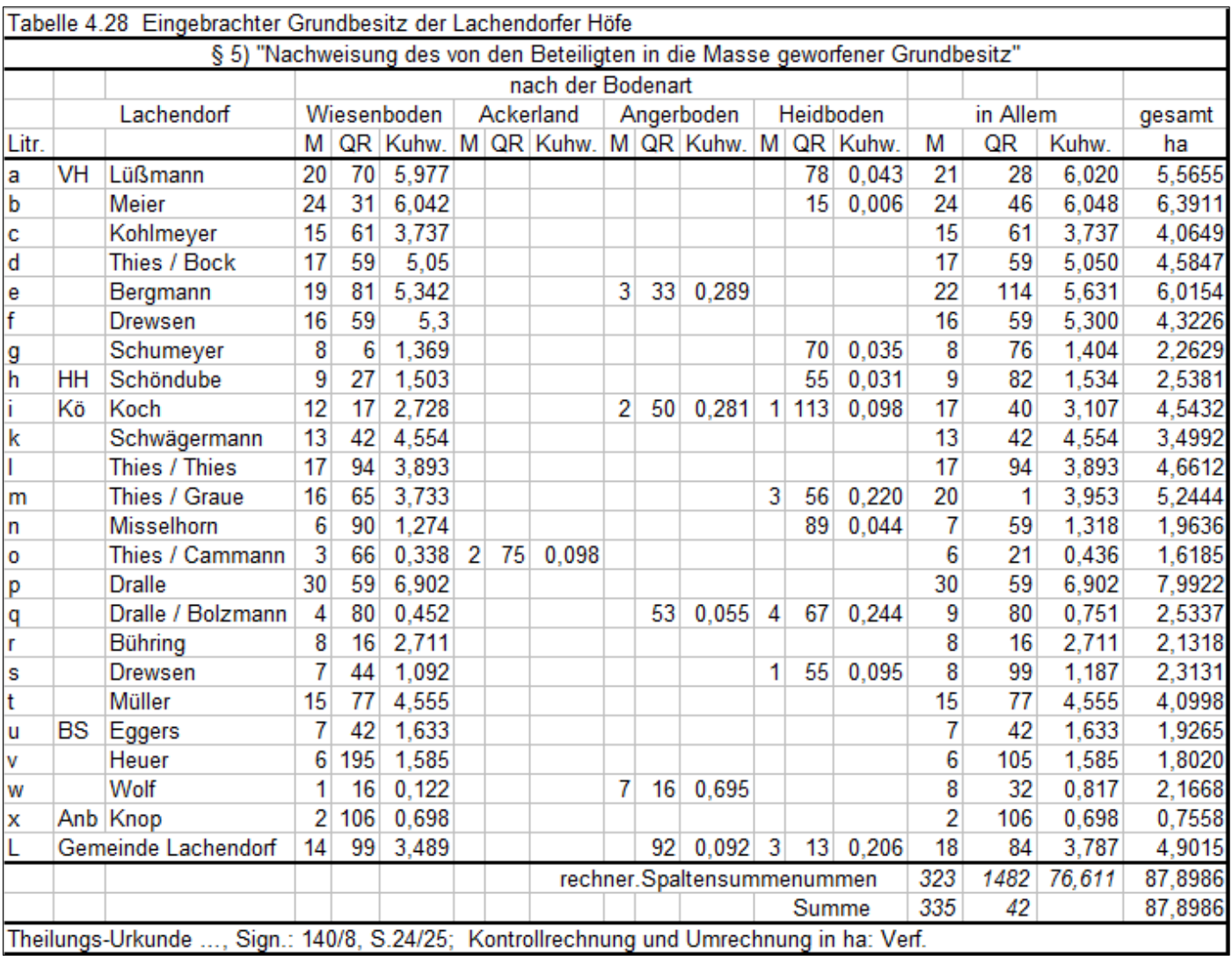

Die Flächenangaben zum Gesamtgebiet belegen die absolute Dominanz des Grünlandes in diesem Gebiet.

Wegen der hohen Bedeutung dieses Wiesengebietes für die Futterversorgung des Nutzviehs und die große Zahl der Interessenten war dieses Verfahren für die beteiligten Bauern von sehr großer, teils existentieller Bedeutung und außerordentlich schwierig und komplex.

Über die unterschiedlichen Rechte und Interessen, die zu regeln und abzufinden waren, geben die folgende Tabelle und Auszüge aus der Teilungs-Urkunde beredte Auskunft:

Aus dem Rezess zur Entfrettung und Verkoppelung der Aller- und Trockenen Wiesen; $§ 4^{1}$ „Feststellung der Berechtigungen und Ermittlung der hierfür zustehenden Entschädigungen“. „Die bei vorliegender Verkoppelung zu berücksichtigenden Nutzungsrechte der Interessenten bestehen in der Nutzung der privaten Grundstücke mit Ausschluss der Vor- und Nachweide.

Die gemeinschaftliche Weide ist von Eingesessenen der Dorfschaften Lachendorf, Oppershausen und Nordburg ausgeübt.

Teilungsmaßstab.

A. Private Grundstücke

Die privaten Grundstücke werden den einzelnen Interessenten nach Abzug des Weideäquivalents, also servitutsfrei, wie solches der folgende $\S$ nachweiset, jedoch unter Berücksichtigung der nachstehenden, während des Verfahrens eingetretenen Besitzstandsveränderungen zurück gegeben.

Theilungs-Urkunde (Abschrift) über die Entfrettung und Verkoppelung der Aller- und trockenen Wiesen bei Lachendorf, Amt Celle

${ }^{1}$ ebd. S. $13 \mathrm{ff}$. 
1. Die Köthner Wegener und Müller in Höfer haben ihr gemeinschaftliches Grundstück in den trockenen Wiesen, No. 22 und 23 der Karte, an den Brinksitzer Wolf in Lachendorf verkauft.

2. Der dem Köthner Carst. Hrch. Dralle in Lachendorf irtümlich angerechnete Gemeinheitsanschnitt gehört dem Köthner Carst. Hrch. Koch zu Lachendorf und ist letzterem zugesetzt.

B. Gemeindegrundstücke

An den Gemeindewiesen der Dorfschaft Lachendorf partizipieren die 7 Vollhöfe, 1 Halbhof und die 12 Köthner jeder mit einem vollen Teile, die 3 Brinksitzer aber jeder nur mit 1/3 Teil.

Die Gemeindewiesen der Dorfschaft Oppershausen werden nach demselben Verhältnis verteilt nach welchem das Weideäquivalent der Dorfschaft Oppershausen zur speziellen Verteilung kommt, also mit letzterem zusammen.

C. Generelle Auseinandersetzung des Weideäquivalents.

Von dem ganzen Weideäquivalent ist die Weidequote der Meyerschen Erben in Schwachhausen abzusetzen, da diese Wiese als weidefrei anerkannt ist.

canfr. No. actar: 120

Das übrige Weideäquivalent, nachdem davon die Anteile der Gutsbesitzer Lüßmann und Schumeyer in Lachendorf von dem Weideäquivalente von der Bunkenburgschen Wies in Absatz gebracht sind, gehört den 3 berechtigten Ortschaften Nordburg, Oppershausen und Lachendorf zu gleichen Teilen, jedoch hat die Dorfschaft Oppershausen die Gemeinde Nordburg von dem Weideäquivalent auf einer begrenzten Fläche mit 2/9 derselben abzufinden.

D. Spezielle Auseinandersetzung der Weideäquivalente.

1. Von dem Weideäquivalent der Dorfschaft Lachendorf erhalten die 20 Reihestellen, die 3 Brinksitzer und die Schule jede als Zusatz zu dem bei der Privatteilung ausgeworfenen Haushaltsbedürfnisse nachbargleich 60 QR: 0,136 Kuhw. und die 5 Anbauern in Lachendorf jeder 20 QR: 0,045 Kuhw..

Der Rest des Weideäquivalents wird unter allen Interessenten, den Vollhöfnern, Halbhöfner, Köthner, Brinksitzer, Anbauern und der Schule nach dem bei der Privatteilung vereinbartem Simplas, wobei für die Schule 12 Simplas angenommen sind, verteilt."

\begin{tabular}{|c|c|c|c|c|c|c|c|c|c|c|c|c|c|}
\hline & & § 5) Nach & 15 & ng 0 & von de & en Beteil & iligt & die Masse $\mathrm{g}$ & worfener Grun & bes & sitz & & \\
\hline & & & & & lle Inter & essente & en oh & ne Lachendorf & & & & & \\
\hline & & & & & Allem & & & & & & & in Allem & \\
\hline Litr. & Ort & Höfe & M & $Q R$ & ha & Kuhw. & Litr. & Ort & Höfe & M & QR & ha & Kuhw. \\
\hline aa & Oppershausen & Gut & 14 & 61 & 3,803 & 3,044 & $\mathrm{ca}$ & Gockenholz & Vollhöfner & 12 & 59 & 3,274 & 3,286 \\
\hline$a b$ & & Vollhöfner & 7 & 22 & 1,883 & 3,120 & $\mathrm{cb}$ & & & 7 & 50 & 1,944 & 1,506 \\
\hline ac & & Halbhof & 8 & 82 & 2,276 & 2,302 & $\mathrm{cc}$ & & & 15 & 101 & 4,152 & 4,684 \\
\hline ad & & Köthner & 13 & 64 & 3,547 & 5,171 & da & Ohe & & 3 & 61 & 0,920 & 1,589 \\
\hline ae & & & 6 & 91 & 1,771 & 1,057 & $\mathrm{db}$ & & & 5 & 4 & 1,319 & 1,993 \\
\hline af & & & 11 & 2 & 2,888 & 3,860 & ea & Rebberlah & & 14 & 72 & 3,827 & 5,768 \\
\hline ag & & & 4 & 37 & 1,129 & 0,782 & $\mathrm{eb}$ & & & 12 & 60 & 3,276 & 4,694 \\
\hline ah & & & 7 & 105 & 2,064 & 2,170 & ec & & & 8 & 78 & 2,267 & 2,816 \\
\hline ai & & & 4 & 61 & 1,182 & 2,057 & $\mathrm{fa}$ & Habighorst & Gut & 6 & 36 & 1,651 & 1,373 \\
\hline ak & & & 2 & 14 & 0,555 & 1,452 & $\mathrm{fb}$ & & Vollhöfner & 3 & 47 & 0,889 & 1,392 \\
\hline al & & & 4 & 82 & 1,228 & 0,470 & fc & & & & 90 & 0,197 & 0,283 \\
\hline $\mathrm{am}$ & & Altenteiler & 9 & 29 & 2,422 & 1,119 & ga & Eschede & & 3 & 88 & 0,979 & 1,769 \\
\hline $\mathrm{O}$ & & Gemeinde & 4 & 74 & 1,210 & 1,042 & ha & Kragen & & 2 & 96 & 0,734 & 1,202 \\
\hline ba & Beedenbostel & Köthner & 7 & 96 & 2,044 & 2,155 & ia & Jarnsen & Vollhöfner & 6 & 111 & 1,815 & 2,069 \\
\hline bb & & & 7 & 69 & 1,985 & 1,991 & la & Bunkenburg & Vollhöfner & 10 & 113 & 2,868 & 4,568 \\
\hline bc & & & 9 & 49 & 2,466 & 2,653 & $\mathrm{ma}$ & Ahnsbeck & & 8 & 61 & 2,230 & 2,436 \\
\hline bd & & & 6 & 92 & 1,774 & 2,033 & $\mathrm{mb}$ & & Brinksitzer & 4 & 46 & 1,149 & 1,528 \\
\hline be & & & 6 & 55 & 1,693 & 1,547 & et & & Gemeinde & 1 & 17 & 0,299 & 0,174 \\
\hline bf & & & 5 & 39 & 1,396 & 1,186 & na & Schwachhausen & Gut & 6 & 111 & 1,815 & 1,900 \\
\hline bg & & & 7 & 40 & 1,922 & 2,422 & $n b$ & & Köthner & 9 & 37 & 2,440 & 0,495 \\
\hline bh & & & 9 & 70 & 2,512 & 2,518 & $\mathrm{nc}$ & & & 1 & 73 & 0,422 & 0,242 \\
\hline bi & & & 6 & 45 & 1,671 & 1,532 & oa & Wienhausen & & 5 & 72 & 1,468 & 3,431 \\
\hline bk & & & 9 & 23 & 2,409 & 3,169 & pa & Offensen & & 2 & 102 & 0,747 & 0,569 \\
\hline bl & & & 4 & 72 & 1,206 & 1,384 & $\mathrm{pb}$ & & & 2 & 45 & 0,623 & 1,057 \\
\hline bm & & & 10 & 6 & 2,634 & 2,138 & $\mathrm{pc}$ & & & 2 & 90 & 0,721 & 0,156 \\
\hline bn & & & 5 & 72 & 1,468 & 1,986 & qa & Nordburg & Brinksitzer & 6 & 90 & 1,769 & 2,262 \\
\hline bo & & & 9 & 118 & 2,617 & 2,710 & D & Königl. Finanzmi & isterium & 30 & 44 & 7,959 & 8,044 \\
\hline bp & & & 2 & 112 & 0,769 & 0,861 & G & Gemeinsch. Räu & me und Wes & 3 & 17 & 0,823 & 0,358 \\
\hline $\mathrm{bq}$ & & die Kirche & 5 & 4 & 1,319 & 1,649 & G & Das Weideä & quivalent & 124 & 58 & 32,628 & 34,030 \\
\hline & & & & & & & & & & sges: & amt: & 141,048 & 155,254 \\
\hline
\end{tabular}


Detaillierte Regelungen vermittelt ein Auszug aus $\S 4^{1}$ :

„Die zur Correction des Schwarzwassers abgetretenen, in der Abfindunsgberechnung speziell aufgeführten Grundstücke, werden nicht in Grund und Boden, sondern durch die SchwarzwasserCommission in Geld vergütet.

Zu den neuen Wegen und Gräben und gemeinschaftlich reservierten Räumen werden die alten, im Taxationsregister verzeichneten Wege und Gräben und die von der Gemeinde Lachendorf in die gemeinschaftliche Masse geworfenen alten Wege, vewandt, und wird die mehr erforderliche Fläche auf die sämtlichen Interessenten der Aller- und trockenen Wiesen, mit Ausschluss der behufs Grenzregulierung und Vertauschung herangezogenen, oder in anderen Feldmarken zu den Wegen pp. Beitragspflichtigen Grundstücke, nach Verhältniß des Werts der Abfindungen repartirt.

Die vom Wegebeitrag befreiten Grundstücke sind in der Abfindungsberechnung speziell aufgeführt. Auf Grundlage des vorstehend beschriebenen Teilungsmaßstabes und des Taxationsregisters ist die einem jeden Interessenten planmäßig gebührende Abfindung in der Auseinandersetzungsberechnung festgestellt."

Beleg für die Begradigung - Correction - des Schwarzwassers aus $\S 6 .^{2}$

Nachweisung der zur Correction des Schwarzwasserflusses abgetretenen Grundstücke

Diese Flächen wurden nicht in Grund und Boden sondern in Geld entschädigt

1. Köthner Veth (Schwägermann), Lachendorf, Wiesenboden; Litr. $k 11$ QR, 0,073 Kuhw.

2. v.d. Wense, Gut in Oppershausen, Wiesenboden, Litr. aa 16 QR; 0,089 Kuhw.

3. v.d. Wense, Halbhöfnerstelle, Oppershausen, Wiesenboden, Litr. af 39 QR; 0,260 Kuhw.

4. Köthner Denecke, Oppershausen, Wiesenboden, Litr. ai

5. Köthner Kammann, Oppershausen, Wiesenboden, Litr. ak

32 QR; 0,142 Kuhw.

6. Köthner Giese, Wienhausen, Wiesenboden, Litr. ca

7. Vollhöfner v.d. Ohe, Rebberlah, Wiesenboden, Litr. ea

8. Das Domänium, Wiesenboden, Litr. D

Summe:

9 QR; 0,060 Kuhw.

27 QR; 0,104 Kuhw.

56 QR; 0,368 Kuhw.

6 QR; 0,040 Kuhw.

Überhaupt: 1 M 76 QR; 1,136 Kuhw.

Regelungen für Grenzabstände bei Bebauung und für Bepflanzungen: ${ }^{3}$

1. Grenzabstand bei Bebauung von 1 Ruthe $(R)$ zur Koppelgrenze und $1 / 2 R$ an Wegen; aber $2 R$, wenn Nachbargrundstück in den Mittagsschatten gerät.

2. Abgrabungen und Vertiefungen müssen Grenzabstand von 3 Fuß einhalten.

3. Hochstämmige Bäume müssen 16 Fuß Grenzabstand zu Koppeln, 4 Fuß zu Wegen einhalten. ”, Obstbäume und Schlaghölzer, so wie Bäume, welche alle Jahre gekappt werden, können 6 Fuß von den Grenzen der Koppeln angepflanzt werden."

Überhängende Zweige müssen entfernt werden.

Bäume und Buschwerk auf Koppeln, die in andere Hände übergingen, mussten bis zum 1. Mai 1866 weggeräumt sein, sonst fällt es unentgeltlich dem neuen Koppelbesitzer zu.

Diese Regelungen haben sich z.T. bis heute erhalten, z.B. die Regelung über den Grenzabstand groBer Bäume und das Entfernen überhängender Zweige. Also gehen sogar Regelungen unseres Nachbarschaftsrechts in den Siedlungen teilweise bis auf die Agrarreformen des 19. Jahrhunderts zurück,

Regelungen zur Einfriedung von Koppeln in $\$ 15^{4}$ :

Befriedigung der Koppeln

Alle Koppeln werden mit Grenzsteinen markiert.

Es steht jedem frei, seine Koppeln mit „Planken, Stakette, Hecken oder Gräben einseitig einzufriedigen".

In $\S 13^{5}$ wird das endgültige Ziel der Reform festgelegt, nämlich die totale Privatisierung der Grundstücke hinsichtlich der Nutzung und die völlige Aufhebung irgendwelcher gemeinschaftlicher Nutzungsrechte.

„Künftige Benutzung der Abfindungen“

„Die sämtlichen in dem, diesem Rezeß angehängtem Verteilungsregister aufgeführten Grundstücke, sind durch Abstellung der Weide und sonstigen Servitute privatives Eigentum der Beteiligten gewor-

\footnotetext{
${ }^{1}$ Teilungs-Urkunde, S. $20 \mathrm{ff}$

${ }^{2}$ Teilungs-Urkunde, S. $28 \mathrm{f}$.

${ }^{3}$ Teilungs-Urkunde, S. $47 \mathrm{f}$

${ }^{4}$ Teilungs-Urkunde, S. $49 \mathrm{f}$

${ }^{5}$ Teilungsurkunde, S. $46 \mathrm{ff}$
} 
den, und werden denselben zur einseitigen privativen Benutzung damit überwiesen, sofern nicht Ausnahmen in diesem Rezeß gemacht sind, und unter nachfolgenden Beschränkungen."

Festlegung der Unabänderlichkeit der Regelungen dieser Reform zum Schluss ${ }^{1}$ :

„Da der Zweck dieser Teilungsurkunde lediglich auf die Sicherstellung der gegenseitigen Gerechtsame und Verpflichtungen, so wie aller aus dieser Verkoppelung hervorgegangenen Einrichtungen gerichtet ist, so haben alle Teilnehmer der genausten Befolgung ihres Inhalts zu allen Zeiten unbedingt zu unterwerfen, wobei die künftige Abänderung der rezessmäßigen Bestimmungen durch Verjährung ausgeschlossen sein soll.

Zur Urkunde dessen ist dieser Planrezess nach geschehener Vorlesung von sämtlichen Beteiligten oder deren Vertreter eigenhändig vollzogen worden. ...

So geschehen Lachendorf, den 18. Januar 1866"

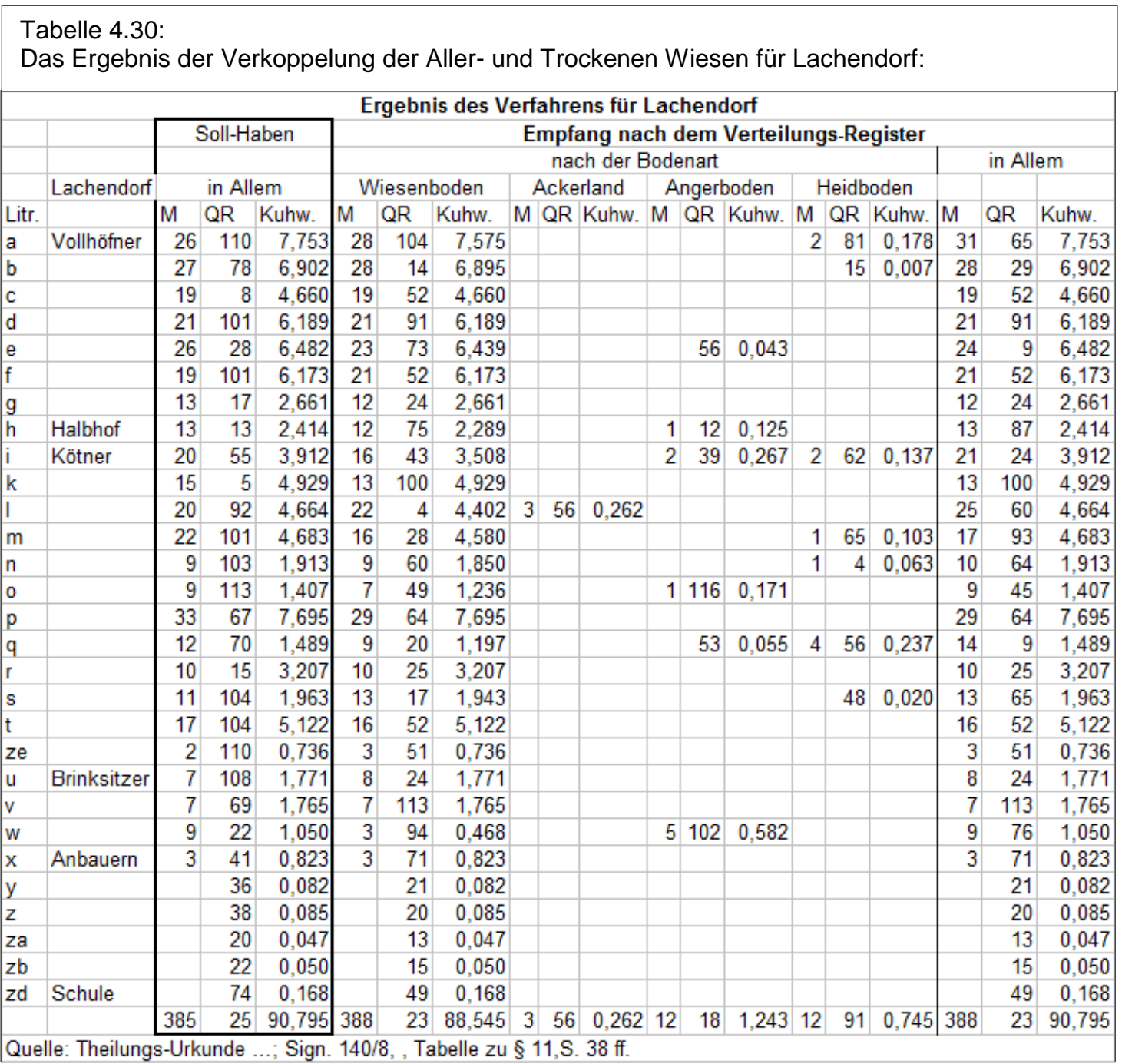

Die Ergebnisse der Reformen werden ausdrücklich gegen eine spätere Revision abgesichert, sie sollten für immer und uneingeschränkt gelten.

Den Reformern und den Interessenten, die den Rezess mit ihrer persönlichen Unterschrift bestätigen mussten, ist die Bedeutung und Endgültigkeit der Rezess-Regelungen sicherlich voll bewusst gewesen. Sie hatten damit die alte Agrarordnung abgeschafft und standen damit vor einer völlig neuen Situation, ihre Höfe zu führen und die Landnutzung völlig eigenständig und eigenverantwortlich zu gestalten.

\footnotetext{
${ }^{1}$ Teilungs-Urkunde, S. 73
} 
Auch in dieser Verteilung zeigt sich die Zweiteilung in Höfner und Kötner einerseits und die kleinen Hofstellen andererseits. Die Brinksitzer bilden auch hier eine Zwischengruppe, die eine Grundausstattung an Wiesenboden erhält. Die 5 Anbauern bekommen bis auf eine Ausnahme weniger als einen Morgen und die $9^{1}$ Abbauern gehen in den Aller- und Trockenen Wiesen ganz leer aus.

Ökonomisches Ziel der Reformen war die Erhaltung bzw. Schaffung leistungsfähiger bäuerlicher Betriebe. Die Zuteilungen entsprachen dem in die Reform eingebrachten privaten Besitz, vergrößert um die Anteile, die sich aus den abgelösten Weide- bzw. Nutzungsrechten und aufgeteilten Gemeinheiten ergaben. Weil die Höfe nicht nur in ihrer alten Substanz erhalten blieben sondern sich vergrößerten und vollständig privater Nutzung unterlagen, war die freiwillige Zustimmung der Bauern gegeben.

\subsubsection{Gesamtergebnis der Teilungen und Verkoppelungen für die Lachendorfer Höfe}

Nach mehr als 2 Jahrzehnten waren die wesentlichen Reformen zur Neuordnung der landwirtschaftlichen Nutzflächen im Jahr 1866 abgeschlossen.

Die Bauern verfügten allein über ihr Nutzland. Weiderechte, Flurzwang und Abgaben waren für alle Zeiten abgelöst. Die alte Agrarordnung war damit unwiderruflich beseitigt.

Mit dem Endergebnis der neuen Landzuteilung gingen die Höfe in eine neue Epoche der Landbewirtschaftung und auch des Grundbesitzes.

Mit den Reformen waren einerseits die rechtlichen Grundlagen für eine neue Agrarordnung geschaffen und andererseits mit der Neuordnung der Flur auch eine neue räumliche Struktur der Agrarlandschaft.

Die Agrarreformen des 19. Jahrhunderts stellen also einen klaren Paradigmenwechsel in der Agrarverfassung dar.

Es ist daher weiter zu fragen, ob dieser grundsätzliche Wandel auch zu einem Paradigmenwechsel in der bäuerlichen Wirtschaftsweise und dann dadurch auch zu einem neuen Muster der Landnutzung und Neugestaltung der bäuerlichen Kulturlandschaft geführt hat.

Die Agrarreformen haben jedenfalls die rechtlichen Voraussetzungen dafür geschaffen, dass sich aus dem an die Dorfgemeinschaft und die Grundherrschaft gebundenen Bauern ein unternehmerischer Landwirt entwickeln konnte.

Die Hoftypen und deren Hierarchie hatten sich aber durch die Reformen wegen des Prinzips der Besitzstandswahrung nicht verändert, was Tabelle $4.31^{2}$ und besonders auch Tabelle 4.32 deutlich belegen.

Nur bei der Einordnung der Brinksitzer liefern die verschiedenen Tabellen im Rezess von 1859 ein unterschiedliches Bild, obgleich der Versuch von vier Anbauern zur Hochstufung (s.o.) zum Brinksitzer verworfen worden war.

Das Ergebnis dieser Reformen bildet aber dennoch die Grundlage und den Ausgangspunkt für die Entwicklung der modernen Agrarstruktur hinsichtlich des landwirtschaftlichen Besitzes und der Parzellengliederung der Landschaft, die bis heute in den Flurkarten dokumentiert ist.

\footnotetext{
${ }^{1}$ Im Verteilungsregister der Verkoppelung der Feldmark Lachendorf werden insgesamt 9 Abbauern benannt.

${ }^{2}$ In der Chronik der Gemeinde Lachendorf, Bd. II - Lachendorfer Höfe - von M. Wittmann ist bei den Angaben über die Flächen, die die Höfe aufgrund der Reformen erhalten haben, nur das Ergebnis der Spezialteilung und Verkoppelung der Feldmark Lachendorf, also der Rezess von 1857/1859, berücksichtigt worden. Die Flächenangaben (in Morgen und Ruthen statt Quadratruten, s. z.B. S. 28) für Acker, Wiesen, Anger- und Heidboden entsprechen für jeden Hof genau den Daten in der Tabelle „Recapitulatio“ am Ende des Rezesses von 1859.

Die Zuteilungen aus der Verkoppelung der Aller- und Trockenen Wiesen im Rezess von 1866 wurden fälschlicherweise nicht berücksichtigt.

Im Jahrbuch des Landwirtschaftlichen Vereins Beedenbostel von 1961 sind für die Höfe unter Angabe der Jahreszahl 1857 nur die Flächen nach dem Stand des Rezesses von 1857 (endgültig genehmigt 1859) berücksichtigt. Auch hier fehlen die Flächen aus dem Rezess von 1866.
} 


\begin{tabular}{|c|c|c|c|c|c|c|c|c|c|c|c|c|}
\hline \multicolumn{13}{|c|}{ Verkoppelungen } \\
\hline Jahr & & \multicolumn{5}{|c|}{1859} & \multicolumn{4}{|c|}{1866} & \multicolumn{2}{|r|}{ gesamt } \\
\hline Hoftyp & & Acker & Wiesen & Anger & Heide & $\Sigma$ & Acker & Wiesen & Anger & Heide & $\Sigma$ & $\Sigma$ \\
\hline \multirow[t]{8}{*}{ Vollhöfner } & & ha & ha & ha & ha & ha & ha & ha & ha & ha & ha & ha \\
\hline & 1 & 39,50 & 0,00 & 4,25 & 47,55 & 91,31 & & 7,57 & 0,00 & 0,70 & 8,27 & 99,58 \\
\hline & 2 & 24,60 & 3,42 & 5,43 & 37,44 & 70,88 & & 7,37 & 0,00 & 0,03 & 7,40 & 78,29 \\
\hline & 3 & 34,80 & 0,00 & 6,52 & 25,19 & 66,51 & & 5,09 & 0,00 & 0,00 & 5,09 & 71,61 \\
\hline & 4 & 47,47 & 4,20 & 5,14 & 46,98 & 103,79 & & 5,70 & 0,00 & 0,00 & 5,70 & 109,49 \\
\hline & 5 & 27,46 & 1,31 & 6,25 & 49,32 & 84,35 & & 6,19 & 0,12 & 0,00 & 6,31 & 90,66 \\
\hline & 6 & 24,15 & 0,66 & 3,36 & 136,61 & 164,78 & & 5,62 & 0,00 & 0,00 & 5,62 & 170,40 \\
\hline & 7 & 29,51 & 4,84 & 9,68 & \begin{tabular}{|l|}
37,01 \\
\end{tabular} & 91,04 & & 3,20 & 0,00 & 0,00 & 3,20 & 94,24 \\
\hline \multirow[t]{2}{*}{ Halbhöfner } & 1 & 23,55 & 0,78 & 6,30 & 32,14 & 62,77 & & 3,31 & 0,29 & 0,00 & 3,60 & 66,37 \\
\hline & & Acker & Wiesen & Anger & Heide & $\Sigma$ & Acker & Wiesen & Anger & Heide & $\Sigma$ & $\Sigma$ \\
\hline \multirow[t]{14}{*}{ Kötner } & & ha & ha & ha & ha & ha & ha & ha & ha & ha & ha & ha \\
\hline & 1 & 24,07 & 1,34 & 7,85 & 35,34 & 68,59 & & 4,29 & 0,61 & 0,66 & 5,56 & 74,15 \\
\hline & 2 & 12,28 & 0,00 & 2,20 & 32,48 & 46,96 & & 2,49 & & 0,27 & 2,76 & 49,72 \\
\hline & 3 & 28,25 & 2,42 & 5,01 & 30,49 & 66,17 & & 1,94 & 0,52 & 0,00 & 2,46 & 68,63 \\
\hline & 4 & 16,17 & 1,96 & 1,82 & 34,86 & 54,81 & & 4,31 & & 0,00 & 4,31 & 59,12 \\
\hline & 5 & 22,05 & 2,25 & 5,94 & 26,08 & 56,31 & & 4,25 & & 0,40 & 4,66 & 60,97 \\
\hline & 6 & 11,26 & 0,00 & 3,44 & 17,44 & 32,13 & & 2,68 & & 0,00 & 2,68 & 34,81 \\
\hline & 7 & 29,38 & 1,57 & 1,28 & 28,38 & 60,62 & & 3,44 & & 0,10 & 3,55 & 64,17 \\
\hline & 8 & 24,68 & 3,59 & 2,97 & 32,99 & 64,24 & & 7,74 & & 0,00 & 7,74 & 71,98 \\
\hline & 9 & 18,61 & 1,14 & 2,36 & 29,74 & 51,86 & & 2,40 & 0,12 & 1,17 & 3,69 & 55,55 \\
\hline & 10 & 16,83 & 2,50 & 1,44 & 30,53 & 51,29 & & 0,90 & & 0,00 & 0,90 & 52,19 \\
\hline & 11 & 26,56 & 0,42 & 3,77 & 45,03 & 75,78 & 0,91 & 5,78 & & 0,00 & 5,78 & 81,55 \\
\hline & 12 & 10,16 & 0,02 & 3,00 & 24,85 & 38,03 & & 3,63 & & 0,00 & 3,63 & 41,65 \\
\hline & & Acker & Wiesen & Anger & Heide & $\Sigma$ & & Wiesen & Anger & & $\Sigma$ & $\Sigma$ \\
\hline \multirow[t]{5}{*}{ Brinksitzer } & & ha & ha & ha & ha & ha & & ha & ha & & ha & ha \\
\hline & 1 & 2,66 & & 3,10 & 6,81 & 12,57 & & 0,99 & 1,53 & & 2,52 & 15,09 \\
\hline & 2 & 1,40 & & 0,85 & 7,88 & 10,13 & & 2,15 & & & 2,15 & 12,28 \\
\hline & 3 & 4,70 & & 2,32 & 12,33 & 19,36 & & 2,08 & & & 2,08 & 21,44 \\
\hline & & Acker & Wiesen & Anger & Heide & $\Sigma$ & & Wiesen & Anger & & $\Sigma$ & $\Sigma$ \\
\hline \multirow[t]{7}{*}{ Anbauern } & & ha & ha & ha & ha & ha & & ha & ha & & ha & ha \\
\hline & 1 & 1,73 & 0,00 & 1,16 & 10,22 & 13,11 & & & & & 0,00 & 13,11 \\
\hline & 2 & 3,42 & 0,11 & 1,84 & 6,46 & 11,83 & & 0,04 & & & 0,04 & 11,87 \\
\hline & 3 & 0,18 & 0,00 & 0,76 & 7,92 & 8,87 & & 0,03 & & & 0,03 & 8,89 \\
\hline & 4 & 6,20 & 0,00 & 0,69 & 15,86 & 22,74 & & 0,03 & & & 0,03 & 22,78 \\
\hline & 5 & 0,06 & 0,00 & 0,65 & 9,26 & 9,98 & & 0,94 & & & 0,94 & 10,92 \\
\hline & & Acker & Wiesen & Anger & Heide & $\Sigma$ & & Wiesen & Anger & & $\Sigma$ & $\Sigma$ \\
\hline \multirow[t]{10}{*}{ Abbauer } & & ha & ha & ha & ha & ha & & ha & ha & & ha & ha \\
\hline & 1 & 1,09 & 0,00 & 0,34 & 0,25 & 1,68 & & & & & & 1,68 \\
\hline & 2 & 0,47 & 0,00 & 0,21 & 0,58 & 1,25 & & & & & & 1,25 \\
\hline & 3 & 0,50 & 0,00 & 0,29 & 0,23 & 1,02 & & & & & & 1,02 \\
\hline & 4 & 0,38 & 0,00 & 0,06 & 0,28 & 0,72 & & & & & & 0,72 \\
\hline & 5 & 0,46 & 0,00 & 0,10 & 0,14 & 0,70 & & & & & & 0,70 \\
\hline & 6 & 0,54 & 0,00 & 0,04 & 0,00 & 0,59 & & & & & & 0,59 \\
\hline & 7 & 0,48 & 0,00 & 0,05 & 0,97 & 1,50 & & & & & & 1,50 \\
\hline & 8 & 0,00 & 0,00 & 0,21 & 0,00 & 0,21 & & & & & & 0,21 \\
\hline & 9 & 0,32 & 0,00 & 0,07 & 0,02 & 0,41 & & 0,41 & & & 0,41 & 0,81 \\
\hline & & 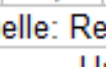 & & n 1859 ; & & & & & & & & \\
\hline
\end{tabular}




\subsubsection{Veränderungen in der Landschaft durch die Reformen}

Die sichtbaren reformbedingten Änderungen in der Landschaft waren unmittelbar nach vollständiger Umsetzung und rechtlicher Verbindlichkeit der Reformen sehr unterschiedlich.

In der Gemeinheit, der Lachendorfer Abfindung, auf der Allerheide änderte sich unmittelbar noch nichts, denn die Wirtschaftsweise konnte sich erst langsam verändern und die neuen Parzellengrenzen fielen in der Heide nicht auf. Nur die neuen Gemarkungsgrenzen, markiert durch Wall und Graben, sowie die neu eingemessenen Wege gliederten die weite Heidelandschaft.

In den Aller- und Trockenen Wiesen veränderte sich das Landschaftsbild durch das neu geschaffene klare, gradlinige Wegenetz, in das die geometrische Parzellenstruktur eingepasst wurde. Die Wiesenlandschaft hat dadurch sicherlich von seiner Natürlichkeit verloren, behielt bzw. bekam aber durch Bepflanzung an den Wegen und erhaltene Baumgruppen und Gehölze einen parkähnlichen Charakter. Der Waldrand im Nordwesten des Kartenausschnittes blieb erhalten und wurde nicht begradigt zur Anpassung an die Parzellengrenzen im Grünland. Da die Verkoppelungskarte von 1861 noch kein Grabensystem zeigt, muss angenommen

Kartenbild 4.1 Verkoppelung der Allerwiesen

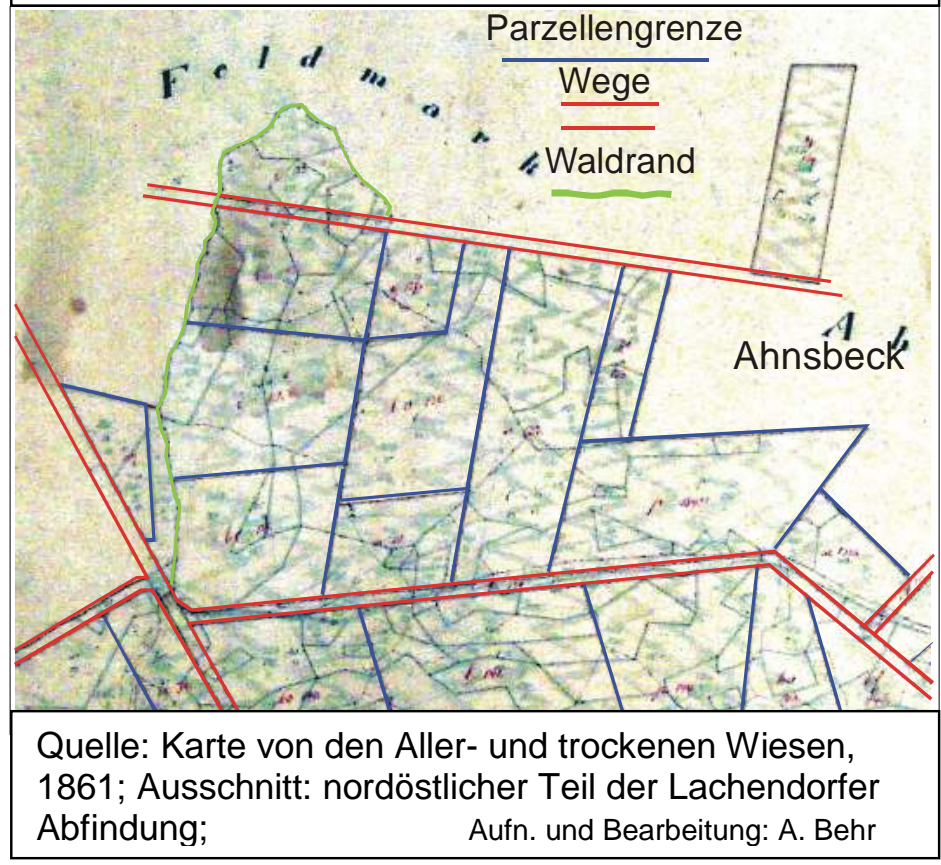
werden, dass dies erst nach Fertigstellung der Teilung entlang der Parzellengrenzen und Wege angelegt worden ist.

Am weitaus stärksten veränderte sich zunächst aber das Landschaftsbild in den Ackerländereien auf den Geestplatten. Auch hier wurde ein klares, möglichst gradliniges Wege- und Straßennetz geschaffen. Die wesentliche Veränderung ging aber von der Abschaffung der Gewanne mit den meist geschwungen verlaufenden zahlreichen Langstreifen aus. Die alte Langstreifenflur mit schmalen Ackerbeeten wich einer Parzellenstruktur mit klarem geometrischem Muster.

Durch die Verkoppelung ist also das augenfälligste Element der alten Kulturlandschaft, das bis 1850 die Ackergebiete strukturierte und bestimmte, für immer aus der Kulturlandschaft verschwunden. Die Kartenausschnitte aus der Verkoppelungskarte der Lachendorfer Feldmark von 1852 machen diese Veränderung im Grundriss der Landschaft deutlich.

Die Verkoppelung bedeutete für die Höfe nicht nur die Zusammenlegung von zahlreichen Langstreifen. Die Verkoppelung führte vielmehr zu einer völlig neuen Einteilung der Flur in möglichst rechteckige Parzellen mit geraden und parallelen Längsseiten. Wenn möglich, wurde allerdings - wie auf dem Dürskamp - die generelle Pflugrichtung bei behalten.

Die neue Parzellenstruktur im Verkoppelungsgebiet auf dem Osteraden und in der Melmau östlich der Jarnser Straße verdeutlicht ebenfalls die Beachtung der alten Pflugrichtung in den Langstreifen beim Zuschnitt der neuen Parzellen. Während sich die alten Ackerstreifen nur auf der Kuppe der Bunkenburger Geest beiderseits des Osteraden befanden, also auf den besseren Böden, reichen die neuen Parzellen von der Jarnser Straße bis an den Osteraden. Sie beginnen auf der Terrasse des Lachtetales auf leichtem Sandboden und erreichen über 
den sanften Talhang auch die besseren Böden auf der Geestkuppe. Der jeweilige Parzellenanteil auf der Lachteterrasse, der in der alten Flurordnung noch kein Ackerland war, konnte nach der Reform von dem neuen Besitzer urbar gemacht werden.

Auf der Nordseite der Jarnser Straße reichen die kleinen Parzellen bis an den unregelmäßig belassenen Rand der Talaue der Lachte. Das dortige Grünland war von der Verkoppelung ausgenommen.
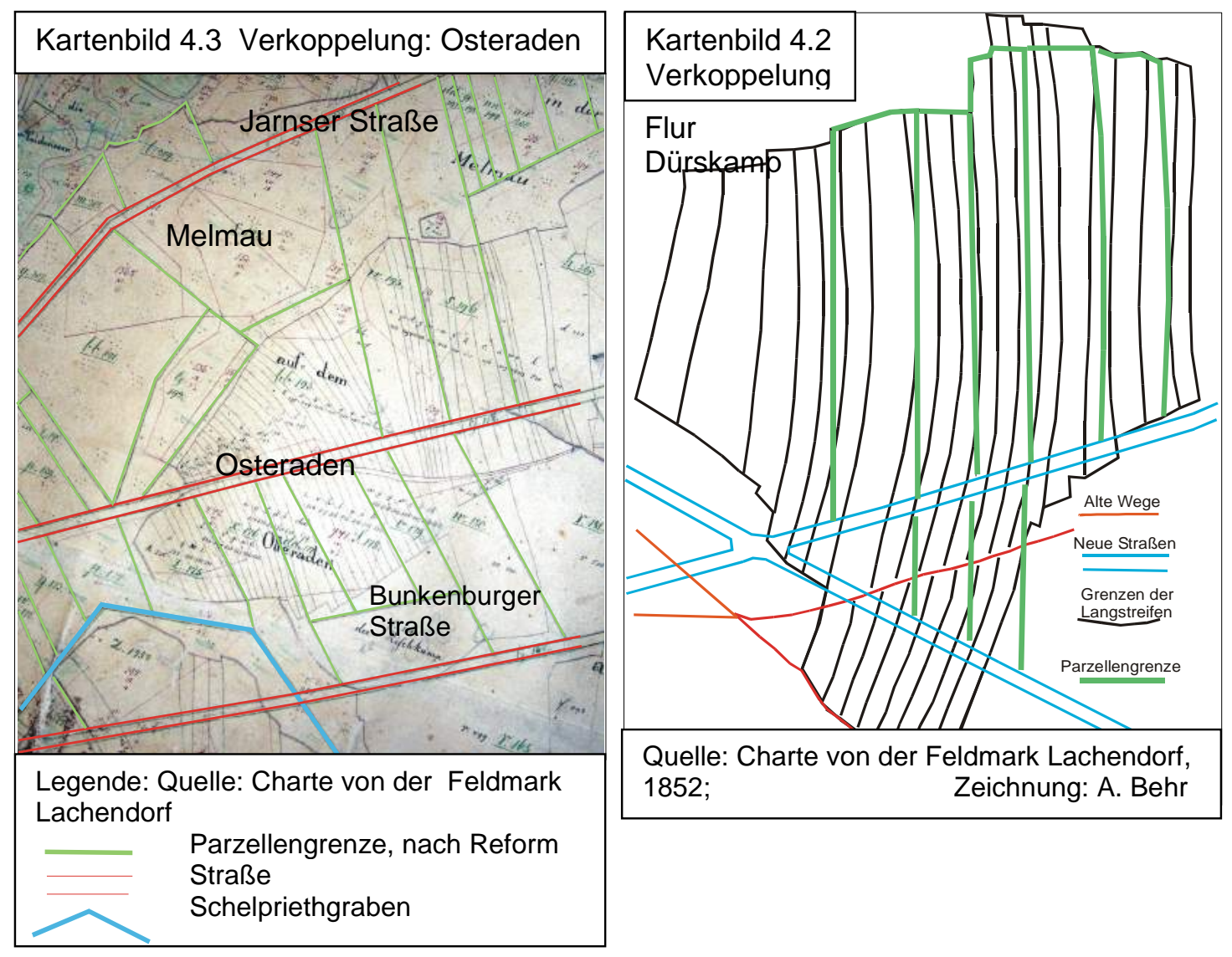

\subsubsection{Feldmark, Gemarkung und Naturraum}

Die Karten zur Generalteilung, Spezialteilung und Verkoppelung belegen, dass die Begriffe Feldmark und Gemarkung nicht identisch waren, wenngleich sie heute meist synonym verwendet werden. Die Kartenausschnitte im Kartenbild 4.4 zeigen wie der Südrand der Feldmark und der Nordrand der Allerheide zusammen passten.

Die Feldmark umfasste nur die Ackerländereien der Höfe des Dorfes, das direkt dem Dorf zustehenden Grünland - hier im Lachtetal - und die dorfeigene Gemeinheit in unmittelbarer Dorfnähe. Die Allerheide als Gemeinheit für mehrere Dörfer sowie die Aller- und trockenen Wiesen als großes Wiesengebiet gehörten nicht zur Feldmark.

Erst mit den Generalteilungen erhielt Lachendorf eine Abfindung aus der Gemeinheit der Allerheide und eine Abfindung in den Aller- und trockenen Wiesen.

Die Zusammenfassung der alten Feldmark mit den beiden Abfindungen bildete dann die neue Gemarkung, deren Grenzen bis heute unverändert blieben und nur bei kommunalen Gebietsreformen (Eingemeindungen) formal aufgehoben wurden.

In den Reformen des 19. Jahrhunderts behielten die Lachendorfer Bauern natürlich ihre bisherige Feldmark, auf die sie vor allem wegen des Ackerlandes nicht hätten verzichten können. 
Außerdem wurden sie - wie oben gezeigt - entsprechend ihrer Nutzungsrechte in der Allerheide sowie in den trockenen Wiesen am Schwarzwasser und den feuchten Wiesen in den Allerdreckwiesen entschädigt bzw. abgefunden, wie es damals im Amtsdeutsch hieß.
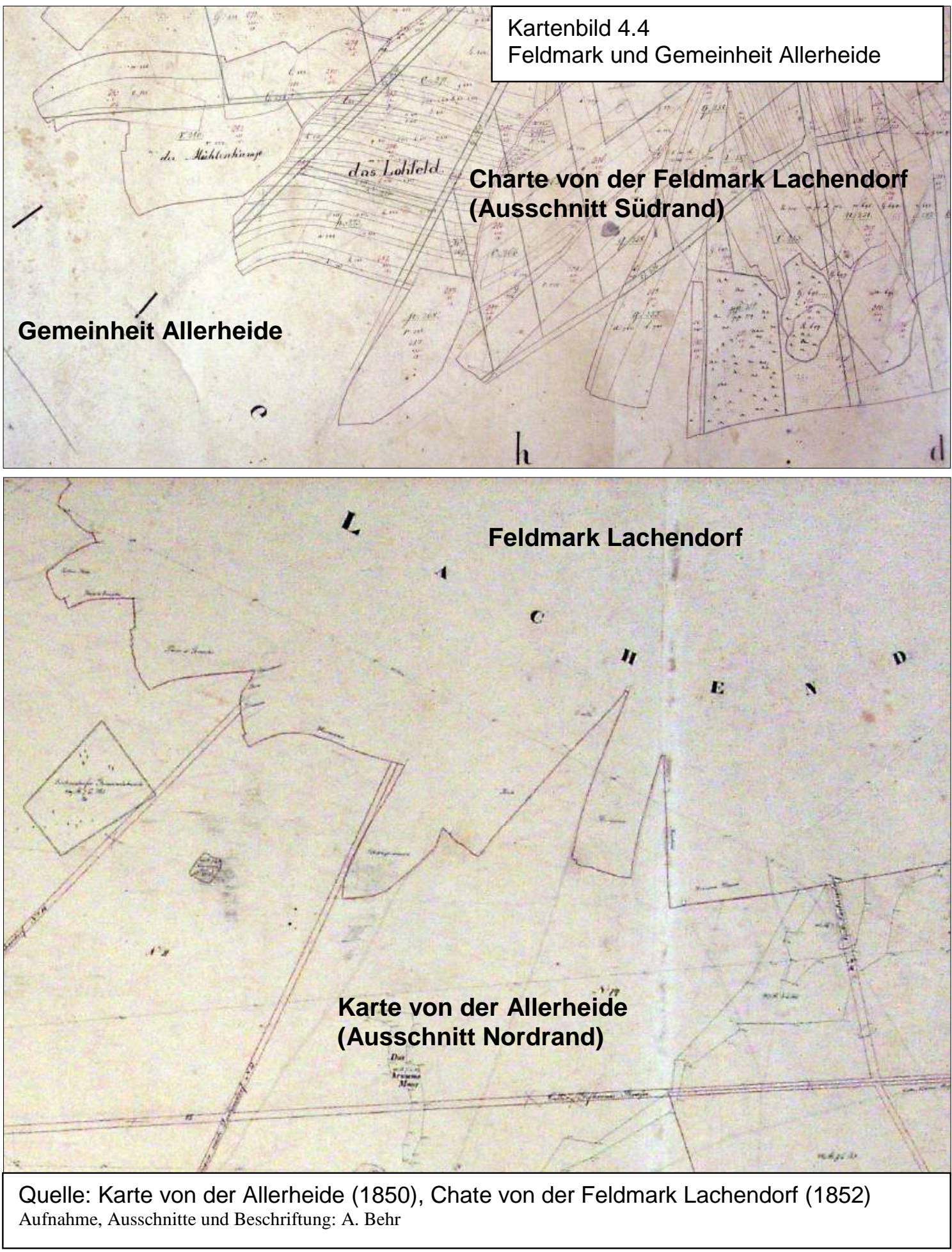

So ergab sich eine Gemarkung der damaligen Dorfgenossenschaft, die sich mit dem Ackerland auf den Geestplatten, der Heide auf dem Schwemmfächer und den Wiesen im Randmoor des Urstromtales ebenfalls ganz genau an den naturräumlichen Bedingungen ausrichtete. Aus dieser natürlichen Bindung ergab sich auch die Form für die Gemarkung: Ein Hauptteil um den Ort, nördlich auf der Gockenholzer und Bunkenburger Geest und im Lach- 
tetal sowie auf dem Schwemmfächer in der Allerheide, dazu im Süden und Südosten ein Wiesengebiet am Schwarzwasser und in den Dreckwiesen, beides verbunden mit einem schmalen nordsüdlich verlaufenden Landstreifen.

Auch die Lachendorfer Gemarkung war flächendeckend Landwirtschaftliche Nutzfläche, auch hier gab es keine davon ausgesonderten Waldflächen.

Die Landschaft des Untersuchungsgebietes war bis in die Mitte des 19. Jahrhunderts eine bäuerlich geprägte und gestaltete Kulturlandschaft, in der alle Flächen, auch die mit Bäumen bestandenen, zur Landwirtschaftlichen Nutzfläche gehörten.

Dies folgte zwingend aus der Wirtschaftsweise:

Das Ackerland wurde im Rahmen des Flurzwanges beim Anbau von Feldfrüchten, vorwiegend Getreide, privatwirtschaftlich genutzt. Aber bereits die Stoppelweide sowie die Beweidung der Brache unterlagen gemeinschaftlicher Nutzung. Auch Wiesen wurden zur Mahd privatwirtschaftlich genutzt, unterlagen aber bezüglich der Vor- und Nachweide der gemeinschaftlichen Nutzung. Alle anderen Flächen galten als Gemeinheit und dienten der Hut und Weide sowie dem Bulten-, Heid- und Plaggenhieb.

Mit den Generalteilungen, der Spezialteilung und Verkoppelung gab es in der neuen Gemarkung neue Besitzparzellen mit neuen Besitzgrenzen. Im Zuge dieser Neugestaltung wurde auch das Wege- und Straßennetz sowie das Grabensystem, insbesondere in den Dreckwiesen, nach genauer Einmessung neu geschaffen.

Das Ergebnis dieser Arbeiten lieferte die moderne Grundstruktur der Flureinteilung und des Verkehrsnetzes, die bis heute unsere Kulturlandschaft gliedern und charakterisieren.

Mit den rechtlichen Reformen der Agrarwirtschaft in der Mitte des 19. Jahrhunderts wurden also bestimmende Merkmale der heutigen Kulturlandschaft geschaffen, die sich ganz wesentlich von der Kulturlandschaft aus der Zeit vor den Reformen unterscheidet.

Die neu geschaffene Gemarkung setzte sich seither aus der ehemaligen Feldmark Lachendorfs sowie den Abfindungen für Lachendorf aus der Allerheide und den Aller- und Trockenen Wiesen zusammen.

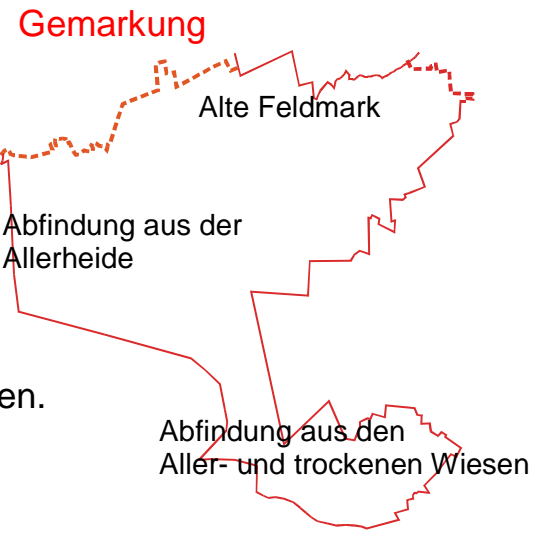

\section{Kap. 4.3 Niedergang und Überwindung der Heidebauernwirtschaft}

\subsection{1 Ökologische Probleme}

„ICh war gewiß nicht vorbereitet, eine schöne Natur zu finden, aber ich dachte nicht, daß das Land so elend wäre. Mich dünkt, es ist der schlechteste Strich von einem solchen Umfange, der mir jemals vorgekommen ist. Der Boden dieses Geländes ist eine ungeheure Sandwüste, die von Natur entweder ganz nackt ist oder Heidekraut oder dürre, stechende Halme hervorbringt. "1

„Nach stundenlanger eintöniger Fahrt durch die Heide ..., auf der wir Vögel selten, Wild überhaupt weder sahen noch spürten, fanden wir am Wege, wenn von Weg und Steg überhaupt zu reden war, einen toten Fuchs liegen, dem mutmaßlich Weltschmerz das Leben genommen hatte."

„... von kärglichen Äckern, elenden und zerfallenen Gehöften und hungrigen Raben, die über das tote Sandmeer einer ,norddeutschen Sierra Morena' flattern."

\footnotetext{
${ }^{1}$ aus Küttners Reisebeschreibungen von 1797
} 
„Wie kahl sind die Heiden seit einem Menschengedenken schon geworden! Welche bedenklichen Blößen zeigen unsere Heiden nicht allenthalben schon! - und viele Feldmarken laufen Gefahr, Sandwehen zu bekommen. "(1862) ${ }^{1}$

Die Heidebauernwirtschaft musste stets mit einer naturgeographisch bedingten Mangelsituation kämpfen: Die Saale-Vereisung hatte nicht nur im Aller-Urstromtal sondern im gesamten Gebiet zwischen Elbe und Aller überwiegend sandige Bodenablagerungen hinterlassen, die sich aufgrund des hohen Sandanteils durch eine niedrige Wasserspeicherkapazität und aufgrund ihres Alters durch einen geringen Nährstoffgehalt, insbesondere wegen der Auslaugung durch einen sehr niedrigen Kalkgehalt auszeichnen.

Die Landnutzung musste also unter diesen Bedingungen ein System finden, das auf nährstoffarmen Böden eine nachhaltige Nutzung zur Erzeugung einer ausreichenden Ackernahrung ermöglichte.

Die ersten Siedler in dieser Gegend trafen keineswegs auf eine Heidelandschaft.

Denn nach Durchlaufen verschiedener, klimatypischer Vegetationsformen in der ausklingenden letzten Eiszeit ${ }^{2}$, die mit ihren Gletschern nicht mehr über die Elbe nach Süden vorgestoßen war, stockte auf den sandigen Böden schließlich ein lichter Eichen-Birkenwald, als der Mensch anfing, unseren Raum durch Viehzucht und zunehmend auch durch Ackerbau zu nutzen.

Die besseren Böden auf Löß und auf lehmiger Grundmoräne, auf denen EichenBuchenwälder vorherrschten, wurden bald gerodet und in Ackerland umgewandelt. Die Verbreitung der Großsteingräber lässt erkennen, daß die Menschen die Bodengüte sehr genau kannten und zunächst die armen Sandböden wie die unzugänglichen Moore mieden.

Die lichten Eichen-Birkenwälder dienten neben der Holznutzung vor allem der Waldweide. Während ein geschlossener Buchen-Hallenwald nur Frühblühern Wachstumsbedingungen bietet und die meiste Zeit des Jahres ohne Unterwuchs erscheint, können in lichten Wäldern Gräser, Kräuter und Sträucher als Unterwuchs und Bodenbedeckung ganzjährig existieren. Gerade die lichten Eichen-Birkenwälder boten also genügend Futter bei der Nutzung als Waldweide.

In der mittelalterlichen Agrarwirtschaft spielte der Wald eine ganz wesentliche Rolle, er war ein unverzichtbarer Teil des landwirtschaftlichen Nutzungssystems. Eine Trennung in Landund Forstwirtschaft war daher noch undenkbar.

Der Wald lieferte nicht nur Bau- und Brennholz und Weide für das Vieh, auch Laubheu und Laubstreu für das Rindvieh sowie Eicheln und Bucheckern für die herbstliche Schweinemast, bevor die Schweine zu Beginn des Winters geschlachtet und zu Rauchwaren und Pökelfleisch verarbeitet werden konnten.

Selbst das Bild der Siedlungen spiegelt die ökologische Situation wider:

Kleine Haufendörfer lagen weit verstreut in einer sehr waldarmen Landschaft, umgeben von einem Kranz aus Ackerparzellen und getrennt durch große, weite Heideflächen, den Gemeinheiten, die gemeinschaftlich genutzt wurden. Größere Haufendörfer wie Lachendorf und Ahnsbeck oder auch das sehr alte Eschede geboten über den Vorteil größerer Grundmoränenflächen oder den Zugang zu natürlichem Grünland wie in den Allerdreckwiesen.

Auf Dauer führten aber Holznutzung und Waldweide mit ihren negativen Folgen für die natürliche Verjüngung des Waldes zu einer Übernutzung und Waldvernichtung ${ }^{3}$,

\footnotetext{
${ }^{1}$ s. H. Brockhoff, a.a.O., S. 22 (alle drei Zitate)

${ }^{2}$ Weichsel-Eiszeit, Ende vor rund 10000 Jahren

${ }^{3}$ Unter den Ursachen für die Entwaldung der Lüneburger Heide wird dem Brennholzbedarf für die

Lüneburger Salzsiederei meist eine weit übertriebene Bedeutung zugemessen.
} 
Die neuen Lichtverhältnisse konnten zwei Pflanzenarten nutzen, die vorher nur im Unterwuchs des Waldes und auf Lichtungen eine bescheidene Rolle gespielt hatten: Die Besenheide (Calluna vulgaris) und der Wacholder (Juniperus communis).

Unter den maritimen Klimabedingungen Nordwestdeutschlands konnte sich als Ersatz für den Laubwald eine Heidevegetation ausbreiten, die den natürlichen ${ }^{1}$ atlantischen Heiden Nordwesteuropas, die aus Schottland und Jütland bekannt sind, ähneln. Unter kontinentaleren, also trockeneren Bedingungen, hätten sich auf nährstoffarmen Standorten vermutlich Magerrasen gebildet, die heute an wenigen Stellen, z.B. im Allertal auf nacheiszeitlichen Dünen, also durch den Boden bedingt, anzutreffen sind.

Die Verbreitung des Wacholders ist eine Folge negativer Selektion ${ }^{2}$ bei der Beweidung: Die quirlig abstehenden spitzen Nadeln des Wacholders schützen inn vor dem Verbiss, und so kann er sich ausbreiten, während blattreiche Futterpflanzen ständig abgefressen und kurz gehalten werden.

Die Klima- und Bodenbedingungen boten also nach der Waldvernichtung nur der gewöhnlichen Heide gute Wachstums- und Ausbreitungsbedingungen. Als Futterpflanze zur Beweidung war die Heide allerdings für Großvieh ungeeignet, nur Schafen, insbesondere der dem Standort angepassten Schnucke ${ }^{3}$, bot die Heide eine ausreichende Weide. So wurde zwangsläufig mit der Ausbreitung der Heide die Heidschnucke zum vorherrschenden Nutztier der Heidebauern.

Während man die trockenen sandigen Standorte der Besenheide den Schnucken überließ, wurden feuchtere Standorte gern in Weiden, sog. natürliches Grünland umgewandelt. Die Bauern erkannten diese Standorte am Pfeifengras und an der Erikaheide. Eine alte Weisheit der Heidebauern verrät dieses ökologische Wissen: Wo Doppheide (Erikaheide) wächst, kann man Weide anlegen.

Den Ackerflächen werden bei ständigem Anbau regelmäßig durch Ernten Nährstoffe entzogen. Die mageren Heideböden litten unter extremem Nährstoffmangel, der sich in abnehmenden Erträgen bemerkbar machte. Da der Boden nur einen sehr geringen, noch zersetzbaren Restmineralgehalt enthält, war die Fähigkeit zur Nachlieferung von Nährstoffen nicht gegeben. Der geringe Humusgehalt ließ ebenfalls keine nennenswerte Nachlieferung von Nährstoffen aus organischer Quelle zu. Eine nachhaltige Landwirtschaft war also ohne Düngung nicht möglich. Andererseits stand als Dünger nur organisches Material, vorwiegend also Viehdung, zur Verfügung.

Die Dreifelderwirtschaft, die nach zwei Nutzungsjahren jeweils ein Brachejahr einschob, reichte auf den armen Sandböden zur Regeneration nicht aus, daher gab es auf den leichten Sandböden auch den sog. ewigen Roggenanbau. Dies war möglich, weil Roggen von allen Getreidearten dem sauren Milieu ${ }^{4}$ der Sandböden am besten angepasst ist und mehrere Jahre nacheinander ohne Fruchtwechsel ${ }^{5}$ angebaut werden kann.

Diese Gegebenheiten führten in der Heide fast direkt in einen Teufelskreis der Armut: Die mangelhafte Futterbasis für Großvieh ließ nur kleine Tierbestände und keine ganzjährige

\footnotetext{
${ }^{1}$ Nach jüngeren Darstellungen können die atlantischen Heiden nur bedingt als „natürlich“ angesehen werden. Nach Svein Haaland spielte das Feuer eine wichtige Rolle (s. S. Haaland; Mit Feuer und Flamme für die Heide)

${ }^{2}$ Weitere Beispiele für Selektion durch Beweidung: Disteln und Brennnesseln sowie in den Alpen auf den Almweiden die Alpenrosen.

${ }^{3}$ Die Abstammung der Heidschnucke ist strittig. Es wird vermutet, dass die Schnucke vom Mufflon abstammt und kein echtes Schaf ist. Dafür spricht die "Schnuckenwolle“, die eigentlich Haare sind (s.a. A. Kuhlmann; Heide und Heidschucken, in: Spuren und Zeichen, Hrsg. Landkreis Celle, 1991, S. 329).

${ }^{4}$ Roggen bringt vergleichsweise gute Wuchsleistungen gerade auf leicht sauren Böden. Der Roggen war also im Vergleich der Getreidearten den Bodenbeschaffenheit der Heidebauernwirtschaft am besten angepasst.

${ }^{5}$ Roggen ist (wie Mais) „,mit sich selbst verträglich“, während andere Kulturpflanzen, insbesondere Kartoffeln, bei mehrjährigem Anbau ohne Fruchtwechsel zu schweren Bodenerkrankungen führen.
} 
Stallhaltung zu, was zu wenig Stallmist führte. Wenig Stallmist bedeutete aber wenig Dünger und damit geringe Ernten. Der kostbare Mist musste für den Anbau von Nahrungspflanzen reserviert bleiben, an eine Stärkung des Futterbaus und damit der Großviehhaltung mit gröBerer Stalldungerzeugung war nicht zu denken. Besonders die Beschaffung von Winterfutter für die Fütterung im Stall gestaltete sich schwierig: Gerade in der trockenen Geest war feuchtes, von Natur aus fruchtbares Grünland zur Heugewinnung Mangelware. Für den Anbau von Futterpflanzen, ohnehin noch weitgehend unbekannt, stand kein Ackerland zur Verfügung, weil die Ackernahrung wegen der geringen Erträge kaum für die Menschen reichte.

Bezeichnend für diese prekäre Futtersituation sind alte Erzählungen vom sog. Schwanzvieh: Wegen des Mangels an Winterfutter waren Rinder im Frühjahr zu Beginn der Weidesaison so geschwächt, dass sie nicht mehr aus eigener Kraft auf die Weide gehen konnten ${ }^{1}$. Man zog sie liegend am Schwanz aus dem Stall auf eine Schleppe, um sie damit auf die Weide zum Grasen zu schleifen². Auch dies war alte Bauernweisheit: „Wer vor den Kühen nichts hat (also kein Futter), der hat auch nichts unter den Kühen (also keine Milch) und nichts hinter den Kühen (also keinen Mist). ${ }^{\text {*3 }}$

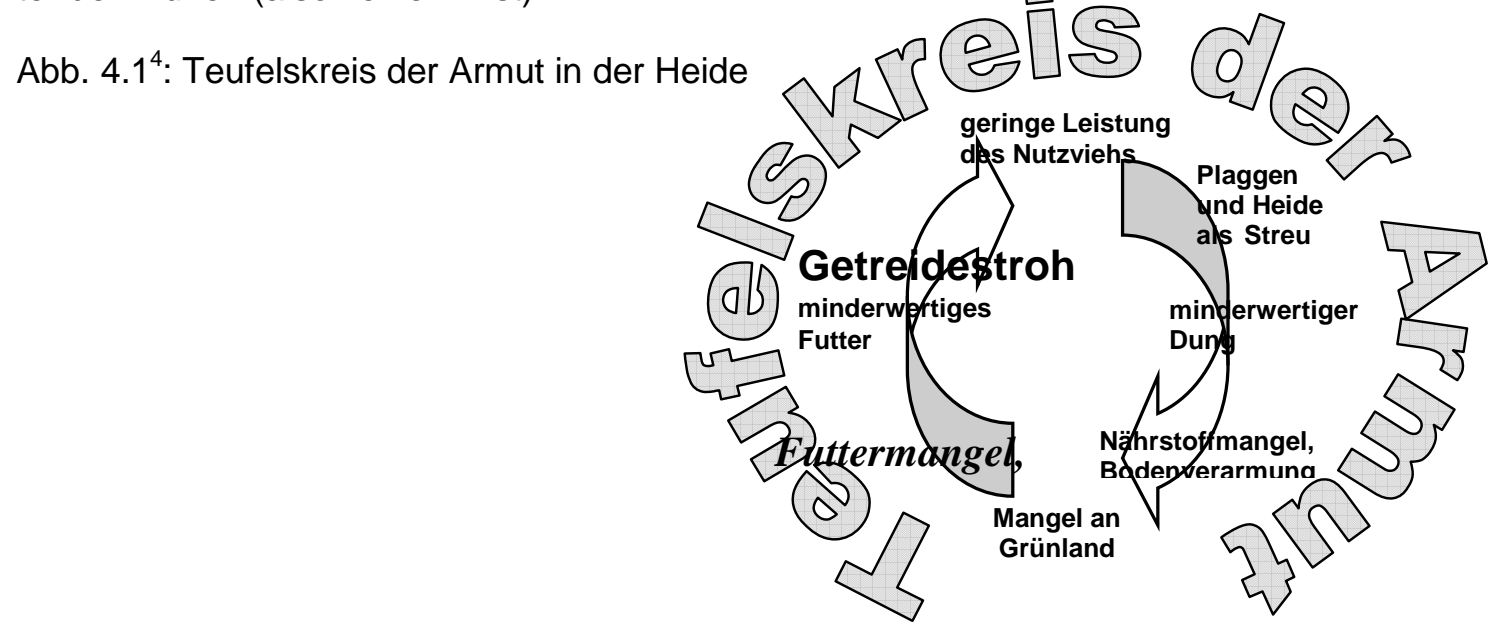

Die Heidebauernwirtschaft beruhte darauf, die Mangelsituation in der Nährstoffversorgung von Acker und Vieh durch eine ständige Nutzung der Heide erträglich zu gestalten. Die Heide diente einerseits als Schaf- und Bienenweide, andererseits als Fläche zur Gewinnung von Heidplaggen und Heidestreu. Die Plaggen düngten direkt den Acker, wurden aber überwiegend wie die gemähte Heide als Einstreu in den Viehställen verwendet und dann erst als Dung auf den Acker gebracht. Man rechnete, dass bei der Plaggendüngung ein Flächenverhältnis von einem Teil Acker zu vier Teilen Heide nötig war.

Auf die alte Weisheit der Heidebauern, dass „die Heide den Acker ernährt“, sei hier nochmals hingewiesen (s. dazu Kap. 3.4.6 - Bodenfruchtbarkeit und Nachhaltigkeit, S. 124). Es war mit dem zeitgenössischen Wissen und der überkommenen Agrartechnik die beste aller Möglichkeiten, den Böden eine oft nur magere, aber einigermaßen sichere Ackernahrung abzugewinnen und einen Viehstapel durchzubringen, der eine Selbstversorgung möglich machte.

Dieses höchst komplexe und ökologisch sehr gut angepasste Nutzungssystem machte es möglich, unter den mageren natürlichen Bedingungen die Menschen über einen langen Zeitraum zu ernähren, ohne fremde Ressourcen in Anspruch zu nehmen.

\footnotetext{
${ }^{1}$ s. H. Becker; Allgemeine historische Agrargeographie, a.a.O., S. 140

${ }^{2}$ vergl. H. Brockhoff, a.a.O., S. 64

3 mdl. Überlieferung vom Vater d. Verf.

${ }^{4}$ Entwurf: A. Behr, s.a. A. Behr, Hg., Der Lutterhof bei Hermannsburg, 2005, S. 75
} 
Um 1800 war allerdings auch aus ökologischen Gründen das Ende der Heidebauernzeit gekommen. Die Heideflächen hatten - in ganz Europa, nicht nur in der Lüneburger Heide - ihre größte Ausdehnung ${ }^{1}$ erreicht und waren vielerorts durch Übernutzung stark devastiert, der frei gelegte Sand kam in Bewegung, fossile Dünen wurden reaktiviert, rezente Dünenbildung flackerte auf. Es gab Sandverwehungen bis in die Dörfer, die durch behördliche Anordnungen durch Anpflanzungen oder Auslegen von Strauchwerk bekämpft werden mussten. ${ }^{2}$

Kulturgeographisch ist also die Heidelandschaft eine Reliktlandschaft, die ihre Entstehung und ihren Bestand einer ehemaligen Wirtschaftsweise verdankt, einer Wirtschaftsweise, die sich mit den damals zur Verfügung stehenden Agrartechniken den ökologischen Bedingungen optimal angepasst hatte.

\subsubsection{Wirtschaftliche Probleme}

\subsubsection{Reproduktive und produktive Arbeit in der Heidelandschaft}

Warum ist es der Heidebauernwirtschaft nicht gelungen, die eigene Kulturlandschaft zu stabilisieren, so wie es in anderen Kulturlandschaften, z.B. in manchen Bewässerungslandschaften und in der alpinen ${ }^{3}$ Kulturlandschaft gelungen ist?

In jeder Kulturlandschaft werden Arbeiten verrichtet, die der Produktion von Nahrungsmitteln und nachwachsenden Rohstoffen dienen. Um die Produktivität der Kulturlandschaft nachhaltig zu sichern, müssen aber auch Arbeiten verrichtet werden, die der Pflege und Erhaltung dieser Kulturlandschaft dienen. Dieser Tatbestand wird besonders deutlich, wenn man von produktiven und reproduktiven Arbeiten ${ }^{4}$ in einer Kulturlandschaft spricht.

Diese Betrachtungsweise verdeutlichen folgende Beispiele aus anderen Kulturräumen:

a) In der hochalpinen Kulturlandschaft ist es den Bergbauern gelungen, einerseits durch intensive, dauerhafte und jährlich wiederholende reproduktive Pflegemaßnahmen die dynamische Naturlandschaft weitgehend zu stabilisieren und andererseits die ökonomische Leistungskraft dauerhaft zu verbessern. ${ }^{5}$

b) Gleiches lässt sich von den Bewässerungskulturen in Südost-Asien sagen: Die ReisTerrassen von Banaue im Banauetal auf Luzon (Philippinen) sind 2000 bis 6000 Jahre alt, gelten als 8. Weltwunder, wurden UNESCO-Weltkulturerbe und sind bei unveränderter Nutzung über Jahrhunderte hoch produktiv. Dieses Beispiel zeigt besonders deutlich, dass zur Stabilität der Landschaft und zum Erhalt ihrer ökonomischen Leistungskraft eine dauernde und regelmäßige Pflege, also ein hoher Anteil an reproduktiver Arbeit unabdingbar ist.

c) Wenn die Leistung der reproduktiven Arbeit wegfällt, verliert die Kulturlandschaft ihre Stabilität und natürliche Prozesse führen zur Dynamik einer Naturlandschaft zurück. Dieser Rückbau einer stabilen Kulturlandschaft durch die dynamischen Prozesse der Natur ist besonders gut in der Terrassenlandschaft der Cinque Terre ${ }^{6}$ an der Ligurischen Küste Italiens zu beobachten: Die reproduktiven Arbeiten sind nötig, um die Terrassen zu erhalten und damit die Erosion möglichst weitgehend zu unterbinden. Werden diese reproduktiven Arbeiten mangels billiger Arbeitskräfte und wegen besserer ökonomischer Alternativen für die Landbevölkerung nicht mehr erbracht, verfällt das Terrassensystem und mit ihm die Stabilität der Kulturlandschaft. Wird auch die Nutzung aufgegeben, beginnt eine Verwilderung und eine standorttypische Sukzession der Vegetation setzt ein.

Auch in der Heidelandschaft war zur Zeit der Heidebauernwirtschaft ein erhebliches Maß an reproduktiver Arbeit nötig: Das Plaggen, gelegentlich auch Abflämmen, der Heide war zur

\footnotetext{
${ }^{1}$ s. Svein Haaland, Feuer und Flamme für die Heide, a.a.O., S. 20

${ }^{2}$ s. Brockhoff, a.a.O., S. 22

${ }^{3}$ Vergl. W. Bätzing, Die Alpen, Frankfurt a. M., 1984

${ }^{4}$ Vergl. W. Bätzing, Orte guten Lebens, Zürich 2009, S. 68 ff.

${ }^{5}$ S. W. Bätzing, a.a.O. 1984 und 2009

${ }^{6}$ S. Geogr. Rundschau, H.4/ 2001, S. 41 ff: Landschaftswandel in den Cinque Terre in Ligurien
} 
Regeneration, also Verjüngung der Heide, unbedingt nötig, muss also als reproduktive Leistung zum Erhalt der Heidelandschaft gewertet werden.

Allerdings trugen die reproduktiven Arbeiten zum Erhalt der Heidelandschaft langfristig nicht zur Stabilisierung und besonders nicht zur Verbesserung der Leistungskraft bei. Im Gegenteil, die reproduktiven Arbeiten für die Heidelandschaft führten zu einer zunehmenden Verarmung der Heiden. Weil die für die Heide notwendigen reproduktiven Arbeiten einen ständigen Raubbau im Nährstoffhaushalt darstellten, konnte das System nicht nachhaltig sein.

In der Heidebauernwirtschaft haben die reproduktiven Arbeiten langfristig die produktiven Arbeiten nicht effizienter gemacht sondern zu abnehmender Fruchtbarkeit und Produktivität geführt. Daher war es nur eine Frage der Zeit, bis das System der Heidebauernwirtschaft sich selbst zerstörte.

Die reproduktiven Arbeiten haben zwar die Heidelandschaft lange Zeit erhalten, aber nicht die Fruchtbarkeit der Landschaft gesichert sondern vielmehr aufgebraucht. Zunehmende Lücken in der Vegetationsdecke, Ausblasungen, Sandverwehungen, Reaktivierung fossiler Dünen und rezente Dünenbildung waren dafür sichtbare Zeichen.

\subsubsection{Wirtschaftliche Konkurrenz für die Heidebauernwirtschaft}

Weltwirtschaftliche Entwicklungen hatten einen gravierenden Einfluss auf den Niedergang der Heidebauernwirtschaft:

- Weiche Schafwolle aus Übersee (Argentinien/Chile, Australien) ersetzte die harte Schnuckenwolle, die in der aufkommenden Textilindustrie nicht mehr konkurrenzfähig war.

- $\quad$ Baumwolle aus den Kolonien verdrängte die Flachsfasern;

- Jute aus Südasien und Sisal aus Mittelamerika und Afrika ersetzten die Hanffaser bei Grobtextilien, z.B. in der Herstellung von Säcken und Tauwerk;

- Zucker konnte in Fabriken aus dem tropischen Zuckerrohr und vor allem aus heimischen Rüben ${ }^{1}$ hergestellt werden und den Honig als Süßstoff entbehrlich machen.

- Die mechanischen Spinn- und Webstühle ersetzten auch die Heimarbeit des Spinnens und Webens, wodurch insbesondere die Frauen entlastet wurden.

- Die Revolutionierung der Düngung durch den Einsatz von Mineraldünger machte den Plaggendung und den Plaggenmist überflüssig.

- Die Schnuckenhaltung verlor ihre zentrale Bedeutung für die bäuerliche Landwirtschaft

Entwicklungen in der Wirtschaft machten einerseits typische Produkte der Heidebauernwirtschaft entbehrlich, eröffneten aber auch völlig neue wirtschaftliche Möglichkeiten, die dann auch die Heidebauernwirtschaft überflüssig und unrentabel machten.

Die Heide verlor ihre integrale und unverzichtbare Stellung im Wirtschaftssystem, einmal wegen der verlorenen Konkurrenzfähigkeit typischer Produkte und vor allem aber, weil die Heide bei den neuen Möglichkeiten der Landwirtschaft als Wirtschaftsfaktor völlig überflüssig geworden war.

Die schnell abnehmende bzw. aufgegebene Nutzung der Heide im System der Heidebauernwirtschaft hat im Übergang bis zur Aufforstung sicherlich dazu geführt, dass die Heide sich selbst überlassen wurde und als ungenutztes, brach gefallenes ehemaliges Kulturland „verwilderte“. Ohne traditionelle Nutzung setzte eine natürliche Sukzession ein, die immer mehr den Eindruck einer natürlichen Landschaft vermittelte.

Dieser Prozess hat möglicherweise mit zu der falschen Auffassung beigetragen, es handele sich bei der Heide um eine Naturlandschaft.

Das urwüchsige Bild einer ungenutzten Landschaft legte den Wunsch nahe, diese Landschaft zu erhalten und dafür unter Schutz zu stellen.

\footnotetext{
${ }^{1} 1804$ wurde die erste Zuckerfabrik in Braunschweig gegründet.
} 


\section{Kap. 4.4 Landwirtschaft und Landschaft in der 2. Hälfte des 19. Jahrhunderts}

\subsubsection{Neue Möglichkeiten für die Landwirtschaft}

„Betrachten wir die Situation des Lüneburger Landes vor 30, 40 Jahren. ${ }^{1}$ Man kann sicher sein, daß sich das Land weder verändern noch seinen Wohlstand mehren konnte. Die geringe Bodenqualität ergab nur mittelmäßige Erzeugnisse und die in geringer Menge. ...

Dem Lüneburger Land fehlten ... die unerläßlichen Faktoren für seine wirtschaftliche Entwicklung. Von außen mußte der Anstoß kommen, um den Rahmen der reinen Selbstversorgerwirtschaft zu sprengen und von außen mußten die Mittel kommen, um Bodenverbesserungen und Veränderungen zu realisieren."²

Diese zeitgenössische Beurteilung der fehlenden Entwicklungschancen der Landwirtschaft in der Lüneburger Heide ist angesichts des ökologischen Zustands weiter Landstriche durchaus nachvollziehbar.

Die Lachendorfer Bauern hatten gegenüber den Bauern in der zentralen Heide allerdings zwei wichtige Standortvorteile: Sie hatten nämlich Zugang zu günstigem Grünland in den Allerdreckwiesen im Urstromtal der Aller. Dadurch war, wie oben bereits erwähnt, ein vergleichsweise hoher Rindviehbestand möglich. Zweitens besaßen sie Ackerland auf Grundmoränenplatten aus dem Drenthe-Stadial der Saalevereisung mit lehmigen Böden. Diese wiesen zwar nicht die natürliche Fruchtbarkeit einer Jungmoränen- oder Bördenlandschaft auf, waren aber doch günstiger als die Böden auf Endmoränen und Sandern in der Hochheide.

Dennoch litten auch die Lachendorfer Bauern unter den engen ökologischen Grenzen des Naturraumes im System der Heidebauernwirtschaft. Dies folgt aus den Berichten über die Nutzungsstreitigkeiten in der Gemeinheit und aus der großen Abfindung, die Lachendorf aus der Gemeinheit der Allerheide erhielt.

Die Abfindungen aus den Reformen stammten natürlich aus der Masse, die in die Reformen eingebracht worden waren. Jeder Hof erhielt - wie oben gezeigt - Ackerland, Wiesen-, Anger- und Heidboden. Die Bauern hätten also auch nach den Reformen bei der alten Wirtschaftsweise bleiben können, denn sie hatten weiterhin die Flächenausstattung für die Heidebauernwirtschaft.

Es verwundert daher auch nicht, dass die Umsetzung der Reformen, deren Implementierung und die Durchsetzung eines neuen Wirtschaftssystems fast ein Jahrhundert in Anspruch nahmen. Die Beharrungskräfte der überkommenen Landbewirtschaftung waren in der Bauernschaft ganz erheblich, und zwar nicht nur aufgrund des geringen Bildungsniveaus der Bauern und der damals noch sehr eingeschränkten Möglichkeiten, Fachwissen und Fachinformationen zu verbreiten.

Der Prozess der Agrarreformen in Deutschland des 19. Jahrhunderts findet deutliche Parallelen in der modernen Agrarentwicklung in manchen Ländern der Dritten Welt. Auch dort treffen von außen initiierte neue Agrartechniken nicht selten auf das Beharrungsvermögen der ortsansässigen und daher auch ortskundigen ländlichen Bevölkerung.

Eine gesunde Skepsis der Bauern gegenüber Neuerungen ist weniger ein Zeichen von mangelnder Bildung und Flexibilität als vielmehr ein Zeichen rationaler Entscheidung aufgrund von tradierter Erfahrung: Für Bauern, insbesondere in der Selbstversorgerwirtschaft, ist Erntesicherheit ein sehr hohes Gut, entscheidet sie doch über das Überleben der Familie. Traditionelle Formen der Landbewirtschaftung legen daher besonderen Wert auf solche Agrar-

\footnotetext{
${ }^{1}$ Gemeint sind etwa die 60er Jahre des 19. Jahrhunderts

${ }^{2}$ Paul Roux; Der Bauer in der Lüneburger Heide und seine Anpassung an die moderne Entwicklung ; In: Science sociale, 21. Jg., 2. Periode, 23. Lieferung, Paris 1906;

Deutsche Übersetzung von W. Gröll, Ehestorf 1963, S. 27
} 
techniken, die erfahrungsgemäß der Erntesicherheit, wenn auch auf niedrigem Niveau, eine große Priorität einräumen. Neue Anbaumethoden und neue Agrartechniken werden erst angenommen, wenn der wirtschaftliche Erfolg sichtbar ist und der Bauer vom Nutzen des Neuen überzeugt ist.

Die Reformen, deren Umsetzung im Lachendorfer Raum mehr als zwei Jahrzehnte gedauert hatte, waren für eine grundlegende Umgestaltung der Wirtschaftsweise aber nur eine notwendige und keine hinreichende Bedingung.

Die Zwänge, die Heidebauernwirtschaft aufzugeben, folgten aus der ökologischen und weltwirtschaftlichen Situation.

Die Möglichkeiten, die Heidebauernwirtschaft durch neue, bessere und leistungsfähigere Formen der Landbewirtschaftung abzulösen, erreichten die Heidebauern von außen, so wie es externe Beobachter wie der französische Wissenschaftler Edmont Demolins ${ }^{1}$ nach seinem Besuch 1867 in der Südheide es vermutet haben.

\subsubsection{Neue Bodennutzung}

Aufgrund der Arbeiten von Albrecht Thaer ${ }^{2}$, dem Arztsohn aus Celle, wurde in den deutschen Landen die weit verbreitete Dreifelderwirtschaft und in der Heide auch die einseitige FeldGraswirtschaft mit häufigem Roggenanbau durch eine vielfältige Fruchtfolge ersetzt. Die Brache wurde mit Feldfutterpflanzen und Hackfrüchten bestellt. Die Gründüngung trug wesentlich zur Bodenverbesserung bei.

Die Einführung des Fruchtwechsels, der Gründüngung und der Hackfrüchte sowie insbesondere der Mineraldüngung revolutionierte das System der Heidebauernwirtschaft. Die Fruchtbarkeit des Ackers konnte durch die Einführung der neuen Anbaumethoden unvorstellbar gesteigert werden. Der Ackeranteil hing auch nicht mehr von der Heidefläche ab, sondern konnte unabhängig davon ausgeweitet werden. Nun war auch eine bessere Futtergewinnung möglich, der Großviehbestand konnte kräftig aufgestockt werden, wodurch sich auch die Produktion von Stalldung stark erhöhte, was wiederum zur Bodenverbesserung und Anreicherung mit Humus beitrug.

Der negative, abwärts gerichtete Teufelskreis der Armut der Heidebauernwirtschaft konnte in eine aufwärts gerichtete Spirale mit positiver Rückkopplung umgewandelt werden. Im neuen System der Landwirtschaft in der Heide spielten von nun an Heideflächen keine Rolle mehr. Die weitgehend geschlossene Hauswirtschaft konnte sich zu einer offenen Marktwirtschaft entwickeln, in der die modernen Produktionsmittel und -formen eine für die Heidebauern unvorstellbare Steigerung der Erträge vom Acker und aus dem Viehstall ermöglicht haben.

Zu neuen Formen der Bodennutzung gehörte auch die Einführung neuer Anbaufrüchte. Dafür ist insbesondere die Kultivierung der Kartoffel ${ }^{3}$ ein gutes Beispiel. Die Kartoffel erwies sich nämlich gerade auf den leichten Heideböden bis heute als sehr erfolgreich und stellte die Ernährung der Bevölkerung sowie die Fütterung der Schweine auf eine neue Grundlage: Die Kartoffel verdrängte Getreide als Grundnahrungsmittel der Menschen und machte eine erfolgreiche Schweinezucht möglich, mit reiner Stallhaltung und Verzicht auf Weidegang sowie Eichel- und Bucheckernmast.

\subsubsection{Bildung}

Unabdingbare Voraussetzung für die Einführung der vielen Neuerungen waren Information und Bildung der Bauern. Deshalb ist es nicht verwunderlich, dass sich im 19. Jahrhundert die landwirtschaftlichen Vereine und Gesellschaften, die sog. Winterschulen, erste Berufsschulen für die Bauernsöhne, und das Angebot an Fachzeitschriften entwickelten.

Überall wurden landwirtschaftliche Vereine gegründet, die für fachliche Bildung und Information sorgten.

\footnotetext{
${ }^{1}$ s. A. Behr (Hrsg.); Der Lutterhof bei Hermannsburg, Verlag Ludwig-Harms-Haus, 2005, S. 13 ff.

${ }^{2}$ Albrecht Daniel Thaer(1752-1828),Begründer der modernen Agrarwissenschaft

${ }^{3}$ Die Kartoffel stammt aus den Hochanden Südamerikas, kam 1565 nach Spanien, Ende des 16. Jahrhunderts nach Mitteleuropa, wurde aber erst nach 1770 verstärkt angebaut.
} 
Für den Raum Lachendorf spielte dafür der „Landwirtschaftliche Verein Beedenbostel“" des vormaligen Amtes Beedenbostel eine ganz wichtige Rolle. Der Verein wurde gegen Ende der örtlichen Reformjahre, am 5. Mai 1861 als Filialverein des Landwirtschaftlichen Provinzialvereins für das Fürstentum Lüneburg gegründet. Der Verein erwarb sich insbesondere Verdienste durch die „Regulierung“ der Höfe, die auf Antrag der Besitzer durch besonders qualifizierte Landwirte vorgenommen wurde, die die Höfe zu einer neuen Wirtschaftsweise und insbesondere zu neuen Fruchtfolgen berieten.

Diese Form der externen Beratung, heute als Arbeit der Beratungsringe selbstverständlich, muss damals ziemlich revolutionär gewesen sein: Jahrhunderte hatten die Väter die Art und Weise der Landbewirtschaftung an ihre Söhne als Hoferben tradiert, grundlegende Änderungen waren weder möglich noch erwünscht.

Der Erfolg der Beratung, der sog. Regulierung“, im 19. Jahrhundert hatte zwei Gründe: Die Not der Heidebauernwirtschaft und die vielerorts sichtbaren Erfolge neuer Wirtschaftsweise.

\subsubsection{Reform der Düngung}

Seit den Forschungen durch Justus v. Liebig ${ }^{2}$ war bekannt, dass Pflanzen anorganische Nährsalze zum Wachstum aus dem Boden aufnehmen. Diese damals grundlegenden neuen Erkenntnisse begründeten den Siegeszug der Mineraldünger, fälschlicherweise als Kunstdünger bezeichnet. Heute weiß man, dass die Pflanzenwurzel nicht Nährsalze aufnimmt, sondern das Nährelement als lon mittels lonenaustausch von den Bodenteilchen ablöst und aufnimmt.

Auf den armen und verarmten Böden begann die mineralische Düngung mit dem Ausbringen von Mergel aus natürlichen Mergelvorkommen.

Diese Kalkgaben durch Mergel verringerten den Kalkmangel der ausgelaugten Böden und verbesserten Bodenfruchtbarkeit zunächst deutlich.

Die Kalkung erhöhte aber auch den $\mathrm{pH}$-Wert des Bodens, wodurch sich die Verfügbarkeit von Nähr- und Spurenelementen im Boden verändert.

Da die Bodenfruchtbarkeit dem Gesetz des Minimumfaktors ${ }^{3}$ unterliegt, verschob sich das Problem von einem Faktor zum nächsten. Bald gerieten das wichtige Spurenelement Kupfer und die Abb. 4.2: Gesetz vom Minimum ${ }^{8)}$ Hauptnährelemente Stickstoff, Phosphor und Kalium ins Minimum:

- Das Mergeln hatte zwar die Verfügbarkeit von Kupfer verbessert, die sehr geringen Reserven im Boden, insbesondere in den Sandböden, waren aber bald erschöpft. Die Folge waren Pflanzenkrankheiten und drastischer Ertragsabfall: Der Boden war ausgemergelt ${ }^{4}$.

\footnotetext{
${ }^{1}$ F. Veth, Hg.; Landwirtschaftlicher Verein Beedenbostel, 1961, Festschrift zum hundertjährigen Bestehen, S. 9

2 Justus von Liebig (1803-1873), dtsch, Chemiker, 1845 geadelt, Begründer der Agrikulturchemie;

${ }^{3}$ A. Behr, u.a.; Mensch und Raum, Gymnasiale Oberstufe, Cornelsen - Berlin 1987, S. 229

${ }^{4}$ Daher kommt die Bedeutung des Wortes ,ausgemergelt": ausgezehrt, die letzten Kräfte sind bis zur Erschöpfung mobilisiert worden. In der Heide hieß es: Der Mergel macht reiche Väter und arme Söhne.
} 
- Erst der Einsatz industriell hergestellter Mineraldünger, insbesondere das Thomasmehl, behob diese Mangelerscheinungen ${ }^{1}$ der Kalkdüngung, weil Thomasmehl auch eine ganze Reihe wichtiger Spurenelemente, dabei auch Kupfer, enthält.

- Als die Geologen die großen europäischen Kalilagerstätten entdeckt hatten, begann auch im Kreis Celle - die große Zeit des Kalibergbaus, von der heute noch Abraumhalden zeugen. Dadurch konnte die Versorgung der Böden mit einem Hauptnährelement erstmals sichergestellt werden.

Die Versorgung der Pflanzen mit Phosphor und Stickstoff erwies sich als weiteres Problem:

- Zunächst erbrachte der Import von Guano ${ }^{2}$ und Salpeter ${ }^{3}$ aus Südamerika, eine erste Phase der Globalisierung im Kolonialzeitalter, die Rettung für die verarmten Böden in Europa und damit auch Rettung vor Hungersnöten einer schnell wachsenden europäischen Bevölkerung. Aber die Reserven an Guano und auch an natürlichem Salpeter ${ }^{4}$ sind sehr begrenzt und der Transport aus Übersee konnte den Bedarf nicht decken.

- Erst die industrielle und großtechnische Herstellung von Thomasmehl ${ }^{5}$ und das HaberBosch $^{6}$-Verfahren konnten die Landwirtschaft mit genügend Phosphor- und Stickstoffdünger versorgen.

- Bei einer optimalen Nährstoffversorgung ist heute auf den leichten Heideböden die Versorgung mit pflanzenverfügbarem Wasser oft der Minimumfaktor, der mit hohen Investitions- und Energiekosten durch künstliche Beregnung ausgeglichen werden kann.

Die Fruchtbarkeit des Ackers war nun nicht mehr durch die Heide begründet, sie war als Futter- und Düngerlieferant völlig überflüssig geworden.

Das alte Sprichwort „die Heide ernährt den Acker“ hatte endgültig und vollständig seine Berechtigung verloren.

Die Heide hatte - nach Jahrhunderten der Unverzichtbarkeit - innerhalb recht kurzer Zeit für die Bauern jedweden Nutzwert völlig verloren. Die Heide als ehemaliger Lieferant von Futter und Dünger wurde nicht mehr benötigt. Die durch Raubbau verarmte Heide wurde zum nutzlosen „Unland“.

Die Heide war aus dem System der Landwirtschaftlichen Nutzflächen ausgeschieden, eine neue, von landwirtschaftlicher Nutzung unabhängige Verwendung der Heide war möglich geworden.

\footnotetext{
${ }^{1}$ Solche Mangelerscheinungen in der Versorgung mit Nähr- und Spurenelementen entspricht genau der Mangelernährung bei Mensch und Tier durch Unterversorgung etwa mit Eiweiß oder Vitaminen.

${ }^{2}$ Guano: über das Spanische aus der indianischen Ketschua-Sprache: Mist; phosphor- und stickstoffreiche Ablagerung von Exkrementen der Seevögel in warmen Trockenklimaten, z.B. an der Westküste Südamerikas,

${ }^{3}$ Salpeter: Bezeichnung für die Salze der Salpetersäure, z.B. Kaliumnitrat

${ }^{4}$ Die für Europa zeitweise lebenswichtigen Importe von Guano und Salpeter aus Südamerika erfolgten lange mit Segelschiffen um das Kap Horn herum. Noch heute kann man am Rande der Atakama in Nordchile die Geistersiedlungen ehemaliger Arbeiter besichtigen, die den Salpeter in der Wüste abgebaut haben. Die angrenzenden Friedhöfe zeugen mit vielen Kindergräbern und frühen Sterbedaten auf den Holzkreuzen von den harten Lebensbedingungen. (Beobachtung des Verf. im Jahr 2000)

${ }^{5}$ Sidney Thomas(1850-1885, brit. Metallurg, Erfinder des Thomas-Verfahrens, bei dem in der Thomasbirne aus phosphorhaltigem Eisenerz Stahl hergestellt wird. Die Thomasschlacke wurde zu hochwertigem Phosphordünger vermalen.

${ }^{6}$ Fritz Haber (1868-1934), Carl Bosch (1874-1940), dtsch. Chemiker, Nobelpreisträger, entwickelten das Verfahren zur Ammoniaksynthese, Grundlage zur Herstellung von Stickstoffdünger.
} 


\subsubsection{Landschaft nach den Agrarreformen in der Gemarkung Lachendorf}

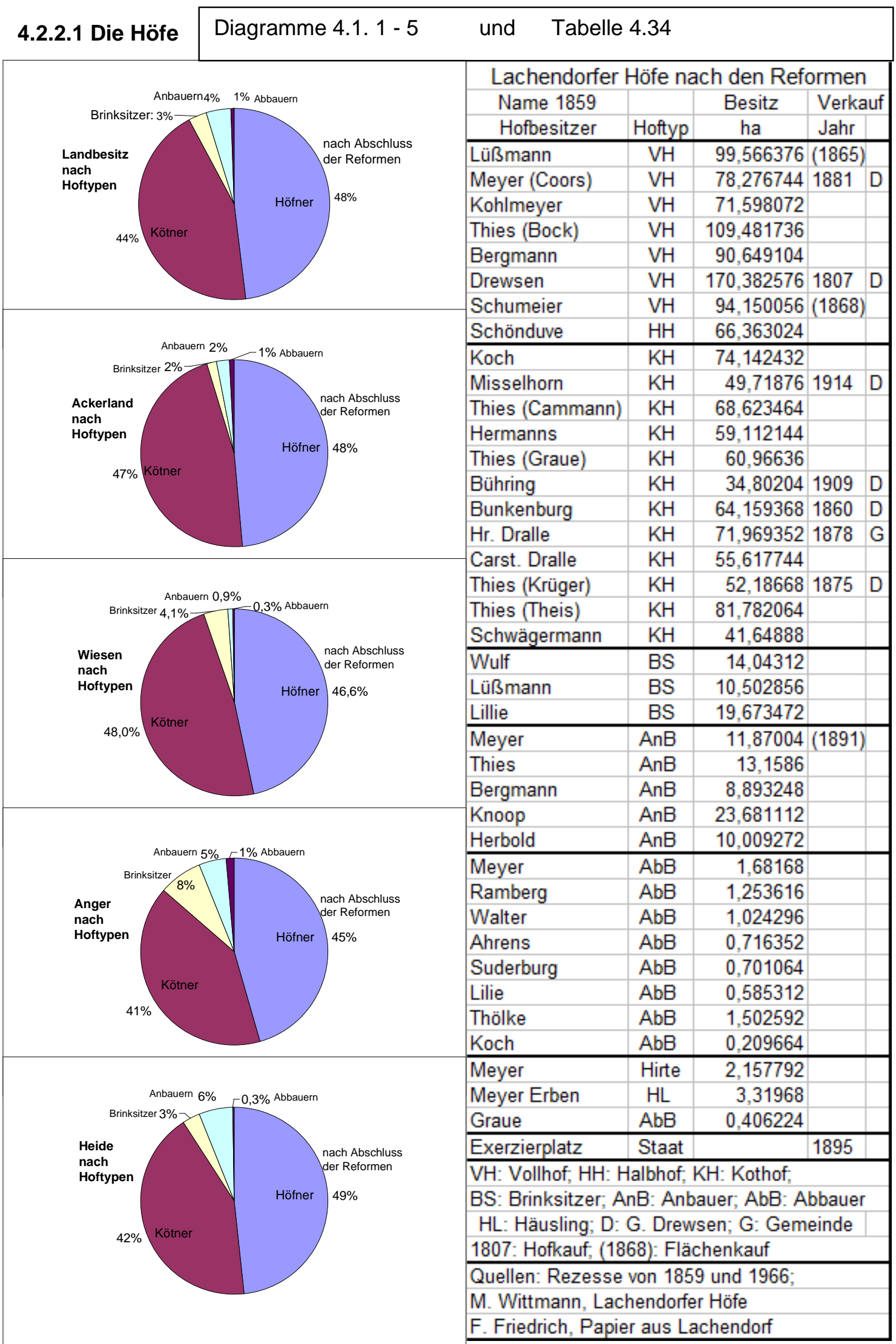


Die Agrarreformen hatten den landwirtschaftlichen Besitz bis auf kleine Reste der Gemeinheit vollständig privatisiert, daher waren jetzt nicht mehr die Dorfgenossenschaft sondern die einzelnen Bauern mit ihren privat und individuell bewirtschafteten Höfen die zukünftigen Akteure bei der Ausgestaltung der Kulturlandschaft.

$\mathrm{Da}$ - wie schon erwähnt - die Hierarchie der Hofgrößen durch die Reformen fast unberührt blieb, hatte sich nach den Reformen an der Betriebsgrößenstruktur zunächst nichts geändert. Maßgeblich für die Landnutzung waren und blieben die Höfner mit 7 Vollhöfen und einem Halbhof sowie die 12 Kötner und mit eher marginaler Bedeutung für das Bild der Agrarlandschaft die 3 Brinksitzer.

Den beiden Hauptgruppen, den Höfnern und Kötnern, gehörten sowohl beim Gesamtbesitz als auch bei Ackerland, Wiesen- und Heidboden jeweils über $90 \%$ und beim Angerboden auch 86\% der jeweiligen Gesamtfläche in der neuen Gemarkung. Dadurch wird die überragende Bedeutung dieser beiden Hoftypen in der Landnutzung deutlich belegt.

Bei den An- und Abbauerstellen, dem Hirten und dem Häusling hat es sich um kleinste Selbstversorgerstellen gehandelt, deren Besitzer im 19. Jahrhundert daher noch keine Möglichkeit hatten, die kleine Landwirtschaft aufzugeben. Diese Kleinstbetriebe haben im Haus-, Hof- und Gartenbereich des Siedlungsbereiches das Bild des Dorfes sicherlich stark mitge-

\section{Diagramme 4.2. 1/2}
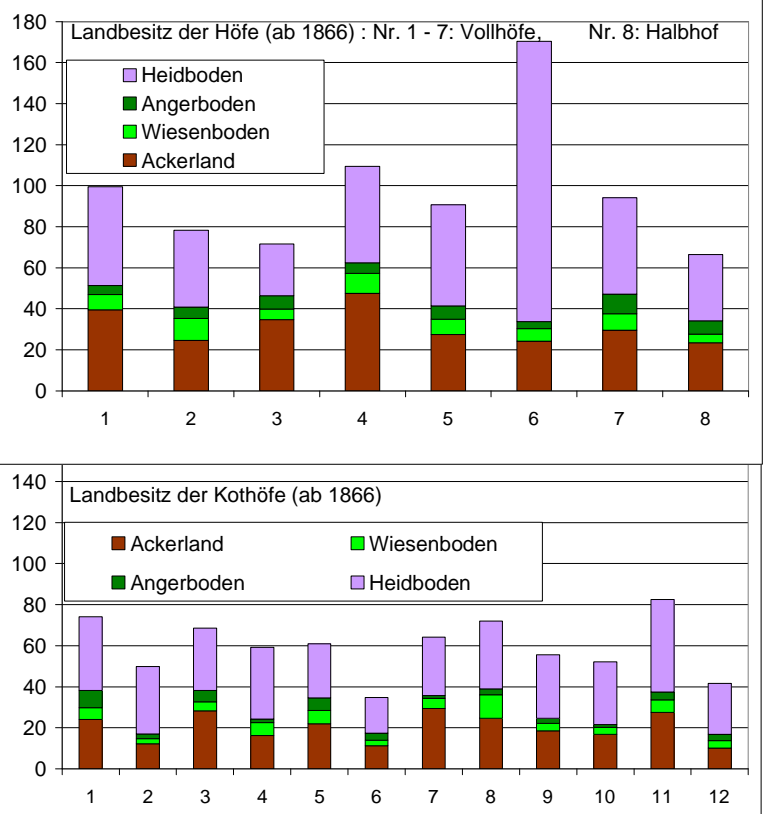
prägt. Für die Gestaltung der offenen Agrarlandschaft haben sie - außer vielleicht durch einige Miniparzellen im Acker- und Wiesenbereich - keine Rolle gespielt.

Die Vollhöfe, der Halbhof, die Kothöfe sowie die Brinksitzer und Anbauern gingen bezüglich ihres Ackerlandes, der Wiesen- und Angerflächen nicht nur wertmäßig sondern auch flächenmäßig fast unverändert aus den Reformen hervor. Aufgrund der Abfindungen aus der Gemeinheit der Allerheide ergab sich aber eine erhebliche Vergrößerung der Betriebsflächen, die allerdings die Unterschiede zwischen den Hoftypen nicht verkleinerte sondern noch vergrößerte,

Der Besitzer der Papierfabrik verfolgte nach der Privatisierung des landwirtschaftlichen Besitzes das Ziel, den bereits 1807 erworbenen Vollhof (Nr. 6) zu einem landtagsfähigen Rittergut ${ }^{1}$ aufzustocken. Dadurch kam eine nicht unerhebliche Dynamik in die örtliche Besitzstruktur, weil bis $1914^{2}$ weitere Höfe ganz oder teilweise und der Exerzierplatz auf der Allerheide angekauft wurden.

Das Rittergut bzw. sein Besitzer spielte sicherlich gesellschaftspolitisch im Ort eine Sonderrolle, der dazu gehörige landwirtschaftliche Betrieb wurde aber wie die übrigen bäuerlichen Betriebe bewirtschaftet.

Hinsichtlich der Aufforstung und dem Urbarmachen von Heideflächen auf der Allerheide war das Gut allerdings führend, weil der Gutsbesitzer über die notwendigen Mittel verfügte.

\footnotetext{
${ }^{1}$ Vergl. dazu: Florian Friedrich, Papier aus Lachendorf seit 1538, a.a.O., S. $86 \mathrm{ff}$.

${ }^{2}$ Die Jahreszahlen für die Auf- und Zukäufe stimmen in den beiden benutzten Quellen von M. Wittmann und F. Friedrich nicht in allen Fällen überein. In der Tabelle 4.34 werden die Jahreszahlen aus der Arbeit von F. Friedrich übernommen.
} 
Die Diagramme 4.2 verdeutlichen die Größenunterschiede zwischen den Hoftypen, aber auch innerhalb der zwei Gruppen. Der Vollhof des Fabrikbesitzers Drewsen, Nr. 6, war durch die besonders große Abfindung beim Heidboden zum weitaus größten Besitz aufgestiegen. Dies war möglich geworden, weil die Papierfabrik eine eigene Abfindung ${ }^{1}$ erhielt.

Die Diagramme verdeutlichen auch, dass das Ackerland und der Heidboden die beiden Schwerpunkte des neuen Besitzes wurden und die Weide- und Futterflächen auf den Angerund Wiesenböden - trotz des Grünlandes in den Aller-Dreckwiesen - in allen Betrieben nur eine geringe Bedeutung hatten.

Mit diesen Voraussetzungen an Grundbesitz konnten und mussten die Bauern in die völlig neue Epoche der Landnutzung und Gestaltung der Agrarlandschaft eintreten. Es wird sich zeigen, dass die neuen Möglichkeiten der Landwirtschaft gravierende und bleibende Folgen für die Gestaltung der Kulturlandschaft bewirkten.

\subsubsection{Ackerland}

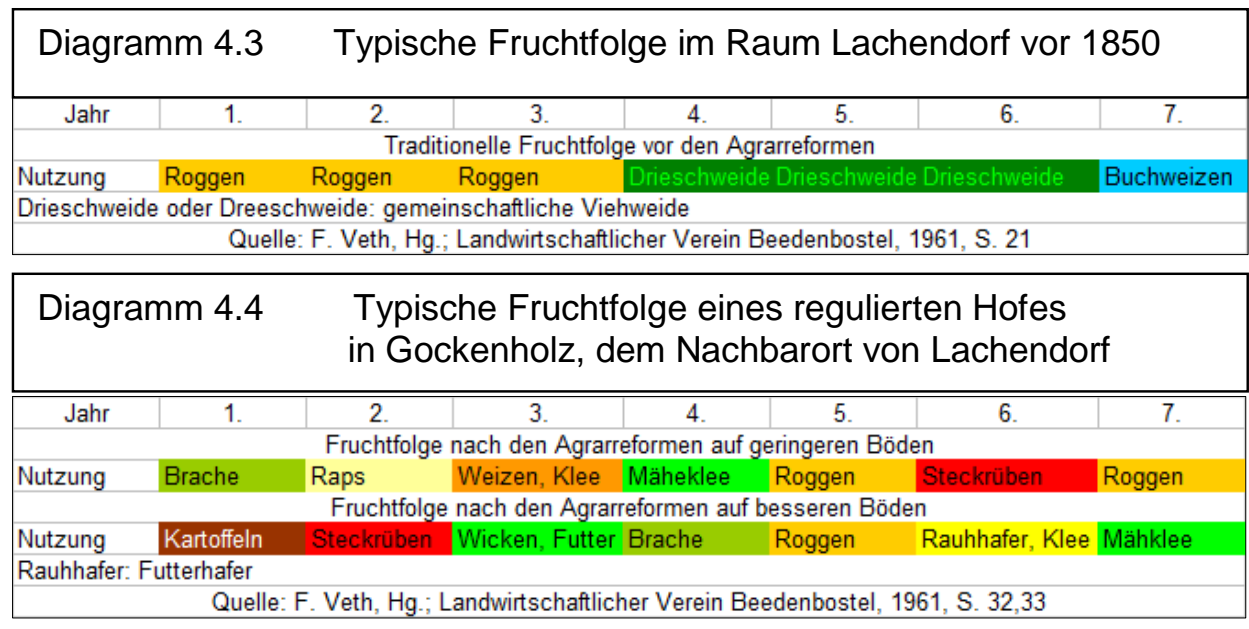

Der Schwerpunkt der privaten Nutzflächen der Höfe lag vor den Reformen eindeutig beim Ackerland und den Wiesen, denn die privaten Anger- und Heideflächen hatten nur einen sehr geringen Umfang. Die Feldmark mit den Ackergewannen muss aus zwei Gründen ein verhältnismäßig einfaches Landschaftsbild geboten haben: Einmal führte die sehr einfache Fruchtfolge zu einem wenig differenzierten Bild des Ackerlandes. Andererseits ergab die Zusammenfassung der privaten Ackerparzellen zu Gewannen mit Flurzwang ein großflächiges Landschaftsbild, das ganz im Gegensatz gestanden haben muss zur großen Anzahl der Parzellen mit Streulage, die zu einem Hof gehörten.

Gleichwohl boten die Gewanne mit den eingestreuten kleinen Heid- und Angerflächen, die Lachendorf in einem Bogen auf den Geestplatten und südlich des Ortes in der Wurzelzone des Schwemmfächers umgaben, ein differenzierteres Landschaftsbild als die Allerheide mit ihrer eher einförmigen Heidelandschaft.

Die neue Flurordnung führte auf den Ackerflächen zu einem ganz neuen Landschaftsbild:

- Die Verkoppelung führte zur deutlichen Reduzierung des Streubesitzes und der Anzahl der Parzellen eines jeden Hofes und damit auch zu größeren Nutzparzellen, den einzelnen Schlägen, die häufig den Besitzparzellen entsprachen, soweit diese wegen ihrer Größe nicht in Schläge unterteilt wurden.

\footnotetext{
${ }^{1}$ Lt. Rezess von 1859: „Verzeichnis der zum Vollhofe und zur Fabrik der Drewsenschen Erben in Lachendorf gehörenden Grundstücke"; Samtgemeinde Lachendorf, Archiv, Sign. 61/5
} 
- Die Gewanne mit Langstreifenflur und Flurzwang verschwanden zugunsten der neuen Parzellen und Koppeln mit bis dahin unbekannter Größe.

- Mit der Langstreifenflur verschwanden auch die Wölbäcker.

Schon durch diese Neuordnung der Flur ergab sich ein abwechslungsreicheres Landschaftsbild. Zur größeren Vielfalt des Ackerlandes führte aber ganz besonders die Umstellung auf neue Fruchtfolgen ${ }^{1}$ und neue Feldfrüchte, wie Kartoffeln, Rüben, Klee, Raps und gelegentlich auch Weizen.

Allerdings gingen im Laufe des 19. Jahrhunderts auch bis dahin charakteristische Nutzpflanzen wie Buchweizen und Flachs, deren Blau der Blüten sicherlich ein markanter Farbtupfer in der alten Agrarlandschaft gewesen sein muss, verloren.

Die totale Neuorientierung der Landwirtschaft hinsichtlich der Ordnung der Flur und der Wirtschaftsweise hat auf dem Ackerland zu einer starken Differenzierung und Vielfalt geführt, so wie es die Diagramme ${ }^{2} 4.3$ und 4.4 im Vergleich verdeutlichen.

Die vielfältigere Fruchtfolge führte wiederum zu größerer Abwechslung im Landschaftsbild, teils zu allen Jahreszeiten, besonders aber in der Vegetationszeit.

\subsubsection{Grünland}

\section{Allerdreckwiesen}

Die Bauern der Lachendorfer Region verfügten seit jeher über günstiges Weide- und Wiesenland in den Dreckwiesen ${ }^{3}$ im Randmoorbereich des Aller-Urstromtales. Zwar lagen diese Wiesenflächen weitgehend im Überschwemmungsbereich der Aller und auf anmoorigen Böden, die einen Weidetritt nicht vertrugen, aber die feuchten Standorte garantierten doch einen sicheren und guten Graswuchs. Damit lieferten die Allerdreckwiesen einen wesentlichen und unverzichtbaren Beitrag besonders zur Fütterung der wichtigen Rindviehbestände.

Die Daten des Rezesses von $1866^{4}$ verdeutlichen die überragende Bedeutung dieses Wiesengebietes hinsichtlich des Landschaftsbildes und der Landwirtschaft.

Im Rezess von 1866 über die Entfrettung und Verkoppelung der Aller- und Trockenen Wiesen werden nicht nur Aufhebung der Gemeinschaftsweide (Entfrettung) und die Neuverteilung der Flächen geregelt, sondern auch Regeln festgehalten, die das zukünftige Landschaftsbild - teils bis auf den heutigen Tag .- stark geprägt haben.

Der $\S 13^{5}$ legt die künftige Nutzung der Abfindungen fest, enthält also für die zukünftige Entwicklung des Raumes die entscheidenden Aussagen:

„Die sämtlichen in dem, diesem Rezeß angehängtem Verteilungsregister aufgeführten Grundstücke, sind durch Abstellung der Weide und sonstigen Servitute privatives Eigentum der Beteiligten geworden, und werden denselben zur einseitigen privativen Benutzung damit überwiesen, sofern nicht Ausnahmen in diesem Rezeß gemacht sind, und unter nachfolgenden Beschränkungen."

Die Beschränkungen und Regelungen in den folgenden Paragraphen beziehen sich auf Grenzabstände für Gebäude, Zäune und Bepflanzungen, die Einfriedung der neuen Koppeln, die Anlage und Unterhaltung der angelegten Wege und Gräben sowie auf die Entwässerung.

Die Regelungen dieses Rezesses, insbesondere in den $\S \S 13-16$ und $\S 18$, enthalten die Grundlagen für die Um- und Ausgestaltung der Aller- und Trockenwiesen an und auf dem Randmoorbereich zu einer Wiesenlandschaft im Tal eines Tieflandflusses.

Der Rezess regelt nicht nur die neuen Besitzverhältnisse, die das Landschaftsbild nur indirekt prägen. Direkte Auswirkung auf das Landschaftsbild haben die Anlage der Gräben und Wege sowie die Bestimmungen über die Markierung von Grenzen, deren Bepflanzung sowie die Nutzung der Wege und Gräben und der gemeinschaftlichen Tränken und Sandgruben.

\footnotetext{
${ }^{1}$ Vergl. F. Veth, Hg.; Landwirtschaftlicher Verein Beedenbostel, 1961, S. 32,33

${ }^{2}$ Die Daten aus der Festschrift des Landwirtschaftlichen Vereins wurden vom Verf. in kolorierte Diagramme umgesetzt, um die Vorstellung von der Veränderung in der Landschaft zu unterstützen.

${ }_{3}^{3}$ Der Name verweist auf die anmoorigen Böden, die bei Durchtrennung der Grasnarbe an den Füßen der Tiere, der Schuhe und Wagenräder hängen blieb. (Anm. d. Verf.)

${ }^{4}$ Rezess über die Verkoppelung ..., 1866, Sign.: 140/8

${ }^{5}$ ebd. S. $46-48$
} 
In $\S 16^{1}$ - „Künftige Benutzung der Wege“ geht es nicht um Wegerechte im Sinne von Benutzung als Verkehrsweg sondern um landwirtschaftliche Nutzung, die den einzelnen Bauern untersagt ist, nämlich insbesondere auch die Beweidung.

Diese Regelung ist ein weiterer Hinweis auf die Futterknappheit, denn offenbar war es üblich, auch Wege abzuweiden. Andernfalls wäre diese Nutzung nicht untersagt worden. $\mathrm{Da}$ aber die Wege gemeinschaftlicher Besitz blieben und unterhalten werden mussten, sollten auch die Nutzung bzw. die Erlöse $^{2}$ daraus der Gemeinschaft zu gute kommen.

Aufgrund der umfangreichen und detaillierten Regelungen, die im Rezess von 1866 festgehalten sind, entstand in den Aller-Dreckwiesen und auch in den Trockenen Wiesen eine geordnete Wiesenund Weidelandschaft mit genau eingemessenen und gradlinig begrenzten Besitzparzellen, dem daran ausgerichteten planmäßigen Wegenetz und einem genau nivellierten umfangreichen Grabensystem zur Entwässerung. Diese Wiesenlandschaft, die wegen des Baumbestandes an den Gräben und Wegen, einigen Einzelbäumen in den Parzellen und kleinen Gehölzgruppen einen Parkcharakter aufwies, hatte fast unverändert bis über die Mitte des 20. Jahrhunderts Bestand.

\section{Trockene Wiesen und Stauwiesen}

Die Trockenen Wiesen westlich der Dreckwiesen und nördlich des Schwarzwassers und des Lorkberges trugen zwar auch schon vor 1850 Grünland, boten aber wegen der anstehenden trockenen Talsande bezüglich der Pflanzenarten einen ganz anderen Standort, mit zwar trockenem und trittsicherem Weideland, aber ohne Ertragssicherheit.

Daher setzte sich bald nach den Reformen die Erkenntnis durch, gemeinschaftlich diesen Standort dauerhaft aufzuwerten.

Lachendorfer und Oppershäuser Bauern folgten einem im 19. Jahrhundert weit verbreiteten Trend: Sie gründeten 1881 eine Bewässerungsgenossenschaft und legten auf einem Teil der trockenen Wiesen Bewässerungswiesen an. Dabei waren die Bedingungen nicht einmal op-

\footnotetext{
1 ebd. S. $59 \mathrm{f}$

${ }^{2}$ Der Verfasser kann sich daran erinnern, dass in seinem Heimatdorf noch bis etwa 1950 die Straßenränder bzw. -gräben von der Realgemeinde zur Nutzung jährlich an Häuslinge oder Kleinbauern vergeben wurden, die dort Futtergras mähten oder ihre Kuh hüteten.
} 
timal: Als Bewässerungswasser konnte auf der Nordseite der Aller nicht direkt Wasser aus der Oker, die im Gegensatz zu der Aller und dem Schwarzwasser nährstoffreicheres Wasser führt $^{1}$, genutzt werden. Das Bewässerungswasser kam als Überschusswasser aus den Stauwiesen von Nienhof ${ }^{2}$, wurde über einen langen Graben herangeführt und unterquerte in einem Düker das Schwarzwasser.

\section{Stauwiesen}

Am 23.11.1881 wurde die „Freie Oppershausen-Lachendorfer Bewässerungsgenossenschaft" mit Sitz in Oppershausen ${ }^{3}$ gegründet. Ab 1882 wurden dann auf 96,1238 $\mathrm{ha}^{4}$ für 20387,51 M Rieselwiesen angelegt. Zur Gesamtanlage gehörten 2,9 km Zuleitung, 0,8 km Ableitung, 5 Stauschleusen von 2,5, - 4 m I. W., 4 massive Brücken von 2,5 - $4 \mathrm{~m} \mathrm{I}$. W., zwei Düker von 0,80 m Durchmesser und $11 \mathrm{~m}$ bzw. $16 \mathrm{~m}$ Länge sowie 6 Durchlässe von je $80 \mathrm{~cm}$ Durchmesser.

Man hat sogar das Dünengebiet des Lorkberges durchstochen, um auch südlich davon in einem Mäanderbogen der Aller bewässern zu können.

Die Ausdehnung des Stauwiesengebietes ergab sich einerseits aus der Lage der Trockenen Wiesen nördlich von Schwarzwasser und Aller als südlicher Grenze. Die nördliche Grenze und damit die Trassenführung des Hauptzuleitungskanals ergab sich aus dem Gefälle des Allertales im Quer- und Längsprofil, insbesondere aber aus der Höhenlage des Abflusses aus den Stauwiesen bei Nienhof. Vom Austritt aus diesem Stauwiesengebiet musste bis zum Abfluss aus den Oppershausen-Lachendorfer Stauwiesen ein Gefälle eingehalten werden, da die Wasserzufuhr nur auf natürlichem Gefälle beruhte.

Der hohe technische und finanzielle Aufwand bei vergleichsweise kleiner Fläche (212 M/ha Erstellungskosten) belegt erneut den großen und dringenden Futterbedarf für die Tierhaltung auf den Höfen.

Die Bewässerung erfolgte als Grabeneinstau bis zur leichten Ausuferung von November bis März, dann sorgten halbvolle Gräben für das Feuchthalten bis zur Ernte, zu der das Wasser ganz abgelassen wurde. Nach der Mahd erfolgte wieder ein leichter Einstau bis die Gräben gut voll waren. Der erste Schnitt wurde als Heu eingebracht, der zweite Schnitt auch teilweise abgeweidet ${ }^{5}$.

Mit diesen Stauwiesen wurde auf trockenen Talsanden im Urstromtal eine Wiesenlandschaft geschaffen, die durchaus als standorttypischer Feuchtwiesenbiotop bezeichnet werden kann. So resultierte aus der rein wirtschaftlich motivierten Intensivierung von minderwertigem Grünland zur Behebung von Futtermangel eine Wiesenlandschaft, die den Lebensraum für typische Pflanzen- und Tierarten aus den natürlicherweise feuchten Aller- und Dreckwiesen künstlich erweiterte. Insbesondere boten die Stauwiesen zusammen mit dem großen Areal der Aller- und Dreckwiesen einen von Verkehr und Siedlung ungestörten Lebensraum für die Kulturfolger aus der Gruppe der typischen Wiesenvögel wie Brachvogel, Uferschnepfe und Bekassine.

Die Stauwiesen wurden also zu einem besonderen Element der Kulturlandschaft, das für einen scheinbar „natürlichen“ Standort mit einem breiten natürlichen Artenspektrum sorgte. Das künstlich angelegte Stauwiesenareal ergänzte und vergrößerte den naturnah wirkenden Grünlandstandort der Dreckwiesen hinsichtlich Flora und Fauna sowie auch im gesamten Landschaftsbild.

Die Stauwiesen erweiterten das ertragreiche Grünlandareal und bereicherten die Kulturlandschaft im Allertal.

\footnotetext{
1 s. Kap. 2

2 Mündliche Auskunft (1966) von Herrn Hackemann, Oppershausen, Vorsteher des Stauwiesenverbandes sowie Topographische Karte, Orohydrographische Ausgabe

${ }^{3}$ Quelle der Daten zu den Stauwiesen: Kreisarchiv Celle, unveröffentlichte Originalakten

${ }^{4}$ Akte 653- 62, Landkreis Celle, Straßen- und Wasserbauabteilung

${ }^{5}$ Mündliche Auskunft (1966) von Herrn Hackemann, Oppershausen
} 
Bereits in den Jahren von 1865 - 1867 waren auf dem Lachenkamp, nördlich der Lachte im Westen der Gemarkung, Rieselwiesen angelegt worden ${ }^{1}$. Bewässert wurde mit Abfallwasser der Papierfabrik, das über einen Kanal, der fast parallel zur Lachte nach W verläuft, herangeführt wurde. Um eine ständige Wasserversorgung zu gewährleisten, wurde der Kanal bis zum Oberwasser der Lachte verlängert ${ }^{2}$.

Diese frühe landeskulturelle Maßnahme des Drewsenschen Vollhofes zeigt, dass der Besitzer der Papierfabrik auch in seinen landwirtschaftlichen Betrieb investierte und bei Modernisierungs- und Intensivierungsmaßnahmen offenbar mit gutem Beispiel voranging. Aufgrund der geringen Größe wurden diese Rieselwiesen aber nicht landschaftsprägend.

\subsubsection{Allerheide - Heide - Wald}

Nach Abschluss der Generalteilung und Spezialteilung der Gemeinheiten auf der Allerheide begann für diesen Gemarkungsteil eine völlig neue Phase der Landschaftsentwicklung und Bodennutzung.

Die erste Bedingung ist im Rezess von 1861 über die Generalteilung unmissverständlich festgelegt, nämlich die Aufhebung aller Rechte und die Übertragung auf die einzelnen Dörfer.

\section{„§ 22. Künftige Benutzung der Abfindungen}

Alle auf den verteilten Revieren als der Allerheide icl. dem Osterbruchmoore, dem Lachendorfer Moor, dem Westermoor, der Allerohe und dem Allerhorn, sowie auch auf den nicht zum Teilungsobjekte gehörenden Reviere, dem Altenceller Risch und den Altenceller Fuhren bisher ausgeübten gemeinschaftlichen Nutzungen werden in Folge der Generalteilung hiermit aufgehoben, und gehen die statt der seitherigen gemeinschaftlichen Gerechtsamen für die einzelnen Berechtigten ausgemittelten Äquivalente in einem völlig privativem Zustand auf die einzelnen Ortschaften über. ${ }^{‘ 3}$

Damit waren die alte Gemeinschaftsweide und andere gemeinschaftliche Nutzung verschiedener Ortschaften für immer aufgehoben: Ein Grundpfeiler der alten Agrarordnung, die gemeinschaftliche Nutzung von Flächen, war beseitigt worden.

Das bedeutete aber noch nicht die Abkehr von der alten Wirtschaftsweise, denn die Nutzungsrechte in der neuen Dorfgemarkung gingen auf den Ort, also die Dorfgemeinschaft, d.h. die Gemeinschaft der Bauern bzw. deren Höfe über.

Die sehr aufwändige Anlage der Grenzgräben legt den Schluss nahe, dass weiterhin von einer Beweidung der Gemeinheiten ausgegangen wurde. Die Gräben sollten nicht nur die Grenze markieren sondern sicherlich auch dafür sorgen, dass die neuen Weidebereiche eingehalten wurden und man das Vieh leichter daran hindern konnte, auf unbefugten Flächen zu grasen ${ }^{4}$. Die aufwändigen Grenzgräben hatten unzweifelhaft die Aufgabe eines Zaunes zu erfüllen. Für Zäune aus Holz fehlte vor Ort das Material und Drahtzäune ${ }^{5}$ waren noch unbekannt, Gräben also die einzige Möglichkeit der deutlichen Abgrenzung in der freien Landschaft.

\footnotetext{
${ }^{1}$ Schulchronik II, S. 50

${ }^{2}$ Die rückwärtige Verlängerung des Kanals erfolgte 1871, (Schulchronik II, S. 50), ist aber bis heute selbst in den amtlichen Katasterplankarten 1:5000 nicht eingezeichnet.

${ }^{3}$ Plan-Rezess über die Generalteilung der "Communion-Reviere“ ..., 1861, Sign.: 61/8, S. $71 \mathrm{f}$

${ }^{4}$ Die Bedeutung der Grenzgräben für das Weidevieh wird durch eine Begebenheit aus der Gemeinde Hermannsburg im nördlichen Kreis Celle verdeutlicht: Die Bauern verklagten den Grundherrn J. H. v. Hasselhorst, weil dieser einen Grenzgraben hatte zuschütten lassen und das Vieh der Hermannsburger Bauern auf dessen Weiden gewechselt hatte. Offenbar hatten die herrschaftlichen Knechte das Vieh der Bauern „krumm und lahm geschlagen“, weshalb die Bauern die Obrigkeit baten, „den von Hasselhorst anzuhalten, einen Zaun zu ziehen“. Quelle: unveröffentlichtes Hausbuch des Lutterhofes bei Hermannsburg, S. 41/42, zitiert in: A. Behr (Hg.); Der Lutterhof bei Hermannsburg, 2005, S. 70 ${ }^{5}$ Der Stacheldraht nur aus Metall wurde erstmals 1873 zur Einzäunung von Weiden in den USA eingesetzt.
} 
Als einfache Grenzmarkierung hätte man sicherlich keine so aufwändigen, in Handarbeit angelegte Gräben ausgeworfen, insbesondere dann nicht, wenn man gleich von einer Aufforstung oder von einer Kultivierung zu Ackerland ausgegangen wäre.

Heute haben diese Gräben ihre Funktion verloren und können als kulturhistorische Relikte des 19. Jahrhunderts eingestuft werden, die sich auch nur unter Wald erhalten haben. Bei anderer Nutzung sind sie als nutzlose und viel Raum einnehmende Hindernisse längst durch Einebnen beseitigt worden.

Die Generalteilung gab also offenbar allein noch keine Grundlage für eine veränderte Wirtschaftsweise und damit auch keine Grundlage für einen Wandel in der Kulturlandschaft.

Diese ehemals freien Weidegebiete waren zu damaliger Zeit auch keineswegs Ödland, das nach den Agrarreformen kultiviert wurde. Vielmehr war es unverzichtbares Kulturland der damaligen Landwirtschaft.

Die Generalteilung war ein Rechtsakt, der noch nicht unmittelbar zur Änderung der Wirtschaftsweise und so auch nicht direkt zum Wandel der Kulturlandschaft führte. Dies lässt sich recht gut an der Behandlung der Immenstellen auf der Allerheide belegen.

Die Immenstellen auf der Lachendorfer Allerheide, die insgesamt eine Fläche von 2,2607 ha umfassten, sind sorgfältig als private Parzellen innerhalb der alten Gemeinheit und der Abfindungen an die Dorfschaften vermessen und ausgewiesen worden. Das bedeutet, dass der Wirtschaftszweig der Bienenhaltung und damit der Honiggewinnung durch den Erhalt der Immenstellen auf privaten Grundstücken garantiert wurde. Nur auf dem an die Militärverwaltung verkauften Exerzierplatz musste die Immenstelle des Kötners Koch ${ }^{1}$ von $61 \mathrm{QR}=$ 0,1332 ha aufgegeben werden, wurde aber anderweitig entschädigt.

Die Immenstellen in der Heide bestanden meist aus Ringwällen zum Aufstellen der Immenkörbe. Als Relikte einer vergangenen Kulturlandschaft sind sie unter Wald noch teilweise erhalten.

Die Höfe hatten durch die Reform einen
nicht unerheblichen Gewinn an
Wirtschaftsflächen ${ }^{2}$ zu verzeichnen,
überwiegend natürlich bei den Anger- und
Heideflächen, weil die vor den Reformen
überwiegend der Gemeinschaftsverfügung
unterlagen. Nach der Spezialteilung standen
auch diese Flächen den Hofbesitzern zur
freien und alleinigen Verfügung.

In der Zeit der Heidebauernwirtschaft hatte sich auf der Allerheide eine kulturtypische Heidelandschaft gebildet, die einen ursprünglichen, klimatypischen Tab. 4.36

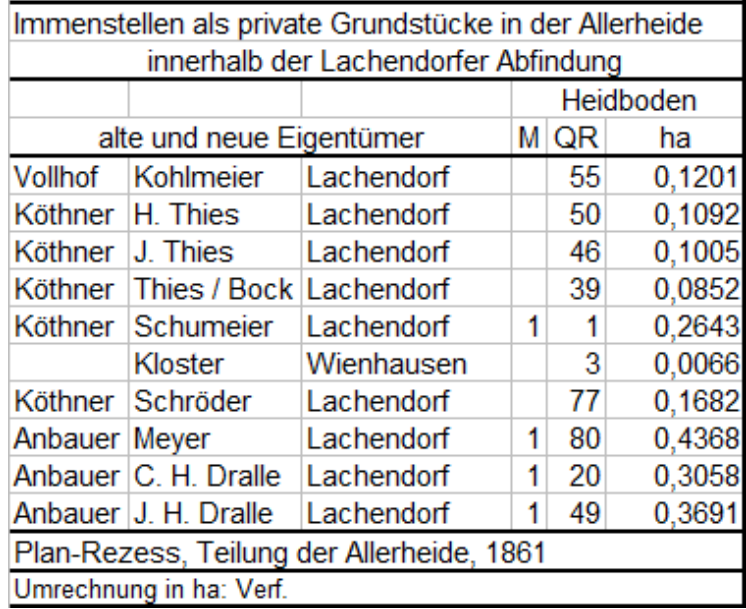
Laubmischwald abgelöst hatte. Dies war eine Folge der natürlichen Ausstattung dieses Raumes und der lange üblichen Wirtschaftsweise:

Der Schwemmfächer der Lachte ist geprägt von Sanden mit meist sehr geringer Wasserspeicherkapazität. Auf diesem trockenen Standort dürfte schon von Natur aus ein recht lichter Laubmischwald gestockt haben. Der lockere Kronenschluss ermöglichte sicherlich einen Unterwuchs, zu dem wegen der nährstoffarmen und trockenen Böden die Besenheide (calluna vulgaris) und die Drahtschmiele (Deschampsia flexuosa) und der Wacholder (Juniperus communis) gehört haben werden.

\footnotetext{
${ }^{1}$ Rezess von 1861 , Sign.: $61 / 8$, S. 47

${ }^{2}$ Der Flächenzuwachs wurde errechnet als Differenz der durch die Reform erhaltenen und in die Reform eingebrachten Flächen.
} 
Da die Wuchsleistung aufgrund der Bodengüte gering ist, war die Regenerationsfähigkeit des standorttypischen Laubwaldes gegenüber einer Raubbauwirtschaft am Wald schnell erschöpft. Holnutzung, insbesondere aber die Waldweide sowie die Streu- und Laubheugewinnung dürften in der Allerheide schon sehr früh zur Devastierung des natürlichen Waldes geführt haben.

Standortgemäß breiteten sich mit zunehmender Belichtung Heide und Gräser als flächendeckende Vegetation aus. So zeigt die Kurhan. Karte von 1779 das typische Bild einer weiten, fast völlig baumlosen Heidelandschaft auf dem Schwemmfächer der Lachte im Urstromtal der Aller.

Aber recht schnell wurde klar, dass man die neuen „Ödländereien“ durch Aufforstung ganz neu nutzen konnte, zumal im 19. Jahrhundert trotz oder gerade wegen des Beginns des Kohlezeitalters ein enormer Holzbedarf, z.B. im Bergbau, bestand.

Da die Aufgabe der Heidebauernwirtschaft im Laufe des 19. Jahrhunderts erfolgte, hat sich auch in dieser Zeit das Bild der Kulturlandschaft der Allerheide vollständig gewandelt: Aus einer Heidelandschaft wurde eine Waldlandschaft, allerdings nicht als naturnaher Laubwald durch natürliche Sukzession einer Wiederbewaldung sondern als Aufforstung zu Nadelholzforsten, überwiegend mit Kiefern.

Die Aufforstung erforderte erheblichen Aufwand, nicht nur finanzielle Mittel für das Pflanzgut, sondern auch erheblichen Kraft- und Arbeitsaufwand, insbesondere beim Pflügen der Heide.

Der Umbruch war aus zwei Gründen notwendig: Einmal musste eine vegetationsfreie Pflanzfurche für die Baumsetzlinge geschaffen werden und zum anderen musste der weit verbreitete Heidepodsol mit einer verhärteten Orterde- oder gar Ortsteinschicht aufgebrochen werden, um die Wasserleitfähigkeit des Bodens zu verbessern.

Zur Begrenzung des Pflugaufwandes kam auch auf der Allerheide die von ProvinzialForstminister Georg Quaet-Faslem entwickelte Pflugtechnik ${ }^{1}$ zum Einsatz: Mit einem Beetpflug wurden parallele, 2,4 m breite Streifen zu je 7 Furchen gepflügt und jeweils dazwischen 1,6 m breite ungepflügte Streifen belassen. Das Pflügen erfolgte in zwei Schritten: der Vorpflug diente zum Abschälen der Heidnarbe, der Tiefpflug zum Umbruch bis 0,60 m Tiefe. Der dazu benutzte sog. Schwingflug ${ }^{2}$ benötigte die Zugleistung von 4 bis 6 Pferden. Das Pflanzen der Setzlinge erfolgte dann mit dem Keilspaten nach Benetzen der Wurzeln. ${ }^{3}$

Der Wechsel von Streifen mit erhaltenem Orterdeband (ungepflügter Balken) und zerstörtem Orterdehorizont (Pflugbeet), führt zu starken Wuchsunterschieden ${ }^{4}$ und ist daher für den Landschaftshaushalt recht wichtig.

Der Drewsensche Hof, 1882 als Rittergut Lachendorf, Nr. 54 des Cantons Gifhorn, von der Lüneburger Ritterschaft als landtagsfähiges Rittergut ${ }^{5}$ anerkannt, machte sich die Erfahrungen von G. Quaet-Faslem zu nutze und übertrug inm nach Ankauf des Exerzierplatzes im Jahr 1885 die Aufforstung der 252 Morgen Heide ${ }^{6}$. Gegen Ende des Jahrhunderts nach Abschaffung der Schnucken wurden weiterte 90 Morgen geringwertigen Ackers und 150 Morgen Heide unter gleicher Leitung, ebenfalls mit Kiefern und Fichten ${ }^{7}$, aufgeforstet. Dieser Betrieb bzw. sein Besitzer hatte die Beziehungen und Mittel, eine hochqualifizierte Fach-

\footnotetext{
${ }^{1}$ s. Georg Quaet-Faslem; Die Forstkultur auf den Heidflächen bei Niebeck im Lüneburgschen, Burckardt-Hefte, Jg. 1875, Heft VI

${ }^{2}$ Der Schwingpflug, früher auch teilweise Schwungpflug genannt, ist ein einschariger Beetpflug, bei dem der Pflugbaum vorn keine Unterstützung (etwa ein Rad) hat und die sog. Stellung direkt mit der Zugvorrichtung verbunden wird. Vergl. dazu W. Hamm; Das Ganze der Landwirtschaft, a.a.O., S. 2021

${ }^{3}$ s. G. Quaet-Faslem, a.a.O.: Genaue Darstellung der 1867 begonnenen Aufforstung der Klosterforst Niebeck bei Unterlüß

${ }^{4}$ vgl. Moll, H.W. , Beobachtungen über den Einfluss der Bodenbearbeitung auf die Wuchsverhältnisse älterer Heideaufforstungsflächen, in: Sonderdr. aus '.'Forstarchiv", 26. Jg., H. 2 v. 15.2.55, S. 25 - 30, Hannover-Waldhausen 1955

${ }^{5}$ s. F. Friedrich, Papier aus Lachendorf, a.a.O., S. 85

${ }^{6}$ ebenda, S. 86

${ }^{7}$ ebenda, S. 86
} 
kraft zu engagieren und hochwertiges technisches Gerät einzusetzen. Der Heideumbruch erfolgte hier mit dem sog. Rajol-Pflug ${ }^{1}$, einem Untergrundpflug zur Tiefenkultur, der den Oberboden wendet und den Unterboden nur lockert und damit die Orterde aufbricht.

Auf dem ehemaligen Exerzierplatz, der im Auftrage des Rittergutes aufgeforstet wurde, später in den Besitz der Klosterforst Miele (Abteilung 208², im SW des Ortes westlich der Straße nach Oppershausen) und heute Staatsforst ist, haben sich Pflugbeete besonders gut erhalten.

Die Aufforstungen erfolgten sonst nicht großflächig und insgesamt zeitlich nicht einheitlich, sodass im Laufe des 19. und bis ins 20 Jahrhundert ein buntes Mosaik aus Heideflächen und Wald verschiedener Altersstufen entstand mit meist scharfen, gradlinigen Bestandsgrenzen, die sich nach den Besitz- bzw. Parzellengrenzen richteten.

Wegen der Spezialteilung an die Lachendorfer Höfe entstand trotz des großen Besitzanteils des Rittergutes, der nicht arrondiert war, auf der ehemaligen Gemeinheit der Allerheide ein buntes Mosaik der Besitzparzellen und bei der Umwandlung in Wald ein „Bauernwald“.

Obgleich der Wald nun nicht mehr zur landwirtschaftlichen Nutzfläche gerechnet wurde, erhielten die neuen Waldflächen auch einen neuen betrieblichen Wert für die Höfe, nachdem die Heide ihren Wert fast vollständig verloren hatte. Die wirtschaftliche Bedeutung des Waldes für die Höfe hatte lange zeit zwei Aspekte: Zum einen bringt der Wald einen jährlichen Wertzuwachs, der als Rücklage und für Investitionen zur Verfügung steht, sobald schlagreifes Holz herangewachsen ist. Der zweite Aspekt betrifft die Arbeit auf den Höfen: Solange noch zahlreiche Arbeitskräfte zur Verfügung standen bzw. unbedingt in der Saison der Feldarbeit benötigt wurden, gab der Wald in den Wintermonaten willkommene Arbeitsmöglichkeiten für die sonst unterbeschäftigten Dauerarbeitskräfte auf den Höfen.

Das Landschaftsbild der Allerheide muss in der 2. Hälfte des 19. Jahrhunderts ein weder vorher noch später vorhandenes sehr abwechslungsreiches Bild ergeben haben. Durch die zeitlich gestaffelten Aufforstungen gab es ein buntes Mosaik von unterschiedlichen Landschaftsstadien, von der noch vorhandenen Heide über umgebrochene Heide mit Anpflanzungen bis zu Kiefernwald, ebenfalls in verschiedenen Wuchsstadien.

Da die alten Heideflächen immer weniger bzw. überhaupt nicht mehr traditionell genutzt wurden, wird sich auch auf diesen Flächen eine natürliche Sukzession eingestellt haben.

Der grundlegende Landschaftswandel auf der Allerheide wird durch die Gegenüberstellung des Nutzungsspektrums um 1850 und der Waldstruktur um 1972 in Tabelle 4.37 nochmals sehr deutlich. Die Bezugsräume der beiden Tabellen sind zwar nicht identisch, das heutige Waldgebiet in der Allerheide liegt aber vollständig innerhalb des ehemaligen Amtes Beedenbostel.

\begin{tabular}{|c|c|c|c|}
\hline \multicolumn{4}{|c|}{ Tabelle 4. 37} \\
\hline \multicolumn{4}{|c|}{ Nutzung der Allerheide um 1850} \\
\hline \multicolumn{4}{|c|}{ Bereich des ehem. Amtes Beedebostel } \\
\hline \multicolumn{2}{|c|}{ Nutzungsart } & ha & $\%$ \\
\hline \multicolumn{2}{|c|}{ Nadelholzbestand } & 0,8892 & 0,08 \\
\hline \multicolumn{2}{|c|}{ Ellernholzbestand } & 3,2746 & 0,29 \\
\hline \multicolumn{2}{|c|}{ Heid- und Plaggenhieb } & 472,6326 & 41,97 \\
\hline \multicolumn{2}{|c|}{ Bultenhieb } & 87,2199 & 7,75 \\
\hline \multicolumn{2}{|c|}{ Wiese } & 542,7606 & 48,20 \\
\hline \multicolumn{2}{|c|}{ unbrauchbar } & 1,8479 & 0,16 \\
\hline \multicolumn{2}{|c|}{ private Grundstücke } & 17,4238 & 1,55 \\
\hline \multicolumn{3}{|c|}{$\begin{array}{ll}\text { Summe } & 1126,0486\end{array}$} & 100,00 \\
\hline \multicolumn{4}{|c|}{ Plan-Rezess, §9, S. 18/19; Sign. 61/8 } \\
\hline \multicolumn{4}{|c|}{\begin{tabular}{l|l} 
& Waldstruktur 1972 \\
\end{tabular}} \\
\hline & \multicolumn{3}{|c|}{ Gemarkung Lachendorf } \\
\hline & Baumart & ha & $\%$ \\
\hline \multirow{5}{*}{$\begin{array}{l}\text { elle } \\
\text { bei } \\
\text { tige }\end{array}$} & Eiche & 12,70 & 1,66 \\
\hline & anderes Laubholz & 27,60 & 3,60 \\
\hline & Fichte & 18,50 & 2,42 \\
\hline & Kiefer & 707,10 & 92,32 \\
\hline & Summ & 765,90 & 100,00 \\
\hline & $\begin{array}{r}\text { Quelle: Agrarstruk } \\
\text { a.a.O. }\end{array}$ & $\begin{array}{l}\text { kturelle Vorp } \\
\text { S. } 79 \mathrm{f}\end{array}$ & planung. \\
\hline
\end{tabular}

\subsubsection{Neue Kulturlandschaft um 1900}

Nach etwa einem halben Jahrhundert hatte sich eine neue Kulturlandschaft herausgebildet.

Zwar war weiterhin die naturbedingte Dreiteilung der Gemarkung auf den Geestplatten mit vorwiegend Acker, Grünland in den Allerwiesen und am Schwarzwasser und dem weitge-

\footnotetext{
${ }_{1}^{1}$ ebenda, S. 86, s.a.: http://5dic.de/Lexikon_der_gesamten_Technik/page/Pflug.17

${ }^{2}$ Laut Erläuterungsbericht der forstlichen Standortkartierung handelt es sich erwiesenermaßen um

Pflugbeete, Erläuterungen Miele, S. $51 \mathrm{ff}$
} 
hend in Wald umgewandelte Schwemmfächer zu erkennen, aber die Ackerländereien und besonders die ehemaligen Heideflächen hatten ihren Landschaftscharakter stark verändert, nur die Wiesenlandschaft hatte ihren Charakter trotz des modernen, geometrischen Wegeund Grabennetzes bewahrt, war durch die Stauwiesen sogar landschaftlich erweitert worden. Insbesondere unterschied sich die Landschaft von der vor den Reformen auch durch das geplante und exakt eingemessene Wege-, Straßen- und Grabennetz, das die Landschaft bis heute fast unverändert strukturiert.

Die Karte der Landnutzung um 1900 (Karte 4.3) macht dies im Vergleich zur Karte um 1840 (Karte 4.1) sehr deutlich.

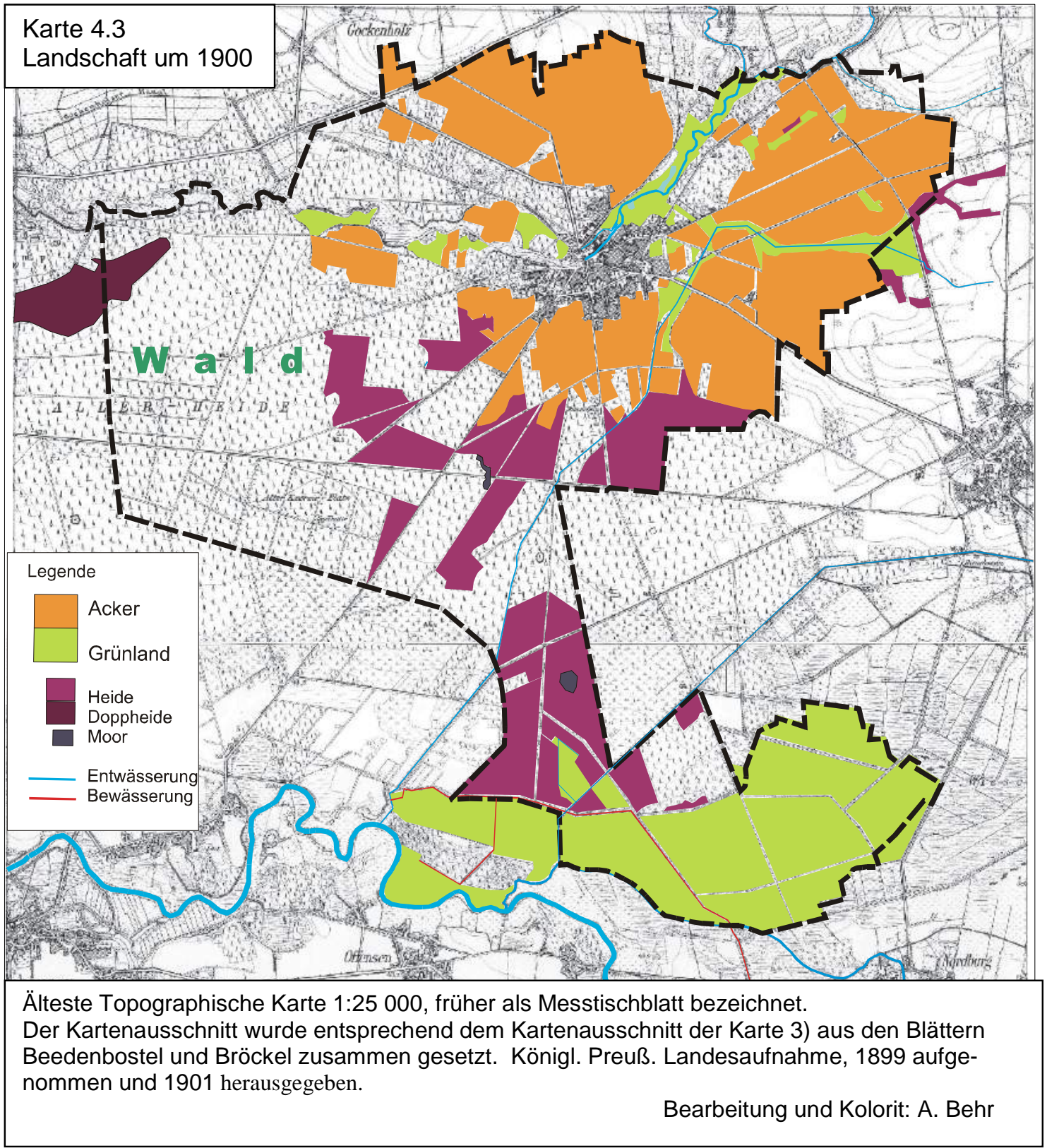

Kap. 5: Kulturlandschaft im 20. Jahrhundert 


\section{Kapitel 5 Kulturlandschaft im 20. Jahrhundert}

\section{Kap. 5.1 Ausbau und Stagnation in der 1. Hälfte des 20. Jahrhunderts}

Die vor 1900 begonnene Umgestaltung der Allerheide wurde fortgesetzt und abgeschlossen, überwiegend durch Aufforstung der früheren Heideflächen, aber auch durch die Anlage von Weiden:

Ein größerer Weidekomplex entstand westlich des Trockenwiesenweges, etwa gegenüber vom östlich gelegenen Krähenmoor. Dies Gebiet entsprach der ehemaligen „zum Bultenhiebe benutzten Fläche vor den Allerwiesen“, wie es im Rezess von 1859 in §5) erwähnt wird. Man kann davon ausgehen, dass die Bultenhiebsfläche überwiegend von Pfeifengras geprägt war, das als Standortzeiger für Grundfeuchte gilt. Die Umwandlung in Weide war also ökologisch sinnvoll und aufgrund der Entfernung zum Dorf auch wirtschaftlich. Diese Interpretation wird auch gestützt durch die Kartierung von $1966^{1}$, die südlich der Weide im Kiefernhochwald Bestände von Pfeifengras erfasste.

Eine weitere Weide wurde ganz im Westen der Gemarkung am Rande des Postmoores angelegt. Auch dieser Standort war ökologisch sinnvoll gewählt, da dort 1966 außerhalb der Weide Bestände von Pfeifengras und Glockenheide, beides Zeigerpflanzen für Grundfrische, kartiert werden konnten.

Grünlandstreifen entlang der Tiefenlinien von zwei Trockentälern, einmal unweit des damaligen nordwestlichen Ortsausgangs nördlich der Straße nach Celle und zum anderen östlich des Dorfes im Oberlauf des Schelpriethgrabens und im kleinen Moor am Ostrand des Dorfes, wurden teils etwas vergrößert bzw. verändert, besonders aber mit geraden Grenzen versehen, um auf den benachbarten Äckern klare und gerade Schlaggrenzen zu haben, die ein rationelles Bearbeiten, insbesondere beim Pflügen, erlauben.

Die Erweiterung der Grünlandflächen auch auf trockeneren Standorten verdeutlicht, dass die Tierhaltung in der Landwirtschaft eine wichtige Rolle spielte und dass die Höfe offenbar auf die Kombination von Ackerbau und Viehhaltung ausgerichtet waren.

Im Süden des Dorfes in der Wurzelzone des Schwemmfächers, entlang der Straße nach Oppershausen und auf der Lachteterrasse am Weg nach Jarnsen, hat es einige kleinere Veränderungen unterschiedlicher Art gegeben: einige Ackerflächen wurden aufgeforstet, einige Heide- und Waldparzellen urbar gemacht.

Die Begradigung der Grenzen von Nutzparzellen und die Beseitigung von kleinsten, oft unregelmäßig begrenzten Flächen mit Resten von Heide und Baumbestand innerhalb von Acker und Grünland lässt erkennen, dass die Landnutzung zunehmend rationeller und intensiver betrieben wurde.

Die klare geometrische Struktur, die die Landschaft nach den Reformen Mitte des 19. Jahrhunderts überall durch ein neues Straßen-, Wege- und Grabensystem sowie die neuen Parzellengrenzen erhalten hatte, wurde durch die Maßnahmen der Aufforstung und Kultivierung zu Acker und Grünland noch leicht verstärkt.

Insgesamt hat es in der 1. Hälfte des 20. Jahrhunderts aber keine großflächigen und grundsätzlichen Veränderungen in der Kulturlandschaft gegeben.

Dies war angesichts der politischen und agrarpolitischen Rahmenbedingungen in der ersten Hälfte des Jahrhunderts auch nicht anders zu erwarten. Die Landwirtschaft konnte sich wegen kriegs- und wirtschaftsbedingter Notlagen sowie politischer Vorgaben zur Nahrungserzeugung nicht so entwickeln wie es bereits aufgrund der wissenschaftlichen und agrartechnischen Kenntnisse möglich gewesen wäre.

\footnotetext{
${ }^{1}$ s. Vegetationskartierung des Verf. von 1966
} 


\section{Kap. 5.2 Landwirtschaft und Landschaft Mitte der 60er Jahre}

\subsubsection{Gestalter der Kulturlandschaft}

Die Daten über Grundbesitz und Flächenanteile machen deutlich, dass die ursprüngliche große, seit den Agrarreformen des 19. Jahrhunderts bestehende Übereinstimmung von Gemarkung und Besitz aller Höfe des Dorfes sich stark verändert hatte: 1965 wurden von der gesamten Gemarkungsfläche 29,8\% nicht von Lachendorf aus bewirtschaftet und $24,2 \%$ waren Grundbesitz nicht landwirtschaftlicher Eigentümer. In diesen großen Anteilen ist aber jeweils der Waldbesitz des Klosterfonds in der Verwaltung der Klosterforst Miele mit 319,24 ha enthalten.

\begin{tabular}{|c|c|c|}
\hline \multicolumn{3}{|l|}{$\begin{array}{ll}\text { Tabelle 5.1 } & \begin{array}{l}\text { Grundbesitz 1965, } \\
\text { Gemarkung Lachendorf }\end{array}\end{array}$} \\
\hline Flächenanteile & ha & ha \\
\hline Katasteramtliche Gesamtfläche & & 1927,35 \\
\hline \multicolumn{3}{|c|}{ Land- und forstwirtschaftlicher Besitz in der Gemarkung } \\
\hline Betriebe mit Flächen über 0,5 ha & 1148,12 & \\
\hline Betriebe mitFlächen unter 0,5 ha & 128,25 & \\
\hline \multicolumn{3}{|l|}{ Flächen außerhalb land- und forstwirtschaftllicher } \\
\hline Betriebe & 237,82 & \\
\hline Besitz auswärtiger Grundeigentümer & 413,16 & \\
\hline Summe & & 1927,35 \\
\hline \multicolumn{3}{|l|}{ Wirtschaftsflächen in der Gemarkung, die nicht } \\
\hline von Lachendorf aus bewirtschatet wrden, & & 573,88 \\
\hline \multicolumn{3}{|c|}{ Wirtschaftsflächen, die von Lachendorf aus bewirtschatet werden, } \\
\hline aber nicht in der Gemarkung Lachendorf liegen. & & 123,21 \\
\hline Gesamtwirtschaftsfläche Lachendorfer Betriebe & & 1476,68 \\
\hline \multicolumn{3}{|l|}{ Quelle: Bodennutzungserhebung 1965} \\
\hline Gemeindeverwaltung Lachendorf & & \\
\hline
\end{tabular}

Die Flächen der Realgemeinde und der Verkoppelungsinteressenten sind Quelle: Bodennutzungserhebung 1965 Gemeinschaftsbesitz der Lachendorfer Höfe, die aus den Agrarreformen des 19. Jahrhunderts hervorgegangen sind. Es handelt sich dabei um Wald und hauptsächlich Wege- und Grabenland, das gemeinsam genutzt und unterhalten werden muss.

Dieser Gemeinschaftsbesitz und die Flächen der Verkehrswege, die im Besitz der Öffentlichen Hand sind, bieten kaum Potenzial, dass zu Veränderungen in der Kulturlandschaft beitragen könnte.

Tabelle 5.2 Gemarkung Lachendorf Grundbesitz 1965 nicht landwirtschaftlicher Eigentümer \begin{tabular}{|l|c|}
\hline Art des Eigentümers bzw. des Eigentums & ha \\
\hline Wadbeiz der Kostefost Migle
\end{tabular} \begin{tabular}{|l|l|}
\hline Waldbesitz der Klosterforst Miele & 319,24 \\
\hline
\end{tabular} $\begin{array}{ll}\text { Realgemeinde Lachendorf, nur Wald } & 19,1\end{array}$ Verkoppelungsinteressenten von Lachendorf, hauptsächlich Wegeland und Gräben Interessenten an der Verkoppelung der Allerund Trockenen Wiesen vom 7.2.1866 Landkreis Gelle, Straßen.

Land Niedersachsen, Straßen Osthannoversche Eisenbahn AG, Gelle Politische Gemeinde, Wege, Straßen Bauplätze Restbesitz des ehemaligen Rittergutes, Papierfabrik gesamt:

Quelle. Liegenschaftsbuch der Gemeinde Lachendorf Gemeindeverwaltung Lachendorf

Anders verhält es sich hinsichtlich der Siedlungsentwicklung. Mit dem starken Bevölkerungswachstum nach 1945 gab es vermehrten Wohnraumbedarf, der die politische Gemeinde veranlasste, mit der Ausweisung von Baugebieten das flächenmäßige Wachstum der Siedlung zu fördern. Dadurch wurde die politische Gemeinde zu einem zunehmend wichtiger werdenden Akteur bei der Gestaltung der Kulturlandschaft, insbesondere auch durch die Ausweisung von Gewerbegebieten.

Letztlich sind es auch alle Bewohner einer Siedlung, die durch ihren Wirtschafts- und Lebensstil das Siedlungsbild und damit auch ein Stück Kulturlandschaft gestalten und prägen. Dieser Aspekt wird in einem späteren Kapitel wieder aufgegriffen.

\begin{tabular}{|l|c|c|c|r|}
\hline \multicolumn{4}{|c|}{ Tabelle 5.3 Lachendorf, Bevölkerung } \\
\hline \multicolumn{4}{|c|}{ Einwohnerentwicklung, 1939-1966 } \\
\hline Jahr & 1939 & 1950 & 1965 & 1966 \\
\hline Anzahl & 950 & 1910 & 256 & 2307 \\
\hline Helmke, Fr., Der Speicher, Heimatbuch für den Landkreis Celle, \\
\hline Gelle 1930, S. 608 f, Landkreis Celle, Kreisverwaltung \\
\hline
\end{tabular}


Dennoch, trotz aller Bodenmobilität seit den Agrarreformen:

In einer land- und forstwirtschaftlich genutzten

Gemarkung mit einer dörflichen Siedlung sind die Land- und

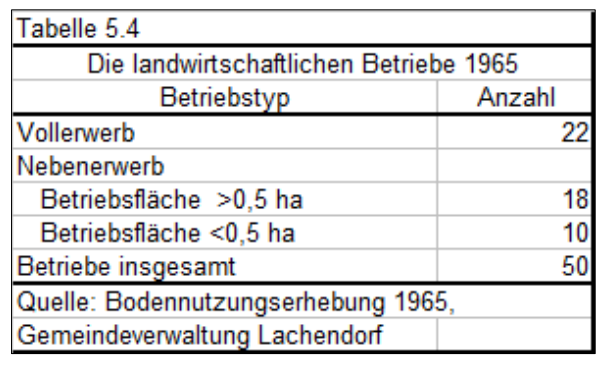

Forstwirte die bestimmenden Akteure bei der Ausgestaltung der Kulturlandschaft. Denn außerhalb der Siedlung ist es die Landnutzung, die flächendeckend die Kulturlandschaft gestaltet und prägt.

Seit Landwirtschaftliche Nutzfläche und Wald getrennt sind und der Wald nicht mehr wie früher verschiedenen gemeinschaftlichen Nutzungsformen unterliegt, bilden die Wälder und Forsten ein recht stabiles Element in der Kulturlandschaft, zumal wenn die Umwandlung von Wald in andere Nutzungsformen strengen gesetzlichen Bestimmungen unterliegt.

Dynamik in der Kulturlandschaft weisen heute nur die Landwirtschaftliche Nutzflächen, also Acker und Grünland, sowie die Flächen der Siedlungserweiterung auf. Erstere wirken großflächig landschaftsprägend. Siedlungsentwicklung wirkt dagegen zwar flächenmäßig weit weniger, optisch, ästhetisch und funktional aber doch mit großer Raumwirkung.

Daher gilt zunächst der Gruppe der Landwirte bzw. Höfe ${ }^{1}$ bei der Analyse der Landschaft das besondere Augemerk:

Mitte der 60er Jahre wurden in Lachendorf statistisch 22 landwirtschaftliche Vollerwerbsbetriebe gezählt, die als Hauptakteure bei der Ausgestaltung des bäuerlichen Kulturlandes, das die Acker- und Grünländereien umfasst, angesehen werden können.

Dazu kamen noch insgesamt 28 Nebenerwerbsbetriebe mit einem relativ geringen Anteil an der landwirtschaftlichen Nutzfläche und einige Ausmärker, die nicht näher erfasst wurden.

Da Landwirtschaftliche Nutzfläche und Wald - wie bereits dargelegt - seit der Aufgabe der Heidebauernwirtschaft klar von einander getrennt waren, lag die Gestaltung der Waldareale bei einem etwas anderen Kreis. Neben den Waldbesitzern unter den aktiven Landwirten gehörten auch Waldbesitzer dazu, die ihren landwirtschaftlichen Betrieb nur noch im Nebenerwerb führten oder bereits aufgegeben hatten.

Ein bedeutender auswärtiger Waldbesitzer war der Niedersächsische Klosterfonds, der in Zuständigkeit des Klosterforstamtes Miele in der Lachendorfer Gemarkung auf der Allerheide nur teilweise arrondierte 319,24 ha Wald bewirtschaftete. Die Waldflächen waren durch den Verkauf des Rittergutes in den Besitz der Klosterkammer gekommen. Das Vegetationsbild dieser Klosterforst unterschied sich nicht von den Bauernwäldern auf der Allerheide. Klosterforst und der Bauernwald mit zahlreichen Besitzern wiesen - bis auf die kompakte Fläche des ehemaligen Exerzierplatzes - eine Gemengelage auf und der Baumbestand ging auf der gesamten Allerheide auf die Aufforstungen vor und nach 1900 zurück.

\footnotetext{
${ }^{1}$ s. Tabelle 5.5
} 


\subsubsection{Wirtschaftssystem und Landnutzung der Betriebe (1965)}

In den Jahrzehnten nach dem Ende der Heidebauernwirtschaft und der Aufforstung der ehemaligen Heideflächen hatte sich im Laufe des 20. Jahrhunderts eine neue Betriebsstruktur entwickelt, die anhand der statischen Daten von 1965 dargelegt wird. Die Auswirkungen auf die Kulturlandschaft können dann mittels der Nutzungskartierung von 1966 belegt werden.

\begin{tabular}{|c|c|c|c|c|c|c|c|}
\hline \multicolumn{8}{|c|}{ Ackernutzung 1965 , in ha } \\
\hline \multicolumn{2}{|c|}{ Wintergetreide } & \multicolumn{2}{|c|}{ Hackfrucht } & \multicolumn{2}{|c|}{ Sonderkulturen } & \multicolumn{2}{|l|}{ Futter } \\
\hline Roggen & 132,84 & Kartoffeln & & Gemüse & 1,71 & Ackerwiesen & 2 \\
\hline Weizen & 1,5 & Frühe & 9,46 & Blumen, Zierpfl. & & Ackerweide & 7,27 \\
\hline Gerste & 32,97 & Mittelfrühe & 41,72 & Handelsgewächse & 0,24 & Grünmais & 18,65 \\
\hline Gemenge & 11,69 & Späte & 57,73 & & & andere Futterpfl. & 0,24 \\
\hline \multicolumn{2}{|c|}{ Sommergetreide } & Zuckerrüben & 42,14 & & & \multicolumn{2}{|c|}{ Gründüngung, brach } \\
\hline Roggen & & Futterrüben & 15,26 & & & Hauptfr.Gründüngung & 1,35 \\
\hline Weizen & 4,54 & Kohlrüben & 3,5 & & & brach & 0,13 \\
\hline Gerste & 64,72 & & & & & & \\
\hline Hafer & 25,09 & & & & & & \\
\hline Gemenge & 20,22 & & & & & & \\
\hline \multicolumn{8}{|c|}{ Quelle: Bodennutzungserhebung 1965, Gemeindeverwaltung Lachendorf } \\
\hline
\end{tabular}

Tabelle 5.7 Gemeinde Lachendorf 1965

\begin{tabular}{|c|c|c|c|}
\hline \multicolumn{4}{|c|}{ Die Nutzfläche der landwirtschaftlichen Betriebe, 1965} \\
\hline & Betriebe & Betriebe & insgesamt \\
\hline Nutzungsart & unter 0,5 ha & über 0,5 ha & ha \\
\hline Acker & 20 & 490,03 & 510,03 \\
\hline Haus- und $\mathrm{Nu}$ & 8,25 & 14,17 & 22,42 \\
\hline Ziergärten & & 9,56 & 9,56 \\
\hline Obstanlagen & & 0,71 & 0,71 \\
\hline \multicolumn{2}{|c|}{ Wiesen ohne Streuwiesen } & 136,29 & 136,29 \\
\hline Viehweiden & & 120,21 & 120,21 \\
\hline \multicolumn{2}{|c|}{ Streuwiesen, Hutungen } & 22,63 & 22,63 \\
\hline \multicolumn{2}{|c|}{ nicht genutzte Flächen } & 6,94 & 6,94 \\
\hline \multicolumn{2}{|c|}{ unkultivierte Moorfläche } & 1,95 & 1,95 \\
\hline \multicolumn{2}{|c|}{ Ödland, Unland } & 25,87 & 25,87 \\
\hline \multicolumn{2}{|c|}{ Gebäude, Hofflächen } & 19,99 & 19,99 \\
\hline Gewässer & & 0,36 & 0,36 \\
\hline Wegeland & & 39,31 & 39,31 \\
\hline gesamt & 28,25 & 888,02 & 916,27 \\
\hline Waldfläche *) & & 322,59 & 322,59 \\
\hline \multicolumn{4}{|c|}{ *) nur Waldfläche der statistisch erfassten } \\
\hline \multicolumn{4}{|c|}{ landwirtschaftlichen Betriebe } \\
\hline \multicolumn{4}{|c|}{ Quelle: Bodennutzungserhebung 1965 , } \\
\hline \multicolumn{3}{|c|}{ Gemeindeverwaltung Lachendorf } & \\
\hline
\end{tabular}

Die Übersichten in den Tabellen 5.6 - 5.8 zeigen eine große Vielfalt an verschiedenen Nutzungen, vom Acker mit etwa einem Viertel und Grünland mit einem Siebtel der Nutzfläche bis hin zu Ödland und einer sehr kleinen Moorfläche ${ }^{1}$. Aber auch die Ackernutzung zeigt eine große Bandbreite von verschiedenen Getreidearten mit Schwerpunkten bei Roggen und Sommergerste, einem deutlichen Hackfruchtanteil und dem Anbau von Zwischenfrüchten für Futter und Gründüngung.

\footnotetext{
${ }^{1}$ Vermutlich ist mit dieser kleinen Moorfläche das Krähenmoor gemeint, das in den Jahren 1965/66 noch einen Moortümpel und Wollgrasbestände aufwies. (s. Abb. 2.17)
} 
Wenn man - wie in Diagramm 5.1 dargestellt - jeweils das Winter- und Sommergetreide und die Hackfrüchte zusammenfasst, ergibt sich fast noch oder wieder das Bild der verbesserten Dreifelderwirtschaft, in der je $1 / 3$ des Ackers mit Winter- und Sommergetreide bestellt und die Brache durch den Anbau von Hackfrüchten, Feldfutter und Gründüngung ersetzt wurde.

Die Anbauschwerpunkte, nämlich Roggen und Gerste beim Getreide und Kartoffeln bei den Hackfrüchten, sind zweifellos den Böden geschuldet. Darin spiegeln sich gut die örtlichen

Bodenverhältnisse, denn auf den relativ sauren Böden mit durchweg weit unter 40 Bodenpunkten haben Roggen und Kartoffeln im Vergleich zu anderen Anbaufrüchten gute Wachstumsbedingungen.

Der Zwischenfruchtanbau für Futter und Gründüngung lässt erkennen, dass beide Faktoren berücksichtigt wurden: Betriebseigener Futterbau und Förderung der Bodenfruchtbarkeit.

Die Tabelle 5.9 zeigt aber dennoch ein äußerst differenziertes Bild: Einmal die starke Differenzierung bei Getreide und Hackfrucht in jeweils mehrere unterschiedliche

Feldfrüchte, zum anderen erste Anzeichen einer Spezialisierung durch den geringen Anbau von Sonderkulturen und schließlich das Auftreten einer neuen Feldfrucht, den Mais.

Diese beiden Tabellen verdeutlichen die Betriebsstrukturen der 22 Vollerwerbsbetriebe von 1965. Bei aller Verschiedenheit lassen sich einige wesentliche gemeinsame Merkmale feststellen: Alle Betriebe kombinieren Ackerbau und Viehhaltung bzw. -zucht. Alle Betriebe halten Milchkühe, dabei nur wenige eine Kuhzahl, die

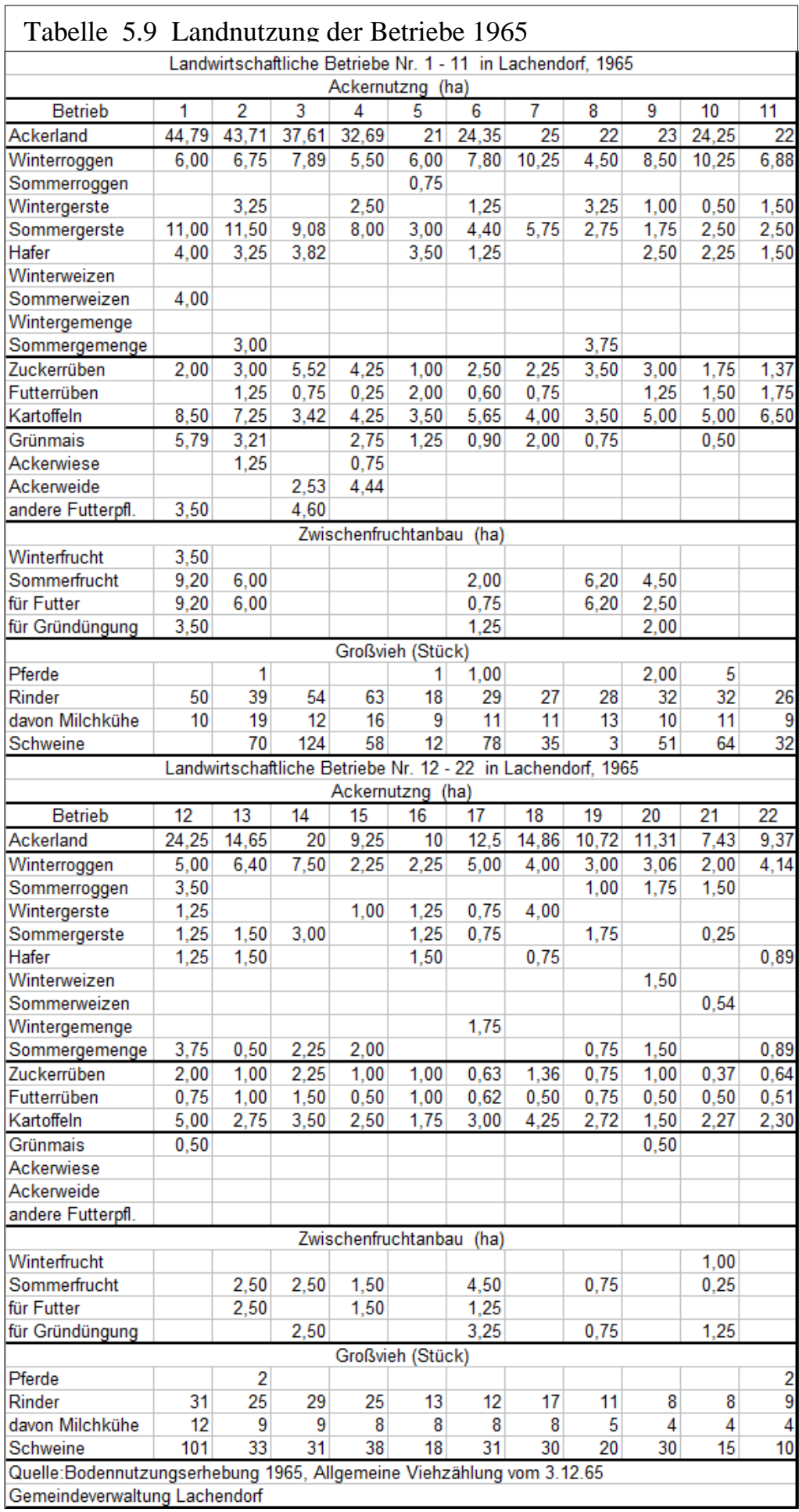


eine Melkanlage vermuten lässt. Es gibt keinen Betrieb mit großen Beständen einer Nutztierart, wenngleich in der Schweinehaltung einige größere Bestände vorhanden sind, die über einen traditionellen Bauernhof hinausgehen. Bei der Schweinmast sind also erste Anzeichen einer Intensivierung und Spezialisierung zu beobachten. Die Zahl der Pferde lässt erkennen, dass die Motorisierung bereits gut entwickelt ist, denn Höfe ohne Pferde bzw. ohne wenigstens ein Gespann könnten die Feldarbeit, die sich aus den Ackerflächen ergibt, ohne motorisierte Zugmaschine nicht leisten. Bemerkenswert ist die hohe Bedeutung betriebseigenen Futteranbaus: Hafer, Futterrüben, Rübenblatt und anderes Feldfutter, dazu auch Futtermais.

Zusammen mit dem Zwischenfruchtanbau kann man auf eine abwechslungsreiche und vielgliedrige Fruchtfolge schließen.

Insgesamt handelte es sich um nicht spezialisierte Mischbetriebe mit Ackerbau und Veredelungswirtschaft und traditionelle bäuerliche Familienbetriebe. Dies galt auch für den Betrieb, der sich im Besitz des Hauptgesellschafters der Papierfabrik befand, denn dieser Betriebe wurde von einem Verwalterehepaar bewirtschaftet, wie die anderen bäuerlichen Betrieb auch.

Für diese große Vielfalt an Feldfüchten, teils mit sehr geringem Flächenanteil, gibt es zwei Hauptgründe: betriebswirtschaftliche und arbeitswirtschaftliche.

Aufgrund der gemischten Betriebsstruktur mit Ackerbau und Viehhaltung gab es einen starken innerbetrieblichen Stoffkreislauf bzw. Austausch zwischen Acker und Viehstall: Kartoffeln (als Dämpfkartoffeln) und Gerste (als Schrot) für die Schweinemast, Silage vom Zuckerrübenblatt, Futterrüben und Getreideschrot für Milchkühe und andere Rinder, Hafer und Haferstroh (als Häcksel) für die Pferde, sicherlich auch Getreide für Federvieh. Die Vielfalt an Nutztieren erforderte also eine Vielfalt auf dem Acker, solange Futter betriebsintern produziert wurde.

Die Technisierung der Feldarbeit hatte zwar bereits lange vor 1965 begonnen, zumal einige wichtige Maschinen zunächst für die Pferdebespannung entwickelt worden waren: z.B. die Drillmaschine zum Sähen von Getreide und Zuckerrüben, der Selbstbinder für die Getreideernte, der Düngerstreuer und der Kartoffelroder. Seit Jahrzehnten gab es bereits eine Reihe von einfachen, von Pferden gezogenen Geräten für Pflanz- und Pflegearbeiten, z.B. mehrreihige Hack-, Loch- und Häufelgeräte für den Kartoffelanbau, Köpfschlitten für das Köpfen des Rübenblattes vor dem Roden der Rübe sowie Mähmaschinen und Heuwender in der Grünlandwirtschaft. Für die nächste Generation von Maschinen, z.B. Miststreuer, Mähdrescher, spezielle Legemaschinen für Rüben- und Maissaat, Vollernter für Kartoffeln, Rüben und Mais sowie Ballenpressen zur Bergung von Stroh und Grassilage waren dann unbedingt wegen des notwendigen Antriebs über die Zapfwelle motorisierte Zugmaschinen nötig, bevor die großen Erntemaschinen als Selbstfahrer in Gebrauch kamen.

Bis in die 60er Jahre spielte aber bei der Aussaat, der Pflege und der Ernte der Kulturen die Handarbeit noch eine große Rolle. Als Beispiele für Feldarbeiten, die noch vielfach Handarbeit erforderten, seien genannt: Kartoffeln pflanzen, Zuckerrüben hacken und vereinzeln, Aufstellen der Getreidegarben zu Stiegen, Aufladen und Einbringen der Garben, Kartoffeln aufsammeln und aufladen, Rübenblatt köpfen und silieren, Rüben aufladen und abfahren.

Arbeitsspitzen mussten zur Vermeidung von Überlastung und Leerzeiten möglichst vermieden werden. Viele Arbeiten, die heute vollständig durch Maschinen erledigt werden, wurden noch ganz per Hand (z.B. Jäten) oder mit Geräten (z.B. Eggen oder Hackgeräten), also halbmechanisch, ausgeführt. Andere Arbeiten sind durch Pflanzenzüchtung überflüssig geworden oder werden durch den Einsatz chemischer Mittel ersetzt.

Am Kartoffel- und Zuckerrübenanbau lässt sich das gut verdeutlichen:

Kartoffeln wurden von Hand gelegt, während der Wachstumszeit mehrfach mit dem Häufelpflug angehäufelt zur mechanischen Bekämpfung der Ackerunkräuter. Frühe, mittelfrühe und späte Kartoffeln verlängerten im Herbst die Erntezeit und entzerrten so den starken Arbeitsaufwand bei der Kartoffelernte. Auf den Ersatz von Handarbeit bei der Kultur von Zuckerrüben wurde bereits in Kapitel 1) hingewiesen.

Einerseits galt es auf den Höfen, Arbeitsspitzen der Feldarbeit möglichst zu minimieren, anderseits musste man auch bestrebt sein, die Arbeitskräfte möglichst gleichmäßig auszulasten, was bei reiner Feldarbeit wegen des jahreszeitlichen Rhythmus nicht möglich ist. Da bot 
die Arbeit in der Veredelungswirtschaft, also im und für den Stall eine gute Möglichkeit. Für Familienbetriebe kam noch ein Einkommensaspekt hinzu: Einnahmen aus der Ackerwirtschaft sind hauptsächlich saisonal nach den Ernten möglich. Einnahmen aus der Veredelungswirtschaft können gleichmäßiger im Jahr erzielt werden, insbesondere das monatlich erwirtschaftete Milchgeld, das im Laufe des Jahres nur mit den Laktationszyklen der Milchkühe schwankt.

Die ökologische Vielfalt und der Artenreichtum auf den Äckern waren also weder Bedingung noch Zweck sondern vielmehr die Folge betriebs- und arbeitswirtschaftlicher sowie einkommensbedingter Strukturen der Landwirtschaft. Die ökologisch positiv zu wertende Vielfalt war eine unbeabsichtigte Folge der gemischt-bäuerlichen Wirtschaftsweise, allerdings mit einem erwünschten und geförderten positiven Effekt auf die Bodenfruchtbarkeit.

Zweifellos profitierte von diesen betriebsbedingten und agrartechnischen Bedingungen auch die ökologische Vielfalt der „Wildflora“, also aller nicht gezielt angebauten Nutzpflanzen. Je nach Kulturart und vor allem je nach Zeitpunkt der Bodenbearbeitung bilden sich ohne chemische Bekämpfung typische Acker-Pflanzengesellschaften, z.B. Getreide- oder Hackfruchtunkraut-Gesellschaften. Aber auch die Bodenfruchtbarkeit bzw. die Versorgung mit Nährstoffen ist für die Verbreitung von Ackerunkräutern ${ }^{1}$ wichtig, denn die bessere Versorgung mit Mineraldünger hat z.B. die Ausbreitung Stickstoff liebender Pflanzen sehr gefördert.

Andererseits hat natürlich die Verbreitung und die Artenvielfalt von Un- bzw. Wildkräutern auf dem Acker als Nahrungsangebot auch Einfluss auf die Fauna, etwa auf den Bestand von Niederwild und insbesondere wegen des Samenangebotes auf verschiedene Vogelarten.

Der großen Vielfalt an Ackerfrüchten entsprach also auch eine recht große Vielfalt in der „wilden“ Flora und Fauna, die sich aufgrund des Nährstoffhaushaltes der Böden und der Wachstumsbedingungen in den verschiedenen Kulturpflanzenbeständen erhalten bzw. entwickeln konnte. In den Jahrzehnten seit Einführung des Mineraldüngers und der damit erzielten guten Nährstoffversorgung der Böden hat sich das Artenspektrum und vor allem die Artenhäufigkeit der Ackerwildkräuter grundlegend verändert.

Eine wesentlich geringere Rolle in der Veränderung des Artenspektrums spielen dagegen die invasiven Arten, die zu den Neophyten gerechnet werden. Im Bereich der Kulturpflanzen kommt es gelegentlich zur Einwanderung neuer Arten durch verunreinigtes importiertes Saatgut.

Ein als recht problematisch eingestufter Neophyt, die Herkulesstaude (Abb. 5.1), wächst seit einigen Jahren ${ }^{2}$ auch in den Allerwiesen am Rand von Entwässerungsgräben.

Die folgenden Karten 5.1.1 - 3 dokumentieren die Landnutzung von 1966. Da die Farben - insbesondere die gelben Farbtöne - wegen der langen Lagerung zwischen Erstellung 1967 und Digitalisierung 2012 nicht mehr eindeutig identifizierbar sind, wurden die verschiedenen Ackerkulturen mit Signaturen (kleine

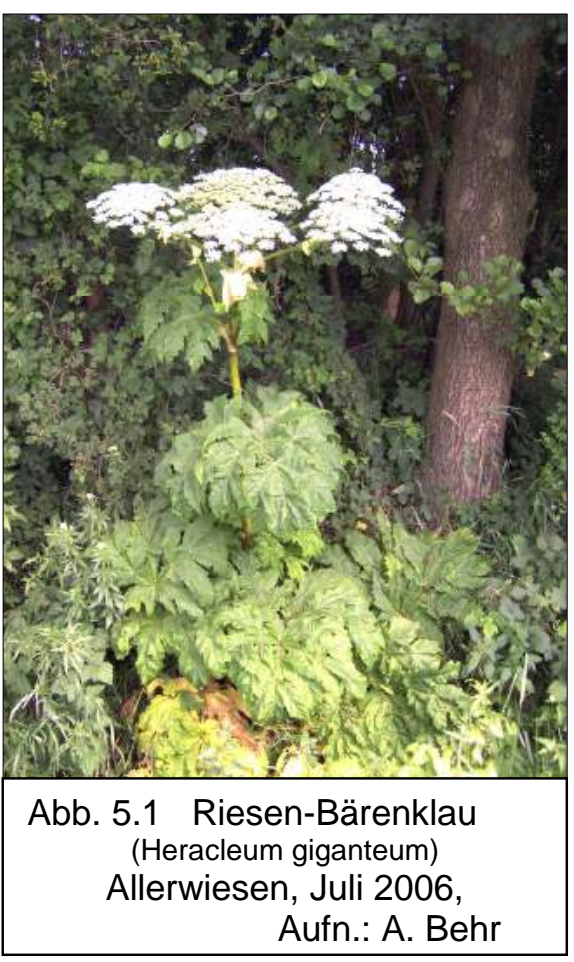
Buchstaben) belegt. So sind die Karten wieder eindeutig lesbar.

\footnotetext{
${ }^{1}$ Unkraut und Wildkraut: Im Zusammenhang mit Ackerbau wird aus ökonomischer Sicht der Begriff „Unkraut“ verwendet, im ökologischen Zusammenhang der Begriff „Wildkraut“. „Unkräuter“ im ökonomischen, ackerbaulichen Bezug sind nicht nur Kräuter im botanischen Sinn sondern z.B. auch Gräser. Anm. d. Verf.

${ }^{2}$ Die Pflanze wurde vor 2000 vom Verf. in den Allerwiesen nicht beobachtet.
} 


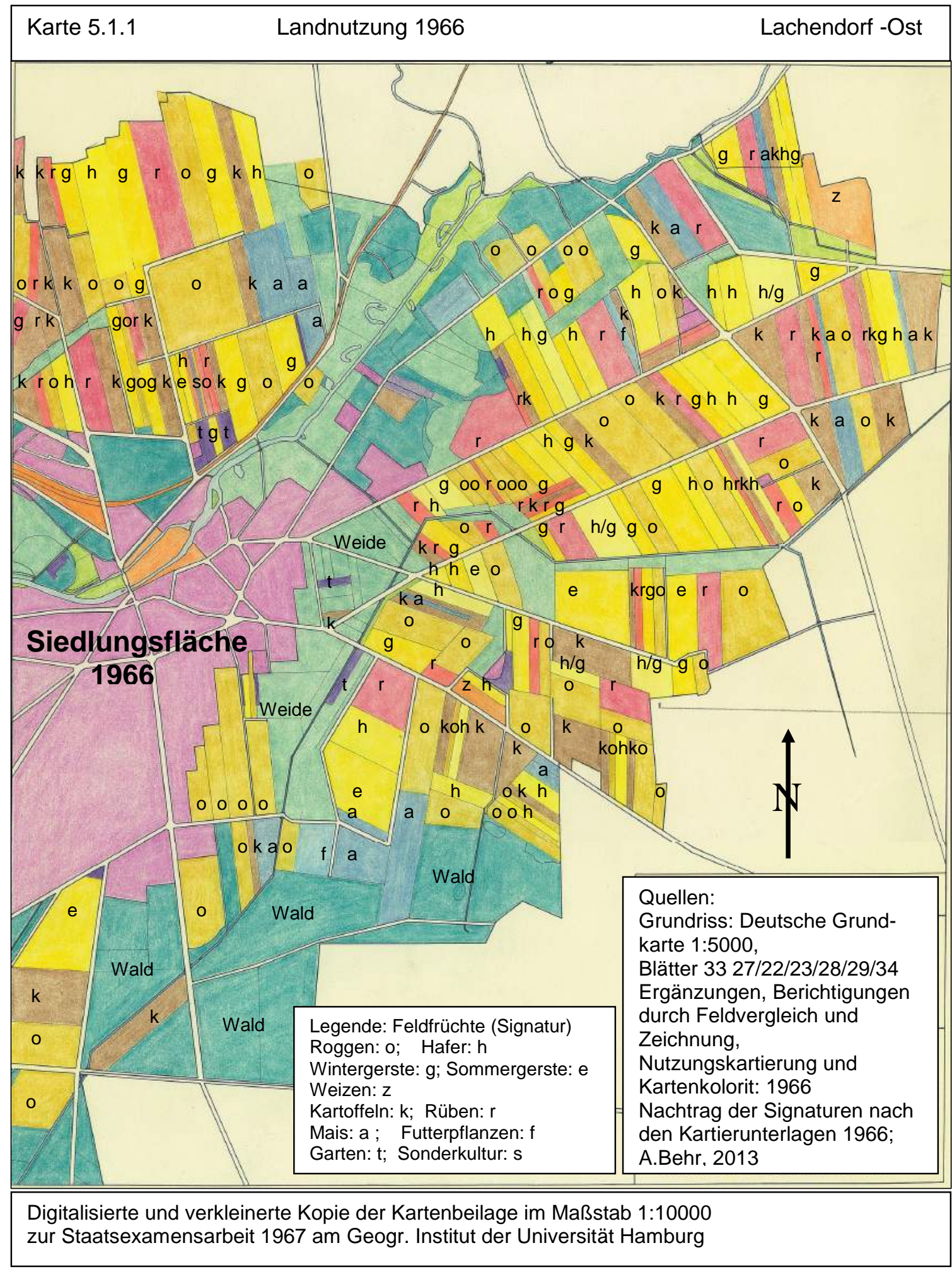

Seit dem 19. Jahrhundert hat sich die Lage der Ackerflächen bis zur Mitte des 20. Jahrhunderts in der Lachendorfer Gemarkung kaum verändert. Schwerpunkt des Ackerlandes waren und blieben die Flächen auf den Grundmoränen beiderseits des Lachtetales nördlich des Ortes. Die geringwertigen Ackerböden südlich des Ortes auf dem Schwemmfächer wurden seit Mitte des 20. Jahrhunderts mehr und mehr als Bauland frei gegeben bzw. verkauft. 


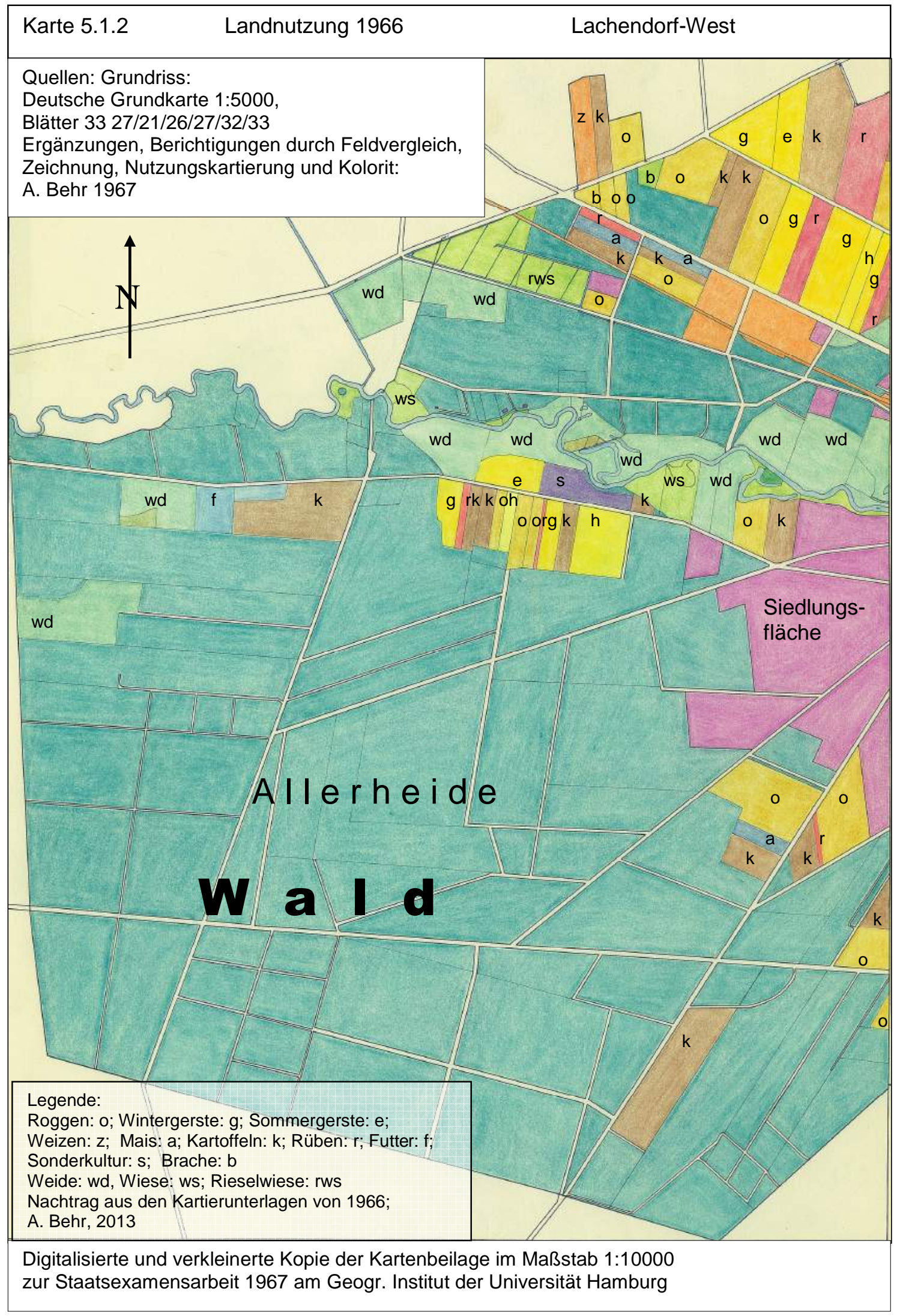

Seit Abschluss der Agrarreformen Mitte des 19. Jahrhunderts hat sich über etwa 100 Jahre die Parzellenstruktur ebenfalls kaum geändert, weil dem Landverkauf meist vorhandene Parzellen zugrunde gelegt wurden und weil die Betriebe im Wesentlichen bei der Bewirtschaf- 
tung der damals zugeteilten Schläge blieben. Auch die bis etwa 1950 vorherrschende Anspannung mit Pferden hat dafür gesorgt, dass die einzelnen Ackerschläge nicht zu groß wurden und große Besitzparzellen zur Bewirtschaftung in mehrere Schläge aufgeteilt worden waren.

Der kriegsbedingte Mangel in der Versorgung der Böden mit Nährstoffen konnte nach 1945 relativ schnell wieder behoben werden, sodass die Bodenfruchtbarkeit aufgrund von guter Nährstoffversorgung, einer vielfältigen Fruchtfolge und guter Bodenbearbeitung ein bis dahin noch nie erreichtes Niveau erlangen konnte.

So prägte das Ackerland einerseits ein vielfältiges und differenziertes Anbauspektrum, das sich aufgrund der gesamtwirtschaftlichen und betrieblichen Bedingungen entwickelt hatte. Andererseits hatte sich ebenfalls aufgrund der hohen Bodenfruchtbarkeit aber auch wegen des begrenzten Einsatzes chemischer Mittel ein breites Artenspektrum der Un- bzw. Wildkräuter entwickeln können.

Die Nutzungskartierung von 1966 zeigt die Ackerflächen - entsprechend der Analyse der Betriebsstrukturen - in einem sehr kleinräumigen, vielfältigen und abwechslungsreichen Mosaik, wobei die gelben Farben für die verschiedenen Getreidearten dominieren, braune Flächen für Kartoffeln und rote für Rüben stehen sowie blaue für Mais.

Die Aufteilung in die einzelnen Ackerschläge zeigt ein deutlich engmaschigeres Muster als die Besitzparzellen.

Die Ackerflächen boten wegen der Kleinkammerung einen auffälligen Kontrast zu den einheitlichen Flächen mit Kiefernwald und der großräumigen Wiesen- und Weidelandchaft im Süden der Gemarkung nördlich des Schwarzwassers.

Karte 5.1.3
$\begin{aligned} & \text { Wald } \\ & \text { wd }\end{aligned}$




\subsubsection{Grünland um 1966}

Die Betriebsstrukturen aller 22 Vollerwerbsbetriebe von 1965 weisen ein für die Kulturlandschaft sehr wichtiges Merkmal auf: Die Kombination von Ackerbau mit Viehhaltung, insbesondere mit Rindern und Milchkühen. Diese Betriebsstruktur und die um 1966 übliche Milchkuhhaltung mit Anbindestall, Stallfütterung und Weidegang im Sommer bedeuteten, dass das Grünland eine sehr wichtige Komponente des Wirtschaftssystems war. Das Grünland hatte also um 1966 aufgrund der Betriebsstrukturen einen wichtigen und unverzichtbaren Stellenwert in der Kulturlandschaft.

Die Grünlandstandorte haben sehr unterschiedlichen Charakter, einerseits wegen ihrer naturgeographischen Situation und andererseits wegen der unterschiedlichen Entwicklung der Nutzung.

In den 60er Jahren des 20. Jahrhunderts gab es in der Gemarkung insgesamt 7 Grünlandstandorte sehr unterschiedlicher Größe und Bedeutung:

Zwei sehr kleine Fläche mit dem Flurnamen Punnewisch und Lachenkamp, das Grünlandband in der Talaue der Lachte, Grünlandflächen mit Flurnamen Postmoor, Krähenmoor und Auf dem Moore sowie das große zusammenhängende Grünlandgebiet der AllerDreckwiesen und der Trockenen Wiesen.

Punnewisch

Die sehr kleine Grünlandfläche liegt im Mündungsbereich eines kleinen Trockentales in das Lachtetal. Die Nutzung als Grünland ist eine Folge des Grundwasserregimes, das ohne Drainage keine Ackernutzung zulässt.

Lachenkamp

Das kleine Gebiet der Riesenwiesen auf dem Lachenkamp wurde schrittweise aufgegeben: Zunächst stellte man die Berieselung ein, später auch den Grabeneinstau. Die Flächen wurden aber 1965/66 weiterhin als Grünland genutzt, da der Hof neben Ackerbau auch intensiv Tierhaltung betrieb.

Talaue der Lachte

Für die Höfe, die in der Lachteaue Weiden besaßen, war die Talaue ein wichtiger Grünlandstandort für die Milchviehhaltung, hatte aber mit starken Wasserstandsschwankungen des Abflussregimes erhebliche agrar- bzw. betriebswirtschaftliche Bedeutung.

Dies verdeutlicht die Darstellung des Abflussregimes der Lachte in Kapitel 2). Dabei ist besonders wichtig die Tatsache, dass die höchsten Hochwässer außer im Oktober immer den Ausuferungspunkt überschritten, d.h. es war zu allen Jahreszeiten mit einer Überflutung der Talaue zu rechnen. Die Hochwassergefahr in den Sommermonaten stellte ein ernsthaftes Handicap für die landwirtschaftlichen Betriebe dar, insbesondere für solche mit Milchviehhaltung, denn bei früher üblichem täglichem Weidegang ohne umfangreiche Stallfütterung führten Sommerhochwässer wegen der Wirkung auf Menge und Qualität des Graswuchses zu schwankenden Milcherträgen.

\section{Auf dem Moore}

Diese Grünlandfläche am östlichen Ortsrand beiderseits der Straße nach Ahnsbeck bzw. westlich der Straße nach Bunkenburg setzte sich noch als schmaler Grünlandstreifen nach Nordosten beiderseits des Schelpriethgrabens fort. Naturgeographisch handelt es sich um ein größeres Trockental in der lehmigen Bunkenburger Geestplatte, das am Ostrand der Wurzelzone des Lachte-Schwemmfächers ins Urstromtal mündet. Es war ursprünglich durch Ablagerungen der „Ur-Lachte“ und Dünen hinsichtlich des Abflusses vom Lachtetal getrennt, weswegen es auch zum natürlichen Einzugsgebiet der Aller und nicht der Lachte gehörte. Aufgrund des Grundwasserregimes und der anmoorigen Auflage war das Gebiet lange für die Grünlandnutzung prädestiniert. Bereits die Kurhan. Landesaufnahme von 1779 verzeichnet diese Talform mit Wiesennutzung ${ }^{1}$. Die Preußische Landesaufnahme von 1901 kartierte

\footnotetext{
${ }^{1}$ s. Kurhan. Landesaufnahme, Blatt 103 Celle, 1779
} 
hier ebenfalls Grünland, wobei das Quellgebiet des Schelpriethgrabens als Bruchboden ohne Ackernutzung dargestellt wird.

Im Jahr 1966 wurde der Oberlauf des Schelpriethgrabens durchgehend von einem schmalen Grünlandband entlang der Tiefenlinie des Trockentales begleitet. Dieser Grünlandstreifen erweiterte sich östlich des Dorfes beim Eintritt in das Urstromtal zu einer größeren Grünlandfläche „auf dem Moore“.

Postmoor und Krähenmoor

Beide Grünlandgebiete sind weder auf der Kurhan. Landesaufnahme von 1779 noch auf der Preußischen von 1901 verzeichnet. Der Moortümpel des Krähenmoores östlich des Trockenwiesenweges ist noch von Heideflächen mit einzelnen Nadelbäumen umgeben und das Postmoor reicht mit einem östlichen Ausläufer bis in die Lachendorfer Gemarkung hinein 1 . Beide Grünlandstandorte sind also erst im 20. Jahrhundert angelegt worden. Die natürlichen Bedingungen waren dafür aber nicht ungünstig, denn der hohe Grundwasserstand und die teils anmoorige Auflage legten ohne Entwässerung eine Grünlandnutzung nahe. Als dafür günstige Zeigerpflanzen aus der Kartierung 1966 können die Dopp- oder Erikaheide (Erica tetralix) und Pfeifengras (Molinia coerulea) genannt werden. Während die Umgebung der Fläche am Rande des Postmoores 1901 vollständig aufgeforstet war, sind die späteren Grünlandflächen nordwestlich des Krähenmoores und westlich des Trockenwiesenweges noch als Heide ausgewiesen. Aufgrund des häufigen Vorkommens von Pfeifengras im Wald am Randes der Weiden kann man annehmen, dass diese Flächen im 19. Jahrhundert noch zu den Bereichen gehörten, auf denen der Bultenhieb zur Gewinnung von Streu betrieben wurde.

Aller- und Trockene Wiesen

Das große, ehemals geschlossene Grünlandgebiet besteht entsprechend der Namensgebung aus zwei naturräumlich sehr unterschiedlichen Teilen. Die Aller- oder auch Dreckwiesen im östlichen Teil auf Anmoor und Niedermoorböden gehören zu einem großen Randmoor im Aller-Urstromtal. Die Trockenen Wiesen dagegen gehören zu einem Talsandbereich nördlich des Schwarzwassers, ebenfalls im Urstromtal. Die alten Namen dieser Landschaften charakterisieren die natürlichen Eigenschaften dieser Standorte sehr gut.

Hinsichtlich der Grünländereien im Aller-Urtsromtal, den Aller- und trockenen Wiesen, war der Untersuchungszeitraum von 1965/66 aus heutiger Sicht äußerst günstig, weil damals noch eine Kulturlandschaft angetroffen wurde, die man aufgrund des Landschaftsbildes sowie des Artenspektrums, insbesondere auch der Vogelwelt, als typische Wiesenlandschaft bezeichnen kann. Durch die Regulierung von Aller und Schwarzwasser war aber um 1966 auch schon ein Grundstein für einen Landschaftswandel geschaffen worden, der sich durch Nutzungswandel in den nächsten Jahren immer stärker durchsetzte.

Die Aller-Dreckwiesen

In den Aller- bzw. Dreckwiesen lag das Hauptproblem in einem für intensive Nutzung zu hohen Grundwasserstand und der Überschwemmungsgefahr durch die Aller, insbesondere über den Rückstau in das untere Schwarzwasser.

Dem zu hohen Grundwasser und der Vernässung wurde mit einem engmaschigen Grabensystem begegnet, das natürlich genau auf das geringe Gefälle und die Feinmorphologie abgestimmt wurde. Dies System der Entwässerungs- bzw. Abzugsgräben ist bis heute fast unverändert vorhanden und funktionsfähig.

Durch diese Entwässerung wurden die Ertragskraft und vor allem die Ertragssicherheit entscheidend gestärkt. Aufgrund der Böden mit Anmoorgley und Niedermoorauflage galten die Dreckwiesen über Jahrhunderte als „absolutes“ Grünland. Insbesondere dort, wo die Grasnarbe auf moorigem Boden keinen Weidetritt vertrug, war nur eine Nutzung als Wiese möglich, auf denen in nassen Sommern sogar die Heuwerbung schwierig war, wenn die Befahrbarkeit der Grasnarbe eingeschränkt war.

\footnotetext{
${ }^{1}$ s. Preußische Landesaufnahme von 1901
} 
Die Überschwemmungsgefahr durch Allerhochwasser konnte nur durch eine starke Regulierung der Aller und des unteren Schwarzwassers erreicht werden. Die dazu erforderlichen Maßnahmen wurden in einem Zeitraum von gut 100 Jahren umgesetzt.

Auf den historischen Karten von $1781^{1}$ und $1839^{2}$ wird der Unterlauf des Schwarzwassers westlich von Nordburg und nördlich von Schwachhausen in seinem natürlichen, stark mäandrierenden Verlauf dargestellt. Der § 6) im Rezess von 1866 belegt, dass es im Zusammenhang mit der Verkoppelung der Aller- und Trockenen Wiesen eine Korrektion des Schwarzwassers gegeben hat. Die Karte von $1901^{3}$ zeigt dann auch einen völlig begradigten bzw. geglätteten Verlauf des Schwarzwassers westlich von Nordburg. Unbegradigt blieb nur der letzte kleine Flussabschnitt östlich des Lorkberges unmittelbar vor der Mündung in die Aller.

Diese Korrektur des Schwarzwassers und einige Flussbaumaßnahmen an der Aller änderten wenig an den grundsätzlichen natürlichen Bedingungen in den Dreckwiesen: hoher Grundwasserstand, gelegentliche Überschwemmungen und Niedermoorböden. Das Gebiet wurde zu einer einheitlichen Kulturlandschaft geformt, die man als naturnahe Wiesenlandschaft bezeichnen kann. Das Grünland galt aufgrund des Boden- und Grundwasserhaushaltes dieses Standortes als „natürliches Grünland“, da unter den herrschenden natürlichen Bedingungen eine andere Nutzung nicht möglich war.

Die Wiesen- und Weidelandschaft hat aber nur solange Bestand, wie der wirtschaftende Mensch durch Mähen (Mahd) und/oder Beweidung die natürliche Bewaldung verhindert und die Landschaft offen hält. Auch auf diesem Feuchtstandort des gemäßigten außertropischen Klimas gilt das Prinzip der Wasser- und Lichtkonkurrenz ${ }^{5}$ : Kampf der Bäume gegen Gräser, den bei genügend Feuchtigkeit wegen der Lichtkonkurrenz immer die Bäume gewinnen.

Einen gewissen Eindruck vom naturnahen Landschaftsbild in den Aller-Dreckwiesen vermittelt der kleine Bruchwald am äußersten östlichen Rand der südlichen Lachendorfer Gemarkung.

Für das Artenspektrum eines Grünlandes spielt aber auch die Nutzung eine sehr wichtige Rolle. So unterscheidet sich das Artenspektrum einer Weide stark von dem einer reinen Wiese, denn einige Pflanzen vertragen keinen Weidetritt, andere kein Mähen. Auch der Zeitpunkt des Mähens spielt eine große Rolle: Pflanzen, die sich über Samen vermehren, verschwinden, wenn frühzeitig vor der Samenreife gemäht wird.

Um 1966 wurden die reinen Wiesen in den Aller-Dreckwiesen traditionell bewirtschaftet, also spät - Ende Juni/Anfang Juli - zum ersten Schnitt gemäht, der der traditionellen Heugewinnung durch Lufttrocknung auf der Wiese diente.

Die Wiesenlandschaft der Dreckwiesen bot mit dem Baumbestand an Wegen und Gräben, Einzelbäumen und kleinen Baumgruppen das Bild einer sehr ästhetischen Parklandschaft, von der bis in die 2. Hälfte des 20. Jahrhunderts ein besonderer Reiz ausging, weil die Landschaft fernab von Siedlungen und Straßen mit ihrer Ruhe, den weiten Wiesenflächen ohne Zäune, dem reichen Bestand an typischen Wiesenvögeln, den je nach Jahreszeit unterschiedlich aufleuchtenden Blüten an den Gräben und in den Wiesen ein besonderes Flair vermittelte.

Aber gerade die besondere Ausstrahlung dieser Landschaft, die mit ihrem Artenreichtum und ihrer Ästhetik beeindruckte, ist das Ergebnis einer Kulturleistung, also eine Kultur- und keine Naturlandschaft.

\footnotetext{
${ }_{1}^{1}$ Kurhannoversche Landesaufnahme, Blatt 111, Gr. Eicklingen

${ }^{2}$ Topographischer Atlas von A. Papen, Blatt Celle

${ }^{3}$ Preußische Landesaufnahme von 1899, Blatt 3427 Bröckel, herausgegeben 1901

${ }^{4}$ s. dazu: Chr. Seiler; Die Aller - ein Fluss verändert seinen Lauf, Celle 2002

${ }^{5}$ Vergl. H. Walter u. S. Breckle, Ökologie der Erde, Bd. 2, Stuttgart 1984, Kap. 3.3.1 Holzpflanzen und Gräser als Antagonisten, S. $124 \mathrm{ff}$
} 


\subsection{Prägung der Kulturlandschaft durch die Reformen des 19. Jahrhunderts}

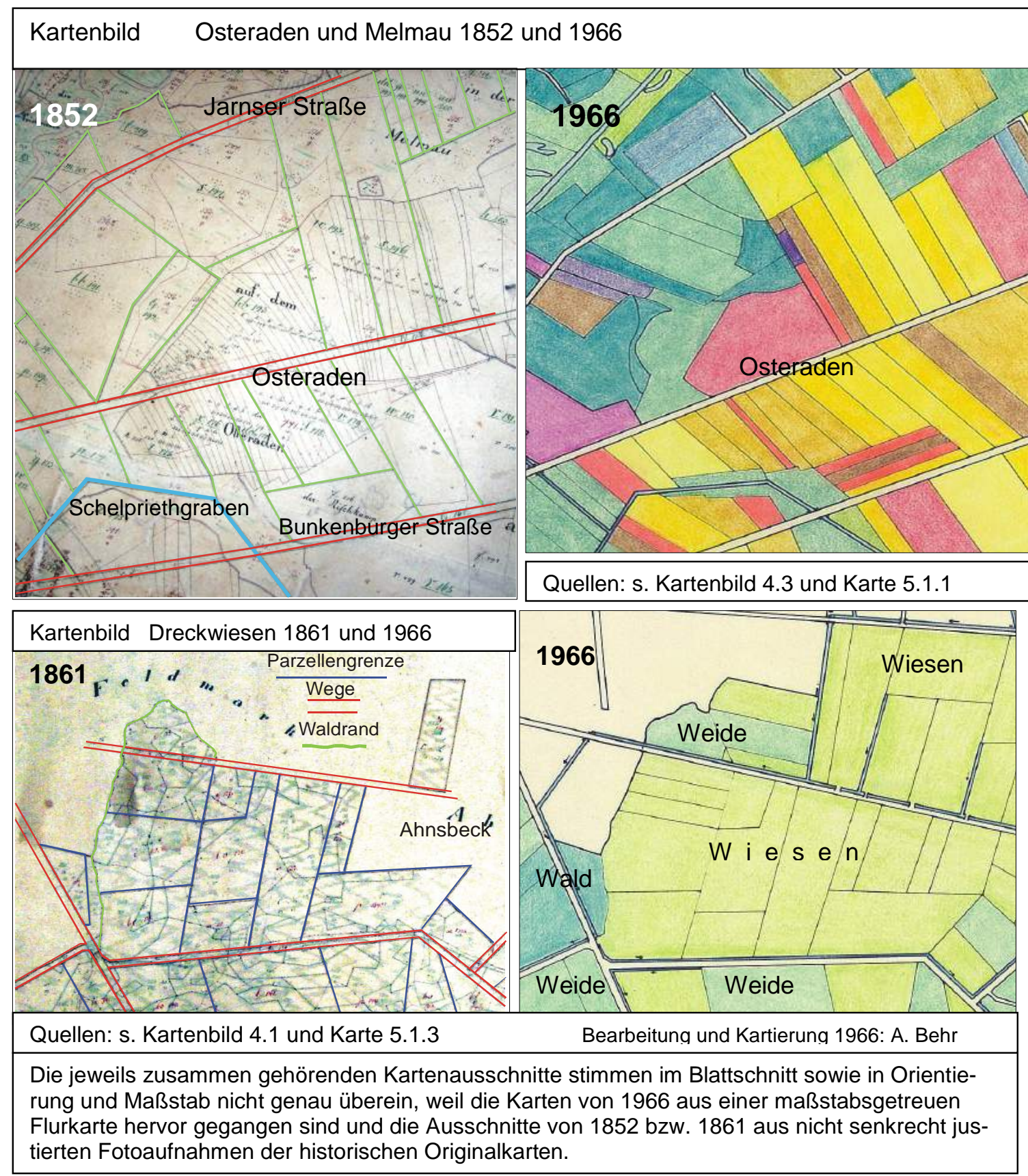

Die Agrarreformen des 19. Jahrhunderts haben durch die Generalteilung, Spezialteilung und Verkoppelung nicht nur die rechtlichen Bedingungen der Landwirtschaft verändert.

Das Ergebnis der Reformen war vielmehr die völlige Auslöschung fast aller typischen Elemente der alten Kulturlandschaft im Landschaftsbild.

Dies betraf nicht nur die Landnutzung aufgrund der veränderten Wirtschaftsweise sondern auch die alte Grundstruktur mit Langstreifen und Wölbäckern im Ackerland sowie die ungegliederte Heide- und Wiesenlandschaft. 
Durch die neue Parzellenstruktur für die gesamte neue Gemarkung erhielt die Kulturlandschaft eine geometrische Gliederung. Die neu eingemessenen Parzellen waren bis auf ganz wenige Ausnahmen Vierecke, wo möglich sogar Rechtecke oder Parallelogramme, wenigstens aber Trapeze, also Parzellen mit wenigstens zwei parallelen Seiten. Das neue streng geometrische Grundmuster der Flur wurde noch durch die neuen Wege und Straßen verstärkt, die sich im konkreten Verlauf von dem unregelmäßig gewachsenen Wegenetz der alten Kulturlandschaft deutlich unterschieden.

Auf den Ackerflächen wurde die neue Flurstruktur unmittelbar nach den Reformen augenfällig, weil die neuen Parzellen die Pflugrichtung und die Ausrichtung der Schläge bestimmten. So lange die Schlageinteilung noch aus der Pferdezeit stammte, war sie deutlich differenzierter als die Parzellen, aber die vielen kleinen Schläge richteten sich an den neuen Parzellen aus.

In den Aller- und Dreckwiesen wurde die neue Flurstruktur durch zunächst nur durch die neu vermessenen Wege deutlich, dann aber verstärkt durch das Hauptgrabensystem. Eine weitere Landschaftsgliederung erfolgte durch die Aufteilung größerer Parzellen in kleinere Nutzparzellen, teils mit eigenen Gräben versehen und als Weiden auch mit Zäunen abgegrenzt.

Eine Besonderheit verrät der Kartenvergleich bzgl. der Dreckwiesen: Die historische Karte von 1861 zeigt die Lachendorfer Abfindung in den Aller- und trockenen Wiesen und damit den dadurch entstandenen südlichen Lachendorfer Gemarkungsteil. Die Karte von 1966, die sich ebenfalls auf die Gemarkung bezieht, belegt, dass im Nordosten des Kartenausschnittes die Lachendorfer Abfindung und damit auch die Gemarkung noch nach Fertigstellung der Karte vergrößert wurde. Dadurch wurde auch eine Parzelle, die auf der Karte von 1861 als Exklave in der Ahnsbecker Gemarkung lag, in die Lachendorfer Gemarkung mit einbezogen. Das Beispiel verdeutlicht nochmals die Flexibilität und Sorgfalt bei der Umsetzung der Reformen. Dies wiederum trug ganz sicher dazu bei, dass das Ergebnis der Reformen eine so starke und nachhaltige Wirkung auf das Landschaftsbild entfaltete und bis heute bewahrte.

Auf der Allerheide dürfte die neue Parzelleneinteilung zunächst überhaupt nicht ins Auge gefallen sein, weil sich die Wirtschaftsweise der Höfe erst langsam änderte. Als die Bauern allerdings anfingen, ihre Parzellen auf der Allerheide aufzuforsten, wurde auch hier die neue geometrische Grundstruktur sichtbar. Durch unterschiedlichen Baumbestand und verschiedene Altersklassen ist der Wald auf der Allerheide bis heute ganz klar nach der im Zuge der Spezialteilung der Lachendorfer Abfindung auf der ehemaligen Gemeinheit auf der Allerheide entstandenen Parzellenstruktur gegliedert.

Insgesamt bekam die Kulturlandschaft eine klare geometrische, exakt vermessene Grundstruktur, die sich über gut ein Jahrhundert fast unverändert erhalten hat und auch noch heute die Kulturlandschaft gliedert und strukturiert.

Die planvoll erstellte geometrische Grundstruktur unserer Kulturlandschaft ist ausschließlich das Ergebnis der Agrarreformen des 19. Jahrhunderts und damit nicht älter als 150 Jahre.

\section{Kap. 5.4 Strukturwandel und Kulturlandschaft}

\subsubsection{Stauwiesen am Schwarzwasser}

Mitte der 60er Jahre des vorigen Jahrhunderts gab es für die Stauwiesen eine neue Situation: Der neue Mündungsarm des Schwarzwassers durchschnitt, fast parallel zum Zuleitungsgraben, das gesamte Stauwiesengebiet nördlich des Lorkberges und die Allerregulierung schnitt ein Bewässerungsgebiet südlich des Lorkberges vom Zufluss ab.

Es war zur Bauzeit dieser großen Flussbaumaßnahme keineswegs geplant, die Stauwiesen aufzugeben. Denn noch während der ersten Baumaßnahmen an Aller und Schwarzwasser 
beschloss die Verbandsversammlung am 29.2.64 ${ }^{1}$ die Beibehaltung des Staurechtes im Staugraben und vertagte die Entscheidung über die Bewässerungstechnik - nämlich Berieselung oder Grabeneinstau - auf das kommende Jahr. Die Verbandsversammlung verpachtete auch in den Jahren 1964 und 1966 die Fischereirechte im Staugraben, z.B. im Jahr 1966 bis zur Lachendorfer Gemarkungsgrenze für 50 DM/Jahr.

Die wasserbaulichen Maßnahmen einschließlich eines erforderlichen Dükers wurden so umgesetzt, dass die Stauwiesen beiderseits des neuen Schwarzwassers weiterhin bewässert werden konnten. Nur die Teilfläche südlich des Lorkberges konnte nicht wieder an das Grabensystem der Stauwiesen angeschlossen werden, weshalb sich auf der Verbandsversammlung 1968 auch ein Eigentümer weigerte, die Beiträge zu entrichten.

Aber die Stauwiesen verloren offenbar schnell ihre wirtschaftliche Bedeutung. Bereits auf der Verbandsversammlung am 21.3.1968 ${ }^{2}$ stellten Lachendorfer Mitglieder den Antrag auf baldmögliche Auflösung des Verbandes wegen zu hoher Kosten ${ }^{3}$ und weil die Bewässerung nicht mehr rentabel sei. Zwar waren $50 \%$ der Verbandsfläche vertreten und stimmten für Auflösung, aber $50 \%$ der Grundeigentümer waren überhaupt nicht anwesend, weil sie vermutlich auch kein Interesse am Fortbestand der Stauwiesen hatten. Nach einer Diskussion wird anhand der Hebeliste nach Flächengröße abgestimmt: Einstellung der Bewässerung und Auflösung des Verbandes fordern 65,5758 ha $(68 \%)$, dagegen votieren 13,1634 ha (14\%) und 17,2541 ha $(18 \%)$ sind nicht anwesend.

Der Landkreis Celle übernimmt die Aufgabe, das Auflösungsverfahren mit den notwendigen Eigentumsübertragungen und der Verwendung des Verbandsvermögens durchzuführen. Der Regierungspräsident in Lüneburg erteilt am 29.8. 1973 die Genehmigung zur Auflösung des Verbandes, am 28.9. 1974 werden die Eigentumsübertragungen notariell beurkundet und am 20.11.1975 erfolgt die Bekanntmachung durch den Landkreis Celle, dass der OppershausenLachendorfer Stauwiesenverband aufgelöst sei. ${ }^{4}$

Nach dem rechtlichen Ende des Stauwiesenverbandes folgte in wenigen Jahren die fast vollständige Beseitigung der Anlagen: Gräben und Grüppen wurden verfüllt oder eingeebnet, Durchlässe und Brücken bis auf wenige, nun funktionslose Reste beseitigt. Nach nur 94 Jahren verschwanden ein vom Menschen geschaffener Biotop und ein besonderes Element der Kulturlandschaft vollständig aus dem Landschaftsbild.

Die seltenen Reste, wie die gemauerte Brücke mit Durchlass über den ehemaligen, jetzt zugeschütteten Zuleitungsgraben,

sind dem Verfall preisgegeben. Vermutlich in wenigen Jahren wird kaum noch jemand die ehemalige Funktion dieses Bauwerkes erklären können.

Die Stauwiesen waren unwirtschaftlich geworden: Ein zu hoher Unterhaltungs- und Pflegeaufwand stand in keinem Verhältnis zum Ertrag der Wiesen. Besonders für die Lachendorfer Landwirte war die Entfernung vom Hof sehr groß, zumal für eine Weidenutzung durch Milchvieh.

So dauerte es nicht lange nach der Einstellung der Bewässerung, bis die Stauwiesen umgebrochen und zu Ackerland gemacht wurden. Bei der Ackernutzung spielt die Entfernung zum Hof keine entscheidende Rolle, weil man nicht regelmäßig sondern nur bei Arbeitsanfall die Entfernung überwinden muss.

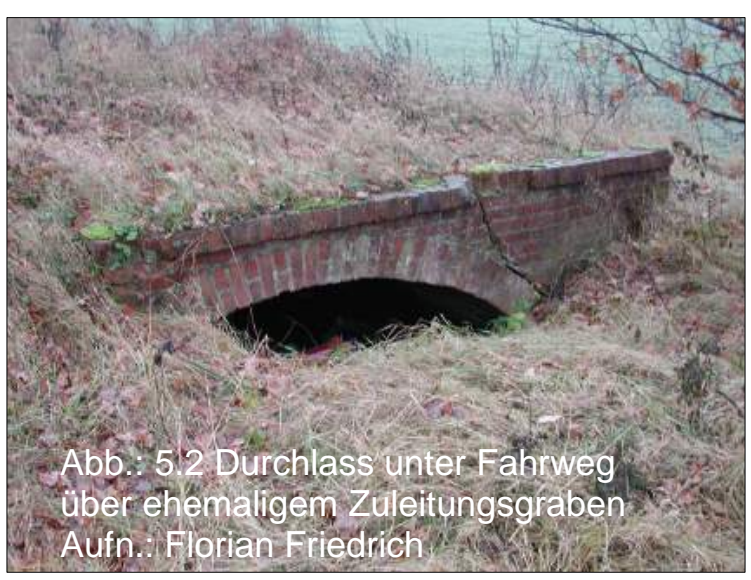

\footnotetext{
${ }_{1}^{1}$ Originalakte: Oppershausen-Lachendorfer Stauwiesenverband, Kreisarchiv Celle, unveröffentlicht

${ }^{2}$ s. Originalakte, Kreisarchiv Celle

${ }^{3}$ It. Protokoll: ca. $105 \mathrm{DM} / \mathrm{ha}$

${ }^{4}$ Originalakten zum Oppershausen-Lachendorfer Stauwiesenverband, Kreisarchiv Celle, unveröffentlicht
} 
Übrigens, am Nordrand des Lorkberges hatte es bereits um 1800 einen schmalen Ackerstreifen ${ }^{1}$ gegeben, der sich in einer kleinen Parzelle erhalten hatte und nun Teil eines größeren Ackerareals wurde.

Die Baumaßnahmen an Schwarzwasser und Aller waren nicht die Ursachen für die Aufgabe der Bewässerungswiesen, sondern deren Unwirtschaftlichkeit und die große Entfernung von Lachendorf. Mit zunehmender Aufgabe der Viehwirtschaft der Lachendorfer Höfe nahm in den nächsten Jahrzehnten die Umwandlung der aufgelassenen Stauwiesen in Ackerland zu. Die Kartensequenz 5.2 zeigt einmal den Wandel der geschlossenen Wiesen- und Weidelandschaft zu Ackerland und zum anderen beim Vergleich der Karten von 1972 und 2010 die Reduzierung der Parzellenzahl und damit die deutliche Vergrößerung der einzelnen Schläge. Beim Wandel dieses speziellen Elements der Kulturlandschaft greifen mehrere Faktoren ineinander: Wasserbauliche Maßnahmen als Voraussetzung, als Ursachen dann die allgemeine Unwirtschaftlichkeit aufgrund der Betriebs- und Unterhaltungskosten der Stauanlagen, Entfernung der Stauwiesen von den Höfen, insbesondere bezüglich Lachendorf, und schließlich der Strukturwandel in der Landwirtschaft mit der Aufgabe der Viehwirtschaft in den meisten Betrieben.

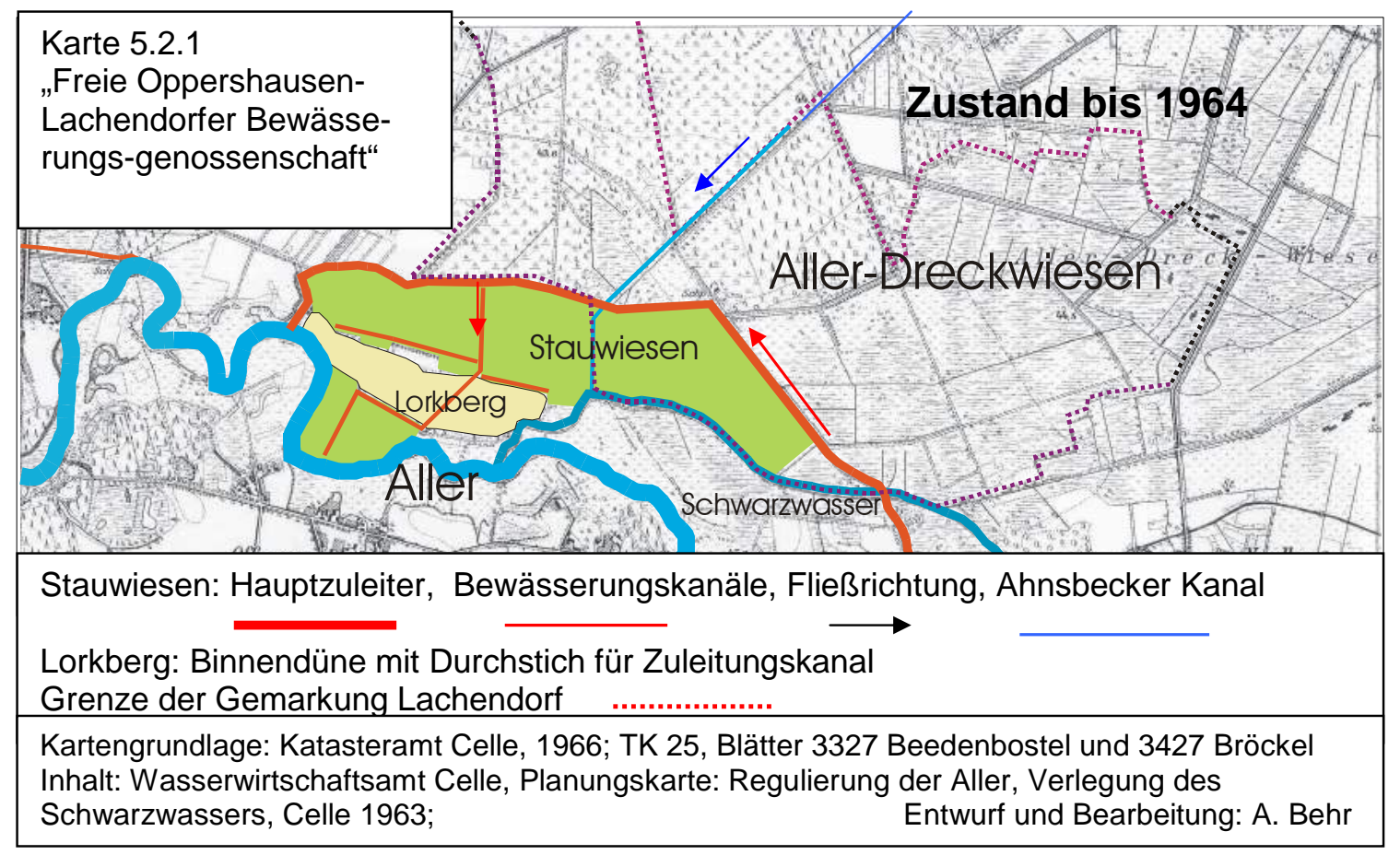

\footnotetext{
${ }^{1}$ s. Kurhannoversche Landesaufnahme, Blatt 111, Gr. Eicklingen
} 

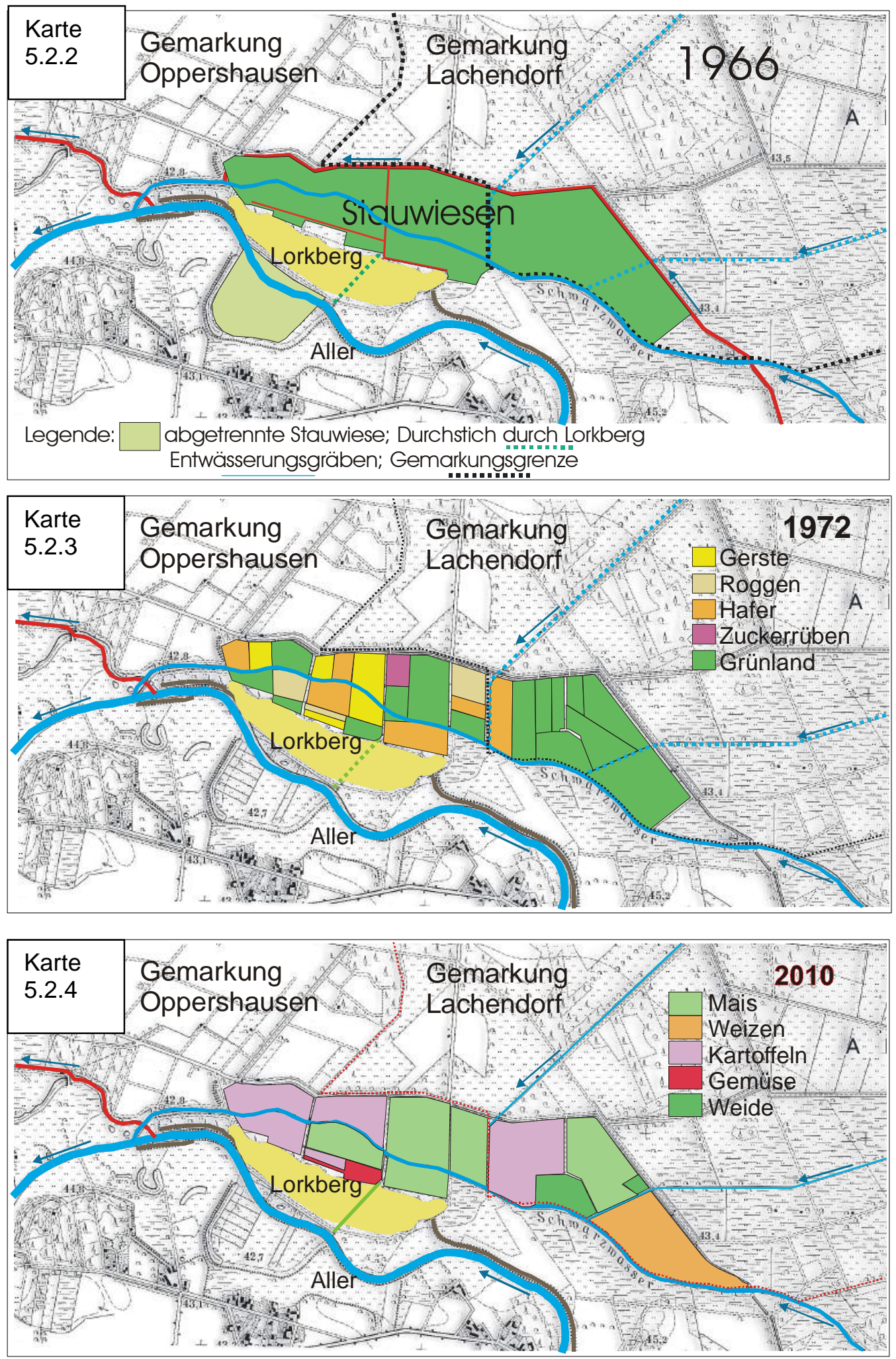

Kartengrundlage: s. Karte 5.2.1; Kartierungen: Verf. 


\subsubsection{Vom Strukturwandel zum Landschaftswandel}

In den Jahrzehnten zwischen 1965/66 und 2012 hat sich bei den landwirtschaftlichen Betrieben ein tiefgreifender Strukturwandel vollzogen: Von den 22 im Jahr1965 statistisch erfassten Vollerwerbsbetrieben wurden 2009 nur noch 10 Höfe bewirtschaftet, davon 7 im Haupterwerb (Nr. 1 - 7) und 3 im Nebenerwerb (Nr. 8 - 10). Im Jahr 2010 gab es dann nur noch 9 Betriebe $^{1}$, weil die Hofstelle des Betriebes Nr. 10 in Lachendorf zum Jahresende verkauft ${ }^{2}$ wurde.

\begin{tabular}{|l|r|r|r|r|r|r|r|r|r|r|r|}
\hline \multicolumn{10}{|c|}{ Tabelle 5.10 } & \multicolumn{10}{|c|}{ Grundbesitz und Viehbestände } \\
der aktiven Betriebe 2009
\end{tabular}

Die Daten der Tabelle 5.10 verdeutlichen besonders den betrieblichen Strukturwandel beim Blick auf die Nutzviehbestände: Von 7 Haupterwerbsbetrieben hatten 2009 nur noch zwei Milchkuhhaltung, verbunden mit Nachzucht und Mast. Diese beiden Betriebe verfügen über vergleichsweise wenig Ackerland und einen recht großen Grünlandanteil. Die Spezialisierung auf Rindvieh mit starker Intensivierung ist also offenbar durch Lage und jeweiligen Grundbesitz begründet.

Zwei andere Betriebe betreiben Schweinemast, die sich neben dem Schwerpunkt Ackerwirtschaft heute betriebswirtschaftlich kapitalintensiv und arbeitsextensiv organisieren lässt. Im Wesentlichen sind es reine Ackerbaubetriebe mit einem zusätzlichen Betriebszweig.

Die Mutterkuhhaltung bei zwei Betrieben ist sicherlich der Nutzung von vorhandenem Grünland geschuldet, das bei Betrieb Nr. 1 direkt in der Lachteaue an das Hofgelände grenzt. Dieser Wirtschaftszweig ist als Nebenerwerb einzustufen.

Die Pferdehaltung bzw. Pferdezucht dreier Betriebe ist dagegen nur sehr bedingt betriebswirtschaftlich zu erklären, denn der Ackerbau benötigt keine Pferde mehr. Vielmehr verlangt die Pferdezucht ein hohes Maß an Fachkenntnissen, Risikobereitschaft und Passion der Betriebsleitung.

Die Schafhaltung zweier Betriebe kann dagegen auch als unbedeutender betrieblicher $\mathrm{Ne}$ benerwerb eingestuft werden.

Von 10 Betrieben wirtschaften nur noch vier Betriebe mit Nutzvieh, das betrieblich von echter wirtschaftlicher Bedeutung ist. Die Konzentration auf reinen Ackerbau sowie die Spezialisierung und Bestandsvergößerungen in der Nutzviehhaltung sind die wesentlichen Merkmale des landwirtschaftlichen Strukturwandels der vergangenen Jahrzehnte.

Das Merkmal der Betriebsvergrößerung im Ackerbau zeigt sich auch an der Streulage der Nutzflächen der verschiedenen Betriebe, die in zahlreichen benachbarten Gemarkungen und

\footnotetext{
${ }^{1}$ Quelle der Betriebsdaten: Kontrollausdrucke Flächen GFN 2009, Landwirtschaftskammer Niedersachsen, Bezirksstelle Uelzen; Schriftliche Datenerhebung bei den Landwirten durch den Verf.

${ }^{2}$ Fernmündl. Mitteilung der Besitzerin an den Verf.
} 
im Fall des Betriebs Nr. 5 sogar Flächen in der Altmark bewirtschaften. Anders als in der Viehwirtschaft spielen Entfernungen zwischen Hofstelle und Nutzfläche heute keine großen Probleme dar, weil aufgrund der Motorisierung die Entfernung schneller als mit Pferden überwunden werden kann und weil die große Leistungsfähigkeit der heutigen Maschinen es ermöglicht, die erforderlichen Ackerarbeiten in kürzester Zeit mit wenigen Fahrten zwischen Hof und Acker zu erledigen.

\begin{tabular}{|c|c|c|c|c|c|c|c|c|c|}
\hline \multicolumn{10}{|c|}{ Landwirtschaftliche Nutzfläche in anderen Gemarkungen } \\
\hline 1 & 2 & 3 & 4 & 5 & 6 & 7 & 8 & 9 & 10 \\
\hline Eschede. & Ahnsbeck & Jarnsen & Oppershausen & Altmark: & Eldingen & & Gockenholz & Höfer & Ahnsbeck \\
\hline Habighorst & Jarnsen & & Ahnsbeck & Bornsen & Ahnsbeck & & Ahnsbeck & & \\
\hline Höfer & Oppershausen & & & Diersdorf & & & & & \\
\hline Garßen & & & & & & & & & \\
\hline Ahnsbeck & & & & & & & & & \\
\hline Gockenholz & & & & & & & & & \\
\hline
\end{tabular}

\begin{tabular}{|c|c|c|c|c|c|c|c|c|c|c|}
\hline \multicolumn{11}{|c|}{ Tabelle 5.12 Aktive Betriebe 2009} \\
\hline \multicolumn{11}{|c|}{ Ackernutzung 2009} \\
\hline Betrieb Nr. & 1 & 2 & 3 & 3 & 5 & 6 & 7 & 8 & 8 & $\begin{array}{l}9 \\
9\end{array}$ \\
\hline Feldfrucht & ha & ha & ha & ha & ha & ha & ha & ha & ha & ha \\
\hline Winterweizen & & & 3,24 & 2,46 & 6 14,84 & $4 \quad 8,31$ & & & 3,37 & \\
\hline Winterroggen & 55,04 & & 13,61 & & 12,48 & B 14,09 & & & & \\
\hline Wintergerste & 15,61 & & 11,83 & 7,97 & & & & & 2,79 & 1,7 \\
\hline Sommergerste & 70,11 & 23,8 & & & & 1,89 & 920,93 & & 6,22 & \\
\hline Sommerhafer & & 10,15 & & & 2,66 & & & & & \\
\hline Triticale & 41,8 & 8,6 & 7,49 & 9,55 & & & & & 4,27 & \\
\hline Körnermais & & & & & & & & 27,96 & & \\
\hline Silomais als Futterfläche & 24,69 & 44,94 & 31,82 & 47,8 & 32,17 & 27,85 & 5,44 & & 3,99 & \\
\hline Runkel-/Futterrüben & & & 0,1 & & & & & & & \\
\hline Feld-/Ackergras & & 5,47 & 0,12 & 9,46 & & & & & 0,94 & \\
\hline Kleegras & & & & & & & 4,75 & & & \\
\hline Zuckerrüben & 55,41 & 26,31 & & & 8,05 & 2,28 & & & & 1,34 \\
\hline Kartoffeln & 81,98 & 15,78 & 0 & 0 & 15,33 & 0 & 11,73 & 0 & 0 & 0 \\
\hline Gemüse Freiland & & & & & & 1,42 & & & & \\
\hline Blumen, Zierpflanzen, Freiland & & & & & & 0,13 & & & & \\
\hline Erdbeeren, Freiland & & & & & & 2,47 & & & & \\
\hline Beerenobst & & & & & & 1,06 & & 25,41 & & \\
\hline Summe: & 344,64 & 135,05 & 68,21 & | 77,24 & 85,53 & 59,5 & $5 \quad 42,85$ & \begin{tabular}{|l|l}
5 & 53,37
\end{tabular} & 721,58 & $\begin{array}{lll}8 & 3,04\end{array}$ \\
\hline & & & & & & elle & Uelzen & & & \\
\hline
\end{tabular}

Die Anbaustruktur der Ackernutzung zeigt folgende Merkmale: Die Betriebe Nr. $1-5$ und 7 haben sich auf den Anbau von nur 4 bis 7 Feldfrüchte konzentriert. Betrieb Nr. 6 hat sich zusätzlich zu traditionellen Anbauprodukten auf Sonderkulturen, Nebenerwerbsbetrieb Nr. 6 auf den Anbau von Körnermais und 25 ha Beerenobst (Kulturheidelbeeren) spezialisiert.

Betrieb Nr. 10 bewirtschaftete 2009 nur noch Restflächen vor der Betriebsaufgabe ${ }^{1}$ zum Ende des Jahres.

Als neue Feldfrucht tritt mit mäßigem Anteil an der Getreidefläche auch Triticale $^{2}$ auf. Eine überdurchschnittliche Fläche nimmt der Maisanbau, überwiegend Silomais, ein.

Der Vergleich mit 1965 zeigt, dass alle Haupterwerbsbetriebe deutlich in der Nutzfläche gewachsen sind und das Anbauspektrum traditioneller Ackerkulturen verkleinert wurde.

\footnotetext{
${ }^{1}$ s. Fußnote 2)

${ }^{2}$ Die Kreuzung aus Roggen und Weizen wurde Anfang des 20. Jahrhunderts in Ungarn entdeckt, allerdings mit unfruchtbaren Nachkommen. Die endgültige Züchtung gelang erst in den 60er Jahren und der Anbau begann in den 70er Jahren des 20. Jahrhunderts. Mdl. Auskunft von Dr. Reinhard von Broock, Lochow-Petkus - Bergen
} 
Diese beiden Hauptmerkmale der betrieblichen Außenwirtschaft dürften sich aber nur sehr eingeschränkt in der Kulturlandschaft bemerkbar machen, nämlich nur in den mittleren Schlaggrößen des Ackerlandes und in einer geringeren Vielfalt an Nutzpflanzen auf dem Acker.

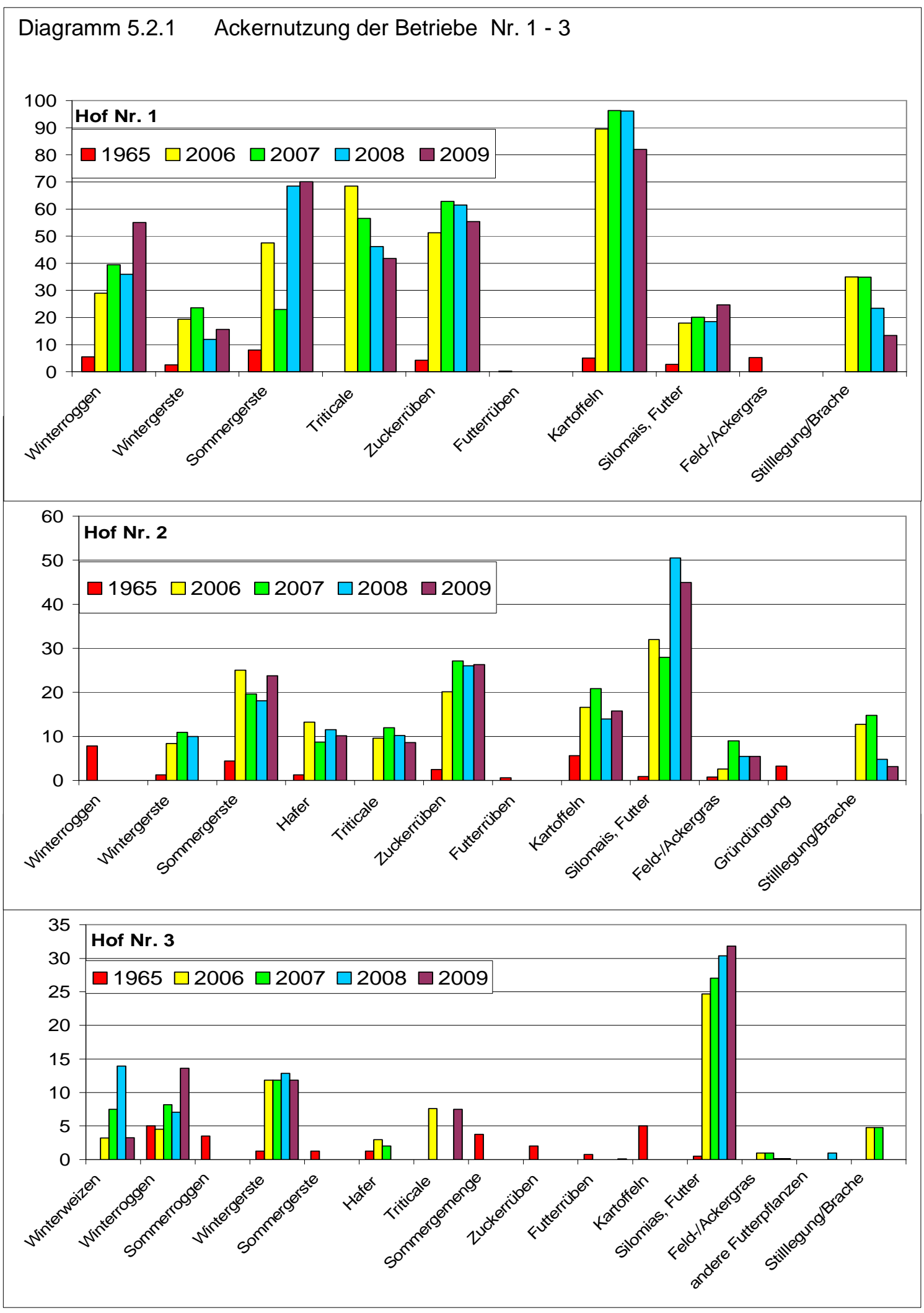




\section{Diagramm 5.2.2 Ackernutzung der Betriebe Nr. 4-6}
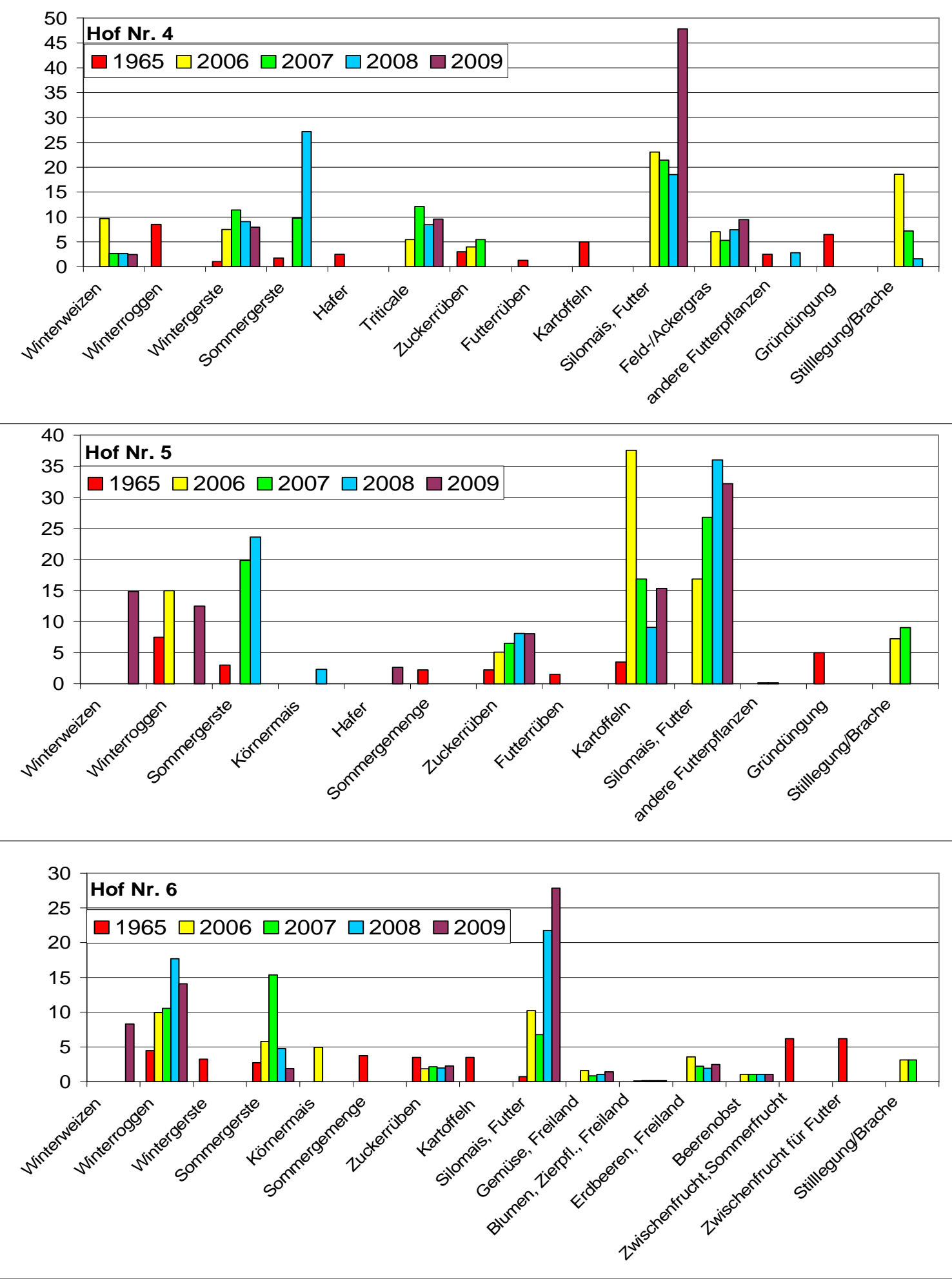


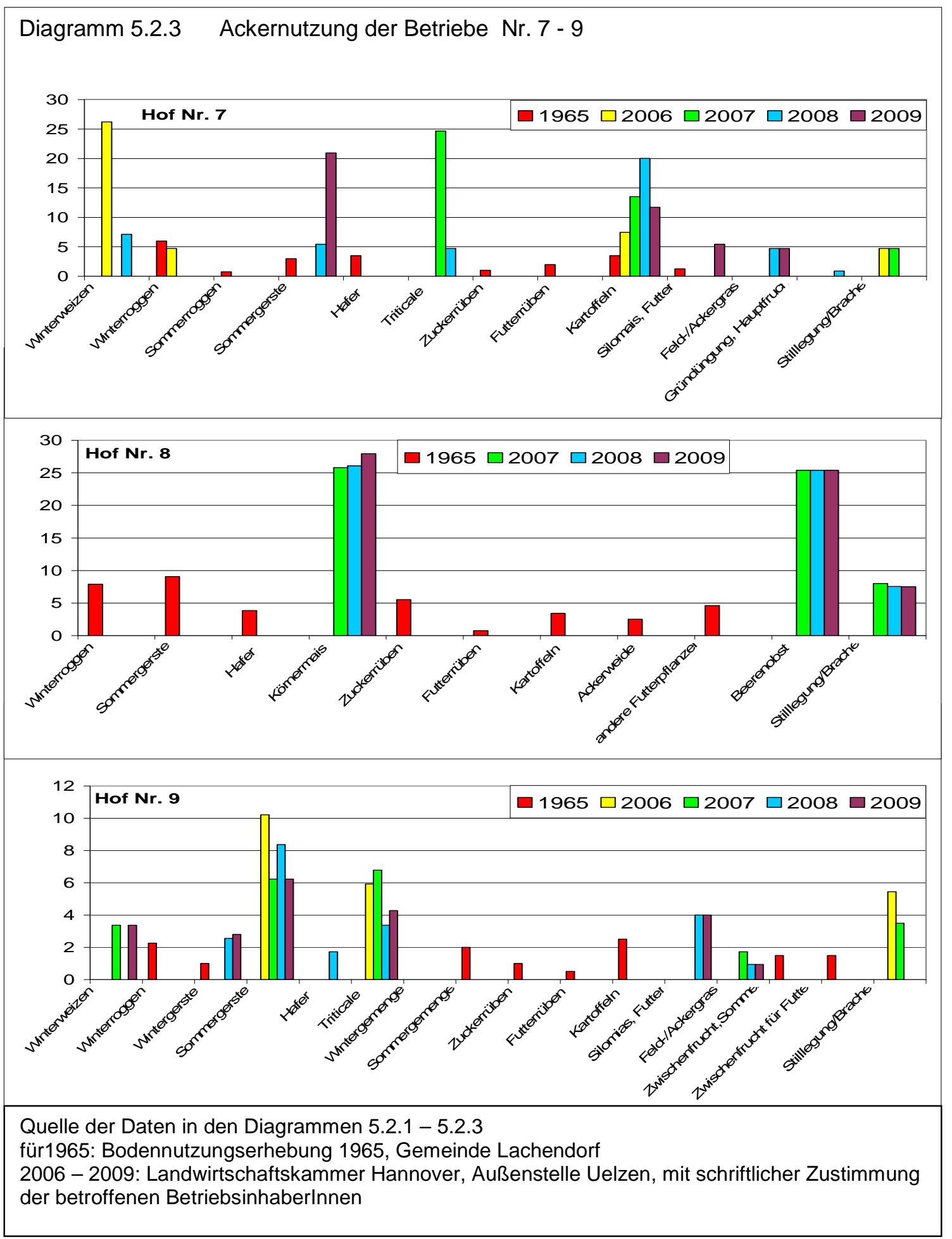




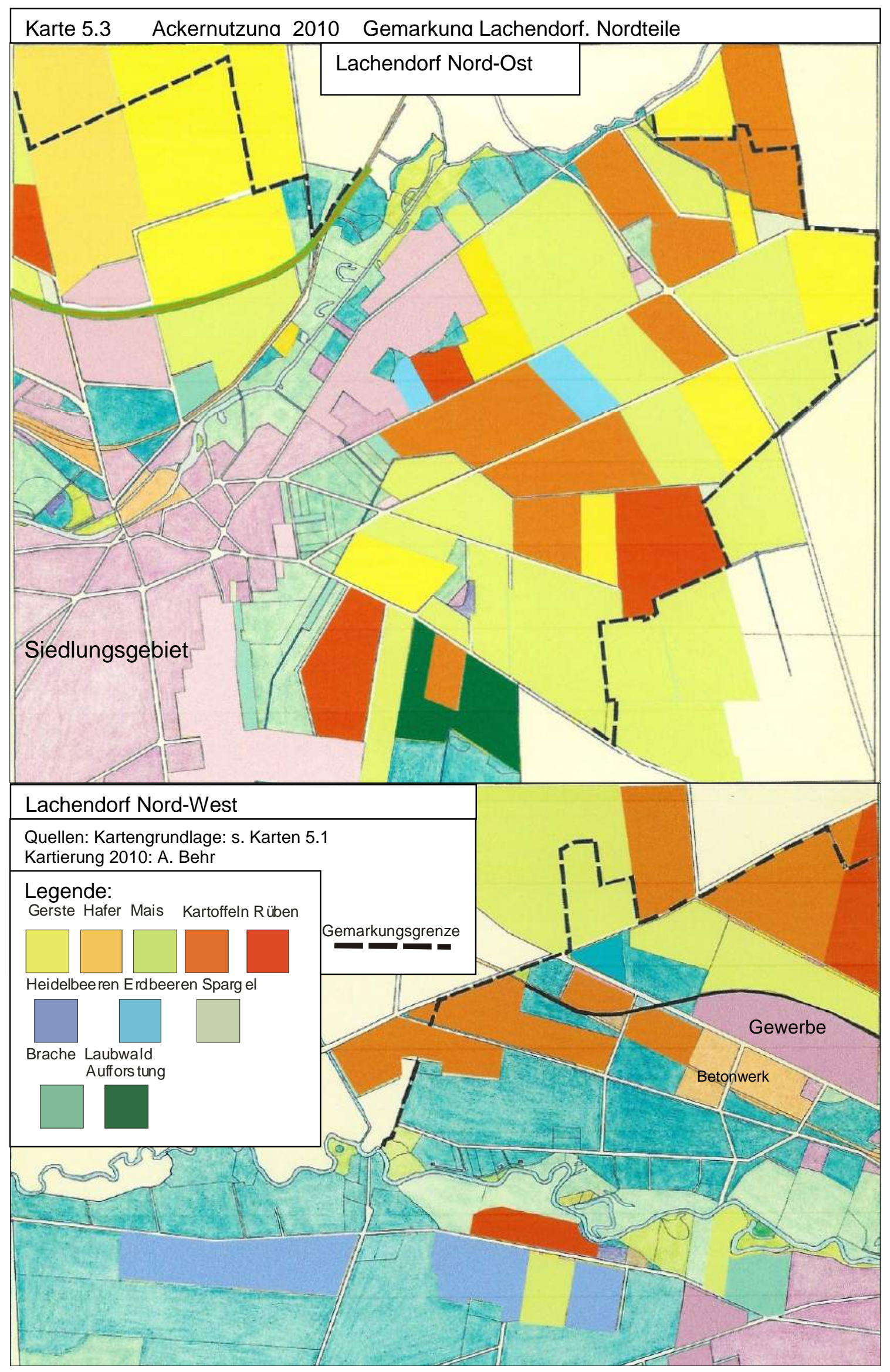


Das Wachsen der Betriebe, vorwiegend im Ackerbau, und das geringere und teils veränderte Anbauspektrum dürften sich also nur auf den Bereich des Ackerlandes auswirken.

Die Anbaudiagramme der im Jahr 2010 noch aktiven landwirtschaftlichen Betriebe zeigen die Ackernutzung von 2006 - 2009 im Vergleich zu 1965. Darin werden nochmals die drei Hauptmerkmale des Strukturwandels im Ackerbau verdeutlicht und belegt: Aufstockung der landwirtschaftlichen Nutzfläche je Betrieb, Reduzierung des Anbauspektrums und Verschiebung des Anbauspektrums. Die Zunahme des Weizenanbaus ist bedingt durch den Getreidemarkt und ermöglicht durch die erreichte hohe Bodenfruchtbarkeit auch auf Böden, die traditionell nicht als "Weizenböden“ gelten.

Für die Aufstockung der Nutzflächen bieten die Haupterwerbsbetriebe naturgemäß typische Beispiele, für die Reduzierung des Anbauspektrums sind besonders die Nebenerwerbsbetriebe gute Beispiele.

Hof Nr. 3 hat den Hackfruchtanbau mit Rüben und Kartoffeln ganz aufgegeben, Hof Nr. 4 den Anbau von Futterrüben und Kartoffeln. Beide Betriebe haben große Maisflächen im Anbauspektrum. Die Betriebe sind auf Rinderhaltung mit Milchkühen spezialisiert, brauchen also betriebsintern als Futter weder Kartoffeln noch Rübenblattsilage, seit Maissilage diese ersetzt.

Hof Nr. 6 ist mangels Betriebsflächen innerbetrieblich expandiert durch den Anbau von Sonderkulturen mit Gemüse und Obst sowie einen Hofladen.

Während die Anbaudiagramme den Strukturwandel der Betriebe verdeutlichen, zeigt die Nutzungskartierung des Ackerlandes aus dem Jahr 2010 die Auswirkungen auf die Kulturlandschaft:

Das Nutzflächenmuster in Karte 5.3 verstärkt noch deutlich den Strukturwandel zu größeren Schlageinheiten und einem reduzierten Anbauspektrum auf dem Acker. Auffällig ist auch, dass die Gemarkungsgrenze keine Rolle mehr hinsichtlich der Schlageinteilung und Bewirtschaftung spielt.

Die Gründe für den Wandel zu größeren Ackerparzellen sind betrieblicher bzw. agrartechnischer und ökonomischer Art: Da Handarbeit auf dem Feld keine Rolle mehr spielt und Großgeräte und -maschinen zum Einsatz kommen, sind möglichst große Nutzparzellen erwünscht. Wegen der Leistungsfähigkeit der heutigen Landmaschinen muss der Betrieb auch nicht mehr beim Anbau auf einen möglichst gleichmäßigen Arbeitsanfall achten; der Anbau kann sich im Rahmen der Standortbedingungen auf die betrieblich und gesamtökonomisch günstigsten Anbaufrüchte konzentrieren.

Für größere Betriebe mit Vollmechanisierung wären sicherlich noch wesentlich größere Nutzparzellen bzw. Schläge als früher möglich und wünschenswert, aber aufgrund der besitzrechtlichen und insbesondere aufgrund der relativ kleinräumigen naturgeographischen Struktur in der Lachendorfer Flur nur sehr begrenzt durchsetzbar. Daher hat das Wachstum der landwirtschaftlichen Betriebe nur einen marginalen Einfluss auf das Bild der Kulturlandschaft.

Wesentlich größer ist dagegen der Einfluss des Anbauspektrums der Kulturpflanzen auf das Landschaftsbild, aber auch auf die Ökologie von Fauna und Flora:

Die Landschaft des Ackerlandes hat sich in den letzten Jahrzehnten deutlich verändert: Getreide und Hackfrüchte haben Anteile am Acker verloren, Sonderkulturen, Futterbau und besonders der Mais haben ihre Anteile vergrößert. Außerdem wurde die Vielfalt der Ackerfrüchte deutlich reduziert, insbesondere im Zwischenfruchtanbau.

Der optische Eindruck einer Ackerbaulandschaft ist naturgemäß stark jahreszeitlich geprägt: Durch Veränderungen im Anbau hat sich auch das jahreszeitliche Bild des Ackerlandes geändert. Mit geringerem Anteil an Wintergetreide nimmt das Grün der Wintersaat als optisches Landschaftselement im Winterhalbjahr ab und das Braun der unbestellten Felder zu, zumal ganz offensichtlich nur wenig Zwischenfruchtbau betrieben wird. 
Verstärkter Maisanbau führt dazu, dass wegen der späten Aussaat und des recht großen Pflanzenabstandes der Boden erst recht spät von den Kulturpflanzen bedeckt ist, die Ackerfarbe also lange den optischen Eindruck prägt.

Andererseits tragen die Sonderkulturen zur optischen Differenzierung des Landschaftsbildes bei, insbesondere die größeren Blaubeerplantagen, die als Dauerkultur nicht mehr einem Fruchtwechsel auf dem Acker unterliegen.

In den Sommermonaten hat sich das gewohnte Landschaftsbild stark verändert, wenn das Gelb des Getreides nicht mehr den Acker wie früher dominiert, sondern das Grün der Maisbestände, das sich erst im Herbst mehr zum Braun der reifen Maispflanze vor der Ernte verändert, große Teile des Ackerlandes beherrscht.

Wenn der Mais fast ein Viertel des Ackerlandes einnimmt, wird er zur beherrschen Feldfrucht des Ackerlandes und damit zu einem bestimmenden Element der heutigen Kulturlandschaft.

Nun hat es aber noch einen entscheidenden betrieblichen Strukturwandel gegeben, wie Tabelle 5.10 belegt: Es hat eine sehr starke Entkoppelung des Ackerbaus von der Viehhaltung stattgefunden zu reinen Ackerbaubetrieben ohne jegliche Nutztierhaltung. Aber auch die Nutztierhaltung hat sich vom Ackerbau entkoppelt, weil die Tierhaltung nicht mehr allein auf betriebseigenem Futter basiert, also Ackerbau nicht mehr unbedingt Voraussetzung für Tierhaltung ist. Bei den Lachendorfer Betrieben mit Nutztierhaltung ist diese Extremform der Trennung der Tierhaltung vom betrieblichen Ackerbau aber nicht gegeben, mindestens nicht bei den beiden Betrieben mit Rinderzucht, die innerbetrieblich Maissilage als Futtergrundlage erzeugen.

Die Betriebe haben sich also zu spezialisierten, (fast) reinen Ackerbau- bzw. Marktfruchtbetrieben oder zu spezialisierten Veredelungsbetrieben mit ergänzendem Ackerbau entwickelt. Gemischtwirtschaftlich orientierte Betriebe wie 1965 gibt es nicht mehr.

Dieses Merkmal des landwirtschaftlichen Strukturwandels wirkt sich in mehrfacher Hinsicht aus: Die reinen Ackerbaubetriebe benötigen kein Grünland mehr und sind wegen des $\mathrm{Be}$ darfs an Ackerland daran interessiert, Grünland umzubrechen, wo immer die Boden- und Grundwasserverhältnisse dies zulassen. Schweinemast wird heute nicht vorwiegend mit betriebseigenem Futter betrieben, daher kann dieser Betriebszweig relativ isoliert vom übrigen Betrieb und mit wenig Auswirkungen - abgesehen von Stallanlagen im Außenbereich - auf die Kulturlandschaft geführt werden. Betriebe mit Rinderzucht und Milchkuhhaltung benötigen Futterflächen auf dem Acker und Weiden für den sommerlichen Weidegang des Jungviehs. Die Milchkühe können angesichts der heute üblichen Milchleistung den täglichen Weidegang allenfalls ergänzend nutzen bei intensiver Fütterung mit Kraftfutter und ständiger Stallhaltung. Das Melken im Sommer auf einer weit entfernten Weide mit einem mobilen Melkstand, wie es um 1966 noch in den Allerwiesen üblich war, ist heute betriebswirtschaftlich und technisch ${ }^{1}$ ausgeschlossen.

Also hat auch die Betriebstruktur der Betriebe mit Viehwirtschaft deutlich Auswirkungen auf das örtliche Grünland:

Kleinere Grünlandparzellen verschwanden ganz aus der Kulturlandschaft: So der schmale Grünlandstreifen am Oberlauf des Schelpriethgrabens in der Tiefenlinie des Trockentales östlich des Dorfes in der Bunkenburger Lehmplatte. Diese Grasflächen wurden umgebrochen und zu den auf beiden Seiten des Grabens anschließenden Äckern geschlagen. Eine Grünlandnutzung war wegen der geringen Größe und schlechten Zuwegung unrentabel, die Vergrößerung der anschließenden Ackerparzellen aber durchaus erwünscht.

Der ehemalige Grünlandstreifen westlich des Ortes, ebenfalls standorttypisch in einem Trockental, hier der Gockenholzer Geestinsel, angelegt, gehört inzwischen zum Gewerbegebiet "Im Bulloh".

Die ehemaligen Rieselwiesen im Westen der Gemarkung, die im 19. Jahrhundert seitens des Rittergutes eingerichtet worden waren und bereits um 1966 nicht mehr als Rieselwiesen, aber noch als Grünland genutzt wurden, sind ebenfalls ganz in Ackerland umgewandelt wor-

\footnotetext{
${ }^{1}$ Melkablagen sind heute so groß, dass ein mobiler Einsatz technisch unmöglich ist.
} 
den, weil der heutige Betrieb, der aus dem Rittergut hervorgegangen ist, ein Ackerbaubetrieb ist, der ackerfähiges Grünland entsprechend der Betriebsart umgewandelt hat.

Das Grünland im Krähenmoor ist zu Acker kultiviert und eine ehemalige Weide am Rande des Postmoores gehört heute zusammen mit den dortigen früheren Ackerflächen zu einer Heidelbeerplantage.

Erhalten blieb bis heute das Grünland am Ostrand des Dorfes, dem ehemaligen Kleinen Moor. Dies ist bedingt durch zwei unmittelbar benachbarte Betriebe, einer mit Milchkuhhaltung und einer mit Pferdezucht.

Die Entscheidung, ob eine ehemals aufgrund ökologischer Bedingungen angelegte Grünlandfläche erhalten blieb oder in eine andere Nutzungsform überführt wurde, war ganz offenbar nicht ökologisch sondern rein betriebswirtschaftlich bedingt.

Die Talaue der Lachte, bis weit in die 2. Hälfte des 20. Jahrhunderts ausschließlich als Grünland, vorwiegend als Weide und Mähweide genutzt, zeigt in den letzten Jahrzehnten je nach Lage eine unterschiedliche Landschaftsentwicklung. Oberhalb der Papierfabrik entstand aus einer ehemaligen Weide ein privater kleiner Park, der unmittelbar an die Lachte grenzt. Unterhalb der Straßenbrücke entstand in „Deecken Masch“ hinter dem neuen Rathaus eine öffentliche Parkfläche.

Die Weiden oberhalb des Ortes werden weiter für Rinderhaltung genutzt. Unterhalb des Ortes sind einige wenige Parzellen am Rande der Aue umgebrochen, die Aueweiden sind hier aber weitgehend erhalten, weil in der Aue mit der Gefahr der Überschwemmung bei Hochwasser nicht ausgeschlossen werden kann. Daher hält der direkt am Nordrand der Aue angesiedelte Betrieb noch einige Rinder und Mutterkühe, um dieses nicht ackerfähige Grünland sinnvoll zu nutzen, obgleich der Betrieb eigentlich ein reiner Ackerbaubetrieb ist.

Ebenso wie das Grünland in der Talaue der Lachte galten die feuchten Aller-Dreckwiesen lange Zeit als natürliches Grünland, weil wegen des Grund- und Bodenwassers sowie der Hochwassergefahr einerseits und wegen der teils anmoorigen Böden eine Ackerfähigkeit nicht gegeben war.

Das Bodenwasserregime und die Bodenart hatten in diesen Gebieten - vermutlich über Jahrhunderte - für eine durch Wiesen und Weiden, Baumgruppen und Einzelbäume geprägte offene Parklandschaft gesorgt, die dem Betrachter als Naturlandschaft erschienen sein mag, aber dennoch eine reine, allenfalls naturnahe Kulturlandschaft war.

Die Regulierung der Aller und des Schwarzwassers mit einer stärkeren Drainierung der Dreckwiesen, die Verwallung am Mündungsbereich des Schwarzwassers zur Verhinderung von Überschwemmungen und die Aufgabe der Stauwiesen schufen die wesentlichen Voraussetzungen für einen tiefgreifenden Landschaftswandel in den Trockenen Wiesen und dann auch in den Aller-Dreckwiesen in den vergangenen vier Jahrzehnten, so wie es bereits seit Mitte der 1960er Jahre in den ehemaligen Stauwiesen zu beobachten war.

Der eigentliche Grund für diesen Landschaftswandel ist aber der Strukturwandel der landwirtschaftlichen Betriebe. Mit der Aufgabe der Viehhaltung, insbesondere der Milchkuhhaltung, verlor das Grünland seine betriebswirtschaftliche Bedeutung bzw. Notwendigkeit. Die Ausdehnung des Ackerbaus, durch Einsatz von Agrartechnik leicht möglich, vergrößerte die Nachfrage nach Ackerland. So wurde mehr und mehr Grünland umgebrochen und der Ackernutzung zugeführt. Der Prozess begann auf den von Natur trockenen Böden der ehemaligen Stauwiesen und drang immer weiter auch in die Aller- und Dreckwiesen vor.

Dieser Nutzungswandel hatte tiefgreifende Folgen für die typische Flora und Fauna der Wiesenlandschaft, aber auch für das Landschaftsbild.

Das ehemalige Stauwiesengebiet ist zu einer auch optisch reinen Ackerbaulandschaft geworden, weil der Hauptzuleiter und die Bewässerungsgräben verfüllt wurden und im Landschaftsbild nicht mehr vorhanden sind.

Die Aller- und Dreckwiesen, in denen das Wege- und Grabensystem unverändert besteht und auch wegen der notwendigen Entwässerung bestehen bleiben wird, haben den Charakter einer Parklandschaft weitgehend erhalten, dennoch aber bietet sich ein stark verändertes Landschaftsbild, das sich jahreszeitlich mit dem Anblick der Ackerflächen und den verschiedenen Feldfrüchten verändert, weil die Wiesenlandschaft in eine Ackerflur umgewandelt 
wurde. Diese Ackerflächen wurden zunächst ganz traditionell mit dem üblichen Anbauspektrum beackert, in den letzten Jahren war hier aber eine besonders Starke Zunahme des Anbaus mit Mais festzustellen.

Dadurch ist auch in den Dreckwiesen der besondere landschaftliche Reiz einer „ungestörten“ Wiesenlandschaft weitgehend verloren gegangen. Die alte Kulturlandschaft hat sich durch Nutzungswandel zu einer neuen Kulturlandschaft gewandelt, die sich bereits wiederum durch ein sich wandelndes Anbauspektrum im Landschaftsbild verändert hat.

Innerhalb der Lachendorfer Gemarkung hat sich der südliche Teil, die Trockenen Wiesen und die Allerdreckwiesen, in den Jahrzehnten zwischen 1970 und 2010 am stärksten verändert. Die großflächige, weiträumige Wiesen- und Weidelandschaft mit teilweise parkähnlicher Struktur hat diesen besonderen Landschaftscharakter zweifellos gegen eine Agrarlandschaft mit dominierendem Ackerbau eingebüßt. Andererseits ist aber trotz des starken Nutzungswandels eine abwechslungsreiche und gut gegliederte Kulturlandschaft erhalten geblieben, weil das notwendige Grabensystem einen größeren Zuschnitt der Parzellen und damit einen großflächigen Ackerbau nicht zulässt.

Auch in diesem Landschaftsteil waren die Wasserbaumaßnahmen nur die notwendige Bedingung für die Ackerfähigkeit des vorherigen „absoluten“ Grünlandes. Zur Umnutzung des Grünlandes zu Ackerland führte aber vor allem der Strukturwandel der landwirtschaftlichen Betriebe.

Die Abbildung 5.2 und die Kartenfolge 5.4.1/2 veranschaulichen und belegen diesen Nutzungs- und Landschaftswandel

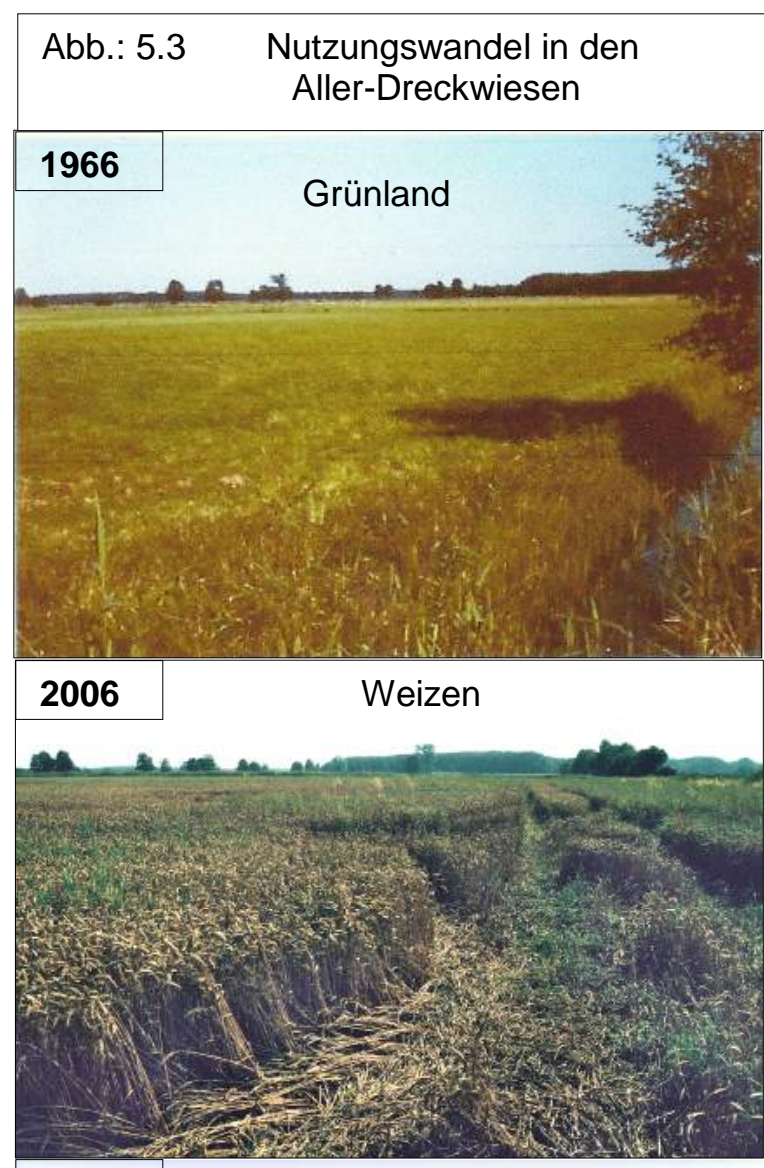

2013

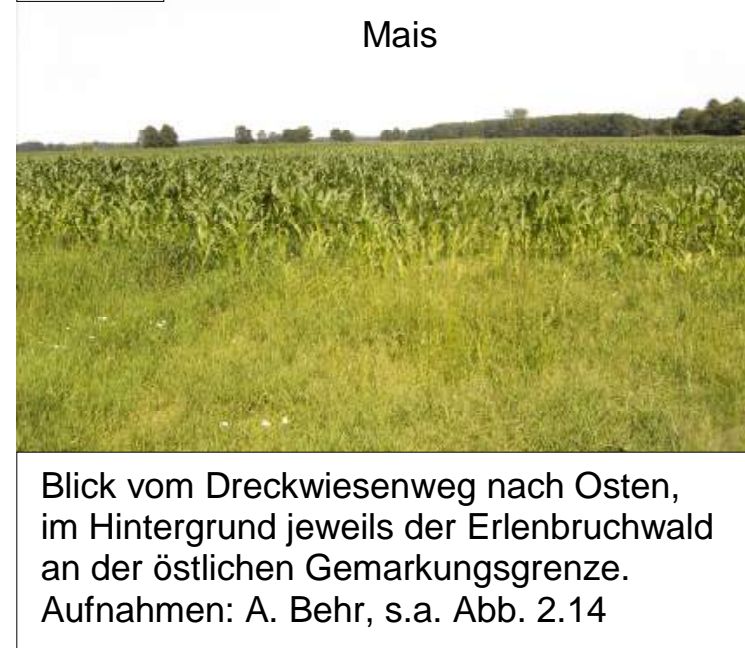
insgesamt, insbesondere aber auch die Merkmale der vergrößerten Nutzparzellen und ganz besonders den zunehmenden Maisanbau im 21. Jahrhundert.

Dabei sei nochmals darauf hingewiesen, dass die Umwandlung des Grünlandes in Acker und der seit wenigen Jahren dominierende Anbau von Mais zwei verschiedene Trends darstellen. Die Aufgabe der bäuerlichen Mischwirtschaft mit Ackerbau und Viehzucht führte zum Umbruch des Grünlandes. Die langfristig staatlich garantierten Einspeisevergütungen für "grünen“ Strom führten zu einem Boom bei den Biogasanlagen und dadurch zu einer gesteigerten Nachfrage nach „Energiemais“. Auf den frisch umgebrochenen Grünlandflächen hat sich der Maisanbau als besonders ertragreich erwiesen. Der Landschaftswandel zum „Maisgürtel“ ist also ökonomisch begründet und subventionsorientiert. 
Die ehemaligen Grünlandböden mit einer geringen Anmoorauflage bringen nach Umbruch durchweg trotz der geringen Bodenwerte - nicht nur bei Mais - gute Erträge, allerdings ohne steigende Düngergaben nicht auf Dauer. Entwässerte Niedermoorböden sind zwar gut ackerfähig, verlieren aber an Fruchtbarkeit durch den Aufbrauch des angereicherten Humus. Es handelt sich also um einen nicht nachhaltigen Nutzungswandel. ${ }^{1}$

Trotz dieses Nutzungswandels hat sich die Eigenart der Landschaft nicht total verändert: Zwar wurde die reine Wiesen- und Weidelandschaft durch eine Ackerbaulandschaft ersetzt, die Weite des Landschaftsbildes ist aber erhalten geblieben.

Im östlichen Teil der Aller-Dreckwiesen, in der Gemarkung Ahnsbeck, wird durch Landschaftund Naturschutz ${ }^{2}$ versucht, ein Stück dieser ehemaligen Wiesenlandschaft zu erhalten.

\footnotetext{
${ }^{1}$ vergl. K. Stahr u.a., Bodenkunde und Standortlehre, a.a.O., S. 182

${ }^{2}$ s. Kap. 7
} 

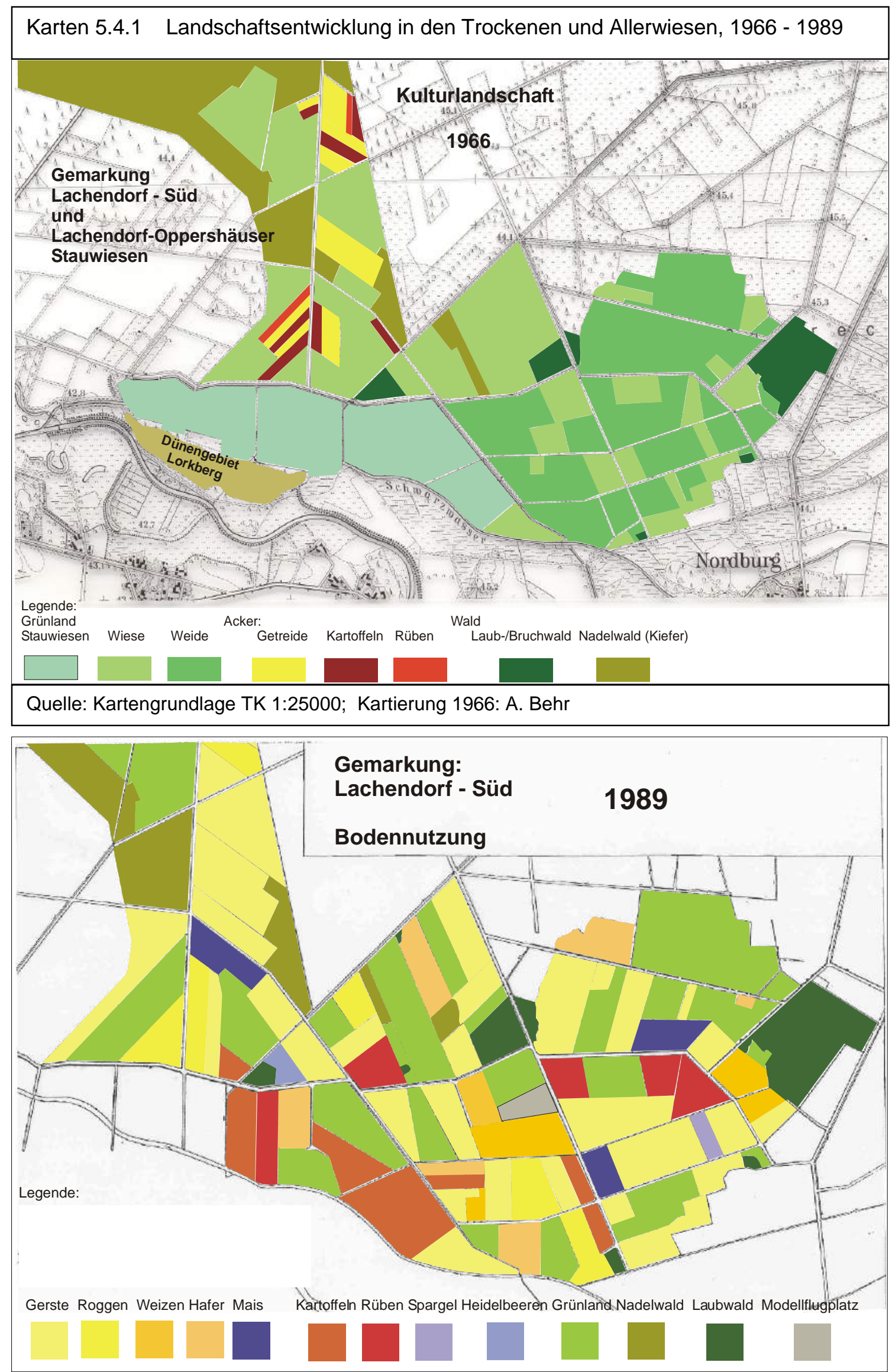

Quelle: Kartengrundlage: s. Karte 5.3

Kartierung 1989: A. Behr 

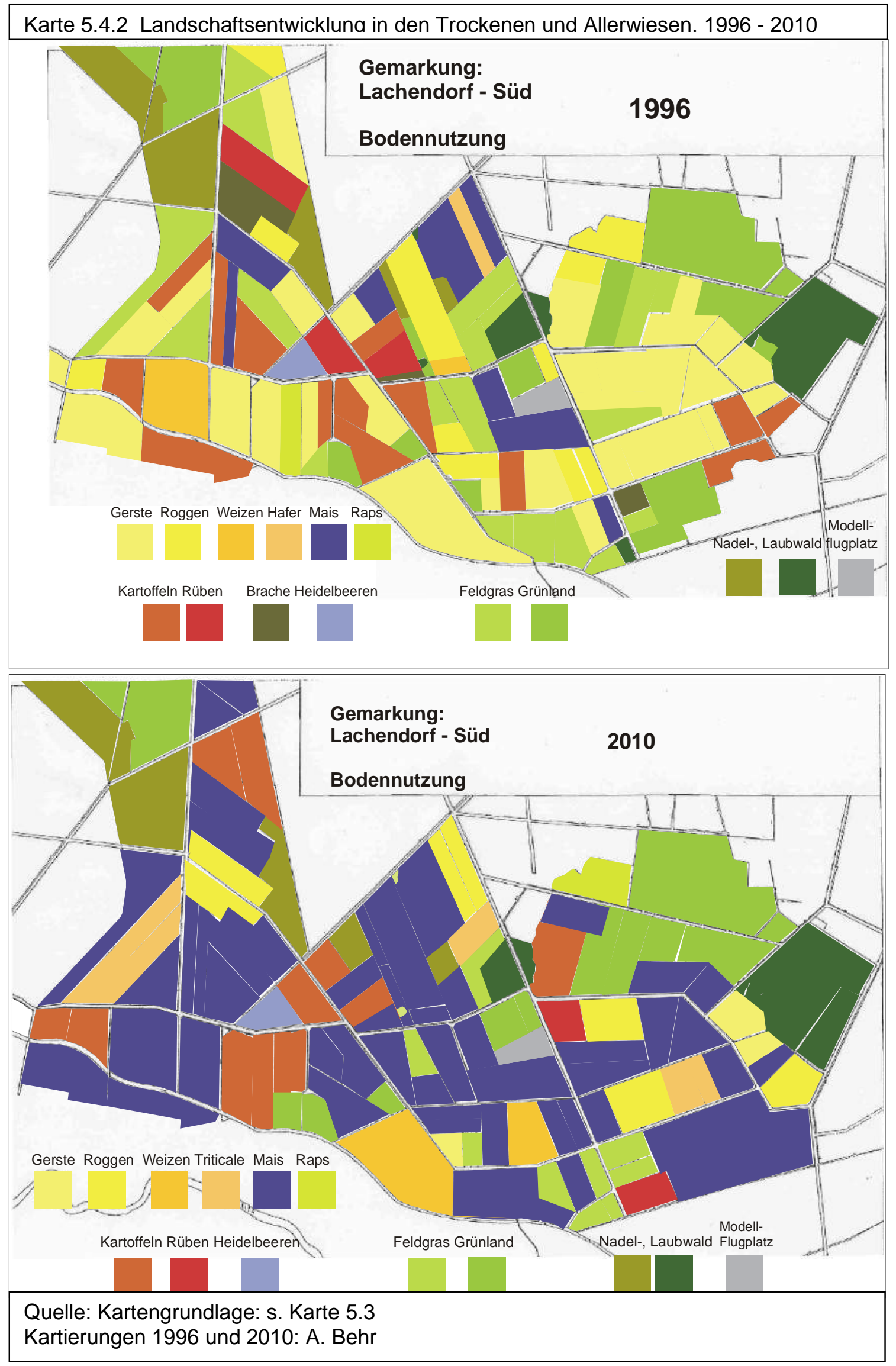


\section{Kap. 5.5 Siedlung und Kulturlandschaft}

Siedlungen sind zweifellos ein wichtiges Element unserer Kulturlandschaft. Deshalb muss trotz der naturgeographisch-ökologischen und agrarwirtschaftlichen Schwerpunkte dieser Arbeit ein Blick auf die Siedlungsentwicklung geworfen werden. Dabei geht es ausschließlich um die Beurteilung der räumlichen Siedlungsentwicklung. ${ }^{1}$ Historisches zur Dorfentwicklung ist an anderer Stelle ${ }^{2}$ bereits dargestellt. Für eine Betrachtung von Siedlungsaufriss und Siedlungsarchitektur ist hier ebenso wenig der Platz wie für die Analyse der äußeren und inneren Verkehrsstruktur.

Über Jahrhunderte war in den Dörfern allein die bäuerliche Bevölkerung ortsbestimmend, weil die nicht landwirtschaftlich orientierte bzw. abhängige Bevölkerung außerordentlich klein war. Auch die unterbäuerliche Schicht sowie auch nichtbäuerliche Familien waren wenigstens durch Nutzgärten sowie Kleinviehhaltung an der Landnutzung beteiligt. Bis zu den Agrarreformen im 19. Jahrhundert gab es in vielen Dörfern auch „Bauern ohne Land“"3, die nur Nutzungsrechte für Vieh in der Gemeinheit hatten

Lachendorf stellte seit Gründung der Papierfabrik ${ }^{4} 1538$ einen Sonderfall eines Bauerndorfes mit einem herzoglich begründeten und geförderten Gewerbebetrieb dar, der sich nach und nach zur Fabrik entwickelte. Der langjährige Pächter bzw. Besitzer dieser Papiermühle hatte sicherlich im Dorf eine gesellschaftliche Sonderstellung, war aber auch in die bäuerliche Struktur durch den Kauf von Höfen und deren Bewirtschaftung, zeitweise als Rittergut, integriert. Dieser moderne Industriebetrieb prägt bis heute das Ortszentrum oberhalb der Lachtebrücke und der alte Schornstein ist noch als weithin sichtbare Landmarke erhalten.

Erst im 20. Jahrhundert, besonders nach 1945, gewann der nichtbäuerliche Bevölkerungsanteil immer mehr an Bedeutung und begann durch Bautätigkeit das Siedlungsbild immer mehr zu prägen. Da für die Ausweisung von Baugebieten sowie den Ausbau der Infrastruktur und die Ausweisung von Gewerbeflächen die politische Gemeinde zuständig ist, erlangten Rat und Verwaltung mit dem Wachstum der Bevölkerungsanzahl und der Öffentlichen Aufgaben eine stetig wachsenden Bedeutung für die Entwicklung der Siedlung. Im Ortsbereich bestimmen so die politischen Entscheidungsträger ganz direkt und dauerhaft das Bild der Kulturlandschaft.

Die öffentlichen Interessen und Planungen stehen aber nicht immer in Einklang mit den Interessen der meist privaten oder auch staatlichen Grundbesitzer.

Lachendorf ist es aber nicht nur gelungen, durch eine aktive Baulandpolitik und Erschließung immer neuer Bebauungsgebiete das Wachstum des Ortes bis in die Gegenwart zu fördern. Auch durch eine aktive Ansiedlungspolitik und eine konsequente Förderung der regionalen Zentralität ist es gelungen, zum zentralen Verwaltungs- und

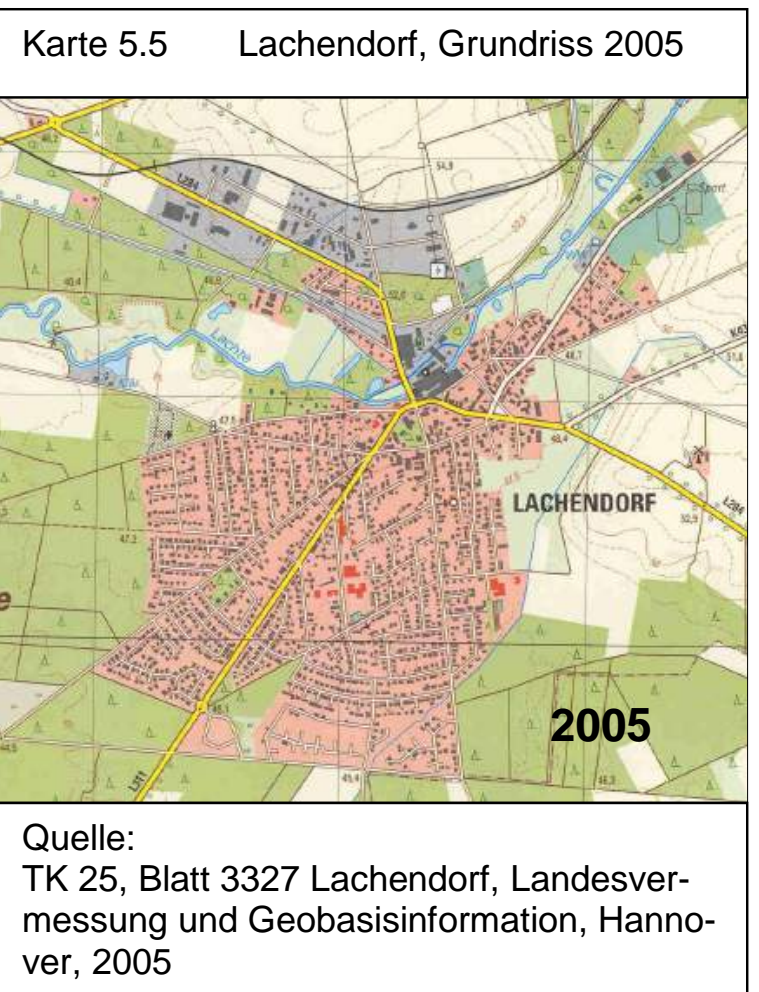

\footnotetext{
${ }^{1}$ Es kann nicht Absicht dieses Kapitels sein, die Geschichte des Ortes Lachendorf darzulegen, das ist bereits in den Lachendorfer Chroniken I und II von M. Wittmann und K. Seebo geschehen.

2 s. M. Wittmann u. K. Seebo, Lachendorf, Chronik der Gemeinde Lachendorf, Bd. I, Lachendorf 1988

${ }^{3}$ s. H. Küster; Geschichte der Landschaft in Mitteleuropa, a.a.O., S. 321

${ }^{4}$ Zur Geschichte der Papierfabrik: s. F. Friedrich, a.a.O.
} 
Dienstleistungszentrum im Osten des Kreises Celle aufzusteigen und sich so zu einem Grundzentrum mit mittelzentralen Teilfunktionen ${ }^{1}$ zu entwickeln.

Dies wird besonders deutlich an der Entwicklung Lachendorfs als Schul ${ }^{2}$-, Kirchen- und Verwaltungsstandort:

Die alte einklassige Dorfschule bezog 1831 den 2. Neubau eines Schulhauses, ab 1875 gab es ein zweites Schulhaus und zwei Lehrer, ab 1903 drei Lehrer und ab 1947 die 4. Lehrerstelle. Im Jahr 1963 erfolgte die Einweihung der Mittelpunktschule. 1979 erhielt der Ort eine Realschule und 2005 ein Gymnasium.

Über Jahrhunderte gehörte Lachendorf als Außendorf zum Kirchspiel Beedenbostel. Erst seit den 1960er Jahren hat Lachendorf eine eigene Pfarrstelle und ist inzwischen selbständige Kirchengemeinde der Landeskirche Hannovers mit Gemeindezentrum und eigener Kirche ${ }^{3}$. Fast zeitgleich wurde auch eine katholische Kirche gebaut, sodass Lachendorf dann zusammen mit der ev.-luth. Freikirche über drei christliche Kirchen verfügt.

Ähnlich erfolgreich entwickelte sich der Ort im Bereich der Dienstleistungen und der Verwaltung. Die erste Samtgemeinde gründet Lachendorf 1968 zusammen mit Ahnsbeck und Gockenholz. Im gleichen Jahr zieht die Gemeindeverwaltung aus einer Holzbaracke an der Oppershäuser Straße in einen Neubau neben der Lachtebrücke ein. Ab 1973 ist Lachendorf mit den eingemeindeten Dörfern Gockenholz, Jarnsen und Bunkenburg der zentrale Ort für die gleichnamige Samtgemeinde Lachendorf, zu der auch Ahnsbeck, Beedenbostel, Hohne und Eldingen gehören.

Die Zunahme der Zentralität Lachendorfs geht im Bereich der Verwaltung und Bildung und teilweise auch der Grundversorgung auf Kosten der Nachbarorte. Das ursprüngliche regionale Grundzentrum Beedenbostel, früher Sitz der Amtsvogtei, wurde von Lachendorf abgelöst.

Der Grundriss der Siedlung zeigt eine sehr deutlich ausgeprägte funktionale Gliederung in Dorfkern mit Dienstleistungen und Fabrikgelände, Wohngebiete mit integrierten Schulen, Kindergarten und Kirchen, Gewerbegebiet mit Bahnanschluss und Einkaufszentrum, Freizeitgelände und am Ostrand das alte Dorf, das bis heute durch die alten Höfe geprägt ist und fast noch einen in sich geschlossenen traditionellen Dorfteil bildet. Das Zentrum an der Ackerstraße erhält durch umfangreiche Sanierungen und Neubauten einen eher städtischen Charakter. In der Planung des Ortsgrundrisses ist es gelungen, die mehr traditionellen dörflichen Teile sowie den noch landwirtschaftlich geprägten Ortsteil teilweise zu erhalten und die Neubaugebiete, z.T. allerdings mit einer sehr engen Bebauung, als geschlossene Wohngebiete zu entwickeln.

Die gesamte Siedlung zeigt eine

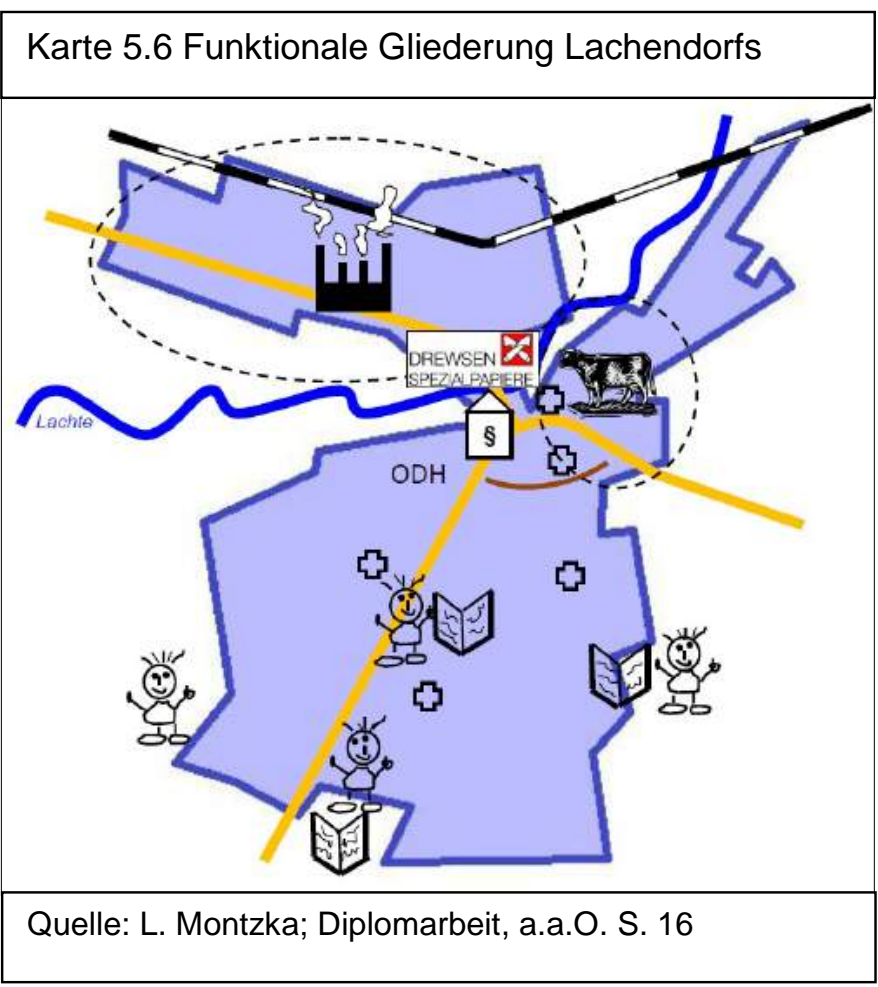

\footnotetext{
${ }^{1}$ s. Benennung der TK 25000: Blatt 3327: früher Beedenbostel, heute Lachendorf

${ }^{2}$ Vgl. dazu Wittmann, a.a.O., S. $153 \mathrm{ff}$ und S. $198 \mathrm{ff}$

${ }^{3}$ Die Kirchengebäude der ev. landeskirchlichen und der katholischen Gemeinde sind auf den amtlichen Karten (s. TK 25, Blatt 3327 Lachendorf bzw. Karte 5.5) bis heute nicht als Signatur verzeichnet. (Anm. d. Verf.)
} 
klare funktionale Binnengliederung: Alter Ortskern am „Lachteknie“ mit Bauernhöfen und Papierfabrik, Sport- und Freizeitgelände an der Jarnser Straße im Nordosten, Gewerbegebiet an der Celler Straße im Nordwesten, Wohngebiet mit Kindergärten, Schulen und Kirchen im Süden sowie ein modernes Ortszentrum entlang der Ackerstraße mit Dienstleistungsfunktion.

Aufgrund seines Wachstums und seiner heutigen flächenmäßigen Ausdehnung ist der Ort zu einem neuen und prägenden Element der Kulturlandschaft geworden.

Das Dorf Lachendorf hat seinen Siedlungsursprung am Südufer des Lachteknies, also am Ausgang des Lachtetales in das Urstromtal der Aller bzw. direkt an der Lachte in der Wurzelzone des LachteSchwemmfächers. Die Lage am Fluss mit Zugang zu frischem Wasser und zur Anlage von Wiesen und Weiden in der Aue, am Fuß der Geestplatten mit Lehmböden guter natürlicher Fruchtbarkeit und am Ursprung des einst bewaldeten Schwemmfächers sowie in hochwassersicherer Lage am Rande des Urstromtales muss als bevorzugte Siedlungslage und als typische Ökotopengrenzlage ${ }^{1}$ charakterisiert werden.

Urkundlich $^{2}$ sicher belegt ist die Existenz von Lachendorf in einem Güterverzeichnis ${ }^{3}$ des Cyriacus-Stiftes in Braunschweig, das aus den Jahren zwischen 1219 und 1225 datiert. Vermutlich reicht die Besiedlung am Lachteknie aber weit in das 1. Jahrtausend n. Chr. bis in die Landnahmephase zurück.

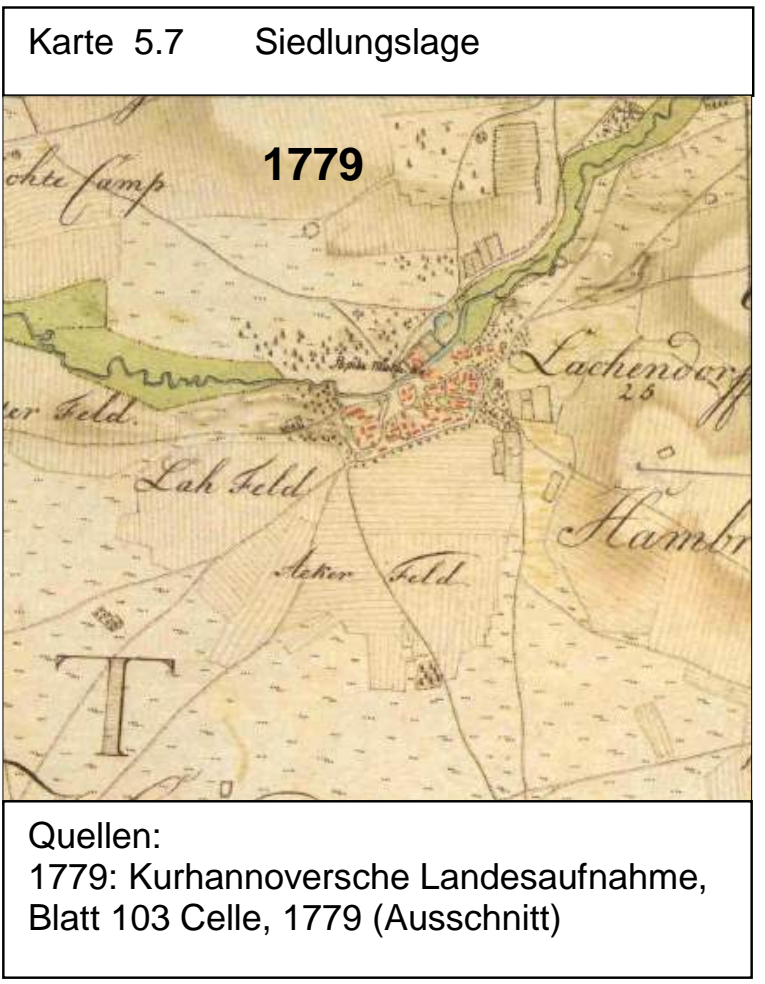
Noch ältere Siedlungsspuren sind durch Grabungsfunde bis in die Steinzeit belegt ${ }^{4}$. Frühe Spuren menschlicher Besiedlung fanden sich 1965 in der Gemarkung. Ein Grabhügel wurde als bronzezeitlich datiert und eine Nachbestattung als früheisenzeitlich. ${ }^{5}$

Die Kurhannoversche Landesaufnahme von 1779 nennt $25^{6}$ Feuerstellen, die sich eng südlich des Lachteknies bzw. hauptsächlich östlich des Lachteübergangs zusammenscharen. Die Karte von Papen aus dem Jahr 1839 bestätigt Lage und Ausdehnung des Ortes.

Ein Großbrand im Jahr $1850^{7}$ vernichtete einen Großteil des Bauerndorfes. Der Wiederaufbau veränderte das Dorfbild erheblich, weil nun die Höfe teils weiter auseinander liegend

\footnotetext{
${ }^{1}$ s. Küster, Hansjörg, Geschichte der Landschaft in Mitteleuropa, Beck, München 1997, S. 177

2 vgl. dazu Wittmann u. K. Seebo, Lachendorf, Chronik der Gemeinde, Bd. I, Lachendorf, 1988, S. 11 ff.

${ }^{3}$ ebd., S. 17

${ }^{4} \mathrm{vgl} \mathrm{ebd.} \mathrm{S.} 11$

${ }^{5}$ Grabungsbericht, S. 1

${ }^{6}$ Wittmann nennt irrtümlich in der Lachendorfer Chronik, Bd. I, 26 Feuerstellen der Kurhannoverschen Landesaufnahme von 1779. Es handelt sich offensichtlich um einen Lesefehler wegen der Schreibweise der 5., s. Wittmann, a.a.O., S. 198 7 ebd.
} 
errichtet wurden und sich die Dacheindeckung mit Ziegeln ${ }^{1}$ durchsetzte. Die Ortslage veränderte sich damit aber nicht und die Siedlungsausdehnung ${ }^{2}$ nur unwesentlich.

Erst die Preußische Landesaufnahme von 1899 zeigt eine erste deutliche Siedlungserweiterung, hauptsächlich am Ortsrand südlich der heutigen Ackerstraße, aber auch westlich der Oppershäuser Straße und im Nordosten am Weg nach Jarnsen und am Wirtschaftsweg Osteraden.

Bei der Siedlungserweiterung in der 2. Hälfte des 19. Jahrhunderts hat es sich zeitgemäß hauptsächlich um neue Abbauernstellen gehandelt, die ein kleines eigenes Gehöft mit sehr wenig Ackerland besaßen, das zur Selbstversorgung ${ }^{3}$ diente. Lachendorf bot mit den Beschäftigungsmöglichkeiten außerhalb der Landwirtschaft in der Papierfabrik besonderen Anreiz für die Ansiedlung kleiner Abbauern- und sog. Häuslingsstellen, die nur über eine kleine Hofstelle und Gartenland verfügten.

Die Ansiedlung dieser Haus- und Hofplätze erfolgte entweder auf der Lachteterrasse im Nordosten oder vorwiegend auf den armen Sandböden des Schwemmfächers am Süd- und Südwestrand des Dorfes. Es wurden also nur die geringwertigen Böden für diese erste Siedlungserweiterung in Anspruch genommen.

Das Siedlungsgebiet um 1900 zeigt eine meist nur lockere Bebauung und innerhalb des Ortes Freiflächen und viel Gartenland.

Der Vergleich der Karten von 1779 und 1899 verdeutlicht auch die Unterschiede im Wegeund Straßennetz, von einem gewachsenen Wegenetz zu einem genau vermessenen und streng geometrisch gestalteten Wegesystem, sowohl inner- wie außerörtlich. Dieses klare Wegenetz ist auch eine Folge der genauen Vermessung und geometrischen Gliederung der neuen Besitzparzellen im Zuge der Agrarreformen des 19. Jahrhunderts. Dieses Erbe aus den Agrarreformen bestimmt bis heute im Straßen-, Wege- und Grabennetz unsere Kulturlandschaft.

Das Siedlungswachstum begann in den 50 er Jahren des 20. Jahrhunderts, zunächst durch den Zuzug von Flüchtlingen und Vertriebenen, die sich sehr preisgünstig Bauland kaufen konnten, weil Bauern bereit waren, geringwertiges Ackerland mit 18 20 Bodenpunkten am Südrand des Dorfes auf den armen Sanden des Schwemmfächers zu veräußern.

Die Einwohnerzahl stieg auch in den letzten drei Jahrzehnten des 20. Jahrhunderts fast kontinuierlich an: von etwa 3500 Anfang der 1970er Jahre auf knapp 6000 im 1.

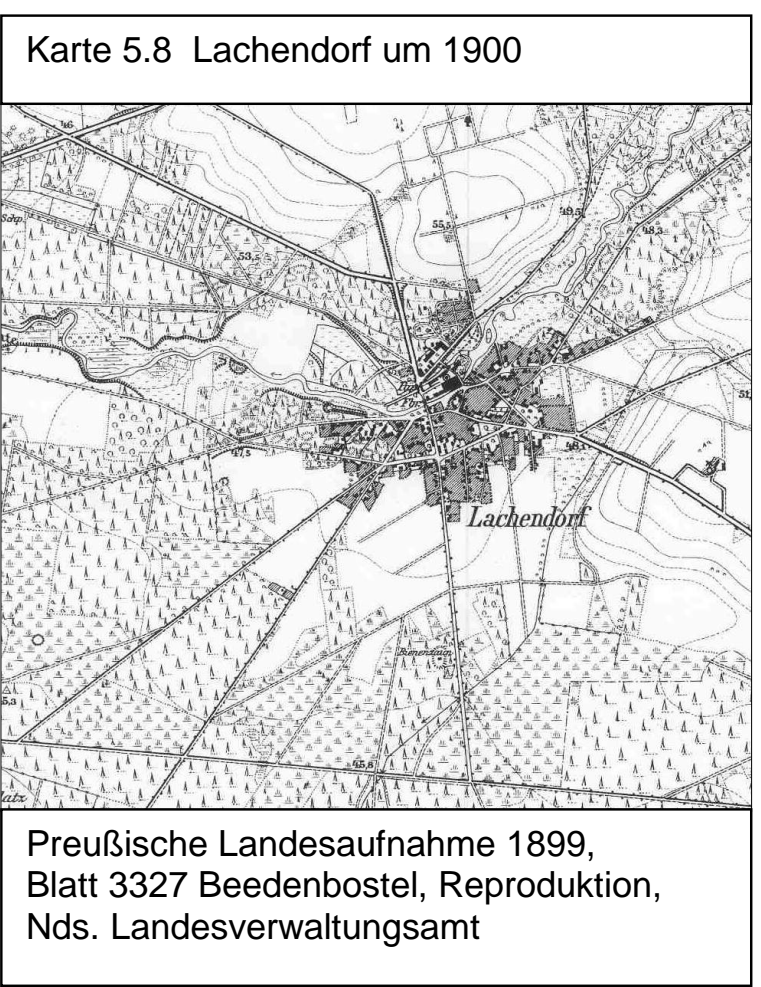
Jahrzehnt des 21. Jahrhunderts, ab 2006/6 allerdings stagnierend ${ }^{4}$.

Bis Anfang der 1990er Jahre konzentriert sich das Wachstum der Wohnbaugebiete wie bisher auf die bisherigen Ackerflächen am Süd- und Südwestrand des Ortes. Inzwischen ist das

\footnotetext{
${ }^{1}$ ebd.

2 Das Classifications- und Vermessungs-Register der Feldmark Lachendorf (Samtgemeinde Lachendorf, Archiv-Akten 61/9), das zur Vorbereitung der Verkoppelung nach 1852 erstellt wurde, benennt für mehrere Höfe noch „Hofstelle und Bauplatz", ein sicherer Hinweis auf den Wiederaufbau mehrerer Gehöfte.

${ }^{3}$ Dazu gehörten auch die Haltung von Federvieh und das Mästen von einigen Schweinen, im Wesentlichen mit Kartoffeln und Küchenabfällen.

${ }^{4}$ s. Montzka, L.; Entwicklung eines kommunalen Flächenmanagements ..., a.a.O., S. 4, Abb. 2
} 
bebaute Gebiet im Süden bis an den Ahnsbeck-Altenceller Weg vorgedrungen und an der Oppershäuser Straße mit dem Bau des Gymnasiums sogar darüber hinaus in das Flurstück Reitbahn. Auch im Südwesten, westlich der Oppershäuser Straße, ist das ehemalige geringwertige Ackerland bebaut. Im Westen reicht das Baugebiet bis an den Wald heran und hat „im Gehege“ auch eine ehemalige Forstfläche ${ }^{1}$ eingenommen.

Am Nordostrand an der Jarnser Straße hat die Gemeinde mit dem Sportplatz, der Tennisanlage, Kanuclub und Disco ein Freizeitgelände erhalten, das die mageren Sandböden der Lachteterrasse sinnvoll nutzt, wobei einige Binnendünen morphologisch beseitigt worden sind.

Die Talaue der Lachte blieb außer im Bereich der Papierfabrik unbebaut, erfuhr im Ortskern unterhalb der Straßenbrücke aber eine Umwandlung von einer Weide in ein Parkgelände.

Erst seit den 1980er Jahren greift die Ortsentwicklung von den armen Sandböden des Schwemmfächers und der Lachteterrasse auch auf bessere Böden der Geestplatten über:

Der Talrand des Urstromtales nördlich der Straße vom Ort zum Heideeck, also der Südrand der Gockenholzer Geestplatte, wurde durch das Gewerbegebiet „Im Bulloh“ der landwirtschaftlichen Nutzung entzogen. Einen weiteren starken Verlust an Ackerland bedeutete die Verlegung der Bahnstrecke, die ursprünglich die Gockenholzer Geestplatte in einem Bogen entlang der Fußfläche umrundete und jetzt in einem tiefen Einschnitt bis kurz vor Beedenbostel zerschneidet. Die ursprüngliche Streckenführung parallel zum Geesthang bis in den Ort und dann auf der Terrasse des Lachtetales talaufwärts nach Beedenbostel wurde sicherlich beim Bau kurz nach 1900 nicht aus ökologischen Gründen zur Schonung der Geestplatte mit wertvollen Lehmböden gewählt. Die ursprüngliche Trasse hatte zwei Gründe: Mit der Umrundung der Geestinsel umging man das starke Gefälle des Talhanges, der mit der neuen Trasse in einem tiefen Einschnitt überwunden wird. Die alte Trasse machte auch einen Bahnhof direkt am Ortsrand möglich, der damals wegen des Personenverkehrs nach Celle auch dringend erwünscht war. Der Personenverkehr ist längst eingestellt und der Bahnhof wurde aufgelassen.

Mit dem Bebauungsplan „Kleines Bulloh“ wird das Gewerbegebiet weiter nach Norden über die Bahntrasse und den Gockenholzer Weg hinaus auf der Gockenholzer Lehmplatte erweitert: Im Jahr 2012 mit einer Biogasanlage und 2013 mit einer ebenerdigen Photovoltaikanlage auf ehemaligem Acker nördlich entlang des Gockenholzer Weges.

Das neueste Baugebiet, genannt „Sandbruche“, wird den Südwesthang der Bunkenburger Lehmgeest zu Bauland machen und damit auch diese Böden der landwirtschaftlichen Nutzung entziehen. Dies Baugebiet mit reiner Wohnbebauung wird allerdings durch leichte Hanglage und einer Exposition nach Südwesten zu den bevorzugten Wohnstandorten des Ortes gehören. An der Gockenholzer Geestinsel hat man diesen Vorzug für ein Wohngebiet nicht genutzt, weil der Hang als Gewerbe- und Dienstleistungsgebiet außerhalb des bisherigen Ortes an der Ausfallstraße nach Celle verplant wurde.

Die Studie zur Agrarstrukturellen Vorplanung von 1972 geht davon aus, dass der Land- und Forstwirtschaft der gesetzlich verbriefte Vorrang bei der Nutzung des Bodens eingeräumt wird. Im Bundesraumordnungsgesetz von 1965 wird festgelegt, „daß gute Böden nur im unbedingt notwendigen Umfang für außerlandwirtschaftliche Zwecke in Anspruch genommen werden sollen." ${ }^{2}$ Die Studie weist auch darauf hin, dass gute Böden standortspezifisch als „Böden mit höchsten Standortwerten“3 zu beurteilen sind. Als gute Böden sind also in der Gemarkung unbedingt die lehmigen Böden auf den Grundmoränen, den Geestplatten, einzustufen.

\footnotetext{
${ }^{1}$ Die westlich angrenzende Forst, ehemals Klosterforst, heute Staatsforst, steht aus besitzrechtlichen Gründen sicher nicht zur Ortserweiterung zur Verfügung. Das Baugebiet „im Gehege“ stellte die Klosterforst in den 1970er Jahren als Erbbaugrundstücke zur Verfügung.

2 ebenda, S. 92

${ }^{3}$ ebenda, S. 93
} 


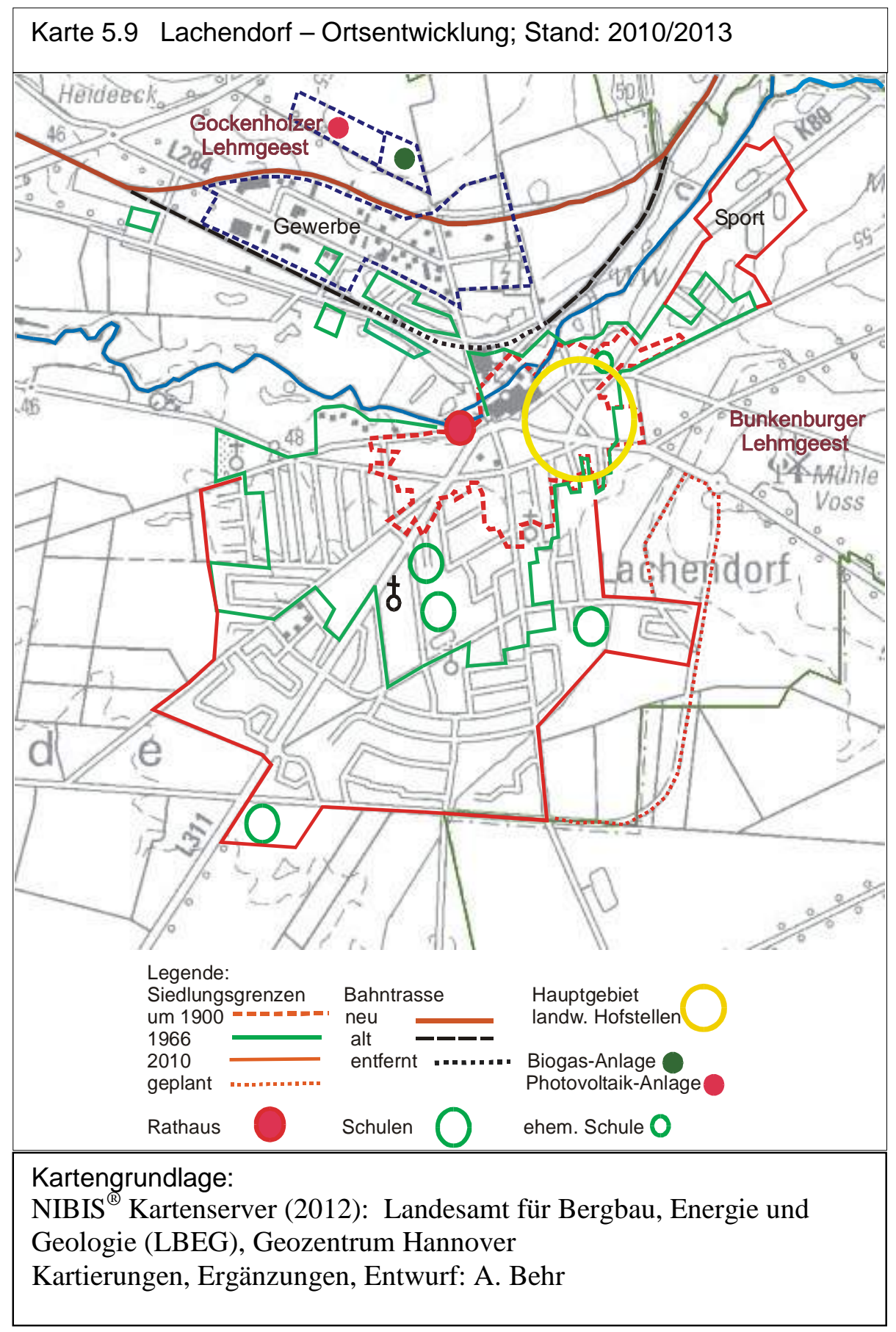

Die Siedlungserweiterungen der Baugebiete „Im Bulloh“, „Kleines Bulloh“ und „Sandbruche“ erfüllen die Forderung des Gesetzes von 1965 offensichtlich aber nicht, obgleich die Planungen der Gemeinde streng nach Recht und Gesetz erfolgten:

Das Gebiet „Im Bulloh“ wurde bereits in den 1980er Jahren beplant, als es noch keine Pflicht zur Umweltverträglichkeitsprüfung (UVP) gab ${ }^{1}$. Die gute Verkehrslage an der Ausfallstraße nach Celle und die Bereitschaft der Landbesitzer zum Verkauf der Flächen hatten offenbar einen höheren Stellenwert als der Schutz von gutem Ackerboden.

Bezüglich des Baugebietes "Sandbruche“ hat es eine Vorprüfung gegeben, die allerdings zu dem Ergebnis kam, dass keine Pflicht zur Umweltverträglichkeitsprüfung bestand².

\footnotetext{
${ }^{1}$ Schriftl. Mitteilung von Gemeindedirektor J. Warncke, Lachendorf, Mai 2013

${ }^{2}$ Schriftl. Mitteilung von Gemeindedirektor J. Warncke, Lachendorf, Mai 2013
} 
Für das Baugebiet „Kleines Bulloh“ wurde eine Umweltverträglichkeitsprüfung ${ }^{1}$ durchgeführt, die den Standort sehr genau analysierte und bewertete.

Die UVP beschreibt und bewertet den Standort nach den Schutzgütern Mensch, Pflanzen und Tiere, Boden, Wasser, Klima, Landschaft sowie Kultur- und sonstige Sachgüter ${ }^{2}$, wobei die Schutzgüter Mensch, Pflanzen und Tiere sowie Landschaft im übergeordneten Raum erfasst werden, um Auswirkungen auch außerhalb des Plangebietes zu berücksichtigen ${ }^{3}$.

Folgende Schutzgüter werden It. Gutachten erhebliche Auswirkungen erleiden:

„Für das Schutzgut Pflanzen und Tiere sind somit erhebliche Auswirkungen durch Teilverluste ... und Funktionsbeeinträchtigungen des Gockenholzer Weges durch Isolation und Schallimmissionen zu konstatieren.

Im Hinblick auf die Realisierung des Bebauungsplans bestehen für das Schutzgut Boden in erster Linie Empfindlichkeiten gegenüber Versiegelung, Verdichtung sowie Bodenauf- und-abtrag. Der dauerhafte Verlust aller Bodenfunktionen (Pflanzenstandort, Wasserspeicher, Lebensraum für Mikroorganismen und Bodentiere, Gasaustausch) infolge einer Vollversiegelung durch Bebauung gilt als erhebliche Auswirkung für das Schutzgut Boden.

Für das Schutzgut Wasser sind die mit der geplanten Bebauung einhergehenden Flächenversiegelungen von Bedeutung, da sie zu einem großflächigen Verlust von Grundwasserneubildungsflächen führen. In Hinblick auf die Lage des Plangebietes innerhalb des „Gebietes mit besonderer Bedeutung für die Wassergewinnung" werden die Flächenversiegelungen deshalb ... als erhebliche Auswirkungen bewertet. Der Eintrag von Schadstoffen in das Grundwasser kann aufgrund der geringen Durchlässigkeit der Bodenschichten und der Absorptionsfähigkeit des schluffig-lehmigen Bodensubstrates ausgeschlossen werden.

Zur Vielfalt, Eigenart und Schönheit des Landschaftsbildes im Plangebiet trägt im Wesentlichen der Gockenholzer Weg mit seinen Strauch-Baumhecken bei, die zur Landesstraße L 282 in eine Birkenallee übergehen. Auch das Feldgehölz aus jungen Sträuchern und Bäumen in der östlichen Verlängerung des Gockenholzer Weges hat eine gliedernde Wirkung für das Plangebiet. Allerdings liegen die für das Landschaftsbild und die Erholungseignung der Landschaft prägnanten Strukturen außerhalb des geplanten Gewerbegebietes (z.B. Eichenmischwälder, Lachteaue). Die Erlebniswirksamkeit des Plangebietes ist deshalb und auch aufgrund der Vorbelastungen durch technische Gebäude in den bestehenden Gewerbegebieten, Windenergieanlagen und Schallimmissionen der Landesstraßen eingeschränkt. Sichtbeziehungen bestehen von der Landesstraße L 282 aus in Richtung Lachendorf und aus dem Osten des Untersuchungsraumes nach Gockenholz. Somit weisen die Strukturen des Gockenholzer Weges und die Sichtbeziehungen die höchsten Empfindlichkeiten für das Schutzgut Landschaft gegenüber Verlust und Überbauung bzw. Unterbrechung auf. Erhebliche Auswirkungen ergeben sich bei dem Bau des geplanten Gewerbegebietes durch Beeinträchtigungen der Strukturen am Gockenholzer Weg, deren Funktion als gliederndes, belebendes Landschaftselement durch die Bebauung vermindert wird. 'A

Der errechnete Kompensationsflächenbedarf kann It. Gutachten zu einem Drittel im Plangebiet ausgeglichen, die anderen Zweidrittel auf einer externen Fläche:

„Die Ersatzleistungen sind auf einer ... großen, gemeindeeigenen Ackerfläche am Ahnsbecker Kanal vorgesehen, die zur Entwicklung von Natur und Landschaft zur Verfügung steht. Zielsetzung der Ersatzmaßnahme ist die Entwicklung eines extensiv genutzten, mesophilen Grünlandes über Brachestadien. Ferner soll die Fläche randlich im Norden und Osten von Gehölzsegmenten eingefasst werden." 5

Hier soll und kann nicht die Seriosität der Umweltverträglichkeitsstudie kritisiert werden, ganz im Gegenteil. Die Studie benennt ganz klar Auswirkungen der Umnutzung zum Gewerbegebiet auf die kleinräumig wichtigsten natürlichen Schutzgüter, nämlich Pflanzen und Tiere, Boden und Wasser. Teilverluste, Funktionsbeeinträchtigung, Versiegelung, Verdichtung, Aufund Abtrag von Boden, Verlust der Bodenfunktionen, Flächenversiegelung, Beeinträchtigung von Grundwasserneubildung und Schadstoffeintrag sind allesamt messbare Faktoren, die nachgewiesenermaßen durch die Überplanung zum Gewerbegebiet empfindliche und erhebliche Auswirkungen bewirken.

\footnotetext{
${ }^{1}$ s. Bebauungsplan Nr. 22, Gewerbegebiet „Kleiens Bulloh“, Umweltverträglichkeitsstudie, Samtgemeinde Lachendorf

${ }^{2}$ ebenda, S. $9 \mathrm{ff}$ (Die o. aufgeführte Reihenfolge der Schutzgüter entspricht der Reihenfolge in der UVP.)

${ }^{3}$ ebenda, S. 53

${ }^{4}$ ebenda, S. 54 - 55

${ }^{5}$ ebenda, S. 56
} 
Nur der Ausschluss von Schadstoffeintrag ins Grundwasser aufgrund des schluffig-lehmigen Bodensubstrats muss in Frage gestellt werden. Die Planungsfläche liegt zwar vollständig im Bereich der Geestplatte, überwiegend sogar auf der verebneten Kuppe. Aber aufgrund der Nähe zum Hang des Urstromtales mit der örtlich größten Reliefenergie muss befürchtet werden, dass ggf. kontaminiertes Wasser oberflächlich abfließt und im Fuß des Talhanges versickert, weil dort die Überdeckung der wenig durchlässigen Lehme mit sehr durchlässigen Talsanden zunimmt, die darüber hinaus auch noch über eine geringe Speicherkapazität verfügen.

Bei der Beurteilung des Schutzgutes Boden wurde der im örtlichen Vergleich hohe Bodenwert auf der Geestplatte nicht berücksichtigt und damit für die Landwirtschaft der dauerhafte Verlust als Ackerboden in Kauf genommen. Der Wert als Ackerboden ist in der UVP offenbar kein Kriterium. Für diese Bodenfunktion wäre auch in der Lachendorfer Flur kein Ausgleich möglich, wenn man den Wert für die ortsansässigen Ackerbaubetriebe und die Nahrungsproduktion berücksichtigen würde.

Durch die Nutzung von Ackerland auf guten Böden zur Energieerzeugung wird ein Problem der Raumnutzung deutlich, das sich fast zwangsläufig ergibt, wenn staatlich gesetzte Ziele durch Subventionen verfolgt werden und deren Umsetzungen der privaten unternehmerischen Initiative obliegen: Für den Betrieb mit Grundbesitz auf der Gockenholzer Lehmgeest war der durch das $E E G^{1}$ gegebene wirtschaftliche Anreiz offenbar so groß, dass trotz guter Böden (38 - 41 Bodenpunkte) die Energieerzeugung in einer Biogas- und einer Photovoltaikanlage wirtschaftlich lukrativer erschien als die Ackernutzung zur Erzeugung von Nahrungsmitteln oder agrarischen Rohstoffen. Für einen Ackerbaubetrieb mit Grundbesitz auf dem Lachte-Schwemmfächer macht es wirtschaftlich offenbar Sinn, auf sog. Grenzertragsböden mit 17 - 19 Bodenpunkten im Fruchtfolgezyklus auch Zuckerrüben anzubauen.

Die räumliche Verteilung von privatem bäuerlichem Grundbesitz, die aus der Spezialteilung und Verkoppelung im 19. Jahrhundert hervor gegangen ist, machte eine den Böden und Standorten sehr gut angepasste bäuerliche Mischwirtschaft möglich, be- bzw. verhindert aber heute eine optimale Anpassung der Bodennutzung an die standörtlichen Gegebenheiten. Die heutigen Agrarbetriebe haben im Vergleich zu früher unterschiedliche wirtschaftliche Strukturen und Ausrichtungen. Diesen unterschiedlichen Betriebstypen und -zielen entspricht aber nicht die überkommene Verteilung des Grundbesitzes im Hinblick auf optimale Bodennutzung der zur Verfügung stehenden unterschiedlichen Böden.

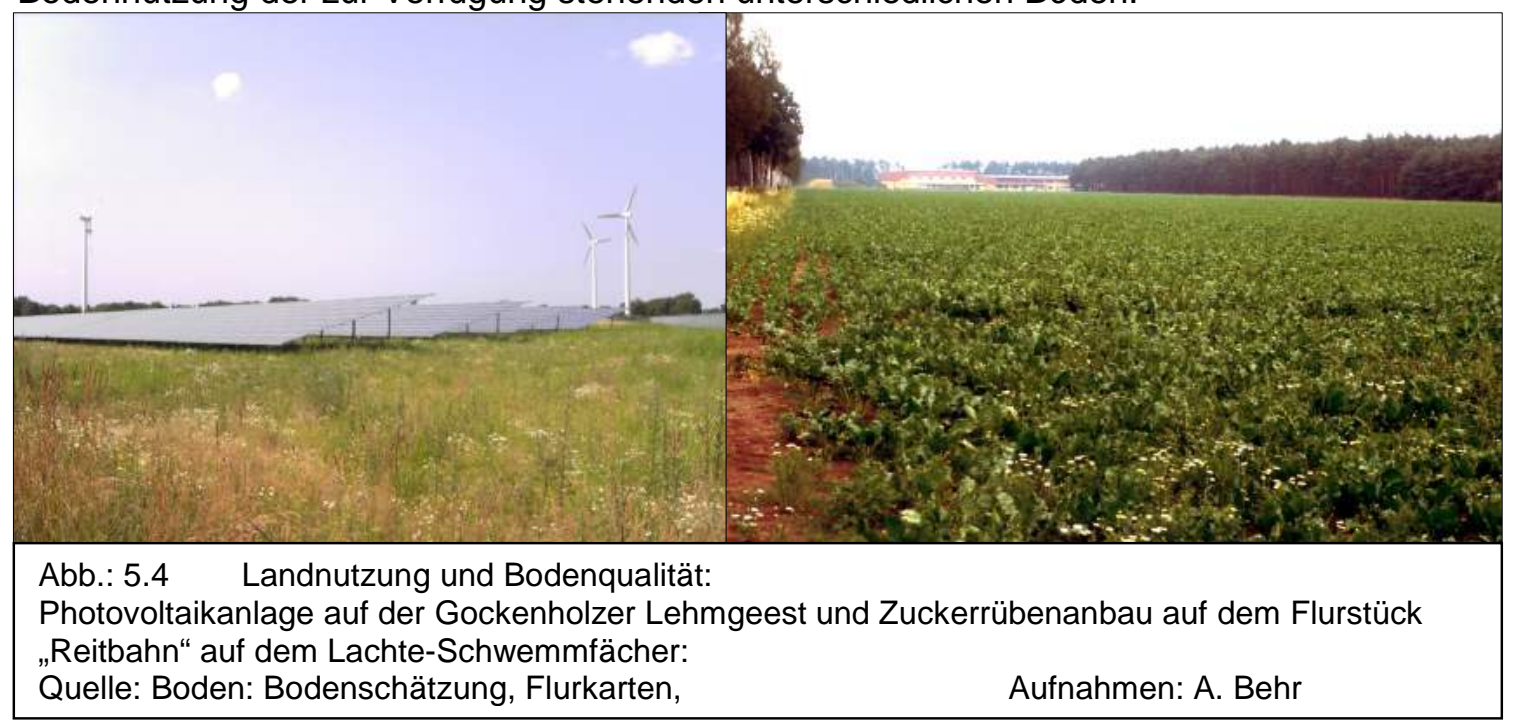

Beim Schutzgut Landschaft kommen ganz neue Bewertungskriterien zum Einsatz, nämlich Vielfalt, Eigenart und Schönheit des Landschaftsbildes, die nur aus der Sicht des bewertenden Menschen positive Merkmale sind, die sich aber einer ökologischen oder wissenschaftli-

\footnotetext{
${ }^{1}$ Erneuerbare-Energien-Gesetz
} 
chen Begründung entziehen. Dies wird besonders an den Begriffen „Sichtbeziehungen“ und "Erlebniswirksamkeit“ deutlich. Bemerkenswert ist bezüglich des Stellenwertes dieser beiden Faktoren, dass ihre Beeinträchtigung im neuen Bebauungsgebiet durch bereits vorhandene, benachbarte Beplanung und Bebauung gemindert wird. Das bedeutet im Umkehrschluss, dass eine bereits vorhandene Beeinträchtigung des Landschaftsbildes die weitere Beeinträchtigung in der unmittelbaren Nachbarschaft weniger gravierend macht. Dies trifft für das vom Menschen wahrgenommene und als „schön“ oder „nicht schön“ empfundene Landschaftsbild unzweifelhaft zu, kann aber kein ökologisches Kriterium sein.

Bezüglich der Flächenkompensation bzw. der Ausgleichsflächen für Eingriffe in Natur und Landschaft liegt ein grundsätzliches Dilemma vor, das weder gesetzlich noch planerisch zu beheben ist. Das Instrument des Flächenausgleichs ist möglicherweise ein unumgängliches und unverzichtbares Planungselement, um konkrete Raumplanung auch unter Umweltgesichtspunkten verantwortlich betreiben zu können. Im strengen ökologischen Sinne ist es aber ein Widerspruch in sich.

Flächenverbrauch kann grundsätzlich nicht ersetzt werden. Denn da die Erdoberfläche endlich ist und alle Standorte bereits besetzt sind, können Ausgleichsflächen keine neuen, bisher nicht vorhandenen Flächen ${ }^{1}$ einnehmen. Flächenausgleich für Eingriffe in Natur und Landschaft kann es nur geben durch Eingriffe in Natur und Landschaft an einem anderen Standort. Die „Entwicklung von Natur und Landschaft“ auf einem Ausgleichsstandort kann nur dadurch erreicht werden, dass die dort bereits vorhandene Natur und Landschaft an diesem Standort verändert, gestört oder gar zerstört werden.

Im konkreten Fall wird als Ausgleichsfläche für das Gewerbegebiet „Kleines Bulloh“, das auf der Gockenholzer Geestplatt liegt, eine Ackerfläche am Ahnbecker Kanal herangezogen, die in einem völlig anderen Naturraum, nämlich dem Aller-Urstromtal, liegt und demzufolge über völlig andere Standort-, insbesondere Bodeneigenschaften verfügt. Ein Ersatz für die auf Dauer zerstörten Braunerden auf sandigem Substrat und den Pseudogley-Braunerden und Pseudogleyen auf lehmigem Substrat können die Talsandböden im Allertal nicht sein.

Die Entwicklung der Ausgleichsfläche zu „extensiv genutztem, mesophilem Grünland über Brachestadien, das randlich im Norden und Osten von Gehölzsegmenten eingefasst werden ${ }^{\text {2 }}$ soll, erzeugt sicherlich neue Ökotope und ein neues Landschaftselement, aber auf Kosten eines vorher bereits existierenden Systems. Das kann man nur begründen, wenn man die Entwicklung der Ersatzflächen als eine Aufwertung des alten Standortes einstuft. Aber dieser Aufwertung liegen keine ökologischen Begründungen zugrunde, sondern anthropogene Wertmaßstäbe, die überwiegend kulturell und historisch gewachsen sind.

Das grundsätzliche Dilemma der Ausgleichsflächen kann nicht aufgelöst, sondern nur durch Setzungen überwunden werden. Sonst wären Planungen mit zwangsläufigen Umnutzungen nicht möglich.

Eine zwar sehr kleinräumige aber andererseits recht typische Veränderung im Bild der Kulturlandschaft kann man an der Entwicklung der Gärten in und außerhalb des Ortes beobachten.

Die TK 25 von 1899 verdeutlicht, dass die Siedlungsfläche keineswegs dicht bebaut war, vielmehr ein großer Teil als Gartenland ausgewiesen ist. Aufgrund des um 1900 noch hohen Selbstversorgergrades - insbesondere auf dem Lande - kann man davon ausgehen, dass es sich um intensiv bewirtschaftete Nutzgärten handelte, in denen Obst und besonders das Gemüse für den häuslichen Verzehr kultiviert wurden.

Gärten innerorts haben sich in den letzten Jahrzehnten - wie fast überall in den Dörfern von Nutzgärten mit Gemüse und Obst zu meist reinen Ziergärten mit gelegentlichen kleinen Resten eines Nutz- bzw. Hobbygartens verwandelt. Diese Gärten stellen mit ihrem Artenreichtum an Bäumen, Sträuchern, Stauden und Sommerblumen ein neues Siedlungs- und

\footnotetext{
${ }^{1}$ Neue Flächen, die (noch) nicht Standort von Ökosystemen sind, entstehen rezent nur durch vulkanische oder geologisch-tektonische Ereignisse bzw. Prozesse.

${ }^{2}$ s. Bebauungsplan Nr. 22, Gewerbegebiet „Kleiens Bulloh“, Umweltverträglichkeitsstudie, Samtgemeinde Lachendorf, S. 56
} 
Kulturlandschaftselement dar, das auch eine besondere ökologische Beachtung verdient hat. Die modernen Ziergärten bieten im Vergleich mit den früheren Nutzgärten neben vielen eher unscheinbaren Arten gerade der Vogelwelt einen neuen Lebensraum. Nachdem bereits seit mehreren Jahrzehnten die Amsel zum Gartenvogel wurde, haben z.B. auch Eichelhäher, Elstern, Krähen und Grünspechte die Ziergärten als Lebensraum entdeckt, seit sie nicht mehr bejagt werden dürfen.

Die heute weitverbreitete Möglichkeit, auch in durchlässigen Gartenböden mit Hilfe von Folien Gartenteiche anzulegen, hat in vielen Gärten kleine Ökotope mit einer sehr vielfältigen Flora und Fauna geschaffen, die in den reinen Nutzgärten keine Existenzgrundlage hatten.

Gärten außerhalb des Ortes entwickeln sich oft anders. Dafür sind die sog. „Langen Gärten“ am Nordostrand des Ortes auf gutem Boden mit sehr günstiger Südexposition auf dem Geesthang an der Einmündung des Lachtetales ins Allertal ein sehr gutes Beispiel. Die Anlage dieser Gärten geht mindestens bis ins 19. Jahrhundert zurück.

Sie waren sehr begehrt und ertragreich und um 1965 noch vollständig sehr intensiv als Gartenland zur Eigenversorgung bewirtschaftet. Im Jahr 2010 waren alle Parzellen als Nutzgarten aufgelassen, die meisten Gärten völlig verwildert oder als naturnaher Blumengarten noch extensiv genutzt. Auf einer Parzelle hat ein Club einen Standort gefunden, um dem Hobby der Hundehaltung nachzugehen.

Der Wandel der innerörtlichen Kulturlandschaft, der an der Gartengestaltung besonders sichtbar wird, ist eindeutig gesamtgesellschaftlich und nicht agrarwirtschaftlich bedingt: Die Bewirtschaftung eines Nutzgartens im Sinne von Subsistenzwirtschaft oder gar zur Existenzsicherung ist nicht mehr erforderlich. Außerdem sind Wissen und Können bzgl. der Bewirtschaftung eines Nutzgartens vielfach nicht mehr vorhanden. Durch die häufige Trennung von Wohn- und Arbeitsort mit teils langen Fahrzeiten fehlen häufig auch Zeit und Kraft für eine intensive Gartennutzung. Gärten dienen heute vorwiegend der Freizeitgestaltung und Erholung, aber nicht mehr der ergänzenden Eigenversorgung. Gärten außerhalb der

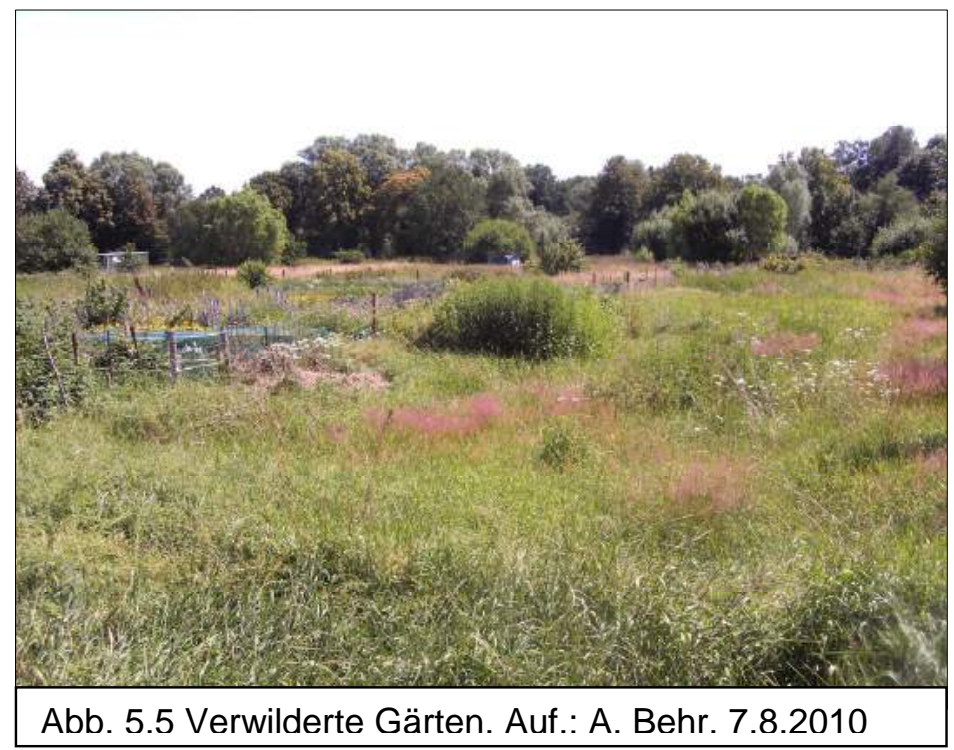
geschlossenen Ortschaft ohne direkte Anbindung an das Wohnhaus sind der Verwilderung preisgegeben. Zur landwirtschaftlichen Nutzung ist die Parzellenstruktur zu klein und besitzrechtlich sehr differenziert.

Diese veränderte Gartennutzung und die daraus folgende Gartengestaltung haben nicht nur Folgen für das optische Siedlungs- bzw. Landschaftsbild, sondern auch sehr große Auswirkungen auf das Artenspektrum: In Haus- und Ziergärten finden sich zunehmend importierte Pflanzenarten in verschiedensten Zuchtformen, die das Nahrungsangebot für heimische Fauna durchaus einschränken können. Andererseits gleichen die Ziergärten eher lichten Strauch- und Waldgesellschaften und bieten daher der Vogel- und Insektenwelt mehr Lebensraum als die früheren reinen Nutzgärten. In verwilderten Gärten setzt eine natürliche Sukzession ein, die zunächst die Biodiversität erhöht, bis ein volles Waldstadium erreicht ist, in der klimatisch und edaphisch bedingt meist nur wenige Baumarten dominieren.

Die Entwicklung des Ortes hat im Ort selbst und in seinem Weichbild zu einer wesentlichen und optisch prägenden Veränderung der Kulturlandschaft geführt. 


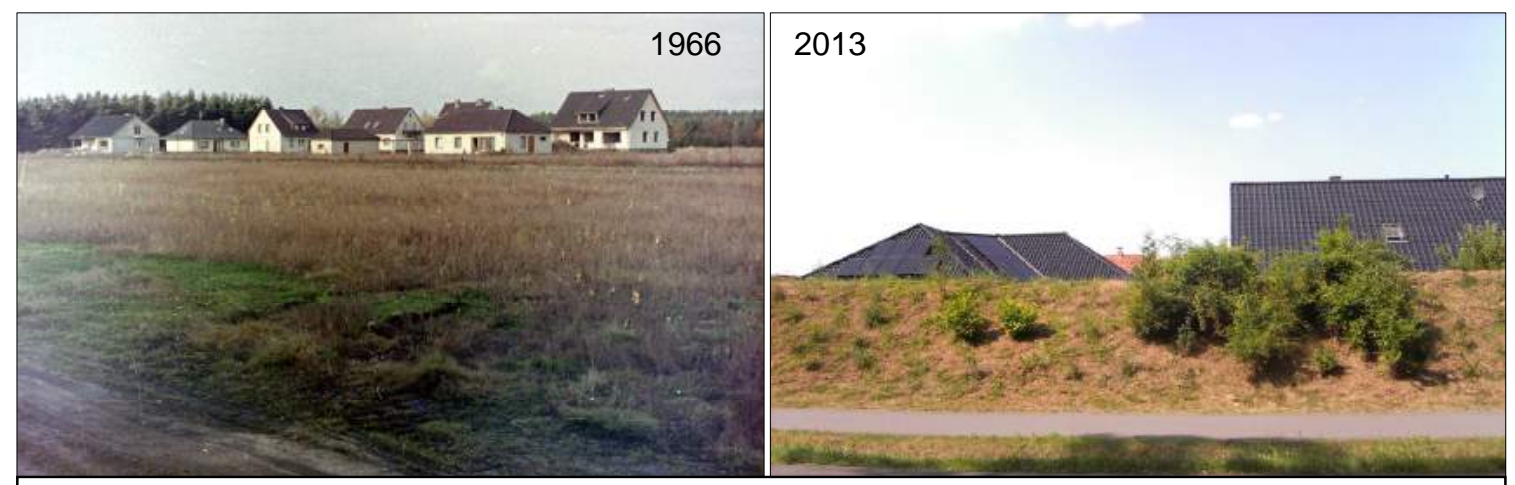

Abb. 5.6 Siedlungsausbau: Blick vom Ahnsbeck-Altenceller Weg nach Norden Das Baugebiet am Südrand des Ortes ist gegen den zur Straße ausgebauten Weg mit einem Sichtund Lärmschutzwall abgegrenzt.

Aufnahmen: A. Behr
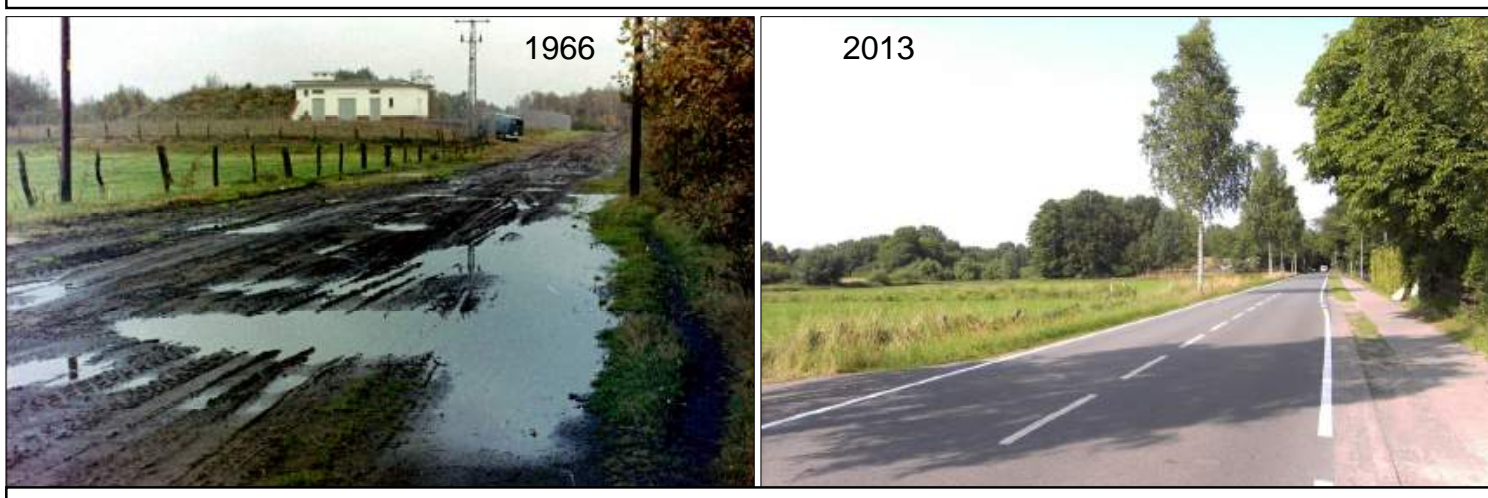

Abb. 5.7 Ausbau der Infrastruktur: Vom Jarnser Weg zur Jarnser Straße (im Hintergrund das alte Wasserwerk der Gemeinde)

Aufnahmen: A. Behr
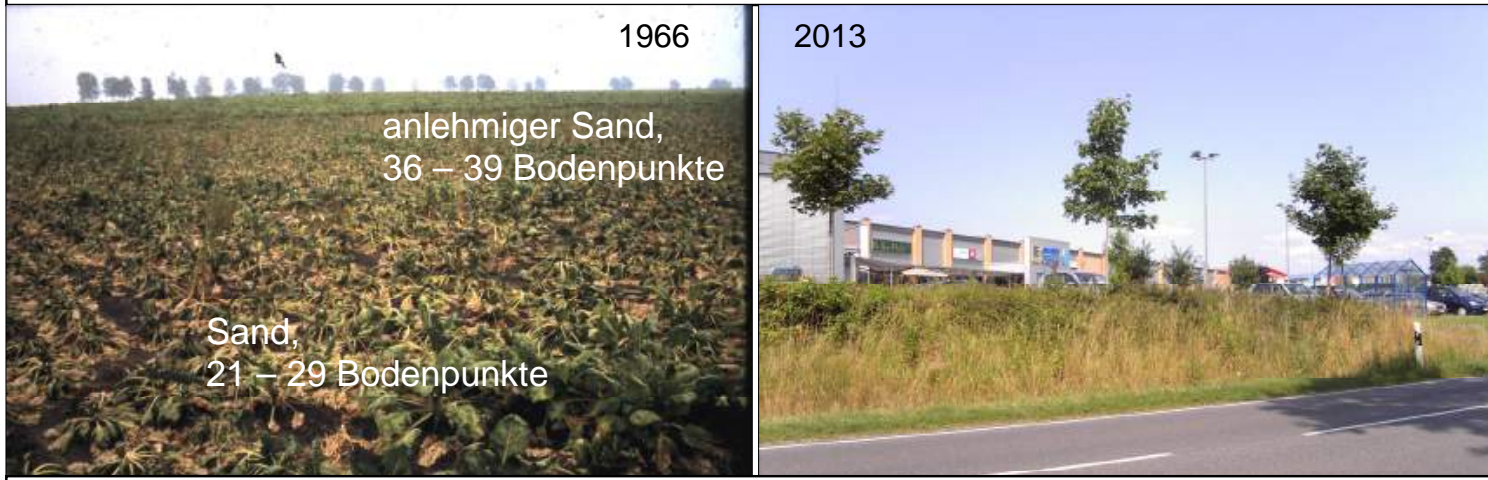

Abb. 5.8 Urstromtalhang zwischen Celler Straße(vorn) und Gockenholzer Weg (oben) Vom Acker zum Gewerbegebiet

Aufnahmen: A. Behr

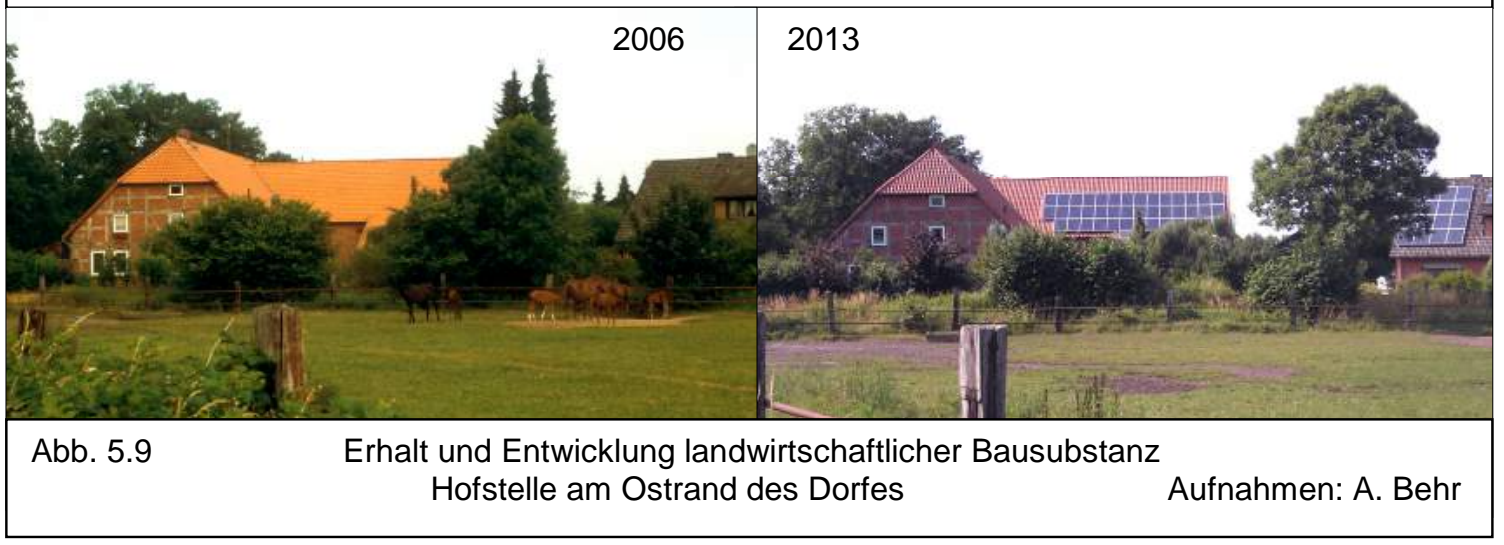

Kap.6 Wirtschaftssystem, Landnutzung und Landschaft 


\section{Kapitel 6 Wirtschaftsystem, Landnutzung und Landschaft}

\subsection{Von Hofstellen zu landwirtschaftlichen Betrieben}

\begin{tabular}{|c|c|c|c|c|c|c|c|c|c|c|c|c|}
\hline \multicolumn{13}{|c|}{ Tabelle 6.1} \\
\hline \multicolumn{13}{|c|}{ Höfe in Lachendorf } \\
\hline \multirow{3}{*}{\begin{tabular}{|r|} 
Lfd. Nr. \\
Rezess \\
v. 1859 \\
\end{tabular}} & \multirow{2}{*}{$\begin{array}{c}\text { ältester } \\
\text { Nachweis }\end{array}$} & \multirow{2}{*}{1663} & \multicolumn{3}{|c|}{ Rezesse } & \multirow{2}{*}{\multicolumn{2}{|c|}{$\begin{array}{c}\text { Landerwerb } \\
\text { Rittergut }\end{array}$}} & \multicolumn{2}{|c|}{1965} & \multicolumn{2}{|c|}{2010} & 2011 \\
\hline & & & 1859 & 1859 & 1866 & & & \multirow{2}{*}{\multicolumn{5}{|c|}{$\begin{array}{c}\text { Landwirtschaftliche Betriebe } \\
\text { Rangfolge nach } L N\end{array}$}} \\
\hline & & Hofart & Litera & Hofart & Hofart & \multicolumn{2}{|c|}{$1807-1914$} & & & & & \\
\hline 1 & 1478 & $\mathrm{VH}$ & $a$ & $\mathrm{VH}$ & $\mathrm{VH}$ & & Flächen & \multirow{2}{*}{\multicolumn{2}{|c|}{$\begin{array}{ll}3 & \text { VE }\end{array}$}} & \multirow[t]{2}{*}{8} & $\mathrm{NE}$ & $\mathrm{NE}$ \\
\hline 2 & 1606 & $\mathrm{VH}$ & b & $\mathrm{VH}$ & $\mathrm{VH}$ & 2. $\mathrm{VH}$ & 1881 & & & & & \\
\hline 3 & 1589 & $\mathrm{VH}$ & c & VH & $\mathrm{VH}$ & & & 9 & VE & 4 & VE & VE \\
\hline 4 & 1500 & $\mathrm{VH}$ & d & $\mathrm{VH}$ & $\mathrm{VH}$ & & & 5 & VE & 7 & VE & VE \\
\hline 5 & 1490 & $\mathrm{VH}$ & e & $\mathrm{VH}$ & $\mathrm{VH}$ & & & 14 & VE & 5 & VE & VE \\
\hline 6 & 1589 & $\mathrm{VH}$ & $f$ & $\mathrm{VH}$ & $\mathrm{VH}$ & 1. VH & 1807 & 4 & VE & 1 & VE & VE \\
\hline 7 & 1589 & $\mathrm{VH}$ & $\mathrm{g}$ & $\mathrm{VH}$ & $\mathrm{VH}$ & & Flächen & 2 & VE & \multicolumn{3}{|c|}{ Ländereien verkauft } \\
\hline 8 & 1490 & $\mathrm{HH}$ & $\mathrm{h}$ & $\mathrm{HH}$ & $\mathrm{HH}$ & & & 10 & VE & & VE & VE \\
\hline 9 & 1427 & $\mathrm{KH}$ & $\mathrm{s}$ & $\mathrm{KH}$ & $\mathrm{KH}$ & & & 1 & VE & \multicolumn{3}{|c|}{ verp. an Ifd. Nr. 25} \\
\hline 10 & 1589 & $\mathrm{KH}$ & u & $\mathrm{KH}$ & $\mathrm{KH}$ & $\mathrm{KH}$ & & & & & & \\
\hline 11 & 1589 & $\mathrm{KH}$ & i & $\mathrm{KH}$ & $\mathrm{KH}$ & & & & & & & \\
\hline 12 & 1589 & $\mathrm{KH}$ & $\mathrm{t}$ & $\mathrm{KH}$ & $\mathrm{KH}$ & & & 15 & VE & 9 & NE & NE \\
\hline 13 & 1606 & $\mathrm{KH}$ & $r$ & $\mathrm{KH}$ & $\mathrm{KH}$ & & & 12 & VE & 3 & VE & VE \\
\hline 14 & 1431 & $\mathrm{KH}$ & $\mathrm{n}$ & $\mathrm{KH}$ & $\mathrm{KH}$ & & Flächen & & & & & \\
\hline 15 & 1428 & $\mathrm{KH}$ & k & $\mathrm{KH}$ & $\mathrm{KH}$ & $\mathrm{KH}$ & & & & & & \\
\hline 16 & 1589 & $\mathrm{KH}$ & I & $\mathrm{KH}$ & $\mathrm{KH}$ & & & 6 & VE & & rerbt a & an Ifd. $\mathrm{Nr} .8$ \\
\hline 17 & 1427 & $\mathrm{KH}$ & $\mathrm{m}$ & $\mathrm{KH}$ & $\mathrm{KH}$ & & & & & & & \\
\hline 18 & 1500 & $\mathrm{KH}$ & 0 & $\mathrm{KH}$ & $\mathrm{KH}$ & $\mathrm{KH}$ & & & & & & \\
\hline 19 & 1428 & $\mathrm{KH}$ & $q$ & $\mathrm{KH}$ & $\mathrm{KH}$ & & & 7 & VE & & & \\
\hline 20 & 1589 & $\mathrm{KH}$ & p & $\mathrm{KH}$ & $\mathrm{KH}$ & & & 13 & VE & & & \\
\hline 21 & 1685 & BS & $\mathrm{v}$ & BS & BS & & & 21 & VE & & & \\
\hline 22 & 1606 & BS & $\mathrm{x}$ & BS & BS & & & & VE & & & \\
\hline 23 & 1694 & BS & w & BS & BS & & & 8 & VE & 6 & VE & VE \\
\hline 24 & 1691 & BS & z & AnB & AnB & & & & VE & & & \\
\hline 25 & k.A. & & $\mathrm{y}$ & AnB & $A n B$ & & & & & & & \\
\hline 26 & k.A. & & aа & AnB & AnB & & & & & & & \\
\hline 27 & k.A. & & bb & AnB & AnB & & & & & & etriebs & sverlegung \\
\hline 28 & k.A. & & $\mathrm{cc}$ & AnB & AnB & & & 11 & VE & & ins $\mathrm{Na}$ & achbardorf \\
\hline 29 & k.A. & & dd & $\mathrm{AbB}$ & & & & 22 & VE & 10 & $\mathrm{NE}$ & \\
\hline 30 & k.A. & & ee & $\mathrm{AbB}$ & & & & 16 & VE & & & \\
\hline 31 & k.A. & & ff & $\mathrm{AbB}$ & & & & 17 & VE & & & \\
\hline 32 & k.A. & & gg & $\mathrm{AbB}$ & & & & 18 & VE & & & \\
\hline 33 & k.A. & & hh & $\mathrm{AbB}$ & & & & 19 & VE & & & \\
\hline 34 & k.A. & & ii & $\mathrm{AbB}$ & & & & 20 & VE & & & \\
\hline 35 & k.A. & & II & $\mathrm{AbB}$ & & & & & & & & \\
\hline 36 & k.A. & & $\mathrm{mm}$ & $\mathrm{AbB}$ & & & & & & & & \\
\hline 37 & k.A. & & $\mathrm{nn}$ & Hirte & & & & & & & & \\
\hline 38 & k.A. & & 00 & $\mathrm{HL}$ & & & & & & & & \\
\hline 39 & k.A. & & $\mathrm{vv}$ & $\mathrm{AbB}$ & & & & & & & & \\
\hline Zu Jahres & len des La & anderwer & rbs dur & ch C. Dre & ewsen & ibt es : & den Qell & n Witt & tmann & und & d Fried & Irich \\
\hline teilweise & nterschiedlic & he Anga & ben, die & e im Rah & men die & eser $\mathrm{Ar}$ & it nist & berprü & ift wur & en. & (Anm & d. Verf.) \\
\hline Quellen: & ezesse von & 1859 un & id 1866 & & & & & & & & & \\
\hline M. Wittm & nn, Lachend & forfer Hö & $\mathrm{ffe}, \mathrm{Chr}$ & ronik de & r Gemei & nde Lac & chendorf, $\mathrm{E}$ & Bd. II, & 2. A & ufl. 1 & 1998 & \\
\hline F. Friedric & h, Papieraus & Lachen & ndorf se & eit 1538 . & & & & & & & & \\
\hline Bodennut & ungserhebu & ng 1965 & , Geme & eindever & waltung & Lache & idorf & & & & & \\
\hline Schriftlich & Auskünfte & der Betr & riebsleit & iterlnnen & & & & & & & & \\
\hline
\end{tabular}

Bis zu den Agrarreformen im 19. Jahrhundert hat es aufgrund des Agrarrechtes, das den Hofbesitzern kein freies Verfügungsrecht über die Hofstelle einräumte, ein über lange Zeit fest gefügtes und unverändertes hierarchisches System der Höfe gegeben. Diese Struktur wurde auch durch die Reformen selbst nicht beseitigt, denn die Höfe wurden - wie bereits im Detail gezeigt - genau nach dem eingebrachten Besitz und den Nutzungsrechten abgefunden. Durch die Reformen erhielten die Hofbesitzer nun aber die volle Verfügung, also auch das private Veräußerungsrecht für ihren Hof, sowohl als Ganzes wie auch in Teilen ihrer Ländereien. 
Die Reformen waren also die notwendige Voraussetzung für Bodenmobilität, die dann auch in der 2. Hälfte des 19. Jahrhunderts kräftig einsetzte. Dies geschah in Lachendorf allerdings aufgrund eines Sonderfalles, nämlich durch das Bestreben des Eigentümers der Papierfabrik, durch Landkauf auch zum Rittergutsbesitzer aufzusteigen.

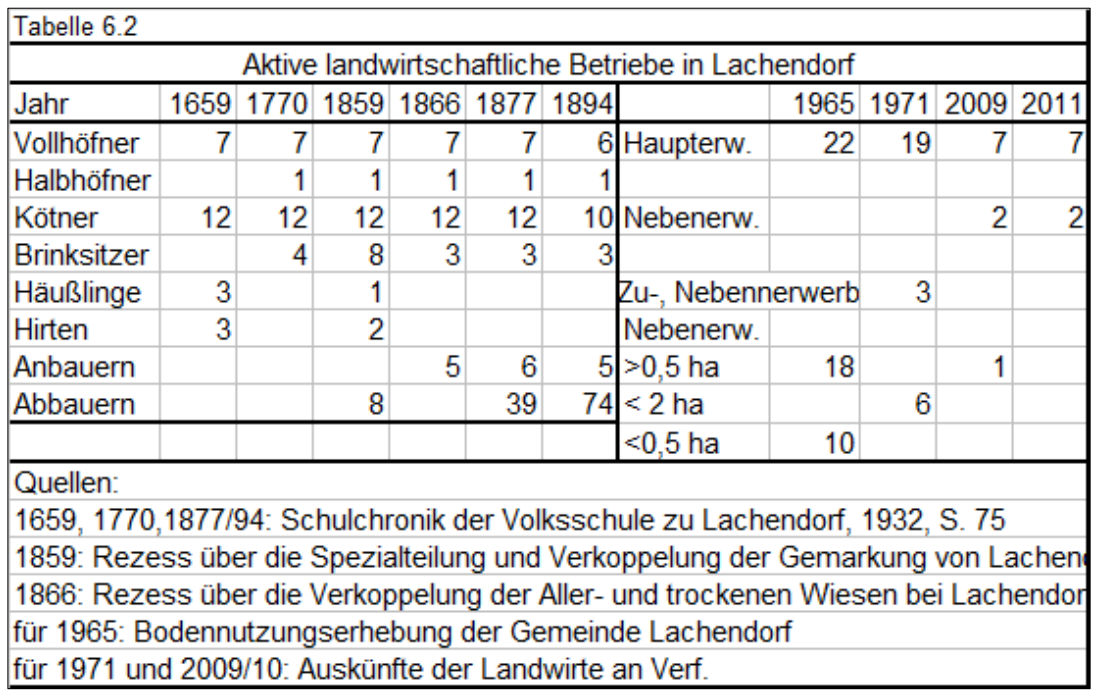

Neben diesem Sonderfall des unfangreichen Landkaufs für ein Rittergut sind durchaus auch zeittypische Merkmale zu beobachten:

Die Anzahl der Voll-, Halb- und Kothöfe sowie der Brinksitzer hat sich nach den Reformen für ein halbes Jahrhundert nur durch die Zusammenfassung zum Rittergut verändert. Die Höfe waren also offenbar so aus den Reformen hervorgegangen, dass sie der Besitzerfamilie eine ausreichende und als gesichert angesehene Existenzgrundlage boten.

Die bis zu den Reformen erforderlichen Hirtenstellen waren mit der Abschaffung der gemeinsamen und freien Weide überflüssig. Da die Hirten sicherlich eine kleine Landwirtschaft selbst führten, sind die Stellen später vermutlich als Abbauernstellen angesehen worden.

Bemerkenswert ist die Entwicklung der An- und Abbauernstellen: Während es in der festgefügten Agrarordnung vor den Reformen nur insgesamt 13 solcher Stellen gab, stieg die Zahl der Abbauernstellen, also der kleinsten Betriebe, bereits bis 1877 auf 39 und bis zum Ende des Jahrhunderts auf über 70. Dies war eine Folge des Bevölkerungswachstums einerseits und der zeittypischen, vor allem auf dem Lande noch üblichen und auch notwendigen, Selbstversorgung mit Grundnahrungsmitteln andererseits. Diese Abbauernstellen mit jeweils weniger als 0,5 ha Nutzfläche waren aber sicherlich Nebenerwerbsstellen.

Gab es Ende des 19. Jahrhunderts mit 6 Vollhöfen, einem Halbhof, 10 Kothöfen, 3 Brinksitzern und 5 Anbauernstellen insgesamt 25 Betriebe, die in der Zeit als Haupt- oder Vollerwerbsbetriebe gelten können, so war die Zahl der Haupterwerbsbetriebe in den 6 Jahrzehnten bis 1965 nur um 3 auf 22 Betriebe im Haupterwerb gesunken. Allerdings muss hinzugefügt werden, dass von den 22 Haupterwerbsbetrieben im Jahr 1965 nur 15 in direkter Folge aus der Gruppe der ehemals 25 Betriebe hervorgegangen sind. Die anderen 7 Haupterwerbsbetriebe von 1965 hatten sich aus anderen An- und Abbauernstellen entwickelt, ${ }^{1}$ die erst nach den Reformen entstanden waren.

Gerade dieses Merkmal macht deutlich, dass es nach den Reformen aufgrund der individuellen Zuständigkeit und Verantwortlichkeit sehr stark auf die Betriebsführung ankam und der vererbte Besitz nicht mehr die ausschlaggebende, nahezu alleinige Garantie für die Bestandssicherung eines landwirtschaftlichen Betriebes war.

Festzuhalten ist aber, dass die Gesamtzahl der Betriebe, die 1965 als Haupterwerbs- und Familienbetriebe in einer freien Agrarordnung geführt wurden, nur wenig niedriger war als die Gesamtzahl der Existenz sichernden Betriebe in der starren Agrarordnung vor den Reformen.

\footnotetext{
${ }^{1}$ Quellen für die Daten: s. Quellen für Tabelle 6.2
} 
gemischtwirtschaftlicher Betrieb mit Ackerbau und Nutztierhaltung bewirtschaftet und war damals nach bewirtschafteter landwirtschaftlicher Nutzfläche nicht der größte Betrieb in Lachendorf. Bei der Wirkung der Betriebsstrukturen auf die Landnutzung und die Kulturlandschaft muss dieser Betrieb also nicht als Sonderfall betrachtet werden.

Diese Feststellungen verdeutlichen aber, dass trotz aller Individualisierung und Eigenverantwortlichkeit in der Betriebsführung und vorhandener Bodenmobilität der ererbte oder erworbene Besitz doch eine wichtige Voraussetzung für den Fortbestand landwirtschaftlicher Betriebe war und ist.

\subsection{Prognose und Wirklichkeit}

\begin{tabular}{|c|c|c|c|c|}
\hline \multicolumn{5}{|c|}{ Tabelle $6.4 \quad$ Lachendorf } \\
\hline \multicolumn{5}{|c|}{ Bestandsentwicklung der landwirtschaftllichen Betriebe } \\
\hline & \multicolumn{4}{|c|}{ Modell I } \\
\hline & Bestand & Aufstockung & Abstockung & Ziel \\
\hline & 1970 & zu Vollerw. & zu Nebenerw. & Vollerwerb \\
\hline Vollerwerbsbetriebe & 11 & & & \\
\hline Übergangsbetriebe & 12 & 5 & 7 & 16 \\
\hline \multirow[t]{4}{*}{ Nebenerwerbsbetriebe } & 5 & & & \\
\hline & \multicolumn{4}{|c|}{ Modell II } \\
\hline & Bestand & Aufstockung & Abstockung & Ziel \\
\hline & 1970 & zu Vollerw. & zu Nebenerw. & Vollerwerb \\
\hline Vollerwerbsbetriebe & 7 & & & \\
\hline Übergangsbetriebe & 16 & 8 & 8 & 15 \\
\hline Nebenerwerbsbetriebe & 5 & & & \\
\hline \multicolumn{5}{|c|}{ Modell I: Roheinkommen je Betrieb: $25000 \mathrm{DM} / \mathrm{a}$} \\
\hline \multicolumn{5}{|c|}{ Modell II: Roheinkommen je Betrieb: 35000 DM/a } \\
\hline \multicolumn{5}{|c|}{ Quelle: Agrarstrukturelle Vorplanung von 1972, S. 112} \\
\hline
\end{tabular}

Im Jahr 1972 wurde eine von der Landwirtschaftskammer Hannover erstellte Untersuchung zur Agrarstruktur des Lachendorfer Nahbereichs veröffentlicht, die nach einer sorgfältigen Bestandanalyse eine Prognose für die Entwicklung der landwirtschaftlichen Betriebe vorlegt.

Wenngleich die „agrarstrukturelle Vorplanung“ von 1972 keinen eindeutigen Zeithorizont für die erstellten Prognosen angibt, muss doch festgestellt werden, dass bereits nach 4 Jahrzehnten die Zielvorgaben für die Betriebszahlen ${ }^{1}$ weit unterschritten waren: Statt 16 bzw. 15 Vollerwerbsbetriebe nur noch 7, statt 7 bzw. 8 im Nebenerwerb nur noch 2.

Die Studie ${ }^{2}$ weist mit Recht darauf hin, dass die Zielzahlen für Auf- und Abstockung rein rechnerisch ermittelt wurden, wobei volle Bodenmobilität ${ }^{3}$ vorausgesetzt wurde, d.h. dass die durch Betriebsaufgabe oder Abstockung frei werdende landwirtschaftliche Nutzfläche auch wirklich den Betrieben zur Verfügung steht, die Flächen zur Aufstockung benötigen.

Dies wäre allerdings keine freie, marktwirtschaftliche Bodenmobilität sondern eine gerichtete. Der Preis für Pacht oder Kauf landwirtschaftlicher Nutzflächen richtet sich ja nicht nur nach dem jeweiligen Ertragswert sondern vor allem nach Angebot und Nachfrage sowie den finanziellen Möglichkeiten von potenziellen „Aufstockern“. Dies zeigt sich auch tatsächlich an dem sehr unterschiedlichen Wachstum ${ }^{4}$ der Nutzflächen der 7 noch verbliebenen Vollerwerbsbetriebe.

Die Studie weist auch mit vollem Recht auf zwei Unwägbarkeiten einer rechnerischen Prognose hin: Der Nutzflächenbedarf für Vollerwerbsbetriebe ist auch stark abhängig von der

\footnotetext{
${ }^{1}$ Die Zahlen für die jeweiligen Betriebstypen in der Tabelle 6.4 stimmen nicht mit den entsprechenden Zahlen der anderen Tabellen überein. Das liegt an den unterschiedlichen Zuordnungskriterien. In Tabelle 6.4 werden dafür Betriebseinkommen zugrunde gelegt, die bei den anderen Erhebungen nicht berücksichtigt wurden. Die Zahlen sind daher direkt nur eingeschränkt vergleichbar.

${ }^{2}$ vergl. zu diesem Absatz: Agrarstrukturelle Vorplanung , Celle 1972, S. $110 \mathrm{ff}$

${ }^{3}$ ebenda S. 111

${ }^{4}$ s. Tabelle 6.3
} 
Betriebsstruktur, denn reine Ackerbaubetriebe ${ }^{1}$ benötigen für ein auskömmliches Betriebseinkommen wesentlich mehr Fläche als spezialisierte Veredelungsbetriebe, die wesentliche Teile der Produktionsmittel am Markt zukaufen können. Auch die Individualität einer jeden Betriebsleitung muss bei einer solchen Prognose verständlicherweise unberücksichtigt bleiben².

Die Prognose berechnet nach einer festen Formel ${ }^{3}$ die Anzahl y der Betriebe, die die Richtbetriebsgröße erreichen werden, unter Berücksichtigung der Anzahl b der Übergangsbetriebe, der den Übergangsbetrieben zur Verfügung stehenden landwirtschaftlichen Nutzfläche f und der Richtbetriebsgröße z.

Das Ergebnis dieser Prognose im Vergleich zur tatsächlichen Entwicklung zeigt in der Rückschau die sehr begrenzte Aussagekraft für ein Einzelbeispiel eines Dorfes mit einer nur kleinen Anzahl von Betrieben. Großräumig mag sich die Berechnungsformel als aussagekräftiger erweisen, weil sich bei einer großen Probandenzahl die individuellen Unterschiede eher ausgleichen bzw. gegenseitig aufheben.

Im hier untersuchten Einzelfall eines einzigen Dorfes hatte die Wirklichkeit die Prognose jedenfalls bereits in 4 Jahrzehnten deutlich überholt.

Für den Zusammenhang von Landwirtschaft bzw. Landbewirtschaftung und Landschaft ist die Anzahl der Betriebe allerdings von untergeordneter Bedeutung gegenüber deren Wirtschaftsform bzw. Wirtschaftsweise. Wenn alle Betriebe die gleiche Betriebsstruktur und die gleiche Wirtschaftsform aufweisen, ist die Anzahl der Betriebe vergleichsweise für die Ausgestaltung der Kulturlandschaft eher völlig unerheblich.

Daher wird im nächsten Kapitel der Wirtschaftsform der Betriebe besondere Aufmerksamkeit geschenkt.

\footnotetext{
${ }^{1}$ ebenda, S. 111

2 ebenda, S. 111

${ }^{3}$ ebenda, S. 108
} 


\subsection{Wirtschaftssysteme und Kulturlandschaft} Landwirtschaftliche Wirtschaftssysteme

1)

\section{Geschlossene Hauswirtschaft}

\section{Selbstversorgung}

gemeinschaftsorientiert

naturbasiert

2)

Gemischtwirtschaftlicher

\section{Betriebsorientierung}

geringe Selbstversorgung

Marktorientierung

wissenschaftsbasiert

Kreislaufwirtschaft
Abbildung 6.1 Familienbetrieb
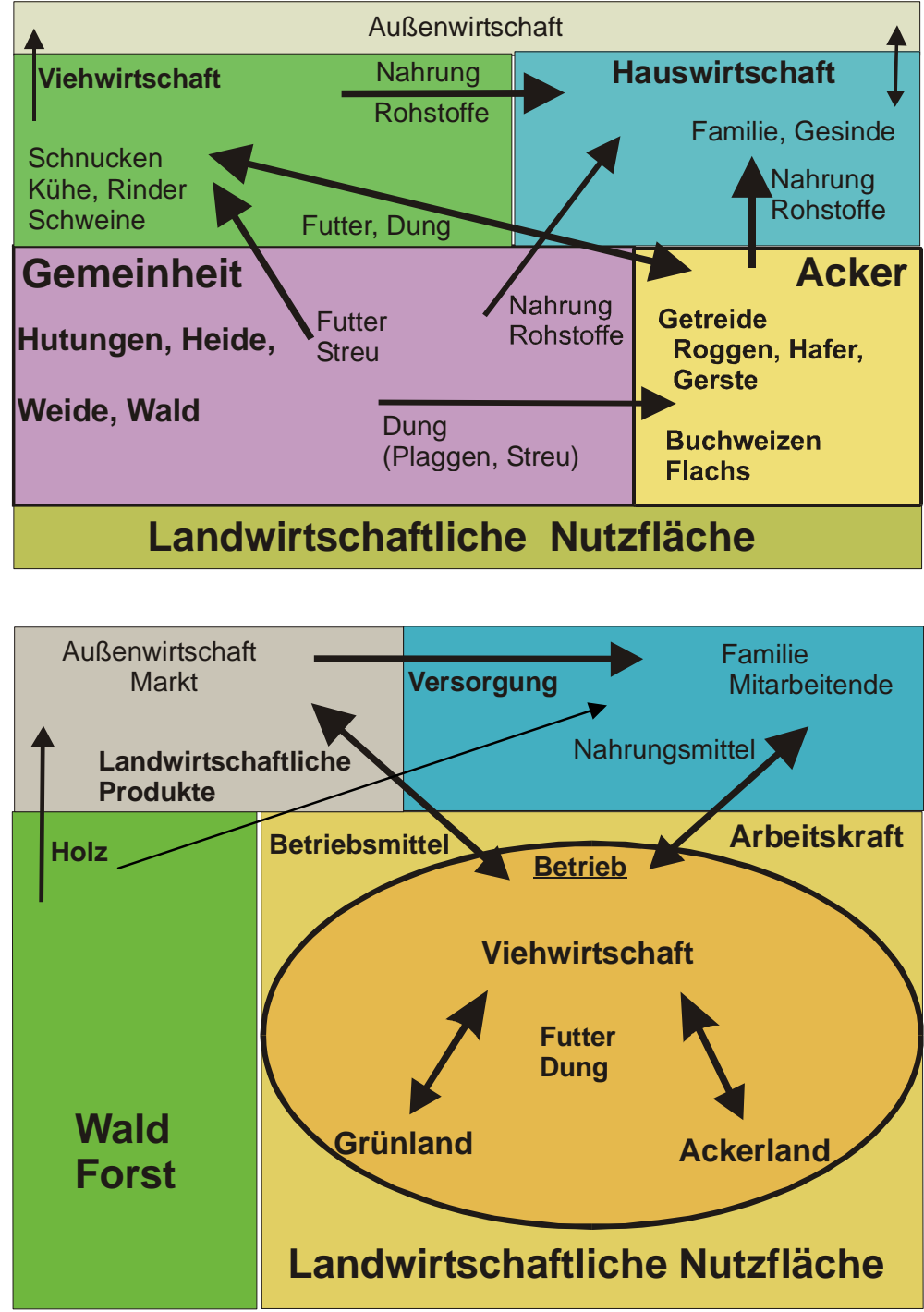

3)

\section{Spezialisierte Agrarbetriebe}

\section{Marktorientierung}

preis-, subventionsorientiert

wissenschaftsund technikbasiert

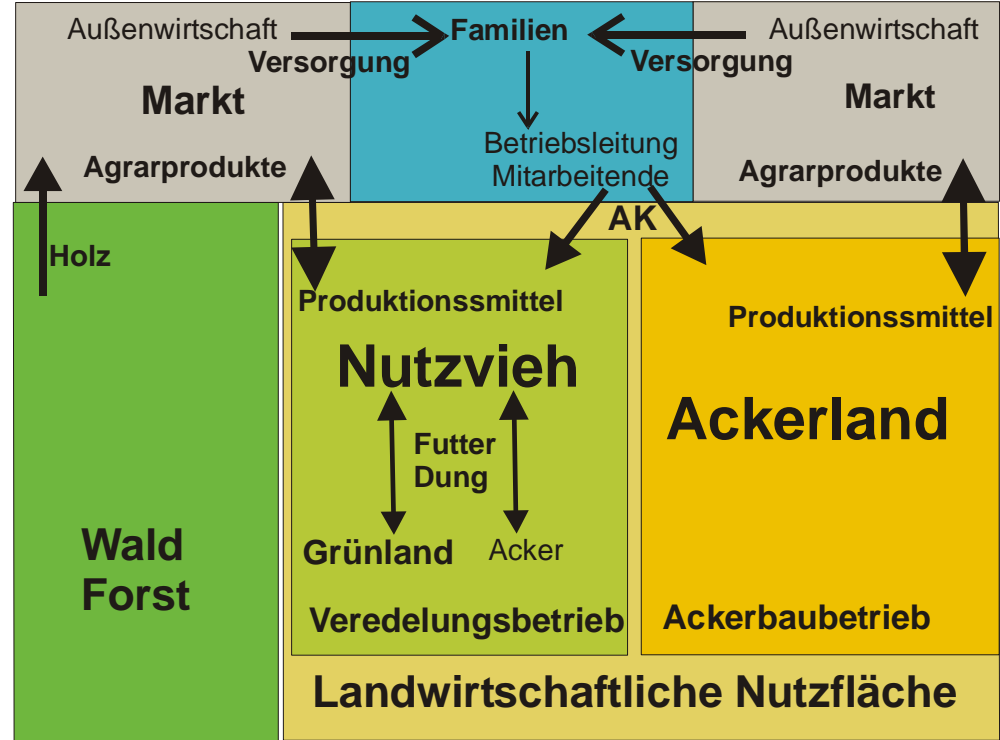


Das betriebliche Wirtschaftssystem in der Landwirtschaft hat sich in den vergangenen zwei Jahrhunderten mehrfach grundlegend geändert. Dies geschah auf sehr verschiedene Weise und mit großer unterschiedlicher Intensität. Da sind zu nennen der steigende Nahrungsbedarf einer wachsenden Bevölkerung bei gleichzeitig geringer Leistungskraft der traditionellen Landwirtschaft, neue Kulturpflanzen und Naturdünger aus Übersee, tiefgreifende Reformen der Agrarordnung und Neuordnung der Agrarlandschaft, vor allem aber die Erkenntnisse der Agrarwissenschaft und der Bodenkunde bzw. der Bodenfruchtbarkeit und des Nährstoffhaushaltes, die Entwicklung der Pflanzen- und Tierzucht sowie des chemischen Pflanzenschutzes und schließlich die Entwicklungen in der Agrartechnik, nicht zu vergessen die zunehmende Ausbildung und fachliche Kompetenz der in der Landwirtschaft tätigen Menschen.

Diese Faktoren hatten im Laufe der letzten 200 Jahre jeweils unterschiedliche Bedeutung für die Veränderungen in der Landwirtschaft. In der Mitte des 19. Jahrhunderts führte diese Entwicklung, die ihre Triebkräfte überwiegend außerhalb der praktischen Landwirtschaft hatte, zu einer ersten großen Umwälzung der Agrarwirtschaft und damit auch der Agrarlandschaft. Der Prozess der Veränderung setzte sich aber fort und ist bis heute nicht zum Abschluss gekommen.

Nach der tiefen Zäsur durch die Agrarreformen Mitte des 19. Jahrhunderts hat es keinen ähnlichen Einschnitt gegeben, die Entwicklung verlief teils kontinuierlich, teils auch sprunghaft, vor allem aber mit unterschiedlicher Geschwindigkeit in den einzelnen Bereichen.

Dennoch lassen sich drei Phasen unterschiedlicher Wirtschaftsweisen und Betriebsführungen in der Landwirtschaft trotz teils fließender Übergänge unterscheiden: Das Zeitalter der geschlossenen Hauswirtschaft mit überwiegender Subsistenzwirtschaft, die Phase des von der Eigentümerfamilie geführten Mischbetriebes und schließlich die Phase des markt- und gewinnorientierten Agrarunternehmens.

\subsubsection{Geschlossene Hauswirtschaft der Heidebauern}

Vor der Neuorientierung durch Agrarreformen und wissenschaftliche Grundlegung im 19. Jahrhundert war die Landwirtschaft nahezu vollständig von den natürlichen Standortbedingungen abhängig. Je geringer die natürliche Standortqualität, umso stärker waren die Höfe nur auf Selbstversorgung ausgerichtet. Die Bodenfruchtbarkeit des Ackers konnte sich nur aus der natürlichen Nachlieferung des Bodens, den geringen, im Stall erzeugten Mengen an Dung und dem Transfer von Mineralien und/oder Biomasse aus Wald, Bruch oder Heide und anderen Flächen, die als Hutungen zur Beweidung und zur Gewinnung von Futter und Streu zur Verfügung standen. Für die dauerhafte Nutzung des Ackers mussten also Flächen zur Verfügung stehen, die den Nährstoffverlust des Ackers durch die Entnahme der Ernten kompensieren konnten.

Das Heidebauernsystem ist für die vorwissenschaftliche Wirtschaftsweise ein besonders gutes Beispiel: Die geschlossene Hauswirtschaft war auf Selbstversorgung ausgerichtet und hatte so nur einen sehr begrenzten wirtschaftlichen Außenkontakt für unverzichtbare Dinge des täglichen Lebens, die man nicht selbst herstellen konnte. Beispielhaft für die geschlossene Hauswirtschaft auch außerhalb der Ernährung sei auf die Wolle - eigentlich Haare der Schnucken und auf den Flachsanbau hingewiesen. So wurden die notwendigen Rohstoffe zum Spinnen und Weben selbst erzeugt. Vom Lutterhof, unweit von Lachendorf bei Hermannsburg an der Örtze gelegen, wird berichtet ${ }^{1}$, dass auch das Leder für Schuhwerk aus dem Fell eines selbst geschlachteten Rindes stammte und von einem Schuster vor Ort auf dem Hof verarbeitet wurde.

Als Kompensationsflächen für Nährstoffergänzung auf dem Acker standen die Heiden und Hutungen zur Verfügung, die durch dauernden Materialentzug zwangsläufig dem Raubbau und damit der Verarmung und Degradierung ausgesetzt waren.

\footnotetext{
${ }^{1}$ Bericht von Edmont Demolins aus dem Jahr 1867; La petite culture en famille-souche, le „Bauer" du Lunebourg, zitiert in: A. Behr, Hg., Der Lutterhof bei Hermannsburg, a.a.O., S. 18
} 
Es verwundert daher nicht, wenn nach Jahrhunderten der Heidebauernwirtschaft die Landschaft einen verarmten und öden Eindruck hinterließ, so wie inn Zeitgenossen beschrieben haben:

„Ich war gewiß nicht vorbereitet, eine schöne Natur zu finden, aber ich dachte nicht, daß das Land so elend wäre. Mich dünkt, es ist der schlechteste Strich von einem solchen Umfange, der mir jemals vorgekommen ist. Der Boden dieses Geländes ist eine ungeheure Sandwüste, die von Natur entweder ganz nackt ist oder Heidekraut oder dürre, stechende Halme hervorbringt." "1"

„Nach stundenlanger eintöniger Fahrt durch die Heide ..., auf der wir Vögel selten, Wild überhaupt weder sahen noch spürten, fanden wir am Wege, wenn von Weg und Steg überhaupt zu reden war, einen toten Fuchs liegen, dem mutmaßlich Weltschmerz das Leben genommen hatte." ${ }^{2}$

„... von kärglichen Äckern, elenden und zerfallenen Gehöften und hungrigen Raben, die über das tote Sandmeer einer ,norddeutschen Sierra Morena' flattern. ${ }^{3}$

„Wie kahl sind die Heiden seit einem Menschengedenken schon geworden! Welche bedenklichen Blößen zeigen unsere Heiden nicht allenthalben schon! - und viele Feldmarken laufen Gefahr, Sandwehen zu bekommen“4

Die Degradation der Hutungen und Heiden war aber nicht nur eine Folge des Nährstoffentzuges durch Plaggen- und Streugewinnung sondern auch eine Folge der freien Beweidung durch Schnucken und „Hornvieh“ (Rinder) sowie auch Schweine und Gänse. Diese Formen der doppelten Nutzung haben die Landschaft stark geprägt, denn sie haben zur Übernutzung geführt und vor allem eine natürliche Verjüngung aller Baumarten, insbesondere der Laubbäume, verhindert.

Bei den großen Gemeinschaftsweiden zwischen den einzelnen Dorfgemarkungen handelte es sich um „Gemeinschaftsreviere“, also Gemeinheiten mehrerer Dörfer. Diese Rechtsform des Gemeinschaftsbesitzes ermöglichte eine intensive Nutzung durch alle Interessenten ohne Verpflichtung zur Pflege oder Erhaltung der Leistungskraft der Nutzflächen. ${ }^{5}$

Durch die Stoppelweide nach Getreideanbau, die Beweidung der Brache, die Vor- und Nachweide der Wiesen waren nicht nur die Gemeinheiten der Beweidung ausgesetzt, sondern alle Landschaftsteile, wenn auch teils zu eingeschränkten Zeiten und jahreszeitlich unterschiedlicher Intensität.

Dies bedeutete, dass die gesamte Landschaft, völlig anders als heute, außerhalb der Hofund Gartenflächen zur freien Beweidung zur Verfügung stand. Diese Nutzungsform war ein ganz wesentliches Element der Gestaltung der Kulturlandschaft. Deshalb war auch die Abschaffung dieser Weideberechtigungen eine wesentliche Voraussetzung für die Neugestaltung der Kulturlandschaft nach den Agrarreformen Mitte des 19. Jahrhunderts. Ohne Aufgabe der Weiderechte und der Gemeinschaftsweide wäre weder eine Aufforstung bzw. Wiederbewaltung noch eine Intensivierung des Ackerbaus möglich gewesen.

Das Wirtschaftssystem der geschlossenen Hauswirtschaft, eingebettet in eine festgefügte Dorfgenossenschaft und eingebunden in eine starre Agrarordnung sowie angewiesen ausschließlich auf die natürlichen Standortbedingungen und ohne Zugang zu anderen Ressourcen, konnte auf Dauer nur eine Kulturlandschaft hervorbringen, wie sie um 1800 im norddeutschen Raum weit verbreitet war.

\footnotetext{
${ }^{1}$ aus Küttners Reisebeschreibungen von 1797, zitiert in: A. Behr, Hg.; Der Lutterhof bei Hermannsburg, a.a.O., S. 77

${ }^{2}$ s. H. Brockhoff, a.a.O., S. 22

${ }^{3} \mathrm{ebd}$.

${ }_{5}^{4}$ ebd.

${ }^{5}$ Die Beweidung dieser „Gemeinschaftsreviere“ kann hinsichtlich der Landschaftspflege nicht mit der Almwirtschaft in den Alpen verglichen werden. Im Hochgebirge werden ungepflegte Almweiden schnell zerstört, weil wegen der hohen Reliefenergie die Erosion sofort dort angreift, wo die Vegetationsdecke Lücken aufweist. Im Flachland mit sehr geringer Reliefenergie machen sich Schäden in der Vegetationsdecke nur sehr langsam bemerkbar. Auf Sandboden kommt es erst bei größeren Freilegungen zu Sandverwehungen.
} 
Diese Analyse der Folgen einer Wirtschaftsweise auf die Landschaft traf im Lachendorfer Raum ganz sicher vollständig auf die Allerheide und die angrenzenden Flächen zu, die zu der großen Gemeinheit der umliegenden Dörfer und Güter gehörten.

Obgleich die Allerheide genau diesem Bild entsprach, war die Situation für die Lachendorfer Bauern doch insgesamt etwas besser, einerseits wegen der lehmigen Böden auf Grundmoräne, vor allem aber weil sie im Allertal im Randmoorbereich der Dreckwiesen über größere Grünlandflächen verfügten, die durch hohen Grundwasserstand und gelegentliche Überschwemmungen gute Wachstumsbedingungen für Gras boten.

Aus allem ergibt sich folgende Schlussfolgerung:

Die Kulturlandschaft um 1800 und die zeitgenössische Wirtschaftsweise bedingten sich gegenseitig und gehören untrennbar zusammen als Folge der herrschenden unmittelbaren und totalen Naturabhängigkeit sowie der zeitgenössischen Agrarstruktur und Agrartechnik.

\subsubsection{Familienbäuerliche Mischwirtschaft}

Nachdem Mitte des 19. Jahrhunderts die Agrarreformen die Bauern von den Fesseln der alten Agrarordnung befreit hatten und neue Erkenntnisse zur Landnutzung und neue Agrartechniken sich langsam Bahn brachen, entwickelte sich aus der gemeinschaftsorientierten und ganz naturbasierten Landnutzung der familiengeführte bäuerliche Mischbetrieb mit Ackerbau und Nutztierwirtschaft. In dieses Wirtschafts- und Betriebssystem flossen im Laufe von etwa 100 Jahren zwischen Mitte des 19. und des 20. Jahrhunderts immer mehr die Erkenntnisse der Agrarwissenschaft und die Möglichkeiten moderner Agrartechnik ein.

Wesentliche Merkmale dieses neuen Wirtschaftssystems sind:

- die Einführung der Fruchtfolge,

- die Aufgabe der Ackerbrache und Einführung von Hackfrüchten,

- $\quad$ neue Kulturpflanzen im Anbauspektrum,

- die Einführung „künstlicher“ Düngung mit Mineraldünger,

- Gezielte Pflanzenzüchtung und die Einführung von neuem Saatgut,

- Gezielte Züchtung beim Nutzvieh, insbesondere in der Milchviehhaltung durch Herdbuchverbände und Milchkontrollvereine,

- die Einführung von Geräten und Maschinen, zunächst in der Außenwirtschaft, im 20. Jahrhundert aber auch in der Binnenwirtschaft.

- Die Anwendung von biologischen und chemischen Mitteln zum Pflanzenschutz.

Die Einführung von mehrgliedrigen Fruchtfolgen mit verschiedenen Getreidearten und Hackfrüchten im Zusammenhang mit Düngung wie Mergel, Guano und dann Mineraldüngern erhöhte die Bodenfruchtbarkeit sowie die Leistungsfähigkeit des Ackers und machte somit die Düngergewinnung aus Plaggen- und Bultenhieb unwirtschaftlich und total überflüssig.

Der Anbau von Futterpflanzen auf dem Acker und zunehmende Stallfütterung des Nutzviehs machte die freie Gemeinschaftsweide ebenfalls überflüssig. Die neue Futtersituation für das Nutzvieh war vor allem der Einführung der Kartoffel und der Rüben zu danken.

Diese betriebsinternen Verbesserungen hatten gravierende Auswirkungen auf das Landschaftsbild: Die Gemeinheiten, die über Jahrhunderte zum Plaggen- und Bultenhieb und zur Beweidung genutzt worden waren und um 1800 deutliche Spuren der Übernutzung zeigten, waren überflüssig geworden. Aus der Perspektive des wirtschaftlichen Nutzens für den Landwirt wurden die Flächen zu „Unland“ und konnten außerhalb des bäuerlichen Betriebs einer anderen Nutzung zugeführt werden.

Wie auf der Allerheide entstanden überall auf ähnlichen Flächen mit geringen, degradierten Böden nun neue Wälder, allerdings keine standortgemäßen Laub- oder Mischwälder sondern Nadelholz-, meist Kiefernforsten.

Die veränderte Wirtschaftsweise der bäuerlichen Betriebe war also ein wesentlicher Grund für die großen Aufforstungen auf Kosten der Heideflächen und der weitgehend baumlosen Hutungen. Aufgrund der neuen Wirtschaftsweisen war in der Kulturlandschaft wieder Platz für Wald, dessen Anteil an der gesamten Landfläche innerhalb von weniger als 100 Jahren in der Südheide bis auf 50\% - stark angestiegen ist. 
Der Waldbesitz der Höfe, entstanden aus den Allmenden, wurde als „Bauernwald“ zu einem dritten betrieblichen Standbein neben dem eigentlichen landwirtschaftlichen Betrieb. Dieser Wald diente auch als finanzielle Ressource für besondere Anlässe und Investitionen.

Die Intensivierung des Ackerbaus mit einer verbesserten Markt- und Futterversorgung hatte zwei wichtige Folgen: Der innerbetriebliche Stoffkreislauf zwischen Acker und Viehstall nahm beträchtlich zu, kann sogar als typisches und charakteristisches Merkmal des zeitgenössischen bäuerlichen Familienbetriebes angesehen werden. Aber auch der außerbetriebliche Austausch nahm erheblich zu, weil die Bauern durch den steigenden Verkauf von auf dem Acker und im Stall erzeugten Agrarprodukten zunehmend über Mittel verfügten, Produktionsmittel wie Dünger, Saatgut und technische Ausstattung am Markt einzukaufen.

Die Entwicklung innerbetrieblicher Stoffkreisläufe ging also einher mit einer zunehmenden Verzahnung der landwirtschaftlichen Betriebe mit dem Markt, sowohl für die Weiterverarbeitung der Agrarprodukte wie auch für den Einkauf von Betriebsmitteln.

Diese verbesserte wirtschaftliche Situation der Betriebe hatte auch bis heute sichtbare Konsequenzen für die Dörfer und ihr Ortsbild. Nicht wenige der alten großen Fachwerkhäuser, sowohl Wohn- wie Wirtschaftsgebäude, die noch heute Dorfbilder prägen, sind in der 2. Hälfte des 19. Jahrhunderts gebaut worden. Alte Bilder von Bauernkaten, Rauchhäusern und schäbigen, verfallenden Häusern belegen, wie stark sich die Bausubstanz gerade auf den Bauernhöfen nach dem wirtschaftlichen Aufschwung der Landwirtschaft verbessert hat.

Die Agrarreformen hatten mit der Spezialteilung und besonders mit der Verkoppelung die alte Flurordnung mit den Gewannen, Zelgen und Streifenflur beseitigt und eine neue Flurstruktur mit Besitzparzellen und Schlägen geschaffen, die bis heute in der Agrarlandschaft gut zu erkennen ist. Die Reformen schufen das formale, geometrische Grundmuster der heutigen Agrarlandschaft und die neue Wirtschaftsweise hatte ein neues Landschaftsbild auch auf dem Ackerland zur Folge. Durch Fruchtfolgesysteme, Aufgabe der Brache und neue Ackerfrüchte entstand ein weit bunteres Landschaftsbild auf dem Acker als zu Zeiten der Dreifelderwirtschaft mit Winter- und Sommergetreide und Brache. Auch der steigende Futterbedarf wegen der Intensivierung bei der Haltung der verschiedenen Nutztierarten trug zur Vielfalt auf dem Acker bei: Mehrbedarf an Zugkraft war vor der Motorisierung nur durch mehr Pferde möglich, für die Hafer angebaut werden musste. Für Rindvieh war der Anbau von verschiedenen Rübenarten, nämlich Futter- und Steckrüben sowie Zuckerrüben mit Doppelnutzung von Blatt und Rübe, wichtig. Getreide wurde nicht nur wegen des Kornertrages angebaut, sondern auch für die Strohgewinnung, bei Hafer auch als Futter, bei Roggen und Gerste zur Einstreu und Dungerzeugung.

Aufgrund der gesamtwirtschaftlichen Entwicklung gingen aber auch zwei traditionelle Anbauprodukte verloren, nämlich der Anbau von Buchweizen und Flachs. Damit verschwand auch das auffällige Blau ganzer Felder im Landschaftsbild, wenn diese Pflanzen in Blüte stehen.

Die Intensivierung des Ackerbaus hatte eine sehr starke Verbesserung der Bodenfruchtbarkeit und damit eine große Ertragssteigerung zur Folge. Mit optimaler Nährstoffversorgung durch Natur- und Mineraldung konnten auch auf sog. leichteren Böden anspruchsvollere Nutzpflanzen angebaut werden. Weizen und Zuckerrüben hatten lange Zeit ihren Schwerpunkt in den Börden mit hoher natürlicher Fruchtbarkeit, erst mit gesteigerter Bodenfruchtbarkeit konnten diese Kulturpflanzen auch auf Geestböden erfolgreich angebaut werden. Durch den Einsatz künstlicher Beregnung können Zuckerrüben sogar auf einem Flurstück in der Allerheide, der „Reitbahn“, auf Sandboden mit weniger als 20 Bodenpunkten kultiviert werden.

Die Steigerung der Bodenfruchtbarkeit durch eine verbesserte Bodenstruktur und einen guten Nährstoffhaushalt wirkte sich auch auf das Artenspektrum der Wildflora und Fauna aus, insbesondere auf Menge und Vielfalt der Ackerwildkräuter, Unkräuter aus der Sicht des ökonomisch orientierten Landbaus. Solange die Bekämpfung der Ackerwildkräuter vorwiegend mechanisch betrieben wurde, konnte sich ein reiches Artenspektrum entwickeln, das wieder- 
um neben Kulturpflanzen wie Klee, Luzerne und Feldgras die Futterbasis für Wild verbesserte.

Die bäuerliche Gemischtwirtschaft, die durch Fruchtwechsel, Mineraldünger und Saatzucht, also externe Faktoren, ungeahnten Aufschwung genommen hatte, zeichnete sich durch ein hohes Maß innerbetrieblicher Kreisläufe ${ }^{1}$ und Stabilität aus, die auf ökologische Vielfalt und Stabilität angewiesen war.

Innerhalb dieser Phase der bäuerlichen Gemischtbetriebe gab es aber auch Veränderungen in der Nutzungsintensität verschiedener landwirtschaftlich genutzter Landschaftselemente: Die Intensität der Ackernutzung nahm über die gesamte Periode deutlich zu, allerdings nicht kontinuierlich, weil die Verbesserung des Nährstoffhaushaltes aufgrund von Mangelversorgung mit Düngemitteln und anderen Betriebsmitteln während der Kriegs- und unmittelbaren Nachkriegszeiten während des 20. Jahrhunderts nicht gewährleistet war.

Bei der Nutzung an Gräben, Straßen und Wegen sowie kleinster Parzellen mit ungünstiger Lage und unregelmäßigem Zuschnitt erfolgte ein Nutzungswandel aus ganz anderen, nämlich gesellschaftlich-ökonomischen Gründen: Solange es viele Kleinstbetriebe gab, die zur Selbstversorgung ein oder zwei Schweine und evtl. auch eine Kuh hielten, wurden die Randstreifen von Gräben, Straßen und Wegen intensiv zur Futtergewinnung durch das Mähen des Grases oder durch Abhüten genutzt und damit gleichzeitig regelmäßig "gepflegt“. Sogar die Obstbäume an den Gemeindestraßen wurden noch bis in die 1950er Jahre genutzt durch eine öffentliche Versteigerung des jährlichen Ertrages an den Meistbietenden, der die Ernte dann selbst erledigte.

Mit zunehmendem Wohlstand wurden diese Kleinstbetriebe aufgegeben und damit auch die Nutzung von Flächen, die für die hauptberufliche Erwerbslandwirtschaft keinen Anreiz zur Landnutzung boten.

Straßengräben, Wegeränder und ähnliche Flächen fielen brach, verwilderten und mussten fortan von der Öffentlichen Hand unterhalten bzw. gepflegt werden. Natürlich hatte dieser Wechsel von intensiver Nutzung, vorwiegend durch mehrfaches Mähen und Abernten, zu extensiver Pflege mit jährlich höchstens einer Mahd und Mulchen des Mähgutes eine starke Veränderung des Pflanzenspektrums zur Folge. Die Straßenränder verbuschten teilweise und die Obstgehölze an den Straßen überalterten und wurden inzwischen weitgehend gerodet und durch Bepflanzung mit heimischen oder standortfremden Baumarten ersetzt.

Auch für die Vogelwelt und Niederwild änderten sich die Lebensbedingungen, teils auch positiv, weil verwilderte und extensiv genutzte Streifen in der Landschaft mehr Rückzugs- und Deckungsmöglichkeiten und auch mehr Nahrung bieten, weil mehr Pflanzen zur Samenreife gelangen können. Andererseits führt eine intensive Nutzung einer Grasflora zu einer sehr geschlossenen und dichten Grasnarbe, die sich bei Extensivierung auflockert und der Erosion mehr Angriffsfläche bietet.

Das Grünland, das aus der Agrarlandschaft vor den Reformen übernommen worden war, erfuhr ebenfalls eine Intensivierung durch Düngung, z.B. mit Jauche aus der Tierhaltung. Dies machte sich aber im Landschaftsbild nicht besonders bemerkbar.

Im Lachendorfer Raum wurden die Wiesen und Weiden in der Lachteaue sowie an Aller und Schwarzwasser wie vor den Reformen, jetzt allerdings ausschließlich von den einzelnen Betrieben, intensiv genutzt. Die Grünländereien erfuhren sogar - wie bereits erwähnt - auf grundfeuchten Standorten der Allerheide und als Stauwiesen eine Erweiterung.

\subsubsection{Spezialisierte Agrarwirtschaft}

\subsubsection{1 „Wachse oder weiche“}

Der Übergang von der Gemischtwirtschaft der bäuerlichen Familienbetriebe zu den spezialisierten und hoch technisierten Agrarbetrieben der Gegenwart erfolgte etwa ab den 1970er Jahren. Wesentliche Merkmale der heutigen Agrarwirtschaft sind:

\footnotetext{
${ }^{1}$ s. J. Radkau; Die Ära der Ökologie, a.a.O., S. 163/163; dort ist von „inhärenter ökologischer Stabilität der Landwirtschaft" die Rede.
} 
- Äußeres Wachstum durch Aufstockung der Nutzfläche oder inneres Wachstum durch Spezialisierung;

- Überbetriebliche Zusammenarbeit durch Maschinenringe (in Lachendorf seit 1963)

- Trennung von Ackerbau und Viehwirtschaft: reine Ackerbaubetriebe und spezialisierte Viehwirtschaft mit - je nach Nutztierart - Grünland, ergänzendem Ackerbau oder auch ohne betriebseigene Nutzflächen,

- Hochleistungssaatgut und Hochleistungszucht bei Nutztieren,

- Einsatz chemischer Mittel von der Saatgutbehandlung über die Wachstumsphase mit Bekämpfung von Schädlingen und Unkraut bis zur Erntesicherung,

- Beginn des Anbaus von genveränderten Kulturpflanzen,

- Hoher Technisierungsgrad bei abnehmendem Arbeitskräftebesatz,

- Vergrößerung der Ackerschläge,

- Geringeres Anbauspektrum und einfachere Fruchtfolgen,

- Anbau von Sonder- bzw. Spezialkulturen.

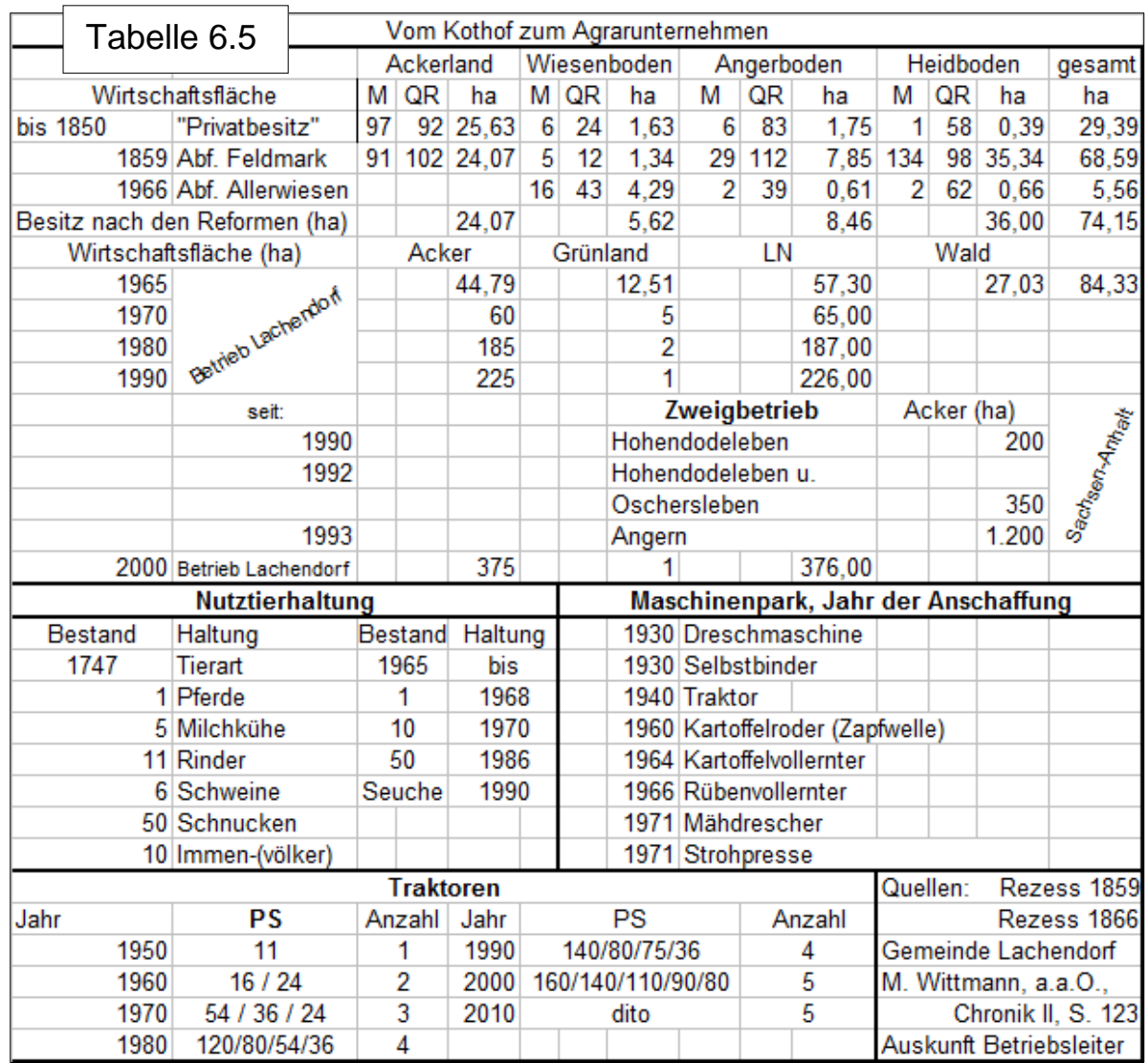

Die Entwicklung eines Kothofes zum modernen Agrarbetrieb verdeutlicht beispielhaft die Tabelle 6.5, der ein konkreter Lachendorfer Hof zugrunde liegt.

Bezeichnend ist, dass sich vom Kothof zum familienbäuerlichen Mischbetrieb innerhalb von etwa 100 Jahren die Betriebsfläche nur moderat um 10 ha wuchs. In dieser Zeit wurde die Heide nur zu gut Zweidrittel aufgeforstet, die Ackerfläche aber fast verdoppelt. Starkes Wachstum zeigte die Binnenwirtschaft, indem sich der Milchkuhbestand verdoppelte und die Schweinezucht sehr stark ausgeweitet wurde. In der zeit des familienbäuerlichen Mischbetriebes fand also vorwiegend ein innerbetriebliches Wachstum und eine Intensivierung in Außen- und Binnenwirtschaft statt.

Die Technisierung hatte aber bereits in den letzten Jahrzehnten der bäuerlichen Mischwirtschaft einen recht hohen Stand. Die Entwicklung der Anzahl der Traktoren und insbesondere die PS-Zahlen zeigen, dass zunächst nur die Pferde als Zugtiere langsam ersetzt wurden. Die Entwicklung erst in den letzten Jahrzehnten lässt den Trend zu Großmaschinen erkennen. 
Nach der Grundtechnisierung erfolgt dann 1970 mit der Abschaffung der Milchkühe der eigentliche Strukturwandel zum Großbetrieb als reiner Ackerbaubetrieb.

Es gibt noch eine ganze Reihe von Entwicklungen in der modernen Landwirtschaft, die mit der Entwicklung moderner Technologien zusammenhängen, z.B. computer- und satellitengestützte Feldarbeit, computergesteuerte Fütterung, von Gen- und Samenbanken abhängige Tierzüchtung, um nur einige Beispiele zu nennen. Diese Entwicklungen haben aber vor allem betrieblich-ökonomische Konsequenzen und sind nur begrenzt landschaftlich wirksam. Anders verhält es sich mit der Entwicklung von genveränderten Nutzpflanzen. Deren weitere Entwicklung und Freigabe für den großflächigen Anbau würde sicherlich das Anbauspektrum verändern. Mit dem Anbauspektrum aufgrund von konventioneller Züchtung und Genveränderungen verändert sich - ungewollt aber zwingend - auch das Artenspektrum in der "wilden“ Fauna und Flora ${ }^{1}$. Allerdings ist auch diese Entwicklung ambivalent, denn der Anbau genveränderter Pflanzen kann auch zu einer erheblichen Reduzierung beim Einsatz chemischer Pflanzenschutzmittel führen. Dies wäre z.B. hinsichtlich des aus ökologischen ökonomischen unbedingt Bienenschutzes $^{2}$ dringend erforderlich.

Mit zunehmender Technisierung insbesondere in der Bewirtschaftung des Ackers konnten die Betriebe ihre Ackerfläche „aufstocken“, d.h. vergrößern. Die

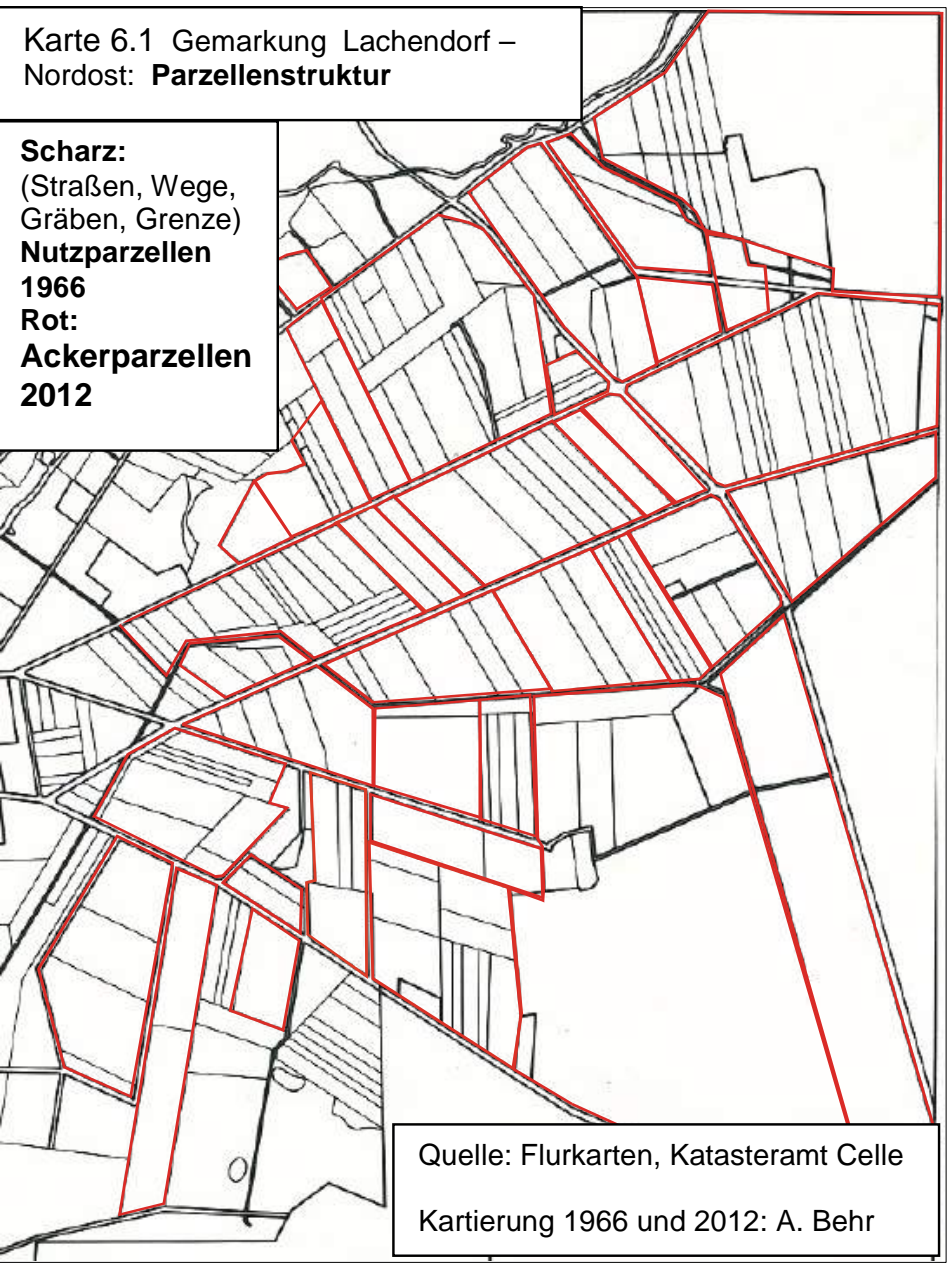

Technisierung war also eine grundlegende Voraussetzung für das Wachstum der Betriebsgrößen und gleichzeitig für kleinere Betriebe - wegen fehlender Mittel bzw. fehlender Rentabilität des Maschineneinsatzes - der Grund für die Betriebsaufgabe. Der Maschineneinsatz mit zunehmender Maschinengröße bzw. Arbeitsbreite machte kleine Schläge unrentabel. Dies führte zu einer neuen, großzügigen Nutzparzellenstruktur auf den Ackerkämpen.

Dies führt zweifellos zu einer optisch weniger gegliederten Ackerbaulandschaft.

Die Gliederung der Ackerflächen in Nutzparzellen war 1966 erheblich enger als die Besitzstruktur, d.h. zahlreiche Besitzparzellen waren zur Nutzung nochmals unterteilt. Im Jahr 2012 ergab sich ein differenziertes Bild: Teils entsprachen die Nutzparzellen auch den Besitzpar-

\footnotetext{
${ }^{1}$ Ein Beispiel ist die Unverträglichkeit einer Rapssorte (konventionelle Neuzüchtung; sog. 00-Raps, nicht genverändert) für das Rehwild; in: Zeitschrift für Jagdwissenschaft, 1987, Volume 33, Issue 33, pp 191-205

2 Der Leiter des Celler Bieneninstituts und der Kreislandwirt werben für Blühstreifen auf dem Acker und für ungemähte Flächen in Gärten, Parks und öffentlichen Plätzen, z.B. Verkehrsinseln. Cellesche Zeitung, 17. 7. 2013, S. 1 und 19.7.13, S, 8
} 
zellen, vielfach wurden aber Besitzparzellen und zahlreiche frühere Schläge zu großen Ackerschlägen zusammen gefasst. Während 1966 die Gemarkungsgrenze nur in Einzelfällen nicht gleichzeitig Schlaggrenze war, spielte sie 2012 als Schlaggrenze praktisch keine Rolle mehr.

Große Schläge und ein reduziertes Nutzpflanzenspektrum in den einzelnen Betrieben müssen aber insgesamt nicht zu Lasten der Fruchtfolge und der Bodenfruchtbarkeit gehen. Spezialisierte Betriebe können untereinander Flächen tauschen ${ }^{1}$ und damit in der Landschaft eine Fruchtfolge ermöglichen, die der einzelne Betrieb nicht mehr einhalten kann.

Im Hinblick auf die Gestaltung bzw. Prägung der Kulturlandschaft ist nicht das Wachstum der bewirtschafteten Nutzfläche der wichtigste Faktor des betrieblichen Strukturwandels, sondern die Aufgabe der Viehwirtschaft, insbesondere der Milchkuhhaltung, in vielen Betrieben. War in der Gemischtwirtschaft der bäuerlichen Landwirtschaft das Grünland ein wichtiger und unverzichtbarer Bestandteil der betrieblichen Nutzfläche, so ist das Grünland nun in den reinen Ackerbaubetrieben überflüssig und wurde, wo immer möglich, in Ackerland umgewandelt.

Diese Tendenz zu mehrheitlich reinen Ackerbaubetrieben ohne Grünlandnutzung ist derzeit der wichtigste Faktor, der sich mit deutlichen Veränderungen in der Kulturlandschaft bemerkbar macht.

Landschaften mit großen geschlossenen Grünlandflächen wie in den Aller- und Dreckwiesen der Lachendorfer und angrenzender Gemarkungen erfahren gegenwärtig einen grundlegenden Landschaftswandel von einer Wiesen- und Weidelandschaft zu Ackerbaulandschaften. Dieser Landschaftswandel wird vielfach dem zunehmenden Maisanbau zur Energiegewinnung angelastet. Für den Bereich der Aller- und Dreckwiesen trifft dies allerdings nicht zu, denn die Nutzungskartierungen seit 1966 auf der Kartenfolge 5.4 belegen eindeutig, dass das Grünland für den Anbau verschiedener Feldfrüchte mit üblicher Fruchtfolge umgebrochen wurde. Der Mais fand dann erst etwas später Eingang in die Ackernutzung des ehemaligen Grünlandes, allerdings in den letzten Jahren mit zunehmender Tendenz.

Der Maisanbau war also nicht die Ursache für die Umnutzung von Grünland, sondern der Strukturwandel zu reinen Ackerbaubetrieben.

In der Phase der Wirtschaftsweise heutiger Agrarbetriebe, die wissenschafts- und technikbasiert, aber auch markt- und subventionsorientiert wirtschaften, findet weiterhin eine Intensivierung statt, die auf einer hohen Bodenfruchtbarkeit beruht und auf eine sehr hohe Ertragskraft ausgerichtet ist. Wegen des Zwanges oder der Tendenz zu hohen Erträgen setzt die Landwirtschaft alle zur Verfügung stehenden und erlaubten Mittel ein, um das Ertragspotenzial optimal auszunutzen. Die konkreten Erträge eines jeden Jahres sind nach wie vor vom Boden und dem jeweiligen Witterungsverlauf abhängig. Die enormen Ertragssteigerungen der letzten 5 Jahrzehnte sind allerdings ganz wesentlich auf zwei Faktoren zurückzuführen: Einmal die Pflanzenzüchtung ${ }^{2}$ und zum anderen der zeitlich und örtlich guten Bodenbearbeitung zusammen mit den optimalen Saat- und Ernteterminen sowie Dünge- und Pflegemaßnahmen in der Wachstumszeit. Diese Feldarbeiten, die zum Höchstertrag unter den speziellen Bedingungen eines jeden Jahres ganz wesentlich beitragen, kann der Landwirt aufgrund seiner heutigen technischen Ausrüstung und der Leistungskraft seiner Spezialmaschinen in sehr kurzer Zeit und damit unter Berücksichtigung des Bodenzustandes und der Witterung zum optimalen Zeitpunkt erledigen.

Die Wirtschaftsweise moderner Agrarproduktion hat neben enormen Ertragssteigerungen auch dazu geführt, dass die Ertragsabstände zwischen den leichten Sandböden und den

\footnotetext{
${ }^{1}$ Flächentausch ist im Gemüsebau, der strengen Fruchtwechsel verlangt, bei Großbetrieben üblich und unabdingbar, die ihre Anbauflächen für Gemüse regelmäßig mit Flächen für konventionellen landwirtschaftlichen Anbau tauschen. So z.B. praktiziert von dem Betrieb „Gemüsegarten, Behr-AG“ im Kreis Harburg mit über 2000 ha Freilandgemüse, überwiegend auf Pachtflächen.

${ }^{2}$ Hinweis von Landwirt K. Koch, Lachendorf
} 
Lehmböden auf der Grundmoräne gesunken sind: Wurden in den 1960er Jahren z.B. bei Roggen auf Sandboden nur 59\% des Ertrages auf Lehmboden erzielt, so waren es um 2010 $75 \%$. Zuckerrüben und Weizen wurden zu der Zeit nur auf den Lehmböden angebaut, heute erzielt der Zuckerrübenanbau auf der Reitbahn mit 20 Bodenpunkten 93\% der Erntemenge, die auf Lehmboden mit 30 - 40 Bodenpunkten erzielt wird. Die Ertragsdifferenz zwischen Böden unterschiedlicher natürlicher Leistungskraft ist deutlich kleiner geworden.

Das bedeutet einerseits, dass natürliche Standortunterschiede heute beim Ertrag eine geringere Rolle spielen als früher, und andererseits, dass die Landwirtschaft sich weniger an natürlichen Standortunterschieden orientieren muss. Daraus folgt wiederum für die Kulturlandschaft, dass kleinräumige Anpassungen an das naturräumliche Gefüge zugunsten einer einheitlichen und möglichst großflächigen Ackernutzung aufgegeben werden und die Kulturlandschaft an Vielfalt und Abwechslungsreichtum verliert.

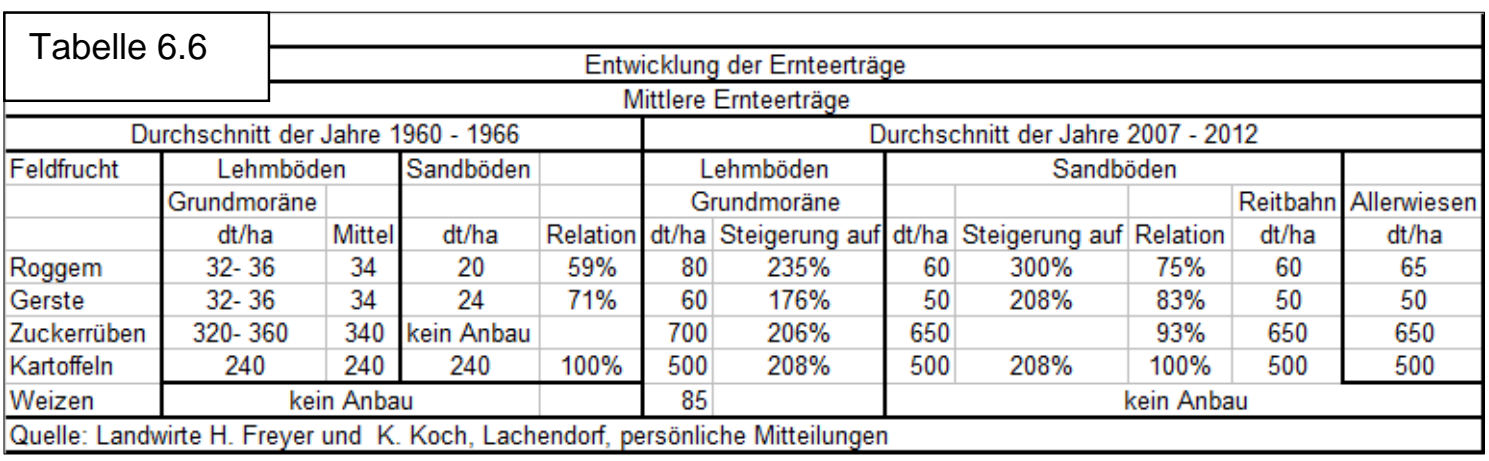

Dies bedeutet auch, dass für Acker- und Grünlandpflanzen, die nicht zu den gewünschten Kulturpflanzen gehören, immer weniger Platz gelassen wird. Die schon lange übliche Reinkultur mit nur jeweils einer Kulturpflanze pro Schlag wird heute weitgehend auch gegenüber Bei- oder Wildpflanzen mit Hilfe von Bioziden durchgesetzt. Das bedeutet, dass manche Pflanzenart, die früher das optische Bild von Ackerflächen, insbesondere durch farbenprächtige Blüten, bereichert hat, heute aus der ackerbaulichen Kulturlandschaft verschwunden ist oder nur noch künstlich - räumlich konzentriert und subventioniert - auf Ackerrandstreifen belassen und erhalten wird.

Das optische und damit auch ästhetische Bild von Ackerland ist heute monotoner geworden gegenüber der Zeit, als eine konsequente Bekämpfung von Unkräutern noch nicht möglich war Heute führen Vorgaben der Agrarpolitik zur Subventionierung von Ackerrandstreifen, auf denen nicht gespritzt werden darf, zu artenreichen, oft auch reich und bunt blühenden Umrandungen von Feldern, die nach Aussehen und Artenzahl in strengem Gegensatz zur Reinkultur des Ackers stehen.

Verständliche ökonomische Interessen des Ackerbau treibenden Landwirts und ökologische Erfordernisse zum Schutze der Biodiversität und des Artenschutzes stehen sich gerade in der Frage des Umgangs mit Un- bzw. Wildkräutern ${ }^{1}$ oft diametral gegenüber.

Die Zusammenschau von Agrarverfassung und Agrartechnik auf der einen Seite und Gestaltung der Kulturlandschaft auf der anderen Seite im Zeitraum der vergangenen 200 Jahre zeigt ganz deutlich, wie landwirtschaftliche Wirtschaftsweise und Betriebsstruktur die dazugehörige Wirtschaftslandschaft gestalten und prägen.

Die Wirtschaftsweise der Heidebauernzeit hatte eine Kulturlandschaft geschaffen, die sich durch fast waldlose, degradierte und verarmte weite Heideflächen und Hutungen, wenig vielfältige und ertragsarme Ackergewanne sowie naturnahe Wiesen und Weiden auszeichnete.

\footnotetext{
${ }^{1}$ Wer nie ein Getreidefeld mit blühenden Kornblumen und Mohn gesehen hat, kann den ästhetischen Reiz eines solchen Anblicks nicht nachvollziehen. Wer nie eine Getreidegarbe mit Disteln mit bloßen Händen - Arbeitshandschuhe waren früher unüblich - anfassen musste, kann den Wert von „Unkrautfreiheit" nicht verstehen. Anm. d. Verf.
} 
Die Wirtschaftsweise der gemischtwirtschaftlichen bäuerlichen Familienbetriebe hat eine Kulturlandschaft mit einem hohen Waldanteil statt baumloser Heiden ermöglicht, eine geordnete, intensiv genutzte Wiesen- und Weidelandschaft mit teilweise Parkcharakter sowie eine sehr ertragreiche, vielfältige, abwechslungsreiche und kleinstrukturierte, oft auch optisch ästhetische Ackerlandschaft geschaffen.

Die Wirtschaftsweise der Agrarwirtschaft lässt die Waldareale unberührt, vereinfacht das Landschaftsbild des Ackers durch größere Nutzparzellen, geringeres Anbauspektrum, konsequente Bekämpfung aller Wildpflanzen als unerwünschtes und Ertrag minderndes Unkraut und wandelt Grünland, soweit es die Boden- und Grundwasserverhältnisse es nur einigermaßen zulassen, in Ackerland um. Die Tendenz zu großen Nutzparzellen und damit zur Vereinfachung der Flurstruktur des Ackerlandes ist noch nicht abgeschlossen und wird sich mit dem Wachstum einiger Betriebe bei gleichzeitiger Reduzierung der Anzahl der Betriebe weiter fortsetzen. Der Umwandlung von Grünland sind natürliche und auch administrative Grenzen gesetzt, der Landschaftswandel im Grünlandbereich scheint aber aufgrund der Betriebsstrukturen derzeit nicht umkehrbar zu sein. Dies könnte nur auf dem Gesetzes- oder Verordnungswege begrenzt oder behindert werden.

In den letzten 200 Jahren haben neben vielen kleinen, teils fast unmerklichen Veränderungen in der Kulturlandschaft, die aufgrund allgemeiner und gesellschaftlicher Entwicklungen zu beobachten waren, insbesondere zwei bedeutende, auch flächenmäßig große Veränderungen durch neue landwirtschaftliche Wirtschaftsweisen stattgefunden: Die Aufforstung oder Wiederbewaldung und die Umwandlung von ehemals „natürlichem“ Grünland in Ackerland.

Dagegen werden die alten Ackerflächen überwiegend weiter genutzt, allerdings mit einer jeweils veränderten Feinstruktur, die sich von den Gewannen mit Streifenflur über die kleinteilige Schlagstruktur zu großflächiger Schlagstruktur, teils ohne Berücksichtigung besitzrechtlicher Grenzen, entwickelt.

\subsubsection{Spezialisierung und Kulturlandschaft - Beispiel Mais}

Die drei hier vorgestellten Wirtschaftssysteme sind von grundsätzlich unterschiedlicher Offenheit geprägt:

Die Hauswirtschaft in Verbindung mit der Heidebauernwirtschaft war ein fast geschlossenes Wirtschaftssystem, das aufgrund der herrschenden Mangelsituation auf einem niedrigen ökonomischen Niveau verharren musste.

Die bäuerliche Gemischtwirtschaft ist dagegen ein offenes System, denn die Produktion von Nahrungsmitteln und Rohstoffen vom Acker und aus dem Viehbestand für den Markt kann kein geschlossenes System sein, auch wenn es in der bäuerlichen Gemischtwirtschaft einige betriebsbedingte Stoffkreisläufe gibt. Die Marktproduktion auf hohem Niveau setzt einen dauerhaften Zustrom von Energie und den Betriebsmitteln Mineraldünger und Pflanzenschutzmitteln voraus.

Die moderne Agrarwirtschaft hat diese Offenheit noch verstärkt, weniger auf dem Acker, wo durch genaue Analyse und gezielten Einsatz der Düngerverbrauch sogar teilweise rückläufig ist, als vielmehr in der Veredelungswirtschaft durch den Einsatz von importierten Futtermitteln.

Die Ambivalenz der Wirkung von Landnutzung im Naturhaushalt mag besonders der Maisanbau verdeutlichen, der oft gerade aus ökologischer Sicht kritisiert wird.

Der Wasserbedarf von Mais in der Hauptvegetationszeit ist sehr hoch und muss bei ausbleibendem Niederschlag durch Beregnung - meist aus Grundwasser - unbedingt ergänzt werden, wenn Ernteausfälle vermieden werden sollen. Maisanbau auf leichten Böden und angesichts hoher Niederschlagsvariabilität ist also hinsichtlich der Ressource Wasser sehr anspruchsvoll und somit nicht unproblematisch. ${ }^{1}$

\footnotetext{
${ }^{1}$ s. Kap. 2.2.7: Grundwasserabsenkung durch Beregnung
} 
Solange der Mais als Silage verfüttert wurde, muss natürlich - wie bei allen anderen Kulturpflanzen auch - der Nährstoffentzug durch die abgeerntete Biomasse wieder ersetzt werden. Bei Maisanbau für die Biogaserzeugung kann dagegen ein Nährstoffkreislauf (und Sauerstoffkreislauf) entstehen: Die Maispflanze entzieht beim Wachstum dem Boden neben Wasser Nährelemente, entnimmt der Luft Kohlenstoffdioxid und produziert mit Hilfe von Sonnenenergie Biomasse, die zur Energieerzeugung verwertet wird. Im Substrat der Biogasanlage verbliebene Nährsalze können dem Acker wieder zugeführt werden. Bei der Verwertung von Mais in der Biogasanlage und der Rückführung des Substrates, der Gärreste, werden dem Boden erhebliche Anteile der durch den Maisanbau entzogenen Nährelemente zurückgegeben, bei Stickstoff bis zu 30\% des Bedarfs, bei Phosphor bis über $40 \%$ und bei Kalium kann sogar eine Überversorgung stattfinden ${ }^{1}$. Intensiver Anbau von „Energiemais“ kann also in der Wirtschaftsweise reiner Ackerbaubetriebe wieder zu betriebsbedingten Kreisläufen führen und damit die Offenheit des Wirtschaftssystems reduzieren. ${ }^{2}$

Da die Aussaat von Mais, das sog. Legen, erst im späten Frühjahr erfolgen kann und es dann recht lange dauert, bis die einzeln in Reihen stehenden Maispflanzen den Boden vollständig bedecken, sind Maisfelder bis in den Frühsommer hinein stärker erosionsgefährdet als unter anderen Kulturpflanzen. Dieser berechtigte Kritikpunkt am Maisanbau kann aber durch angepasste Kulturtechniken behoben werden: Zwischenfruchtanbau kann dafür sorgen, dass die Ackerkrume im Winter und Frühjahr nicht unbedeckt der Witterung ausgesetzt ist. Der Anbau von Mais kann dann als Direktsaat ohne Pflügen ${ }^{3}$ erfolgen, dafür notwendige Maschinen sind auf dem Markt. Diese Anbauform ohne Pflügen ist hinsichtlich Energieverbrauch besonders effizient.

Der Maisanbau für die Energieerzeugung erweist sich gerade auf den leichten Böden als besonders effizient gegenüber dem Anbau von Getreide und Hackfrüchten, die auf Bördeböden höhere Erträge erzielen. Wegen komparativer Vorteile ${ }^{4}$ des Maisanbaus auf Geest- gegenüber Bördeböden bleibt der Maisanteil bisher in der Börde bei unter 10\% der Nutzfläche, während er auf der Geest eine Flächenanteil von 25\% und mehr erreichen kann. Im Kreis Celle hat sich beispielsweise der Flächenanteil von Mais von 1988 bis 2010 versechsfacht ${ }^{5}$. Der Anbau von Mais, der auf traditionellen Ackerflächen ebenso gut wie auf bisherigem Grünland angebaut werden kann, hebt in der überkommenen Kulturlandschaft die gewohnte Trennung ${ }^{6}$ von Acker und Grünland teilweise auf.

Die Umwandlung der früheren Wiesenlandschaft im Südteil der Lachendorfer Gemarkung erfolgte - wie bereits dargelegt - im Zuge der Spezialisierung zu reinen Ackerbaubetrieben ohne Bedarf an Grünland. Die überwiegende Nutzung dieser durch Grünlandumbruch gewonnenen Ackerflächen durch Maisanbau ist aber eindeutig eine Folge der Subventionen für die Energieerzeugung aus nachwachsenden Rohstoffen, denn der Mais wird fast ausschließlich als Energiemais ${ }^{7}$ angebaut. Wenn dieser Flächenanteil in den Aller- und Dreckwiesen an Mais weiterhin beibehalten wird, kommt es unweigerlich zu Monokultur im Maisanbau, denn bei über $50 \%$ Flächenanteil ist innerhalb dieses Gebietes keine Fruchtfolge mehr möglich.

Das Hochwasser im Mai $2013^{8}$ hat aufgezeigt, dass in den Aller- und Dreckwiesen auch nach der „Regulierung“ von Aller und Schwarzwasser eine Überschwemmung selbst in der

\footnotetext{
${ }^{1}$ vergl. Biogasportal.de, Leitfaden Biogas, Fachagentur Nachwachsende Rohstoffe e.V. (Hg.), 5. Aufl., Gülzow, 2010, S. 221

${ }^{2}$ Es ist durchaus widersprüchlich, wenn aus Naturschutzgründen der Anbau von Energiemais kritisiert wird, der gegenüber Marktfrüchten eine größere Kreislaufwirtschaft bzgl. der Nährstoffe zulässt.

${ }^{3}$ In der ehemaligen Provinz Transvaal der RSA konnte der Verf. im Jahr 1986 sehr erfolgreichen

Maisanbau in echter Monokultur beobachten, in der schon einige Jahre mit Direktsaat und ohne Pflügen (Zero-Tillage) gearbeitet wurde.

${ }^{4}$ Diese Vorteile ergeben sich allerdings wesentlich aus der Einspeisevergütung von Strom aufgrund des EEG und der Entwicklung der Getreidepreise am Markt.

${ }^{5}$ Mdl. Mitteilung von Kreislandwirt J. Mente

${ }^{6}$ vergl. H.-J. Küster, Geschichte der Landschaft in Mitteleuropa, a.a.O., S. 360 f.

${ }^{7}$ Seit 2012 gib es auch in Lachendorf eine Biogasanlage.

${ }^{8}$ s. Kapitel 2.2 Hydrologie
} 
Vegetationszeit nicht grundsätzlich ausgeschlossen werden kann. Nun hat sich aber gerade der Mais im Gegensatz etwa zu Kartoffeln als besonders tolerant gegenüber kurzfristiger Überflutung erwiesen. Während der Mais nach Abfluss des Wassers fast unbeschadet weiter wuchs, mussten die Kartoffeläcker auch nach kurzzeitiger Überflutung umgebrochen werden. Als neue Kultur nach dem Hochwasser kam aufgrund des Zeitpunktes im Juni nur noch Mais als wirtschaftliche Alternative infrage. Ökologisch wäre auch der Anbau von Gras oder Gemenge möglich gewesen, allerdings mit geringeren monetären Ertragsaussichten.

Sollten sich die Klimaprognosen hinsichtlich Erwärmung bestätigen und starke Sommerhochwässer zunehmen, dann hätte der Maisanbau zusätzliche Vorteile gegenüber bisher regionaltypischen Kulturpflanzen: Einerseits kann Mais als C4-Pflanze hohe Energieeinstrahlung gut nutzen und andererseits kurze Überflutung ohne große Schäden tolerieren.

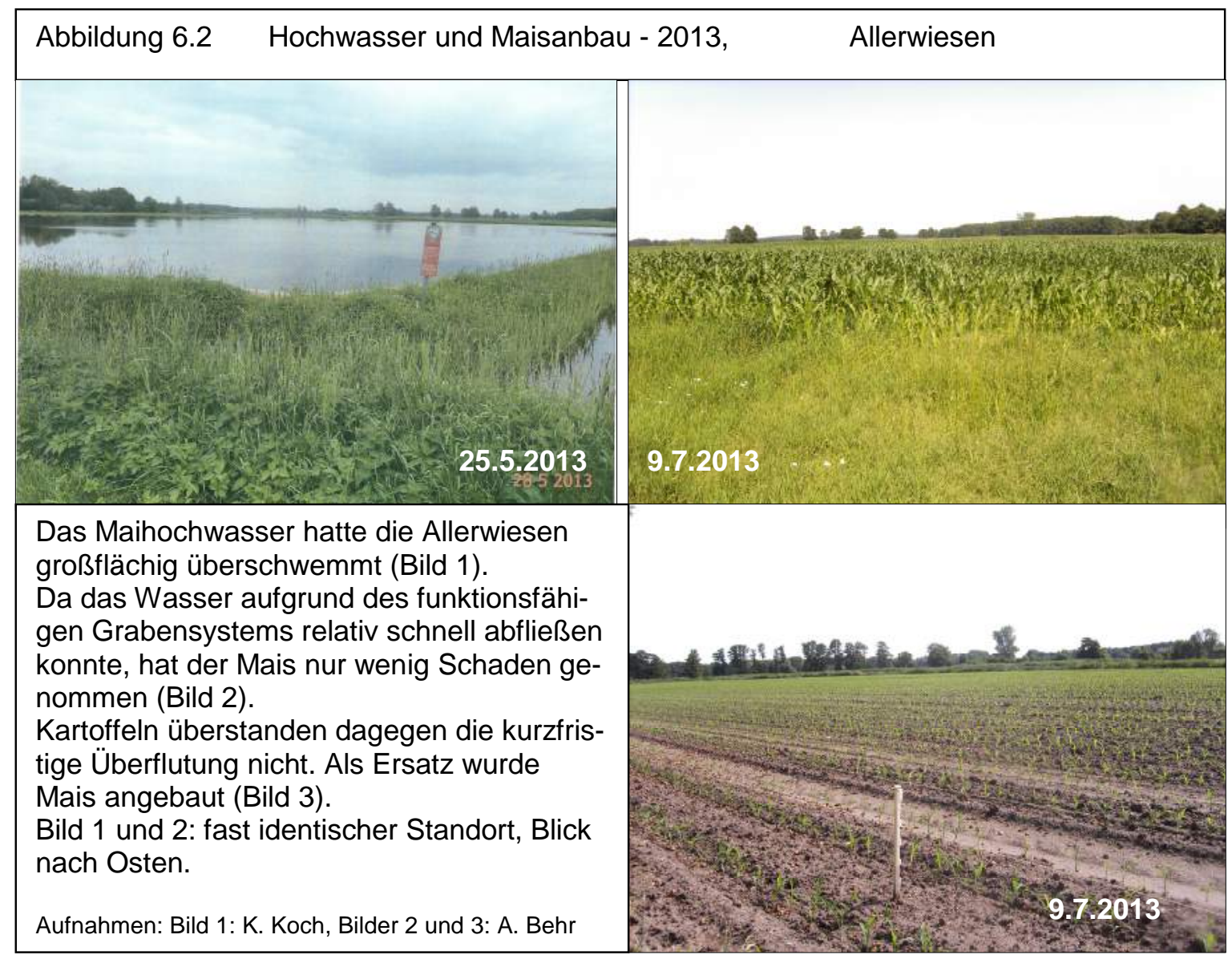

Wenn schwere Hochwässer wie im Mai 2013 häufiger werden sollten, wird sich aus ökonomischen und ökologischen Gründen aber die Notwendigkeit ergeben, unabhängig vom Maisanbau, über Ackerbau allgemein in möglichen Überschwemmungsgebieten zu reflektieren. Dabei spielt es keine Rolle, ob die Häufigkeit der Hochwässer eine Folge des Klimawandels oder natürlicher Klimaschwankungen ist. Die Rückumwandlung von Ackerflächen in Grünland in der Ausdehnung der 1960er Jahre wäre ohne Folgen für die Betriebsstrukturen sicherlich nicht möglich. Da die Landnutzung der spezialisierten Agrarwirtschaft sich wesentlich nach Bedingungen des Marktes und der Agrarsubventionen richtet und weniger nach Standortbedingungen, wäre eine Rückführung von Ackerland in Grünland kaum ohne gesetzliche Eingriffe denkbar. Sollte auf den ehemaligen Grünländereien auf Dauer aus ökonomischen Gründen Ackerbau wegen des zu hohen Ernterisikos unrentabel sein, würden die Flächen voraussichtlich brach fallen, weil die weit von den benachbarten Dörfern entfernten Flächen als Grünland für Veredelungsbetriebe uninteressant sind. Das Brachfallen größerer Flächen würde den Landschaftsschutz und den Naturschutz vor neue Herausforderungen 
und Aufgaben stellen. Wenn man in den Aller- und Dreckwiesen brach gefallene Flächen Grünland oder Acker - der natürlichen Sukzession überlassen würde, entstünde eine neue Landschaft, die im Landschaftsbild weder der früheren offenen Wiesenlandschaft noch der heutigen Ackerbaulandschaft entspräche.

Die Beispiele zeigen, dass Agrartechnik, Anbauformen, Bodenbearbeitung und agrarpolitische Entscheidungen und Vorgaben die Rücksicht auf Standortunterschiede verringern können und das kleinräumige Bild einer Kulturlandschaft nach Artenvielfalt und deren kleinräumiger Verteilung, also das optische Bild der Kulturlandschaft, deutlich beeinflussen und bestimmen.

\subsection{Von der Kulturlandschaft der bäuerlichen Mischwirtschaft zur Kulturlandschaft der spezialisierten Agrarwirtschaft.}

Im familienbäuerlichen Mischbetrieb waren aus markt- und arbeitswirtschaftlichen Gründen der Ackerbau und die Veredelungswirtschaft unverzichtbare und gleichberechtigte Betriebszweige, die innerbetrieblich eng miteinander verflochten waren. Dadurch ergaben sich innerbetriebliche Stoffkreisläufe für die Erzeugung von betriebseigenem Futter sowie die betriebsinterne Verwertung von Gülle und Mist. Dies wirkte sich positiv auf die Fruchtfolgesysteme und die Bodenfruchtbarkeit aus. Insbesondere sorgte die Mischwirtschaft mit Nutzvieh dafür, dass die Betriebe neben Acker über genügend Grünland verfügen mussten, das insbesondere für die Rinderzucht und die Milchkuhhaltung gebraucht wurde. Der Bedarf an Grünland sorgte dafür, dass Flächen, die aus hydrologischen Gründen für den Ackerbau ungeeignet schienen, als Grünland genutzt wurden. Aus rein betriebswirtschaftlichen Gründen ergab sich so eine Landnutzung, die sich den natürlichen ökologischen Bedingungen eng anpassen konnte. Die Talaue der Lachte, die kleinen Moorflächen in der Gemarkung und die Dreckwiesen im Randmoorbereich des Urstromtales boten einen komparativen Vorteil für Grünland gegenüber Ackernutzung. Da das Grünland unbedingt betrieblich nötig war, wurden alle Flächen mit natürlichem Vorteil gegenüber Acker auch als Grünland genutzt. Aus betrieblichen Gründen hat man in der Lachendorfer Gemarkung auch trockene Standorte mit geringer Grundfeuchte auf dem Schwemmfächer, die ehemaligen Bultenhiebsflächen, zu Grünland gemacht und auf den Trockenen Wiesen sogar Stauwiesen angelegt.

Die Feststellung, dass die bäuerliche Mischwirtschaft „noch für ein ausgewogenes Verhältnis von Acker und Grünland sorgte“, ist allerdings eine nur scheinbar objektive Sachaussage, die aber mit einem verkappten Werturteil verbunden ist. „Ausgewogen“ ist ein Wertbegriff, der insbesondere nicht ökologisch begründbar ist.

Die spezialisierte Agrarwirtschaft hat mit der Tendenz zu reinen Ackerbaubetrieben den Bedarf an Grünland stark reduziert und den für Ackerland stark erhöht. Als Folge dieser betrieblichen Konzentration auf Ackerbau bzw. der Aufgabe ${ }^{1}$ von Rinderzucht mit Milchkuhhaltung wurde Grünland, wo irgend möglich, zu Acker umgebrochen. In der Lachendorfer Gemarkung zuerst die Stauwiesen, dann die anderen Trockenen Wiesen an Aller und Schwarzwasser und schließlich drangt der Ackerbau immer mehr in die Dreckwiesen vor.

Die Problematik dieses betriebswirtschaftlich induzierten Nutzungswandels zeigt sich sehr deutlich beim extremen Hochwasser im Mai 2013: Seit der Aller- und Schwarzwasserregulierung zu Beginn der 1960er Jahre waren die ehemaligen Überschwemmungsflächen am Schwarzwasser und in den Aller-Dreckwiesen nicht mehr überschwemmt worden. Im Mai 2013 richtete das Hochwasser auf den dortigen Ackerflächen erhebliche Schäden an. ${ }^{2}$

Hieran zeigt sich, dass sich die bäuerliche Mischwirtschaft aufgrund der Betriebstruktur leichter an die ökologische Differenzierung des Naturraumes anpassen konnte als die spezialisierte Agrarwirtschaft.

\footnotetext{
${ }^{1}$ Schweinehaltung lässt sich auch als selbständiger Betriebszweig unabhängig vom Ackerbau und ohne innerbetriebliche Vernetzung betreiben.

${ }^{2}$ Mdl. Mitteilung von Landwirt Karsten Koch, Lachendorf
} 
Der Übergang von der Heidebauernwirtschaft zur bäuerlichen Mischwirtschaft hatte die Heide überflüssig gemacht und eine Aufforstung ermöglicht. Eine Umwandlung der Heide in Ackerland kam weit überwiegend wegen der Bodenqualität und der langen Übernutzung nicht in Betracht. So konnte die Aufforstung zu einer ökonomischen Aufwertung der ehemaligen Heidflächen führen. Aus ökologischer Sicht war dieser Nutzungswandel aber keine Aufwertung sondern eine Umwertung, denn das Ökosystem Heide wurde durch das Ökosystem Wald abgelöst. Erst das Verschwinden des Heidesystems machte es in der Landschaftswahrnehmung der Zeitgenossen, vorwiegend den städtischen, wertvoll.

Der Übergang von der bäuerlichen Mischwirtschaft zur spezialisierten Agrarwirtschaft mit überwiegend reinen Ackerbaubetrieben macht das Grünland überflüssig. Die wirtschaftlichste Alternative für die Ackerbaubetriebe ist die Umnutzung in Ackerland. Anders als die Heideflächen, die mit der Aufforstung aus der landwirtschaftlichen Nutzfläche ausschieden, werden die nicht mehr benötigten Grünländereien landwirtschaftliche Nutzflächen bleiben, weil die Nachfrage nach Ackerland tendenziell steigt und die Böden des bisherigen Grünlandes eine ertragreiche Beackerung ${ }^{1}$ durchaus ermöglichen. Auf diesen Flächen wird der Ackerbau nur durch die hydrologischen Bedingungen begrenzt oder sein Ernterisiko vergrößert.

Da die bisherigen Grünländereien auch ackerfähig sind und die verbleibenden Veredelungsbetriebe das frei werdende Grünland nicht vollständig übernehmen können, wird die Tendenz zur Umnutzung von Grünland in Acker bestehen bleiben.

Auf Dauer gibt es hinsichtlich des Landschaftsbildes bzw. der Nutzungsrisiken nur wenige Möglichkeiten:

Durch öffentlich finanzierte Maßnahmen werden Grünländereien zum Schutze des Landschaftsbildes erhalten.

Durch öffentliche Maßnahmen wird die Grünlandnutzung gefördert, insbesondere extensive Nutzungsformen, die sich gut mit Zielen des Landschafts- und Artenschutzes (Naturschutz) kombinieren lassen.

Der Ackerbau auf ehemaligen Grünlandflächen mit der Gefahr gelegentlicher Überschwemmungen wird unter Hinnahme des Ernterisikos beibehalten.

Dieses Ernterisiko könnte nur durch sehr teure und aufwändige Bedeichungen vermieden werden, die aber derzeit im Widerspruch zu notwendigen Maßnahmen des Hochwasserschutzes stehen, der den Flüssen bei Hochwasser wieder mehr Raum geben will, um Dörfer und Städte vor Überflutungen bei extremen Pegelständen zu bewahren.

Die hoch technisierte, spezialisierte Agrarwirtschaft, die bei ausschließlicher Ausrichtung auf Ertragsmaximierung und Effizienz nicht gleichzeitig ökologische Vielfalt und kleinräumige Anpassung an ein naturräumliches Standortmosaik verwirklichen kann, muss durch ihre Landbewirtschaftung zwangsläufig die Kulturlandschaft der bäuerlichen Mischwirtschaft verändern. Wenn sich dieser wirtschaftlich bedingte Landschaftswandel als Zerstörung der Kulturlandschaft und als schädlicher wie irreparabler Eingriff in den Naturhaushalt erweist, gibt es mehrere Möglichkeiten: Die wirtschaftlichen Rahmenbedingungen werden gesellschaftspolitisch so geändert, dass die Landwirtschaft ökologisch verträglich gewinnbringend arbeiten kann. Oder die überkommene Kulturlandschaft wird unter Schutz gestellt, als „Reliktlandschaft" erhalten, wobei die Gesellschaft die reproduktiven Kosten tragen muss. Derzeit gibt es allerdings auch in der modernen Landwirtschaft Tendenzen, ökologische Belange wieder stärker zu berücksichtigen: Einmal durch die Bewegung des ökologischen Landbaus, zum anderen aber auch im hoch technisierten, konventionellen Landbau, teils wegen steigender Kosten für Betriebsmittel, teils wegen der allerneuesten technischen Möglichkeiten des „Precision Farming“, deren Entwicklung aber erst am Beginn steht.

In den zwei Übergängen zwischen den drei landwirtschaftlichen Wirtschaftssystemen der letzen 200 Jahre ist es zu einem deutlichen Wandel in der Kulturlandschaft gekommen:

Aus Heide wurde vorwiegend Wald, aus Grünland überwiegend Acker, nur die seit Jahrhunderten als Acker genutzten Flächen blieben aus Gründen der Bodengüte in allen Wirtschaftssystemen als Acker erhalten.

\footnotetext{
${ }^{1}$ s. Tabelle 6.6: Erträge in den Allerwiesen
} 
Karte 3.3 (Acker, Wiesen und Weiden um 1800) in Kapitel 3, Karte 4.1 (Landschaft und Landnutzung um 1840) und 4.3 (Landschaft um 1900) in Kapitel 4 und die folgenden Karten 6.2 (Landnutzung und Landschaft 1966) und 6.3 (Landnutzung und Landschaft 2012) dokumentieren diesen Landschaftswandel in zwei Jahrhunderten:

In den 1960er Jahren wurde im Rahmen der bäuerlichen Mischwirtschaft das gesamte Grünland, sowohl in der Talaue der Lachte wie auch die Dreck-, Trocken- und Stauwiesen entsprechend der zeittypischen Agrartechnik intensiv und regelmäßig genutzt, teils als Weide für Jungvieh und Milchkühe und teils als zweischürige Wiese zur Heuwerbung. Lediglich die schmalen Grünlandstreifen beiderseits des oberen Schelpriethgrabens in der Bunkenburger Geestplatt östlich des Ortes zeigten Merkmale des Brachfallens.

Das restliche Stückchen Heide auf der Allerheide war auch bereits durch Kiefernsämlinge aus dem benachbarten Wald bedroht.

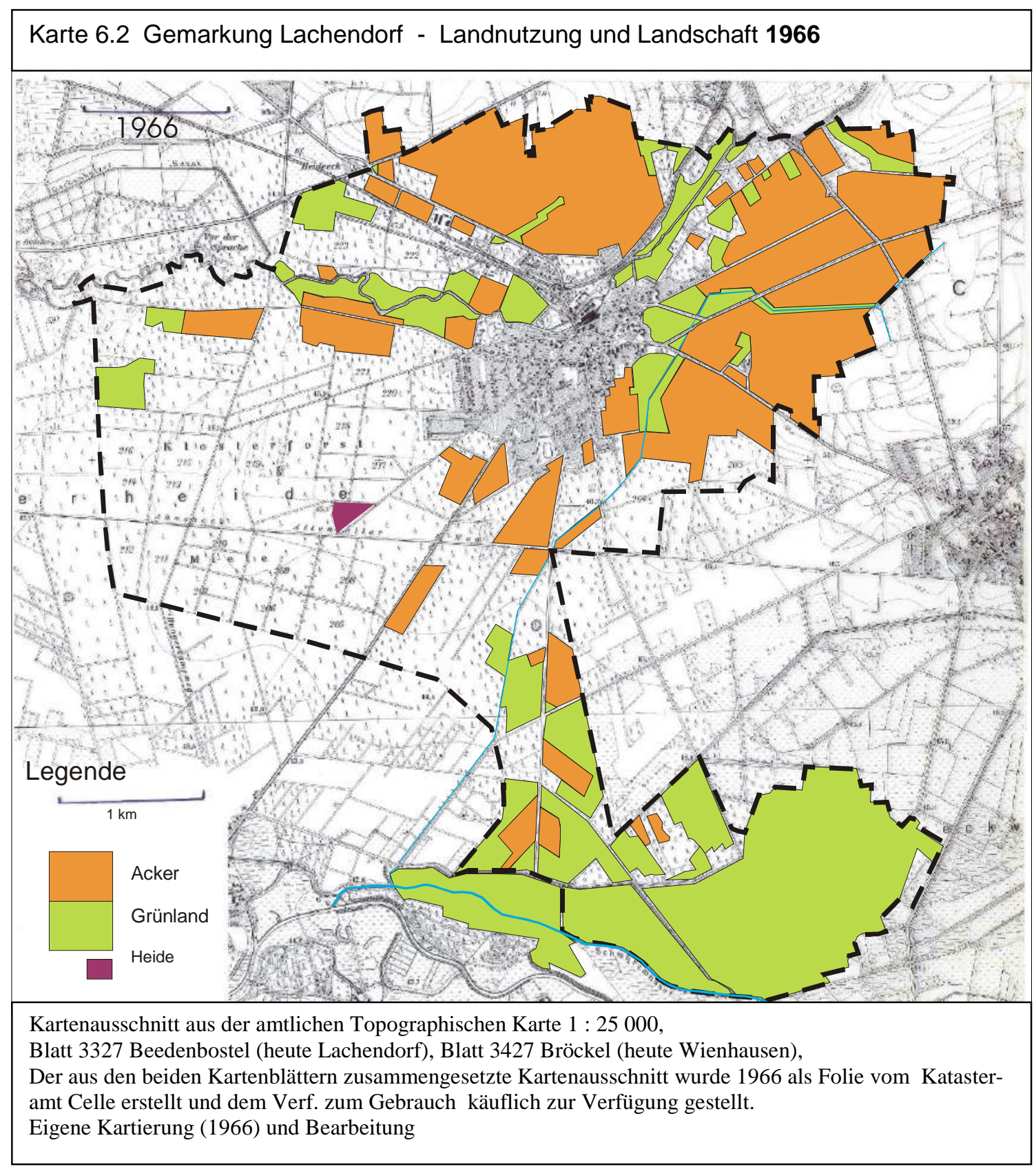




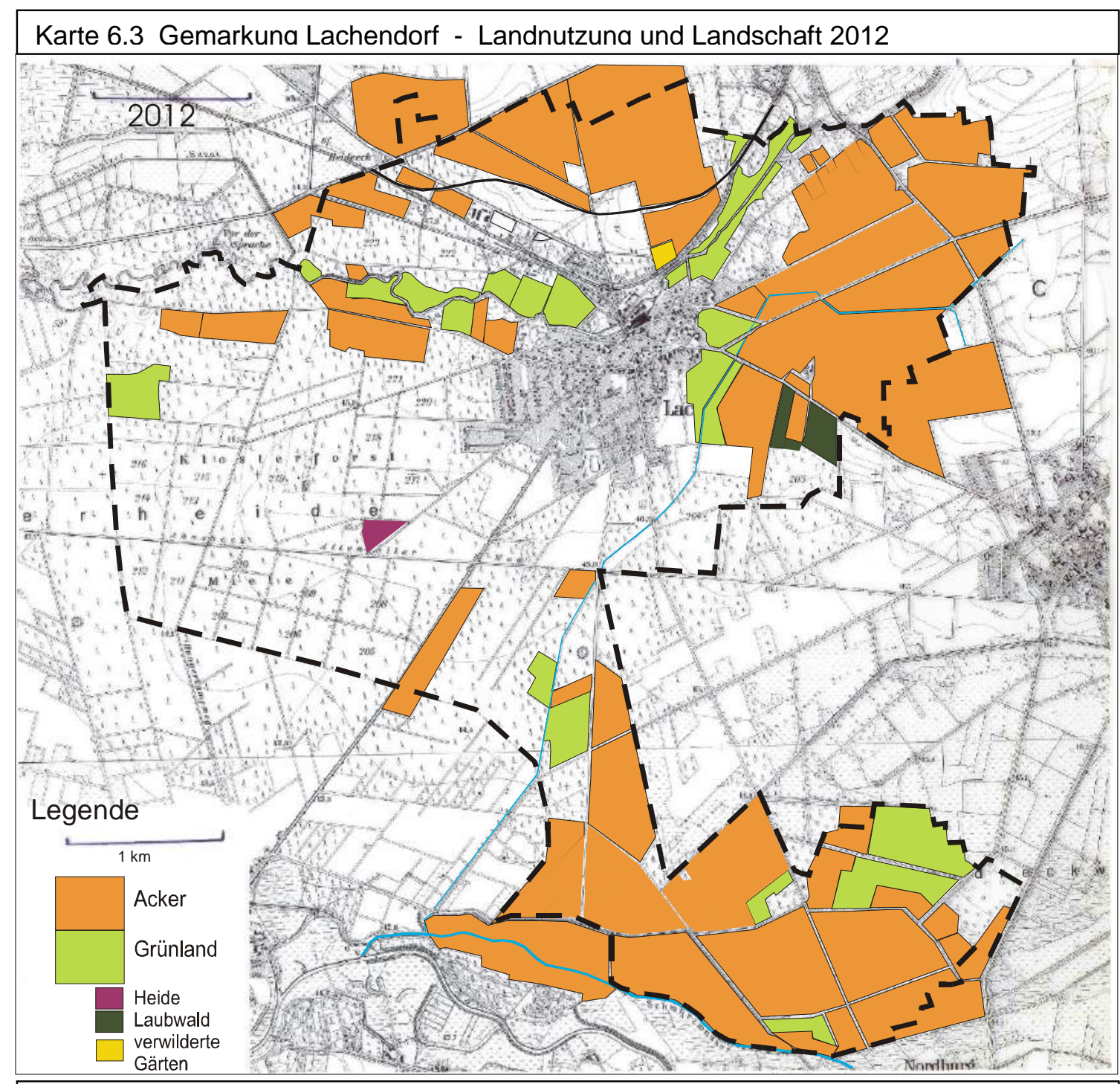

Kartenausschnitt aus der amtlichen Topographischen Karte $1: 25$ 000,

Blatt 3327 Beedenbostel (heute Lachendorf), Blatt 3427 Bröckel (heute Wienhausen),

Der aus den beiden Kartenblättern zusammengesetzte Kartenausschnitt wurde 1966 als Folie vom Katasteramt Celle erstellt und dem Verf. zum Gebrauch käuflich zur Verfügung gestellt.

Kartierung (2012) und Bearbeitung: A. Behr

In den Jahrzehnten seit 1970 ist im Umkreis der Siedlung durch Wohnbebauung, Gewerbegebiet und Infrastrukturmaßnahmen Ackerland für die landwirtschaftliche Nutzung verloren gegangen. Am südlichen Siedlungsrand betraf dies sehr leichte Böden, die als „Grenzertragsböden“ eingestuft werden können. Im nördlichen Bereich betraf dies die besten Böden in der Gemarkung.

Im Südteil der Gemarkung wurde die Wiesenlandschaft inzwischen überwiegend in eine Ackerbaulandschaft umgewandelt. Aus der Sicht der Bodengüte und der Überschwemmungsgefahr sind die neuen Ackerflächen allenfalls flächenmäßig ein Ausgleich für die Ackerverluste im Umkreis des wachsenden Ortes.

In der räumlichen Anordnung der Bodennutzung mit Heide, Wald, Grünland/Acker und Acker ist in allen Epochen der Landnutzung das naturgeographische Raummuster erkennbar. Die 
natürlichen Standortunterschiede haben also durchgehend das Landnutzungsmuster bestimmt.

Die konkrete Landnutzung wurde allerdings innerhalb des natürlichen Nutzungspotenzials in jeder Epoche aufgrund der Wirtschaftsweise, der jeweils zur Verfügung stehenden Agrartechnik und der jeweils herrschenden Agrarpolitik gestaltet.

Während die natürlichen Rahmenbedingungen in ihrer Bedeutung für die Landnutzung mit zunehmender Bedeutung der wissenschaftlich-technischen Hilfsmittel abgenommen haben, hat sich der Einfluss der (Agrar-)Politik auf die Landnutzung deutlich erhöht.

Da die Kulturlandschaft - anders als früher - neben der agrar- und forstwirtschaftlichen Nutzung weitere Raumansprüche für Erholung und Freizeit, als Siedlungs- und Verkehrsraum und als Natur und Landschaft erfüllen muss, befinden sich Land- und Forstwirtschaft wegen des grundsätzlich begrenzten Raumangebotes in einer zunehmenden Raumkonkurrenz. Aufgrund eines gestiegenen Umweltbewusstseins der Öffentlichkeit und einer Überversorgung mit Nahrungsmitteln einerseits und Umweltbelastungen durch gewisse Formen moderner Agrarwirtschaft andererseits steht die Landwirtschaft in einem zunehmenden Rechtfertigungsdruck für ihre konventionellen Wirtschaftsweisen. Land- und Forstwirtschaft werden nicht mehr ausschließlich als Gestalter und Bewahrer unserer Kulturlandschaft gesehen.

Die unumgängliche Veränderung der Kulturlandschaft im Zuge sich ändernder Wirtschaftsweise wird als Bedrohung der überkommenen Kulturlandschaft und sogar als Naturzerstörung wahrgenommen.

Ein gesellschaftlicher Konsens über Formen der Landnutzung und die damit verbundene Gestaltung und Prägung unserer Kulturlandschaft wäre nicht nur wünschenswert sondern zwingend erforderlich. 


\section{Kapitel 7 Natur - Nutzung - Kulturlandschaft}

\subsection{Naturräume und Kulturlandschaft}

Die räumliche Struktur der Kulturlandschaft zeigt im Raum Lachendorf eine hohe Übereinstimmung mit der naturräumlichen Gliederung. Bis zur Umgestaltung der Dreckwiesen galt diese Übereinstimmung für die gesamte Gemarkung unter allen landwirtschaftlichen Wirtschaftsweisen und bäuerlichen Betriebsstrukturen.

Es verwundert nicht, dass die Heidebauernwirtschaft in ihrer totalen Abhängigkeit von den natürlichen Standortbedingungen diese im Rahmen ihrer agrartechnischen Möglichkeiten optimal nutzte: Grundmoräne als Ackerland, die Talaue und die Anmoorflächen in den Randmoorbereichen als "natürliches“ Grünland und die trockenen Sandböden des Schwemmfächers und der Talsandflächen als Heide und Hutungen.

Die Ackergewanne südlich und westlich des Ortes bilden eine Ausnahme von der direkten Anpassung der Nutzung an den natürlichen Standort. Diese Äcker auf der Wurzelzone des Schwemmfächers können sicherlich eher als Ausdruck des Mangels an gutem Ackerland denn als Anpassung an den Naturraum interpretiert werden.

Das Nutzungsmuster der Landschaft entsprach also insgesamt sehr genau der naturräumlichen Gliederung.

Die bäuerliche Gemischtwirtschaft in der 2. Hälfte des 19. und 1. Hälfte des 20. Jahrhunderts zeigt ebenfalls eine sehr genaue Anpassung an die naturräumliche Landschaftsstruktur: Die Ackerflächen auf den lehmigen und besseren sandigen Böden wurden weiter als Acker genutzt. Dabei kam es sogar zu einer Feinabstimmung zwischen natürlichem Standort und Nutzung, denn Tiefenlinien von Trockentälern der Grundmoränenplatten wurden zwischen den benachbarten Ackerschlägen als schmale Grünlandstreifen genutzt.

Auch das „natürliche“ Grünland in der Lachteaue und in den Dreckwiesen blieb als Wiesenund Weidelandschaft erhalten. Auf dem Schwemmfächer der Lachte und den Talsanden am Schwarzwasser, den Trockenen Wiesen, kam es ebenfalls zu einer kleinräumigen Ausrichtung der Nutzung auf den natürlichen Standort: In den Trockenen Wiesen wurden leistungsfähige Stauwiesen und auf grundfeuchten Flächen des Schwemmfächers wurden Weiden angelegt: Im Kleinen Moor östlich des Ortes, im Postmoor im Westen und im Krähenmoor im Süden der Gemarkung sowie auf der ehemaligen Bultenhiebsfläche mit dem Standortzeiger Pfeifengras westlich des Trockenwiesenweges.

Die trockenen Gebiete des Schwemmfächers überließen die Bauern der Aufforstung. Diese im Zuge der Spezialteilung erhaltenen Parzellen standen auch am ehesten zum Verkauf, wie sich am Landkauf ${ }^{1}$ des Rittergutes ablesen lässt.

Zur klaren Anpassung der landwirtschaftlichen Nutzung passt auch, dass der Ort mit neuer Wohnbebauung nach 1945 zuerst nur nach Süden, Südwesten und Westen wuchs, weil die Bauern bereit waren, das minderwertige Ackerland auf dem Schwemmfächer, das nur zwischen 17 und 20 Bodenpunkte aufwies, als Bauland zu verkaufen. Der Verkauf von Bauland brachte offenbar deutliche finanzielle Vorteile gegenüber einer weiteren Nutzung als Ackerland. Sicherlich war es betriebswirtschaftlich auch wesentlich günstiger, den Ackerbau auf den besseren Böden zu intensivieren als auf den als Grenzertragsböden bezeichneten Sandböden Anbau zu betreiben, der auf den sehr trockenen, durchlässigen Böden zusammen mit der großen Niederschlagsvariabilität sehr unsicher war und keine Erntesicherheit bot, zumal in den 1950er Jahren die Feldberegnung noch nicht den heutigen technischen Stand erreicht hatte.

Auch für die gegenwärtige Agrarwirtschaft bleibt der Schwerpunkt des Ackerbaus auf den Böden der Grundmoräne. Ackerbaubetriebe nutzen nicht ackerfähiges oder hofnahes Grünland in einem betrieblichen Neben- oder Zusatzbereich, etwa zur Mutterkuhhaltung in der Lachteaue oder als Koppel in der Pferdezucht.

\footnotetext{
${ }^{1}$ vergl. F. Friedrich, Papier aus Lachendorf, a.a.O., S. $85 \mathrm{ff}$.
} 
Als neues Ackerlandareal sind die ehemaligen Stauwiesen am Schwarzwasser sowie die Trockenen Wiesen und große Teile der Dreckwiesen hinzugekommen. Auch dies ist eine betrieblich gesteuerte sinnvolle Anpassung an die anthropogen veränderten natürlichen Standorte. Die Stauwiesen waren nach Einstellung der Bewässerung zum Ackerbau ebenso geeignet wie die Trockenen Wiesen. In den Dreckwiesen sind die ursprünglichen natürlichen Bedingungen durch die Flussbaumaßnahmen an Aller und Schwarzwasser so verändert worden, dass auch dieser Standort ackerfähig geworden ist.

Durch menschlichen Eingriff in das Fluss- und Grundwasserregime ist in den Dreckwiesen ein neuer Standort geschaffen worden, den man nicht mehr als „natürlichen“ Grünlandstandort bezeichnen kann. Die Agrarwirtschaft nutzt diesen Standort nun im Rahmen der vorherrschenden Betriebstruktur als geeigneten Ackerstandort. Die Agrarwirtschaft hat also nicht den natürlichen Standort umgewandelt, sondern die veränderte Standortqualität erlaubte eine andere Nutzung.

Insgesamt hat sich die land- und auch die forstwirtschaftliche Landnutzung dem Muster der naturräumlichen Raumstruktur angepasst und die jeweiligen Naturräume entsprechend den Möglichkeiten ihrer Wirtschaftsweise überwiegend standortgemäß genutzt.

Nur die politische gesteuerte Siedlungserweiterung hat sich - wie bereits dargelegt - bei den jüngsten Erweiterungen nicht an den natürlichen Standortbedingungen orientiert.

Das Gebot des sorgfältigen und nachhaltigen Umgangs mit der Ressource Boden, die weder vermehrbar noch recycelbar ist, wurde bei den jüngsten Ortserweiterungen missachtet!

Diese Vernachlässigung des Schutzes und der Bewahrung von Boden ist kein lokaler Einzeloder Sonderfall. In der allgemeinen Umweltdebatte spielt der Boden im Vergleich mit Wasser und Atmosphäre eine untergeordnete Rolle ${ }^{1}$. Sachlich ist das aus zwei Gründen nicht gerechtfertigt: Boden gehört - wie Wasser und Luft - zu den essentiellen Grundlagen des Lebens und insbesondere unserer Ernährung. Eine Säuberung wie bei Wasser und Luft mit technischen Hilfsmitteln ist nur bei einer Bodenart möglich. Boden als Pedon, als Durchdringungskomplex von Litho-, Athmo-, Hydro- und Biosphäre mit einer zeitlichen Entwicklungsgeschichte kann nicht gereinigt oder recycelt werden, ohne ihn zu zerstören.

\subsection{Landnutzung und Artenvielfalt}

Seit der Konferenz von Rio 1992 ist Biodiversität ein wichtiger Begriff in der ökologischen Diskussion und insbesondere in der Umweltdebatte ${ }^{2}$.

Der Begriff, im naturwissenschaftlichen Sinne benutzt, beinhaltet aber keine Wertung. Ein Standort, ein Ökosystem kann nicht aufgrund hoher oder niedriger Artenvielfalt bewertet werden, denn zwischen natürlichen Systemen kann es keine wertende Rangfolge geben. Erst wenn man der Artenvielfalt einen positiven Wert beimisst, also etwa Artenreichtum höher bewertet als Artenarmut, kann man Standorte und Kulturlandschaften nach Biodiversität bewerten. Das würde aber bedeuten, dass extreme Standorte mit geringer Anzahl hoch spezialisierten, evtl. „bedrohter“ Arten geringer bewertet werden müsste als ein häufig vorkommender Standort mit größerer Artenfülle. Artenvielfalt und Artenschutz können also durchaus zueinander konträr stehen. Biodiversität korrespondiert weder direkt mit Bodenfruchtbarkeit noch mit dem Schutzziel „Natur Natur sein lassen“"3.

Biodiversität allein liefert zwar wichtige Daten für die deskriptive und analytische Sachebene, aber nicht für die Wertebene.

Deshalb können auch verschiedene Kulturlandschaften aufgrund unterschiedlicher Artenvielfalt nicht wertend sondern nur beschreibend verglichen werden.

\footnotetext{
${ }_{1}^{1}$ vergl. J. Radkau; Die Ära der Ökologie, a.a.O., S. $81 \mathrm{f}$

${ }^{2}$ vergl. ebenda S. $588 \mathrm{ff}$

${ }^{3}$ s. J. Radkau; Die Ära der Ökologie, a.a.O., S. 589
} 


\subsubsection{Von den Heiden zum Wald}

Bei dem Übergang von Heiden und Hutungen zu Wald bzw. Forst ergeben sich für die Pflanzen ganz neue Konkurrenzbedingungen: Herrschte in den Heiden und Hutungen der Allerheide auf den trockenen Sandböden des Schwemmfächers besonders Wasserkonkurrenz, so wandelte sich dieser Standortfaktor unter Wald zur vorherrschenden Lichtkonkurrenz.

Nutzungsbedingt herrschte Selektion vor allem durch Beweidung, aber auch durch Plaggen, Mähen und evtl. auch Brennen bzw. Abflämmen. Die Heiden und Hutungen boten je nach kleinräumiger Standortdifferenzierung auf dem Schwemmfächer vielen „Spezialisten“ der Fauna und Flora Wachstumsbedingungen und Lebensraum, der mit der Aufforstung und Bewaldung verloren ging. Schon allein aufgrund der Lichtkonkurrenz zwischen Bäumen bzw. Holzgewächsen allgemein einerseits und Gräsern und Kräutern andererseits wurden letztere zurück gedrängt ${ }^{1}$. Für das typische Artenspektrum der Heiden und Hutungen trifft folgende Aussage zu: „Entwaldete Regionen mit heruntergewirtschafteten Böden verfügen nicht selten über eine hohe Artenvielfalt." 2

Evident wird die Verschiebung des Artenspektrums auch in der Vogelwelt: Gehören z.B. Lerchen und Ziegenmelker zu den typischen Arten offener Heiden, aber nicht z.B. Spechte und Rabenvögel, die in Offenlandschaften kaum Nistmöglichkeiten finden.

Beim Landschaftswandel des 19. Jahrhunderts von den Heiden und Hutungen zum Wald hat es zweifellos eine Veränderung der Biodiversität gegeben, viel gravierender waren aber die Veränderungen im Artenspektrum. Es gab sowohl in der Flora wie auch in der Fauna Gewinner und Verlierer, so wie es immer bei jedem Landschaftswandel der Fall ist. Das typische Artenspektrum der Heiden und Hutungen, eine Konsequenz aus natürlichen Standortbedingungen, Wirtschaftsweise und Techniken der Landnutzung ist durch eine grundlegende Änderung der Wirtschaftsweise in ein ebenso typisches Artenspektrum der Wälder und Forsten überführt worden.

Da sich die Bewaldung fast ausschließlich nicht durch natürliche Sukzession sondern durch planmäßige Aufforstung vollzog, ergab sich eine weitere Ursache für das neue Artenspektrum: Wegen der Bepflanzung im Engverband, die bei den Aufforstungen angewandt wurde, kommt es in den jeweiligen Parzellen mit einheitlicher Bepflanzung zu einer Sukzession des Bestandes: Der Unterwuchs der Forstkulturen richtet sich vorwiegend nach der Bestandsentwicklung und dem Bestandsalter der Bäume. Dies ist eine künstlich verschärfte Form der Lichtkonkurrenz. Dichter Wald entwickelt je nach Baumbestand und Kronenschluss ein standortabhängiges und bestandstypisches Artenspektrum, das aber die Artenvielfalt der offenen Landschaft ${ }^{3}$ nicht erreicht.

Ein beredtes Beispiel für diese Konkurrenzsituation boten die Waldbrandflächen zwischen Eschede und Oldendorf nach 1975: Im abgebrannten Wald, reinem Kiefernforst, gab es keine Kraut- und Strauchschicht. In den Jahren danach bildete sich spontan auf natürlichem Wege ein dichter Bewuchs, in dem das Wald-Weidenröschen (Epilobium augustifolium) flächendeckende Bestände bildete und so zu einem temporär völlig

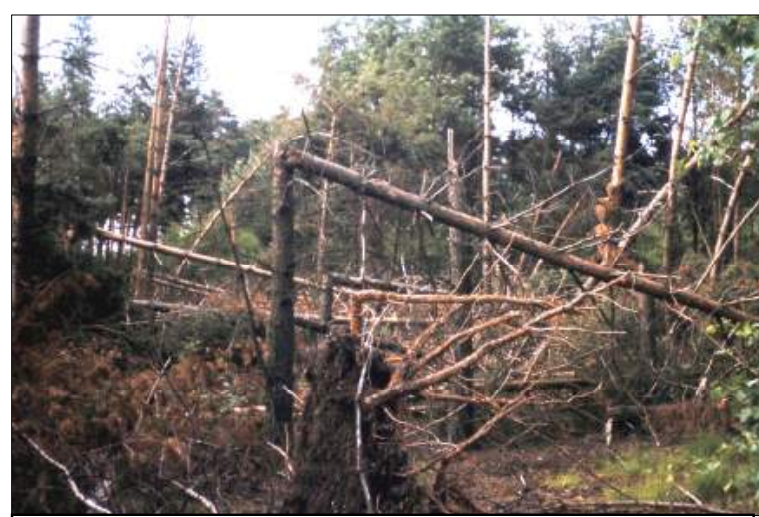

Abb. 7.1 Windbruch im Kiefernforst auf der Allerheide, November 1972; Aufn. A. Behr neuen Landschaftsbild mit weiter Sicht über ein rot-violettes Blütenmeer sorgte. Die Aufforstung beendete dieses kurzfristige Landschaftsbild bzw. beeindruckende Landschaftserlebnis.

\footnotetext{
${ }^{1}$ s.a. H. Walter u. S. Breckle; Ökologie der Erde, Bd. 2, a.a.O. , S. 124: Holzpflanzen und Gräser als Antagonisten

${ }_{2}^{2}$ J. Radkau,; Die Ära der Ökologie, a.a.O., S. 589

${ }^{3}$ ebenda
} 
Zwar haben der Orkan im November 1972 und der Waldbrand im August 1975 - anders als in anderen Waldflächen des Kreises Celle - im Wald auf der Allerheide keine größeren Schäden angerichtet, Abbildung 7.1 - aufgenommen am damaligen Südrand des Ortes, heute Baugebiet - zeigt aber, wie anfällig Kiefernstangenholz in einem Bestand mit einheitlicher Altersklasse für Windbruch ist.

\subsubsection{Wandel auf dem Acker}

Bei den Ackerländereien der Gemarkung hat es im 19. Jahrhundert mit dem Wechsel der Wirtschaftsweise keinen grundlegenden Nutzungswandel gegeben, vielmehr zeichnet sich das Ackerland, trotz neuer Parzellen- und Schlageinteilung, durch eine über Jahrhunderte bestehende Nutzungskontinuität aus. Dennoch hat sich die Biodiversität auf den Ackerflächen unter der bäuerlichen Gemischtwirtschaft erheblich verändert, und zwar in mehrfacher Hinsicht:

Neue Kulturpflanzen als Hauptkultur, als Futterpflanzen und für den Zwischenfruchtanbau und als Gründüngung haben das Artenspektrum der Nutzpflanzen trotz des Verschwindens einiger alter Kulturpflanzen ${ }^{1}$ erhöht. Die Böden erfuhren durch intensivere Bodenbearbeitung und stärkere Humuswirtschaft eine deutliche Verbesserung der Bodenstruktur und der Bodengare, so dass im Zusammenwirken mit mineralischer Düngung eine erheblich höhere Bodenfruchtbarkeit erreicht werden konnte.

In der alten Dreifelderwirtschaft mit 2/3 Getreide und 1/3 Brache, die auch noch der Beweidung unterlag, wurden dem Boden durch den Anbau hauptsächlich Getreidestoppeln zugeführt. Zusammen mit den Plaggen ergab das eine organische Düngung mit einem sehr ungünstigen $\mathrm{C} / \mathrm{N}-$ Verhältnis, sodass für die Humifizierung und Mineralisierung keine günstigen Bedingungen vorlagen. Unter diesen Voraussetzungen konnte sich auf den vorhandenen Böden, insbesondere den trockenen Sandböden, kein reiches Bodenleben entwickeln. Besonders mit der Einführung von Gründüngung, aber auch mit neuen Kulturpflanzen Kartoffeln und Rüben, erhielten die Böden einen höheren Anteil Biomasse mit einem zum Abbau erforderlichen besseren $\mathrm{C} / \mathrm{N}$-Verhältnis. Leguminosen mit einem $\mathrm{C} / \mathrm{N}-$ Verhältnis von $<30$ werden eben wesentlich besser und schneller mineralisiert als Streu von Eiche, Birke, Nadel- und Heidestreu mit einem $\mathrm{C} / \mathrm{N}-$ Verhältnis $>30 .{ }^{2}$ Gerade Heide, also auch Plaggen, erweist sich in diesem Zusammenhang als besonders ungünstig.

Durch die Bodenverbesserung ergab sich ein stark verbessertes Bodenleben. Durch die erhöhte Bodenfruchtbarkeit, insbesondere durch die bessere Versorgung mit Stickstoff, auch günstigere Wachstumsbedingungen für Wildpflanzen, was wiederum das Nahrungsangebot für die Fauna bereicherte.

Der Ackerbau der gemischtbäuerlichen Wirtschaftsweise hat das Artenspektrum und die Individuenzahl im Boden und auf dem Boden erheblich gesteigert und damit die Biodiversität positiv beeinflusst. Diese Entwicklung war ungebrochen, solange die Bekämpfung von Ackerwildkräutern, Gräsern, Pilzen und Insekten, die landwirtschaftlich wegen ihrer Ertrag mindernden Wirkung als Unkräuter und Schädlinge eingestuft werden mussten, nur mechanisch von Hand oder mit einfachen Geräten möglich war. Mit Einführung von Herbiziden, Fungiziden und Insektiziden, zusammenfassend Biozide und abwertend als

\begin{tabular}{|c|c|c|}
\hline \multicolumn{3}{|l|}{ Tabelle 7.1} \\
\hline \multirow{2}{*}{\multicolumn{3}{|c|}{$\begin{array}{c}\text { Floristische Aufnahme } \\
\text { am Gockenholzer Weg, April bis August } 2002\end{array}$}} \\
\hline & & \\
\hline & \multicolumn{2}{|c|}{ Anzahl } \\
\hline \multirow[t]{3}{*}{ Pflanzen } & häufig bis & vereinzelt, \\
\hline & prägend- & nicht prägend, \\
\hline & dominant & zerstreut \\
\hline Gehölze & 4 & 15 \\
\hline \multicolumn{3}{|l|}{ Krautschicht } \\
\hline Feuchte- und Nässezeiger & 1 & 6 \\
\hline Magerkeits-/Trockenzeiger & 6 & 11 \\
\hline Stickstoff- uns Störungszeiger & 23 & 25 \\
\hline \multicolumn{3}{|c|}{$\begin{array}{l}\text { Quelle: Umweltverträglichkeitsprüfung, S. } 60 \text { f. } \\
\text { Bebauungsplan Nr. 22, Gewerbegebiet "Kleines Bulloh" } \\
\text { Gemeinde Lachendorf, Gemeindeverwaltung }\end{array}$} \\
\hline
\end{tabular}
Pestizide bezeichnet, begann ein gezielter und kontrollierter Eingriff in die Biodiversität, der auch - zwar unbeabsichtigt aus Unkenntnis oder pauschaler Mittelwirkung - auch Nützlinge nicht verschonte.

\footnotetext{
${ }_{1}^{1}$ Auf das Verschwinden von Buchweizen und Flachs wurde bereits hingewiesen.

${ }^{2}$ vergl. Scheffer-Schachtschabel, a.a.O., S. 287
} 
Die bäuerliche Gemischtwirtschaft mit ihrer hohen Integration von Ackerbau und Viehhaltung und vielfachen betrieblichen Stoffkreisläufen hat auf dem Acker vor dem flächendeckenden Einsatz von chemischen Mitteln ein Optimum an Biodiversität im Laufe der Kulturlandschaftsentwicklung erreicht.

Eine floristische Bestandaufnahme ${ }^{1}$ am Gockenholzer Weg, also auf gleichnamiger Geestplatte mit Lehmböden, hat aufgezeigt, wie breit gefächert das floristische Artenspektrum in Mitten dieses bevorzugten Ackerbaugebietes ist. Insbesondere die hohe Zahl der Stickstoffund Störungszeiger belegt die aktuelle Nährstoffversorgung.

Diese Artenvielfalt hätte im 18. Jahrhundert aufgrund der Bodenverarmung und Mangelsituation an Nährstoffen aller Art nicht erreicht werden können.

Die Vielfalt ist aber inzwischen in der Agrarproduktion durch gezielten Einsatz industriell erzeugter „Pflanzenschutzmittel“ wieder bedroht.

Der Vergrößerung der Ackerparzellen im Zuge der zunehmenden betrieblichen Konzentration und Technisierung sind auf den beiden Ackerarealen, der Gockenholzer und Bunkenburger Geestplatte, recht enge Grenzen gesetzt. Einmal sind beide Areale durch das Lachtetal mit Grünland und Baumbestand

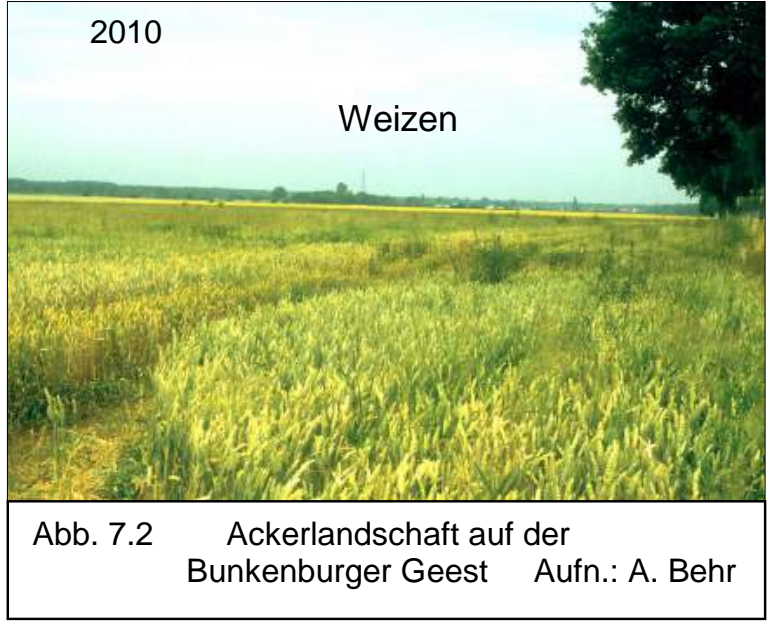
getrennt und zu anderen durch öffentliche Straßen mit Straßenbäumen sowie befestigten Wirtschaftswegen mit Hecken recht stark gegliedert. Selbst wenn das gesamte Ackerareal der Gemarkung nur noch von einem landwirtschaftlichen Betrieb bewirtschaftet werden sollte, kann daher keine großflächige und ausgeräumte Ackerbaulandschaft entstehen.

Eine auffällige optische Veränderung hat das Ackerland besonders auf den Getreideflächen während der Erntezeit von Juli bis September aufgrund der technischen Entwicklung erfahren. Bestimmten früher wochenlang die Stiegen aus Getreidegarben das Landschaftsbild, so sind es heute für kurze Zeit die großen Strohrollen. ${ }^{2}$ Der flächendeckende Einsatz des Mähdreschers und die Ballenpresse haben diesen Wandel ermöglicht.

\subsubsection{Veränderungen im Grünland}

Die große zusammenhängende Grünlandfläche im Allertal muss für die Zeit der bäuerlichen Gemischtbetriebe differenziert betrachtet werden:

Das Gebiet der Stauwiesen erfuhr während der Zeit der Bewässerungswirtschaft nicht nur eine Aufwertung hinsichtlich der Ertragskraft sondern sicherlich auch eine Bereicherung der Biodiversität, dabei aber auch eine Verschiebung des Artenspektrums vom typischen Pflanzenbestand trockener zu bewässerten Wiesen.

Die nicht zu Stauwiesen umgewandelten trockenen Wiesen - zwischen den Stauwiesen im Westen und den Dreckwiesen im Osten gelegen - trugen bei der Kartierung 1966 teilweise noch den Charakter von extensiv bewirtschafteter Waldweide mit einem besonderen Artenspektrum, das mit zunehmender Intensivierung verringert wurde. Insgesamt blieb in diesem Gemarkungsteil die Artenvielfalt relativ hoch, weil die Landschaft durch Bewuchs an den Gräben und einem reichen Baumbestand einer offenen Parklandschaft ähnelte.

Die Dreckwiesen auf den Niedermoorböden des Randmoores im Urstromtal waren aufgrund der Spezialteilung und Verkoppelung mit einem bis heute unveränderten Wege- und Grabensystem neu erschlossen worden. Das Grabensystem sorgte für eine geregelte Entwässerung bei gleichzeitiger gelegentlicher Überschwemmung aus der Aller und Rückstau im Schwarzwasser und einem hohen Grundwasserstand aufgrund der noch wenig „regulierten“

\footnotetext{
${ }^{1}$ K. Schröder-Effinghausen, Umweltverträglichkeitsstudie, infraplan mbH, Celle 2002, S. 60 f

${ }^{2}$ s. dazu die Bilder auf Seite 4
} 
Aller. Allein aufgrund der stärkeren Entwässerung dürfte sich bereits bald nach Fertigstellung des Grabensystems im 19. Jahrhundert eine Verschiebung im Artenspektrum von Sauergräsern zu Süßgräsern eingestellt haben.

Diese Naturbedingungen unterteilten die Dreckwiesen in zwei Bereiche, nämlich Grünland zur Beweidung und Grünland, dessen Grasnarbe keinen Weidetritt von Rindvieh vertrug und deshalb ausschließlich als Wiese zur Heuwerbung genutzt werden konnte. In der Landschaft waren diese Unterschiede augenfällig an den Stacheldrahtzäunen der Weiden und den zaunfreien Wiesen erkennbar.

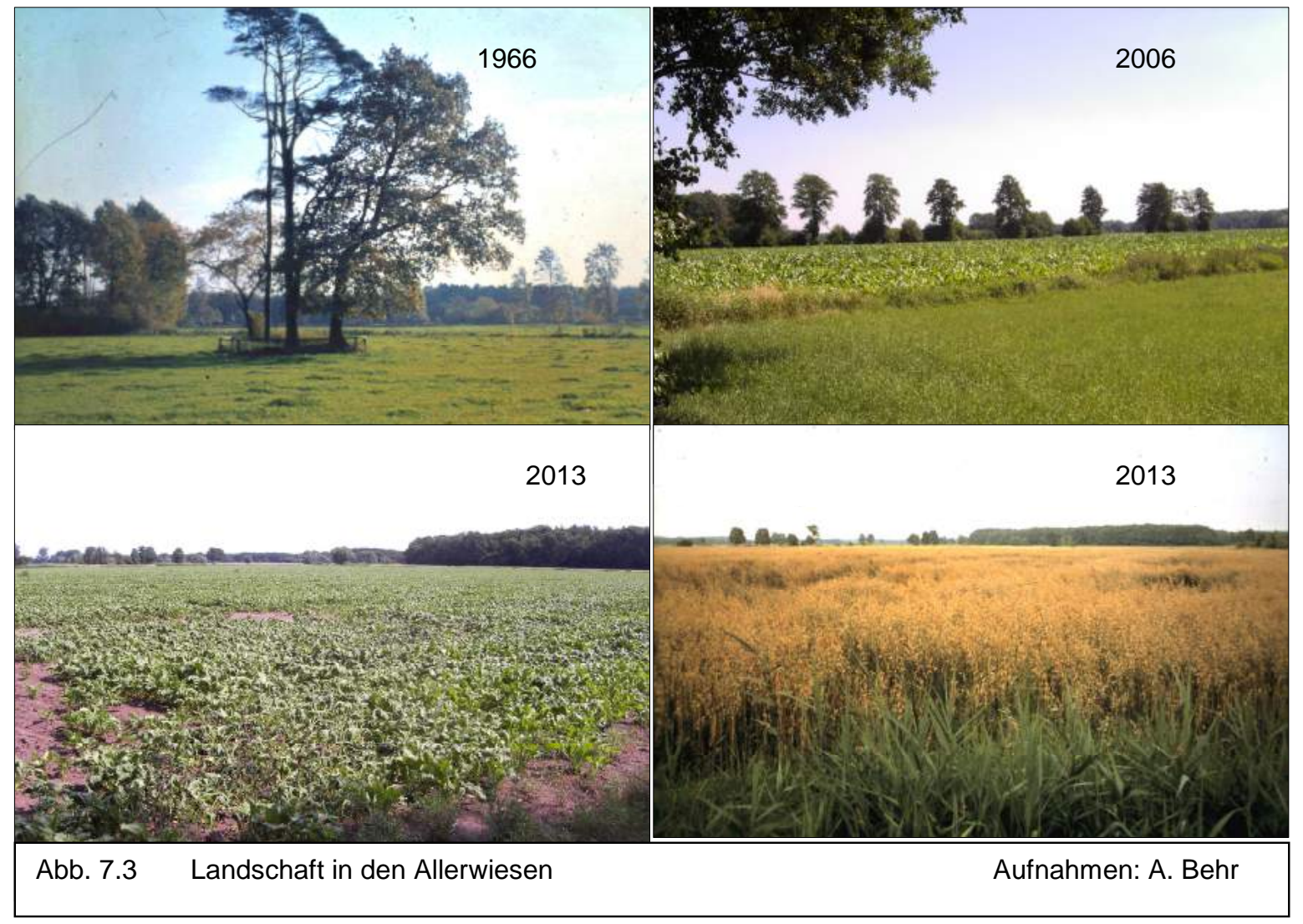

Diese unterschiedliche Nutzung von Grünland als Weide oder Wiese hat einen hohen Einfluss auf das Artenspektrum der verschiedenen Gräser und Wiesenkräuter, da die Arten unterschiedlich auf Weidetritt und ständiges Grasen der Tiere bzw. auf den ein- bis zweimaligen jährlichen Grasschnitt ${ }^{1}$ reagieren. Als Besonderheit der Weiden kommt noch das ganz spezielle Artenspektrum durch Dunghaufen und auf Lagerplätzen der Weidetiere hinzu, insbesondere durch Jungvieh, das dauerhaft während der Vegetationsperiode auf den Weiden gehalten wurde.

Die bäuerliche Gemischtwirtschaft hat also auch auf den Grünländereien eine Kulturlandschaft mit einer hohen Biodiversität geschaffen.

Die Aussage, dass „die bäuerliche Wirtschaftsweise bis ins 19. Jahrhundert, vor der großen

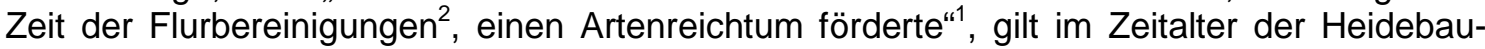

\footnotetext{
${ }^{1}$ Auf die Wirkung der zeitlichen Verschiebung des Mähens auf das Artenspektrum wurde schon hingewiesen.

${ }^{2}$ Sicherlich waren die Spezialteilungen und Verkoppelungen der Agrarreformen des 19. Jahrhunderts auch eine Form der Flurbereinigung, aber in ihrer Wirkung auf die Landschaftsstruktur nicht mit modernen Flurbereinigungen des 20. Jahrhunderts vergleichbar. Möglicherweise kommt in der zitierten Sichtweise aber auch der Gegensatz zwischen Gebieten mit Realteilung in Süddeutschland und Anerbenrecht in Norddeutschland zu Ausdruck.
} 
ernwirtschaft sicherlich nur für die Heideflächen, die zu Wald wurden. Bezüglich Acker und Grünland kann man eher - jedenfalls unter den hier betrachteten Naturbedingungen - davon ausgehen, dass die bäuerliche Gemischtwirtschaft mit dem großen Aufschwung der Bodenfurchtbarkeit eine höhere Artenvielfalt ermöglichte als die Mangelwirtschaft der Heidebauern vor 1850. Denn auch auf den als „absolutes Grünland“ geltenden Allerdreckwiesen herrschte bis ins 19. Jahrhundert Mangelwirtschaft. Die Bauern hatten für die Wiesen und Weiden keinen Dung übrig, der schon nicht für den Acker reichte. Wiesen erhielten sicherlich überhaupt keinen Dung außer während der kurzen Vor- und Nachweide direkt durch das Weidevieh. Deshalb waren die Wiesen auch nur einschürig, aber sicherlich sehr artenreich mit vielen Gräsern und Kräutern, insbesondere auch wegen der späten $\mathrm{Mahd}^{2}$ nach der Samenreife.

Mit dem Wandel von einer reinen Wiesen- und Weidelandschaft zu einer Ackerbaulandschaft hat sich zwar die Nutzung wesentlich geändert, dagegen aber nicht wesentlich das optische Landschaftsbild. Insbesondere im Bereich der ehemaligen Trockenen Wiesen blieb die Landschaft klein strukturiert und vielfach gegliedert durch Baumreihen und Gehölzgruppen. Der Charakter einer Parklandschaft blieb im Bereich der ehemaligen Trockenen Wiesen weitgehend erhalten und die Dreckwiesen beeindrucken auch als Ackerbaulandschaft durch Weite und Einsamkeit.

\subsubsection{Wandel durch Spezialisierte Agrarwirtschaft}

Die heutige Agrarwirtschaft lässt den Wald weiterhin unberührt, hat aber teils erhebliche Auswirkungen auf die Biodiversität der landwirtschaftlichen Nutzflächen.

Der moderne Ackerbau ist mittels Hochleistungssorten, regelmäßiger Bodenanalysen bzgl. der Nährstoffversorgung für gezielte mineralische Düngung, intensiver mechanischer Bodenbearbeitung und Beregnungsmöglichkeit zum Ausgleich der Niederschlagsvariabilität auf Ertragsmaximierung ausgerichtet. Die reinen Ackerbaubetriebe, die inzwischen in Dörfern wie Lachendorf, das nicht in einer Region mit dem Schwerpunkt tierischer Veredelungswirtschaft liegt, in der Mehrzahl sind, verfügen nicht über Naturdung aus der Viehwirtschaft. Organisches Material wird dem Boden also nur direkt aus Ernteabfällen und Gründüngung, deren Anbaufläche eher gesunken ist, zugeführt.

Einen flächenmäßig begrenzten aber nicht unbedeutenden Sonderfall bildet das Rübenblatt: In der bäuerlichen Gemischtwirtschaft war das Rübenblatt lange Zeit eine sehr willkommene Futterquelle als Silage für Rinder, insbesondere Milchkühe. Inzwischen hat der Mais das Rübenblatt als Silage völlig verdrängt. Rübenblatt verbleibt auf dem Acker als Biomasse zur Einarbeitung in den Boden und zur Mineralisierung, wobei sich das sehr gute $\mathrm{C} / \mathrm{N}-$ Verhältnis im Rübenblatt als sehr vorteilhaft erweist. In der Übergangsphase von der Rübenblatt- zur Maissilage haben reine Ackerbaubetriebe das Rübenblatt an Betriebe mit Viehhaltung verkauft, dabei aber genau abgewogen zwischen dem Erlös für das Rübenblatt und den Kosten für eingesparten Mineraldünger.

Es besteht bei reinem Ackerbau, der sich allein auf chemische Düngung konzentriert, die Gefahr, dass der Boden nur oder wenigstens vorwiegend als Substrat zur Vermittlung von Nährsalzen und Wasser an die Pflanzen angesehen wird. Damit verliert der belebte, gare Boden an Bedeutung und es kommt dann zu einer Verarmung des Bodenlebens. Es wird aber unter den gegenwärtigen Bedingungen nicht zu einer grundsätzlichen Bodendegradation führen, weil der ertragsorientierte Ackerbau auf eine dauerhaft hohe Bodenfruchtbarkeit angewiesen ist.

Gefährdet ist im modernen Ackerbau der Boden durch Wassererosion wegen der großen Schläge ohne genügende Berücksichtigung der Hangrichtung und durch lange Zeiten im Winter und Frühjahr ohne Vegetationsbedeckung. In der Lachendorfer Gemarkung besteht diese Gefahr wegen der geringen Reliefenergie nur an den Talhängen des Allertales und in geringerem Ausmaß an den Talhängen des Lachtetales und der Trockentäler in den Geestplatten. Winderosion ist in der Lachendorfer Gemarkung keine Gefahr wegen der ver-

\footnotetext{
1 J. Radkau; Die Ära der Ökologie", a.a.O., S. 73

${ }^{2}$ s.o. Kap. 3.2 .5
} 
gleichsweise kleinen Schlagstrukturen und der strukturreichen Landschaft insgesamt. Eine weitere, noch junge Gefahr besteht in der Bodenverdichtung durch den Bodendruck von Großgeräten.

Die wesentliche und im Gegensatz zu verringertem Bodenleben sichtbare Veränderung der Biodiversität durch modernen Ackerbau ist eine Folge des Einsatzes von chemischen Mitteln zur Bekämpfung von Wildkräutern und Insekten aller Art. Dieser chemische Pflanzenschutz für die Kulturpflanzen muss zwangsläufig die Artenvielfalt in Fauna und Flora verringern, weil er das Wachstum von Wildpflanzen be- und verhindert und damit die Futterbasis für zahlreiche Tierarten schmälert oder gar ganz vernichtet.

Die größte Flächenwirkung in der Kulturlandschaft bewirkt aber die Tendenz der Betriebe zu reinem Ackerbau in den Grünländereien. Durch Umbruch von Grünland zu Acker kommt es nicht nur zu einer starken und grundlegenden Verschiebung im Artenspektrum, sondern auch zu einem stark veränderten Landschaftsbild.

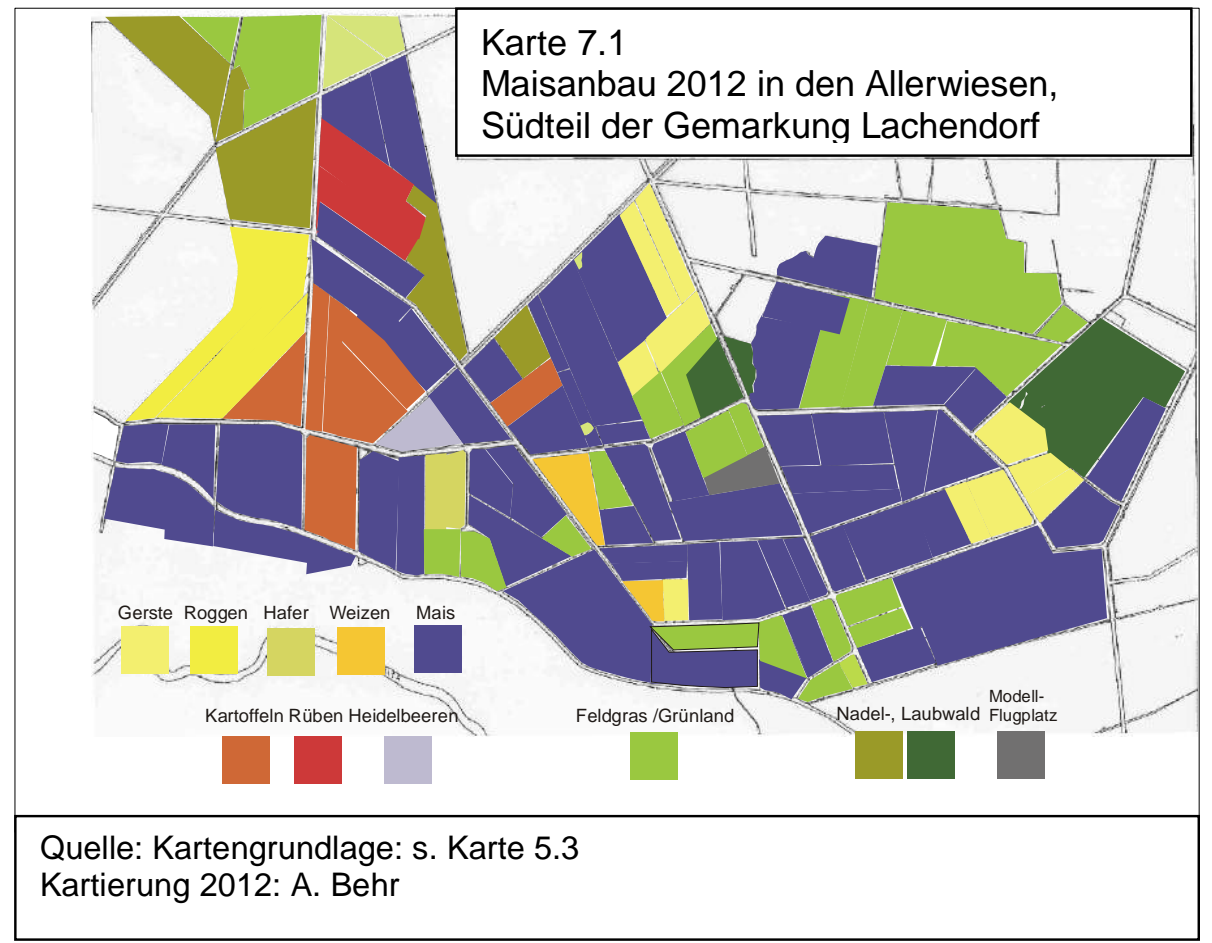

In der Lachendorfer Gemarkung ist das mit steigender Tendenz seit etwa 4 Jahrzehnten zu beobachten.

Im Artenspektrum bedeutet dieser Landschaftswandel z.B. das weitgehende oder totale Verschwinden der typischen Wiesenvögel wie etwa Großer Brachvogel, Bekassine oder Kiebitz, die Mitte der 1960er Jahre in den Dreckwiesen regelmäßig beobachtet werden konnten ${ }^{1}$. Aber auch bei dieser Änderung des Artenspektrums gibt es Verlierer und Gewinner, denn durch das andere Futterangebot auf den Äckern als auf den vorherigen Wiesen und Weiden hat sich die Fauna verändert.

Als besonders gravierend wird die optische Beeinflussung des Landschaftsbildes durch den Mais empfunden, weil niemand den deutlich über $2 \mathrm{~m}$ hohe Mais überblicken kann. Obgleich dieser Zustand nur höchstens ein Drittel der Vegetationszeit von Mais einnimmt, spielt er im Empfinden der Menschen doch eine große Rolle, weil diese Zeit mit der „optischen Behinderung " für einen ungehinderten Landschaftsgenuss genau in die Hauptjahreszeit des Spazierengehens fällt, von Juli bis September, je nach Körpergröße des Betrachters unterschiedlich lange. Dieses vom Mais verursachte Landschaftsproblem ist rein ästhetischer und nicht öko-

\footnotetext{
${ }^{1}$ Eigene Beobachtungen des Verf., die sogar eine Schwarzstorchsichtung umfasste.
} 
logischer Natur. Ein Flächenanteil von 24\% - wie in der Lachendorfer Flur - ist ökologisch als noch unbedenklich zu bewerten, da der Mais wie alle anderen Kulturpflanzen in Reinkultur ${ }^{1}$ innerhalb einer Fruchtfolge und nur in wenigen Fällen für einige aufeinander folgende Jahre in Monokultur angebaut wird. Dabei muss auch berücksichtigt werden, dass aus der Sicht der Bodenfruchtbarkeit mehrjähriger Maisanbau unproblematisch ist, weil Mais - übrigens wie Roggen - mit sich selbst verträglich ist. Problematisch ist ein exzessiver Maisanbau auf das Artenspektrum der Flora, weil alle anderen Pflanzen im Maisfeld meist radikal chemisch beseitigt werden. Problematisch ist der Mais auch hinsichtlich der Fauna, weil die Maisbestände vielen Tieren kaum Lebensraum bieten, dem Schwarzwild allerdings Deckung und Nahrung in einem Ausmaß, wie es hiesige Ackerflächen noch nie geboten haben.

Die Entwicklung der Landnutzung in der ehemaligen reinen Wiesenlandschaft der Lachendorfer Gemarkung entspricht also einem allgemeinen Trend zum reinen Ackerbaubetrieb als Folge des Strukturwandels der Landwirtschaft und in der Tendenz zu vermehrtem Maisanbau aufgrund der Agrar- und Energiepolitik. Dabei nutzt die Agrarwirtschaft die überaus günstigen Eigenschaften der Kulturpflanze Mais für eine hoch technisierte Produktionsweise.

\subsubsection{Reinkultur und Artenvielfalt}

In der Umweltdiskussion über Landwirtschaft wird häufig der Anbau in Monokultur kritisiert, obwohl richtigerweise Reinkultur gemeint ist. Kulturpflanzen werden aus Gründen der Bearbeitungsfähigkeit je Schlag in Reinkultur angebaut, was bei Mischkultur wesentlich schwieriger und ineffizienter ist. Bei den meisten der hiesigen Kulturpflanzen ist aber Reinkultur mit Fruchtwechsel verbunden, weil Pflanzen wie z.B. Kartoffeln und Zuckerrüben und besonders viele Gemüsearten keine Monokultur vertragen. Aus dem Anbau auf großen Feldern darf daher nicht auf Monokultur ${ }^{2}$ geschlossen werden.

Die einheitlich bestellten Gewanne der Dreifelderwirtschaft mit Flurzwang haben vermutlich ein einheitlicheres und monotoneres Landschaftsbild erzeugt als eine heutige Feldstruktur mit Reinkultur und einer größeren Anzahl von Feldfrüchten.

Abgesehen von einer verringerten Biodiversität im geschlossenen Wald im Vergleich mit der Offenlandschaft der Heiden und Hutungen hat die Wirtschaftsweise der bäuerlichen Gemischtwirtschaft auf den landwirtschaftlichen Nutzflächen in den letzten zwei Jahrhunderten eine Phase besonders hoher Biodiversität und damit ökologischer Vielfalt hervorgebracht. Diese Vielfalt im Artenspektrum und in vielen Fällen auch bei der Individuenzahl konnte vorher in der alten Agrarordnung aufgrund der Naturbedingungen und der aus Not und durch Raubbau erzeugten Mangelsituation nicht erreicht werden. Unter der heutigen Wirtschaftsweise kann die erreichte Vielfalt vermutlich wegen der eingesetzten Agrartechnik und der Betriebsstrukturen nicht aufrecht erhalten werden. Insbesondere der gezielte und sehr effektive Einsatz von Bioziden verringert den Bestand an Wildpflanzen mit unvermeidbaren Folgen auch für die Fauna. Dies wird besonders deutlich beim Einsatz von Neonikotinen ${ }^{3}$ im Pflanzenschutz und den daraus folgenden Problemen für die Bienen. Hier stehen sich nicht nur die verständlichen Wirtschaftsinteressen der Landwirte und der Imker gegenüber. Im Interesse aller ist es erforderlich, eine Umwelt zu erhalten, in der die für Natur und Mensch unverzichtbaren Bienen leben können.

\footnotetext{
${ }^{1}$ In der hiesigen Landwirtschaft ist es schon seit sehr langer Zeit üblich, einjährige Feldfrüchte in Reinkultur, d.h. pro Schlag nur eine Frucht, anzubauen und diese Reinkulturen in ein festes oder flexibles Fruchtfolgesystem einzufügen. Erst wenn eine einjährige Feldfrucht mehrere Jahre hintereinander auf demselben Schlag ohne Fruchtwechsel angebaut wird, kann man von Monokultur sprechen. Daher sind die Begriffe Monokultur und Reinkultur genau zu unterscheiden. Bei mehrjährigen Kulturpflanzen sollte man von Dauerkultur reden, bei denen ein jährlicher oder mehrjähriger Fruchtwechsel gar nicht möglich ist.

${ }^{2}$ vergl. H. Küster, Geschichte der Landschaft in Mitteleuropa, a.a.O., S. 357, wo eine solche Gleichsetzung vorgenommen und nicht zwischen Monokultur und Reinkultur unterschieden wird.

${ }^{3}$ s. Cellesche Zeitung, 19.7.2013, S. 8
} 


\subsubsection{Naturräumliche Einheiten und Artenvielfalt}

Die Entwicklung der Artenvielfalt und des Artenspektrums ist bezüglich der naturräumlichen Einheiten und ihrer Nutzung unterschiedlich zu bewerten:

Auf der Allerheide, dem Schwemmfächer der Lachte im Urstromtal, kann man ein Optimum annehmen für die Zeit um 1900, als es noch Heideflächen und bereits Aufforstungen gab, sodass das jeweils typische, aber sehr unterschiedliche Artenspektrum nebeneinander vorhanden war.

Die Ackergebiete auf den Geestplatten hatten vermutlich ihr Optimum hinsichtlich Artenvielfalt und -spektrum etwa zwischen 1950, als die Nährstoffversorgung der Böden wieder gegeben war, und 1970/80, als der Strukturwandel auch die Ackernutzung stärker zu verändern begann. Aufgrund der kleinen Ackerschläge, die aus der Zeit der reinen Pferdeanspannung stammten, gab es eine kleinräumige und enge Anpassung an die naturräumlichen Bedingungen und damit eine große Vielfalt im Landschaftsbild.

Die durch das Wirtschaftssystem ermöglichte hohe Biodiversität belegt beispielhaft die Aussage, dass „maximale Biodiversität keineswegs mit ökologischer Stabilität identisch ist." ${ }^{1}$ Die Kulturlandschaft einer bäuerlichen Gemischtwirtschaft bedarf einer dauerhaften und intensiven Pflege, die sich aus der Landnutzung ergeben muss bzw. diese für den Landwirt rentabel macht. Andernfalls werden die reproduktiven höher als die produktiven Kosten, was die Wirtschaftsweise langfristig unwirtschaftlich machen würde.

Die Wirtschaftsweise der spezialisierten Agrarwirtschaft nimmt wegen der größeren Schlageinheiten weniger Rücksicht auf kleinräumige naturräumliche Differenzierung. Damit kommt es zu einer geringeren landschaftlichen Vielfalt mit zwangsläufigen Auswirkungen auf Artenvielfalt und -spektrum.

Hinsichtlich des viel beklagten Rückgang der Artenvielfalt (Artenschwund ${ }^{2}$ ) in der heutigen Agrarlandschaft muss allerdings darauf verwiesen werden, dass die große Artenvielfalt, die als bedroht angesehen wird, nicht natürlich ist. Vielmehr ist sie kulturbedingt, denn sie wurde durch die Wirtschaftsweise der bäuerlichen Mischwirtschaft im Rahmen der natürlichen Standortbedingungen ermöglicht.

Wenn jede Kulturlandschaft das Ergebnis aus Zusammenspiel von natürlichen Standorten und Wirtschaftsweise ist, dann gilt das auch für die jeweilige Artenvielfalt und das je spezifische Artenspektrum.

\subsection{Natur-, Arten-, Landschaftsschutz}

Aus den bisherigen Darlegungen folgt, dass zwischen Wirtschaftsweise und Kulturlandschaft mehr als ein sehr enger Zusammenhang besteht. Jedes landwirtschaftliche Wirtschaftssystem bestimmt mit seiner je typischen Betriebsstruktur und zeitgenössischen Agrartechnik im Rahmen der vorgegebenen Naturbedingungen und herrschenden Agrarordnung ${ }^{3}$ die jeweils typische Agrarlandschaft, eine Kulturlandschaft sui generis. Das landwirtschaftliche Wirtschaftssystem bestimmt nicht nur das optisch erfassbare Landschaftsbild, sondern auch solche Faktoren, die gemeinhin als Naturfaktoren bezeichnet werden, wie Bodenfruchtbarkeit, Artenspektrum und Artenvielfalt. In einer land- und forstwirtschaftlichen Kulturlandschaft prägt die Landnutzung über ihren Eingriff in den Naturhaushalt und über „Manipulation“ von Naturfaktoren die Landschaft, die natürlich auch als Kulturlandschaft aus Natur besteht.

Weiter folgt aus dem engen Zusammenhang zwischen Wirtschaftsweise und Kulturlandschaft, dass eine Kulturlandschaft, im Gegensatz zu einer Naturlandschaft, durchaus stabil ist solange sich das Wirtschaftssystem nicht ändert. Dann und nur dann bleibt eine Kulturlandschaft ohne besondere Schutzmaßnahmen im Zuge der gerade üblichen Land- und Forstwirtschaft erhalten.

\footnotetext{
${ }^{1}$ J. Radkau; Die Ära der Ökologie, a.a.O., S. 589

2 s. NHB; Die Rote Mappe 2013, S. 9 ff

${ }^{3}$ Zur Agrarordnung sollte in diesem Zusammenhang auch die Agrarpolitik gezählt werden. Anm. d. Ver.
} 
Kulturlandschaften, zu denen es das zugehörige Wirtschaftssystem nicht mehr gibt, sind Reliktlandschaften. Sollen diese erhalten werden, bedarf es besonderer Pflegemaßnahmen, die die zugehörige Wirtschaftsweise fortsetzen, nachahmen oder mit anderen technischen Mitteln adäquat ersetzen.

Da Pflege- und Schutzmaßnahmen ein komplexes Wirtschaftssystem nicht vollständig ersetzen können, kann eine Kulturlandschaft als Reliktlandschaft nicht als Ganzes, weder flächenmäßig noch inhaltlich - bewahrt werden" ${ }^{1}$.

Bei der Umwandlung der Allerheide in Wald im 19. Jahrhundert hat es im Raum Lachendorf - soweit bekannt - keine Bestrebungen zum Erhalt der Heidelandschaft gegeben. Dafür gibt es mehrere Gründe, teils offenkundiger, teils spekulativer Art:

- Die Bauern waren an einer schnellen wirtschaftlich sinnvollen Nachnutzung der nicht mehr benötigten Heiden und Hutungen interessiert. Das Rittergut bzw. sein Besitzer ${ }^{2}$ verfügte über Mittel und Verbindungen für eine fachgerechte Aufforstung. Das hatte sicherlich Vorbildcharakter für den entstehenden Bauernwald.

- In der Südheide gab es nicht so große zusammenhängende Heideflächen wie auf den Endmoränenzügen der Zentral- und Nordheide. Die Allerheide umfasste zwar mit den angrenzenden Revieren eine große geschlossene Heidefläche, diese bildete aber neben dem Urstromtal mit seinen Randmooren und den fruchtbaren Geestinseln auf lehmiger Grundmoräne ${ }^{3}$ nur ein Landschaftselement, das nicht den Gesamtraum bestimmte.

- Anders als die Heideflächen in der Nordheide lagen die Heiden und Hutungen der Südheide nicht im Weichbild einer Groß- und Weltstadt (wie Hamburg), aus der Impulse und Mäzene für die Erhaltung der Heidelandschaft hätten kommen können. Auch Persönlichkeiten wie Pastor Wilhelm Bode in Egestorf ${ }^{4}$, die sich für den Erhalt der Heidelandschaft einsetzen konnten, weil sie davon wirtschaftlich nicht abhängig waren, sind in der Südheide nicht hervorgetreten.

- Als der Schutz der Heidelandschaft unter dem Begriff des Naturschutzes zu einem gesellschaftlich erstrebenswerten Ziel wurde, war die Allerheide bereits weitgehend aufgeforstet. Als gegen Ende des 20. Jahrhunderts in Lachendorf der Gedanke diskutiert wurde, für den Tourismus eine letztes Restfläche mit Heide, mitten im Kiefernforst gelegen und schon mit Kiefern durchsetzt, unter Schutz zu stellen, war es für die Schaffung eines Schutzgebietes, welches das ehemalige Landschaftsbild der Allerheide hätte bewahren können, bereits zu spät.

Als die Stauwiesen aufgegeben und in wenigen Jahren in Ackerland umgewandelt wurden, gab es auch keine nachhaltig wirkenden Bestrebungen des Landschaftsschutzes in der Form eines irgendwie ausgerichteten Naturschutzes.

Dies änderte sich aber mit der Umwandlung der Weiden und Wiesen in den Allerdreckwiesen. Hier war durch die Umwandlung von Grünland in Acker ein großes Feuchtgebiet bedroht, dass die bäuerliche Gemischtwirtschaft zu einer intensiv genutzten Wiesenlandschaft mit teilweisem Parkcharakter gestaltet hatte.

Die wirkliche Bedrohung für dieses sog. natürliche Grünland auf Anmoorböden waren allerdings die Flussbaumaßnahmen zur „Regulierung“ von Aller und Schwarzwasser. Dadurch wurde der Grundwasserstand abgesenkt und vor allem die großflächigen und nicht seltenen Überschwemmungen unterbunden. Ohne diese Maßnahmen wären die Dreckwiesen längst nicht im heutigen Umfang ackerfähig geworden. Die Landwirtschaft hat nur die neuen, vom Menschen gemachten Naturbedingungen im Rahmen der herrschenden Agrarwirtschaft genutzt.

\footnotetext{
${ }^{1}$ Vergl. dazu auch H.-J. Küster; Geschichte der Landschaft in Mitteleuropa, a.a.O., S. 366 ff.

${ }^{2}$ s. F. Friedrich, Papier aus Lachendorf, a.a.O., S. $82 \mathrm{ff}$

${ }^{3}$ Auch die sehr fruchtbare Bergener Flotsandinsel nördlich von Celle und westlich des Örtzetales wäre hier als ein Landschaftselement zu nennen, das nicht dem Typ der Heidelandschaft entsprach. Anm. d. Verf.

${ }^{4}$ s.a. P. Roux; Der Bauer in der Lüneburger Heide, Paris 1906, Deutsche Übersetzung: Ehestorf 1993
} 
Der südliche Lachendorfer Gemarkungsteil umfasst im Westen vorwiegend Flächen der sog. Trockenen Wiesen und greift nach Osten mit kontinuierlichem Übergang immer weiter in die Dreckwiesen vor, deren Zentrum dann in der östlich angrenzenden Ahnsbecker Gemarkung liegt. An dieser Bodensukzession von West nach Ost, von trockenen Talsanden zu Anmoorgleyen, hat sich auch die Umwandlung in Ackerland orientiert. Im Lachendorfer Gemarkungsteil gibt es nur noch ganz im Osten zusammenhängende Grünlandflächen. In der Ahnsbecker Gemarkung, im zentralen Teil der Dreckwiesen, ist es gelungen, ein Gebiet unter Schutz zu stellen.

An diesem Beispiel des Naturschutzgebietes „Allerdreckwiesen“ lässt sich sehr gut das Geflecht von Natur-, Arten- und Kulturlandschaftsschutz demonstrieren:

\section{Verordnung ${ }^{1}$ zum Naturschutzgebiet „Allerdreckwiesen“ (Auszug)}

\section{§ 2 Schutzzweck}

1) Sicherung und Entwicklung der landschaftlichen Eigenart der Allerdreckwiesen mit ausgedehnten offenen Grünlandbereichen, die mit Wäldern, Gebüschen, Hecken und Einzelgehölzen durchsetzt und dadurch reich strukturiert sind;

2) Erhaltung und Entwicklung des Gebietes als Rast-, Brut- und Nahrungsgebiet für Vögel, insbesondere der Wiesenvögel und des Weißstorchs;

3) Erhaltung, Förderung und Entwicklung- der durch Standort und extensive Nutzung geprägten Grünlandgesellschaften, insbesondere des Feuchtgrünlandes,

4) der naturnahen Gehölzbestände, insbesondere der Erlenbruchwälder,

5) der Röhrichte, Rieder und Hochstaudenfluren;

6) Erhaltung der im Gebiet wild vorkommenden Tier- und Pflanzenarten.

\section{§ 3 Verbote}

(Aufzählung von unzulässigen Aktivitäten, z.B. Zelten u.ä., Verlassen der Wege, frei laufende Hunde, Einbringen von Pflanzen und Tieren)

\section{§ 4 Zulässige Handlungen}

Die landwirtschaftliche Bewirtschaftung der privateigenen Grünlandflächen als Dauergrünland wie folgt:

a. ohne Umbruch und Neueinsaat außer der Nachsaat bei Wildschadenflächen,

b. ohne Anwendung von Bioziden,

c. ohne Walzen und Schleppen in der Zeit vom 1. April bis 30. Juni,

d. ohne weitergehende Entwässerung,

e. Mahd von innen nach außen oder von einer Seite zur anderen,

f. ohne Veränderung der Bodengestalt,

g. ohne Geflügelhaltung,

h. Düngung bis $80 \mathrm{~kg} \mathrm{~N} / \mathrm{ha}$ Mineraldünger pro Jahr, jedoch ohne Gülleausbringung,

i. Mahd ab 20. Juni eines jeden Jahres, soweit die Bezirksregierung Lüneburg nicht einem früheren Mahdzeitpunkt auf Antrag zugestimmt hat,

j. $\quad$ die landwirtschaftliche Bewirtschaftung der in der mitveröffentlichten Karte dargestellten privateigenen Ackerflächen ohne das Aufbringen von Klärschlamm; eine Beregnung ist mit Erlaubnis der Bezirksregierung zulässig; die einzelstammweise Holzentnahme aus privateigenen Waldflächen;

k. die ordnungsgemäße mechanische Unterhaltung der Gräben, soweit sie privateigene Wirtschaftsflächen entwässern;

"Natur gestalten, Wasser halten", das war der Grundgedanke bei unserem Projekt der Wiederver-

\footnotetext{
${ }^{1}$ Gekürzt und zusammengefasst aus: Amtsblatt der Bezirksregierung Lüneburg Nr. 4 vom 15.02.1994, S. 55;

Hervorhebungen durch Fettdruck vom Verf.
} 
nässung der Allerdreckwiesen. Fertig gestellt im Frühjahr 2009 ist es ein voller Erfolg. Über zwei Sandfänge, Betonleitungen, KG-Rohre und einen offenen Graben leiten wir das Wasser vom Ahnsbecker Kanal in die Wiedervernässungsfläche mit einer Größe von ca ,1 ha. "T

„Oberstes Ziel ist die Erhöhung der Artenvielfalt und Individuendichte aller gebietstypischen Arten. Dies soll idealerweise durch weitere Vernässungs- und Wasserrückhaltungsmaßnahmen und durch weitere Extensivierung landwirtschaftlicher Flächen erreicht werden. In dem Zusammenhang planen wir die Anlage von Grünlandbrachestreifen auf allen öffentlichen Ländereien im NSG. Auch Grabenstaue werden da, wo möglich, angestrebt. Die Artenvielfalt auf bestimmten Flächen der Öffentlichen Hand bestätigt schon jetzt, dass das Bewirtschaftungsmanagement zum Teil auf dem richtigen Weg ist.

Die landwirtschaftlichen Flächen der Öfftl. Hand werden ja verpachtet - jahrweise. Diese Flächen sollen bis auf wenige Ausnahmen weiterhin als Grünland extensiv genutzt werden. Als Ausnahmen sind Flächen zu verstehen, die gar nicht mehr bewirtschaftet werden sollten. So ist auch in der NSG-VO niedergeschrieben. ${ }^{2}$

In den Dokumenten ${ }^{3}$ werden die allgemeinen Ziele der Verordnung und die konkreten Ziele der betreuenden Naturschutzgruppe dargelegt. Die Landnutzung wird auf eine Form eingeschränkt, die Intensivierungen verbietet und ungefähr der Nutzung durch die bäuerliche Gemischtwirtschaft vor einigen Jahrzehnten entspricht, die heute als extensiv gilt, zu ihrer Zeit aber durchaus eine intensive Nutzung des Grünlandes als Weide oder als zweischürige Wiese zur Heuwerbung war. Während das Ziel des Schutzes bzw. Erhalts der Kulturlandschaft eher allgemein bzw. diffus in §2) festgelegt wird, gibt es zum Artenschutz - explizit zum Vogel- und Pflanzenschutz wesentlich konkretere Aussagen.

Die konkreten Maßnahmen der betreuenden NABU-Gruppe zielen auf eine Wiedervernässung von Teilflächen. $\mathrm{Da}$ aber wegen der dauerhaften wasserbaulichen Maßnahmen an Aller und Schwarzwasser der natürliche $\mathrm{Zu}$ stand nicht wieder hergestellt werden kann, erfolgt nun eine Vernässung ${ }^{4}$ aus dem Ahnsbecker Kanal ${ }^{5}$, einem Entwässerungskanal aus der nördlich gelegenen Geestplatte. Die zu vernässen-

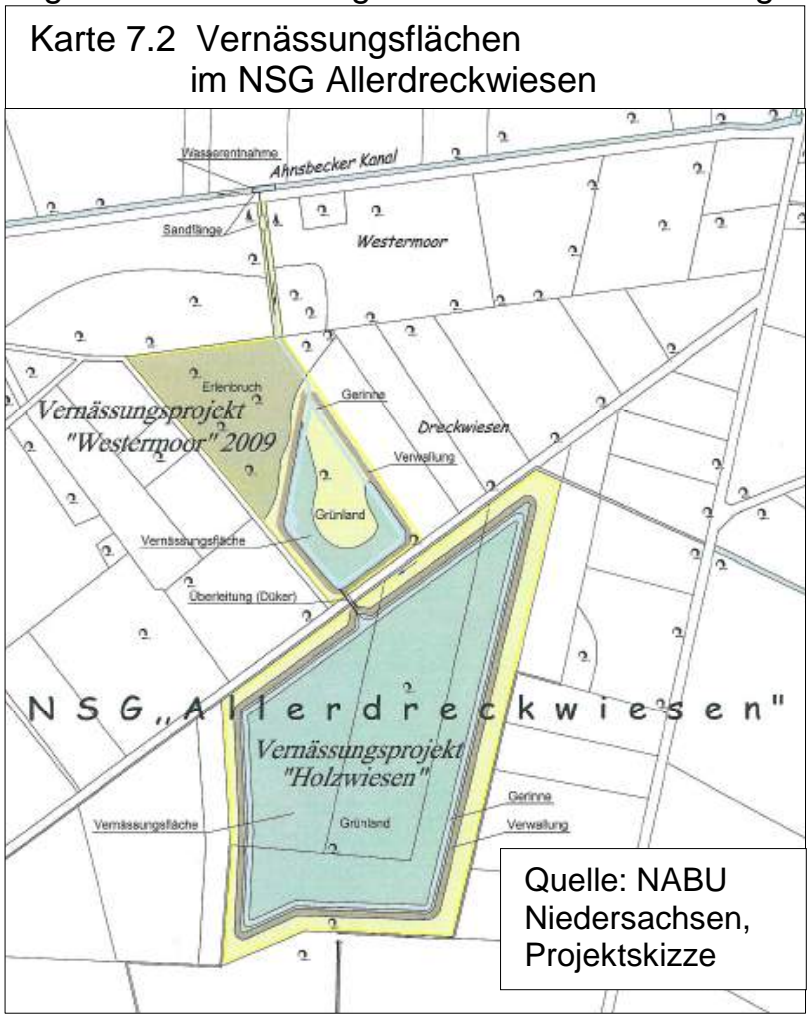
den Flächen werden mit einer Umwallung und einem innen verlaufenden Graben (Gerinne) versehen. Durch den Wasserzulauf aus dem Entwässerungsgraben, dessen Wasserführung vom Niederschlag und der Evaporation in dessen Einzugsgebiet abhängt, ergibt sich ein anderes hydrologisches Regime als ursprünglich über die Aller.

\footnotetext{
${ }^{1}$ http://www.nabu-lachendorf.de/projekte/wiedervern\%C3\%A4ssung-allerdreckwiesen/

${ }^{2}$ Schriftl. Mitteilung von Ulrich Pittius, NABU Lachendorf e.V., Oktober 2011

${ }^{3}$ Die Dokumente sind hier zusammengefasst und verkürzt beigefügt, soweit sie für die hier behandelte Thematik wichtig erscheinen.

${ }^{4}$ s. U. Pittius; Neues aus den Allerdreckwiesen, a.a.O., S. 36

${ }^{5}$ Dieser Entwässerungskanal ist bereits auf der Kurhan. Landesaufnahme von 1779 als „Neue Mohrs Grabe" verzeichnet.
} 
Optisch wurde das Landschaftsbild durch Verwallungen und Mulden, Einstellung der Grabenräumung bzw. Verfüllen von Gräben, Dauerbrachen und Schilfgalerien entlang verlandender Gräben verändert. ${ }^{1}$

Mit diesen Maßnahmen ist es zweifellos gelungen, das Landschaftsbild des Schutzgebietes stärker zu strukturieren sowie insbesondere die Biodiversität zu erhöhen. Das Schutzziel „Artenschutz“ konnte überzeugend erreicht werden, wie der Bericht ${ }^{2}$ aus dem Jahr 2013 mit Angaben zu Rast- und Brutvogelarten sowie dem verbesserten Futterangebot auf den Brachstreifen eindrucksvoll belegt. Der Vergleich mit der angrenzenden „Normallandschaft" ist aber nur normativ zulässig, denn eine Landschaftsveränderung zieht immer eine Veränderung des Artenspektrums nach sich, die nur aufgrund gesetzter Ziele und Normen bewertet werden kann. Innerhalb verschiedener Landschaften kann es kein naturgegebenes Ranking geben.

Was allerdings aufgrund der Maßnahmen, die im Artenschutz so erfolgreich sind, nicht erreicht werden kann, ist der Erhalt der „ursprünglichen“ Wiesenlandschaft. Das liegt einerseits an der Flächengröße, denn das Schutzgebiet kann trotz der beachtlichen Größe von 568 ha nicht das Landschaftsbild der Trockenen und Dreckwiesen erhalten, wie es bis in die 1960er Jahre bestanden hat. Ein Teil der o.g. Schutzmaßnahmen läuft auch direkt kontraproduktiv zu dem Ziel, die „alte“ Kulturlandschaft zu erhalten. Denn in der Kulturlandschaft aus Wiesen und Weiden aus der Wirtschaftsweise der bäuerlichen Gemischtwirtschaft gehören keine Verwallungen, keine Brachstreifen, keine Mulden und keine Schilfgalerien, weil all diese Landschaftselemente den dringend benötigten Nutzwert minderten. Zu diesem Kulturlandschaftsbild gehörten aber Stacheldrahtzäune, jährlich grundgesäuberte Gräben, grasendes Vieh auf der Sommerweide und ein bis zwei Grasschnitte im Jahr ohne Rücksicht auf Brutund Setzzeiten sowie Samenreife einzelner Pflanzenarten. Nutzung und Nutzzeiten richteten sich ausschließlich nach Jahreszeiten, der Witterung und den betrieblichen Arbeitsabläufen der bäuerlichen Wirtschaft.

Die Kulturlandschaft, deren Verschwinden heute bedauert wird und durch Schutzmaßnahmen aufgehalten bzw. verhindert werden soll, hat allerdings nur etwa ein Jahrhundert bestanden, nämlich zwischen den Reformen, die in den Aller- Trockenen Wiesen 1866 abgeschlossen waren, und den Wasserbaumaßnahmen sowie dem Strukturwandel der Landwirtschaft ab den 1960er Jahren.

Aus rein ökologischer Sicht ist die eine Form der Kulturlandschaft nicht „richtiger“, „,normaler“ oder „,besser“ als die andere. Dies gilt auch für die Landschaft, die sich aufgrund von Schutzmaßnahmen entwickelt, die auch eine Kulturlandschaft und keine Naturlandschaft ist. Wenn allerdings der Artenschutz, insbesondere der Vogelschutz für die Gruppe der Wiesenvögel, ein definiertes Ziel des Naturschutzgebietes „Allerdreckwiesen“ ist, dann ist das Projekt als höchst erfolgreich zu beurteilen! Der Naturschutz schafft im Naturschutzgebiet „Allerdreckwiesen" auch eine eigene Kulturlandschaft, die sich aufgrund der in der Landschaft durchgeführten Maßnahmen bzw. Eingriffe herausbildet.

Wenn man Naturschutz nicht auf die Extremform „Natur Natur sein lassen“ beschränkt, muss es - explizit festgelegt oder intuitiv erfasst - eine Idee oder einen Plan geben, was man schützen will und wie sich das Objekt entwickeln bzw. welcher Zustand angestrebt werden soll. Hinter den Schutzmaßnahmen muss also ein Schutzziel stehen, sonst kann es keine Übereinkunft über das umzusetzende Maßnahmenbündel geben. Schutzmaßnahmen zielen in der Regel auf einen zu erreichenden Endzustand, sie streben also einen stabilen Zustand der Landschaft an. Damit erfüllt zielabhängiger Naturschutz das wichtigste Kriterium einer Kulturlandschaft, nämlich das Streben nach Stabilität, ganz im Gegensatz zur Natur, die eben gerade nicht stabil sondern auf Veränderung ausgerichtet ist.

Aus diesem Gesichtswinkel unterscheidet sich Naturschutz prinzipiell weder von der Arbeit eines Gärtners bei der Gestaltung eines Parks noch von der Arbeit des Land- oder Forstwirts. Alle betreiben zielgerichtete Landnutzung durch selektive Eingriffe in die Natur der

\footnotetext{
${ }^{1}$ s. U. Pittius, a.a.O., S. 37

${ }^{2}$ ebenda, S. $35 \mathrm{ff}$

${ }^{3}$ ebenda, S. 37 (Der Begriff „Normallandschaft“ steht auch im Originaltext in Anführungsstrichen.)
} 
Landschaft. Die Unterschiede liegen im Zweck der jeweiligen Landnutzung: Für Land- und Forstwirte ist der Zweck ihrer Landnutzung die Produktion für die Selbstversorgung und den Markt, für den Landschaftsarchitekten, der einen Park gestaltet, ist es die perfekte Gestaltung der Natur nach rein optisch-ästhetischen Gesichtspunkten, für den Naturschützer ist es eine bestimmte Natur, die z.B. durch ein bestimmtes Artenspektrum, bestimmte Ökotope oder auch durch die Lebensraumansprüche einer einzigen Art charakterisiert sein kann.

Bei jeder dieser Formen von Landnutzung und Landschaftsgestaltung gibt es zwangsläufig Auswirkungen auf die Biodiversität, immer mit Gewinnern und Verlierern. Jede Form der Landnutzung beruht auf selektiven, nicht aus der Natur abgeleiteten und auch nicht ökologisch begründbaren, Eingriffen in den Landschaftshaushalt.

Jede sorgsame und auf Nachhaltigkeit ausgerichtete Landnutzung, sowohl in der Land- und Forstwirtschaft so auch in Parks und Schutzgebieten, schützt Natur, direkt durch gezielte Eingriffe zur Erreichung der eigenen Ziele und indirekt durch unbeabsichtigte Folgewirkungen in der jeweils gestalteten Kulturlandschaft.

So hat eben jede Landnutzung Kollateralwirkungen positiver und negativer Art. Dabei enthält die Einstufungen in positive und negative Auswirkungen bereits wieder eine Werteskala, die sich ökologisch weder ableiten noch begründen lässt ${ }^{1}$.

Ziele und Zwecke unterschiedlicher Landnutzung induzieren natürlich unterschiedliche Interessen, die bei gegensätzlichen Zielen und Zwecken zu mehr oder minder schweren Konflikten führen (können). Auch diese Konflikte basieren oft nicht oder nicht nur auf ökologischen Faktoren.

Auch dazu liefert die Gemarkung Lachendorf zwei interessante Beispiele:

Ziel und Zweck des Naturschutzes in den Allerdreckwiesen ist einmal der Artenschutz, zum anderen aber ein ästhetisches Ziel, nämlich die Erhaltung der als besonders „schön“ empfundenen Wiesenlandschaft als parkähnliche Offenlandschaft. Dieses Ziel steht im klaren Widerspruch zum Interesse der Landwirtschaft, statt wenig oder unrentabler Grünlandwirtschaft ertragreichen, weil subventionierten Ackerbau zu betreiben. Die Unterschutzstellung eines Teilgebietes der Allerdreckwiesen sichert das Naturschutzziel gegenüber den Interessen der Landwirtschaft.

Als die Siedlungserweiterung auf dem Rändern der Geestplatten unwiederbringlich wertvollen Ackerboden der landwirtschaftlichen Produktion entzog, gab es - soweit bekannt - keine Bemühungen, aus wichtigen ökologischen und ökonomischen Gründen diese Ackerböden unter Schutz zu stellen und sie der hergebrachten Nutzung zu erhalten.

In beiden Fällen handelt es sich um landwirtschaftliches Kulturland, das aus ökologischer Sicht gleichermaßen schützenswert gewesen wäre. Die Böden der Geestplatten wären als Ackerland sogar aus ökonomischer Sicht schützenswert, sie haben aber keine Lobby gefunden. Der Schutz von Wiesenvögeln in einer als schön empfundenen Landschaft findet stärkere Beachtung als der Schutz von Pseudogleyen auf glazialer Grundmoräne. Die hier in der Gegenüberstellung bewusst gewählten Begriffe beleuchten, wie stark die Bewertung von Schutzgütern der Natur emotional bedingt ist. „Das liegt wohl daran, dass man ein Problem wie Artenschwund leichter vermitteln kann. Bilder von wunderschönen, bedrohten Tieren und Pflanzen berühren uns. Aber Boden? Der sieht für viele Menschen nur aus wie Dreck." ${ }^{2}$

\subsection{Zukunft der Lachendorfer Kulturlandschaft}

Die weitere Entwicklung der Kulturlandschaft in der Gemarkung Lachendorf und angrenzender Gemarkungen mit ähnlicher Struktur hängt von der Entwicklung der gesellschaftlichen, wirtschaftlichen und politischen Rahmenbedingungen ab.

Die Agrarstrukturelle Vorplanung von 1972 prognostiziert: „Von der gesamten Fläche des Untersuchungsraumes werden noch $90 \%$ land- und forstwirtschaftlich genutzt. An diesem Zustand wird sich in absehbarer Zeit nichts ändern, so daß auch in Zukunft die Land- und Forstwirtschaft das Gesicht dieses östlichen Teiles des Landkreises Celle prägen wird.“3

\footnotetext{
${ }^{1}$ vergl. J. Radkau; Die Ära der Ökologie, a.a.O., S. 582

2 J. Flasbarth im Interview zum Thema: Wir verlieren den Boden; in: Die Zeit, Nr. 26, 22.6.2011, S. 39

${ }^{3}$ Nahbereich Lachendorf, Agrarstrukturelle Vorplanung, a.a.O., S. 88
} 
Im Gegensatz zur Prognose über die Entwicklung der Betriebszahlen hat sich bis jetzt diese Vorhersage bestätigt: Das Landschaftsbild der Gemarkung Lachendorf wird weiterhin ganz wesentlich durch die Land- und Forstwirtschaft geformt und bestimmt. Hinzu gekommen sind zwei weitere Akteure mit Landschaft prägender Wirkung ganz unterschiedlicher Art und Wirkung: Siedlung und Naturschutz.

Die ausgedehnten Waldflächen auf dem Schwemmfächer und entlang des Lachtetales unterhalb des Ortes werden sich nach Lage und Ausdehnung voraussichtlich nicht ändern, einmal weil die Umnutzung von Wald gesetzlichen Regelungen unterliegt, zum anderen weil die Böden auch bei großer Nachfrage nach Ackerland keinen Anreiz zur Kultivierung bieten. Der nicht unbeträchtliche staatliche Waldanteil (ehemals Klosterforst Miele) ist sicherlich dauerhaft als Wald bzw. Forst gesichert. In den Wäldern wird es eine dauernde Sukzession nach Bestandsalter und Umtrieb geben. Ob es einen Umbau der Nadelholzforsten zu mehr naturnahem Baumbestand geben wird, hängt von der staatlichen Forstpolitik und den Holzpreisen ab. Einen rein ökologisch ausgerichteten Umbau wird es aus Kostengründen kurzfristig weder in den Staats- noch in den Privatwäldern geben. Je nach Menge des hiebreifen Holzes und der Holzpreise hat der Wald eine nicht unwichtige ökonomische Bedeutung, insbesondere für auslaufende landwirtschaftliche Betriebe, die die Waldbewirtschaftung auch nach Betriebsaufgabe mit Hilfe der Forstbetriebsgemeinschaft weiter betreiben können.

Das große zusammenhängende Waldgebiet der Allerheide auf den Sanden des Schwemmfächers ist heute als eine standortgemäße Landnutzung einzustufen, die - außer am westlichen und südwestlichen Siedlungsrand - nicht mit anderer Landnutzung konkurriert.

Die Erholungsfunktion dieser Waldfläche ist aber trotz der Nähe zu Lachendorf und auch zu Celle aber als sehr begrenzt einzustufen, einmal wegen der ausgedehnten Kiefernforsten mit nur wenigen Sichtachsen, vor allem aber auch wegen des flachen Reliefs, das keine Plätze mit Aus- oder Landschaftsübersicht ermöglicht. Als Wander- und Erholungsgebiet fehlt diesen Waldflächen eine strukturierte Offenheit, die gleichzeitig das Gefühl von Schutz und Übersicht bietet. Die Waldflächen auf der Allerheide - obgleich auch Kulturland - bieten aber nicht die stark gegliederte Offenheit und Lieblichkeit einer gepflegten und positiv bewerteten Kulturlandschaft. Dichte, geschlossene Wälder werden eher als Bedrohung empfunden. ${ }^{1}$

Aufgrund der Wald- und Landschaftsstruktur böte nur der Wald an der Lachte unterhalb des Ortes die besten Voraussetzungen für die Erholungs- und Erlebnisfunktion des Waldes, denn dort gibt es Misch- und Laubwald, z.T. mit reichem und vielfältigem Unterwuchs beiderseits des Flusslaufes, der mit seinem wenig begradigten Lauf und abwechslungsreichen Mäanderbögen einen naturnahen Eindruck vermittelt und immer wieder überraschende und abwechslungsreiche Blicke über die Lachte und die Aue erlaubt.

Zu den Ackerflächen stellt die Agrarstrukturelle Vorplanung richtig fest: „Alle für eine Ackernutzung geeigneten Flächen sind ihrer günstigen Standorte wegen schon seit ewigen Zeiten für den Ackerbau in Anspruch genommen." ${ }^{2}$ Das Ackerland wird sich - wie in den vergangenen Jahrhunderten - als stabiles Element der Kulturlandschaft erweisen, soweit es nicht durch Siedlung, Verkehr oder Gewerbe in Anspruch genommen wird.

Die Grünlandflächen - ehemalige und noch vorhandene - müssen aufgrund der sehr unterschiedlichen natürlichen Standorte differenziert betrachtet werden.

Das Grünland auf dem Kleinen Moor am Ostrand des Dorfes und die Weiden westlich des Trockenwiesenweges südlich des Ortes scheint gesichert, solange es noch Betriebe mit Rindviehhaltung und Pferdezucht gibt, die dieses Grünland als Weide nutzen. Sollten diese Betriebe aufgeben, könnte dies Grünland auch in Acker umgenutzt werden. Die Weiden am Ostrand des Ortes kämen auch für eine Siedlungserweiterung in Frage, weil sie unmittelbar an die bisherige Siedlung anschließen und an der Straße nach Ahnsbeck und Bunkenburg

\footnotetext{
${ }^{1}$ s. B. Köhler und A. Preiß, Informationsdienst Naturschutz Niedersachsen, 1/2000, S. 30

${ }^{2}$ Nahbereich Lachendorf, Agrarstrukturelle Vorplanung 1972, a.a.O., S. 95
} 
verkehrsgünstig liegen. Damit würde allerdings auch der Ostrand des Ortes seinen bisher noch erhaltenen dörflich-ländlichen Charakter endgültig verlieren.

Das Grünland in den Trockenen und Allerdreck-Wiesen befindet sich, wie bereits dargelegt, seit wenigen Jahrzehnten in einem grundlegenden Wandlungsprozess, der noch nicht abgeschlossen ist. Der Trend zum Ackerbau könnte großflächig nur durch einen Rückbau der Aller- und Schwarzwasserregulierung aus den 1960er Jahren erreicht werden, weil dann größere Landschaftsteile wie in den vergangenen Jahrhunderten nicht ackerfähig wären. Diese Entwicklung scheint aber derzeit absolut unvorstellbar und unrealistisch.

Eine Rücknahme der Ackerfähigkeit durch wasserbauliche Maßnahmen hätte aber nicht automatisch und zwingend die Rückkehr zur Wiesenlandschaft zur Folge, wie sie bis in die 1960 er Jahre bestanden hat. Eine Rückkehr zur Wiesenlandschaft setzte eine landwirtschaftliche Struktur voraus, die dieses Grünland brauchen würde und es wirtschaftlich nutzen könnte. Andernfalls käme es zum Brachfallen von ungenutztem Grünland, das von den landwirtschaftlichen Betrieben aufgrund der Hydrologie nicht umgenutzt werden könnte.

Das Brachfallen hätte eine natürliche Sukzession zu standortgemäßen Waldgesellschaften zur Folge. Dann gäbe es nur zwei Möglichkeiten der Landschaftsgestaltung: Natur Natur sein lassen, also jedweden Eingriff zu unterlassen, oder es als Naturschutzgebiet mit einem bestimmten Schutzziel zu entwickeln und dann dauerhaft zu pflegen.

Realistischerweise kann man annehmen, dass die Trockenen Wiesen in absehbarer Zeit völlig ackerbaulich genutzt werden, dass die Dreckwiesen - soweit es der Boden und die Besitzverhältnisse zulassen - in Ackerland umgewandelt und dass Reste der Dreckwiesen als Naturschutzgebiet mit den Zielen Artenund Landschaftsschutz genutzt werden. Die Umwandlung in Ackerland ist dabei auch davon abhängig, wie stark sich die wasserbaulichen Maßnahmen auf das Grundwasserregime auf Dauer auswirken, weil das ursprüngliche Niedermoor durch Trockenlegung einer Mineralisierung unterliegt. Dieser Prozess wiederum führt zu günstigeren Bedingungen für Ackerbau. Aus den lange Zeit als „absolutes Grünland" geltenden Dreckwiesen ist aufgrund wasserbaulicher Maßnahmen und den Möglichkeiten der Agrarwirtschaft potenzielles Ackerland geworden. Die Agrarstrukturelle Vorplanung von 1972 hat diesen Prozess des Nutzungswandels weder hinsichtlich des bisher erfolgten Ausmaßes noch hinsichtlich der angebauten Feldfrüchte ${ }^{1}$ vorhergesehen. Das liegt zweifellos daran, dass die Prognose von 1972 die Schnelligkeit des betrieblichen Struk-

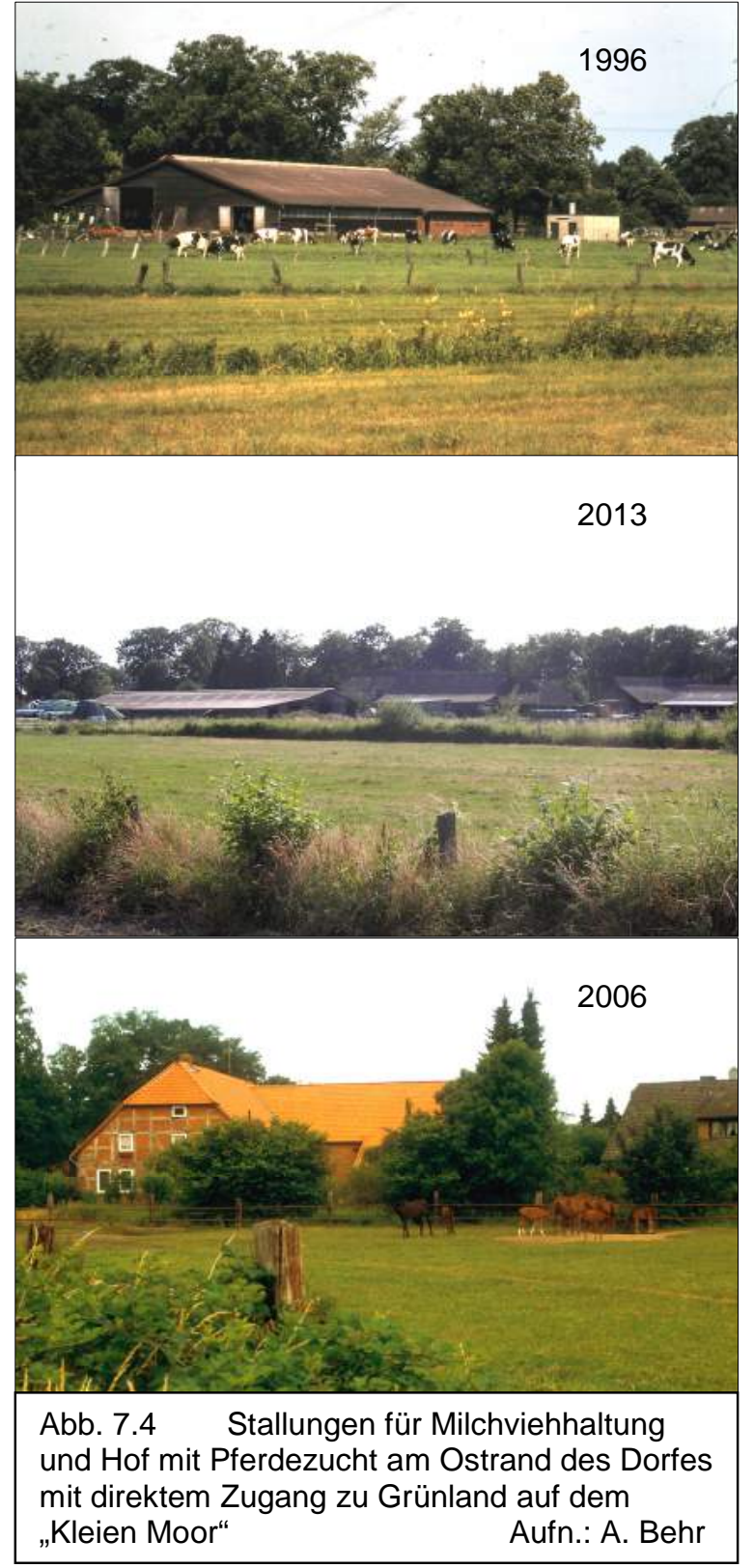

\footnotetext{
${ }^{1}$ ebenda, S. 96
} 
turwandels unterschätzt hat und die Entwicklung des Maisanbaus als Futter- und Energiepflanze nicht vorhersehen konnte.

Die Allerdreckwiesen haben teilweise ihren besonderen Landschaftscharakter verloren und damit auch einen hohen Wert für Freizeit und Erholung eingebüßt, obgleich die Weite des Landschaftsbildes erhalten blieb.

Wieder anders ist das Grünland in der Lachteaue zu beurteilen: Aufgrund des betrieblichen Strukturwandels ist es als Grünland nicht mehr von existenzieller Bedeutung für die Landwirtschaft. Andererseits ist es aber auch nicht ackerfähig wegen des Grundwasser- und Abflussregimes in der Talaue des Lachtetales. Derzeit wird es noch als Weide für Jungvieh von den Betrieben mit Viehwirtschaft und durch Mutterkuhhaltung eines Ackerbaubetriebes genutzt. Die Zukunft dieser Nutzungsformen ist aber durchaus nicht gesichert. Eine Nutzungsaufgabe in der Flussaue würde ohne Pflegemaßnahmen auch zu einer natürlichen Sukzession mit Verbuschung und Wiederbewaldung führen. Dies hätte vermutlich kurzfristig eine erhöhte Biodiversität zur Folge, die aber langfristig nicht erhalten bliebe, weil sich dominante Arten - schon aufgrund von Lichtkonkurrenz - flächenhaft durchsetzen würden. Eine Verbuschung der Aue würde auch das Abflussregime erheblich beeinflussen und die Überschwemmungen in der Aue vermutlich erhöhen und sicherlich verlängern.

Die Agrarstrukturelle Vorplanung hat für die Lachteaue einen interessanten Vorschlag gemacht, nämlich die Umwandlung der Lachtewiesen in Wasserflächen. „Dadurch würde man den Erholungswert der Landschaft erheblich verbessern“ und „auch das Problem der fortschreitenden Verwilderung ${ }^{1}$ könnte damit gelöst werden“ " 2 . Durch das 2009 eingerichtete Naturschutzgebiet „Lachte“ ist diese Option der Landnutzung allerdings hinfällig geworden. Dies Naturschutzgebiet „Lachte“ umfasst die gesamte Talaue der Lachte und ist mit den angrenzenden Naturschutzgebieten „Frembeck“, „Lutter“, „Obere Lachte, Kainbach, Jafelbach“ sowie dem "Schweinebruch" vernetzt. ${ }^{3}$ Das NSG ist Zeil des Europäischen Ökologischen Netzes „Natura 2000“ und FFH-Gebiet. ${ }^{4}$

Schutzgegenstand ist die Lachte als naturnaher Heidebach am Südrand der Lüneburger Heide ... und die meist schmale Niederung der Lachte ${ }^{5}$. Das Naturschutzgebiet erstreckt sich entlang der Lachte oberhalb und unterhalb der Lachendorfer Gemarkung. Viele der aufgeführten besonders schützenswerten Lebensgemeinschaften und Biotope liegen außerhalb dieser Gemarkung. Hier soll nur auf die landwirtschaftlichen Nutzflächen im Naturschutzgebiet eingegangen werden, weil sie für die Entstehung und den Fortbestand der Kulturlandschaft entscheidend sind.

In § 2 (2) heißt es: „Allgemeiner Schutzzweck für das NSG ist die Erhaltung, Pflege und naturnahe Entwicklung der Lachte, ihrer von naturraumtypischen Überschwemmungen geprägten Bachniederung und angrenzender Bereiche als Lebensstätte schutzbedürftiger Tier- und Pflanzenarten und deren Lebensgemeinschaften sowie als Landschaft von Seltenheit, besonderer Eigenart, Vielfalt und herausragender Schönheit.

Besonderer Schutzzweck (Erhaltungsziele) für das NSG im FFH-Gebiet ist die Erhaltung oder Wiederherstellung eines günstigen Erhaltungszustandes durch

1. den Schutz und die Entwicklung insbesondere von

$\ldots$

e) artenreichen, mageren Wiesen, artenreichem Feuchtgrünland sowie Pfeifengras-Wiesen,

§ 4 Freistellungen

(3) Freigestellt ist die ordnungsgemäße landwirtschaftliche Bodennutzung nach guter fachlicher Praxis auf den in der maßgeblichen Karte dargestellten Flächen und nach folgenden Vorgaben:

1. die Nutzung der in der maßgeblichen Karte mit Kreuzschraffur dargestellten Ackerflächen,

2. die Umwandlung von Acker in Grünland und die anschließende Nutzung gemäß Nummer 3,

\footnotetext{
${ }^{1}$ Natürliche Sukzession unter dem Ziel „Natur Natur sein lassen“ wird in einer Kulturlandschaft gemeinhin als Verwilderung bezeichnet, worin eine rein optisch-ästhetische Bewertung von Landschaft zum Ausdruck kommt.

${ }^{2}$ Nahbereich Lachendorf, Agrarstrukturelle Vorplanung, a.a.O., S,. 96/97

${ }^{3}$ Verordnung über das Naturschutzgebiet „Lachte“ ..., § 1); Nieders. Landesbetrieb für Wasserwirtschaft, Küsten- und Naturschutz, Hannover, den 27.3. 2009

${ }^{4}$ ebenda, §2 (4)

${ }^{5}$ ebenda, § $2(1)$
} 
3. die Nutzung der in der maßgeblichen Karte punktiert dargestellten Dauergrünlandflächen

a) ohne Behandlung mit chemischen Pflanzenschutzmitteln; zulässig ist die partielle Bekämpfung von Problemkräutern,

b) ohne Veränderung der Bodengestalt,

c) ohne Ausbringung von Jauche oder Gülle auf einem10 m breiten Streifen parallel zur Böschungsoberkante der Lachte,

d) ohne Erneuerung der Grasnarbe durch Umbruch, zulässig sind Über- oder Nachsaaten, auch im Scheiben oder Schlitzdrillverfahren sowie die Beseitigung von Wildschäden durch Fräsen oder Schlegeln und Neueinsaat der Schadstellen; bei einem Wildschadensanteil von mehr als $50 \mathrm{v}$. H. eines Schlages sind diese Maßnahmen zur Beseitigung von Wildschäden nach Anzeige bei der zuständigen Naturschutzbehörde auf dem ganzen Schlag zulässig,

e) ohne ackerbauliche Zwischennutzung,

4. die Unterhaltung und Instandsetzung bestehender Entwässerungseinrichtungen ohne die Anlage zusätzlicher Entwässerungseinrichtungen,

\& 6 Pflege- und Entwicklungsmaßnahmen

(2) Dem Schutzzweck dienende Maßnahmen können - soweit erforderlich - in einem Pflege- und Entwicklungsplan für das NSG dargestellt werden. ${ }^{1}$

Das Naturschutzkonzept für die Lachteaue zielt - wie das Konzept für die Allerdreckwiesen auf Artenschutz und Biodiversität. Das Konzept ist ganz wesentlich auf die Erhaltung einer Landschaft ausgerichtet, wie sie durch die bäuerliche Gemischtwirtschaft seit Mitte des 19. Jahrhunderts entstanden ist. Auch dieser Naturschutz zielt auf die Stabilisierung und dauerhafte Erhaltung einer Kulturlandschaft, deren zugehörige Wirtschaftsform weitgehend nicht mehr wirksam ist.

So lange landwirtschaftliche und auch forstwirtschaftliche Landnutzung gewillt ist. sich ökonomisch in der Lage sieht oder dazu durch Ausgleichszahlungen angehalten werden kann, die Nutzungsauflagen, die im Naturschutz „Freistellungen“ sind, zu erfüllen, kann das Konzept erfolgreich sein und die gewünschte Form der Kulturlandschaft erhalten. Sollten diese Voraussetzungen nicht mehr gegeben sein, müsste für die Erhaltung ein neues Pflegekonzept einschließlich Finanzierung aufgestellt werden oder das Gebiet müsste der natürlichen Sukzession überlassen werden. Beide Konzepte wären Naturschutz, allerdings mit Zielen, die sich gegenseitig ausschließen, und mit ganz unterschiedlichen Landschaften.

Die Kulturlandschaft der Gemarkung Lachendorf - und die angrenzenden Räume der Mittleren Südheide zwischen Örtze und Ise sowie das Mittlere Allertal zwischen Gifhorn und Celle - wurde noch vor 200 Jahren flächendeckend allein von der Landnutzung der Bauern geprägt. Selbst die Dörfer mit inren Angerflächen für Futter und den Eichen für Schweinemast, Bau- und Brennholz waren von dieser Wirtschaftsweise bestimmt und damit integrale Bestandteile der damaligen Kulturlandschaft.

Ab Mitte des 19. Jahrhunderts kam es zur Trennung von Wald und Landwirtschaftlicher Nutzfläche, in der es auch zur exakten Trennung von Acker und Grünland kam. In der Landwirtschaftlichen Nutzfläche führte die bäuerliche Gemischtwirtschaft zu einem Optimum der Biodiversität sowohl bei Nutzpflanzen und -tieren wie auch in der „wilden“ Flora und Fauna.

Gegen Ende des 20. Jahrhunderts wurde der Raumanspruch für Siedlung, Verkehr und Gewerbe zunehmend größer und die moderne Agrarwirtschaft bewirkte teils gravierende Veränderungen in der überkommenden Kulturlandschaft. Diese Entwicklung brach dem Naturschutz Bahn, der sich zu einer wichtigen Gestaltungskraft der Landschaft entwickelte.

In der gegenwärtigen Kulturlandschaft konkurrieren mit jeweils großen Raumansprüchen und unterschiedlichen, teils konträren Ansprüchen und Zielen die Menschen mit ihren differenzierten Bedürfnissen, die Land- und Forstwirtschaft und der Naturschutz um den einen gemeinsamen, nicht vermehrbaren Raum. Aus dem Zusammenspiel dieses Mit- und Gegeneinanders von Nutzungsinteressen und Nutzungskonflikten entsteht aus der tradierten eine

\footnotetext{
${ }^{1}$ Verordnung über das Naturschutzgebiet „Lachte“ ..., § 1); Nieders. Landesbetrieb für Wasserwirtschaft, Küsten- und Naturschutz, Hannover, den 27.3. 2009, Hervorhebungen durch Fettdruck vom verf.
} 
neue Kulturlandschaft, in deren Strukturen sich die naturräumliche Gliederung des Raumes nicht mehr so deutlich abbildet, wie das in vorindustriellen Kulturlandschaften der Fall war.

Aus der Landschaft mit dominanter Heide, Ackerflächen und großen Grünlandarealen wurde eine Wald-Acker-Grünland-Landschaft in der Zeit zwischen 1850 und etwa 1970. Diese bäuerliche Kulturlandschaft entwickelt sich seither zunehmend zu einer Wald-AckerbauLandschaft mit einem prägenden Flächenanteil Siedlung und Infrastruktur.

Die heutige Siedlung prägt die Kulturlandschaft ganz neu und wesentlich stärker als das Dorf in früheren Zeiten, sowohl hinsichtlich der flächenhaften Ausdehnung wie auch im Grundriss und ganz besonders im Aufriss, also in der optischen Wahrnehmung des Ortsbildes.

Durch die sehr flächenintensiven Erweiterungen für Wohnen, Versorgung und Gewerbe ist die Siedlungsfläche zu einem bestimmenden Faktor in der Kulturlandschaft geworden.

Der Ort hat seinen Charakter als „Bauerndorf mit Papierfabrik“ verloren hat und ist zu einem Grundzentrum mit den Hauptfunktionen Wohnen und Bildung sowie mittelzentralen Teilfunktionen im Dienstleistungsbereich geworden.

Das ehemalige Bauerndorf hat auch heute noch im alten Ortskern aufgrund älterer Bausubstanz und großer Gartengrundstücke und den nicht mehr und noch bewirtschafteten Bauernhöfen teilweise noch dörflichen Charakter. Aber eine wesentliche Veränderung im alten Dorfkern mit den Bauernhöfen hat bereits begonnen, wird sich aber noch fortsetzen und gerade diesen Dorfteil besonders stark verändern: Durch die Aufgabe zahlreicher Bauernhöfe verlieren ganze Gehöfte ihre wirtschaftliche Bedeutung und damit ihren Wert. Wohngebäude können meist umgenutzt werden, aber für die bäuerlichen Wirtschaftsgebäude gibt es nur selten günstige Nachnutzungen. Ohne wirtschaftlich tragfähige Nachnutzung ist aber ein Erhalt dieser Gebäude auf Dauer unmöglich. Verfall und Abriss können in einer Übergangszeit Teile des Dorfes prägen. Aktive Bauernhöfe müssen aus betriebswirtschaftlichen und finanziellen Gründen neue, moderne Wirtschaftsgebäude errichten, die sich im Baustil völlig von den traditionellen Fachwerkbauten unterscheiden.

Durch moderne Bausubstanz auf sehr kleinen Grundstücken in Neubaugebieten, durch das moderne Ortszentrum sowie die Bausubstanz im Gewerbe- und Dienstleistungsgebiet ist in den nicht bäuerlich geprägten Ortsteilen der dörfliche Charakter bereits weitgehend verloren gegangen.

Das Siedlungsbild des Dorfes hat sich im Laufe der letzten 5 - 7 Jahrzehnte im Vergleich zu den anderen Landschaftselementen am stärksten verändert.

Diese Veränderung wird weitergehen, weil das traditionelle bäuerliche bzw. landwirtschaftliche Element im Ortsbild weiter abnehmen wird. Einerseits wegen der weitergehenden Konzentration in der Landwirtschaft, im Ortsbild aber besonders deshalb, weil die traditionellen Bauernhöfe in Zukunft ihr Gesicht mit modernen Wirtschaftsgebäuden stark verändern werden.

Die Kulturlandschaft außerhalb des Ortes wird sich entsprechend der wirtschaftlichen Entwicklung und der zukünftigen Raumnutzung durch Land- und Forstwirtschaft, durch Tourismus und Freizeitgestaltung sowie Naturschutz verändern.

Das Beispiel verdeutlicht, dass eine Kulturlandschaft sich im Zuge allgemeiner wirtschaftlicher und gesellschaftlicher Entwicklung zwangsläufig auch verändern wird und muss.

Eine flächendeckende Erhaltung einer Reliktlandschaft ist weder wirtschaftlich möglich noch ökologisch notwendig. 

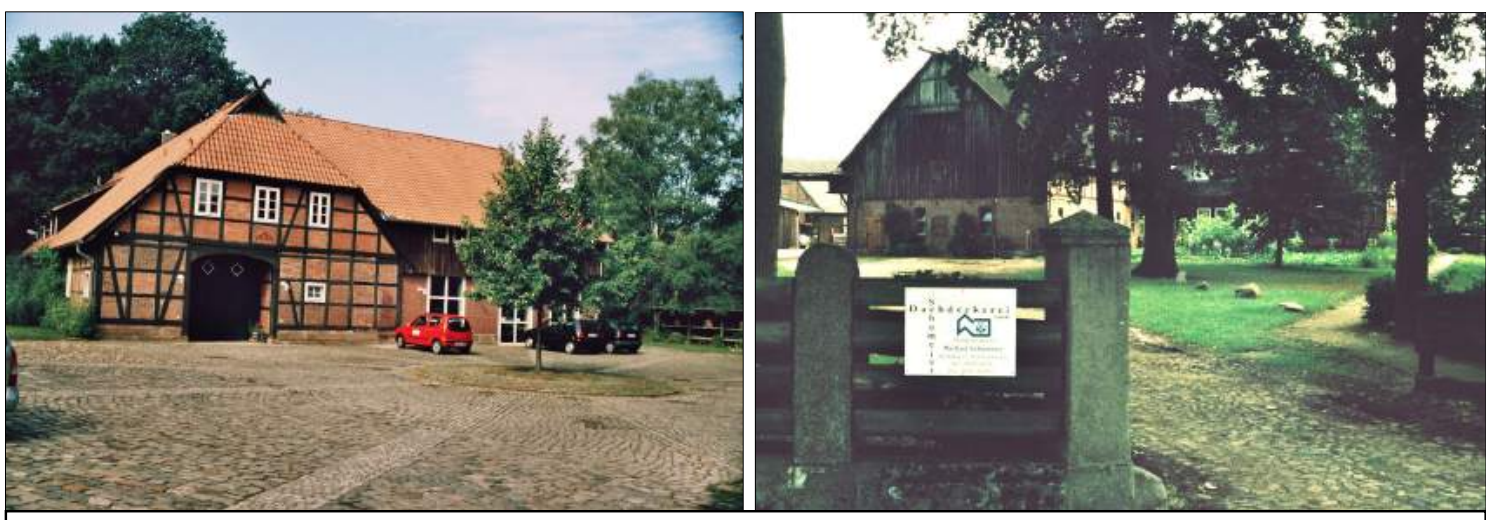

Abb. 7.5 Umnutzung von bäuerlichen Anwesen: links: Veranstaltungszentrum der Gemeinde; rechts: Gewerbebetrieb (Dachdecker); Aufn.; A. Behr
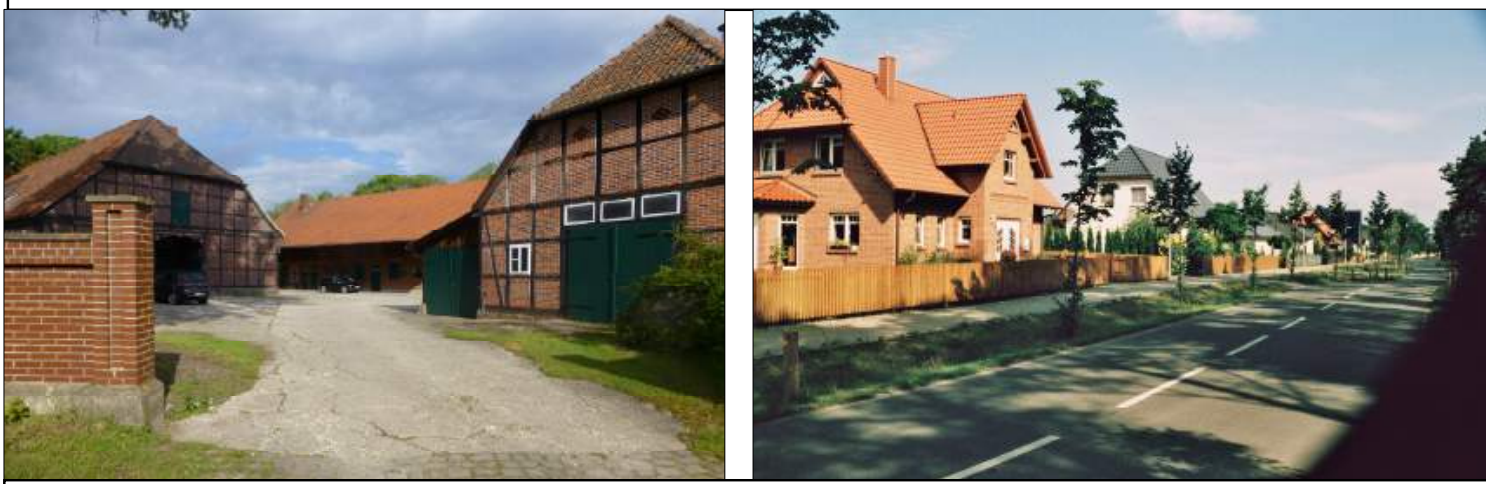

Abb. 7.6 Altes und neues Dorf:

links: stillgelegte Hofstelle (Aufn. K. Koch); rechts: Neubaugebiet (Aufn.: A. Behr) 


\section{Kapitel 8 Zusammenfassung}

Die Analyse des Naturraumes in Kapitel 2 hat gezeigt, dass die Gemarkung Lachendorf innerhalb einer Aufschüttungslandschaft aus dem Saale-Glazial Anteil hat an zwei natürlichen Großräumen, nämlich Grundmoränen aus dem Drenthestadium einerseits und dem Urstromtal des Warthestadiums andererseits.

Diese beiden Großräume werden morphologisch durch einen deutlich im Gelände erkennbaren Erosionsrand, dem nördlichen Talrand des Allertales, getrennt.

In der nördlichen Lachendorfer Gemarkung wird die kuppige Grundmoränenlandschaft durch das Tal der Lachte in die Bunkenburger und Gockenholzer Geestplatte getrennt. Das Lachtetal, aus einer warthezeitlichen Schmelzwasserrinne entstanden, mündet bei Lachendorf in das Aller-Urstromtal. Vor dieser Talmündung hat die Ur-Lachte einen riesigen Schwemmfächer aufgeschüttet. Am nördlichen Rand

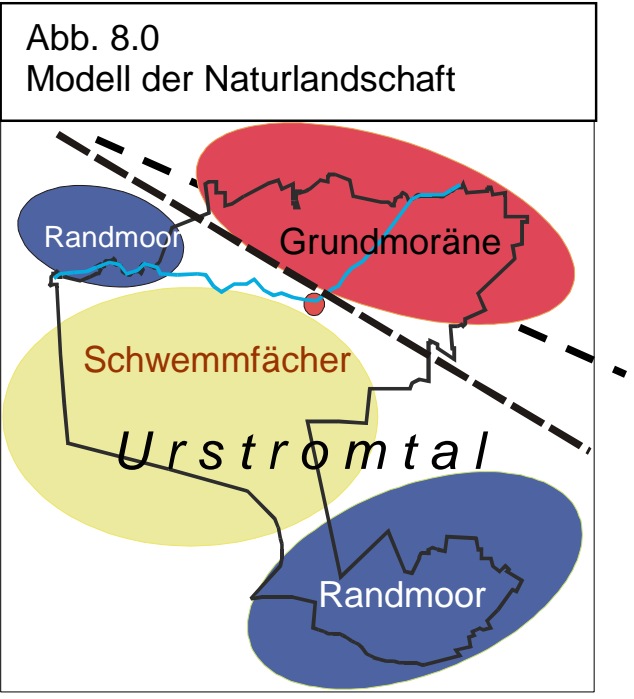
des Urstromtales haben sich im Schatten des Schwemmfächers Randmoore ausgebildet, der heutige Schweinebruch im Nordwesten Lachendorfs und die Allerdreckwiesen im Südosten.

Die drei hauptsächlichen Naturräume - Geestplatten auf der Grundmoräne, Schwemmfächer und Randmoor im Urstromtal unterscheiden sich deutlich hinsichtlich geologischem Aufbau, Bodenwasserhaushalt und Bodenformen.

Hinsichtlich der landwirtschaftlichen Nutzung sind die Unterschiede der Böden von besonderer Bedeutung: Auf den Geestplatten finden sich auf lehmigem Substrat Braunerden und Pseudogleye mit überwiegend geringer Podsolierung und 30 - 45 Bodenpunkten. Den Schwemmfächer bestimmten Podsole auf Sand mit meist weniger als 20 Bodenpunkten. Im Randmoor der Allerdreckwiesen hatten sich vor der Flussregulierung Anmoor und AnmoorGleye entwickelt.

Auf dem Hintergrund dieser klaren dreigliedrigen naturbedingten Raumstruktur haben sich im Laufe der Zeit drei unterschiedliche kulturräumliche Landschaftsstrukturen entwickelt. In der Phase der Heidebauernwirtschaft, die mindestens seit dem Mittelalter die Landwirt-

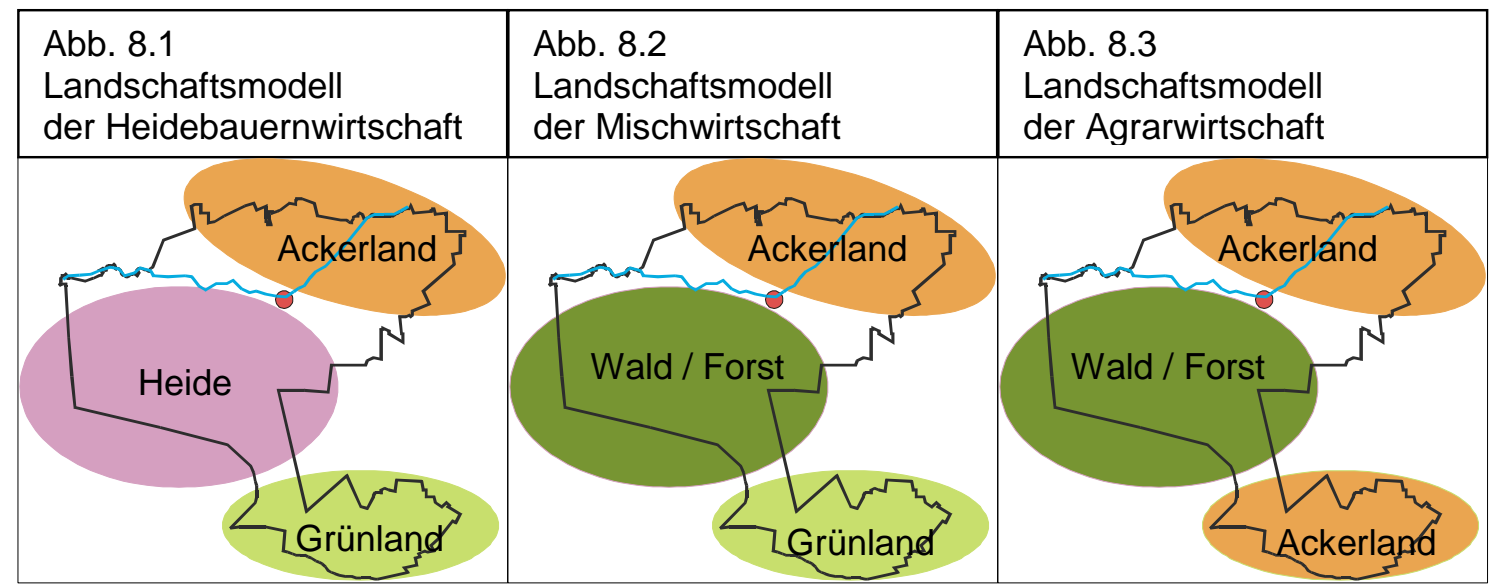

schaft bestimmte und erst mit den Agrarreformen des 19. Jahrhunderts ihr Ende fand, wurde die gesamte Landschaft als landwirtschaftliche Nutzfläche gebraucht: Die Böden mit der höchsten natürlichen Fruchtbarkeit auf den Geestplatten wurden als Ackerland für die Dreifelderwirtschaft benötigt. Die sehr feuchten und von häufigen Überschwemmungen bedroh- 
ten Allerwiesen wurden als Dauergrünland genutzt. Auf den nährstoffarmen Sanden des Schwemmfächers hatte sich nach der Waldvernichtung eine Heidelandschaft entwickelt, die integraler und unverzichtbarer Bestandteil der Heidebauernwirtschaft war, weil die Heide zum Heid- und Plaggenhieb sowie als Weide bzw. Hutung für das Vieh, insbesondere die Schnucken, benötigt wurde. Die Heide sicherte durch Zufuhr von organischem und in geringem Maße auch mineralischem Material auf den Acker dessen geringe Ertragskraft.

Die Gemarkung ist ein Ergebnis der Generalteilungen innerhalb der Agrarreformen: Aus der ehemaligen Feldmark, die nur die Ackerflächen sowie dorfnahe Anger- und Heideflächen umfasste, und den Abfindungen aus den Gemeinschaftsrevieren der Allerheide sowie den Aller- und Dreckwiesen entstand die neue Wirtschaftsfläche des Dorfes. Die Gemarkung mit ihren Anteilen am Ackerland auf der Grundmoräne, der Heide auf dem Schwemmfächer und dem Grünland im Randmoor der Allerdreckwiesen umfasste genau die landwirtschaftliche Nutzfläche, die von den Bauern der Dorfgenossenschaft für ihre damalige Wirtschaftsweise benötigt wurde.

Gemarkungen ${ }^{1}$ wie die Lachendorfs dokumentieren also in ihrem räumlichen Zuschnitt den Wirtschaftsraum am Ende der Heidebauernzeit und sind damit ein Relikt aus der Heidebauernwirtschaft.

Die Heidebauernwirtschaft hatte im Rahmen der zeitgenössischen Agrarwirtschaft bzw. Agrartechnik eine optimale Anpassung an die naturräumlichen und ökologischen Bedingungen entwickelt. Die Wirtschaftsweise führte allerdings zu einer ständigen Ausbeutung der Heideflächen und damit zu ihrer Zerstörung. Die Heidebauernwirtschaft war also trotz optimaler Anpassung an die natürlichen Bedingungen nicht nachhaltig.

Die Verbesserungen der Bodenfruchtbarkeit und der Tragkraft durch Fruchtwechsel, Gründüngung und mineralische Düngung sowie Feldfutterbau und neue Feldfrüchte konnte die Abhängigkeit von der Heide beseitigen.

Die Heide verlor ihre zentrale Stellung im Wirtschaftsystem, schied aus der landwirtschaftlichen Nutzfläche aus und wurde aus der Sicht der Landwirtschaft zu Unland, dass dann aber innerhalb einiger Jahrzehnte aufgeforstet wurde. Die fast geschlossene Heidefläche innerhalb der Gemarkung Lachendorfs wurde in ein ebenso geschlossenes Waldgebiet umgewandelt, das bis heute Bestand hat.

Auf der Grundlage der neuen agrarwirtschaftlichen Erkenntnisse und neuer Agrartechniken entwickelte sich eine familienbäuerliche Landwirtschaft, die in allen Betrieben als Mischwirtschaft mit Ackerbau und Viehhaltung gestaltet wurde. Die Außen- und Binnenwirtschaft dieser landwirtschaftlichen Wirtschaftsweise war stark miteinander verknüpft durch betriebseigenen Futterbau auf dem Acker, betriebsinterne Verwertung von mehrfach genutzten Ackerfrüchten ${ }^{2}$, Produktion von Naturdung für den Acker und starker Verknüpfung von Acker und Grünland über die verschiedenen Nutztierarten. Durch die enge Verzahnung von Außen- und Binnenwirtschaft kam es auch zu vielfältigen Stoffkreisläufen innerhalb eines Betriebes.

Diese Wirtschaftsweise hatte ein großes Artenspektrum auf dem Acker und im Stall zur Folge. Die Pferdeanspannung in der bäuerlichen Landwirtschaft hatte auch bis weit ins 20. Jahrhundert hinein für eine kleinräumige, den Bodenverhältnissen eng angepasste Schlageinteilung und -größe gesorgt.

So konnte sich durch die familienbäuerliche Mischwirtschaft eine ökologisch sehr vielfältige und dem kleinräumigen Mosaik der naturräumlichen Struktur eng angepasste Nutz- bzw. Kulturlandschaft entwickeln.

\footnotetext{
${ }^{1}$ Gemarkungsgrenzen wurden seitdem nur im Zuge von Flurbereinigungen (Beispiel Lachendorf - Beedenbostel) verändert oder begradigt und bei Zusammenschlüssen zwischen ehemals selbständigen Gemeinden aufgehoben (Beispiel Lachendorf - Gockenholz und Lachendorf - Jarnsen und Bunkenburg).

${ }^{2}$ Z.B. Kartoffeln als Marktfrucht und Schweinefutter; Zuckerrübe als Rübe zur Zuckergewinnung und das Blatt als Silage zu Rinderfutter; Getreide als Marktfrucht und das Stroh (Roggen, Gerste) als Einstreu zur Dungproduktion oder als Futter (Hafer).
} 
Die ökologische Vielfalt war aber nicht Ursache sondern Ergebnis dieser Wirtschaftsweise, einerseits aus Gründen der Bodenfruchtbarkeit, besonders aber aus betriebswirtschaftlichen bzw. arbeitswirtschaftlichen Gründen. Über die Vielfalt der Ackerfrüchte konnte die Arbeit in der Vegetationsperiode besser verteilt werden als bei einer Spezialisierung. Im Viehstall gab es stets ganzjährig Arbeit, besonders aber wegen der durchgängigen Aufstallung in den Wintermonaten mit wenig Arbeit im Außenbereich. Die Mischwirtschaft ermöglichte auch Einkommen zu verschiedenen Jahreszeiten, die Milchproduktion sogar monatlich.

Die vielfältige Kulturlandschaft, die wegen ihrer landschaftlichen Schönheit und ihres Artenreichtums, gerade auch bei wilder Flora und Fauna, hoch geschätzt wird, folgt in ihrer räumlichen Struktur auch der naturräumlichen Gliederung, ist aber in ihrer Ausgestaltung das Ergebnis der familienbäuerlichen Wirtschaftsweise mit Mischbetrieben.

Aufgrund hoher Technisierung mit großer Leistungskraft aller Geräte und Maschinen in der Außen- und Binnenwirtschaft mit fast vollständiger Mechanisierung aller Arbeitsabläufe auf dem Feld und im Stall sowie starker Marktorientierung sowohl beim Verkauf agrarischer Produkte als auch beim Einkauf von Betriebsmitteln wie Energie, Futter, Dünger und Pflanzenschutzmittel konnten landwirtschaftliche Betriebe bei abnehmendem Arbeitskräftebesatz die Mischwirtschaft aufgeben und sich zu spezialisierten Ackerbau- oder spezialisierten Veredelungsbetrieben entwickeln. Damit waren die Grundlagen für ein bisher unmögliches Wachstum der Betriebe gegeben, aber auch für viele Betriebsaufgaben.

Diese Wirtschaftsweise der modernen Agrarwirtschaft führte zu einem reduzierten Artenspektrum bei den Nutzpflanzen, zu möglichst großen Schlageinheiten du zu geringerer Berücksichtigung ökologischer Standortunterschiede.

Besonders gravierend wirkt sich aber diese Wirtschaftsweise auf das Grünland aus: Reine Ackerbaubetriebe benötigen kein Grünland mehr, sind aber an der Aufstockung der Ackerfläche interessiert. Veredelungsbetriebe können aufgrund der intensiven Nutztierhaltung kaum noch Grünland bewirtschaften, das nicht unmittelbar an der Hofstelle liegt.

So wurde das Grünland in der südlichen Lachendorfer Gemarkung in den Trockenen Wiesen, den Allerdreckwiesen sowie in den Stauwiesen überflüssig und, wo immer möglich und erlaubt, in Ackerland umgewandelt.

Während sich auf dem Schwemmfächer sowie im Randmoor und angrenzenden Talsandflächen durch Änderung der Wirtschaftsweise grundlegender Nutzungswandel, einmal von der Heide zum Wald und zum anderen vom Grünland zum Acker, vollzogen hat, sind die Geestplatten, solange sie landwirtschaftlicher Nutzung unterlagen, durch Ackerbau geprägt. Alle hier behandelten landwirtschaftlichen Wirtschaftsweisen benötigten Ackerland, das die Bauern natürlich auf den besten und ertragreichsten Böden, also auf den lehmigen Böden der Grundmoräne, anlegten und dauerhaft bewirtschafteten. Allein aufgrund der Bodengüte waren und bleiben die Geestplatten die für Ackerbau bevorzugten Areale.

Der absolute Vorrang der bodenbedingten Ackernutzung auf den Geestplatten wird erst seit Ende des 20. Jahrhunderts in Frage gestellt. Die Siedlungserweiterung, insbesondere durch Gewerbegebiete, hat sich inzwischen bis auf die Geestplatten vorgeschoben und Acker auf guten Böden verdrängt.

Die Landwirtschaft hat aufgrund ihrer grundsätzlichen Beziehungen zum Naturhaushalt mit jeder Wirtschaftsweise eine Kulturlandschaft geschaffen, in deren räumlichem Muster man die naturräumliche Struktur und ökologische Differenzierung erkennen kann.

Die Ausgestaltung der jeweiligen Kulturlandschaft ist aber eine Folge der jeweils zeitgenössischen Agrarwirtschaft und Agrartechnik.

Mit dem Wandel landwirtschaftlicher Wirtschaftsweise und Agrartechnik hat sich die Kulturlandschaft trotz unveränderter natürlicher Raumstruktur innerhalb von zwei Jahrhunderten stark verändert.

Nur nicht landwirtschaftlich orientierte Landnutzungen können auch Kulturlandschaften schaffen, in deren räumlichem Muster die naturräumlichen bzw. ökologischen Bedingungen keine Raum prägende Rolle mehr spielen. 
Da der Strukturwandel in der Landwirtschaft offenbar noch weitergeht und durch die Agrarpolitik eher unterstützt als gebremst wird, ist auch von einem weiteren Wandel der landwirtschaftlich geprägten Kulturlandschaft auszugehen.

Natur- und Landschaftsschutz und Landwirtschaft sind durch diese Entwicklungen in ein Spannungsfeld geraten, in dem die Differenzen derzeit eher zu als abnehmen.

Landwirtschaft wird die natürlichen Bedingungen ihres jeweiligen Standortes immer so zu nutzen versuchen, dass die Landnutzung unter den jeweils zeitgenössischen gesellschaftlichen Bedingungen und agrarwirtschaftlichen Möglichkeiten ökonomisch erfolgreich ist.

Allerdings hat sich die Naturabhängigkeit der Landwirtschaft im Laufe der letzten 150 Jahre ganz erheblich verschoben und verringert. Durch sog. landeskulturelle Maßnahmen und Meliorationen sowie durch weltweite Vernetzungen im Zuge der Globalisierung hat die Landwirtschaft darüber hinaus zusätzliche Möglichkeiten erhalten, die Landnutzung unabhängig von den natürlichen Standorten ökonomisch erfolgreich zu betreiben. So konnte sich auch Landwirtschaft entwickeln, die weit über die natürliche Tragkraft ihres Standortes hinaus geht und dabei auch in Kauf nimmt, Naturfaktoren des eigenen Standortes zu beschädigen oder gar zu zerstören.

Moderne, hoch technisierte, global eingebundene und rein ökonomisch ausgerichtete Landwirtschaft steht in der Gefahr, eine Kulturlandschaft zu schaffen, die weder nachhaltig die landwirtschaftliche Existenz sichert noch gesellschaftlich gewünscht oder akzeptiert wird.

Moderne Landwirtschaft muss sich daher auch den Problemen und Aufgaben des Landschafts- bzw. Naturschutzes sowie ökologischen Problemen öffnen und stellen.

$\mathrm{Da}$ es andererseits in einer flächendeckenden Kultur- und Nutzlandschaft keinen reinen $\mathrm{Na}$ turschutz geben kann, muss in einer Kulturlandschaft ein Landschaftsmanagement entwickelt werden, in dem die verschiedenen Aspekte wie Artenschutz, Schutz des Landschaftsbildes und Biotopschutz, aber auch Gewässer- und Grundwasserschutz und insbesondere Bodenschutz integriert sind.

Die sektorale Ausrichtung von Naturschutzmaßnahmen wird auch an Beispielen aus der Lachendorfer Gemarkung deutlich: Der Naturschutz in den Allerdreckwiesen ist als Artenschutz höchst erfolgreich, kann aber das Landschaftsbild einer parkähnlichen Wiesenlandschaft nicht bewaren. Die Ausweitung des Bau- und Gewerbegebietes auf die guten Böden der Lehmgeest wurde gesetzeskonform durch weit entfern liegende Ausgleichsflächen völlig anderen ökologischen Charakters ohne jegliche Berücksichtigung von Bodenschutzzielen umgesetzt.

Hauptziele eines Landschaftsmanagements in einer Kulturlandschaft sollten Nachhaltigkeit und Ressourcenschutz sein. Landschaftsschutz in einer Kulturlandschaft darf sich nicht auf Einzelaspekte beschränken, sondern muss als hochkomplexe und gesamtgesellschaftliche Aufgabe verstanden und umgesetzt werden. 


\section{Materialverzeichnis ${ }^{1}$}

\section{Kapitel 1:}

Karte 1.1

Abb. 1.1

Kapitel 2:

Karte 2.1

Karte 2.2

Karte 2.3

Karte 2.4

Karte 2.5

Karte 2.6

Karte 2.7

Karte 2.8

Karte 2.9

Karte 2.10

Karte 2.11

Karte 2.12

Karte 2.13:

Karte 2.14:

Karte 2.15:

Karte 2.16:

Karte 2.17

Karte 2.18

Karte 2.19

Karte 2.20

Karte 2.21

Karte 2.22

Karte 2.23

Karte 2.24

Karte 2.25

Karte 2.26

Kartenbild

Kartenbild 2.2 Das Krumme Moor

Tabelle $2.1 \quad$ Bohrprofile

Tabelle 2.2 Daten zu den Klimabezirken

Tabelle 2.3 Monatsgang der Tagessummen ausgewählter Jahre und Monate

Tabelle 2.4 Lachte, Anzahl der Tage mit $<100 \mathrm{~cm}$ und $>150 \mathrm{~cm}$ Pegelstand

Diagramm 2.1

Diagramm 2.2

Diagramm 2.3.1

Diagramm 2.3.2

Diagramm 2.3.2

Diagramm 2.4.1

Diagramm 2.4.2

Lachendorf und Umgebung 2004

Modell zur Landschaftswahrnehmung

Eisrandlagen Lüneburger Heide

Geologische Übersichtskarte Südheide

Südheide Glazialmorphologische Gliederung

Lachter Geest Naturräumliche Gliederung

Geologie

Mittleres Allertal - naturräumliche Struktur

Hydrologische Räume

Orohydrographische Struktur

Niederschlagsgebiete

Überschwemmungsgebiet der Aller

Aller und Schwarzwasser - Flussregulierungen

Aller

Bodenlandschaften

Bodentypen

Gemarkung des Ortes im Naturraum

Bodenschätzung, Bunkenburger Geest

Böden und Vegetation (1966), Allerheide - Westteil)

Lachte, Überschwemmungsbereich

Wirtschaftliches Nutzungspotenzial Geologisches Profil Südheide

Abflussverhalten der Lachte; Winter- und Sommermonate Lachendorf: Niederschlag und Pegelstand vom 7.5. bis 9.6.2013 Station Lachendorf; Abflussverhalten der Lachte (Beispieljahr 2007) Station Lachendorf; Abflussverhalten der Lachte (Beispieljahr 2007) Pegelstände an Lachte, Schwarzwasser und Aller (1961-1965) Hochwasser, Aller und Schwarzwasser, Mai 2013

\footnotetext{
${ }^{1}$ Die Materialien sind nach Kapitelzugehörigkeit sortiert und je Materialart im Kapitel durchnumeriert. Bei den „Kartenabbildungen“ handelt es sich um Ausschnitte aus den Karten, die für die Agrarreformen des 19. Jahrhunderts angefertigt wurden und noch im Original erhalten sind. Diese Karten sind nicht digitalisiert und dürfen auch nicht kopiert werden. Daher wurden von Teilen der karten digitale Fotos angefertigt, die dann am PC bearbeitet wurden. Da wegen der fehlenden Vorrichtung keine justierten Senkrechtaufnahmen angefertigt werden konnten, kann es bei der Darstellung zu Verzerrungen gekommen sein, die keiner exakten Kartenprojektion entsprechen. Daher wurde für diese Materialgruppe der o.g. Begriff gewählt.
} 
Diagramm 2.5

Diagramm 2.6

Diagramm 2.6

Diagramm 2.7

Diagramm 2.8

Diagramm 2.9

Diagramm 2.10

Diagramm 2.11.1

Diagramm 2.11.2

Diagramm 2.11

Diagramm 2.12

Diagramm 2.13

Diagramm 2.14

Diagramm 2.15

Diagramm 2.16

Abb. 2.1:

Abb. 2.2:

Abb. 2.3.1

Abb. 2.3.2

Abb. 2.4

Abb. 2.5

Abb. 2.6

Abb. 2.7

Abb. 2.8

Abb. 2.9

Abb. 2.10

Abb. 2.11

Abb. 2.12

Abb. 2.13

Abb. 2.14

Abb. 2.15

Abb. 2.16

Abb. 2.17

Abb. 2.18

Abb. 2.19

Abb. 2.20

Abb. 2.21

Abb. 2.22
Ganglinie des Grundwassers im Schwemmfächer und Niederschlag Ganglinie des Grundwassers auf der Geest

Klimadiagramm

Mittlere Häufigkeit der Windrichtungen in \%

Stationen in Celle: Niederschläge

Lachendorf: Niederschläge: Abweichung vom Mittel (1941 - 2010)

Lachendorf: Mittel der Jahrzehnte und Mittel 1941 - 2010

Lachendorf: Niederschlag: Extreme und mittlere Monatssummen

Lachendorf: Niederschlag: maximale Abweichung vom Monatsmittel

Variabilität der Monatssummen, Periode 1941 - 2010

Station Lachendorf: Niederschlag: Monatssummen ausgewählter Jahre

Örtliche Niederschlagsvariabilität: Lachendorf - Bargfeld

Station Lachendorf: Jahresniederschläge 1941 - 2012

Niederschlag, Monatssummen Mai - August (1970 - 1979)

Niederschlag: 1.6. - 15.7.1973

Profil Allertal

Bodenprofil 1 - Aufwehung über gekapptem Podsol

Hochwasser Lachte, 20.1.2008

Hochwasser Lachte, 27.5.2013

Bodenprofile, Pseudovergleyung

Bodenprofil Reliktpodsol unter Dünensand

Bodenprofil Heidepodsol

Bodenprofile, Podsole

Bodenprofil Anmoor-Gley - Aller-Dreckwiesen

Podsole auf dem Flurstück Reitbahn

Bunkenburger Geest, Hang zum Lachtetal

Allerheide, am Altenceller Weg

Kiefernwald auf der Allerheide

Legende: Karten 2.22 und 2.23

Ackerbau im Allertal: Kartoffeln 2010

Allertal - „naturnahe“ Landschaft?

Burbusch 1966

Krähenmoor 1966 und 2013

Lachte, Talaue mit Weidebaum

An der Lachte - Schönheit der Landschaft

Bodenerosion durch Bodenbearbeitung

Zuckerrübenanbau. Gockenholzer Geest und Schwemmfächer

Ertragsentwicklung bei Weizen

Kapitel 3:

Karte 3.1

Karte 3.2

Karte 3.3

Karte 3.4

Karte 3.5

Karte 3.6

Kartenbild 3.1 Lachte 1852

Landschaftsbild Ende des 18. Jahrhunderts, Umgebung von Lachendorf

Landschaftsbild Ende des 18. Jahrhunderts, Aller und Schwarzwasser

Acker, Wiesen und Weiden um 1800

Gewanne und Streifenflur

Alte Gemarkungsgrenze mit Streifenflur

Streifenflur und Höfe - Flur Dürskamp

Kartenbild 3.2 Schwarzwasser, Begradigung (1861)

Kartenbild 3.3 Lachendorf 1852, Höfe

Kartenbild 3.4 Allerheide 1850

Tabelle 3.0 Boden auf der Bunkenburger Geest, Klassifikation 1852

Tabelle 3.1

Tabelle 3.2

Tabelle 3.3

Tabelle 3.4

Hofstellen und Streubesitz in Lachendorf Ende des 18. Jahrhunderts:

Feldmark Lachendorf, Bodenverteilung, mit Diagramm

Gemeinheit in der Feldmark des Dorfes

Heidboden mit Holzbestand 1852

Tabelle 3.5 Erhebung in den Gemeinheitsrevieren, mit Diagrammen 
Tabelle 3.6

Tabelle 3.7

Tabelle 3.8

Tabelle 3.9

Tabelle 3.10

Tabelle 3.11

Diagramm 3.1

Diagramm 3.2

Diagramm 3.3

Diagramm 3.4

Abb. 3.1

Abb. 3.2

Abb. 3.3

Abb. 3.4

Abb. 3.5

Abb. 3.6
Abfindungen in der Allerheide

Verkoppelungsgebiet in den Aller- und trockenen Wiesen, mit Diagramm

Lachendorfer Anteil an Aller- und Trockenwiesen

Anteil aller anderen Interessenten

Modellhafte Nutzflächenverteilung zur Zeit der Heidebauernwirtschaft

Typische Fruchtfolgen der Heidebauernwirtschaft „Holzbestände“ im Gemeinschaftsbesitz des Dorfes Lachendorf Taxation der Landnutzung um 1850

Bodenanteile für die Gemarkung Lachendorf

System der Dreifelderwirtschaft

Pflugtechnik mit dem Beetpflug

Zusammen und auseinander pflügen eines Ackers

Das System der Heidebauernwirtschaft

Plaggenhieb und Plaggentransport

Weidelandschaft, P. Potter, 1648

Flurstück Reitbahn, Ackerland auf ehemaliger Heide

\section{Kapitel 4:}

\section{Karte 4.1}

Landschaft und Landnutzung um 1840

Karte 4.2 Wege- und Grabennetz in den Lachendorfer Dreckwiesen

Karte 4.3 Landschaft um 1900

Karte 4.4 Flurnamen, Gemarkung Lachendorf

Kartenbild 4.1 Verkoppelung der Allerwiesen

Kartenbild 4.2 Verkoppelung, Flur Dürskamp

Kartenbild 4.3 Verkoppelung: Osterade

Kartenbild 4.4 Feldmark und Allerheide

Tabelle 4.1 Gesamtfläche der Generalteilung: Vermessung und Bonitierung

Tabelle 4.2 Wertmaßstab für die Bonitierung in der Allerheide

Tabelle 4.3 Beispiele für Klassifizierung und Bonitierung

Tabelle 4.4 Abfindungen in der Allerheide

Tabelle 4.5 Summe der Abfindungen in der Allerheide

Tabelle 4.6 Gesamtflächen zur Spezialteilung und Verkoppelung

Tabelle 4.7 Beispiele aus der Taxationstabelle

Tabelle 4.8 Anzahl der Vermessungsparzellen

Tabelle 4.9 Maßstab für die Bonitierung

Tabelle 4.10 Gesamtergebnis der Bonitierung der Feldmark

Tabelle 4.11 Klassifizierung des Ackerlandes Lachendorfer Höfe

Tabelle 4.12 Beispiele der Vermessung und Wertermittlung

Tabelle 4.13 Beispiele der Klassifizierung aus dem Vermessungsregister

Tabelle 4.14.1 Gemeinheiten in der Feldmark Lachendorf - Gemeindebesitz

Tabelle 4.14.2 Gemeinheiten in der Feldmark Lachendorf - Gemeinheiten des Dorfes

Tabelle 4.15 Wertberechnung zur Gemeinheit des Dorfes (Originaldaten)

Tabelle 4.16.1 Ein Vollhof im Verfahren der Spezialteilung und Verkoppelung (Teil a)

Tabelle 4.16.2 Vollhof im Verfahren (Teil b)

Tabelle 4.16.3 Vollhof im Verfahren (Teil c)

Tabelle 4.16.4 Soll und Haben des Vollhofes (Teil d)

Tabelle 4.16.5 Kothof: Nutzflächen vor der Reform

Tabelle 4.16.6 Kothof: Zusammenfassung

Tabelle 4.16.7 Kothof: Ergebnis der Reformen in der Feldmark Lachendorf

Tabelle 4.17 Flurstücke: Classification, Fläche, Lage in der Feldmark

Tabelle 4.18 Individuelle Abfindungen

Tabelle 4.19 Zusammenstellung des privaten Besitzes der Interessenten

Tabelle 4.20 Abfindungen 1

Tabelle 4.21 Abfindungen 2

Tabelle 4.22 Abfindungen 3

Tabelle 4.23 Beiträge 1 
Tabelle 4.24 Beiträge 2

Tabelle 4.25.1 Nummerische Zusammenstellung des Sollhabens der Lachendorfer

Tabelle 4.25.2 Ergebnis der Spezialteilung und Verkoppelung in der Feldmark Lachendorf

Tabelle 4.26 Verkoppelungsgebiet der Wiesen

Tabelle 4.27 Aus der Teilungsurkunde

Tabelle 4.28 Nachweis des eingebrachten Grundbesitzes: Lachendorfer Höfe

Tabelle 4.29 Nachweis des eingebrachten Grundbesitzes: Ausmärker

Tabelle 4.30 Das Ergebnis der Verkoppelung der Aller- und Trockenen Wiesen für Lachendorf

Tabelle 4.31 Gesamtergebnis der Reformen für die Lachendorfer Höfe

Tabelle 4.32 Hoftypen in Lachendorf zur Zeit der Reformen

Tabelle 4.33 Bodenverteilung in der Gemarkung Lachendorf mit Abschluss der Reformen

Tabelle 4.34 Lachendorfer Höfe nach den Reformen

Tabelle 4.35 Flächenzuwachs der Lachendorfer Höfe

Tabelle 4.36 Immenstellen als private Grundstücke in der Allerheide

Tabelle 4.37 Nutzung der Allerheide um 1850 und Waldstruktur 1972

Diagramm 4.1. 1 - 5 Lachendorfer Höfe nach den Reformen

Diagramm 4.2 Besitzflächen der Höfner und Kötner

Diagramm 4.3 Typische Fruchtfolge im Raum Lachendorf vor 1850

Diagramm 4.4 Typische Fruchtfolge eines regulierten Hofes

Diagramm 4.5

Diagramm 4.6

Abb. 4.1 in Gockenholz, dem Nachbarort von Lachendorf

Abb. 4.2

Lachendorfer Wiesen - Aller- und Trockene Wiesen

Wiesen und Hoftypen

Teufelskreis der Armut in der Heide

Kapitel 5:

Karte 5.1.1

Karte 5.1.2

Karte 5.1.3

Karte 5.2.1

Karte 5.2.2

Karte 5.2.3

Karte 5.2 .4

Karte 5.3

Karte 5.4.1

Karte 5.4.2

Karte 5.5

Karte 5.6

Karte 5.7

Gesetz vom Minimum

Karte 5.8

Landnutzung 1966 - Lachendorf- Ost

Landnutzung 1966 - Lachendorf-West

Landnutzung 1966 - Lachendorf-Süd

Bewässerungsgenossenschaft, Stauwiesen bis 1964

Stauwiesen 1966

Stauwiesen 1972

Stauwiesen 2010

Ackernutzung 2010, Lachendorf Nord-Ost und Nord-West

Landschaftsentwicklung in den Trockenen und Aller-Wiesen 1966 und 1989

Landschaftsentwicklung in den Trockenen und Aller-Wiesen 1996 und 2010

Lachendorf, Ortsgrundriss 2005

Funktionale Gliederung Lachendorfs

Siedlungslage, Ort 1779

Lachendorf, Ort um 1900

Karte $5.9 \quad$ Lachendorf, Ortsentwicklung (Stand 2012)

Kartenbild 5.1 Osteraden -Melmau 1852 und 1966

Kartenbild 5.2 Dreckwiesen 1861 und 1966

Tabelle 5.1 Flächenanteile, Gemarkung Lachendorf

Tabelle 5.2 Grundbesitz nicht landwirtschaftlicher Eigentümer

Tabelle 5.3 Bevölkerungsentwicklung 1939-1966 in Lachendorf

Tabelle 5.4 Landwirtschaftliche Betriebe 1965

Tabelle 5.5 Betriebsgrößen

Tabelle 5.6 Ackernutzung 1965

Tabelle 5.7 Nutzflächen der landwirtschaftlichen Betriebe

Tabelle 5.8 Anbau von Zwischenfrüchten 1965

Tabelle 5.9 Landnutzung und Nutzviehbestand der Betriebe Nr. 1-22 der Gemeinde Lachendorf 1965

Tabelle 5.10 Grundbesitz und Viehbestand der aktiven Betrieb 2009

Tabelle 5.11 Landwirtschaftliche Nutzflächen in anderen Gemarkungen 
Tabelle 5.12 Ackernutzung 2009

Diagramm 5.1 Ackernutzung 1965

Diagramme 5.2.1 Ackernutzung der Betriebe Nr. 1-3

Diagramme 5.2.2 Ackernutzung der Betriebe Nr. 4-6

Diagramme 5.2.3 Ackernutzung der Betriebe Nr. 7-9

Abb. 5.1 Riesen-Bärenklau in den Allerwiesen, 2006

Abb. 5.2 Durchlass unter Fahrweg über ehemaligem Zuleitungsgraben

Abb. 5.3 Nutzungswandel in den Aller-Dreckwiesen, 1966, 2006 und 2011

Abb. 5.4 Landnutzung und Bodenqualität

Abb. 5.5 Verwilderte Gärten, 2010

Abb. 5.6 Siedlungsausbau

Abb. 5.7 Ausbau der Infrastruktur

Abb. 5.8 Vom Acker zum Gewerbegebiet, Urstromtalhang an der Celler Straße

Abb. 5.9 Erhalt und Entwicklung landwirtschaftlicher Bausubstanz

Kapitel 6

Karte 6.1

Karte 6.2

Karte 6.3

Tabelle 6.1

Tabelle 6.2

Tabelle 6.3

Tabelle 6.4

Tabelle 6.5

Tabelle 6.6

Abb. 6.1

Abb. 6.2
Landnutzung und Landschaft 1966

Landnutzung und Landschaft 2010

Nutzungsparzellen 1966 und 2012

Höfe in Lachendorf

Aktive landwirtschaftliche Betriebe in Lachendorf

Landwirtschaftliche Betriebe 2010

Bestandsentwicklung der landwirtschaftlichen Betriebe

Vom Kothof zum Agrarbetrieb

Ernteerträge

Landwirtschaftliche Wirtschaftssysteme

Hochwasser und Maisanbau 2013

\section{Kapitel 7:}

Karte 7.1

Karte 7.2

Tabelle 7.1

Abb. 7.1

Abb. 7.2

Abb. 7.3

Maisanbau in den Allerwiesen 2012, Südteil der Gemarkung Lachendorf

Vernässungsflächen, NSG Allerdreckwiesen

Abb. 7.4

Abb. 7.5

Floristische Aufnahme am Gockenholzer Weg

Windbruch im Kiefernforst

Ackerlandschaft auf der Bunkenburger Geest

Landschaft in den Allerwiesen

Stallungen für Milchviehhaltung und Hof mit Pferdezucht am Ostrand des Dorfes mit direktem Zugang zu Grünland auf dem „Kleinen Moor“

Abb. 7.6 Altes und neues Dorf

\section{Kapitel 8:}

Abb. 8.0

Abb. 8.1

Abb. 8.2

Modell der Naturlandschaft

Abb. 8.3

Landschaftsmodell der Heidebauernwirtschaft

Landschaftsmodell der Mischwirtschaft

Landschaftsmodell der Agrarwirtschaft 


\section{Literaturverzeichnis}

1. Abel, W., Agrarkrisen und Agrarkonjunkturen, Harnburg 1966, 2. Aufl.

2. Abel, W., Der Pauperismus in Deutschland, Nds. Landeszentrale für polit. Bildung, Hannover 1970

3. Abraham, H., Geographische Gesichtspunkte der Ackerflächen, Svensk geogr. Arsbok, Bd. 39, Lund 1963, engl. Zusammenfassung

4. Babel, A., Die Allerdreckwiesen sind in Gefahr; Celleche Zeitung, 12. Juni 1999, S. 20

5. Bätzing, W., Die Alpen, Frankfurt a.M., 1984

6. Bätzing, W., Orte guten Lebens, Zürich 2009

7. Bauer, H., Die Kurhannoversche Landesaufnahme des 18. Jahrhunderts, Hannover 1993

8. Barkhausen, K.-L., Reisen in die Lüneburger Heide 1794 - 1894, Soltau 2003

9. Becker, H., Allgemeine historische Agrargeographie, Teubner Studienbücher Geographie, Stuttgart 1998

10. Beckmann, W., Untersuchungen zum Landschaftshaushalt in Auen der Hauensteiner Murg, Hamburg 1965

11. Behr, A., Feldarbeit, Agrarökologische Raumanalyse; in: Praxis Geographie, 10/1982, S. $10-14$

12. Behr, A., Agrarwirtschaft in der Südheide; in: Exkursionsführer, 20. Deutscher Schulgeographentag 1986, Höller und Zwick, Braunschweig 1986, S. 83 - 86

13. Behr, A., Celle und die Südheide; in: Exkursionsführer Braunschweig, Vom Harz zur Heide; L. Bäuerle u. W. Klie (Hg.), Braunschweig 1990, S. 147 - 155

14. Behr, A., Der Lutterhof, ein Bauernhof im Wandel der Zeit, Hermannsburg 2005

15. Bund Heimat und Umwelt, Hg., Landwirtschaft und Umwelt, Bonn 2011

16. Bonsen, U., Die Entwicklung des Siedlungsbildes und der Agrarstruktur der Landschaft Schwansen vom Mittelalter bis zur Gegenwart, Schriftenr. d. Geogr. Inst. Kiel, Kiel 1966

17. Bruns, A., Hrsg., Der Landkreis Celle, Oldenburg i.O.1966

18. Carol. N., Zehn Grundsätze über Geographie und Landschaft, Pet. Mit t. 101 Jg., H. 2, 1957, S. 97-98

19. Coesfeld, L., Wie viel Mais vertragen unsere Böden?, Sonderdruck aus dlz - Die landtechnische Zeitschrift 3/84, München 1984

20. Charisius, H., In der Maiswüste; in: Die Zeit, Nr. 20 vom 10.5.2012, S. 38

21. Charisius, H., Schleichende Vergiftung; in: Die Zeit, Nr. 20 vom 10.5.2012, S. 39

22. Deutsches Maiskomitee e.V., Bedeutung des Maisanbaues in Deutschland, www.maiskomitee.de vom 25.2.2011

23. Deutsches Maiskomitee e.V., Schädlinge im Mais - Westlicher Maiswurzelbohrer, www.maiskomitee.de, 2013

24. Deutscher Wetterdienst, Hrsg., Klima-Atlas von Niedersachsen, Offenbach/M. 1964

25. Dewers, F., Geologische Auswirkungen der früheren bäuerlichen Heidewirtschaft in Nordwest-Deutaschland, Natur und Volk, Bd. 65, Frankfurt/M. 1935, S. 483-490

26. Drachenfels, O. v.; Überarbeitung der Naturräumlichen Regionen Niedersachsens, Informationsdienst Naturschutz Niedersachsen 30. Jg., H. 4, S. 249 -252, Hannover 2010

27. Ellenberg, H., Wiesen und Weiden und ihre standörtliche Bedeutung, Landwirtschaftliche Pflanzensoziologie, Bd. 2, Stuttgart 1952

28. Entrup, N. L. ,Th. Breitschuh u. H. Meßner, Nachhaltigkeit landwirtschaftlicher Betriebe mit Maisanbau, Hg.: Deutsches Maiskomitee e.V., www.maiskomitee.de, Oktober 2011

29. Fachagentur nachwachsende Rohstoffe e.V. (Hg.); Leitfaden Biogas - Von der Gewinnung zur Nutzung, 5. Auflage, Gülzow 2010

30. Feise, J., Der Ackerbau in der Provinz Hannover in seinen Beziehungen zu Boden und Klima, Oldenburg 1936

31. Finck, A., Pflanzenernährung in Stichworten, 2. Aufl., Hirt-Verlag, Kiel 1975

32. Friedrich, F., Papier aus Lachendorf seit 1538, Firma Drewsen Lachendorf, 2007 
33. Gaede, M. und J. Härtling; Umweltbewertung und Umweltprüfung; Das geogr. Seminar, Westermann, Braunschweig 2010

34. Gehrden, R. v., Die Bodenverwehungen in Niedersachsen 1947-51, Hrsg. K. Brüning, Hannover, 1954

35. Geozentrum Hannover: NIBIS ${ }^{\circledR}$ Kartenserver (2012): Landesamt für Bergbau, Energie und Geologie (LBEG),

36. Glaser, R., Klimageschichte Mitteleuropas, 2. Aufl., Darmstadt 2008

37. Goltz, Th. Frh.v.d., Geschichte der deutschen Landwirtschaft, Stuttgart, Berlin 1903

38. Gradmann, R., Unsere Flußtäler irn Urzustand, Ztschr. d. Ges. f. Erdk., Berlin 1932, S. 1-17

39. Gripp, K., Über die äußerste Grenze der letzten Vereisung in Nordwest-Deutschland, Mitte d. Geogr. Ges. Hamburg, 36, 1924, S. 159-245

40. Haase, G., Hanggestaltung und ökologische Differenzierung nach dem Catena-Prinzip, Pet. Mit t. 105 Jg., 1961, S. 1-8

41. Haase, G., Zur Anlage von Standort-Aufnahme-Karten bei landschaftsökologischen Untersuchungen, Geogr. Ber., 9. Jg. 1964, S.257-270

42. Haase, O., Landschaftsökologische Detailuntersuchungen und naturräumliche Gliederung, Pet. Mit t. 108 Jg., 1964, S. 8-30

43. Hamm, W., Das ganze der Landwirtschaft in Bildern; Leipzig 1872, Nachdruck Hannover 2002

44. Hamman, W., Die Kulturlandschaft im südlichen Einzugsbereich der Schmalen Aue, einem Teilgebiet der Lüneburger Heide, Hamburg, 1962

45. Harbort, E., Wissenschaftliche Ergebnisse der Aufnahme der Blätter Gelle und Beedenbostel, in: Ber. über die wiss. Ergebnisse der geol. Aufnahme im Jahre $1911 \mathrm{Jb}$. d. kgl. preuß. Landesanstalt f. 1911, Bd. 32, T. 2, S. 497-503

46. Helmke, Fr. u. H. Hohls, Der Speicher, Heimatbuch für den Landkreis Celle, Celle 1930, Nachdruck: Hermannsburg 1990

47. Henkel, H., Der ländliche Raum, Studienbücher Geographie, Berlin, Stuttgart 2004

48. Hirsch, E. u.a., Das Gartenreich Dessau-Wörlitz, ein Reiseführer, Hamburg 1996

49. Hövermann, J. u. W. Tietze, Die natürlichen Landschaften Niedersachsens, Geogr. Rdsch., Jg. 9, 1957,S. 163-168

50. Hollstein, W., Landschafts- und Bodengeschichte der Lüneburger Heide, Amt für Bodenforschung, Bd. 84, S. 282-289

51. Illies, H., Formengeschichte und Entwässerung des Unterelbe-Gebietes während der Eiszeiten, Harnburg 1951

52. Knapp. R., Die Pflanzengesellschaften in Mitteleuropa, Einführung in die Pflanzensoziologie, Ho 2, Stuttgart 1948

53. Köhler, B. u. A. Preuß; Erfassung und Bewertung des Landschaftsbildes, Informationsdienst Naturschutz Niedersachsen, 1/2000

54. Küster, H., Geschichte der Landschaft in Mitteleuropa, München, 1999

55. Küster, H., Das ist Ökologie, München 2005

56. Küster, H., Die Entdeckung der Lüneburger Heide als „schöne Natur“; In:Themenportal Europäische Geschichte 2010. http://www.europa.clioonline.de/2010/Article $=429$.

57. Kugler, H., Aufgaben, Grundsätze und methodische Wege für großmaßstäbiges geomorphologisches Kartieren, Pet. Mitt. 109. Jg., 1965, S. 241-257

58. Landkreis Celle, Hrsg., Spuren und Zeichen, Celle 1991

59. Mak, G., Wie Gott verschwand aus Jorwerd; Der Untergang des Dorfes in Europa, btbVerlag 2007

60. Manshard, W., Einführung in die Agrargeographie der Tropen, BIHochschultaschenbücher Mannheim 1968

61. Meisel, S., Die naturräumlichen Einheiten auf Blatt 73, Celle, Geogr. Landesaufnahme 1:200000, Hrsg. Institut für Landesaufnahme, Bad Godesberg, 1960

62. Meteorologisches Amt für Nordwest-Deutschland, 60-jährige Mittelwerte des Niederschlages, 1891-1930, Harnburg 1952 
63. Meynen, E., J. Schmithüsen u.a., Handbuch der naturräumlichen Gliederung Deutschlands, Bd. 1, Bad Godesberg 1962; Bd. 2, Bad Godesberg 1961

64. Miedaner, Th., Von der Hacke bis zur Gen-Technik, Frankfurt 2006

65. Moll, H.W., Beobachtungen über den Einfluß der Bodenbearbeitung auf die Wuchsverhältnisse älterer Heideaufforstungsflächen, in: Sonderdruck aus "Forstarchiv", 26. Jg., H. 2 v. 15.2.1955, S. 25-30, Hannover-Waldhausen 1955

66. Mückenhausen, E., Entstehung, Eigenschaften und Systematik der Böden der Bundesrepublik Deutschland, Frankfurt/M. 1962

67. Meyer, G.-U., Die Dynamik der Agrarformationen; Göttinger Geographische Abhandlungen, Heft 75, Göttingen 1980

68. Montzka, L., Entwicklung eines kommunalen Flächenmanagements in Zeiten des Demografischen Wandels am praktischen Beispiel Lachendorf; unveröff. Diplomarbeit im Studiengang „Verwaltung“, Kommunale Hochschule für Verwaltung in Niedersachsen, 2012

69. Neef, E., Der Bodenwasserhaushalt als ökologischer Faktor, Ber. zur dt. Landeskunde, Bd. 25, H. 2, 1960, S. 272-282

70. Neef, E., Zur großmaßstäbigen landschaftsökologischen Forschung, Pet. Mitt. 108. Jg., 1964, S. 1-7

71. Netz, R., Gefügegerechte Signaturen auf geologischen und morphologischen Karten, Geogr. Taschenbuch 1960/61, S. 494-498

72. NHB, (Hg.); Die Rote Mappe 2013 des Niedersächsischen Heimatbundes e.V.

73. Oberbeck. G., Die mittelalterliche Kulturlandschaft des Gebietes um Gifhorn, Braunschweig 1955

74. Onderscheka, K. u.a; Gehäufte Rehwildverluste nach Aufnahme von 00-Raps; in: Zeitschrift für Jagdwissenschaft, 1987, Volume 33, S. 191 - 205

75. Otremba, E., Allgemeine Agrar- und Industriegeographie, Erde und Weltwirtschaft, Bd. 3, Stuttgart 1960

76. Paffen, K., Die natürliche Landschaft und ihre räumliche Gliederung, Forsch. z. dt. Landeskunde, Bd. 68, Remagen 1953

77. Panne, K., Hg., Albrecht Thaer - Der Mann gehört der Welt; Celle 2002

78. Pfeifer, G. und A. Schlüter, Die kleinräumige Kartierung landwirtschaftlicher Nutzflächen und ihre kulturgeographische Bedeutung, Pet.Mitt. 870 Jg., 1941, S. 153-167

79. Pittius, U., Neues aus den Allerdreckwiesen; in: NABU - Kreisverband Celle e.V.Rundbrief 2013

80. Quaet-Faslem, G., Der Forstkulturbetrieb auf den Heidflächen bei Niebeck im Lüneburgschen; Burckardt-Hefte, Jg. 1875, H. VI

81. Raabe, E., Über die Gräser in Schleswig-Holstein, Mitt. d. Arbeitsgem. F. Floristik in Schleswig-Holstein und Hamburg, H. 3, Kiel 1951

82. Radkau. J., Die Ära der Ökologie - eine Weltgeschichte; München 2011

83. Reichholf, J. H., Eine kurze Naturgeschichte des letzten Jahrtausends, Frankfurt a.M., 2007

84. Schacherer, A.; Ackerwildkräuter, Nieders. Landesamt für Ökologie, Merkblatt Nr. 22, Auflage von 1992

85. Schmithüsen, J., "Fliesengefüge der Landschaft" und "Ökotop", Ber. z. dt. Landeskunde 5,1948 , S. $74-83$

86. Schröder-Effinghausen, K., Umweltverträglichkeitsstudie, Bebauungsplan Nr. 22, Gewerbegebiet „Kleines Bulloh“, Gemeinde Lachendorf, Gesellschaft für Infrastrukturplanung $\mathrm{mbH}$, Celle, 2004

87. Schroeder-Lanz, H., Morphologie des Estetales, Hamburger Geogr. Studien, H. 18, Harnburg 1964

88. Schwarz, G., Zusammenhänge der Verkoppelung in Niedersachsen, Tagungsber. u. wiss. Abh. d. dt. Geographentages Essen 1953,S. 187-194

89. Seiler, Chr., Die Aller - ein Fluss verändert seinen Lauf, Celle 2002

90. Spering, F., Agrarlandschaft und Agrarformationen im deutsch-niederländischen Grenzgebiet des Emslandes und der Provinzen Drenthe/Overijssel; Göttinger Geographische Abhandlungen, Heft 76, Göttingen 1981 
91. Temme, A., Celle, Siedlungs- und Wirtschaftsgeographie einer niedersächsischen Stadt und ihres Lebensraumes, Hannover 1937

92. Tödter, H. R., Kulturhistorisches Lexikon, Bereich Nord-Hannover; PD-Verlag, Heidenau, 2010

93. Troll, C., Luftbildplan und ökologische Bodenforschung, Ztschr. d. Ges. f. Erdk., Berlin 1939, Bd. 7/8, S. 241-298

94. Türschmann, H., Das Postmoor, 100 Jahre Bodenverbesserung und Landschaftspflege im Postmoor, Endeholz 2010 (Hrsg.: Bodenverband Postmoor Steinhorst/Räderloh

95. Tüxen R., Über die Vegetation der nordwestdeutschen Binnendünen, Jb. d. Geogr. Ges. Hannover 1928, S. 71-93

96. Tüxen, R., Die Schrift des Bodens, Angewandte Pflanzensoziologie, H. 14, Stolzenau/Weser 1957

97. Uhden, 0., Erläuterungen zur Wasserwirtschaftskarte von Niedersachsen, Hannover 1951

98. Veth, F., Hg., Landwirtschaftlicher Verein Beedenbostel, 1961, Festschrift zum hundertjährigen Bestehen

99. Vock, H.-J., Der agrarstrukturelle Wandel im mittleren Niedersachsen; Göttinger Geographische Abhandlungen, Heft 92, Göttingen 1991

100. Weibel, L., Probleme der Landwirtschaftsgeographie, Verh. u. wiss. Abh. des 25. dt. Geographentages, Nauheim 1934, S. 100-117

101. Walter, H., Einführung in die Phytologie, Bd. 4, T. 2, Vegetation Mitteleuropas mit den Alpen von H. Ellenberg, Stuttgart 1963

102. Wächter, H.-H., Die Landwirtschaft Niedersachsens vom Beginn des 19. bis zur Mitte des 20. Jahrhunderts, Bremen-Horn, 1959

103. Warnecke, E. F., Die Wirtschaftslandschaft der Heidebauernzeit, Geogr. Rdsch. 8. Jg., 7/1956, S. 279-282

104. Weizsäcker, C. F., Frh. v., Die Geschichte der Natur, Göttingen 1965, 6. Aufl.

105. Welte, A., Die Bedeutung der Ortsgemarkungen für die Siedlungsgeographie, Geogr. Anz.36. Jg., 7/1935, S. 145-153

106. Wittmann, M. u. K. W. Seebo, Lachendorf, Beiträge zur Geschichte des Dorfes, Chronik der Gemeinde Lachendorf, Bd. I, Lachendorf 1988

107. Wittmann, M., Lachendorfer Höfe, Beiträge zur Geschichte des Dorfes, Chronik der Gemeinde Lachendorf, Bd. II, Lachendorf, 2. Aufl. 1998

108. Wöbse, H.-H., Landschaftsästhetik - eine Aufgabe für den Naturschutz?, NNABerichte 1/93, S. 3 - 7

109. Woldstedt, F. Über Endmoränen in der südlichen Lüneburger Heide, Abh. d. Nat. Ver. Bremen, Bd. 31, 1939140, H. 2/3, S. 236-246

110. Woldstedt, F., Norddeutschland und angrenzende Gebiete im Eiszeitalter, Stuttgart 1955, 2.Aufl.

Unveröffentlichte Quellen:

1. Moll, H.W., Erläuterungsbericht zur Standorts- und Vegetationskartierung des Klosterforstamtes Miele, Aufnahme abgeschlossen im Dez. 1959 Sachverzeichnis der Forstmeisterstelle Miele unter Nr. 1.25

2. Moll, H.W., Standorttypenkarten Klosterforstamt Miele, Kartenband, 1:10000, Sachverzeichnis der Forstmeisterstelle unter Nr. 1,25

3. Landkreis Celle, Straßenbau- und Wasserwirtschaftsabteilung, Entwurfsbericht für die Regulierung der Mittelaller, Verlegung des Schwarzwassers, aufgestellt 1963; Wasserwirtschaftsamt Celle, Wasserstandshaupttabellen der Pegel Lachendorf (Lachte), Neuhaus (Schwarzwasser) und Langlingen (Aller), Pegelstammbuch des Pegels Lachendorf; Landkreis Gelle, Straßenbau- und Wasserwirtschaftsabteilung, mdl. Auskünfte der Herren Prepenz, Krammaicke und Ernst (1966)

4. Laux, F., Grabungsbericht über die Ausgrabungen bei Lachendorf vom 19.5.18.6.1964, Maschinenschrift 
5. Georg Drewsen, Papierfabrik, Festschrift zur Einweihung der Kraftzentrale, Maschinenschrift

6. Hauptlehrer Mitze, Lachendorf, Schulchronik, von Lehrer Tiemann 1883 begonnen, in der vorliegenden Arbeit als Schulchronik I bezeichnet

7. Hauptlehrer Mitze, Lachendorf, Schulchronik der Volksschule zu Lachendorf, von Hauptlehrer Dageförde 1932 begonnen, in der vorliegenden Arbeit als Schulchronik II bezeichnet.

8. Gemeindeverwaltung Lachendorf, Bodennutzungserhebung von 1965, Viehzählungslisten von 1957, 1960, 1965 und 1966; Liegenschaftsbuch der Gemeinde Lachendorf, Stand vom 30.8.1965

9. Niedersächsischer Landesbetrieb für Wasserwirtschaft, Küsten- und Naturschutz, (NLWKN), Betriebsstelle Verden, Wasserstände und Abflussdaten der Pegel Lachendorf (Lachte), Neuhaus (Schwarzwasser) und Langlingen (Aller) sowie Grundwasserstände der Grundwasserpegel GD 51 und GD 62 in der Lachendorfer Gemarkung

10. Schriftliche und mündliche Auskünfte von Landwirten:

a. 1966:

i. Landwirt Adolf Hackemann, Oppershausen, Vorsteher des Oppershausen-Lachendorfer Stauwiesenverbandes

ii. Landwirte aus Lachendorf: H. Freyer, K. Koch, U. Schmeling, W. Trumann

b) 2009 ff: Deecke, J., Deecke, R., Dralle, Koch, Lüchau, Meier, Müller, Schmeling, Schumeier, Schürfeld, Thies

11. käuflich erworbenes Material:

a. Kartenausschnitt aus der amtlichen Topographischen Karte $1: 25$ 000, Blatt 3327 Beedenbostel (heute Lachendorf), Blatt 3427 Bröckel (heute Wienhausen),

Der aus den beiden o. g. Kartenblättern zusammengesetzte Kartenausschnitt wurde 1966 als Folie vom Katasteramt Celle erstellt und dem Verf. zum Gebrauch zur Verfügung gestellt..

b. Landwirtschaftskammer Niedersachsen, Soltau-Fallingbostel:

Kontrollausdrucke Flächen GFN, 2006 - 2009, aller aktiven landwirtschaftlichen Betriebe

c. Deutscher Wetterdienst Offenbach; Niederschlagswerte der Station Lachendorf, 1941 - 2012

12. Akten aus dem Bestand der Samtgemeinde Lachendorf:

a. Register über die Abfindung der Dorfschaft Lachendorf auf der Allerheide, Amt Beedenbostel, o.J., (Sign.: 61/6)

b. Recess über die Generaltheilung verschiedener Gemeinheiten von Gockenholz und Alvern, Gockenholz, Alvern und Ohe und Gockenholz und Lachendorf, Amt Beedenbostel, 1839, Fotokopie, ohne Signatur

c. Recess über die Generaltheilung des Schweinebruchs $1832-1838$, (Sign.:Stadtarchiv Celle, 4 A 85)

d. Rezess über die Generaltheilung der Gemeinheiten und der Vor- und Nachweide auf den Wiesen im Schweinebruch in der Vogtei Celle, 1834, (Stadtarchiv Celle)

e. Classifications- und Vermessungs-Register der Feldmark Lachendorf, o.J., (Sign.: 61/9)

f. Vermessungsregister von der Feldmark Lachendorf, Amt Beedenbostel, o.J. (Sign. 61/10)

g. Taxations-Tabelle über die Abschätzung der Feldmark Lachendorf, 1852, (Sign.: 61/4)

h. Taxations-Register zur Spezial-Theilung und Verkoppelung der Feldmark Lachendorf, o.J., (Sign.: 61/4) 
i. Receß über die Spezialtheilung und Verkoppelung der Feldmark Lachendorf, Amt Beedenbostel, 1858/59, (Sign.: 61/5)

j. Regulativ über die künftige Benutzung der Abfindungen, über Befriedigung der Koppeln, erste Instandsetzung und künftige Unterhaltung der Wege, der Wegegräben, der Brücken, Siele und Abzugsgräben pp. Gegenseitige Verpflichtungen der beteiligten hinsichtlich des Wasserlaufs, Concurrenz zu den Theilungskosten pp. In Spezial-Theilungs und Verkoppelungs-Angelegenheit von Lachendorf, O.J., (Sign.: 61/7)

k. Theilungs-Urkunde über die Entfrettung und Verkoppelung der Aller- und trockenen Wiesen bei Lachendorf, Amt Celle, 1866, (Sign.: 140/8)

I.

13. Karten zu den Agrarreformen

Zentrale Altablage der Ämter für Niedersächsische Landentwicklung beim LGLN, Regionaldirektion Hannover

1. Karte von der Allerheide, Celle 156, Allerheide, Karte Celle 62, Ifd. Nr. 4

2. Charte von der Feldmark Lachendorf, Celle 226, Feldmark Lachendorf

3. Charte von den Aller- und trockenen Wiesen, Celle 290

\title{
Tabellarischer Lebenslauf
}

\author{
Zur Person \\ Vorname: Artur \\ Nachname: Behr \\ Geburtsdatum: 21.10.1938 \\ Geburtsort: $\quad$ Horndorf, Kr. Lüneburg
}

\section{Studium}

Ab SS 1960 Studium der Fächer Mathematik, Geographie und Pädagogik an der Universität Hamburg

1965 Tutor im Studentenwohnheim Übersee-Kolleg

1967 1. Staatsexamen für das Höhere Lehramt

Schriftlich Hausarbeit bei Prof. Dr. A. Kolb: „Die Agrarstruktur der Lachendorfer Gemarkung"

1968/69 Referendariat am Staatlichen Studienseminar Celle

1969 2. Staatsexamen für das Höhere Lehramt

Schriftliche Hausarbeit: „Entwicklungshilfe und Entwicklungspolitik im Gemein-

Berufstätigkeit schaftskundeunterricht, Unterrichtsversuch in Kl. 13“

1969 Studienassessor am Kaiserin-Auguste-Viktoria Gymnasium in Celle

WS 1970/71: Gasthörer am Institut für Bodenkunde, Universität Hamburg

1971 Ernennung zum Studienrat,

Berufung zum Fachleiter für Erdkunde am Staatlichen Studienseminar Celle

$1972 \quad$ Ernennung zum Studiendirektor

1989 Berufung zum Schulleiter am Christian Gymnasium Hermannsburg,

2004 Ernennung zum Oberstudiendiretzung in den Ruhestand

Berufsbezogene Nebentätigkeiten:

Mitarbeit in der Lehrplankommission für Erdkunde des Nds. Kultusministeriums

Schulbuchautor bei den Verlagen Hirt, Schroedel, Cornelsen

Unterrichtsprojekt „Kulturlandschaft Heide“ in Jgst. 12 (Schuljahr 02/03) bei „denkmal aktiv, Kulturerbe macht Schule“, eine Aktion der Deutschen Stiftung Denkmalschutz

Im Ruhestand:

Unterrichtsprojekt zum Thema „Die Region im Unterricht“; Stiftung Niedersachsen, Hannover 
Veröffentlichungen:

1) Entwicklungshilfe und Entwicklungspolitik im Gemeinschaftskundeunterricht; in: Schule und Dritte Welt, Nr. 12, BMZ Bonn, 1970

2) Feldarbeit, Agrarökologische Raumanalyse; Praxis Geographie, 10/1982, S. 10 - 14

3) Agrarwirtschaft in der Südheide; in: Exkursionsführer, 20. Deutscher Schulgeographentag 1986, Höller und Zwick, Braunschweig 1986, S. 83 - 86

4) Celle und die Südheide; in: Exkursionsführer Braunschweig, Vom Harz zur Heide; L. Bäuerle u. W. Klie (Hg.), Braunschweig 1990, S. 147 - 155

5) „Die Chinesen ernähren sich selbst“- Chinas Landwirtschaft im Umbruch; in: Praxis Geographie, 1/2005, S. 14 - 17

6) Der Lutterhof bei Hermannsburg, ein Bauernhof im Wandel der Zeit, Hermannsburg 2005

7) Schulbücher Erdkunde, Mitarbeit im jeweiligen Autorenteam

Schwerpunkte der Beiträge: Landwirtschaft, Böden, Dritte Welt, Ökosysteme, Klima

a. Geographie thematisch, Hirt-Schroedel, Bd. 5/6: 1977; Bd. 7/8: 1978; Bd. 9: 1980

b. Mensch und Raum, Gymnasium KI. 11; Schroedel 1984

c. Mensch und Raum, Gymnasiale Oberstufe, Cornelsen-Schroedel, 1987

d. Mensch und Raum, Seydlitz, Gymnasium Kl. 11, Cornelsen-Schroedel, 1988

e. Mensch und Raum, Geographie, Geoökologie und Umweltfragen, Cornelsen 1996

f. Mensch und Raum, Gymnasium Niedersachsen, Bd.7: 1996; Bd. 8: 1995; Bd. 10: 1997

Der Bd. 10 erhielt den Agrar-Schulbuchpreis 2002 für die „außerordentlich gute Darstellung der Landwirtschaft" von der information.medien.agrar e.V. (i.m.a.)

g. Mensch und Raum, Gymnasiale Oberstufe, CVK-Schroedel, 1987 und Cornelsen-Schroedel 1992

h. Mensch und Raum, Oberstufe Geographie, Cornelsen, 2007 


\section{Anhang ${ }^{1}$}

Im Anhang werden die Rezesse zu den Agrarreformen des 19. Jahrhunderts zusammen mit den amtlichen Dokumenten zur Bewertung (Taxation), Klassifikation und Vermessung wiedergegeben.

Der Anhang ergibt so eine Vertiefung zum Kapitel 3 und insbesondere zu Kapitel 4.

Inhalt:

Anhang

300

Generalteilung

Register $^{2}$

über die Abfindung der Dorfschaft Lachendorf auf der Allerheide,

Amt Beedenbostel

Plan-Rece $\beta^{3}$

über die Generalteilung der Communion-Reviere Allerheide, Lachendorfer Moor, Westernmoor, Allerhorn und Allerohe

Amt Celle und Beedenbostel

Spezialteilung und Verkoppelung

Taxations-Tabelle ${ }^{4}$ über die Abschätzung der Feldmark Lachendorf

Classifications- und Vermessungs-Register ${ }^{5}$ der Feldmark Lachendorf

Taxations-Register zur Spezial-Theilung und Verkoppelung ${ }^{6}$ der Feldmark Lachendorf

$\operatorname{Rece}^{7}$

365

über die Spezialtheilung und Verkoppelung der Feldmark

Lachendorf nebst Vertheilungs-Register

Amt Beedenbostel

Theilungs-Urkunde ${ }^{8}$

418

über die Entfrettung und Verkoppelung der Aller- und trockenen Wiesen

bei Lachendorf, Amt Celle

\footnotetext{
${ }^{1}$ Übertragung der Originale und Zusammenstellung des Anhangs: Artur Behr

${ }^{2}$ Quelle: Samtgemeinde Lachendorf, Archiv Akten, Fach/Nr. 61/6

${ }^{3}$ Bei den Titeln der Rezesse wurde die historische Schreibweise beibehalten. Die Texte wurden aus den handschriftlich in Sütterlin verfassten Dokumenten übertragen.

Die Schreibweisen des Textes, insbesondere bei Namen, Fachbegriffen und Fremdwörtern wurden weitgehend beibehalten, um den Charakter des Zeitdokumentes zu erhalten.

${ }^{4}$ Samtgemeinde Lachendorf, Archiv Akten, Fach/Nr. 61/4

${ }^{5}$ Samtgemeinde Lachendorf, Archiv Akten, Fach/Nr. 61/9

${ }^{6}$ Samtgemeinde Lachendorf, Archiv Akten, Fach/Nr. 61/4

${ }^{7}$ Samtgemeinde Lachendorf, Archiv Akten, Fach/Nr. 61/5

${ }^{8}$ Samtgemeinde Lachendorf, Archiv Akten, Fach/Nr. 140/8
} 
Register ${ }^{1}$

über die Abfindung der Dorfschaft Lachendorf auf der Allerheide, Amt Beedenbostel

\begin{tabular}{|c|c|c|c|c|c|c|c|}
\hline \multicolumn{8}{|c|}{ Wertverhältnisse } \\
\hline \multicolumn{8}{|c|}{ für die Abfindung der Dorfschaft Lachendorf auf der Allerheide } \\
\hline \multicolumn{2}{|c|}{ Ackerland } & \multicolumn{2}{|c|}{ Angerboden } & \multicolumn{2}{|c|}{ Heidboden } & \multicolumn{2}{|c|}{ Moorboden } \\
\hline Klasse & M/Kuhw. & Klasse & M/Kuhw. & Klasse & M/Kuhw. & Klasse & M/Kuhw. \\
\hline 1. & 16 & 1. & 5 & 1. & 8 & 1. & 10 \\
\hline 2. & 20 & 2. & 6 & 2. & 10 & 2. & 12 \\
\hline \multicolumn{2}{|c|}{ Wiesenboden } & 3. & 8 & 3. & 12 & 3. & 16 \\
\hline 1. & 4 & 4. & 10 & 4. & 14 & 4. & 20 \\
\hline 2. & 5 & 5. & 12 & 5. & 16 & \multicolumn{2}{|c|}{ Bruchboden } \\
\hline 3. & 6 & & & 6. & 20 & 1. & 8 \\
\hline 4. & 8 & & & 7. & 25 & 2. & 10 \\
\hline \multicolumn{4}{|c|}{ Anm.: M/Kuhw.; Morgen pro Kuhweide } & 8. & 30 & 3. & 12 \\
\hline \multicolumn{8}{|c|}{ Register über die Abfindung der Dorfschaft Lachendorf auf der Allerheide } \\
\hline
\end{tabular}

\begin{tabular}{|c|c|c|c|c|c|c|c|}
\hline \multirow{6}{*}{$\begin{array}{l}\text { 등 } \\
\text { 응 } \\
\text { 응 } \\
\text { 힘 } \\
\text { 운 }\end{array}$} & \multirow{6}{*}{ 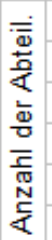 } & \multirow{2}{*}{\multicolumn{2}{|c|}{$\begin{array}{l}\text { Klassifikation der Flurstücke } \\
\text { der Lachendorfer Abfindung }\end{array}$}} & \multirow{3}{*}{$\begin{array}{l}\frac{ㄷ}{\mathrm{w}} \\
\text { 응 }\end{array}$} & \multirow{6}{*}{ 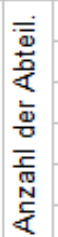 } & \multirow{2}{*}{\multicolumn{2}{|c|}{$\begin{array}{l}\text { Klassifikation der Flurstücke } \\
\text { der Lachendorfer Abfindung }\end{array}$}} \\
\hline & & & & & & & \\
\hline & & \multicolumn{2}{|c|}{$\begin{array}{c}\text { der Lachendorfer Abfindung } \\
\text { auf der Allerheide }\end{array}$} & & & \multicolumn{2}{|c|}{$\begin{array}{c}\text { der Lachendorter Abfindung } \\
\text { auf der Allerheide }\end{array}$} \\
\hline & & & & \multirow{3}{*}{$\begin{array}{l}\frac{Y}{2} \\
\frac{d}{0} \\
\frac{0}{2}\end{array}$} & & & \\
\hline & & & & & & & \\
\hline & & & & & & & \\
\hline \multirow[t]{3}{*}{1} & & \multicolumn{2}{|c|}{ Auf der Allerheide an der Altenceller Grenze } & 50 & & \multicolumn{2}{|r|}{ Nördlich am Exerzierplatz } \\
\hline & 8 & Angerboden & & & 1 & Heidboden & \\
\hline & 42 & \multirow[t]{2}{*}{ Heidboden } & & 54 & & \multicolumn{2}{|c|}{ Westlich am Exerzierplatz } \\
\hline \multirow[t]{2}{*}{6} & & & Beim Birkenbusche & & 3 & Heidboden & \\
\hline & 12 & Heidboden & & 55 & & \multicolumn{2}{|c|}{ Bei Thies olim Cammanns Immenstelle } \\
\hline \multirow[t]{2}{*}{11} & & \multicolumn{2}{|c|}{ Bei Schönduves Immenstelle } & & 2 & Heidboden & \\
\hline & 1 & Heidboden & & 5 & & \multicolumn{2}{|c|}{ Weg von Gockenholz nach Wienhausen } \\
\hline \multirow[t]{2}{*}{14} & \multicolumn{3}{|c|}{ Bei Drewschen Busche und dem Krummen Moor } & & 6 & Heidboden & \\
\hline & 5 & Heidboden & & 10 & & \multicolumn{2}{|c|}{ Der Lachendorfer Celler Weg } \\
\hline \multirow[t]{2}{*}{16} & & \multicolumn{2}{|c|}{ Bei der Lachendorfer Kuhweide } & & 2 & Heidboden & \\
\hline & 6 & Heidboden & & 13 & & Der La & chendorfer-Oppershäuser Weg \\
\hline \multirow[t]{4}{*}{35} & & \multicolumn{2}{|c|}{ Auf dem Lachendorfer Moore (s. Tabelle) } & & & Heidboden & \\
\hline & 16 & Angerboden & & 15 & \multicolumn{3}{|c|}{ Weg von Lachendorf nach den Aller-Dreckwiesen } \\
\hline & 1 & Moorboden & & & 3 & Heidboden & \\
\hline & 14 & Heidboden & & 57 & & & Der Celle Gifhorner Weg \\
\hline \multirow[t]{4}{*}{41} & & Bei Misselh & Is Kämpen, hinter dem Fischteich, & & 5 & Heidboden & \\
\hline & & $\operatorname{im~} \mathrm{Kr}$ & enmoore und im Hockrehmen & 34 & & Der W & eg auf dem lachendorfer Moore \\
\hline & 10 & Angerboden & & & 2 & Angerboden & \\
\hline & 31 & Heidboden & & & 5 & Heidboden & \\
\hline 48 & & & stlich am Exerzierplatz & 38 & & & Der Canal \\
\hline & & Heidboden & & & 7 & ohne Angabe & \\
\hline
\end{tabular}

\footnotetext{
${ }^{1}$ Quelle: Samtgemeinde Lachendorf, Archiv Akten, Fach/Nr. 61/6
} 
Das Flurstück Nr. 35, „Auf dem Lachendorfer Moore“ wird exemplarisch vollständig wiedergegeben:

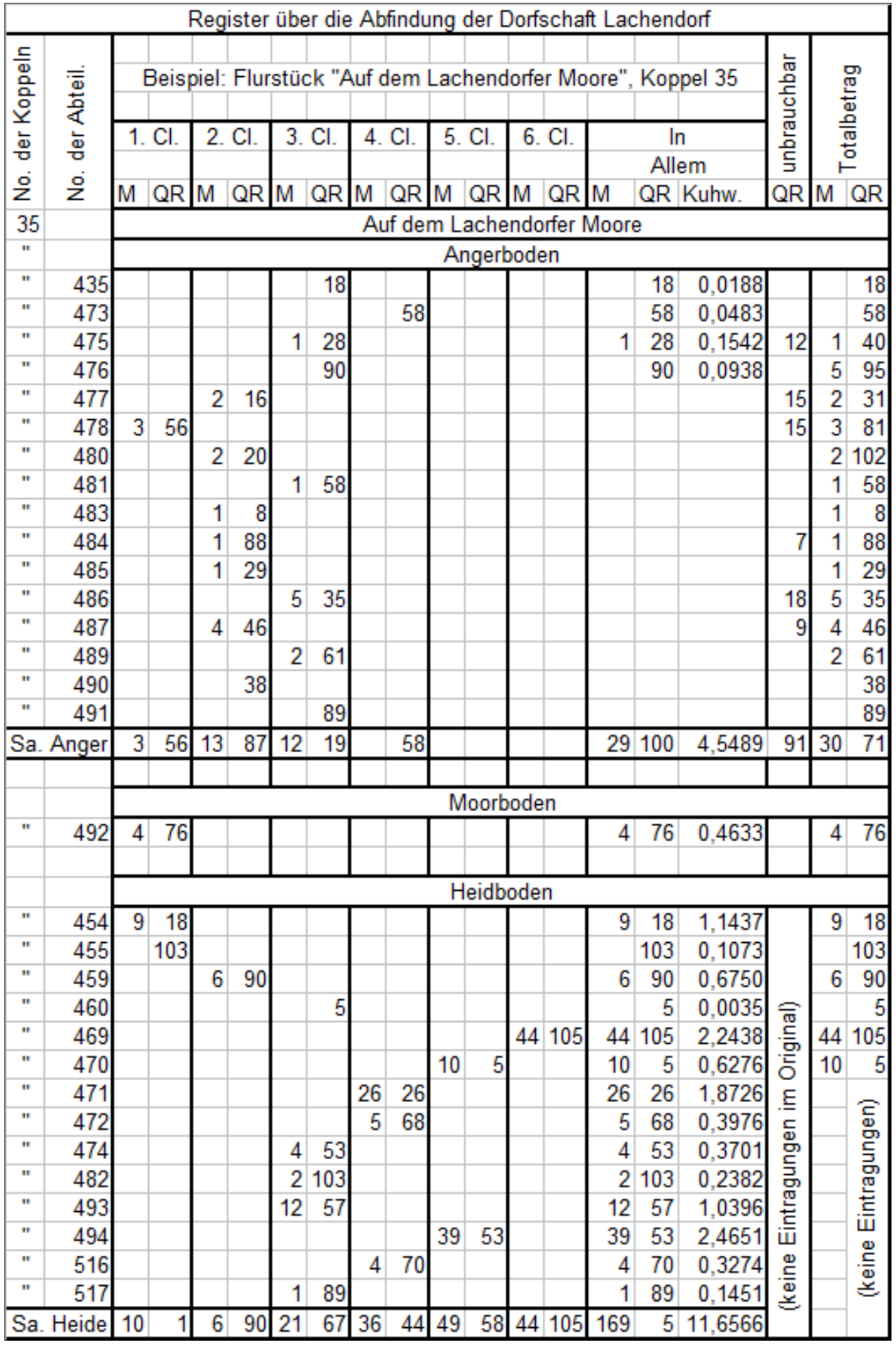


Innerhalb der Abfindung der Dorfschaft gab es auch private Grundstücke:

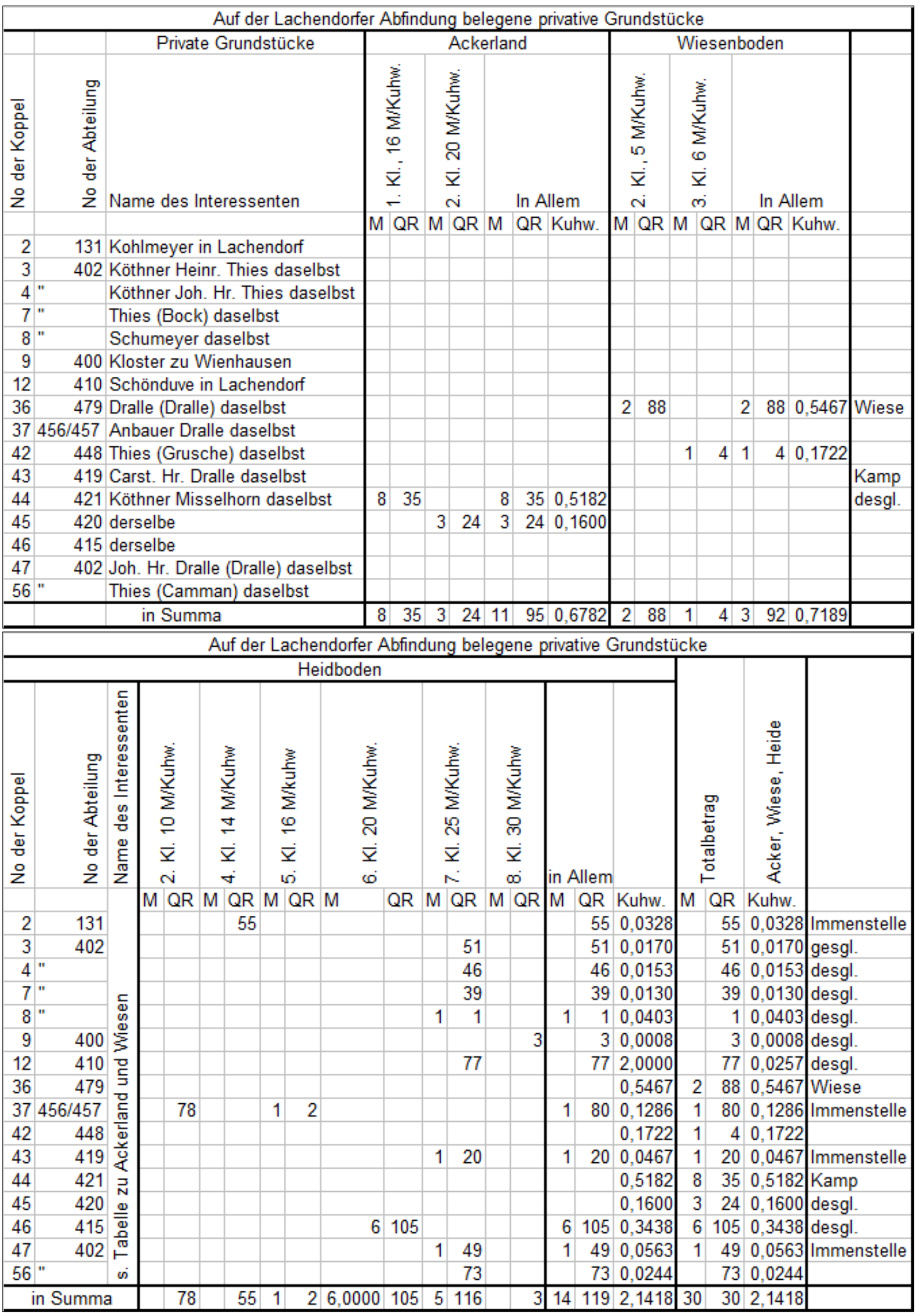


In der Zusammenfassung ergibt sich für die Abfindung der Dorfschaft Lachendorf auf der Allerheide folgende Klassifikation, Bewertung (Taxation) und Vermessung:

\begin{tabular}{|c|c|c|c|c|c|c|c|c|c|c|c|c|c|c|c|c|}
\hline \multirow[t]{4}{*}{ Wiederholung } & \multicolumn{3}{|c|}{ Moorboden } & \multicolumn{13}{|c|}{ Angerboden } \\
\hline & \multirow{2}{*}{\multicolumn{3}{|c|}{$\begin{array}{c}1 . \mathrm{Cl} \\
10 \mathrm{Mrg}\end{array}$}} & \multicolumn{2}{|c|}{ 1. $\mathrm{Cl}$. } & \multicolumn{2}{|c|}{ 2. $\mathrm{Cl}$. } & \multicolumn{2}{|c|}{ 3. $\mathrm{Cl}$} & \multicolumn{2}{|c|}{ 4. Cl. } & \multicolumn{2}{|c|}{ 5. Cl. } & & & \\
\hline & & & & \multirow{2}{*}{\multicolumn{2}{|c|}{$\begin{array}{c}5 \mathrm{Mrg} \\
\text { pro }\end{array}$}} & \multicolumn{2}{|c|}{$6 \mathrm{Mrg}$} & \multicolumn{2}{|c|}{$8 \mathrm{Mrg}$} & \multicolumn{2}{|c|}{$10 \mathrm{Mrg}$} & \multicolumn{2}{|c|}{$12 \mathrm{Mrg}$} & & & \\
\hline & \multicolumn{2}{|c|}{ pro } & & & & \multirow{2}{*}{\multicolumn{2}{|c|}{$\begin{array}{c}\text { pro } \\
\text { Kuhw. }\end{array}$}} & & oro & & pro & & pro & & \multicolumn{2}{|c|}{$\ln$} \\
\hline \multirow[t]{2}{*}{ Benennung der Gegend } & \multicolumn{2}{|c|}{ Kuhw. } & & \multicolumn{2}{|c|}{ Kuhw. } & & & \multicolumn{2}{|c|}{ Kuhw. } & \multicolumn{2}{|c|}{ Kuhw. } & \multicolumn{2}{|c|}{ Kuhw. } & \multicolumn{3}{|c|}{ Allem } \\
\hline & M & QR & Kuhw. & M & QR & $M$ & QR & M & QR & M & QR & $\mathrm{M}$ & QR & $M$ & QR & Kuhw. \\
\hline An der Altenceller Grenze & & & & & & 5 & 115 & 9 & 80 & 8 & 29 & & & 23 & 104 & 3,0256 \\
\hline Beim Birkenbusch & & & & & & & & & & & & & & & & \\
\hline Bei Schönduves Immenstelle & & & & & & & & & & & & & & & & \\
\hline Bei Drewsens Busch a. dem Krummen Moor & & & & & & & & & & & & & & & & \\
\hline Bei der lachendorfer Kuhweide & & & & & & & & & & & & & & & & \\
\hline Auf dem Lachendorfer Moore & 4 & 76 & 0,4633 & 3 & 56 & 13 & 87 & 19 & 19 & & 58 & & & 29 & 100 & 4,5439 \\
\hline Bei Misselhorns Kämpen pp. & & & & 11 & 31 & 6 & 71 & 5 & 9 & & 117 & & & 23 & 108 & 4,0821 \\
\hline östlich vom Exerzierplatz & & & & & & & & & & & & & & & & \\
\hline Nordöstlich demselben & & & & & & & & & & & & & & & & \\
\hline Nördlich demselben & & & & & & & & & & & & & & & & \\
\hline Westlich demselben & & & & & & & & & & & & & & & & \\
\hline Bis Thies al. Cammanns Immenstelle & & & & & & & & & & & & & & & & \\
\hline In Allem & 4 & 76 & 0,4633 & 14 & 87 & 26 & 33 & 26 & 108 & 9 & 84 & & 4 & 77 & 72 & 11,6566 \\
\hline Der Gockenholz-Wienhäuser Weg & & & & & & & & & & & & & & & & \\
\hline Der Lachendorf-Celler Weg & & & & & & & & & & & & & & & & \\
\hline Der Lachendorf-Oppershäuser Weg & & & & & & & & & & & & & & & & \\
\hline Der Lachendorfer Wiesenweg & & & & & & & & & & & & & & & & \\
\hline desgl. Auf dem Lachendorfer Moore & & & & & & & 17 & & & & & & 4 & & 21 & 0,0264 \\
\hline der Canal & & & & & & & & & & & & & & & & \\
\hline Der Celler-Gifhorner Weg & & & & & & & & & & & & & & & & \\
\hline Summa der Wege & & & & & & & 17 & & & & & & 4 & & 21 & 0,0264 \\
\hline Summa der Lachendorfer Abfindung & 4 & 76 & 0,4633 & 14 & 87 & 26 & 50 & 26 & 108 & 9 & 84 & & 4 & 77 & 93 & 11,6830 \\
\hline dazu privative Grundstücke & & & & & & & & & & & & & & & & \\
\hline Summa & 4 & 76 & 0,4633 & 14 & 87 & 26 & 50 & 26 & 108 & 9 & 84 & & 4 & 77 & 93 & 11,6830 \\
\hline
\end{tabular}

\begin{tabular}{|c|c|c|c|c|c|c|c|c|c|c|c|c|c|c|c|c|c|c|c|c|}
\hline \multirow{6}{*}{$\begin{array}{l}\frac{c}{\mathrm{c}} \\
\frac{\mathrm{a}}{2} \\
\frac{\mathrm{a}}{\mathrm{O}} \\
\frac{\mathrm{y}}{2} \\
\frac{\mathrm{d}}{0} \\
\frac{0}{2}\end{array}$} & & \multicolumn{19}{|c|}{ Heidboden } \\
\hline & & \multicolumn{2}{|c|}{ 1. $\mathrm{Cl}$} & \multicolumn{2}{|c|}{ 2. $\mathrm{Cl}$. } & \multicolumn{2}{|c|}{ 3. $\mathrm{Cl}$. } & \multicolumn{2}{|c|}{ 4. Cl. } & \multicolumn{2}{|c|}{ 5. $\mathrm{Cl}$} & \multicolumn{2}{|c|}{ 6. Cl. } & \multicolumn{2}{|c|}{ 7. $\mathrm{Cl}$. } & \multicolumn{2}{|c|}{ 8. $\mathrm{Cl}$. } & & & \\
\hline & & \multicolumn{2}{|c|}{$8 \mathrm{Mrg}$} & \multicolumn{2}{|c|}{$10 \mathrm{Mrg}$} & \multicolumn{2}{|c|}{$12 \mathrm{Mrg}$} & \multicolumn{2}{|c|}{$14 \mathrm{Mrg}$} & \multicolumn{2}{|c|}{$16 \mathrm{Mrg}$} & \multicolumn{2}{|c|}{$20 \mathrm{Mrg}$} & \multicolumn{2}{|c|}{$25 \mathrm{Mrg}$} & \multicolumn{2}{|c|}{$30 \mathrm{Mrg}$} & \\
\hline & Benennung & \multicolumn{2}{|c|}{ pro } & \multicolumn{2}{|c|}{ pro } & \multicolumn{2}{|c|}{ pro } & \multicolumn{2}{|c|}{ pro } & & oro & & pro & pro & ro & & ro & & In & \\
\hline & & & & & ahw. & $\mathrm{Ku}$ & hw. & & uhw. & & uhw. & & uhw. & Kuh & hw. & Kul & thw. & & Alle & \\
\hline & & M & QR & M & QR & $\mathrm{M}$ & QR & $\mathrm{M}$ & QR & M & QR & M & QR & M & QR & M & $\mathrm{QR}$ & M & QR & Kuhw. \\
\hline & An der Altenceller Grenze & & & & 73 & 11 & 9 & 27 & 78 & 321 & 2 & 95 & 9 & 350 & 59 & & & 505 & 40 & 23,0036 \\
\hline & Beim Birkenbusch & & & & & 2 & 19 & & & 5 & 94 & 14 & 29 & 599 & 77 & 11 & 61 & 633 & 40 & 25,6224 \\
\hline & Bei Schönduves Immenstelle & & & & & & & & & & & & & 123 & 33 & & & 123 & 33 & 4,9310 \\
\hline & Bei Drewsens Busch a. dem K & rumn & men I & Mo & & & & & & & & 12 & 30 & 147 & 54 & & & 159 & 84 & 0,5105 \\
\hline & Bei der lachendorfer Kuhweide & & & & & & & & & & & 7 & 78 & 86 & 43 & & 29 & 94 & 30 & 3,8449 \\
\hline 35 & Auf dem Lachendorfer Moore & 10 & 1 & 6 & 90 & 21 & 67 & 36 & 44 & 49 & 58 & 44 & 105 & & & & & 169 & 5 & 11,6566 \\
\hline & Bei Misselhorns Kämpen pp. & 16 & 62 & 14 & 60 & 8 & 92 & 7 & 7104 & 24 & 15 & 350 & 55 & 321 & 34 & 1 & 46 & 744 & 108 & 36,7350 \\
\hline & östlich vom Exerzierplatz & & & & & & & & & & & & & 5 & 68 & & & 5 & 68 & 0,2227 \\
\hline & Nordöstlich demselben & & & & & & & & & & & & & 65 & 80 & & & 65 & 80 & 2,6267 \\
\hline & Nördlich demselben & & & & & & & & & & & & & 8 & 10 & & & 8 & 10 & 0,3233 \\
\hline & Westlich demselben & & & & & & & & & & & & & 89 & 91 & 17 & 59 & 107 & 30 & 4,1734 \\
\hline & Bis Thies al. Cammanns Imme & nstel & & & & & & & & & & & & 82 & 88 & 4 & 105 & 87 & 73 & 3,4718 \\
\hline & In Allem & 26 & 63 & 21 & 103 & 43 & 67 & 71 & 36 & 100 & 49 & 524 & 66 & 1880 & 37 & 35 & 60 & 2704 & 1 & 123,1219 \\
\hline & Der Gockenholz-Wienhäuser V & & & & & & 5 & & & & 61 & & 119 & 8 & 12 & & 63 & 10 & 20 & 0,4264 \\
\hline 10 & Der Lachendorf-Celler Weg & & & & & & & & & & & & & 4 & 71 & & & 4 & 71 & 0,1836 \\
\hline & Der Lachendorf-Oppershäuser & Weg & & & & & & & & & & & & 7 & 34 & & & 7 & 34 & 0,2914 \\
\hline 15 & Der Lachendorfer Wiesenweg & & & & & & & & & & & & 32 & 1 & 114 & & & 2 & 26 & 0,0914 \\
\hline & desgl. Auf dem Lachendorfer M & oore & & & & & 55 & & 101 & & 40 & & 40 & & & & & 1 & 116 & 0,1258 \\
\hline 38 & der Canal & & & & & & & & & & & & & & & & & & & \\
\hline & Der Celler-Gifhorner Weg & & & & & & & & & & & & 6 & 18 & 78 & & 20 & 18 & 104 & 0,7540 \\
\hline & Summa der Wege & 26 & 63 & 21 & 103 & & 60 & & 101 & & 101 & 1 & 77 & 40 & 69 & & 83 & 45 & 11 & 1,8826 \\
\hline & a. der Lachendorfer Abfindung & 26 & 63 & 21 & 103 & 44 & 7 & 72 & 217 & 701 & 30 & 526 & 23 & 1920 & 106 & 36 & 23 & 2749 & 12 & 125,0045 \\
\hline & dazu privative Grundstücke & & & & 78 & & & & 55 & 1 & 2 & 6 & 105 & 5 & 116 & & 3 & 14 & 119 & 0,7447 \\
\hline & Summa & 26 & 63 & 22 & 61 & 44 & 7 & 72 & 272 & 2102 & 32 & 533 & 8 & 1926 & 102 & 36 & 26 & 2764 & 11 & 125,7492 \\
\hline & merkung: in Summa der Wege: & 26 & 63 & 21 & 103 & & & chen & nweise & se eing & getras & & & & & & & & & \\
\hline
\end{tabular}




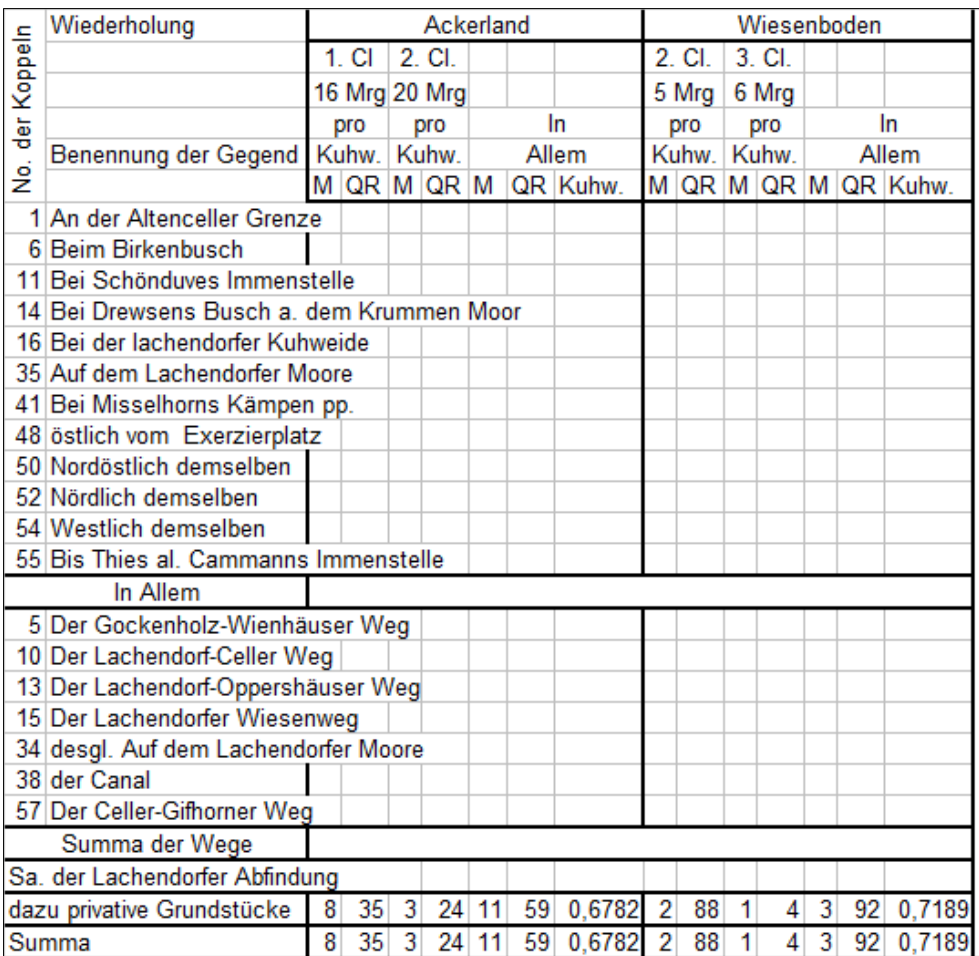

\begin{tabular}{|c|c|c|c|c|c|c|c|}
\hline & & Brau & chbar & \multicolumn{2}{|c|}{ 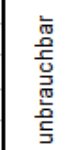 } & \multicolumn{2}{|c|}{ 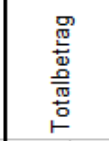 } \\
\hline & $M$ & QR & Kuhw. & M & QR & M & QR \\
\hline \multirow{24}{*}{ 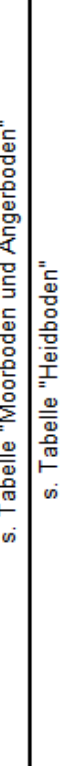 } & 529 & 24 & 26,0292 & & & 529 & 24 \\
\hline & 633 & 40 & 25,6224 & & & 633 & 40 \\
\hline & 123 & 33 & 2,931 & & & 123 & 33 \\
\hline & 159 & 84 & 6,5105 & & & 159 & 84 \\
\hline & 94 & 30 & 3,8449 & & & 94 & 30 \\
\hline & 203 & 61 & 16,6688 & & 91 & 204 & 22 \\
\hline & 768 & 96 & 40,8171 & & & 768 & 96 \\
\hline & 5 & 68 & 0,2227 & & & 5 & 68 \\
\hline & 65 & 80 & 2,6267 & & & 65 & 80 \\
\hline & 8 & 10 & 0,3233 & & & 8 & 10 \\
\hline & 107 & 30 & 4,1734 & & & 107 & 30 \\
\hline & 87 & 73 & 3,4718 & & & 87 & 73 \\
\hline & 2786 & 29 & 135,2418 & & 91 & 2787 & \\
\hline & 10 & 20 & 0,4264 & & & 10 & 20 \\
\hline & 4 & 71 & 0,1836 & & & 4 & 71 \\
\hline & 7 & 34 & 0,2914 & & & 7 & 34 \\
\hline & 2 & 26 & 0,0914 & & & 2 & 26 \\
\hline & 2 & 17 & 0,1622 & & 3 & 2 & 20 \\
\hline & & & & 1 & 106 & 1 & 106 \\
\hline & 18 & 104 & 0,754 & & & & \\
\hline & 45 & 32 & 1,909 & 1 & 109 & 47 & 21 \\
\hline & 2831 & 61 & 137,1508 & 2 & 80 & 2834 & 21 \\
\hline & 30 & 30 & 2,1418 & & & 30 & 30 \\
\hline & 2861 & 91 & 139,2926 & 2 & 80 & 2864 & 551 \\
\hline
\end{tabular}

Quelle: Register über die Abfindung der Dorfschaft Lachendorf auf der Allerheide, Amt Beedenbostel, o.J.

Samtgemeinde Lachendorf, Archiv Akten, Fach/Nr. 61/6

In der hier wiedergegebenen Akte wird die äußerst genau und sorgfältig durchgeführte Bewertung und Vermessung der Abfindung der Dorfschaft Lachendorf auf dem Gemeinschaftsrevier der Allerheide samt den dort befindlichen privaten Grundstücken deutlich.

Die genaue Klassifikation und Bewertung im Rahmen der Generalteilung wurde dann auch zur Grundlage der Spezialteilung der ehemaligen Gemeinheiten genutzt, die zusammen mit der Verkoppelung durchgeführt wurde.

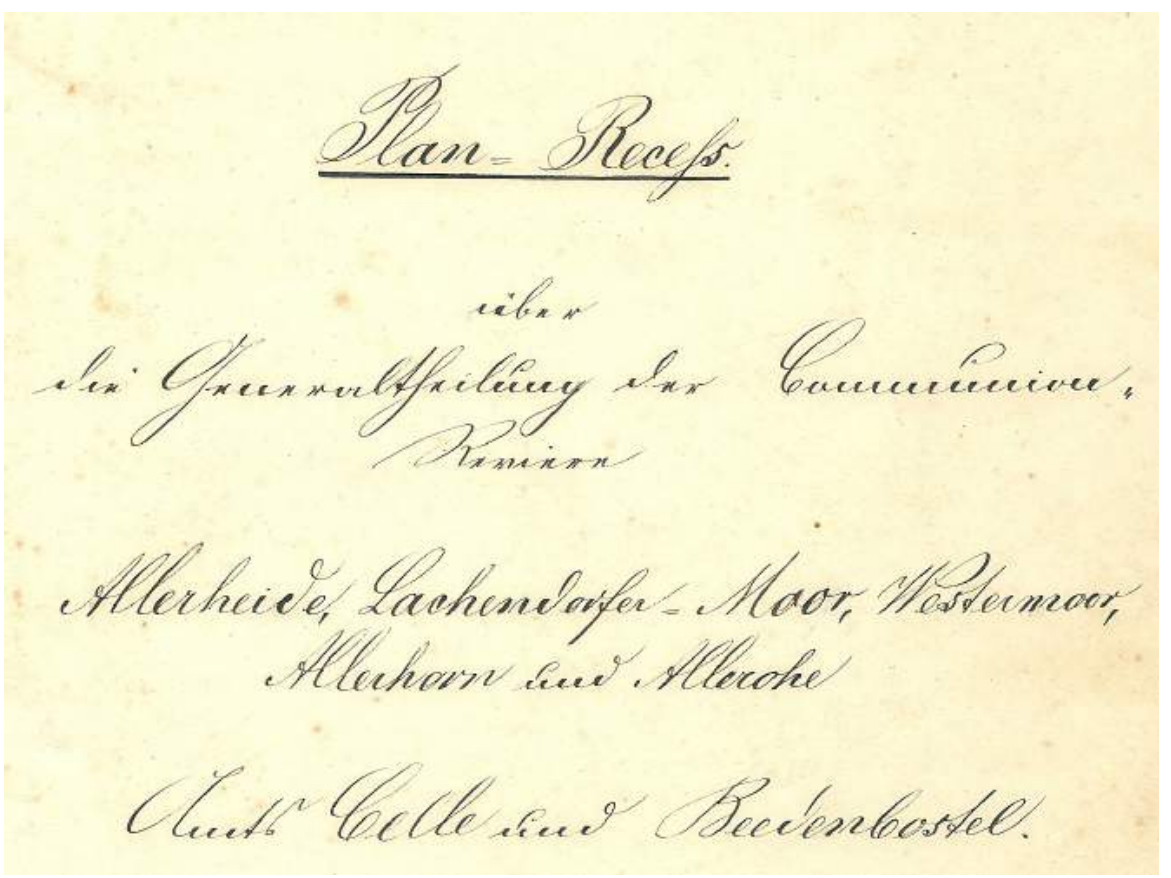


Für die Gemeinde Lachendorf, Ahnsbeck und Oppershausen, zur Aufbewahrung in der Gemeindelade zu Lachendorf ${ }^{1}$

\author{
Plan-Rece ${ }^{2}$ \\ über die Generaltheilung der Communion-Reviere \\ Allerheide, Lachendorfer Moor, Westernmoor, Allerhorn und Allerohe \\ Amt Celle und Beedenbostel ${ }^{3}$
}

Inhaltsverzeichnis

$\S 1$. Provocation und Erkenntnis

$\S 2$. Kostenpunkt

$\S 3$. Teilungs-Commission

Aufgestellt durch H. Michaal

$\S 4$. Bezeichnung des Teilungsobjektes und Lage der Grenzen

$\S 5$. Vermessung und Bonitierung

$\S 6$. Edictalladung

$\S 7$. Beteiligte und deren Vertretung

pag. $\quad 1$

$\S 8$. Angabe der Berechtigungen der einzelnen Beteiligten

$\S 9$. Auseinandersetzung der verschiedenen Nutzungsrechte

$\S 10$. Abfindung der Stadt Celle

$\S 11$. Abfindung der Güter Schwachhausen und Offensen:
A. Abfindung des Gutes Schwachhausen
B. Abfindung des Gutes Offensen
C. Beitragsquote zu den Abfindungen

$\S 22$. Abfindung der a.g. ${ }^{4}$ Herrschaft für die Grundherrschaft

A. Vergleich

B. Ausführung des Vergleichs und Beitragsquote der beteiligten Ortschaften

$\S 13$. Auseinandersetzung der Güter und Dorfes Oppershausen mit den

Ortschaften Altencelle, Osterloh und Lachtehausen
A. Vergleich

B. Ausführung des Vergleichs

$\S 14$. Auseinandersetzung zwischen Altencelle, Osterloh und Lachtehausen einerseits und Lachendorf und Ahnsbeck andererseits:
A. Vergleich
33
B. Ausführung des Vergleichs
34

$\S 15$. Festsetzung einer Grenze zwischen Lachendorf und Ahnsbeck einerseits und dem Gute und Dorf Oppershausen andererseits:

$\S 16$. Ausweisung eines Exerzierplatzes für die Königliche Militärverwaltung zu Hannover

$\S 17$ : Auseinandersetzung der beiden Gemeinden Lachendorf und Ahnsbeck
A. Vergleich
B. Ausführung des Vergleichs

$\S 18$. Auseinandersetzung zwischen den Ortschaften Altencelle und Osterloh einerseits und Ortschaft Lachtehausen incl. Der Försterstelle andererseits

$\S 19$. Auseinandersetzung zwischen den beiden Ortschaften Altencelle und Osterloh

A. Vergleich

57

B. Ausführung des Vergleichs

\footnotetext{
${ }^{1}$ Der Rezess ist handschriftlich in Sütterlin verfasst, für Orts- und Personennamen wurden aber lateinische Buchstaben verwandt. Quelle: Samtgemeinde, Archiv Akten, Fach/Nr. 61/8 Plan-Receß von 1861;

Abb. auf S. 6: Deckblatt des Originalrezesses

Der hier vorgelegte Text gibt den vollständigen Rezess in lateinischer Schrift wieder.

${ }^{2}$ Die Rechtschreibung wurde der modernen Regelung angepasst, außer bei Fachbegriffen und bei heute nicht mehr benutzten oder unbekannten Ausdrücken. Die Zeichensetzung wurde weitgehend beibehalten und teilweise ergänzt, um die Lesbarkeit der zeitgenössischen Ausdrucksweise zu erleichtern.

${ }^{3}$ Samtgemeinde Lachendorf, Archiv Akten, Fach/Nr. 61/8

4 a.g.: aller gnädigste
} 
$\S 20$. Vergleiche der Ortschaft Altencelle mit den Ortschaften Osterloh und Lachtehausen wegen gegenseitiger Weidegerechtsame in den Altencelle Fuhren und einigen anderen Revieren

$\begin{array}{ll}\text { A. Vergleich zwischen Altencelle und Osterloh } & 67\end{array}$

B. Vergleich zwischen Altencelle und Lachtehausen $\quad 69$

§ 21. Angelegte Wege und Triften $\quad 70$

$\S 22$. Künftige Benutzung der Abfindungen $\quad 72$

$\S 23$. Befriedigung der Abfindungen 73

$\S 24$. Erste Instandsetzung und künftige Unterhaltung der Wege

$\S 25$. Künftige Benutzung der Wege

76

§ 26. Entscheidung etwaiger Irrungen und Streitigkeiten 77

§ 27. Erfüllung und Dauer des Rezesses 77

Nachdem die Generalteilung der Allerheide und der angrenzenden Communion-Reviere Allerhorn, Allerohe, Lachendorfer Moor und Westernmoor vollendet und die Abfindungen den Beteiligten überwiesen worden, so ist nunmehr jedem legalen Abschluss derselben der nachstehende, die Stelle des Plans mit vertretende Rezess ausgefertigt.

\section{$\S 1$. Provocation und Erkenntnis}

Der Antrag auf Generalteilung der Allerheide ist von sämtlichen beteiligten Ortschaften, ausgenommen Lachendorf, gestellt und später auch auf Generalteilung der Allerohe, des Lachendorfer Moores und des Westernmoores ausgedehnt.

$\mathrm{cfr}^{1}$. No. act. 2. 5. 8. 9. 26.

Protocoll v. (21. März, 17. Mai) u. (16. August) 1844

$$
\text { " (22. März 1845) u. (30. März) u. (10. Juni) } 1846
$$

Königliche Landdrostei zu Lüneburg hat darauf die Generalteilung der Allerheide sowie der anderen genannten Communion-Reviere für stattnehmig (statthaft) erkannt und dabei bestimmt, dass die Gemeinde Lachendorf trotz ihres Widerspruches zu den Kosten des Teilungsverfahrens heran zu ziehen sei.

( No. act. 1. Rescr. K. L. vom 20. August 1844,

$$
\text { " "26, " " " "16. Febr. }{ }^{2} 1847 \text { ) }
$$

\section{§ 2. Kostenpunkt}

Hinsichtlich des Kostenpunktes ist unter den Beteiligten folgendes vergleichsweise festegestellt.

1. Die Kosten betreffend die Ausscheidung eines Exerzierplatzes trägt die Kriegsverwaltung allein. (cfr. No. act. 171. Prot. Vom 6. Nov. 1852)

2. 2. Zu sämtlichen bis incl. den 21. Nov. 1853 die Auseinandersetzung betreffenden Commissionskosten tragen bei:

a: Gut und Dorf Oppershausen 1 Teil

b. Dorf Ahnsbeck 1 Teil

c. Dorf Lachendorf 1 Teil

d. die Dörfer Altencelle, Lachtehausen und Osterloh zusammen 1 Teil

Summa 4 Teile

3. Die nach dem 21. Nov. 1853 erwachsenen Commissionskosten, wegen Auseinandersetzung der Gemeinden Altencelle, Lachtehausen und Osterloh, werden von diesen drei Gemeinden allein getragen ohne, dass die anderen drei Gemeinden und das

\footnotetext{
${ }^{1}$ conferatur: (lat. [man] vergleiche

${ }^{2}$ Die Monatsnamen werden, falls nicht ausgeschrieben, sehr unterschiedlich abgekürzt und hier so jeweils übernommen.
} 
Gut Oppershausen einen Beitrag dazu liefern. Unter den erstgedachten drei Gemeinden werden diese Kosten nach dem Werte ihrer Abfindungen repartirt.

4. Alle nach dem 21. November 1853 noch entstandenen und entstehenden, die sämtlichen Teilungs-Interessenten betreffenden Commissionskosten z.B. wegen Aufstellung und Vollziehung des Rezesses werden von allen in Frage kommenden Interessenten zu gleichen Teilen gestanden und tragen dazu bei.
a. Gut und Dorf Oppershausen
1 Teil
b. die Gemeinde Ahnsbeck
c. die Gemeinde Lachendorf
d. die Gemeinde Altencelle
$1 "$
e. die Gemeinde Lachtehausen
f. die Gemeinde Osterloh

$$
\begin{array}{lll}
1 " \prime & \\
1 " & \\
1 " & \\
1 " & \\
6 & & \text { Teile }
\end{array}
$$

5. Die Kosten wegen der technischen Bearbeitung: als Classification, Taxation, Vermessung, Aufstellung des Taxationsregisters und die Einteilungskosten werden nicht zusammen geworfen, sondern für den im Bezirk des Amtes Celle belegenen Anteil einerseits und den im Bezirk des Amtes Beedenbostel belegenen Anteil des Teilungsobjektes andererseits getrennt und besonders ermittelt, und trägt zu diesen Kosten jede Interessentenschaft als:

a. Das Gut und Dorf Oppershausen,

b. Die Gemeinde Lachendorf,

c. Die Gemeinde Ahnsbeck,

d. Die Gemeinde Altencelle

e. Die Gemeinde Osterloh

f. Die Gemeinde Lachtehausen,

nach dem Bonitätswert der erhaltenen Abfindung bei, jedoch nur in sofern, als die Abfindung vermessen und bonitiert ist.

(cfr. No. act 13: Prot. vom 21. Nov. 1853)

Zum gemeinschaftlichen Rechnungsführer ist der Syndicus Christoph Meyer zu Oppershausen erwählt. Derselbe bekömmt für seine Mühwaltung 2\% der Ausgaben.

(cfr. No. act 5, Prot. Vom 22. März 1845)

Nach dessen Tode ist sein Sohn Heinrich Wilhelm Meyer an dessen Stelle gewählt und ihm dieselbe Vergütung bewilligt.

(cfr. No. act 246)

\section{§ 3. Teilungskommission}

Das Commissarium zur Bearbeitung dieser Teilungssache ist dem Amtsassessor, jetzigem Amtsrichter Siemens zu Celle und dem L. O. Conducteur, jetzigem Landes-OecnomieCommissair Holekamp zu Celle übertragen.

(cfr. No. act 1, Reser. K. L. vom 20. August 1844)

\section{§ 4. Bezeichnung des Teilungsobjektes nach Lage und Grenzen}

Das Teilungsgebiet, dessen westlicher Teil im Amte Celle und dessen östlicher Teil im früheren Amte Beedenbostel belegen ist, bildet einen vollständig zusammenhängenden Komplex, der begrenzt wird:

Im Norden durch die herrschaftliche Forst Sprache und durch die Lachendorfer Feldmark,

im Osten durch die Lachendorfer und Ahnsbecker Feldmarken,

im Süden durch die Dreck- und Allerwiesen, durch die Aller und durch die Feldmark Oppershausen und im Westen durch die Osterbruchwiesen.

Die Grenzen haben sich als unbestritten herausgestellt. 


\section{$\S 5$. Vermessung und Bonitierung}

Die Dorfschaft und das Gut Oppershausen sind durch örtlich festgestellte Grenzen vergleichsweise vom Teilungsobjekt abgefunden, weshalb nur die den übrigen Beteiligten verbliebenen Flächen der Allerheide, das Lachendorfer Moor und das Westernmoor im Jahr 1850 durch den Geometer Michael einer Vermessung unterzogen und nach dem vorgeschriebenen Maßstab von 100 Ruthen gleich 6 Zoll kartiert sind.

Die Grenzen sind dabei durch die Vorsteher Vieth aus Altencelle, Syndicus Thies aus Lachendorf und Syndicus Dierks aus Ahnsbeck angewiesen.

Auf Beeidigung der Grenzanweiser ist von den Interessenten verzichtet.

(cfr. No. act. 25, Prot. vom 4. Juni 1846)

Die Bonitierung des nach Abfindung des Gutes und Dorfes Oppershausen verbliebenen Teilungsobjektes ist durch den Oeconomen Höfermann aus Eldingen, Oeconomen Michaelis aus Wienhausen und Vorsteher Benecke aus Eschede unter Leitung des LandesOeconomie-Commissairs Holekamp ausgeführt.

(cfr. No. act. 111, Prot. v. 25. Sept. 1850, act. 113 Prot. vom 26. Sept. 1850)

Die Resultate der Vermessung und Bonitierung sind im „Vermeß- und Taxations-Register“ zusammen gestellt und hat sich danach incl. der im Teilungsobjekte belegenen privaten Ackerländereien, Wiesen und Immenstellen für jede Bodenart in summa ergeben:

\begin{tabular}{|l|l|l|l|l|l|l|}
\hline & \multicolumn{3}{|l}{$\begin{array}{l}\text { 1. auf dem Reviere im } \\
\text { Amte Celle }\end{array}$} & \multicolumn{3}{l|}{$\begin{array}{l}\text { 2. auf dem Reviere im } \\
\text { früheren Amte Beeden- } \\
\text { bostel }\end{array}$} \\
\hline Bodenart & Mg. & QR & Kuhw. & Mg. & QR & Kuhw. \\
\hline Ackerland & & & & 21 & 56 & 1,1770 \\
\hline Wiesenboden & & & & 7 & 51 & 1,4074 \\
\hline Angerboden & 24 & 110 & 4,7175 & 108 & 56 & 14,8793 \\
\hline Moorboden & 344 & 99 & 28.6784 & 22 & 28 & 1,5346 \\
\hline Bruchboden & 61 & 92 & 6,5964 & 134 & 22 & 11,1319 \\
\hline Heidboden & 1634 & 76 & 102,5581 & 3995 & 32 & 137,0508 \\
\hline & 2076 & 20 & 142,5504 & 4289 & 5 & 217,2110 \\
\hline unbrauchbar & & 36 & & 7 & 6 & \\
\hline Summe & 2076 & 56 & & 4296 & 11 & \\
\hline
\end{tabular}

Nach geschehener Revision der Vermessungsarbeiten sind die Resultate der Vermessung und Bonitierung den Beteiligten vorgelegt und von ihnen als richtig anerkannt.

(cfr. No. act 140. Prot. v. 25. Sept. 1851)

\section{§ 6. Edictalladung ${ }^{1}$}

Die Edictalladung zur Anmeldung aller unbekannten Ansprüche an das Teilungsobjekt, und auch an die Altenceller Fuhren, ist auf gesetzlich vorgeschriebene Weise zur öffentlichen Kenntnis gebracht.

(cfr. No. act. 49, Edictall. v. 19. Aug. 1847)

Zu dem darauf abgehaltenen Edictaltermine sind folgende Ansprüche angemeldet:

1. von der Stadt Celle die Berechtigung zur Kuhweide auf der ganzen Allerheide,

2. von dem Gute Schwachhausen die Berechtigung zur Winterweide mit 300 Stück Schafen,

3. von dem Gute Offensen die Berechtigung zur Winterweide mit Schafen,

4. von dem Kloster Wienhausen die Berechtigung zu 8 Bienenstellen auf der Allerheide. Von Seiten der Interessenten ist die Berechtigung zu einer Stelle im s.g.

\footnotetext{
${ }^{1}$ Edict = Edikt: obrigkeitliche Bekanntmachung (Lutherzeit); öffentlich-rechtliche Bekanntmachung
} 
Birkenbusch auf der Allerheide zugestanden, zu mehreren aber in Abrede gestellt.

Der irrtümlich erhobene Anspruch ist nicht weiter verfolgt.

(cfr. No. act. 52. Prot. vom 23. Sept. 1847)

\section{$\S 7$. Beteiligte und deren Vertretung}

Bei der vorliegenden Generalteilung sind die nachfolgend aufgeführten Interessenten beteiligt:

1. die a.g. Herrschaft, vertreten durch den Cammer-Commissair Dreyer zu Celle. (cfr. No. act. 39. Vollmacht desselben vom 16. März 1847)

2. die Gemeinde Ahnsbeck incl. des Miliusschen Hofes daselbst.

Behuf Vertretung der Gemeinde sind zu Syndicen erwählt und bevollmächtigt:

a. der Geschworene Carsten Heinr. Dierks

b. der Köthner Carsten Heinrich Thies und

c. der Brinksitzer Hinrich Christoph Dierks

Der erste ist auch zugleich zur Vertretung der Schule zu Ahnsbeck beordert. (cfr. No. act. 2. Prot. v. ${ }^{1}$ April 1844

" $\quad, \quad 24$. Vollmacht des Dierks für die Schule

3. die Gemeinde Lachendorf 31. Erk. d. Th. C. v. 1. Nowbr. 1846)

Die Vertretung derselben ist durch die bestellten Syndicen

a: Geschworener Johann Heinrich Thies und

b. Köthner Carsten Heinrich Schwägermann geschehen.

Ersterer ist auch bevollmächtigt, das Interesse der Schule zu Ahnsbeck wahr zu nehmen.

(cfr. No. act. 2. Prot. v. 20. August 1844,

" " "24. Vollmacht v. 24. März 1846)

4. die Gemeinde Altencelle

Das Interesse derselben ist wahrgenommen durch die Syndicen

a. Vollhöfner Christoph Peters,

b. Köthner Diedrich Fehlmann,

c. Brinksitzer Christoph Biermann.

(cfr. No. act. 4. Prot. v. 18. März 1845)

5. die Gemeinde Osterloh, deren Interesse durch die zu Syndicen bestellten Vollhöfner Uetzmann und Warnecke vertreten worden ist.

(cfr. No. act. 3. Prot. v. 18. Mai 1845)

Dem ersteren ist später das Syndicat entzogen und nach dem Tode des letzteren ist der Sohn desselben, der jetzige Vollhöfner Hinrich Warnecke, zum alleinigen Syndicus für Osterloh erwählt und bevollmächtigt.

(cfr. No. act. 123. Prot. v. 15. Oct. 1850)

6. die Gemeinde Lachtehausen

Zu Syndicen für Lachtehausen sind ernannt:

a. der Vollhöfner Meine und

b. " " Uhle

(cfr. No. act. 2. Prot. v. 17. Mai 1844)

7. die Stadt Celle, deren Vertretung dem Stadtsecretair Hattendorff zu Celle übertragen worden ist. (cfr. No. act. 54. Vollmacht vom 8. Septbr. 1847)

8. das von der Wensesche Gut zu Oppershausen, vertreten durch den Oberappelations-Gerichts-Procurator Wolde, als Vormund der Erben des Gutes.

\footnotetext{
${ }^{1}$ Auslassung auch im Original
} 
9. die Gemeinde Oppershausen.

Zur Vertretung derselben sind

a. der Amts- und Gemeindegeschworene Christoph Meyer und

b. der Vollköthner Christian Runze

zu Syndicen bestellt.

(cfr. No. act. 2. Prot. v. 25 Septbr. 1844)

Für die Schule zu Oppershausen ist der Vollhöfner Gehrke daselbst bevollmächtigt.

(cfr. No. act. 24. vom 11. Juni 1846)

10. das vormals Schenk von Winterstedtsche Allodial-Gut ${ }^{1}$ Offensen

zu dessen Vertretung der Oeconom Gorden zu Schwachhausen beordert worden.

(cfr. No. act. 55 und 72)

11. Das vormals von Schenksche Lehngut Schwachhausen.

Die Vertretung desselben ist dem Amts-Assessor von Finkh zu Eicklingen übertragen.

(cfr. No. act. 33. Vollmacht desselben vom 9. September 1847)

12. die Königliche Militärverwaltung zu Hannover wegen Ankaufs eines Exerzierplatzes auf der Allerheide.

Zu den desfalligen Verhandlungen ist von der Königl. Militair-Verwaltung der Obrist Lieutnant Gelher, Commandeur des Regiments Herzog von Cambridge Dragoner zu Celle bevollmächtigt worden.

(cfr. No. act. 166)

\section{$\S 8$. Angabe der Berechtigungen der einzelnen Beteiligten}

1. Die Gemeinden Ahnsbeck und Lachendorf sind berechtigt zum Holze, zur Weide und zum Heid-, Plaggen- und Bultenhieb auf dem im früheren Amte Beedenbostel belegenen Teile der Allerheide, auf dem Lachendorfer Moor und auf dem Westermoor, die Gemeinde Lachendorf hat außerdem noch auf einem Teile der Heide innerhalb des Amtes Celle und auf der Allerohe die Berechtigung zur Weide.

2. Die Gemeinden Altencelle und Osterloh sind berechtigt zum Holze, zur Weide mit Hornvieh und Schafen, zum Heide-, Plaggen- und Bultenhieb auf dem Teilungsobjekt innerhalb der früheren Grenzen des Amtes Celle.

3. Die Gemeinde Lachtehausen incl. der Försterstelle und der Mühle zu Lachtehausen hat Berechtigung zur Weide mit Hornvieh und Schafen auf einem Teil innerhalb der früheren Grenzen des Amtes Celle.

4. Die Stadt Celle ist auf der Allerheide berechtigt zur Weide mit Hornvieh.

5. Das Gut und Dorf Oppershausen sind zur Weide mit Hornvieh und Schafen, zum Holze, zum Heide- und Plaggenhieb und zum Bultenhieb auf einem Teil der Allerheide, auf der Allerohe und dem Allerhorn berechtigt.

6. Die beiden Güter Offensen und Schwachhausen sind zur Winterweide mit Schafen berechtigt, im Falle es durch Zufrieren der Aller möglich ist mit den Schafen die Allerheide zu erreichen.

7. wird hier noch bemerkt, dass die Ortschaften Altencelle und Osterloh sowie Altencelle und Lachtehausen auf verschiedenen in den Feldmarken dieser drei Ortschaften belegenen Reviere Anspruch auf gegenseitige Weide-Gerechtsame erhoben, deren Abstellung bei Gelegenheit der Generalteilung der Allerheide mit geschieht.

\footnotetext{
${ }^{1}$ s. $\S 11$
} 


\section{§ 9. Auseinandersetzung der verschiedenen Nutzungsrechte}

Behuf Trennung der verschiedenen Nutzungsrechte ist bei jeder Classifications-Abteilung von den Taxatoren angegeben, der wievielte Teil davon auf die eine oder die andere Benutzungsart entfällt und sind die desfallsigen Äquivalente im Taxations-Register berechnet. Dasselbe ergibt, soweit das Teilungsobjekt vermessen und bonitiert worden:

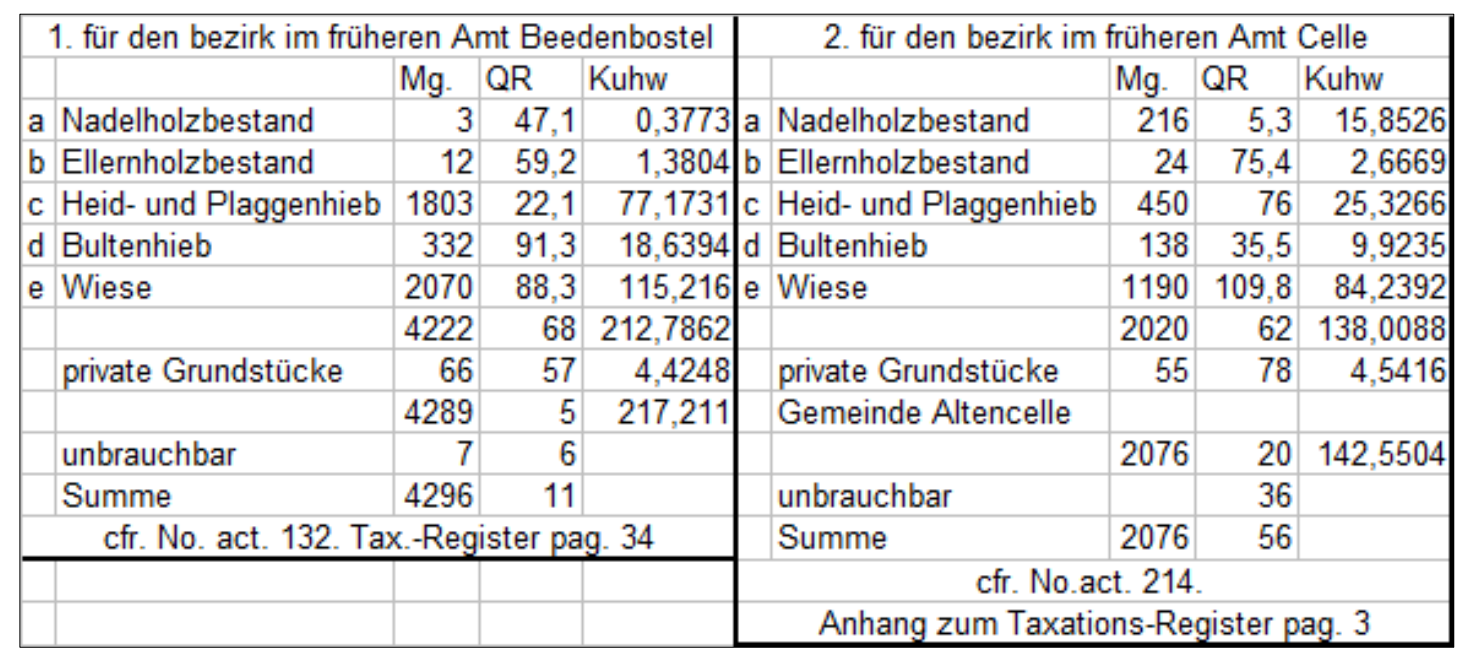

\section{$\S 10$. Abfindung der Stadt Celle}

Wegen des Professums der Stadt Celle hinsichtlich dessen die Syndici den beteiligten Ortschaften eingeräumt, dass seitens der profitierenden Stadt mit einigen städtischen Kühen samt Bullen in langjährigen Zwischenräumen ein Umtrieb um nur über einen Teil der zu teilenden Distrikte stattgefunden habe, ist mit den Vertretern der Stadt Celle, dem Stadtsekretair Hattendorff ein Vergleich abgeschlossen und vom Magistrat der Stadt Celle bestätigt, worauf die Stadt Celle für ihre beanspruchte Weidegerechtsame eine Abfindung von

$$
\text { vierzig Taler Courant }
$$

nach Vollziehung und Bestätigung dieses Rezesses von Seiten der beteiligten Gemeinden ausbezahlt wird, und die Stadt Celle von den bereits erwachsenen und den noch erwachsenden Kosten befreit bleibt.

(cfr. No. act. 52. Prot. v. 23. Sept. 1847

" , , 64 Schreiben des Magistrats der Stadt Celle vom 19. Oktober 1847)

Die Beitragsquote zu dieser der Stadt Celle zu zahlenden 40 Talern beträgt nach der zwischen den Syndicen der beteiligten Ortschaften getroffenen Übereinkunft:
1. für die Gemeinde Altencelle:
für 480 Kuhhäupter
2. " " , Osterloh
3. " " " Lachtehausen
4. für das Gut u. die Gemeinde Oppershausen
5. für die Gemeinde Ahnsbeck
$6 ., ", \quad$ Lachendorf Summa

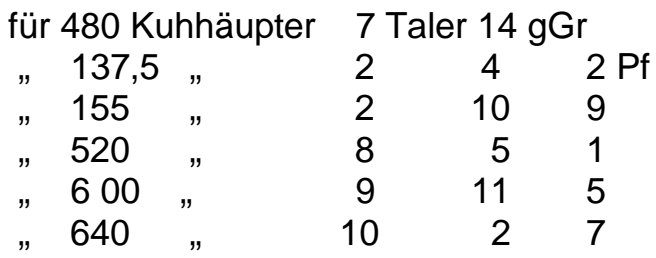 2532,5 Kuhhäupter 40 RTh

(cfr. No. act. 40. Prot. v. 26. März 1847

" $" \quad$ 70. Schreiben der Commission an die Syndicen vom 27. Decbr. 1847) 


\section{$\S 11$. Abfindung der Güter Schwachhausen und Offensen}

A. Abfindung des Gutes Schwachhausen

Zwischen den vom Königlichen Ministerium der Lehnssachen zu Hannover bestellten Vertreter des an die a.g. Herrschaft zurückgefallenen vormals von Schenkschen Lehngutes zu Schwachhausen, dem Amtsassessor von Finkh zu Gr. Eicklingen und den Syndicen der beteiligten Ortschaften ist folgender Vergleich abgeschlossen, und vom Königlichem Lehns-Ministerium zu Hannover bestätigt.

Es wird für die profitierte Winterweide der Gutsschafe dem Gute Schwachhausen und für dasselbe dem Königlichen Lehns-Ministerium eine Abfindung von sechzig Talern

am 2. Januar 1848 ausbezahlt und bleibt das Gut von allen Kosten befreit.

Das Gut Schwachhausen entsagt dagegen am 2. Januar 1848 auf immer aller Ansprüche an das Teilungsobjekt.

(cfr. No. act. 67. Prot. v. 15. Nowbr. 1847

\section{B. Abfindung des Gutes Offensen}

Wegen der, von dem vormals Schenk von Winterstedtschem Allodialgute ${ }^{1}$ zu Offensen auf einem Teil der Allerheide in Anspruch genommenen Winterweide für die Gutsschafe ist zwischen den Syndicen der Beteiligten Ortschaften und dem Gutspächter Gordon zu Schwachhausen, als ad acta bevollmächtigten Substituten des weil. Cassierers Hostmann zu Celle, als Mandator der Benificial Erbinnen des Gutes, ein Vergleich abgeschlossen und vom weil. Cassirer Holtmann zu Celle bestätigt, wonach dem Gute eine Abfindung von

\section{Fünfundvierzig Talern}

am 2. Januar 1848 ausbezahlt wird, und das Gut von allen bisherigen und künftigen Teilungskosten befreit bleibt, wogegen dann von dem gedachten Tage an das Gut Offensen aller und jeder Berechtigung an die zum Teilungsobjekte gehörenden Reviere entsagt. (cfr. No act 67, Prot. v. 15 Novbr. 1847

cfr. No. act. 69. Erklärung des Cassirers Holtmann zu Celle)

Die Berechtigung der Güter Schwachhausen und Offensen erstreckt sich nur über die Fläche des Teilungsobjektes wo außer den Gütern die Dorfschaften Lachendorf und Ahnsbeck und das Gut und Dorf Oppershausen allein berechtigt sind, weshalb auch die übrigen Ortschaften zu den Abfindungen der beiden Güter nicht concurrieren.

(cfr. No. act. 41. Prot. v. 22. April 1847)

Nach getroffener Übereinkunft tragen zu den Abfindungen der Güter von resp. 60 und 45 zusammen von 105 RTh bei:

1. das Dorf und Gut Oppershausen

2. die Gemeinde Lachendorf

3. „ „ Ahnsbeck

Summa
520 Kuhhäupter 31 Taler gGr. 7 Pf.

$640 \quad 38$ Taler $4 \mathrm{gGr} .4 \mathrm{Pf}$.

$600 \quad 35$ Taler $19 \mathrm{gGr} .1 \mathrm{Pf}$.

$1760, \quad 105$ Taler $^{2}$

(cfr. No. act. 41. Prot. vom 22. April 1847

cfr. No. act.70. Schreiben der Commission an die Syndicen vom 27. Decbr. 1847)

Die Abfindungssummen der beiden Güter Offensen und Schwachhausen sind an die Vertreter derselben laut der beigefügten Abschriften von den Quittungen der Empfänger vom 3. und 5. Januar 1848 ausgestellt.

(cfr. No. 82 und 83)

\footnotetext{
${ }^{1}$ Eigengut: nach mittelalterlichem Recht ein Besitz, über den der Eigentümer frei verfügen konnte und für dessen Erträge ursprünglich auch keine Steuern an den Landesherrn fällig waren. Gegensatz: Lehnsgut, das dem Lehnsnehmer nicht uneingeschränkt gehörte.

${ }^{2}$ Folgerungen für die benutzten Münzeinheiten: Gesamtsumme $=104$ Taler 23 ggr. $12 \mathrm{Pf}=105$ Taler; d.h. 23 ggr. $12 \mathrm{Pf}=1$ Taler, d.h. $12 \mathrm{Pf}=1$ ggr und $24 \mathrm{ggr}=1$ Taler
} 


\section{$\S 12$. Abfindung der a.g. Herrschaft für die Grundherrschaft}

A. Vergleich

In Folge eines, bereits vor Einleitung der Allerheide Teilung zwischen der Gemeinde Lachendorf und den damaligen Vertreter der a.g. Herrschaft, dem Cammer-Commissair Kirchner abgeschlossenen Vergleiches, nach welchem die Gemeinde Lachendorf der a.g. Herrschaft zur Abfindung der superflui auf den Lachendorfer Gemeinheiten eine Fläche von 60 Morgen abtreten sollte, sind bei der jetzigen Teilung der Allerheide, die eine Abgabe für Grundherrschaft betreffenden Verhandlungen zwischen dem Mandator Königlicher Domainen Cammer, dem Cammer-Commissair Dreyer und den Syndicen von Lachendorf eines Teils und den Syndicen der übrigen beteiligten Ortschaften andernteils besonders gepflogen, und ist nach mehrfachen Verhandlungen folgender Vergleich zwischen ihnen abgeschlossen:

Die a.g. Herrschaft erhält als Abfindung für die Grundherrschaft

1. von der Gemeinde Lachendorf 35 Morgen

2. und von den übrigen Gemeinden zusammen 25 Morgen

überhaupt also ein Areal von

60 Morgen

an die herrschaftliche Sprache angelegt.

Gegen Empfangnahme dieser Fläche verzichtet die a.g. Herrschaft in ihrer Eigenschaft als Grundeigentümerin nicht nur auf alle und jede Ansprüche, die ihr in dieser Eigenschaft am Teilungsobjekte, nämlich an der Allerheide, dem Lachendorfer Moor, dem Westernmoor, der Allerohe und dem Allerhorn zustanden, sondern sie begibt sich zugleich aller und jeder Ansprüche, die sie an den sonstigen Gemeinheiten der Interessenten in Rücksicht der des superflui und dessen Ausflüsse bisher gehabt hat, mit Ausnahme ihrer Ansprüche an das superfluum ${ }^{1}$ auf dem Schmarloh, welche in salvo ${ }^{2}$ bleiben sollen, so dass also bei demnächstigen Spezialteilungen der Interessenten oder sonstigen Kulturverbesserungen die a.g. Herrschaft in jener Hinsicht ex nexu ${ }^{3}$ bleibt.

$$
\begin{aligned}
& \text { cfr. No. act. 81. Prot. vom 4. März } 1848 \\
& \text { " } \quad, 84, \quad \text { 3. April } 1848 \\
& \text { " , } \quad 92, \quad, \quad \text { 7. Juli } 1848 \\
& 93 \text { Schreiben des Cammer-Commissairs Dreyer vom 15. Sept. 1848) }
\end{aligned}
$$

B. Ausführung des Vergleichs und Beitragsquote der beteiligten Ortschaften

Die vorhergehend festgestellte Abfindung der a.g. Herrschaft ist der Sprache an der südöstlichen Ecke angelegt und dem Mandatar Königlicher Domainen-Cammer am 13. Oktober 1852 ange- und überwiesen.

(cfr. No act 165. Prot. v. 13. Oktbr. 1852)

Der in der herrschaftlichen Abfindung belegene Lachendorf-Celler Fußsteig ist von Seiten der Gemeinde Lachendorf der a.g. Herrschaft mit 21 QRuthen = 0,0170 Kuhweiden entschädigt. Später hat jedoch die a.g. Herrschaft ihre Abfindung der Gemeinde Altencelle für Bauholz-Berechtigung in der herrschaftlichen Interessentenforst (cfr. No. act. 237 b) Scheuerbruch abgetreten, und hat darauf zwischen dieser Ortschaft und der Gemeinde Lachendorf ein Grenzvergleich stattgefunden, wodurch der Fußsteig in die Lachendorfer Abfindung fällt, so ist die Entschädigung für denselben an die Gemeinde Lachendorf zurückgefallen.

Das Beitragsverhältnis zu den, von Seiten der Interessenten excl. Lachendorf der a.g. Herrschaft abgetretenen 25 Morgen ist vergleichsweise festgestellt, und concurriren Interessenten daran in demselben Verhältnis nach welchem die Stadt Celle abgefunden ist.

Danach tragen zu der Abfindung der a.g. Herrschaft bei:

\footnotetext{
${ }^{1}$ Superfluum (lat: Überfluss: Anspruchsübersteigender Ertrag einer verpfändeten Sache (Wikipedia)

${ }^{2}$ Lat.; als ganzes

${ }^{3}$ Ex nexu (lat.) außer Verbindung; Exnexuation: Abtrennung, Aufhebung einer dinglichen Verpflichtung (Brockhaus - Kl. Konversations-Lexikon)
} 
1. die Gemeinde Altencelle für 480 Kuhhäupter $6 \mathrm{M}^{1} 41 \mathrm{QR}=0,6535$ Kuhweiden

2. " " Osterloh "137,5 " $" 98 "=0,1872$ "

3. " " Lachtehausen " 155 " 2 " $6=0,2113$ "

4. das Dorf und Gut Oppershausen für 520 " 6 " $6104,=0,7077$,

5. die Gemeinde Ahnsbeck "600 " 7 "111 " = 0,5398 "

Summa/Transport für 1892,5 Kuhhäupter $25 \mathrm{M}$. - QR $=2,2995$ Kuh.

6. die Gemeinde Lachendorf nach Separat-Verhandlungen $35 \mathrm{M}=2,3843$, Summa

(cfr. No. act. 97. Prot. vom 23. Juni 1849

$60 \mathrm{Mg} .=4,6838$ Kuhw.

" , " 145 Berechnung der herrschaftliche Abfindung)

$\S 13$. Auseinandersetzung des Gutes und Dorfes Oppershausen mit den Ortschaften Altencelle und Osterloh und Lachtehausen.

A. Vergleich

Behuf Auseinandersetzung des Gutes und Dorfes Oppershausen mit den Ortschaften Altencelle, Osterloh und Lachtehausen ist zwischen den Syndicen genannter Ortschaften und dem Vertreter des Gutes zu Oppershausen der nachfolgende Vergleich abgeschlossen.

1. die im früheren Amte Celle belegenen Gemeinden Altencelle, Osterloh und Lachtehausen geben die außerhalb der Amtsgrenzen in Anspruch genommene WeideBerechtigung nicht nur auf der Fläche, wo sie solche gemeinschaftlich in Anspruch genommen, sondern auch auf dem Bezirke, wo Osterloh die Weide nur allein exercirt hat, auf und treten

2. an das Gut und Dorf Oppershausen für deren Weide-Berechtigung auf dem im Bezirk des früheren Amtes Celle belegenen Teil der Allerheide, der dazu gehörenden Fuhren und dem Osterbruchmoore

Zweihundert und fünfundzwanzig Morgen von diesem Bezirke ab.

3. Diese Abfindung wird längs der Amtsgrenze von den Osterbruchwiesen bis zu dem neuen Ahnsbeck-Celler Wege abgetreten und durch eine gerade Linie von den Osterbruchwiesen an mit der früheren Amtsgrenze bis wohin sie sich etwas östlich schwenkt, parallel gegen die Gemeinden im früheren Amt Celle begrenzt.

(cfr. No. act. 40. Prot. v. 26. März 1847,

B. Ausführung des Vergleichs

48. Erklärung des Vertreters des Gutes zu Oppershausen)

In Folge des vorstehenden Vergleichs ist die dem $\mathrm{Amte}^{2}$ und Dorfe Oppershausen zugesagte Abfindung auf der Karte in vorgeschriebener Weise angelegt und berechnet mit 225 Morgen $=13,3843$ Kuhweiden.

Hiervon ist der Beitrag des Gutes und Dorfes Oppershausen zu der Abfindung der a.g. Herrschaft $($ s. $\S 12)=6$ Morgen $104 \mathrm{QR}=0,7077$ Kuhweiden parallel längst der Abfindungslinie mit $10 \mathrm{Mg}$. 68,3 QR = 0,7077 Kuhweiden abgesetzt und ist dem Gute und Dorf Oppershausen demnach eine Abfindung von 214 Mg. 51,7 QR _ 12,6766 Kuhweiden verblieben, welche Fläche an Ort und Stelle abgesteckt und den Interessenten angewiesen ist.

(cfr. No. act. 145 Berechnung und

" " $\quad 146$ Prot. v. 11. Octbr. 1851)

\footnotetext{
${ }^{1}$ Die Abkürzung für Morgen ist im Original unterschiedlich und ist hier wie im Original widergegeben.

${ }^{2}$ Vermutlich Schreibfehler: statt „Amt“ wäre lt. Kontext „Gut“ richtig.
} 
$\S 14$. Auseinandersetzung zwischen Altencelle, Osterloh und Lachtehausen einerseits und Lachendorf und Ahnsbeck andererseits.

\section{A. Vergleich}

Die Ortschaften Altencelle, Osterloh und Lachtehausen begeben sich ihrer außerhalb der Grenze des früheren Amtes Celle in Anspruch genommenen Berechtigungen in demselben Maße wie bei dem Vergleich mit Oppershausen (§ 13) und treten an die Gemeinde Lachendorf für deren Weide-Berechtigung auf dem, im Bezirk des früheren Amtes Celle belegenen Teil der Allerheide, von diesem Teil

\section{Einhundert Morgen}

ab. In dieser Fläche ist indess der Raum, den die Gemeinde Lachendorf und Ahnsbeck innerhalb des Bezirks des früheren Amtes Celle an die Königliche Domainen-Cammer abgetreten haben, mit inbegriffen.

Die an die Gemeinde Lachendorf abzutretende Fläche wird durch eine gerade, mit der früheren Amtsgrenze gleichlaufende Linie von dem, den Ortschaften Altencelle, Osterloh und Schwachhausen verbliebenen Bezirke getrennt.

(cfr. No. act. 40. Prot, v. 26 März 1847)

B. Ausführung des Vergleichs

Den Bestimmungen vorstehenden Vergleichs zufolge ist der Gemeinde Lachendorf innerhalb der Grenze des früheren Amtes Celle eine Fläche von 100 Morgen = 5,4790 Kuhweiden abgemessen und den betreffenden Syndicen angewiesen.

Nachdem jedoch die a.g. Herrschaft ihre Abfindung von 60 Morgen an die Gemeinde Altencelle abgetreten hat, so ist auf den Wunsch der Syndicen von Lachendorf und Ahnsbeck die Grenze zwischen diesen Ortschaften begradigt, indem Altencelle einen Teil der herrschaftlichen Abfindung an Lachendorf abgegeben hat, und dafür längs der neuen Lachendorfer Grenze nach der Bonität entschädigt worden ist.

(cfr. No. act. 145 Berechnung der Lachendorfer Abfindung, cfr. No. act. 192. Protokoll v. 5. Februar 1853, cfr. No. act. 209. Begradigung der Grenze.)

$\S 15$. Feststellung einer Grenze zwischen Lachendorf und Ahnsbeck einerseits und dem Gut und Dorf Oppershausen andererseits.

Wegen Ausscheidung des Gutes und Dorfes Oppershausen aus der Gemeinschaft mit den Gemeinden Lachendorf und Ahnsbeck ist folgende Grenze zwischen den Beteiligten verabredet und an Ort und Stelle bezeichnet.

Sie fängt in der früheren Amtsgrenze bei dem Punkte an wo die Grenze zwischen Altencelle und Lachendorf, von Norden herkommend dieselbe berührt, an und geht in südlicher Richtung zu einem Hügel zwischen Thies und Rehwinkels Immenzaune. Von diesem Hügel erstreckt sie sich dann in gerader östlicher Richtung nach der nordwestlichen Ecke des Fischteiches zu, und ist, damit Oppershausen einen Umzug um das Land erhält, etwa 30 Schritt rückwärts von der gedachten Ecke ein kleiner Hügel aufgeworfen. Von hier geht die Grenze etwas mehr links am Lande vorbei in gerader Linie zu einem gleichfalls etwa 30 Schritt von der nordöstlichen Ecke des Fischteiches aufgeworfenen Hügel und schwenkt sich dann südlich zu einem etwa 20 Schritt von der nordöstlichen Ecke von Böckers Land entfernt aufgeworfenen Hügel, von welchem die Grenze auf der nordöstlichen Ecke von Cammanns Kamp zu einem daselbst aufgeworfenen Hügel sich erstreckt.

Von diesem Hügel folgt die Grenze dann in südlicher Richtung dem Graben vor gedachtem Kampe bis aan die südöstliche Ecke desselben zu einem daselbst aufgeworfenen Hügel, und erstreckt sich von hier ab in gleicher südlicher Richtung und gerader Linie über die Heide auf die Grenze zwischen Schöndubes und Hans Heinrich Schellers Wiesen, wie solche von Süden her kommt, und ist sowohl an diesem Endpunkte, wie auch in der Mitte dieser geraden Linie zwischen hier und Thies-Cammanns Kamp ein neuer Grenzhügel aufgeworfen. Von dem Hügel vor den Wiesen geht dann die Grenze immer an den Wiesen als der Grenze der Weide entlang bis zur Aller. 
Das ganze Weiderevier rechts dieser Linie incl. der Allerohe wird dem Gute und Dorf Oppershausen privatim abgetreten, und gibt auch die Gemeinde Lachendorf ihre Stoppelweide auf den Twiehölzern ${ }^{1}$ ohne weitere Entschädigung auf.

Indem nun das Gut und Dorf Oppershausen durch diese beschriebene Grenzlinie von der Allerheide und allen damit in Verbindung stehenden und zur Auseinandersetzung gezogenen Reviere der sämtlichen interessierten Gemeinden getrennt worden, und aller ihrer außerhalb dieser Linie gehabten Benutzungen für immer entsagen, geschieht ein Gleiches von den übrigen Gemeinden auf den für Oppershausen ausgeworfenen Weide-Revieren.

Für die Allerohe, worauf außer Oppershausen Lachendorf nur allein zur Schafweide berechtigt gewesen, ist demselben ein besonderes Revier auf der Allerheide zur privativen Schafheide ausgesetzt. Bei der Auseinandersetzung zwischen Lachendorf und Ahnsbeck ist jedoch dieses Revier wieder zur Masse gezogen und kommt daher weiter nicht in Frage.

Auf der für Oppershausen nur gemittelten, vorhin beschriebenen Abfindungen werden die Wiesenwege und eine Trift drei Ruthen breit nach der Aller zum Trinken des Viehs und zum Waschen der Schafe in der Aller den Gemeinden Lachendorf und Ahnsbeck vorbehalten. Ebenso wird dem Gute und Dorfe Oppershausen eine drei Ruthen breite Trift vor und längs den Wiesen bis zu Drewes Furt behuf Beweidung der Allerwiesen vorbehalten. Diese Trift soll indessen nicht benutzt werden, wenn alle Wiesen leer oder abgehütet sind, mithin die Trift auf denselben ohne Unterbrechung stattfinden kann.

Die in der so festgestellten Abfindung für das Gut und Dorf Oppershausen belegene Immenstelle des Vollhöfners Carsten Heinrich Lüßmann zu Lachendorf verbleibt demselben.

(cfr. No. act. 41. Prot. v. 22. April 1847,

" " $\quad 43 . \quad, \quad 3$. Juli 1847,

" , " $205, \quad, \quad$ 8. Februar 1853,

" " " 48 Erklärung des Vertreters des Gutes Oppershausen v. 16. August 1847)

Im Laufe des weiteren Teilungsverfahrens hat die für das Gut und Dorf Oppershausen ausgemittelte Grenze eine Veränderung erhalten, nachdem die Linie von dem Hügel zwischen Thies und Rehwinkels Immenstelle bis zum ersten Hügel von dem Fischteich, an diesem Ende bis zu dem etwa 30 Schritt von der nordöstlichen Ecke des Fischteiches entfernt liegenden Hügel verrückt und am anderen Ende zwischen Thies und Rehwinkels Immenzäunen um ebensoviel nach der entgegengesetzten Richtung herumgedreht ist.

(cfr. No. act. 192. Prot. v. 5 Febr. 1853)

\section{§16. Ausweisung eines Exerzierplatzes für die Königliche Militärverwaltung Hannover}

In Gemäßheit der Verordnung vom 24. Mai 1829, die Benutzung von Exerzierplätzen betreffend, ist vom Königlichen Kriegs-Ministerium zu Hannover auf der Allerheide ein Exerzierplatz von 240 Morgen Größe in Anspruch genommen.

( cfr. No act 156 )

In Folge dessen sind mit den auf der Allerheide interessierten Ortschaften Verhandlungen zugelegt, da jedoch die von der Militairverwaltung zum Exerzierplatz beanspruchte Fläche auf den den Gemeinden Lachendorf und Ahnsbeck bereits zugefallenen Revieren belegen ist, so haben die übrigen Gemeinden erklärt, keinen Anspruch an diese Fläche machen zu wollen.

(cfr. No. act. 163. Prot. v. 13. Octbr. 1852)

Die Verhandlungen wegen Ausweisung eines Exerzierplatzes sind darauf mit den Syndicen beider Ortschaften Lachendorf und Ahnsbeck allein weiter fortgeführt und sind dieselben mit dem Vertreter der Königlichen Militairverwaltung dem Oberst Lieutenant Gelher überein gekommen,

dass ein Exerzierplatz von 240 Morgen Größe gegen Erlegung des, durch Abfindung von sachverständigen Männern festzustellenden Kaufpreises der Königlichen Militairverwaltung überlassen werden solle.

(cfr. No. act. 165. Prot. v. 13. October 1852

\footnotetext{
${ }^{1}$ Offenbar ein Flurname, der aber sonst im Rezess nicht vorkommt und im Original auch entgegen der sonstigen Praxis in Sütterlin geschrieben ist.
} 


$$
" \quad, \quad 171 . \quad, \quad, \quad 6 . \text { Novbr. 1852) }
$$

Zu dem Ende sind

der Oeconom Jens zu Wardböhmen,

" Hoppe zu Wienhausen,

der Forstamts Auditor Duckstein zu Helmerkamp

zu Schätzern erwählt und nach vorheriger Instruktion mit dem Taxatoren-Eide belegt.

(cfr. No. act. 172. Instruktion

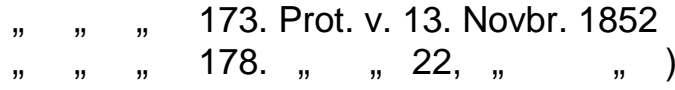

Diese drei Achtsmänner haben darauf den jährlichen Wert von 240 Morgen nach Abzug aller Unkosten und der jährlichen Grundsteuer auf 91 RTh $12 \mathrm{gGr}$ festgestellt, worauf derselbe mit 3\% kapitalisiert die Schlusssumme von 3050 RTh ergibt, wovon jedoch für den ersten achtjährigen Turnus die Hälfte de jährlichen Ertrages mit 366 RTh abzusetzen ist.

(cfr. No. act. 179. Gutachten vom 23. November 1852)

Aufgrund dieser Abschätzung haben der Vertreter Königlicher Kriegsverwaltung und die Syndicen der beiden Gemeinden Lachendorf und Ahnsbeck sich dahin geeinigt, dass für Abtretung von 240 Morgen an die Königliche Militairverwaltung den beiden Gemeinden Lachendorf und Ahnsbeck die Summe von 2684 RTh ausbezahlt werden solle.

(cfr. No. act. 184. Prot. vom November 1852

$\quad \quad, \quad, \quad$ 187. Schreiben des O.L. Gelher vom 9. Dezember 1852)

Außer den 240 Morgen ist von den beiden Gemeinden Lachendorf und Ahnsbeck der Königlichen Militairverwaltung noch die nötige Fläche zu zwei 21/2 ruthigen Wegen von den Hauptwegen auf der Allerheide ab nach dem Exerzierplatze überlassen.

Die Fläche dieser beiden Wege beträgt 53 und 49 QR zusammen 102 QR. Später sind diese Wege auf 3.0 verbreitert. Diese zur Verbreiterung erforderliche Fläche hat die Gemeinde Lachendorf allein hergegeben, sie beträgt für beide Wege $22 \mathrm{QR}$, so dass also die ganze Fläche der beiden Wege sich auf 1 Morgen 4 QR beläuft.

Diese 1 Morgen 4 QR werden nach denselben Prinzipien, wie der Exerzierplatz selbst, von der Königlichen Militairverwaltung erstanden.

(cfr. No. act. 184. Prot. v. 24. Nowbr. 1852; cfr. No. act 199 Prot. v. 11. April 1853)

Nachdem so die Kaufsumme des Exerzierplatzes festgestellt worden, so ist derselbe nebst den beiden zugehörigen Wegen in vorher verabredeter Form örtlich ausgestellt und dem Mandator Königlicher Militairverwaltung am 11. April 1853 ange- und überwiesen und der Kaufpreis den Syndicen der beiden Gemeinden Lachendorf und Ahnsbeck an demselben Tage mit:

$2684 \mathrm{RTh}-\mathrm{gGr}$ Und der der beiden Wege von den Hauptwegen nach dem Exerzierplatze mit 11 RTh $13 \mathrm{gGr}$

In summa $2695 \mathrm{RTh} 13 \mathrm{gGr}$

Ausbezahlt worden, wodurch die Fläche des Exerzierplatzes wie auch die dazu gehörenden beiden Wege von dem Tage an in den privativen Besitz der Königlichen Militairverwaltung übergegangen ist.

Die Gemeinden Lachendorf und Ahnsbeck entsagen aller und jeder Anrechte an dem ausgesteckten Exerzierplatze und den beiden dazu gehörenden Wegen und übernehmen auch die Garantie, dass der ausgesteckte Exerzierplatz die Fläche von 240 Morgen wirklich enthält.

(cfr. No. act. 199. Prot. v. 11. April 1853)

Die auf dem Exerzierplatz ${ }^{1}$ abgetretenen Termin belegene Immenstelle des Kötners Carsten Koch zu Lachendorf geht als solche ein und wird dem Eigentümer von der Gemeinde Lachendorf anderweitig entschädigt.

(cfr. No. act. 178. Prot. v. 20. Novbr. 1852)

\footnotetext{
${ }^{1}$ Hier fehlt vermutlich im Originaltext das Wort „zum“
} 


\section{$\S 17$. Auseinandersetzung der beiden Gemeinden Lachendorf und Ahnsbeck}

\section{A. Vergleich}

Behuf Auseinandersetzung der beiden Gemeinden Lachendorf und Ahnsbeck ist zwischen den Syndicen der beiden Ortschaften der nachfolgende Vergleich abgeschlossen:

1. Die privaten Immenstellen und die Wiese des Vollmeiers Lüßmann zu Lachendorf auf dem Teilungsrevier werden den jetzigen Besitzern reserviert.

(cfr. No act. 192, Prot. v. 5. Febr. 1853

Die Immenstelle des pp. Carsten Koch zu Lachendorf auf dem von Königlicher Militairverwaltung aquirierten Exerzierplatz geht jedoch ein und wird pp. Koch von der Gemeinde Lachendorf anderweitig. entschädigt.

(cfr. No act. 178, Prot. v. 22. Novbr. 1852)

2. Alle übrigen Flächen der Allerheide, des Lachendorfer Moores, des Western Moores und des Kammerwinkels, überhaupt alle zwischen Lachendorf und Ahnsbeck gemeinschaftlichen Flächen, soweit sie jetzt in Teilung begriffen und auf der Karte verzeichnet sind, imgleichen die bisherige privativen Holz-, Heide- und Plaggenhiebsflächen so wie auch die privativen Kuhweiden der beiden Gemeinden und die früher der Gemeinde Lachendorf privatim zugefallene Fläche vor den trockenen Wiesen bei Cammanns Kamp so wie auch die aus dem Bezirke des früheren Amtes Celle herübergekommenen 100 Morgen werden zu einem Ganzen vereinigt.

(cfr. No. act. 192. Prot. v. 5. Febr. 1853)

3. Die beiden Brinksitzer Gockenholz und Lindmüller zu Ahnsbeck haben früher zusammen 9 Morgen in der Allerheide ausgewiesen erhalten, da sie bislang indessen nur 6 Morgen und 29 QR in Besitz gehabt haben und die Grenzen der ausgewiesenen Fläche verloren sind, so soll innen die noch fehlende Fläche von 2 Morgen und $91 \mathrm{QR}$ abgemessen werden.

(cfr. No. act: 204. Prot. v. 8. Febr. 1853)

Diese $2 \mathrm{Mg} 91 \mathrm{QR}$ nebst den von dem Königlichen Ministerium angekaufte Exerzierplatz werden von der Ahnsbecker und Lachendorfer Gesamtfläche gekürzt und erhält dann von dem Rest die Gemeinde Lachendorf zwei Teile und die Gemeinde Ahnsbeck einen Teil.

4. Von den Kaufgeldern für den abgetretenen Exerzierplatz erhält die Gemeinde Lachendorf gleichfalls zwei Teile und die Gemeinde Ahnsbeck einen Teil.

5. Jede der beiden Gemeinden wird der Anteil, welche dieselbe zu den an die a.g. Herrschaft abgetretenen 60 Morgen beigetragen hat, gekürzt.

6. Die erforderlichen Wege und Triften steht jede Gemeinde auf ihrer Abfindung, ohne Beitrag der anderen.

7. Die Hauptwege und Triften werden in der Ahnsbecker Abfindung der Gemeinde Lachendorf noch besonders vorbehalten, doch solle dieselben nicht über 21/2 R breit angelegt werden.

(cfr. No. act. 192. Prot. v. 5. Februar 1853)

\section{B. Ausführung des Vergleichs}

Die nach vorstehendem Vergleich aufgestellte Auseinandersetzungs-Berechnung ergibt, dass von dem Teilungsobjekte erhalten sollen:

Ahnsbeck 1357 Mrg. 84,3 QR = 69,2212 Kuhweisen

Lachendorf 2695 Mrg. 97,7 QR = 137,1135 Kuhweiden)

$\mathrm{Zu}$ der Abfindung der Gemeinde Lachendorf kommt noch hinzu:

1. die Entschädigung für den Fußsteig in der Abfindung der a.g. Herrschaft, welche Entschädigung durch die Grenzbegradigung zwischen Altencelle und Lachendorf an letztere Gemeinde zurückfällt (vide $§ 14$ )

$\begin{array}{rcc}- \text { M. } & 31 \quad \text { QR }=0,0170 \text { Kuhw. } \\ 2696 \text { M. } & 8,7 \text { QR }=137,1315,\end{array}$

2. die Immenstelle des Carsten Koch zu Lachendorf auf dem verkauften Exerzierplatze, welche die Gemeinde Lachendorf dem pp. Koch anderweitig zu entschädigen hat

Die Abfindung der Gemeinde Lachendorf beträgt demnach $61 \mathrm{QR}=0,0203 \mathrm{Kuhw}$. 
Nach Vorstehendem sollen also erhalten:

Ahnsbeck $1357 \mathrm{Mrg} 84,3 \mathrm{QR}=69,2212 \mathrm{Kuhw}$.

Lachendorf 2696 Mrg. 69,7 QR = 137,1508 Kuhw.

Zusammen $4054 \mathrm{Mrg} 34$ QR $=206,3720$ Kuhw.

(cfr. No. act 208 Auseinanders.-Berechnung)

Die Ortslage der Abfindungen ist durch Verhandlung mit den Syndicen der beiden Ortschaften vergleichsweise festgestellt und sind die Abfindungslinien darauf örtlich abgesteckt und den Syndicen angewiesen.

Nach dem Verteilungsregister haben erhalten:

1. die Gemeinde Lachendorf 2831 M. $60 \mathrm{QR}=137,1508$ Kuhw.

2. die Gemeinde Ahnsbeck 1221 M. 52 QR = 69,2212 Kuhw.

Summa 4052 M. $113 \mathrm{QR}=206,3720 \mathrm{Kuhw}$.

Die zugeteilte Summe differiert mit der in der Auseinandersetzungs-Berechnung angegebenen Fläche um 1 Mrg. 41 QR, welche bei dem Grenzvergleich zwischen Lachendorf und Altencelle (vide ${ }^{1} \S 14$ ) letztere Ortschaft mehr bekommen hat.

$\S 18$ Auseinandersetzung zwischen den Ortschaften Altencelle und Osterloh einerseits und der Ortschaft Lachtehausen incl. der Försterstelle andererseits.

Behuf Ausscheidung der Gemeinde Lachtehausen incl. der Försterstelle daselbst aus der Gemeinschaft mit Altencelle und Osterloh auf der Allerheide ist zwischen den betreffenden Vertretern folgender Vergleich abgeschlossen:

Die Gemeinde Lachtehausen incl. der dortigen Försterstelle erhält für ihre bisherigen Berechtigungen auf der Allerheide, mit Einschluss der Altenceller Fuhren, eine reine Abfindung von 11 bonitierten Kuhweiden ohne irgend eine Kürzung als Abgabe an die a.g. Herrschaft für die bisherigen Grundrechte und Beitrag zu den Wegen und Abzugsgräben.

Dies Abfindung bekommt die Gemeinde Lachtehausen in einer Fläche von ihrer Grenze an, mit Einschluss des, der Dorfschaft Altencelle privatim gehörenden s.g. Risches, das zu diesem Zwecke mit vermessen und bonitiert ist und wird im Osten durch eine gerade Linie von der Sprache nach dem s.g. Langenförth zu begrenzt.

Diese Fläche von 11 bonitierten Kuhweiden wird der Gemeinde Lachtehausen ganz privatim übergeben, und gehen die bisher etwa darüber geführten Wege mit Ausschluss der Wiesenfahrwege und der Wege nach den privativen Büschen ein.

Wegen der zur Försterstelle zu Lachtehausen gehörenden herrschaftlichen Immenstelle auf dem den Gemeinden Altencelle und Osterloh verbleibenden Teil der Allerheide ist folgendes beschlossen:

Die a.g. Herrschaft gibt die bisherige Immenstelle auf und erhält dafür eine Entschädigung von 60 QR nach der Durchschnitts-Bonität derselben privatim.

Diese Entschädigung wird vorläufig der Lachtehäuser Abfindung angeschlossen und wird es der a.g. Herrschaft und der Gemeinde Lachtehausen überlassen, sich über die Lage derselben zu einigen. Findet eine solche gütliche Einigung aber nicht statt, so wird diese Immenstelle innerhalb der Lachtehäusener Abfindung an der Sprache, in der Ecke, wo die Lachtehäuser-Altenceller Grenzlinie an die Sprache stößt, angelegt.

In diesem Falle dient dann als Weg dahin der Celler-Ahnsbecker Weg und der Abfahrweg aus der Sprache.

(cfr. No. act. 220. Prot. v. 1. April 1854,

" " 230. Schreiben des Cammer-Commissairs Dreyer vom 30. April 1844)

Die Weide-Gerechtsame der Gemeinde Lachtehausen in dem, in dem Teilungsgebiete am Langenförth belegenen s.g. Küsterbusch der Küsterstelle zu Altencelle verbleibt derselben in Gemeinschaft mit Altencelle nach wie vor und dient als Trift dahin der Celler- Ahnsbecker Weg.

\footnotetext{
${ }^{1}$ lat. siehe
} 
Durch die Anlage dieses Weges ist der Busch jedoch um $76 \mathrm{QR}=0,0300$ Kuhweiden verkleinert, welche Fläche der Küsterstelle von der Gemeinde Altencelle noch zu entschädigen ist.

Von dieser abgeschnittenen Fläche hat die Gemeinde Lachtehausen ihre Weide-Abfindung verlangt, das Weideäquivalent ist daher vergleichsweise festgestellt zu 1/30 der Fläche, wovon Lachtehausen $1 / 4$ erhält. Dies beträgt $0,6 \mathrm{QR}=0,0003$ Kuhweiden.

(cfr. No. act. 221. Prot. v. 7. April 1854)

(cfr. No. 228. Auseinandersetzungsberechnung)

Die ganze Lachtehäuser Abfindung von der Allerheide beträgt demnach:

1. für Weide-Gerechtsame auf den Communion-Revieren 11,0000 Kuhw.

2. für Weide-Gerechtsame auf

der vom s.g. Küsterbusche abgeschnittene Fläche 0,0003 Kuhw.

3. die Entschädigung für die herrschaftliche Immenstelle $\quad=60 \mathrm{QR}=0,0357 \mathrm{Kuhw}$.

Summa 11,0360 Kuhw.

Diese so festgestellte Abfindung der Gemeinde Lachtehausen incl. der Försterstelle daselbst ist auf der Karte verzeichnet, örtlich abgesteckt und den beteiligten Interessenten angewiesen.

Nachdem Verteilungsregister hat die Gemeinde Lachtehausen erhalten:

\begin{tabular}{lc} 
& $120 \mathrm{Mg} .106 \mathrm{QR}=11,0360$ Kuhw. \\
Unbrauchbar & $25 \mathrm{QR}$ \\
\hline Summa & $121 \mathrm{Mg} 11 \mathrm{QR}$
\end{tabular}

$\S 19$ Auseinandersetzung zwischen den beiden Ortschaften Altencelle und Osterloh.

A. Vergleich

Zwischen den beiden Ortschaften Altencelle und Osterloh ist behuf ihrer Auseinandersetzung auf der Allerheide folgende Übereinkunft getroffen:

1. den abgeschätzten Laubholzbestand erhält Altencelle allein,

2. das gemeinschaftliche Nadelholz wird dergestalt verteilt, dass davon erhält:

$$
\begin{aligned}
& \text { Altencelle } 241 \text { Teile und } \\
& \text { Osterloh } 29,
\end{aligned}
$$

3. der abgeschätzte Bultenhieb wird unter beiden Gemeinden nach den Feuerstellen verteilt und erhält dann

Altencelle 59 Teile und

Osterloh 6 ,

4. die Altencelle und Osterloh verbleibende Weide so wie auch der abgeschätzte Plaggen- und Heidhieb soll nachdem zu den Orten genommenen ViehbesteuerVerzeichnisse unter Berücksichtigung der Bestimmungen des Protokolls vom 8. April 1846 No. act 17 verteilt werden.

Demnach wird der Viehbestand angenommen:

a) für Altencelle

\begin{tabular}{ll}
300 Stück altes Hornvieh & $=300$ Weidekühe \\
60 "junges $"$ & 30 \\
$1500 "$ Schafe & 150 \\
\hline Summa & 480 Weidekühe
\end{tabular}

b) für Osterloh

$\begin{array}{ll}75 \text { Stück alte Hornvieh } & =75 \text { Weidekühe } \\ 25 \text { " junges " } & 12,5 " \\ 500 \text { Schafe } & =50\end{array}$

5. Zu den Wegen wird von jeder gemeinde nach Maßgabe der Gesamtabfindung beigetragen.

(cfr. No. act. 210. Protokoll v. 29. Juli 1853)

B. Ausführung des Vergleichs 
Nachdem Taxations-Register pag. 18 beträgt der ganze in die Teilung genommene Grundbesitz innerhalb der grenzen des früheren Amtes Celle

Dazu kommen diejenigen Flächen, welche behuf Anlage

2076 M. 20 QR $=132,5504$ Kuhw.

der Wege von privativen Grundstücken einzelner

Interessenten in die Masse geworfen sind, als

1. von Leifert zu Altencelle

2. von der Küsterstelle zu Altencelle

Und beträgt demnach die ganze Summe des

Teilungsobjektes

Kuhw.

Hiervon haben bereits zugeteilt erhalten:

1. die a.g. Herrschaft und zwar denjenigen Anteil, welchen die Örter Altencelle, Osterloh und Lachtehausen und das Gut und Dorf Oppershausen zu der ganzen herrschaftlichen Abfindung beigetragen haben

2. Lachendorf und Ahnsbeck

3. Dorf und Gut Oppershausen

4. Lachtehausen

17 M. $9 \mathrm{QR}=1,7597 \mathrm{Kuhw}$.

$1 \mathrm{M} .11 \mathrm{QR}=0,0780$,

2078 M. $\quad 7$ QR $=142,7084$

Summa
Nach Absatz dieser Flächen bleibt von dem

Teilungsobjekte innerhalb der Amtsgrenzen

$100, \quad=5,4791$,

$214,51,=12,6766$,

$120,106,=11,0360$

452 Mg. 46,7 QR = 30,9514 Kuhw.

Hiervon wird abgesetzt:

1. diejenige Fläche, welche Altencelle privatim

gehört, das Risch und das Langenförth

2. die Entschädigung des pp. Leifert zu Altencelle

für abgetretenen Grundbesitz behuf Anlage der Wege

3. des gleichen der Küsterstelle zu Altencelle

Summa

und bleibt an Communion-Revieren für

Altencelle und Osterloh

Hiervon der Betrag der Wege in den

Communion-Revieren abgesetzt mit

Bleibt zwischen Altencelle und Osterloh zur

Verteilung

1625 M. 80,3 QR = 111,7570 Kuhw.

Laut der Auseinandersetzungsberechnung erhalten dann

1. Altencelle

2. Osterloh

55 M. $78 \quad Q R=4,5416$ Kuhw.

$96 \mathrm{QR}=0,0800$

1M. $11 \mathrm{QR}=0,0780$ "

57 M. $65 \quad \mathrm{QR}=4,6996$ Kuhw.

1568 M. 15,3 QR =107,0574 Kuhw.

$19,10,=1.1999$,

$1549 \mathrm{M} \quad 5,3 \mathrm{QR}=105,8575$ Kuhw.

1249 M. $80,4 \mathrm{QR}=85,9082$ Kuhw.

$299,44,9 \mathrm{QR}=19,9493$,

Außer der Abfindung uns den wirklichen Communion-Revieren

mit Osterloh soll Altencelle erhalten:

1. das in die Masse geworfene privative Risch

und das Langenförth

2. die ganze herrschaftliche Abfindung für

Bauholz-Berechtigung in der forstlichen

Interessentenforst Scheuerbruch

Summa

55 M. $78 \mathrm{QR}=4,5416$ Kuhw.

Dazu die Abfindung aus den

Communion-Revieren mit Osterloh

Soll Altencelle erhalten

$60, \quad=4,6838$ Kuhw.

115 M. 78 QR $=9,2254$ Kuhw.

$1365 \mathrm{M} 38,4 \mathrm{QR}=95,1336 \mathrm{Kuhw}$.

Die Küsterstelle zu Altencelle hat $1 \mathrm{Mg} .11 \mathrm{QR}=0,0780$ Kuhweiden privativen Grundbesitz behuf Anlage der Wege in die Masse geworfen, welche derselben wieder entschädigt werden müssen. Zu diesem zwecke sind derselben $55 \mathrm{QR}=0,0381$ Kuhweiden an den s.g. Küsterbusch hinangelegt und gebühren daher der Küsterstelle

zu Altencelle noch

Aus demselben Grunde wie die Küsterstelle soll der

Köthner Leifert zu Altencelle erhalten
- M. $76 \mathrm{QR}=0,0399 \mathrm{Kuhw}$.

$96 \mathrm{QR}=0,0800$ 
Diese Entschädigung für abgetretenen privativen Grundbesitz übernimmt vorläufig die Gemeinde Altencelle und werden erst bei nachfolgender Spezialteilung der AllerheideAbfindung der Küsterstelle und Leifert zu Altencelle zugeteilt.

Die Gesamtsumme der Abfindungen incl. der besonderen Entschädigungen für die Küsterstelle und Leifert zu Altencelle sollen demnach betragen:
1. für Altencelle
1366 M. 90,4 QR = 95,2535 Kuhw.
2. für Osterloh
$299,44,9,=19,9493$
$1666 \mathrm{Mg} .15,3 \mathrm{QR}=115,2028$ Kuhw.

Summa
(cfr. No. act. 228. Auseinandersetzungs-Berechnung)

Hiervon betragen die Holzbestandsflächen

1. für Altencelle

a. (No. act. 228. pag 13)

b. die von der a.g. Herrschaft auf der

Allerheide erhaltene Holzbestandsfläche

$$
\text { Summa }
$$

$218 \mathrm{Mg} .33,1 \mathrm{QR}=16,8944$ Kuhw.

$\begin{aligned} 60 \mu & =4,6838 \\ 278 \mathrm{Mg} .33,1 \mathrm{QR} & =21,5782 \text { Kuhw. }\end{aligned}$

\section{2. für Osterloh}

(No. act. 228 pag 14)

$$
\text { 22Mg. 47,6 QR = 1,6251 Kuhw. }
$$

Nachdem so die Abfindungen der beiden Ortschaften Altencelle und Osterloh nach der getroffenen Übereinkunft berechnet worden, ist den Syndicen derselben die Auseinandersetzungs-Berechnung vorgelegt und von ihnen als richtig anerkannt.

(cfr. No. act. 227. Prot. v. 23. April 1854)

Wegen Ortslage der Abfindungen sind mit den Syndicen Verhandlungen zugelegt und ist dieselbe vergleichsweise festgestellt und nach örtlicher Absteckung derselben angewiesen.

Nach dem Verteilungsregister haben zugeteilt erhalten:

$$
\text { Altencelle } \quad 1372 \mathrm{Mg} .103 \mathrm{QR}=95,2535 \mathrm{Kuhw} \text {. }
$$

\begin{tabular}{ccc} 
Osterloh & 294, & $73,3 \mathrm{QR}=19,9493$. \\
\hline Summa & $1667 \mathrm{Mg}$. & $56,3 \mathrm{QR}=115,2028$ Kuhw.
\end{tabular}

(cfr. No. act. 235)

Die wirklich verteilte Fläche differiert mit der, in der Auseinandersetzungs-Berechnung angegebenen um $1 \mathrm{Mg}$. $41 \mathrm{QR}$, welche Fläche bei der Grenzbegradigung zwischen Altencelle und Lachendorf erstere Ortschaft erhalten hat.

(cfr. $\S 14$ u. 17 dieses Rezesses und No. act. 209 Berechnung wegen Begradigung der Grenze.)

Die in der Altenceller Abfindung belegenen Immenstellen sind bei der Auseinandersetzung zwischen Altencelle und Osterloh mit in die gemeinschaftliche Teilungsmasse geworfen, weil die in dem Altenceller-Osterloher Bezirke auf der Allerheide belegenen denselben Bonitäten unterworfen sind, sowohl hinsichtlich des Holzes, wie der Weide, dem Heid- und Plaggenhieb und dem Bultenhieb, wie die übrigen Flächen der Allerheide und die Besitzer der Immenstellen nur das Recht haben, ihre Immen darauf zu stellen, welches Recht innen auch wie vor unbenommen bleibt.

In der Altenceller Abfindung sind mit je einer Immenstelle belegen

1. Vollhöfner Joh. Hr. Lindemann zu Altencelle

2. Großköthner Christian Bruns

3. Kleinköthner Heinrich Ohlens " "

4. " Heinr. Sohnemann ", "

5. $\quad$ Christian Hoppe zu Osterloh 
$\S 20$. Vergleich der Ortschaft Altencelle mit den Ortschaften Osterloh und Lachtehausen wegen gegenseitiger Weide-Gerechtsame in den Altenceller Fuhren und auf einigen anderen Revieren.

Wegen Aufhebung gegenseitiger Weidegerechtsame der Ortschaften Altencelle mit den Ortschaften und Lachtehausen in den nicht zum Allerheide-Teilungsobjekte gehörenden Altenceller Fuhren und auf einigen anderen Revieren sind unter den Beteiligten folgende Vergleiche abgeschlossen:

A. Vergleich zwischen Altencelle und Osterloh

Die Gemeinde Altencelle verzichtet auf ihre Weide-, Trift- und Hut-Berechtigung in allen auf der Osterloher Feldmark belegenen Revieren, als: auf dem Pferdelager, dem Bullenberge, vor den großen Wahlen, im Allerhoog, im Redder vor dem Pferdelager nach der Schafspetze,

Münchewasser genannt und vor der Schafspetze bei Schäfers Garten, tritt an Osterloh von ihren Flächen (außerhalb der Osterloher Grenze) von Wallheinckes Gehren nach Uetzmanns Wahlern zu 2 Morgen ab - das Holz wird Altencelle reserviert und räumt endlich der Gemeinde Osterloh vom Desfelde ab eine Trift nach dem Bockmannsförth zu, in dreiruthiger Breite ein:

Dagegen gibt die Gemeinde Osterloh ihre Ansprüche zur Mithude in den Altenceller Fuhren auf.

Sohnemanns Wiese bleibt von diesem Vergleiche ausgeschlossen.

(cfr. No. act. 16 Prot. v. 6. April 1846

" " 17 " 8 . " ,)

Nach geschehener Generalteilung der Allerheide ist die für Osterloh reservierte Trift durch die Altenceller Fuhren nach dem Bockmannsförth unnötig geworden, weshalb dieselbe von selbst eingeht.

Wegen der von Altencelle an Osterloh in den Fuhren abzugebenden zwei Morgen ist bei Gelegenheit der Verkoppelung und Spezialteilung der Osterloher Feldmark ein anderweitiger Vergleich zwischen den betreffenden Syndicen dahin abgeschlossen, dass Osterloh von den Altenceller Fuhren hinter den Gehren an der Osterloher Grenze 1 Morgen 110 QR uns auBerdem den durch diese Abfindung führenden Altenceller-Osterloher Weg einer Ruthe Breite entschädigt erhalten soll. Danach beträgt die ganze Abfindung für die Gemeinde Osterloh 1 Morgen 118 QR, welche Fläche derselben bei der Spezialteilung der Altenceller Fuhren zugeteilt werden muss.

(cfr. No. act. 101 der Osterloher Verk. und Spezialteilungs-Acte. Protokoll v. 20. Febr. 1851)

\section{B. Vergleich zwischen Altencelle und Lachtehausen}

Die beiden Gemeinden Altencelle und Lachtehausen geben ihre gegenseitig erhobenen Weideansprüche auf den gegenseitigen Revieren auf, so dass Lachtehausen die Heide hinter dem Felde nebst den Fuhren und dem Neuenbrink privatim erhält, und ebenso Altencelle seine Fuhren, sowohl die privativen als die gemeinschaftlichen und das Risch von aller Weide frei, privatim erhält.

Außerdem tritt Altencelle den Heidwinkel zwischen Uetzmanns Kamp und dem Neuengehäge zu dem Gesamtbetrage von 1 Morg. 90 QR an Lachtehausen ab. Der Abtrieb des Holzes und der Weg nach den Wiesen wird jedoch der Gemeinde Altencelle vorbehalten.

Der Gemeinde Lachtehausen wird von deren Felde ab nach Neuengehäge auf dem Wege durch Hoppes Busch eine Trift von 2 R. Breite zugestanden.

(cfr. No. act. 16. Protokoll vom 6. April 1846) 


\section{$\S 21$. Angelegte Wege und Triften}

Behuf Auseinandersetzung des vermessenen und bonitierten Teils der Allerheide unter die Ortschaften Lachendorf und Ahnsbeck und die Ortschaften Altencelle, Osterloh und Lachtehausen sind folgende Wege und Triften angelegt:

A. im früheren Amte Beedenbostel

Der Ahnsbeck-Celler Weg $3 \mathrm{R}$ breit

" Lachendorf-Celler Weg 21/2 R breit

" Lachendorf-Oppershäuser Weg 21/2 R breit

„Gocekenholz_Oppershäuser Weg 21/2 R breit

Der Lachendorfer Wiesenweg, von Lachendorf bis an den Ahnsbeck-Celler Weg 31/2 R breit, von da nach den Wiesen 21/2 R breit.

B. im früheren Bezirk des Amtes Celle

Der Ahnsbeck-Celler Weg 3 R breit

Der Altenceller-Ahnsbecker und Lachendorfer Weg im Langenförth 3 breit

Der Abführung aus der Sprache $2 \mathrm{R}$ breit und ist dabei im öffentlichen Interesse von beiden Ämtern nichts zu erinnern gefunden.

(cfr. No. act. 241 u. 247)

\section{$\S 22$ Künftige Benutzung der Abfindungen}

Alle auf den verteilten Revieren als: der Allerheide incl. den Osterbruchmoore, dem Lachendorfer Moore, dem Westernmoor, der Allerohe und dem Allerhorn, so wie auch auf den nicht zum Teilungsgebiete gehörenden Revieren, dem Altenceller Risch und den Altenceller Fuhren bisher ausgeübten gemeinschaftlichen Nutzungen werden in Folge der Generalteilung hiermit aufgehoben, und gehen die statt der seitherigen gemeinschaftlichen Gerechtsamen für die einzelnen Berechtigten ausgemittelten Äquivalente in einen völlig privativen Zustand auf die einzelnen Ortschaften über.

\section{$\S 23$ Befriedigung der Abfindungen}

Sämtliche neue Grenzen der einzelnen Ortschaften werden mit fünf Fuß breiten Gräben versehen, wozu jede der beiden benachbarten Ortschaften das halbe Terrain hergibt und auch die Kosten der ersten Verrichtung und künftigen Unterhaltung bestreitet.

Der Auswurf aus den Gräben wird nach beiden Seiten geworfen.

(cfr. No. act. 40 Prot. v. 26. März 1847

$$
\begin{aligned}
& \text { \# , } \quad 43 \text { \# } \quad \text { 3. Juli } 1847 \\
& \text { " " } " 213 \text { " " } \quad 21 \text {. Novbr. } 1853 \\
& \text { " } " \quad \text { " } " 220 \quad \text { " }, \quad \text { 1. April 1854) }
\end{aligned}
$$

$\S 24$ Erste Instandsetzung und künftige Unterhaltung der Wege

Ahnsbeck-Celler Weg (Gifhorn-Celler-Straße) wird im Langenförthe mit 6 Fuß breiten Gräben an jeder Seite versehen.

Die Breite der Gräben an den übrigen Wegen ist auf 4 Fuß festgestellt. (cfr. No. act. 140. Prot. v. 23. August 1851)

Eine jede Gemeinde, mit Ausnahme der Gemeinden Altencelle und Osterloh, soll die in ihrer Abfindung vorhandenen, neu angelegten oder noch anzulegenden Wege, sowohl die öffentlichen als Privatwege in fahrbaren Stand setzen und unterhalten und das dazu erforderliche Material von eigenem Grund und Boden entnehmen.

(cfr. No. act. 213. Prot. v. 21 November 1853)

Die beiden im Bezirk des Amtes Celle angelegten Wege: der Ahnsbeck-Celler Weg und die Abfahrung aus der Sprache, erstere aber nur auf der Allerheide und im Langenförthe bis an die Grenze der Altenceller privativen Weide, werden von Altencelle und Osterloh gemeinschaftlich hergestellt und unterhalten und zwar nach demselben Verhältnis, wie sie zu der auf die Wege verwandten Fläche concurrirt haben. 
Der Ahnsbeck-Celler Weg im Risch und auf dem Teile des Langenförthes, wo Altencelle allein berechtigt gewesen, wird von der Gemeinde Altencelle allein hergerichtet und unterhalten.

(cfr. No.act. 213. Prot. v. 21. November 1853)

Nach der Auseinandersetzungs-Berechnung haben zu den auf den Altenceller-Osterloher Communion-Revieren angelegten Wegen beigetragen:

\begin{tabular}{lcl} 
Altencelle & 15 Morg. $47 \mathrm{QR}=0,9738$ Kuhw. \\
Osterloh & $3, .43,=0,2261$, \\
\hline Summa & $19 \mathrm{mg} .10 \mathrm{QR}=1,1999$ Kuhw.
\end{tabular}

in abgerundeten Zahlen

Altencelle $\quad 43$ Teile

Osterloh $\quad 10$ Teile

\section{$\S 25$. Künftige Benutzung der Wege}

Die etwaigen Nebennutzungen der auf den Comminion-Revieren im Bezirk des Amtes Celle angelegten Wege als: den Ahnsbeck-Celler Wege und dem Abfuhrwege aus der Sprache gebührt den beiden Gemeinden Altencelle und Osterloh und partizipieren sie davon in dem Verhältnis wie sie zur Anlegung dieser Wege beitragen und zur Instandsetzung und Unterhaltung beitragen müssen: in abgerundeten Zahlen

Altencelle mit 43 Teilen und

Osterloh mit 10 Teilen.

Die etwaige Nebennutzung der übrigen angelegten Wege bemisst jede Gemeinde nach ihrer Abfindung allein.

$\S 26$. Entscheidung etwaiger Irrungen und Streitigkeiten

Alle etwaigen Irrungen und Streitigkeiten, welche in der Teilung selbst ihre Quelle haben und nach den Gesetzen über Teilungen und Verkoppelungen zu beurteilen sind, sollen auf administrativem Wege, mit Ausschluss prozessualischen Verfahren entschieden werden.

\section{§. 27 Erfüllung und Dauer des Rezesses}

Der Zweck dieses Plan-Rezesses ist auf die Sicherstellung der gegenseitigen Gerechtsamen und Verpflichtungen gerichtet. Die Interessenten verpflichten sich hiermit zur gegenseitigen Erfüllung der darin enthaltenen Bestimmungen.

Jede Handlung oder Sache, die daher in der Folge denselben zuwider sollte vorgenommen werden, wird im voraus für unstatthaft erklärt und soll selbst der Einwand einer längst erfolgten Verjährung oder Verkürzung über oder unter die Hälfte dagegen niemals zugelassen werden.

Zur Urkunde dessen ist dieser Plan-Rezess von den Vertretern sämtlicher Interessenten eigenhändig vollzogen und soll das vollzogene Exemplar nach erfolgter Bestätigung der Königlichen Landdrostei Lüneburg nebst der Karte und der Akten in der Registratur des Königlichen Amtes Celle aufbewahrt, auch eine beglaubigte Abschrift davon der Königlichen Landdrostei Lüneburg übersandt und auch den Interessenten beglaubigte Abschriften zugestellt werden.

So geschehen: Lachendorf, am 28. August 1861

Hr. Christoph Diercks, Syndicus von Ahnsbeck

Schmalstich, Vorsteher daher

Schwägermann, Syndicus von Lachendorf

Lüßmann, Vorsteher daher

Peters, Syndicus von Altencelle

H. Heide, J. H. Hoppenstedt, Syndici von Lachtehausen

Kuntze, Syndicus von Oppershausen 
Die vorstehenden Unterschriften werden hierdurch als eigenhändig vollzogen attestiert.

Lachendorf, am 28. August 1861

Die Teilungskommission

gez. Siemens, Holekamp

Vorstehender Rezess wird hierdurch bestätigt.

Lüneburg, 14. September 1861

(L.S.)

Königlich Hannoversche Landdrostei

gez. Böhmer

Siegel für die richtige Abschrift Holekamp (als Unterschrift)

Actum Lachendorf, im Thieschen Wirtshause, am 28. August 1861

Gegenwärtig:

Amtsrichter Siemans,

ich, der Landes-Oec. Commissair Holekamp

Nachdem von Königlicher Landdrostei der über die Generalteilung der Allerheide, des Lachendorfer Moores, des Westernmoores, der Allerohe und des Allerhorns entworfene, die Stelle des Plans mit vertretende Rezess genehmigt worden, so war zur Sublimation und in Ermangelung aufschiebender Hindernisse zugleich zur Vollziehung desselben Termin auf heute angesetzt worden und dazu, durch die am 19. v. M. abgelassene, durch Insurtion im 61. Stücke der Lüneburgschen und 76. Stücke der Celleschen Anzeigen, auch durch Anschlag vor den Amtsstuben zu Celle und Beedenbostel zur öffentlichen Kunde gebrachte, den Vertretern der Beteiligten aber besonders insinnierte Edictalladung ${ }^{1}$ die bekannten Teilnehmer und die Grundherren bei Strafe des Ausschlusses mit ihren etwaigen Einreden gegen die planmäßige Ausführung, die etwaigen Guts-, Dienst-, Erbenzins und Lehnsherren, die Lehns- und Fideicommißfolger ${ }^{2}$, oder sonstigen Personen denen eine Einwirkung auf die Ausführung der Teilung zusteht, aber unter der Verwarnung, dass jeder, welcher seine Rechte nicht geltend mache, es sich beizumessen habe, wenn deren Sicherstellung unterbleibe, geladen worden.

Zur Vollziehung des Rezesses waren die Vertreter noch unter der Verwarnung geladen worden, dass für die Ausbleibenden der Rezess als vollzogen angenommen werden solle.

In Folge dessen hatten sich vor der Teilungs-Commission eingefunden:

1. für die Gemeinde Ahnsbeck der Syndicus Brinks. Hr. Chrsistoph Diercks und der Vorsteher Johann Heinrich Schmalstich

2. für die Gemeinde Lachendorf der Syndicus Schwägermann und der Vorsteher Lüßmann

3. für die Gemeinde Altencelle der Syndicus Peters

4. für die Gemeinde Osterloh war niemand erschienen.

5. für die Gemeinde Lachtehausen der Syndicus Meine und Syndicus Hoppenstedt,

6. für die Gemeinde Oppershausen der Syndicus Kuntze

Weiter hatte sich niemand eingefunden.

Die Ladungen waren dokumentiert zu den Akten gekommen.

Nach eröffnetem Termine erklärten zunächst die Syndicen von Lachtehausen: der auf der Lachtehausen- Altenceller Grenze neu angelegte Weg nach der Sprache hätte nach den früheren Verhandlungen auf dem Altenceller Terrain angelegt werden müssen, während er

\footnotetext{
${ }^{1}$ S. $\S 6$

${ }^{2}$ Fideicommiß bedeutet ,zu treuen Händen“: Einrichtung deutschen Rechts, nach dem Familienvermögen (meist Grundbesitz) in der Regel geschlossen in der Hand eines Familiengliedes bleibt, dem nur die Erträge zur freien Verfügung stehen.
} 
anscheinend irrtümlich auf der Lachtehäuser Seite angelegt worden sei und werde daher Untersuchung, ob es sich so verhalte, du eventuell Berichtigung beantragt.

Der Syndicus von Altencelle war damit einverstanden, dass, wenn ein Irrtum bei Anlegung des fraglichen Weges vorgekommen sein sollte, solcher noch nachträglich auch nach geschehener Vollziehung des Rezesses berichtigt werde.

Commissionsseitig

wurde Comparenten darauf eröffnet, dass der Geometer Michaal beauftragt werden solle, Nachmessung vorzunehmen und dann as Resultat mitgeteilt werden solle.

Hierauf trugen Comparenten von Oppershausen, Ahnsbeck, Lachendorf und Lachtehausen noch vor, da ihre Abfindung bereits auf ihre Spezialteilungs- und Verkoppelungskarten aufgenommen seien, so glaubten sie es für nicht erforderlich, dass sich die anzufertigende Karten-Copie mit auf ihre Abfindung erstrecke, und erbäten, bei Königlicher Landdrostei zu beantragen, dass innen die Kosten erlassen würden.

Als hierauf der Rezess verlesen werden sollte, erklärten Comparenten ${ }^{1}$, dass, da der Rezess ihnen im Termine am 20. August v. Jahres vollständig vorgelesen worden und nichts verändert worden sei, sie auf eine nochmalige Verlesung verzichten und inn vollziehen wollten, und ist darauf der Rezess von allen Comparenten eigenhändig unterschrieben.

Vorgelesen und genehmigt wurde der Termin damit geschlossen.

Geschehen wie oben

$$
\text { zur Beglaubigung }
$$

$$
\text { gez. Siemens Holekamp }
$$

Nach geschlossenem Termine wurde noch beantragt, den Interessenten 2 beglaubigte Abschriften des Rezesses auszufertigen,

eine für die Ortschaften Altencelle, Osterloh und Lachtehausen zur Aufbewahrung in der Gemeindelade zu Altencelle,

eine zweite für die Ortschaften Oppershausen, Ahnsbeck und Lachendorf zur Aufbewahrung in der Gemeindelade zu Lachendorf, und solche bewilligt.

$$
\text { zur Beglaubigung gez. Holekamp }
$$

Für die richtige Abschrift

Holelamp ${ }^{2}$

\footnotetext{
${ }^{1}$ comparenten (lat.) hier: die Erschienenen

${ }^{2}$ Handschriftlich von Holekamp mit eigenhändiger Unterschrift angefügt.
} 


\section{Verteilungs-Register \\ der \\ Communionsweide Allerheide}

\begin{tabular}{|c|c|c|c|c|c|c|c|c|c|c|c|c|c|c|c|c|c|c|}
\hline \multirow{4}{*}{\begin{tabular}{|l|} 
Nr. der \\
Abfin- \\
dungen
\end{tabular}} & \multirow{2}{*}{$\begin{array}{c}\text { Abfindung } \\
\text { der Gemeinde Lachtehausen }\end{array}$} & \multirow{2}{*}{\multicolumn{3}{|c|}{ Angerboden }} & \multirow{2}{*}{\multicolumn{3}{|c|}{ Bruchboden }} & \multirow{2}{*}{\multicolumn{3}{|c|}{ Moorboden }} & \multirow{2}{*}{\multicolumn{2}{|c|}{ Heidboden }} & & & & \multirow[b]{2}{*}{ un- } & \multirow{2}{*}{\multicolumn{2}{|c|}{ Total- }} \\
\hline & & & & & & & & & & & & & \multicolumn{3}{|c|}{ zu Allem } & & & \\
\hline & incl. der Försterstelle & Fläch & & Wert & Fläche & Wer & & Fläche & Wert & & Fläche $\mathrm{V}$ & Wert & Fläc & iche Wert & & rauchb & Bet & trag \\
\hline & zu Lachtehausen & $M Q F$ & $2 \mathrm{R}$ & Kuhw & $M Q R$ & Kuhs & & $M \quad Q R$ & Kuhw & & M $Q R$ & Kuhw & M & Kuhn & w & $\mathrm{M} Q \mathrm{R}$ & $M$ & $Q R$ \\
\hline & Im Risch und hinter den & & & & & & & & & & & & & & & & & \\
\hline & Geschewiesen & 7 & 811 & 1,1571 & & & & & & & 113 & 9,8789 & 120 & $\begin{array}{ll}106 & 11,03 \\
\end{array}$ & & 25 & 121 & 11 \\
\hline & & & & & & & & & & & & & & & & & & \\
\hline & Abfindung & & & & & & & & & & & & & & & & & \\
\hline & der Gemeinde Altencelle incl. & & & & & & & & & & & & & & & & & \\
\hline & des von der a.g. Herrschaft an & & & & & & & & & & & & & & & & & \\
\hline & die Gemeinde Altencelle abge- & & & & & & & & & & & & & & & & & \\
\hline & tretenen Superfluums im Be- & & & & & & & & & & & & & & & & & \\
\hline & trage von $60 \mathrm{M}=4,6838 \mathrm{Kuhw}$. & & & & & & & & & & & & & & & & & \\
\hline $2 \mathrm{~V}$ & Vor Bockmanns Förth & 1 & 28 & 0,1473 & & & & & & & 7102 & 0,3737 & 9 & 0,52 & & 6 & 9 & 16 \\
\hline $3 \mathrm{~V}$ & Vor der Geschewiese & & 27 & 0,0254 & & & & & & & 135 & 0,0880 & 1 & 0,11 & & & 1 & 62 \\
\hline & Zwischen der Sprache und & & & & & & & & & & & & & & & & & \\
\hline & dem Ahnsbecker Wege & 15 & 87 & 2,2159 & & & & 349 & 0,242 & & 154 & 54,0915 & 872 & 1756,54 & & & 872 & 17 \\
\hline 70 & Der Ahnsbeck-Celler Weg im Risch & & 56 & 0,0389 & & & & & & & \begin{tabular}{l|l|l}
4 & 109 & 0
\end{tabular} & 0,2727 & 5 & $\begin{array}{ll}45 & 0,31\end{array}$ & & 2 & 5 & 47 \\
\hline & Im Risch an den Altenceller priv. Fuh & ren & & & & & & & & & 6 & 0,3759 & 6 & 0,37 & & & 6 & \\
\hline $9 \mathrm{~V}$ & Vorn im Langenförth & & 64 & 0,0444 & & & & & & & & & & 0,04 & 444 & & & 64 \\
\hline $10 \mathrm{~V}$ & Weg von Ahnsbeck nach dem & & & & & & & & & & & & & & & & & \\
\hline & Langenförth & & 240 & 0,0167 & & & & & & & & & & 0,01 & 167 & & & 24 \\
\hline $11 \mathrm{D}$ & Das Langeförth und das Osterbruch & 610 & 01 & 0,8214 & 45 & 5,038 & & 239 & 19,403 & & $\begin{array}{ll}40 & 12\end{array}$ & 12,0576 & 478 & 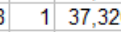 & & 3 & 478 & 4 \\
\hline & Summa & 252 & $27 \quad 3$ & 3,3100 & 45 & 5,038 & & $236 \quad 52$ & 19,645 & & $47 \quad 67$ & 67,2594 & 1372 & $2103 \quad 95,25$ & & 11 & 11372 & 2114 \\
\hline rechn. & Kontrolle der Kuhweiden-Werte & & & 3,3100 & & 5,038 & & & 19,645 & & & 57,2594 & & 95,25 & & & & \\
\hline Nr. der & Abfindung & & & & & & & & & & & & & & & & & \\
\hline Abfin- & der Küsterstelle zu & & Ang & gerboc & den & Bruc & chb & boden & & oorbo & Doden & Heid & dbod & den & & zu All & \|lem & \\
\hline dungen & Altencelle & & Fläch & & Wert & läch & & Wert & Fläc & che & Wert & Fläche & & Wert & Fläcl & & We & ert \\
\hline & & M & $\mathrm{M} \mathrm{QF}$ & $2 \mathrm{R}$ & Kuhw M & QF & $R$ & Kuhw & $\mathrm{MO}$ & QR & Kuhw & $M Q R$ & & Kuhw & $\mathrm{M}$ & QR & Kuh & hw \\
\hline & Am Küsterbusch & & & 280 , & 0233 & & & & & & & 27 & 27 & 0,0148 & & 55 & 0,0 & 381 \\
\hline & & & & & & & & & & & & & & & & & & \\
\hline & Abfindung & & & & & & & & & & & & & & & & & \\
\hline & der Gemeinde Osterloh & & & & & & & & & & & & & & & & & \\
\hline & Hinter den Osterbruchwiese & & & & 9 & 40 & 0,3 & 0,8668 & 81 & 306 & 6,770720 & 204 & 312 & $\begin{array}{l}2,311829 \\
\end{array}$ & 947 & 73,3 & 19,9 & 493 \\
\hline & & & & & & & & & & & & & & & & & & \\
\hline & Abfindung & & & & & & & & & & & & & & & & & \\
\hline & der Gemeinde Oppershaus & & & & & & & & & & & & & & & & & \\
\hline & An der Oppershäuser Feldn & mark & & & 6 & 74 & 4,7 & 0,6914 & 27 & 172 & \begin{tabular}{|l|l|}
2,2618 & 18 \\
\end{tabular} & 180 & 30 & 9,723421 & 145 & 51,7 & 12,6 & 766 \\
\hline No. der & Abfindung & & & Anger & rboden & & Aoort & rboden & & Heidb & boden & & $z u A$ & Allem & & un- & Tota & \\
\hline Abfin- & der Gemeinde Lachendorf & & & läche & Wert & Fläo & che & Wert & Fläc & che & Wert & Fläc & & Wert & & chbe & Betr & \\
\hline dungen & & & M & QR & Kuhw & $\mathrm{M}$ & QR & Kuhw & M & QR & Kuhw & $\mathrm{M}$ & QR & Kuhw & $\mathrm{M}$ & QR I & M & QR \\
\hline 1 & 1 An der Altenceller Grenze & & 23 & 3104 & 3,0256 & & & & 505 & 40 & 23,0036 & $\begin{array}{l}6 \quad 529 \\
6\end{array}$ & 24 & 26,0292 & & & 529 & 24 \\
\hline 6 & 6 Beim Birkenbusch & & & & & & & & 633 & 40 & 25,6224 & 633 & 40 & 25,6224 & & & 633 & 40 \\
\hline 11 & 1 Bei Schönduves Immenstelle & & & & & & & & 123 & 33 & 4,9310 & 123 & 33 & 2,931 & & & 123 & 33 \\
\hline 14 & 4 Bei Drewsens Busch a. dem Kru & ummen & en Mo & loor & & & & & 159 & 84 & 0,5105 & 159 & 84 & 6,5105 & & & 159 & 84 \\
\hline 16 & 6 Bei der lachendorfer Kuhweide & & & & & & & & 94 & 30 & 3,8449 & 94 & 30 & 3,8449 & & & 94 & 30 \\
\hline 35 & 5 Auf dem Lachendorfer Moore & & 29 & 9100 & 4,5439 & 4 & 76[ & 0,4638 & 169 & 5 & 11,6566 & 203 & 61 & 16,6688 & & 81 & 204 & 22 \\
\hline 41 & 1 Bei Misselhorns Kämpen pp. & & 23 & 3108 & 4,0821 & & & & 744 & 108 & 36,7350 & 768 & 96 & 40,8171 & & & 768 & 96 \\
\hline 48 & 8 östlich vom Exerzierplatz & & & & & & & & 5 & 68 & 0,2227 & 5 & 68 & 0,2227 & & & 5 & 68 \\
\hline 50 & Nordöstlich demselben & & & & & & & & 65 & 80 & 2,6267 & 65 & 80 & 2,6267 & & & 65 & 80 \\
\hline 52 & 2 Nördlich demselben & & & & & & & & 8 & 10 & 0,3233 & 8 & 10 & 0,3233 & & & 8 & 10 \\
\hline 54 & 4 Westlich demselben & & & & & & & & 107 & 30 & 4,1734 & 107 & 30 & 4,1734 & & & 107 & 30 \\
\hline 55 & 5 Bie Thies ol. Cammanns Immens & istelle & & & & & & & 87 & 73 & 3,4718 & 87 & 73 & 3,4718 & & & 87 & 73 \\
\hline 5 & 5 Der Gockenholz-Wienhäuser We & & & & & & & & 10 & 20 & 0,4264 & 10 & 20 & 0,4264 & & & 10 & 20 \\
\hline 10 & Der Lachendorf-Celler Weg & & & & & & & & 4 & 71 & 0,1836 & 4 & 71 & 0,1836 & & & 4 & 71 \\
\hline 13 & 3 Der Lachendorf-Oppershäuser W & & & & & & & & 7 & 34 & 0,2914 & 7 & 34 & 0,2914 & & & 7 & 34 \\
\hline 15 & Der Lachendorfer Wiesenweg & & & & & & & & 2 & 26 & 0,0914 & 2 & 26 & 0,0914 & & & 2 & 26 \\
\hline 34 & 4 desgl. Auf dem Lachendorfer Mo & pore & & 21 & 0,0264 & & & & 1 & 116 & 0,1258 & 2 & 17 & 0,1622 & & 3 & 2 & 20 \\
\hline 38 & der Canal & & & & & & & & & & & & & & 1 & 106 & 1 & 106 \\
\hline 57 & Der Celler-Gifhorner Weg & & & & & & & & 18 & 104 & 0,7540 & 18 & 104 & 0,754 & & & & \\
\hline & Summa & & 77 & 93 & 11,6830 & 4 & 76[ & 0,4633 & 2749 & 12 & 125,0045 & 52831 & 61 & 137,1508 & 2 & 70 & 2834 & 11 \\
\hline & & & & & & & & Schreibf & fehler & & & & & & & & & \\
\hline
\end{tabular}




\begin{tabular}{|c|c|c|c|c|c|c|c|c|c|c|c|c|c|c|c|c|c|c|c|c|}
\hline \multirow{3}{*}{\begin{tabular}{|l|} 
Nr. der \\
Abfin- \\
dungen \\
\end{tabular}} & \multirow{3}{*}{$\begin{array}{c}\text { Abfindung } \\
\text { der Gemeinde Ahnsbeck }\end{array}$} & \multicolumn{3}{|c|}{ Angerboden } & \multicolumn{3}{|c|}{ Bruchboden } & \multicolumn{3}{|c|}{ Moorboden } & \multicolumn{3}{|c|}{ Heidboden } & \multicolumn{3}{|c|}{ zu Allem } & \multirow{2}{*}{\multicolumn{2}{|c|}{$\begin{array}{c}\text { un- } \\
\text { brauchb }\end{array}$}} & \multirow{2}{*}{\multicolumn{2}{|c|}{$\begin{array}{l}\text { Total- } \\
\text { Betrag }\end{array}$}} \\
\hline & & \multicolumn{2}{|c|}{ Fläche } & \multirow{2}{*}{$\begin{array}{l}\text { Wert } \\
\text { Kuhw }\end{array}$} & \multicolumn{2}{|c|}{ Fläche } & \multirow{2}{*}{$\begin{array}{l}\text { Wert } \\
\text { Kuhw }\end{array}$} & \multicolumn{2}{|c|}{ Fläche } & \multirow{2}{*}{$\begin{array}{l}\text { Wert } \\
\text { Kuhw }\end{array}$} & \multicolumn{2}{|c|}{ Fläche } & \multirow{2}{*}{\begin{tabular}{|l|} 
Wert \\
Kuhw
\end{tabular}} & \multicolumn{2}{|c|}{ Fläche } & Wert brauchb & & & & \\
\hline & & $M$ & QR & & $M$ & QR & & $M$ & QR & & $M$ & QR & & $M$ & QR & Kuhw & $\mathrm{M}$ & QR & $M$ & QR \\
\hline 17 & Bei Heuers und Dierks Land & & & & & & & & & & 137 & 59 & 5,4948 & 137 & 59 & 5,4948 & & & 137 & 59 \\
\hline 24 & Bei der Wulfhörnsche & 4 & 109 & 0,4746 & 31 & 104 & 2,6555 & 2 & 36 & 0,1150 & 430 & 89 & 23,4529 & 469 & 98 & 26,6980 & & & 469 & 98 \\
\hline 30 & Das Westernmoor & & & & 102 & 38 & 8,5264 & 15 & 36 & 0,9563 & 8 & 41 & 0,5855 & 125 & 115 & 10,0682 & & & 125 & 115 \\
\hline 31 & Auf dem Lachendorfer Moore & 24 & 26 & 2,5903 & & & & & & & 87 & 79 & 6,0480 & 111 & 75 & 8,6363 & & & 111 & 75 \\
\hline \multirow{2}{*}{39} & Westlich dem & & & & & & & & & & & & & & & & & & & \\
\hline & Lachendorfer Wiesenweg & 2 & 53 & 0,2442 & & & & & & & 359 & 95 & 17,3776 & 362 & 28 & 17,6218 & & & 362 & 28 \\
\hline 21 & Der Ahnsbeck-Celler Weg & & & & & & & & & & 5 & 60 & 0,2198 & 5 & 64 & 0,2198 & & & 5 & 64 \\
\hline 33 & " Lachendorfer Wiesenweg & & 29 & 0,0337 & & & & & & & 8 & 64 & 0,4466 & 8 & 93 & 0,4803 & & & 8 & 93 \\
\hline \multirow[t]{6}{*}{29} & " Der Canal in der Abfindung & & & & & & & & & & & & & & & & 4 & 56 & 4 & 56 \\
\hline & Summa & 31 & 97 & 3,3428 & 134 & 22 & 11,1819 & 17 & 72 & 1,0713 & 1037 & 101 & 53,6252 & 1221 & 52 & 69,2212 & 4 & 56 & 1225 & 108 \\
\hline & & & & & & & & & & & & & & & & & & & & \\
\hline & Abfindung & & & & & & & & & & & & & & & & & & & \\
\hline & der Brinksitzer Gockenholz & & & & & & & & & & & & & & & & & & & \\
\hline & und Lindmüller zu Ahnsbeck & & & & & & & & & & & & & & & & & & & \\
\hline 22,23 & Am Ahnsbeck-Celler Wege & & & & & & & & & & 1 & 7 & 0,0423 & 1 & 7 & 0,0423 & & & 1 & 7 \\
\hline \multirow[t]{5}{*}{25,26} & Am alten Celler Wege & & & & & & & & & & 1 & 84 & 0,0838 & 1 & 84 & 0,0838 & & & 1 & 84 \\
\hline & Summa & & & & & & & & & & 2 & 91 & 0,1261 & 2 & 91 & 0,1261 & & & 2 & 91 \\
\hline & & & & & & & & & & & & & & & & & & & & \\
\hline & Die Königliche Militair- & & & & & & & & & & & & & & & & & & & \\
\hline & Verwaltung & & & & & & & & & & & & & & & & & & & \\
\hline 53 & Der Exerzierplatz & & & & & & & & & & 240 & & 9,5808 & & & & & & & \\
\hline \multirow{3}{*}{$\begin{array}{l}49 \\
51\end{array}$} & Der Weg an der östl. Seite de & ssell & ben & $3 \mathrm{R}$ breit & & & & & & & & 65 & 0,0217 & & 65 & 0,0217 & & & & \\
\hline & " " " " nördl. " " & & $3 \mathrm{R}$ & $"$ & & & & & & & & 59 & 0,0197 & & 59 & 0,0197 & & & & \\
\hline & Summa & & & & & & & & & & 241 & 4 & 9,6222 & 241 & 4 & 9,6222 & & & & \\
\hline
\end{tabular}

\begin{tabular}{|c|c|c|c|c|c|c|c|c|c|c|c|c|c|c|c|c|c|c|c|}
\hline \multirow{4}{*}{ 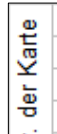 } & & & & & & & & & & & & & & & & & & & \\
\hline & & \multirow{3}{*}{$\begin{array}{c}\text { Private } \\
\text { Grundstücke }\end{array}$} & & \multicolumn{3}{|c|}{ Ackerland } & \multicolumn{3}{|c|}{ Wiesenboden } & \multicolumn{3}{|c|}{ Angerboden } & \multicolumn{3}{|c|}{ Heidboden } & \multicolumn{3}{|c|}{ zu Allem } & \\
\hline & & & & \multicolumn{2}{|c|}{ Fläche } & \multirow{2}{*}{$\begin{array}{l}\text { Wert } \\
\text { Kuhw }\end{array}$} & \multicolumn{2}{|c|}{ Fläche } & \multirow{2}{*}{$\begin{array}{c}\text { Wert } \\
\text { Kuhw }\end{array}$} & \multicolumn{2}{|c|}{ Fläche } & \multirow{2}{*}{$\begin{array}{c}\text { Wert } \\
\text { Kuhw }\end{array}$} & \multicolumn{2}{|c|}{ Fläche } & \multirow{2}{*}{$\begin{array}{l}\text { Wert } \\
\text { Kuhw }\end{array}$} & \multicolumn{2}{|c|}{ Fläche } & \multirow{2}{*}{\multicolumn{2}{|c|}{$\begin{array}{l}\text { Wert } \\
\text { Kuhw }\end{array}$}} \\
\hline & & & & $M$ & $\mathrm{QR}$ & & $\mathrm{M}$ & $Q R$ & & $\mathrm{M}$ & $\mathrm{QR}$ & & M & $Q R$ & & $\mathrm{M}$ & QR & & \\
\hline 亡̌̀ & 1. Inne & erhalb der Lachendorfer & Abfindung & & & & & & & & & & & & & & & & \\
\hline 2 & & Kohlmeier & Lachendorf & & & & & & & & & & & 55 & 0,0328 & & 55 & 0,0328 & I \\
\hline 3 & Köthner & Heinrich Thies & Lachendorf & & & & & & & & & & & 51 & 0,0170 & & 51 & 0,0170 & I \\
\hline 4 & Köthner & Johann $\mathrm{Hr}$. Thies & Lachendorf & & & & & & & & & & & 46 & 0,0153 & & 46 & 0,0153 & I \\
\hline 7 & Köthner & Thies / Bock & Lachendorf & & & & & & & & & & & 39 & 0,0130 & & 39 & 0,0130 & I \\
\hline 8 & Köthner & Schumeier & Lachendorf & & & & & & & & & & 1 & 1 & 0,0403 & 1 & 1 & 0,0403 & 1 \\
\hline 9 & & Kloster & Wienhausen & & & & & & & & & & & 3 & 0,0008 & & 3 & 0,0008 & I \\
\hline 12 & Köthner & Schröder & Lachendorf & & & & & & & & & & & 77 & 0,0257 & & 77 & 0,0257 & I \\
\hline 36 & Köthner & Dralle / Dralle & Lachendorf & & & & 2 & 88 & 0,5467 & & & & & & & 2 & 88 & 0,5467 & Wi \\
\hline 37 & Anbauer & Meyer & Lachendorf & & & & & & & & & & 1 & 80 & 0,1286 & 1 & 80 & 0,1286 & \\
\hline 42 & & Thies / Grusche & Lachendorf & & & & 1 & 4 & 0,1722 & & & & & & & 1 & 4 & 0,1722 & I \\
\hline 20 & & Carsten Heinr.Dralle & Lachendorf & & & & & & & & & & 1 & 20 & 0,0467 & 1 & 20 & 0,0467 & A \\
\hline 44 & Köthner & Misselhorn & Lachendorf & 8 & 35 & 0,5182 & & & & & & & & & & 8 & 35 & 0,5182 & A \\
\hline 45 & Köthner & Misselhorn & Lachendorf & 3 & 24 & 0,1600 & & & & & & & & & & 3 & 24 & 0,1600 & \\
\hline 46 & & derselbe & Lachendorf & & & & & & & & & & 6 & 105 & 0,3438 & 6 & 105 & 0,3438 & I \\
\hline 47 & & Joh. Hr. Dralle / Dralle & Lachendorf & & & & & & & & & & 1 & 49 & 0,0563 & 1 & 49 & 0,0563 & \\
\hline 56 & & Thies / Cammann & Lachendorf & & & & & & & & & & & 73 & 0,0244 & & 73 & 0,0244 & \\
\hline & 2. $\ln n$ & nerhalb der Ahnsbecker & Abfindung & & & & & & & & & & & & & & & & \\
\hline 18 & & Heuer & Ahnsbeck & 5 & 97 & 0,2904 & & & & & & & & & & 5 & 97 & 0,2904 & $\mathrm{~A}$ \\
\hline 19 & & Dierks & Ahnsbeck & 4 & 20 & 0,2084 & & & & & & & & & & 4 & 20 & 0,2084 & A \\
\hline 20 & & Kohlmeier & Lachendorf & & & & & & & & & & & 34 & 0,0113 & & 34 & 0,0113 & 1 \\
\hline 27 & & Schwägermann & Lachendorf & & & & & & & & & & & 66 & 0,0275 & & 66 & 0,0275 & I \\
\hline 28 & & Lüßmann / Salgen & Lachendorf & & & & 3 & 79 & 0,6885 & & & & 1 & 41 & 0,0958 & 5 & & 0,7843 & WW \\
\hline 32 & & derselbe & Lachendorf & & & & & & & & & & 1 & 14 & 0,0798 & 1 & 14 & 0,0798 & 1 \\
\hline 40 & & die a.g. Herrschaft & & & & & & & & & & & & 104 & 0,0433 & & 104 & 0,0433 & I \\
\hline & & & Summa & 21 & 56 & 1,1770 & 7 & 51 & 1,4074 & & & & 19 & 18 & 1,0024 & 48 & 5 & 3,5868 & \\
\hline & & & & & & & & & & & & & & & & & & & \\
\hline & Wege de & er Gemeinde Altencelle & und Osterloh & & & & & & & & & & & & & & & & \\
\hline 6 & Der Ahns & sbeck-Celler Weg & & & & & & & & 1 & 42 & 0,1465 & 15 & 3 & 0,8357 & 16 & 45 & 0,9822 & \\
\hline 4 & Der Abfur & hrweg aus der Sprache & & & & & & & & & 17 & 0,0142 & 2 & 68 & 0,2035 & 2 & 85 & 0,2177 & \\
\hline & & Summa & & & & & & & & 1 & 59 & 0,1607 & 17 & 71 & 1,0392 & 19 & 10 & 1,1999 & \\
\hline & & & & & & & & & & & & & & & & & & & \\
\hline & $\mathrm{Zu}$ & den Wegen haben beiz & utragen & & & & & & & & & & & & & & & & \\
\hline & & Altencelle & & & & & & & & & & & & & & 15 & 47 & 0,9738 & \\
\hline & & Osterloh & & & & & & & & & & & & & & 9 & 83 & 0,2261 & \\
\hline Ann & merkunger & n (im Original ausgesch & rieben) & & & & & & & & & & & & & & & & \\
\hline & 1 & Immenstelle & & & & & & & & & & & & & & & & & \\
\hline & A & Ackerkamp & & & & & & & & & & & & & & & & & \\
\hline & W & Wiese & & & & & & & & & & & & & & & & & \\
\hline & WW & Wiese die Wulfhörnsch & & & & & & & & & & & & & & & & & \\
\hline
\end{tabular}


Wiederholung

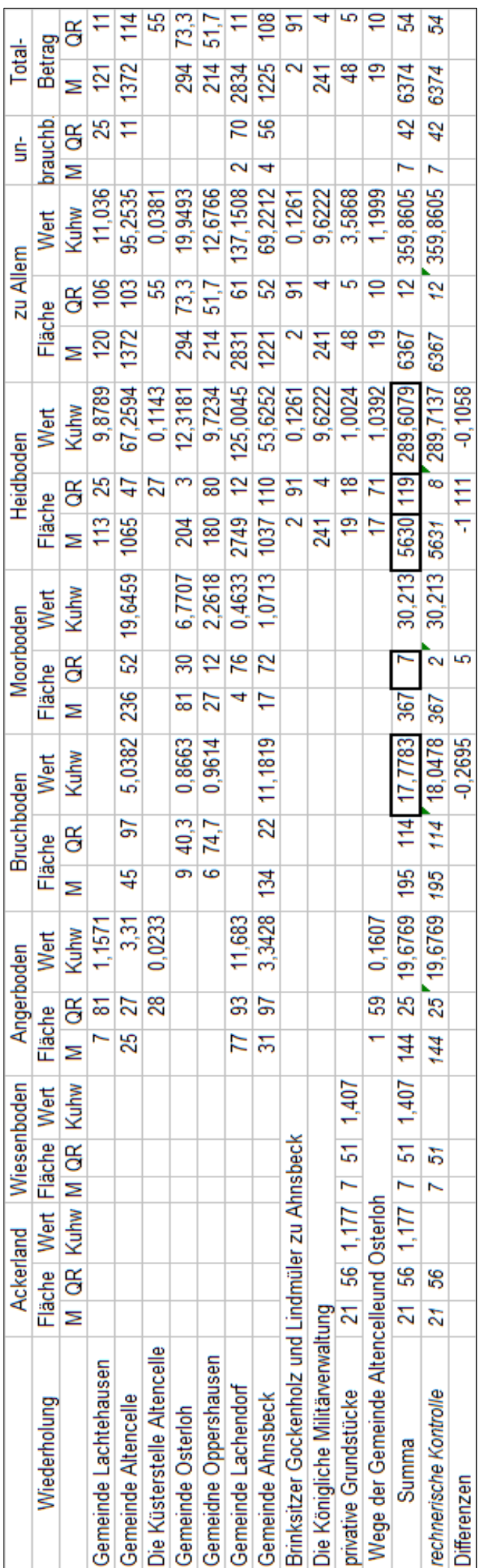

\section{Zur Vergleichung}

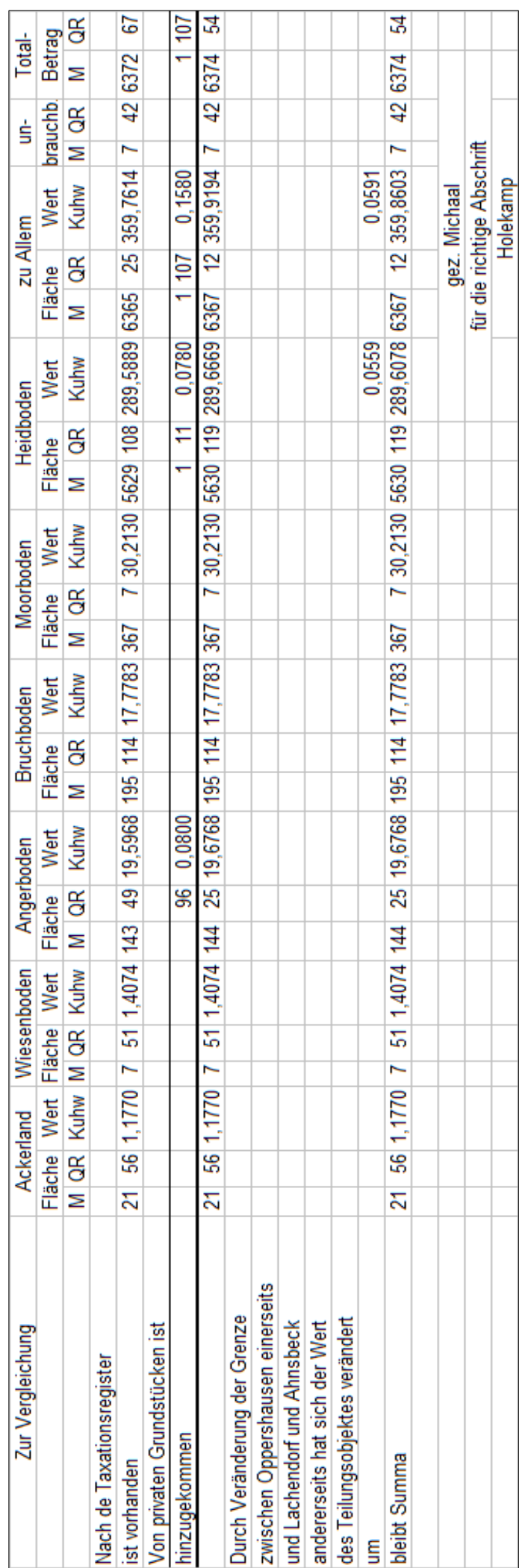

Übertragung aus dem Original, Erfassung in Tabellen, einzelne Kontrollrechnungen und Fußnoten: Artur Behr 


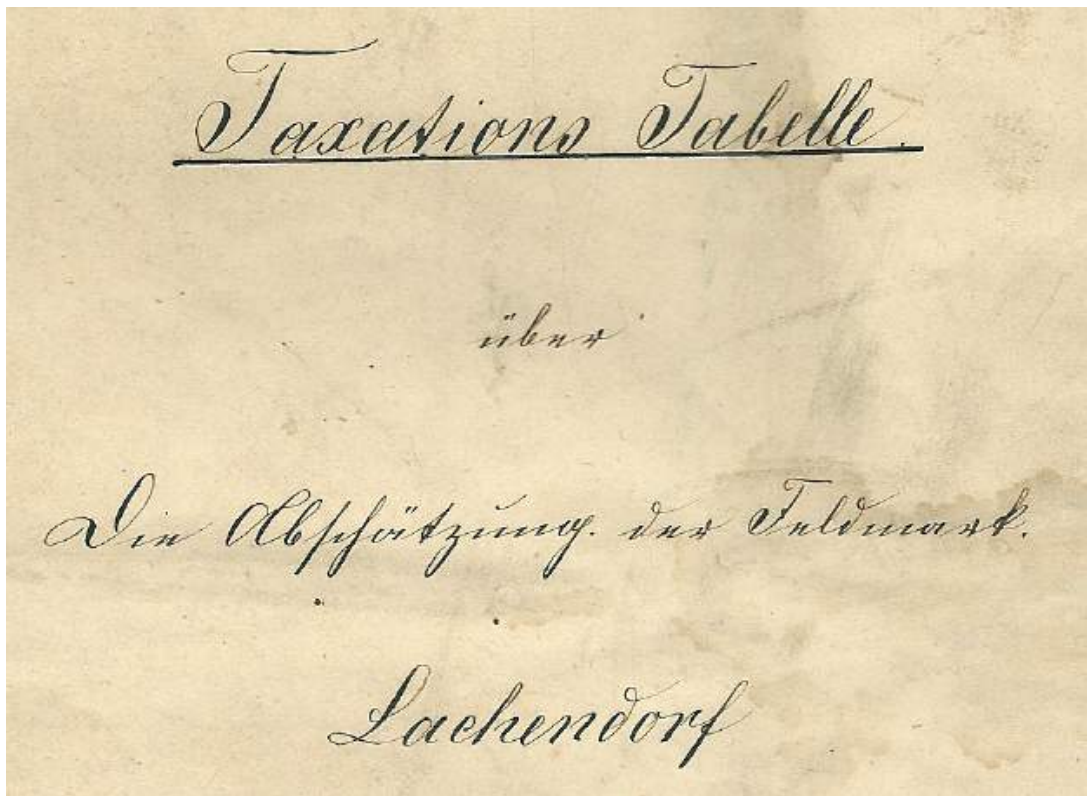

Bevor der „Rezess über die Spezialteilung und Verkoppelung der Feldmark Lachendorf, Amt Beedenbostel“ im Jahr 1859 endgültig zum Abschluss gebracht werden konnte, waren umfangreiche Vorarbeiten zur Bewertung („Classification“ und „Taxation“) und Vermessung nötig.

Die Neuordnung der Flur begann mit einer genauen Abschätzung, der „Taxation“" der gesamten damaligen Feldmark, die 1852 abschließend vorlag und der folgender Bewertungsschlüssel zugrunde gelegt worden war.

\begin{tabular}{|c|c|c|c|c|c|c|c|c|c|c|c|c|c|c|}
\hline \multicolumn{15}{|c|}{ Anzahl der Morgen je "Kuhweide" } \\
\hline \multicolumn{15}{|c|}{ in jeder Klasse der vier Bodenarten } \\
\hline Klasse & 1 & 2 & 3 & 4 & 5 & 6 & 7 & 8 & 9 & 10 & 11 & 12 & \begin{tabular}{|l|l|}
13 & 14 \\
\end{tabular} & 15 \\
\hline Ackerland & 3 & 3,5 & 4 & 4,5 & 5 & & 7 & 7,5 & 9 & 10,5 & 12 & 15 & \begin{tabular}{|l|l|}
18 & 21 \\
\end{tabular} & \\
\hline Wiese & 1 & 1,75 & 2 & 2,5 & 3 & 3,5 & 4 & 5 & 6 & 7,5 & 9 & 10,5 & 12 & \\
\hline Anger & 2,5 & 3 & 3,5 & 4 & 4,5 & & 6 & 7 & 7,5 & 8 & 9 & 10,5 & 12 & \\
\hline Heide & 4 & 4,5 & 5 & 6 & 7 & 7,5 & 8 & 9 & 10,5 & 12 & 15 & 18 & 2125 & 40 \\
\hline \multicolumn{15}{|c|}{ Taxationstabelle über die Abschätzung der Feldmark Lachendorf } \\
\hline \multicolumn{15}{|c|}{ erschlossen aus der Taxationstabelle von 1852} \\
\hline
\end{tabular}

\footnotetext{
${ }^{1}$ Abb. oben: Deckblatt der Taxationstabelle, Kopie, 1852, Samtgemeinde Lachendorf, Archiv Akten, Fach/nr. 61/4
} 


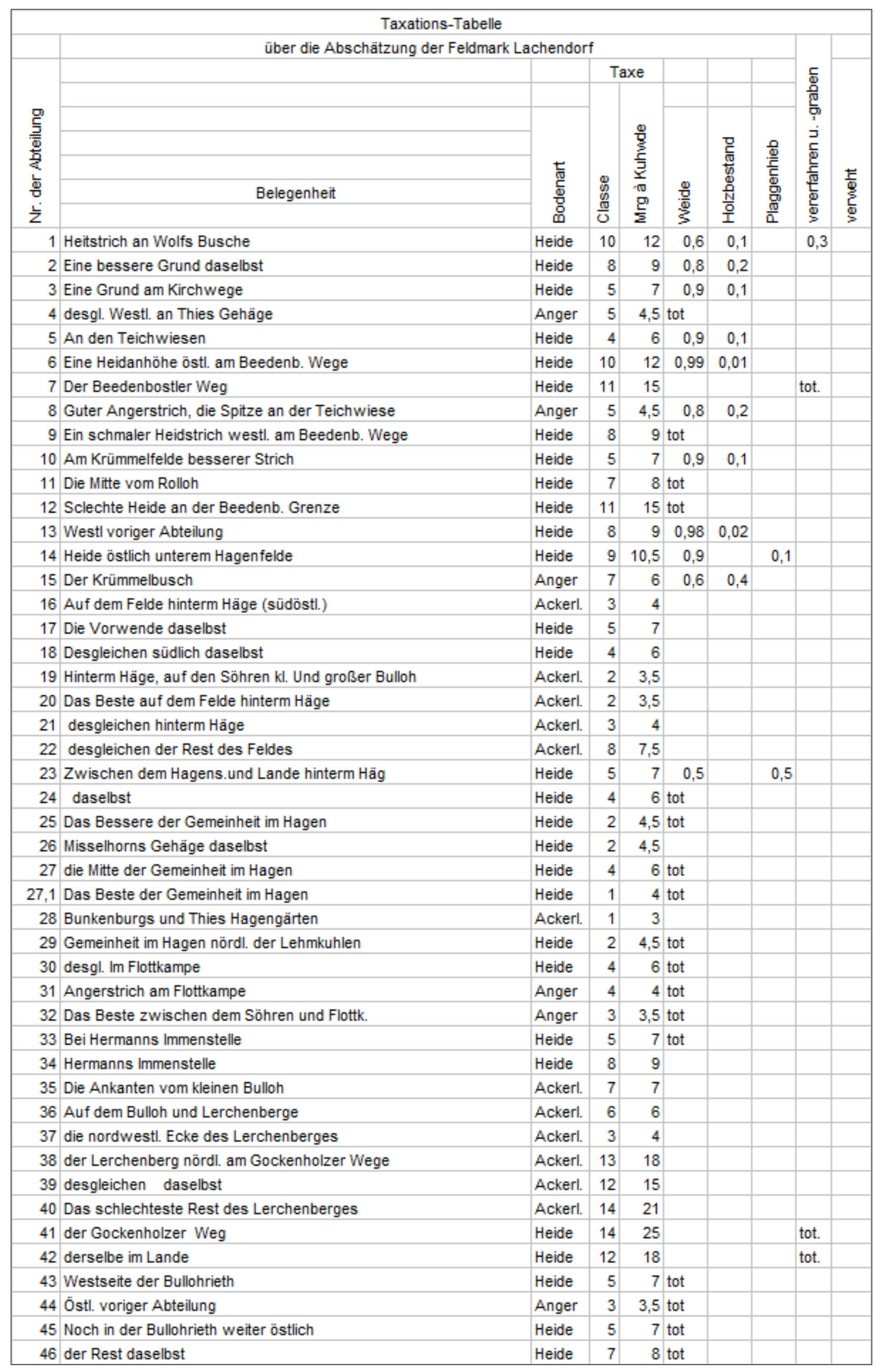




\begin{tabular}{|c|c|c|c|c|c|c|c|c|c|}
\hline 47 & Coors-Meyers Schwarzenkampe & Ackerl. & 5 & 5 & & & & & \\
\hline 48 & Gemeinheit am Schwarzenkampe & Heide & 5 & 7 & 0,8 & & 0,2 & & \\
\hline 49 & desgleichen daselbst & Heide & 4 & 6 & 0,6 & & 0,4 & & \\
\hline 50 & Auf Bock-Thies ..... U. kl. Bulloh & Ackerl. & 3 & 4 & & & & & \\
\hline 51 & Auf dem kleinen Bulloh u. Söhren & Ackerl. & 4 & 4,5 & & & & & \\
\hline 52 & An Drallen Immengehäge & Ackerl. & 6 & 6 & & & & & \\
\hline 53 & Drallen Immengehäge & Heide & 4 & 6 & & & & & \\
\hline 54 & Über Drallen Immenzaun & Ackerl. & 4 & 4,5 & & & & & \\
\hline 55 & Auf dem Krümmel an Schumeyers Legde & Ackerl. & 3 & 4 & & & & & \\
\hline 56 & der Graben an Lüßmanns Krümmel & Heide & 8 & 9 & & & & & \\
\hline 57 & der Anberg auf Lüßmanns Krümmel & Ackerl. & 7 & 7 & & & & & \\
\hline 58 & die schlechtesten südöstl. Enden des Krümmels & Ackerl. & 12 & 15 & & & & & \\
\hline 59 & der Krümmel die südl. Enden & Ackerl. & 9 & 9 & & & & & \\
\hline 60 & derselbe an den Kohlgärten & Ackerl. & 6 & 6 & & & & & \\
\hline 61 & desgleichen die Mitte & Ackerl. & 4 & 4,5 & & & & & \\
\hline 62 & Schumeyers Holzlegde & Anger & 5 & 4,5 & & & & & \\
\hline 63 & die nordöstl. Ecke des Hagenfeldes & Ackerl. & 6 & 6 & & & & & \\
\hline 64 & Rest des Hagenfeldes und Nordostl.des Krümmelb. & Ackerl. & 2 & 3,5 & & & & & \\
\hline 65 & der Krümmel bei Bunkenbergs Hagengarten & Ackerl. & 2 & 3,5 & & & & & \\
\hline 66 & daselbst über den Kohlgärten & Ackerl. & 4 & 4,5 & & & & & \\
\hline 67 & die Lehmkuhlen u. der Weg im Langenbalken & Anger & 7 & 6 & & & & tot. & \\
\hline 68 & Südöstseite der Langengärten & Ackerl. & 6 & 6 & & & & & \\
\hline 69 & Eine schlechte Stelle daselbst am Beedenbost. Wege & Ackerl. & 9 & 9 & & & & & \\
\hline 70 & die südwestliche Ecke der Gärten & Ackerl. & 7 & 7 & & & & & \\
\hline 71 & die Ostseite derselben & Ackerl. & 1 & 3 & & & & & \\
\hline 72 & der Hagen nördlich in den Langengärten & Anger & 3 & 3,5 & & & & & \\
\hline 73 & die Mitte der Langengärten & Ackerl. & 3 & 4 & & & & & \\
\hline 74 & die Westseite derselben & Ackerl. & 3 & 4 & & & & & \\
\hline 75 & die nordwestliche Rest derselben & Ackerl. & 4 & 4,5 & & & & & \\
\hline 76 & Schmidt Meyers Krümmegärten & Ackerl. & 9 & 9 & & & & & \\
\hline 77 & Drallen Garten im Langenbalken Nordseite & Ackerl. & 11 & 12 & & & & & \\
\hline 78 & derselbe Südseite & Ackerl. & 7 & 7 & & & & & \\
\hline 79 & der Weg zwischen Drallen Garten und den Moorgärten & Anger & 11 & $9 \mathrm{t}$ & tot & & & & \\
\hline 80 & Auf dem Flottkampe die südöstl. Ecke & Ackerl. & 6 & 6 & & & & & \\
\hline 81 & Auf dem Flottkampe die südl. schlechten Enden & Ackerl. & 13 & 18 & & & & & \\
\hline 82 & daselbst die Nordwestseite & Ackerl. & 2 & 3,5 & & & & & \\
\hline 83 & daselbst die feuchten Enden & Ackerl. & 3 & 4 & & & & & \\
\hline 84 & daselbst der Rest & Ackerl. & 4 & 4,5 & & & & & \\
\hline 85 & die Sandberge westl. am Quälohsheg & Heide & 14 & 25 & & & & & tot \\
\hline 86 & Etwas ebenere Gmht. (Gemeinheit) am Flottkampe & Heide & 13 & $21 \mathrm{t}$ & tot & & & & \\
\hline 87 & Schlechte Sandberge daselbst & Heide & 14 & 25 & & & & & tot \\
\hline 88 & Noch überm Flottkampe & Heide & 13 & $21 \mathrm{t}$ & tot & & & & \\
\hline 89 & der Eichnbestand an den Moorgärten & Heide & 10 & 12 & 0,6 & 0,4 & & & \\
\hline 90 & Zwischen den Moorgärten und Quählohsheg & Heide & 14 & 25 & & & & & tot \\
\hline 91 & das Quälohsgehäge & Heide & 13 & 21 & & tot & & & \\
\hline 92 & Nördlich an Drewsen neuem Hofe & Heide & 13 & 21 & & 0,98 & 0,02 & & \\
\hline 93 & Lüßmanns Gehäge an den Moorgärten & Heide & 13 & 21 & & & & & \\
\hline 94 & Zwischen den Moorgärten und Drewswn Hofe & Heide & 12 & 18 & & & & & tot \\
\hline 95 & Ein Angerstrich in den Moorgärten & Anger & 13 & $12 t$ & tot & & & & \\
\hline 96 & In den Moorgärten die Westseite & Ackerl. & 12 & 15 & & & & & \\
\hline 97 & daelbst der Hagen & Heide & 12 & 18 & & & & & \\
\hline 98 & daselbst nördlich & Ackerl. & 6 & 6 & & & & & \\
\hline 99 & daselbst noch im Angerstrich & Ackerl. & 8 & 7 & & & & & \\
\hline 100 & daselbst die Mitte & Ackerl. & 3 & 4 & & & & & \\
\hline 101 & daselbst der Rest Südostseite & Ackerl. & 5 & 5 & & & & & \\
\hline 102 & der Beedenbostler Weg am Krümmelfelde & Heide & 10 & 12 & & & & & \\
\hline
\end{tabular}




\begin{tabular}{|c|c|c|c|c|c|c|c|c|c|}
\hline 103 & An der Lachte östl. der Anlagen & Anger & 6 & 5 & tot & & & & \\
\hline 104 & der Eichenbestand am Beedenbostler Wege & Anger & 7 & 6 & 0,9 & 0,1 & & & \\
\hline 105 & Zwischen den Teichwiesen u. Beedenbosteler Wege & Heide & 7 & 9 & 0,95 & 0,05 & & & \\
\hline 106 & der gute Angerwinkel an der Lachte unterm Krümmel & Anger & 1 & 2,5 & tot & & & & \\
\hline 107 & Westl. voriger Abteilung & Anger & 3 & 3,5 & tot & & & & \\
\hline 108 & An Drewsen Anlagen und dem Wege & Anger & 11 & 9 & tot & & & & \\
\hline 109 & An der Lachte wstl. Voriger Abteilung & Anger & 13 & 12 & tot & & & & \\
\hline 110 & der Beedenbistler Weg neben Drewsen neuem Hofe & Heide & 13 & 21 & & 0,04 & 0,96 & & \\
\hline 111 & Drewsen neuer Hof & Heide & 13 & 21 & & & & & \\
\hline 112 & Eichenbestand westl.an Drewswn Hofe & Heide & 12 & 18 & 0,3 & 0,7 & & & \\
\hline 113 & Ein schmaler Strich an der alten Lachte & Heide & 12 & 18 & 0,9 & 0,1 & & & \\
\hline 114 & Noch an der alten Lachte & Heide & 13 & 21 & & & & & tot \\
\hline 115 & die ausgeflossenen Stellen ander Stockau & Heide & 11 & 15 & tot & & & & \\
\hline 116 & die Hügelreihe in der Stockauheide & Heide & 12 & 18 & 0,6 & & 0,4 & & \\
\hline 117 & die Stockauheide unterm Lerchenberge & Heide & 11 & 15 & 0,9 & & 0,1 & & \\
\hline 118 & dieselbe im ebenen Strich & Heide & 10 & 12 & 0,8 & & 0,2 & & \\
\hline 119 & die Nords. Von Drallen Ackerland in der Stockau & Ackerl. & 9 & 10,5 & & & & & \\
\hline 120 & der rest derselben & Ackerl. & 7 & 7 & & & & & \\
\hline 121 & Westl. voriger Abteilung & Wiese & 11 & 9 & & & & & \\
\hline 122 & der Grabenwall an der Stockau & Heide & 10 & 12 & & & & & \\
\hline 123 & der beste Wiesenboden in der Stockau & Wiese & 3 & 2 & & & & & \\
\hline 124 & die Ostseite der Stockau & Anger & 8 & 7 & & & & & \\
\hline 125 & Im Bunger ein Wiesenstrich an der Lachte & Wiese & 5 & 3 & & & & & \\
\hline 126 & daselbst das Ackerland & Ackerl. & 3 & 4 & & & & & \\
\hline 127 & daselbst desgleichen & Ackerl. & 1 & 3 & & & & & \\
\hline 128 & daselbst östl. voriger Abteilung & Anger & 6 & 5 & & & & & \\
\hline 129 & Nord- und Ostseite von Thies Bunger & Anger & 6 & 5 & & & & & \\
\hline 130 & das Land in Thies Bunger & Ackerl. & 3 & 4 & & & & & \\
\hline 131 & die West- und Südseite desselben & Wiese & 7 & 4 & & & & & \\
\hline 132 & die bessere Wiesenstelle daselbst & Wiese & 5 & 3 & & & & & \\
\hline 133 & der schlechte sũdöstl. Theil daselbst & Anger & 8 & 7 & & & & & \\
\hline 134 & das Beste vom Stockaunanger & Anger & 3 & 3,5 & tot & & & & \\
\hline 135 & Südlich voriger Abteilung & Anger & 4 & 4 & tot & & & & \\
\hline 136 & Wieder südlich voriger Abteilung & Anger & 5 & 4,5 & tot & & & & \\
\hline 137 & Noch im Stockauanger an der Lachte & Anger & 7 & 6 & tot & & & & \\
\hline 138 & daselbst die Mitte & Anger & 8 & 7 & tot & & & & \\
\hline 139 & der Rest der Stockau an der alten Lachte & Heide & 10 & 12 & tot & & & & \\
\hline 140 & die alte Lachte & Heide & 11 & 15 & tot & & & & \\
\hline 141 & die Nordwests. Der großen Masch & Heide & 10 & 12 & tot & & & & \\
\hline 142 & der Rest derselben & Heide & 13 & 21 & 0,4 & 0,4 & & & 0,2 \\
\hline 143 & die westl. Spitze zwischen den beiden Lachtearmen & Heide & 12 & 18 & tot & & & & \\
\hline 144 & daselbst weiter östllich & Heide & 15 & 40 & & & & tot. & \\
\hline 145 & der Damm an Drewsen Torfschoppen & Heide & 13 & 21 & tot & & & & \\
\hline 146 & die Ostseite vom Dürskampe & Ackerl. & 2 & 3,5 & & & & & \\
\hline 147 & das Schlechtere die Mitte des Dürskampes & Ackerl. & 5 & 5 & & & & & \\
\hline 148 & Noch auf dem Dürskampe südlich voriger & Ackerl. & 12 & 15 & & & & & \\
\hline 149 & der Anberg daselbst & Ackerl. & 13 & 18 & & & & & \\
\hline 150 & der Rest dieSüdwests. daselbst & Ackerl. & 11 & 12 & & & & & \\
\hline 151 & Ein Heidwinkel zwischen dem Lachenkampe u. Dürskampe & Heide & 11 & 15 & 0,6 & & 0,4 & & \\
\hline 152 & Der Celler Eg am Dürskampe & Heide & 13 & 21 & & & & tot. & \\
\hline 153 & Nördlich des Dürskampe südlich am Wege & Ackerl. & 12 & 7 & & & & & \\
\hline 154 & Nordwestlich des Lerchenberges südl. am Wege & Ackerl. & 13 & 18 & & & & & \\
\hline 155 & Die Ost- und Südseite desselebn daselbst & Ackerl. & 12 & 15 & & & & & \\
\hline 156 & Die Grund auf dem Lerchenberge daselbst & Ackerl. & 11 & 12 & & & & & \\
\hline 157 & Der Rest des Dürskampes sūdl. am Wege & Ackerl. & 7 & 7 & & & & & \\
\hline 158 & Der Weg zwischen dem Dürskampe und dem Lachenkampe & Heide & 10 & 12 & & & & tot. & \\
\hline
\end{tabular}




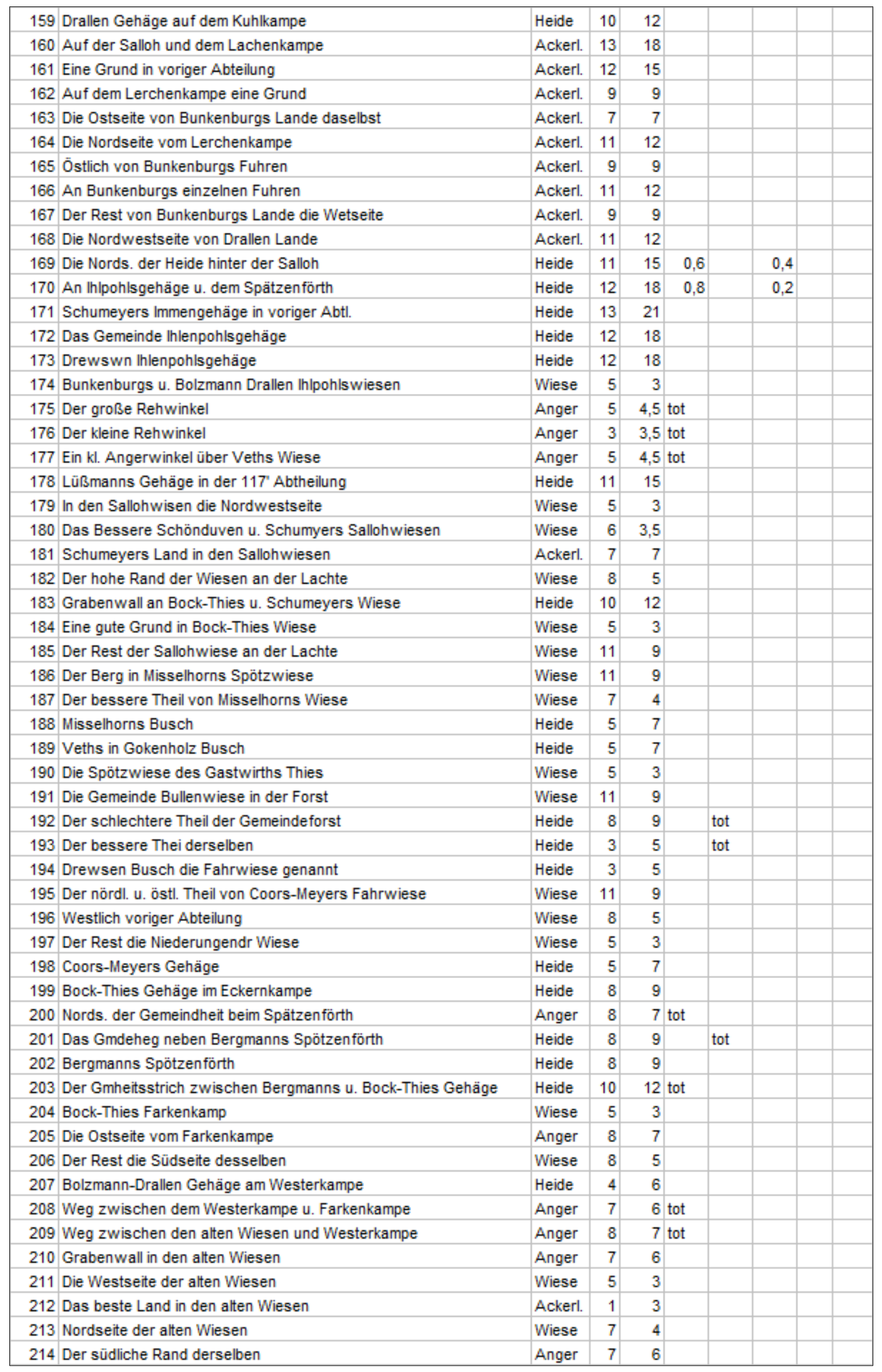




\begin{tabular}{|c|c|c|c|c|c|c|c|c|c|}
\hline 215 & Der Rest die Ostseite derselben & Anger & 8 & 7 & & & & & \\
\hline 216 & Ein schlechter Gemheitswinkel an der alten Wiese & Heide & 9 & 10,5 & tot & & & & \\
\hline 217 & Schlechte Stelle des Weges am Westerkamp & Heide & 13 & 21 & & & & tot. & \\
\hline 218 & Nördlich voriger Abtheilung & Anger & 4 & 4 & tot & & & & \\
\hline 219 & Zwischen dem Westerkampe und der Lachte & Anger & 7 & 6 & tot & & & & \\
\hline 220 & Zwischen dem Westerkampe und den Behrenswiesen & Heide & 10 & 12 & 0,2 & & & 0,8 & \\
\hline 221 & Grabenaufwurf an den Behrenswwiesen & Anger & 8 & 7 & & & & & \\
\hline 222 & In den Behrenswiesen die Westseite & Wiese & 3 & 2 & & & & & \\
\hline 223 & Nordseite von Thies Behrenswiese & Wiese & 5 & 3 & & & & & \\
\hline 224 & Am Bock-Thies Grützkessel & Wiese & 8 & 5 & & & & & \\
\hline 225 & Das Beste von Bock-Thies Grützkessel & Wiese & 5 & 3 & & & & & \\
\hline 226 & In den Behrenswiesen und im Bunger & Anger & 11 & 9 & & & & & \\
\hline 227 & Das beste Land in den Behrenswiesen & Ackerl. & 1 & 3 & & & & & \\
\hline 228 & Die Südosts. des Landes daselbst & Ackerl. & 10 & 10,5 & & & & & \\
\hline 229 & Im Bunger eine Grund & Ackerl. & 4 & 4,5 & & & & & \\
\hline 230 & Der Rest der hohe Rand des Bunger & Ackerl. & 7 & 7 & & & & & \\
\hline 231 & Vor der Behrenswiese & Anger & 10 & 8 & 0,7 & & 0,3 & & \\
\hline 232 & Der Weg vor dem Theilbusche & Heide & 11 & 15 & 0,5 & & & 0,5 & \\
\hline 233 & An der Lachte eine ebenere Fläche & Heide & 10 & 12 & tot & & & & \\
\hline 234 & Östlch voriger Abtheil. kl. Angergrund & Anger & 6 & 5 & tot & & & & \\
\hline 235 & Wieder östl. der vorigen Abtheilung & Heide & 11 & 15 & tot & & & & \\
\hline 236 & In der Lachtekrümmung ein kleiner Angerwinkel & Anger & 8 & 7 & tot & & & & \\
\hline 237 & Die Nordseite der Sandberge & Heide & 12 & 18 & tot & & & & \\
\hline 238 & Ebene Heide vor dem Theilbusche & Heide & 11 & 15 & 0,9 & & 0,1 & & \\
\hline 239 & Heideberge sūdlich voriger Abtheil. & Heide & 12 & 18 & tot & & & & \\
\hline 240 & In den Sandbergen die lehmigen Stellen & Heide & 8 & 9 & 0,4 & & & 0,6 & \\
\hline 241 & Zwischen dem Theilbusche u. Lande überm Westerkampe & Heide & 12 & 18 & 0,5 & & & 0,5 & \\
\hline 242 & Hoher Strich am Rehrkamp u. Westerfelde & Heide & 11 & 15 & 0,3 & & & 0,7 & \\
\hline 243 & Die Sandwiesen auf dem linken Lachteufer & Heide & 13 & 21 & 0,1 & 0,03 & & & 0,87 \\
\hline 244 & An Bunkenburgs, Drallen, Bührings usw. Höfen & Heide & 9 & 10,5 & & 0,1 & & 0,9 & \\
\hline 245 & Tischler Herbolds Garten beim Hause & Ackerl. & 10 & 12 & & & & & \\
\hline 246 & desselben Hof und Baustelle & Anger & 13 & 12 & & & & & \\
\hline 247 & Nordöstl. des Theilbusches vor dem Westerkampe & Heide & 12 & 18 & & & & & \\
\hline 248 & Die Südwests.der Büsche & Heide & 11 & 15 & & & & & \\
\hline 249 & Der Rest desselben & Heide & 10 & 12 & & & & & \\
\hline 250 & Auf dem Westerkampe die Nordostseite & Ackerl. & 9 & 9 & & & & & \\
\hline 251 & Eine sandige Stelle westl. voriger Abteilung & Ackerl. & 12 & 15 & & & & & \\
\hline 252 & Wieder westlich voriger Abteilung & Ackerl. & 10 & 10,5 & & & & & \\
\hline 253 & Die höhere Nordseite des Westernkapes & Ackerl. & 9 & 9 & & & & & \\
\hline 254 & Die Mitte desselben & Ackerl. & 7 & 7 & & & & & \\
\hline 255 & Die Grund auf der Nordwests. desselben & Ackerl. & 5 & 5 & & & & & \\
\hline 256 & Die südlichen schlechten Enden desselben & Ackerl. & 12 & 15 & & & & & \\
\hline 257 & Der Rest nördl. u. östl. voriger Abteilung & Ackerl. & 9 & 10,5 & & & & & \\
\hline 258 & Westseite von Bührinhs Lande überm Westerkamp & Ackerl. & 13 & 18 & & & & & \\
\hline 259 & Südwestseite des Landes überm Westerkamp & Ackerl. & 11 & 12 & & & & & \\
\hline 260 & Gastwirth Thies Gehäge & Heide & 11 & 15 & & & & & \\
\hline 261 & Die Mitte des Feldes überm Westerkampe & Ackerl. & 11 & 12 & & & & & \\
\hline 262 & Die Südostseite desselben & Ackerl. & 9 & 9 & & & & & \\
\hline 263 & Die Nordseite, Rest desselben & Ackerl. & 12 & 15 & & & & & \\
\hline 264 & Weg zwischen esternkampe und dem Feld darūber & Heide & 12 & 18 & & & & tot. & \\
\hline 265 & Am Rehrkampe & Heide & 11 & 15 & 0,6 & & 0,2 & 0,2 & \\
\hline 266 & Die Westseite von Bührings Rehrkampe & Ackerl. & 12 & 15 & & & & & \\
\hline 267 & Die Mitte desselben & Ackerl. & 11 & 12 & & & & & \\
\hline 268 & Hohe, schlechte Stellen auf dem Westerkampe u. Rehrkampe & Ackerl. & 13 & 18 & & & & & \\
\hline 269 & Eine Grund in voriger Abtheilung & Ackerl. & 11 & 12 & & & & & \\
\hline 270 & Bührings Gehäge am Rehrkampe & Heide & 12 & 18 & & & & & \\
\hline
\end{tabular}




\begin{tabular}{|c|c|c|c|c|c|c|c|c|}
\hline 271 & Die Heide zwischen dem Rehrkampe und Mühlekampe & Heide & 13 & 21 & 0,4 & & 0,6 & \\
\hline 272 & Joh. Hr. Drallen Immenheg in voriger Abtheil. & Heide & 12 & 18 & & & & \\
\hline 273 & Eine Grund auf dem Westerfelde & Ackerl. & 7 & 7 & & & & \\
\hline 274 & Östlich voriger Abtheilung & Ackerl. & 8 & 7,5 & & & & \\
\hline 275 & Die Nord- u. Osts. des Westerfeldes nördl. des Weges & Ackerl. & 10 & 10,5 & & & & \\
\hline 276 & Abbauer Thölke Garten beim Hause & Ackerl. & 9 & 9 & & & & \\
\hline 277 & desselben Hof und Baustelle & Anger & 12 & 10,5 & & & & \\
\hline 278 & Die Wege zwischen dem Mühlenfelde u. Lohfelde & Heide & 13 & 21 & & & & tot. \\
\hline 279 & Die Ostseite des Mühlenfeldes & Ackerl. & 12 & 15 & & & & \\
\hline 280 & Vor der Niederung im Mühlenfelde & Ackerl. & 10 & 10,5 & & & & \\
\hline 281 & Die Grund auf dem Mühlenfelde & Ackerl. & 9 & 9 & & & & \\
\hline 282 & Auf der Süd- und Nords. des Mühlenfeldes & Ackerl. & 12 & 15 & & & & \\
\hline 283 & Der Rest die Westseite desselben & Ackerl. & 10 & 10,5 & & & & \\
\hline 284 & Die Kanten des Lohfeldes am Wege nach der Heide & Ackerl. & 12 & 15 & & & & \\
\hline 285 & Östlich voriger Abtheil. eine Niederung & Ackerl. & 9 & 9 & & & & \\
\hline 286 & Wieder östl. der beiden vorigen Abtheil. & Ackerl. & 11 & 12 & & & & \\
\hline 287 & Noch auf dem Lohfelde u. die Südseite vom Brömmerkamp & Ackerl. & 12 & 15 & & & & \\
\hline 288 & Die Nordseite des Brömmerkampes & Ackerl. & 11 & 12 & & & & \\
\hline 289 & Das Lohfeld nördlich vom Brömmerkamp & Ackerl. & 10 & 10,5 & & & & \\
\hline 290 & Am Opperhäuser Wege die vorige Abtheil. & Ackerl. & 11 & 12 & & & & \\
\hline 291 & Auf dem Westerfelde zwischen dem Opperhäuser u. Celler Wege & Ackerl. & 8 & 7,5 & & & & \\
\hline 292 & daselbst die Spitze & Ackerl. & 9 & 9 & & & & \\
\hline 293 & Der Oppershäuser Weg westl. der Ackern & Heide & 13 & 21 & & & & tot. \\
\hline 294 & Der Oppershäuser Weg zwischen den Ackern u. Kochs & Heide & 12 & 18 & & & & tot. \\
\hline 295 & Die Westseite der Ackern & Ackerl. & 13 & 18 & & & & \\
\hline 296 & Östlich voriger Abtheilung & Ackerl. & 12 & 15 & & & & \\
\hline 297 & Auf Bunkenburgs Silberberge & Ackerl. & 11 & 12 & & & & \\
\hline 298 & Östlich voriger Abtheilung & Ackerl. & 10 & 10,5 & & & & \\
\hline 299 & Auf den Ackern hinter Thölken Hause & Ackerl. & 7 & 7 & & & & \\
\hline 300 & Östlich in der Grund daselbst & Ackerl. & 8 & 7,5 & & & & \\
\hline 301 & Eine hohe Stelle bei Surburgs Hause & Ackerl. & 10 & 10,5 & & & & \\
\hline 302 & Abbauer Suderburgs Baustelle & Anger & 12 & 10,5 & & & & \\
\hline 303 & Auf den Ackern westl. des Oppershäuser Weges & Ackerl. & 9 & 9 & & & & \\
\hline 304 & Abbauer Graue Baustelle & Anger & 11 & 9 & & & & \\
\hline 305 & Nordwestl. des Landes überm Ackern & Ackerl. & 12 & 15 & & & & \\
\hline 306 & Hohe Stelle daselbst & Ackerl. & 13 & 18 & & & & \\
\hline 307 & Die Wests. derselben u. Kochs Neueland & Ackerl. & 12 & 15 & & & & \\
\hline 308 & Hermanns Heidkamp & Ackerl. & 12 & 15 & & & & \\
\hline 309 & Eine Heidwinkel an Drewsen Gehäge & Heide & 12 & 18 & 0,4 & 0,1 & 0,5 & \\
\hline 310 & Tischler Herbolds Land in der Allerheide & Ackerl. & 14 & 21 & & & & \\
\hline 311 & Drewsen Gehäge daselbst & Heide & 12 & 18 & & & & \\
\hline 312 & Bunkenburgs Gehäge & Heide & 13 & 21 & & & & \\
\hline 313 & Zwischen Drewsen Gehäge u. dem & Heide & 12 & 18 & 0,6 & & 0,4 & \\
\hline 314 & Eine Rieth am Rusterheesekampe & Heide & 11 & 15 & 0,4 & & 0,6 & \\
\hline 315 & Südseite von Misselhorns Rusterheese & Ackerl. & 11 & 12 & & & & \\
\hline 316 & Misselhorns Rusterheese & Ackerl. & 13 & 18 & & & & \\
\hline 317 & Eine niedere Stelle südlich auf dem Ackern & Ackerl. & 12 & 15 & & & & \\
\hline 318 & <nördlich der vorigen Abteilung & Ackerl. & 13 & 18 & & & & \\
\hline 319 & Östlich voriger Abteilung & Ackerl. & 12 & 15 & & & & \\
\hline 320 & Mitte auf den Ackern & Ackerl. & 11 & 12 & & & & \\
\hline 321 & Rest des Feldes auf den Ackern westl. des Weges & Ackerl. & 9 & 9 & & & & \\
\hline 322 & Abbauer Joh. Hr. Lillie Baustelle & Anger & 11 & 9 & & & & \\
\hline 323 & Abbauer Ahrens Baustelle & Anger & 11 & 9 & & & & \\
\hline 324 & Auf den Ackern östl. des Wiesenweges & Ackerl. & 9 & 9 & & & & \\
\hline 325 & Südlich voriger Abtheilung & Ackerl. & 10 & 10,5 & & & & \\
\hline 326 & Bock-Thies Seekamp & Ackerl. & 12 & 15 & & & & \\
\hline
\end{tabular}




\begin{tabular}{|c|c|c|c|c|c|c|c|}
\hline 327 & Die Südseite von Bergmanns Seekampe & Ackerl. & 8 & 7,5 & & & \\
\hline 328 & Die Ostseite der Kampgärten & Ackerl. & 2 & 3,5 & & & \\
\hline 329 & Die Wests. der Kampgärten u. der Rest des Feldes & Ackerl. & 3 & 4 & & & \\
\hline 330 & Rambergs, Bührings u. Walters Gärten beim Hause & Ackerl. & 6 & 6 & & & \\
\hline 331 & Rambergs Baustelle & Anger & 7 & 6 & & & \\
\hline 332 & Walters Baustelle & Anger & 7 & 6 & & & \\
\hline 333 & Kochs Schwarzekamp u. südlich daran herum & Ackerl. & 6 & 6 & & & \\
\hline 334 & Ein Gemeinheitswinkel an voriger Abtheil. & Heide & 10 & 12 & 0,4 & 0,6 & \\
\hline 335 & Die Südseite von Coors-Meyers Lande & Ackerl. & 9 & 9 & & & \\
\hline 336 & Der Heidplack und Wiesenweg oben auf den Ackern & Heide & 13 & 21 & tot & & \\
\hline 337 & Die Südseite von Thies Rusterheese & Ackerl. & 10 & 10,5 & & & \\
\hline 338 & Nördlich voriger Abtheilung & Ackerl. & 12 & 15 & & & \\
\hline 339 & Zwischen dem Schwarzenkamp u. voriger Anthl. & Ackerl. & 11 & 12 & & & \\
\hline 340 & Die heidwüchsige Anhöhe im Bährenblau & Heide & 10 & 12 & tot & & \\
\hline 341 & Ein Heidstreifen im Seekampe u. Sandbruche & Heide & 11 & 15 & 0,4 & 0,6 & \\
\hline 342 & Bock-Thies Immenheg & Heide & 11 & 15 & & & \\
\hline 343 & Ein besserer Angerstrich im Bährenblau & Anger & 11 & 9 & tot & & \\
\hline 344 & Wieder ein Angerstrich im Sandbruchsfelde & Anger & 7 & 6 & tot & & \\
\hline 345 & An Kochs und Misselhorns alten Gärten & Anger & 2 & 3 & tot & & \\
\hline 346 & Kochs u. Misselhorns alten Gärten & Ackerl. & 1 & 3 & & & \\
\hline 347 & Die tiefen Riethen auf dem Moore & Anger & 11 & 9 & 0,2 & & 0,8 \\
\hline 348 & Die alten Lehmkuhlen westl. voriger Abthl. & Anger & 7 & 6 & 0,7 & & 0,3 \\
\hline 349 & Alte Lehmkuhlen am Ahnsbecker Wege neben der Brücke & Anger & 6 & 5 & 0,7 & & 0,3 \\
\hline 350 & Eine gänzlich vergrabene schmale Spitze am Wege & Anger & 11 & 9 & 0,4 & & 0,6 \\
\hline 351 & Ein ebener Angerstrich an den Kampgärten & Anger & 4 & 4 & tot & & \\
\hline 352 & An Grusche Thies Hofe & Anger & 11 & 9 & tot & & \\
\hline $352 a$ & Grusche Thies Hof & Anger & 11 & 9 & & & \\
\hline 353 & Schumeyers Hof u. Baustelle & Anger & 7 & 6 & tot & & \\
\hline 354 & Der Schulhof und Garten & Anger & 7 & 6 & & & \\
\hline 355 & Bergmanns u. Misselhorns Hof und Baustelle & Anger & 7 & 6 & & & \\
\hline \multirow[t]{2}{*}{356} & Coors-Meyers, Bunkenburgs, Lüßmanns und & & & & & & \\
\hline & Cammann-Thies Hof und Baustelle & Anger & 7 & 6 & & & \\
\hline 357 & Anbauer Lillie Hof und Baustelle & Anger & 7 & 6 & & & \\
\hline 358 & Bolzmann-Drallen u. J. H. Drallen Baustellen & Anger & 7 & 6 & & & \\
\hline 359 a & Būhrings Hof und Baustelle & Anger & 7 & 6 & & & \\
\hline 359 & Anbauers Christoph Thies Baustelle & Anger & 7 & 6 & & & \\
\hline 360 & Kohlmeyers Hof und Baustelle & Anger & 7 & 6 & & & \\
\hline 361 & Gastwirth Thies Hof und Baustelle & Anger & 7 & 6 & & & \\
\hline 362 & Bock-Thies Hof und Baustelle & Anger & 7 & 6 & & & \\
\hline 363 & Gemeinde Hirtenhaus & Anger & 7 & 6 & & & \\
\hline 364 & Hermanns Hof und Baustelle & Anger & 7 & 6 & & & \\
\hline \multirow[t]{2}{*}{365} & Drewswn Erben u. Schwägermanns Hof und & & & & & & \\
\hline & Baustellen, auch Gärten beim Hause & Anger & 7 & 6 & & & \\
\hline 366 & Drewsen Erben Frabrikgebäude und Hof & Anger & 7 & 6 & & & \\
\hline 367 & Der Garten am Überfalle & Ackerl. & 1 & 3 & & & \\
\hline 368 & Der neue Garten & Ackerl. & 6 & 6 & & & \\
\hline 369 & Anbauer Kochs Hof und Baustelle & Anger & 7 & 6 & & & \\
\hline 370 & Grusche Thies alter Hof und Kochs Hof & Anger & 7 & 6 & & & \\
\hline 371 & Anbauer Carsten $\mathrm{Hr}$. Meyers Hof & Anger & 7 & 6 & & & \\
\hline 372 & Das Gemeinde Hirtenhaus & Anger & 7 & 6 & & & \\
\hline 373 & Anbauer Joh. Hr. Wulf Hof & Anger & 7 & 6 & & & \\
\hline 374 & Anbauer Christoph Lüßmann desgl. & Anger & 7 & 6 & & & \\
\hline 375 & Anbauer Bergmanns desgl. & Anger & 7 & 6 & & & \\
\hline 376 & Anb. J.H. Knoop u. Abbauer Meyers Hofe & Anger & 7 & 6 & & & \\
\hline 377 & Halbneyers Schöndube Hof und Baustelle & Anger & 7 & 6 & & & \\
\hline 378 & Köthner Thies-Thies Westseite des Hofes & Anger & 7 & 6 & & & \\
\hline
\end{tabular}




\begin{tabular}{|c|c|c|c|c|c|c|c|c|}
\hline 379 & Sämtliche Straßen und die Gemeinheit im Dorfe & Anger & 7 & 6 & 0,6 & 0,4 & & \\
\hline 380 & Auf dem Sandbruche die Südwestseite & Ackerl. & 7 & 15 & & & & \\
\hline 381 & Süds. von Misselhorns Seekampe und Panstätte & Ackerl. & 13 & 18 & & & & \\
\hline 382 & Die südöstliche Ecke der Panstätte & Ackerl. & 12 & 15 & & & & \\
\hline 383 & Eine hohe Stelle auf der Wests. des Sandbruchs & Ackerl. & 14 & 21 & & & & \\
\hline 384 & Auf dem Sandbruche, Panstätte u. Kuhlkampe & Ackerl. & 9 & 9 & & & & \\
\hline 385 & Die Mitte vom Sandbruche u. Kuhlkampe & Ackerl. & 3 & 4 & & & & \\
\hline 386 & Das Beste die Nordwests. vom Sandbruche & Ackerl. & 2 & 3,5 & & & & \\
\hline 387 & Nördlich der 385 Abtheilung & Ackerl. & 5 & 5 & & & & \\
\hline 388 & Die Nordostseite des Kuhlkampes & Ackerl. & 4 & 9 & & & & \\
\hline 389 & Am Ahnsbecker Wege Rest der Panstätte & Ackerl. & 7 & 7 & & & & \\
\hline 390 & Der Ahnsbecker Weg & Heide & 8 & 9 & & & & tot. \\
\hline 391 & Ahnsbecker Weg, weiter westl. & Anger & 8 & 7 & & & & tot. \\
\hline 392 & Wests. des Sandbruchs nördl. des Ahnsbecker Weges & Ackerl. & 2 & 3,5 & & & & \\
\hline 393 & Die Mitte desselben & Ackerl. & 5 & 5 & & & & \\
\hline 394 & Meyers Land u. das Bessere daneben auf dem Sandbruche & Ackerl. & 3 & 4 & & & & \\
\hline 395 & Die Mählegden unterm Sandbruche & Wiese & 5 & 3 & & & & \\
\hline 396 & Das Schlechte auf der Südostseite des Sandbruchs & Ackerl. & 11 & 12 & & & & \\
\hline 397 & Ōstlich voriger Abtheilung & Ackerl. & 5 & 5 & & & & \\
\hline 398 & Das Beste auf Kohlmeyers Schelprieth & Ackerl. & 2 & 3,5 & & & & \\
\hline 399 & Auf Lüßmanns Schelprieth & Ackerl. & 3 & 4 & & & & \\
\hline 400 & Die Nordseite des Schelpriethfeldes & Ackerl. & 2 & 3,5 & & & & \\
\hline 401 & Kochs Kurzerkamp & Ackerl. & 5 & 5 & & & & \\
\hline 402 & Die Heide an Kochs Kurzenkamp & Heide & 5 & 7 & 0,5 & & 0,5 & \\
\hline 403 & Die Heide überm Sandbruche & Heide & 11 & 15 & 0,5 & & 0,5 & \\
\hline 404 & Die Gemeinheit bei der Windmühle herum & Heide & 10 & 12 & 0,5 & & 0,5 & \\
\hline 405 & Bührings Land neben der Windmühle & Ackerl. & 10 & 10,5 & & & & \\
\hline 406 & Das Müllerhaus und die Windmühle & Anger & 7 & 6 & & & & \\
\hline 407 & Drewsen alte Immenstelle bei der Mühle & Ackerl. & 9 & 9 & & & & \\
\hline 408 & Westseite des Landes am Mühlenwege u. der Sieben & Ackerl. & 8 & 7,5 & & & & \\
\hline 409 & Ōstlich voriger Abtheilung & Ackerl. & 11 & 6 & & & & \\
\hline 410 & Ein kl. Gemeinheitswinkel am Ahnsbecker Wege & Heide & 8 & 9 & 0,5 & & 0,5 & \\
\hline 411 & Die Südseite von Thies Lande beim Dornbusche & Ackerl. & 8 & 7,5 & & & & \\
\hline 412 & Die Mitte dessselben & Ackerl. & 6 & 6 & & & & \\
\hline 413 & Auf dem Felde überm Sandbruche & Ackerl. & 5 & 5 & & & & \\
\hline 414 & daselbst & Ackerl. & 3 & 4 & & & & \\
\hline 415 & Bei Striepen Immenzaun & Ackerl. & 3 & 4 & & & & \\
\hline 416 & Die großen Heidbolten daselbst & Heide & 6 & 7,5 & & & & \\
\hline 417 & Auf dem Schelpriethfelde & Ackerl. & 6 & 6 & & & & \\
\hline 418 & daselbst u. Wests. des Brandtkampes & Ackerl. & 3 & 4 & & & & \\
\hline 419 & Der Rest dees Brandtkampes & Ackerl. & 5 & 5 & & & & \\
\hline 420 & Das Moor u. die Heide im Brande & Heide & 10 & 12 & 0,5 & & 0,5 & \\
\hline 421 & Der Beedenbost.-Ahnsbecker Weg & Heide & 11 & 15 & & & & tot. \\
\hline 422 & Westlich von der Brandtkuhle & Heide & 9 & 10,5 & 0,4 & & 0,6 & \\
\hline 423 & Die Brandtkuhle & Heide & 13 & 21 & 0,1 & & 0,9 & \\
\hline 424 & Zwischen Schumeyers u. Sonemanns Lande & Heide & 6 & 7,5 & 0,4 & & 0,6 & \\
\hline 425 & Schumeyers Land bei der Brandtkuhle & Ackerl. & 3 & 4 & & & & \\
\hline 426 & Bei Drewsen Gehäge u. Lüßmanns Altenkampe & Heide & 4 & 6 & 0,5 & & 0,5 & \\
\hline 427 & Drewsen Gehäge & Heide & 4 & 6 & & & & \\
\hline 428 & Heide westlich von Drewsen Gehäge & Heide & 8 & 9 & 0,4 & & 0,6 & \\
\hline 429 & Südosts.des Feldes bei der Brandrkuhle & Ackerl. & 6 & 6 & & & & \\
\hline 430 & Südwests des Feldes bei der Brandtkuhle & Ackerl. & 8 & 7,5 & & & & \\
\hline 431 & Das Schlechte daselbst & Ackerl. & 9 & 9 & & & & \\
\hline 432 & Nordwestseite Rest desselben & Ackerl. & 5 & 5 & & & & \\
\hline 433 & Der Ahnbseck-Beedenbostl. Weg südl. des Bunkenburger Weges & Heide & 9 & 10,5 & & & & tot. \\
\hline 434 & Die Südostseite des Hohenkampes & Ackerl. & 8 & 7,5 & & & & \\
\hline
\end{tabular}




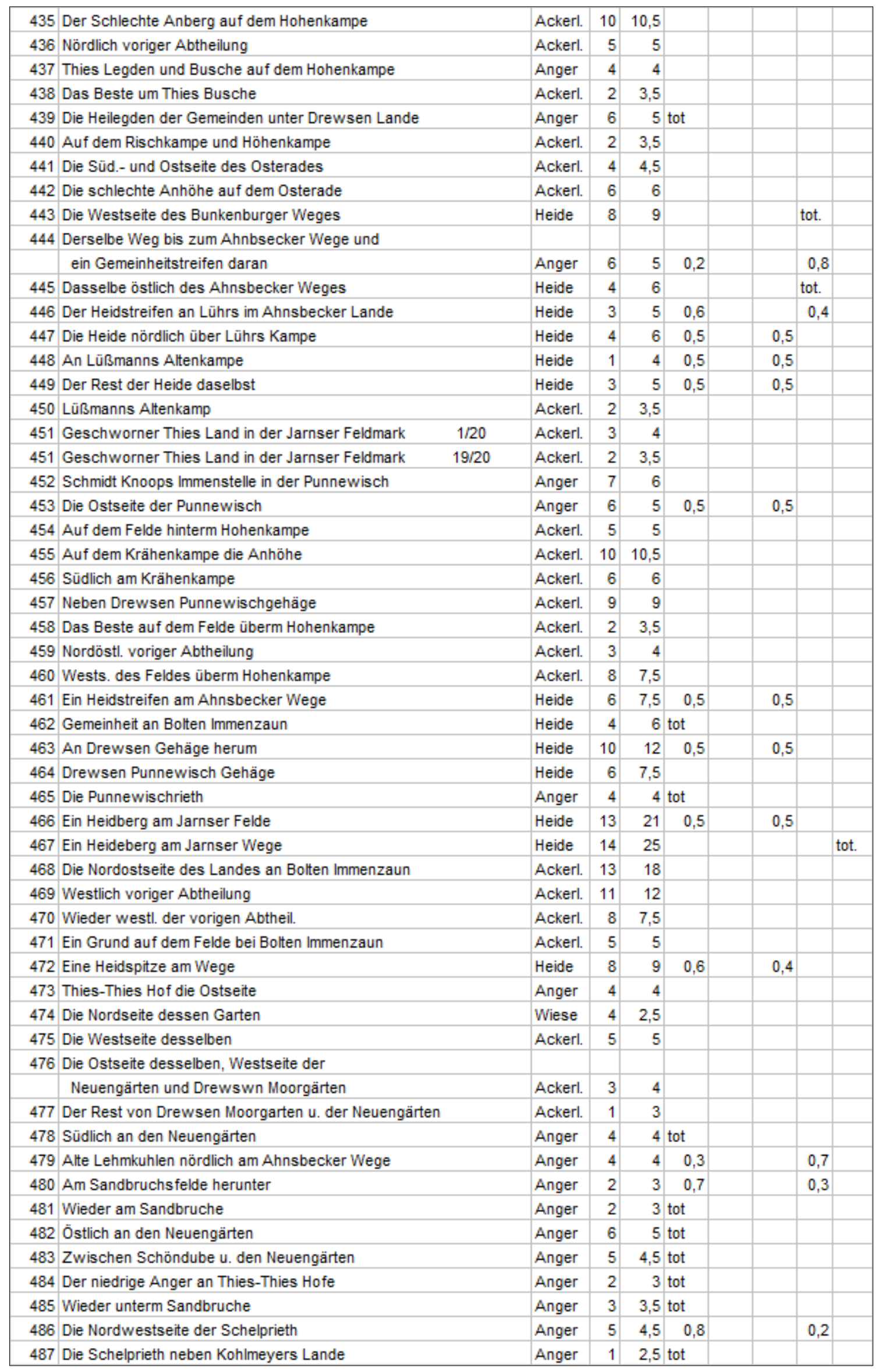




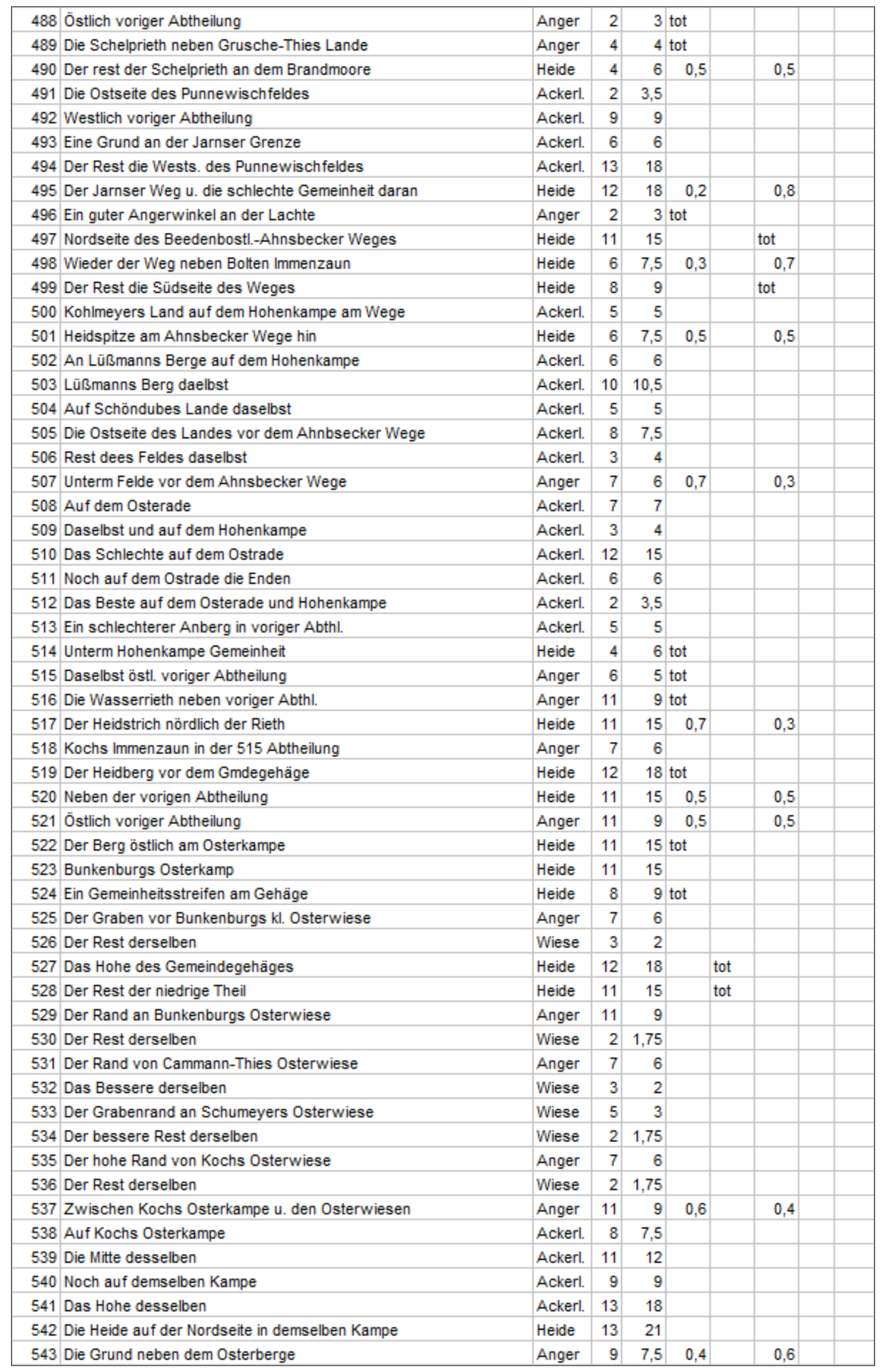




\begin{tabular}{|c|c|c|c|c|c|c|c|c|}
\hline 544 & Der Berg an voriger Abtheilung & Heide & 12 & 18 & 0,5 & & 0,5 & \\
\hline 545 & Grabenauswurf an Drallen Wiese & Anger & 11 & 9 & & & & \\
\hline 546 & Der Rest derselben & Wiese & 2 & 1,75 & & & & \\
\hline 547 & Auf Bolzmann-Drallen Wiese der Graben & Anger & 7 & 6 & & & & \\
\hline 548 & Auf derselben die Wiesenfläche & Wiese & 3 & 2 & & & & \\
\hline 549 & Der Rand an Thies-Thies Wiese & Anger & 13 & 12 & & & & \\
\hline 550 & Der Rest derselben & Wiese & 3 & 2 & & & & \\
\hline 551 & Ein Grund im Mellmau & Heide & 10 & 12 & 0,5 & & 0,5 & \\
\hline 552 & Neben der vorigen das Bessere & Anger & 11 & 9 & tot & & & \\
\hline 553 & Der hohe Heidstrich am Mellmau & Heide & 10 & 12 & tot & & & \\
\hline 554 & Die Sandwehe unterm Osterade & Heide & 13 & 21 & 0,4 & & & 0,6 \\
\hline 555 & Der bessere Gemeinheitsrand am Osterade & Anger & 4 & 4 & 0,9 & & 0,2 & \\
\hline 556 & Die Riede nördl. der vorigen Abtheilung & Anger & 9 & 7,5 & tot & & & \\
\hline 556 a & Ein niedriger Heidstrich im Mellmau & Heide & 11 & 15 & 0,5 & & 0,5 & \\
\hline 557 & Christoph Thies Lohnegarten & Wiese & 7 & 4 & & & & \\
\hline 558 & Thies-Thies Lohnegarten & Heide & 13 & 21 & & & & \\
\hline 559 & Der Rand von Drewsen Eselwiese & Anger & 7 & 6 & & & & \\
\hline 560 & Der Rest derselben & Wiese & 3 & 2 & & & & \\
\hline 561 & Köthner Ties Grashofwiese & Wiese & 2 & 1,75 & & & & \\
\hline 562 & Die Gemeinde Bullenwiese in der Forst & Wiese & 6 & 3,5 & & & & \\
\hline 563 & Der Rand von Kochs Grashofe & Anger & 11 & 9 & & & & \\
\hline 564 & Der Rest von Kochs Grashofe & Wiese & 2 & 1,75 & & & & \\
\hline 565 & Die Sandstellen beim Dorfe & Heide & 14 & 25 & 0,3 & & & 0,7 \\
\hline 566 & Die Grund am Hauberge & Anger & 11 & 9 & tot & & & \\
\hline 567 & Der Rand am Dorfe & Anger & 13 & 12 & tot & & & \\
\hline 568 & Der rest der Gemeinheit daselbst & Heide & 12 & 18 & tot & & & \\
\hline 569 & Der Holzbestand in Drewsen Bremmerwiese & Anger & 6 & 5 & & & & \\
\hline 570 & Der hohe Rand daselbst & Wiese & 5 & 3 & & & & \\
\hline 571 & Der Rest derselben & Wiese & 2 & 1,75 & & & & \\
\hline 572 & Thies kleine Teichweise der Rand & Anger & 3 & 3,5 & & & & \\
\hline 573 & Das Übrige davon & Wiese & 3 & 2 & & & & \\
\hline 574 & Die Nords. von Bergmanns Wiese & Wiese & 4 & 2,5 & & & & \\
\hline 575 & Auf Bergmanns und Schumeyers Wiesen & Anger & 3 & 3,5 & & & & \\
\hline 576 & Der Rest der Wiesen bis zur Höferschen & Wiese & 2 & 1,75 & & & & \\
\hline 577 & Gastwirth Thies Busch & Heide & 4 & 6 & & & & \\
\hline 578 & Der Gemeinde Wolfsbusch & Heide & 8 & 9 & & tot & & \\
\hline 579 & Thies in Höfer Wiese & Wiese & 4 & 2,5 & & & & \\
\hline 580 & Der Rand an Hermanns Wiesen & Anger & 6 & 5 & & & & \\
\hline 581 & Das Schlechte auf derselben Wiese & Wiese & 4 & 2,5 & & & & \\
\hline 582 & Der Rest derselben & Wiese & 2 & 1,75 & & & & \\
\hline 583 & Bock-Thies Wiese & Wiese & 2 & 1,75 & & & & \\
\hline 584 & Die Grund auf Köthner J. H. Drallen Wiese & Wiese & 3 & 2 & & & & \\
\hline 585 & Der Anger an Drallen Lande & Anger & 6 & 5 & & & & \\
\hline 586 & Der Rest der Wiese bis ans Land & Wiese & 5 & 3 & & & & \\
\hline 587 & Das Hohe von Drallen Lande & Ackerl. & 9 & 9 & & & & \\
\hline 588 & Der Rest des Landes & Ackerl. & 5 & 5 & & & & \\
\hline 589 & Die abgegrabene Fläche von Cammann-Thies Lande & Wiese & 5 & 3 & & & & \\
\hline 590 & Der Rand an der Aschau & Anger & 9 & 7,5 & & & & \\
\hline 591 & Die Süds. von Cammann-Thies Lande am Vogelheerde & Ackerl. & 5 & 5 & & & & \\
\hline 592 & Die Neuenwiese im Vogelheerde & Wiese & 5 & 3 & & & & \\
\hline 593 & Die Nordseite des Landes daselbst & Ackerl. & 3 & 4 & & & & \\
\hline 594 & Thies Wiese am Vogelberge & Wiese & 2 & 1,75 & & & & \\
\hline 595 & Drewsen Meinsche Wiese & Wiese & 5 & 3 & & & & \\
\hline 595 & Drewsen Meinsche Wiese & Wiese & 8 & 5 & & & & \\
\hline 596 & Drewsen Mühlenwiese & Wiese & 5 & 3 & & & & \\
\hline 596 & Drewsen Mühlenwiese & Wiese & 2 & 1,75 & & & & \\
\hline
\end{tabular}




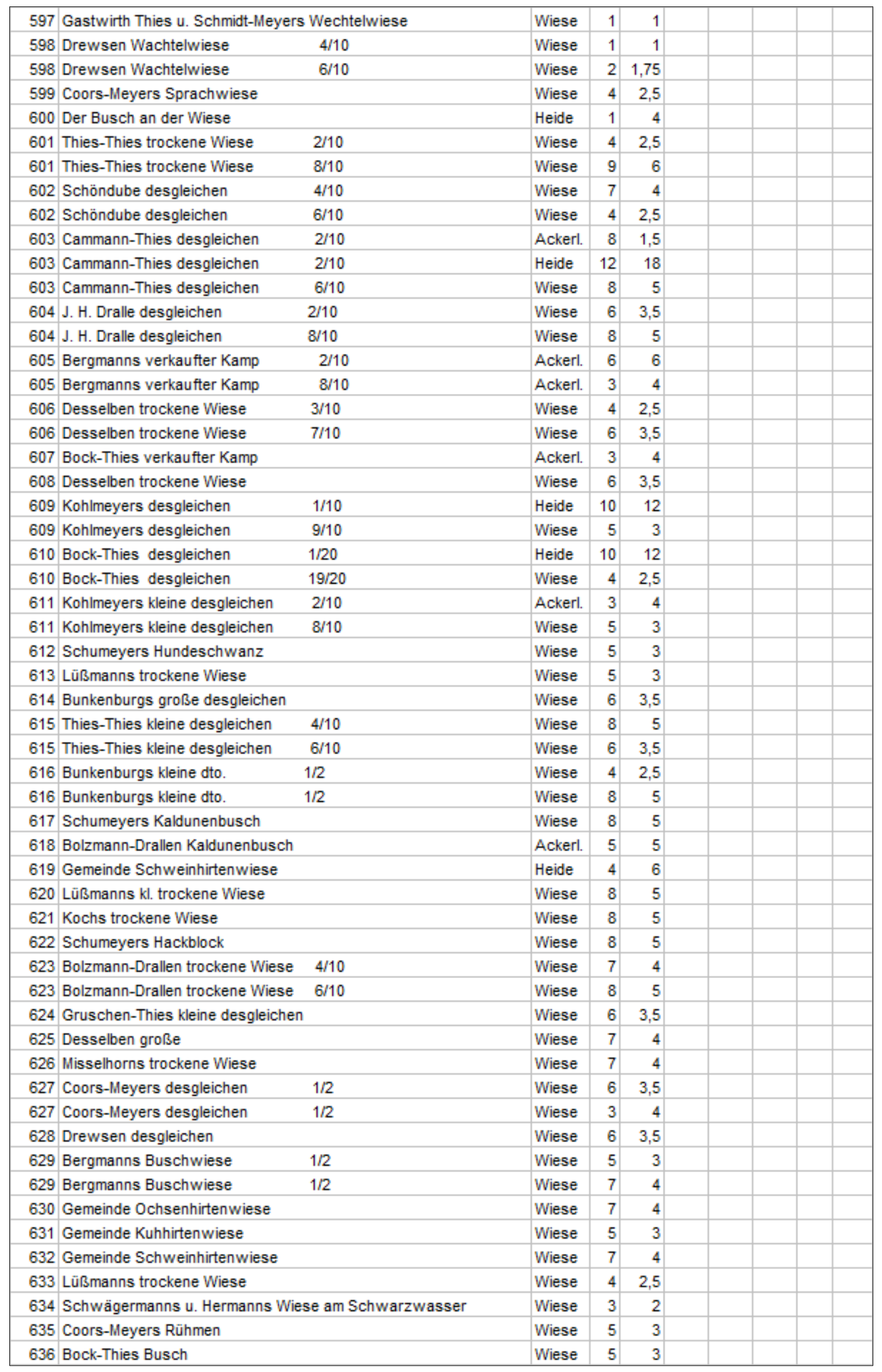




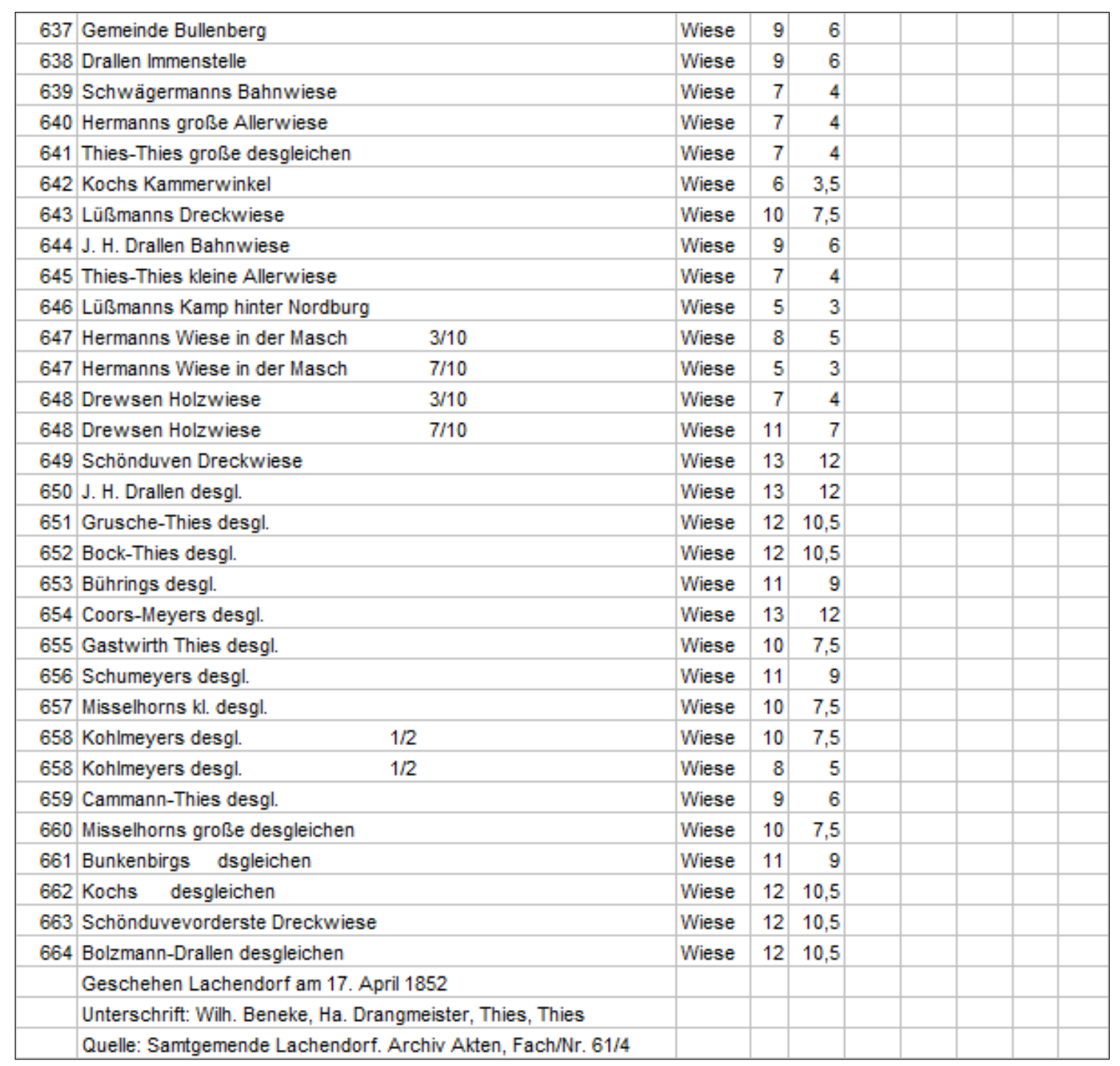

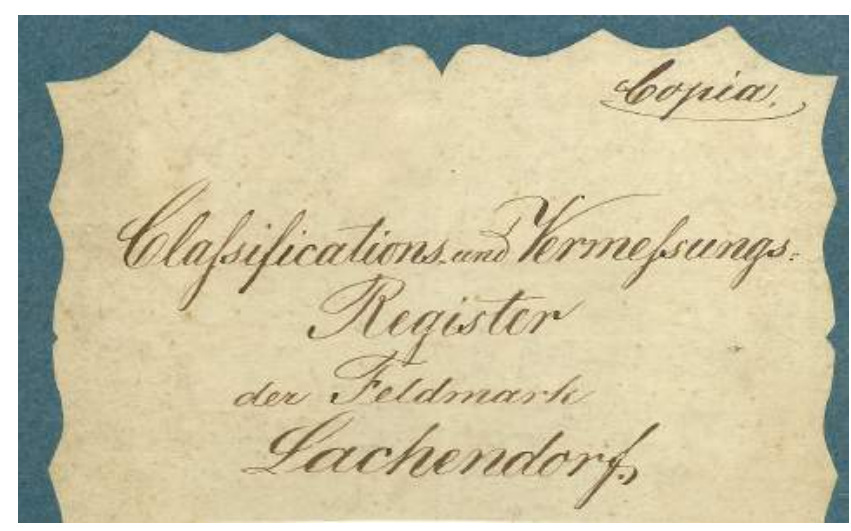

Nach dieser Abschätzung (Taxation) erfolgte die genaue Vermessung aller vorher bewerteten Flurstücke. Das Ergebnis ist in Teil A des „Classifications- und Vermessungs-Registers der Feldmark Lachendorf"1, gegliedert nach Ackerland, Wiesenboden. Angerboden und Heidboden, festgehalten.

\footnotetext{
${ }^{1}$ Abb. oben: Aufkleber mit Titel der Originalkopie, Samtgemeinde Lachendorf, Archiv Akten, 61/9
} 
Ackerland

\begin{tabular}{|c|c|c|c|c|c|c|c|c|c|}
\hline & & Class & sificat & tions- -4 & uind $\mathrm{V}$ & Verme & essung & ngs-R & Regist \\
\hline q & & & & & & & & & \\
\hline 穿 & Benennung & & & & & & & & \\
\hline 范 & der & & & & & & & & \\
\hline 要 & Gegend & & 1. & 2. & & 3. & & 4 & \\
\hline 2 & & M & QR & M & QR & M & QR & M & QR \\
\hline 16 & Hinterm Häge & & & & & 5 & 58 & & \\
\hline 19 & Hinterm Häge, auf dem Söhren & & & 172 & 27 & & & & \\
\hline 20 & Das Beste auf dem Felde hinterm Häge & & & 6 & 78 & & & & \\
\hline 21 & Das Gleiche hinterm Häge & & & & & 17 & 43 & & \\
\hline 22 & Desgleichen der Rest des Feldes & & & & & & & & \\
\hline 28 & Bunkenburg und Thies Hagengärten & 1 & 8 & & & & & & \\
\hline 35 & Die Ankanten vom kl. Bulloh & & & & & & & & \\
\hline 36 & Auf dem Bulloh und Lercheberge & & & & & & & & \\
\hline 37 & Die nordwestl. Ecke des Lerchenberges & & & & & 2 & 20 & & \\
\hline 38 & Der Lerchenberg nördl. vom Gockenholzer Wege & & & & & & & & \\
\hline 39 & Desgleichen daselbst & & & & & & & & \\
\hline 40 & Der schlechteste Rest des Lerchenberges & & & & & & & & \\
\hline 47 & Coors-Meyer Schwarzenkamp & & & & & & & & \\
\hline 50 & Auf Bock-Thies Hesteroh u. kl. Bulloh & & & & & 8 & 48 & & \\
\hline 51 & Auf dem kl. Bulloh und Söhren & & & & & & & 15 & 115 \\
\hline 52 & An Drallen Immengehäge & & & & & & & & \\
\hline 54 & Über Drallen Immenzaune & & & & & & & 12 & 65 \\
\hline 55 & Auf dem Krūmmel u. Schumeyer Legde & & & & & 1 & 58 & & \\
\hline 57 & Der Anberg auf Lüßmanns Krūmmel & & & & & & & & \\
\hline 58 & Die schlechtesten sūdw. Enden des Krūmmel & & & & & & & & \\
\hline 59 & Der Krümmel die sūdl. Enden & & & & & & & & \\
\hline 60 & Dieselben an den Kohlgärten & & & & & & & & \\
\hline 61 & Desgleichen die Mitte & & & & & & & 9 & 104 \\
\hline 63 & Die nordöstl. Ecke des Hagenfeldes & & & & & & & & \\
\hline 64 & Rest des Hagenfeldes u. nordöstl. d. Krūmmel & & & 28 & 60 & & & & \\
\hline 65 & Der Krümmel bei Bunkenburgs Hagengarten & & & 11 & 42 & & & & \\
\hline 66 & Daselbst über den Kohlgärten & & & & & & & 3 & 6 \\
\hline 68 & Nordostseite der Langengärten & & & & & & & & \\
\hline 69 & Eine schlechte Stelle daselbst am Beedbstl. Wege & & & & & & & 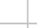 & \\
\hline 70 & Die nordwestliche Ecke der Gärten & & & & & & & & \\
\hline 71 & Die Ostseite derselben & 3 & 16 & & & & & & \\
\hline 73 & Die Mitte der Langengärten & & & & & 2 & 29 & & \\
\hline 74 & Die Westseite derselben & & & & & & 109 & & \\
\hline 75 & Die Nordwestseite Rest derselben & & & & & & & & 71 \\
\hline 76 & Schmidt Meyers Krūmmelgarten & & & & & & & & \\
\hline 77 & Drallen Garten im Langenbalk, Nordseite & & & & & & & & \\
\hline 78 & Derselbe die Sūdseite & & & & & & & & \\
\hline 80 & Auf dem Flottkampe die sūdöstl. Ecke & & & & & & & & \\
\hline 81 & Daselbst die sūdl. schlechten Ecken & & & & & & & & \\
\hline 82 & Daselbst die Nordwestseite & & & 26 & 28 & & & & \\
\hline 83 & Daselbst die feuchten Enden & & & & & 41 & 116 & & \\
\hline 84 & Daselbst der Rest & & & & & & & 10 & 60 \\
\hline 96 & In den Moorgärten die Westseite & & & & & & & & \\
\hline 98 & daselbst nördlich & & & & & & & & \\
\hline 100 & daselbst die Mitte & & & & & 1 & 27 & & \\
\hline 101 & daselbst der Rest Südwestseite & & & & & & & & \\
\hline 119 & Die Nords. von Drallen Ackerland Stockau & & & & & & & & \\
\hline 120 & Der Rest desselben & & & & & & & & \\
\hline 126 & Im Bunger das Ackerland & & & & & 21 & 100 & & \\
\hline 127 & Daselbst desgleichen & 1 & 90 & & & & & & \\
\hline 130 & Das Land in Thies Bunger & & & & & & 39 & & \\
\hline 146 & Die Ostseite vom Dürskampe & & & 38 & 20 & & & & \\
\hline 147 & Das Schlechtere die Mitte desselben & & & & & & & & \\
\hline 148 & Noch daselbst sūdl. voriger Abteil. & & & & & & & & \\
\hline 149 & Der Anberg daselbst & & & & & & & & \\
\hline 150 & Der Rest, die Südwests. daselbst & & & & & & & & \\
\hline 153 & Nords. d. Dürskampes sūdlich am Wege & & & & & & & & \\
\hline 154 & Nordwests. d. Lerchenberges sūdlich am Wege & & & & & & & & \\
\hline 155 & Die Ost- und Sūdseite desselben daselbst & & & & & & & & \\
\hline 156 & Die Grund auf dem Lerchenberge das. & & & & & & & & \\
\hline 157 & Der Rest des Dürskampes sūdl. am Wege & & & & & & & & \\
\hline 160 & Auf der Salloh u. dem Lachenkampe & & & & & & & & \\
\hline 161 & Eine Grund in voriger Abteilung & & & & & & & & \\
\hline 162 & Auf dem Lachekampe eine Grund & & & & & & & & \\
\hline 163 & Die Osts. von Bunkenburgs Lande daselbst & & & & & & & & \\
\hline 164 & Die Nords. vom Lachenkampe & & & & & & & & \\
\hline 165 & Ōstlich vor Bunkenburgs Fuhren & & & & & & & & \\
\hline 166 & An Bunkenburgs einzelnen Fuhren & & & & & & & & \\
\hline 167 & Der Rest von Bunkenburgs Lande, Wests. & & & & & & & & \\
\hline 168 & Die Nordwests. von Drallen Lande & & & & & & & & \\
\hline 181 & Schumeyers Land in den Sallohwiesen & & & & & & & & \\
\hline 212 & Das Beste in den alten Wiesen & 2 & 28 & & & & & & \\
\hline 227 & Nördlich der vorigen Abteilung & 5 & 28 & & & & & & \\
\hline 228 & Das Beste Land an den Behrenswiesen & & & & & & & & \\
\hline 229 & Die Südosts. des Landes daselbst & & & & & & & 2 & 10 \\
\hline 230 & Im Bünger eine Grund & & & & & & & & \\
\hline 245 & Der Rest, der hohe Rand des Büngers & & & & & & & & \\
\hline 250 & Tischler Herbolds Garten beim Hause & & & & & & & & \\
\hline 251 & Auf dem Westerkampe die Nordosts. & & & & & & & & \\
\hline 252 & Eine sandige Stelle westl. voriger Abteilung & & & & & & & & \\
\hline 253 & Wieder westl. voriger Abteilung & & & & & & & & \\
\hline 254 & Die höhere Nords. des Westerkampes & & & & & & & & \\
\hline 255 & Die Mitte desselben & & & & & & & & \\
\hline
\end{tabular}




\begin{tabular}{|c|c|c|c|c|c|c|c|c|c|}
\hline ๘ & & & & & & & & & \\
\hline 堊 & Benennung & & & & & & & & \\
\hline 훈 & der & & & & & & & & \\
\hline$\stackrel{0}{0}$ & Gegend & & 1. & 2 & & 3 & 3. & 2 & 4. \\
\hline $2^{\circ}$ & & M & $Q R$ & M & QR & M & QR & M & QR \\
\hline 256 & Die Grund auf d. Nordwests. desselben & & & & & & & & \\
\hline 257 & Die sūdl. schlechteren Enden desselben & & & & & & & & \\
\hline 258 & Der Rest nördl. u. östl. voriger Abteilung & & & & & & & & \\
\hline 259 & Wests. von Bührings Lande überm Westerkampe & & & & & & & & \\
\hline 261 & Südwests. des Landes überm Westerkampe & & & & & & & & \\
\hline 262 & Mitte des Feldes überm Westerkampe & & & & & & & & \\
\hline 263 & Die Sūdostseite desselben & & & & & & & & \\
\hline 266 & Die Nordseite Rest desselben & & & & & & & & \\
\hline 267 & Die Wests. von Bührings Rehrkampe & & & & & & & & \\
\hline 268 & Die Mitte desselben & & & & & & & & \\
\hline 269 & Hohe, schlechte Stellen auf d. Westerf. u. Rehrkpe & & & & & & & & \\
\hline 273 & Eine Grund in voriger Abteilung & & & & & & & & \\
\hline 274 & Eine Grund auf dem Westerfelde & & & & & & & & \\
\hline 275 & Ōstlich voriger Abteilung & & & & & 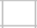 & & & \\
\hline 276 & Die Nord- u. Osts. des Westerf. nördl. d. Weges & & & & & & & & \\
\hline 279 & Abbauer Thölke Garten beim Hause & & & & & & & & \\
\hline 280 & Die Ostseite des Mühlenfeldes & & & & & & & & \\
\hline 281 & Vor der Niederung im Mühlenfelde & & & & & & & & \\
\hline 282 & Die Grund auf dem Mühlenfelde & & & & & 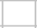 & & & \\
\hline 283 & Auf der Süd-u. Nords. des Mühlenfeldes & & & & & 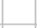 & & & \\
\hline 284 & Der Rest, die Westseite desselben & & & & & & & & \\
\hline 285 & Die Stanten des Lohfeldes am Wege nach 5 Heide & & & & & & & & \\
\hline 286 & Ōstlich voriger Abteilung eine Niederung & & & & & & & & \\
\hline 287 & Wieder östl. der beiden vorigen Abteilungen & & & & & & & & \\
\hline 288 & Noch auf dem Lohf. u. d. Sūdseite vom Brömmerkpe & & & & & 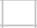 & & & \\
\hline 289 & Die Nordseite des Brömmerkampes & & & & & & & & \\
\hline 290 & Das Lohfeld nördl. am Brömmerkampe & & & & & & & & \\
\hline 291 & Am Oppershäuser Wege in voriger Abteilung & & & & & & & & \\
\hline 292 & Auf dem Westerfeld zwisch. Oppersh. u. Celler Weg & & & & & & & & \\
\hline 295 & Daselbst die Spitze & & & & & 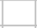 & & & \\
\hline 296 & Die Westseite der Ackern & & & & & & & & \\
\hline 297 & Östlich voriger Abteilung & & & & & & & & \\
\hline 298 & Auf Bunkenburgs Silberberg & & & & & & & & \\
\hline 299 & Östlich voriger Abteilung & & & & & & & & \\
\hline 300 & Auf den Ackern hinter Thölkes Hause & & & & & 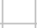 & & & \\
\hline 301 & Ōstlich an der Grund daselbst & & & & & 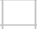 & & & \\
\hline 303 & Eine hohe Stelle bei Surburgs Hause & & & & & & & & \\
\hline 305 & Auf den Ackern westl. Oppershaus. Weges & & & & & & & & \\
\hline 306 & Nordwestl. des Landes übern Ackern & & & & & & & & \\
\hline 307 & Hohe Stelle daselbst & & & & & 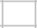 & & & \\
\hline 308 & Die Wests. desselben u. Kochs Neueland & & & & & & & & \\
\hline 310 & Hermanns Heidkamp & & & & & & & & \\
\hline 315 & Tischler Herbolds Land an d. Allerheide & & & & & & & & \\
\hline 316 & Südseite von Misselhorns Rūsterheese & & & & & & & & \\
\hline 317 & Miselhorns Rūsterheese & & & & & & & & \\
\hline 218 & Eine niedrige Stelle sūdl. auf $d$. Ackern & & & & & & & & \\
\hline 319 & Ōstlich voriger Abteilung & & & & & & & & \\
\hline 320 & Mitten auf den Ackern & & & & & & & & \\
\hline 321 & Reste d. Feldes auf d. Ackern westl. d. Weges & & & & & & & & \\
\hline 324 & Auf den Ackern östl. des Wiesenweges & & & & & & & & \\
\hline 325 & Südlich voriger Abteilung & & & & & & & & \\
\hline 326 & Bock-Thies Seekamp & & & & & & & & \\
\hline 327 & Die Südseite von Bergmanns Seekampe & & & & & & & & \\
\hline 328 & Die Ostseite der Kampgärten & & & 3 & 37 & & & & \\
\hline 329 & Die Wests. d. Kampgärten u. d. Rest d. Feldes & & & & & 5 & 49 & & \\
\hline 330 & Rambergs, Bührings u. Walters Gärten b. Haus & & & & & & & & \\
\hline 333 & Kochs Schwarzenkamp u. sũdl. davon herum & & & & & & & & \\
\hline 335 & Sūds. von Coors-Meyers Lande & & & & & & & & \\
\hline 337 & Die Südseite von Thhies Rūsterheese & & & & & & & & \\
\hline 338 & Nördlich voriger Abteilung & & & & & & & & \\
\hline 339 & Zwischen dem Schwarzenkampe u. voriger Abtl. & & & & & & & & \\
\hline 346 & Kochs und Misselhorns alte Gärten & 1 & 46 & & & & & & \\
\hline 367 & Der Garten am Überfalle & 1 & 109 & & & & & & \\
\hline 368 & Der neue Garten & & & & & & & & \\
\hline 380 & Auf dem Sandbruche die Sũdwestseite & & & & & & & & \\
\hline 381 & Süds. v. Misselhorns Seekampe u. d. Pannstätte & & & & & & & & \\
\hline 382 & Die sūdöstl. Ecke der Pannstätte & & & & & & & & \\
\hline 383 & Eine hohe Stelle auf d. Wests. Sandbruchs & & & & & & & & \\
\hline 384 & Auf dem Sandbruche, Pannstätte u. Kuhlkampe & & & & & & & & \\
\hline 385 & Die Mitte vom Sandbruche und Kuhlkampe & & & & & 29 & 45 & & \\
\hline 386 & Das Beste, die Nordwests. vom Sandbruche & & & 26 & 90 & & & & \\
\hline 387 & Nördlich der 385 Abteilung & & & & & & & & \\
\hline 388 & Nordosts. d. Kuhlkampes & & & & & & & & \\
\hline 389 & Am Ahnbsecker Wege, Rest der Pannstätte & & & & & & & & \\
\hline 392 & Wests. d. Sandbruchs nördl. d. Ahnsbecker Weges & & & 20 & 103 & & & & \\
\hline 393 & Die Mitte desselben & & & & & & & & \\
\hline 394 & Meyers Land u. d. Bessere auf dem Sandbruche & & & & & 4 & 104 & & \\
\hline 396 & Das Schlechte auf der Sūdosts. des Sandbruchs & & & & & & & & \\
\hline 397 & Ōstlich voriger Abteilung & & & & & & & & \\
\hline 398 & Das Beste auf Kohlmeyers Schelprieth & & & 1 & 102 & & & & \\
\hline 399 & Auf Lüßmanns Schelprieth & & & & & 10 & 108 & & \\
\hline 400 & Die Nords. des Schelpriethfeldes & & & 36 & 7 & & & & \\
\hline 401 & Kochs Krūgerkamp & & & & & & & & \\
\hline 405 & Bührinhgs Land neben der Windmühle & & & & & & & & \\
\hline
\end{tabular}




\begin{tabular}{|c|c|c|c|c|c|c|c|c|c|c|c|c|c|c|c|c|c|c|c|c|c|c|c|c|c|c|c|c|}
\hline ๑ & & & & & & & & & & & & & A. Clas & ssifica & ations & ss-Re & egister & & & & & & & & & & & \\
\hline 空 & Benennung & & & & & & & & & & & & & & kerlan & & & & & & & & & & & & & \\
\hline 힌 & der & & & & & & & & & & & & & & asser & & & & & & & & & & & & & \\
\hline 这 & Gegend & & 1. & 2 & & 3 & 3. & & 4. & 5 & 5. & 6 & & 7. & & & 8. & & 9. & & 10. & & 11. & & 12. & & 13. & \\
\hline$z^{\circ}$ & & M & QR & M & QR & M & QR & M & QR & M & QR & M & QR & M O & $Q R$ & M & QR & M & QR & M & QR & M & QR & M & QR & $M$ & QR & M \\
\hline 407 & Drewsen alte Immenstelle bei der Mühle & & & & & & & & & & & & & & & & & & 45 & & & & & & & & & \\
\hline 408 & Wests. d. Landes am Mühlenwege u. d. Sieben & & & & & & & & & & & & & & & 5 & 13 & & & & & & & & & & & \\
\hline 409 & Ōstlich voriger Abteilung & & & & & & & & & & & 10 & 18 & & & & & & & & & & . & & & & & \\
\hline 411 & Die Süds. von Thies Lande beim Dornbusche & & & & & & & & & & & & & & & 6 & 4 & & & & & & 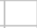 & & & 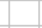 & & \\
\hline 412 & Die Mitte desselben & & & & & & & & & & & 6 & 11 & & & & & & & & & & . & & & ( & & \\
\hline 413 & Auf dem Felde übern Sandbruche & & & & & & & & & 26 & 57 & & & & & & & & & & & & & & & & & \\
\hline 414 & daselbst & & & & & 9 & 26 & & & & & & & & & & & & & & & & & & & & & \\
\hline 415 & Bei Striepen Immenzaun & & & & & 2 & 30 & & & & & & & & & & & & & & & & & & & & & \\
\hline 417 & Auf dem Schelpriethfelde & & & & & & & & & & & 8 & 28 & & & & & & & & & & . & & & 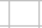 & & \\
\hline 418 & Daselbst u. Wests. des Brandtkampes & & & & & 21 & 2 & & & & & & & & & & & & & & & & 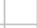 & & & 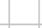 & & \\
\hline 425 & Schumeyers Land bei der Brandtkuhle & & & & & 4 & 74 & & & & & & & & & & & & & & & & & & & & & \\
\hline 429 & Sūdosts. d. Feldes bei der Brandtkuhle & & & & & & & & & & & 6 & 39 & & & & & & & & & & & & & & & \\
\hline 430 & Südwests. d. Feldes bei der Brandtkuhle & & & & & & & & & & & & & & & 2 & 103 & & & & & & & & & & & \\
\hline 431 & Das Schlechte desselben & & & & & & & & & & & & & & & & & 12 & 93 & & & & & & & ( & & \\
\hline 432 & Nordwests., Rest desselben & & & & & & & . & & 3 & 32 & & & & & & & & & & & & 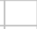 & & & 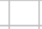 & & \\
\hline 434 & Die Sũdosts. des Hohenfeldes & & & & & & & & & & & & & & & 2 & 67 & & & & & & 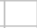 & & & 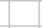 & & \\
\hline 435 & Der schlechte Anberg des Hohenfeldes & & & & & & & & & & & & & & & & & . & & 5 & 62 & & 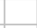 & & & 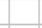 & & \\
\hline 436 & Nördlich voriger Abteilung & & & & & & & & & 5 & 56 & & & & & & & 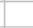 & & & & & 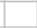 & & & 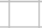 & & \\
\hline 438 & Das Beste an Thies Busche & & & 9 & 5 & & & & & & & & & & & & & & & & & & 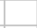 & & & 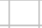 & & \\
\hline 440 & Auf dem Rischkampe u. Hohenkampe & & & 102 & 51 & & & & & & & & & & & & & & & & & & 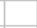 & & & te & & \\
\hline 441 & Die Sūd- u. Osts. des Ostrerades & & & & & & & 12 & 1 & & & & & & & 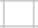 & & 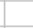 & & & & & 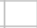 & & & 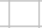 & & \\
\hline 442 & Die schlechte Anhöhe auf dem Osterade & & & & & & & & & & & 5 & 48 & & & . & & & & & & & & & & & & \\
\hline 419 & Der Rest des Brandtkampes & & & & & & & & & 4 & 28 & & & & & . & & . & & & & & . & & & & & \\
\hline 450 & Lüßmanns Alterkamp & & & 9 & 25 & & & & & & & & & & & & & & & & & & . & & & . & & \\
\hline 451 & Geschworener Thies in Jarnser Feldmark & & & & in Eint & & & & & & & & & & & & & & & & & & 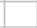 & & & ( & & \\
\hline 454 & Auf dem Felde hinterm Hohenkampe & & & & & & & & & 1 & 50 & & & & & 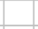 & & 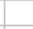 & & & & & 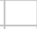 & & & 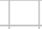 & & \\
\hline 455 & Auf dem Krähenkampe die Anhöhe & & & & & & & & & & & & & & & 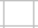 & & & & 1 & 16 & & 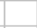 & & & 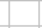 & & \\
\hline 456 & Sũdlich am Krähenkampe & & & & & & & & & & & 5 & 103 & & & . & & & & & & & & & & & & \\
\hline 457 & Über Drewsen Punnewisch Gehäge & & & & & & & & & & & & & & & & & & 105 & & & & . & & & & & \\
\hline 458 & Das Beste auf dem Felde hinterm Hohenkampe & & & 74 & 56 & & & & & & & & & & & & & & & & & & 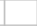 & & & 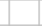 & & \\
\hline 459 & Nordöstl. voriger Abteilung & & & & & 6 & 90 & & & & & & & & & & & 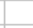 & & 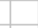 & & & 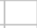 & & & 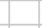 & & \\
\hline 460 & Wests. d. Feldes übern Hohenkampe & & & & & & & & & & & & & & & 11 & 25 & & & & & & & & & & & \\
\hline 468 & Nordwests. d. Landes an Bolten Immenzaun & & & & & & & & & & & & & & & & & & & & & & & & & 1 & 101 & \\
\hline 469 & Westlich voriger Abteilung & & & & & & & & & & & & & & & & & & & & & 11 & 55 & & & & & \\
\hline 470 & Wieder westlich voriger Abteilung & & & & & & & & & & & & & & & 11 & 48 & & & & & & & & & 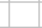 & & \\
\hline 471 & Eine Grund auf $d$. Felde bei Bolten Immenzaun & & & & & & & & & 1 & 92 & & & & & 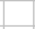 & & & & & & & 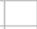 & & & 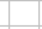 & & \\
\hline 475 & Die Wests. von Theis-Thies Hofe & & & & & & & & & 1 & 58 & & & & & 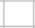 & & & & & & & . & & & . & & \\
\hline 476 & Die Osts. desselben d. Neuengärten u. Drewsen Moorgarten & & & & & 2 & 104 & & & & & & & & & & & & & & & & & & & & & \\
\hline 477 & Der Rest von Drewsen Moorgarten u. Neuengärten & 5 & 119 & & & & & & & & & & & & & & & & & & & & & & & & & \\
\hline 491 & Die Osts. des Punnewischfeldes & & & 18 & 75 & & & & & & & & & & & & & & & & & & & & & & & \\
\hline 492 & Westlich voriger Abteilung & & & & & & & & & & & & & & & & & 6 & 6102 & & & & . & & & 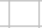 & & \\
\hline 493 & Eine Grund an der Jarnser Grenze & & & & & & & & & & & 1 & 30 & & & . & & & & & & & . & & & 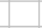 & & \\
\hline 494 & Der Rest der Wests. d. Punnewischfeldes & & & & & & & & & & & & & & & & & & & & & & & & & & 101 & \\
\hline 500 & Kohlmeyers Land auf d. Hohenkampe am Wege & & & & & & & & & & 94 & & & & & & & & & & & & & & & & & \\
\hline 502 & An Lüßmanns Berge auf dem Hohenkampe & & & & & & & & & & & 7 & 1 & & & & & & & & & & & & & & & \\
\hline 503 & Lüßmanns Berg daselbst & & & & & & & & & & & & & & & & & & & 5 & 43 & & & & & & & \\
\hline 504 & Auf Schönduven Landes daselbst & & & & & & & & & 19 & 85 & & & & & & & & & & & & & & & & & \\
\hline 505 & Die Osts. d. Landes vor den Ahnsbecker Stege & & & & & & & & & & & & & & & 2 & 66 & & & & & & & & & & & \\
\hline 506 & Rest des Feldes daselbst & & & & & 3 & 40 & & & & & & & & & & & & & & & & & & & & & \\
\hline 508 & Auf dem Osterade & & & & & & & & & & & & & 1 & 75 & & & & & & & & & & & & & \\
\hline 509 & daselbst auf dem Hohenkampe & & & & & 37 & 41 & & & & & & & & & & & & & & & & & & & & & \\
\hline 510 & Das Schlechte auf dem Osterade & & & & & & & & & & & & & & & & & & & & & & . & 2 & 13 & & & \\
\hline 511 & Noch auf dem Osterade die Enden & & & & & & & & & & & 6 & 89 & & & & & & & & & & & & & & & \\
\hline 512 & Das Beste auf dem Osterade u. Hohenkampe & & & 45 & 50 & & & & & & & & & & & & & & & & & & & & & & & \\
\hline 513 & Ein schlechterer Anberg in voriger Abteilung & & & & & & & & & 1 & 112 & & & & & & & & & & & & & & & & & \\
\hline 538 & Auf Kochs Osterkampe & & & & & & & & & & & & & & & 2 & 12 & & & & & & & & & & & \\
\hline 539 & Die Mitte desselben & & & & & & & & & & & & & & & & & & & & & 1 & 76 & & & & & \\
\hline 540 & Noch auf demselben Kampe & & & & & & & & & & & & & & & & & 1 & 1100 & & & & & & & & & \\
\hline 541 & Das Hohe desselben & & & & & & & & & & & & & & & & & & & & & & & & & 2 & 20 & \\
\hline 587 & Das Hohe von Drallen Lande & & & & & & & & & & & & & & & & & & 46 & & & & & & & & & \\
\hline 588 & Der Rest des Landes & & & & & & & & & 1 & 75 & & & & & & & & & & & & & & & & & \\
\hline 591 & Die Süds. von Cammann Thies Lande am Vogelherde & & & & & & & & & 2 & 83 & & & & & & & & & & & & & & & & & \\
\hline 593 & Die Nords. des Landes daselbst & & & & & & 81 & & & & & & & & & & & & & & & & & & & & & \\
\hline 603 & Cammann Thies desgleichen & & & kein Ein & ntrag & & & & & & & & & & & & & & & & & & & & & & & \\
\hline 605 & Bergmanns verkaufter Berg & & & kein Ein & ntrag & & & & & & & & & & & & & & & & & & & & & & & \\
\hline
\end{tabular}




\section{Wiesenboden}

\begin{tabular}{|c|c|c|c|c|c|c|c|c|c|c|c|c|c|c|c|c|c|c|}
\hline \multicolumn{19}{|c|}{ Classifications- und Vermessungs-Register der Feldmark Lachendorf } \\
\hline \multirow{5}{*}{$\frac{\frac{9}{0}}{\frac{\pi}{0}}$} & & & & & & & & & Classific & cations- $\mathrm{R}$ & Regist & ster & & & & & & \\
\hline & Benennung & \multicolumn{17}{|c|}{ Wiesenboden } \\
\hline & der & \multicolumn{17}{|c|}{ Klassen } \\
\hline & Gegend & 1. & & 2. & & 3. & & 4. & 5. & 6. & & 7. & & 8. & 9. & 10. & & 11. \\
\hline & & $M Q R$ & & $Q R$ & $M C$ & $Q R$ & $\mathrm{MC}$ & QR & $M Q R$ & $M Q R$ & Mo & QR & m & QR & $M Q R$ & $M Q R$ & & QR \\
\hline 121 & Westl. von Drallen Ackerland im Stockau & & & & & & & & & & & & & & & & 1 & 1 \\
\hline 123 & Der beste Wiesenboden in der Stockau & & & & 3 & 103 & & & & & & & & & & & & \\
\hline 125 & Im Bunger, eine Wiesenst. an d. Lachte & & & & & & & & 37 & & & & & & & & & \\
\hline 131 & Die West- u. Südseite von Thies Bunger & & & & & & & & & & & 82 & & & & & & \\
\hline 132 & Die bessere Wiesenstelle daselbst & & & & & & & & 99 & & & & & & & & & \\
\hline 174 & Bunkenburg-Bolzmann Drallen Ihlpohlwiese & & & & & & & & 57 & & & & & & & & & \\
\hline 179 & In den Sallohwiesen die Nordwestseite & & & & & & & & 34 & & & & & & & & & \\
\hline 180 & Das Bessere auf Schönduven-Schumeiers Sallohwiese & & & & & & & & & 9 & 2 & & & & & & & \\
\hline 182 & Der hohe Rand $\mathrm{d}$. Wiesen an der Lachte & & & & & & & & & & & & 3 & 101 & & & & \\
\hline 184 & Ein gute Grund in Bock-Thies Wiese & & & & & & & & 66 & & & & & & & & & \\
\hline 185 & Der Rest der Sallohwiesen an der Lachte & & & & & & & & & & & & & & & & 2 & 56 \\
\hline 186 & Der Berg in Misselhorns Spötzwiese & & & & & & & & & & & & & & & & & 114 \\
\hline 187 & Der bessere Teil derselben & & & & & & & & & & & 99 & & & & & & \\
\hline 190 & Die Spötzwiesen des Gastwirts Thies & & & & & & & & 92 & & & & & & & & & \\
\hline 191 & Die Gemeinde-Bullenwiese in d. Forst & & & & & & & & & & & & & & & & & 58 \\
\hline 195 & Nördl. u. östl. Teil von Coors-Meyr Fahrwiese & & & & & & & & & & & & & & & & 3 & 40 \\
\hline 196 & Westl. voriger Abteilung & & & & & & & & & & & & 1 & 86 & & & & \\
\hline 197 & Der Rest die Niederungen der Wiese & & & & & & & & 94 & & & & & & & & & \\
\hline 204 & Bock-Thies Farkenkamp & & & & & & & & 15 & & & & & & & & & \\
\hline 206 & Der Rest, die Südseite desselben & & & & & & & & & & & & 2 & 37 & & & & \\
\hline 211 & Die Westseite $d$. alten Wiesen & & & & & & & & 43 & & & & & & & & & \\
\hline 213 & Nordseite der alten Wiesen & & & & & & & & & & 13 & 32 & & & & & & \\
\hline 222 & In den Behrenswiesen die Westseite & & & & 4 & 4 & & & & & & & & & & & & \\
\hline 223 & Nordseite von Thies Behrenswiese & & & & & & & & 84 & & & & & & & & & \\
\hline 224 & An Bock-Thies Grützekessel & & & & & & & & & & & & 1 & 86 & & & & \\
\hline 225 & Das Beste von Bock-Thies Grützkessel & & & & & & & & 109 & & & & & & & & & \\
\hline 395 & Die Mehlegden unterm Sandbruche & & & & & & & & 2118 & & & & & & & & & \\
\hline 474 & Die Nords. von Theis-Thies Garten & & & & & & & 71 & & & & & & & & & & \\
\hline 526 & Der Rest von Bunkenburge kl. Osterwiese & & & & & 112 & & & & & & & & & & & & \\
\hline 533 & Der Grabenrand an Schumeiers Osterwiese & & & & & & & & 56 & & & & & & & & & \\
\hline 534 & Der bessere Rest derselben & & 2 & 32 & & & & & & & & & & & & & & \\
\hline 536 & Der Rest von Kochs Osterwiese & & 2 & 20 & & & & & & & & & & & & & & \\
\hline 546 & Der Rest von Drallen Wiese & & 2 & 8 & & & & & & & & & & & & & & \\
\hline 548 & Bolzmann Drallen Wiesenfläche & & & & 1 & 3 & & & & & & & & & & & & \\
\hline 550 & Der Rest von Theis Thies Wiese & & & & 1 & 1 & & & & & & & & & & & & \\
\hline 557 & Christioph Thies Lohnegarten & & & & & & & & & & 15 & 58 & & & & & & \\
\hline 560 & Der Rest von Drewsen Eselwiese & & & & & 84 & & & & & & & & & & & & \\
\hline 561 & Köthner Thies Grashofwiese & & 4 & 112 & & & & & & & & & & & & & & \\
\hline 562 & Die Gemeinde Bullenwiese & & & & & & & & & 140 & & & & & & & & \\
\hline 564 & Der Rest von Kochs Grashofe & & 2 & 112 & & & & & & & & & & & & & & \\
\hline 570 & Der hohe Rand von Drewsen Bremmerwiese & & & & & & & & 60 & & & & & & & & & \\
\hline 571 & Der Rest derselben & & 1 & 38 & & & & & & & & & & & & & & \\
\hline 573 & Das Übrige von Thies kl. Teichwiese & & & & & 42 & & & & & & & & & & & & \\
\hline 574 & Die Nordseite von Bergmanns Wiese & & & & & & & 119 & & & & & & & & & & \\
\hline 576 & Der Rest der Wiesen bis zur Höferschen & & 11 & 68 & & & & & & & & & & & & & & \\
\hline 579 & Thies in Höfer Wiese & & & & & & 3 & 53 & & & & & & & & & & \\
\hline 581 & Das Schlechte auf Hermanns pp. Wiese & & & & & & 2 & 3 & & & & & & & & & & \\
\hline 582 & Der Rest derselben & & 4 & 68 & & & & & & & & & & & & & & \\
\hline 583 & Bock-Thies Wiese & & 1 & 1 & & & & & & & & & & & & & & \\
\hline 584 & Die Grund auf Köthner J. Hr. Drallen Wiese & & & & & 79 & & & & & & & & & & & & \\
\hline 586 & Der Rest der Wiese bis ans Land & & & & & & & & 79 & & & & & & & & & \\
\hline 589 & Die abgegrabene Fläche vor Cammann-Thies Lande & & & & & & & & 80 & & & & & & & & & \\
\hline 592 & Die Neuewiese im Vogelherde & & & & & & & & 101 & & & & & & & & & \\
\hline 594 & Thies Wiese am Vogelberge & & 1 & 3 & & & & & & & & & & & & & & \\
\hline 530 & Bunkenburgs Osterwiese & & 1 & 10 & & & & & & & & & & & & & & \\
\hline 532 & Cammann-Thies Osterwiese & & & & 4 & 29 & & & & & & & & & & & & \\
\hline 597 & Gastwirt Thies u. Schmidt-Meyers Wachtelwiese & & & & & & & & & & & & & & & & & \\
\hline 598 & Drewsen Wachtelwiese in der Sprache & & & & & & & & & & & & & & & & & \\
\hline 599 & Coors Meyers Sprachewiese & 离 & & & & & & & & & & & & & & & & \\
\hline 601 & Theis-Thies trockene Wiese & 帝 & & & & & & & & & & & & & & & & \\
\hline 602 & Schönduves desgleichen & 这 & & & & & & & & & & & & & & & & \\
\hline 603 & Cammann-Thies desgleichen &.$\stackrel{\oplus}{\leftrightarrows}$ & & & & & & & & & & & & & & & & \\
\hline 604 & J. Hr. Dralle desgleichen & $\stackrel{\oplus}{\Perp}$ & & & & & & & & & & & & & & & & \\
\hline & $\begin{aligned} \text { Quelle: Classifications- und } \\
\end{aligned}$ & essung: & & & & & & & idorf & & & & & & & & & \\
\hline
\end{tabular}




\section{Angerboden}

\begin{tabular}{|c|c|c|c|c|c|c|c|c|c|c|c|c|c|c|c|c|c|c|c|c|c|c|c|}
\hline & Class & fications & - und & d Verm & ness & sungs- 1 & $\operatorname{Re}$ & gister o & der & Feldme & ark Le & Lachen & idorf & & & & & & & & & & \\
\hline 9 & & & & & A. $\mathrm{Cl}$ & lassific & cati & ions-Re & egis & & & & & & & & & & & & & & \\
\hline 莺 & & & & & & & & & & & & Ange & rbod & den & & & & & & & & & \\
\hline 0 & Benennung & & & & & & & & & & & Kla: & ssen & & & & & & & & & & \\
\hline$\stackrel{0}{0}$ & der & 1. & & 2. & & 3. & & 4. & & 5. & & 6. & & 7. & & 8. & 9. & & 10. & & 11. & 12 & 2. \\
\hline$\stackrel{i}{2}$ & Gegend & $M Q R$ & M & QR & $M$ & QR & M & QR & M & QR & $M C$ & QR & $M$ & QR & M & QR & $M Q R$ & M & QR & $M$ & QR & $M C$ & QR \\
\hline 4 & Eine Grund westl. an Thies Gehäge & & & & & & & & & 115 & & & & & & & & & & & & & \\
\hline 8 & Guter Angerstrich, d. Spitze an d. Teichwiese & & & & & & & & 1 & 53 & & & & & & & & & & & & & \\
\hline 15 & Der Krümmelbusch & & & & & & & & & & & & 1 & 13 & & & & & & & & & \\
\hline 31 & Angerstreifen am Flottkamp & & & & & & 1 & 83 & & & & & & & & & & & & & & & \\
\hline 32 & Das Beste zwischen Söhren und Flottkamp & & & & 4 & 12 & & & & & & & & & & & & & & & & & \\
\hline 44 & Ōstlich an der Bullohrieth & & & & 1 & 90 & & & & & & & & & & & & & & & & & \\
\hline 62 & Schumeiers Holzlegde & & & & & & & & & 97 & & & & & & & & & & & & & \\
\hline 67 & Die Lehmkuhlen a. d. Weg in Langenbalk & & & & & & & & & & & & 3 & 24 & & & & & & & & & \\
\hline 72 & Der Hagen nördlich in den Langengärten & & & & & 10 & & & & & & & & & & & & & & & & & \\
\hline 79 & Der Weg zwischen Drallen Gart. U. Moorgarten & & & & & & & & & & & & & & & & & & & 1 & 59 & & \\
\hline 95 & Ein Angerstrich an den Moorgärten & & & & & & & & & & & & & & & & & & & & & & \\
\hline 99 & In den Moorgärten ein Angerstrich & & & & & & & & & & & & & & & 37 & & & & & & & \\
\hline 103 & An der Lachte östl. der Anlagen & & & & & & & & & & & 93 & & & & & & & & & & & \\
\hline 104 & Der Eichenbestand am Beedenbosteler Wege & & & & & & & & & & & & & 79 & & & & & & & & & \\
\hline 106 & Der gute Angerwinkel a. d. Lachte unterm Krümmel & 3 & & & & & & & & & & & & & & & & & & & & & \\
\hline 107 & Westlich voriger Abteilung & & & & & 27 & & & & & & & & & & & & & & & & & \\
\hline 108 & An Drewsen Anlagen u. dem Stege & & & & & & & & & & & & & & & & & & & 2 & 3 & & \\
\hline 109 & An der Lachte westl. voriger Abteilung & & & & & & & & & & & & & & & & & & & & & & \\
\hline 124 & Die Ostseite der Stockau & & & & & & & & & & & & & & & 38 & & & & & & & \\
\hline 128 & Im Bunger östl. voriger Abteilung & & & & & & & & & & & 14 & & & & & & & & & & & \\
\hline 129 & Nord- u. Ostseite von Thies Bunger & & & & & & & & & & & 84 & & & & & & & & & & & \\
\hline 133 & Der schlechte südwestl. Teil daselbst & & & & & & & & & & & & & & & 95 & & & & & & & \\
\hline 134 & Das Beste vom Stockauanger & & & & 2 & 50 & & & & & & & & & & & & & & & & & \\
\hline 135 & Südllich voriger Abteilung & & & & & & 3 & 60 & & & & & & & & & & & & & & & \\
\hline 136 & Wieder sūdlich voriger Abteilung & & & & & & & & 5 & 67 & & & & & & & & & & & & & \\
\hline 137 & Noch im Stockauanger an d. Lachte & & & & & & & & & & & & 2 & 16 & & & & & & & & & \\
\hline 138 & daselbst die Mitte & & & & & & & & & & & & & & 9 & 20 & & & & & & & \\
\hline 175 & Der große Rehwinkel & & & & & & & & & 102 & & & & & & & & & & & & & \\
\hline 176 & Der kleine Rehwinkel & & & & & 58 & & & & & & & & & & & & & & & & & \\
\hline 177 & Ein kl. Angerwinkel über Veths Wiese & & & & & & & & & 6 & & & & & & & & & & & & & \\
\hline 200 & Nords. der Gemeinheit beim Spötzenförth & & & & & & & & & & & & & & 2 & 82 & & & & & & & \\
\hline 205 & Die Ostseite vom Farkenkampe & & & & & & & & & & & & & & 1 & 56 & & & & & & & \\
\hline 208 & Weg zwischen Westerkamp u. Farkenkamp & & & & & & & & & & & & & 64 & & & & & & & & & \\
\hline 209 & Weg zwischen den alten Wiesen u. Westerkamp & & & & & & & & & & & & & & & 70 & & & & & & & \\
\hline 210 & Grabenwall an den alten Wiesen & & & & & & & & & & & & & 12 & & & & & & & & & \\
\hline 214 & Der südl. Rand derselben & & & & & & & & & & & & 1 & 32 & & & & & & & & & \\
\hline 215 & Der Rest die Ostseite derselben & & & & & & & & & & & & & & & 60 & & & & & & & \\
\hline 218 & Nördllich voriger Abteilung & & & & & & & 42 & & & & & & & & & & & & & & & \\
\hline 219 & Zwischen dem Westerkampe u. d. Lachte & & & & & & & & & & & & & 80 & & & & & & & & & \\
\hline 221 & Grabenaufwurf a. d. Behrenswiesen & & & & & & & & & & & & & & & 49 & & & & & & & \\
\hline 226 & In den Behrenswiesen u. im Bunger & & & & & & & & & & & & & & & & & & & 1 & 101 & & \\
\hline 231 & Vor der Behrenswiese & & & & & & & & & & & & & & & & & 1 & 68 & & & & \\
\hline 234 & Ōstl. voriger Abtl. kl. Angergrund & & & & & & & & & & & 98 & & & & & & & & & & & \\
\hline 236 & In der Lachtekrümmung ein kl. Angerstrich & & & & & & & & & & & & & & & 87 & & & & & & & \\
\hline 246 & Tischler Herbolds Hof und Baustelle & & & & & & & & & & & & & & & & & & & & & & \\
\hline 277 & Anbauer Thölke Hof du Baustelle & & & & & & & & & & & & & & & & & & & & & & 24 \\
\hline 302 & Abbauer Suderburgs Baustelle & & & & & & & & & & & & & & & & & & & & & & 45 \\
\hline 304 & Abbauer Graue Baustelle & & & & & & & & & & & & & & & & & & & & 34 & & \\
\hline 322 & Abbauer Joh. Hr. Lillie Baustelle & & & & & & & & & & & & & & & & & & & & 18 & & \\
\hline 323 & Abbauer Ahrens Baustelle & & & & & & & & & & & & & & & & & & & & 26 & & \\
\hline 331 & Bambergs Baustelle & & & & & & & & & & & & & 70 & & & & & & & & & \\
\hline 332 & Walters Baustelle & & & & & & & & & & & & & 56 & & & & & & & & & \\
\hline 343 & Ein besserer Angerstrich im Bärenblau & & & & & & & & & & & & & & & & & & & 26 & 5 & & \\
\hline 344 & Wieder ein Angerstrich im Sandbruchsfelde & & & & & & & & & & & & 3 & 88 & & & & & & & & & \\
\hline 345 & An Kochs u. Misselhorns alten Gärten & & 5 & 54 & & & & & & & & & & & & & & & & & & & \\
\hline 347 & Die tiefen Riethen auf dem Moore & & & & & & & & & & & & & & & & & & & 6 & 119 & & \\
\hline 348 & Die alten Lehmkuhlen westl. voriger Abtl. & & & & & & & & & & & & 7 & 85 & & & & & & & & & \\
\hline 349 & Alte Lehmkuhlen am Ahnsbecker Wege & & & & & & & & & & 1 & 56 & & & & & & & & & & & \\
\hline 350 & Eine gänzllich vergrabene Spitze am Wege & & & & & & & & & & & & & & & & & & & & 114 & & \\
\hline 351 & Ein ebener Angerstrich an d.Kampgärten & & & & & & 5 & 68 & & & & & & & & & & & & & & & \\
\hline 352 & An Grusche-Thies Hofe & & & & & & & & & & & & & & & & & & & 1 & 70 & & \\
\hline $352 a$ & Grusche-Thies Hofe & & & & & & & & & & & & & & & & & & & & 95 & & \\
\hline 353 & Schumyers Hof und Baustelle & & & & & & & & & & & & 2 & 1 & & & & & & & & & \\
\hline 354 & Der Schulhof und garten & & & & & & & & & & & & & 30 & & & & & & & & & \\
\hline 355 & Bergmanns u. Misselhorns Hof u. Baustelle & & & & & & & & & & & & 2 & 81 & & & & & & & & & \\
\hline 356 & Coors Meyers, Bunkenburgs, Lüßmanns, Thies Hof u & Baustell & & & & & & & & & & & 7 & 119 & & & & & & & & & \\
\hline 357 & Anbauer Lillie Hof und Baustelle & & & & & & & & & & & & & 40 & & & & & & & & & \\
\hline 358 & Bolzmann-Drallen u. J. Hr. Dralle Baustelle & & & & & & & & & & & & 4 & 9 & & & & & & & & & \\
\hline $358 \mathrm{a}$ & Bührings Hof und Baustelle & & & & & & & & & & & & 1 & 10 & & & & & & & & & \\
\hline
\end{tabular}




\begin{tabular}{|c|c|c|c|c|c|c|c|c|c|c|c|c|c|c|c|c|c|c|c|c|c|c|c|}
\hline$\Phi$ & & & & & & A. $\mathrm{Cl}$ & lassifi & catio & ions- $R$ & egist & & & & & & & & & & & & & \\
\hline 嘀 & & & & & & & & & & & & & Ange & erbod & den & & & & & & & & \\
\hline 方 & Benennung & & & & & & & & & & & & & assen & & & & & & & & & \\
\hline $\bar{\Phi}$ & der & & 1. & 2 & 2. & & 3. & & 4. & & 5. & & 6. & & 7. & & 8. & 9. & 9. & 10. & & 11. & 12 \\
\hline$\stackrel{i}{2}$ & Gegend & $M C$ & QR & $M$ & $Q R$ & M & $Q R$ & $M$ & $Q R$ & $M$ & $Q R$ & $\mathrm{MC}$ & QR & M & $Q R$ & $M$ & QR & $M Q$ & QR & $M Q R$ & M & QR & $M$ \\
\hline 359 & Anbauer Chr. Thies Baustelle & & & & & & & & & & & & & & 29 & & & & & & & & \\
\hline 360 & Kohlmeyers Hof und Baustelle & & & & & & & & & & & & & & 114 & & & & & & & & \\
\hline 361 & Gastwirt Thies Hof und Baustelle & & & & & & & & & & & & & 1 & 26 & & & & & & & & \\
\hline 362 & Bock-Thies Hof und Baustelle & & & & & & & & & & & & & 2 & 13 & & & & & & & & \\
\hline 363 & Gemeinde Hirtenhaus & & & & & & & & & & & & & & 48 & & & & & & & & \\
\hline 364 & Hermanns Hof und Baustelle & & & & & & & & & & & & & 1 & 19 & & & & & & & & \\
\hline 365 & Drewsen Erben und Schwägermanns Hof u. Bausteller & & & & & & & & & & & & & 2 & 24 & & & & & & & & \\
\hline 366 & Drewsen Erben Fabrikgebäude und Hof & & & & & & & & & & & & & 2 & 29 & & & & & & & & \\
\hline 369 & Anbauer Kochs Hof und Baustelle & & & & & & & & & & & & & & 59 & & & & & & & & \\
\hline 370 & Grusche-Thies alter Hof u. Kochs Hof & & & & & & & & & & & & & 4 & 81 & & & & & & & & \\
\hline 371 & Anbauer Carsten Hr. Meyers Hhof & & & & & & & & & & & & & & 51 & & & & & & & & \\
\hline 372 & Das Gemeinde Hirtenhaus & & & & & & & & & & & & & & 12 & & & & & & & & \\
\hline 373 & Anbauer Joh. Hr. Wulf Hof & & & & & & & & & & & & & & 31 & & & & & & & & \\
\hline 374 & Anbauer Christoph Lüßmanns desgl. & & & & & & & & & & & & & & 63 & & & & & & & & \\
\hline 375 & Anbauer Bergmanns desgl. & & & & & & & & & & & & & & 29 & & & & & & & & \\
\hline 376 & Anb. J. Hr. Knoop u. Abauer Meers Hof & & & & & & & & & & & & & & 60 & & & & & & & & \\
\hline 377 & Halbmeier Schönduve Hof u. Baustelle & & & & & & & & & & & & & 2 & 63 & & & & & & & & \\
\hline 378 & Köthner Theis-Thies Westseite des Hofes & & & & & & & & & & & & & & 58 & & & & & & & & \\
\hline 379 & Sämtlliche Straßen und Gemeinheiten im Dorfe & & & & & & & & & & & & & 21 & 107 & & & & & & & & \\
\hline 391 & Der Ahnsbecker Weg weiter westlich & & & & & & & & & & & & & & & 1 & 26 & & & & & & \\
\hline 406 & Das Müllerhaus und die Windmühle & & & & & & & & & & & & & & 46 & & & & & & & & \\
\hline 437 & Thies Legden u. Büsche auf $d$. Hohenkampe & & & & & & & 2 & 90 & & & & & & & & & & & & & & \\
\hline 439 & Die Geidlegden d. Gemmeinde unter Drewsen Land & & & & & & & & & & & 1 & 32 & & & & & & & & & & \\
\hline 444 & Der Bunkenb. Weg bis zum Ahnsb. Wege u. ein Gemeir & nheit: & itsstre & eifen & dara & & & & & & & & 109 & & & & & & & & & & \\
\hline 452 & Schmidt Knoop Immenstelle in d. Punnewisch & & & & & & & & & & & & & & 72 & & & & & & & & \\
\hline 453 & Die Ostseite der Punnewisch & & & & & & & & & & & 9 & 12 & & & & & & & & & & \\
\hline 465 & Die Punnewischrieth & & & & & & & 4 & 68 & & & & & & & & & & & & & & \\
\hline 473 & Theis-Thies Hof die Ostseite & & & & & & & & 54 & & & & & & & & & & & & & & \\
\hline 478 & Südlich an den Neuengärten & & & & & & & 2 & 64 & & & & & & & & & & & & & & \\
\hline 479 & Alte Lehmkuhl. nördlich am Ahnsbecker Wege & & & & & & & 1 & 93 & & & & & & & & & & & & & & \\
\hline 480 & Am Sandbruchsfelde herunter & & & 1 & 116 & & & & & & & & & & & & & & & & & & \\
\hline 481 & Wieder am Sandbruche & & & & 85 & & & & & & & & & & & & & & & & & & \\
\hline 482 & Östlich an den Neuengärten & & & & & & & & & & & 14 & 8 & & & & & & & & & & \\
\hline 483 & Zwischen Schönduve u. d. Neuengärten & & & & & & & & & 6 & 100 & & & & & & & & & & & & \\
\hline 484 & Der niedrige Anger an Theis-Thies Hofe & & & 3 & 118 & & & & & & & & & & & & & & & & & & \\
\hline 485 & Wieder unterm Sandbruche & & & & & 12 & 78 & & & & & & & & & & & & & & & & \\
\hline 486 & Die Nordwestseite der Schelprieth & & & & & & & & & 4 & 12 & & & & & & & & & & & & \\
\hline 487 & Die Schelprieth neben Grusche-Thies Lande & 5 & 60 & & & & & & & & & & & & & & & & & & & & \\
\hline 496 & Ein guter Angerwinkel an de Lachte & & & & 46 & & & & & & & & & & & & & & & & & & \\
\hline 507 & Unterm Felde vor dem Ahnsbecker Wege & & & & & & & & & & & & & 6 & 62 & & & & & & & & \\
\hline 515 & Daselbst östlich voriger Abteilung & & & & & & & & & & & 15 & 106 & & & & & & & & & & \\
\hline 516 & Die Wasserrieth neben voriger Abteilung & & & & & & & & & & & & & & & & & & & & 4 & 62 & \\
\hline 518 & Kochs Immenzaun in der 515 Abteilung & & & & & & & & & & & & & & 54 & & & & & & & & \\
\hline 521 & Ōstlich voriger Abteilung & & & & & & & & & & & & & & & & & & & & 5 & 18 & \\
\hline 525 & Der Graben an Bunkenwurges kl. Osterwiese & & & & & & & & & & & & & & 55 & & & & & & & & \\
\hline 529 & Der Rand an Bunkenburgs gr. Osterwiese & & & & & & & & & & & & & & & & & & & & & 40 & \\
\hline 531 & Der Rand an Cammann-Thies Osterwiese & & & & & & & & & & & & & 1 & & & & & & & & & \\
\hline 535 & Der hohe Rand von Kochs Osterwiese & & & & & & & & & & & & & & 62 & & & & & & & & \\
\hline 537 & Zwischen Kochs Osterkampe und den Osterwiesen & & & & & & & & & & & & & & & & & & & & 2 & 70 & \\
\hline 543 & Die Grund neben dem Osterberge & & & & & & & & & & & & & & & & & 58 & 86 & & & & \\
\hline 545 & Grabenauswurf an Drallen Wiese & & & & & & & & & & & & & & & & & & & & & 45 & \\
\hline 547 & Auf Bolzmann-Drallen Wiese der Graben & & & & & & & & & & & & & & 46 & & & & & & & & \\
\hline 549 & Der Rand an Theis-Thies Wiese & & & & & & & & & & & & & & & & & & & & & & \\
\hline 552 & Neben der 551 Abteilung & & & & & & & & & & & & & & & & & & & & & 51 & \\
\hline 555 & Der bessere Gemeinheitsrand am Osteraden & & & & & & & 1 & 95 & & & & & & & & & & & & & & \\
\hline 556 & Die Riede nördlich der vorigen Abteilung & & & & & & & & & & & & & & & & & 38 & 83 & & & & \\
\hline 559 & Der Rand von Drewsen Eselwiese & & & & & & & & & & & & & & 39 & & & & & & & & \\
\hline 488 & In der Schelprieth & & & 14 & 116 & & & & & & & & & & & & & & & & & & \\
\hline 489 & Neben Thies Lande & & & & & & & & 100 & & & & & & & & & & & & & & \\
\hline 563 & Der Rand in Kochs Grashofe & & & & & & & & & & & & & & & & & & & & & 90 & \\
\hline 566 & Die Grund am Heuberge & & & & & & & & & & & & & & & & & & & & 1 & 87 & \\
\hline 567 & Der Rand am Dorfe & & & & & & & & & & & & & & & & & & & & & & \\
\hline 569 & Der Holzbestand in Drewsen Brennerwiese & & & & & & & & & & & & 103 & & & & & & & & & & \\
\hline 572 & Thies kleine Teichwiese & & & & & & 29 & & & & & & & & & & & & & & & & \\
\hline 575 & Auf Bergmanns u. Schumeiers Wiesen & & & & & & 104 & & & & & & & & & & & & & & & & \\
\hline 580 & Der Rand an Hermanns Wiesen & & & & & & & & & & & & 99 & & & & & & & & & & \\
\hline 585 & Der Anger an Drallen Lande & & & & & & & & & & & & 53 & & & & & & & & & & \\
\hline 590 & Der Rand an der Aschau & & & & & & & & & & & & & & & & & & 96 & & & & \\
\hline & & & & & & & & & & & & & & & & & & & & & & & \\
\hline & Quelle: Classifications- und & ssun & ing & Regis & ste & & Idmar & La & ache & & & & & & & & & & & & & & \\
\hline
\end{tabular}




\section{Heidboden}

\begin{tabular}{|c|c|c|c|c|c|c|c|c|c|c|c|c|c|c|c|c|c|c|c|c|c|c|c|c|c|c|c|c|}
\hline & & & & issifi & icatic & ons & s- un & $\mathrm{Ve}$ & ermes & ssun & ngs- & $\operatorname{Re}$ & giste & er de & ler $\mathrm{F}$ & Feldr & mark & Lac & chen & idorf & & & & & & & & \\
\hline$\Phi$ & & & & & & & & & & Clas & issific & catic & ons- $-R$ & Regis & & & & & & & & & & & & & & \\
\hline 喜 & & & & & & & & & & & & & & & & & eidbod & & & & & & & & & & & \\
\hline 인 & Benennung & & & & & & & & & & & & & & & & Klasse & & & & & & & & & & & \\
\hline ष & der & 1. & 1. & 2 & 2. & & 3. & 4 & 4. & & 5. & & 6. & 7 & 7. & & 8. & 9 & 9. & & 10. & & 11. & & 12. & & 13. & 1 \\
\hline$\frac{9}{2}$ & Gegend & M C & QR & M & $Q R$ & M & $Q R$ & M & QR & M & $Q R$ & M & $Q R$ & M & $Q R$ & M & $Q R$ & M & QR & M & $Q R$ & M & $Q R$ & M & QR & M & $Q R$ & M \\
\hline 1 & Heidstrich an Wolfs Busche & & & & & & & & & & & & & & & & & & & 1 & 47 & & & & & & & \\
\hline 2 & Eine bessere Grund daselbst & & & & & & & & & & & & & & & 1 & 8 & & & & & & & & & & & \\
\hline 3 & Eine Grund am Kirchwege & & & & & & & & & 3 & 32 & & & & & & & & & & & & & & & & & \\
\hline 5 & An den Teichwiesen & & & & & & & 2 & 46 & & & & & & & & & & & & & & & & & & & \\
\hline 6 & Ein Heidanhöhe östl. v. Beedenbosteler We & & & & & & & & & & & & & & & & & & & 7 & 38 & & & & & & & \\
\hline 7 & Der Beedenbosteler Weg & & & & & & & & & & & & & & & & & & & & & 1 & 101 & & & & & \\
\hline 9 & Ein schmaler Heidstrich westl. daselbst & & & & & & & & & & & & & & & & 92 & & & & & & & & & & & \\
\hline 10 & Am Krümmelfelde besserer Strich & & & & & & & & & 3 & 1 & & & & & & & & & & & & & & & & & \\
\hline 11 & Die Mitte vom Rolloh & & & & & & & & & & & & & 3 & 69 & & & & & & & & & & & & & \\
\hline 12 & Schlechte Heide an der Beedenbosteler Gre & enze & & & & & & & & & & & & & & & & & & & & 3 & 23 & & & & & \\
\hline 13 & Westl. voriger Abteilung & & & & & & & & & & & & & & & 2 & 85 & & & & & & & & & & & \\
\hline 14 & Heide östlich unterm Hagenfelde & & & & & & & & & & & & & & & & & 5 & 6 & & & & & & & & & \\
\hline 17 & Die Vorwenden hinterm Häg & & & & & & & & & & 49 & & & & & & & & & & & & & & & & & \\
\hline 18 & Desgleichen sūdlich daselbst & & & & & & & & 51 & & & & & & & & & & & & & & & & & & & \\
\hline 23 & Zwischen dem Hagens. u. hinterm Häg & & & & & & & & & & 43 & & & & & & & & & & & & & & & & & \\
\hline 24 & daselbst & & & & & & & & 52 & & & & & & & & & & & & & & & & & & & \\
\hline 25 & Das Bessere der Gemeinheit im Hagen & & & 22 & 112 & & & & & & & & & & & & & & & & & & & & & & & \\
\hline 26 & Misselhorns Gehäge daselbst & & & & 63 & & & & & & & & & & & & & & & & & & & & & & & \\
\hline 27 & Die Mitte der Gemeinheit im Hagen & & & & & & & 19 & 106 & & & & & & & & & & & & & & & & & & & \\
\hline $27 a$ & Das Beste der Gemeinheit im Hagen & 6 & 32 & & & & & & & & & & & & & & & & & & & & & & & & & \\
\hline 29 & Gemeinht. im Hagen nördl. der Lehmkuhlen & & & 14 & 55 & & & & & & & & & & & & & & & & & & & & & & & \\
\hline 30 & Gemeinheit im Hagen am Flottkamp & & & & & & & & 92 & & & & & & & & & & & & & & & & & & & \\
\hline 33 & Bei Hermanns Immenstelle & & & & & & & & & 2 & 35 & & & & & & & & & & & & & & & & & \\
\hline 34 & Hermanns immenstelle & & & & & & & & & & & & & & & & 69 & & & & & & & & & & & \\
\hline 41 & Der Gockenholzer Weg & & & & & & & & & & & & & & & & & & & & & & & & & & & 3 \\
\hline 42 & Derselbe im Lande & & & & & & & & & & & & & & & & & & & & & & & & 88 & & & \\
\hline 43 & Westseite der Bullohsrieth & & & & & & & & & & 116 & & & & & & & & & & & & & & & & & \\
\hline 45 & Noch in derselben weiter östlich & & & & & & & & & 1 & & & & & & & & & & & & & & & & & & \\
\hline 46 & Der Rest derselben & & & & & & & & & & & & & 1 & 27 & & & & & & & & & & & & & \\
\hline 48 & Gemeinheit am Schwarzenkamp & & & & & & & & & & 94 & & & & & & & & & & & & & & & & & \\
\hline 49 & Desgleichen daselbst & & & & & & & & 27 & & & & & & & & & & & & & & & & & & & \\
\hline 53 & Drallen Immengehäge & & & & & & & & 34 & & & & & & & & & & & & & & & & & & & \\
\hline 56 & Graben an Lüßmanns Krūmmel & & & & & & & & & & & & & & & & 52 & & & & & & & & & & & \\
\hline 85 & Die Sandberge westl. am Quälohshäge & & & & & & & & & & & & & & & & & & & & & & & & & & & 25 \\
\hline 86 & Etwas ebenere Gemeinheit am Flottkamp & & & & & & & & & & & & & & & & & & & & & & & & & 6 & 3 & \\
\hline 87 & Schlechte Sandberge daselbst & & & & & & & & & & & & & & & & & & & & & & & & & & & 3 \\
\hline 88 & Noch überm Flottkampe & & & & & & & & & & & & & & & & & & & & & & & & & 4 & 90 & \\
\hline 89 & Der Eichenbestand an den Moorgärten & & & & & & & & & & & & & & & & & & & 1 & 77 & & & & & & & \\
\hline 90 & Zwischen den Moorgärten u. Quälohshäg & & & & & & & & & & & & & & & & & & & & & & & & & & & 7 \\
\hline 91 & Das Quälohsgehäge & & & & & & & & & & & & & & & & & & & & & & & & & 7 & 16 & \\
\hline 92 & Nördlich an Drallen neuen Hofe & & & & & & & & & & & & & & & & & & & & & & & & & 11 & 98 & \\
\hline 93 & Lüßmanns Gehäge an den Moorgärten & & & & & & & & & & & & & & & & & & & & & & & & & & 20 & \\
\hline 94 & Zwischen den Moorgärten und Drewsen $\mathrm{H}$ & & & & & & & & & & & & & & & & & & & & & & & 2 & 62 & & & \\
\hline 97 & In den Moorgärten der Hagen & & & & & & & & & & & & & & & & & & & & & & & & 24 & & & \\
\hline 102 & Der Beedenbosteler Weg am Krümmelfeld & & & & & & & & & & & & & & & & & & & 2 & 86 & & & & & & & \\
\hline 105 & Zwischen den Teichwiesen u. Beedenbost & t1. We & & & & & & & & & & & & & & & 79 & & & & & & & & & & & \\
\hline 110 & Der Beedensosteler Weg neben Drewsen n & neuen & $\mathrm{m} \mathrm{Ho}$ & & & & & & & & & & & & & & & & & & & & & & & 1 & 30 & \\
\hline 111 & Drewsen neuer Hof & & & & & & & & & & & & & & & & & & & & & & & & & 3 & 60 & \\
\hline 112 & Eichenbestand westl. von Drewsen Hofe & & & & & & & & & & & & & & & & & & & & & & & 3 & 102 & & & \\
\hline 113 & Ein schmaler Strich an der alten Lachte & & & & & & & & & & & & & & & & & & & & & & & 2 & 4 & & & \\
\hline 114 & Noch an der alten Lachte & & & & & & & & & & & & & & & & & & & & & & & & & 1 & 66 & \\
\hline 115 & Die ausgeschossenen Stellen an der Stock & & & & & & & & & & & & & & & & & & & & & 10 & 6 & & & & & \\
\hline 116 & Die Hūgelreihe an der Stockauheide & & & & & & & & & & & & & & & & & & & & & & & 25 & 102 & & & \\
\hline 117 & Die Stockauheide & & & & & & & & & & & & & & & & & & & & & 59 & 26 & & & & & \\
\hline 118 & Dieselbe ein oberer Strich & & & & & & & & & & & & & & & & & & & 11 & 111 & & & & & & & \\
\hline 122 & Der Grabenwall an der Stockau & & & & & & & & & & & & & & & & & & & & 15 & & & & & & & \\
\hline 139 & Der Rest der Stockau an der alten Lachte & & & & & & & & & & & & & & & & & & & 3 & 42 & & & & & & & \\
\hline 140 & Die alte Lachte & & & & & & & & & & & & & & & & & & & & & 4 & 6 & & & & & \\
\hline 141 & Die Nordwests. der großen Masch & & & & & & & & & & & & & & & & & & & 7 & 68 & & & & & & & \\
\hline 142 & Der Rest derselben & & & & & & & & & & & & & & & & & & & & & & & & & 11 & 29 & \\
\hline 143 & Die westl. Spitze zwischen den Lachtearm & & & & & & & & & & & & & & & & & & & & & & & 1 & 24 & & & \\
\hline 144 & daselbst weiter östlich & & & & & & & & & & & & & & & & & & & & & & & & & & & \\
\hline 145 & Der Damm an Drewsen Torfschuppen & & & & & & & & & & & & & & & & & & & & & & & & & 1 & 59 & \\
\hline 151 & Heidwinkel zwischen d. Lachen-u. Dürska & & & & & & & & & & & & & & & & & & & & & 3 & 58 & & & & & \\
\hline
\end{tabular}




\begin{tabular}{|c|c|c|c|c|c|c|c|c|c|c|c|c|c|c|c|c|c|c|c|c|c|c|c|c|c|c|c|c|}
\hline ( & & & & & & & & & A. $\mathrm{Cl}$ & lassifi & icatic & ions- $R$ & Regis & ister & & & & & & & & & & & & & & \\
\hline 壱 & & & & & & & & & & & & & & & & eidbod & & & & & & & & & & & & \\
\hline 힌 & Benennung & & & & & & & & & & & & & & & Klasse & & & & & & & & & & & & \\
\hline क्ष & der & 1. & & 2. & & 3. & & 4. & & 5. & & 6. & & 7. & & 8. & & 9. & & 10. & & 11. & & 12. & & 13. & & 14. \\
\hline i & Gegend & $M \quad Q R$ & $\mathrm{M}$ & QR & M & $Q R$ & M & QR & M & QR & M & QR & M & $Q R$ & M & $Q R$ & M & QR & M & QR & M & QR & m & QR & M & $Q R$ & M & QR \\
\hline 152 & Der Celler Weg am Dürskampe & & & & & & & & & & & & & & & & & & & & & & & & & 39 & & \\
\hline 153 & Der Weg zwischen dem Dürs- u. Lachenkam & & & & & & & & & & & & & & & & & & & 46 & & & & & & & & \\
\hline 159 & Drallen Gehäge auf dem Stuhlkamp & & & & & & & & & & & & & & & & & & 3 & 6 & & & & & & & & \\
\hline 169 & Die Nords. der Heide hinter der Salloh & & & & & & & & & & & & & & & & & & & & 9 & 43 & & & & & & \\
\hline 170 & Am Ihlpolsgehäge und dem Spötzenferth & & & & & & & & & & & & & & & & & & & & & & 13 & 118 & & & & \\
\hline 171 & Schumeiers Immengehäge in vor. Abtl. & & & & & & & & & & & & & & & & & & & & & & & & & 35 & & \\
\hline 172 & Das Gemeinde Ihlpolsgehäge & & & & & & & & & & & & & & & & & & & & & & 2 & 100 & & & & \\
\hline 173 & Drewsen Ihlenpohlsgehäge & & & & & & & & & & & & & & & & & & & & & & & 116 & & & & \\
\hline 178 & Lüßmanns Gehäge in der 117. Abtl. & & & & & & & & & & & & & & & & & & & & 2 & 74 & & & & & & \\
\hline 183 & Grabenwall an Bock-Thies u. Schumeiers Wie & Viese & & & & & & & & & & & & & & & & & & 74 & & & & & & & & \\
\hline 188 & Misselhorns Busch & & & & & & & & & 26 & & & & & & & & & & & & & & & & & & \\
\hline 189 & Veths in Gockenholz Busch & & & & & & & & & 113 & & & & & & & & & & & & & & & & & & \\
\hline 192 & Der schlechtere Teil der Gemeindeforst & & & & & & & & & & & & & & 40 & 14 & & & & & & & & & & & & \\
\hline 193 & Der bessere Teil der Gemeindeforst & & & & 2 & 54 & & & & & & & & & & & & & & & & & & & & & & \\
\hline 194 & Drewsen Busch die Fahrwiese genannt & & & & 2 & 110 & & & & & & & & & & & & & & & & & & & & & & \\
\hline 198 & Coors-Meyers Gehäge & & & & & & & & 4 & 26 & & & & & & & & & & & & & & & & & & \\
\hline 199 & Bock-Thies Gehäge im Eckernkamp & & & & & & & & & & & & & & 3 & 96 & & & & & & & & & & & & \\
\hline 201 & Das Gemeindehäg neben Bergmanns Spötzk & kampe & & & & & & & & & & & & & 1 & 11 & & & & & & & & & & & & \\
\hline 202 & Bergmanns Spötzkamp & & & & & & & & & & & & & & 3 & 67 & & & & & & & & & & & & \\
\hline 203 & Gemeinheitsstrich zwischen Bock-Thies u. & Bergma & anns t & Häg & & & & & & & & & & & & & & & & 58 & & & & & & & & \\
\hline 207 & Bolzmann Drallen Häg am Westerkamp & & & & & & 3 & 34 & & & & & & & & & & & & & & & & & & & & \\
\hline 216 & Ein schlechter Gemhtswinkel an den alten W & Viesen & & & & & & & & & & & & & & & 2 & 8 & & & & & & & & & & \\
\hline 217 & Schlechte Stelle des Wegs am Westerkampe & & & & & & & & & & & & & & & & & & & & & & & & & 66 & & \\
\hline 220 & Zwischen dem Westerkpe. und Behrenswie & esen & & & & & & & & & & & & & & & & & & 46 & & & & & & & & \\
\hline 232 & Der Weg vor dem Teilbusche & & & & & & & & & & & & & & & & & & & & 1 & 100 & & & & & & \\
\hline 233 & An der Lachte eine ebene Fläche & & & & & & & & & & & & & & & & & & 6 & 89 & & & & & & & & \\
\hline 235 & Wieder östl. der vorigen Abteilung & & & & & & & & & & & & & & & & & & & & 1 & 82 & & & & & & \\
\hline 237 & Die Nords. der Sandberge & & & & & & & & & & & & & & & & & & & & & & 3 & 54 & & & & \\
\hline 238 & Ebene Heide vor dem Teilbusche & & & & & & & & & & & & & & & & & & & & 5 & 51 & & & & & & \\
\hline 239 & Heidberge sūdlich voriger Abteilung & & & & & & & & & & & & & & & & & & & & & & 2 & 10 & & & & \\
\hline 240 & In den Sandbergen die lehmigen Stellen & & & & & & & & & & & & & & 4 & 116 & & & & & & & & & & & & \\
\hline 241 & Zwischen dem Teilbusche $u$. Lande überm $\mathrm{V}$ & Westerk & & & & & & & & & & & & & & & & & & & & & 2 & 117 & & & & \\
\hline 242 & Hoher Strich am Rehrkampe u. Westerfelde & & & & & & & & & & & & & & & & & & & & 4 & 70 & & & & & & \\
\hline 243 & Die Sandwehen auf dem linken Lachteufer & & & & & & & & & & & & & & & & & & & & & & & & 45 & 81 & & \\
\hline 244 & An Bunkenburgs, Drallen, Bührings u. s. w. & Höfe & & & & & & & & & & & & & & & 11 & 184 & & & & & & & & & & \\
\hline 247 & Nordosts. d. Teilbusches vor dem Westerkan & ampe & & & & & & & & & & & & & & & & & & & & & 8 & 108 & & & & \\
\hline 248 & Die Südwestseite der Büsche & & & & & & & & & & & & & & & & & & & & 4 & 91 & & & & & & \\
\hline 249 & Der Rest derselben & & & & & & & & & & & & & & & & & & 3 & 19 & & & & & & & & \\
\hline 260 & Gastwirth Thies Gehäge & & & & & & & & & & & & & & & & & & & & 4 & 88 & & & & & & \\
\hline 264 & Weg zwischen d. Westerkmpe. u. d. Felde de & daüber & & & & & & & & & & & & & & & & & & & & & & 107 & & & & \\
\hline 265 & Am Rehrkampe _ _ fältt aus - & & & & & & & & & & & & & & & & & & & & & & & & & & & \\
\hline 270 & Bühringsgehäge am Rehrkampe & & & & & & & & & & & & & & & & & & & & & & & 69 & & & & \\
\hline 271 & Die Heide zwischen dem Rehr- u. Mühlenkam & mpe & & & & & & & & & & & & & & & & & & & & & & & 16 & 118 & & \\
\hline 272 & J. Hr. Drallen Immenstelle in voriger Abtl. & & & & & & & & & & & & & & & & & & & & & & & 33 & & & & \\
\hline 278 & Die Wege zwischen dem Mūhlen- $u$. Lohfelde & & & & & & & & & & & & & & & & & & & & & & & & 1 & 35 & & \\
\hline 293 & Der Opprshäuser Weg westl. des Ackern & & & & & & & & & & & & & & & & & & & & & & & & 1 & 42 & & \\
\hline 294 & Derselbe zwischen den Ackern und Kochs 1 & Neuelar & & & & & & & & & & & & & & & & & & & & & 2 & 48 & & & & \\
\hline 309 & Ein Heidwink. an Drewsen Gehäge & & & & & & & & & & & & & & & & & & & & & & 7 & 78 & & & & \\
\hline 311 & Drewsen Gehäge an der Allerheide & & & & & & & & & & & & & & & & & & & & & & 14 & 44 & & & & \\
\hline 312 & Bunkenburgs Gehäge & & & & & & & & & & & & & & & & & & & & & & & & 4 & 90 & & \\
\hline 313 & Zwischen Drewsen Gehäge u. Rüsterheese & & & & & & & & & & & & & & & & & & & & & & 5 & 10 & & & & \\
\hline 314 & Eine Rieth am Rüsterheesekampe & & & & & & & & & & & & & & & & & & & & 21 & 92 & & & & & & \\
\hline 334 & Ein Gemhtswinkel an voriger Abteilung & & & & & & & & & & & & & & & & & & & 60 & & & & & & & & \\
\hline 336 & Heidpfleck u. Wiesenweg auf den Ackern & & & & & & & & & & & & & & & & & & & & & & & & 2 & 32 & & \\
\hline 340 & Die heidwüchsige Anhöhe im Bärenblau & & & & & & & & & & & & & & & & & & 4 & 70 & & & & & & & & \\
\hline 341 & Ein Heidstreifen am Seekampe und Sandbruc & & & & & & & & & & & & & & & & & & & & 5 & 100 & & & & & & \\
\hline 342 & Thies-Bock Immengehäge & & & & & & & & & & & & & & & & & & & & & 72 & & & & & & \\
\hline 390 & Der Ahnsbecker Weg & & & & & & & & & & & & & & 4 & 18 & & & & & & & & & & & & \\
\hline 402 & Die Heide an Kochs kurzem Kampe & & & & & & & & 3 & 48 & & & & & & & & & & & & & & & & & & \\
\hline 403 & Die Heide übern Sandbruche & & & & & & & & & & & & & & & & & & & & 7 & 48 & & & & & & \\
\hline 404 & Die Gemeinheit bei der Windmühle & & & & & & & & & & & & & & & & & & 4 & 35 & & & & & & & & \\
\hline 410 & Ein kl. Gemhtswinkel am Ahnbecker Wege & & & & & & & & & & & & & & & 79 & & & & & & & & & & & & \\
\hline 416 & Die großen Heidbalken bei Striepen Immenza & & & & & & & & & & 1 & 84 & & & & & & & & & & & & & & & & \\
\hline 420 & Das Moor und die Heide im Brande & & & & & & & & & & & & & & & & & & 2 & 78 & & & & & & & & \\
\hline 421 & Der Beedenbostl.-Ahnsbecker Weg & & & & & & & & & & & & & & & & & & & & & 8 & & & & & & \\
\hline
\end{tabular}




\begin{tabular}{|c|c|c|c|c|c|c|c|c|c|c|c|c|c|c|c|c|c|c|c|c|c|c|c|c|c|c|c|}
\hline \multirow{5}{*}{ 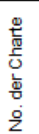 } & \multicolumn{27}{|c|}{ A. Classifications-Register } \\
\hline & \multirow{4}{*}{$\begin{array}{c}\text { Benennung } \\
\text { der } \\
\text { Gegend }\end{array}$} & \multicolumn{26}{|c|}{ Heidboden } \\
\hline & & \multicolumn{26}{|c|}{ Klassen } \\
\hline & & \multicolumn{2}{|c|}{1.} & 2. & & 3. & 4. & 4. & 5. & & 6. & 7. & 8. & 8. & 9. & & 10. & 11 & 11. & 12 & 2. & 13 & 3. & 14 & & 15 & 15. \\
\hline & & $M$ & QR & $M \quad Q R$ & $M$ & $Q R$ & M & QR $M$ & M $Q R$ & $M$ & QR & $M Q R$ & $M$ & QR & $M Q P$ & $2 R$ & QR & $M$ & QR & $M$ & $Q R$ & $M$ & QR & $M$ & QR & M C & $Q R$ \\
\hline 422 & Westl. von der Brandtkuhle & & & & & & & & & & & & & & 182 & 32 & & & & & & & & & & & \\
\hline 423 & Die Brandkuhle & & & & & & & & & & & & & & & & & & & & & & 22 & & & & \\
\hline 424 & Zwischen Schumeiers u. Sonemanns Land & fällt & t wes & & & & & & & & & & & & & & & & & & & & & & & & \\
\hline 426 & Bei Drewsen Gehäge u. Lüßmanns Altenkp & & & & & & 2 & 52 & & & & & & & & & & & & & & & & & & & \\
\hline 427 & Drewsen Gehäge & & & & & & 4 & 86 & & & & & & & & & & & & & & & & & & & \\
\hline 428 & Heide westl. von Drewsen Gehäge & & & & & & & & & & & & & 63 & & & & & & & & & & & & & \\
\hline 433 & Der Ahnsbecker-Beedenbstl. Weg sūdl. d. & Bunk & kenbu & urger Weg & eges & & & & & & & & & & 54 & 54 & & & & & & & & & & & \\
\hline 443 & Die Wests. des Bunkenburger Weges & & & & & & & & & & & & 1 & 104 & & & & & & & & & & & & & \\
\hline 445 & Derselbe östlich des Ahnsbecker Weges & & & & & & & 69 & & & & & & & & & & & & & & & & & & & \\
\hline 446 & Der Heidstreifen an Lūhrs in Ahnsbeck. La & ifällt & t wes & & & & & & & & & & & & & & & & & & & & & & & & \\
\hline 447 & Die Heide nördlich über Lührskampe & fällt & t weg & & & & & & & & & & & & & & & & & & & & & & & & \\
\hline 448 & An Lüßmanns alten Kampe & fällt & t wes & & & & & & & & & & & & & & & & & & & & & & & & \\
\hline 449 & Reste der Heide daselbst & fällt & t we & & & & & & & & & & & & & & & & & & & & & & & & \\
\hline 461 & Heidstreifen am Ahnsbecker Wege & & & & & & & & & 2 & 18 & & & & & & & & & & & & & & & & \\
\hline 462 & Gemeinheit an Bolten Immenzaun & & & & & & 2 & 86 & & & & & & & & & & & & & & & & & & & \\
\hline 643 & An Drewsen Gehäge herum & & & & & & & & & & & & & & & 3 & 116 & & & & & & & & & & \\
\hline 464 & Drewsen Punnewisch Gehäge & & & & & & & & & 8 & 91 & & & & & & & & & & & & 42 & & & & \\
\hline 466 & Ein Heidberg am Jarnser Felde & & & & & & & & & & & & & & & & & & & & & & & & & & \\
\hline 467 & Ein Heidberg am Jarnser Wege & & & & & & & & & & & & & & & & & & & & & & & & 50 & & \\
\hline 472 & Eine Heidspitze am Wege & & & & & & & & & & & & & 24 & & & & & & & & & & & & & \\
\hline 490 & Der Rest der Schelprieth a.d. Brandmoore & & & & & & 6 & 22 & & & & & & & & & & & & & & & & & & & \\
\hline 495 & Der Jarnser Weg u. d. schlechte Gmht. Dara & & & & & & & & & & & & & & & & & & & 2 & 29 & & & & & & \\
\hline 497 & Nords. d. Beedenbosteler-Ahnsbecker Weg & & & & & & & & & & & & & & & & & 1 & 26 & & & & & & & & \\
\hline 498 & Wieder der Weg nach Bolten Immenzaun & & & & & & & & & & 78 & & & & & & & & & & & & & & & & \\
\hline 499 & Der Rest die Südseite des Weges & & & & & & & & & & & & 2 & 24 & & & & & & & & & & & & & \\
\hline 501 & Heidspitze am Ahnsbecker Wege hin & & & & & & & & & & 110 & & & & & & & & & & & & & & & & \\
\hline 514 & Gemeinheit unterm Hohenkampe & & & & & & 5 & 62 & & & & & & & & & & & & & & & & & & & \\
\hline 517 & Der Heidstrich nördlich der Rieth & & & & & & & & & & & & & & & & & 12 & 50 & & & & & & & & \\
\hline 519 & Der Heidberg vor dem Gmdgehäge & & & & & & & & & & & & & & & & & & & 5 & 68 & & & & & & \\
\hline 520 & Neben der vorigen Abteilung & & & & & & & & & & & & & & & & & 5 & 112 & & & & & & & & \\
\hline 522 & Der Berg östl. am Osterkampe & & & & & & & & & & & & & & & & & & 56 & & & & & & & & \\
\hline 523 & Bunkenburgs Osterkamp & & & & & & & & & & & & & & & & & 4 & 42 & & & & & & & & \\
\hline 524 & Ein Gemeinheitstreifen am Gehäge & & & & & & & & & & & & 1 & 46 & & & & & & & & & & & & & \\
\hline 527 & Das Hohe des Gemeindegehäges & & & & & & & & & & & & & & & & & & & 2 & 12 & & & & & & \\
\hline 528 & Der Rest der niedrige Teil & & & & & & & & & & & & & & & & & 2 & 14 & & & & & & & & \\
\hline 542 & Die Heide auf d. Nords. in dems. Kampe & & & & & & & & & & & & & & & & & & & & & & 88 & & & & \\
\hline 544 & Der Berg an voriger Abtl. & & & & & & & & & & & & & & & & & & & 6 & 15 & & & & & & \\
\hline 551 & Eine Grund im Melmau & & & & & & & & & & & & & & & 8 & 77 & & & & & & & & & & \\
\hline 553 & Der hohe Heidstreifen am Melmau & & & & & & & & & & & & & & & 2 & 118 & & & & & & & & & & \\
\hline 554 & Die Sandwehe unterm Osterade & & & & & & & & & & & & & & & & & & & & & 4 & 78 & & & & \\
\hline 556 & Ein niedriger Heidstrich am Melmau & & & & & & & & & & & & & & & & & 8 & 4 & & & & & & & & \\
\hline 558 & Theis-Thies Lehnegarten & & & & & & & & & & & & & & & & & & & & & & 83 & & & & \\
\hline 565 & Die Saneschellen beim Dorfe & & & & & & & & & & & & & & & & & & & & & & & 49 & 97 & & \\
\hline 568 & Der Rest der Gemeinheit daselbst & & & & & & & & & & & & & & & & & & & 2 & 22 & & & & & & \\
\hline 677 & Gastwirth Thies Busch & & & & & & 5 & & & & & & & & & & & & & & & & & & & & \\
\hline 578 & Der Gemeinde Wolfsbusch & & & & & & 80 & & & & & & & & & & & & & & & & & & & & \\
\hline 600 & Der Busch an der Wiese & & & & & & & & & & & & 5 & 12 & & & & & & & & & & & & & \\
\hline 603 & Cammen Thies trockene Wiese & ohn & ne $\mathrm{E}$ & intrag & & & & & & & & & & & & & & & & & & & & & & & \\
\hline 609 & Kohlmeyers trockene Wiese & ohn & ne $E$ & intrag & & & & & & & & & & & & & & & & & & & & & & & \\
\hline 610 & Bock-Thies trockene Wiese & ohn & ne $E$ & intrag & & & & & & & & & & & & & & & & & & & & & & & \\
\hline 619 & Gemeinde Schweinehirtenwiese & ohn & ne $E$ & intrag & & & & & & & & & & & & & & & & & & & & & & & \\
\hline & & & & Quelle: & Clas & ssific & ations. & - und $\mathrm{V}$ & Verme & & & gister & er Fel & idmark & & dorf & & & & & & & & & & & \\
\hline
\end{tabular}

\section{Zusammenfassung}

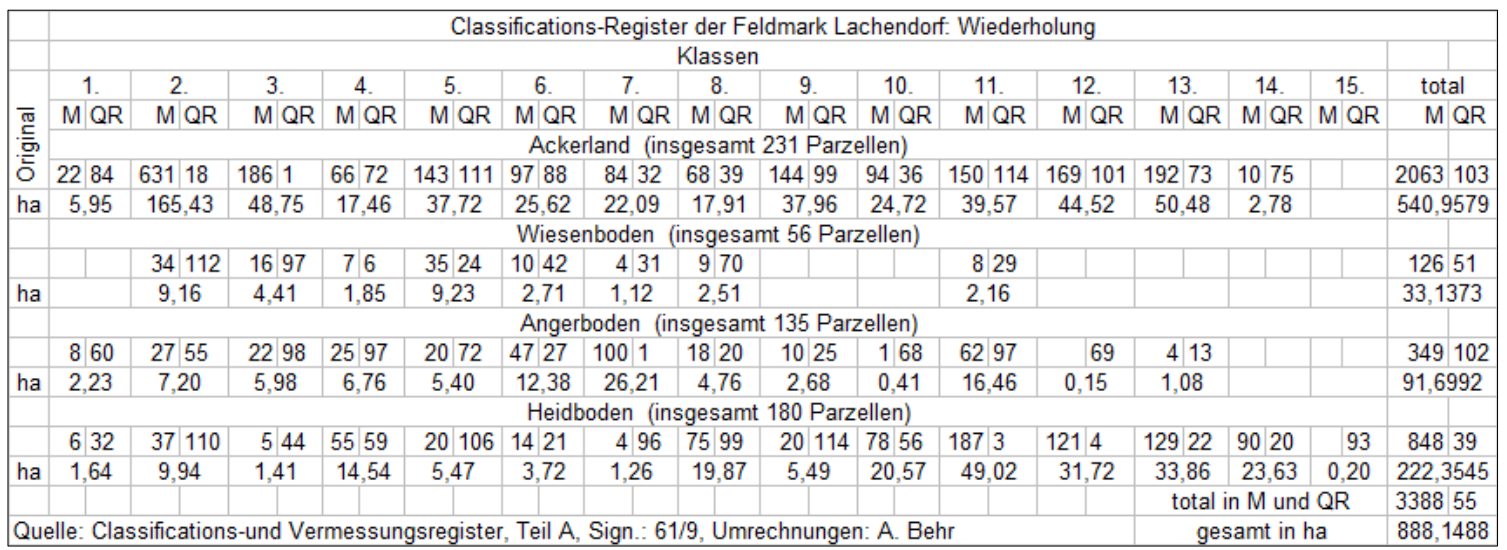


In Teil A des "Classifications- und Vermessungs-Registers der Feldmark Lachendorf" sind nicht alle Parzellen der „Taxations-Tabelle“ aufgeführt.

Während alle Parzellen mit Anger- und Heidboden erfasst sind, wurden einige wenige Ackerparzellen und zahlreiche Wiesenbodenparzellen der Taxations-Tabelle ( ab Nr.533) im "Classifications-Verzeichnis“ nicht berücksichtigt.

Aufgrund der Bezeichnungen der hier nicht klassifizierten Parzellen kann man annehmen, dass diese damals außerhalb der Feldmark ${ }^{1}$ lagen und erst mit der Entfrettung ${ }^{2}$ und Verkoppelung der Aller- und trockenen Wiesen erfasst wurden.

Im Teil B des „Classifications- und Vermessungs-Registers der Feldmark von Lachendorf“ werden für jeden Hof alle in der damaligen Feldmark gelegenen Parzellen an Ackerland, Wiesen-, Anger- und Heideboden nach Belegenheit in der Flur, Klassifikation und Vermessung in Morgen und Quadratruten aufgeführt, allerdings noch ohne die Bewertung nach Kuhweiden.Die Wertermittlung in Kuhweiden erfolgte in der Zusammenfassung für jeden Hof.

Als Beispiele werden hier die Flurstücke eines Brinksitzers und eines Köthners vor und nach der Reform dargestellt:

\begin{tabular}{|c|c|c|c|c|c|c|c|c|c|c|c|c|c|c|c|c|c|c|c|c|c|c|c|c|c|}
\hline \multicolumn{26}{|c|}{ Vermessung und Wertermittlung eines Hofes } \\
\hline \multicolumn{26}{|c|}{ Beispielhof: Brinksitzer Christoph Lüßmann } \\
\hline Klasse & \multicolumn{2}{|c|}{1.} & \multicolumn{2}{|c|}{2.} & \multicolumn{2}{|c|}{3.} & \multicolumn{2}{|c|}{4.} & \multicolumn{2}{|c|}{5.} & \multicolumn{2}{|c|}{6.} & \multicolumn{2}{|c|}{7.} & \multicolumn{2}{|c|}{8.} & \multicolumn{2}{|c|}{9.} & \multicolumn{2}{|c|}{10.} & \multicolumn{2}{|c|}{11.} & \multicolumn{3}{|c|}{ total } \\
\hline Flurbezeichnung & M & QR & M & QR & M & QR & M & QR & $\mathrm{MC}$ & QR & $M$ & QR & M & QR & $M$ & QR & M & QR & M & QR & $M$ & QR & M & QR & Kuhw. \\
\hline Ackerland & & & & & & & & & & & & & & & & & & & & & & & & & \\
\hline Osterraden & & & & & & 79 & & & & & & 68 & & & & & & & & & & & 1 & 27 & \\
\hline Osterraden & & & & & & 114 & & & & & & & & & & & & & & & & & & 114 & \\
\hline Punnewischfeld & & & 4 & 12 & & & & & & & & & & & & & & & & & & & 4 & 112 & \\
\hline Hohenkampe & & & 6 & 36 & & & & 16 & & & & & & & & & & & & & & & 6 & 52 & \\
\hline Sandbruche & & & & 100 & & 32 & & & 1 & 80 & & & & & & & & & & & & 119 & 3 & 111 & \\
\hline Neuegärten & & 12 & & & & & & & & & & & & & & & & & & & & & & 12 & \\
\hline Kampgärten & & & & 23 & & & & & & & & & & & & & & & & & & & & 23 & \\
\hline Summe Acker & & 12 & 12 & 31 & 1 & 105 & & 16 & 1 & 80 & & 68 & & & & & & & & & & 119 & 17 & 91 & 4,558 \\
\hline Wiesenboden & & & & & & & & & & & & & & & & & & & & & & & & & \\
\hline Sandbruche & & & & & & 42 & & & & & & & & wei & idepf & fflich & & & & & & & & 42 & 0,117 \\
\hline Angerboden & & & & & & & & & & & & & & & & & & & & & & & & & \\
\hline Beim Hause & & & & & & & & & & & & & & 63 & & & & & & & & & & 63 & 0,088 \\
\hline gesamt & & & & & & & & & & & & & & & & & & & & & & & 36 & 47 & 4,763 \\
\hline
\end{tabular}

Quele: Classifications- und Vermessungsregister, Teil B; Sign.: 61/9, Lit. w

Rezess über die Spezialteilung und Verkoppelung der Feldmark Lachendorf

Brinksitzer ... hat zugeteilt erhalten:

\begin{tabular}{|c|c|c|c|c|c|c|c|c|c|c|c|c|}
\hline \multirow[b]{2}{*}{ Flurbezeichnung } & \multicolumn{3}{|c|}{ Ackerland } & \multicolumn{3}{|c|}{ Angerboden } & \multicolumn{3}{|c|}{ Heidboden } & \multicolumn{3}{|c|}{ total } \\
\hline & $M$ & QR & Kuhw- & M & QR & Kuhw. & M & QR & Kuhw. & M & QR & Kuhw- \\
\hline Hohenkampe & 9 & 47 & 2,517 & & & & & 26 & 0,024 & 9 & 73 & 2,541 \\
\hline Osterraden & 8 & 50 & 1,671 & 5 & 20 & 0,644 & 1 & 96 & 0,087 & 15 & 28 & 2,402 \\
\hline Neue Gärten & & 16 & 0,045 & & 114 & 0,211 & & & & 1 & 10 & 0,256 \\
\hline Beim Haue & & & & & 119 & 0,162 & & & & & 119 & 0,162 \\
\hline Auf dem Moore & & & & 1 & 61 & 0,367 & & 2 & 0,001 & 1 & 63 & 0,368 \\
\hline Vor Drallen Osterwiese & & & & & & & 2 & 106 & 0,213 & 2 & 106 & 0,213 \\
\hline Hinterm Canale & & & & & 30 & 0,067 & & & & & 30 & 0,067 \\
\hline Am Exerzierplatz & & & & & & & 35 & 48 & 1,593 & 35 & 48 & 1,593 \\
\hline Summe & 17 & 113 & 4,233 & 8 & 104 & 1,451 & 40 & 38 & 1,918 & 67 & 15 & 7,602 \\
\hline
\end{tabular}

\footnotetext{
${ }^{1}$ Die Feldmark umfasste ursprünglich nur die allein von den Lachendorfer Höfen und der Dorfgemeinschaft (und einigen wenigen Ausmärkern) genutzten Flächen, vor allem das Ackerland, dazu Wiesen-, Anger- und Heidboden. Die überörtlichen Gemeinschaftsreviere auf der Allerheide sowie die Aller- und trockenen Wiesen gehörten bis zum Abschluss der Reformen nicht zur Feldmark Lachendorfs. Historisch ist also die Gleichsetzung von Feldmark und Gemarkung nicht korrekt.

${ }^{2}$ Ablösung der Gemeinschaftsweide
} 


\begin{tabular}{|c|c|c|c|c|c|c|c|c|c|c|c|c|c|c|c|c|c|c|c|c|c|c|}
\hline$\frac{\mathrm{g}}{\mathrm{T}}$ & Litt s & & & & & & & & & & & & & & Acke & rerlan & & & & & & \\
\hline 帘 & Der Köthner Carsten Heinr. & & & & & & & & & & & & & Klass & & & & & & & & \\
\hline i. & Koch & & 1. & 2 & 2. & 3. & & 4. & & 5. & & 6. & 7 & 7. & 8 & 3. & 9. & & 10. & & 11. & 12 \\
\hline 운 & Benennung & M & QR I & M & QR & $M$ QR & $M$ & QR & $M$ & $Q R$ & M & QR & M & QR & M C & QR & $\mathrm{M}$ QR & R $M$ & QR & $\mathrm{M}$ & QR & M 0 \\
\hline 15 & Auf dem Dürskampe & & & 4 & 102 & & & & & & & & & & & & & & & & & \\
\hline 52 & Auf der Salloh & & & & & & & & & & & & & 3 & & & & & & & & \\
\hline 81 & Auf dem Lerchenberge & & & & & & & & & & & & & 107 & & & & & & 1 & 75 & \\
\hline 86 & & & & & & & & & & & & & & & & & & & & 1 & 16 & \\
\hline 89 & & & & & & & & & & & & & & & & & & & & & 66 & \\
\hline 118 & Auf der Salloh & & & & 112 & & & & & & & 118 & & & & & & & & & & \\
\hline 121 & & & & & 29 & & & & & & & 90 & & & & & & & & & & \\
\hline 149 & & & & 2 & 4 & & & & & 6 & & & & 33 & & & & & & & & \\
\hline 156 & & & & 1 & 51 & 26 & & & & 5 & & & & 39 & & & & & & & & \\
\hline 177 & & & & 2 & 28 & & 1 & & & & & & & & & & & & & & & \\
\hline 209 & Auf dem Flottkamp & & & & & 5 & & 72 & & & & & & & & & & & & & & \\
\hline 218 & & & & 1 & 2 & & & 10 & & & & & & & & & & & & & & \\
\hline 242 & Der Moorgarten & & & & & & & & & 27 & & & & & & & & & & & & \\
\hline 284 & Auf dem Krūmmel & & & 1 & 14 & & & 92 & & & & 22 & & & & & & & & & & \\
\hline 287 & & & & & 73 & & & 44 & & & & 8 & & & & & & & & & & \\
\hline 301 & & & & & 56 & & & 24 & & & & & & & & & & 30 & & & & \\
\hline 335 & Der Osterkamp & & & & & & & & & & & & & & 2 & 12 & 110 & 00 & & 1 & 76 & \\
\hline 406 & Auf dem Osterraden & & & & & 92 & & & & & & & & 2 & & & & & & & & \\
\hline 416 & & & & & & 111 & & & & & & 47 & & & & & & & & & & \\
\hline 436 & Auf dem Hohenkampe & & & & 13 & & & & & 3 & & 46 & & & & & & 1 & 21 & & & \\
\hline 454 & Auf dem Punnewischfelde & & & 8 & 54 & & & & & & & & & & & & & & & & & \\
\hline 458 & Bei Bolten Immenzaun & & & 3 & 114 & & & & & & & & & & 2 & 30 & & & & & & \\
\hline 506 & Auf dem osterraden & & & & 24 & & & 10 & & & & & & & & & & & & & & \\
\hline 559 & Der Kurzekamp & & & & & & & & 2 & 96 & & & & & & & & & & & & \\
\hline 565 & Auf dem Sandbruche & & & & 61 & & & & 4 & 90 & & & & & & & & & & & 84 & \\
\hline 578 & & & & & 80 & & & & & & & & & & & & & & & & & \\
\hline 608 & In den Neuengärten & & 25 & & & & & & & & & & & & & & & & & & & \\
\hline 614 & Der alte Garten & & 80 & & & & & & & & & & & & & & & & & & & \\
\hline 616 & Auf dem Sandbruche, südl. & & & 1 & 28 & & & & & & & & & & & & & & & & & \\
\hline 624 & Auf dem Sandruche, sũdl. & & & & 97 & & & & & & & & & & & & & & & & & \\
\hline 674 & Der Schwarzekamp & & & & & & & & & & 2 & 94 & & & & & & & & & & \\
\hline 688 & In den Ackern & & & & & & & & & & & 13 & & & & & 1 & 30 & 83 & & & \\
\hline 714 & & & & & & & & & & & & & & & & & & 01 & & & 116 & \\
\hline 753 & & & & & & & & & & & & & & & & & 13 & 35 & 8 & 8 & 4 & \\
\hline 718 & & & & & & & & & & & & & & & & & & 45 & & & 92 & \\
\hline 775 & Das Neueland & & & & & & & & & & & & & & & & & & & & & \begin{tabular}{l|l}
6 & 1 \\
9
\end{tabular} \\
\hline 727 & & & & & & & & & & & & & & & & & & & & & 24 & \\
\hline 737 & Übern Ackern & & & & & & & & & & & & & & & & & & & & & \\
\hline 793 & & & & & & & & & & & & & & & & & & & & & & \\
\hline 800 & Auf dem Lohfelde & & & & & & & & & & & & & & & & & & 88 & & 42 & \\
\hline 872 & & & & & & & & & & & & & & & & & & 11 & 51 & & 42 & \\
\hline 831 & Zwischen dem Oppersh. U. Cell & ller W & & & & & & & & & & & & & & 25 & & & & & & \\
\hline 841 & & & & & & & & & & & & & & & & 44 & & & & & & \\
\hline 857 & Auf dem Westerfelde & & & & & & & & & & & & & & & 13 & & & 51 & & & \\
\hline 867 & & & & & & & & & & & & & & 98 & & & & & & & & \\
\hline 431 & Auf dem hohen Kampe & & & 1 & 52 & & & & & & & & & & & & & & & & & \\
\hline 911 & Auf dem Westerkampe & & & & & & & & & & & & & & & & & 37 & & & & \\
\hline 931 & & & & & & & & & & & & & & 110 & & & & 45 & & & & \\
\hline & Litt. s, Summa Ackerland & & 105 & 32 & 70 & 3 & $\begin{array}{ll}6 & 3\end{array}$ & 12 & 7 & 107 & 5 & 78 & 3 & 32 & 5 & 4 & \begin{tabular}{l|l}
6 & 7 \\
\end{tabular} & \begin{tabular}{l|l}
74 & 3 \\
\end{tabular} & 361 & 18 & 37 & 10 \\
\hline$\stackrel{\mathscr{2}}{\mathrm{L}}$ & & & & & & & & & & & & & & $\mathrm{b}, \mathrm{Wi}$ & liese & enboc & & & & & & \\
\hline$\frac{\pi}{0}$ & Der Köthner Carsten Heinr. & & & & & & & & & & & & & Klass & & & & & & & & \\
\hline$i$ & Koch & & 1. & 2 & 2. & 3. & & 4. & & 5. & & 6. & & 7. & 8 & & 9. & & 10. & & 11. & 12 \\
\hline i & Benennung & $M$ & QR I & M & QR & $M Q R$ & $M$ & QR & M & $Q R$ & M & QR & M & $Q R$ & M C & QR & $M Q R$ & R $M$ & $Q R$ & $M$ & QR & $\mathrm{M} O$ \\
\hline 333 & Die Osterwiese & & & 2 & 20 & & & & & & & & & & & & & & & & & \\
\hline 343 & Der Grashof & & & 2 & 112 & & & & & & & & & & & & & & & & & \\
\hline 578 & Auf dem Sandbruche & & & & & & & 4 & & & & & & & & & & & & & & \\
\hline 953 & Der Farkenkamp & & & & & & & & & & & & & & 1 & 33 & & & & & & \\
\hline 956 & & & & & & & & 40 & & & & & & & & & & & & & & \\
\hline & Litt. s, Summa Wiesenboden & & & 5 & 12 & & & 44 & & & & & & & 1 & 33 & & & & & & \\
\hline & & & & & & & & & & & & & & $\mathrm{c}, \mathrm{A}$ & Anger & rbod & & & & & & \\
\hline 333 & An der Osterwiese & & & & & & & & & & & & & 62 & & & & & & & & \\
\hline 343 & An dem Grashofe & & & & & & & & & & & & & & & & & & & & 90 & \\
\hline 345 & Hofraum & & & & & & & & & & & & 3 & 82 & & & & & & & & \\
\hline 422 & Immenstelle unterm Osterraden & & & & & & & & & & & & & 54 & & & & & & & & \\
\hline 953 & Am Farkenkampe & & & & & & & & & & & & & & 1 & 24 & & & & & & \\
\hline 956 & & & & & & & & & & & & & & 1 & & & & & & & & \\
\hline 242 & Am Moorgarten & & & & & & & & & & & & & & & 10 & & & & & & \\
\hline & Litt. s, Summa Angerboden & & & & & & & & & & & & 4 & 79 & 1 & 34 & & & & & 90 & \\
\hline & & & & & & & & & & & & & & d, $\mathrm{H}$ & Heidd & dbod & & & & & & \\
\hline 335 & Auf dem Osterkampe & & & & & & & & & & & & & & & & & & & & & \\
\hline 902 & In den Büschen vor dem Wester & erkpe & & & & & & & & & & & & & & & & & & & 32 & \\
\hline & Litt. s, Summa Heideboden & & & & & & & & & & & & & & & & & & & & 32 & \\
\hline
\end{tabular}




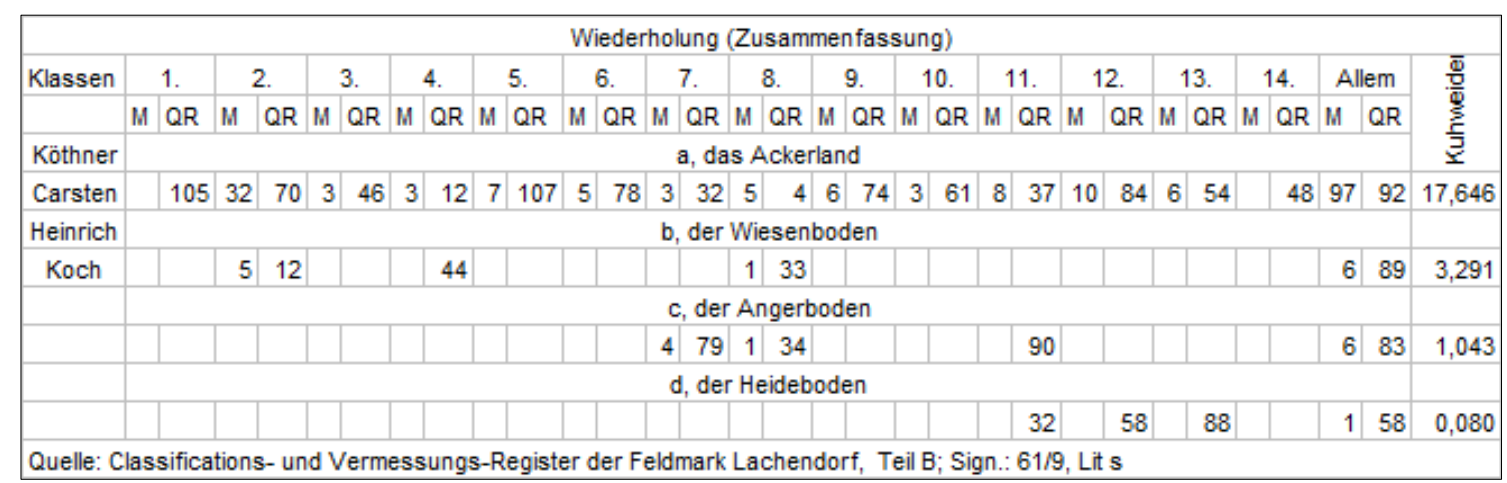

\begin{tabular}{|c|c|c|c|c|c|c|c|c|c|c|c|c|c|c|c|c|c|}
\hline \multicolumn{18}{|c|}{ Rezess über die Spezialteilung und Verkoppelung der Feldmark Lachendorf } \\
\hline \multirow{5}{*}{ 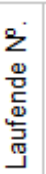 } & \multirow{5}{*}{ 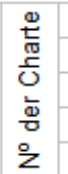 } & & & & & & & & & & & & & & \multirow{2}{*}{\multicolumn{3}{|c|}{ Überhaupt }} \\
\hline & & Litt: $s$ & & & & & & & & & & & & & & & \\
\hline & & Der Köthner Carsten Heinr. & & & & & & & & & & & & & \multicolumn{3}{|c|}{ brauchbarer } \\
\hline & & Koch & \multicolumn{3}{|c|}{ Ackerland } & \multicolumn{3}{|c|}{ Wiesenboden } & \multicolumn{3}{|c|}{ Angerboden } & \multicolumn{3}{|c|}{ Heidboden } & \multicolumn{3}{|c|}{ Boden } \\
\hline & & hat zugeteilt erhalten. & $\mathrm{M}$ & QR & Kuhw. & M & QR & Kuhw. & M & QR & Kuhw. & M & QR & Kuhw. & M & QR & Kuhw. \\
\hline 1 & 233 & Auf der Pannstätte 7 & 23 & 67 & 3,591 & & & & & 90 & 0,008 & & 4 & 0,002 & 23 & 80 & 3,601 \\
\hline 2 & 196 & Auf dem Osterraden 6 & 8 & 37 & 1,850 & & & & 6 & 88 & 1,221 & 1 & 42 & 0,112 & 16 & 47 & 3,183 \\
\hline 3 & 216 & \& 221 Bei Bolten Immenzaun 8 & 33 & 21 & 5,327 & & & & & 45 & 0,119 & 3 & 21 & 0,412 & 36 & 85 & 5,858 \\
\hline 4 & 218 & Auf dem Punnewischefelde 9 & 18 & 41 & 5,205 & & & & 4 & 98 & 0,943 & & & & 23 & 19 & 6,148 \\
\hline 5 & 210 & Der Osterkamp 5 & 7 & 88 & 0,740 & 2 & 20 & 1,238 & 4 & 50 & 0,579 & 1 & 29 & 0,067 & 15 & 67 & 2,624 \\
\hline 6 & 235 & Der alte Garten 3 & & 88 & 0,244 & & & & 1 & 33 & 0,356 & & & & 2 & 1 & 0,600 \\
\hline 7 & 97 & Der Grashof 2 & & & & 2 & 112 & 1,676 & 1 & 107 & 0,178 & & 54 & 0,025 & 5 & 33 & 1,879 \\
\hline 8 & 94 & Beim Hause 1 & & & & & & & 3 & 100 & 0,639 & & & & 3 & 100 & 0,639 \\
\hline 9 & 194 & In der kleinen Mellmau 4 & & & & & & & 6 & 48 & 0,745 & 12 & 58 & 0,845 & 18 & 106 & 1,590 \\
\hline 10 & & Vor den Wiesen 12 & & & & & & & & & & & 19 & 0,020 & & 19 & 0,020 \\
\hline 11 & & Hinterm Krähenmoor 11 & & & & & & & & 16 & 0,013 & 41 & 92 & 2,065 & 41 & 108 & 2,078 \\
\hline 12 & & Am Oppershäuser Felde & & & & & & & & & & & & & & & \\
\hline 13 & & zwische den Wegen 10 & & & & & & & & & & 15 & 45 & 0,721 & 15 & 45 & 0,721 \\
\hline 14 & & Am Oppershäuser Wege 13 & & & & & & & & & & 48 & 80 & 1,947 & 48 & 80 & 1,947 \\
\hline 15 & & Am Exerzierolatz 14 & & & & & & & & & & 5 & 68 & 0,223 & 5 & 68 & 0,223 \\
\hline 16 & & An der Pannstätte ad 7 & & & & & & & & & & 4 & 66 & 0,191 & 4 & 66 & 0,191 \\
\hline & & (rechnerische Kontrolle) & & & 16,957 & & & 2,914 & & & 4,801 & & & 6,630 & & & 31,302 \\
\hline & & Summa: & 91 & 102 & 16,957 & 5 & 12 & 2,914 & 29 & 112 & 4,801 & 134 & 98 & 6,630 & 261 & 84 & 31,302 \\
\hline
\end{tabular}

Um deutlich zu machen, welche Wirkung die Verkoppelung hinsichtlich der Parzellenzahl hatte und wie durch die Spezialteilung insbesondere die Fläche an Heidboden wuchs, wird hier für beide Höfe die Zuteilung eingefügt, wie sie im Rezess von 1859 als Ergebnis der Reformen dann festgehalten wurde.

Das Vermessungsregister fasst für alle Höfe, die an der Feldmark Lachendorf beteiligt waren, das Ergebnis der Klassifikation und Vermessung in je einer Übersicht für Ackerland, Wiesen- und Anger- sowie Heidboden zusammen. 
Das Ackerland:

\begin{tabular}{|c|c|c|c|c|c|c|c|c|c|c|c|c|c|c|c|c|c|c|c|c|c|c|c|c|c|c|c|c|c|c|c|c|}
\hline \multicolumn{33}{|c|}{ Vermessungs-Register, Wiederholung (Zusammenfassung) } \\
\hline \multirow[b]{6}{*}{ 운 } & & \multicolumn{31}{|c|}{ Ackerland } \\
\hline & & \multicolumn{28}{|c|}{ Klassen } & \multirow{2}{*}{\multicolumn{2}{|c|}{ total }} & \\
\hline & & & 1. & 2. & & 3. & 3. & 4. & 4. & 5 & & 6. & 6. & 7. & 7. & 8. & & 9 & 9. & 10 & 10. & 11 & & 12 & 12. & & 13. & 14 & 4. & & & Wert \\
\hline & & & & & & & & & & & & & orgen & pro K & Kuhw & veide & e für & Acke & erland & & & & & & & & & & & & & \\
\hline & & & 3 & 3,5 & 5 & 4 & 4 & 4,5 & 5 & 5 & 5 & 6 & 6 & 7 & 7 & 7,5 & & & 9 & 10 , & 0,5 & 1 & & & 15 & & 18 & 2 & 21 & tote & tal & Wert \\
\hline & & M & QR I & M C & QR I & M & QR I & M C & QR & M & QR I & M & $Q R$ & M & QR 1 & $M \quad Q$ & QR & M & QR & M C & QR & M & QR & M & QR & M & QR & M C & QR & M & QR & Kuhw. \\
\hline $\mathrm{a}$ & VH & & 85 & 46 & 96 & 26 & 23 & 2 & 32 & 9 & 74 & 10 & 93 & 8 & 42 & & 45 & 6 & 116 & 11 & 5 & 3 & 66 & 10 & 107 & 10 & 111 & & 56 & 148 & 111 & 29,098 \\
\hline b & VH & 2 & 39 & 38 & 16 & 5 & 5 & 7 & 45 & 3 & 63 & 1 & 116 & \begin{tabular}{l|l}
5 & 1 \\
$r$
\end{tabular} & 105 & \begin{tabular}{l|l}
3 & 1
\end{tabular} & 110 & 9 & 85 & 9 & 3 & 2 & 68 & 3 & 35 & 6 & \begin{tabular}{l|l|}
5 & 49
\end{tabular} & 2 & 24 & 101 & 43 & 19,796 \\
\hline c & VH & & 48 & 28 & 38 & 24 & 65 & 1 & 83 & 4 & 12 & 6 & 43 & 6 & 98 & \begin{tabular}{l|l}
10 & 1
\end{tabular} & 110 & 13 & 67 & 4 & 28 & 7 & 1 & 3 & 54 & 12 & 16 & 1 & 1 & 124 & 64 & 22,489 \\
\hline d & VH & & 55 & 55 & 29 & 10 & 74 & 4 & 62 & 9 & 40 & 4 & 13 & 41 & 103 & 4 & 71 & 12 & 73 & 5 & 27 & 4 & 86 & 22 & 103 & 19 & $\begin{array}{ll}9 & 112\end{array}$ & & 55 & 159 & 63 & 28,396 \\
\hline e & VH & & 84 & 22 & 57 & 13 & 8 & 3 & 41 & 13 & 91 & 6 & 35 & 6 & 9 & 21 & 116 & 8 & 65 & 4 & 10 & 21 & 2 & 2 & 37 & 7 & 64 & & 100 & 112 & 119 & 19,429 \\
\hline$f$ & $\mathrm{VH}$ & 1 & 32 & 45 & 5 & 11 & 72 & 4 & 29 & 4 & 11 & 5 & 11 & 6 & 27 & 1 & 96 & 12 & 2 & 6 & 19 & 1 & 117 & 3 & 3 & 21 & 35 & & 56 & 124 & 35 & 23,422 \\
\hline$g$ & VH & 1 & 37 & 42 & 50 & 14 & 34 & 4 & 94 & 1 & 23 & 5 & 92 & 6 & 55 & 11 & 108 & 8 & 32 & 5 & 78 & 7 & 117 & 6 & 98 & 15 & $\begin{array}{ll}5112 \\
\end{array}$ & & 94 & 123 & 64 & 23,062 \\
\hline h & $\mathrm{HH}$ & & 94 & 42 & 78 & 6 & 89 & 1 & 93 & 14 & & 4 & 12 & $\begin{array}{ll}3 & 1\end{array}$ & 109 & 3 & 7 & 4 & 22 & 3 & 119 & 3 & 32 & 3 & 100 & 3 & \begin{tabular}{l|l|} 
& 52 \\
\end{tabular} & & 66 & 96 & 33 & 20,565 \\
\hline i & $\mathrm{KH}$ & & 73 & 25 & 80 & 3 & 23 & 5 & 103 & 13 & 84 & 9 & 65 & 4 & 99 & \begin{tabular}{l|l}
8 & 1
\end{tabular} & 119 & 4 & 95 & 14 & 111 & 5 & 48 & 9 & 29 & 2 & 5 & & 22 & 108 & 116 & 18,996 \\
\hline k & $\mathrm{KH}$ & 1 & 14 & 17 & 72 & 1 & 8 & 6 & 80 & & 87 & 1 & 84 & 8 & 5 & & & 10 & 28 & 3 & 83 & 16 & 96 & 6 & 56 & 3 & 65 & & 60 & 78 & 18 & 12,266 \\
\hline 1 & $\mathrm{KH}$ & 1 & 46 & 16 & 44 & 9 & 16 & 6 & 91 & 4 & 58 & & 95 & 2 & 6 & 5 & 59 & 5 & 59 & 4 & 118 & 15 & 21 & 17 & 7 & 12 & 112 & & 18 & 102 & 30 & 15,188 \\
\hline $\mathrm{m}$ & $\mathrm{KH}$ & & 24 & 14 & 3 & 1 & 18 & 1 & 79 & 5 & 28 & 3 & 103 & 1 & 68 & & & 7 & 78 & 1 & 96 & 14 & 12 & 7 & 116 & 14 & $\begin{array}{l}4 \\
4\end{array}$ & & 23 & 73 & 62 & 10,163 \\
\hline$n$ & $\mathrm{KH}$ & & 24 & 2 & 36 & 1 & 56 & & & 2 & 40 & 2 & 35 & & 52 & 3 & 64 & 1 & 115 & 4 & 30 & 7 & 115 & 14 & 15 & 11 & 11 & & & 51 & 13 & 5,246 \\
\hline$n$ & $\mathrm{KH}$ & & & & & & & & & & & & & & & & & & rich & htiger & er We & & 15 & & It. Kor & ontrollir & Irechn & nung & & & & \\
\hline 0 & $\mathrm{KH}$ & & 22 & 29 & 84 & 1 & 44 & 2 & 34 & 1 & 97 & 2 & 14 & 3 & 99 & & & 1 & 26 & 1 & 19 & 5 & 92 & 3 & 94 & 8 & $\begin{array}{l}3 \quad 29 \\
\end{array}$ & & 29 & 61 & 83 & 12,104 \\
\hline$p$ & $\mathrm{KH}$ & & 61 & 16 & 92 & & 73 & & 39 & 9 & 100 & & 77 & & 49 & & 18 & & & & 2 & 3 & 89 & 9 & 96 & & & & 10 & 42 & 106 & 8,306 \\
\hline q & $\mathrm{KH}$ & 1 & 84 & 21 & 83 & 19 & 70 & 4 & 107 & 8 & 86 & 6 & 94 & $\begin{array}{ll}5 & 1\end{array}$ & 108 & 12 & 13 & 8 & 87 & 2 & 95 & 5 & 68 & 5 & 25 & 3 & 53 & & & 107 & 13 & 20,316 \\
\hline $\mathrm{r}$ & $\mathrm{KH}$ & & 22 & 42 & 75 & 5 & 35 & & 4 & & & 4 & 104 & & & & 49 & 6 & 102 & 2 & 20 & 5 & 16 & 13 & 46 & & 101 & & & 81 & 94 & 16,769 \\
\hline s & $\mathrm{KH}$ & & 105 & 32 & 70 & 3 & 46 & 3 & 12 & 7 & 107 & 5 & 78 & 3 & 32 & 5 & 4 & 6 & 74 & 3 & 61 & 8 & 37 & 10 & 84 & 6 & 54 & & 48 & 97 & 92 & 17,646 \\
\hline $\mathrm{t}$ & $\mathrm{KH}$ & & 106 & 14 & 117 & 1 & 37 & 1 & 16 & 5 & 22 & 4 & 94 & 2 & 46 & & 53 & 1 & 35 & 3 & 74 & 6 & 56 & 10 & 112 & 12 & 23 & & & 65 & 71 & 9,818 \\
\hline u & $\mathrm{KH}$ & & 110 & & & 1 & 37 & & & 9 & 45 & 4 & 8 & & 92 & & 55 & 4 & 4 & & & 1 & 70 & 1 & 34 & 17 & 111 & & & 41 & 86 & 5,017 \\
\hline $\mathrm{v}$ & BS & & 12 & 7 & 112 & & 109 & & 94 & & 9 & & 4 & & 4 & & & & 21 & & & & & & 24 & & & & & 10 & 29 & 2,769 \\
\hline w & BS & & 12 & 12 & 31 & 1 & 105 & & 16 & 1 & 80 & & 68 & & & & & & & & & 1 & 19 & & & & & & & 17 & 91 & 4,558 \\
\hline $\mathrm{x}$ & BS & & 12 & & 92 & & 24 & & 16 & 1 & 54 & & 49 & & 110 & & & & & & & & & & & & & & & 3 & 117 & 0,821 \\
\hline$y$ & $A B$ & & 48 & 5 & 91 & & & & & & & & & & & & & & & & & & & & & & & & & 6 & 19 & 1,778 \\
\hline$z$ & $A B$ & & 17 & & 34 & 7 & 77 & 1 & 2 & 3 & 50 & & 109 & & 12 & & & 1 & 12 & & 72 & & 48 & & & & & & & 15 & 73 & 3,326 \\
\hline aa & $A B$ & & & & 30 & & & & & & & & & & & & & & & & & & & & & & & & & & 30 & 0,071 \\
\hline $\mathrm{bb}$ & $A B$ & & 38 & 10 & 56 & 1 & 108 & & 12 & 5 & 96 & 1 & 118 & & & 11 & 114 & & 105 & & & 1 & 49 & 1 & 20 & & & & & 26 & 116 & 5,886 \\
\hline $\mathrm{cc}$ & $A B$ & & & & & & & & & & & & & & & & & & & & 29 & & & & & & & 2 & 13 & 2 & 42 & 0,123 \\
\hline dd & AbB & & & & 47 & & 83 & 1 & 88 & & & & & & 16 & & & & 88 & & & & & & & & & & & 3 & 82 & 0,771 \\
\hline ee & $A b B$ & & & & & & 38 & & & & 113 & & & & 85 & & & & & & & & & & & & & & & 1 & 116 & 0,369 \\
\hline $\mathrm{ff}$ & $A b B$ & & & & & 1 & 8 & & & & & & 36 & & & & 17 & & 48 & & & & & & & & & & & 1 & 109 & 0,380 \\
\hline $9 g$ & $A b B$ & & & & & & & & & & & & & & & & & 1 & 63 & & & & & & & & & & & 1 & 63 & 0,170 \\
\hline hh & AbB & & & & & & & & & & & & & & & & & & 82 & & 90 & & 36 & & & & & & & 1 & 88 & 0,172 \\
\hline ii & $A b B$ & & & & & & & & & & & & & & & & & & 70 & & & & & & & 1 & 75 & & & 2 & 25 & 0,155 \\
\hline$\|$ & $A b B$ & & & & & & & & & & & & & & & & 2 & 1 & 86 & & & & & & & & & & & 1 & 88 & 0,193 \\
\hline $\mathrm{nn}$ & $\mathrm{Hi}$ & & & 5 & 42 & & & & & & 66 & & & & & & & & & & & & & & & & & & & 5 & 108 & 1,639 \\
\hline 00 & Hä & & & 6 & 30 & & & & & & & & & & & & & & & & & & & & & & & & & 6 & 30 & 1,786 \\
\hline $\mathrm{vr}$ & $A b B$ & & & & & & & & & & & & & & & & & 1 & 2 & & 13 & & 17 & & & & & & & 1 & 32 & 0,135 \\
\hline $\mathrm{pp}$ & $\mathrm{FaD}$ & 3 & 10 & 15 & 42 & 1 & 35 & & & & & 1 & 32 & & & & & & & & & & & & & & & & & 20 & 119 & 5,948 \\
\hline S & Sch & & & & 82 & & 36 & & & & & & & & & & & & & & & & & & & & & & & & 118 & 0,270 \\
\hline G & Gmd & 1 & 90 & 1 & 21 & 1 & 115 & & & & 6 & & 8 & & & & 9 & 1 & 37 & & 34 & & 36 & & 80 & & 62 & & & 8 & 16 & 1,706 \\
\hline K & $\mathrm{Ki}$ & & & 3 & 54 & & & & & & & & 78 & & 41 & & & & & & & & & 1 & 46 & & & & & 5 & 99 & 1,235 \\
\hline $\mathrm{rr}$ & AVH & & & 2 & 88 & & & & & & 97 & & & & & & & & & & & & & & & & 7 & & & 3 & 72 & 0,946 \\
\hline ss & AVH & & & 2 & 81 & 5 & 112 & & & & 32 & & & & & & & & & & & & & & & & & & & 8 & 105 & 2,301 \\
\hline $\mathrm{Su}$ & umme & 22 & 84 & 631 & 18 & 186 & 1 & 66 & 72 & 143 & 111 & 97 & 88 & 84 & 32 & 68 & 39 & 144 & 99 & 94 & 36 & 150 & 114 & 169 & 101 & 192 & 73 & 10 & 75 & 2063 & 103 & 375,600 \\
\hline & & & & & Que & elle: Cl & Classif & IC & tions- & & rme & es & ungs-f & & $\mathrm{co}$ & der & & & & & f, Teil & $\mathrm{BVe}$ & ermes & ssungs & gs-Reg & & & & & & & \\
\hline
\end{tabular}

Im Original sind die damaligen Hofbesitzer alle namentlich genannt, die hier nicht übernommen wurden.

Für jeden Interessenten ist hier in Spalte 2 - wie Original - der Hoftyp genannt:

Abkürzungen: VH: Vollhöfner oder Vollmeier; HH: Halbmeier, $\mathrm{KH}$ : Köthner;

BS: Brinksitzer; AB: Anbauer; AbB: Abbauer; Hi: Hirte; Hä: Häusling;

FaD: Georg Drewsen Erben Papierfabrik; S: Schule; Gmd: Gemeinde;

Ki: Kirche Beedenbostel ${ }^{1}$;

rr und ss: Ausmärker: Vollmeier aus Gockenholz

\footnotetext{
${ }^{1}$ Lachendorf gehörte zur Kirchengemeinde Beedenbostel
} 
Der Wiesenboden:

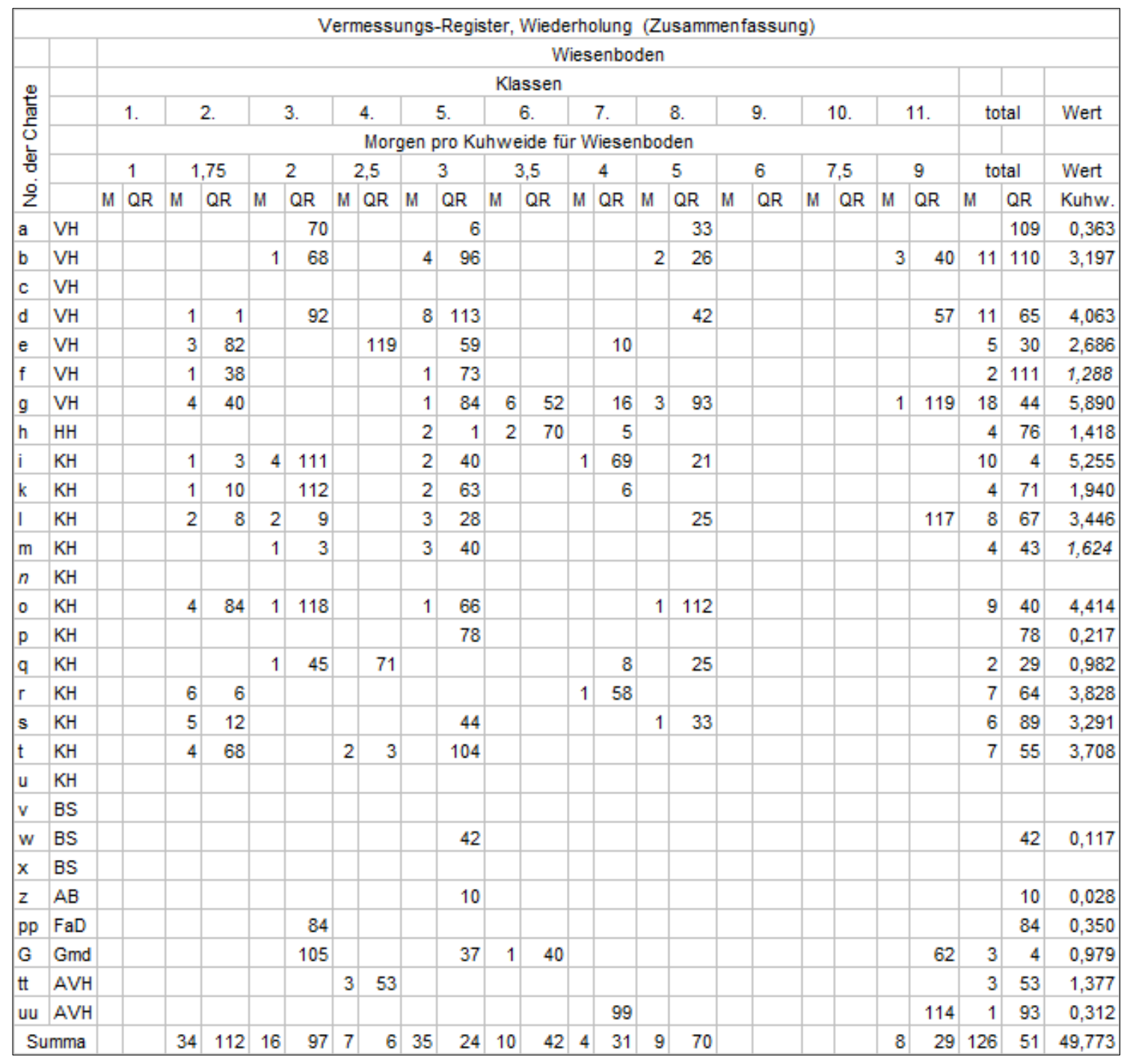

Abkürzungen in Spalte 2: s. Ackerland; tt Ausmärker, Vollmeier aus Höfer; uu: Ausmärker, Vollmeier aus Gockenholz 


\section{Der Angerboden}

\begin{tabular}{|c|c|c|c|c|c|c|c|c|c|c|c|c|c|c|c|c|c|c|c|c|c|c|c|c|c|c|c|}
\hline \multirow{6}{*}{ 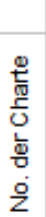 } & & \multicolumn{26}{|c|}{ Angerboden } \\
\hline & & \multicolumn{23}{|c|}{ Klassen } & \multirow{2}{*}{\multicolumn{2}{|c|}{ total }} & \multirow[b]{2}{*}{ Wert } \\
\hline & & \multicolumn{2}{|c|}{1.} & \multicolumn{2}{|c|}{2.} & \multicolumn{2}{|c|}{3.} & \multicolumn{2}{|c|}{4.} & \multicolumn{2}{|c|}{5.} & \multicolumn{2}{|c|}{6.} & 7. & & & 8. & 9 & & 10 & 0. & 11. & 12. & 13. & & & \\
\hline & & & & & & & & & & & lorge & en pr & ro Ku & hweid & de für & r An & gerbo & oden & & & & & & & & & \\
\hline & & & 2,5 & & 3 & & 3,5 & 4 & 4 & 4, & 5 & & 5 & 6 & & & 7 & 7, & 5 & 8 & 3 & 9 & 10,5 & 12 & tot & tal & Wert \\
\hline & & $M$ & QR & M & $Q R$ & $M$ & QR & M & $Q R$ & M & $Q R$ & M & $Q R$ & M & QR & M & QR & $M$ & $Q R$ & $M O$ & QR $M$ & QR $M$ & QR & $M Q R$ & $M$ & QR & Kuhw. \\
\hline a & VH & & & & & & 2 & & & & & & & 1 & 86 & & 11 & & & & & & & & 1 & 99 & 0,304 \\
\hline b & VH & & & & & & 2 & & & & & & & 2 & 119 & & 38 & & & & & 34 & & & 3 & 73 & 0,580 \\
\hline c & VH & & & & & & 1 & & & & & & & & 114 & & & & & & & & & & & 115 & 0,161 \\
\hline d & VH & & & & & & & & & & & & & 2 & 13 & & 6 & & & & & 37 & & & 2 & 56 & 0,392 \\
\hline $\mathrm{e}$ & VH & & & & & & 29 & & & & & & & 1 & 98 & & & & & & & & & & 2 & 7 & 0,372 \\
\hline$f$ & VH & & & & & & & & & & & & 103 & & 114 & & 12 & & & & & 28 & & & 2 & 17 & 0,370 \\
\hline$g$ & VH & & & & & & 65 & & & & 97 & & & 2 & 48 & & 60 & & & & & & & & 4 & 30 & 0,805 \\
\hline h & $\mathrm{HH}$ & & & & & & & & & & & & & 2 & 72 & & & & & & & 13 & & & 2 & 85 & 0,445 \\
\hline i & KH & & & & & & 1 & 2 & 90 & & & & 84 & 2 & 45 & & 109 & & 96 & & & & & & 7 & 65 & 1,462 \\
\hline k & KH & & & & & & & & & & & & & 2 & 98 & & & & & & & 58 & & & 3 & 36 & 0,523 \\
\hline 1 & KH & & & & & & 2 & & & & & & 67 & 2 & 35 & & 6 & & & & & 118 & & & 3 & 108 & 0,614 \\
\hline $\mathrm{m}$ & $\mathrm{KH}$ & & & & & & & & & & & & & 2 & 20 & & & & & & & & & & 2 & 20 & 0,361 \\
\hline$n$ & KH & & & & & & & & & & & & & 1 & 10 & & & & & & & & & & 1 & 10 & 0,181 \\
\hline 0 & $\mathrm{KH}$ & & & & & & 39 & & & & & & & 1 & 26 & & 23 & & & & & 6 & & & 1 & 94 & 0,329 \\
\hline$p$ & $\mathrm{KH}$ & & & & & & & & & & & & & 1 & 34 & & 25 & & & & & 8 & & & 1 & 67 & 0,251 \\
\hline$q$ & $\mathrm{KH}$ & & & & & & & & 54 & & & & & & 77 & & 11 & & & & & 4 & & 50 & 1 & 76 & 0,271 \\
\hline$r$ & KH & & & & & & & & & & & & & & 66 & & & & & & & 95 & & & 1 & 41 & 0,180 \\
\hline s & $\mathrm{KH}$ & & & & & & & & & & & & & 4 & 79 & 1 & 34 & & & & & 90 & & & 6 & 83 & 1,043 \\
\hline t & $\mathrm{KH}$ & & & & & & 2 & & & & & & 99 & 1 & 19 & & & & & & & & & & 2 & & 0,363 \\
\hline u & $\mathrm{KH}$ & & & & & & & & & & & & & 1 & 13 & & & & & & & & & & 1 & 13 & 0,185 \\
\hline $\mathrm{v}$ & BS & & & & & & & & & & & & & & 31 & & & & & & & & & & & 31 & 0,043 \\
\hline$w$ & BS & & & & & & & & & & & & & & 63 & & & & & & & & & & & 63 & 0,088 \\
\hline$x$ & BS & & & & & & & & & & & & & & 40 & & & & & & & & & & & 40 & 0,056 \\
\hline y & $A B$ & & & & & & & & & & & & & & 29 & & & & & & & & & & & 29 & 0,040 \\
\hline$z$ & $A B$ & & & & & & & & & & & & & & 51 & & & & & & & & & & & 51 & 0,071 \\
\hline aa & $A B$ & & & & & & & & & & & & & & 29 & & & & & & & & & & & 29 & 0,040 \\
\hline bb & AB & & & & & & & & & & & & & & 104 & & & & & & & & & & & 104 & 0,145 \\
\hline$c c$ & $A B$ & & & & & & & & & & & & & & & & & & & & & & & 10 & & 10 & 0,007 \\
\hline dd & $\mathrm{AbB}$ & & & & & & & & & & & & & & 28 & & & & & & & & & & & 28 & 0,039 \\
\hline ee & AbB & & & & & & & & & & & & & & 70 & & & & & & & & & & & 70 & 0,097 \\
\hline $\mathrm{ff}$ & AbB & & & & & & & & & & & & & & 56 & & & & & & & & & & & 56 & 0,078 \\
\hline$g g$ & $\mathrm{AbB}$ & & & & & & & & & & & & & & & & & & & & & 26 & & & & 26 & 0,024 \\
\hline hh & $\mathrm{AbB}$ & & & & & & & & & & & & & & & & & & & & & & 45 & & & 45 & 0,036 \\
\hline ii & $A b B$ & & & & & & & & & & & & & & & & & & & & & 18 & & & & 18 & 0,017 \\
\hline$\|$ & $\mathrm{AbB}$ & & & & & & & & & & & & & & & & & & & & & & 24 & & & 24 & 0,019 \\
\hline $\mathrm{mm}$ & $A b B$ & & & & & & & & & & & & & & 59 & & & & & & & & & & & 59 & 0,082 \\
\hline vv & $A b B$ & & & & & & & & & & & & & & & & & & & & & 34 & & & & 34 & 0,032 \\
\hline $\mathrm{pp}$ & $\mathrm{FaD}$ & & & & & & & & & & & & & 2 & 114 & & & & & & & & & & 2 & 114 & 0,492 \\
\hline S & Sch & & & & & & & & & & & & & & 50 & & & & & & & & & & & 50 & 0,069 \\
\hline G & Gmd & 8 & 60 & 27 & 55 & 21 & 75 & 22 & 73 & 19 & 95 & 44 & 34 & 55 & 11 & 14 & 45 & 9 & 49 & 16 & $68 \quad 58$ & 8 & & \begin{tabular}{l|l}
3 & 73
\end{tabular} & 286 & 46 & 57,076 \\
\hline & Imme & 8 & 60 & 27 & 55 & 22 & 98 & 25 & 97 & 20 & 72 & 47 & 27 & 100 & 1 & 18 & 20 & 10 & 25 & 16 & \begin{tabular}{l|l}
68 & 62 \\
\end{tabular} & 97 & 69 & \begin{tabular}{|l|l|}
4 & 13 \\
\end{tabular} & 349 & 102 & 67,743 \\
\hline
\end{tabular}

Abkürzungen in Spalte 2: s. Ackerland; 
Der Heidboden:

\begin{tabular}{|c|c|c|c|c|c|c|c|c|c|c|c|c|c|c|c|c|c|c|c|c|c|c|c|c|c|c|c|c|c|c|c|c|}
\hline \multicolumn{33}{|c|}{ Vermessungs-Register, Wiederholung (Zusammenfassung) } \\
\hline \multirow{6}{*}{ 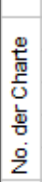 } & & \multicolumn{31}{|c|}{$\begin{array}{ll}\text { Heide } \\
\end{array}$} \\
\hline & & \multicolumn{28}{|c|}{ Klassen } & \multirow{2}{*}{\multicolumn{2}{|c|}{ total }} & \multirow[b]{2}{*}{ Wert } \\
\hline & & & 1. & & 2. & & 3. & 4. & & 5 & & 6. & 6. & 7. & & 8. & 9 & 9. & 10 & 0. & 11. & & 12 & & 13 & 3. & 14 & & 15. & & & \\
\hline & & \multicolumn{28}{|c|}{ Morgen pro Kuhweide für Heide } & & & \\
\hline & & \multicolumn{2}{|c|}{4} & \multicolumn{2}{|c|}{4,5} & \multicolumn{2}{|c|}{5} & \multicolumn{2}{|c|}{6} & \multicolumn{2}{|c|}{7} & \multicolumn{2}{|c|}{7,5} & 8 & \multicolumn{2}{|c|}{9} & 10 & 0,5 & 12 & 12 & 15 & & 18 & 8 & 21 & 1 & 25 & & 40 & tot & tal & Wert \\
\hline & & M & QR & M & QR & M & QR & M & QR I & M & QR 1 & $\mathrm{MOC}$ & QR $M$ & $\mathrm{QR}$ & M & QR & $M C$ & QR I & M & QR & $M$ & $Q R$ & M & QR & M & QR & M C & $\begin{array}{ll}\text { QR } & M\end{array}$ & $\mathrm{~A} \mathrm{QR}$ & M & QR & Kuhw. \\
\hline a & VH & & & & & & & & 51 & & & & & & & 52 & & & & 61 & 3 & 32 & & 40 & & 20 & & & & 5 & 16 & 0,406 \\
\hline b & VH & & & & & & & & & 4 & 26 & & & & & & & & & & & 56 & 1 & 38 & & & & & & 6 & & 0,707 \\
\hline c & VH & & & & & & & & & & 49 & & & & & & & & & & & 29 & & 64 & & & & & & 1 & 22 & 0,104 \\
\hline d & VH & & & & & & & & & & & & & & 3 & 96 & & & 1 & 38 & 1 & 25 & & 6 & & & & & & 6 & 45 & 0,616 \\
\hline e & VH & & & & & & & & & & & & & & 4 & 67 & & & & & & & & 3 & & & & & & 3 & 70 & 0,396 \\
\hline$f$ & VH & & & & & 2 & 110 & & & & & & & & & & & & & & & 54 & 2 & 108 & & & & & & 6 & 32 & 0,774 \\
\hline$g$ & VH & & & & & & & & & & & & & & & & & & & 46 & & & & & & 35 & & & & & 71 & 0,046 \\
\hline h & $\mathrm{HH}$ & & & & & & & & & & & & & & & & & & & & & 11 & 1 & 75 & & & & & & 1 & 86 & 0,096 \\
\hline i & $\mathrm{KH}$ & & & & & & & & & & & & & & & & & & & 81 & & 71 & & 3 & & & & & & 1 & 35 & 0,097 \\
\hline k & $\mathrm{KH}$ & & & & & & & & & & & & & & & & & & & & 4 & 42 & & 59 & 2 & 10 & & & & 6 & 111 & 0,417 \\
\hline I & $\mathrm{KH}$ & & & & & & & & 34 & & & & & & & & & & 3 & 6 & & 29 & & 87 & & & & & & 4 & 36 & 0,358 \\
\hline $\mathrm{m}$ & $\mathrm{KH}$ & & & & & & & 3 & 34 & & & & & & & & & & & & & & & & & & & & & 3 & 34 & 0,547 \\
\hline$n$ & $\mathrm{KH}$ & & & & & & & & & & & & & & & & & & & & & & & 69 & & & & & & & 69 & 0,032 \\
\hline 0 & $\mathrm{KH}$ & & & & & & & 5 & 80 & & & & & & & & & & & & 4 & 88 & & 12 & & & & & & 10 & 60 & 1,266 \\
\hline$p$ & $\mathrm{KH}$ & & & & & & & & & & & & & & & & & & & 42 & & 35 & & & & & & & & & 77 & 0,049 \\
\hline$q$ & $\mathrm{KH}$ & & & & & & & & & & & & & & & & & & & 10 & & 67 & 1 & 88 & & 83 & & & & 3 & 8 & 0,173 \\
\hline r & $\mathrm{KH}$ & & & & & & & & & & & & & & & & & & & & & & & & & & & & & & & \\
\hline s & $\mathrm{KH}$ & & & & & & & & & & & & & & & & & & & & & 32 & & 58 & & 88 & & & & 1 & 58 & 0,080 \\
\hline t & $\mathrm{KH}$ & & & & & & & & & & & & & & & 69 & & & & & & & & & & & & & & & 69 & 0,064 \\
\hline u & $\mathrm{KH}$ & & & & 63 & & & & & & & & & & & & & & & & & & & & & & & & & & 63 & 0,117 \\
\hline $\mathrm{pp}$ & $\mathrm{FaD}$ & & & & & & & 4 & 86 & & & 8 & 91 & & & & & & & & & & 14 & 44 & 3 & 60 & & & & 31 & 41 & 2,919 \\
\hline G & Gmd & 6 & 32 & 37 & 47 & 2 & 54 & 41 & 14 & 15 & 12 & 5 & \begin{tabular}{l|l}
50 & 4
\end{tabular} & 96 & 67 & 55 & 20 & 114 & 72 & 22 & 170 & 32 & 95 & 90 & 121 & 86 & 90 & 20 & 93 & 751 & 97 & 62,287 \\
\hline$r r$ & AVH & & & & & & & & & & 113 & & & & & & & & & & & & & & & & & & & & 113 & 0,135 \\
\hline uu & AVH & & & & & & & & & & 26 & & & & & & & & & & & & & & & & & & & & 26 & 0,031 \\
\hline & umme & 6 & 32 & 37 & 110 & 5 & 44 & 55 & 59 & 20 & 106 & 14 & \begin{tabular}{l|l}
21 & 4 \\
\end{tabular} & 496 & 75 & 99 & 20 & 114 & 77 & 56 & 187 & 3 & 121 & 4 & 129 & 22 & 90 & 20 & 93 & 848 & 39 & 71,717 \\
\hline & & & & & Quelle & e: C & lassi & ificati & ions- & - und & Vern & mess & sungs & -Regis & ster & $\operatorname{der} F$ & Feldm & mark L & Lach & hendo & lorf, $T$ & Teil B & 3 Verm & messu & ungs- & -Regis & ister; & Sig.:6 & & & & \\
\hline
\end{tabular}

Abkürzungen in Spalte 2: s. Ackerland; rr und uu: Ausmärker, Vollhöfner aus Gockenholz

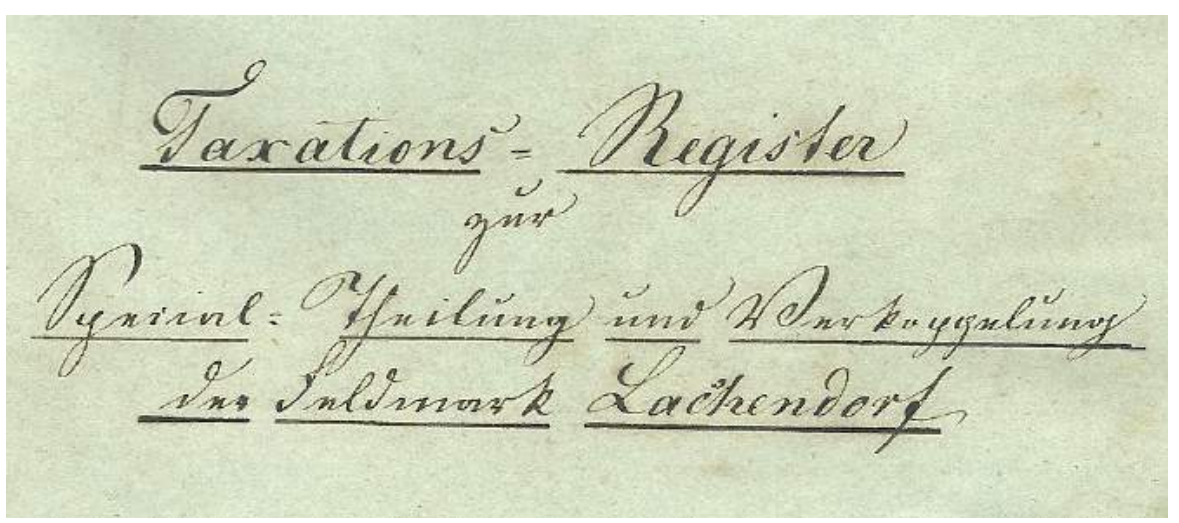

Im „Taxationsregister“"1 sind die Wertberechnungen verschiedener Berechtigungen festgehalten:

\footnotetext{
${ }^{1}$ Abb. oben: Deckblatt des Taxationsregisters, Samtgemeinde Lachendorf, Archiv Akten, Fach/Nr. 61/4
} 


\begin{tabular}{|c|c|c|c|c|c|c|c|c|c|c|c|c|c|c|c|c|c|}
\hline \multicolumn{18}{|c|}{ I: Wertberechnung des bisherigen Besitzstandes, } \\
\hline \multicolumn{18}{|c|}{ wie ihn die das Vermessungs-Register in der Wiederholung ergibt. } \\
\hline & (Seite 1) & & \multicolumn{3}{|c|}{ Ackerland } & \multicolumn{3}{|c|}{ Wiesenboden } & \multicolumn{3}{|c|}{ Angerboden } & \multicolumn{3}{|c|}{ Heidboden } & \multicolumn{3}{|c|}{ Total } \\
\hline & \multicolumn{2}{|c|}{ Name des Interessenten } & M & QR & Kuhw. & M & QR & Kuhw. & M & QR & Kuhw. & M & QR & Kuhw. & M & QR & Kuhw. \\
\hline$a$ & Vollhof & Lüßmann & 148 & 111 & 29,098 & & 109 & 0,363 & 1 & 99 & 0,304 & 5 & 16 & 0,406 & 156 & 95 & 30,171 \\
\hline b & & Meyer (Coors) & 101 & 43 & 19,796 & 11 & 110 & 3,197 & 3 & 73 & 0,580 & 6 & & 0,707 & 122 & 106 & 24,280 \\
\hline c & & Kohlmeyer & 124 & 64 & 22,489 & & & & & 115 & 0,161 & 1 & 22 & 0,104 & 126 & 81 & 22,754 \\
\hline d & & Thies (Bock) & 159 & 63 & 28,396 & 11 & 65 & 4,063 & 2 & 56 & 0,392 & 6 & 45 & 0,616 & 179 & 109 & 33,467 \\
\hline e & & Bergmann & 112 & 119 & 19,492 & 5 & 30 & 2,686 & 2 & 7 & 0,372 & 3 & 70 & 0,396 & 123 & 106 & 22,946 \\
\hline$f$ & & Drewsen Erben & 124 & 35 & 23,422 & 2 & 111 & 1,288 & 2 & 17 & 0,370 & 6 & 32 & 0,774 & 135 & 75 & 25,854 \\
\hline$g$ & & Schumeier & 123 & 64 & 23,062 & 18 & 44 & 5,890 & 4 & 30 & 0,805 & & 71 & 0,046 & 146 & 89 & 29,803 \\
\hline $\mathrm{h}$ & Halbhof & Schöndube & 96 & 33 & 20,565 & 4 & 76 & 1,418 & 2 & 85 & 0,445 & 1 & 86 & 0,096 & 105 & 40 & 22,524 \\
\hline$i$ & Köthner & Thies (Cammann) & 108 & 116 & 18,996 & 10 & 4 & 4,255 & 7 & 65 & 1,462 & 1 & 35 & 0,097 & 127 & 100 & 24,810 \\
\hline k & & Bunkenburg & 78 & 18 & 12,266 & 4 & 71 & 1,940 & 3 & 36 & 0,523 & 6 & 111 & 0,417 & 92 & 116 & 15,146 \\
\hline I & & Dralle & 102 & 30 & 15,188 & 8 & 67 & 3,446 & 3 & 108 & 0,614 & 4 & 36 & 0,358 & 119 & 1 & 19,606 \\
\hline $\mathrm{m}$ & & Dralle(Bolzmann) & 73 & 62 & 10,163 & 4 & 43 & 1,624 & 2 & 20 & 0,361 & 3 & 34 & 0,547 & 83 & 39 & 12,695 \\
\hline$n$ & & Bühring & 51 & 13 & 5,246 & & & & 1 & 10 & 0,181 & & 69 & 0,032 & 52 & 92 & 5,459 \\
\hline 0 & & Thies (Krüger) & 61 & 83 & 12,104 & 9 & 40 & 4,414 & 1 & 94 & 0,329 & 10 & 60 & 1,266 & 83 & 37 & 18,113 \\
\hline$p$ & & Schwägermann & 42 & 106 & 8,306 & & 78 & 0,217 & 1 & 67 & 0,251 & & 77 & 0,049 & 45 & 88 & 8,823 \\
\hline$q$ & & Thies (Theis) & 107 & 13 & 20,316 & 2 & 29 & 0,982 & 1 & 76 & 0,271 & 3 & 8 & 0,173 & 114 & 6 & 21,742 \\
\hline$r$ & & Thies (Graue) & 81 & 94 & 16,769 & 7 & 64 & 3,828 & 1 & 41 & 0,180 & & & & 90 & 79 & 20,777 \\
\hline s & & Koch & 97 & 92 & 17,646 & 6 & 89 & 3,291 & 6 & 83 & 1,043 & 1 & 58 & 0,080 & 112 & 82 & 22,060 \\
\hline $\mathrm{t}$ & & Hermanns & 65 & 71 & 9,818 & 7 & 55 & 3,708 & 2 & & 0,363 & & 69 & 0,064 & 75 & 75 & 13,953 \\
\hline u & & Misselhorn & 41 & 86 & 5,017 & & & & 1 & 13 & 0,185 & & 63 & 0,117 & 43 & 42 & 5,319 \\
\hline $\mathrm{v}$ & Brink- & Wulf & 10 & 29 & 2,769 & & & & & 31 & 0,043 & & & & 10 & 60 & 2,812 \\
\hline w & sitzer & Lüßmann & 17 & 91 & 4,558 & & 42 & 0,117 & & 63 & 0,088 & & & & 18 & 76 & 4,763 \\
\hline $\mathrm{x}$ & & Lillie & 3 & 117 & 0,821 & & & & & 40 & 0,056 & & & & 4 & 37 & 0,877 \\
\hline & & Betrag der Seite & 1935 & 113 & 346,240 & 117 & 47 & 46,727 & 55 & 29 & 9,379 & 64 & 2 & 6,345 & \begin{tabular}{|l|l|}
52172
\end{tabular} & 71 & 408,691 \\
\hline & (Seite 2) & & & Ackerla & and & & liesenb & boden & & Angerb & ooden & & Heidbo & oden & & Tota & \\
\hline & & & $M$ & QR & Kuhw. & $M$ & QR & Kuhw. & $M$ & QR & Kuhw. & $\mathrm{M}$ & QR & Kuhw. & $M$ & QR & Kuhw. \\
\hline$y$ & Anbauer & Thies & 6 & 19 & 1,778 & & & & & 29 & 0,040 & & & & 6 & 48 & 1,818 \\
\hline$z$ & & Meyer & 15 & 73 & 3,326 & & 10 & 0,028 & & 51 & 0,071 & & & & 16 & 14 & 3,425 \\
\hline aa & & Bergmann & & 30 & 0,071 & & & & & 29 & 0,040 & & & & & 59 & 0,111 \\
\hline $\mathrm{bb}$ & & Knoop & 26 & 116 & 5,886 & & & & & 104 & 0,145 & & & & 27 & 100 & 6,031 \\
\hline $\mathrm{cc}$ & & Herbold & 2 & 42 & 0,123 & & & & & 10 & 0,007 & & & & 2 & 52 & 0,130 \\
\hline dd & Abbauer & Meyer & 3 & 82 & 0,771 & & & & & 28 & 0,039 & & & & 3 & 110 & 0,810 \\
\hline ee & & Ramberg & 1 & 116 & 0,369 & & & & & 70 & 0,097 & & & & 2 & 66 & 0,466 \\
\hline ff & & Walter & 1 & 109 & 0,380 & & & & & 56 & 0,078 & & & & 2 & 45 & 0,458 \\
\hline gg & & Ahrens & 1 & 63 & 0,170 & & & & & 26 & 0,024 & & & & 1 & 89 & 0,194 \\
\hline hh & & Suderburg & 1 & 88 & 0,172 & & & & & 45 & 0,036 & & & & 2 & 13 & 0,208 \\
\hline ii & & Lillie & 2 & 25 & 0,155 & & & & & 18 & 0,017 & & & & 2 & 43 & 0,172 \\
\hline ॥ & & Thölke & 1 & 88 & 0,193 & & & & & 24 & 0,019 & & & & 1 & 112 & 0,212 \\
\hline $\mathrm{mm}$ & & Koch & & & & & & & & 59 & 0,082 & & & & & 59 & 0,082 \\
\hline $\mathrm{nn}$ & Hirte & Meyer & 5 & 108 & 1,639 & & & & & & & & & & 5 & 108 & 1,639 \\
\hline 00 & Häusling & Meyer Erben & 6 & 30 & 1,786 & & & & & & & & & & 6 & 30 & 1,786 \\
\hline w & Abbauer & Graue & 1 & 32 & 0,135 & & & & & 34 & 0,032 & & & & 1 & 66 & 0,167 \\
\hline $\mathrm{pp}$ & Papierfabrik & Georg Drewsen Erben & 20 & 119 & 5.948 & & 84 & 0,350 & 2 & 114 & 0,492 & 31 & 41 & 2,919 & 55 & 118 & 9.709 \\
\hline S & Schule & Lachendorf & & 118 & 0,270 & & & & & 50 & 0,069 & & & & 1 & 48 & 0,339 \\
\hline G & Gemeinde & Lachendorf & 8 & 16 & 1,706 & 3 & 4 & 0,979 & 286 & 46 & 57,076 & 751 & 97 & 62,297 & 71049 & 43 & 122,058 \\
\hline $\mathrm{K}$ & Kirche & Beedenbostel & 5 & 99 & 1,235 & & & & & & & & & & 5 & 99 & 1,235 \\
\hline rr & Vollhof & Veth, Gockenholz & 3 & 72 & 0,946 & & & & & & & & 113 & 0,135 & 4 & 65 & 1,081 \\
\hline ss & Vollhof & Schumeier, ebd. & 8 & 105 & 2,301 & & & & & & & & & & 8 & 105 & 2,301 \\
\hline $\mathrm{tt}$ & Vollhof & Thies, Höfer & & & & 3 & 53 & 1,377 & & & & & & & 3 & 59 & 1,377 \\
\hline uu & Vollhof & Misselhorn, Gockenholz & & & & 1 & 93 & 0,312 & & & & & 26 & 0,031 & 1 & 119 & 0,343 \\
\hline & Von & voriger Seite & 1935 & 113 & 346,240 & 117 & 47 & 46,727 & 55 & 29 & 9,379 & 64 & 2 & 6,345 & \begin{tabular}{|l|l|}
5 & 2172
\end{tabular} & 71 & 408,691 \\
\hline & & Total & 2063 & 103 & 375,600 & 126 & 51 & 49,773 & 349 & 102 & 67,743 & 848 & 39 & 71,727 & 73388 & 55 & 564,843 \\
\hline & rechne & erische Überprüfung & 2038 & 3103 & 375,663 & $115^{\prime}$ & 1371 & 49,773 & 333 & '2022' & 67,743 & '838' & 1239 & 71,727 & $7^{\prime} 3361$ & 3301 & 564,906 \\
\hline & & Umrechnung: $\mathrm{QR}$ in $\mathrm{Mrg}$. & & 25,9 & & & 11,4 & & & 16,9 & & & 10,3 & & & 27,5 & \\
\hline & & Summe Mrg und QR & 2063 & 103 & & 126 & 51 & & 349 & 102 & & 848 & 39 & & 3388 & 61 & \\
\hline & & Fehler & & & 0,063 & Kuhw & veiden & & & & & & & & & & 0,063 \\
\hline & & Fehler & & & & & & & & & & & & & & 6 & QR \\
\hline & & & & Es & andelt sic & & reile un & Additi & & & & & & & & & \\
\hline & & -Register zur S & & eilung & und Verko & & a & & & & & & & & & & \\
\hline & & Negroter 2 cur & & & & & & & & & & & & & & & \\
\hline
\end{tabular}




\begin{tabular}{|c|c|c|c|c|c|c|c|c|}
\hline \multicolumn{9}{|c|}{ II. Wertberechnung der Wiesenweide } \\
\hline \multirow{2}{*}{\multicolumn{3}{|c|}{$\begin{array}{l}\text { Der Wiesenweide } \\
\text { unterworfene Flächen }\end{array}$}} & & \multirow{3}{*}{\multicolumn{2}{|c|}{$\begin{array}{c}\text { Name des } \\
\text { Interessenten }\end{array}$}} & \multicolumn{3}{|c|}{ Größe der } \\
\hline & & & & & & \multicolumn{3}{|c|}{ Wiesenweide } \\
\hline \multirow[t]{2}{*}{ M } & \multirow{2}{*}{$\mathrm{QR}_{109}$} & \multicolumn{2}{|l|}{ Kuhw. } & & & M & QR & Kuhw. \\
\hline & & 0,363 & a & Vollmeier & Lüßmann & & 15 & 0,052 \\
\hline 11 & 110 & 3,197 & b & & Meyer (Coors) & 1 & 84 & 0,457 \\
\hline 11 & 65 & 4,063 & d & & Thies (Bock) & 1 & 78 & 0,580 \\
\hline 5 & 30 & 2,686 & e & & Bergmann & & 90 & 0,384 \\
\hline 1 & 13 & 0,369 & $\mathrm{f}$ & & Drewsen Erben & & 19 & 0,053 \\
\hline 18 & 44 & 5,890 & g & & Schumeier & 2 & 75 & 0,841 \\
\hline 4 & 76 & 1,418 & $\mathrm{~h}$ & Halbmeier & Schöndube & & 79 & 0,203 \\
\hline 10 & 4 & 4,255 & i & Köthner & Thies (Cammann) & 1 & 53 & 0,608 \\
\hline 4 & 71 & 1,940 & $\mathrm{k}$ & & Bunkenburg & & 79 & 0,277 \\
\hline 8 & 67 & 3,446 & I & & Dralle & 1 & 27 & 0,492 \\
\hline 4 & 43 & 1,624 & $\mathrm{~m}$ & & Dralle(Bolzmann) & & 75 & 0,232 \\
\hline 9 & 40 & 4,414 & 0 & & Thies (Krüger) & & 40 & 0,630 \\
\hline & 78 & 0,217 & $p$ & & Schwägermann & 1 & 11 & 0,031 \\
\hline 2 & 29 & 0,982 & $q$ & & Thies (Thies) & & 38 & 0,140 \\
\hline 1 & 14 & 0,638 & r & & Thies (Graue) & & 19 & 0,091 \\
\hline 3 & 97 & 1,615 & $\mathrm{~s}$ & & Koch & & 65 & 0,231 \\
\hline 7 & 55 & 3,708 & $\mathrm{t}$ & & Hermanns & 1 & 8 & 0,529 \\
\hline & 42 & 0,117 & w & Brinksitzer & Lüßmann & & 6 & 0,017 \\
\hline 3 & 53 & 1,377 & tt & Vollmeier & Thies, Höfer & & 59 & 0,197 \\
\hline 109 & 82 & 42,319 & & & Summa II & 15 & 80 & 6,045 \\
\hline
\end{tabular}

Anmerkung: Die Wiesenweide wird berechnet zu 1/7 der Fläche und des Werths der weidepflichtigen Wiesen.

\begin{tabular}{|c|c|c|c|c|c|}
\hline \multirow[t]{2}{*}{ III. } & \multirow{2}{*}{\multicolumn{5}{|c|}{$\begin{array}{c}\text { Wertberechnung der cultivierten Gemeinde-Grundstücke } \\
\text { und Holzbestandräume }\end{array}$}} \\
\hline & & & & & \\
\hline \multicolumn{2}{|r|}{ a. Ackerland } & & M & QR & Kuhw. \\
\hline 1 & Hirtengarten in den Kampgärten & & & 63 & 0,150 \\
\hline \multirow[t]{3}{*}{2} & Im Bunger & & 3 & 89 & 1,070 \\
\hline & & Summa a & 4 & 26 & 1,220 \\
\hline \multirow{2}{*}{\multicolumn{2}{|c|}{ b. Wiesenboden }} & & & & \\
\hline & & & & & \\
\hline 1 & Die Bullenwiese beim Dorfe & & 1 & 40 & \\
\hline 2 & desgl in der ... & & & 58 & \\
\hline \multirow[t]{2}{*}{3} & im Bunger & & 1 & 26 & \\
\hline & & Summa b & 3 & 4 & 0,979 \\
\hline \multirow{2}{*}{\multicolumn{2}{|c|}{ c. Angerboden }} & & & & \\
\hline & & & & & \\
\hline \multicolumn{2}{|r|}{ 1, cultivierte Gemeinde-Grundstücke } & & M & QR & Kuhw. \\
\hline & Hirtenhäuser an Meyers Hofe & & & 12 & 0,013 \\
\hline & desgl an Bock-Thies Hofe & & & 48 & 0,050 \\
\hline & & Summa 1 & & 60 & 0,063 \\
\hline
\end{tabular}




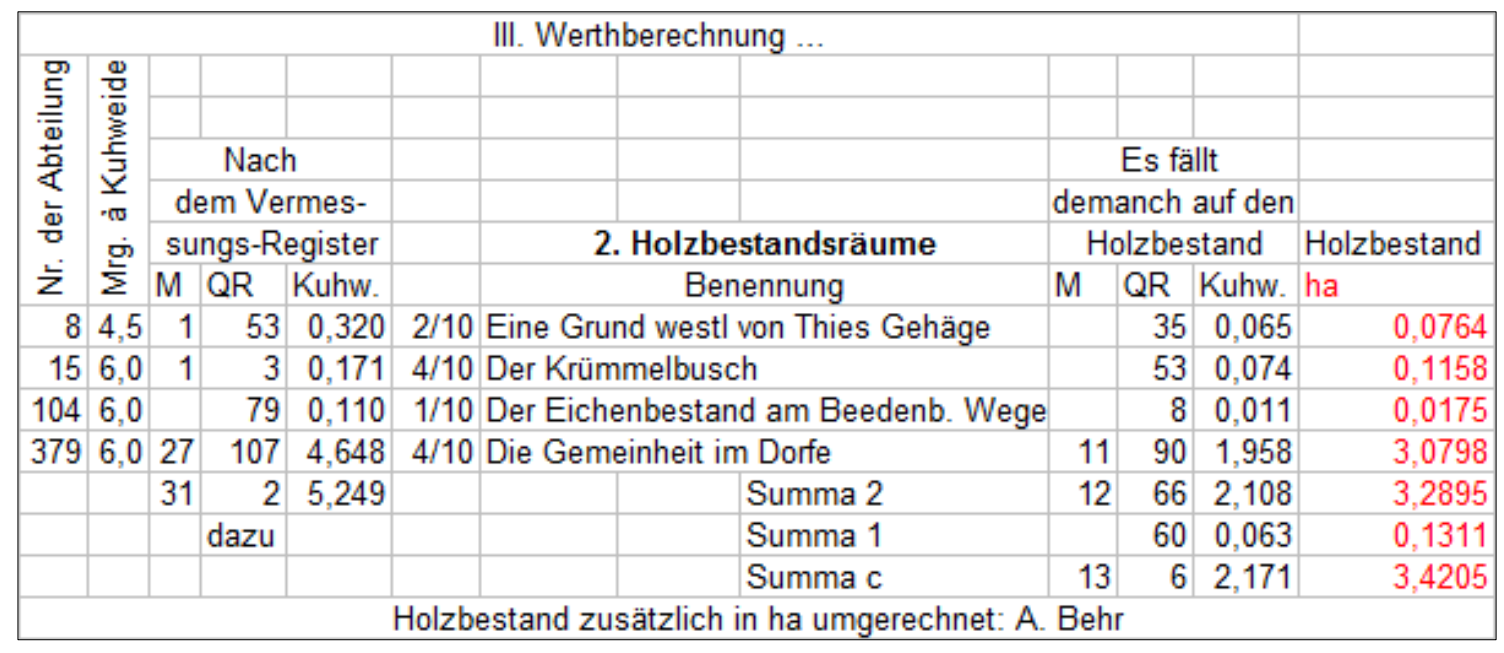

\begin{tabular}{|c|c|c|c|c|c|c|c|c|c|c|c|}
\hline \multicolumn{12}{|c|}{ III. Werthberechnung } \\
\hline \multicolumn{12}{|c|}{ d. Heidboden } \\
\hline \multirow{7}{*}{ 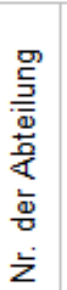 } & \multirow{7}{*}{ 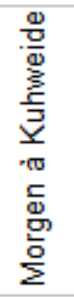 } & & & & \multirow{7}{*}{ 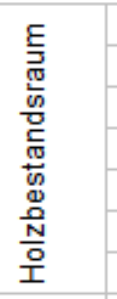 } & & & & & & \\
\hline & & & & & & & & & & & \\
\hline & & & & & & & & & & & \\
\hline & & & & & & & & & & & \\
\hline & & \multirow{2}{*}{\multicolumn{3}{|c|}{$\begin{array}{c}\text { Nach dem } \\
\text { Vermesungsregister }\end{array}$}} & & & & & \multirow{2}{*}{\multicolumn{3}{|c|}{$\begin{array}{c}\text { demnach auf den } \\
\text { Holzbestand }\end{array}$}} \\
\hline & & & & & & & & & & & \\
\hline & & M & QR & Kuhw. & & \multicolumn{3}{|c|}{ Benennung } & M & QR & Kuhw. \\
\hline 1 & 12 & 1 & 47 & 0,116 & $1 / 10$ & \multicolumn{3}{|c|}{ Heidstrich an Wolfs-Busche } & & 17 & 0,012 \\
\hline 2 & 9 & 1 & 8 & 0,119 & $1 / 5$ & \multicolumn{3}{|c|}{ Eine bessere Grund daselbst } & & 26 & 0,024 \\
\hline 3 & 7 & 3 & 32 & 0,467 & $1 / 10$ & \multicolumn{3}{|c|}{ Eine Grund am Kirchwege } & & 39 & 0,047 \\
\hline 5 & 6 & 2 & 46 & 0,397 & $1 / 10$ & \multicolumn{3}{|c|}{ Auf den Teichwiesen } & & 29 & 0,040 \\
\hline 6 & 12 & 7 & 38 & 0,610 & $1 / 100$ & \multicolumn{3}{|c|}{ Oestlich am Beedenbosteler Wege } & & 9 & 0,006 \\
\hline 10 & 7 & 3 & 1 & 0,430 & $1 / 10$ & \multicolumn{3}{|c|}{ Am Krümmelfelde } & & 36 & 0,043 \\
\hline 13 & 9 & 3 & 69 & 0,397 & $1 / 50$ & \multicolumn{3}{|c|}{ An der Beedenbosteler Grenze } & & 6 & 0,005 \\
\hline 89 & 12 & 1 & 77 & 0,137 & $2 / 5$ & \multicolumn{3}{|c|}{\begin{tabular}{|l|l} 
An den Moorgärten \\
\end{tabular}} & & 79 & 0,055 \\
\hline 91 & 21 & 7 & 16 & 0,340 & tot. & \multirow{2}{*}{\multicolumn{3}{|c|}{$\begin{array}{l}\text { Das Quälohsgehäge } \\
\text { Nördlich an Drewsen neuen Hofe }\end{array}$}} & 7 & 16 & 0,340 \\
\hline 92 & 21 & 11 & 98 & 0,563 & $1 / 50$ & & & & & 28 & 0,011 \\
\hline 105 & 9 & & 79 & 0,073 & $1 / 20$ & \multicolumn{4}{|c|}{ Zwischen d.Teichwiesen u.d. Beedenb. Wege } & 4 & 0,004 \\
\hline 110 & 21 & 1 & 30 & 0,059 & $1 / 25$ & \multicolumn{4}{|c|}{ Neben Drewsen neuen Hofe } & 6 & 0,002 \\
\hline 112 & 18 & 3 & 102 & 0,214 & $7 / 10$ & \multirow{2}{*}{\multicolumn{4}{|c|}{$\begin{array}{l}\text { Westlich Drewsen neuen Hofe } \\
\text { An der alten Lachte }\end{array}$}} & 83 & 0,150 \\
\hline 113 & 18 & 2 & 4 & 0,113 & $1 / 10$ & & & & & 24 & 0,011 \\
\hline 142 & 21 & 11 & 29 & 0,535 & $2 / 5$ & \multicolumn{3}{|c|}{ Der Rest der großen Masch } & 4 & 60 & 0,214 \\
\hline 172 & 18 & 2 & 100 & 0,157 & tot. & \multicolumn{3}{|c|}{ Der Gemeinde Ihlpohlsgehäge } & 2 & 100 & 0,157 \\
\hline 192 & 9 & 40 & 14 & 4,457 & tot. & \multicolumn{3}{|c|}{ Der schlechteste Teil der Gemeindeforst } & 40 & 14 & 4,457 \\
\hline 193 & 5 & 2 & 54 & 0,490 & tot. & \multicolumn{3}{|c|}{ Der bessere Teil derselben } & 2 & 54 & 0,490 \\
\hline 201 & 9 & 1 & 11 & 0,121 & tot. & \multicolumn{3}{|c|}{ Neben Bergmanns Spötzkampe } & 1 & 11 & 0,121 \\
\hline 243 & 21 & 45 & 81 & 2,175 & $1 / 30$ & \multicolumn{3}{|c|}{ Sandwehen am linken Lachteufer } & 1 & 63 & 0,073 \\
\hline 244 & 10,5 & 11 & 84 & 1,114 & $1 / 10$ & An Dralle & unckenburgs $\mathrm{g}$. & Höfen & 1 & 20 & 0,111 \\
\hline 309 & 18 & 7 & 78 & 0,425 & $1 / 10$ & An Drews & Gehäge & & & 92 & 0,043 \\
\hline 527 & 18 & 2 & 12 & 0,117 & tot. & Beim Ahı & ecker Wege & & 2 & 12 & 0,117 \\
\hline 528 & 15 & 2 & 14 & 0,141 & tot. & daselbst & & & 2 & 14 & 0,141 \\
\hline 578 & 9 & 5 & 12 & 0,567 & tot. & Der Gem & le Wolfsbusch & & 5 & 12 & 0,567 \\
\hline
\end{tabular}


IV. Werthberchnung der Weide-, Plaggen- und Bultenhiebs-Masse

Die sämmtlichen genossenschaftlichen Grundstücke betragen nach der unter I zugelegten Wertberechnung

\begin{tabular}{|c|c|c|c|c|c|c|c|c|c|c|c|c|c|c|}
\hline \multicolumn{3}{|c|}{ Ackerland } & \multicolumn{3}{|c|}{ Wiesenboden } & \multicolumn{3}{|c|}{ Angerboden } & \multicolumn{3}{|c|}{ Heidboden } & \multicolumn{3}{|c|}{ Total } \\
\hline M & QR & Kuhw. & $\mathrm{M}$ & $\mathrm{QR}$ & Kuhw. & $M$ & $\mathrm{QR}$ & Kuhw. & $M$ & QR & Kuhw. & $M$ & QR & Kuhw. \\
\hline 8 & 16 & 1,706 & 3 & 4 & 0,979 & 286 & 46 & 57,08 & 751 & 97 & 62,3 & 1049 & 43 & 122,1 \\
\hline & & & & & & & & & & & & & & \\
\hline \multicolumn{15}{|c|}{ Davon gehen ab: } \\
\hline \multirow{2}{*}{\multicolumn{15}{|c|}{ Die sub III berechneten cultivierten Gemeinde-Grundstücke und Holzbestandsräume mit }} \\
\hline & 26 & 1,22 & 3 & 4 & 0,979 & 13 & 6 & 2,171 & 76 & 14 & 7,241 & 96 & 50 & 11,61 \\
\hline & & & & & & & & & & & & & & \\
\hline \multirow{2}{*}{\multicolumn{15}{|c|}{$\begin{array}{l}\text { Es bleiben also dann an genossenschaftlicher Weide-, Plaggen- und Bultenhiebsmasse übrig } \\
\begin{array}{c|c|c|c|}\text { Ackerland } & \text { Wiesenboden } & \text { Angerboden } & \text { Heidboden }\end{array}\end{array}$}} \\
\hline & & & & & & & & & & & & & & \\
\hline $\mathrm{M}$ & QR & Kuhw. & $\mathrm{M}$ & QR & Kuhw. & M & QR & Kuhw. & M & QR & Kuhw. & $\mathrm{M}$ & QR & Kuhw. \\
\hline 3 & 110 & 0,486 & & & & 273 & 40 & 54,91 & 675 & 83 & 55,06 & 952 & 113 & 110,4 \\
\hline & & & & & & a & eq & ter, Sig & : $61 / 4$ & & & & & \\
\hline
\end{tabular}

Nachdem alle Bewertungen, Vermessungen und Wertermittlungen für alle Ansprüche und Interessen durchgeführt worden waren, konnte die Zuteilung aller Höfe festgelegt, in der Verkoppelungskarte verzeichnet und den Interessenten im Gelände angewiesen werden.

Schließlich wurde nach Zustimmung („Vollziehung“) aller Beteiligten („Interessenten“) der Rezess ${ }^{1}$ rechtskräftig. Damit war die Neuordnung der Feldmark und der Abfindung auf der Allerheide abgeschlossen.

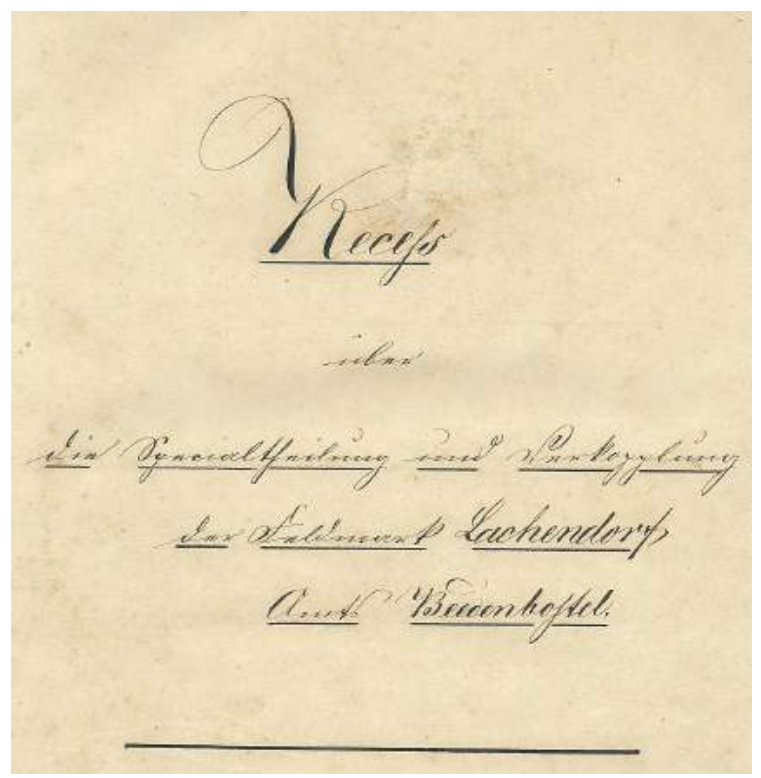

\footnotetext{
${ }^{1}$ Abb. oben: Deckblatt der Originalkopie für die Gemeinde Lachendorf, Samtgemeinde Lachendorf, Archiv Akten, Sig. 61/5
} 


\section{Rece $^{1}$}

über die Spezialtheilung und Verkoppelung

der Feldmark Lachendorf

nebst Vertheilungs-Register ${ }^{2}$

Amt Beedenbostel

Inhalt \& Verzeichnis zu dem Planrecesse über die Verkoppelung der Feldmark Lachendorf

$\S 1$. Allgemeine Bezeichnung der im Rezess behandelten Auseinandersetzung

S. 1

$\S 2$. Provocation

S. 1

$\S 3$. Bestimmung des Flächengehalts und Ertragswerts

S. 3

$\S 4$. Darstellung der bei der Auseinandersetzung zu berücksichtigenden Nutzungsrechte S. 4

$\S 5$. Auseinandersetzung der verschiedenen Berechtigungen und Nutzungsrechte

S. 7

§. Nachweisung der einem jeden Berechtigten zustehende Abfindung

S. 16

§. Örtliche Einteilung

S. 87

$\S 8$. Schließliche Bestimmungen

$\S 9$. Schluß

S. 87

99

\section{Receß}

über die Spezialtheilung und Verkoppelung der Feldmark Lachendorf

$\S 1$

Allgemeine Bezeichnung der im Rezeß behandelten Auseinandersetzungen.

Der nachstehende Rezeß behandelt die im Privatwege zu Stande gebrachte Spezialteilung und Verkoppelung der Feldmark Lachendorf, Amt Beedenbostel.

\footnotetext{
1 „Copia“: Kopie der Gemeinde Lachendorf, Samtgemeinde Lachendorf, Archiv Akten, Fach/Nr. 61/5: Rezeß über die Spezialteilung und Verkoppelung der Feldmark von Lachendorf 1858/59

Das Original ist im Text durchgehend handschriftlich in Sütterlin verfasst, nur die Eigennamen sind mit lateinischen Buchstaben geschrieben.

${ }^{2}$ Im Titel ist die Schreibweise des Originals übernommen worden, sonst wurde sie weitgehend der modernen Rechtschreibung angepasst. Bei heute wenig oder gar nicht gebräuchlichen Wörtern und bei Fremdwörtern wurde aber die Schreibweise des Originals beibehalten.
} 
$\S 2$

\section{Provocation}

Die sämtlichen mit Grundstücken angesessenen und zur Gemeinheit berechtigten Eingesessenen von Lachendorf, als

\begin{tabular}{|c|c|c|c|c|}
\hline \multirow{2}{*}{\begin{tabular}{|l|} 
Brand- \\
Cassen Nr.
\end{tabular}} & \multirow[b]{2}{*}{ Littera } & \multicolumn{2}{|r|}{ Namen der Interessenten } & \multirow[b]{2}{*}{ Gutsherrschaft } \\
\hline & & & & \\
\hline 1 & a & Vollmeier & Carsten Heinrich Lüßmann & Herrschaft \\
\hline 2 & b & & Joh. Heinrich Meyer (Coors) & dergl. \\
\hline 3 & c & & Heinrich Wilh. Kohlmeyer & dergl. \\
\hline 4 & d & & Johann Hr. Thies /Bock & dergl. \\
\hline 5 & e & & Heinrich Christoph Bergmann & dergl. \\
\hline 6 & f & & Georg Drewsen Erben & dergl. \\
\hline 7 & g & & Carsten Heinrich Schumeyer & dergl. \\
\hline 8 & $\mathrm{~h}$ & Halbmeier & Christoph Heinr. Schöndube & dergl. \\
\hline 11 & i & Köthner & Joh. Hr. Thies (Cammann) & dergl. \\
\hline 15 & k & & Joh. Hr. Bunkenburg & frei \\
\hline 16 & I & & Joh. Hr. Dralle (Dralle) & Herrschaft \\
\hline 17 & $\mathrm{~m}$ & & Carsten $\mathrm{Hr}$. Dralle (Bolzmann) & dergl. \\
\hline 14 & $\mathrm{n}$ & & Joh. Hr. Bühring & dergl. \\
\hline 18 & 0 & & Joh. Hr. Thies (Krüger) & dergl. \\
\hline 20 & p & & Carsten $\mathrm{Hr}$. Schwägermann & dergl. \\
\hline 19 & $q$ & & Joh. Hr. Thies (Thies) & dergl. \\
\hline 13 & $r$ & & Hr. Christoph Thies (Graue) & frei \\
\hline 9 & s & & Carsten Hr. Koch & Herrschaft \\
\hline 12 & $\mathrm{t}$ & & Jürgen $\mathrm{Hr}$. Hermanns & dergl. \\
\hline 10 & u & & Carsten $\mathrm{Hr}$. Misselhorn & frei \\
\hline 22 & $\mathrm{v}$ & Brinksitzer & Joh. Hr. Wulf & Herrschaft \\
\hline 24 & w & & Christoph Lüßmann & dergl. \\
\hline 23 & $\mathrm{x}$ & Brinksitzer & Joh. Hr. Lilie nunc Eggers & dergl. \\
\hline 34 & $\mathrm{y}$ & Anbauer & Christoph Thies & dergl. \\
\hline 21 & z & & Carsten Heinrich Christoph. Meyer & dergl. \\
\hline 28 & aa & & Carsten Heinrich Bergmann & dergl. \\
\hline 25 & bb & & Carsten Joh. Hr. Knoop & dergl. \\
\hline 35 & cc & & Carsten Wilhelm Herbold & frei \\
\hline 29 & dd & Abbauer & Georg Fr. Meyer & Herrschaft \\
\hline \multirow[t]{6}{*}{36} & ee & & Friedrich Ramberg & frei \\
\hline & $\mathrm{ff}$ & & Gottfried Walter & Herrschaft \\
\hline & gg & & Heinrich Ahrens & dergl. \\
\hline & $\mathrm{hh}$ & & Christoph Suderburg & dergl. \\
\hline & ii & & Hr. Lilie & dergl. \\
\hline & $\|$ & & Carsten Hr. Thölke & dergl. \\
\hline \multirow[t]{4}{*}{27} & $\mathrm{~mm}$ & & Heinrich Koch & dergl. \\
\hline & $\mathrm{nn}$ & Häusling & Joh. Hr. Meyer & \\
\hline & 00 & Häusling & Meyers Erben & \\
\hline & w & Abbauer & Joh. Hr. Graue & \\
\hline \multirow[t]{2}{*}{26} & $\mathrm{pp}$ & \multicolumn{2}{|c|}{ Georg Drewsen Erben Papierfabrik } & Herrschaft \\
\hline & $\mathrm{S}$ & & Die Schule & \\
\hline
\end{tabular}

haben die Spezialteilung ihrer Gemeinheiten mit Ausschluss der Forsten und die Verkoppelung ihrer privativen Grundstücke mit Ausnahme der Wiesen, Höfe, Gärten und in fremden Feldmarken belegenen Grundstücke unter gleichzeitiger Aufhebung der auf diesen der Verkoppelung unterzogenen Grundstücken ruhenden Stoppel- und Wiesenweide beschlossen und die Ausführung derselben dem Geometer Francke zu Beedenbostel übertragen. 
$\S 3$

Bestimmung des Flächengehalts und des Ertragswerts.

Zu dem Ende ist auf Antrag der Interessenten eine Vermessung du Bonitierung nicht allein aller in die Teilungs- und Verkoppelungsmasse geworfenen Grundbesitzungen, sondern auch derjenigen privativen Grundstücke, welche wegen ihres Einflusses auf die Auseinandersetzung der Interessenten unter sich oder auf den Teilungsmaßstab in Frage kommen könnten, vorgenommen mit Ausnahme jedoch der Allerheide-Abfindung, zu deren Auseinandersetzung die behuf Generalteilung der Allerheide aufgenommene Karte benutzt ist.

Die Vermessung ist von dem Geometer Francke geschehen, die Bonitierung unter Leitung des Geometers Francke von den erwählten Classificatoren und Taxatoren:

Hofbesitzer Benecke in Eschede,

Hofbesitzer Drangmeister in Beedenbostel

Köthner Thies (Cammann) und

Köthner Gastwirt Thies, letztere beiden aus Lachendorf.

Die Resultate der Vermessung und Bonitierung, welche im Ganzen betragen haben:

\begin{tabular}{|l|l|l|l|l|}
\hline & Morgen & Quadratruten & Kuhweiden & $\mathrm{ha}^{\mathrm{l}}$ \\
\hline Ackerland & 2076 & 88 & 376,441 & 544,332574 \\
\hline Wiesenboden & 131 & 23 & 50,825 & 34,386648 \\
\hline Angerboden & 428 & 64 & 79601 & 112,322872 \\
\hline Heidboden & 3776 & 67 & 204,293 & 989,873705 \\
\hline
\end{tabular}

Zu Allem 6413 Mg. 2 QRth = 711,160 Kuhw. sind den Interessenten ordnungsmäßig speziell vorgelegt und von ihnen als richtig anerkannt.

$\S 4$.

Darstellung der bei der Auseinandersetzung zu berücksichtigenden Nutzungsrechte.

Nach Angabe der Eingesessenen von Lachendorf kommen bei der Spezialteilung ihrer Gemeinheiten und der Verkoppelung der privaten Besitzungen folgende Berechtigungen und Nutzungsrechte in Frage:

1. Das Eigentumsrecht an den privaten Besitzungen, und zwar außer für die einheimischen Interessenten nach wegen der in der Lachendorfer Feldmark belegenen Grundstücke auch für nachfolgende auswärtige Besitzer, als

Die Kirche in Beedenbostel,

Vollmeier Veth in Gockenholz,

Vollmeier Schumeyer daselbst,

Vollmeier Thies in Höfer,

Vollmeier Misselhorn in Gockenholz,

das Kloster Wienhausen.

2. Die wechselseitige Stoppel- und Wiesenbehütung der einheimischen Interessenten untereinander, und auf den Grundstücken einiger auswärtiger Besitzer

3. Die Stoppelweideberechtigung der Gemeinde Gockenholz auf einem kleinen Teil der Lachendorfer Ackerländereien, die sog. Bulloh, und die Wiesenweideberechtigung derselben auf einigen der Verkoppelung nicht mit unterzogenen Lachendorfer Wiesen.

\footnotetext{
${ }^{1}$ Die Umrechnung erfolgte vom Verf. nach folgenden Größen: 1Morgen = 120 Quadratruten $=0,26211$ ha, 1 Quadratrute $=21,8425 \mathrm{~m}^{2}$, Calenberger Maß, Gesetz in Hannover seit 1836
} 
4. Die Wiesenweideberechtigung der Gemeinde Lachendorf auf einigen in der Feldmark Lachendorf belegenen Gockenholzer Wiesen.

5. Das Teilnehmungsrecht an den kultivierten Gemeinde-Grundstücken incl. der Gemeinde Baulichkeiten und den Holzbeständen.

6. Die Berechtigung zum Bultenhiebe.

7. Die Berechtigung zur Weide, zum Heid- und Plaggenhiebe.

8. Der Anspruch mehrerer einheimischer Interessenten auf eine Entschädigung für von ihren privaten Grundstücken vor der Verkoppelung zu den Wegen abgegebenen Flächen.

9. Die Benutzung der Wege im Allgemeinen.

In Folge einer vom Königlichen Amte Beedenbostel zur Ausmittelung unbekannter Berechtigten und ihrer Nutzungsechte erlassenen öffentlichen Ladung sind folgende Ansprüche angemeldet:

a) Von Seiten mehrerer einheimischer Interessenten der Anspruch für angekaufte Grundstücke abgefunden zu werden.

b) Von den Abbauern Lilie, Ramberg, Meyer und Thölke auf eine Abfindung als Anbauer.

c) Von dem Königlichen Amt Beedenbostel alle dem Domanio zugestandneen Rechte und Berechtigungen namentlich die Grundherrlichen Rechte.

Außerdem ist nachträglich

d) Von dem Vertreter der Königlichen Domänen-Cammer, Cammer-Commissair Dreyer zu Celle, die Verpflichtung der Gemeinde Lachendorf der herrschaftlichen Hausvoigtstelle zu Beedenbostel jedes dritte Jahr eine Feuereiche im Wert von $3 \mathrm{RT} 10 \mathrm{gGr}$ und $3 \mathrm{Pf}$ zu prästiren ${ }^{1}$ angemeldet.

$\S 5$

Auseinandersetzung der verschiedenen Berechtigungen und Nutzungsrechte

Was nun zunächst die im vorigen $\S$ sub $a-d$ aufgeführten Ansprüche betrifft, so wird darüber Folgendes bemerkt:

ad a: Der Anspruch mehrerer einheimischer Interessenten auf eine Abfindung für angekaufte Grundstücke ist durch Vergleich festgestellt und berücksichtigt.

ad b: Über den Anspruch der 4 Abbauern Lilie, Romberg, Meyer und Thölke in Lachendorf ist durch ein aus rechtskundigen Personen zusammengesetztes Schiedsgericht entschieden und derselbe als unbegründet verworfen.

ad c: Die Amtsseitig geschehene Anmeldung der Rechte und Berechtigungen des Domanii ist, da die grundherrlichen Rechte bereits abgefunden sind, ohne Erfolg geblieben.

ad d: Die Verpflichtung der Gemeinde Lachendorf der Herrschaftlichen Hausvoigtstelle zu Beedenbostel je ums dritte Jahr eine Feuereiche im Wert von 3 RT 10 gGr 3 Pf zu prästiren bleibt bestehen.

Was dann weiter die im vorigen $\S$ sub $1-9$ angegebenen Berechtigungen und Nutzungsrechte anlangt, so ist zu deren Auseinandersetzung Nachstehendes vergleichsweise verabredet und festgestellt:

1)

Die Interessenten erhalten für das Eigentumsrecht an den privativen Grundstücken ihre alten Besitzungen nach Abzug der Wiesenweide-Äquivalente und der zu den Wegen und sonstigen gemeinsamen Anlagen zu leistenden Beiträge ungekürzt zurück.

\footnotetext{
${ }^{1}$ prästiren: heute: prästieren - entrichten, leisten, für etwas haften (Duden)
} 
2)

Die Stoppelweide, welche die einheimischen Interessenten seither gegenseitig auf ihren Ackerländereien ausgeübt haben, wird compensanda ${ }^{1}$ aufgehoben.

3)

Das für die Stoppelweideberechtigung der Gemeinde Lachendorf auf fremden Grundstücken feststehende Äquivalent wird mit der alten Wegemasse im Ackerlande vereinigt, dann erhält die Gemeinde Gockenholz erhält für die Stoppelweideberechtigung auf Lachendorfer Grundstücken davon vergleichsweise - Mg $98 \mathrm{QR}=0,231$ Kuhweiden, und der Rest wird zur neuen Wegemasse verwandt.

4)

Die seither von der Gemeinde Gockenholz auf Lachendorfer und umgekehrt von der Gemeinde Lachendorf auf Gockenholzer Wiesen ausgeübte Weide wird ein gegen das andere aufgehoben, so dass künftig die Gemeinde Gockenholz oder ein einzelnes Mitglied derselben keine Lachendorfer Wiesen, und die Gemeinde Lachendorf oder ein einzelnes Mitglied derselben keine Gockenholzer Wiesen mehr behüten darf, die von den beiden Gemeinden Gockenholz und Lachendorf bisher gemeinschaftlich ausgeübte Weide auf den Alvernschen Holzbauwiesen wird von der Gemeinde Lachendorf aufgegeben und fällt der Gemeinde Gockenholz alleine zu.

5)

Das Äquivalent der Wiesenweide, welches die einheimischen Interessenten auf ihren eigenen Wiesen und auf der Wiese des Vollhöfners Thies aus Höfer ausgeübt haben, und welches zu 1/7 der Fläche und des Wertes der weidepflichtigen Wiesen abgenommen werden soll, wird unter die 20 Reihestellen, Litt. a - n incl. und die 3 Brinksitzer Litt. v, w \& $x$ nach Maßgabe der zur Verteilung der gemeinschaftlichen Weide, Heide- und Plaggenhiebsmasse vergleichsweise festgestellten Simpla verteilt.

6)

Die kultivierten Gemeindegrundstücke incl. der Gemeindebaulichkeiten und die Holzbestandräume, wovon die 20 Reihestellen $\mathrm{a}-\mathrm{n}$ incl. nachbarlich und die 3 Brinksitzer Litt v, w \& $\mathrm{x}$ zusammengenommen gleich einer Reihestelle partizipieren, sollen nicht verteilt, vielmehr eine gleiche Fläche unter möglichster Zusammenlegung der Holzbestände zur ferneren gemeinschaftlichen Benutzung wieder angelegt werden.

Zu dem Ende soll nun zwar jedem Teilnehmer der inm nach dem angegebenen Verhältnisse davon zukommende Teil abgerechnet, nach gleichem Verhältnis aber auch der $\square$ eitrag zu den neuen Flächen wieder gekürzt werden,

7)

Die Bultenhiebsmasse, wozu die seither zum Bultenhiebe benutzte Fläche vor den Allerwiesen gerechnet werden soll, wird unter die 7 Vollmeier, 1 Halbmeier, 12 Köthner, 3 Brinksitzern, 5 Anbauern, die Schule und die Drewsensche Papierfabrik also unter 30 Stellen nachbarlich verteilt.

8)

Von der gemeinschaftlichen Weide, Heide- und Plaggenhiebsmasse sollen die Interessenten zunächst für die von der Verkoppelung zu den Wegen abgetretenen Flächen und sonstigen Separat-Ansprüchen entschädigt werden und zwar:

1. Der Vollmeier Lüßmann für die wegen Befreiung seines Immengehäges von der Weide früher abgegebenen Fläche: Heidboden: - Mg $30 \mathrm{QR}=0,010$ Kuhw.

2. Der Vollhöfner Meyer (Coors)

a. für die zum Beedenbosteler Wege von den Langengärten abgegebene Fläche: Angerboden: - Mg $3 \mathrm{QR}=0,006$ Kuhw.

b. für die vom Hofe zum Wege nach den Allerwiesen abgegebenen Fläche: Angerboden: - Mg 56 QR = 0,075 Kuhw.

3. Der Vollmeier Thies (Bock) für den zur Dorfstraße abgegebenen Teil seines Hofes: Angerboden: - Mg $30 \mathrm{QR}=0,042$ Kuhweiden

\footnotetext{
${ }^{1}$ gegenseitig
} 
4. Der Vollmeier Bergmann für seine der Gemeinde irrtümlich zugerechneten Heidbalken im Schelpriethsfelde: Heidboden: - Mg 24 QR = 0,160 Kuhweiden.

5. Der Vollmeier Drewsen Erben für die von den Langengärten zum Beedenbosteler Wege früher abgegebenen Fläche: Angerboden: - Mg 2 QR = 0,004 Kuhweiden.

6. Der Halbhöfner Schöndube

a. für die zum Beedenbosteler Wege früher abgetretene Fläche : Angerboden: $\mathrm{Mg} 3 \mathrm{QR}=0,006$ Kuhweiden

b. für den der Gemeinde irrtümlich zugerechneten Heidbalken im Schelpriethsfelde: Heidboden: - Mg 60 QR = 0,067 Kuhweiden

c. für die am neuen Hofe zu wenig erhaltene Fläche: Heideboden: - Mg $57 \mathrm{QRt}=$ 0,019 Kuhweiden.

7. Der Köthner Thies (Cammann) für die von den Langengärten zum Beedenbosteler Wege früher abgetretene Fläche: Angerboden: $-\mathrm{Mg} 3 \mathrm{QR}=0,006$ Kuhweiden.

8. Der Köthner Bunkenburg für Übernahme des Fußweges von Ahnsbeck und Lachendorf nach dem sog. Ahnsbecker Stege, durch die inn daselbst zugeteilte, später an Schöndube abgetretene Koppel, wobei inm diese Entschädigung aber verblieben ist: Heideboden: - Mg $30 \mathrm{QR}=0,021$ Kuhweiden.

9. Der Köthner Schwägermann für die frühere Abgabe von den Langengärten zum Lachendorfer Wege: Angerboden: - Mg $3 \mathrm{QR}=0,006$ Kuhweiden.

10. Der Köthner Thies (Thies) für die vom neuen Hofe zu wenig erhaltene Fläche: Angerboden: - Mg $11 \mathrm{QR}=0,015$ Kuhweiden.

11. Der Köthner Bock für die in den Exerzierplatz gefallene Immenstelle Heideboden: Mg $61 \mathrm{QR}=0,020$ Kuhweiden.

12. Der Köthner Hermanns für die zum Lachendorfer Wege von den Langen Gärten früher abgegebene Fläche: Angerboden: - Mg 4 QR = 0,008 Kuhweiden.

13. Der Abbauer Kock für den zum Wege abgegebenen Hofraum und für die Nutzung seines Brunnens: Angerboden: - Mg $37 \mathrm{QR}=0,051$ Kuhweiden.

14. Der Abbauer Romberg für Übernahme der Befriedigung an Walters Hof und Garten: Angerboden: $30 \mathrm{QR}=0,067$ Kuhweiden.

15. Der Abbauer Suderburg für die beim Hause angenommenen Sandberge: Heidboden: - Mg 48 QR = 0,049 Kuhweiden.

16. Der Abbauer Thölke desgleichen Heidboden: - Mg 96 QR = 0,140 Kuhweiden.

Sodann sollen von der Weide, Heid- und Plaggenhiebsmasse erhalten:

17. Georg Drewsen Erben Papierfabrik für die nach dem Erbenzinsbriefe und der Erklärung der Teilungs-Interesssenten als zur Gemeinheit berechtigt zugestandenen: 10 12 Kühe, 4 Zugochsen und 16-20 Schweine nach Verhältnis des in der Steuerrolle für sämtliche Gemeinheitsberechtigte enthaltenen Viehbestandes zu den herausgeschätzten Kuhweiden zu berechnen mit 10,150 bonitierten Kuhweiden.

18. Die 7 Vollmeier, 1 Halbmeier, 12 Köthner und die 3 Brinksitzer erhalten jeder für das Haushaltsbedürfnis 2 bonitierte Kuhweiden.

19. Die 5 Anbauern erhalten für das Haushaltsbedürfnis jeder 1,5 bonitierte Kuhweiden.

20. Die Schulstelle erhält von der Weide-, Heide- und Plaggenhiebsmasse 3 bonitierte Kuhweiden.

21. Der Abbauer Schmidt Meyer erhält vergleichsweise 0,125 bonitierte Kuhweiden.

Der nach Abzug dieser sub 1 - 21 incl. verzeichneten Vorabnahmen von der Weide, Heidund Plaggenhiebsmasse bleibende Rest wird nach folgenden aus dem privativen Besitz an Ackerland und Wiesen, unter Berücksichtigung auch der der Verkoppelung nicht unterzogenen Ackerländereien und Wiesen, vergleichsweise festgestellten Simpla verteilt, und werden danach abgefunden: 


\begin{tabular}{|c|c|c|c|c|c|c|c|}
\hline \multirow{3}{*}{ 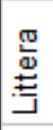 } & \multicolumn{2}{|r|}{ Abfindung } & \multirow{3}{*}{ Simpla } & \multirow{3}{*}{$\begin{array}{l}\frac{\pi}{\Phi} \\
\stackrel{ \pm}{ \pm}\end{array}$} & & \multirow[b]{2}{*}{ Name der } & \multirow[b]{2}{*}{ Simpla } \\
\hline & & Name der & & & & & \\
\hline & & Interessenten & & & & Interessenten & \\
\hline a & Vollhöfner & Lüßmann & 279 & u & & Carst. Hr. Misselhorn & 110 \\
\hline b & & Meyer & 251 & $\mathrm{v}$ & Brinksitzer & Joh. Hr. Wulf & 16 \\
\hline c & & Kohlmeyer & 245 & w & & Christ. Lüßmann & 17 \\
\hline d & & Thies /Bock & 320 & $\mathrm{x}$ & Brinksitzer & Joh. Hr. Lilie & 4 \\
\hline e & & Bergmann & 240 & $y$ & Anbauer & Chr. Thies & 12 \\
\hline$f$ & & Drewsen & 243 & $z$ & & Chr. Hr. Meyer & 13 \\
\hline g & & Schumeyer & 242 & aa & & Hr. Bergmann & 1 \\
\hline h & Halbhof & Schöndube & 204 & bb & & Joh. Hr. Knoop & 26 \\
\hline i & Köthner & Joh. Hr. Thies (Cammann) & 220 & $\mathrm{CC}$ & & Wilh. Herbold & 2 \\
\hline $\mathrm{k}$ & & Joh. Hr. Bunkenburg & 166 & dd & Abbauer & Freidrich Meyer & 5 \\
\hline I & & Joh. Hr. Dralle & 199 & ee & & Friedrich Ramberg & 2 \\
\hline $\mathrm{m}$ & & Chr. Hr. Dralle (Bolzmann) & 147 & ff & & Gottfried Walter & 4 \\
\hline $\mathrm{n}$ & & Joh. Hr. Bühring & 96 & gg & & Heinrich Ahrens & 1 \\
\hline 0 & & Joh. Hr. Thies (Krüger) & 140 & hh & & Christoph Suderburg & 0 \\
\hline$p$ & & Carst. Hr. Schwägermann & 103 & & & Hr. Lilie & 1 \\
\hline$q$ & & Joh. Hr. Thies (Theis) & 198 & II & & Carsten Hr. Thölke & 2 \\
\hline r & & Chr- Thies (Graue) & 183 & $\mathrm{nn}$ & Hirte & Joh. Hr. Meyer & 6 \\
\hline s & & Carst. Hr. Koch & 195 & 00 & Häusling & Meyer Erben & 6 \\
\hline $\mathrm{t}$ & & Jürgen $\mathrm{Hr}$. Hermanns & 141 & & $\mathrm{ZuA}$ & Allem für Simpla & 4040 \\
\hline
\end{tabular}

9)

Zu den zu den neuen Wegen, den gemeinschaftlichen Sand- und Lehmgruben, den Tränken, Abzugsgräben pp. Verwandten Flächen tragen die 7 Vollmeier, der Halbmeier, die 12 Köthner, die 3 Brinksitzer und die Drewsensche Papierfabrik nach dem Kuhweidenwert ihrer Gesamtabfindung bei, dagegen sind die An- und Abbauern, die Häuslinge, die Schule und die auswärtigen Grundbesitzer von jeglichem Beitrage dazu frei.

10)

Zugleichen tragen die Vollmeier, der Halbmeier, die Köthner, die Brinksitzer und die Drewsensche Papierfabrik unter gleichfaltiger Ausschließung der An- und Abbauer, der Häuslinge, der Schule und der auswärtigen Grundbesitzer, zu den verkauften Flächen nach Maßgabe der bei Abfindung aus der Weide, Heid- und Plaggenhiebsmasse für sie festegestellten Simpla bei; wobei für die Drewsensche Papierfabrik die Anzahl der Simpla nach ihrer Abfindung zu 183 Simpla berechnet wird, und nehmen nach diesem Verhältnisse teil an den aufgekommenen Geldern.

$\S 6$

Nachweisung der einem jeden Berechtigten gebührenden Abfindungen.

Nachdem nun im Vorstehenden die Grundzüge des Teilungs-Maßstabes dargelegt sind, so werden nachstehend unter Angabe der nach den vorgenommenen Schätzungen und abgeschlossenen Vergleichen auf die verschiedenen zur Abfindung gelangenden Nutzungsarten und Berechtigungen fallenden Äquivalente und die davon jedem Interessenten gebührenden Abfindungen nachgewiesen, und sollen demnach erhalten:

1.

Für den privativen Besitz nach Abzug der Wiesenweide, wie das umstehende Verzeichnis ergibt:

2.

Die Stoppelweide-Äquivalente der Gemeinde Lachendorf auf fremden Grundstücken: 
Ackerland: - Mg $46 \mathrm{QR}=0,080$ Kuhw.

Die alten Wege im Ackerlande betragen:

Ackerland: $3 \mathrm{Mg} 110 \mathrm{QR}=0,486$ Kuhw.

Zu Allem: $\quad 4 \mathrm{Mg} 36 \mathrm{QR}=0,566 \mathrm{Kuhw}$.

Davon erhält die Gemeinde Gockenholz für Stoppelweide-Berechtigung auf Lachendorfer Gebiet:

- $\mathrm{Mg} 98 \mathrm{QR}=0,335 \mathrm{Kuhw}$.

Der Rest: $\quad 3 \mathrm{Mg} 58 \mathrm{QR}=0,335 \mathrm{Kuhw}$. wird zur neuen Wegemasse verwandt.

3.

Das Wiesenweide-Äquivalent

Wiesenboden: 15 Morgen $97 \mathrm{QR}=6,093 \mathrm{Kuhw}$.

wird unter die Vollmeier, den Halbmeier, die Köthner und Brinksitzer nach Maßgabe der für sie zur Abfindung aus der Weide, Heid- und Plaggenhiebsmasse festgestellten Simpla verteilt.

Der umstehende Nachweis liefert das Sollhaben davon für jeden einzelnen Interessenten.

\begin{tabular}{|c|c|c|c|c|c|c|c|c|c|c|c|}
\hline \multicolumn{12}{|c|}{ Verteilung des Wiesenweide-Äquivalentes } \\
\hline \multirow{4}{*}{ 愛 } & & \multirow[b]{4}{*}{ Namen der Interessenten } & \multirow{3}{*}{\multicolumn{3}{|c|}{\begin{tabular}{|c|} 
Von der Wiesen- \\
weide erhalten: \\
Wiesenboden \\
\end{tabular}}} & \multirow{4}{*}{. } & & \multirow[b]{4}{*}{ Namen der Interessenten } & \multirow{3}{*}{\multicolumn{3}{|c|}{\begin{tabular}{|l|} 
Von der Wiesen \\
weide erhalten: \\
Wiesenboden
\end{tabular}}} \\
\hline & & & & & & & & & & & \\
\hline & & & & & & & & & & & \\
\hline & & & $\mathrm{Mg}$ & QRt & Kuhw. & & & & $\mathrm{Mg}$ & QRt & Kuhw. \\
\hline a & VM & Lüßmann & 1 & 14 & 0,429 & $\mathrm{n}$ & Kö & Joh. Hr. Bühring & & 46 & 0,148 \\
\hline b & VM & Meyer & 1 & & 0,387 & 0 & Kö & Joh. Hr. Thies (Krüger) & & 67 & 0,216 \\
\hline c & VM & Kohlmeyer & & 118 & 0,377 & $\mathrm{p}$ & Kö & Carst. Hr. Schwägermann & & 49 & 0,159 \\
\hline d & VM & Thies /Bock & 1 & 33 & 0,492 & $q$ & Kö & Joh. Hr. Thies (Theis) & & 95 & 0,305 \\
\hline e & VM & Bergmann & & 115 & 0,370 & & Kö & Chr- Thies (Graue) & & 88 & 0,282 \\
\hline$f$ & VM & Drewsen & & 117 & 0,374 & s & Kö & Carst. Hr. Koch & & 93 & 0,300 \\
\hline$g$ & VM & Schumeyer & & 116 & 0,373 & & Kö & Jürgen $\mathrm{Hr}$. Hermanns & & 68 & 0,217 \\
\hline h & $\mathrm{HM}$ & Schöndube & & 98 & 0,314 & $\mathrm{u}$ & Kö & Carst. Hr. Misselhorn & & 53 & 0,169 \\
\hline i & Kö & Joh. Hr. Thies (Cammann) & & 105 & 0,338 & & BS & Joh. Hr. Wulf & & 7 & 0,024 \\
\hline $\mathrm{k}$ & Kö & Joh. Hr. Bunkenburg & & 80 & 0,255 & w & BS & Christ. Lüßmann & & 8 & 0,025 \\
\hline I & Kö & Joh. Hr. Dralle & & 95 & 0,306 & $\mathrm{x}$ & BS & Joh. Hr. Lilie & & 2 & 0,007 \\
\hline $\mathrm{m}$ & Kö & Chr. Hr. Dralle & & 70 & 0,226 & & & Summa & 15 & 97 & 6,093 \\
\hline
\end{tabular}

4.

Die kultivierten Gemeinde Grundstücke incl. der Gemeindebaulichkeiten und den Holzbestandsräumen bestehen nach dem angeschlossenen TaxationsRegister pag. 6 aus:

ferner

nach dem angeschlossenen Auszuge aus dem

\begin{tabular}{|l|l|l|r|}
\hline & Mg & QRt & Kuhweiden \\
\hline Ackerland & 4 & 26 & 1,22 \\
\hline Wiesenboden & 3 & 4 & 0,979 \\
\hline Angerboden & 13 & 6 & 2,171 \\
\hline Heidboden & 76 & 14 & 7,241 \\
\hline & 96 & 50 & 11,611 \\
\hline
\end{tabular}

Taxations-Register von der Allerheide aus:

1. den privativen Holzbestandsräumen der Gemeinde Lachendorf in der Allerheide, wobei die die Bruchruten über halb zu voll, gerechnet dagegen unter halb weggelassen sind: $\quad$ Heideboden $6 \mathrm{Mg} .68 \mathrm{QR}=0,789$ Kuhw.

2. aus dem mit der Gemeinde Ahnsbeck gemeinschaftlich genutzten Holzbeständen, welche für Lachendorf für zur Hälfte gerechnet werden:

Heideboden $3 \mathrm{Mg} 77 \mathrm{QR}=0,398$ Kuhw. und

3. aus dem nach dem Taxations-Register von der Allerheide nicht als Holzbestand angenommenen Gehäge hinter dem Mühlenkampe

Heidboden $9 \mathrm{Mg} 75 \mathrm{QR}=0$, $385 \mathrm{Kuhw}$. 
überhaupt also aus:

\begin{tabular}{|l|l|l|l|}
\hline & Mg & QRt & Kuhweiden \\
\hline Ackerland & 4 & 26 & 1,22 \\
\hline Wiesenboden & 3 & 4 & 0,979 \\
\hline Angerboden & 13 & 6 & 2,171 \\
\hline Heidboden & 95 & 114 & 8,813 \\
\hline Total & 116 & 30 & 13,183 \\
\hline
\end{tabular}

Der davon jedem Interessenten nach dem angegebenen Verhältnisse zu berechnende Anteil wird in der Total umstehenden Tabelle nachgewiesen.

\section{Berechnung des}

Anteils jedes einzelnen Interessenten an den Holzbestandsräumen, den kultivierten Gemeinde-Grundstücken und Gemeinde Baulichkeiten ${ }^{1}$

\begin{tabular}{|c|c|c|c|c|c|c|c|c|c|c|c|c|c|c|c|c|c|}
\hline \multirow{3}{*}{ 莺 } & & \multirow{3}{*}{$\begin{array}{l}\text { Namen der } \\
\text { Interessenten }\end{array}$} & \multirow{2}{*}{\multicolumn{3}{|c|}{ Ackerland }} & \multirow{2}{*}{\multicolumn{3}{|c|}{ Wiesenboden }} & \multirow{2}{*}{\multicolumn{3}{|c|}{ Angerboden }} & \multirow{2}{*}{\multicolumn{3}{|c|}{ Heidboden }} & \multirow{2}{*}{\multicolumn{3}{|c|}{$\begin{array}{c}\text { überhaupt brauch- } \\
\text { barer Boden }\end{array}$}} \\
\hline & & & & & & & & & & & & & & & & & \\
\hline & & & M & QR & Kuhw. & M & QR & Kuhw. & $\mathrm{M}$ & QR & Kuhw. & M & QR & Kuhw. & $\mathrm{M}$ & QR & Kuhw. \\
\hline a & Vollmeier & Lüßmann & & 24 & 0,058 & & 18 & 0,047 & & 74 & 0,103 & 4 & 68 & 0,419 & 5 & 64 & 0,627 \\
\hline b & Vollmeier & Meyer & & 25 & 0,058 & & 17 & 0,047 & & 74 & 0,103 & 4 & 68 & 0,419 & 5 & 64 & 0,627 \\
\hline c & Vollmeier & Kohlmeyer & & 24 & 0,059 & & 18 & 0,046 & & 74 & 0,103 & 4 & 68 & 0,420 & 5 & 64 & 0,628 \\
\hline d & Vollmeier & Thies /Bock & & 25 & 0,058 & & 17 & 0,047 & & 74 & 0,103 & 4 & 68 & 0,420 & 5 & 64 & 0,628 \\
\hline e & Vollmeier & Bergmann & & 24 & 0,059 & & 18 & 0,046 & & 74 & 0,103 & 4 & 68 & 0,420 & 5 & 64 & 0,628 \\
\hline$f$ & Vollmeier & Drewsen & & 24 & 0,058 & & 18 & 0,047 & & 74 & 0,103 & 4 & 68 & 0,420 & 5 & 64 & 0,628 \\
\hline g & Vollmeier & Schumeyer & & 24 & 0,058 & & 18 & 0,047 & & 74 & 0,103 & 4 & 68 & 0,420 & 5 & 64 & 0,628 \\
\hline h & Halbmeier & Schöndube & & 24 & 0,058 & & 18 & 0,047 & & 74 & 0,103 & 4 & 68 & 0,420 & 5 & 64 & 0,628 \\
\hline i & Köthner & Joh. Hr. Thies (Cammann) & & 24 & 0,058 & & 18 & 0,047 & & 74 & 0,103 & 4 & 68 & 0,420 & 5 & 64 & 0,628 \\
\hline k & Köthner & Joh. Hr. Bunkenburg & & 24 & 0,058 & & 17 & 0,047 & & 75 & 0,103 & 4 & 68 & 0,420 & 5 & 64 & 0,628 \\
\hline I & Köthner & Joh. Hr. Dralle & & 24 & 0,058 & & 17 & 0,047 & & 75 & 0,103 & 4 & 68 & 0,420 & 5 & 64 & 0,628 \\
\hline $\mathrm{m}$ & Köthner & Chr. Hr. Dralle & & 24 & 0,058 & & 17 & 0,047 & & 75 & 0,103 & 4 & 68 & 0,420 & 5 & 64 &, 628 \\
\hline$n$ & Köthner & Joh. Hr. Bühring & & 24 & 0,058 & & 17 & 0,047 & & 75 & 0,103 & 4 & 68 & 0,420 & 5 & 64 & 0,628 \\
\hline 0 & Köthner & Joh. Hr. Thies (Krüger) & & 24 & 0,058 & & 17 & 0,047 & & 75 & 0,104 & 4 & 68 & 0,419 & 5 & 64 & 0,628 \\
\hline$p$ & Köthner & Carst. Hr. Schwägermann & & 24 & 0,058 & & 17 & 0,047 & & 75 & 0,104 & 4 & 68 & 0,419 & 5 & 64 & 0,628 \\
\hline$q$ & Köthner & Joh. Hr. Thies (Theis) & & 24 & 0,058 & & 17 & 0,046 & & 75 & 0,104 & 4 & 69 & 0,420 & 5 & 65 & 0,628 \\
\hline$r$ & Köthner & Chr- Thies (Graue) & & 24 & 0,058 & & 17 & 0,046 & & 75 & 0,104 & 4 & 69 & 0,420 & 5 & 65 & 0,628 \\
\hline s & Köthner & Carst. Hr. Koch & & 24 & 0,058 & & 17 & 0,046 & & 75 & 0,104 & 4 & 69 & 0,419 & 5 & 65 & 0,627 \\
\hline $\mathrm{t}$ & Köthner & Jürgen $\mathrm{Hr}$. Hermanns & & 24 & 0,058 & & 17 & 0,046 & & 75 & 0,104 & 4 & 69 & 0,419 & 5 & 65 & 0,627 \\
\hline $\mathrm{u}$ & Köthner & Carst. Hr. Misselhorn & & 24 & 0,058 & & 17 & 0,046 & & 75 & 0,104 & 4 & 69 & 0,419 & 5 & 65 & 0,627 \\
\hline v & Brinksitzer & Joh. Hr. Wulf & & & & & & & & & & & & & & & \\
\hline w & Brinksitzer & Christ. Lüßmann & & 24 & 0,058 & & 17 & 0,046 & & 75 & 0,104 & 4 & 69 & 0,420 & 5 & 65 & 0,628 \\
\hline$x$ & Brinksitzer & Joh. Hr. Lilie & & & & & & & & & & & & & & & \\
\hline & & Summa & 4 & 26 & 1,22 & 3 & 4 & 0,979 & 13 & 6 & 2,171 & 95 & 114 & 8,813 & 116 & 30 & 13,183 \\
\hline
\end{tabular}

\footnotetext{
${ }^{1}$ Anmerkung: Bei Tabellen, die sich im Original über mehrere Seiten erstrecken, sind in der Übertragung die Zwischensummen der einzelnen Seiten des Originals nicht mit übertragen worden.
} 
5.

Die seither zum Bultenhiebe benutzte Fläche vor den Allerwiesen beträgt:

Heidboden: $173 \mathrm{Mg} 81 \mathrm{QR}=12,120$ Kuhw.

Dieselbe wird unter die Vollhöfner, den Halbhöfner, die Köthner, Brinksitzer, die Anbauern, die Schule und Drewsen Erben Papierfabrik nachbarlich verteilt.

Die jedem Teilnehmer davon gebührende Abfindung wird umstehend nachgewiesen.

Von der Bultenhiebsfläche sollen erhalten.

\begin{tabular}{|c|c|c|c|c|c|c|c|c|c|c|c|}
\hline \multicolumn{12}{|c|}{ Abfindung aus der Bultenhiebsmasse } \\
\hline \multirow{3}{*}{$\stackrel{\frac{\pi}{\omega}}{ \pm}$} & & \multirow{3}{*}{$\begin{array}{l}\text { Bultenhiebsmasse } \\
\text { Namen der Interessenten }\end{array}$} & & & \multirow{3}{*}{$\stackrel{\frac{\pi}{\Phi}}{ \pm}$} & & \multirow{3}{*}{$\begin{array}{l}\text { Bultenhiebsmasse } \\
\text { Namen der Interessenten }\end{array}$} & & & \\
\hline & & & \multicolumn{3}{|c|}{ Heidboden } & & & & \multicolumn{3}{|c|}{ Heidboden } \\
\hline & & & M & QR & Kuhw. & & & & M & QR & Kuhw. \\
\hline a & VM & Lüßmann & 5 & 95 & 0,404 & $q$ & Kö & Joh. Hr. Thies (Theis) & 5 & 95 & 0,404 \\
\hline b & VM & Meyer & 5 & 95 & 0,404 & r & Kö & Chr- Thies (Graue) & 5 & 95 & 0,404 \\
\hline c & VM & Kohlmeyer & 5 & 95 & 0,404 & s & Kö & Carst. Hr. Koch & 5 & 95 & 0,404 \\
\hline d & VM & Thies /Bock & 5 & 95 & 0,404 & $\mathrm{t}$ & Kö & Jürgen $\mathrm{Hr}$. Hermanns & 5 & 95 & 0,404 \\
\hline e & VM & Bergmann & 5 & 95 & 0,404 & $\mathrm{u}$ & Kö & Carst. Hr. Misselhorn & 5 & 95 & 0,404 \\
\hline$f$ & VM & Drewsen & 5 & 95 & 0,404 & v & BS & Joh. Hr. Wulf & 5 & 95 & 0,404 \\
\hline$g$ & VM & Schumeyer & 5 & 95 & 0,404 & w & BS & Christ. Lüßmann & 5 & 94 & 0,404 \\
\hline h & $\mathrm{HM}$ & Schöndube & 5 & 95 & 0,404 & $\mathrm{x}$ & BS & Joh. Hr. Lillie & 5 & 94 & 0,404 \\
\hline $\mathrm{i}$ & Kö & Joh. Hr. Thies (Cammann) & 5 & 95 & 0,404 & $\mathrm{y}$ & AnB & Chr. Thies & 5 & 94 & 0,404 \\
\hline $\mathrm{k}$ & Kö & Joh. Hr. Bunkenburg & 5 & 95 & 0,404 & $z$ & AnB & Chr. Hr. Meyer & 5 & 94 & 0,404 \\
\hline I & Kö & Joh. Hr. Dralle & 5 & 95 & 0,404 & aa & AnB & Hr. Bergmann & 5 & 94 & 0,404 \\
\hline $\mathrm{m}$ & Kö & Chr. Hr. Dralle & 5 & 95 & 0,404 & bb & AnB & Joh. Hr. Knoop & 5 & 94 & 0,404 \\
\hline $\mathrm{n}$ & Kö & Joh. Hr. Bühring & 5 & 95 & 0,404 & $\mathrm{CC}$ & AnB & Wilh. Herbold & 5 & 94 & 0,404 \\
\hline 0 & Kö & Joh. Hr. Thies (Krüger) & 5 & 95 & 0,404 & S & Die $S$ & Schule in Lachendorf & 5 & 94 & 0,404 \\
\hline$p$ & Kö & Carst. Hr. Schwägermann & 5 & 95 & 0,404 & $\mathrm{pp}$ & G. D & rewsen Erben Papierfabrik & 5 & 94 & 0,404 \\
\hline & & & & & & & & Summa & 173 & 81 & 12,120 \\
\hline
\end{tabular}




\section{Zusammenstellung des privativen Besitzes der Interessenten nach Abzug der Wiesenweide-Äquivalente.}

\begin{tabular}{|c|c|c|c|c|c|c|c|c|c|c|c|c|c|c|c|c|c|}
\hline \multirow{4}{*}{ 党 } & \multirow{4}{*}{\multicolumn{2}{|c|}{ Namen }} & \multirow{3}{*}{\multicolumn{3}{|c|}{ Ackerland }} & \multirow{3}{*}{\multicolumn{3}{|c|}{ Wiesenboden }} & \multirow{3}{*}{\multicolumn{3}{|c|}{ Angerboden }} & \multirow{3}{*}{\multicolumn{3}{|c|}{ Heidboden }} & \\
\hline & & & & & & & & & & & & & & & & & \\
\hline & & & & & & & & & & & & & & & $\begin{array}{c}\text { Überhaupt } \\
\text { brauchbarer } \\
\text { Boden }\end{array}$ & & \\
\hline & & & $M$ & QR & Kuhw. & \multirow[t]{2}{*}{$M$} & \multirow{2}{*}{\begin{tabular}{c|} 
QR \\
94
\end{tabular}} & \multirow{2}{*}{$\begin{array}{r}\text { Kuhw. } \\
0,311\end{array}$} & \multirow{2}{*}{$\begin{array}{r}M \\
1\end{array}$} & \multirow{2}{*}{$\begin{array}{r}\text { QR } \\
99\end{array}$} & Kuhw. & M & QR & Kuhw. & $\mathrm{M}$ & QR & Kuhw. \\
\hline$a$ & VM & Lüßmann & 148 & 111 & 29,098 & & & & & & 0,304 & 5 & 16 & 0,406 & 156 & 80 & 30,119 \\
\hline b & VM & Meyer & 101 & 43 & 19,796 & 10 & 26 & 2,740 & 3 & 73 & 0,580 & 6 & & 0,707 & 121 & 22 & 23,823 \\
\hline c & VM & Kohlmeyer & 124 & 64 & 22,489 & & & & & 115 & 0,161 & 1 & 77 & 0,137 & 127 & 16 & 22,787 \\
\hline d & VM - & Thies /Bock & 159 & 63 & 28,396 & 10 & 90 & 3,768 & 2 & 56 & 0,392 & 6 & 84 & 0,629 & 179 & 53 & 33,185 \\
\hline e & VM & Bergmann & 112 & 119 & 19,429 & 4 & 60 & 2,302 & 2 & 7 & 0,372 & 3 & 70 & 0,396 & 123 & 16 & 22,499 \\
\hline$f$ & VM & Drewsen & 125 & 35 & 23,505 & 2 & 92 & 1,235 & 2 & 17 & 0,370 & 6 & 32 & 0,774 & 136 & 56 & 25,884 \\
\hline$g$ & VM & Schumeyer & 123 & 64 & 23,062 & 15 & 89 & 5,049 & 4 & 30 & 0,805 & 1 & 72 & 0,086 & 145 & 15 & 29,002 \\
\hline $\mathrm{h}$ & $\mathrm{HM}$ & Schöndube & 96 & 33 & 20,565 & 3 & 117 & 1,215 & 2 & 85 & 0,445 & 2 & 43 & 0,122 & 103 & 38 & 22,347 \\
\hline i & Kö & Joh. Hr. Thies (Cammann) & 108 & 116 & 18,996 & 8 & 71 & 3,647 & 7 & 65 & 1,462 & 1 & 108 & 0,121 & 127 & & 24,226 \\
\hline k & Kö & Joh. Hr. Bunkenburg & 78 & 18 & 12,266 & 3 & 112 & 1,663 & 3 & 36 & 0,523 & 6 & 111 & 0,417 & 92 & 37 & 14,869 \\
\hline I & Kö & Joh. Hr. Dralle & 102 & 30 & 15,188 & 10 & 8 & 3,501 & 3 & 108 & 0,614 & 5 & 85 & 0,414 & 121 & 111 & 19,717 \\
\hline $\mathrm{m}$ & Kö & Chr. Hr. Dralle & 73 & 62 & 10,163 & 3 & 88 & 1,392 & 2 & 20 & 0,361 & 4 & 54 & 0,594 & 83 & 104 & 12,510 \\
\hline$n$ & Kö & Joh. Hr. Bühring & 51 & 13 & 5,246 & & & & 1 & 10 & 0,181 & & 69 & 0,0 & 62 & 92 & 5,459 \\
\hline 0 & Kö & Joh. Hr. Thies (Krüger) & 61 & 83 & 12,104 & 8 & & 3,784 & 1 & 94 & 0,329 & 10 & 106 & 1,281 & 82 & 43 & 17,498 \\
\hline$p$ & Kö & Carst. Hr. Schwägermann & 42 & 106 & 8,306 & & 67 & 0,186 & 1 & 67 & 0,251 & & 77 & 0,049 & 45 & 77 & 8,792 \\
\hline$q$ & Kö & Joh. Hr. Thies (Theis) & 107 & 13 & 20,316 & 1 & 111 & 0,842 & 1 & 76 & 0,271 & 3 & 59 & 0,190 & 114 & 19 & 21,619 \\
\hline$r$ & Kö & Chr- Thies (Graue) & 81 & 94 & 16,769 & 8 & 49 & 3,909 & 1 & 41 & 0,180 & & & & 91 & 64 & 858 \\
\hline s & Kö & Carst. Hr. Koch & 97 & 92 & 17,646 & 6 & 24 & 3,060 & 6 & 83 & 1,043 & 1 & 58 & 0,080 & 112 & 17 & 829 \\
\hline $\mathrm{t}$ & Kö & Jürgen $\mathrm{Hr}$. Hermanns & 65 & 71 & 9,818 & 6 & 47 & 3,179 & 2 & & 0,363 & & 69 & 0,064 & 74 & 67 & \\
\hline u & Kö & Carst. Hr. Misselhorn & 53 & 25 & 5,695 & & & & 1 & 13 & 0,185 & 7 & 48 & 0,461 & 61 & 86 & 341 \\
\hline v & BS & Joh. Hr. Wulf & 10 & 29 & 2,769 & & & & & 31 & 0,043 & & & & 10 & 60 & 2,812 \\
\hline w & BS & Christ. Lüßmann & 17 & 91 & 4,558 & & 36 & 0,100 & & 63 & 0,088 & & & & 18 & 70 & 4,746 \\
\hline $\mathrm{x}$ & BS & Joh. Hr. Lilie & 3 & 117 & 0,821 & & & & & 40 & 0,056 & & & & 4 & 37 & 0,877 \\
\hline$y$ & AnB & Chr. Thies & 6 & 19 & 1,778 & & & & & 29 & 0,040 & & & & 6 & 48 & 1,818 \\
\hline$z$ & AnB & Chr. Hr. Meyer & 15 & 73 & 3,326 & & 10 & 0,028 & & 51 & 0,071 & 1 & 80 & 0,129 & 17 & 94 & 554 \\
\hline aa & AnB & $\mathrm{Hr}$. Bergmann & & 30 & 0,071 & & & & & 29 & 0,040 & & & & & 59 & 0,111 \\
\hline $\mathrm{bb}$ & AnB. & Joh. Hr. Knoop & 26 & 116 & 5,886 & & & & & 104 & 0,145 & & & & 27 & 100 & 6,031 \\
\hline $\mathrm{CC}$ & AnB & Wilh. Herbold & 2 & 42 & 0,123 & & & & & 10 & 0,007 & & & & 2 & 52 & 130 \\
\hline dd & $\mathrm{AbB}$ & Freidrich Meyer & 3 & 82 & 0,771 & & & & & 28 & 0,039 & & & & 3 & 110 & 810 \\
\hline ee & $\mathrm{AbB}$ & Friedrich Ramberg & 1 & 116 & 0,369 & & & & & 70 & 0,097 & & & & 2 & 66 & 466 \\
\hline ff & $\mathrm{AbB}$ & Gottfried Walter & 1 & 109 & 0,380 & & & & & 56 & 0,078 & & & & 2 & 45 & 0,458 \\
\hline gg & $\mathrm{AbB}$ & Heinrich Ahrens & 1 & 63 & 0,170 & & & & & 26 & 0,024 & & & & 1 & 89 & 194 \\
\hline hh & $\mathrm{AbB}$ & Christoph Suderburg & 1 & 88 & 0,172 & & & & & 45 & 0,036 & & & & 2 & 13 & 0,208 \\
\hline ii & $\mathrm{AbB}$ & Hr. Lilie & 2 & 25 & 0,155 & & & & & 18 & 0,017 & & & & 2 & 43 & 0,172 \\
\hline$\|$ & $\mathrm{AbB}$ & Carsten Hr. Thölke & 1 & 88 & 0,193 & & & & & 24 & 0,019 & & & & 1 & 112 & 0,212 \\
\hline $\mathrm{mm}$ & $\mathrm{AbB}$ & Heinrich Koch & & & & & & & & 59 & 0,082 & & & & & 59 & 0,082 \\
\hline $\mathrm{nn}$ & $\mathrm{Hi}$ & Joh. Hr. Meyer & 5 & 108 & 1,639 & & & & & & & & & & 5 & 108 & 1,639 \\
\hline 00 & Hs & Meyer Erben & 6 & 30 & 1,786 & & & & & & & & & & 6 & 30 & 1,786 \\
\hline vv & $\mathrm{AbB}$. & Joh. Hr. Graue & 1 & 32 & 0,135 & & & & & 34 & 0,032 & & & & 1 & 66 & 0,167 \\
\hline $\mathrm{pp}$ & G. Dre & rewsen Erben Papierfabrik & 20 & 119 & 5,948 & & 84 & 0,350 & 2 & 114 & 0,492 & 31 & 41 & 2,919 & 55 & 118 & 9,709 \\
\hline S & Die S & Schule in Lachendorf & & 118 & 0,270 & & & & & 50 & 0,069 & & & & 1 & 48 & 0,339 \\
\hline K & Die Ki & Kirche in Beedenbostel & 5 & 99 & 1,235 & & & & & & & & & & 5 & 99 & 1,235 \\
\hline $\mathrm{rr}$ & VM & Veth in Gockenholz & 3 & 72 & 0,946 & & & & & & & & 113 & 0,135 & 4 & 65 & 1,081 \\
\hline ss & VM & Schumeier in Gockenholz & 8 & 105 & 2,301 & & & & & & & & & & 8 & 105 & 2,301 \\
\hline tt & VM - & Thies in Höfer & & & & 2 & 114 & 1,180 & & & & & & & 2 & 114 & 1,180 \\
\hline uu & VM & Misselhorn in Gockenholz & & & & 1 & 93 & 0,312 & & & & & 26 & 0,031 & 1 & 119 & 0,343 \\
\hline & Kloste & ter Wienhausen & & & & & & & & & & & 3 & 0,001 & & 3 & 0,001 \\
\hline & & Summa & 2068 & 26 & 374,655 & 112 & 42 & 43,753 & 63 & 56 & 10,667 & 111 & 61 & 10,175 & 2164 & 113 & 439,250 \\
\hline
\end{tabular}


6.

Die gesamten Gemeinheiten betragen nach den Taxations-Registern

1. Angerboden

a. in den Gemeinheiten beim Dorfe:

$273 \mathrm{M} 40 \mathrm{QR}=54,905$ Kuhw.

b. in der Allerheide:

Sa. Angerboden:

2. Heideboden

$77 \mathrm{M} 93 \mathrm{QR}=11,683 \mathrm{Kuhw}$.

$351 \mathrm{M} 13 \mathrm{QR}=66,588 \mathrm{Kuhw}$.

a. in den Gemeinheiten beim Dorfe: $\quad 675 \mathrm{M} 83 \mathrm{QR}=55,046$ Kuhw.

b. in der Allerheide incl. des Moorbodens $2753 \mathrm{M} 88 \mathrm{QR}=125,467$ Kuhw.

In Allem:

Sa. Heidboden

3429 M 51 QR $=180,512$ Kuhw.

Dazu kömmt nun zunächst der Anteil der Gemeinde Lachendorf an dem an Königliches Kriegsministerium verkauften Exerzierplatz in der Allerheide mit

Heidboden: $160 \mathrm{Mg} 1 \mathrm{QR}=6,400$ Kuhw.

Sodann kommen hinzu wegen irrtümlicher Berechnung einzelner Abteilungen und verschie-

dener Aufmessung der Allerheidegrenze:

Angerboden: - M $109 \mathrm{QR}==, 175$ Kuhw.

Heidboden: - M 61 QR =0,020 Kuhw.

Es geht ab wegen irrtümlicher der 309 Abteilung:

Heidboden:1 Mg $-\mathrm{QR}=0,056$ Kuhw.

und ergibt sich dann ein Totalbestand von:

Angerboden: $352 \mathrm{M} 2 \mathrm{QR}=66,763 \mathrm{Kuhw}$.

Heidboden: 3588 M 112 QR $=186,577$ Kuhw.

Zu Allem: 3940 M 114 QR $=253,640$ Kuhw.

Hiervon gehen nun wieder vorab die nach pos. 4 als Holzbestand zu rechnenden Teile der Allerheide, und die nach pos. 5 als Bultenhieb verteilte Fläche mit überhaupt:

Heideboden $193 \mathrm{Mg} 61 \mathrm{QR} ; 13,692$ Kuhw.

und bleiben dann übrig:

Angerboden: $352 \mathrm{M} 2 \mathrm{QR}$; 66, $763 \mathrm{Kuhw}$.

Heideboden: 3395 M 51 QR; 173,185 Kuhw.

Zu Allem 3747 M 53 QR; 239,948 Kuhw.

Von dieser Summe gehen nun zunächst wieder ab die in $\S 5-5$ sub pos $1-16$ incl. aufgeführten Separat-Abfindungen und Entschädigungen mit

Angerboden $1 \mathrm{M} 62 \mathrm{QR}=0,289 \mathrm{Kuhw}$.

Heideboden: 4 M $46 \mathrm{QR}=0,486$ Kuhw.

Zu Allem: $5 \mathrm{M} 108 \mathrm{QR}=0,775 \mathrm{Kuhw}$.

und bleibt dann ein Bestand von:

Angerboden: $350 \mathrm{M} 60 \mathrm{QR}=66,474 \mathrm{Kuhw}$.

Heidboden: 3391 M $5 \mathrm{QR}=172,699$ Kuhw.

Zu allem: $\quad 3741 \mathrm{M} 65 \mathrm{QR}=239,173 \mathrm{Kuhw}$.

Von dieser Masse sind nun wieder vorabzunehmen das Haushaltsbedürfnis und die vergleichsweise festgestellten Abfindungen der Interessenten, und gehen damit ab:

1. Die Abfindung der Drewsenschen Papierfabrik $=10,150$ bonitierte Kuhweiden

2. Das Haushaltsbedürfnis

a. für 7 Vollmeier Litt.a $-g$ à 2 bon. Kuhweiden $=14,000$ Kuhw.

b. für 1 Halbmeier: $\mathrm{h}$-------- 2,000 Kuhw.

c. für 12 Köthner: $1-u$---------------------24,000 Kuhw.

d. für 3 Brinksitzer: v, w, x ----------------------- 6,000 Kuhw. 
e. für 5 Anbauern: y - cc à 11/2 -------------------7,000 Kuhw.

f. Die Abfindung des Schmidt Meyer vergleichsweise festgestellt zu $1 / 5$ 0,125 Kuhw.

g. Die Abfindung der Schule vergleichsweise festgestellt zu 3 bonitierten Kuhweiden ---------- 3,000 Kuhw.

Zu Allem 66,775 Kuhw.

Nach Verhältnis des Werts zur Fläche der oben gebliebenen Teilungsmasse kommen auf 1 bonitierte Kuhweide $=15 \mathrm{M} 80 \mathrm{QR}$, wovon auf Angerboden: $1 \mathrm{M} 60 \mathrm{QR}=0,270$ Kuhw. fallen. Heideboden: $14 \mathrm{M} 20 \mathrm{QR}=0,730 \mathrm{Kuhw}$.

Es gehen mithin für das Haushaltsbedürfnis und die vergleichsweise festgestellten Abfindungen mit überhaupt $=66,775$ bonitierte Kuhweiden $a b$ :

Angerboden: $100 \mathrm{M} 20 \mathrm{QR}=18,029 \mathrm{Kuhw}$.

Heideboden: $\quad 945$ M 117 QR $=48,746$ Kuhw.

Zu Allem: $\quad 1046 \mathrm{M} 17 \mathrm{QR}=66,775 \mathrm{Kuhw}$.

Die umstehende Tabelle weist die den Interessenten für das Haushaltsbedürfnis und die vergleichsweise festgestellten Abfindungen gebührenden Flächen nach. 


\section{Nachweisung der jedem Interessenten für das Haushaltsbedürfnis und die vergleichsweise festgestell- ten Abfindungen gebührenden Flächen.}

\begin{tabular}{|c|c|c|c|c|c|c|c|c|c|c|c|}
\hline \multirow{3}{*}{$\stackrel{\frac{\pi}{\omega}}{\frac{\omega}{ \pm}}$} & \multirow{3}{*}{\multicolumn{2}{|c|}{\begin{tabular}{|c|c|} 
& \\
Namen der Interessenten
\end{tabular}}} & \multirow{3}{*}{\multicolumn{3}{|c|}{\begin{tabular}{l}
\multicolumn{2}{c}{ Angerboden } \\
M QR Kuhw.
\end{tabular}}} & \multirow{2}{*}{\multicolumn{3}{|c|}{ Heidboden }} & \multirow{2}{*}{\multicolumn{3}{|c|}{ In Allem }} \\
\hline & & & & & & & & & & & \\
\hline & & & & & & M & QR & Kuhw. & \multicolumn{3}{|c|}{ QR Kuhw. } \\
\hline 愛 & Vollmeier & Lüßmann & 3 & & 0,540 & 28 & 40 & 1,460 & 31 & 40 & 2,000 \\
\hline b & Vollmeier & Meyer & 3 & & 0,540 & 28 & 40 & 1,460 & 31 & 40 & 2,000 \\
\hline c & \multirow{2}{*}{$\begin{array}{l}\text { Vollmeier } \\
\text { Vollmeier }\end{array}$} & Kohlmeyer & 3 & & 0,540 & 28 & 40 & 1,460 & 31 & 40 & 2,000 \\
\hline d & & Thies /Bock & 3 & & 0,540 & 28 & 40 & 1,460 & 31 & 40 & 2,000 \\
\hline e & Vollmeier & Bergmann & 3 & & 0,540 & 28 & 40 & 1,460 & 31 & 40 & 2,000 \\
\hline$f$ & Vollmeier & Drewsen & 3 & & 0,540 & 28 & 40 & 1,460 & 31 & 40 & 2,000 \\
\hline$g$ & \multirow{2}{*}{$\begin{array}{l}\text { Vollmeier } \\
\text { Halbmeier }\end{array}$} & Schumeyer & 3 & & 0,540 & 28 & 40 & 1,460 & 31 & 40 & 2,000 \\
\hline h & & Schöndube & 3 & & 0,540 & 28 & 40 & 1,460 & 31 & 40 & 2,000 \\
\hline i & Köthner & Joh. Hr. Thies (Cammann) & 3 & & 0,540 & 28 & 40 & 1,460 & 31 & 40 & 2,000 \\
\hline $\mathrm{k}$ & Köthner & Joh. Hr. Bunkenburg & 3 & & 0,540 & 28 & 40 & 1,460 & 31 & 40 & 2,000 \\
\hline I & Köthner & Joh. Hr. Dralle & 3 & & 0,540 & 28 & 40 & 1,460 & 31 & 40 & 2,000 \\
\hline $\mathrm{m}$ & Köthner & Chr. Hr. Dralle & 3 & & 0,540 & 28 & 40 & 1,460 & 31 & 40 & 2,000 \\
\hline$n$ & Köthner & Joh. Hr. Bühring & 3 & & 0,540 & 28 & 40 & 1,460 & 31 & 40 & 2,000 \\
\hline & Köthner & Joh. Hr. Thies (Krüger) & 3 & & 0,540 & 28 & 40 & 1,460 & 31 & 40 & 2,000 \\
\hline $\mathrm{p}$ & Köthner & Carst. Hr. Schwägermann & 3 & & 0,540 & 28 & 40 & 1,460 & 31 & 40 & 2,000 \\
\hline & Köthner & Joh. Hr. Thies (Theis) & 3 & & 0,540 & 28 & 40 & 1,460 & 31 & 40 & 2,000 \\
\hline & Köthner & Chr- Thies (Graue) & 3 & & 0,540 & 28 & 40 & 1,460 & 31 & 40 & 2,000 \\
\hline s & Köthner & Carst. Hr. Koch & 3 & & 0,540 & 28 & 40 & 1,460 & 31 & 40 & 2,000 \\
\hline $\mathrm{t}$ & Köthner & Jürgen $\mathrm{Hr}$. Hermanns & 3 & & 0,540 & 28 & 40 & 1,460 & 31 & 40 & 2,000 \\
\hline u & Köthner & Carst. Hr. Misselhorn & 3 & & 0,540 & 28 & 40 & 1,460 & 31 & 40 & 2,000 \\
\hline $\mathrm{v}$ & Brinksitzer & Joh. Hr. Wulf & 3 & & 0,540 & 28 & 40 & 1,460 & 31 & 40 & 2,000 \\
\hline w & Brinksitzer & Christ. Lüßmann & 3 & & 0,540 & 28 & 40 & 1,460 & 31 & 40 & 2,000 \\
\hline $\mathrm{x}$ & Brinksitzer & Joh. Hr. Lilie & 3 & & 0,540 & 28 & 40 & 1,460 & 31 & 40 & 2,000 \\
\hline $\mathrm{y}$ & Anbauer & Chr. Thies & 2 & 30 & 0,405 & 21 & 30 & 1,095 & 23 & 60 & 1,500 \\
\hline$z$ & Anbauer & Chr. Hr. Meyer & 2 & 30 & 0,405 & 21 & 30 & 1,095 & 23 & 60 & 1,500 \\
\hline aa & Anbauer & Hr. Bergmann & 2 & 30 & 0,405 & 21 & 30 & 1,095 & 23 & 60 & 1,500 \\
\hline bb & Anbauer & Joh. Hr. Knoop & 2 & 30 & 0,405 & 21 & 30 & 1,095 & 23 & 60 & 1,500 \\
\hline $\mathrm{cc}$ & Anbauer & Wilh. Herbold & 2 & 30 & 0,405 & 21 & 30 & 1,095 & 23 & 60 & 1,500 \\
\hline dd & Abbauer & Friedrich Meyer & & 23 & 0,034 & 1 & 92 & 0,091 & 1 & 115 & 0,125 \\
\hline S & Die Schule & in Lachendorf & 4 & 60 & 0,810 & 42 & 60 & 2,190 & 47 & & 3,000 \\
\hline $\mathrm{pp}$ & Georg Drev & vsen Erben Papierfabrik & 15 & 27 & 2,740 & 143 & 95 & 7,410 & 159 & 2 & 10,150 \\
\hline & & Summa summarum & 100 & 20 & 18,029 & 945 & 117 & 48,746 & 1046 & 17 & 66,775 \\
\hline
\end{tabular}

Die nach Abzug der vorstehend für das Haushaltsbedürfnis pp. zu berechnenden Flächen verbleibenden Gemeinheiten im Betrag von:

Angerboden: $250 \mathrm{M} 40 \mathrm{QR}=48,445 \mathrm{Kuhw}$.

Heideboden: 2445 M 8 QR $=123,953$ Kuhw.

zu Allem: 2695 M 48 QR $=172,953$ Kuhw.

werden nach den vereinbarten Simpla, wie solche in $\S 5$ angegeben, verteilt:

Die umstehende Berechnung liefert den Nachweis des Sollhabens davon für jeden einzelnen Interessenten. 
Nachweisung der jedem Interessenten nach den vereinbarten Simpla gebührenden Abfindung.

\begin{tabular}{|c|c|c|c|c|c|c|c|c|c|c|c|}
\hline \multirow{3}{*}{ } & \multirow{2}{*}{\multicolumn{2}{|c|}{ Namen der Interessenten }} & & \\
\hline & & & \multicolumn{3}{|c|}{ Angerboden } & \multicolumn{3}{|c|}{ Heidboden } & \multicolumn{3}{|c|}{ zu Allem } \\
\hline & & & $\mathrm{M}$ & QR & Kuhw. & M & QR & Kuhw. & M & QR & Kuhw. \\
\hline a & Vollmeier & Lüßmann & 17 & 34 & 3,346 & 168 & 102 & 8,560 & 186 & 16 & 11,906 \\
\hline b & Vollmeier & Meyer & 15 & 66 & 3,01 & 151 & 108 & 7,701 & 167 & 54 & 10,711 \\
\hline c & Vollmeier & Kohlmeyer & 15 & 22 & 2,938 & 148 & 33 & 7,517 & 163 & 55 & 10,455 \\
\hline d & Vollmeier & Thies /Bock & 19 & 99 & 3,837 & 193 & 80 & 9,818 & 213 & 59 & 13,655 \\
\hline e & Vollmeier & Bergmann & 14 & 105 & 2,878 & 145 & 30 & 7,363 & 160 & 15 & 10,241 \\
\hline $\mathrm{f}$ & Vollmeier & Drewsen & 15 & 7 & 2,914 & 147 & 8 & 7,455 & 162 & 15 & 10,369 \\
\hline g & Vollmeier & Schumeyer & 14 & 119 & 2,902 & 146 & 55 & 7,425 & 161 & 54 & 10,327 \\
\hline h & Halbmeier & Schöndube & 12 & 77 & 2,446 & 123 & 55 & 6,259 & 136 & 12 & 8,705 \\
\hline i & Köthner & Joh. Hr. Thies (Cammann) & 13 & 76 & 2,638 & 133 & 17 & 6,750 & 146 & 93 & 9,388 \\
\hline k & Köthner & Joh. Hr. Bunkenburg & 10 & 34 & 1,991 & 100 & 56 & 5,093 & 110 & 90 & 7,084 \\
\hline I & Köthner & Joh. Hr. Dralle & 12 & 40 & 2,386 & 120 & 52 & 6,106 & 132 & 92 & 8,492 \\
\hline $\mathrm{m}$ & Köthner & Chr. Hr. Dralle & 9 & 13 & 1,763 & 88 & 116 & 4,510 & 98 & 9 & 6,273 \\
\hline $\mathrm{n}$ & Köthner & Joh. Hr. Bühring & 5 & 113 & 1,151 & 58 & 18 & 2,946 & 64 & 11 & 4,097 \\
\hline 0 & Köthner & Joh. Hr. Thies (Krüger) & 8 & 81 & 1,678 & 84 & 87 & 4,295 & 93 & 48 & 5,973 \\
\hline $\mathrm{p}$ & Köthner & Carst. Hr. Schwägermann & 6 & 46 & 1,235 & 62 & 40 & 3,160 & 68 & 86 & 4,395 \\
\hline$q$ & Köthner & Joh. Hr. Thies (Theis) & 12 & 33 & 2,374 & 119 & 100 & 6,075 & 132 & 13 & 8,449 \\
\hline r & Köthner & Chr- Thies (Graue) & 11 & 41 & 2,195 & 110 & 90 & 5,615 & 122 & 11 & 7,810 \\
\hline s & Köthner & Carst. Hr. Koch & 12 & 10 & 2,338 & 118 & 2 & 5,983 & 130 & 12 & 8,321 \\
\hline t & Köthner & Jürgen $\mathrm{Hr}$. Hermanns & 8 & 89 & 1,69 & 85 & 40 & 4,326 & 94 & 9 & 6,016 \\
\hline u & Köthner & Carst. Hr. Misselhorn & 6 & 98 & 1,319 & 66 & 69 & 3,375 & 73 & 47 & 4,694 \\
\hline v & Brinksitzer & Joh. Hr. Wulf & & 119 & 0,192 & 9 & 82 & 0,491 & 10 & 81 & 0,683 \\
\hline w & Brinksitzer & Christ. Lüßmann & 1 & 7 & 0,204 & 10 & 35 & 0,522 & 11 & 42 & 0,726 \\
\hline $\mathrm{x}$ & Brinksitzer & Joh. Hr. Lilie & & 30 & 0,048 & 2 & 51 & 0,123 & 2 & 81 & 0,171 \\
\hline $\mathrm{y}$ & Anbauer & Chr. Thies & & 89 & 0,144 & 7 & 31 & 0,368 & 8 & 0 & 0,512 \\
\hline$z$ & Anbauer & Chr. Hr. Meyer & & 96 & 0,156 & 7 & 104 & 0,399 & 8 & 80 & 0,555 \\
\hline aa & Anbauer & $\mathrm{Hr}$. Bergmann & & 7 & 0,012 & & 73 & 0,031 & & 80 & 0,043 \\
\hline bb & Anbauer & Joh. Hr. Knoop & 1 & 73 & 0,312 & 15 & 88 & 0,798 & 17 & 41 & 1,110 \\
\hline cc & Anbauer & Wilh. Herbold & & 15 & 0,024 & 1 & 25 & 0,061 & 1 & 40 & 0,085 \\
\hline dd & Abbauer & Freidrich Meyer & & 37 & 0,06 & 3 & 3 & 0,153 & 3 & 40 & 0,213 \\
\hline ee & Abbauer & Friedrich Ramberg & & 15 & 0,024 & 1 & 25 & 0,061 & 1 & 40 & 0,085 \\
\hline $\mathrm{ff}$ & Abbauer & Gottfried Walter & & 30 & 0,048 & 2 & 50 & 0,123 & 2 & 80 & 0,171 \\
\hline gg & Abbauer & Heinrich Ahrens & & 7 & 0,012 & & 73 & 0,031 & & 80 & 0,043 \\
\hline ii & Abbauer & Hr. Lilie & & 7 & 0,012 & & 73 & 0,031 & & 80 & 0,043 \\
\hline$\|$ & Abbauer & Carsten Hr. Thölke & & 15 & 0,024 & 1 & 25 & 0,061 & 1 & 40 & 0,085 \\
\hline $\mathrm{nn}$ & Hirte & Joh. Hr. Meyer & & 45 & 0,072 & 3 & 76 & 0,184 & 4 & 1 & 0,256 \\
\hline 00 & Häusling & Meyer Erben & & 45 & 0,072 & 3 & 76 & 0,184 & 4 & 1 & 0,256 \\
\hline & & Summe & 250 & 40 & 45,445 & 2445 & 81 & 123,953 & 2695 & 48 & 172,398 \\
\hline
\end{tabular}

$\mathrm{Zu}$ den neuen Wegen, den gemeinschaftlichen Sand- und Lehmgruben, den Tränken und Abzugsgräben sind verwandt:

Ackerland: $\quad 70 \mathrm{M} 109 \mathrm{QR}=11,407 \mathrm{Kuhw}$.

Wiesen: $\quad 64 \mathrm{QR}=0,177 \mathrm{Kuhw}$.

Angerboden: $27 \mathrm{M} \quad 78 \mathrm{QR}=5,387 \mathrm{Kuhw}$.

Heideboden: 165 M 116 QR = 10,143 Kuhw.

Zu Allem: $265 \mathrm{M} \quad 7 \mathrm{QR}=27,114 \mathrm{Kuhw}$. 
Davon geht nun ab die alte Wegefläche im Ackerlande mit:

Ackerland: 3 M 58 QR = 0,335 Kuhw. und

bleiben übrig:

Ackerland: $\quad 67 \mathrm{M} \quad 51 \mathrm{QR}=11,072 \mathrm{Kuhw}$.

Wiesenboden: $\quad 64 \mathrm{QR}=0,177$ Kuhw.

Angerboden: $27 \mathrm{M} 78 \mathrm{QR}=5,387 \mathrm{Kuhw}$.

Heideboden: 165 M $116 \mathrm{QR}=10,143$ Kuhw.

Zu Allem: $\quad 261 \mathrm{M} \quad 69 \mathrm{QR}=26,779 \mathrm{Kuhw}$.

wozu die 7 Vollmeier, der 1 Halbmeier, die 12 Köthner, die 3 Brinksitzer und die Drewsensche Papierfabrik nach dem Kuhweidenwerte ihrer Gesamtabfindung beizutragen haben.

Der Beitrag jedes einzelnen Interessenten dazu wird umstehend nachgewiesen.

Zu den neuen Wegen, den Sandgruben, Abzugsgräben haben beizutragen.

\begin{tabular}{|c|c|c|c|c|c|c|c|c|c|c|c|c|c|c|c|c|c|}
\hline \multirow{3}{*}{ 农 } & \multirow{2}{*}{\multicolumn{2}{|c|}{ Namen der Interessenten }} & \multirow{3}{*}{\multicolumn{3}{|c|}{$\begin{array}{l}\text { Ackerland } \\
\text { M QR Kuhw. }\end{array}$}} & \multirow{2}{*}{\multicolumn{3}{|c|}{ Wiesenboden }} & \multirow{2}{*}{\multicolumn{3}{|c|}{ Angerboden }} & \multirow{2}{*}{\multicolumn{3}{|c|}{ Heidboden }} & \multicolumn{3}{|c|}{ überhaupt } \\
\hline & & & & & & & & & & & & & & & \multicolumn{3}{|c|}{ brauchbarer Boder } \\
\hline & & & & & & M & QR & Kuhw. & M & $Q R$ & Kuhw. & M & $Q R$ & Kuhw. & M & $Q R$ & Kuhw. \\
\hline a & Vollmeier & Lüßmann & 4 & 69 & 0,754 & & 5 & 0,013 & 1 & 105 & 0,366 & 11 & 34 & 0,688 & 17 & 93 & 1,821 \\
\hline b & Vollmeier & Meyer & 3 & 99 & 0,629 & & 4 & 0,010 & 1 & 69 & 0,307 & 9 & 51 & 0,575 & 14 & 103 & 1,521 \\
\hline c & Vollmeier & Kohlmeyer & 3 & 83 & 0,607 & & 3 & & 1 & 62 & 0,296 & 9 & 20 & & 14 & 48 & 1,466 \\
\hline d & Vollmeier & Thies & 5 & 10 & & & 5 & & 2 & 10 & & 12 & 58 & & 19 & 83 & 2,016 \\
\hline e & Vollme & Bergm & 3 & 79 & & & 3 & & 1 & 60 & & 9 & & & 14 & 22 & 1,452 \\
\hline f & Vollme & Drews & 4 & & & & 4 & & 1 & 77 & & 9 & 98 & & 15 & 59 & 587 \\
\hline $\mathrm{g}$ & Volln & Schi & 4 & 37 & 0,7 & & 4 & & 1 & 91 & & 10 & 7 & & 16 & 83 & 709 \\
\hline $\mathrm{h}$ & Halb & Schö & 3 & 57 & 0 , & & 3 & & 1 & 50 & & 8 & 6( & & 13 & 56 & 380 \\
\hline i & Köthner & Joh. . & 3 & 87 & 612 & & 4 & & 1 & 63 & 296 & 9 & 2 & & 14 & 54 & 480 \\
\hline k & Köth & Joh. & 2 & 66 & 418 & & 2 & & 1 & 6 & 203 & 6 & 30 & & 9 & 104 &, 010 \\
\hline I & Köth & Joh. & 3 & 22 & 0,522 & & 3 & 0,009 & 1 & 36 & 254 & 7 & 98 & 0,477 & 12 & 39 & 1,262 \\
\hline $\mathrm{m}$ & Köthr & Chr. & 2 & 26 & 0,364 & & 2 & 0,006 & & 110 & 176 & 5 & 5 & & 8 & 73 &, 882 \\
\hline$n$ & Köth & Joh. & 1 & 34 & 0,210 & & 1 & 0,004 & & 63 & 102 & 3 & 19 & & 4 & 117 & 0,509 \\
\hline 0 & Köth & Joh. Hr. Th & 2 & 82 & 0,441 & & 3 & 0,007 & 1 & 12 & 215 & 6 & 75 & 0,406 & 10 & 52 & 1,069 \\
\hline p & Köthner & Carst. Hr. S & 1 & 76 & 0,270 & & 2 & 0,004 & & 81 & 0,134 & 4 & & & 6 & 48 & 0,655 \\
\hline q & Köthner & Joh. Hr. Thie & 3 & 43 & 0,552 & & 3 & 0,009 & 1 & 46 & 0,27 & 8 & 34 & 0,5 & 13 & 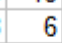 & 1,337 \\
\hline r & Köthner & Chr- T & 3 & 27 & 0,528 & & 3 & 0,008 & 1 & 38 & 0,26 & 7 & 111 & 0,483 & 12 & 59 & 1,279 \\
\hline s & Köthner & Carst. & 3 & 46 & 0,554 & & 3 & 0,009 & 1 & 46 & 0,27 & 8 & 35 & 0,507 & 13 & 10 & 1,340 \\
\hline $\mathrm{t}$ & Köthner & Jürge & 2 & 35 & 0,375 & & 2 & 0,006 & & 113 & 0,185 & 5 & 74 & 0,342 & 8 & 104 & 0,908 \\
\hline u & Köthner & Carst & 1 & 52 & 0,235 & & 1 & 0,003 & & 71 & 0,113 & 3 & 63 & 0,218 & 5 & 67 & 0,569 \\
\hline $\mathrm{v}$ & Brinksitzer & Joh. 1 & & 74 & 0,101 & & 1 & 0,0 & & 30 & 0,0 & 1 & 62 & 0,094 & 2 & 47 & 0,245 \\
\hline w & Brinksitzer & Chris & & 98 & 0,134 & & 1 & 0,002 & & 40 & 0,064 & 2 & & 0,1 & 3 & 20 & 0,324 \\
\hline $\mathrm{x}$ & Brinksitzer & Joh. 1 & & 44 & 0,060 & & & & & 18 & 0,03 & & 110 & 0, & 1 & 52 & 0,147 \\
\hline $\mathrm{pp}$ & Drews & sen $\mathrm{Er}$ & 2 & 5 & 0,335 & & 2 & 0,005 & & 101 & 0,163 & 5 & 2 & 0,308 & & 110 & 0,811 \\
\hline & & Summa & 67 & 51 & 11,072 & & 64 & 0,177 & 27 & 78 & 5,387 & 165 & 116 & 10,143 & 261 & 69 & 26,779 \\
\hline
\end{tabular}

Zu den Gemeindeforsten, den Gemeindebaulichkeiten pp. sind verwandt:

Wiesenboden $1 \mathrm{M} 98 \mathrm{QR}=0,435 \mathrm{Kuhw}$.

Angerboden $4 \mathrm{M} 34 \mathrm{QR}=0,534 \mathrm{Kuhw}$.

Heidboden $104 \mathrm{M} 45 \mathrm{QR}=8,370$ Kuhw.

Zu Allem: $\quad 110$ M 57 QR = 9, 339 Kuhw.

Dazu haben die Vollmeier, der Halbmeier und die Köthner nachbarlich und die 3 Brinksitzer zusammen gleich einer Reihestelle beizutragen.

Auf der umstehenden Seite wird der Beitrag dazu für jeden Einzelnen nachgewiesen. 


\section{Zu den reservierten Gemeindeforsten, Gemeindebaulichkeiten und cultivierten Ge- meinde-Grundstücken haben beizutragen.}

\begin{tabular}{|c|c|c|c|c|c|c|c|c|c|c|c|c|c|c|}
\hline \multirow{3}{*}{ 焉 } & \multirow{2}{*}{\multicolumn{2}{|c|}{ Namen der Interessenten }} & \multirow{2}{*}{\multicolumn{3}{|c|}{ Wiesenboden }} & \multirow{2}{*}{\multicolumn{3}{|c|}{ Angerboden }} & \multirow{2}{*}{\multicolumn{3}{|c|}{ Heidboden }} & \multirow{2}{*}{\multicolumn{3}{|c|}{$\begin{array}{c}\text { überhaupt } \\
\text { rauchbarer Boden }\end{array}$}} \\
\hline & & & & & & & & & & & & & & \\
\hline & & & $\mathrm{M}$ & QR & Kuhw. & M & QR & Kuhw. & $\mathrm{M}$ & QR & Kuhw. & $\mathrm{M}$ & QR & Kuhw. \\
\hline a & Vollmeier & Lüßmann & & 11 & 0,020 & & 24 & 0,026 & 4 & 117 & 0,399 & 5 & 32 & 0,445 \\
\hline b & Vollmeier & Meyer & & 11 & 0,020 & & 24 & 0,026 & 4 & 117 & 0,399 & 5 & 32 & 0,445 \\
\hline c & Vollmeier & Kohlmeyer & & 11 & 0,020 & & 24 & 0,026 & 4 & 117 & 0,399 & 5 & 32 & 0,445 \\
\hline d & Vollmeier & Thies /Bock & & 11 & 0,020 & & 24 & 0,026 & 4 & 117 & 0,399 & 5 & 32 & 0,445 \\
\hline e & Vollmeier & Bergmann & & 11 & 0,020 & & 24 & 0,026 & 4 & 117 & 0,399 & 5 & 32 & 0,445 \\
\hline$f$ & Vollmeier & Drewsen & & 11 & 0,020 & & 24 & 0,026 & 4 & 117 & 0,399 & 5 & 32 & 0,445 \\
\hline g & Vollmeier & Schumeyer & & 10 & 0,021 & & 25 & 0,026 & 4 & 116 & 0,398 & 5 & 31 & 0,445 \\
\hline h & Halbmeier & Schöndube & & 10 & 0,021 & & 25 & 0,026 & 4 & 116 & 0,398 & 5 & 31 & 0,445 \\
\hline i & Köthner & Joh. Hr. Thies (Cammann) & & 10 & 0,021 & & 25 & 0,026 & 4 & 116 & 0,398 & 5 & 31 & 0,445 \\
\hline k & Köthner & Joh. Hr. Bunken & & 10 & 0,021 & & 25 & 0,025 & 4 & 116 & 0,3 & 5 & 31 & 0,445 \\
\hline I & Köthner & Joh. Hr. Dralle & & 10 & 0,021 & & 24 & 0,025 & 4 & 117 & 0,399 & 5 & 31 & 0,445 \\
\hline $\mathrm{m}$ & Köthner & Chr. Hr. Dralle & & 10 & 0,021 & & 24 & 0,025 & 4 & 117 & & 5 & 31 & 0,445 \\
\hline $\mathrm{n}$ & Köthner & Joh. Hr. Bühring & & 11 & 0,021 & & 24 & 0,025 & 4 & 116 & 0,399 & 5 & 31 & 0,445 \\
\hline 0 & Köthner & Joh. Hr. Thies (Krüger) & & 11 & 0,021 & & 24 & 0,025 & 4 & 116 & & 5 & 31 & 0,445 \\
\hline$p$ & Köthner & Carst. Hr. Schwägermann & & 10 & 0,021 & & 25 & 0,026 & 4 & 116 & 0,398 & 5 & 31 & 0,445 \\
\hline$q$ & Köthner & Joh. Hr. Thies (Theis) & & 10 & 0,021 & & 25 & 0,025 & 4 & 116 & 0,398 & 5 & 31 & 0,444 \\
\hline$r$ & Köthner & Chr- Thies (Graue) & & 10 & 0,021 & & 25 & 0,025 & 4 & 116 & 0,398 & 5 & 31 & 0,444 \\
\hline s & Köthner & Carst. Hr. Koch & & 10 & 0,021 & & 25 & 0,025 & 4 & 116 & 0,398 & 5 & 31 & 0,444 \\
\hline $\mathrm{t}$ & Köthner & Jürgen $\mathrm{Hr}$. Hermanns & & 10 & 0,021 & & 25 & 0,025 & 4 & 116 & 0,398 & 5 & 31 & 0,444 \\
\hline $\mathrm{u}$ & Köthner & Carst. Hr. Misselhorn & & 10 & 0,021 & & 25 & 0,025 & 4 & 116 & 0,398 & 5 & 31 & 0,444 \\
\hline v & Brinksitzer & Joh. Hr. Wulf & & 4 & 0,007 & & 8 & 0,008 & 1 & 79 & 0,133 & 1 & 91 & 0,148 \\
\hline w & Brinksitzer & Christ. Lüßmann & & 3 & 0,007 & & 8 & 0,008 & 1 & 79 & 0,133 & 1 & 90 & 0,148 \\
\hline $\mathrm{x}$ & Brinksitzer & Joh. Hr. Lilie & & 3 & 0,007 & & 8 & 0,008 & 1 & 79 & 0,133 & 1 & 90 & 0,148 \\
\hline & & Summa & 1 & 98 & 0,435 & 4 & 34 & 0,534 & 104 & 45 & 8,37 & 110 & 37 & 9,339 \\
\hline
\end{tabular}

Zu den zum Verkauf reservierten Flächen sind verwandt:
Ackerland
$71 \mathrm{QR}=0,069 \mathrm{Kuhw}$.
Angerboden $8 \mathrm{M} 92 \mathrm{QR}=2,148 \mathrm{Kuhw}$.
Heideboden $163 \mathrm{M} 88 \mathrm{QR}=6,601 \mathrm{Kuhw}$.

Zu Allem $173 \mathrm{M} 11 \mathrm{QR}=8,818 \mathrm{Kuhw}$.

Dazu tragen die 7 Vollmeier, 1 Halbmeier, 12 Köthner, 3 Brinksitzer und die Drewsensche Papierfabrik nach Maßgabe der Simpla, wonach sie von den Gemeinheiten abgefunden worden, bei, wie solches umstehend geschieht. 


\section{Zu den verkauften Grundstücken haben beizutragen.}

\begin{tabular}{|c|c|c|c|c|c|c|c|c|c|c|c|c|c|c|c|}
\hline & \multirow{3}{*}{$\stackrel{\frac{\pi}{\omega}}{\stackrel{ \pm}{ \pm}}$} & \multirow{2}{*}{\multicolumn{2}{|c|}{ Namen der Interessenten }} & \multirow{2}{*}{\multicolumn{3}{|c|}{ Ackerland }} & \multirow{2}{*}{\multicolumn{3}{|c|}{ Angerboden }} & \multirow{2}{*}{\multicolumn{3}{|c|}{ Heidboden }} & \multicolumn{3}{|c|}{ überhaupt } \\
\hline & & & & & & & & & & & & & brauc & chbare & er Boden \\
\hline & & & & M & QR & Kuhw. & M & $Q R$ & Kuhw. & M & QR & Kuhw. & M & $Q R$ & Kuhw. \\
\hline 279 & a & Vollmeier & Lüßmann & & 5 & 0,005 & & 71 & 0,145 & 11 & 3 & 0,444 & 11 & 79 & 0,594 \\
\hline 251 & b & Vollmeier & Meyer & & 4 & 0,004 & & 64 & 0,13 & 9 & 111 & 0,4 & 10 & 59 & 0,534 \\
\hline 245 & c & Vollmeier & Kohlmeyer & & 4 & 0,004 & & 62 & 0,127 & 9 & 83 & 0,391 & 10 & 29 & 0,522 \\
\hline 320 & d & Vollmeier & Thies /Bock & & 6 & 0,006 & & 81 & 0,166 & 11 & 78 & 0,509 & 12 & 45 & 0,681 \\
\hline 240 & e & Vollmeier & Bergmann & & 4 & 0,004 & & 61 & 0,125 & 9 & 58 & 0,382 & 10 & 3 & 0,511 \\
\hline 243 & f & Vollmeier & Drewsen & & 4 & 0,004 & & 62 & 0,126 & 9 & 73 & 0,387 & 10 & 19 & 0,517 \\
\hline 242 & g & Vollmeier & Schumeyer & & 4 & 0,004 & & 61 & 0,126 & 9 & 69 & 0,385 & 10 & 14 & 0,515 \\
\hline 204 & h & Halbmeier & Schöndube & & 3 & 0,003 & & 53 & 0,106 & 8 & 7 & 0,325 & 8 & 63 & 0,434 \\
\hline 220 & & Köthner & Joh. Hr. Thies (Cammann) & & 4 & 0,004 & & 57 & 0,114 & 8 & 82 & 0,35 & 9 & 23 & 0,468 \\
\hline 166 & k & Köthner & Joh. Hr. Bunkenburg & & 3 & 0,003 & & 42 & 0,086 & 6 & 67 & 0,264 & 6 & 112 & 0,353 \\
\hline 199 & & Köthner & Joh. Hr. Dralle & & 3 & 0,003 & & 51 & 0,103 & 7 & 104 & 0,318 & 8 & 38 & 0,424 \\
\hline 147 & $\mathrm{~m}$ & Köthner & Chr. Hr. Dralle & & 3 & 0,003 & & 37 & 0,076 & 6 & 97 & 0,234 & 7 & 17 & 0,313 \\
\hline 96 & $\mathrm{n}$ & Köthner & Joh. Hr. Bühring & & 2 & 0,002 & & 24 & 0,05 & 3 & 95 & 0,153 & 4 & 1 & 0,205 \\
\hline 140 & 0 & Köthner & Joh. Hr. Thies (Krüger) & & 3 & 0,002 & & 35 & 0,073 & 5 & 64 & 0,223 & 5 & 102 & 0,298 \\
\hline 103 & p & Köthner & Carst. Hr. Schwägermann & & 2 & 0,002 & & 26 & 0,053 & 4 & 8 & 0,164 & 4 & 36 & 0,219 \\
\hline 195 & $q$ & Köthner & Joh. Hr. Thies (Theis) & & 4 & 0,003 & & 50 & 0,102 & 7 & 99 & 0,317 & 8 & 33 & 0,422 \\
\hline 183 & r & Köthner & Chr- Thies (Graue) & & 3 & 0,003 & & 46 & 0,095 & 7 & 29 & 0,292 & 7 & 78 & 0,39 \\
\hline 195 & s & Köthner & Carst. Hr. Koch & & 3 & 0,003 & & 50 & 0,101 & 7 & 85 & 0,311 & 8 & 18 & 0,415 \\
\hline 141 & & Köthner & Jürgen $\mathrm{Hr}$. Hermanns & & 2 & 0,002 & & 36 & 0,073 & 5 & 69 & 0,225 & 5 & 107 & 0,3 \\
\hline 110 & u & Köthner & Carst. Hr. Misselhorn & & 2 & 0,002 & & 28 & 0,057 & 4 & 42 & 0,175 & 4 & 72 & 0,234 \\
\hline 16 & & Brinksitzer & Joh. Hr. Wulf & & & & & 4 & 0,008 & & 76 & 0,026 & 0 & 80 & 0,034 \\
\hline 17 & w & Brinksitzer & Christ. Lüßmann & & & & & 4 & 0,009 & & 81 & 0,027 & 0 & 85 & 0,036 \\
\hline 4 & $\mathrm{x}$ & Brinksitzer & Joh. Hr. Lilie & & & & & 1 & 0,002 & & 19 & 0,007 & 0 & 20 & 0,009 \\
\hline 183 & & Die Drewser & nsche Papierfabrik & & 3 & 0,003 & & 46 & 0,095 & 7 & 29 & 0,292 & 7 & 78 & 0,39 \\
\hline & & & Summa & & 71 & 0,069 & 8 & 92 & 2,148 & 163 & 88 & 6,601 & 173 & 11 & 8,818 \\
\hline
\end{tabular}

Anmerkung: Erste Spalte: ohne Überschrift, Bedeutung der Zahlen: Simpla, s. § 5, Zif. 8): Tabelle der Simpla 


\section{Summarische Zusammenstellung des Sollhaben der Interessenten}

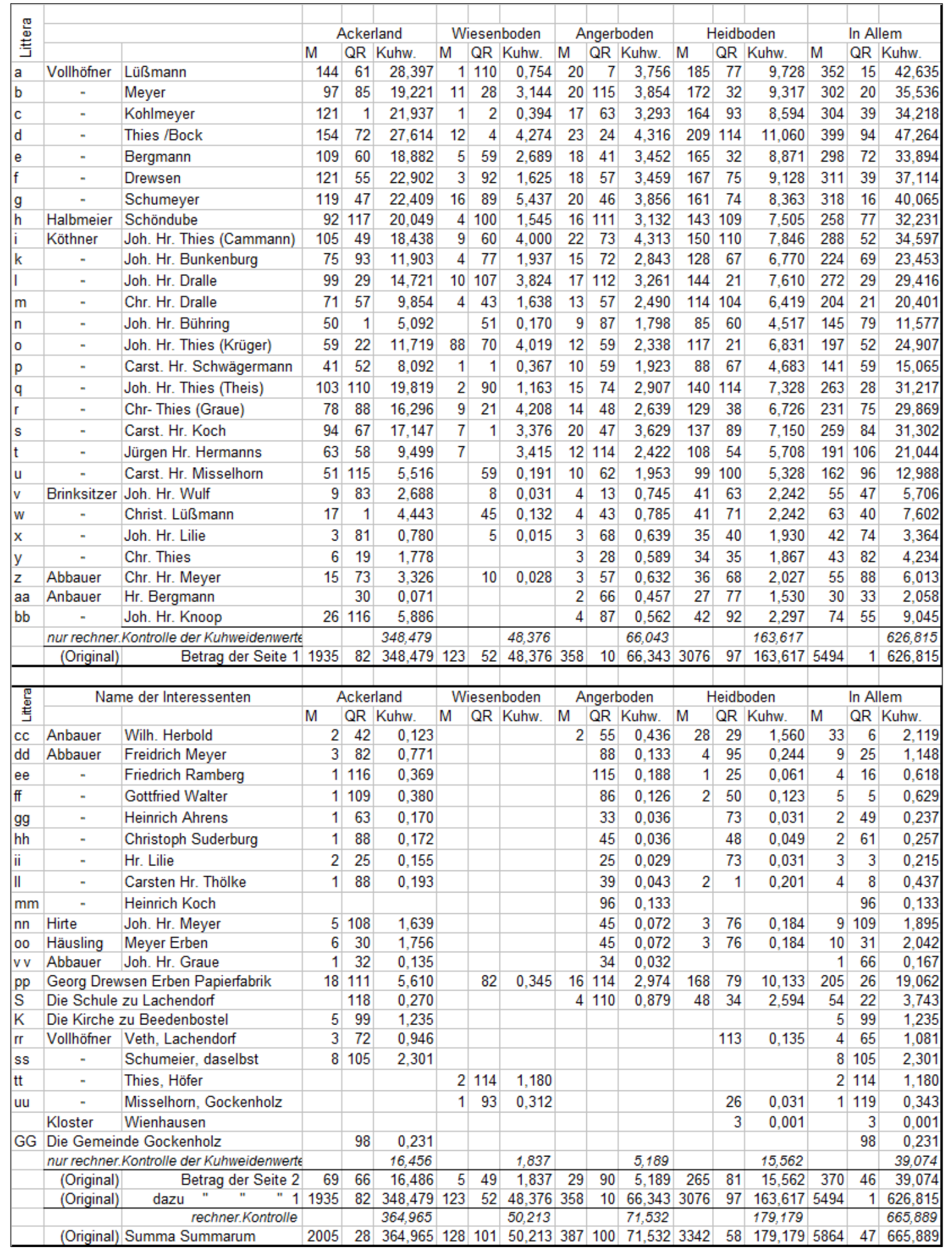




\section{Verzeichnis \\ von den in der Feldmark Lachendorf angelegten Wegen, Sandgruben, Tränken und Abzugsgräben}

\begin{tabular}{|c|c|c|c|c|c|c|c|}
\hline \multirow{5}{*}{ 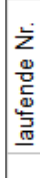 } & \multirow{5}{*}{ 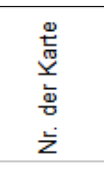 } & \multirow{5}{*}{ Benenung der Wege } & \multirow{5}{*}{\begin{tabular}{|l} 
Breite \\
nach \\
Ruthen
\end{tabular}} & & \multirow{5}{*}{ 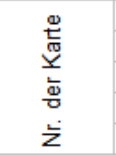 } & \multirow[b]{3}{*}{ Benenung der Wege } & \multirow[b]{3}{*}{ Breite } \\
\hline & & & & \multirow{4}{*}{ 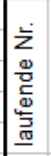 } & & & \\
\hline & & & & & & & \\
\hline & & & & & & & nach \\
\hline & & & & & & & Ruthen \\
\hline & & a) Öffentlliche Wege & & & & b) Koppelwege & \\
\hline 1 & 15 & Der Weg von Lachendorf nach Celle & $21 / 2 \& 3$ & 1 & 18 & Der Weg nach dem Lachtekamp & $21 / 2$ \\
\hline 2 & 16 & Der Weg nach Alvern & $21 / 2$ & 2 & 55 & Der Weg vor dem Flottkampe & $21 / 2$ \\
\hline 3 & 25 & Der Weg nach Gockenholz & $21 / 2$ & 3 & 20 & Der Weg vor den Wiesen & $21 / 2$ \\
\hline 4 & 74 & Der Weg nach Beedenbostel & $21 / 2$ & 4 & 291 & Der wWeg über'n Westerkamp & $21 / 2$ \\
\hline 5 & 274 & Der Weg übers Lohfeld nach Celle & $21 / 2$ & 5 & 282 & Der Weg südl. am Westerkamp & $21 / 2$ \\
\hline 6 & 269 & Der Weg nach Oppershausen & $21 / 2$ & 6 & 252 & Die Trift nach den Wiesen & $31 / 2$ \\
\hline 7 & 242 & Der Weg bei Rombergers Hause & 1 & 7 & 256 & Der Weg durch die Ackern & $21 / 2$ \\
\hline 8 & 231 & Der Weg nach Ahnsbeck & $21 / 2$ & 8 & 279 & Der Weg nach Bührings Mühlenkamp & $11 / 2$ \\
\hline 9 & 149 & Der Weg nach der Windmühle & 2 & 9 & 230 & Der Weg nach Bergmanns Koppel & 2 \\
\hline 10 & 153 & desgl. Von Ahnsbeck nach der Windmühle & 2 & 10 & 159 & Der Weg nach der Schelprieth & $21 / 2$ \\
\hline 11 & $168 \& 169$ & Der Weg nach Bunkenburg & $21 / 2$ & 11 & 185 & Der Weg übern Hohenkamp & $21 / 2$ \\
\hline 12 & 214 & Der Ahnsbecker Kirchweg & 3 & 12 & 220 & Die Bunkenburger Trift & 3 \\
\hline 13 & 205 & Der Weg nach Jarnsen & $21 / 2$ & 13 & 205 & Der Weg in den Neuengärten & $11 / 2$ \\
\hline 14 & 129 & Die Dorfstraße & $2 \& 21 / 2$ & 14 & 64 & Der Weg auf dem Hagen & $21 / 2$ \\
\hline 15 & 293 & Weg nach der Spätzförth & $21 / 2$ & 15 & & Weg nach $\mathrm{Hr}$. Dralle Allerqwiesen & $21 / 2$ \\
\hline 16 & " & Der Gockenholzer Wienhäuser Weg & 2 & 16 & $101 \& 187$ & Trift nach der Tränke beim Bohnegarten & 7 \\
\hline 17 & $"$ & Der Lachendorfer Celler Weg & $21 / 2$ & 17 & 17 & Der Weg im Kuhlkampe & $21 / 2$ \\
\hline 18 & $"$ & Der Lachendorf Oppershäuser Weg & $21 / 2$ & 18 & 19 & Der Weg auf der Salloh & $21 / 2$ \\
\hline 19 & " & Der Ahnsbecker Celler Weg & 3 & 19 & & Trift für Cammanns Thies und Hermanns & $21 / 2$ \\
\hline 20 & $"$ & Weg von Oppershausen nach Ahnsbeck & $21 / 2$ & 20 & 60 & Der vWeg nach i Koppel auf dem Flottkamp & $11 / 2$ \\
\hline & & & & 21 & 41 & Trift von Flottkampe nach der Stockau & $21 / 2$ \\
\hline & & & & 22 & & Trift nach dem Bährenblau & $21 / 2$ \\
\hline $\bar{z}$ & 莺 & & & 23 & & Der Lachendorfer Wiesen Weg & $31 / 2$ \\
\hline$\frac{\Phi}{\square}$ & 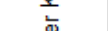 & Benenung & & 24 & & Der Pannenweg & $31 / 2$ \\
\hline 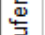 & 这 & & & 25 & & Die Oppershäuser Trift westl. des Canals & $21 / 2$ \\
\hline$\underline{\underline{\sigma}}$ & $\bar{L}$ & & & 26 & & Weg nach Drallen Wiese & $21 / 2$ \\
\hline & & c) Sandgruben, freie Plätze, & & 27 & & Oppershäuser Wiesen Weg & $21 / 2$ \\
\hline & & Abzugsgräben und Tränken & & 28 & & Weg nach der Forst & $21 / 2$ \\
\hline 1 & 157 & Am Ahnsbecker Weg & $0 \mathrm{M} 78 \mathrm{G}$ & 29 & & Trift für Cammanns Thies und Hermanns & $21 / 2$ \\
\hline 2 & 164 & Der Abzugsgraben bis zur Brücke & $1 / 2$ : breit & 30 & & Weg nach Diecks aus Ahnsbeck Wiese & 2 \\
\hline 3 & 237 & Der Abzugsgraben bis zur Brücke & $1 / 2$ : breit & 31 & & Weg nach dem Postmoor & $21 / 2$ \\
\hline 4 & 92 & Zwischen den beiden Flüssen & $2 \mathrm{M} 24 \mathrm{Q}$ & 32 & & Weg nach Schumeier u. Thies (Thies) Koppel & $21 / 2$ \\
\hline 5 & 215 & Tränke bei der Bunkenburger Trift & $0 \mathrm{M} 114 \mathrm{C}$ & 33 & & Weg nach der Forst & $21 / 2$ \\
\hline 6 & 77 & Am Kirchwege & $3 \mathrm{M} 88 \mathrm{Q}$ & 34 & & Bock (Thies) Trift & 3 \\
\hline 7 & 204 & Lehmgrube am Ahnsbecker Wege & $1 \mathrm{M} 14 \mathrm{Q}$ & 35 & & Weg nach Drallen Wiese & $21 / 2$ \\
\hline 8 & $"$ & Der Canal & 1: breit & 36 & & Weg übern Ackern & $21 / 2$ \\
\hline 9 & " & Abzuugsgraben südl. des Ahnsbecker Celler & $1 / 2$ : breit & 37 & & Oppershäuser Trift & $21 / 2$ \\
\hline 10 & $"$ & Abzugsgraben & $1 / 2$ : breit & 38 & & Weg am Canale & $21 / 2$ \\
\hline
\end{tabular}


$\S 7$

Örtliche Einteilung

Wegen der Lage der den Interessenten zuzuteilenden Koppeln ist mit denselben verhandelt und danach verfahren.

Hinsichtlich der wirklich zu Teil gewordenen Abfindungen wird auf das diesem Rezesse sub Litt: angeschlossenen Verteilungs-Register hingewiesen.

$\S 8$

Schließliche Bestimmungen

1. Künftige Nutzung der Abfindungen

a. verbleibende oder neue Servitute

Alle bislang auf Lachendorfer Grundstücken, soweit sie der Teilung und Verkoppelung unterzogen sind, geruht habenden Servitute sind aufgehoben.

Es erhalten demnach die Interessenten die innen nach dem Verteilungs-Register zugeteilten Koppeln der Regel nach privatim, ausgenommen jedoch die nachstehend aufgeführten in der Teilung neubegründeten Servitute, als:

a) Der Halbmeier Schöndube ist verpflichtet, den Fußweg von Ahnsbeck nach Beedenbostel und von Lachendorf nach Beedenbostel über das Ahnsbecker Steg durch seine Koppel vor dem Ahnsbecker Stege zu jeder Zeit zu dulden und frei und ungehindert liegen zu lassen, dabei ist jedoch zu bemerken, daß der Fußweg von Lachendorf nach Beedenbostel in der Art umgelagert wird, dass derselbe vom Jarnser Weg da abgehen soll wo die Thies-Cammannsche Koppel gegen Schöndube aufhört.

b) Der Vollhöfner Lüßmann hat Weg und Trift nach der Schönduveschen jetzt Bunchenburgschen Sallohwiese durch seine Sallohkoppel bei der Immenstelle zu leiden.

c) Der Köthner Thies (Graue) hat den Fahr- und Fußweg nach Drewschen Eselwiese und der Gemeinde Bullenwiese durch seine vor diesen Wiesen am Dorfe belegenen Koppel zu leiden, und erhält dafür die Nachweide auf der Gemeinde Bullenwiese als Entschädigung.

d) Der Vollhöfner Schumeier hat den Fahrweg für den Köthner Thies (Theis) nach dessen Heidkoppel durch seine Heidkoppel am Ahnsbecker Celler Wege zu leiden.

b. Art und Umfang der Benutzung gemeinschaftlicher Räume

Die Benutzung der reservierten gemeinschaftlichen Sand- und Lehmgruben, welche zunächst und hauptsächlich zur Verbesserung der neuen Wege abgelegt sind, ist zwar allen einheimischen Interessenten zum eigenen Bedarf gleichfalls gestattet, jedoch ist jeder Teilnehmer zu einer ordnungsgemäßen Ausübung der Benutzung verpflichtet.

Ebenso ist allen Interessenten die Benutzung der angelegten Tränken gestattet.

An den reservierten Gemeindeforsten, den Gemeindebaulichkeiten und cultivierten Gemeinde Grundstücken haben nur die 20 Reihestellen Litt. A bis u incl. und die 3 Brinksitzer v, w \& x Anteil, und zwar die 20 Reihestellen nachbargleichen, die 3 Brinksitzer zusammen den Anteil einer Reihestelle, weshalb dann die Disposition darüber oder über die etwa daraus zu löhnenden Pacht oder Kaufgeldern den jedesmaligen Teilnehmern nach Verhältnis der Teilnahme zusteht.

Die Bewirtschaftung und Beaufsichtigung der Forsten richtet sich nach den allgemeinen landespolizeilichen Vorschriften.

An den zum Verkauf ausgesetzten Räume haben nur die 20 Reihestellen, die 3 Brinksitzer und die Drewsensche Papierfabrik Anteil und zwar nach Verhältnis der Simpla, womit sie aus der Gemeinheit abgefunden wurden. Es werden daher die daraus zu lösenden Kaufgelder nach diesem Verhältnis unter die Teilnehmer verteilt. 
c. Beschränkungen in der Nutzung der Grundstücke.

Baut jemand auf seinem alten Gehöfte neu, so muß er mit dem Gebäude 2 Fuß von des Nachbars Grenze entfernt bleiben, werden aber Gebäude auf Grundstücken, welche mit dem alten Gehöft nicht in Verbindung stehen, aufgerichtet, so sind solche mindestens 32 Fuß von des Nachbars Grenze aufzurichten.

Von den Wegen und gemeinschaftlichen Plätzen müssen neue Gebäude 2 Fuß entfernt bleiben.

Leitern zum Decken der Gebäude dürfen auf des Nachbars Grundstücke gesetzt werden.

Trägt jemand ein Grundstück ab, so muß er damit, wenn der Nachbar eine Befriedigung auf der Grenze hat, einen Fuß davon zurückbleiben, und in dreifüßiger Passirung abschregen.

Der Vollmeier Schumeier verpflichtet sich ausdrücklich, das inm zwischen seinem Hofe und der Schule zugeteilte von Wegen umgebene Dreieck niemals mit Gebäuden zu besetzen.

Der Gemeinde Lachendorf bleibt noch während 3 Jahren das Recht von dem Köthner Hermanns zugeteilten früher Schönduveschen Hofplatz den Boden soweit abzufahren, bis er mit der anliegenden Fläche eben ist, und hat Hermanns zu dem Zwecke für eine paßliche Anfahrt durch Anlegung eines Tors an dieser Stelle zu sorgen.

Die Besetzung dieses Platzes mit Gebäuden ist dem p. Hermanns gleichfalls ausdrücklich untersagt.

\section{d: Bepflanzung und Besaamung der Koppeln}

Bei Anpflanzungen und Besaamung der Koppeln soll, wenn der Nachbar seine Grundstücke zu Acker oder Wiese cultiviert, das hochstämmige Laubholz 32 Fuß, alles Nadelholz, die Kopf- und Obstbäume 16 Fuß, das Schlagholz 6 Fuß und Hecken und Knicke, wenn sie einseitig gehalten werden, 3 Fuß von der Grenze entfernt bleiben.

Legt der Grenznachbar ebenfalls Holz an, oder hat bereits Holz angelegt, so soll es gestattet sein so weit mit dem Holze hinan zutreten, dass die vereinbarten Grenzmerkmale dadurch nicht verdunkelt werden.

Werden die Koppeln zum Heidhiebe oder zur Weide genutzt so soll mit der Holzanzucht von Nadelholz bis auf 8 Fuß, mit Schlagholz bis auf 3 Fuß an die Grenze hinangegangen werden dürfen.

An den Wegen können Anpflanzungen bis auf 3 Fuß von der Grenzlinie des Weges vorgenommen werden.

Hecken zu Befriedigung der Grundstücke dürfen bis auf einen Fuß von der Wegegrenze gesetzt werden.

Auf den Höfen und Gärten im Dorf ist es gestattet bis auf 8 Fuß mit allen Holzarten an des Nachbars Grenze hinanzutreten.

e. Wegnahme der in den Abfindungen noch vorhandenen Holzungen, Hecken, Befriedigungen $\mathrm{p}$ :

Alle jetzt vorhandenen Bäume und Holzungen, welche den Grenzen näher stehen als vorhin bestimmt worden, brauchen vor ihrer Abständigkeit oder Haubarkeit nicht weggenommen zu werden, und gelten die obigen Bestimmungen nur für den neuen Anwuchs und die neuen Anpflanzungen.

Das auf den Besitz eines anderen übergegangene Grundstücken befindliche Holz soll von dem Holzeigentümer nach Verlauf eines Jahres der Abgabe des Grundstücks entfernt sein, und wenn es Baumholz ist ausgerodet oder 11/2 Fuß über der Erde, wenn es Buschholz ist aber glatt an der Erde abgehauen.

Ist das Holz in der bestimmten Zeit nicht entfernt, so fällt es dem neuen Koppelbesitzer als Eigentum zu.

Die übrigen beweglichen Gegenstände als Baulichkeiten, Hecken, Befriedigungen, Grenzsteine pp. müssen ebenfalls 1 Jahr nach Abgabe der Koppel entfernt sein, widrigenfalls der frühere Eigentümer das Eigentumsrecht daran verliert. 
Alle auf den neuen Wegen befindlichen Befriedigungen, Hecken, Bäume usw. müssen sofort weggenommen werden.

f. Vorschriften zur Befriedigung und Begrenzung der Koppeln.

Die Höfe, Garten und sonstigen Plätze im Dorfe müssen den allgemeinen polizeilichen Vorschriften entsprechend und so wehrbar eingefriedigt werden, dass der Überlauf des Viehs dadurch vollständig gehindert wird.

Wegen Herstellung und Unterhaltung der Befriedigungen im Dorfe sollen, wenn die Grundstücke in ihrer alten Lage bleiben, auf bei den vor der Teilung darüber Hergebrachten bleiben.

Gehen aber die Grenzen und Eigentümer aus der Teilung neu hervor, so hat jeder Nachbar die Herstellung und Unterhaltung der halben Befriedigung zu übernehmen.

Sollte eine bisher bestandene Grenze zwar neu gebildet, indessen nur etwas von der alten Richtung verlegt worden, also eigentlich in die Stelle einer alten eingegangenen treten, so gilt für die neue Grenze was für die alte hergebracht ist.

Tritt der Fall ein, daß eine Fläche, welche seither von jeder Seite eingefriedet war, verteilt wird, also jetzt nur eine Befriedigung erforderlich zu werden, so übernimmt die Befriedigung jeder zur Hälfte.

Im übrigen bleibt die Art der Begrenzung den beiden Anliegenden zwar überlassen, jedoch ist jeder zu einer sicheren Begrenzung seiner Grundstücke verpflichtet, und soll, falls sich die Grenznachbarn nicht einigen können, ein 3 Fuß breiter Graben als Regel der Begrenzung gelten, wozu jeder die halbe Fläche hergibt, den halben Auswurf übernimmt und seine Hälfte sofort machen muss, sobald der eine seine Hälfte verrichten will.

Alle toten Befriedigungen kommen unmittelbar auf die grenze zu stehen.

Alle an den Wegen, gemeinschaftlichen Plätze erforderlichen Befriedigungen von Planken, Schluchter, Staketen, aufgesetzten Gräben, Hecken pp. werden ohne Zutun der Gemeinde von dem betreffenden Koppelbesitzer allein hergestellt und unterhalten, ausgenommen jedoch die an den Gemeindebaulichkeiten und deren Umgebung etwa herzustellenden Befriedigungen.

Übrigens sind die der ganzen Gemeinde oder einem Teil derselben gehörenden Grundstücke mit dem anliegenden Koppelbesitzern auf verlangen zu gleichen Teilen mit 3füßigen Grenzgräben zu versehen.

Die Verpflichtung der Gemeinde am Schulhause die erforderlichen Befriedigungen herzustellen und zu unterhalten bleibt nach wie vor bestehen.

Die Feldmarksgrenzen sind ausgenommen im Ackerlande und falls nicht schon Grenzgräben vorhanden mit 4 Fuß breiten Gräben zu bezeichnen, welche der an der Grenze liegende Koppelbesitzer gemeinschaftlich mit der ganzen Interessentenschaft zu gleichen Teilen herzurichten hat. Die demnächstige Unterhaltung dieser Gräben fällt jedoch dem Koppelbesitzer allein zu, so wie derselbe auch das Terrain allein dazu hergeben muß.

Alle Befriedigungen dürfen nicht höher als 6 Fuß angelegt werden.

g. Instandsetzung und künftige Unterhaltung der Wege, Wegegräben, Abzugsgräben \&p.

Alle neu angelegten Wege werden mit entsprechend breiten Gräben versehen, ausgenommen jedoch der Regel nach die Wege im Dorfe und die unter 24 Fuß breit abgesteckten Wege.

Dienen die Wegegräben zum Abzuge des Wassers zugleich, so sind sie nach dem Gefälle auszugraben, und können in diesem Falle auch Gräben an den Wegen im Dorfe vorgerichtet werden.

Die erste Instandsetzung und künftige Unterhaltung der Wege und Wegegräben, nicht weniger die erste Herstellung und künttige Unterhaltung der Brücken und Siele in den Wegen, der Stege, Handweiser, Schlagbäumen, Warnungstafeln pp., so weit die Dorfgemeinde überhaupt dazu verpflichtet ist, geschieht von allen einheimischen Interessenten ohne Unterschied nach dem Kuhweidenwerte der Gesamt-Abfindung; ebenso werden auch die Abzugsgräben von der ganzen Interessentenschaft gestanden. 
Die Beschaffung aller gemeinschaftlichen Verrichtungen wird teils unter Bekanntmachung der zur ordnungsmäßigen Ausführung dienlichen Bedingungen an den Mindestfordernden abgegeben, also für bares Geld gemacht, teils auch durch Gemeinschaftsdienst hergerichtet.

Geschieht das Letztere, so sollen dabei folgende Bestimmungen gelten:

1. Das Maß der Dienstleistungen wird durch den Kuhweidenwert der Gesamt-Abfindung gegeben.

2. Niemand ist verpflichtet mit dem Spanne zu dienen, der nicht selbst Spanne hat.

3. $\quad$ Für jeden Handdiensttag, wozu nur erwachsene Personen geschickt werden dürfen, sollen in barem Gelde $=60 \mathrm{gGr}$ gerechnet werden .

4. Für jeden mit 1 Pferde geleistet Spanndiensttag werden mit Einschluss des Fuhrmanns 4 Handdiensttage oder 1 RT bares Geld gerechnet.

5. Jeder mit 2 Pferden gediente Tag wird mit Einschluss des Fuhrmanns zu 7 Handdiensttagen oder 1RT $18 \mathrm{gGr}$ gerechnet.

6. Ein mit 2 Ochsen geleisteter Spanndiensttag wird dem mit 1 Pferde gleich zu 1 RT Geld gerechnet.

7. Die Bestellung zu den Gemeindediensten geschieht durch den Gemeindevorstand oder durch den etwa zu bestellenden Wegevogt, und ist im Falle, der Bestellung wird nicht Folge geleistet, wird neben einer festzusetzenden Ordnungsstrafe der vorhin für die betreffenden verschiedenen Dienstleistungen angenommene Geldwert zu erlegen.

Alle über die Wege und Abzugsgräben erforderlichen Übergänge nach den Koppeln und in den Koppeln werden von den betreffenden Koppelbesitzern auf ihre Kosten vorgerichtet und unterhalten.

h. Künftige Benutzung der Wege, Gräben \&p:

Die Benutzung der sämtlichen gemeinschaftlichen Wege zur Passage und zum Treiben mit dem Vieh steht jedermann frei und ungehindert zu.

Sämtliche Communicationswege sollen mit Bäumen bepflanzt werden, die Bäume sind auf der einen Seite zur Bildung eines Fußweges in genügender Weite von der Grabenkante zu setzen.

Alle sonstigen Nebennutzungen auf den Wegen sind der Regel nach verboten, jedoch soll es einem Gemeindebeschluss überlassen bleiben, ob Nebennutzungen auf den Koppelwegen, welche die Erhaltung der Wege nicht beeinträchtigen, zum Nutzen der Gemeindekasse meistbietend verpachtet werden sollen.

Das Anlegen von Mieten, Kartoffelkuhlen pp. in den Wegegräben ist untersagt, dagegen dürfen dieselben gleich den Grenz- und Koppelgräben zur Ableitung des Grund- und Regenwassers von jedem benutzt werden, und sind deshalb stets in gutem Stande zu erhalten, weshalb dann auch in folgenden Gräben keine Auffuhrbänke stehen bleiben dürfen, sondern gehörige Wegeübergänge von den Koppelbesitzern hergerichtet werden müssen.

i. Concurrenz zu den Teilungskosten

Die gemeinsamen Teilungskosten werden von jedem Interessenten mit Ausschluss der auswärtigen Grundbesitzer und der Schule, für welche letztere die Schulgemeinde eintritt, nach dem Kuhweidenwerte seiner Gesamt-Abfindung getragen, wobei jedoch zu bemerken, dass den Forst-Interessenten der Anteil davon und den Teilnehmern an den zum Verkauf reservierten Stämme nach dem Anteil davon zuzusetzen ist.

k. Anlage gemeinschaftlicher Abzugsgräben, gegenseitige Verpflichtung der Beteiligten hinsichtlich des Wasserlaufs.

Zur Entwässerung der Feldmark werden die natürlichen Wasserzüge beibehalten.

Außerdem werden die angelegten Abzugsgräben, die Wege- und Koppelgräben zu Ent- und Bewässerungen benutzt. 
Bei allen außer diesen Anlagen annoch erforderlichen Wasserzügen gilt die allgemeine Regel, dass jeder unterhalb liegende verpflichtet ist, das inm von oberhalb belegenen Grundstücken zufließende Wasser aufzunehmen und weiter zu schaffen.

Zu diesem Ende müssen auf den Grenzen der Wiesen, Feld- und Gemeinheitskoppeln dann jedes Mal 3 Fuß breite Gräben von den Koppelbesitzern vorgerichtet und im zugbaren Stande erhalten werden, wenn solche zur Entwässerung der oberhalb befindlichen Grundstücke erforderlich sind, und dürfen durch keine anderen Grenzmerkmale ersetzt werden.

$\S 9$

Schluß

Da der vorliegende Rezeß lediglich die Sicherstellung der rechte und Gerechtsame der Interessenten bezweckt, so verpflichten sich dieselben zu einer unverbrüchlichen Festhaltung an den Bestimmungen des Recesses, und entsagen allen dagegen vorzubringenden Einwände und Ausflüchten ausdrücklich, wie sie solches durch eigenhändige Unterschrift bezeugen.

So geschehen Beedenbostel, am 16. Oktober 1857.

Thies, Meyer, Schöndube, Schwägermann, Hermanns, Schumeier, Lüßmann, Karsten Heinrich Koch, Johann Heinrich Thies, Wiellahn Herbold, Johann Heinrich Graue, Bergmann, Bergmann, Vormund der Meierschen Erben, Bergmann, Thies Anb., Johann Heinrich Wilhelm Eggers, Knoop, Thies, Dralle, Wulf, Koch, Drewsen

und so geschehen zu Beedenbostel den 5. Februar 1858.

Friedrich Meyer, Johann Heinrich Thies, Karsten Heinrich Lüßmann, Johann Heinrich Meyer, Heinrich Wilhelm Kohlmeyer, Heinrich Bunckenburg, Carsten Heinrich Dralle, Bühring, Johanhim Thies, Karsten Heinrich Misselhorn, Carsten Heinrich Thölke, Meyer, Häusling, Johann Heinrich

und so geschehen Beedenbostel am 10. Februar 1858.

Heinrich Ahrens, Friedrich Ramberg, G. Wolter, H. Lilje, C. Surburg

Auch so geschehen zu Beedenbostel am 10 April 1858.

Heinrich Friedrich Tiemann, Schullehrer, laut Vollmacht Königl. Consistorii vom 20. März 1858

ferner: Gesehen zu Celle den 7. Februar 1859

Dreyer Cammer-Commissair,

als Domanial-Vertreter laut Vollmacht v. 7. Aug. 1854 unter Bezugnahme auf die annectirten Protokolle des Königl. Amts Beedenbostel v. 21. d. M. und des Königl. Amts Celle vom heutigen Tage.

Originalisierte Abschrift

Geschehen am Amte Beedenbostel, am 5. Februar 1858

betreffend : die Vollziehung des Recesses über die im Privat-Wege vorgenommene Specialteilung und Verkoppelung in Lachendorf.

Zur Vollziehung des Receesses erschienen auf die Ladung vom 27. v. Mts

1. der Syndicus, Vorsteher Thies - Ruschen 
2. der Syndicus Vollmeier Thies - Bock

3. der Syndicus Schmidt Meyer

4. der Geometer Franke

5. der Vollmeier Carsten Heinrich Lüßmann

6. der Vollmeier Joh. Heinrich Meyer - Coors

7. der Vollmeier Hr. Wilh. Kohlmeyer

8. der Köthner Joh. Hr, Bunkenburg

9. der Köthner Joh. Hr. Dralle - Dralle

10. der Köthner Joh. Hr. Bühring

11. der Köthner Joh. Hr. Thies - Thies

12. der Köthner Carsten Hr. Misselhorn

13. der Abbauer Heinrich Ahrens

14. der Abbauer Carst. Hr. Thölke

15. der Häusling Joh. Hr. Meyer

und

16. der Schullehrer Tiemann, mithin fehlte:

1. der Abbauer Friedr. Ramberg,

2. der Abbauer Gottfried Wölter

3. der Abbauer Christoph Suderburg

und

4. Abbauer Heinrich Lilie

Köthner Joh. Hr. Dralle zeigte an, daß er von dem Abbauer Wolter Auftrag habe, und Syndicus Vorsteher Thies erklärte Gleiches wegen des Abbauers Friedr. Ramberg.

Ap: term:

Erklärten sämtliche Comparenten, daß sie mit dem Inhalte des Recesses vollständig bekannt wären, und daher auf die Verlesung desselben verzichteten.

Hierauf

sind diejenigen, welche dem Receß noch nicht unterschrieben haben, über die Bereitwilligkeit zur Vollziehung oder ihre Weigerungsgründe vernommen wie folgt; und ist darauf vom Syndicus resp. Geometer Franke sofort Nachstehendes erwidert:

1. Vollmeier Carsten Heinr. Lüßmann:

Zum Nutze seiner neu angelegten Wiese am Gerlohsgehäge verlange er eigentümlich einen Streifen aus der anliegenden Gemeinheit, welche er zum Schutze gegen Sandwehen mit Holz besetzen beabsichtigt.

Wenn das geschehen, sei er zur Vollziehung bereit.

Geometer Franke

Die angegebene Gemeinheit sei zur Gemeindeforst ausgesetzt, welche er durch die beantragte Anlegung nicht zu kürzen berechtigt sei, weshalb er den Antrag hiermit ablehne.

Amtsseitig

ist dem Interessenten empfohlen, den Gegenstand in Überlegung zu nehmen und möglichst durch Vereinbarung den Einwand zu beseitigen.

2. Vollmeier Joh. Hr. Meyer - Coors:

Er sei zur Vollziehung des Recesses bereit.

3. Vollmeier Hr. Wilh. Kohlmeyer:

Er verlange einen Weg zu seinem Immenzaun, in der Ahnsbecker Feldmark belegen. Sobald dieser Weg angelegt sei, sei er zur Vollziehung des Recesses ebenfalls bereit.

Geometer Franke 
Wenn Kohlmeyer den Weg früher, vor Anlegung der Koppeln, verlangt hätte, so würde derselbe angelegt sein, jetzt habe die Anlage ihre Schwierigkeiten. Syndici:

Den Fußweg gestehen sie zu, nicht aber den Fahrweg, welcher nur einige wenige Male im Jahr benutzt werde, da Kohlmeier auf einigen Umwegen zur Immenstelle gelangen könne.

Kohlmeier

war mit diesem Zugeständnisse nicht zufrieden, weshalb die Differenz durch Schiedsrichter zu beseitigen bleibt.

Mit

diesem Vorerhalte, erklärte Kohlmeier, sei er zur Vollziehung des Recesses bereit.

4. Vollmeier Joh. Hr. Thies - Bock:

Er verlange, dass die auf der Karte angegebene Trift von dem Bulloh nach der Tränke an den Bullohwiesen abgesteckt werde, und sei er, sobald das geschehen, zur Vollziehung bereit.

Geometer Franke:

Sobald es das Wetter gestatte, werde die Trift abgesteckt.

Thies:

Mit diesem Vorbehalt sei er zur Vollziehung bereit.

5. Köthner Joh. Hr. Bunkenburg:

Er sei zur Vollziehung des Recesses bereit.

6. Köthner Joh. Hr. Dralle - Dralle:

Er trete der Erklärung von Bock-Thies bei, und sei mit der Verteilung des Torfmoores nicht zufrieden.

Was letzteren Gegenstand betrifft, so ist darüber die weitere Verhandlung bis zum Schlusse des Protokolls amtseitig ausgesetzt.

7. Köthner Joh. Hr. Bühring:

Er sei zur Vollziehung des Recesses bereit.

8. Köthner Joh. Hr. Thies - Theis

a. Er könne die Grenze seiner Koppel am Bunkenburger Weg nicht auffinden, und verlange, dass inm dieselbe angewiesen werde.

b. Er habe in der Nähe seines Hofes ein Immengehäge gehabt, welches inm ohne seine Zustimmung genommen sei, er verlange die Rückgabe desselben.

c. Auch sei er nicht damit einverstanden, dass ihm sein Holzbusch im Westerkamp genommen sei; und endlich

d. sei er mit der Verteilung des Torfmoores nicht zufrieden.

Geometer Franke

ad a, handele es sich um die Feldmarksgrenze, welche er nicht anzuweisen verpflichtet sei.

Vereinbart

daß Syndici, Geomater Franke und Reclamant sich allerehestens am Ort und Stelle begeben, und die Grenze ausweisen wollen.

$a d b$, erklärte p. Franke, daß Reclamant schon früher Recurs über diesen Gegenstand eingelegt, aber nicht verfolgt habe.

ad c, Wie vorhin ad b.

ad d, ist die Verhandlung wegen des Torfmoores bis zum Schlusse des Protokolls ausgesetzt.

Köthner Thies - Theis:

Er habe den eingelegten Recurs nicht verfolgen können, weil er die erbetenen Protokolle nicht erhalten.

Schließlich

hat sich Reclamant, mit Vorbehalt dieser Reklamation, zur Vollziehung des

Recesses bereit erklärt.

9. Köthner Carsten Heinrich Misselhorn. 
In seiner Koppel in der Allerheide befinde sich eine Bienenstelle, dem Carsten Heinr. Dralle - Bolzmann zugehörig, worüber vereinbart sei, daß dieselbe verlegt werden sollte.

Sobald diese Verlegung geschehen sei, sei er zur Vollziehung des Recesses bereit. Geometer Franke.

Die Reklamation sei richtig und werde er dieselbe sofort abstellen.

$$
\text { Misselhorn }
$$

Mit dem obigen Vorbehalt sei er zur sofortigen Vollziehung des Recesses bereit.

10. Anbauer Syndicus Georg Fr. Meyer.

Er reklamiere, daß die Verkoppelung und Gemeinheitsteilung nicht so zur Ausführung gekommen sei, als von dem Herrn Amtmann Gadenstedt zu Protokoll niedergeschrieben sei.

Postea. Diese allgemeine Reklamtion wolle er aufgeben. Dagegen aber sei er mit der Verteilung des Torfmoores nicht zufrieden, und wolle darauf seine Reklamation beschränken.

\section{Amtsseitig}

ist die Verhandlung darüber bis zum Schlusse des Protokolls ausgesetzt. Reklamant

Mit Vorbehalt dieser Reklamation sei er zur Vollziehung des Recesses bereit.

11. Für Abbauer Frdr. Ramberg erklärt Vorsteher Thies, daß derselbe zur Vollziehung des Recesses bereit sei.

12. Für Abbauer Gottfried Wolter zeigt Köthner Joh. Hr, Dralle rect. Carst. Hr. Dralle an, daß derselbe mit der Verteilung des Torfmoores nicht zufrieden sei, sonst aber nichts vorzubringen habe.

13. Abbauer Heinrich Ahrens.

Seine Heidkoppel sei noch nicht begrenzt. Sobald dieses geschehen sei, wolle er den Receß vollziehen.

Geometer Franke.

Die Grenzphähle möchten verloren gegangen sein. Er wolle die Wiederherstellung nächstens vornehmen.

Ahrens

Mit diesem Vorbehalte wolle er den Receß vollziehen.

14. Abbauer Carst. Heinr. Thölke

Er reklamiere wie Ahrens wegen der Grenze seiner Heidkoppel, und sei auch mit der Verteilung des Torfmoores nicht zufrieden.

Mit diesem Vorbehalte sei er zur Vollziehung des Recesses bereit.

Die

Verhandlung über die Verteilung des Torfmoores ist bis zum Schluss des Protokolls ausgesetzt.

15. Häusling Joh. Hr. Meyer.

Er sei zur Vollziehung des Recesses bereit.

16. Schullehrer Tiemann.

Er lehne die Vollziehung des Recesses bis dahin ab, daß er vom königlichen Consistorio Vollmacht erhalten habe

\section{Schließlich}

ist nunmehr die Verhandlung über die einzelnen Reklamationen wegen der Verteilung des Torfmoores wieder aufgenommen.

\section{Es haben reklamiert}

1. Köthner Joh. Hr. rect. Carsten Heinrich Dralle - Dralle

2. Köthner Joh. Hr. Thies - Theis ${ }^{1}$

3. Anbauer Syndicus Georg Frdr. Meyer

4. Abbauer Gottfried Wolter

\footnotetext{
${ }^{1}$ Die Schreibweise des 2. Namens ist nicht einheitlich: meistens Theis, aber auch Thies
} 
5. Abbauer Carsten Hr. Thölke

Dieselben haben hierauf ihre Reklamationen folgendermaßen ausgeführt:

1. Köthner Dralle für sich allein:

Er könne seine Abfindung nicht nutzbar machen, weil er nicht darauf kommen könne.

Geomater Franke:

Die Moorkoppel liege am s.g. Dammwege, wovon derselbe Gebrauch machen könne und müsse.

Reklamant:

Von dem Wege könne er keinen Gebrauch machen, weil er sonst über den sehr breiten Graben eine sehr kostspielige Brücke bauen müsse, wozu er sich nicht verstehen könne.

Amtsseitig

ist die Reklamation zur weiteren Untersuchung durch Sachverständige verwiesen.

2. Köthner Joh. Hr. Thies - Theis

reklamiert wie vorhin Dralle, weshalb derselbe mit der Reklamation zur weiteren Untersuchung durch Sachverständige ebenfalls verwiesen ist.

3. Köthner Dralle

Köthner Thies

Anbauer Meyer

Abbauer Wolter und

Abbauer Thölke

gemeinschaftlich.

Die Schule habe von jeher ihre Feuerung aus dem gemeinschaftlichen Torfmoore erhalten. Nachdem nunmehr das Torfmoor geteilt sei, solle jeder Interessent zur Heizung der Schulstube Feuerung liefern.

Da dieses den früheren Verhältnissen nicht entspreche, so müssten sie darauf dringen, dass für die Heizung der Schulstube, diesen früheren Verhältnissen entsprechend, von der Interessentenschaft gesorgt werde.

Die Sache wurde hierauf vielfach besprochen, und stellten sich dabei folgende Fragen heraus:

1. die Schulstelle zur Heizung der Schulstube die Abfindung mit erhalten, oder nur für die Berechtigung allein? Und

2. können Abbauer und Häusling insbesondere, so wie die reklamierenden Hauswirte, den übrigen Interessenten gegenüber verlangen, dass zur Heizung der Schulstube eine besondere Moorkoppel ausgesetzt $b$ wird?

Geometer Franke entfernte sich während der weiteren Besprechung, nachdem jedoch bis hinzu die Verhandlung vorgelesen war.

Reklamanten erklärten sodann

ad 1.

Da der Geometer Franke bereits erklärt habe, dass die Schulstelle für die Schulstube nicht abgefunden sei, sondern nur ihre berechtigte Abfindung erhalte, so wollten sie die Untersuchung dieser Frage hiermit aufgeben.

ad 2.

Sie wollten sich für die Gesamtheit nicht aufopfern, und auch diese Frage verneinen; mithin

ihre ganze Reklamation wegen des Torfmoores in Betreff der Schule und Schulstube hiermit aufgeben.

\section{Schließlich}

unterschrieben sämtliche Interessenten den Receß und erklärten Dralle und Thies - Theis, dass sie ihre Reklamation wegen des Abfuhrweges von der Moorkoppel hiermit aufgeben wollten, nachdem innen zuvor vom Gemeinde-Vorsteher und Beamten gestattet ist, durch den Graben an der Moorkoppel nach dem Dammwege für einen Abfuhrdamm mit einer Röh- 
re im Untergrunde zu legen, wodurch das sich ansammelnde Wasser im Graben abfließen kann.

Vorgelesen und genehmigt.

Zur Beglaubigung

(L.S.) gez. Ebert

Fortgesetzt daselbst am 20. Februar 1858

Nachdem die im vergangenen Termin ausgebliebenen Interessenten

Abbauer Heinr. Ahrens

" Friedr. Ramberg

" Gottfr. Wolter

" Heinr. Lilie und

" Chrisoph Surburg

Den Rezeß am 10. Febr. durch ihre Namensunterschrift vollzogen hatten, erschienen heute auf Ladung vom 15. d. Mts.

1. Vollmeier Hr. Chrst. Bergmann Bnd. Cass. Nr. 5

2. " Carst. Hr. Schumeier " ", 7

3. Halbmeier Chrstph Hr. Schöndube " " " 8

4. Köthner Joh. Hr. Thies - Cammann " " " 11

5. " Carst. Hr. Dralle - Bolzmann " " " 17

6. “ Joh. Hr. Thies - Krüger 18

7. “ Carst. Hr. Schwägermann 20

8. “ Hr. Chrph Thies - Graue, Vorsteher 13

9. „ Carst. Hr. Koch 9

10. Witwe Köthner Jürg. Hr. Hermanns, beb Müller 12

11. Brinksitzer Joh. Hr. Wulf 22

12. " Christoph Lüßmann 24

13. " Joh. Hr. Lilie, jetzt Joh. Hr. Wilhelm Eggers 23

14.Anbauer Christoph Thies 34

15. " Carst. Christoph Meyer 21

16. " " Carst. Rect. Jürgen Hr. Bergmann 28

17. “ Joh. Hr. Knop 25

18. " Wilhelm Herbold 35

19. " Heinrich Koch 27

20. für Häusl. Joh. Friedr. Meyer Erben, der Vormund Bergmann

21. Abbauer Joh. Hr. Graue

Sämtlichen Comparenten wurde die Unterschrift des Recesses zur Ansicht verstellt, worauf dieselben die Unterschrift anerkannten, Vormund Bergmann jedoch erklärte, dass er die Genehmigung der Obervormundschaft vorbehalte, wesfalls denselben aufgegeben ist, dieselbe forderhand nachzuliefern.

Vorgelesen und genehmigt.

Zur Beglaubigung

(L. S@) (gez.) Ebert

Fortgesetzt daselbst am 12. März 1858

Der Vorsteher Thies aus Lachendorf sistierte die nachgenannten Teilungs-Interessenten, welche wegen ihrer zu dem Recesse am 5. v. Mts. Gemachten Erinnerungen die nachstehenden Erklärungen abgaben:

ad 1. Vollmeier Carsten Hr. Lüßmann:

Er sei zufrieden gestellt und nehme seinen Einwand nunmehr hiermit zurück.

ad 3. Vollmeier Heinr. Wilh. Kohlmeier:

Er sei nicht zufrieden gestellt und wolle seine Reclamation nicht aufgeben.

ad 4. Vollmeier Joh. Heinr. Thies - Bock: 
Die Trift sei jetzt abgesteckt, und sei er zufrieden.

ad 5. Köthner Joh. Heinr. Dralle alias Dralle wie p. Thies alias Bock

ad 8. Köthner Joh. Hr. Thies alias Theis

Vorsteher Thies zeigte an, daß derselbe ebenfalls zufrieden gestellt sei.

$\mathrm{Da}$ indeß derselbe nicht anwesend war, so wurde dem Vorsteher erwidert, daß Reclament solches hieselbst zu Protokoll selbst anerkennen müsse.

ad 9. Köthner Carst. Heinr. Misselhorn:

Die Bienenstelle sei verlegt, und der daher zufrieden.

ad 11. hatte Abbauer Ramberg,

ad 12. Abbauer Wolter und

ad 13. Abbauer Ahrens den Receß laut Protokoll vom 20. Febr. Ohne Vorbehalt vollzogen, weshalb daran Erinnerungen dadurch erledigt waren.

ad 14. Abbauer Thölke

war nicht anwesend, und Hatte dafür ebenfalls noch seine Erklärung der geschehe-

nen Zufriedenstellung abzugeben.

ad 16. Schullehrer Tiemann:

Die Genehmigung des Königlichen Consistorii blieb noch immer vorbehalten.

Die übrigen Reklamationen waren durch die Schlussversammlung vom 5. Febr. Erledigt.

Vorgelesen und genehmigt.

Zur Beglaubigung

(L. S.) (gez.) Ebert

Fortgesetzt daselbst am 13. Febr.

ad 17. Abbauer Thölke zeigte an, dass er jetzt zufrieden sei.

Vorgelesen und genehmigt.

Zur Beglaubigung

(L. S.) (gez.) Ebert

Fortgesetzt daselbst am 24. März 1858

Vorsteher Thies (Ruschen) fand sich mit Vollmeier Kohlmeier und Vollmeier Thies (Bock) ein, und überreichten Comparenten das anliegende, heute vom Geometer Franke aufgenommene Vergleichsprotokoll, welches vorgelesen und von ihm genehmigt wurde.

p. Kohlmeier erklärte, dass er nunmehr zufrieden sei, und seinen Einwand gegen den Receß hiermit aufgebe.

Vorgelesen und genehmigt.

Zur Beglaubigung

(L. S.) 8gez.) Ebert

Forstgesetzt daselbst am 25. März 1858

Vorsteher Thies erschien mit dem Köthner Joh. Hr. Thies - Theis, und zeigt letzterer an, dass er sich mit dem ersteren und dem Krüger Thies wegen des Immengehäges und des Holzbusches geeinigt habe, weshalb er seinen Einwand gegen den Receß hiermit zurücknehme.

Vorgelesen und genehmigt.

Zur Beglaubigung

(L. S.) (gez.) Ebert

Fortgesetzt daselbst am 10. April 1858

Schullehrer Tiemann aus Lachendorf überreichte die anliegende Vollmacht des Königlichen Consistorii vom 20. v. Mts., und erklärte, dass er nunmehr zur Vollziehung des Recesses bereit sei. Es wurde darauf der Receß von ihm vollzogen.

Vorgelesen und genehmigt.

Zur Beglaubigung

(L. S.) (gez.) Ebert 
Fortgesetzt daselbst am 12. Juni 1858

Herr E. Drewsen aus Lachendorf ließ sich den Receß vorlegen, und erklärte, dass er seine Namenunterschrift und den Inhalt des Recesses hiermit anerkennen wolle.

Abschrift:

Vorgelesen und genehmigt.

Zur Beglaubigung

(L. S.) (gez.) Ebert

Geschehen Beedenbostel am 24. März 1858

Ad acta betreffend die Specialteilung und Verkoppelung von Lachendorf erschienen vor dem unterzeichneten Geometer nachbenannte Personen aus Lachendorf:

Vorsteher Thies,

Vollhöfner Thies / Bock / und

Vollhöfner Johlmeier

und gaben Folgendes zu vernehmen:

Es sei zur Beseitigung der Differenz, welche in ihrer Teilungs-Angelegenheit noch wegen eines dem Vollhöfner Kohlmeier zugestandenen Weges nach dessen Immenstelle in der Ahnsbecker Feldmark vorliege, folgender Vergleich abgeschlossen:

Der Vollhöfner Thies /Bock/ räumt dem Vollhöfner Kohlmeier das Recht ein, durch seine Koppel in den Ackern und im Bährenblau nach der vorhin bezeichneten Immenstelle zu fahren, gesteht ihm dabei auch zu über seinen Hof zu fahren, solange er Thies selbst vom Hofe ab einen Weg in der Ackerkoppel beim Hause, welcher nach dem Bährenblau zu führt, liegen lasse. Lasse er „Thies“ diesen Weg aber eingehen, so soll Kohlmeier gehalten sein den Hauptweg durch die Ackern so lang nachzufahren, bis er auf dem Weg, welchen Thies von da ab in seiner Bährenblaukoppel liegen läßt, zu seiner Immenstelle gelangen kann.

Der Vollmeier Thies /Bock/ erhält für Übernahme dieses Weges eins für alles Acht $T$ Cour. Aus der Gemeinde-Casse.

Vorgelesen und genehmigt.

Zur Beglaubigung

(gez.) Franke

Zur Beglaubigung der Abschrift:

(L. S.) (gez.) Ebert

Originalisierte Abschrift:

Geschehen am Amt Beedenbostel am 21. Jan. 1859

betreffend: den Teilungs- und Verkoppelungs-Receß von Lachendorf

Auf Ladung vom 16. d. M. erschienen beide Syndici:

Vorsteher Thies und

Vollmeier Joh. Heinrich Thies / Bock/

Und ließen sich über die Erinnerungen des Cammer-Commissaits Dreyer vom 14. d. M. zu dem Teilung \&p. Recesse folgendermaßen vernehmen:

ad 2. werde zugestanden, dass der Herrschaft die Fischereiberechtigung in der Lachte und Aschau zustehe, auch zugestanden, dass bei der Ausübung derselben das Ufer betreten werden dürfe.

Es sei daher nichts dabei zu erinnern, dass solches nachträglich zu dem Recesse bemerkt würde.

ad 3. werde die Unverständlichkeit aberkannt.

Es ist daher nach Verlesung und Genehmigung den Syndicis der Receß übergeben, um die fehlenden Worte durch den Geometer Franke nachtragen zu lassen.

Vorgelesen und genehmigt.

Zur Beglaubigung 


\section{(L. S.) (gez.) Ebert}

Geschehen Celle d. 7. Febr. 1859

Erschienen der Herr Cammer-Commissair Dreyer von hier und erklärte, dass er seine unter dem vorstehenden Recesse (vor dem Protokolle des Königl. Amtes Beedenbostel vom 5. Febr. V. J.) befindliche Unterschrift als von inm eigenhändig vollzogen damit anerkenne, zugleich aber zu dem in $\S 4$, sub $9 \mathrm{c}$ des Recessses enthaltenen amtlichen professo und der im $\S 5$ ad c sich befindenden bezüglichen Bemerkungen hiermit erklären wolle:

„er räume ein, dass das Domanium bei Gelegenheit der Generalteilung der Allerheide auch in Anschauung des hier in Frage stehenden Teilungsobjektes bereits für die grundherrlichen Rechte abgefunden sei und dass daher hier von einem Anspruch auf ein etwaiges Superfluum abstrahiert werde."

In fidem

(gez.) Stölting

Gegen den Inhalt des vorstehenden Recesses ist in Bezug auf das öffentlliche Interesse nichts zu erinnern gefunden.

Lüneburg, den 7. April 1860

Königlich Hannoversche Landdrostei

$$
\text { (L. S.) (gez) E. v. Torney }
$$

In Betreff der Gemeinheits-Teilung von Lachendorf besonders wegen der der Amtsgehülfenstelle in Beedenbostel zu prästirenden Feuer-Eiche beauftragen und bevollmächtigen Wir damit den Herrn Cammer-Commissair Dreyer zu Celle die Rechte des Domanii bei den eingeleiteten qu. Verhandlungen nachzugehen und zu vertreten, die dabei erforderlichen Erklärungen und Zustimmungen abzugeben, Vergleiche abzuschließen, den Aufzustellenden Receß zu vollziehen, sich eine oder mehrere Afterbevollmächtigte zu substituiren ${ }^{1}$ und überhaupt alle bei diesen Verhandlungen vorkommenden Geschäfte, aber vorbehältlich der dem genannten Bevollmächtigten oder dessen Afterbevollmächtigten gegen Uns obliegenden Verantwortlichkeit, Namens Unserer vorzunehmen.

Urkundlich dessen ist diese Vollmacht von Uns ausgestellt und vollzogen.

Hannover, d. 7. August 1854

Königlich Hannoversche Domainen-Cammer

(L. S.) (gez.) Rumann

Vollmacht für

Den Herrn Cammer-Commissair Dreyer zu Celle

Vollmacht:

Da der Schulvorstand von Lachendorf wegen persönlicher Beteiligung der Mehrzahl seiner Mitglieder gesetzlich behindert ist, in den Verhandlungen wegen der Gemeinheitsteilung und Verkoppelung von Lachendorf die Schulstelle zu vertreten, so beauftragen Wir den Herrn Schullehrer Tiemann zu Lachendorf, das Interesse der genannten Schulstelle daselbst in vorgedachter Gemeinheitsteilung- und Verkoppelungssache wahrzunehmen, indem Wir denselben zu allen bei dem Teilungs- und Verkoppelungsgeschäfte vorkommenden Verhandlungen, namentlich zum Abschlusse von Vergleichen ermächtigen.

Urkundlich des hierunter gelegten Consistorial-Siegels und gewöhnlicher Unterschrift. Hannover, den 20. März 1858

Königlich Hannoversches Consistorium, Abteilung für Volksschulsachen

(L. S.) (gez.) Bergmann

Copia:

\footnotetext{
${ }^{1}$ substituiren: heute: substituieren - ersetzen
} 
In Erwiderung auf den Bericht vom 21. Dezember v. J. die Beteiligung der Schulstelle zu Lachendorf bei der Gemeinheitsteilung und Verkoppelung daselbst betreffen, erklären wir Uns mit der Annahme der für die Schulstelle zu Lachendorf örtlich ausgemittelten Abfindungen von 40 Morgen 101 QRth. Zum Werte von 3,743 Kuhweiden einverstanden und lassen den Herrn die für den Schullehrer Thiemann zu Lachendorf als Vertreter der genannten Schulstelle ausgefertigte Vollmacht hieneben zu gehen.

Hannover, den 20. März 1858

Königlich Hannoversches Consistorium für Volksschulsachen.

$$
\text { (gez.) Bergmann }
$$

An die Herren Kirchen-Commissarien von Lachendorf

$$
\text { Pro copia (gez.) Lueder }
$$

Copia:

Geschehen vor Königlichem Amtsgerichte Celle, Abteilung IV.

am 9. September 1859

In Folge Schreibens des Königlichen Amtes Celle vom 19/24 August c.

Betreffend

Erteilung der obervormundschaftlichen Genehmigung zu dem Abschlusse des aufgenommenen Recesses über die Spezialteilung und Verkoppelung der Feldmark Lachendorf,

für

die Meyersche und Thiessche Vormundschaft zu Lachendorf,

waren zu Erörterung der Sache auf heute die betreffenden Vormünder vorgeladen:

Es erschienen nun

1) die Meyerschen Vormünder

Jürgen Heinrich Bergmann und

Carsten Heinrich Lüßmann

beide aus Lachendorf

2) der Thiessche Vormund Carsten Heinnrich Schwägermann daher.

Nach deren übereinstimmenden Erklärungen ergab sich, dass das Resultat der fraglichen Teilung wesentlich zum Besten ihrer Curanden gereicht und ist daher die obervormundschaftliche Genehmigung nun erteilt, auch ist denselben beglaubigte Abschrift dieses bewilligt, womit sie dem Königlichen Amte diese obervormundschaftliche Genehmigung nachgewiesen haben werden.

Vorgelesen, genehmigt

Zur Beglaubigung

(L. S.) gez. Reinking

Insinuirt am 21. September 1859

(gez.) Schulz

Gerichtsvoigt 


\section{Verteilungs-Register von der Feldmark Lachendorf} (sowie der Aller- und trockenen Wiesen ${ }^{1}$ )

\section{Vollhöfner und Halbhöfner $\mathrm{a}-\mathrm{h}$}

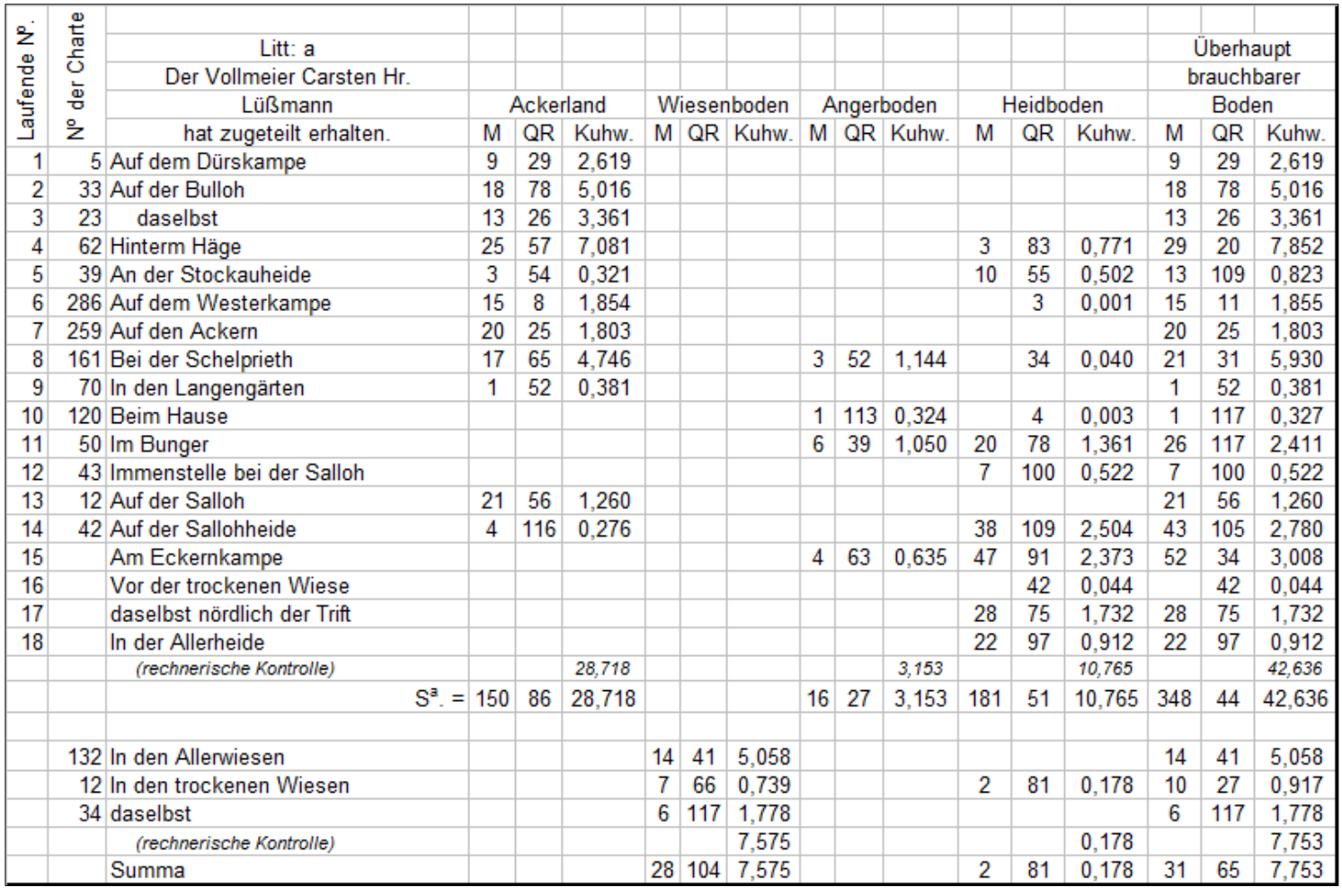

\begin{tabular}{|c|c|c|c|c|c|c|c|c|c|c|c|c|c|c|c|c|c|}
\hline \multirow{5}{*}{ 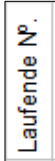 } & \multirow{5}{*}{ 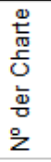 } & & & & & & & & & & & & & & & & \\
\hline & & Litt: b & & & & & & & & & & & & & \multicolumn{3}{|c|}{ Überhaupt } \\
\hline & & Der Vollmeier Joh. Heinrich & & & & & & & & & & & & & \multicolumn{3}{|c|}{ brauchbarer } \\
\hline & & Meyer (Coors) & \multicolumn{3}{|c|}{ Ackerland } & \multicolumn{3}{|c|}{ Wiesenboden } & \multicolumn{3}{|c|}{ Angerboden } & \multicolumn{3}{|c|}{ Heidboden } & \multicolumn{3}{|c|}{ Boden } \\
\hline & & hat zugeteilt erhalten. & M & QR & Kuhw. & M & QR & Kuhw. & M & QR & Kuhw. & M & QR & Kuhw. & $M$ & QR & Kuhw. \\
\hline 1 & 29 & Auf der Bulloh & 33 & 53 & 4,438 & & & & & 112 & 0,281 & 1 & 42 & 0,154 & 35 & 87 & 4,873 \\
\hline 2 & 58 & Auf dem Flottkampe & 13 & 66 & 3,544 & & & & 1 & 85 & 0,285 & 9 & 21 & 1,812 & 24 & 32 & 5,641 \\
\hline 3 & 61 & Hinterm Häge & 24 & 102 & 7,085 & & & & & & & 8 & 17 & 1,552 & 32 & 119 & 8,637 \\
\hline 4 & 260 & In den Ackern & 17 & 83 & 1,989 & & & & & & & & 10 & 0,005 & 17 & 93 & 1,994 \\
\hline 5 & 69 & In den Langengärten & 1 & 3 & 0,253 & & & & & & & & & & 1 & 3 & 0,253 \\
\hline 6 & & Die Fahrwiese & & & & 8 & 100 & 1,975 & & & & 4 & 26 & 0,602 & 13 & 6 & 2,577 \\
\hline 7 & 122 & Beim Hause & & & & & & & 2 & 38 & 0,386 & 1 & 20 & 0,111 & 3 & 58 & 0,497 \\
\hline 8 & 46 & Im Bunger & 3 & 34 & 0,398 & 4 & 25 & 1,712 & 1 & 48 & 0,341 & 5 & 41 & 0,383 & 14 & 28 & 2,834 \\
\hline 9 & & In der Allerheide am Birkenbusch & & & & & & & & & & 72 & 42 & 2,664 & 72 & 42 & 2,664 \\
\hline 10 & & Vor den Wiesen hinterm Canale & & & & & & & 2 & 9 & 0,264 & 9 & 38 & 0,685 & 11 & 47 & 0,949 \\
\hline 11 & & Bei Meyers Immenstelle & & & & & & & & & & 10 & 61 & 1,152 & 10 & 61 & 1,152 \\
\hline 12 & & Im Hockrehmen & & & & & & & 12 & 34 & 2,064 & 21 & 22 & 1,401 & 33 & 56 & 3,465 \\
\hline & & (rechnerische Kontrolle) & & & 17,707 & & & 3,687 & & & 3,621 & & & 10,521 & & & 35,536 \\
\hline & & Summa & 93 & 101 & 17,707 & 13 & 5 & 3,687 & 20 & 86 & 3,621 & 142 & 100 & 10,521 & 270 & 52 & 35,536 \\
\hline & & & & & & & & & & & & & & & & & \\
\hline & 63 & Anschnitt an den Allerwiesen & & & & & 83 & 0,043 & & & & & & & & 83 & 0,043 \\
\hline & 50 & In den Allerwiesen & & & & 10 & 107 & 2,112 & & & & & 15 & 0,007 & 11 & 2 & 2,119 \\
\hline & 69 & daselbst & & & & 4 & 67 & 0,808 & & & & & & & 4 & 67 & 0,808 \\
\hline & 91 & daselbst & & & & 11 & 117 & 3,932 & & & & & & & 11 & 117 & 3,932 \\
\hline & & (rechnerische Kontrolle) & & & & & & 6,895 & & & & & & 0,007 & & & 6,902 \\
\hline & & Summa & & & & 28 & 14 & 6,895 & & & & & 15 & 0,007 & 28 & 29 & 6,902 \\
\hline
\end{tabular}

\footnotetext{
${ }^{1}$ Den Daten für die einzelnen Höfe aus dem „Rezeß über die Spezialteilung und Verkoppelung der Feldmark von Lachendorf“" von 1858/59 sind hier auch die Daten aus der „Teilungsurkunde über die Entfrettung und Verkoppelung der Aller- und trockenen Wiesen bei Lachendorf, Amt Celle"von 1866 beigefügt.
} 


\begin{tabular}{|c|c|c|c|c|c|c|c|c|c|c|c|c|c|c|c|c|c|}
\hline \multirow{5}{*}{ 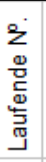 } & \multirow{5}{*}{ 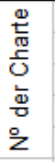 } & & & & & & & & & & & & & & & & \\
\hline & & Litt: c & & & & & & & & & & & & & \multicolumn{3}{|c|}{ Überhaupt } \\
\hline & & Der Vollmeier Wilhelm & & & & & & & & & & & & & \multicolumn{3}{|c|}{ brauchbarer } \\
\hline & & Kohlmeyer & \multicolumn{3}{|c|}{ Ackerland } & \multicolumn{3}{|c|}{ Wiesenboden } & \multicolumn{3}{|c|}{ Angerboden } & \multicolumn{3}{|c|}{ Heidboden } & \multicolumn{3}{|c|}{ Boden } \\
\hline & & hat zugeteilt erhalten. & M & QR & Kuhw. & M & QR & Kuhw. & M & QR & Kuhw. & M & QR & Kuhw. & M & QR & Kuhw. \\
\hline 1 & 2 & Auf dem Dürskampe & 9 & 74 & 1,893 & & & & & & & & & & 9 & 74 & 1,893 \\
\hline 2 & 26 & Auf dem Kuhlkampe & 1 & 103 & 0,156 & & & & & & & & 9 & 0,003 & 1 & 112 & 0,159 \\
\hline 3 & 63 & Hinterm Häge & 16 & 119 & 3,840 & & & & & & & 6 & 56 & 0,657 & 23 & 55 & 4,497 \\
\hline 4 & 287 & Auf dem Westerkampe & 9 & 106 & 1,389 & & & & & & & & 17 & 0,008 & 10 & 3 & 1,397 \\
\hline 5 & 271 & Auf dem Lohfelde & 24 & 57 & 2,487 & & & & & & & & & & 24 & 57 & 2,487 \\
\hline 6 & 266 & Auf den Ackern & 10 & 119 & 0,794 & & & & & & & 1 & 28 & 0,066 & 12 & 27 & 0,860 \\
\hline 7 & 160 & In der Schelprieth & 21 & 91 & 4,492 & & & & 1 & 45 & 0,539 & 1 & 24 & 0,098 & 24 & 40 & 5,129 \\
\hline 8 & 223 & Hinterm Hohenkampe & 34 & 118 & 8,352 & & & & & & & 1 & 114 & 0,274 & 36 & 112 & 8,656 \\
\hline 9 & 240 & In den Kampgärten & 2 & 24 & 0,562 & & & & 5 & 2 & 1,107 & & & & 7 & 26 & 1,669 \\
\hline 10 & 49 & Im Bunger & & & & & & & 5 & 38 & 0,995 & 4 & 83 & 0,348 & 10 & 1 & 1,343 \\
\hline 11 & 48 & daselbst & & & & & & & 5 & 10 & 0,962 & 1 & 2 & 0,071 & 6 & 12 & 1,033 \\
\hline 12 & & Im Postmoore & & & & & & & 8 & 12 & 0,932 & 68 & 14 & 3,480 & 76 & 26 & 4,412 \\
\hline 13 & & An den Ackern & & & & & & & & & & & 42 & 0,014 & & 42 & 0,014 \\
\hline 14 & & Am Dammwege & & & & & & & & & & 10 & 104 & 0,669 & 10 & 104 & 0,669 \\
\hline & & (rechnerische Kontrolle) & & & 23,965 & & & & & & 4,535 & & & 5,688 & & & 34,218 \\
\hline & & Summa & 132 & 91 & 23,995 & & & & 24 & 107 & 4,535 & 96 & 13 & 5,688 & 253 & 91 & 34,218 \\
\hline & & & & & & & & & & & & & & & & & \\
\hline & 123 & An den Ahnsbecker Dreckwiesen & & & & 4 & 85 & 0,857 & & & & & & & 4 & 85 & 0,857 \\
\hline & 25 & In den trockenen Wiesen & & & & 14 & 87 & 3,803 & & & & & & & 14 & 87 & 3,803 \\
\hline & & (rechnerische Kontrolle) & & & & & & 4,660 & & & & & & & & & 4,660 \\
\hline & & Summa & & & & 19 & 52 & 4,660 & & & & & & & 19 & 52 & 4,660 \\
\hline
\end{tabular}

\begin{tabular}{|c|c|c|c|c|c|c|c|c|c|c|c|c|c|c|c|c|c|}
\hline \multirow{5}{*}{ 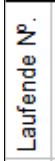 } & \multirow{5}{*}{ 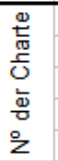 } & & & & & & & & & & & & & & & & \\
\hline & & Litt: d & & & & & & & & & & & & & \multicolumn{3}{|c|}{ Überhaupt } \\
\hline & & Der Vollmeier Joh. Heinr. & & & & & & & & & & & & & \multicolumn{3}{|c|}{ brauchbarer } \\
\hline & & Thies (Bock) & \multicolumn{3}{|c|}{ Ackerland } & \multicolumn{3}{|c|}{ Wiesenboden } & \multicolumn{3}{|c|}{ Angerboden } & \multicolumn{3}{|c|}{ Heidboden } & \multicolumn{3}{|c|}{ Boden } \\
\hline & & hat zugeteilt erhalten. & $\mathrm{M}$ & QR & Kuhw. & $M$ & QR & Kuhw. & $M$ & QR & Kuhw. & $\mathrm{M}$ & QR & Kuhw. & M & QR & Kuhw. \\
\hline 1 & 32 & Auf dem Bulloh & 22 & 12 & 5,690 & & & & & & & & & & 22 & 12 & 5,690 \\
\hline 2 & 38 & An der Stockauheide & 4 & 52 & 0,279 & & & & & & & 9 & 25 & 0,530 & 13 & 77 & 0,809 \\
\hline 3 & 246 & Auf den Ackern & 36 & 44 & 3,985 & & & & 7 & 45 & 0,828 & 15 & 93 & 1,105 & 59 & 62 & 5,918 \\
\hline 4 & 232 & Auf der Pannstätte & 41 & 5 & 5,981 & & & & 2 & 12 & 0,233 & 6 & 50 & 0,428 & 49 & 67 & 6,642 \\
\hline 5 & 226 & Hinterm Hohenkampe & 24 & 29 & 6,926 & & & & & & & & & & 24 & 29 & 6,926 \\
\hline 6 & 140 & In den Neuengärten & 1 & 59 & 0,475 & & & & & 64 & 0,107 & & & & 1 & 115 & 0,582 \\
\hline 7 & & Die Wormstädtsche & & & & 1 & 1 & 0,576 & & & & & & & 1 & 1 & 0,576 \\
\hline 8 & 293 & Der Farkenkamp & & & & 9 & 58 & 2,853 & 2 & 94 & 0,468 & 1 & 76 & 0,151 & 13 & 108 & 3,472 \\
\hline 9 & 113 & Beim Hause & & & & & & & 2 & 33 & 0,380 & & & & 2 & 33 & 0,380 \\
\hline 10 & & Das Gehäge im Eckernkampe & & & & & & & & & & 3 & 96 & 0,422 & 3 & 96 & 0,422 \\
\hline 11 & 296 & In den Behrenswiesen & & 1 & 0,522 & 5 & 66 & 2,050 & 1 & 62 & 0,178 & & 31 & 0,020 & 8 & 107 & 2,770 \\
\hline 12 & 232 & Auf der Pannstätte & & 49 & 6,501 & & & & & & & & & & 49 & 110 & 6,501 \\
\hline 13 & 293 & Beim Spätzeförth & & & & & & & 2 & 24 & 0,314 & & 22 & 0,015 & 2 & 46 & 0,329 \\
\hline 14 & & Am Gehäge am Eckernkampe & & & & & & & & & & & 97 & 0,050 & & 97 & 0,050 \\
\hline 15 & & Am Farkenkampe & & & & & & & & & & & 21 & 0,011 & & 21 & 0,011 \\
\hline 16 & & An der Pannstätte u. an den Ackern & & & & & & & & & & 85 & 50 & 3,481 & 85 & 50 & 3,481 \\
\hline 17 & & \multicolumn{6}{|c|}{ Zwischen d. Wege nach d. Wiese u. Abzugsgräben } & & & & & 25 & 36 & 1,105 & 25 & 36 & 1,105 \\
\hline 18 & & Beim Krähenmoore & & & & & & & & 101 & 0,084 & 30 & 30 & 1,516 & 31 & 11 & 1,600 \\
\hline & & (rechnerische Kontrolle) & & & 30,359 & & & 5,479 & & & 2,592 & & & 8,834 & & & 47,264 \\
\hline & & Summa & 181 & 30 & 30,359 & 16 & 5 & 5,479 & 19 & 75 & 2,592 & 179 & 27 & 8,834 & 395 & 118 & 47,264 \\
\hline & & & & & & & & & & & & & & & & & \\
\hline & 13 & In den trockenen Wiesen & & & & 7 & 74 & 1,722 & & & & & & & 7 & 74 & 1,722 \\
\hline & 79 & In den Allerwiesen & & & & 14 & 17 & 4,467 & & & & & & & 14 & 17 & 4,467 \\
\hline & & (rechnerische Kontrolle) & & & & & & 6,189 & & & & & & & & & 6,189 \\
\hline & & Summa & & & & 21 & 91 & 6,189 & & & & & & & 21 & 91 & 6,189 \\
\hline
\end{tabular}




\begin{tabular}{|c|c|c|c|c|c|c|c|c|c|c|c|c|c|c|c|c|c|}
\hline \multirow{5}{*}{ 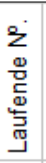 } & \multirow{5}{*}{ 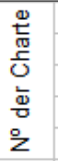 } & & & & & & & & & & & & & & & & \\
\hline & & Litt: e & & & & & & & & & & & & & \multicolumn{3}{|c|}{ Überhaupt } \\
\hline & & Der Vollmeier Christoph & & & & & & & & & & & & & \multicolumn{3}{|c|}{ brauchbarer } \\
\hline & & Bergmann & \multicolumn{3}{|c|}{ Ackerland } & \multicolumn{3}{|c|}{ Wiesenboden } & \multicolumn{3}{|c|}{ Angerboden } & \multicolumn{3}{|c|}{ Heidboden } & \multicolumn{3}{|c|}{ Boden } \\
\hline & & hat zugeteilt erhalten. & M & QR & Kuhw. & M & QR & Kuhw. & M & QR & Kuhw. & M & QR & Kuhw. & M & QR & Kuhw. \\
\hline 1 & 8 & Unterm Dürskampe & 2 & 11 & 0,174 & & & & & & & 1 & 21 & 0,078 & 3 & 32 & 0,252 \\
\hline 2 & 9 & Auf dem lachenkampe & 22 & 24 & 2,239 & & & & & & & 2 & 39 & 0,162 & 24 & 63 & 2,401 \\
\hline 3 & 253 & Übern Ackern & 7 & 112 & 0,441 & & & & & & & 11 & 114 & 0,630 & 19 & 106 & 1,071 \\
\hline 4 & 248 & Auf den Ackern & 13 & 102 & 1,457 & & & & & 3 & 0,004 & & 66 & 0,048 & 14 & 51 & 1,509 \\
\hline 5 & 147 & Auf dem Sandbruche & 20 & 41 & 5,148 & & 41 & 0,114 & 2 & 5 & 0,566 & 2 & 27 & 0,173 & 24 & 114 & 6,001 \\
\hline 6 & 155 & In den Sieben & 33 & 11 & 7,019 & & & & & & & 1 & 5 & 0,121 & 34 & 16 & 7,140 \\
\hline 7 & 241 & In den Kampgärten & 4 & 113 & 1,157 & & & & 5 & 59 & 0,983 & & & & 10 & 52 & 2,140 \\
\hline 8 & 83 & Die Teichwiese & & 40 & 0,022 & 4 & 81 & 2,501 & & 83 & 0,169 & & 84 & 0,063 & 6 & 48 & 2,755 \\
\hline 9 & 117 & Beim Hause & & & & & & & 3 & 7 & 0,510 & & & & 3 & 7 & 0,510 \\
\hline 10 & 292 & Der Spötzkamp & & & & & & & & & & 3 & 67 & 0,395 & 3 & 67 & 0,395 \\
\hline 11 & 144 & Auf dem Moore & & & & & & & 1 & 14 & 0,319 & & & & 1 & 14 & 0,319 \\
\hline 12 & & Beim Spötzkampe & & & & & & & & & & 4 & 103 & 0,349 & 4 & 103 & 0,349 \\
\hline 13 & & Beim Birkenbusche & & & & & & & & & & 117 & 88 & 4,863 & 117 & 88 & 4,863 \\
\hline 14 & & Hinter Drewswn Gehäge & & & & & & & & & & 16 & & 0,664 & 16 & & 0,664 \\
\hline 15 & & Hinterm Vanale & & & & & & & 11 & 52 & 1,893 & 26 & 4 & 1,632 & 37 & 56 & 3,525 \\
\hline & & (rechnerische Kontrolle) & & & 17,657 & & & 2,615 & & & 4,444 & & & 9,178 & & & 33,894 \\
\hline & & Summa & 104 & 94 & 17,657 & 5 & 2 & 2,615 & 23 & 103 & 4,444 & 188 & 18 & 9,178 & 321 & 97 & 33,894 \\
\hline & & & & & & & & & & & & & & & & & \\
\hline & 66 & Anschnitt von den Allerwiesen & & & & & 18 & 0,019 & & 56 & 0,043 & & & & & 74 & 0,062 \\
\hline & 10 & In den trockenen Wiesen & & & & 9 & 30 & 1,808 & & & & & & & 9 & 30 & 1,808 \\
\hline & 72 & In den Allerwiesen & & & & 14 & 25 & 4,812 & & & & & & & 14 & 25 & 4,812 \\
\hline & & (rechnerische Kontrolle) & & & & & & 6,639 & & & 0,043 & & & & & & 6,682 \\
\hline & & Summa & & & & 23 & 73 & 6,439 & & 56 & 0,043 & & & & 24 & 9 & 6,482 \\
\hline & & & & & & & & & & & & & & & & & \\
\hline & & Litt: $f$ & & & & & & & & & & & & & & & \\
\hline$z_{\omega}$ & $\frac{\pi}{\frac{\pi}{5}}$ & Der Vollmeier Georg & & & & & & & & & & & & & & Jberha & aupt \\
\hline 崖 & 0 & Drewsen Erben & & & & & & & & & & & & & & rauch & barer \\
\hline$\stackrel{\infty}{5}$ & $\frac{ \pm}{0}$ & haben zugeteilt erhalten. & & Acker & rland & & iesen & aboden & & angert & boden & & Heidbc & den & & Bode & \\
\hline 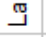 & $\stackrel{\circ}{z}$ & für die Fabrik und den Vollhof & M & QR & Kuhw. & M & QR & Kuhw. & $M$ & QR & Kuhw. & M & QR & Kuhw. & M & QR & Kuhw. \\
\hline 5 & 65 & Auf dem Krümmel & 64 & 88 & 16,463 & & & & 2 & 60 & 0,472 & 44 & 54 & 8,048 & 111 & 82 & 24,983 \\
\hline 4 & 54 & In den Moorgärten u. am Hofe & 3 & 76 & 0,750 & & & & 1 & 45 & 0,146 & 25 & 70 & 1,234 & 30 & 71 & 2,130 \\
\hline 10 & 150 & Bei der Windmühle & & 95 & 0,090 & & & & & 46 & 0,064 & 4 & 59 & 0,365 & 5 & 80 & 0,519 \\
\hline 11 & 219 & Das Punnewischgehäge & & 5 & 0,005 & & & & & & & 9 & 21 & 1,224 & 9 & 26 & 1,229 \\
\hline 7 & 91 & Beim Hause & 2 & 30 & 0,693 & & & & 2 & 47 & 0,399 & 1 & 32 & 0,060 & 5 & 109 & 1,152 \\
\hline 6 & 90 & Der Brömmer & & & & 1 & 98 & 0,919 & 3 & 63 & 0,465 & & 33 & 0,014 & 5 & 74 & 1,398 \\
\hline 8 & 109 & Bei der Scheure & & & & & & & 1 & 87 & 0,288 & & & & 1 & 87 & 0,288 \\
\hline 3 & 52 & Vor dem Quälohsgehäge & & & & & & & & & & 2 & & 0,100 & 2 & & 0,100 \\
\hline 2 & 51 & An der alten Lachte & & & & & & & & & & 8 & 11 & 0,463 & 8 & 112 & 0,463 \\
\hline 12 & 254 & Das Gehäge über den Ackern & & 63 & 0,028 & & & & & & & 16 & 22 & 0,900 & 16 & 83 & 0,928 \\
\hline 13 & & Die Fahrwiese & & & & & & & & & & 2 & 110 & 0,583 & 2 & 110 & 0,583 \\
\hline 9 & 100 & Die Eselswiese & & & & & 84 & 0,350 & & 39 & 0,054 & & & & 1 & 3 & 0,404 \\
\hline 1 & 22 & Auf der Bulloh & 20 & 18 & 5,387 & & & & & & & 1 & 1 & 0,150 & 21 & 19 & 5,537 \\
\hline & & Am Postmoore & & & & & & & & & & 179 & 114 & 7,364 & 179 & 114 & 7,364 \\
\hline & & Bei Cammann Thies Immenstelle & & & & & & & & & & 87 & 73 & 3,472 & 87 & 73 & 3,472 \\
\hline & & Westl.am Exerzierplatz & \} & Zuse & amenhän & ngen & d, nu & ur durch & We & ege $g$ & etrennt. & 107 & 30 & 4,173 & 107 & 30 & 4,173 \\
\hline & & Am Birkenbusch & $\int$ & & & & & & & & & 22 & 49 & 0,897 & 22 & 49 & 0,897 \\
\hline & & Hinterm Canale & & & & & & & & 73 & 0,101 & 7 & 85 & 0,455 & 8 & 38 & 0,556 \\
\hline & & (rechnerische Kontrolle) & & & 23,416 & & & 1,269 & & & 1,989 & & & 29,502 & & & 56,176 \\
\hline & & Summa & 92 & 15 & 23,146 & 2 & 62 & 1,269 & 12 & 100 & 1,989 & 521 & 25 & 29,502 & 628 & 82 & 56,176 \\
\hline & & & & & & & & & & & & & & & & & \\
\hline & 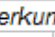 & 19. Ler speziente ivcriwers der zurt a & & . & UIII VOIIIS & Ore & gehör & irenden & Grun: & Toto & icke find & 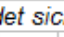 & I & EIII ve & temur & 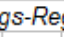 & gister. \\
\hline & & & & & & & & & & & & & & & & & \\
\hline & 138 & Vor den Dreckwiesen & & & & 8 & 102 & 2,050 & & & & & & & 8 & 102 & 2,050 \\
\hline & 65 & Anschnitt von den Allerwiesen & & & & & 10 & 0,004 & & & & & & & & 10 & 0,004 \\
\hline & 71 & In den Allerwiesen & & & & 12 & 60 & 4,119 & & & & & & & 12 & 60 & 4,119 \\
\hline & & (rechnerische Kontrolle) & & & & & & 6,173 & & & & & & & & & 6,173 \\
\hline & & Summa & & & & 21 & 52 & 6,137 & & & & & & & 21 & 52 & 6,137 \\
\hline
\end{tabular}




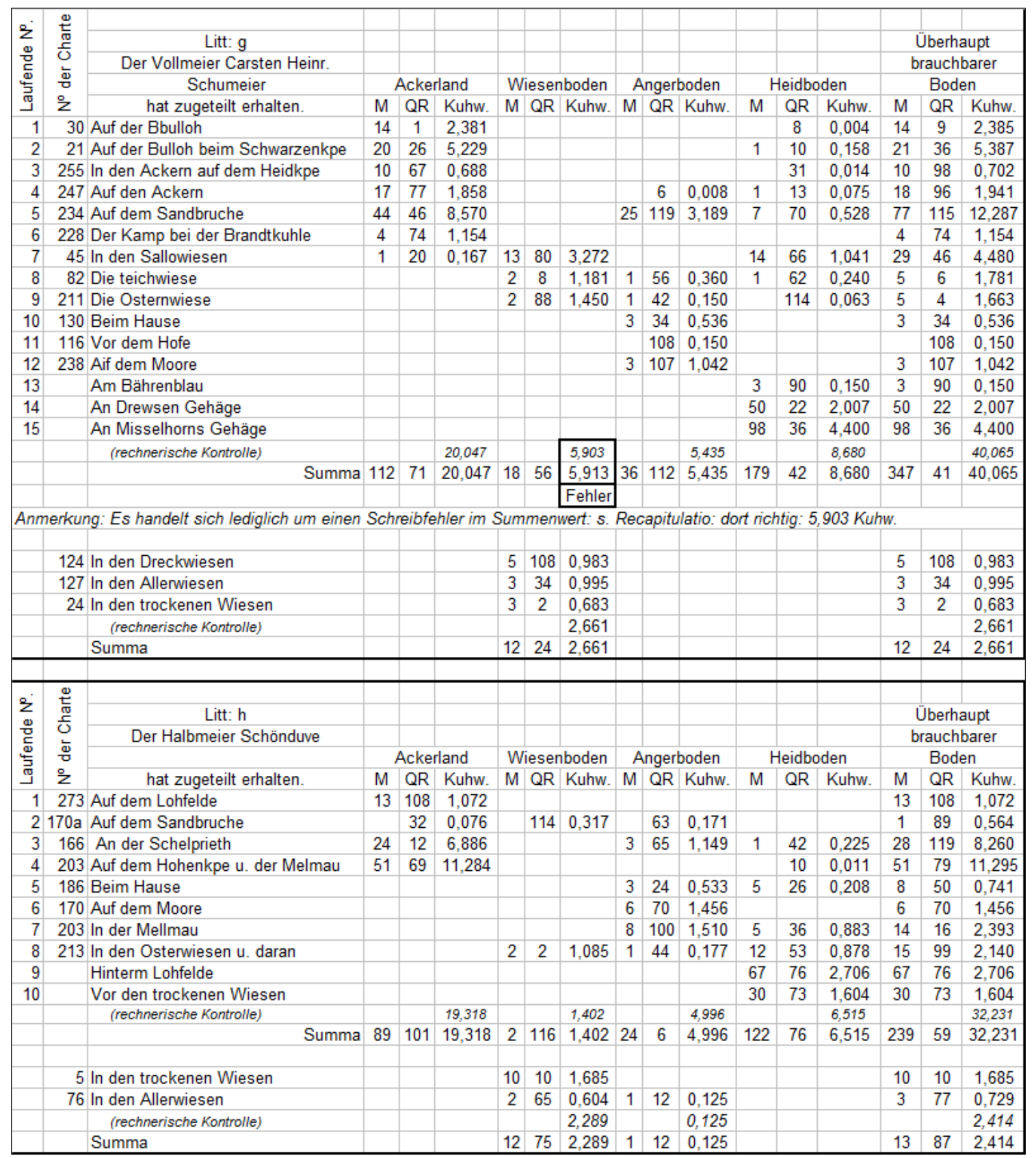




\section{Köthner i und k}

\begin{tabular}{|c|c|c|c|c|c|c|c|c|c|c|c|c|c|c|c|c|c|}
\hline \multirow{5}{*}{ 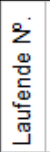 } & \multirow{5}{*}{ 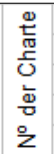 } & & & & & & & & & & & & & & & \\
\hline & & Litt: i & & & & & & & & & & & & & \multicolumn{3}{|c|}{ Überhaupt } \\
\hline & & Der Köthner Joh. Heinrich & & & & & & & & & & & & & & auch & barer \\
\hline & & Thies (Cammann) & & Ackerl & land & Wi & esen & boden & & ngert & boden & & leidbc & oden & & Bod & \\
\hline & & hat zugeteilt erhalten. & $\mathrm{M}$ & QR & Kuhw. & M & QR & Kuhw. & M & QR & Kuhw. & $\mathrm{M}$ & QR & Kuhw. & M & QR & Kuhw. \\
\hline 1 & 57 & Auf dem Flttkampe u. dem Söhren & 20 & 45 & 5,309 & & & & 1 & 16 & 0,283 & & 56 & 0,095 & 21 & 117 & 5,687 \\
\hline 2 & 288 & Auf dem Westerkampe & 8 & 41 & 1,177 & & & & & & & & 9 & 0,004 & 8 & 50 & 1,181 \\
\hline 3 & 257 & Auf den Ackern & 10 & 39 & 0,680 & & & & & & & & 13 & 0,006 & 10 & 52 & 0,686 \\
\hline 4 & 250 & daselbst & 10 & 29 & 0,972 & & & & & & & & 6 & 0,005 & 10 & 35 & 0,977 \\
\hline 5 & 245 & Abbauer Heuers Langfatst & 1 & 52 & 0,159 & & & & & & & & & & 1 & 52 & 0,159 \\
\hline 6 & 156 & Beim Dornbusche & 14 & 27 & 2,286 & & & & & & & & 20 & 0,119 & 1 & 47 & 2,305 \\
\hline 7 & 167 & Auf dem Hohenkampe & 33 & 106 & 7,775 & & & & 3 & 106 & 0,914 & 2 & 63 & 0,322 & 14 & 35 & 9,011 \\
\hline 8 & & Beim Vogelheerde & 3 & 44 & 0,705 & 1 & 61 & 0,503 & & 96 & 0,107 & & & & 40 & 81 & 1,315 \\
\hline 9 & 71 & In den Langengärten & & 83 & 0,215 & & & & & & & & & & 5 & 83 & 0,215 \\
\hline 10 & & Beim Vogelberge & & & & 1 & 3 & 0,586 & & & & & & & & 3 & 0,586 \\
\hline 11 & 212 & Die Osterwiese & & & & 4 & 29 & 2,120 & 1 & & 0,167 & 12 & 65 & 0,771 & 1 & 94 & 3,058 \\
\hline 12 & 119 & Beim Hause & & & & & & & 1 & 109 & 0,318 & & 3 & 0,002 & 17 & 112 & 0,320 \\
\hline 13 & 47 & Zum Bunger & 4 & 109 & 1,373 & 2 & 57 & 0,878 & 8 & 58 & 1,757 & 2 & 46 & 0,159 & 1 & 30 & 4,167 \\
\hline 14 & 146 & Auf dem Moore & & & & & & & 1 & 31 & 0,315 & & & & 1 & 31 & 0,315 \\
\hline 15 & 299 & Neben dem Bunger & & & & & & & & 78 & 0,130 & 14 & 90 & 1,003 & 15 & 48 & 1,133 \\
\hline 16 & & Am Westerkampe & & & & & & & & & & 1 & 3 & 0,041 & 1 & 3 & 0,041 \\
\hline 17 & & Am Gehäge in der Allerheide & & & & & & & & & & 75 & 50 & 3,017 & 75 & 50 & 3,017 \\
\hline 18 & & Hinterm Canale & & & & & & & & & & 6 & 93 & 0,424 & 6 & 93 & 0,424 \\
\hline & & (rechnerische Kontrolle) & & & 20,651 & & & 4,087 & & & 3,991 & & & 5,968 & & & 34,597 \\
\hline & & Summa: & 107 & 95 & 20,651 & 9 & 30 & 4,087 & 19 & 14 & 3,991 & 116 & 37 & 5,868 & 252 & 56 & 34,597 \\
\hline & & & & & & & & & & & & & & Fehler & & & \\
\hline
\end{tabular}

Anmerkung: Im Original ist bei der Ifd. No. 3 (Auf den Ackern) die Gesamtfläche von 10 M 52 QR und 0,686 Kuhweiden nochmals unter "Unbrauchbar" ohne weitere Bemerkung aufgeführt.

Kuhweidenwert von 0,119 für 20 QR Heideboden: Schreibfehler; richtig: 0,019

Begründung: Die rechn. Summe (für Heidboden) ist um 1/10 gegenüber Original zu groß.

Rechn. Summe (lfd. Nr. 6, beim Dornbusche) mit dem Wert 0,119 ergibt 2,405, also auch 1/10 mehr als im Original.

74 In den Allerwiesen

Wiesen Litt: o

\begin{tabular}{|c|c|c|c|c|c|c|c|c|c|c|c|c|c|c|c|c|c|}
\hline \multirow{5}{*}{ 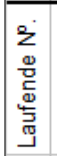 } & \multirow{5}{*}{ 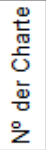 } & & & & & & & & & & & & & & & & \\
\hline & & Litt: $\mathrm{k}$ & & & & & & & & & & & & & \multicolumn{3}{|c|}{ Überhaupt } \\
\hline & & Der Köthner Johann Heinr. & & & & & & & & & & & & & \multicolumn{3}{|c|}{ brauchbarer } \\
\hline & & Bunkenburg & \multicolumn{3}{|c|}{ Ackerland } & \multicolumn{3}{|c|}{ Wiesenboden } & \multicolumn{3}{|c|}{ Angerboden } & \multicolumn{3}{|c|}{ Heidboden } & \multicolumn{3}{|c|}{ Boden } \\
\hline & & hat zugeteilt erhalten. & M & QR & Kuhw. & M & QR & Kuhw. & M & QR & Kuhw. & M & QR & Kuhw. & M & QR & Kuhw. \\
\hline 1 & 10 & Auf dem lachenkampe & 27 & 36 & 2,772 & & & & & & & & 18 & 0,013 & 27 & 54 & 2,785 \\
\hline 2 & 35 & Auf dem Flottkampe u. den Söhren & 26 & 9 & 6,667 & & & & 2 & 30 & 0,643 & 1 & 84 & 0,213 & 30 & 3 & 7,523 \\
\hline 3 & 265 & Auf den Ackern & 15 & 117 & 1,220 & & & & & & & & 78 & 0,034 & 16 & 75 & 1,254 \\
\hline 4 & $68 a$ & In den Langengärten & & 69 & 0,136 & & & & & & & & & & & 69 & 0,136 \\
\hline 5 & 1 & Auf dem Dürskamp & 17 & 101 & 2,464 & & & & & & & & & & 17 & 101 & 2,464 \\
\hline 6 & 13 & Die Ihlphlswwiese & & & & 2 & 17 & 0,714 & & & & 1 & 96 & 0,100 & 3 & 113 & 0,814 \\
\hline 7 & 123 & Beim hause & & & & & & & 2 & 20 & 0,361 & & 41 & 0,033 & 2 & 61 & 0,394 \\
\hline 8 & 11 & Auf der Salloh & & & & & & & & & & 16 & 101 & 1,040 & 40 & 116 & 2,734 \\
\hline 9 & 300 & Vor Herbold's Hause & 24 & 15 & 1,694 & & & & & 20 & 0,033 & 3 & 64 & 0,194 & 3 & 84 & 0,227 \\
\hline 10 & 40 & Beim Quälohsgehäge & & & & & & & & 34 & 0,081 & 12 & 82 & 0,632 & 13 & 22 & 0,729 \\
\hline 11 & 44 & Schönduves Sallohwiese & & & & & & & & & & & & & 3 & 104 & 1,165 \\
\hline 12 & & Übern Ackern & & 26 & 0,016 & & & & & & & 1 & 67 & 0,062 & 1 & 67 & 0,062 \\
\hline 13 & & Am Oppershäuser Wege & & & & 3 & 104 & 1,165 & & & & 56 & 34 & 2,251 & 56 & 34 & 2,251 \\
\hline 14 & & Vor den trockenen Wiesen & & & & & & & & & & 1 & 18 & 0,144 & 1 & 18 & 0,144 \\
\hline 15 & & daselbst nördlich der Trift & & & & & & & & & & 11 & 71 & 0,771 & 11 & 71 & 0,771 \\
\hline & & (rechnerische Kontrolle) & & & 14,969 & & & 1,879 & & & 1,118 & & & 5,487 & & & 23,453 \\
\hline & & Summa: & 112 & 13 & 14,969 & 6 & 1 & 1,879 & 4 & 104 & 1,118 & 108 & 34 & 5,487 & 231 & 32 & 23,453 \\
\hline & & & & & & & & & & & & & & & & & \\
\hline & & Wiesen Litt: s (ab 1865. Drewsen) & & & & & & & & & & & & & & & \\
\hline & 22 & In den trockenen Wiesen & & & & 13 & 17 & 1,943 & & & & & 48 & 0,020 & 13 & 65 & 1,963 \\
\hline
\end{tabular}


Köthner I und m

\begin{tabular}{|c|c|c|c|c|c|c|c|c|c|c|c|c|c|c|c|c|c|}
\hline \multirow{5}{*}{ 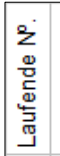 } & \multirow{5}{*}{ 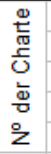 } & \multirow[b]{2}{*}{ Litt: I } & & & & & & & & & & & & & & \\
\hline & & & & & & & & & & & & & & & \multicolumn{3}{|c|}{ Überhaupt } \\
\hline & & Der Köthner Johann Heinr. & & & & & & & & & & & & & & raucht & barer \\
\hline & & Dralle (Dralle) & & Acker & land & & iesen & aboden & & ingerb & boden & & Heidbo & oden & & Bode & den \\
\hline & & hat zugeteilt erhalten. & $\mathrm{M}$ & QR & Kuhw. & M & QR & Kuhw. & M & QR & Kuhw. & M & QR & Kuhw. & M & QR & Kuhw. \\
\hline 1 & 37 & Af dem Kuhlkampe & 10 & 107 & 0,866 & & & & & & & 10 & 97 & 0,761 & 21 & 84 & 1,627 \\
\hline 2 & 31 & Auf der Bulloh & 14 & 14 & 3,521 & & & & & & & & & & 14 & 14 & 3,521 \\
\hline 3 & 56 & Auf dem Flottkampe u. den Söhren & 24 & 73 & 5,960 & & & & & 116 & 0,259 & & 34 & 0,047 & 25 & 103 & 6,266 \\
\hline 4 & 276 & Auf dem Westerfelde & 13 & 4 & 1,453 & & & & & & & 1 & 24 & 0,057 & 14 & 25 & 1,510 \\
\hline 5 & & Vor dem Beedenbosteler Stege & 2 & 1 & 0,368 & 1 & 38 & 0,549 & & 53 & 0,088 & & & & 3 & 92 & 1,005 \\
\hline 6 & 72 & In den Langengärten & & 79 & 0,206 & & & & & & & & & & & 79 & 0,206 \\
\hline 7 & 209 & Die Osterwiese & & & & 2 & 8 & 1,181 & & 45 & 0,042 & 1 & 86 & 0,134 & 4 & 19 & 1,257 \\
\hline 8 & 125 & Beim Hause & & & & & & & 2 & 35 & 0,382 & 2 & 92 & 0,169 & 5 & 7 & 0,551 \\
\hline 9 & 294 & Auf dem Westerkampe & 19 & 50 & 3,084 & 7 & 69 & 2,419 & 2 & 67 & 0,424 & 2 & 75 & 0,223 & 32 & 21 & 6,150 \\
\hline 10 & 37 & An der Stockau Heide & 5 & 49 & 0,361 & & & & & & & 4 & 84 & 0,315 & 10 & 13 & 0,676 \\
\hline 11 & 37 & $\begin{array}{llll} & " & " & "\end{array}$ & 3 & 77 & 0,226 & & & & & & & 5 & 80 & 0,375 & 9 & 37 & 0,601 \\
\hline 12 & 145 & Auf dem Moore & & & & & & & & 100 & 0,225 & & & & & 100 & 0,225 \\
\hline 13 & & Die Stoppelweide auf Vöths & & & & & & & & & & & & & & & \\
\hline 14 & & Lutterlohs und Laue Lande & & 46 & 0,080 & & & & & & & & & & & 46 & 0,080 \\
\hline 15 & & Am Postmoore & & & & & & & & 87 & 0,073 & 78 & 109 & 3,588 & 76 & 76 & 3,661 \\
\hline 16 & & In der Allerheide & & & & & & & & & & 11 & 82 & 0,467 & 11 & 82 & 0,467 \\
\hline 17 & & An der Wiese hintern Canale & & & & 2 & 88 & 0,547 & 3 & 19 & 0,513 & 5 & 64 & 0,453 & 11 & 51 & 1,513 \\
\hline & & (rechnerische Kontrolle) & & & 16,125 & & & 4,696 & & & 2,006 & & & 6,589 & & & 29,316 \\
\hline & & Summa: & 94 & 20 & 16,125 & 13 & 83 & 4,696 & 11 & 42 & 2,006 & 125 & 104 & 6,589 & 245 & 9 & 29,416 \\
\hline & & & & & & & & & & & & & & & & & \\
\hline $\begin{array}{l}\text { Anm } \\
\text { 2) } L f\end{array}$ & $\begin{array}{l}\text { herkur } \\
\text { fd. } \mathrm{Nr}\end{array}$ & $\begin{array}{l}\text { ung.: 1) Lfd. Nr.15 (am Postmoor): Gesamtwert: S } \\
\text { r. } 7 \text { (die Osterwiese): Gesamtwert der Zeile: Schr }\end{array}$ & $a b t$ & ibfehl & ler $76 \mathrm{M}$ & rec & chner & isch ric & g:tig: & 791 & M 76 & & & & & & \\
\hline dann & $n$ ergi & ibt die letzte Spaltensumme auch rechnerisch 29 & & I & bereinsti & $m I m$ & ung $n$ & mit dem & Orig & IgII & & & & & & & \\
\hline & & & & & & & & & & & & & & & & & \\
\hline & & Wiesen Litt: $p$ & & & & & & & & & & & & & & & \\
\hline & $134 \mid$ & In den Allerwiesen & & & & 13 & 29 & 3,775 & & & & & & & 13 & 29 & 3,775 \\
\hline & 68 & Wiese vor den Allerwiesen & & & & 2 & 83 & 0,336 & & & & & & & 2 & 83 & 0,336 \\
\hline & 144 I & In den Allerwiesen & & & & 13 & 72 & 3,584 & & & & & & & 13 & 72 & 3,584 \\
\hline & & (rechnerische Kontrolle) & & & & & & 7,695 & & & & & & & & & 7,695 \\
\hline & & Summa & & & & 29 & 64 & 7,695 & & & & & & & 29 & 64 & 7,695 \\
\hline
\end{tabular}

\begin{tabular}{|c|c|c|c|c|c|c|c|c|c|c|c|c|c|c|c|c|c|}
\hline \multirow{5}{*}{ 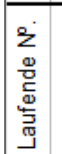 } & \multirow{5}{*}{ 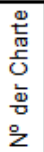 } & & & & & & & & & & & & & & & & \\
\hline & & Litt: $m$ & & & & & & & & & & & & & \multicolumn{3}{|c|}{ Überhaupt } \\
\hline & & Der Köthner Carsten Hr. & & & & & & & & & & & & & & rauch & abarer \\
\hline & & Dralle (Bolzmann) & \multicolumn{3}{|c|}{ Ackerland } & \multicolumn{3}{|c|}{ Wiesenboden } & \multicolumn{3}{|c|}{ Angerboden } & \multicolumn{3}{|c|}{ Heidboden } & \multicolumn{3}{|c|}{ Boden } \\
\hline & & hat zugeteilt erhalten. & M & QR & Kuhw. & M & QR & Kuhw. & $M$ & QR & Kuhw. & $\mathrm{M}$ & QR & Kuhw. & M & QR & Kuhw. \\
\hline 1 & 3 & Auf dem Dürskampe & 6 & 46 & 1,482 & & & & & & & & & & 6 & 46 & 1,482 \\
\hline 2 & 27 & Zwischen den Wegen das. & 2 & 18 & 0,151 & & & & & & & & 8 & 0,003 & 2 & 26 & 0,154 \\
\hline 3 & 36 & Auf dem Flottkampe u. den Söhren & 6 & 62 & 1,522 & & & & & 96 & 0,228 & & & & 7 & 38 & 1,750 \\
\hline 4 & 24 & Auf den Söhren & 14 & 97 & 3,332 & & & & & & & & & & 14 & 97 & 3,332 \\
\hline 5 & 290 & Auf dem Westerkampe & 10 & 26 & 1,361 & & & & & & & 3 & 34 & 0,547 & 13 & 60 & 1,908 \\
\hline 6 & 277 & Auf dem Wetserfelde & 16 & 52 & 1,251 & & & & & & & 1 & 52 & 0,088 & 17 & 104 & 1,339 \\
\hline 7 & 68 & In den Langengärten & 1 & 39 & 0,272 & & & & & 9 & 0,008 & & & & 1 & 48 & 0,280 \\
\hline 8 & 208 & Die Osterwiese & & & & 1 & 3 & 0,513 & & 46 & 0,064 & 2 & 71 & 0,201 & 4 & & 0,778 \\
\hline 9 & 14 & Die Ihlphlswiese u. auf der Salloh & 7 & 40 & 0,407 & 3 & 40 & 1,111 & & 71 & 0,161 & 7 & 3 & 0,388 & 18 & 34 & 2,067 \\
\hline 10 & 126 & Beim Hause & & & & & & & 1 & 99 & 0,297 & 2 & 12 & 0,112 & 3 & 106 & 0,409 \\
\hline 11 & 298 & Im Bunger & 5 & 102 & 1,042 & & & & & 118 & 0,122 & 3 & 21 & 0,243 & 10 & 1 & 1,407 \\
\hline 12 & & Hinterm Westerkampe & & & & & & & & & & 69 & 20 & 2,843 & 69 & 20 & 2,843 \\
\hline 13 & & Vor den trockenen Wiesen & & & & & & & 2 & 10 & 0,317 & 1 & & 0,114 & 3 & 10 & 0,431 \\
\hline 14 & & Hinterm Hockrehmen & & & & & & & 2 & 37 & 0,413 & 11 & 109 & 1,050 & 14 & 26 & 1,463 \\
\hline 15 & & Vor Kochs Wiese & & & & & & & & & & 9 & 8 & 0,652 & 9 & 8 & 0,652 \\
\hline \multirow[t]{4}{*}{16} & & Immenstelle an der Ahnsbecker Grenze & & & & & & & & & & 2 & 77 & 0,106 & 2 & 77 & 0,106 \\
\hline & & (rechnerische Kontrolle) & & & 10,820 & & & 1,624 & & & 1,610 & & & 6,347 & & & 20,401 \\
\hline & & Summa: & 71 & 2 & 10,820 & 4 & 43 & 1,624 & 9 & 1 & 1,610 & 113 & 55 & 6,347 & 197 & 101 & 20,401 \\
\hline & & & & & & & & & & & & & & & & & \\
\hline \multicolumn{18}{|c|}{ Anm. d. Verf.: Bei lfd. Nr. 10 (Beim Hause) muss es beim Angerboden 94 statt 99 QR heißen, } \\
\hline \multicolumn{18}{|c|}{ nur dann stimmen die Summenwerte der zugehörigen Spalten (9 M1 QR) und der Zeile von Ifd. Nr.10 (3 M $106 \mathrm{QR})$ rechnerisch. } \\
\hline & & & & & & & & & & & & & & & & & \\
\hline & & Wiesen Litt: $\mathrm{q}$ & & & & & & & & & & & & & & & \\
\hline & 30 & In den trockenen Wiesen & & & & 7 & 28 & 0,995 & & 53 & 0,055 & 3 & 48 & 0,184 & 11 & 9 & 1,234 \\
\hline & 23 & daselbst & & & & 1 & 112 & 0,202 & & & & 1 & 8 & 0,053 & 3 & 0 & 0,255 \\
\hline & & (rechnerische Kontrolle) & & & & & & 1,197 & & & 0,055 & & & 0,237 & & & 1,489 \\
\hline & & Summa & & & & 9 & 20 & 1,197 & & 53 & 0,055 & 4 & 56 & 0,237 & 14 & 9 & 1,489 \\
\hline
\end{tabular}




\section{Köthner $\mathrm{n}$ und o}

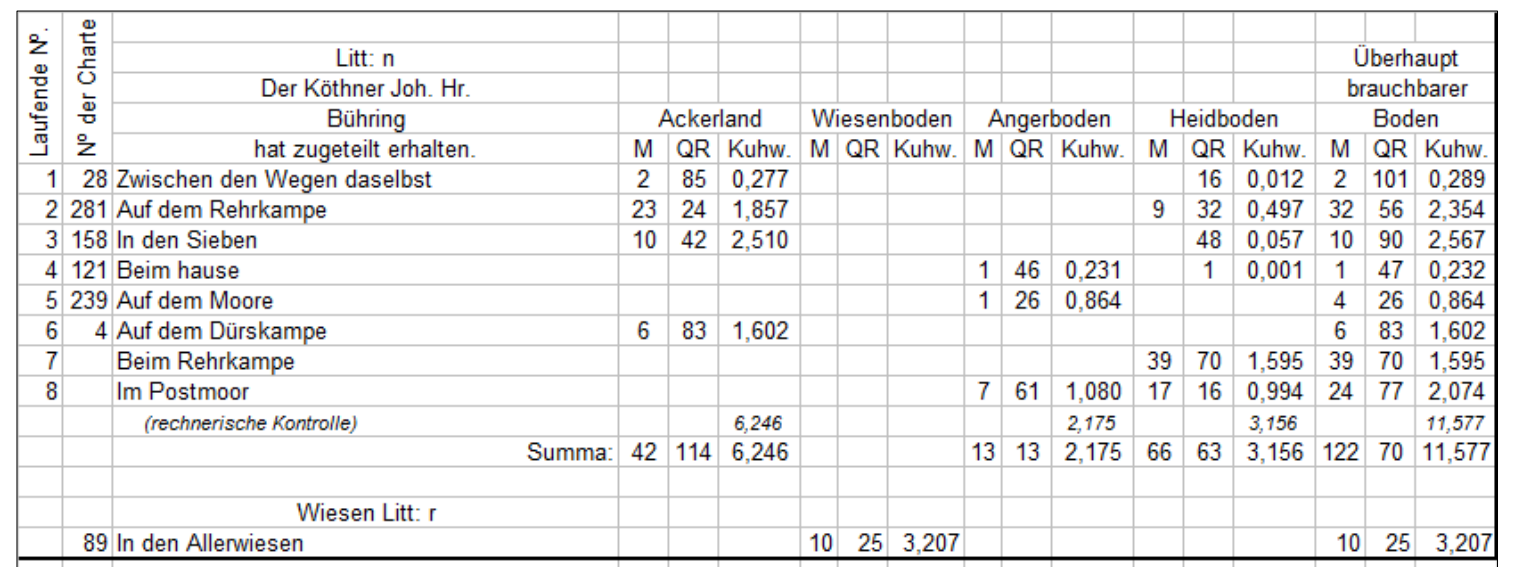

\begin{tabular}{|c|c|c|c|c|c|c|c|c|c|c|c|c|c|c|c|c|c|}
\hline \multirow{5}{*}{ 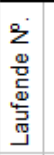 } & \multirow{5}{*}{ 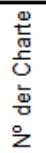 } & \multirow{2}{*}{ the } & & & & & & & & & & & & & \multirow{2}{*}{\multicolumn{3}{|c|}{ Überhaupt }} \\
\hline & & & & & & & & & & & & & & & & & \\
\hline & & Der Köthner J. Hr. Thies & & & & & & & & & & & & & \multicolumn{3}{|c|}{ brauchbarer } \\
\hline & & (Krüger) & \multicolumn{3}{|c|}{ Ackerland } & \multicolumn{3}{|c|}{ Wiesenboden } & \multicolumn{3}{|c|}{ Angerboden } & \multicolumn{3}{|c|}{ Heidboden } & \multicolumn{3}{|c|}{ Boden } \\
\hline & & hat zugeteilt erhalten. & M & $Q R$ & Kuhw. & M & QR & Kuhw. & M & $Q R$ & Kuhw. & M & $Q R$ & Kuhw. & M & QR & Kuhw. \\
\hline 1 & 59 & Auf dem Söhren $\quad 1$ & 13 & 4 & 3,541 & & & & & & & 9 & 115 & 2,172 & 22 & 119 & 5,713 \\
\hline 2 & 284 & Auf dem Wesernkampe & 9 & 62 & 0,719 & & & & & & & 8 & 90 & 0,602 & 18 & 32 & 1,321 \\
\hline 3 & 285 & Überm Westerkampe & 20 & 44 & 1,791 & & & & & & & 5 & 46 & 0,532 & 25 & 90[ & 2,143 \\
\hline 4 & 184 & Auf dem Hohenkampe & 17 & 5 & 4,157 & & & & & 18 & 0,030 & & 102 & 0,113 & 18 & 5 & 4,300 \\
\hline 5 & 139 & In den Neuengärten & 1 & 12 & 0,367 & & & & & 49 & 0,082 & & & & 1 & 61 & 0,449 \\
\hline 6 & 84 & Die Plumbschen & 1 & 40 & 0,131 & & 42 & 0,175 & & 54 & 0,135 & & 112 & 0,091 & 3 & 8 & 0,532 \\
\hline 7 & 85 & Die große Plumbaschen & & & & 1 & 18 & 0,657 & & & & & & & 1 & 18 & 0,657 \\
\hline 8 & 79 & Die teichwiese & & & & 3 & 66 & 2,029 & & 111 & 0,211 & 6 & 106 & 1,143 & 11 & 43 & 3,383 \\
\hline 9 & & Die Spötzeförthswiese & & & & & 92 & 0,259 & & & & & & & & 92[ & 0,256 \\
\hline 10 & 112 & Beim Hause & & & & & & & 2 & 61 & 0,418 & & & & 2 & 61 & 0,418 \\
\hline 11 & & Die Wiesenweide ...*) & & & & & 59 & 0,197 & & & & & & & & 59 & 0,197 \\
\hline 12 & 295 & Vor den Behrenwiesen & 1 & 98 & 0,181 & 3 & 26 & 1,262 & 1 & 4 & 0,176 & & 20 & 0,014 & 6 & 28 & 1,633 \\
\hline 13 & 302 & Neben der großen Masch & & & & & & & & & & 10 & 20 & 0,484 & 10 & 20 & 0,484 \\
\hline 14 & 76 & Am Beedenbosteler Wege & & & & & & & & & & 5 & 112 & 0,618 & 5 & 112 & 0,618 \\
\hline & & Am Postmoor - 15 & & & & & & & & & & 32 & 26 & 1,371 & 32 & 26 & 1,371 \\
\hline & & Am Westernkampe od. 13 & & & & & & & & & & 11 & 20 & 0,469 & 11 & 20 & 0,469 \\
\hline & & daelnst westlich der Trift 14 & & & & & & & & & & 24 & 10 & 0,963 & 23 & 10 & 0,963 \\
\hline & & (rechnerische Kontrolle) & & & 10,887 & & & 4,579 & & & 1,052 & & & 8,572 & & & 24,907 \\
\hline & & Summa: & 64 & 25 & 10,887 & 9 & 63 & 4,576 & 5 & 57 & 1,052 & 116 & 59 & 8,392 & 193 & 84 & 24,907 \\
\hline \multirow{2}{*}{\multicolumn{18}{|c|}{$\begin{array}{l}\text { *) Die Wiesenweide auf Thies aus Höfer } 5 \text {. } \\
\text { Anmerkungen: Die Tabelle enthält insgesa }\end{array}$}} \\
\hline & & & & & & & & & & & & & & & & & \\
\hline \multirow{2}{*}{\multicolumn{18}{|c|}{$\begin{array}{l}\text { Die Kuhweidenwerte für Acker und Anger sind stimmig, ebenso die Spalte mit } \\
\text { der auch mit dem Wert aus der Tabelle "Soll-Haben" in § } 6 \text { übereinstimmt. }\end{array}$}} \\
\hline & & & & & & & & & & & & & & & & & \\
\hline \multirow{3}{*}{\multicolumn{18}{|c|}{$\begin{array}{l}\text { Der Kuhweidenwert für Heidboden enthält offenbar einen Zahlendreher: 0,352 statt 0,532 Kuhweiden; dann stimmt auch der Summenwert. } \\
\text { Wenn der Kuhweidenwert für lfd. Nr. } 9 \text { (Spötzeförthswiese) von 0,259 auf 0,256 verändert wird, stimmt auch der Summenwert. } \\
\text { Dies ist zur Fehelrbehebung zwingend, da sonst kein Kuhweidenwert in der Zeile (Ifd. Nr. 9) vorhanden ist. }\end{array}$}} \\
\hline & & & & & & & & & & & & & & & & & \\
\hline & & & & & & & & & & & & & & & & & \\
\hline & & & & & & & & & & & & & & & & & \\
\hline & & Wiesen Litt: ze & & & & & & & & & & & & & & & \\
\hline & 1331 & In den Dreckwiesen & & & & 3 & 51 & 0,736 & & & & & & & 3 & 51 & 0,736 \\
\hline
\end{tabular}




\section{Köthner $p$ und $q$}

\begin{tabular}{|c|c|c|c|c|c|c|c|c|c|c|c|c|c|c|c|c|c|}
\hline \multirow{5}{*}{ 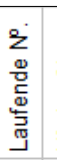 } & \multirow{5}{*}{ 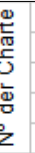 } & \multirow{3}{*}{$\begin{array}{l}\text { Litt: } p \\
\text { Der Köthner Carsten Heinrich }\end{array}$} & & 然 & & & & & & & \multicolumn{3}{|c|}{\begin{tabular}{l|l|l|} 
& &
\end{tabular}} \\
\hline & & & & & & & & & & & & & & & \multicolumn{3}{|c|}{ Überhaupt } \\
\hline & & & & & & & & & & & & & & & & rauch & barer \\
\hline & & Schwägermann & \multicolumn{3}{|c|}{ Ackerland } & \multicolumn{3}{|c|}{ Wiesenboden } & \multicolumn{3}{|c|}{ Angerboden } & \multicolumn{3}{|c|}{ Heidboden } & \multicolumn{3}{|c|}{ Boden } \\
\hline & & hat zugeteilt erhalten. & M & $Q R$ & Kuhw. & M & QR & Kuhw. & $\mathrm{M}$ & $\mathrm{QR}$ & Kuhw. & M & $Q R$ & Kuhw. & M & QR & Kuhw. \\
\hline 1 & 268 & Auf dem Brömmerkampe 7 & 14 & 32 & 1,029 & & & & & & & & 114 & 0,052 & 15 & 26 & 1,081 \\
\hline 2 & 183 & Auf dem Hohenkampe 6 & 24 & 61 & 6,804 & & & & & 17 & 0,028 & & 32 & 0,030 & 24 & 110 & 6,862 \\
\hline 3 & 143 & Hinterm Sandbruche 4 & & & & & 8 & 0,022 & 4 & 69 & 1,161 & & & & 4 & 77 & 1,183 \\
\hline 4 & 108 & Beim Hause 1 & & & & & & & 1 & 40 & 0,222 & & & & 1 & 40 & 0,222 \\
\hline 5 & 107 & Vor dem Hofe 2 & & & & & & & 1 & 77 & 0,274 & & & & 1 & 77 & 0,274 \\
\hline 6 & 174 & Auf dem Moore 3 & & & & & & & 3 & 91 & 1,019 & & 51 & 0,017 & 4 & 22 & 1,036 \\
\hline 7 & 189 & In dem Sandberge beim Lehmgarten 5 & & & & & & & & & & 4 & & 0,160 & 4 & & 0,160 \\
\hline 8 & & In der Allerheide am Oppershäuser Felde 10 & & & & & & & & & & 23 & 31 & 1,168 & 23 & 31 & 1,168 \\
\hline 9 & & daselbst am Abzugsgraben 9 & & & & & & & & & & 43 & 97 & 2,196 & 43 & 97 & 2,196 \\
\hline 10 & & Am Brömmerkampe ad 7 & & & & & & & & & & 8 & 10 & 0,323 & 8 & 10 & 0,323 \\
\hline 11 & & daselbst zwischen den Wegen 8 & & & & & & & & & & 14 & & 0,560 & 14 & & 0,560 \\
\hline & & (rechnerische Kontrolle) & & & 7,833 & & & 0,022 & & & 2,704 & & & 4,506 & & & 15,065 \\
\hline & & Summa: & 38 & 93 & 7,833 & & 8 & 0,022 & 11 & 54 & 2,704 & 94 & 95 & 4,506 & 145 & 10 & 15,065 \\
\hline & & & & & & & & & & & & & & & & & \\
\hline & & Wiesen: Litt: $\mathrm{k}$ & & & & & & & & & & & & & & & \\
\hline & 143 & In den Allerwiesen & & & & 7 & 42 & 1,428 & & & & & & & 7 & 42 & 1,428 \\
\hline & 94 & Am Schwarzwasser & & & & 6 & 58 & 3,501 & & & & & & & 6 & 58 & 3,501 \\
\hline & & (rechnerische Kontrolle) & & & & & & 4,929 & & & & & & & & & 4,929 \\
\hline & & Summa & & & & 13 & 100 & 4,929 & & & & & & & 13 & 100 & 4,929 \\
\hline
\end{tabular}

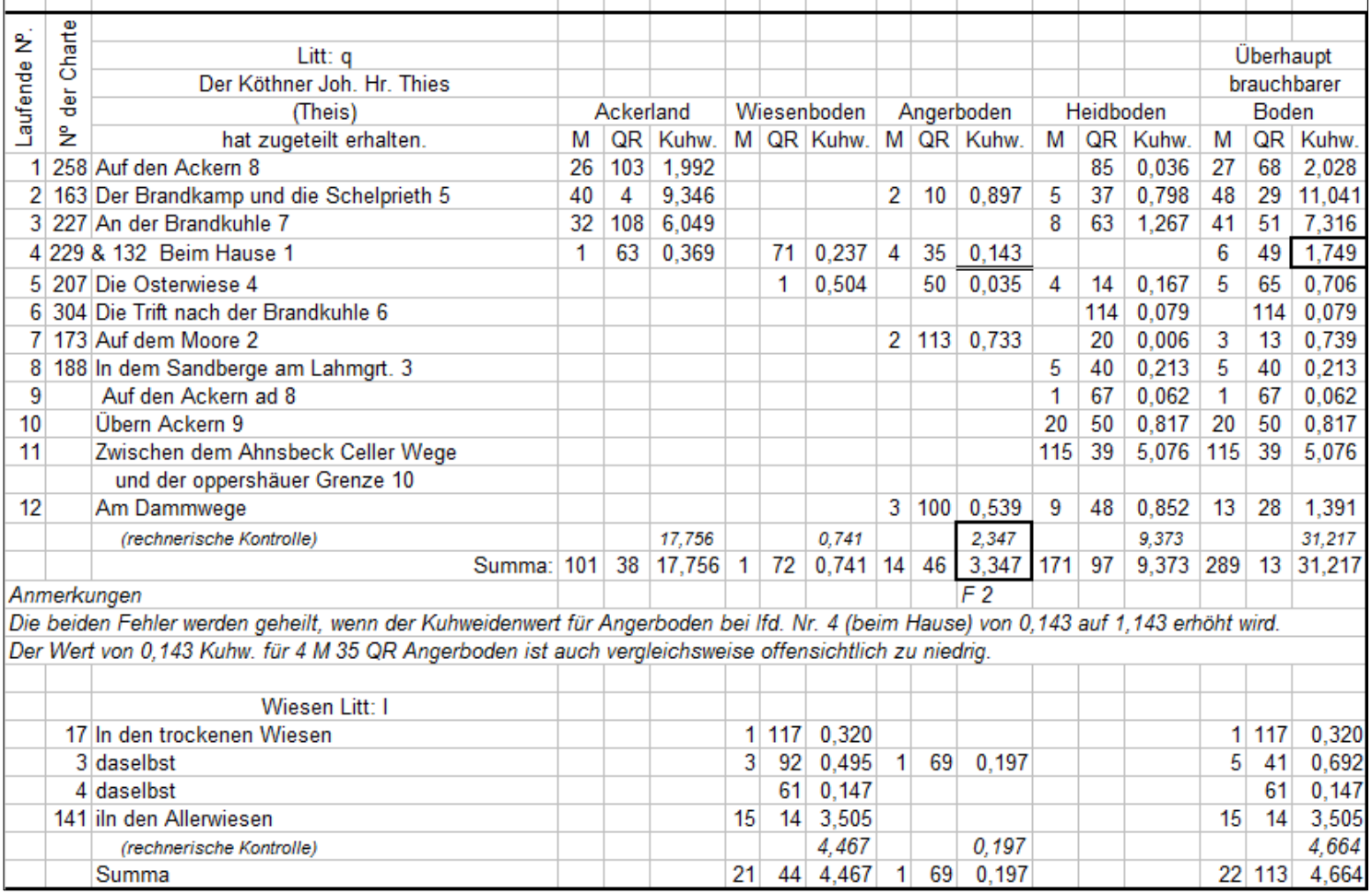




\section{Köthner $r$ und $s$}

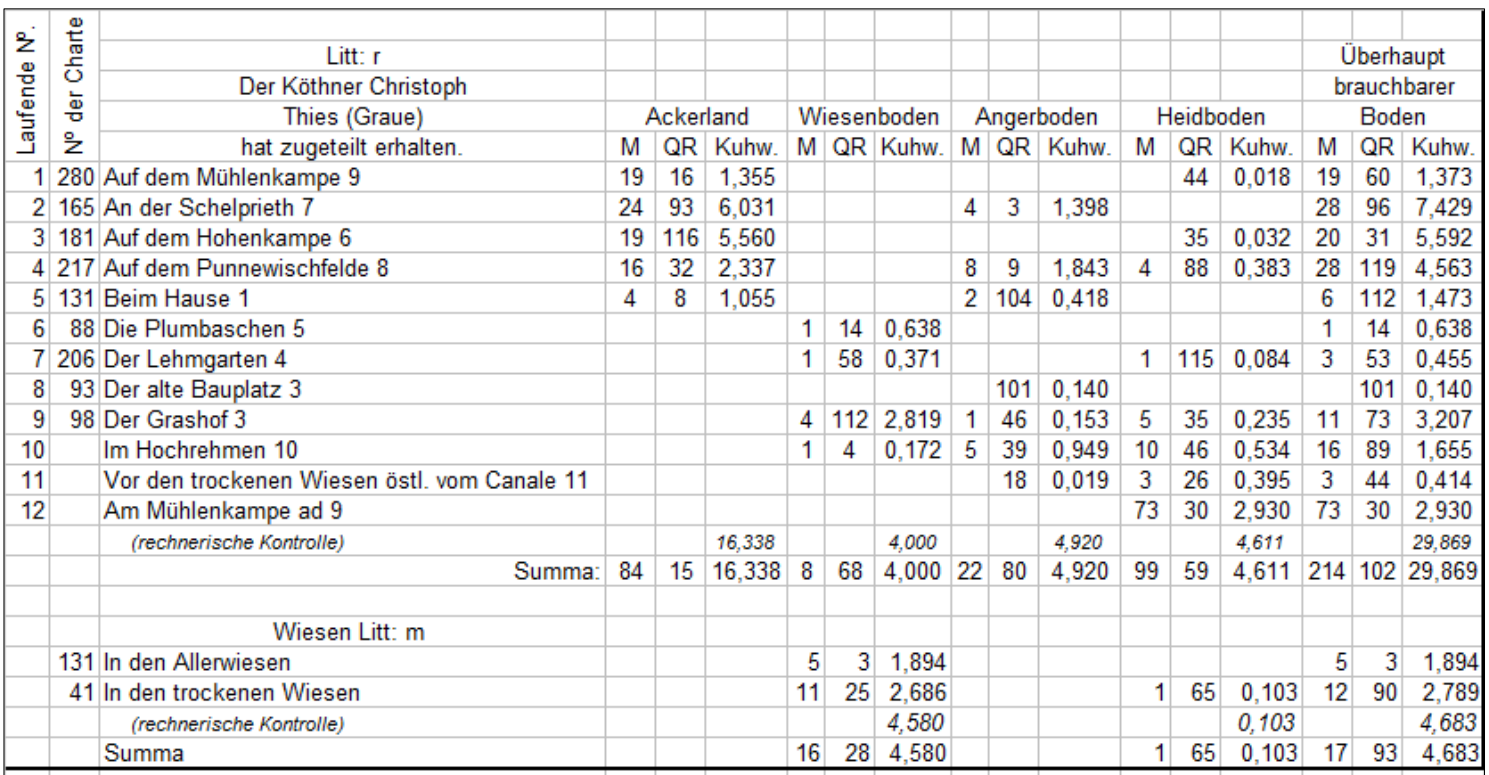

\begin{tabular}{|c|c|c|c|c|c|c|c|c|c|c|c|c|c|c|c|c|c|}
\hline \multirow{5}{*}{\multicolumn{2}{|c|}{ 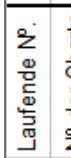 }} & \multirow{2}{*}{\begin{tabular}{|l} 
\\
Litt: $s$
\end{tabular}} & & & & & & & & & & & & & \multirow{2}{*}{\multicolumn{3}{|c|}{ Überhaupt }} \\
\hline & & & & & & & & & & & & & & & & & \\
\hline & \multirow{3}{*}{ 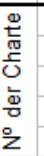 } & Der Köthner Carsten Heinr. & & & & & & & & & & & & & & rauch & barer \\
\hline & & Koch & \multicolumn{3}{|c|}{ Ackerland } & \multicolumn{3}{|c|}{ Wiesenboden } & \multicolumn{3}{|c|}{ Angerboden } & \multicolumn{3}{|c|}{ Heidboden } & \multicolumn{3}{|c|}{ Boden } \\
\hline & & hat zugeteilt erhalten. & M & QR & Kuhw. & M & QR & Kuhw. & M & QR & Kuhw. & M & $Q R$ & Kuhw. & M & QR & Kuhw. \\
\hline & 233 & Auf der Pannstätte 7 & 23 & 67 & 3,591 & & & & & 90 & 0,008 & & 4 & 0,002 & 23 & 80 & 3,601 \\
\hline 2 & 196 & Auf dem Osterraden 6 & 8 & 37 & 1,850 & & & & 6 & 88 & 1,221 & 1 & 42 & 0,112 & 16 & 47 & 3,183 \\
\hline 3 & 216 & \& 221 Bei Bolten Immenzaun 8 & 33 & 21 & 5,327 & & & & & 45 & 0,119 & 3 & 21 & 0,412 & 36 & 85 & 5,858 \\
\hline 4 & 218 & Auf dem Punnewischefelde 9 & 18 & 41 & 5,205 & & & & 4 & 98 & 0,943 & & & & 23 & 19 & 6,148 \\
\hline 5 & 210 & Der Osterkamp 5 & 7 & 88 & 0,740 & 2 & 20 & 1,238 & 4 & 50 & 0,579 & 1 & 29 & 0,067 & 15 & 67 & 2,624 \\
\hline 6 & 235 & Der alte Garten 3 & & 88 & 0,244 & & & & 1 & 33 & 0,356 & & & & 2 & 1 & 0,600 \\
\hline 7 & 97 & Der Grashof 2 & & & & 2 & 112 & 1,676 & 1 & 107 & 0,178 & & 54 & 0,025 & 5 & 33 & 1,879 \\
\hline 8 & 94 & Beim Hause 1 & & & & & & & 3 & 100 & 0,639 & & & & 3 & 100 & 0,639 \\
\hline 9 & 194 & In der kleinen Mellmau 4 & & & & & & & 6 & 48 & 0,745 & 12 & 58 & 0,845 & 18 & 106 & 1,590 \\
\hline 10 & & Vor den Wiesen 12 & & & & & & & & & & & 19 & 0,020 & & 19 & 0,020 \\
\hline 11 & & Hinterm Krähenmoor 11 & & & & & & & & 16 & 0,013 & 41 & 92 & 2,065 & 41 & 108 & 2,078 \\
\hline 12 & & Am Oppershäuser Felde & & & & & & & & & & & & & & & \\
\hline 13 & & zwische den Wegen 10 & & & & & & & & & & 15 & 45 & 0,721 & 15 & 45 & 0,721 \\
\hline 14 & & Am Oppershäuser Wege 13 & & & & & & & & & & 48 & 80 & 1,947 & 48 & 80 & 1,947 \\
\hline 15 & & Am Exerzierolatz 14 & & & & & & & & & & 5 & 68 & 0,223 & 5 & 68 & 0,223 \\
\hline 16 & & An der Pannstätte ad 7 & & & & & & & & & & 4 & 66 & 0,191 & 4 & 66 & 0,191 \\
\hline & & (rechnerische Kontrolle) & & & 16,957 & & & 2,914 & & & 4,801 & & & 6,630 & & & 31,302 \\
\hline & & Summa: & 91 & 102 & 16,957 & 5 & 12 & 2,914 & 29 & 112 & 4,801 & 134 & 98 & 6,630 & 261 & 84 & 31,302 \\
\hline & & & & & & & & & & & & & & & & & \\
\hline & & Wiesen Litt: i & & & & & & & & & & & & & & & \\
\hline & 128 & In den Allerwiesen & & & & 10 & 114 & 3,062 & 2 & 39 & 0,267 & 1 & 91 & 0,088 & 15 & 4 & 3,417 \\
\hline & & In den trockenen Wiesen & & & & 5 & 49 & 0,446 & & & & & 91 & 0,049 & 6 & 20 & 0,495 \\
\hline & & (rechnerische Kontrolle) & & & & & & 3,508 & & & 0,267 & & & 0,137 & & & 3,912 \\
\hline & & Summa & & & & 16 & 43 & 3,508 & 2 & 39 & 0,267 & 2 & 62 & 0,137 & 21 & 24 & 3,912 \\
\hline
\end{tabular}




\section{Köthner t und $u$}

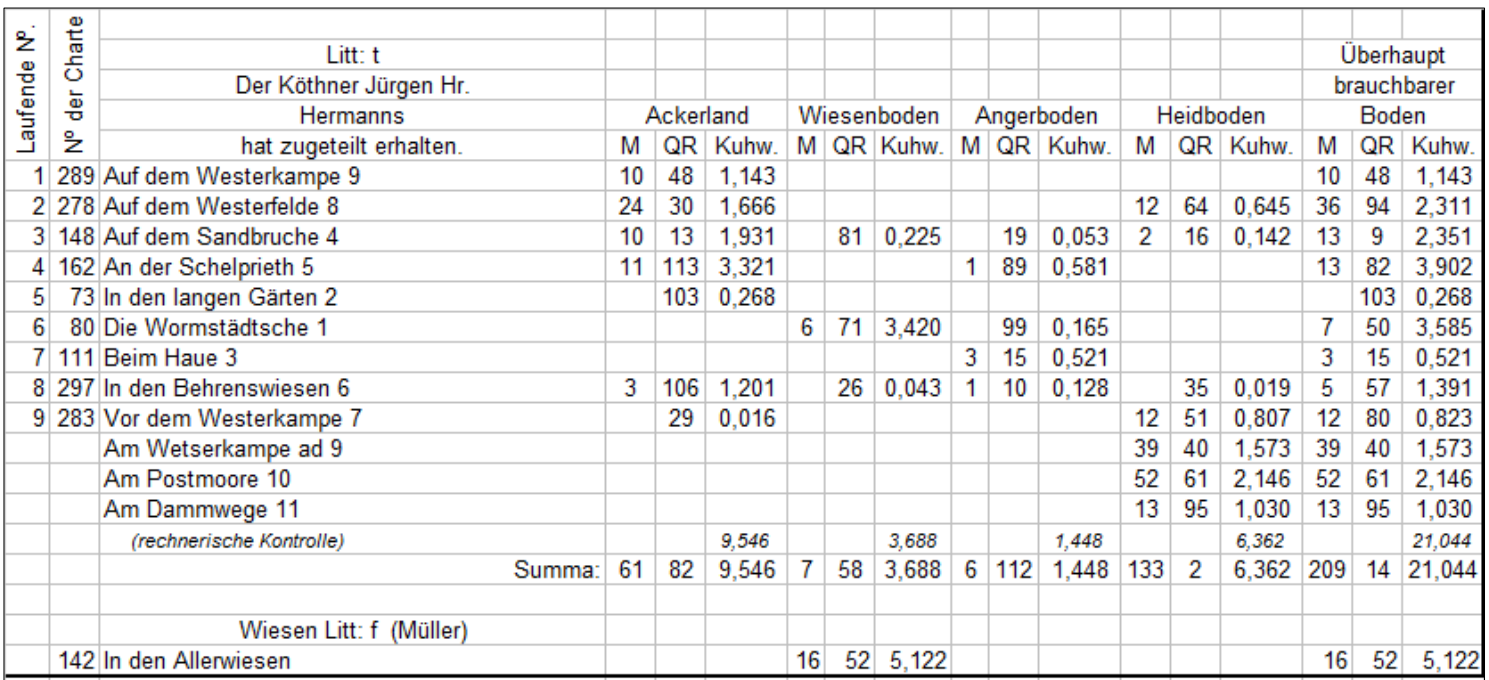

\begin{tabular}{|c|c|c|c|c|c|c|c|c|c|c|c|c|c|c|c|c|c|}
\hline \multirow{5}{*}{ 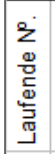 } & \multirow{5}{*}{ 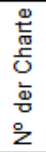 } & & & & & & & & & & & & & & & & \\
\hline & & Litt: u & & & & & & & & & & & & & \multicolumn{3}{|c|}{ Überhaupt } \\
\hline & & Der Köthner Carsten $\mathrm{Hr}$ & & & & & & & & & & & & & \multicolumn{3}{|c|}{ brauchbarer } \\
\hline & & Misselhorn & \multicolumn{3}{|c|}{ Ackerland } & \multicolumn{3}{|c|}{ Wiesenboden } & \multicolumn{3}{|c|}{ Angerboden } & \multicolumn{3}{|c|}{ Heidboden } & \multicolumn{3}{|c|}{ Boden } \\
\hline & & hat zugeteilt erhalten. & M & QR & Kuhw. & M & QR & Kuhw. & M & QR & Kuhw. & $\mathrm{M}$ & QR & Kuhw. & M & QR & Kuhw. \\
\hline 1 & 261 & Vor dem Hofe & 2 & 29 & 0,349 & & & & & & & & & & 2 & 29 & 0,349 \\
\hline 2 & 251 & Auf dem Rüsterheese & 15 & 41 & 1,031 & & & & & & & 4 & 19 & 0,222 & 19 & & 1,253 \\
\hline 3 & 151 & Bei der Windmühle & 1 & 35 & 0,247 & & & & & & & & 75 & 0,063 & 1 & 110 & 0,310 \\
\hline 4 & 234 & Zu den Sieben & 16 & 18 & 2,636 & & & & & & & 4 & 68 & 0,494 & 20 & 86 & 3,130 \\
\hline 5 & 236 & Der alte Gaten & & 78 & 0,217 & & & & 1 & 47 & 0,348 & & & & 2 & 5 & 0,565 \\
\hline 6 & 118 & Beim Hause & & & & & & & 1 & 83 & 0,282 & & 5 & 0,003 & 1 & 88 & 0,285 \\
\hline 7 & 171 & Auf dem Moore & & & & & & & 4 & 28 & 0,979 & & & & 4 & 28 & 0,979 \\
\hline 8 & & Vor der trockenen Wiese & & & & & & & & 57 & 0,048 & & 27 & 0,025 & & 84 & 0,073 \\
\hline 9 & & Am Gehäge westl. des Abzugsgrabens & & & & & & & & & & 65 & 98 & 3,049 & 65 & 98 & 3,049 \\
\hline 10 & & Bei den Kämpen in der Allerheide & 10 & 32 & 0,617 & & & & & & & 23 & 52 & 1,052 & 33 & 84 & 1,669 \\
\hline 11 & & daselbst an der Ahnsbecker Grenze & & 108 & 0,045 & & & & & & & 5 & 72 & 0,224 & 6 & 60 & 0,269 \\
\hline 12 & & Am Hockrehmen & & & & & & & & 74 & 0,097 & 10 & 11 & 0,619 & 11 & 65 & 0,716 \\
\hline 13 & & Am Wege nach dem Postmoor & & & & & & & & & & 8 & 64 & 0,341 & 8 & 64 & 0,341 \\
\hline & & (rechnerische Kontrolle) & & & 5,142 & & & & & & 1,754 & & & 6,092 & & & 12,988 \\
\hline & & Summa: & 46 & 101 & 5,142 & & & & 8 & 49 & 1,754 & 123 & 111 & 6,092 & 179 & 21 & 12,988 \\
\hline & & & & & & & & & & & & & & & & & \\
\hline & & Wiesen Litt: $\mathrm{n}$ & & & & & & & & & & & & & & & \\
\hline & 49 & In den trockenen Wiesen & & & & 9 & 60 & 1,850 & & & & 1 & 4 & 0,063 & 10 & 64 & 1,913 \\
\hline
\end{tabular}


Brinksitzer, Anbauern und Abbauern

\begin{tabular}{|c|c|c|c|c|c|c|c|c|c|c|c|c|c|c|c|c|c|}
\hline \multirow{5}{*}{ 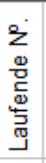 } & \multirow{5}{*}{ 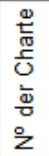 } & & & & & & & & & & & & & & & & \\
\hline & & Litt: v & & & & & & & & & & & & & \multicolumn{3}{|c|}{ Überhaupt } \\
\hline & & Der Brinksitzer Joh. Hr. & & & & & & & & & & & & & \multicolumn{3}{|c|}{ brauchbarer } \\
\hline & & Wulf & \multicolumn{3}{|c|}{ Ackerland } & \multicolumn{3}{|c|}{ Wiesenboden } & \multicolumn{3}{|c|}{ Angerboden } & \multicolumn{3}{|c|}{ Heidboden } & \multicolumn{3}{|c|}{ Boden } \\
\hline & & hat zugeteilt erhalten. & M & QR & Kuhw. & M & QR & Kuhw. & M & QR & Kuhw. & M & QR & Kuhw. & M & QR & Kuhw \\
\hline 1 & 225 & Hinterm Hohenkampe & 6 & 45 & 1,821 & & & & & & & & & & 6 & 45 & 1,821 \\
\hline 2 & 179 & Auf dem Osterraden & 3 & 78 & 0,930 & & & & & & & & 19 & 0,018 & 3 & 97 & 0,948 \\
\hline 3 & 137 & In den Neuengärten & & 14 & 0,039 & & & & 1 & 66 & 0,335 & & & & 1 & 80 & 0,374 \\
\hline 4 & 106 & Beim Hause & & & & & & & 1 & 21 & 0,195 & & & & 1 & 21 & 0,195 \\
\hline 5 & 202 & In der Mellmau & & & & & & & 2 & 48 & 0,403 & & & & 2 & 48 & 0,403 \\
\hline 6 & & Vor dem Krähenmoore & & & & & & & & & & 15 & 26 & 0,609 & 15 & 26 & 0,609 \\
\hline 7 & & Vor Dircks aus Ahnsbeck Wiese & & & & & & & 6 & 84 & 0,940 & & & & 6 & 84 & 0,940 \\
\hline 8 & & Am Canale & & & & & & & & & & 6 & 73 & 0,416 & 6 & 73 & 0,416 \\
\hline & & (rechnerische Kontrolle) & & & 2,790 & & & & & & 1,873 & & & 1,043 & & & 5,706 \\
\hline & & Summa: & 10 & 17 & 2,790 & & & & 11 & 99 & 1,873 & 21 & 118 & 1,043 & 43 & 114 & 5,70 \\
\hline
\end{tabular}

Wiesen Litt: w (Wolf)

75 In den Allerwiesen

\begin{tabular}{lll|l|l|l|}
3 & 94 & 0,408 & 5 & 102 & 0,582
\end{tabular}

$9 \quad 76 \quad 1,050$

\begin{tabular}{|c|c|c|c|c|c|c|c|c|c|c|c|c|c|c|c|c|c|}
\hline \multirow{5}{*}{ 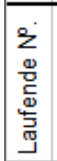 } & \multirow{5}{*}{ 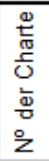 } & & & & & & & & & & & & & & & & \\
\hline & & Litt: w & & & & & & & & & & & & & \multicolumn{3}{|c|}{ Überhaupt } \\
\hline & & Der Brinksitzer Christoph & & & & & & & & & & & & & \multicolumn{3}{|c|}{ brauchbarer } \\
\hline & & Lüßmann & \multicolumn{3}{|c|}{ Ackerland } & \multicolumn{3}{|c|}{ Wiesenboden } & \multicolumn{3}{|c|}{ Angerboden } & \multicolumn{3}{|c|}{ Heidboden } & \multicolumn{3}{|c|}{ Boden } \\
\hline & & hat zugeteilt erhalten. & M & QR & Kuhw. & M & QR & Kuhw. & $M$ & QR & Kuhw. & $\mathrm{M}$ & QR & Kuhw. & $M$ & QR & Kuhw. \\
\hline 1 & 180 & Auf dem Hockrehmen & 9 & 47 & 2,517 & & & & & & & & 26 & 0,024 & 9 & 73 & 2,541 \\
\hline 2 & 195 & Auf dem Osterraden & 8 & 50 & 1,671 & & & & 5 & 2 & 0,644 & 1 & 96 & 0,057 & 15 & 28 & 2,402 \\
\hline 3 & 136 & In den neuen Gärten & & 16 & 0,045 & & & & & 114 & 0,211 & & & & 1 & 10 & 0,256 \\
\hline 4 & 105 & Beim Hause & & & & & & & & 119 & 0,162 & & & & & 119 & 0,162 \\
\hline 5 & 172 & Auf dem Moore & & & & & & & 1 & 61 & 0,367 & & 2 & 0,001 & 1 & 63 & 0,368 \\
\hline 6 & & Vor Drallen Osterwiese & & & & & & & & & & 2 & 106 & 0,213 & 2 & 106 & 0,213 \\
\hline 7 & & Hinterm Canale & & & & & & & & & & & & & & & \\
\hline 8 & & Am Exerzierplatz & & & & & & & & & & & & & & & \\
\hline & & Summa: & 17 & 113 & 4,233 & & & & 8 & 104 & 1,451 & 40 & 38 & 1,918 & 67 & 15 & 7,602 \\
\hline & & (rechnerische Kontrolle) & & & 4,233 & & & & & & 1,384 & & & 0,295 & & & 5,942 \\
\hline & & Differenz & & & 0,000 & & & & & & 0,067 & & & 1,623 & & & 1,660 \\
\hline & & Anmerkumg d. Verf. & & & & & & & & & F1 & & & F2 & & & F3 \\
\hline
\end{tabular}

Es fehlt eine Fläche Angerboden, die der Flur "Hinterm Canale" zugeordnet werden kann und bei 0,067 Kuhweiden aufgrund der Endsumme der Spalte 30 QR Angerboden ergibt.

Es fehlt eine Heidbodenfläche zu 1,623 Kuhw, entsprechend 35 M 48 QR als Ergänzung zur Spaltensumme

Bei Nachtrag obiger Werte ergibt sich folgende, berichtigte Tabelle mit automatischer Berichtigung der Ends Lüßmann

\begin{tabular}{l|l|l|l|l|}
\hline Ackerland & Wiesenboden & Angerboden & Heidboden & Boden
\end{tabular}

\begin{tabular}{l|l|l|l|l|l|l|l|l|l|l|l|l|l|l|l|l|l|l|l} 
hat zugeteilt erhalten. & $M$ & QR & Kuhw. & M & QR & Kuhw. & M & QR & Kuhw. & M & QR & Kuhw. & M & QR & Kuhw. \\
\hline
\end{tabular}

\begin{tabular}{|l|l|l|l|l|l|l|l|l|l|l|l|l|l|l|l|l|l|}
\hline Auf dem Hockrehmen & 9 & 47 & 2,517 & & & 26,024 & 9 & 73 & 2,541 \\
\hline
\end{tabular}

\begin{tabular}{|l|l|l|l|l|l|l|l|l|l|l|l|l|l|l|l|l|l|l|l|}
\hline Auf dem Osterraden & 8 & 50 & 1,671 & & 5 & 2 & 0,644 & 1 & 96 & 0,087 & 15 & 28 & 2,402 \\
\hline
\end{tabular}

\begin{tabular}{|l|l|l|l|}
\hline In den neuen Gärten & 16 & 0,045 \\
\hline
\end{tabular}

Beim Hause

Auf dem Moore

Vor Drallen Osterwiese

Hinterm Canale

Am Exerzierplatz

\begin{tabular}{|c|c|c|c|}
\hline Am Exelzlerpiatz & & & \\
\hline Summa: & 17 & 113 & 4,23 \\
\hline (rechnerische Kontrolle) & & & 4,2 \\
\hline
\end{tabular}

Wiesen Litt: v (Heuer)

64 Anschnitt von den Allerwiesen

70 In den Allerwiesen

(rechnerische Kontrolle)
Summa

(rechnerische Kontrolle)
Summa:

\begin{tabular}{|l|l|l|l|l|}
\hline & & 114 & 0,211 \\
\hline & & 119 & 0,162 \\
\hline & & 1 & 61 & 0,367 \\
\hline
\end{tabular}

\begin{tabular}{|l|l|l|l|l|l|l|}
\hline 114 & 0,211 & & & 1 & 10 & 0,256 \\
\hline
\end{tabular}

\begin{tabular}{ll|l|l|l|}
\hline & 119 & 0,162 \\
\hline & 0,001 & 1 & 63 & 0,368 \\
\hline
\end{tabular}

\begin{tabular}{|c|c|c|c|c|c|}
\hline 2 & 106 & 0,213 & 2 & 106 & 0,213 \\
\hline
\end{tabular}

\begin{tabular}{|l|l|l|l|l|l|l|}
\hline 30 & 0,067 & & & & 30 & 0,067 \\
\hline
\end{tabular}

\begin{tabular}{|l|l|l|l|l|l|}
35 & 48 & 1,593 & 35 & 48 & 1,593 \\
\cline { 2 - 4 }
\end{tabular} \begin{tabular}{|l|l|l|l|l|l|l|l|}
\hline 8104 & 1,451 & 40 & 38 & 1,918 & 67 & 15 & 7,602 \\
\hline 1,451 & & & 1,918 & & & 7,602 \\
\hline
\end{tabular}

233

\begin{tabular}{|l|l|l|l|l|}
\hline 1,451 & 8 & 104 \\
1,451
\end{tabular}

\begin{tabular}{|r|r|r|}
\hline & 23 & 0,025 \\
\hline 7 & 90 & 1,740 \\
\hline & & 1,765 \\
\hline 7 & 113 & 1765 \\
\hline
\end{tabular}

\begin{tabular}{|l|l|l|l|l|}
\hline & & & 23 & 0,025 \\
\hline & & 7 & 90 & 1,740 \\
\hline & & & 1,765 \\
\hline & & 7 & 113 & 1,765 \\
\hline
\end{tabular}

\begin{tabular}{|c|c|c|c|c|c|c|c|c|c|c|c|c|c|c|c|c|c|}
\hline \multirow{5}{*}{ 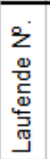 } & \multirow{5}{*}{ 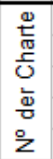 } & & & & & & & & & & & & & & & & \\
\hline & & Litt: $x$ & & & & & & & & & & & & & \multicolumn{3}{|c|}{ Überhaupt } \\
\hline & & Der Brinksitzer Joh. Hr. & & & & & & & & & & & & & \multicolumn{3}{|c|}{ brauchbarer } \\
\hline & & Lillie & \multicolumn{3}{|c|}{ Ackerland } & \multicolumn{3}{|c|}{ Wiesenboden } & \multicolumn{3}{|c|}{ Angerboden } & \multicolumn{3}{|c|}{ Heidboden } & \multicolumn{3}{|c|}{ Boden } \\
\hline & & hat zugeteilt erhalten. & M & QR & Kuhw. & $\mathrm{M}$ & QR & Kuhw. & $\mathrm{M}$ & QR & Kuhw. & M & QR & Kuhw. & M & QR & Kuhw. \\
\hline 1 & 176 & Auf dem Osterraden & 3 & 116 & 1,051 & & & & 2 & 29 & 0,827 & & & & 7 & 25 & 1,878 \\
\hline 2 & 144 & In den neuen Gärten & & 44 & 0,065 & & & & & 78 & 0,158 & & & & 1 & 2 & 0,223 \\
\hline 3 & 124 & Beim Hause & & & & & & & & 40 & 0,056 & 1 & 13 & 0,101 & 1 & 53 & 0,157 \\
\hline 4 & 75 & Am Beedenbosteler Kirchwege & & & & & & & & & & 3 & 25 & 0,302 & 3 & 25 & 0,302 \\
\hline 5 & & Am Wege nach dem Postmoor & & & & & & & & & & 14 & 64 & 0,581 & 14 & 64 & 0,581 \\
\hline 6 & & Hinterm Canale & & & & & & & & & & 4 & 56 & 0,223 & 4 & 56 & 0,223 \\
\hline & & (rechnerische Kontrolle) & & & 1,116 & & & & & & 1,041 & & & 1,207 & & & 3,364 \\
\hline & & Summa: & 5 & 40 & 1,116 & & & & 3 & 27 & 1,041 & 23 & 38 & 1,207 & 31 & 105 & 3,364 \\
\hline & & & & & & & & & & & & & & & & & \\
\hline & & Wiesen Litt: u (Eggers) & & & & & & & & & & & & & & & \\
\hline & 77 & In den Allerwiesen & & & & 8 & 24 & 1,771 & & & & & & & 8 & 24 & 1,771 \\
\hline
\end{tabular}




\begin{tabular}{|c|c|c|c|c|c|c|c|c|c|c|c|c|c|c|c|c|c|}
\hline \multirow{5}{*}{ 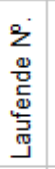 } & \multirow{5}{*}{ 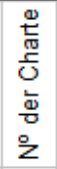 } & & & & & & & & & & & & & & & & \\
\hline & & Litt: y & & & & & & & & & & & & & \multicolumn{3}{|c|}{ Überhaupt } \\
\hline & & Der Anbauer Chrisoph & & & & & & & & & & & & & \multicolumn{3}{|c|}{ brauchbarer } \\
\hline & & Thies & \multicolumn{3}{|c|}{ Ackerland } & \multicolumn{3}{|c|}{ Wiesenboden } & \multicolumn{3}{|c|}{ Angerboden } & \multicolumn{3}{|c|}{ Heidboden } & \multicolumn{3}{|c|}{ Boden } \\
\hline & & hat zugeteilt erhalten. & M & QR & Kuhw. & M & $\mathrm{QR}$ & Kuhw. & $M$ & QR & Kuhw. & $M$ & QR & Kuhw. & M & QR & Kuhw. \\
\hline 1 & 34 & Auf dem Bulloh & 6 & 3 & 1,583 & & & & & & & & & & 8 & 3 & 1,583 \\
\hline 2 & 67 & In den Langengärten & & 69 & 0,080 & & & & & 80 & 0,007 & & & & & 77 & 0,087 \\
\hline 3 & $121 \mathrm{a}$ & Beim Hause & & & & & & & & 45 & 0,063 & & 22 & 0,018 & & 67 & 0,081 \\
\hline 4 & 201 & In der Mellmau & & & & & & & 3 & 118 & 0,650 & & 34 & 0,018 & 4 & 32 & 0,668 \\
\hline 5 & & Am Exerzierplatze & & & & & & & & & & 18 & 70 & 0,743 & 18 & 70 & 0,743 \\
\hline 6 & & daselbst & & & & & & & & & & 8 & 10 & 0,323 & 8 & 10 & 0,323 \\
\hline \multirow[t]{6}{*}{7} & & Hinterm Canale & & & & & & & & & & 11 & 105 & 0,749 & 11 & 105 & 0,749 \\
\hline & & (rechnerische Kontrolle) & & & 1,663 & & & & & & 0,720 & & & 1,851 & & & 4,234 \\
\hline & & Summa: & 6 & 72 & 1,663 & & & & 4 & 51 & 0,720 & 39 & 1 & 1,851 & 50 & 4 & 4,234 \\
\hline & & & & & & & & & & & & & & & & & \\
\hline & & Wiesen Ltt: y (ab 1861 Trumann) & & & & & & & & & & & & & & & \\
\hline & \multicolumn{2}{|r|}{117 In den Allerwiesen } & & & & & 21 & 0,082 & & & & & & & & 21 & 0,082 \\
\hline
\end{tabular}

\begin{tabular}{|c|c|c|c|c|c|c|c|c|c|c|c|c|c|c|c|c|c|}
\hline \multirow{5}{*}{ 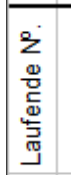 } & \multirow{5}{*}{ 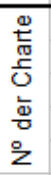 } & \multirow{2}{*}{ Litt: $z$} & & & & & & & & & & & & & & & \\
\hline & & & & & & & & & & & & & & & \multicolumn{3}{|c|}{ Überhaupt } \\
\hline & & \multirow{2}{*}{$\begin{array}{c}\text { Der Anbauer Carsten } \mathrm{Hr} \text {. } \\
\text { Meyer }\end{array}$} & & & & & & & & & & & & & & rauch & barer \\
\hline & & & \multicolumn{3}{|c|}{ Ackerland } & \multicolumn{3}{|c|}{ Wiesenboden } & \multicolumn{3}{|c|}{ Angerboden } & \multicolumn{3}{|c|}{ Heidboden } & \multicolumn{3}{|c|}{ Boden } \\
\hline & & hat zugeteilt erhalten. & M & QR & Kuhw. & M & $Q R$ & Kuhw. & M & QR & Kuhw. & M & QR & Kuhw. & M & QR & Kuhw. \\
\hline & 175 & Auf dem Sandbruche & 8 & 60 & 2,007 & & 50 & 0,139 & 2 & 119 & 0,922 & & & & 11 & 109 & 3,068 \\
\hline 2 & 175 & Auf dem Osterraden & 4 & 65 & 0,810 & & & & 2 & 12 & 0,485 & & 22 & 0,010 & 6 & 99 & 1,305 \\
\hline 3 & 96 & Beim Hause & & & & & & & 1 & 43 & 0,190 & & & & 1 & 43 & 0,190 \\
\hline 4 & 190 & In den Sandbergen am Lehmgarten & & & & & & & & & & 2 & & 0,080 & 2 & & 0,080 \\
\hline 5 & & Hinter Misselhorns Kämpen & & & & & & & & 70 & 0,058 & 11 & 117 & 0,837 & 12 & 67 & 0,895 \\
\hline 6 & & & & & & & & & & & & 10 & 57 & 0,475 & 10 & 57 & 0,475 \\
\hline & & (rechnerische Kontrolle) & & & 2,817 & & & 0,139 & & & 1,655 & & & 1,402 & & & 6,013 \\
\hline & & Summa: & 13 & 5 & 2,817 & & 50 & 0,139 & 7 & 4 & 1,655 & 24 & 76 & 1,402 & 45 & 15 & 6,013 \\
\hline & & & & & & & & & & & & & & & & & \\
\hline & & Wiesen Litt: $z$ & & & & & & & & & & & & & & & \\
\hline & 116 & In den Allerwiesen & & & & & 20 & 0,085 & & & & & & & & 20 & 0,085 \\
\hline
\end{tabular}

\begin{tabular}{|c|c|c|c|c|c|c|c|c|c|c|c|c|c|c|c|c|c|}
\hline \multirow{5}{*}{ 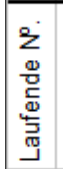 } & \multirow{5}{*}{ 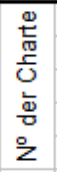 } & & & & & & & & & & & & & & & & \\
\hline & & Litt: aa & & & & & & & & & & & & & \multicolumn{3}{|c|}{ Überhaupt } \\
\hline & & Der Anbauer Heinrich. & & & & & & & & & & & & & \multicolumn{3}{|c|}{ brauchbarer } \\
\hline & & Bergmann & \multicolumn{3}{|c|}{ Ackerland } & \multicolumn{3}{|c|}{ Wiesenboden } & \multicolumn{3}{|c|}{ Angerboden } & \multicolumn{3}{|c|}{ Heidboden } & \multicolumn{3}{|c|}{ Boden } \\
\hline & & hat zugeteilt erhalten. & M & QR & Kuhw. & $M$ & QR & Kuhw. & M & $\mathrm{QR}$ & Kuhw. & M & QR & Kuhw. & M & QR & Kuhw. \\
\hline 1 & 138 & In den Neuengärten & & 82 & 0,228 & & & & & 28 & 0,047 & & & & & 110 & 0,275 \\
\hline 2 & 103 & Beim Hause & & & & & & & 1 & 24 & 0,146 & & 22 & 0,010 & 1 & 46 & 0,156 \\
\hline 3 & 200 & In der Mellmau & & & & & & & 1 & 58 & 0,287 & 2 & 42 & 0,152 & 3 & 100 & 0,439 \\
\hline 4 & & Am Exerzierplatze & & & & & & & & & & 19 & 80 & 0,787 & 19 & 80 & 0,787 \\
\hline 5 & & Hinterm Canale & & & & & & & & & & 8 & 3 & 0,401 & 8 & 3 & 0,401 \\
\hline & & (rechnerische Kontrolle) & & & 0,228 & & & & & & 0,480 & & & 1,350 & & & 2,058 \\
\hline & & Summa: & & 82 & 0,228 & & & & 2 & 110 & 0,480 & 30 & 27 & 1,350 & 33 & 99 & 2,058 \\
\hline & & & & & & & & & & & & & & & & & \\
\hline & & Wiesen Litt: za & & & & & & & & & & & & & & & \\
\hline & 118 & In den Allerwiesen & & & & & 13 & 0,047 & & & & & & & & 13 & 0,047 \\
\hline
\end{tabular}

\begin{tabular}{|c|c|c|c|c|c|c|c|c|c|c|c|c|c|c|c|c|c|}
\hline \multirow{5}{*}{ 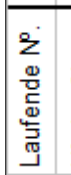 } & \multirow{5}{*}{ 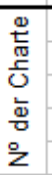 } & \multirow[b]{2}{*}{ Litt. bb } & & & & & & & & & & & & & & & \\
\hline & & & & & & & & & & & & & & & \multicolumn{3}{|c|}{ Überhaupt } \\
\hline & & Der Anbauer Joh. $\mathrm{Hr}$. & & & & & & & & & & & & & \multicolumn{3}{|c|}{ brauchbarer } \\
\hline & & Knoop & \multicolumn{3}{|c|}{ Ackerland } & \multicolumn{3}{|c|}{ Wiesenboden } & \multicolumn{3}{|c|}{ Angerboden } & \multicolumn{3}{|c|}{ Heidboden } & \multicolumn{3}{|c|}{ Boden } \\
\hline & & hat zugeteilt erhalten. & $\mathrm{M}$ & QR & Kuhw. & M & $\mathrm{QR}$ & Kuhw. & M & $Q R$ & Kuhw. & M & QR & Kuhw. & M & $\mathrm{QR}$ & Kuhw. \\
\hline 1 & 193 & Auf dem Osterraden & 13 & 40 & 3,062 & & & & & 88 & 0,183 & 1 & 92 & 0,097 & 15 & 100 & 3,342 \\
\hline 2 & 222 & Hinterm Hohenkampe & 10 & 70 & 2,519 & & & & & & & & 3 & 0,004 & 10 & 20 & 2,523 \\
\hline 3 & 135 & In den Neuengärten & & 20 & 0,056 & & & & 1 & 4 & 0,247 & & & & 1 & 24 & 0,303 \\
\hline 4 & 104 & Beim Hause & & & & & & & & 104 & 0,145 & & & & & 104 & 0,145 \\
\hline 5 & 191 & In der Mellmau & & & & & & & & & & 18 & 111 & 0,932 & 18 & 111 & 0,932 \\
\hline & & Am Krummenmoore & & & & & & & & & & 16 & 48 & 0,656 & 16 & 48 & 0,656 \\
\hline & & Hinterm Krähenmoore & & & & & & & & & & 23 & 45 & 0,144 & 23 & 45 & 1,144 \\
\hline & & (rechnerische Kontrolle) & & & 5,637 & & & & & & 0,575 & & & 1,833 & & & 9,045 \\
\hline & & Summa: & 23 & 77 & 5,637 & & & & 2 & 76 & 0,575 & 60 & 59 & 2,833 & 86 & 92 & 9,045 \\
\hline & & & & & & & & & & & & & & & & & \\
\hline & & Wiesen Litt: $\mathrm{x}$ & & & & & & & & & & & & & & & \\
\hline & 135 & In den Dreckwiesen & & & & 3 & 71 & 0,823 & & & & & & & 3 & 71 & 0,823 \\
\hline
\end{tabular}




\begin{tabular}{|c|c|c|c|c|c|c|c|c|c|c|c|c|c|c|c|c|c|}
\hline \multirow{5}{*}{ 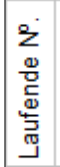 } & \multirow{5}{*}{ 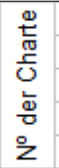 } & & & & & & & & & & & & & & & & \\
\hline & & Litt. cc & & & & & & & & & & & & & \multicolumn{3}{|c|}{ Überhaupt } \\
\hline & & Der Anbauer Wilhelm & & & & & & & & & & & & & \multicolumn{3}{|c|}{ brauchbarer } \\
\hline & & Herbold & \multicolumn{3}{|c|}{ Ackerland } & \multicolumn{3}{|c|}{ Wiesenboden } & \multicolumn{3}{|c|}{ Angerboden } & \multicolumn{3}{|c|}{ Heidboden } & \multicolumn{3}{|c|}{ Boden } \\
\hline & & hat zugeteilt erhalten. & M & QR & Kuhw. & M & $Q R$ & Kuhw. & M & QR & Kuhw. & M & QR & Kuhw. & $\mathrm{M}$ & QR & Kuhw. \\
\hline 1 & 127 & Beim Hause & & 29 & 0,020 & & & & & 10 & 0,007 & 6 & 18 & 0,293 & 6 & 57 & 0,320 \\
\hline 2 & 142 & Im Moore & & & & & & & 1 & 81 & 0,341 & & & & 1 & 81 & 0,341 \\
\hline 3 & 301 & Neben dem Stockau & & & & & & & & 87 & 0,104 & 8 & 65 & 0,440 & 9 & 32 & 0,544 \\
\hline & & Hinterm Canale & & & & & & & & & & 4 & 70 & 0,229 & 4 & 70 & 0,229 \\
\hline & & Am Wege nach dem Postmoore & & & & & & & & & & 13 & 63 & 0,541 & 13 & 63 & 0,541 \\
\hline & & Hinterm Westerkampe & & & & & & & & & & 2 & 65 & 0,144 & 2 & 63 & 0,144 \\
\hline & & (rechnerische Kontrolle) & & & 0,020 & & & & & & 0,452 & & & 1,647 & & & 2,119 \\
\hline & & Summa: & & 29 & 0,020 & & & & 2 & 58 & 0,452 & 35 & 41 & 1,647 & 38 & 8 & 2,119 \\
\hline & & & & & & & & & & & & & & & & & \\
\hline & & Wiesen Litt: zb & & & & & & & & & & & & & & 15 & 0,05 \\
\hline & 119 & In den Allerwiesen & & & & & 15 & 0,05 & & & & & & & & & \\
\hline
\end{tabular}

\begin{tabular}{|c|c|c|c|c|c|c|c|c|c|c|c|c|c|c|c|c|c|}
\hline \multirow{5}{*}{ 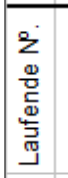 } & \multirow{5}{*}{ 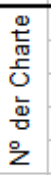 } & \multirow{4}{*}{$\begin{array}{c}\text { Litt. dd } \\
\text { Der Abbauer Wilhelm } \\
\text { Friedrich Meyer }\end{array}$} & & & & & & & & & & & & & & & \\
\hline & & & & & & & & & & & & & & & \multicolumn{3}{|c|}{ Überhaupt } \\
\hline & & & & & & & & & & & & & & & & rauch & barer \\
\hline & & & \multicolumn{3}{|c|}{ Ackerland } & \multicolumn{3}{|c|}{ Wiesenboden } & \multicolumn{3}{|c|}{ Angerboden } & \multicolumn{3}{|c|}{ Heidboden } & \multicolumn{3}{|c|}{ Boden } \\
\hline & & hat zugeteilt erhalten. & M & $\mathrm{QR}$ & Kuhw. & M & $Q R$ & Kuhw. & M & QR & Kuhw. & M & QR & Kuhw. & M & QR & Kuhw \\
\hline 1 & 177 & Auf dem Osterraden & 3 & 44 & 0,772 & & & & & & & & & & 3 & 44 & 0,772 \\
\hline 2 & 66 & In den Langengärten & & 93 & 0,090 & & & & & & & & & & & 93 & 0,090 \\
\hline 3 & 102 & Beim Hause & & & & & & & & 75 & 0,092 & & 29 & 0,009 & & 104 & 0,101 \\
\hline 4 & 197 & In der Mellmau & & & & & & & & 82 & 0,137 & & 87 & 0,048 & 1 & 49 & 0,185 \\
\hline & & (rechnerische Kontrolle) & & & 0,862 & & & & & & 0,229 & & & 0,057 & & & 1,148 \\
\hline & & Summa: & 4 & 17 & 0,862 & & & & 1 & 37 & 0,229 & & 116 & 0,057 & 6 & 50 & 1,148 \\
\hline
\end{tabular}

\begin{tabular}{|c|c|c|c|c|c|c|c|c|c|c|c|c|c|c|c|c|c|}
\hline \multirow{5}{*}{ 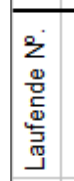 } & \multirow{5}{*}{ 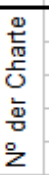 } & & & & & & & & & & & & & & & & \\
\hline & & Litt. ee & & & & & & & & & & & & & \multicolumn{3}{|c|}{ Überhaupt } \\
\hline & & Der Abbauer . & & & & & & & & & & & & & \multicolumn{3}{|c|}{ brauchbarer } \\
\hline & & Fr. Ramberg & \multicolumn{3}{|c|}{ Ackerland } & \multicolumn{3}{|c|}{ Wiesenboden } & \multicolumn{3}{|c|}{ Angerboden } & \multicolumn{3}{|c|}{ Heidboden } & \multicolumn{3}{|c|}{ Boden } \\
\hline & & hat zugeteilt erhalten. & M & QR & Kuhw. & M & QR & Kuhw. & M & QR & Kuhw. & M & QR & Kuhw. & M & QR & Kuhw \\
\hline 1 & 243 & Beim Hause & 1 & 94 & 0,373 & & & & & 96 & 0,133 & & & & 2 & 70 & 0,506 \\
\hline 2 & & Hinterm Westerkamp & & & & & & & & & & 2 & 24 & 0,112 & 2 & 24 & 0,112 \\
\hline & & (rechnerische Kontrolle) & & & 0,373 & & & & & & 0,133 & & & 0,112 & & & 0,618 \\
\hline & & Summa: & 1 & 94 & 0,373 & & & & & 96 & 0,133 & 2 & 24 & 0,112 & 4 & 94 & 0,618 \\
\hline
\end{tabular}

\begin{tabular}{|c|c|c|c|c|c|c|c|c|c|c|c|c|c|c|c|c|c|}
\hline \multirow{5}{*}{ 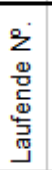 } & \multirow{5}{*}{ 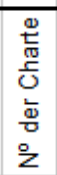 } & \multirow{3}{*}{$\begin{array}{c}\text { Litt. ff } \\
\text { Der Abbauer }\end{array}$} & & & & & & & & & & & & & & & \\
\hline & & & & & & & & & & & & & & & \multirow{2}{*}{\multicolumn{3}{|c|}{$\begin{array}{l}\text { Überhaupt } \\
\text { brauchbarer }\end{array}$}} \\
\hline & & & & & & & & & & & & & & & & & \\
\hline & & Gottfreid Walter & \multicolumn{3}{|c|}{ Ackerland } & \multicolumn{3}{|c|}{ Wiesenboden } & \multicolumn{3}{|c|}{ Angerboden } & \multicolumn{3}{|c|}{ Heidboden } & \multicolumn{2}{|c|}{ Boden } & \multirow[b]{2}{*}{ Kuhw. } \\
\hline & & hat zugeteilt erhalten. & M & $Q R$ & Kuhw. & M & QR & Kuhw. & M & $\mathrm{QR}$ & Kuhw. & $M$ & QR & Kuhw. & $M$ & QR & \\
\hline 1 & & Beim Hause & 1 & 109 & 0,364 & & & & & 66 & 0,092 & & & & 2 & 55 & 0,456 \\
\hline 2 & & In der Mellmau & & & & & & & & 69 & 0,115 & & 105 & 0,058 & 1 & 54 & 0,173 \\
\hline & & (rechnerische Kontrolle) & & & 0,364 & & & & & & 0,207 & & & 0,058 & & & 0,629 \\
\hline & & Summa: & 1 & 109 & 0,364 & & & & 1 & 15 & 0,207 & & 105 & 0,058 & 3 & 109 & 0,629 \\
\hline
\end{tabular}

\begin{tabular}{|c|c|c|c|c|c|c|c|c|c|c|c|c|c|c|c|c|c|}
\hline \\
\hline & \multirow{5}{*}{ 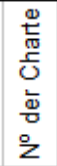 } & & & & & & & & & & & & & & & & \\
\hline \multirow{4}{*}{ 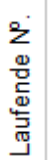 } & & Litt. gg & & & & & & & & & & & & & \multicolumn{3}{|c|}{ Überhaupt } \\
\hline & & Der Abbauer & & & & & & & & & & & & & \multicolumn{3}{|c|}{ brauchbarer } \\
\hline & & Hr. Ahrens & \multicolumn{3}{|c|}{ Ackerland } & \multicolumn{3}{|c|}{ Wiesenboden } & \multicolumn{3}{|c|}{ Angerboden } & \multicolumn{3}{|c|}{ Heidboden } & \multicolumn{3}{|c|}{ Boden } \\
\hline & & hat zugeteilt erhalten. & M & QR & Kuhw. & $M$ & QR & Kuhw. & M & QR & Kuhw. & M & QR & Kuhw. & M & QR & Kuhw \\
\hline 1 & 249 & Beim Hause & 1 & 56 & 0,163 & & & & & 26 & 0,124 & & 10 & 0,008 & 1 & 92 & 0,195 \\
\hline 2 & & Am Ahnsbecker Celelr Wege & & & & & & & & & & & 116 & 0,042 & & 116 & 0,042 \\
\hline & & (rechnerische Kontrolle) & & & 0,163 & & & & & & 0,124 & & & 0,050 & & & 0,237 \\
\hline & & Summa: & 1 & 56 & 0,163 & & & & & 26 & 0,024 & 1 & 60 & 0,050 & 2 & 88 & 0,237 \\
\hline
\end{tabular}




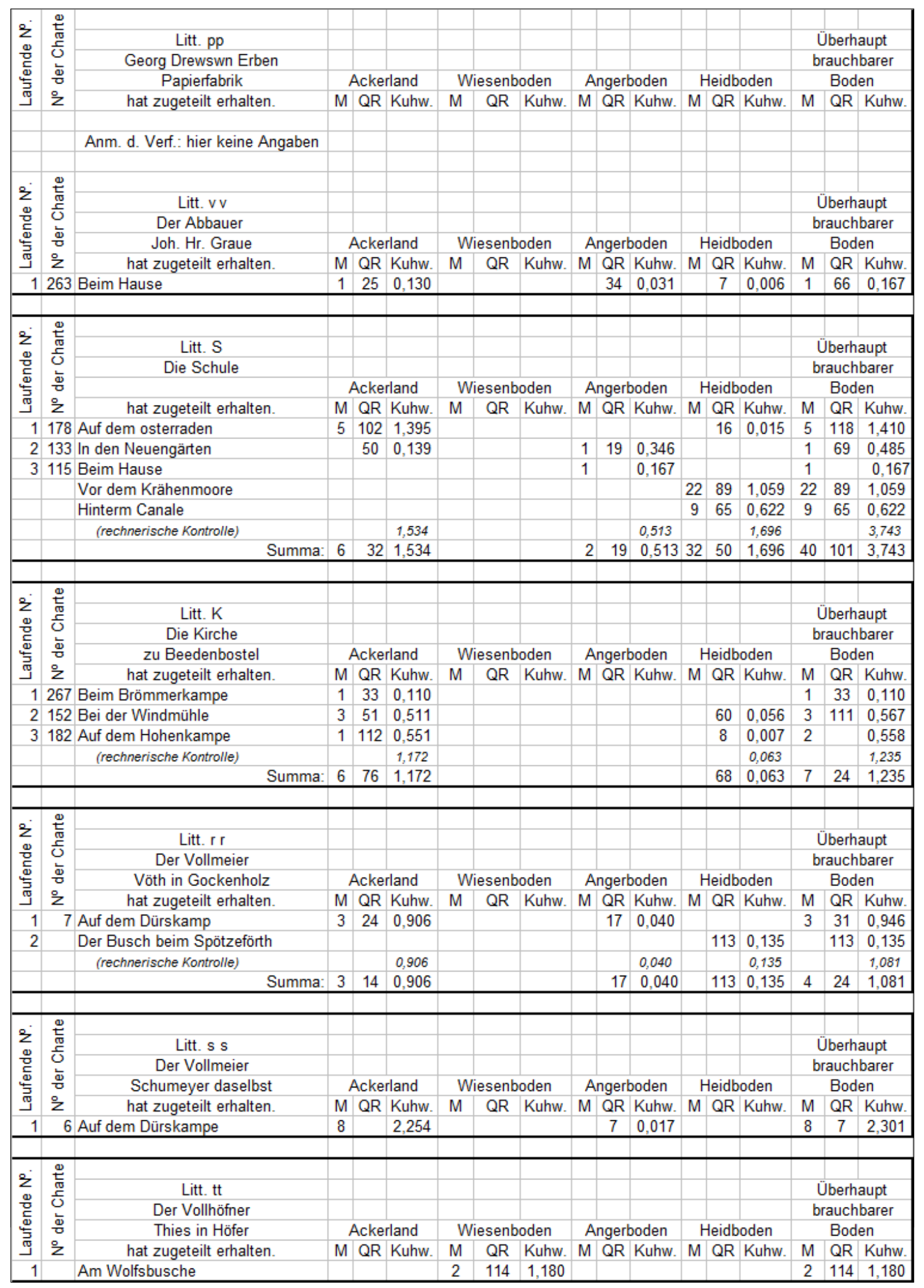




\begin{tabular}{|c|c|c|c|c|c|c|c|c|c|c|c|c|c|c|c|c|c|}
\hline \multirow{5}{*}{ 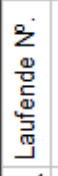 } & \multirow{5}{*}{ 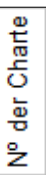 } & & & & & & & & & & & & & & & & \\
\hline & & Litt. uu & & & & & & & & & & & & & \multicolumn{3}{|c|}{ Überhaupt } \\
\hline & & Der Vollmeier & & & & & & & & & & & & & \multicolumn{3}{|c|}{ brauchbarer } \\
\hline & & Misselhorn in Gockenholz & \multicolumn{3}{|c|}{ Ackerland } & \multicolumn{3}{|c|}{ Wiesenboden } & \multicolumn{3}{|c|}{ Angerboden } & \multicolumn{3}{|c|}{ Heidboden } & \multicolumn{3}{|c|}{ Boden } \\
\hline & & hat zugeteilt erhalten. & M & QR & Kuhw. & M & $Q R$ & Kuhw. & M & QR & Kuhw. & M & QR & Kuhw. & M & QR & Kuhw. \\
\hline 1 & & Beim Spötzeförthe & & & & 1 & 93 & 0,312 & & & & & 26 & 0,031 & 1 & 119 & 0,343 \\
\hline & & & & & & & & & & & & & & & & & \\
\hline \multirow{5}{*}{ 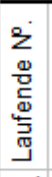 } & \multirow{5}{*}{ 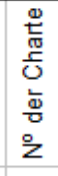 } & & & & & & & & & & & & & & & & \\
\hline & & Litt. ww & & & & & & & & & & & & & \multicolumn{3}{|c|}{ Überhaupt } \\
\hline & & Die Gemeinde & & & & & & & & & & & & & \multicolumn{3}{|c|}{ brauchbarer } \\
\hline & & Gockenholz & \multicolumn{3}{|c|}{ Ackerland } & \multicolumn{3}{|c|}{ Wiesenboden } & \multicolumn{3}{|c|}{ Angerboden } & \multicolumn{3}{|c|}{ Heidboden } & \multicolumn{3}{|c|}{ Boden } \\
\hline & & hat zugeteilt erhalten. & M & $Q R$ & Kuhw. & M & $Q R$ & Kuhw. & M & $Q R$ & Kuhw. & M & $Q R$ & Kuhw. & M & QR & Kuhw. \\
\hline 1 & & Auf dem Dürskampe & & 98 & 0,231 & & & & & & & & & & & 98 & 0,231 \\
\hline
\end{tabular}

\section{Gemeinde:}

\begin{tabular}{|c|c|c|c|c|c|c|c|c|c|c|c|c|c|c|c|c|c|}
\hline \multirow{5}{*}{ 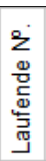 } & \multirow{5}{*}{ 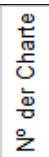 } & & & & & & & & & & & & & & & & \\
\hline & & Litt. G & & & & & & & & & & & & & \multicolumn{3}{|c|}{ Überhaupt } \\
\hline & & Die Gemeinde & & & & & & & & & & & & & \multicolumn{3}{|c|}{ brauchbarer } \\
\hline & & & \multicolumn{3}{|c|}{ Ackerland } & \multicolumn{3}{|c|}{ Wiesenboden } & \multicolumn{3}{|c|}{ Angerboden } & \multicolumn{3}{|c|}{ Heidboden } & \multicolumn{3}{|c|}{ Boden } \\
\hline & & hat zugeteilt erhalten. & M & QR & Kuhw. & M & QR & Kuhw. & $M$ & QR & Kuhw. & $M$ & QR & Kuhw. & M & QR & Kuhw. \\
\hline 1 & 15 & Der Weg von Beedenbostel nach Celle & 2 & 12 & 0,560 & & & & & 74 & 0,162 & 1 & 80 & 0,173 & 4 & 46 & 0,895 \\
\hline 2 & 16 & Der Weg nach Alvern & 6 & 9 & 0,673 & & & & & 20 & 0,048 & & 69 & 0,044 & 6 & 98 & 0,765 \\
\hline 3 & 18 & Der Weg nach dem Lachenkampe & 1 & 101 & 0,120 & & & & & & & 6 & 50 & 0,359 & 8 & 31 & 0,479 \\
\hline 4 & 25 & Der Weg nach Gockenholz & 5 & 9 & 0,228 & & & & & 21 & 0,048 & 2 & 97 & 0,132 & 8 & 7 & 1,408 \\
\hline 5 & 55 & Der Weg vor dem Flottkampe & & 57 & 0,033 & & & & & 5 & 0,005 & & 102 & 0,043 & 1 & 44 & 0,081 \\
\hline 6 & 74 & Der Weg nach Beedenbostel & 1 & 101 & 0,519 & & & & & 10 & 0,009 & 4 & 44 & 0,288 & 6 & 35 & 0,816 \\
\hline 7 & 20 & Der Weg vor den Wiesen & 2 & 32 & 0,126 & & & & & & & 3 & 105 & 0,268 & 6 & 17 & 0,394 \\
\hline 8 & 291 & Der Weg überm Westerkamp & 2 & 119 & 0,446 & & & & & 14 & 0,019 & 4 & 26 & 0,260 & 7 & 39 & 0,725 \\
\hline 9 & 282 & Der Weg südl. am Westernkampe & 1 & 28 & 0,203 & & & & & & & 5 & 36 & 0,365 & 6 & 64 & 0,568 \\
\hline 10 & 274 & Der Weg übers Lohfelde nach Celle & 3 & 52 & 0,332 & & & & & & & & 49 & 0,039 & 3 & 101 & 0,371 \\
\hline 11 & 269 & Der Weg nach Oppershausen & 3 & 14 & 0,343 & & & & & & & & 43 & 0,033 & 3 & 57 & 0,376 \\
\hline 12 & 252 & Die Trift nach den Wiesen & 4 & 97 & 0,695 & & & & & & & 1 & 48 & 0,080 & 6 & 25 & 0,775 \\
\hline 13 & 256 & Der Weg durch die Ackern & 1 & 80 & 0,102 & & & & & & & & 18 & 0,008 & 1 & 98 & 0,110 \\
\hline 14 & 242 & Der Weg bei Rambergs Hause & & 30 & 0,057 & & & & & & & & & & & 30 & 0,057 \\
\hline 15 & 279 & Der Weg nach Bührings Mühlenkamp & & 71 & 0,047 & & & & & & & & 2 & 0,001 & & 73 & 0,048 \\
\hline 16 & 231 & Der Weg nach Ahnsbeck & 3 & 9 & 0,513 & & & & 1 & 82 & 0,277 & 1 & 77 & 0,182 & 6 & 48 & 0,972 \\
\hline 17 & 149 & Der Weg nach der Windmühle & & 22 & 0,021 & & & & & & & & 10 & 0,009 & & 32 & 0,030 \\
\hline 18 & 153 & desgl. Von Ahnsbeck nach der Windmühle & & 45 & 0,064 & & & & & & & & 13 & 0,008 & & 58 & 0,072 \\
\hline 19 & 157 & Am Ahnsbecker Wege & & 78 & 0,074 & & & & & & & & & & & 78 & 0,074 \\
\hline 20 & 230 & Der Weg nach bergmanns Koppel & & 34 & 0,057 & & & & & & & & 12 & 0,014 & & 46 & 0,071 \\
\hline 21 & 159 & Der Weg nach der Schelprieth & 3 & 2 & 0,664 & & 18 & 0,049 & 1 & 61 & 0,376 & & 55 & 0,046 & 5 & 16 & 1,135 \\
\hline & & (rechner. Kontrolle) & & & 5,877 & & & 0,049 & & & 0,944 & & & 2,352 & & & 10,222 \\
\hline & & Latus 1 & 45 & 42 & 6,877 & & 18 & 0,049 & 4 & 47 & 0,944 & 34 & 96 & 2,352 & 84 & 83 & 10,222 \\
\hline & & Anmerkungen: & & & & & & & & & & & & & & & \\
\hline & & Die Summe der Kuhweidenwerte beim Ackerla & and & ist re & chnerisc & nn 7 & EIm & helt klel & ner a & als in & m Ongın & & & & & & \\
\hline & & Vermutung: In Ifd. Nr. 4 , bei $5 M 9$ QR dürfte $c$ & der & Wert & von 0,22 & $28 r$ & Kuhw & eiden zu & kle & ein se & ein. Die & Kont & trollire & hnung de & & & \\
\hline & & Zeilensummen der Kuhweidenwerte ergibt eine & $A b$ & bweic & inung in & Ifd & 1. $\mathrm{Nr}$. & 4: rech & neris & sch: & $0,408, i$ & $m \mathrm{Or}$ & rigina & 1,408 & & & \\
\hline & & Die Summenwerte der Summenzeile (Latus) u & nd & die re & chner. S & Sum & me & der letzt & en $S$ & Spalt & e stimm & en $m$ & nit 10 & 22 übere & & & \\
\hline & & Es handelt sich also um einen Schreibfehler if & $n$ Ifo & d. $\mathrm{Nr}$. & 4. Acke & erlan & $n d: r$ & chtig: 1 , & 228 & 8 stat & It im Ori & ginal & 0,22 & & & & \\
\hline
\end{tabular}




\begin{tabular}{|c|c|c|c|c|c|c|c|c|c|c|c|c|c|c|c|c|c|}
\hline \multirow{5}{*}{ 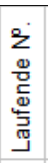 } & \multirow{5}{*}{ 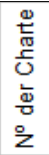 } & & & & & & & & & & & & & & & & \\
\hline & & Litt. G & & & & & & & & & & & & & \multicolumn{3}{|c|}{ Überhaupt } \\
\hline & & Die Gemeinde & & & & & & & & & & & & & \multicolumn{3}{|c|}{ brauchbarer } \\
\hline & & & \multicolumn{3}{|c|}{ Ackerland } & \multicolumn{3}{|c|}{ Wiesenboden } & \multicolumn{3}{|c|}{ Angerboden } & \multicolumn{3}{|c|}{ Heidboden } & \multicolumn{3}{|c|}{ Boden } \\
\hline & & hat zugeteilt erhalten. & M & QR & Kuhw. & M & QR & Kuhw. & $\mathrm{M}$ & QR & Kuhw. & M & QR & Kuhw. & $\mathrm{M}$ & QR & Kuhw. \\
\hline 1 & 95 & Hirtenhaus vor Meiers Garten & & & & & & & 1 & 23 & 0,186 & & & & 1 & 23 & 0,186 \\
\hline 2 & 114 & Hirtenhaus bei der Schule & & & & & & & & 62 & 0,086 & & & & & 62 & 0,086 \\
\hline 3 & 192 & Verkaufte Fläche im Osterraden & & & & & & & 4 & 56 & 0,716 & 3 & 19 & 0,152 & 7 & 75 & 0,868 \\
\hline 4 & 87 & Verkaufte Fläche an der Lachte & & 71 & 0,069 & & & & 3 & 59 & 1,255 & & 49 & 0,035 & 4 & 59 & 1,359 \\
\hline 5 & 303 & Bei Heerboldts Hofe & & & & & & & & & & 7 & 108 & 0,386 & 7 & 10 & 0,386 \\
\hline 6 & 78 & Der Wolfsbusch & & & & & & & & & & 5 & 12 & 0,567 & 5 & 12 & 0,567 \\
\hline 7 & 53 & Das Quälohsgehäge & & & & & & & & & & 25 & 39 & 1,120 & 25 & 39 & 1,120 \\
\hline 8 & & Der Eckernkamp & & & & & 58 & 0,054 & & & & 42 & 68 & 4,947 & 43 & 6 & 5,001 \\
\hline 9 & 128 & Der Backofenplatz an Drallen Hofe & & & & & & & & & & 1 & 21 & 0,056 & 1 & 21 & 0,056 \\
\hline 10 & 99 & Die Bullenwiese in Thies Grashofe & & & & 1 & 40 & 0,381 & & & & & & & 1 & 40 & 0,381 \\
\hline 11 & 89 & Am Beedenbosteler Wege & & & & & & & & 97 & 0,177 & & 20 & 0,014 & & 117 & 0,191 \\
\hline 12 & & & & & & & & & & & & & & & & & \\
\hline 13 & & Anschnitt am Neuengehäge & & & & & & & 2 & 69 & 0,262 & 22 & 37 & 1,294 & 24 & 106 & 1,556 \\
\hline 14 & & Exerzierplatz in der Allerheide & & & & & & & & & & 160 & & 6,400 & 160 & & 6,400 \\
\hline & & (rechner. Kontrolle) & & & 0,069 & & & 0,435 & & & 2,682 & & & 14,971 & & & 18,157 \\
\hline & & Total: & & 71 & 0,069 & 1 & 98 & 0,435 & 13 & 6 & 2,682 & 268 & 13 & 14,971 & 283 & 68 & 18,157 \\
\hline 38 & 17 & Der Weg im Kuhlkampe & 1 & 5 & 0,076 & & & & & & & & 37 & 0,023 & 1 & 42 & 0,099 \\
\hline 39 & 19 & Der Weg auf der Salloh & 1 & 23 & 0,066 & & & & & & & & & & 1 & 23 & 0,066 \\
\hline 40 & & Trift für Cammanns, Thies und Hermanns & & 11 & 0,005 & & & & & & & & & & & 11 & 0,005 \\
\hline 41 & 60 & Der Weg nach i Koppel auf dem Flottkamp & & & & & & & & & & & 46 & 0,078 & & 46 & 0,078 \\
\hline 42 & 204 & Lehmgrube am Ahnsbecker Wege & & & & & & & 1 & 14 & 0,178 & & & & 1 & 14 & 0,178 \\
\hline 43 & 41 & Trift vom Flottkampe nach der Stockau & & & & & & & & & & & 92 & 0,034 & & 92 & 0,034 \\
\hline 44 & & Trift nach dem Behrenblau & 1 & 46 & 0,136 & & & & & 12 & 0,011 & & 19 & 0,013 & 1 & 77 & 0,160 \\
\hline & & (rechner. Kontrolle) & & & 4,516 & & & 0,128 & & & 4,121 & & & 3,068 & & & 11,833 \\
\hline & & Latus 2 & 25 & 33 & 4,516 & & 46 & 0,128 & 21 & 1 & 4,121 & 35 & 102 & 3,068 & 82 & 62 & 11,833 \\
\hline
\end{tabular}

\begin{tabular}{|c|c|c|c|c|c|c|c|c|c|c|c|c|c|c|c|c|c|}
\hline \multirow{5}{*}{ 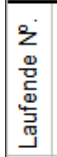 } & \multirow{5}{*}{ 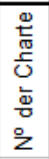 } & & & & & & & & & & & & & & & & \\
\hline & & Litt. G & & & & & & & & & & & & & \multicolumn{3}{|c|}{ Überhaupt } \\
\hline & & Die Gemeinde & & & & & & & & & & & & & \multicolumn{3}{|c|}{ brauchbarer } \\
\hline & & & \multicolumn{3}{|c|}{ Ackerland } & \multicolumn{3}{|c|}{ Wiesenboden } & \multicolumn{3}{|c|}{ Angerboden } & \multicolumn{3}{|c|}{ Heidboden } & \multicolumn{3}{|c|}{ Boden } \\
\hline & & hat zugeteilt erhalten. & M & QR & Kuhw. & M & QR & Kuhw. & M & QR & Kuhw. & M & QR & Kuhw. & M & QR & Kuhw. \\
\hline 45 & & Der Gockenholzer Wienhäuser Weg & & & & & & & & & & 10 & 20 & 0,426 & 10 & 20 & 0,426 \\
\hline 46 & & Der lachendorfer Celler Weg & & & & & & & & & & 4 & 71 & 0,184 & 4 & 71 & 0,184 \\
\hline 47 & & Der Lachendorfer Oppershäuser Weg & & & & & & & & & & 7 & 34 & 0,292 & 7 & 34 & 0,292 \\
\hline 48 & & Der Lachendorfer Wiesenweg & & & & & & & & & & 2 & 26 & 0,091 & 2 & 26 & 0,091 \\
\hline 49 & & Der Dammweg & \multicolumn{3}{|c|}{ unbrauchbar } & & 3 & & & 26 & 0,033 & 2 & 29 & 0,155 & 2 & 55 & 0,188 \\
\hline 50 & & Der Canal & \multicolumn{3}{|c|}{ unbrauchbar } & 1 & 106 & & & & & & & & & & \\
\hline 51 & & Der Ahnsbecker Celler Weg & & & & & & & & & & 18 & 104 & 0,754 & 18 & 104 & 0,754 \\
\hline 52 & & Die Oppershäuser Trift westl. des Canals & & & & & & & & 37 & 0,045 & 3 & 11 & 0,442 & 4 & 28 & 0,487 \\
\hline 53 & & Weg nach Drallen Wiesen & & 34 & 0,014 & & & & & & & 9 & 88 & 0,459 & 10 & 2 & 0,473 \\
\hline 54 & & Oppershäuser Wiesen Weg & & & & & & & & 9 & 0,009 & 4 & 48 & 0,238 & 4 & 57 & 0,247 \\
\hline 55 & & Weg von Oppershausen nach Ahnsbeck & & & & & & & & & & 2 & 117 & 0,151 & 2 & 117 & 0,151 \\
\hline 56 & & \multicolumn{3}{|l|}{ Abzugsgraben südl. des Ahnsbecker Celler Weges } & & & & & & & & 1 & 24 & 0,060 & 1 & 24 & 0,060 \\
\hline 57 & & Weg nach der Forst & & & & & & & & & & 1 & 13 & 0,068 & 1 & 13 & 0,068 \\
\hline 58 & & Trift für Cammanns, Thies u. Hermanns & & & & & & & & & & 1 & 96 & 0,072 & 1 & 96 & 0,072 \\
\hline 59 & & Weg nach Diercks und Ahnsbecks Wiesen & & & & & & & & 110 & 0,153 & & & & & 110 & 0,153 \\
\hline 60 & & Weg nach dem Postmoore & & & & & & & & & & 5 & 46 & 0,222 & 5 & 46 & 0,222 \\
\hline 61 & & Weg nach Schumeyer u. Thies (Theis) Koppel & & & & & & & & & & 1 & 80 & 0,069 & 1 & 80 & 0,069 \\
\hline 62 & & Weg nach der Forst & & & & & & & & 42 & 0,044 & 6 & 107 & 0,409 & 7 & 29 & 0,453 \\
\hline 63 & & Bock-Thies Trift & & & & & & & & & & & 64 & 0,023 & & 64 & 0,023 \\
\hline 64 & & Abzugsgraben & & & & & & & & & & & 48 & 0,019 & & 48 & 0,019 \\
\hline 65 & & Weg nach Drallen Wiesen & & & & & & & & & & 1 & 52 & 0,057 & 1 & 52 & 0,057 \\
\hline 66 & & Weg übern Ackern & & & & & & & & & & 3 & 6 & 0,122 & 3 & 6 & 0,122 \\
\hline 67 & & Oppershäuser Trift & & & & & & & & 46 & 0,038 & 1 & 86 & 0,209 & 2 & 12 & 0,247 \\
\hline \multirow[t]{7}{*}{68} & & Weg am Canale & & & & & & & & & & 3 & 88 & 0,201 & 3 & 88 & 0,201 \\
\hline & & (rechner. Kontrolle) & & & 0,014 & & & & & & 0,322 & & & 4,723 & & & 5,059 \\
\hline & & Latus 3 & & 34 & 0,014 & & & & 2 & 30 & 0,322 & 95 & 38 & 4,723 & 97 & 102 & 5,059 \\
\hline & & Latus 2 & 25 & 33 & 4,516 & & 46 & 0,128 & 21 & 1 & 4,121 & 35 & 102 & 3,068 & 82 & 62 & 11,833 \\
\hline & & Latus 1 & 45 & 42 & 6,877 & & 18 & 0,049 & 4 & 47 & 0,944 & 34 & 96 & 2,352 & 84 & 83 & 10,222 \\
\hline & & (rechner. Kontrolle) & & & 11,407 & & & 0,177 & & & 5,387 & & & 10,143 & & & 27,114 \\
\hline & & Total & 70 & 109 & 11,407 & & 64 & 0,177 & 27 & 78 & 5,387 & 165 & 116 & 10,143 & 265 & 7 & 27,114 \\
\hline
\end{tabular}




\section{Nachweis}

der zum Vollhofe und zur Fabrik der Drewsenschen Erben in Lachendorf gehörenden Grundstücke

\begin{tabular}{|c|c|c|c|c|c|c|c|c|c|c|c|c|c|c|c|c|c|}
\hline \multirow{5}{*}{ 离 } & \multirow{5}{*}{ 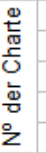 } & \multirow{5}{*}{$\begin{array}{c}\text { Litt.: } f \\
\text { Grundstücke } \\
\text { des Fabrikanten Georg Drewswn Erben, }\end{array}$} & & & & & & & & & & & & & \multirow{2}{*}{\multicolumn{3}{|c|}{ Überhaupt }} \\
\hline & & & & & & & & & & & & & & & & & \\
\hline & & & & & & & & & & & & & & & & aucht & barer \\
\hline & & & \multicolumn{3}{|c|}{ Ackerland } & \multicolumn{3}{|c|}{ Wiesenboden } & \multicolumn{3}{|c|}{ Angerboden } & \multicolumn{3}{|c|}{ Heidboden } & \multicolumn{3}{|c|}{ Boden } \\
\hline & & & $\mathrm{M}$ & $\mathrm{QR}$ & Kuhw. & $\mathrm{M}$ & $Q R$ & Kuhw. & $\mathrm{M}$ & $\mathrm{QR}$ & Kuhw. & M & QR & Kuhw. & M & $\mathrm{QR}$ & Kuhw. \\
\hline & 54 & In den Moorgärten & 3 & 76 & 0,750 & & & & 1 & 45 & 0,146 & 25 & 70 & 1,234 & 30 & 71 & 2,130 \\
\hline & 150 & Bei der Windmühle & & 95 & 0,090 & & & & & 46 & 0,064 & 4 & 59 & 0,365 & 5 & 80 & 0,519 \\
\hline & 219 & Das Punnewischgehäge & & 5 & 0,005 & & & & & & & 9 & 21 & 1,224 & 9 & 26 & 1,229 \\
\hline & 91 & Beim Hause & 2 & 30 & 0,693 & & & & 2 & 47 & 0,399 & 1 & 32 & 0,060 & 5 & 109 & 1,152 \\
\hline & 90 & Der Brömmer & & & & 1 & 98 & 0,919 & 3 & 63 & 0,465 & & 33 & 0,014 & 5 & 74 & 1,398 \\
\hline & 52 & Vor dem Quälohs Gehäge & & & & & & & & & & 2 & & 0,100 & 2 & & 0,100 \\
\hline & 51 & An der alten Lachte & & & & & & & & & & 8 & 112 & 0,463 & 8 & 112 & 0,463 \\
\hline & 254 & Das Gehäge über den Ackern & & 63 & 0,028 & & & & & & & 16 & 22 & 0,900 & 16 & 85 & 0,928 \\
\hline & 100 & Die Eselswiese & & & & & 84 & 0,350 & & 39 & 0,054 & & & & 1 & 3 & 0,404 \\
\hline & & Bei Cammanns Thies Immenstelle & & & & & & & & & & 87 & 73 & 3,472 & 87 & 73 & 3,472 \\
\hline & & Hinterm Canale & & & & & & & & 73 & 0,101 & 7 & 85 & 0,755 & 8 & 38[ & 0,556 \\
\hline & & Auf dem Krümmel & 10 & 95 & 2,946 & & & & & 70 & 0,097 & 18 & 30 & 3,668 & 29 & 75 & 6,711 \\
\hline & & (rechner. Kontrolle) & & & 4,512 & & & 1,269 & & & 1,326 & & & 12,255 & & & 19,062 \\
\hline & & In Allem: & 18 & 4 & 4,512 & 2 & 62 & 1,269 & 9 & 23 & 1,326 & 181 & 57[ & 11,955 & 211 & 26 & 19,062 \\
\hline & & & & & & & & & & & & & & $F 2$ & & & \\
\hline & & & Ges & sehen & und get & billig & & & & & & & & & & & \\
\hline & & & Lach & hend & orf, 16 . & Dezo & cbr. & Dren & & & & & & & & & \\
\hline & & & 1859 & & & & & & & & & & & & & & \\
\hline & & Anmerkungen.: Der gesamte Kuhweidenwert & von $?$ & $\overline{19,06}$ & $\overline{52 \text { ist } a u}$ & $\operatorname{ch~} r \mathrm{te}$. & echr & nerisch & in $\mathrm{Z}$ & eile ut & und $S p a$ & alte ric & chtig! & & & & \\
\hline & & F1: rechn. richtiger. Zeilenwert: 0,856 statt 0,5 & $556: 1$ & folglic & ch: Fehl & er im & $m \mathrm{Ku}$ & ahweider & nwer & it der & $r$ Zeils & beim & Ange & oder Hei & idbod & len vo & on 0,3 . \\
\hline & & 0,101 Kuhw. für 73 QR Angerboden vergleichs & sweis & se rict & htig; dag & gege & en 0 , & $755 \mathrm{Kul}$ & thwei & $\operatorname{den} f$ & für $7 \mathrm{M}$ & $85 \mathrm{QH}$ & $R \mathrm{He}$ & boden & & & \\
\hline & & vergleichsweise zu viel, da oben 8 M 112 QR & nur $m$ & mit 0 , & 463 bew & verte & et $\sin$ & & & & & & & & & & \\
\hline & & Heilung von F1: Heidboden mit 0,477 Kuhw., & dann & & aud & & & & & & & & & & & & \\
\hline
\end{tabular}




\section{Recapitolatio $^{1}$}

\begin{tabular}{|c|c|c|c|c|c|c|c|c|c|c|c|c|c|c|c|c|c|}
\hline \multirow{4}{*}{ 焉 } & & \multirow[t]{2}{*}{ Recapitulatio } & \multicolumn{15}{|c|}{ Verteilungs-Register von der Feldmark Lachendorf } \\
\hline & & & & & & & & & & & & & & & & & \\
\hline & & Name der & \multicolumn{3}{|c|}{ Ackerland } & \multicolumn{3}{|c|}{ Wiesenboden } & \multicolumn{3}{|c|}{ Angerboden } & \multicolumn{3}{|c|}{ Heidboden } & \multicolumn{3}{|c|}{ gesamt } \\
\hline & & Interessenten & M & QR & Kuhw. & M & QR & Kuhw. & M & QR & Kuhw. & M & QR & Kuhw. & M & QR & Kuhw. \\
\hline a & Vollhöfner & Lüßmann & 150 & 86 & 28,718 & & & & 16 & 27 & 3,153 & 181 & 51 & 10,765 & 348 & 44 & 42,636 \\
\hline b & & Meyer & 93 & 101 & 17,707 & 13 & 5 & 3,687 & 20 & 86 & 3,621 & 142 & 100 & 10,521 & 270 & 52 & 35,536 \\
\hline c & & Kohlmeyer & 132 & 2. 91 & 23,995 & & & & 24 & 107 & 4,535 & 96 & 13 & 5,688 & 253 & 91 & 34,218 \\
\hline d & & Thies /Bock & 181 & 11 & 30,359 & 16 & 5 & 5,479 & 19 & 75 & 2,592 & 179 & 27 & 8,834 & 395 & 118 & 47,264 \\
\hline e & & Bergmann & 104 & 94 & 17,657 & 5 & 2 & 2,615 & 23 & 103 & 4,444 & 188 & 18 & 9,178 & 321 & 97 & 33,894 \\
\hline$f$ & & Drewsen & 92 & 15 & 23,416 & 2 & 62 & 1,269 & 12 & 100 & 1,989 & 521 & 25 & 29,502 & 628 & 82 & 56,176 \\
\hline$g$ & & Schumeyer & 112 & 271 & 20,047 & 18 & 56 & 5,903 & 36 & 112 & 5,435 & 179 & 42 & 8,680 & 347 & 41 & 40,065 \\
\hline $\mathrm{h}$ & Halbhof & Schöndube & 89 & 101 & 19,318 & 2 & 116 & 1,402 & 24 & 6 & 4,996 & 122 & 76 & 6,515 & 239 & 59 & 32,231 \\
\hline i & Köthner & Joh. Hr. Thies (Cammann) & 107 & 95 & 20,651 & 9 & 30 & 4,087 & 19 & 14 & 3,991 & 116 & 37 & 5,868 & 252 & 56 & 34,597 \\
\hline k & & Joh. Hr. Bunkenburg & 112 & 13 & 14,969 & 6 & 1 & 1,879 & 4 & 104 & 1,118 & 108 & 34 & 5,487 & 231 & 32 & 23,453 \\
\hline I & & Joh. Hr. Dralle & 94 & 20 & 16,125 & 13 & 83 & 4,696 & 11 & 42 & 2,006 & 125 & 104 & 6,589 & 245 & 9 & 29,416 \\
\hline $\mathrm{m}$ & & Chr. Hr. Dralle & 71 & 2 & 10,820 & 4 & 43 & 1,624 & 9 & 1 & 1,610 & 113 & 55 & 6,347 & 197 & 101 & 20,401 \\
\hline$n$ & & Joh. Hr. Bühring & 42 & 114 & 6,246 & & & & 13 & 13 & 2,175 & 66 & 63 & 3,156 & 122 & 70 & 11,577 \\
\hline 0 & & Joh. Hr. Thies (Krüger) & 64 & 25 & 10,887 & 9 & 63 & 4,576 & 5 & 57 & 1,052 & 116 & 59 & 8,392 & 195 & 84 & 24,907 \\
\hline$p$ & & Carst. Hr. Schwägermann & 38 & 93 & 7,833 & & 8 & 0,022 & 11 & 54 & 2,704 & 94 & 95 & 4,506 & 145 & 10 & 15,065 \\
\hline$q$ & & Joh. Hr. Thies (Theis) & 101 & 38 & 17,756 & 1 & 72 & 0,741 & 14 & 46 & 3,347 & 171 & 97 & 9,373 & 289 & 13 & 31,217 \\
\hline$r$ & & Chr- Thies (Graue) & 84 & 15 & 16,338 & 8 & 68 & 4,000 & 22 & 80 & 4,920 & 99 & 59 & 4,611 & 214 & 102 & 29,869 \\
\hline s & & Carst. Hr. Koch & 91 & 102 & 16,957 & 5 & 12 & 2,914 & 29 & 112 & 4,801 & 134 & 98 & 6,630 & 261 & 84 & 31,302 \\
\hline $\mathrm{t}$ & & Jürgen $\mathrm{Hr}$. Hermanns & 61 & 82 & 9,546 & 7 & 58 & 3,688 & 6 & 112 & 1,448 & 133 & 2 & 6,362 & 209 & 14 & 21,044 \\
\hline u & & Carst. Hr. Misselhorn & 46 & 101 & 5,142 & & & & 8 & 49 & 1,754 & 123 & 111 & 6,092 & 179 & 21 & 12,988 \\
\hline $\mathrm{v}$ & Brinksitzer & Joh. Hr. Wulf & 10 & 17 & 2,790 & & & & 11 & 99 & 1,873 & 21 & 118 & 1,043 & 43 & 114 & 5,706 \\
\hline w & & Christ. Lüßmann & 17 & 113 & 4,233 & & & & 8 & 104 & 1,451 & 40 & 38 & 1,918 & 67 & 15 & 7,602 \\
\hline$x$ & Brinksitzer & Joh. Hr. Lilie & 5 & 40 & 1,116 & & & & 3 & 27 & 1,041 & 23 & 38 & 1,207 & 31 & 105 & 3,364 \\
\hline$y$ & Anbauer & Chr. Thies & 6 & 72 & 1,663 & & & & 4 & 51 & 0,720 & 39 & 1 & 1,851 & 50 & 4 & 4,234 \\
\hline$z$ & & Chr. Hr. Meyer & 13 & 5 & 2,817 & & 50 & 0,139 & 7 & 4 & 1,655 & 24 & 76 & 1,402 & 45 & 15 & 6,013 \\
\hline aa & & $\mathrm{Hr}$. Bergmann & & 82 & 0,228 & & & & 2 & 110 & 0,480 & 30 & 27 & 1,350 & 33 & 99 & 2,058 \\
\hline $\mathrm{bb}$ & & Joh. Hr. Knoop & 23 & 77 & 5,637 & & & & 2 & 76 & 0,575 & 60 & 59 & 2,833 & 86 & 92 & 9,045 \\
\hline $\mathrm{cc}$ & & Wilh. Herbold & & 29 & 0,020 & & & & 2 & 58 & 0,452 & 35 & 41 & & 38 & 8 & 2,119 \\
\hline dd & Abbauer & Freidrich Meyer & 4 & 17 & 0,862 & & & & 1 & 37 & 0,229 & & 116 & 0,057 & 6 & 50 & 1,148 \\
\hline ee & & Friedrich Ramberg & 1 & 94 & 0,373 & & & & & 96 & 0,133 & 2 & 24 & 0,112 & 4 & 94 & 0,618 \\
\hline ff & & Gottfried Walter & 1 & 109 & 0,364 & & & & 1 & 15 & 0,207 & & 105 & 0,058 & 3 & 109 & 0,629 \\
\hline gg & & Heinrich Ahrens & 1 & 56 & 0,163 & & & & & 26 & 0,024 & 1 & 6 & 0,050 & 2 & 88 & 0,237 \\
\hline hh & & Christoph Suderburg & 1 & 91 & 0,169 & & & & & 45 & 0,036 & & 65 & 0,052 & 2 & 81 & 0,257 \\
\hline ii & & Hr. Lilie & 2 & 9 & 0,197 & & & & & 18 & 0,017 & & 1 & 0,001 & 2 & 28 & 0,215 \\
\hline$\|$ & & Carsten Hr. Thölke & 1 & 100 & 0,207 & & & & & 24 & 0,019 & 3 & 84 & 0,211 & 5 & 88 & 0,437 \\
\hline $\mathrm{mm}$ & & Heinrich Koch & & & & & & & & 96 & 0,133 & & & & & 96 & 0,133 \\
\hline $\mathrm{nn}$ & Hirte & Joh. Hr. Meyer & 5 & 92 & 1,596 & & & & & 117 & 0,195 & 1 & 59 & 0,104 & 8 & 28 & 1,895 \\
\hline 00 & Häusling & Meyer Erben & 6 & 30 & 1,786 & & & & & & & 6 & 50 & 0,256 & 12 & 80 & 2,042 \\
\hline w & Abbauer & Joh. Hr. Graue & 1 & 25 & 0,130 & & & & & 34 & 0,031 & & 7 & 0,006 & 1 & 66 & 0,167 \\
\hline $\mathrm{pp}$ & \multicolumn{2}{|c|}{ Georg Drewsen Erben Papierfabrik } & & & & & & & & & & & & & & & 0,000 \\
\hline S & \multicolumn{2}{|c|}{ Die Schule zu Lachendorf } & 6 & 32 & 1,534 & & & & 2 & 19 & 0,513 & 32 & 50 & 1,696 & 40 & 101 & 3,743 \\
\hline G & \multicolumn{2}{|c|}{ Die Gemeinde Lachendorf } & 70 & 109 & 11,407 & & 64 & 0,177 & 27 & 78 & 5,387 & 165 & 116 & 10,143 & 265 & 7 & 27,114 \\
\hline K & Die Kirche $z$ & zu Beedenbostel & 6 & 76 & 1,172 & & & & & & & & 68 & 0,063 & 7 & 24 & 1,235 \\
\hline $\mathrm{rr}$ & Vollmeier & Veth, Lachendorf & 3 & 14 & 0,906 & & & & & 17 & 0,040 & & 113 & 0,135 & 4 & 24 & 1,081 \\
\hline ss & & Schumeier, daselbst & 8 & & 2,284 & & & & & 7 & 0,017 & & & & 8 & 7 & 2,301 \\
\hline $\mathrm{tt}$ & & Thies, Höfer & & & & 2 & 114 & 1,180 & & & & & & & 2 & 114 & 1,180 \\
\hline uu & & Misselhorn, Gockenholz & & & & 1 & 93 & 0,312 & & & & & 26 & 0,031 & 1 & 119 & 0,343 \\
\hline ww & Die Gemein & nde Gockenholz & & 98 & 0,231 & & & & & & & & & & & 98 & 0,231 \\
\hline G & Die Gemein & nde hat zugeteilt erhalten & & 71 & 0,069 & 1 & 98 & 0,435 & 13 & 6 & 2,682 & 268 & 13 & 14,971 & 283 & 68 & 18,157 \\
\hline & & Imma Summarum & 2076 & 88 & 376,441 & 131 & 23 & 50,825 & 428 & 64 & 79,601 & 3776 & 67 & 204,293 & 6413 & 2 & 711,160 \\
\hline & & & & & & & & & & & & & & & & & \\
\hline recht & iner. Überprüt & jung der Summenzeile & 2076 & 88 & 376,441 & 131 & 23 & 50,825 & 428 & 64 & 79,601 & 3776 & 67 & 204,293 & 6413 & 2 & 711,160 \\
\hline recht & n. Überprüfur & ing der Spalten & 2076 & 88 & 376,441 & 131 & 23 & 50,825 & 428 & 64 & 79,601 & 3776 & 67 & 204,293 & 6413 & 2 & 711,160 \\
\hline
\end{tabular}

\footnotetext{
${ }^{1}$ Die Zusammenfassung (Recapitulatio) bezieht sich nur auf die Feldmark Lachendorf aus dem Rezess von 1859, enthält also nicht die Abfindungen in den Aller- und trockenen Wiesen im Rezess von 1866.
} 


\section{Abschrift $^{1}$ \\ Theilungs-Urkunde \\ über die Entfrettung und Verkoppelung der Aller- und trockenen Wiesen bei Lachendorf, Amt Celle ${ }^{2}$}

Inhaltsverzeichnis

$\S 1 \quad$ Provocation, Erkenntnis der Stattnehmigkeit ${ }^{3}$ der Teilung.

Teilungs-Commission ${ }^{4}$

Pag. 1

$\S 2$ Beschreibung der Grundflächen, Begrenzung derselben.

Ermittlung der Größe und des Ertragswertes. 3

§ $3 \quad$ Edictal $^{5}$-Verfahren und Vertretung der Beteiligten 6

$\S 4$ Feststellung der Berechtigungen und Ermittlung der hierfür gebührenden Entschädigungen

$\S 5 \quad$ Nachweisung des von den Beteiligten in die Masse geworfen Grundbesitzes 23

$\S 6$ Nachweisung der zur Correction des Schwarzwasserflusses abgetretenen

Grundstücke

$\S 7$ Übersicht der verschiedenartigen Auseinandersetzungs-Gegenstände 29

§ 8 Angelegte Wege und Triften 31

§ 9 Entwässerung 34

$\S 10$ Zu gemeinsamen zwecken reservierte Räume 35

$\S 11$ Summarische Übersicht der einem jeden Interessenten gebührenden und der amtlich zugeteilten Abfindungen $\quad 36$

$\S 12$ Berücksichtigung des Grundeigentums $\quad 45$

$\S 13$ Künftige Benutzung der Abfindungen $\quad 46$

$\S 14$ Befriedigung der Koppeln 49

$\S 15$ Erste Instandsetzung und künftige Unterhaltung der Wege, Gräben und deren Zubehörungen

$\S 16$ Künftige Benutzung der Wege 59

§ 17 Gegenseitige Verpflichtung rücksichtlich des Wasserlaufs $\quad 60$

$\S 18$ Künftige Benutzung der zu gemeinsamen Zwecken reservierten Räume $\quad 61$

$\S 19$ Berücksichtigung des zehntherrlichen Interesses 62

$\S 20$ Berücksichtigung der auf den Grundstücken haftenden hypothekarischen

Rechte und Reallasten

$\S 21$ Allgemeine Entsagung und Anerkennung 63

$\S 22$ Kostenpunkt 63

$\begin{array}{ll}\text { Schluss } & 73\end{array}$

\footnotetext{
${ }^{1}$ Quelle: Samtgemeinde Lachendorf, Archiv Akten, Fach/Nr. 140/8: Entfrettung und Verkoppelung der Allerund trockenen Wiesen bei Lachendorf, Rezeß von 1866. Es handelt sich hier um eine beglaubigte Abschrift des Originals

2 Die Abschrift des Rezesses ist handschriftlich in Sütterlin verfasst. Die Originalquelle wird hier teils wörtlich, teils als Zusammenfassung wiedergegeben. Wörtliche Wiedergaben aus dem Original sind durch Anführungszeichen gekennzeichnet und kursiv gesetzt.

Fußnoten und Umrechnungen sowie rechnerische Überprüfungen wurden vom Verf. ein- bzw. angefügt.

${ }^{3}$ statthaft, hier als Substantiv

${ }^{4}$ Die Rechtschreibung wurde überwiegend den heute geltenden Regeln angepasst, bei heute ungebräuchlichen oder wenig bekannten sowie Fachbegriffen wurde die zeitgenössische Schreibweise beibehalten.

${ }^{5}$ Edict = Edikt: obrigkeitliche Bekanntmachung (Lutherzeit); öffentlich-rechtliche Bekanntmachung
} 
„Nachdem nun die Entfrettung ${ }^{1}$ und Verkoppelung der Aller- und trockenen Wiesen bei Lachendorf nunmehr zur Ausführung gelangt, so ist darüber nach Vorschrift des Gesetzes vom 30. Juni 1842 der nachstehende, die Stelle des Plans mit vertretende Rezeß ausgefertigt worden."

§1)

Der Antrag auf Entfrettung und Verkoppelung der Aller- und Trockenwiesen der überwiegenden gesetzlichen Stimmenmehrheit der Eigentümer und der Weideberechtigten wurde von der Königl. Landdrostei in Lüneburg für statthaft („stattnehmig“) erklärt.

Desgleichen wurde genehmigt der Antrag der Weideberechtigten und der Dorfschaften Lachendorf, Oppershausen und Nordburg auf generelle Auseinandersetzung des ganzen Weide-Äquivalents in den Aller- und Trockenwiesen sowie die Spezialteilung des diesen Gemeinden zufallenden Weide-Äquivalents und schließlich die von den Lachendorfer Interessenten beschlossene Teilung ihrer gemeinschaftlichen, im Verkoppelungsgebiet gelegenen Wiesen.

§2)

Das Verkoppelungsgebiet bildet eine zusammenhängende Wiesenfläche zwischen den Feldmarken von Oppershausen, Lachendorf, Ahnsbeck, Nordburg und Schwachhausen, zwischen den beiden letzteren ist das Schwarzwasser die Grenze.

Die Vermessung ist 1861 vom Landes-Oeconomie-Commissair Francke vorgenommen und durch Revision bestätigt.

Das Vermessungsresultat wird allen Beteiligten vorschriftsmäßig zur Kenntnis gegeben und nach Erledigung einiger Einwände aktenkundig für rechtens erklärt.

Als Grenzanweiser fungiert der Hirte Kuene aus Lachendorf und wird dafür vereidigt.

Die Bonitierung erfolgt unter der Leitung von Landes-Ökonomie-Kommissar Francke durch die beeidigten Klassifikatoren

Vorsteher Thies aus Oppershausen,

" Thies aus Lachendorf,

" Brockelmann aus Beedenbostel

in Gemeinschaft mit den beeidigten Taxatoren Gutsbesitzer Höfermann von Eldingen,

Vetter von Altencelle

auf der Grundlage erhaltener Instruktionen.

Die Schätzungsergebnisse wurden den Beteiligten vorschriftsmäßig bekannt gemacht und anerkannt. Cfr. No. act. 35.42 u. 65

Das Verkoppelungsgebiet enthält nach dem Vermessungs- und Taxationsregister:

Anm. d. Verf.:

In der handschriftlichen Tabelle des Originals (S. 6) liegt offenbar ein "Zahlendreher" vor.

\begin{tabular}{|l|r|r|r|r|r|}
\hline \multicolumn{5}{|c|}{ Verkoppelungsgebiet Aller- und Trockenwiesen } \\
\hline & $\mathrm{M}$ & QR & Kuhw. & \multicolumn{1}{|c|}{ ha } & \multicolumn{1}{c|}{$\%$} \\
\hline Wiesenboden & 803 & 3 & 224,525 & 210,4809 & 91,93 \\
\hline Ackerland & 33 & 62 & 3,679 & 8,7851 & 3,84 \\
\hline Angerboden & 14 & 4 & 1,412 & 3,6783 & 1,61 \\
\hline Heidboden & 22 & 108 & 1,249 & 6,0023 & 2,62 \\
\hline Summe Original & 837 & 57 & 230,865 & 228,9465 & 100,00 \\
\hline \multicolumn{5}{|c|}{ Rezess S. 6 } \\
\hline rechnerisch richtig: & 873 & 57 & 230,865 & 228,9465 & \\
\hline In der vorliegenden Kopie, S. 6: offenbar "Zahlendreher": \\
\hline Statt 837 M muss es 873 M heißen. \\
\hline \multicolumn{5}{|c|}{} \\
\hline
\end{tabular}

\footnotetext{
${ }^{1}$ Frettung: Recht zur gemeinschaftlichen Weide

Entfrettung: Ablösung bzw. Aufhebung der gemeinschaftlichen Weiderechte.
} 
§3)

Bei einem Gütetermin am 14.. 11. 1861 in Lachendorf werden insgesamt 10 Einzeleinwände bearbeitet und erledigt, teils anerkannt, teils verworfen, teils durch Vergleich oder Abfindung geregelt.

Zur Vertretung des gemeinsamen Interesses des ganzen Verkoppelungsverbandes wurden als Syndicen die Bevollmächtigten aus § 2) ernannt.

Bevollmächtigte:

Ministerium, Abteilung Domänen und Forsten: Cammer-Commissair Dreyer aus Hannover Kirche zu Beedenbostel: Kirchenvorsteher Heinrich Brockelmann aus Beedenbostel

Schule in Lachendorf: Lehrer Tiemann

v.d. Wensesche Gut in Oppershausen: Gutsaufseher Diercks aus Oppershausen

Vertretung der Witwe des Kötners Jürgen Heinrich Hermann in Lachendorf: Kötner Carsten Heinrich Schwägermann

§4)

Feststellung der Berechtigungen und Ermittlung der hierfür zustehenden Entschädigungen.

„Die bei vorliegender Verkoppelung zu berücksichtigenden Nutzungsrechte der Interessenten bestehen in der Nutzung der privaten Grundstücke mit Ausschluss der Vor- und Nachweide.

Die gemeinschaftliche Weide ist von Eingesessenen der Dorfschaften Lachendorf, Oppershausen und Nordburg ausgeübt.

Teilungsmaßstab.

A. Private Grundstücke

Die privaten Grundstücke werden den einzelnen Interessenten nach Abzug des Weideäquivalents, also servitutsfrei, wie solches der folgende $\S$ nachweiset, jedoch unter Berücksichtigung der nachstehenden, während des Verfahrens eingetretenen Besitzstandsveränderungen zurück gegeben.

1. Die Köthner Wegener und Müller in Höfer haben ihr gemeinschaftliches Grundstück in den trockenen Wiesen, No. 22 und 23 der Karte, an den Brinksitzer Wolf in Lachendorf verkauft.

2. Der dem Köthner Carst. Hrch. Dralle in Lachendorf irrtümlich angerechnete Gemeinheitsanschnitt gehört dem Köthner Carst. Hrch. Koch zu Lachendorf und ist letzterem zugesetzt.

B. Gemeindegrundstücke

An den Gemeindewiesen der Dorfschaft Lachendorf partizipieren die 7 Vollhöfe, 1 Halbhof und die 12 Köthner jeder mit einem vollen Teile, die 3 Brinksitzer aber jeder nur mit 1/3 Teil.

Die Gemeindewiesen der Dorfschaft Oppershausen werden nach demselben Verhältnis verteilt nach welchem das Weideäquivalent der Dorfschaft Oppershausen zur speziellen Verteilung kommt, also mit letzterem zusammen.

C. Generelle Auseinandersetzung des Weideäquivalents.

Von dem ganzen Weideäquivalent ist die Weidequote der Meyerschen Erben in Schwachhausen abzusetzen, da diese Wiese als weidefrei anerkannt ist.

Das übrige Weideäquivalent, nachdem davon die Anteile der Gutsbesitzer Lüßmann und Schumeyer in Lachendorf von dem Weideäquivalente von der Bunkenburgschen Wiese in Absatz gebracht sind, gehört den 3 berechtigten Ortschaften Nordburg, Oppershausen und Lachendorf zu gleichen Teilen, jedoch hat die Dorfschaft Oppershausen die Gemeinde Nordburg von dem Weideäquivalent auf einer begrenzten Fläche mit 2/9 derselben abzufinden.

D. Spezielle Auseinandersetzung der Weideäquivalente.

1. Von dem Weideäquivalent der Dorfschaft Lachendorf erhalten die 20 Reihestellen, die 3 Brinksitzer und die Schule jede als Zusatz zu dem bei der Privatteilung ausgeworfenen Haushaltsbedürfnisse nachbargleich 60 QR: 0,136 Kuhw. und die 5 Anbauern in Lachendorf jeder 20 QR: 0,045 Kuhw.. 
Der Rest des Weideäquivalents wird unter allen Interessenten, den Vollhöfnern, Halbhöfner, Köthner, Brinksitzer, Anbauern und der Schule nach dem bei der Privatteilung vereinbartem Simplas, wobei für die Schule 12 Simplas angenommen sind, verteilt."

Es erhalten demnach (in Lachendorf)::

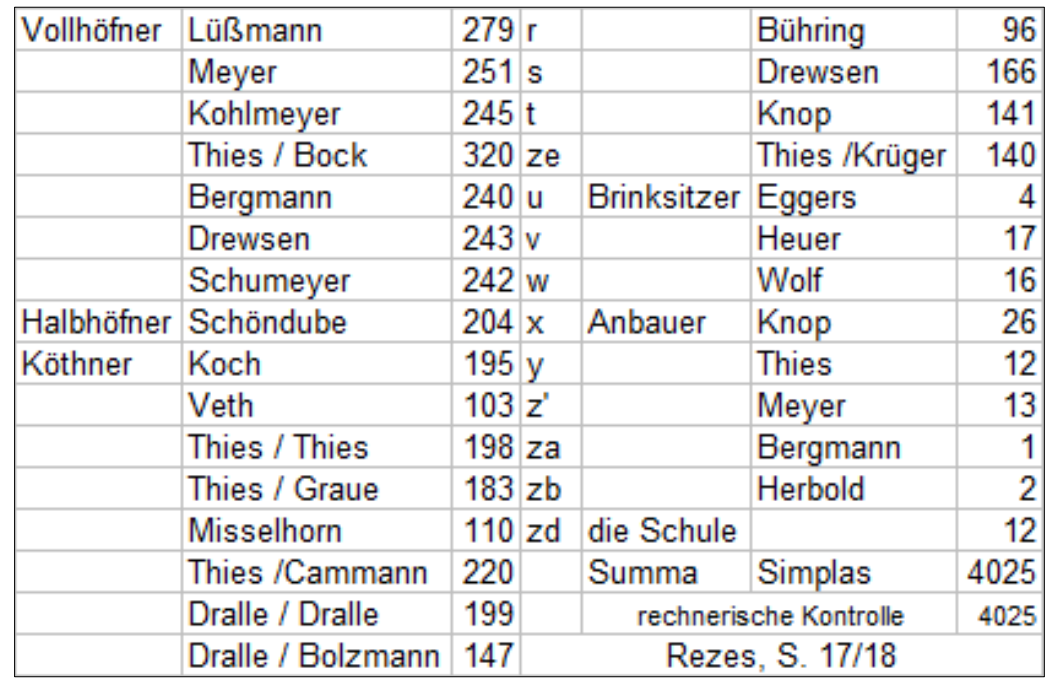

2. Verteilung Oppershausen

Vollhöfner Marwedel erhält vorab aus dem Weide-Äquivalent der Dorfschaft Oppershausen 1/8 Morgen mittlerer Bonität als besondere Entschädigung (ohne weitere Begründung).

Auf die Interessenten des Dorfes Oppershausen entfallen insgesamt 1652 Simplas, davon allein 304 auf das v.d. Wensesche Gut.

„Die zur Correction des Schwarzwassers abgetretenen, in der Abfindunsgberechnung speziell aufgeführten Grundstücke, werden nicht in Grund und Boden, sondern durch die Schwarzwasser-Commission in Geld vergütet.

$\mathrm{Zu}$ den neuen Wegen und Gräben und gemeinschaftlich reservierten Räumen werden die alten, im Taxationsregister verzeichneten Wege und Gräben und die von der Gemeinde Lachendorf in die gemeinschaftliche Masse geworfenen alten Wege, vewandt, und wird die mehr erforderliche Fläche auf die sämtlichen Interessenten der Aller- und trockenen Wiesen, mit Ausschluss der behufs Grenzregulierung und Vertauschung herangezogenen, oder in anderen Feldmarken zu den Wegen pp. Beitragspflichtigen Grundstücke, nach Verhältnis des Werts der Abfindungen repartirt.

Die vom Wegebeitrag befreiten Grundstücke sind in der Abfindungsberechnung speziell aufgeführt.

Auf Grundlage des vorstehend beschriebenen Teilungsmaßstabes und des Taxationsregisters ist die einem jeden Interessenten planmäßig gebührende Abfindung in der Auseinandersetzungsberechnung festgestellt." 
§5)

"Nachweisung des von den Beteiligten in die Masse geworfenen Grundbesitzes"

\begin{tabular}{|c|c|c|c|c|c|c|c|c|c|c|c|c|c|c|c|c|c|}
\hline \multicolumn{18}{|c|}{ Eingebrachter Besitz der Betroffenen in Lachendorf } \\
\hline \multirow[b]{3}{*}{ Litr. } & \multirow{2}{*}{\multicolumn{2}{|c|}{ Lachendorf }} & \multirow{2}{*}{\multicolumn{3}{|c|}{ Wiesenboden }} & \multicolumn{9}{|c|}{ nach der Bodenart } & & & \\
\hline & & & & & & & cke & rland & & ngerk & boden & & Heidb & oden & \multicolumn{3}{|c|}{ in Allem } \\
\hline & & & M & QR & Kuhw. & $\mathrm{M}$ & QR & Kuhw. & M & $Q R$ & Kuhw. & $\mathrm{M}$ & QR & Kuhw. & M & QR & Kuhw. \\
\hline a & VH & Lüßmann & 20 & 70 & 5,977 & & & & & & & & 78 & 0,043 & 21 & 28 & 6,020 \\
\hline b & & Meier & 24 & 31 & 6,042 & & & & & & & & 15 & 0,006 & 24 & 46 & 6,048 \\
\hline c & & Kohlmeyer & 15 & 61 & 3,737 & & & & & & & & & & 15 & 61 & 3,737 \\
\hline d & & Thies / Bock & 17 & 59 & 5,05 & & & & & & & & & & 17 & 59 & 5,050 \\
\hline e & & Bergmann & 19 & 81 & 5,342 & & & & 3 & 33 & 0,289 & & & & 22 & 114 & 5,631 \\
\hline$f$ & & Drewsen & 16 & 59 & 5,3 & & & & & & & & & & 16 & 59 & 5,300 \\
\hline $\mathrm{g}$ & & Schumeyer & 8 & 6 & 1,369 & & & & & & & & 70 & 0,035 & 8 & 76 & 1,404 \\
\hline $\mathrm{h}$ & $\mathrm{HH}$ & Schöndube & 9 & 27 & 1,503 & & & & & & & & 55 & 0,031 & 9 & 82 & 1,534 \\
\hline i & Kö & Koch & 12 & 17 & 2,728 & & & & 2 & 50 & 0,281 & 1 & 113 & 0,098 & 17 & 40 & 3,107 \\
\hline k & & Schwägermann & 13 & 42 & 4,554 & & & & & & & & & & 13 & 42 & 4,554 \\
\hline I & & Thies / Thies & 17 & 94 & 3,893 & & & & & & & & & & 17 & 94 & 3,893 \\
\hline $\mathrm{m}$ & & Thies / Graue & 16 & 65 & 3,733 & & & & & & & 3 & 56 & 0,220 & 20 & 1 & 3,953 \\
\hline $\mathrm{n}$ & & Misselhorn & 6 & 90 & 1,274 & & & & & & & & 89 & 0,044 & 7 & 59 & 1,318 \\
\hline 0 & & Thies / Cammann & 3 & 66 & 0,338 & 2 & 75 & 0,098 & & & & & & & 6 & 21 & 0,436 \\
\hline$p$ & & Dralle & 30 & 59 & 6,902 & & & & & & & & & & 30 & 59 & 6,902 \\
\hline$q$ & & Dralle / Bolzmann & 4 & 80 & 0,452 & & & & & 53 & 0,055 & 4 & 67 & 0,244 & 9 & 80 & 0,751 \\
\hline r & & Bühring & 8 & 16 & 2,711 & & & & & & & & & & 8 & 16 & 2,711 \\
\hline s & & Drewsen & 7 & 44 & 1,092 & & & & & & & 1 & 55 & 0,095 & 8 & 99 & 1,187 \\
\hline $\mathrm{t}$ & & Müller & 15 & 77 & 4,555 & & & & & & & & & & 15 & 77 & 4,555 \\
\hline u & BS & Eggers & 7 & 42 & 1,633 & & & & & & & & & & 7 & 42 & 1,633 \\
\hline $\mathrm{v}$ & & Heuer & 6 & 195 & 1,585 & & & & & & & & & & 6 & 105 & 1,585 \\
\hline w & & Wolf & 1 & 16 & 0,122 & & & & 7 & 16 & 0,695 & & & & 8 & 32 & 0,817 \\
\hline $\mathrm{x}$ & Anb & Knop & 2 & 106 & 0,698 & & & & & & & & & & 2 & 106 & 0,698 \\
\hline \multirow[t]{5}{*}{$\mathrm{L}$} & Gem & neinde Lachendorf & 14 & 99 & 3,489 & & & & & 92 & 0,092 & 3 & 13 & 0,206 & 18 & 84 & 3,787 \\
\hline & & & & & & & & & & \multicolumn{5}{|c|}{ Spaltensummenumme } & 323 & 1482 & 76,611 \\
\hline & & & & & & & & & & & & & & & & 12,35 & \\
\hline & & & & & & & & & & & & \multicolumn{3}{|c|}{ in Allem } & 335 & 42 & 76,611 \\
\hline & & & & & & & & & & & & & & & ha & \multicolumn{2}{|c|}{87,8986} \\
\hline & & & & & & & & & & & & & & & & & \\
\hline
\end{tabular}

Abkürzungen: VH: Vollhöfner; HH: Halbhöfner

Kö: Kötner; BS: Brinksitzer; AnB: Anbauer 
Nachweis des eingebrachten Besitzes der Interessenten der übrigen Dörfer:

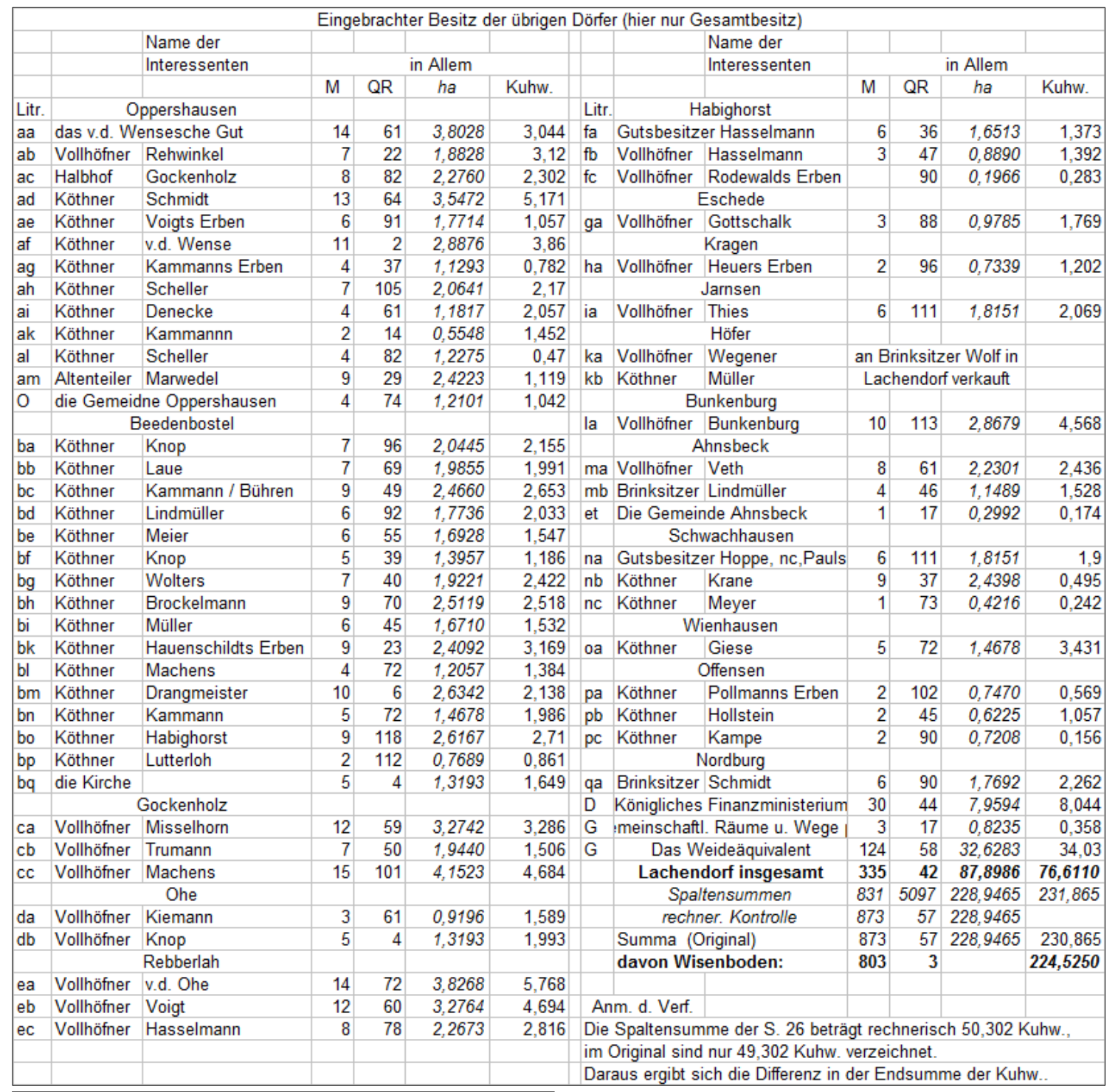

Teilungsurkunde, S. 25 - 27

$\S 6)$

Nachweisung der zur Correction des Schwarzwasserflusses abgetretenen Grundstücke Diese Flächen wurden nicht in Grund und Boden sondern in Geld entschädigt

1. Köthner Veth (Schwägermann), Lachendorf, Wiesenboden; Litr. $k \quad 11$ QR, 0,073 Kuhw.

2. v.d. Wense, Gut in Oppershausen, Wiesenboden, Litr. aa

$16 Q R ; 0,089$ Kuhw.

3. v.d. Wense, Halbhöfnerstele, Oppershausen, Wiesenboden, Litr. af 39 QR;0,260 Kuhw.

4. Köthner Denecke, Oppershausen, Wiesenboden, Litr. ai

5. Köthner Kammann, Oppershausen, Wiesenboden, Litr. ak

32 QR; 0,142 Kuhw.

6. Köthner Giese, Wienhausen, Wiesenboden, Litr. ca

9 QR; 0,060 Kuhw.

7. Vollhöfner v.d. Ohe, Rebberlah, Wiesenboden, Litr. ea

27 QR; 0, 104 Kuhw.

8. Das Domänium, Wiesenboden, Litr. $D$

Summe:

56 QR; 0,368 Kuhw.

$6 Q R ; 0,040$ Kuhw.

Überhaupt: 1 M 76 QR; 1,136 Kuhw. 
§7) Übersicht der verschiedenen Auseinandersetzungs-Gegenstände

\begin{tabular}{|c|c|c|c|c|c|c|c|c|c|c|c|c|c|c|c|}
\hline \multicolumn{16}{|c|}{ Theilungs-Urkunde, $\S 7$} \\
\hline \multicolumn{16}{|c|}{ Übersicht der verschiedenen Auseinandersetzungs-Gegenstände } \\
\hline \multirow[t]{2}{*}{ Bezeichnung der Auseinandersetzungs-Gegenstände } & \multicolumn{15}{|c|}{ nach den Bodenarten } \\
\hline & \multicolumn{3}{|c|}{ Wiesenboden } & \multicolumn{3}{|c|}{ Ackerland } & \multicolumn{3}{|c|}{ Angerboden } & \multicolumn{3}{|c|}{ Heidboden } & \multicolumn{3}{|c|}{ zu Allem } \\
\hline nach dem Taxationsregister & M & QR & Kuhw. & M & QR & Kuhw. & M & QR & Kuhw. & M & QR & Kuhw. & M & QR & Kuhw. \\
\hline 1. Privater und servitusfreier Besitz & 657 & 89 & 185,740 & 32 & 82 & 3,589 & 13 & 32 & 1,320 & 18 & 101 & 0,999 & 722 & 64 & 191,648 \\
\hline \multicolumn{16}{|l|}{ 2. Servitutsfreie Gemeindegrundstücke } \\
\hline a. Der Dorfgemeinsachaft Lachendorf & 14 & 99 & 3,489 & & & & & & & 3 & 7 & 0,204 & 17 & 106 & 3,693 \\
\hline b, Der Dorfgemeinschaft Oppershausen & 4 & 74 & 1,042 & & & & & & & & & & 4 & 74 & 1,042 \\
\hline \multicolumn{16}{|l|}{ 3. Wiesenweide Äquivalente } \\
\hline \multicolumn{16}{|l|}{ a. auf den Wiesen der Meierschen Erben } \\
\hline zu Schwachhausen & & & & & 5 & 0,003 & & & & & & & & 5 & 0,003 \\
\hline b. auf der Wiese des Vollhöfners Bunkenburg & 2 & 23 & 0,914 & & & & & & & & & & 2 & 23 & 0,914 \\
\hline c. auf den übrigen wiedepflichtigen Wiesen & 120 & 61 & 32,982 & & 95 & 0,087 & & & & & 114 & 0,044 & 122 & 30 & 33,113 \\
\hline \multicolumn{16}{|l|}{ 4. Gemeinschaftliche Wege und Gräben, einschließlich } \\
\hline der von Lachendorf eingeworfenen Wegemasse & 3 & 17 & 0,358 & & & & & 92 & 0,092 & & 6 & 0,002 & 3 & 115 & 0,452 \\
\hline zu Allem & 803 & 3 & 224,535 & 33 & 62 & 3,679 & 14 & 4 & 1,412 & 22 & 108 & 1,249 & 873 & 57 & 230,865 \\
\hline \multicolumn{16}{|l|}{ dazu } \\
\hline \multicolumn{16}{|l|}{ 5. Die auf Correction des Schwarzwassers und wegen } \\
\hline Grenzregulierung angeschnittenen Wiesenfläche & 4 & 116 & 3,067 & & & & & 4 & 0,004 & & & & 5 & & 3,071 \\
\hline Summa & 807 & 119 & 227,592 & 33 & 62 & 3,079 & 14 & 8 & 1,416 & 22 & 108 & 1,249 & 878 & 57 & 233,936 \\
\hline rechnerisch überprüft: Verf. & & & & & & & & & & & & & & & \\
\hline Quelle: Teilungs-Urkunde ..., Sign.: 140/8, S. $29 / 30$ & & & & & & & & & & & & & & & \\
\hline
\end{tabular}

§ 8)

Angelegte Wege und Triften

„Im Verkoppelungsobjekt befinden sich öffentliche Wege nicht; die nachfolgenden Koppelwege und Triften sind nur im landwirtschaftlichen Interesse angelegt."

Das Verzeichnis weist insgesamt 22 Wege aus, meist 32 Fuß breit, 2 Wege mit je 16 Fuß und 5 Wege mit 40 Fuß Breite. Alle Wege sind mit Nummern versehen, die in der Verkoppelungskarte verzeichnet sind.

§ 9)

„Entwässerung

Nachfolgende Abzugsgräben sind zur Aufnahme und Ableitung des Wassers angelegt.

Der durch eine besondere Commission begradigte Schwarzwasserfluß liegt auf der Grenze des Verkoppelungs-Objekts und nimmt das Wasser aus dem Verkoppelungsgebiet auf.

1. Abzugsgraben in den Allerwiesen, No. 148 der Charte: 12 Fuß breit

2. Ein weiterer Graben daselbst. No. 80 der Charte, 12 Fuß breit.

3. Ein dritter Graben daelbst. No. 53 der Charte, 12 Fuß breit.

4. Abzugsgraben in den trockenen Wiesen, No. 38 der Charte, 16 Fuß breit.

5. Ein zweiter Graben daselbst, No. 7 der Karte, 8 Fuß breit."

$\S 10)$

Zu gemeinsamen Zwecken reservierte Räume

„Die gemeinsamen Räume, zu Tränken und Sandgruben, welche nach zuvoriger Verhandlung mit den Beteiligten gemeinschaftllich verblieben, sind nachfolgende:"

1. No. 104 der Karte: 1 M 72 QR, an Vollhof Lüßmann für 87 Rth verkauft.

2. No. 40 der Karte: 14 QR; vor Kammanns Wiese

3. No. 17 der Karte: $1 \mathrm{M} 117 \mathrm{QR}$; in den trockenen Wiesen: Die Fläche erhält Kötner Thies (Thies) und gibt dafür von seiner Koppel Nr. 4 der Karte eine wertmäßig gleiche Fläche an den Verkoppelungsverband. Diese Fläche ist No. 4 der Karte mit 4 M 64 QR und 0,320 Kuhweiden.

4. No. 39 der Karte: 60 QR; vor den trockenen Wiesen. 
$\S 11)$

„Summarische Übersicht der einem jeden Interessenten gebührenden und der amtlich zugeteilten Abfindungen."

„In den nachfolgenden Tabellen ist der planmäßige und wirklich erhaltene Grundbesitz nach Maßgabe der im Schlusse der Auseinandersetzungs-Berechnungen und das VerteilungsRegister enthaltenen Tabellen zusammengefasst. “

Teiltabelle für die Beteiligten aus Lachendorf:

Die Tabellen enthalten in Gegenüberstellung für jeden Interessenten das

"Sollhaben der Auseinandersetzungs-Berechnung“, aufgeteilt nach den Bodenarten und $\mathrm{Ge}$ -

\begin{tabular}{|c|c|c|c|c|c|c|c|c|c|c|c|c|c|c|c|c|c|c|c|c|}
\hline \multicolumn{21}{|c|}{ Ergebnis des Verfahrens für Lachendorf } \\
\hline & & \multirow{4}{*}{ Lachendorf } & \multicolumn{3}{|c|}{ Soll-Haben } & \multicolumn{15}{|c|}{ Empfang nach dem Verteilungs-Register } \\
\hline & & & & & & \multicolumn{12}{|c|}{ nach der Bodenart } & \multicolumn{3}{|c|}{ in Allem } \\
\hline & & & \multicolumn{3}{|c|}{ in Allem } & \multicolumn{3}{|c|}{ Wiesenboden } & \multicolumn{3}{|c|}{ Ackerland } & \multicolumn{3}{|c|}{ Angerboden } & \multicolumn{3}{|c|}{ Heidboden } & \multirow[b]{2}{*}{ M } & \multirow[b]{2}{*}{ QR } & \multirow[b]{2}{*}{ Kuhw. } \\
\hline Litr. & & & M & QR & Kuhw. & M & QR & Kuhw. & M & QR & Kuhw. & M & QR & Kuhw. & $\mathrm{M}$ & QR & Kuhw. & & & \\
\hline a & VH & Lüßmann & 26 & 110 & 7,753 & 28 & 104 & 7,575 & & & & & & & 2 & 81 & 0,178 & 31 & 65 & 7,753 \\
\hline b & VH & Meier & 27 & 78 & 6,902 & 28 & 14 & 6,895 & & & & & & & & 15 & 0,007 & 28 & 29 & 6,902 \\
\hline c & VH & Kohlmann & 19 & 8 & 4,660 & 19 & 52 & 4,660 & & & & & & & & & & 19 & 52 & 4,660 \\
\hline d & VH & Thies / Bock & 21 & 101 & 6,189 & 21 & 91 & 6,189 & & & & & & & & & & 21 & 91 & 6,189 \\
\hline e & VH & Bergmann & 26 & 28 & 6,482 & 23 & 73 & 6,439 & & & & & 56 & 0,043 & & & & 24 & 9 & 6,482 \\
\hline$f$ & VH & Drewsen & 19 & 101 & 6,173 & 21 & 52 & 6,173 & & & & & & & & & & 21 & 52 & 6,173 \\
\hline g & VH & Schumeyer & 13 & 17 & 2,661 & 12 & 24 & 2,661 & & & & & & & & & & 12 & 24 & 2,661 \\
\hline h & $\mathrm{HH}$ & Schöndube & 13 & 13 & 2,414 & 12 & 75 & 2,289 & & & & 1 & 12 & 0,125 & & & & 13 & 87 & 2,414 \\
\hline i & Kö & Koch & 20 & 55 & 3,912 & 16 & 43 & 3,508 & & & & 2 & 39 & 0,267 & 2 & 62 & 0,137 & 21 & 24 & 3,912 \\
\hline k & Kö & Schwägermann & 15 & 5 & 4,929 & 13 & 100 & 4,929 & & & & & & & & & & 13 & 100 & 4,929 \\
\hline I & Kö & Thies / Thies & 20 & 92 & 4,664 & 22 & 4 & 4,402 & 3 & 56 & 0,262 & & & & & & & 25 & 60 & 4,664 \\
\hline $\mathrm{m}$ & Kö & Thies / Graue & 22 & 101 & 4,683 & 16 & 28 & 4,580 & & & & & & & 1 & 65 & 0,103 & 17 & 93 & 4,683 \\
\hline $\mathrm{n}$ & Kö & Misselhorn & 9 & 103 & 1,913 & 9 & 60 & 1,850 & & & & & & & 1 & 4 & 0,063 & 10 & 64 & 1,913 \\
\hline 0 & Kö & Thies /Kammann & 9 & 113 & 1,407 & 7 & 49 & 1,236 & & & & 1 & 116 & 0,171 & & & & 9 & 45 & 1,407 \\
\hline$p$ & Kö & Dralle & 33 & 67 & 7,695 & 29 & 64 & 7,695 & & & & & & & & & & 29 & 64 & 7,695 \\
\hline$q$ & Kö & Dralle / Bolzmanr & 12 & 70 & 1,489 & 9 & 20 & 1,197 & & & & & 53 & 0,055 & 4 & 56 & 0,237 & 14 & 9 & 1,489 \\
\hline r & Kö & Bühring & 10 & 15 & 3,207 & 10 & 25 & 3,207 & & & & & & & & & & 10 & 25 & 3,207 \\
\hline $\mathrm{s}$ & Kö & Drewes & 11 & 104 & 1,963 & 13 & 17 & 1,943 & & & & & & & & 48 & 0,020 & 13 & 65 & 1,963 \\
\hline t & Kö & Müller & 17 & 104 & 5,122 & 16 & 52 & 5,122 & & & & & & & & & & 16 & 52 & 5,122 \\
\hline ze & Kö & Thies / Krüger & 2 & 110 & 0,736 & 3 & 51 & 0,736 & & & & & & & & & & 3 & 51 & 0,736 \\
\hline u & BS & Eggers & 7 & 108 & 1,771 & 8 & 24 & 1,771 & & & & & & & & & & 8 & 24 & 1,771 \\
\hline $\mathrm{v}$ & BS & Heuer & 7 & 69 & 1,765 & 7 & 113 & 1,765 & & & & & & & & & & 7 & 113 & 1,765 \\
\hline w & BS & Wolf & 9 & 22 & 1,050 & 3 & 94 & 0,468 & & & & 5 & 102 & 0,582 & & & & 9 & 76 & 1,050 \\
\hline$x$ & Anb & Knop & 3 & 41 & 0,823 & 3 & 71 & 0,823 & & & & & & & & & & 3 & 71 & 0,823 \\
\hline y & Anb & Thies & & 36 & 0,082 & & 21 & 0,082 & & & & & & & & & & & 21 & 0,082 \\
\hline$z$ & Anb & Meier & & 38 & 0,085 & & 20 & 0,085 & & & & & & & & & & & 20 & 0,085 \\
\hline za & Anb & Bergmann & & 20 & 0,047 & & 13 & 0,047 & & & & & & & & & & & 13 & 0,047 \\
\hline$z \mathrm{~b}$ & Anb & Herbold & & 22 & 0,050 & & 15 & 0,050 & & & & & & & & & & & 15 & 0,050 \\
\hline $\mathrm{zd}$ & S & Schule & & 74 & 0,168 & & 49 & 0,168 & & & & & & & & & & & 49 & 0,168 \\
\hline & & rechnerisch & 385 & 25 & 90,795 & 388 & 23 & 88,545 & 3 & 56 & 0,262 & 12 & 18 & 1,243 & 12 & 91 & 0,745 & 388 & 23 & 90,795 \\
\hline
\end{tabular}

samtsoll, und den „Empfang nach dem Verteilungsregister“, ebenfalls aufgeteilt nach Bodenarten und Gesamtabfindung.

Dabei differieren Soll-Haben und Zuteilung in den Flächengrößen, aber nicht in der Bewertung nach Kuhweiden.

Die Tabelle listet für die anderen Orte insgesamt weitere 90 Interessenten aus, sodass schließlich die Gesamtfläche von 878 Morgen und 57 Quadratruten zu 233,936 Kuhweiden neu verteilt ist.

§12)

Das Grundeigentum an den Gemeinheiten in den Feldmarken Lachendorf und Oppershausen steht zwar der a. g. Herrschaft zu, kommt aber hinsichtlich der diesen Gemeinden zufal- 
lenden Weide-Äquivalente nicht in Betracht, zumal der Bevollmächtigte keinen Anspruch angemeldet hat.

§13)

„Künftige Benutzung der Abfindungen“

„Die sämtlichen in dem, diesem Rezeß angehängtem Verteilungsregister aufgeführten Grundstücke, sind durch Abstellung der Weide und sonstigen Servitute privatives Eigentum der Beteiligten geworden, und werden denselben zur einseitigen privativen Benutzung damit überwiesen, sofern nicht Ausnahmen in diesem Rezeß gemacht sind, und unter nachfolgenden Beschränkungen."

Ausnahmen:

1. Grenzabstand bei Bebauung von $1 R^{1}$ zur Koppelgrenze und $1 / 2 R$ an Wegen; aber $2 R$, wenn Nachbargrundstück in den Mittagsschatten gerät.

2. Abgrabungen und Vertiefungen müssen Grenzabstand von $3 \mathrm{FuB}^{2}$ einhalten

3. Hochstämmige Bäume müssen 16 Fuß Grenzabstand zu Koppeln, 4 Fuß zu Wegen einhalten. „Obstbäume und Schlaghölzer, so wie Bäume, welche alle Jahre gekappt werden, können 6 Fuß von den Grenzen der Koppeln angepflanzt werden."

Überhängende Zweige müssen entfernt werden.

Bäume und Buschwerk auf Koppeln, die in andere Hände übergingen, mussten bis zum 1. Mai 1866 weggeräumt sein, sonst fällt es unentgeltlich dem neuen Koppelbesitzer zu.

$\S 14)$

Befriedigung der Koppeln

Alle Koppeln werden mit Grenzsteinen markiert.

Es steht jedem frei, seine Koppeln mit „Planken, Stakette, Hecken oder Gräben einseitig einzufriedigen".

Grenzabstand: 11/2 Fuß, Hecken müssen „außerdem 1 Fuß vom Stamm gehörig geschoren und nicht über 5 Fuß hoch werden."

Etwaige Verpflichtungen zur Einfriedung sind hinfällig.

Kosten zur Einfriedungen an Wegen und gemeinschaftlichen Gräben gehen allein zu Lasten des Eigentümers.

§15)

„Erste Instandsetzung und künftige Unterhaltung der Wege, Gräben und deren Zubehörungen"

„Die sämtlichen im Verkoppelungs-Objekt angelegten Wege und Gräben, so wie die in demselben erforderlichen Brücken oder Siele sind auf gemeinschaftliche Kosten aller Beteiligten vorzurichten und zu unterhalten.

Die sämtlichen Wege werden durch Grenzsteine eingefriedigt, jedoch ist es auch gestattet, die Wege von mindestens 2 Ruthen Breite mit 3füßigen Gräben, wozu das Terrain aus dem Wege zu entnehmen ist, einzufriedigen. Die Erde aus den Weggräben ist zur Erhöhung und Planierung der Wege zu verwenden, und die aus den Entwässerungsgräben gewonnene Erde ist nach beiden Seiten gleichmäßig zu verteilen.

Für das Auflagern der Erde erhalten die anliegenden Koppelbesitzer keine Entschädigung, jedoch steht ihnen Fortschaffung und Verwendung derselben zu ihrem Nutzen frei.

Die sämtlichen Kosten, sowohl der ersten Instandsetzung als auch der zukünftigen Unterhaltung der Wege, Gräben und deren Zubehörungen, sind von allen Teilnehmenden der Verkoppelung nach Verhältnis des Maßstabs ihrer Abfindungen zu tragen, jedoch mit Ausschluss der behuf Grenzregulierung und Vertauschung herangezogenen, das Verkoppelungsobjekt begrenzenden und in anderen Feldmarken zu den Weg pp. Beitragspflichtigen Grundstücke, welche auch von Wegebeiträgen befreit geblieben sind.

\footnotetext{
${ }^{1} \mathrm{R}$ : Ruthe, entspricht $4,67 \mathrm{~m}$

$21 \mathrm{Fu} \beta=12$ Zoll $=29,21 \mathrm{~cm}$
} 
In nachfolgender Tabelle ist nun für jeden einzelnen Interessenten sein Beitrag zu diesen Kosten auf $100 \mathrm{gGr}$ berechnet."

„Nachweisung des Beitrages ${ }^{1}$ der Interessenten zu den Kosten der Instandsetzung und Unterhaltung der Wege, Gräben und den Zubehörungen."

\begin{tabular}{|c|c|c|c|c|c|c|c|c|}
\hline \multicolumn{9}{|c|}{ Beiträge der Interessenten aus Lachendorf zur Unterhaltung der Wege und Gräben } \\
\hline & & & Wert der & befreiter & beitrags- & \multicolumn{3}{|c|}{ Beitrag } \\
\hline & & Namen der & gesamten & Grundbesitz & pflichtiger & \multicolumn{3}{|c|}{$z u$} \\
\hline & & Interessenten & Abfindung & & Grundbesitz & \multicolumn{3}{|c|}{$100 \mathrm{RTh}$} \\
\hline Litr. & & Lachendorf & Kuhw. & Kuhw. & Kuhw. & RTh & $g G r$ & Pf \\
\hline a & $\mathrm{VH}$ & Lüßmann & 7,753 & 3,672 & 4,081 & 1 & 29 & \\
\hline$b$ & $\mathrm{VH}$ & Meier & 6,902 & 0,006 & 6,896 & 3 & 9 & 8 \\
\hline$c$ & VH & Kohlmann & 4,660 & & 4,660 & 2 & 7 & 4 \\
\hline$d$ & VH & Thies / Bock & 6,189 & 0,832 & 5,357 & 2 & 17 & 5 \\
\hline e & $\mathrm{VH}$ & Bergmann & 6,482 & 0,293 & 6,189 & 2 & 29 & 5 \\
\hline$f$ & $V H$ & Drewsen & 6,173 & 0,401 & 5,772 & 2 & 23 & 5 \\
\hline$g$ & $\mathrm{VH}$ & Schumeyer & 2,661 & 0,726 & 1,935 & & 28 & \\
\hline$h$ & $H H$ & Schöndube & 2,414 & 0,031 & 2,383 & 1 & 4 & 5 \\
\hline$i$ & Kö & Koch & 3,912 & 0,377 & 3,535 & 1 & 21 & 1 \\
\hline$k$ & Kö & Veth & 4,929 & & 4,929 & 2 & 11 & 3 \\
\hline l & Kö & Thies / Thies & 4,664 & & 4,664 & 2 & 7 & 5 \\
\hline$m$ & Kö & Thies / Graue & 4,683 & 0,218 & 4,465 & 2 & 4 & 6 \\
\hline$n$ & Kö & Misselhorn & 1,913 & 0,044 & 1,869 & & 27 & \\
\hline 0 & Kö & Thies /Kammann & 1,407 & & 1,407 & & 20 & 4 \\
\hline$p$ & Kö & Dralle & 7,695 & 3,519 & 4,176 & 2 & & 4 \\
\hline$q$ & Kö & Dralle / Bolzmann & 1,489 & 0,206 & 1,283 & & 18 & 6 \\
\hline$r$ & Kö & Bühring & 3,207 & & 3,207 & 1 & 16 & 4 \\
\hline$s$ & Kö & Drewes & 1,963 & 0,095 & 1,868 & & 27 & \\
\hline$t$ & Kö & Müller & 5,122 & & 5,122 & 2 & 14 & 1 \\
\hline$z e$ & Kö & Thies / Krüger & 0,736 & & 0,736 & & 10 & 6 \\
\hline$u$ & $B S$ & Eggers & 1,771 & & 1,771 & & 25 & 6 \\
\hline$v$ & $B S$ & Heuer & 1,765 & & 1,765 & & 25 & 5 \\
\hline w & $B S$ & Wolf & 1,050 & 0,695 & 0,355 & & 5 & 1 \\
\hline$x$ & $A n b$ & Knop & 0,823 & 0,698 & 0,125 & & 1 & 8 \\
\hline$y$ & $A n b$ & Thies & 0,082 & & 0,082 & & 1 & 2 \\
\hline$z$ & $A n b$ & Meier & 0,085 & & 0,085 & & 1 & 2 \\
\hline$z a$ & $A n b$ & Bergmann & 0,047 & & 0,047 & & & 7 \\
\hline$z b$ & $A n b$ & Herbold & 0,050 & & 0,050 & & & 7 \\
\hline$z d$ & $S$ & Schule & 0,168 & & 0,168 & & 2 & 4 \\
\hline reche & risch & & 90,795 & 11,813 & 78,982 & 25 & 381 & 114 \\
\hline Zusa & mmer & nfassung & & & & & 12 RTh u. & $11 \mathrm{gGr} u$ \\
\hline für $L a ́$ & ichen & idorf & Diff & erenz: & & & $21 \mathrm{gGr}$ & $4 \mathrm{P}$ \\
\hline & & rechnerisch & 90,795 & 11,813 & 78,982 & 38 & 2 & 4 \\
\hline & & & Rezess & 5. S. 53 und 54 & 4 (halb) & & & \\
\hline
\end{tabular}

\footnotetext{
${ }^{1}$ Die Kosten werden in Reichsthaler (RTh), guten Groschen (gGr) und Pfennigen (PF) angegeben. Dabei gilt: $1 \mathrm{RTh}=30 \mathrm{gGr}=300 \mathrm{Pf}$, also $1 \mathrm{gGr}=10 \mathrm{Pf}$
} 


\begin{tabular}{|c|c|c|c|c|c|c|c|}
\hline \multicolumn{8}{|c|}{ Zusammenfassung aller Seitenergebnisse } \\
\hline \multicolumn{8}{|c|}{ der Beiträge zur Unterhaltung der Wege und Gräben } \\
\hline & Seite 58 & 26,877 & 10,882 & 15,995 & 7 & 21 & 4 \\
\hline dazu & Seite 53 & 84,954 & 10,420 & 74,534 & 35 & 28 & 2 \\
\hline dazu & Seite 54 & 37,558 & 1,393 & 36,165 & 17 & 13 & 2 \\
\hline dazu & Seite 55 & 10,763 & 1,601 & 9,162 & 4 & 12 & 5 \\
\hline dazu & Seite 56 & 34,949 & 1,213 & 33,736 & 16 & 8 & \\
\hline dazu & Seite 57 & 38,835 & 1,039 & 37,796 & 18 & 6 & 7 \\
\hline & Summa & 233,936 & 26,548 & 207,388 & 100 & & \\
\hline \multicolumn{8}{|c|}{ Rezess S. 58} \\
\hline rechne & Überprüfung & 233,936 & $26,548^{\prime}$ & $207,388^{\prime}$ & 97 & 88 & 20 \\
\hline & & & & & ent & 100 & \\
\hline
\end{tabular}

§ 16) Künftige Benutzung der Wege

„Die bei der Verkoppelung angelegten Wege sind nur im landwirtschaftlichen Interesse zu benutzen.

Nebennutzungen auf denselben sind nur im gemeinschaftlichen Interesse zu verwerten und die dadurch gewonnenen Aufkünfte zur Instandsetzung der Wege pp. zu verwenden.

Einzelnen Beteiligten stehen Nebennutzungen auf den Wegen nicht zu, und wird denselben namentlich das Beweiden mit dem Viehe, das Abplaggen der Wege und Weggräben, ferner das Abfahren der Erde von den Wegen, die Anlage von Mieten und Kuhlen auf demselben und desgleichen wird gänzlich untersagt."

§ 17)

„Gegenseitige Verpflichtung rücksichtlich des Wasserlaufs.

Zur Aufnahme und Ableitung des Wassers dienen die angelegten in $\S 9$ aufgeführten Entwässerungs-Gräben und eventuell die Gräben an den Wegen.

Jeder dem Gefälle nach unterhalb liegende Grundstück ist verpflichtet, das ihm von den oberhalb belegenen Grundstücken zu fließende Wasser aufzunehmen und weiter zu führen.

Bei etwa erforderlich werdenden Erweiterungen der Entwässerungs-Anlagen oder bei Drainierungen von Grundstücken ist der Besitzer der unterhalb liegenden Koppel verpfllichtet, die Anlage eines Grabens oder die Rohrleitung durch seine Koppel gegen vollständige Schadloshaltung zu gestatten."

§ 18)

„Künftige Benutzung der zu gemeinschaftlichen Zwecken reservierten Räume“.

Diese Räume dienen als Viehtränken, die jeder Interessent für sein Vieh nutzen darf, und als Sandgruben, aus denen das Material zur Ausbesserung der Wege zu entnehmen ist.

Die Aufsicht darüber obliegt dem Amtsvorstand von Lachendorf und Oppershausen.

$\S 19)$

"Berücksichtigung des zehntherrlichen Interesses“.

"Auf dem ganzen Verkoppelungs-Objekte haben zehntpflichtige Rechte nicht bestanden."

$\S 20)$ „Berücksichtigung der auf den Grundstücken haftenden hypothekarischen Rechte und Reallasten"

„Die hypothekarischen Rechte und Reallasten, welche auf den seitherigen Grundstücken der Interessenten gehaftet haben, erlöschen in Ansehung der abgetretenen Bestandteile und gehen unter Beibehaltung ihres gegenseitigen Verhältnisses auf die auf deren Stelle eingetragenen Grundstücke ohne Weiteres über. Spezial-Pfandrechte sind nicht vorhanden." 
§ 21) „Allgemeine Entsagung und Anerkennung“

„Die sämtlichen Interessenten entsagen allen ihren Ansprüchen, welche ihnen vor dieser Teilung an den Verkoppelungs-Gegenständen zugestanden haben und treten an deren Stadt in diejenigen Rechte und Verpflichtungen ein, welche ihnen dieser Rezeß beilegt."

\section{$\S 22)^{1}{ }$,Kostenpunkt“}

„Die durch das Verkoppelungsverfahren verursachten gemeinsamen Kosten sind nach Maßgabe des Verkoppelungs-Gesetzes vom 30. Juni 1842 von allen Teilnehmern nach Verhältnis des Wertes der Abfindungen zu tragen, jedoch sind nach dem Gesetze vom 8. November 1856 diejenigen Interessenten, welche an zusammen zu legenden Grundstücken nicht mehr als 2 Morgen zum Durchschnittswerte sämtlicher Grundstücke besitzen, vom Kostenbeitrage befreit, und vom dem Grundbesitzes der übrigen Beteiligten sind gleichfalls sind ebenfalls 2 Morgen zu demselben Durchschnittswerte der von den Kosten frei zu lassen.

Diese Bestimmung bezieht sich indeß nicht auf die für Weideberechtigung den einzelnen Interessenten angefallenen Abfindungen..

Der Durchschnittswert von 2 Morgen des Verkoppelungsobjektes von 8731/2 M: 230,865 Kuhw. beträgt 0,528 Kuhw.

Außerdem sollen die Grundstücke, welche behuf Grenzregulierung und Vertauschung mit in die Verkoppelung gegangen und vom Wegebeitrag befreit geblieben sind, zu den Kosten nicht beitragen, so dass dieselben nur von den eigentlichen Verkoppelungs-Grundstücken übernommen werden.

Zum Rechnungsführer ist der Lehrer Thiemann in Lachendorf ernannt und sind demselben für Mühewaltung 2 pro Cent der Ausgaben zugesichert worden.

Der Rechnungsführer ist auf $\S 147$ des Gesetzes vom 30. Juni 1842 verwiesen und demselben in Bezugnahme auf $\S 66$ der Ministerialbekanntmachung vom 27. März 1843 eine schriftliche Instruction zur Führung der Rechnung enthält.

Das Beitrags-Verhältniß zu den allgemeinen Teilungskosten ist in den nachfolgenden Tabellen nachgewiesen."

\footnotetext{
${ }^{1}$ Original S. 63-66
} 


\begin{tabular}{|c|c|c|c|c|c|c|c|c|c|}
\hline \multicolumn{10}{|c|}{ Kosten der Verkoppelung; Aufteilung für Lachendorf } \\
\hline & & & Wert der & befreiter & Grundbesitz & beitrags- & \multicolumn{3}{|c|}{ Beitrag } \\
\hline & & Namen der & gesamten & 2 Morgen & Grenzre- & pflichtiger & \multicolumn{3}{|c|}{ zu } \\
\hline & & Interessenten & Abfindung & durchsch. & gulierungen & Grundbes. & \multicolumn{3}{|c|}{$100 \mathrm{RTh}$} \\
\hline Litr. & & Lachendorf & Kuhw. & Kuhw. & Kuhw. & Kuhw. & \multicolumn{3}{|c|}{ RTh gGr Pf } \\
\hline a & $\mathrm{VH}$ & Lüßmann & 7,753 & 0,528 & 3,672 & 3,553 & 2 & 3 & 2 \\
\hline b & $\mathrm{VH}$ & Meier & 6,902 & 0,528 & 0,006 & 6,368 & 3 & 23 & 4 \\
\hline c & $\mathrm{VH}$ & Kohlmann & 4,660 & 0,528 & & 4,132 & 2 & 13 & 5 \\
\hline d & $\mathrm{VH}$ & Thies / Bock & 6,189 & 0,528 & 0,832 & 4,829 & 2 & 26 & \\
\hline e & VH & Bergmann & 6,482 & 0,528 & 0,293 & 5,661 & 3 & 10 & 8 \\
\hline$f$ & VH & Drewsen & 6,173 & 0,528 & 0,401 & 5,244 & 3 & 3 & 4 \\
\hline g & VH & Schumeyer & 2,661 & 0,528 & 0,726 & 1,407 & & 25 & 1 \\
\hline h & $\mathrm{HH}$ & Schöndube & 2,414 & 0,528 & 0,031 & 1,855 & 1 & 3 & \\
\hline i & Kö & Koch & 3,912 & 0,528 & 0,377 & 3,007 & 1 & 23 & 5 \\
\hline $\mathrm{k}$ & Kö & Veth & 4,929 & 0,528 & & 4,401 & 2 & 18 & 3 \\
\hline I & Kö & Thies / Thies & 4,664 & 0,528 & & 4,136 & 2 & 13 & 6 \\
\hline $\mathrm{m}$ & Kö & Thies / Graue & 4,683 & 0,528 & 0,218 & 3,937 & 2 & 10 & 1 \\
\hline $\mathrm{n}$ & Kö & Misselhorn & 1,913 & 0,528 & 0,044 & 1,341 & & 23 & 9 \\
\hline 0 & Kö & Thies /Kammar & 1,407 & 0,436 & & 0,971 & & 17 & 3 \\
\hline $\mathrm{p}$ & Kö & Dralle & 7,695 & 0,528 & 3,519 & 3,648 & 2 & 4 & 9 \\
\hline q & Kö & Dralle / Bolzma & 1,489 & 0,528 & 0,206 & 0,755 & & 13 & 4 \\
\hline r & Kö & Bühring & 3,207 & 0,528 & & 2,679 & 1 & 17 & 7 \\
\hline s & Kö & Drewes & 1,963 & 0,528 & 0,095 & 1,340 & & 23 & 8 \\
\hline t & Kö & Müller & 5,122 & 0,528 & & 4,594 & 2 & 21 & 8 \\
\hline ze & Kö & Thies / Krüger & 0,736 & & & 0,736 & & 13 & 1 \\
\hline u & BS & Eggers & 1,771 & 0,528 & & 1,243 & & 22 & 1 \\
\hline $\mathrm{v}$ & BS & Heuer & 1,765 & 0,528 & & 1,237 & & 22 & \\
\hline w & BS & Wolf & 1,050 & 0,122 & 0,695 & 0,233 & & 4 & 2 \\
\hline $\mathrm{x}$ & Anb & Knop & 0,823 & & 0,698 & 0,125 & & 2 & 2 \\
\hline $\mathrm{y}$ & Anb & Thies & 0,082 & & & 0,082 & & 1 & 5 \\
\hline$z$ & Anb & Meier & 0,085 & & & 0,085 & & 1 & 5 \\
\hline za & Anb & Bergmann & 0,047 & & & 0,047 & & & 8 \\
\hline$z b$ & Anb & Herbold & 0,050 & & & 0,050 & & & 9 \\
\hline$z d$ & S & Schule & 0,168 & & & 0,168 & & 3 & \\
\hline rec & chn. & & 90,795 & 11,118 & 11,813 & 67,864 & 28 & 356 & 120 \\
\hline & & Lachendorf & & & & Summe & 40 & 8 & 0 \\
\hline & Reze & ss, S. 67 und 68 & 8 (halb) & & & & & & \\
\hline
\end{tabular}

Schluss

„Da der Zweck dieser Teilungsurkunde lediglich auf die Sicherstellung der gegenseitigen Gerechstsame und Verpflichtungen, so wie aller aus dieser Verkoppelung hervorgegangenen Einrichtungen gerichtet ist, so haben alle Teilnehmer der genausten Befolgung ihres Inhalts zu allen Zeiten unbedingt zu unterwerfen, wobei die künftige Abänderung der rezessmäßigen Bestimmungen durch Verjährung ausgeschlossen sein soll.

Zur Urkunde dessen ist dieser Planrezess nach geschehener Vorlesung von sämtlichen Beteiligten oder deren Vertreter eigenhändig vollzogen worden.

Nach erfolgter Bestätigung desselben durch die Königliche Landdrostei wird dieser Rezess nebst den Kommissionsakten und der Karte bei dem Königlichen Amt Celle aufbewahrt, eine beglaubigte Abschrift derselben aber, nebst Cogni der Karte bei Königlicher Landdrostei zu Lüneburg niedergelegt, und den beiden Gemeinden Lachendorf und Oppershausen jeder eine fernere beglaubigte Abschrift dieser Urkunde zugestellt."

„So geschehen Lachendorf, den 18. Januar 1866“

gez: 55 Unterschriften 
„Dass die vorstehende Teilungsurkunde, nach vorgängiger Verlesung und Genehmigung von den Beteiligten oder deren Vertreter durch eigenhändige Namens-Unterschrift heute vollzogen ist, wird hierdurch beglaubigt.

Für die entbliebenen Interessenten wird in Folge des in der Vorladung zum heutigen Termin gestellten Präjudizes, der Rezess als vollzogen angenommen".

Celle, den 18. Januar 1866 Die Teilungskommission

gez. v. Bock

v. Hademstorff

„Vorstehender Rezess wird hierdurch bestätigt.

Lüneburg, den 7. Februar 1866

Königlich Hannoversche Landdrostei“

gez. von Issendorf

„Die Übereinstimmung des vorstehenden Rezesses mit dem Original wird kommissionsseitig damit beglaubigt".

Celle, den 22. März 1866

Siegel

Unterschrift: v. Hademstorff

L.Ö Commissair

\author{
Geschehen zu Lachendorf, den 18. Januar 1866 \\ Gegenwärtig: \\ Amtsassessor von Bock \\ Landes-Oeconomie-Commissair von Hademstorff
}

„Nachdem die KJönigliche Landdrostei zu Lüneburg den statt Plans entworfenen Rezess über die Entfrettung und Verkoppelung der Aller- und trockenen Wiesen bei Lachendorf genehmigt hate, so war zu dessen Publication und in Ermangelung aufschiebender Hindernisse auch zur Vollziehung Termin auf heute hieselbst angesetzt, wozu die Vorladungen in den Lüneburger und Celler Anzeigen und auf sonst übliche Weise zur öffentlichen Kunde gebracht waren.

Von den Interessenten hatten sich diejenigen eingefunden, welche dem diesem Protokolle angelegten Namensverzeichnis als anwesend aufgeführt sind.

Nach eröffnetem Termine wurde zuerst das Rescript der Königlichen Landdrostei vom 6. v. M. mittels Verlesung eröffnet.

Als dann nahmen die Vollhöfner Lüßmann und Schumeyer noch eine Entschädigung in Anspruch für Nichtnutzung des Weide-Äwuivalents von der Bunkenburgschen Wiese, welches ihnen in der Ahnsbecker Teilung in Anrechnung gebracht sei, welches sie aber jetzt erst in Wirklichkeit erhalten hätten.

Beide Hofbesitzer nahmen für 7 Jahre die Entschädigung in Anspruch.

Nach längerer Besprechung vereinigten sich die beiden Reclamenten mit den weideberechtigten Gemeinden Lachendorf und Oppershausen und zahlen die letzteren ein für alle mal 10 $R T h$, namentlich an Lüßmann 6 RTh und an Schumeyer 4 RTh Entschädigung, wogegen die beiden Hofbesitzer alle weiteren Ansprüche an die beiden Gemeinden in dieser Beziehung fallen lassen.

Es wurde dann der Planrezess mündlich vorgelesen und wurden Ausstellungen nicht weiter vorgebracht, derselbe vielmehr anerkannt, jedoch wurden nachfolgende Bestimmungen getroffen.

Dem Köthner Kammann von Oppershausen verbleibt das Recht über den gemeinschaftlichen Raum No. 46 der Karte, 14 Ruthen groß, nach seiner dahinter liegenden Koppel zu fahren, gehen und Vieh zu treiben.

Von den Anwesenden wurden dann die Sindici'beauftragt die gemeinschaftlich reservierten Räume öffentlich meistbietend zu verkaufen und das Geld in die Teilungskasse zu liefern, auch die nötigen Kaufkontrakte abzuschließen.

\footnotetext{
${ }^{1}$ Sonst meistens verwendete Schreibweise: Syndici
} 
Dem Herrschaftlichen Bevollmächtigten wurde der gemeinschaftliche Raum No. 39 der Karte, 60 QR: 0,034 Kuhw. groß zu dem Taxationspreise von $250 R_{T h}{ }^{1}$, die Kuhweide also zu 8 RTh $15 \mathrm{gGr}$, überlassen und versprach der Herrschaftliche Bevollmächtigte diesen Geldbetrag in die Teilungskasse zu liefern.

Als man dann nochmals versucht hatte den Widerspruch von Thies Bock gegen die von den Sachkundigenvorgeschlagene Koppel-Vertauschung von Lüßmann zu beseitigen, solches aber nicht zu erreichen war, wurde die Entscheidung vom gestrigen Tage eröffnet.

Nach solcher Eröffnung gelang es uns auch diese Angelegenheit zu beseitigen, indem Lüßmann auf Auszahlung von den 14 RTh für den überschießenden Wert seiner abzutretenden Koppel verzichtete und die Genossenschaft dem Thies Bock noch außerdem 3 RTh zubilligte und den aufgelagerten Sand wegzuschaffen.

Endlich beschlossen die Interessenten noch, dass der Dorfschaft Beedenbostel gleichfalls eine begleubigte Abschrift des Rezesses auf gemeinschaftliche Kosten zugeferigt werden solle.

Der Rezess wurde dann von den Comparenten vollzogen.

Der Köthner Meyer von Oppershausen weigerte sich den Rezess zu vollziehen, weil er noch die Anlage eines Fußweges verlange, ließ indess seinen Antrag auf Vorstellung fallen.

Auch glaubte er, dass ihm auch etwa 3 QRuthen fehlten, worauf die Sindici ihm Entschädigung versprachen, wenn er die Richtigkeit der Forderung nachweise.

Derselbe vollzog dann den Rezess.

Vorgelesen und genehmigt, ist Termin geschlossen.

Zur Beglaubigung:

Gez. v. Brock v. Hademstorff

pro copia

Unterschrift: v. Hademstorff

\footnotetext{
${ }^{1}$ Als Symbol für die Geldeinheit wird, wie auch weiter oben, ein heute unbekanntes Symbol verwandt. Folgende Kontrollrechnung belegt, dass es sich um Reichstaler (RTh) handeln muss, wenn man $30 \mathrm{gGr}$ zu einem RTh rechnet: $250: 0,034=8,5$, also Kaufpreis von 250 RTh geteilt durch 0,034 Kuhw. ergibt 8,5, also 8 1/2 RTh $=8$ RTh und $15 \mathrm{gGr}$.
} 


\title{
Verteilungs-Register \\ von \\ den Aller- und trockenen Wiesen \\ ohnweit Lachendorf. \\ Amt Celle
}

Anhang zum Rezesse

\author{
Aufgestellt \\ von \\ Land Oec. Conducteur \\ Francke
}

Auf den Doppelseiten 1 - 39 des Anhangs sind das Gesamtsoll und die Abfindungen nach No. der Karte, Flurbezeichnung, Bodenart und jeweiliger Flächengröße samt Wert für jeden Interessenten aufgeführt.

\begin{tabular}{|c|c|c|c|c|c|c|c|c|c|c|c|c|c|c|c|c|c|}
\hline \multicolumn{18}{|c|}{ Abfindungen für die Interessenten in Lachendorf } \\
\hline \multicolumn{18}{|c|}{ Empfang nach dem Verteilungs-Register } \\
\hline & & Name der & \multicolumn{15}{|c|}{ nach der Bodenart } \\
\hline & & Interessenten & \multicolumn{3}{|c|}{ Wiesenboden } & \multicolumn{3}{|c|}{ Ackerland } & \multicolumn{3}{|c|}{ Angerboden } & \multicolumn{3}{|c|}{ Heidboden } & \multicolumn{3}{|c|}{ in Allem } \\
\hline Litr. & & & M & QR & Kuhw. & M & QR & Kuhw. & M & QR & Kuhw. & M & QR & Kuhw. & M & QR & Kuhw. \\
\hline a & $\mathrm{VH}$ & Lüßmann & 28 & 104 & 7,575 & & & & & & & 2 & 81 & 0,178 & 31 & 65 & 7,753 \\
\hline b & $\mathrm{VH}$ & Meyer & 28 & 14 & 6,895 & & & & & & & & 15 & 0,007 & 28 & 29 & 6,902 \\
\hline c & $\mathrm{VH}$ & Kohlmeyer & 19 & 52 & 4,66 & & & & & & & & & & 19 & 52 & 4,66 \\
\hline d & $\mathrm{VH}$ & Thies /Bock & 21 & 91 & 6,189 & & & & & & & & & & 21 & 91 & 6,189 \\
\hline e & $\mathrm{VH}$ & Bergmann & 23 & 73 & 6,439 & & & & & 56 & 0,043 & & & & 24 & 9 & 6,482 \\
\hline$f$ & $\mathrm{VH}$ & Drewsen & 21 & 52 & 6,173 & & & & & & & & & & 21 & 52 & 6,173 \\
\hline$g$ & $\mathrm{VH}$ & Schumeyer & 12 & 24 & 2,661 & & & & & & & & & & 12 & 24 & 2,661 \\
\hline $\mathrm{h}$ & $\mathrm{HH}$ & Schöndube & 12 & 75 & 2,289 & & & & 1 & 12 & 0,125 & & & & 13 & 87 & 2,414 \\
\hline$i$ & Kö & Koch & 16 & 43 & 3,508 & & & & 2 & 39 & 0,267 & 2 & 62 & 0,137 & 21 & 24 & 3,912 \\
\hline k & Kö & Veth & 13 & 100 & 4,929 & & & & & & & & & & 13 & 100 & 4,929 \\
\hline I & Kö & Thies / Theis & 22 & 4 & 4,402 & 3 & 56 & 0,262 & & & & & & & 25 & 60 & 4,664 \\
\hline $\mathrm{m}$ & Kö & Thies / Graue & 16 & 28 & 4,58 & & & & & & & 1 & 65 & 0,103 & 17 & 93 & 4,683 \\
\hline $\mathrm{n}$ & Kö & Misselhorn & 9 & 60 & 1,85 & & & & & & & 1 & 4 & 0,063 & 10 & 64 & 1,913 \\
\hline 0 & Kö & Thies /Cammann & 7 & 49 & 1,236 & & & & 1 & 116 & 0,171 & & & & 9 & 45 & 1,407 \\
\hline$p$ & Kö & Dralle / Dralle & 29 & 64 & 7,695 & & & & & & & & & & 29 & 64 & 7,695 \\
\hline$q$ & Kö & Dralle / Bolzmann & 9 & 20 & 1,197 & & & & & 53 & 0,055 & 4 & 56 & 0,237 & 14 & 9 & 1,489 \\
\hline r & Kö & Bühring & 10 & 25 & 3,207 & & & & & & & & & & 10 & 25 & 3,207 \\
\hline s & Kö & Drewsen & 13 & 17 & 1,943 & & & & & & & & 48 & 0,02 & 13 & 65 & 1,963 \\
\hline $\mathrm{t}$ & Kö & Müller & 16 & 52 & 5,122 & & & & & & & & & & 16 & 52 & 5,122 \\
\hline ze & Kö & Thies / Krüger & 3 & 51 & 0,736 & & & & & & & & & & 3 & 51 & 0,736 \\
\hline $\mathrm{u}$ & BS & Eggers & 8 & 24 & 1,771 & & & & & & & & & & 8 & 24 & 1,771 \\
\hline $\mathrm{v}$ & BS & Heuer & 7 & 113 & 1,765 & & & & & & & & & & 7 & 113 & 1,765 \\
\hline w & BS & Wolf & 3 & 94 & 0,468 & & & & 5 & 102 & 0,582 & & & & 9 & 76 & 1,05 \\
\hline $\mathrm{x}$ & AnB & Knop & 3 & 71 & 0,823 & & & & & & & & & & 3 & 71 & 0,823 \\
\hline $\mathrm{y}$ & AnB & Thies & & 21 & 0,082 & & & & & & & & & & & 21 & 0,082 \\
\hline$z$ & AnB & Meyer & & 20 & 0,085 & & & & & & & & & & & 20 & 0,085 \\
\hline za & AnB & Bergmann & & 13 & 0,047 & & & & & & & & & & & 13 & 0,047 \\
\hline$z b$ & AnB & Herbold & & 15 & 0,05 & & & & & & & & & & & 15 & 0,05 \\
\hline$z d$ & die & Schule & & 49 & 0,168 & & & & & & & & & & & 49 & 0,168 \\
\hline \multicolumn{2}{|c|}{ rechner. } & Spaltensummen & 348 & 1418 & 88,545 & 3 & 56 & 0,262 & 9 & 378 & 1,243 & 10 & 331 & 0,745 & 376 & 1463 & 90,795 \\
\hline & & Summe: & 359 & 98 & & 3 & 56 & & 12 & 18 & & 12 & 91 & & 388 & 23 & \\
\hline & & & & & & & $2+1$ & & 40/4 & $1(\mathrm{Wi}$ & leo & lung) & & & & & \\
\hline
\end{tabular}


In der folgenden Tabelle sind die Abfindungen aller Lachendorfer Höfe vollständig aufgeführt: Die Abfindungen der einzelnen Interessenten werden auf den Seiten 40 - 45 im Anhang ohne Angabe des jeweiligen Flurstücks wiederholt.

In der nebenstehenden Tabelle sind die Abfindungen der beteiligten Dörfer als Gesamtfläche in Morgen und Quadratruten sowie in ha umgerechnet zusammengefasst.

\begin{tabular}{|c|c|c|c|c|}
\hline \multicolumn{5}{|c|}{ Zuteilungen Aller- und trockene Wiesen } \\
\hline Orte & $\mathrm{x}$ & M & QR & ha \\
\hline Lachendorf & 29 & 388 & 23 & 101,7489 \\
\hline Oppershausen & 34 & 155 & 18 & 40,6664 \\
\hline Beedenbostel & 16 & 106 & 12 & 27,8099 \\
\hline Gockenholz & 3 & 31 & 2 & 8,1298 \\
\hline Ohe & 2 & 8 & 93 & 2,3000 \\
\hline Rebberlah & 3 & 33 & 30 & 8,7152 \\
\hline Habighorst & 3 & 8 & 102 & 2,3197 \\
\hline Eschede & 1 & 2 & 117 & 0,7798 \\
\hline Kragen & 1 & 2 & 116 & 0,7776 \\
\hline Jarnsen & 1 & 7 & 30 & 1,9003 \\
\hline Bunkenburg & 2 & 10 & 33 & 2,6932 \\
\hline Ahnsbeck & 4 & 16 & 32 & 4,2637 \\
\hline Schwachhausen & 1 & 17 & 116 & 4,7092 \\
\hline Wienhausen & 1 & 4 & 109 & 1,2865 \\
\hline Offensen & 4 & 7 & 118 & 2,0925 \\
\hline Nordburg & 3 & 8 & 89 & 2,2913 \\
\hline andere Verwendung & & & & \\
\hline Köngl. Finanzminnisterium & & 29 & 13 & 7,6296 \\
\hline Wege, Gräben pp. & & 39 & 75 & 10,3861 \\
\hline neuer Schwarzwasserfluss & & 1 & 76 & 0,4281 \\
\hline & & 881 & 4 & 230,9276 \\
\hline x: Anzahl der Interesse & ewe & iligen & Ort & \\
\hline Zusammenfas & er & $\mathrm{m}$ An & hang & \\
\hline Rezess, Anh & S. 4 & 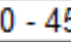 & & \\
\hline
\end{tabular}

Quelle: Theilungs-Urkunde über die Entfrettung und Verkoppelung der Aller- und trockenen Wiesen bei Lachendorf, Amt Celle (Abschrift)

Samtgemeinde Lachendorf, Archiv Akten, Fach/Nr. 140/8

Rezess von 1866 